
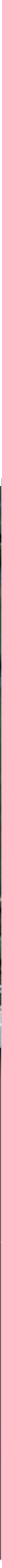

(6)

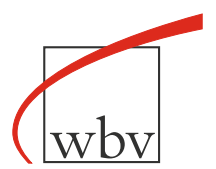




\section{Bildung auf einen Blick 2013 OECD-Indikatoren}

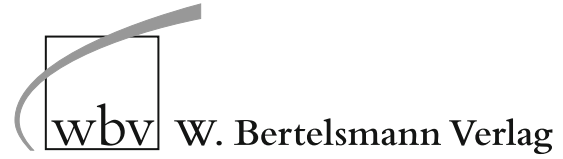


Das vorliegende Dokument wird unter der Verantwortung des Generalsekretärs der OECD veröffentlicht. Die darin zum Ausdruck gebrachten Meinungen und Argumente spiegeln nicht zwangsläufig die offizielle Einstellung der Organisation oder der Regierungen ihrer Mitgliedstaaten wider.

Die englische und die französische Originalfassung wurden von der OECD veröffentlicht unter dem Titel:

Education at a Glance 2013: OECD Indicators

Regards sur l'éducation 2013 : Les indicateurs de l'OCDE

(c) 2013 OECD

Alle Rechte vorbehalten

(C) 2013 Bundesministerium für Bildung und Forschung, Deutschland für die deutsche Übersetzung

(C) 2013 W. Bertelsmann Verlag für diese deutsche Ausgabe

Veröffentlicht in Absprache mit der OECD, Paris

Für die Qualität der deutschen Version und die Übereinstimmung mit dem Originaltext übernimmt das Bundesministerium für Bildung und Forschung die Verantwortung.

\section{Fotos:}

Banque d'images Stocklib (C) Cathy Yeulet

Fotolia.com (c) Feng Yu

Getty Images (C) blue jean images

Korrigenda zu OECD-Veröffentlichungen sind verfügbar unter: www.oecd.org/publishing/corrigenda. 


\section{Vorwort}

Bei der Suche nach einer effektiven Bildungspolitik, die auf wirksame Art und Weise die sozialen und wirtschaftlichen Aussichten des Einzelnen verbessert, die Anreize für eine größere Effizienz bei der Bildungsvermittlung bietet und die dazu beiträgt, Ressourcen zur Bewältigung der steigenden Bildungsnachfrage zu mobilisieren, lenken die Regierungen ihre Aufmerksamkeit in verstärktem Maße auf internationale Vergleiche. Als Teil der Bemühungen in diesem Bereich sieht die OECD-Direktion Bildungswesen eine ihrer Hauptaufgaben in der Entwicklung und Analyse international vergleichbarer, quantitativer Indikatoren, die dann jährlich in Bildung auf einen Blick veröffentlicht werden. Diese Indikatoren bieten sowohl den politischen Entscheidungsträgern als auch den im Bildungswesen Tätigen die Möglichkeit, das eigene Bildungssystem im Licht der Leistungsfähigkeit anderer Länder zu betrachten. Zusammen mit den länderspezifischen Untersuchungen der OECD sind sie darauf ausgelegt, die Regierungen in ihren Bemühungen um Reformen in der Bildungspolitik zu unterstützen und diese zu untersuchen.

Bildung auf einen Blick zielt ab auf die Bedürfnisse einer breit gestreuten Leserschaft - von den Regierungen, die von den bildungspolitischen Erfahrungen anderer Länder lernen wollen, über Wissenschaftler, die Daten für weiter gehende Analysen benötigen, bis zur allgemeinen Öffentlichkeit, die einen Überblick darüber gewinnen möchte, welche Fortschritte das Bildungssystem des eigenen Landes dabei macht, Schüler und Studierende von Weltklasseformat auszubilden. Die Veröffentlichung untersucht die Qualität der Lernergebnisse, die politischen Ansatzpunkte und Bedingungen, die die Bildungserfolge beeinflussen, und die - im weitesten Sinne - individuellen und gesellschaftlichen Erträge von Investitionen in Bildung.

Bildung auf einen Blick ist das Ergebnis langjähriger gemeinsamer Bemühungen der Regierungen der OECD-Länder, der Experten und Institutionen, die im Rahmen des OECD-Programms Indicators of Education Systems (INES) zusammenarbeiten, sowie des Sekretariats der OECD. Die Veröffentlichung wurde erstellt von der Abteilung „Innovation and
Measuring Progress“ der OECD-Direktion Bildung und Kompetenzen unter der Leitung von Dirk Van Damme und Corinne Heckmann, mitgewirkt haben Etienne Albiser, Simone Bloem, Rodrigo CastanedaValle, Eric Charbonnier, Corinne Heckmann, Estelle Herbaut, Karinne Logez, Koji Miyamoto, Joris Ranchin, Cuauhtemoc Rebolledo-Gomez, Gara Rojas González, David Valenciano und Jean Yip. Rhodia Diallo war unterstützend im Bereich Verwaltung tätig; das Lektorat erfolgte durch Marilyn Achiron. Gwenaelle Barach, Marika Boiron, Célia BragaSchich, Elizabeth Del Bourgo, Caroline Israël, Diane Lalancette, Ignacio Marin und Elisabeth Villoutreix haben die Arbeiten fachlich unterstützt sowie bei Analysen und Lektorat mitgewirkt. Die Autoren wurden unterstützt durch die analytischen Arbeiten von Sam Abrams, Francesco Avvisati, Tracey Burns, Sonia Guerriero, Hiroko Ikesako, David Istance, Katarzyna Kubacka, Marco Kools, Pauline Musset, Anna Pons, Miho Taguma, Willam Thorn, Juliana Zapata und Pablo Zoido. Elisabeth Villoutreix koordinierte die Produktion von Bildung auf einen Blick. Die Entwicklung der Veröffentlichung wurde von den Mitgliedsländern durch die INES-Arbeitsgruppe gesteuert und durch die INES-Netzwerke unterstützt. Eine Liste der Mitglieder der verschiedenen Organe sowie der einzelnen Fachleute, die an diesem Bericht und der OECD/INES-Arbeit generell mitgewirkt haben, findet sich am Ende dieser Veröffentlichung.

In den letzten Jahren ist zwar viel erreicht worden, aber die Mitgliedsländer und die OECD setzen ihre Bemühungen fort, spezifische bildungspolitische Fragestellungen noch genauer mit den besten verfügbaren international vergleichbaren Daten zu verknüpfen. Hierbei stellen sich verschiedene Herausforderungen, und es gilt, unterschiedliche Aspekte abzuwägen. Erstens müssen die Indikatoren die Fragen ansprechen, die in den einzelnen Ländern von großer bildungspolitischer Bedeutung sind und bei denen eine international vergleichende Perspektive gegenüber nationalen Analysen und Bewertungen tatsächlich einen Informationsgewinn liefert. Zweitens müssen die Indikatoren zwar so vergleichbar wie möglich sein, gleichzeitig aber auch länder- 
spezifisch genug, um historische, systembedingte und kulturelle Unterschiede zwischen den einzelnen Ländern berücksichtigen zu können. Drittens muss die Darstellung in den Indikatoren so klar wie möglich sein, gleichzeitig aber auch der facettenreichen Realität von Bildungssystemen in der heutigen Welt gerecht werden. Viertens besteht der allgemeine Wunsch, die Zahl der Indikatoren so niedrig wie möglich zu halten, während gleichzeitig ihre Zahl aber groß genug sein muss, um den politischen Entscheidungsträgern in den einzelnen Ländern, die sich teilweise ganz unterschiedlichen bildungspolitischen Herausforderungen gegenübersehen, wirklich von Nutzen zu sein.

Die OECD wird diese Herausforderungen auch weiterhin entschieden angehen und die Entwicklung von Indikatoren nicht nur in den Bereichen vorantreiben, in denen dies möglich und vielversprechend ist, sondern auch in jene Bereiche vordringen, in denen noch sehr viel grundlegende konzeptionelle Arbeit vonnöten ist. Die Weiterentwicklung der Internationalen Schulleistungsstudie PISA und deren Erweiterung durch die internationale OECD-Erhebung zu den Kompetenzen von Erwachsenen (OECD Programme for the International Assessment of Adult Competencies - PIAAC) sowie die internationale Erhebung der OECD zu Lehren und Lernen (OECD Teaching and Learning International Survey - TALIS) sind wichtige Schritte auf dem Weg zur Erreichung dieses Zieles. 


\section{Inhalt}

Editorial

Einleitung

Hinweise für den Leser..................................

Kapitel A Bildungsergebnisse und Bildungserträge $\ldots \ldots \ldots \ldots \ldots \ldots 25$

Indikator A1

Tabelle Ar.ra

Tabelle Ar.2a

Tabelle Ar.3a

Tabelle Ar.4a

Tabelle Ar.5a

Indikator A2

Tabelle A2.ra

Tabelle A2.Ib

Tabelle A2.2a

Tabelle A2.3a

Indikator A3

Tabelle A3.Ia

Tabelle A3.Ib

Tabelle A3.2a

Indikator A4:

Tabelle A4. I

Tabelle A4. 2

Indikator A5

Tabelle A5.Ia

Tabelle A5.Ib

Tabelle A5.2a

Tabelle A5.2b
Über welche Bildungsabschlüsse verfügen Erwachsene? . . . . . . . . 27

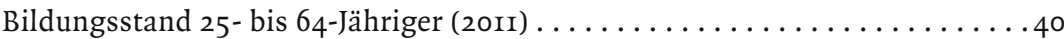
Anteil der Bevölkerung mit mindestens einem Abschluss im Sekundar-

bereich II (in \%), nach Altersgruppe (20II) .............. Anteil der Bevölkerung mit einem Abschluss im Tertiärbereich (in \%), nach Art des Studiengangs und Altersgruppe (20II) . . . . . . . . 42 Entwicklungstendenzen bei Bildungsabschlüssen, nach Altersgruppe, sowie durchschnittlicher jährlicher Anstieg (2000-20II) . . . . . . . . . 43 Bildungsstand von 25- bis 64-Jährigen, nach Ausrichtung des Bildungsgangs (berufsbildend oder allgemeinbildend) und Geschlecht (20II) . . . . 46 6

\section{Wie viele Schüler werden den Sekundarbereich II erfolgreich} abschließen? ............................. 47 Abschlussquoten im Sekundarbereich II und durchschnittliches Abschlussalter (20II) . . . . . . . . . . . . . . . . . . . . . . . . 59 Abschlussquoten im Sekundarbereich II von Schülern, die jünger als 25 Jahre sind (20Ir) . . . . . . . . . . . . . . . . . . . Entwicklung der Abschlussquoten im Sekundarbereich II (Erstabschluss,

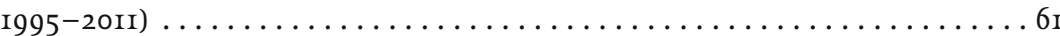
Verteilung der Absolventen von berufsbildenden Bildungsgängen des Sekundarbereichs II, nach Fachrichtung und Geschlecht (20II) . . . . . . . . 62

\section{Wie viele Studierende werden ein Studium im Tertiärbereich}

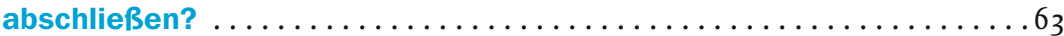
Abschlussquoten und durchschnittliches Abschlussalter im Tertiär-

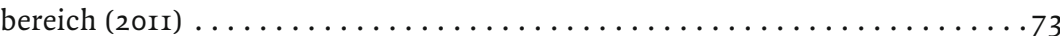
Abschlussquoten im Tertiärbereich von Studierenden, die jünger als

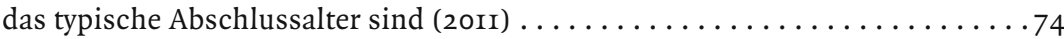
Entwicklung der Abschlussquoten im Tertiärbereich (I995-20II) . . . . . . 75

Wie hoch sind die Erfolgsquoten im Tertiärbereich? . . . . . . . . . 77 Erfolgsquoten im Tertiärbereich (20II) . . . . . . . . . . . . 86 Erfolgsquoten im Tertiärbereich A, nach Vollzeit-/Teilzeitstudium (20II) . . .87

Wie beeinflusst der Bildungsstand die Erwerbsbeteiligung? . . . . . . 89 Beschäftigungsquoten 25- bis 64-Jähriger, nach Bildungsstand (2011) . . . . . I06 Beschäftigungsquoten 25- bis 64-Jähriger, nach Bildungsstand und

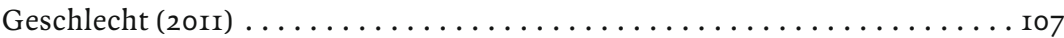
Erwerbslosenquoten 25 - bis 64 -Jähriger, nach Bildungsstand (20II) . . . . . . ro9 Erwerbslosenquoten 25- bis 64-Jähriger, nach Bildungsstand und Geschlecht (20II) ........................... IIO 
Tabelle A5.3a Beschäftigungsquoten, nach Bildungsstand und Altersgruppe (2000,

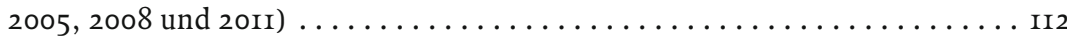

Tabelle A5.4a Erwerbslosenquoten, nach Bildungsstand und Altersgruppe (2000,

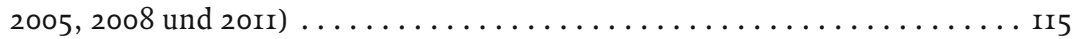

Tabelle A5.5a Erwerbsstatus 25-bis 64-Jähriger, nach Bildungsstand und Ausrichtung

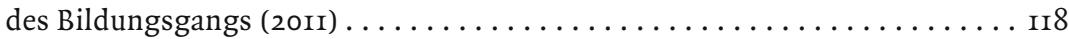

Tabelle A5.6 Anteil der ganzjährig Vollzeitbeschäftigten an allen Personen mit Erwerbseinkommen, nach Bildungsstand und Altersgruppe (20II) . . . . . II9

Indikator A6 Welche Einkommenszuschläge lassen sich durch Bildung erzielen?... I2I Tabelle A6.I Relative Einkommen 25- bis 64-Jähriger mit Erwerbseinkommen, nach Bildungsstand, Geschlecht und Altersgruppe (20II) . . . . . . . . I37

Tabelle A6.2a Entwicklung der relativen Einkommen 25- bis 64-Jähriger mit Erwerbseinkommen, nach Bildungsstand (2000-20II) . . . . . . . . . . . I39

Tabelle A6.2b Entwicklung der relativen Einkommen 25- bis 64-jähriger Männer mit Erwerbseinkommen, nach Bildungsstand (2000-20II) . . . . . . . . I4I

Tabelle A6.2c Entwicklung der relativen Einkommen 25- bis 64-jähriger Frauen mit Erwerbseinkommen, nach Bildungsstand (2000-20II) . . . . . . . . I43

Tabelle A6.3a Einkommensunterschiede zwischen Frauen und Männern, nach Bildungsstand und Altersgruppe (20II) . . . . . . . . . . . . . . . I45

Tabelle A6.3b Entwicklung der Einkommensunterschiede zwischen 25- und 64-jährigen Frauen und Männern, nach Bildungsstand (2000-20II) . . . . . . . I46

Tabelle A6.5a Relative Einkommen von I5- bis 24-jährigen Schülern und Studierenden, nach Bildungsstand und Geschlecht (20II) . . . . . . . . . . . . . . I49

Tabelle A6.5b Anteil junger Erwachsener mit Erwerbseinkommen an allen jungen Erwachsenen, nach Geschlecht, Altersgruppe und Ausbildungsstatus (20II) . . . . I5I

Indikator A7

Welche Anreize bestehen für Investitionen in Bildung? . . . . . . . . I53

Tabelle A7.ra Private Kosten und privater Nutzen für einen Mann, der einen Abschluss im Sekundarbereich II bzw. postsekundaren, nicht tertiären Bereich erwirbt (2009) . . . . . . . . . . . . . . . . . . . . . I73

Tabelle A7.Ib Private Kosten und privater Nutzen für eine Frau, die einen Abschluss im Sekundarbereich II bzw. postsekundaren, nicht tertiären Bereich erwirbt (2009) . . . . . . . . . . . . . . . . . . . . . . . . . . I74

Tabelle A7.2a Staatliche Kosten und staatlicher Nutzen bei einem Mann, der einen Abschluss im Sekundarbereich II bzw. postsekundaren, nicht tertiären

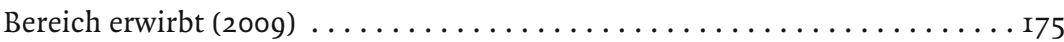

Tabelle A7.2b Staatliche Kosten und staatlicher Nutzen bei einer Frau, die einen Abschluss im Sekundarbereich II bzw. postsekundaren, nicht tertiären

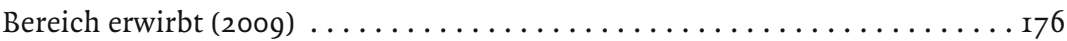

Tabelle A7.3a Private Kosten und privater Nutzen für einen Mann, der einen Abschluss im Tertiärbereich erwirbt (2009) . . . . . . . . . . . . . . . I77

Tabelle A7.3b Private Kosten und privater Nutzen für eine Frau, die einen Abschluss im Tertiärbereich erwirbt (2009) . . . . . . . . . . . . . . I78

Tabelle A7.4a Staatliche Kosten und staatlicher Nutzen bei einem Mann, der einen Abschluss im Tertiärbereich erwirbt (2009) . . . . . . . . . . . . I79

Tabelle A7.4b Staatliche Kosten und staatlicher Nutzen bei einer Frau, die einen Abschluss im Tertiärbereich erwirbt (2009) . . . . . . . . . . . . . . I80

Indikator A8 Was sind die gesamtgesellschaftlichen Auswirkungen von Bildung? .. I8I AII Tabelle A8.I Anteil der Erwachsenen, die fettleibig sind, nach Bildungsstand und

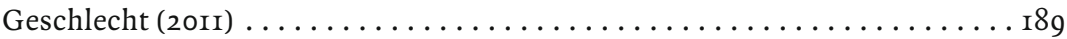

Tabelle A8.2 Anteil der Erwachsenen, die rauchen, nach Bildungsstand und Geschlecht

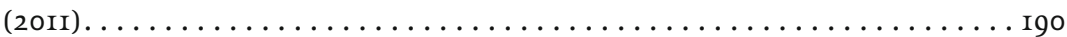


Tabelle A8.3 Unterschied bei der „Wahrscheinlichkeit, fettleibig zu sein“ (in Prozentpunkten), der mit einem höheren Bildungsstand zusammenhängt (20II) . . . I9I

Tabelle A8.4 Unterschied bei der „Wahrscheinlichkeit zu rauchen“ (in Prozentpunkten), der mit einem höheren Bildungsstand zusammenhängt (20II) . . . . I92

Kapitel B Die in Bildung investierten Finanz- und Humanressourcen . . 193

Indikator B1 Wie hoch sind die Ausgaben pro Schüler/Studierenden? . . . . . . . . I97 Tabelle Br.ra Jährliche Ausgaben von Bildungseinrichtungen pro Schüler/Studierenden

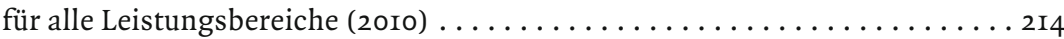

Tabelle Bı.2 Jährliche Ausgaben von Bildungseinrichtungen pro Schüler/Studierenden für eigentliche Bildungsdienstleistungen, zusätzliche Dienstleistungen

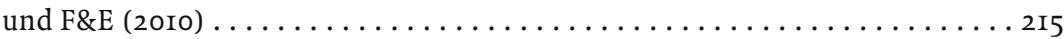

Tabelle Bı.за Kumulierte Ausgaben von Bildungseinrichtungen pro Studierenden für alle Leistungsbereiche während der durchschnittlichen Dauer von

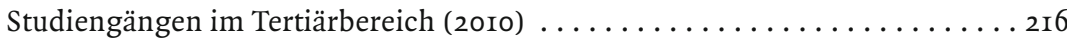

Tabelle Br.4 Jährliche Ausgaben von Bildungseinrichtungen pro Schüler/Studierenden für alle Leistungsbereiche im Verhältnis zum BIP pro Kopf (2010) . . . . . . . 2I7

Tabelle Br.5a Veränderung der Ausgaben von Bildungseinrichtungen pro Schüler im Primar-, Sekundar- und postsekundaren, nicht tertiären Bildungsbereich für alle Leistungsbereiche aufgrund verschiedener Faktoren (I995, 2000,

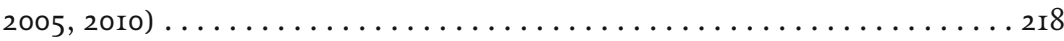

Tabelle BI.5b Veränderung der Ausgaben von Bildungseinrichtungen pro Studierenden im Tertiärbereich für alle Leistungsbereiche aufgrund verschiedener

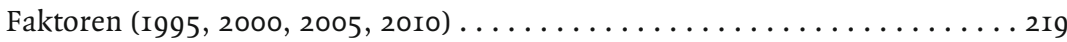

Tabelle Br.6 Jährliche Ausgaben von Bildungseinrichtungen pro Schüler im Sekundarbereich für alle Leistungsbereiche, nach Art des Bildungsgangs (20I0) . . . . 220

Indikator B2 Welcher Teil des Bruttoinlandsprodukts wird für Bildung ausgegeben? ............................ 22I

Tabelle B2.I Ausgaben für Bildungseinrichtungen als Prozentsatz des BIP, nach Bildungsbereich $(\mathrm{I} 995,2000,2005,2010) \ldots \ldots \ldots \ldots \ldots \ldots 33$

Tabelle B2.2 Ausgaben für Bildungseinrichtungen als Prozentsatz des BIP,

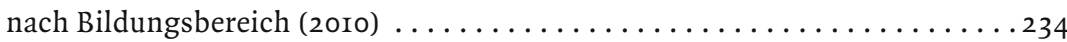

Tabelle B2.3 Ausgaben für Bildungseinrichtungen als Prozentsatz des BIP, nach Herkunft der Mittel und Bildungsbereich (2010) . . . . . . . . . . 235

Tabelle B2.4 Ausgaben für Bildungseinrichtungen als Prozentsatz des BIP,

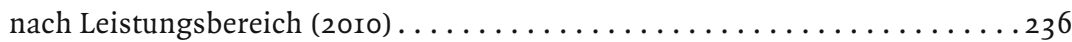

Tabelle B2.5 Veränderung der öffentlichen Ausgaben für Bildungseinrichtungen

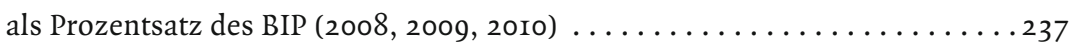

Indikator B3 Wie groß ist der Anteil der öffentlichen und der privaten Ausgaben im Bildungswesen? ............................ 239

Tabelle B3.I Relative Anteile öffentlicher und privater Ausgaben für Bildungseinrichtungen aller Bildungsbereiche $(2000,2010) \ldots \ldots \ldots \ldots \ldots \ldots$ 25

Tabelle B3.2a Relative Anteile öffentlicher und privater Ausgaben für Bildungseinrichtungen, nach Bildungsbereich $(2000,2010) \ldots \ldots \ldots \ldots \ldots 2$

Tabelle B3.2b Relative Anteile öffentlicher und privater Ausgaben für Bildungseinrichtungen im Tertiärbereich $(2000,2010) \ldots \ldots \ldots \ldots \ldots \ldots 253$

Tabelle B3.3 Entwicklung der relativen Anteile öffentlicher Ausgaben für Bildungseinrichtungen im Tertiärbereich und Index der Veränderung dieser Ausgaben zwischen rg95 und 2010. . . . . . . . . . . . . . . . . 254 
Tabelle B3.4 Jährliche öffentliche Ausgaben für Bildungseinrichtungen pro Schüler/

Studierenden, nach Art der Bildungseinrichtung (2010) . . . . . . . . 255

Indikator B4 Wie hoch sind die öffentlichen Gesamtausgaben für Bildung? . . . . . 257

Tabelle B4.I

Öffentliche Gesamtausgaben für Bildung (20I0) . . . . . . . . . . . 268

Tabelle $\mathrm{B} 4.2$

Öffentliche Gesamtausgaben für Bildung (I995, 2000, 2005 und 2010) . . . 269

Tabelle $\mathrm{B} 4 \cdot 3$

Herkunft der Mittel für öffentliche Bildungsausgaben im Primar-,

Sekundar- und postsekundaren, nicht tertiären Bereich, nach staatlicher

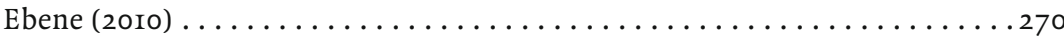

Indikator B5 Wie hoch sind die Studiengebühren und welche öffentlichen Unter-

stützungsleistungen erhalten Studierende? ............. 27I

Tabelle B5.I Geschätzte durchschnittliche jährliche Studiengebühren für inländische

Studierende an Bildungseinrichtungen des Tertiärbereichs A (20II) . . . . . 286

Tabelle B5.2 Verteilung der Finanzhilfen an Studierende im Vergleich zur Höhe der Studiengebühren an Bildungseinrichtungen des Tertiärbereichs A für inländische Studierende in einem Studiengang, der zu einem ersten

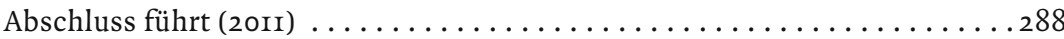

Tabelle B5.3 Durchschnittliche Studiengebühren von Bildungseinrichtungen des Tertiärbereichs, nach Fachrichtung (20II) . . . . . . . . . . . 289

Tabelle B5.4 Öffentliche Unterstützungsleistungen an private Haushalte und andere private Einheiten als Prozentsatz der öffentlichen Gesamtausgaben für Bildung und des BIP, für den Tertiärbereich (20I0) . . . . . . . . . 290

WEB Indikator B6

Indikator B7

Tabelle B7.I

Tabelle B7.2a

Tabelle B7.2b

Tabelle B7.3

Tabelle B7.4a

Tabelle B7.5a

\section{Kapitel C}

Indikator C1

Tabelle Cr.Ia

Tabelle Cr.2

Tabelle Cr.3

Tabelle CI.4

Tabelle CI. 5

Tabelle Cr.6a
Wofür werden Finanzmittel im Bereich der Bildung ausgegeben? . . . . 29I

Welche Faktoren beeinflussen die Höhe der Bildungsausgaben? . . . . 293

Gehaltskosten der Lehrkräfte pro Schüler, nach Bildungsbereich (20II) . . . 307

Faktoren zur Berechnung der Gehaltskosten der Lehrkräfte pro Schüler

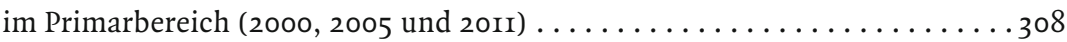

Faktoren zur Berechnung der Gehaltskosten der Lehrkräfte pro Schüler

im Sekundarbereich I (2000, 2005 und 2011) . . . . . . . . . . . 3 Io

Beitrag verschiedener Faktoren zu den Gehaltskosten der Lehrkräfte

pro Schüler im Primarbereich (2000, 2005 und 20II) . . . . . . . . . 3 12

Beitrag verschiedener Faktoren zu den Gehaltskosten der Lehrkräfte

pro Schüler im Sekundarbereich I (2000, 2005 und 20II) . . . . . . . . . . . . 3I3

Beitrag verschiedener Faktoren zu den Gehaltskosten der Lehrkräfte

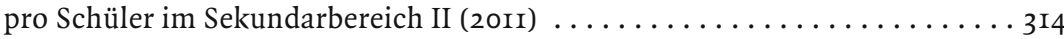

B4

B5

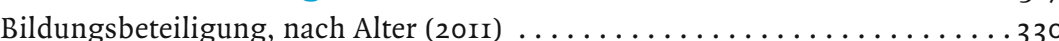

Entwicklung der Bildungsbeteiligung (I995-20II) . . . . . . . . . . 33 I

Bildungsbeteiligung im Sekundarbereich II und im postsekundaren,

nicht tertiären Bereich (20II) . . . . . . . . . . . . . . 332

Verteilung der Schüler im Primar- und Sekundarbereich, nach Art der

Bildungseinrichtung sowie Vollzeit- oder Teilzeitausbildung (20II) . . . . 333

Verteilung der Studierenden im Tertiärbereich (in \%), nach Art der

Bildungseinrichtung sowie Vollzeit- oder Teilzeitstudium (20II) . . . . . . 334

$\mathrm{Zu}$ erwartende Jahre in Ausbildung für 5- bis 39-Jährige (20II) . . . . . . . . 335 
Indikator C2 Welche Systeme zur frühkindlichen Bildung gibt es weltweit? . . . . 337

Tabelle C2.I

Bildungsbeteiligung im Elementar- und Primarbereich, nach Alter

$\mathrm{C} 2$

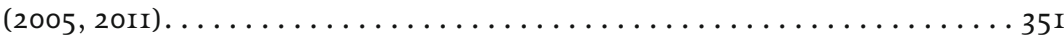

Tabelle C2.2 Merkmale von Bildungsangeboten im Elementarbereich (2010, 20II) .....352

Tabelle C2.3 Merkmale von reinen Bildungsangeboten und integrierten Angeboten

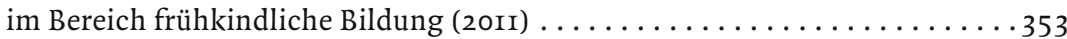

Indikator $\mathrm{C}_{3}$ Wie viele junge Erwachsene werden ein Studium im Tertiär-

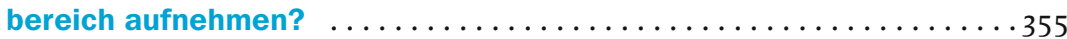

Tabelle $C_{3}$.ra Studienanfängerquoten im Tertiärbereich und durchschnittliches Alter

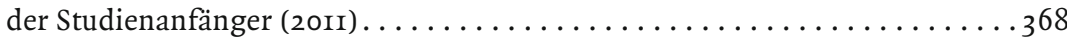

Tabelle $\mathrm{C}_{3} . \mathrm{Ib} \quad$ Studienanfängerquoten von jungen Menschen unterhalb des typischen

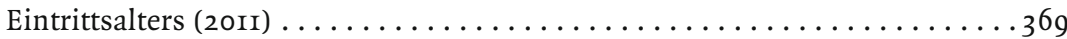

Tabelle $\mathrm{C}_{3.2 \mathrm{a}}$ Entwicklung der Studienanfängerquoten im Tertiärbereich (I995-20II) ....370

Tabelle $\mathrm{C}_{3}$.3a Studienanfänger im Tertiärbereich, nach Fächergruppe (20II) .........3

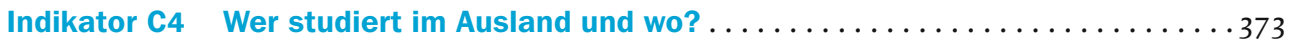

Tabelle $\mathrm{C}_{4}$. I

Die Mobilität internationaler Studierender und ausländische Studierende

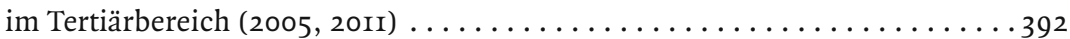

Tabelle $\mathrm{C}_{4.2}$ Verteilung internationaler und ausländischer Studierender im Tertiär-

bereich, nach Fächergruppe (20II) . . . . . . . . . . . . . . . . 393

Tabelle $\mathrm{C}_{4} .3$ Verteilung internationaler und ausländischer Studierender im Tertiär-

bereich, nach Herkunftsland (20II) . . . . . . . . . . . . . . . . . . . 394

Tabelle C4.4 Studierende, die in einem Land studieren, dessen Staatsbürger sie nicht

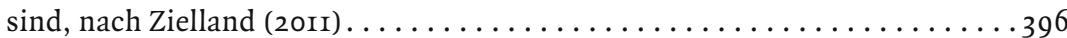

Tabelle $\mathrm{C}_{4.5}$ Mobilität ausländischer und internationaler Studierender (20II) . . . . . . 398

Tabelle C4.6 Entwicklung der Zahl der eingeschriebenen ausländischen Studierenden,

nach Zielregion und Herkunftsregion (2000 bis 20II) . . . . . . . . . 399

Indikator C5 Der Übergang vom (Aus-)Bildungssystem zum Erwerbsleben:

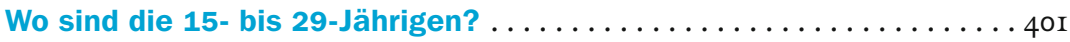

Tabelle $\mathrm{C}_{5}$.ra Zu erwartende Jahre in Ausbildung und nicht in Ausbildung für 15- bis

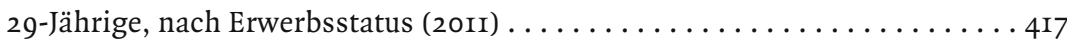

Tabelle C5.2a Anteil I5- bis 29-Jähriger (in \%), die sich in Ausbildung bzw. nicht in

Ausbildung befinden, nach Erwerbsstatus, einschließlich Dauer der

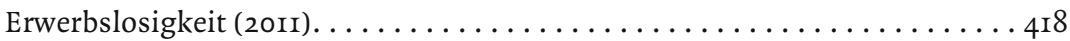

Tabelle $\mathrm{C}_{5}$.3a Anteil 15- bis 29-Jähriger (in \%), die sich in Ausbildung bzw. nicht in

Ausbildung befinden, nach Erwerbsstatus, einschließlich Teilzeit-

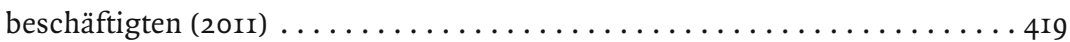

Tabelle $\mathrm{C}_{5.4 \mathrm{a}}$ Entwicklung des Anteils junger Menschen (in \%), die sich in Ausbildung und nicht in Ausbildung befinden (beschäftigt oder nicht beschäftigt),

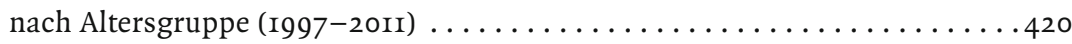

Tabelle C5.5a Anteil I5- bis 29-Jähriger (in \%), die sich in Ausbildung bzw. nicht in Ausbildung befinden, nach Bildungsstand und Erwerbsstatus, einschließlich Dauer der Erwerbslosigkeit (20II) . . . . . . . . . . 423

Tabelle $\mathrm{C}_{5} .6$ Anteil I5- bis 29-Jähriger (in \%), die sich in Ausbildung bzw. nicht in Ausbildung befinden, nach Bildungsstand und Erwerbsstatus, einschließ-

lich Teilzeitbeschäftigten (20II) . . . . . . . . . . . . . 426

Tabelle $\mathrm{C}_{5.7}$ Entwicklung des Anteils 15- bis 29-Jähriger (in \%), die Vollzeit bzw. Teilzeit arbeiten und sich in Ausbildung bzw. nicht in Ausbildung befinden (2006-20II) . . . . . . . . . . . . . . . . . . 429

(1)


Indikator D1 Wie viel Zeit verbringen Schüler im Klassenzimmer? . . . . . . . . 433

Tabelle Di.I

Pflichtunterrichtszeit und vorgesehene Unterrichtszeit in öffentlichen

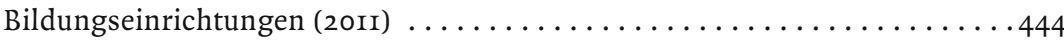

Tabelle Dr.2a

Unterrichtszeit pro Fach im Primarbereich (20II) . . . . . . . . . . . . 445

Tabelle Dr.2b

Unterrichtszeit pro Fach im Sekundarbereich I (20II) . . . . . . . . . 446

Indikator D2

Wie ist die Schüler-Lehrkräfte-Relation und wie groß sind

die Klassen? . . . . . . . . . . . . . . . . . . . . . 447

Tabelle D2.I

Durchschnittliche Klassengröße, nach Art der Bildungseinrichtung

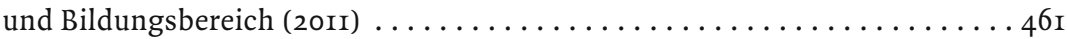

Tabelle D2.2

Lernende-Lehrende-Relation in Bildungseinrichtungen (20II) . . . . . . . 462

Tabelle D2.3

Schüler-Lehrkräfte-Relation, nach Art der Bildungseinrichtung (20II) . . . .463

Indikator D3

Tabelle D3.I

Wie hoch sind die Gehälter der Lehrkräfte? . . . . . . . . . . . . 465

Gesetzliche bzw. vertraglich vereinbarte Gehälter von Lehrkräften zu

unterschiedlichen Zeitpunkten in ihrer beruflichen Laufbahn (20II) . . . . .480

Tabelle D3.2

Vergleich der Gehälter von Lehrkräften (20II) . . . . . . . . . . . 482

Tabelle D3.3

Durchschnittliche tatsächliche Gehälter von Lehrkräften (20II) . . . . . . . . 483

Tabelle $\mathrm{D}_{3} \cdot 4$

Entwicklung der Gehälter von Lehrkräften zwischen 2000 und 20 II . . . . . . 484

Indikator D4

Tabelle D4.I

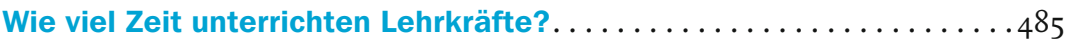

Tabelle D4.2

Aufteilung der Arbeitszeit von Lehrkräften (20II) . . . . . . . . . . . . . 495

Zahl der zu unterrichtenden (Zeit-)Stunden pro Jahr (2000 und

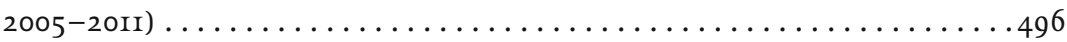

WEB Indikator D5 Wie ist das demografische und das Qualifikationsprofil

der Lehrerschaft? . . . . . . . . . . . . . . . . . . . . 497

DI

D2

D3

D4

Anhang 1

Merkmale der Bildungssysteme

Tabelle XI.ra

Abschlussquoten im Sekundarbereich II: Typisches Abschlussalter

und Art der Abschlussquote (Brutto- bzw. Nettoabschlussquote) (20II) . . . 500

Tabelle XI.Ib

Abschlussquoten im postsekundaren, nicht tertiären Bereich:

Typisches Abschlussalter und Art der Abschlussquote (Brutto- bzw.

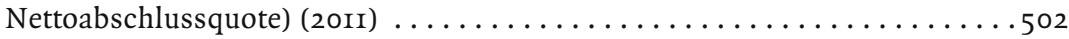

Tabelle XI.Ic

Abschlussquoten im Tertiärbereich: Typisches Abschlussalter und Art der Abschlussquote (Brutto- bzw. Nettoabschlussquote) (20II) . . . . . . . 503

Tabelle XI.Id Studienanfängerquoten: Typisches Eintrittsalter und Art der Studienanfängerquote (Brutto- bzw. Nettoanfängerquote) (20II) . . . . . . . . 505

Tabelle Xı.2a Für die Berechnung der Indikatoren verwendete Haushalts- und Schul-

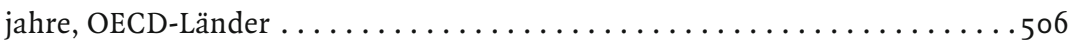

Tabelle XI.2b Für die Berechnung der Finanzindikatoren verwendete Haushalts- und Schuljahre, sonstige G20-Länder . . . . . . . . . . . . . . 507

Anhang 2

Tabelle X2.I

Tabelle X2.2a
Statistische Bezugsdaten

Überblick über das wirtschaftliche Umfeld anhand grundlegender

Kennzahlen (Referenzzeitraum: Kalenderjahr 2010, zu konstanten

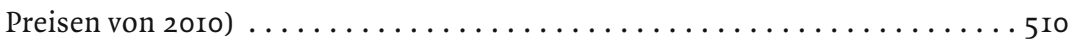

Grundlegende statistische Bezugsdaten (Referenzzeitraum: Kalender-

jahr 20I0, zu konstanten Preisen von 20I0) $\ldots \ldots \ldots \ldots \ldots \ldots \ldots \ldots \ldots \ldots \ldots$ 
Tabelle X2.2b Grundlegende statistische Bezugsdaten (Referenzzeitraum: Kalender-

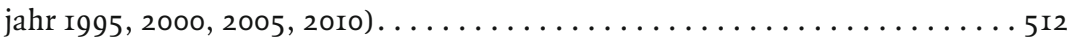

Tabelle X2.3a Gesetzliche bzw. vertraglich vereinbarte Gehälter von Lehrkräften zu unterschiedlichen Zeitpunkten in ihrer beruflichen Laufbahn (20II) . . . . 5 I3

Tabelle X2.3b Entwicklung der Gehälter von Lehrkräften zwischen 2000 und 20II . . . . . 5I5

Tabelle X2.3c Statistische Bezugsdaten zur Berechnung der Gehälter von Lehrkräften

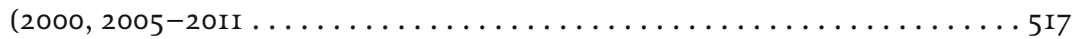

Anhang 3 Quellen, Methoden und technische Hlnweise...........5 519

Mitwirkende an dieser Publikation $\ldots \ldots \ldots \ldots \ldots \ldots \ldots \ldots \ldots \ldots \ldots \ldots \ldots \ldots$

Weiterführende OECD-Publikationen. . . . . . . . . . . . . . . 527 


\section{Editorial}

\section{Lernen in der Krise - Lernend durch die Krise: Jugend, Bildung und Kompetenzen in der globalen Wirtschaftskrise}

Die diesjährige Ausgabe von Bildung auf einen Blick erscheint in einer Zeit, in der die Jugenderwerbslosigkeit Politikern größte Sorgen bereitet. Zwischen 2008 und 20II, d.h. in den Jahren, auf die sich die meisten Daten dieser Ausgabe beziehen, stiegen die Erwerbslosenquoten in den meisten der in dieser Ausgabe erfassten Länder stark an und sind seither auf diesem hohen Niveau geblieben. Gerade junge Menschen sind von Unterbeschäftigung und Erwerbslosigkeit als Folge der globalen Wirtschaftskrise besonders stark betroffen. 20II waren im Durchschnitt aller OECD-Länder I6 Prozent der I5- bis 29-Jährigen weder in Beschäftigung noch in irgendeiner Ausbildung (nach der englischen Abkürzung als NEET bezeichnet: not in employment, education or training), bei den 25- bis 29-Jährigen waren es 20 Prozent. (Von diesen wiederum waren 40 Prozent erwerbslos, mehr als die Hälfte von ihnen länger als 6 Monate, der Rest nahm überhaupt nicht am Arbeitsmarkt teil.) In einigen Ländern sind diese Zahlen noch weit höher, dort ist mehr als ein Drittel der 25- bis 29-Jährigen weder in Beschäftigung noch in Ausbildung. Diese jungen Menschen bezahlen einen sehr hohen Preis für eine Krise, die sie nicht verursacht haben - mit langfristigen Auswirkungen auf ihre Kenntnisse und Fähigkeiten, ihre Arbeitsmoral und ihre Integration in die Gesellschaft. Die demoralisierenden kurzfristigen Auswirkungen auf den Einzelnen, die Familien und die Gesellschaft verlangen dringend nach Antworten auf politischer Ebene, gleichzeitig beeinflussen die unleugbaren längerfristigen Auswirkungen in Form von Kompetenzverlusten, Scarring-Effekten und Demotivation die Aussichten der Länder auf eine nachhaltige wirtschaftliche Erholung.

Die Verteilung der Erwerbslosigkeit in der jüngeren Altersgruppe lässt einige der Faktoren erkennen, die möglicherweise das Risiko der Erwerbslosigkeit erhöhen, woraus sich wiederum Einsichten für politische Maßnahmen gewinnen lassen. Besonders deutlich wird, dass der Bildungsstand sich sehr stark auf die Beschäftigungschancen auswirkt, eine Tatsache, die sich durch die Krise noch weiter verstärkt hat. 20II waren im Durchschnitt aller OECD-Länder 4,8 Prozent der Absolventen des Tertiärbereichs erwerbslos, bei denjenigen mit einer Ausbildung unterhalb des Sekundarbereichs lag diese Zahl dagegen bei I2,6 Prozent. Zwischen 2008 und 20II nahm der Unterschied zwischen der Erwerbslosenquote derjenigen mit einem niedrigen Bildungsstand und derjenigen mit einem hohen Bildungsstand weiter zu: Die Erwerbslosenquote derjeni- 
gen mit einem niedrigen Bildungsstand nahm über alle Altersgruppen hinweg um fast 3,8 Prozentpunkte $z u$, bei denjenigen mit einem hohen Bildungsabschluss lag der Anstieg jedoch nur bei I, 5 Prozentpunkten. Ohne die grundlegenden Kompetenzen, die ein Abschluss im Sekundarbereich II vermittelt, ist man den Risiken eines instabilen Arbeitsmarktes besonders stark ausgesetzt.

In der Krise hat sich auch deutlich gezeigt, dass gute Bildung ein wertvoller Schutz gegen Erwerbslosigkeit sein kann: Die Auswirkungen des Bildungsstandes auf die Erwerbslosigkeit zeigen sich bei jungen Menschen weit stärker als bei älteren Altersgruppen. 20II waren in den OECD-Ländern im Durchschnitt I8, I Prozent der 25- bis 34-Jährigen mit einer Ausbildung unterhalb des Sekundarbereichs erwerbslos gegenüber 8,8 Prozent der 55- bis 64-Jährigen. Bei den 25- bis 34-Jährigen mit einem Abschluss im Tertiärbereich waren im Durchschnitt 6,8 Prozent erwerbslos gegenüber 4,o Prozent der 55- bis 64-Jährigen mit einem entsprechenden Abschluss.

Die Tatsache, dass diese beunruhigenden Entwicklungen keineswegs in allen Ländern zu beobachten sind, deutet darauf hin, dass sie nicht unvermeidbar sind. Die Länder unterscheiden sich sehr stark darin, wie sich die Rezession auf die soziale Lage junger Menschen ausgewirkt hat. Der starke Anstieg der Jugenderwerbslosigkeit, der zwischen 2008 und 201 vor allem unter jungen Menschen mit geringem Bildungsstand in Ländern wie Estland (mit einem Anstieg der Erwerbslosigkeit der 25- bis 34-Jährigen mit einer Ausbildung unterhalb des Sekundarbereichs um 17,6 Prozentpunkte), Griechenland (+ I5, o Prozentpunkte), Irland (+2I,5 Prozentpunkte) und Spanien ( $+\mathrm{I} 6, \mathrm{o}$ Prozentpunkte) zu beobachten war, ist nur allzu bekannt. Weniger bekannt ist jedoch die Tatsache, dass es im gleichen Zeitraum in einigen Ländern zu einem Rückgang der Erwerbslosigkeit bei den gering qualifizierten Jugendlichen kam, so z. B. in Chile (-3,6 Prozentpunkte), Deutschland (-2,I Prozentpunkte), Israel (-o,9 Prozentpunkte), Korea (- I,6 Prozentpunkte), Luxemburg (- I,o Prozentpunkte), Österreich ( $-3,3$ Prozentpunkte) und der Türkei (-I,7 Prozentpunkte). Mehreren anderen Ländern gelang es, den Anstieg wenigstens auf ein mehr oder weniger akzeptables Niveau zu beschränken.

Viele Faktoren beeinflussen die Fähigkeit eines Landes, den Anstieg der Jugenderwerbslosigkeit in Zeiten der Krise zu begrenzen, aber inwieweit institutionelle Rahmenbedingungen den Übergang von der Schule ins Arbeitsleben erleichtern, ist vielleicht einer der wichtigsten Faktoren. Die diesjährige Ausgabe von Bildung auf einen Blick enthält detailliertere Daten zur Ausrichtung der Bildungsgänge (allgemeinbildend versus berufsbildend) im Sekundar- und Tertiärbereich. Ländern mit relativ vielen 25- bis 34-jährigen Absolventen berufsbildender Ausbildungsgänge ist es gelungen, das Erwerbslosigkeitsrisiko junger Menschen mit einem Abschluss im Sekundarbereich II als höchstem Abschluss zu verringern. Allen Ländern mit einem überdurchschnittlich hohen Anteil (32 Prozent) an Absolventen berufsbildender Bildungsgänge, wie Deutschland, Luxemburg, Österreich und Tschechien, ist es gelungen, den Anstieg der Erwerbslosigkeit bei dieser Altersgruppe auf unter 8 Prozentpunkte zu begrenzen. Dagegen stieg in Ländern wie Griechenland, Irland und Spanien, in denen weniger als 25 Prozent der jungen Erwachsenen über einen berufsbildenden Abschluss im Sekundarbereich II verfügen, die Erwerbslosigkeit der 25- bis 34-Jährigen, die lediglich über einen Abschluss im Sekundarbereich verfügen, um mindestens I2 Prozentpunkte an. 
Für junge Menschen, die ihre Ausbildung nicht im Tertiärbereich fortsetzen, ergeben sich durch den Abschluss berufsbildender Bildungsgänge bessere Beschäftigungschancen als durch allgemeinbildende, eher theoretisch ausgerichtete Bildungsgänge im Sekundarbereich II.

Das Berufsbildungssystem spielt daher eine wesentliche Rolle dabei, die Fähigkeiten eines Landes zu stärken, mit sich schnell ändernden Arbeitsmarktbedingungen angemessen umzugehen. Verschiedene OECD-Länder haben bildungspolitische Maßnahmen ergriffen, um berufsbildende Bildungsgänge im Sekundarbereich II und im postsekundaren, nicht tertiären Bereich zu verbessern und auszubauen und so jungen Menschen die Kompetenzen zu vermitteln, die auf dem Arbeitsmarkt verlangt werden. $\mathrm{Zu}$ diesen Programmen gehört oftmals eine umfangreiche berufliche Qualifizierung am Arbeitsplatz, basierend auf breit angelegten Partnerschaften zwischen Schulen und Betrieben. Zwischen 2005 und 201 I stieg die Zahl der Absolventen von berufsbildenden Bildungsgängen des Sekundarbereichs II im Durchschnitt der OECD-Länder um 4,3 Prozentpunkte, in einigen Ländern, vor allem Belgien, Finnland, Irland, Portugal, Österreich und Spanien, betrug diese Steigerung sogar mehr als io Prozentpunkte.

Legt man den Schwerpunkt der Analyse nicht auf den Bildungsabschluss an sich, sondern auf die vermittelten Inhalte, werden die Zusammenhänge zwischen Qualifikationen und Arbeitsmarktergebnissen noch deutlicher. In der diesjährigen Ausgabe von Bildung auf einen Blick werden Daten zu den Fächergruppen der jeweiligen Ausbildung einer genauen Analyse unterzogen. Zwar werden nur die Daten aus einer begrenzten Anzahl von Ländern untersucht, aber diese Daten lassen beispielsweise große Unterschiede bei den Erwerbslosenquoten für Absolventen des Tertiärbereichs in Abhängigkeit von der gewählten Fächergruppe erkennen. Interessanterweise spiegeln diese Unterschiede nicht in vollem Umfang die Segmentierung bei der Arbeitskräftenachfrage und den Löhnen wider, die im Allgemeinen in der Wirtschaft und auf dem Arbeitsmarkt zu finden ist. So übertraf beispielsweise in den Vereinigten Staaten die Erwerbslosenquote der Absolventen der gut bezahlten Fächergruppe Informatik und Informationstechnologie (5,3 Prozent) die der Absolventen der relativ niedrig vergüteten Lehrerausbildungsgänge für den Sekundarbereich (2,4 Prozent), der Fächergruppe mit einer der niedrigsten Erwerbslosenquoten. Der Zusammenhang zwischen der Berufswahl, der Entwicklung von Kenntnissen und Fähigkeiten einer bestimmten Fächergruppe und den tatsächlichen Beschäftigungschancen ist weit vielschichtiger als oftmals angenommen.

Der Bildungsstand beeinflusst nicht nur die Beschäftigungschancen - wie Bildung auf einen Blick aufzeigt -, sondern er wirkt sich auch auf das Erwerbseinkommen aus. Die relativen Einkommen von Erwachsenen mit einem Abschluss im Tertiärbereich belaufen sich im Durchschnitt auf mehr als das I,5-Fache derjenigen mit einem Abschluss im Sekundarbereich II, während diejenigen mit einer Ausbildung unterhalb des Sekundarbereichs II im Durchschnitt 25 Prozent weniger verdienen als diejenigen mit einem Abschluss des Sekundarbereichs II. Durch die Wirtschaftskrise haben sich diese Unterschiede bei den Einkommen noch weiter vergrößert: Der Unterschied zwischen den Erwerbseinkommen gering qualifizierter und hoch qualifizierter Erwerbstätiger lag 2008 im Durchschnitt aller OECD-Länder bei 75 Prozentpunkten, 20II belief er sich auf 90 Prozentpunkte. 
Wer nicht über die grundlegenden Kompetenzen verfügt, die ein Abschluss im Sekundarbereich II vermittelt, kann mit zunehmendem Alter keine deutlichen Einkommenssteigerungen mehr erwarten. Die Einkommensunterschiede zwischen denjenigen mit einem niedrigen und einem hohen Bildungsstand werden tendenziell mit zunehmendem Alter sogar noch größer. Ohne eine Ausbildung im Sekundarbereich verdienen 25- bis 34-Jährige im Durchschnitt 8o Prozent dessen, was Absolventen des Sekundarbereichs verdienen, die 55- bis 64-Jährigen erreichen jedoch nur 72 Prozent des Einkommens der Gleichaltrigen mit einem entsprechend höheren Abschluss. Mit dem Alter nimmt auch der Einkommensvorteil eines Hochschulstudiums zu. Ein 25- bis 34-Jähriger mit einem Abschluss im Tertiärbereich verdient im Durchschnitt 40 Prozent mehr als ein Gleichaltriger mit einem Abschluss im Sekundarbereich, während 55- bis 64-Jährige 73 Prozent mehr verdienen. Ein höherer Bildungsabschluss ermöglicht also nicht nur einen erfolgreichen Einstieg in den Arbeitsmarkt, sondern hat auch langfristige und sich gegenseitig verstärkende Auswirkungen - während des ganzen Lebens. Ein Abschluss im Tertiärbereich zahlt sich langfristig eindeutig aus.

Angesichts des engen Zusammenhangs zwischen Bildung einerseits und Beschäftigungsmöglichkeiten und Einkommen andererseits entwickeln junge Menschen Strategien, um ihre Chancen - lebenslang - durch Investitionen in Bildung zu verbessern. In den letzten Jahren haben sie Bildung im wörtlichen Sinne als „Weg aus der Krise“ genutzt. Da die Opportunitätskosten sanken und es sinnvoll erschien, den Eintritt in einen unsicheren Arbeitsmarkt zu verschieben, entschieden sich viele junge Erwachsene dafür, Erfolg versprechende Kenntnisse und Fähigkeiten zu erwerben, bevor sie den Eintritt in die Arbeitswelt wagen. In den meisten Ländern hat die zunehmende Nachfrage nach Bildungsangeboten über die Schulpflicht hinaus den demografisch bedingten Nachfragerückgang in diesen Altersgruppen mehr als ausgeglichen. 20II waren im Durchschnitt der OECD-Länder 85 Prozent der I5- bis I9-Jährigen im Bildungssystem, und der Anteil der 20- bis 29-Jährigen, die sich in (Aus-)Bildung befanden, stieg von 22 Prozent im Jahr 2000 auf 29 Prozent im Jahr 20Ir. Dementsprechend stieg der Anteil der Erwachsenen mit einem Abschluss im Tertiärbereich zwischen 2000 und $201 \mathrm{I}$ um mehr als Io Prozentpunkte, während der Anteil der Erwachsenen ohne einen Abschluss im Sekundarbereich in gleichem Maße zurückging. 20II verfügten 39 Prozent der 25bis 34-Jährigen in den OECD-Ländern über einen Abschluss im Tertiärbereich.

Die seit Beginn der Rezession zu beobachtenden Veränderungen der Beteiligungs- und Beschäftigungsquoten sowie der Investitionen in Bildung lassen erkennen, wie sich Bildung und erworbene Kompetenzen darauf auswirkten, wie es dem Einzelnen, den Familien und der Gesellschaft insgesamt während der schwierigsten wirtschaftlichen und sozialen Krise der jüngsten Vergangenheit erging. Für hochgebildete junge Menschen mit einem Abschluss in einem stark nachgefragten Fachgebiet war es einfach, einen Arbeitsplatz zu finden, für sie galt die Regel „hoher Bildungsstand = hohes Einkommen“, und sie konnten sich auf ein Leben in Wohlstand einstellen. Für andere brachte ein Abschluss im Tertiärbereich jedoch nicht die erwarteten Ergebnisse, sei es aufgrund eines zu stark schrumpfenden Arbeitsmarktes - wobei oft ältere Arbeitnehmer auf Kosten der jüngeren geschützt wurden - oder weil der Arbeitsmarkt mit Absolventen der gewählten Fachrichtung bereits ausreichend versorgt war oder die betreffenden Fachrichtungen nicht der Nachfrage auf dem Arbeitsmarkt entsprachen. Überqualifizierung und Unterbeschäftigung führten in diesen Fällen zu Enttäuschun- 
gen. Junge Erwachsene mit einem Abschluss im Sekundarbereich II konnten die Beschäftigungskrise dann gut überstehen, wenn sie von Bildungsmaßnahmen profitieren konnten, die sie gut auf die Arbeitswelt vorbereitet hatten. Diejenigen mit einer Ausbildung unterhalb des Sekundarbereichs II, denen es an den in einer komplexen Wirtschaft erforderlichen grundlegenden Kompetenzen mangelte, fanden sich oft auf der falschen Seite einer bildungsbasierten Polarisierung wieder, für sie galt die Regel „niedriger Bildungsstand = niedriges Einkommen“, oder sie gehörten zu den Langzeiterwerbslosen mit geringen Zukunftschancen.

Eine hohe Jugenderwerbslosigkeit ist jedoch selbst während einer Wirtschaftskrise nicht unausweichlich, sie ergibt sich vielmehr aus der Interaktion von wirtschaftlichem Umfeld und bestimmten politischen Entscheidungen. Und wie die Daten aus den ersten Krisenjahren zeigen, hat die Höhe der öffentlichen Bildungsausgaben wenig damit zu tun, ob es einem Land gelingt, die Jugenderwerbslosigkeit erfolgreich einzudämmen oder nicht: Mit wenigen Ausnahmen haben nahezu alle Länder das Niveau der Bildungsausgaben während der Krise mehr oder weniger unverändert beibehalten. Wichtiger sind die Entscheidungen der Länder darüber, wohin die Gelder fließen und welche Maßnahmen entwickelt und umgesetzt werden, um Bildungsangebote effizienter und relevanter zu gestalten. Daten und bildungspolitische Erfahrungen der einzelnen Länder zeigen, welche bildungspolitischen Maßnahmen dazu geeignet sind, die Beschäftigungschancen junger Menschen zu fördern: Sie zielen darauf ab, sicherzustellen, dass alle junge Menschen sowohl grundlegende Kompetenzen als auch „Soft Skills“ wie Teamarbeit, Kommunikations- und Verhandlungsfähigkeiten erwerben und damit jene Anpassungsfähigkeit und Belastbarkeit erlangen, die für den Erfolg in sich schnell ändernden Arbeitsmärkten notwendig sind, die Zahl der Schulabbrecher zu verringern und dafür Sorge zu tragen, dass so viele junge Menschen wie möglich wenigstens einen Abschluss im Sekundarbereich II erwerben (wenn nicht in der Erstschulbildung, dann über den zweiten Bildungsweg), den Sekundarbereich an die Kompetenzanforderungen des Arbeitsmarktes anzupassen, berufsbildende Bildungsgänge zu entwickeln und Ausbildung und Arbeitswelt durch die Integration betrieblicher Ausbildung zu verbinden, flexible Übergangsmöglichkeiten in den Tertiärbereich zu schaffen und eine gute Ausbildungs- und Berufsberatung zu bieten, die es jungen Menschen ermöglicht, fundierte Entscheidungen zu treffen. Das sind genau die bildungspolitischen Maßnahmen, die der im Mai 2013 verabschiedete Youth Action Plan der OECD vorsieht, um die Zukunftsaussichten für junge Menschen und die Gesellschaft insgesamt zu verbessern.

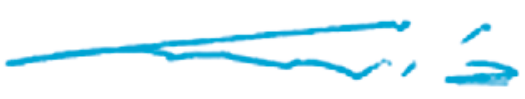

ANGEL GURRÍA

OECD-Generalsekretär 


\section{Die Indikatoren und ihr konzeptioneller Rahmen}

\section{Das zugrunde liegende Referenzsystem}

Bildung auf einen Blick 2013 - OECD-Indikatoren bietet ein umfangreiches aktuelles Spektrum an vergleichbaren Indikatoren, die auf dem Konsens der Fachwelt beruhen, wie der gegenwärtige Stand der Bildung im internationalen Vergleich zu bewerten ist. Die Indikatoren enthalten Informationen zu den in Bildung investierten personellen und finanziellen Ressourcen, zur Funktionsweise und Weiterentwicklung von Bildungssystemen sowie zu den Erträgen der Investitionen in die Bildung. Die Indikatoren sind thematisch gegliedert und jeweils von Informationen zum politischen Kontext und zur Interpretation der Daten begleitet. Die OECD-Indikatoren sind in einen konzeptionellen Rahmen eingestellt,

der zwischen den Akteuren im Bildungssystem unterscheidet - einzelne Schüler und Lehrkräfte, Arten des Unterrichts und Lernumgebungen, Anbieter von Bildungsleistungen sowie das Bildungssystem als Ganzes;

der die Indikatoren in Gruppen zusammenfasst, je nachdem, womit sie sich beschäftigen: die Lernergebnisse von Einzelnen oder ganzen Ländern, die politischen Ansatzpunkte oder Zusammenhänge, die diese Ergebnisse beeinflussen, oder die Gegebenheiten und Bedingungen, die bei politischen Entscheidungen zu berücksichtigen sind; und

der die politischen Fragen identifiziert, auf die sich die Indikatoren beziehen und die in drei Kategorien eingeteilt sind - die Qualität der Bildungserfolge und des Bildungsangebots, Fragen der Chancengerechtigkeit beim Bildungsangebot und den Bildungsergebnissen sowie die Angemessenheit und Effektivität des Ressourcenmanagements.

Die folgende Matrix veranschaulicht die ersten beiden Dimensionen: 


\begin{tabular}{|c|c|c|c|}
\hline & $\begin{array}{l}1 . \\
\text { Bildungs- und } \\
\text { Lernergebnisse }\end{array}$ & $\begin{array}{l}2 . \\
\text { Politische Ansatzpunkte } \\
\text { und Zusammenhänge, } \\
\text { die die Bildungserfolge } \\
\text { beeinflussen }\end{array}$ & $\begin{array}{l}3 . \\
\text { Gegebenheiten und } \\
\text { Bedingungen, die von } \\
\text { der Politik zu berück- } \\
\text { sichtigen sind }\end{array}$ \\
\hline $\begin{array}{l}\text { I. } \\
\text { Einzelne Teilnehmer } \\
\text { am Bildungssystem }\end{array}$ & $\begin{array}{l}\text { 1.I } \\
\text { Qualität und Verteilung } \\
\text { der individuellen } \\
\text { Bildungsergebnisse }\end{array}$ & $\begin{array}{l}2 . I \\
\text { Einstellungen, Engage- } \\
\text { ment und Verhalten } \\
\text { des Einzelnen in Bezug } \\
\text { auf Lehren und Lernen }\end{array}$ & $\begin{array}{l}\text { 3.I } \\
\text { Persönlicher Hintergrund } \\
\text { des einzelnen Lernenden } \\
\text { und Lehrenden }\end{array}$ \\
\hline $\begin{array}{l}\text { Il. } \\
\text { Der Unterricht }\end{array}$ & $\begin{array}{l}\text { 1.II } \\
\text { Qualität des Unterrichts }\end{array}$ & $\begin{array}{l}\text { 2.II } \\
\text { Pädagogische Methoden } \\
\text { und Lernstrategien sowie } \\
\text { das Unterrichtsklima }\end{array}$ & $\begin{array}{l}\text { 3.II } \\
\text { Unterrichts- und Lern- } \\
\text { bedingungen der Lernen- } \\
\text { den und Arbeitsbedin- } \\
\text { gungen der Lehrenden }\end{array}$ \\
\hline $\begin{array}{l}\text { III. } \\
\text { Anbieter von Bildungs- } \\
\text { dienstleistungen }\end{array}$ & $\begin{array}{l}\text { 1.III } \\
\text { Abschlussquoten } \\
\text { und Leistungen der } \\
\text { Bildungseinrichtungen }\end{array}$ & $\begin{array}{l}2 . \text { III } \\
\text { Organisation und } \\
\text { Ausstattung der } \\
\text { Bildungseinrichtungen }\end{array}$ & $\begin{array}{l}\text { 3.III } \\
\text { Merkmale der Anbieter } \\
\text { von Bildungsdienst- } \\
\text { leistungen und ihres } \\
\text { Umfelds }\end{array}$ \\
\hline $\begin{array}{l}\text { IV. } \\
\text { Das Bildungssystem } \\
\text { als Ganzes }\end{array}$ & $\begin{array}{l}\text { 1.IV } \\
\text { Gesamtleistung des } \\
\text { Bildungssystems }\end{array}$ & $\begin{array}{l}2 . I V \\
\text { Systemweite institutio- } \\
\text { nelle Struktur, Zuweisung } \\
\text { von Mitteln und politi- } \\
\text { sche Maßnahmenn }\end{array}$ & $\begin{array}{l}\text { 3.IV } \\
\text { Jeweiliger nationaler, bil- } \\
\text { dungspolitischer, sozialer, } \\
\text { wirtschaftlicher und } \\
\text { demografischer Kontext }\end{array}$ \\
\hline
\end{tabular}

Die einzelnen Dimensionen der Matrix lassen sich wie folgt genauer beschreiben:

\section{Die Akteure im Bildungssystem}

Das Bildungsindikatorensystem der OECD (INES) zielt auf eine Beurteilung der Leistungen der nationalen Bildungssysteme als Ganzes und nicht einzelner Bildungseinrichtungen oder anderer subnationaler Einheiten. Dennoch wird zunehmend anerkannt, dass viele wichtige Aspekte der Entwicklung, der Funktionsweise und der Auswirkungen der Bildungssysteme nur beurteilt werden können, wenn man die Lernergebnisse mit einbezieht und versteht, wie diese mit dem „Input“ und den Prozessen auf der Ebene des Einzelnen und der Institutionen zusammenhängen. Um dies zu berücksichtigen, unterscheidet der konzeptionelle Rahmen der Indikatoren zwischen der Makroebene, zwei Mesoebenen und der Mikroebene der Bildungssysteme. Diese beziehen sich auf

das Bildungssystem als Ganzes,

die Bildungseinrichtungen und Anbieter von Bildungsdienstleistungen,

den Unterricht und die Lernumgebung innerhalb der Bildungseinrichtungen und

die einzelnen Teilnehmer am Bildungssystem.

In gewisser Weise entsprechen diese Ebenen den Einheiten bzw. Gruppen, von denen Daten erhoben werden, aber sie sind deshalb so wichtig, weil sich viele Merkmale des Bildungssystems je nach Ebene ganz unterschiedlich auswirken, was bei der Interpretation der Indikatoren zu berücksichtigen ist. So kann zum Beispiel auf Ebene der Schüler einer Klasse das Verhältnis zwischen Schülerleistungen und Klassengröße negativ sein, wenn Schüler in kleinen Klassen von einer besseren Betreuung durch die Lehrkraft profitieren. Auf Klassen- oder Schulebene werden jedoch oft gezielt schwächere oder 
benachteiligte Schüler in kleineren Klassen zusammengefasst, damit den Schülern mehr Aufmerksamkeit zuteilwird. Auf Schulebene ist daher dann das beobachtete Verhältnis zwischen Klassengröße und Schülerleistung oft positiv (was den Schluss nahelegen würde, dass Schüler in größeren Klassen besser abschneiden als Schüler in kleineren Klassen). Auf den übergeordneten Ebenen der Bildungssysteme wird der Zusammenhang zwischen Schülerleistung und Klassengröße oft durch weitere Aspekte beeinflusst, $z$. B. durch die sozioökonomische Zusammensetzung der Schülerschaft oder durch Faktoren im Zusammenhang mit der Lernkultur in den einzelnen Ländern. Daher haben Analysen in der Vergangenheit, die sich allein auf Daten der Makroebene konzentrierten, gelegentlich zu Schlussfolgerungen geführt, die nicht in die richtige Richtung wiesen.

\section{Ergebnisse, politische Ansatzpunkte und Gegebenheiten}

Die zweite Dimension des zugrunde liegenden Referenzsystems fasst die Indikatoren auf jeder der genannten Ebenen weiter zusammen.

Die Indikatoren der beobachteten Bildungsergebnisse sowie die Indikatoren zu den Auswirkungen von Kenntnissen und Fähigkeiten auf den Einzelnen, die Gesellschaft und die Wirtschaft werden unter Bildungs- und Lernergebnisse zusammengefasst.

- Unter Politische Ansatzpunkte und Zusammenhänge, die die Bildungserfolge beeinflussen, werden Informationen zu den politischen Ansatzpunkten und Bedingungen, die die Erfolge und Ergebnisse auf jeder Ebene beeinflussen, zusammengefasst.

Diese politischen Ansatzpunkte und Zusammenhänge werden typischerweise von Gegebenheiten bestimmt - Faktoren, die die Politik bedingen oder einschränken. Sie werden unter Gegebenheiten und Bedingungen, die von der Politik zu berücksichtigen sind, dargestellt. Es ist zu beachten, dass die Gegebenheiten oder Bedingungen jeweils für eine bestimmte Ebene des Bildungssystems gelten und dass Gegebenheiten auf einer der unteren Ebenen des Systems auf einer höheren Ebene durchaus politische Ansatzpunkte sein können. So sind zum Beispiel für die Schüler und Lehrkräfte einer Schule die Qualifikationen der Lehrkräfte eine gegebene Bedingung, dagegen ist die berufliche Weiterbildung der Lehrkräfte auf Ebene des Bildungssystems ein entscheidender bildungspolitischer Ansatzpunkt.

\section{Bildungspolitische Fragen}

Jede der sich so ergebenen Zellen des Referenzsystems kann dann genutzt werden, um eine Reihe von Fragen aus unterschiedlichen bildungspolitischen Perspektiven zu betrachten. Die bildungspolitischen Perspektiven wurden für dieses Referenzsystem in drei Klassen zusammengefasst, die die dritte Dimension des zugrunde liegenden Referenzsystems von INES bilden:

die Qualität der Bildungsergebnisse und des Bildungsangebots,

- Gleichwertigkeit der Bildungsergebnisse und Chancengleichheit beim Bildungsangebot sowie

Angemessenheit, Effektivität und Effizienz des Ressourcenmanagements. 
Zusätzlich zu den oben erwähnten Dimensionen erlaubt die zeitliche Perspektive, als weitere Dimension des konzeptionellen Rahmens auch dynamische Aspekte der Entwicklung der Bildungssysteme abzubilden.

Die in Bildung auf einen Blick 2013 veröffentlichten Indikatoren fügen sich in dieses Referenzsystem ein, beziehen sich aber häufig auf mehr als eine Zelle der Referenzmatrix.

Die meisten Indikatoren in Kapitel A: Bildungsergebnisse und Bildungserträge beziehen sich auf die erste Spalte der Matrix, in der die Bildungs- und Lernergebnisse erfasst sind. Dennoch bieten beispielsweise die Indikatoren in Kapitel A, die den Bildungsstand verschiedener Generationen messen, nicht nur eine Kennzahl für die Ergebnisse der Bildungssysteme (des „Outputs“), sondern darüber hinaus auch den Kontext für die laufende Bildungspolitik und beeinflussen zum Beispiel die Politik im Bereich lebenslanges Lernen.

Kapitel B: Die in Bildung investierten Finanz- und Humanressourcen liefert Kennzahlen, die entweder politische Ansatzpunkte oder Gegebenheiten darstellen, die von der Politik zu berücksichtigen sind, bzw. gelegentlich beides zusammen. Die Ausgaben pro Schüler/Studierenden sind eine entscheidende bildungspolitische Kennzahl, die sich unmittelbar auf den einzelnen Lernenden auswirkt, denn diese Ausgaben beeinflussen die Lernumgebung in den Schulen sowie die Lernbedingungen im Klassenzimmer.

Kapitel C: Bildungszugang, Bildungsbeteiligung und Bildungsverlauf enthält Indikatoren, die eine Mischung aus Kennzahlen zu Erfolgen, politischen Ansatzpunkten und Zusammenhängen sind. Die Internationalisierung der Bildung und die Übergangsquoten sind beispielsweise insofern Erfolgskennzahlen, als sie die Ergebnisse der bildungspolitischen Maßnahmen und Praktiken auf Ebene des Klassenzimmers, der Schule und des Bildungssystems erfassen. Aber sie können auch den Kontext für bildungspolitische Entscheidungen bieten, indem sie die Bereiche erkennen lassen, in denen ein politisches Eingreifen erforderlich ist, um beispielsweise die Chancengleichheit zu verbessern.

Kapitel D: Das Lernumfeld und die Organisation von Schulen enthält Indikatoren zur Unterrichtszeit, der Arbeitszeit der Lehrkräfte und ihren Gehältern, die nicht nur politische Ansatzpunkte darstellen, die beeinflusst werden können, sondern die auch den Kontext für die Unterrichtsqualität, die Formen des Unterrichts und die Lernerfolge der einzelnen Schüler liefern. In diesem Kapitel werden außerdem Daten zu der Alters- und Geschlechterverteilung der Lehrkräfte und zu den von ihnen zu erfüllenden Qualifikationsanforderungen, der staatlichen Ebene, auf der Entscheidungen in Bildungssystemen getroffen werden, sowie zu den Möglichkeiten für den Übergang und die Zulassung zum Sekundar- und Tertiärbereich vorgestellt.

Es sei darauf hingewiesen, dass Bildung auf einen Blick 2013 auch umfangreiche Daten aus G20-Ländern, die nicht der OECD angehören, enthält (weitere Informationen s. Hinweise für den Leser). 


\section{Hinweise für den Leser}

\section{Statistische Erfassung}

Zwar ist der Geltungsbereich der Indikatoren in vielen Ländern nach wie vor durch unvollständige Daten eingeschränkt, prinzipiell wird jedoch jeweils das gesamte nationale Bildungssystem (innerhalb der nationalen Grenzen) erfasst, unabhängig davon, wer Eigentümer oder Geldgeber der betreffenden Bildungseinrichtungen ist und wie das Bildungsangebot vermittelt wird. Abgesehen von einer Ausnahme (s. u.) sind sämtliche Schüler und Studierende sowie alle Altersgruppen berücksichtigt: Kinder (einschließlich derjenigen, die als Kinder mit einem besonderen pädagogischen Bedarf eingestuft sind), Erwachsene, Inländer, Ausländer sowie Schüler und Studierende, die an Fernkursen, in Sonderschulmaßnahmen oder an (Aus-) Bildungsgängen teilnehmen, die von anderen Ministerien als dem Bildungsministerium angeboten werden, sofern das Hauptziel ist, das Wissen des Einzelnen zu erweitern oder zu vertiefen. Kinder, die jünger als 3 Jahre sind, sind jedoch nur erfasst, wenn sie an Bildungsmaßnahmen teilnehmen, für deren Besuch die Kinder in der Regel mindestens 3 Jahre alt sein sollen. Die berufliche und fachliche Ausbildung am Arbeitsplatz bleibt bei den grundlegenden Angaben zu den Ausgaben für die Ausbildung und zur Bildungsbeteiligung unberücksichtigt, mit Ausnahme der kombinierten schulischen und betrieblichen Ausbildungen, die ausdrücklich als Bestandteil des Bildungssystems gelten.

Bildungsaktivitäten, die als „Erwachsenenbildung“ oder „nicht reguläre Bildung “ eingestuft sind, werden berücksichtigt, sofern diese Aktivitäten fachliche Inhalte vermitteln, die denen „regulärer“ Bildungsgänge entsprechen oder ihnen vergleichbar sind, bzw. sofern die zugrunde liegenden Bildungsgänge zu ähnlichen Abschlüssen führen wie die entsprechenden regulären Bildungsgänge.

Kurse für Erwachsene, die in erster Linie aus allge- meinem Interesse, zur persönlichen Entwicklung, als Freizeitvergnügen oder zur Erholung belegt werden, sind hierbei ausgeschlossen (außer in Indikator $\mathrm{C}_{5}$ zur Teilnahme von Erwachsenen an Bildungsmaßnahmen).

\section{Länderabdeckung}

Die Veröffentlichung enthält Bildungsdaten aus den 34 OECD-Ländern, aus 2 Nicht-OECD-Ländern, die am OECD-Programm Indicators of Education Systems (INES) teilnehmen (Brasilien und die Russische Föderation), sowie aus den sonstigen G20-Ländern, die nicht an INES teilnehmen (Argentinien, China, Indien, Indonesien, Saudi-Arabien und Südafrika). Wenn Angaben zu den sechs zuletzt genannten Ländern vorliegen, sind unter den Tabellen und Abbildungen die jeweiligen Quellen angegeben.

Die statistischen Daten für Israel wurden von den zuständigen israelischen Stellen bereitgestellt, die für sie verantwortlich zeichnen. Die Verwendung dieser Daten durch die OECD erfolgt unbeschadet des völkerrechtlichen Status der Golanhöhen, von Ost-Jerusalem und der israelischen Siedlungen im Westjordanland.

\section{Berechnung von internationalen Mittelwerten}

Für viele Indikatoren ist ein OECD-Durchschnitt angegeben, für manche ein OECD-Gesamtwert (OECD insgesamt).

Der Wert für den OECD-Durchschnitt wird als der ungewichtete Mittelwert der Datenwerte aller OECDLänder berechnet, für die entsprechende Daten vorliegen oder geschätzt werden können. Der OECD-Durchschnitt bezieht sich somit auf einen Durchschnitt von Datenwerten auf Ebene der nationalen Bildungssysteme und kann als Antwort 
auf die Frage dienen, wie ein Indikatorwert für ein bestimmtes Land im Vergleich zum Wert eines typischen Landes bzw. eines Landes mit durchschnittlichen Werten abschneidet. Dabei bleibt die absolute Größe des jeweiligen Bildungssystems unberücksichtigt.

OECD insgesamt wird als der gewichtete Mittelwert der Datenwerte aller Länder berechnet, für die entsprechende Daten vorliegen oder geschätzt werden können. Er spiegelt den Wert eines bestimmten Indikators für die OECD-Länder in ihrer Gesamtheit wider. Dieser Wert dient zu Vergleichszwecken, wenn beispielsweise die Ausgabenzahlen für einzelne Länder mit denen aller OECD-Länder insgesamt verglichen werden sollen, für die jeweils relevante Daten vorliegen, wobei diese OECD-Länder als eine Einheit betrachtet werden. Sowohl der OECD-Durchschnitt als auch OECD insgesamt können durch fehlende Daten für einzelne Länder erheblich beeinflusst werden. Aufgrund der relativ kleinen Zahl der untersuchten Länder wird dies jedoch nicht durch statistische Verfahren ausgeglichen. In den Fällen, in denen eine Kategorie für ein Land nicht zutrifft (gekennzeichnet durch ein „a“) oder der Datenwert für die entsprechende Berechnung vernachlässigbar gering ist (gekennzeichnet durch ein „n“), wird zur Berechnung des OECDDurchschnitts der Wert null angesetzt. In den Fällen, in denen ein Datenpunkt das Verhältnis von zwei Werten angibt, die beide auf ein bestimmtes Land nicht zutreffen (gekennzeichnet durch ein „a“), wird das betreffende Land bei der Berechnung des OECD-Durchschnitts nicht berücksichtigt.

In den Tabellen zur Finanzstatistik, die die Jahre I995, 2000 und 2005 berücksichtigen, wurden sowohl der OECD-Durchschnitt als auch der Wert OECD insgesamt für die Länder berechnet, die Daten sowohl für I995, 2000, 2005 und auch 2009 zur Verfügung stellten. Dies erlaubt einen Vergleich des OECD-Durchschnitts und des Wertes OECD insgesamt im Zeitablauf, der nicht durch fehlende Daten bestimmter Länder für eines der Jahre beeinträchtigt wird.

Bei vielen Indikatoren wird auch ein EU21-Durchschnitt angegeben. Er wird als der ungewichtete
Mittelwert der Datenwerte der 2I Länder berechnet, die sowohl Mitglied der Europäischen Union als auch der OECD sind und für die entsprechende Daten vorliegen oder geschätzt werden können (Belgien, Dänemark, Deutschland, Estland, Finnland, Frankreich, Griechenland, Irland, Italien, Luxemburg, die Niederlande, Österreich, Polen, Portugal, Schweden, die Slowakei, Slowenien, Spanien, Tschechien, Ungarn und das Vereinigte Königreich).

Bei einigen Indikatoren ist auch ein $\mathrm{G}_{2} 0$-Durchschnitt angegeben. Der G20-Durchschnitt wird als der ungewichtete Mittelwert der Datenwerte aller G20Länder berechnet, für die entsprechende Daten vorliegen oder geschätzt werden können (Argentinien, Australien, Brasilien, China, Deutschland, Frankreich, Indien, Indonesien, Italien, Japan, Kanada, Korea, Mexiko, die Russische Föderation, SaudiArabien, Südafrika, die Türkei, das Vereinigte Königreich und die Vereinigten Staaten; die Europäische Union ist das 20. Mitglied der G20-Länder, ist aber bei der Berechnung nicht berücksichtigt). Der G20-Durchschnitt wird nicht berechnet, wenn für China oder Indien keine Daten vorliegen.

Bei den Abschlüssen des Tertiärbereichs wird unterschieden zwischen Erstabschluss und erstem Abschluss. Erstabschluss bezieht sich auf den Studierenden. Es handelt sich um den ersten Abschluss, den der Studierende im Tertiärbereich erlangt. Erster Abschluss und zweiter Abschluss beziehen sich auf konsekutive Studiengänge: z. B. I. Abschluss: Bachelor, 2. Abschluss: Master.

\section{Klassifizierung der Bildungsbereiche}

Die Klassifizierung der Bildungsbereiche beruht auf der Internationalen Standardklassifikation des Bildungswesens (ISCED 1997). ISCED 1997 ist ein Instrument zur Erstellung von internationalen Bildungsstatistiken und unterscheidet zwischen sechs Bildungsbereichen. ISCED I997 wurde kürzlich überarbeitet, und die neue Internationale Standardklassifikation des Bildungswesens (ISCED 20II) wurde im November 20II offiziell verabschiedet. Diese neue Klassifikation wird in der Datenerhebung im Mai 2014 umgesetzt werden. 


\section{Klassifizierung der Bildungsbereiche}

$$
\text { In Bildung auf einen Blick verwendeter Begriff }
$$

\section{Elementarbereich}

Die erste Stufe organisierten Unterrichts, die sehr kleine Kinder an eine schulähnliche Umgebung heranführen soll. Das Mindestalter beträgt 3 Jahre.

\section{Primarbereich}

Er soll eine solide Grundbildung im Lesen, Schreiben, Rechnen sowie ein grundlegendes Verständnis einiger anderer Fächer vermitteln. Eintrittsalter: zwischen 5 und 7 Jahren. Dauer: 6 Jahre.

\section{Sekundarbereich I}

Schließt die Vermittlung der Grundbildung ab, normalerweise stärker fachorientiert mit stärker spezialisierten Lehrkräften. Eintritt erfolgt nach 6 Jahren Besuch des Primarbereichs, Dauer 3 Jahre. In einigen Ländern ist am Ende des Sekundarbereichs I die Schulpflicht erfüllt.

\section{Sekundarbereich II}

Der Unterricht ist fächerspezifischer als im Sekundarbereich I, und die Lehrkräfte sind in der Regel höher qualifiziert. Schüler sollten typischerweise bereits 9 Jahre die Schule besucht haben bzw. den Sekundarbereich I abgeschlossen haben. Das Eintrittsalter liegt im Allgemeinen bei 15 oder 16 Jahren.

\section{Postsekundarer, nicht tertiärer Bereich}

Dieser Bildungsbereich befindet sich aus internationaler Sicht im Grenzbereich zwischen dem Sekundarbereich II und dem postsekundaren Bereich, auch wenn die Bildungsgänge im nationalen Zusammenhang eindeutig als zum Sekundarbereich II oder zum postsekundaren Bereich gehörig angesehen werden können. Der Inhalt dieser Bildungsgänge ist möglicherweise nicht wesentlich anspruchsvoller als der des Sekundarbereichs II, aber nicht so anspruchsvoll wie im Tertiärbereich. Die Dauer des Besuchs beträgt normalerweise zwischen 6 Monaten und 2 Jahren (Vollzeitteilnahme). Die Teilnehmer dieser Bildungsgänge sind in der Regel älter als solche des Sekundarbereichs II.

\section{Tertiärbereich}

\section{Tertiärbereich A}

Weitgehend theoretisch orientierte Studiengänge, die hinreichende Qualifikationen für den Zugang zu weiterführenden forschungsorientierten Studiengängen und Berufen mit hohem Qualifikationsniveau, wie Medizin, Zahnmedizin oder Architektur, vermitteln sollen. Dauer mindestens 3 Jahre (Vollzeitteilnahme), obwohl normalerweise 4 oder mehr Jahre. Derartige Studiengänge werden nicht ausschließlich an Hochschulen angeboten; und umgekehrt erfüllen nicht alle Studiengänge, die national als Hochschulstudium anerkannt werden, die Kriterien für die Einstufung im Tertiärbereich A. Der Tertiärbereich A schließt zweite Abschlüsse wie den „Master“ mit ein.

\section{Tertiärbereich B}

Die Studiengänge sind typischerweise kürzer als im Tertiärbereich A und konzentrieren sich auf praktische/technische/berufsbezogene Fähigkeiten für den direkten Eintritt in den Arbeitsmarkt, obwohl in diesen Studiengängen auch einige theoretische Grundlagen vermittelt werden können. Sie dauern im Tertiärbereich mindestens 2 Jahre (Vollzeitteilnahme).

\section{Weiterführende forschungsorientierte Studiengänge}

Sie führen direkt zu einem Abschluss in einem weiterführenden forschungsorientierten Studiengang, z. B. einer Promotion. Die reguläre Vollzeitstudiendauer eines solchen Programms beträgt in den meisten Ländern 3 Jahre (bei einer Vollzeitausbildungsdauer insgesamt von mindestens 7 Jahren im Tertiärbereich), obwohl die Studierenden häufig länger eingeschrieben sind. Die Studiengänge widmen sich fortgeschrittenen Studien und originären Forschungsarbeiten.
ISCED-Klassifikation (einschl. Unterkategorien)

ISCED 0

ISCED 1

\section{ISCED 2}

Unterkategorien: ISCED 2A bereitet Schüler auf eine weiter gehende allgemeinbildende Ausbildung vor, führt zu ISCED 3A; ISCED 2B ist stärker beruflich orientiert, führt zu ISCED 3B; ISCED $2 \mathrm{C}$ bereitet auf den Eintritt in den Arbeitsmarkt vor.

\section{ISCED 3}

Unterkategorien: ISCED 3A bereitet Schüler auf ein Studium auf Universitätsniveau (ISCED 5A) vor; ISCED 3B bereitet Schüler auf den Besuch beruflich orientierter Studiengänge im Tertiärbereich B (ISCED 5B) vor; ISCED 3 C bereitet Schüler auf den Eintritt in den Arbeitsmarkt oder den Besuch des postsekundaren, nicht tertiären Bildungsbereichs (ISCED 4) vor.

\section{ISCED 4}

Unterkategorien: ISCED 4A bereitet Schüler auf den möglichen Besuch des Tertiärbereichs vor, sowohl auf Universitätsniveau als auch mehr beruflich orientierte Studiengänge; ISCED 4B bereitet Schüler normalerweise auf den Eintritt in den Arbeitsmarkt vor.

ISCED 5

Unterkategorien: ISCED 5A und 5B, s.u.

ISCED 5A

ISCED 5B

ISCED 6 
Im (englischen) Glossar unter www.oecd.org/edu/eag. htm werden die ISCED-Stufen ebenfalls ausführlich erläutert, und in Anhang I ist das typische Abschlussalter für die wichtigsten Bildungsgänge nach ISCED-Bereichen aufgeführt.

\section{Symbole für fehlende Daten und \\ Abkürzungen}

In Tabellen und Abbildungen werden folgende Symbole und Abkürzungen verwendet:

a Daten nicht zutreffend, da die Kategorie nicht zutrifft.

c Zu wenige Beobachtungen, um verlässliche Werte anzugeben (z. B. bei PISA: eine Zelle ist mit weniger als 30 Schülern oder weniger als fünf Schulen besetzt). Diese Daten wurden jedoch bei der Berechnung der länderübergreifenden Durchschnittswerte berücksichtigt.

m Keine Daten verfügbar.

$n \quad$ Die Größenordnung ist entweder vernachlässigbar oder null.

$r \quad$ Die Werte sind unterhalb einer gewissen $\mathrm{Zu}$ verlässigkeitsschwelle und sollten mit Vorsicht interpretiert werden (länderspezifische Definitionen s. Anhang 3).

S. F. Standardfehler.

$w$ Die Daten wurden aufWunsch des betreffenden Landes zurückgezogen.

$x \quad$ Die Daten sind in einer anderen Kategorie oder Spalte der Tabelle enthalten - z. B. bedeutet x(2), dass die Daten in Spalte (2) der Tabelle enthalten sind.

Durchschnitt ist nicht mit anderen Bildungsbereichen vergleichbar.

\section{Weitere Quellen}

Im Internet finden sich unter www.oecd.org/eduleag. htm umfangreiche Informationen zu den bei den Indikatoren verwendeten Berechnungsmethoden, der Interpretation der Indikatoren im jeweiligen nationalen Kontext und den benutzten Datenquellen. Die Website bietet auch Zugang zu den Daten, die den Indikatoren zugrunde liegen, sowie zu einem umfangreichen (englischen) Glossar der Fachbegriffe, die in dieser Publikation verwendet werden.
Alle Änderungen, die nach Drucklegung dieser Veröffentlichung erfolgten, sind unter www.oecd.org/ eduleag.htm aufgeführt.

Bildung aufeinen Blick nutzt den StatLink-Service der OECD. Unter jeder Abbildung und jeder Tabelle von Bildung aufeinen Blick 2013 findet sich eine URL, die zu einer Excel-Arbeitsmappe mit den entsprechenden zugrunde liegenden Daten führt. Diese URL sind dauerhaft eingerichtet und werden langfristig bestehen bleiben. Außerdem können Benutzer der E-Book-Ausgabe von Bildung auf einen Blick direkt auf diese Links klicken. Die entsprechende Arbeitsmappe öffnet sich dann in einem separaten Fenster.

\section{Ländercodes}

Diese Codes werden in einigen Abbildungen verwendet. Im Text der Indikatoren werden die Ländernamen bzw. Bezeichnungen der territorialen Einheiten verwendet. Es ist zu beachten, dass im Text die flämische Gemeinschaft von Belgien als „Belgien (fläm.) “ bezeichnet wird und die französische als „Belgien (frz.)“.

$\begin{array}{llll}\text { ARG } & \text { Argentinien } & \text { ISL } & \text { Island } \\ \text { AUS } & \text { Australien } & \text { ISR } & \text { Israel } \\ \text { AUT } & \text { Österreich } & \text { ITA } & \text { Italien } \\ \text { BEL } & \text { Belgien } & \text { JPN } & \text { Japan } \\ \text { BFL } & \text { Belgien (fläm.) } & \text { KOR } & \text { Korea } \\ \text { BFR } & \text { Belgien (frz.) } & \text { LUX } & \text { Luxemburg } \\ \text { BRA } & \text { Brasilien } & \text { NZL } & \text { Neuseeland } \\ \text { CAN } & \text { Kanada } & \text { MEX } & \text { Mexiko } \\ \text { CHE } & \text { Schweiz } & \text { NLD } & \text { Niederlande } \\ \text { CHL Chile } & \text { NOR Norwegen } \\ \text { CHN China } & \text { POL } \text { Polen } \\ \text { CZE Tschechien } & \text { PRT } & \text { Portugal } \\ \text { DEU Deutschland } & \text { RUS } & \text { Russische } \\ \text { DNK Dänemark } & & \text { Föderation } \\ \text { ENG England } & \text { SAU } & \text { Saudi-Arabien } \\ \text { ESP } & \text { Spanien } & \text { SCO } & \text { Schottland } \\ \text { EST } & \text { Estland } & \text { SVK } & \text { Slowakei } \\ \text { FIN } & \text { Finnland } & \text { SVN } & \text { Slowenien } \\ \text { FRA } & \text { Frankreich } & \text { SWE } & \text { Schweden } \\ \text { GRC Griechenland } & \text { TUR Türkei } \\ \text { HUN Ungarn } & \text { UKM Vereinigtes } \\ \text { IDN Indonesien } & & \text { Königreich } \\ \text { IND Indien } & \text { USA Vereinigte Staaten } \\ \text { IRL Irland } & \text { ZAF } & \text { Südafrika }\end{array}$




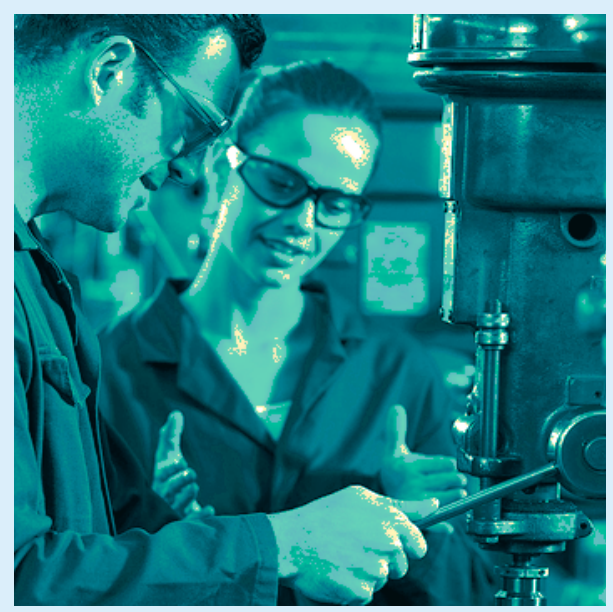

\section{Bildungsergebnisse und Bildungserträge}

Indikator AI

Über welche Bildungsabschlüsse verfügen

Erwachsene?

StatLink: http:||dx.doi.org/10.1787/888932847982

Indikator $\mathrm{A} 2$

Wie viele Schüler werden den Sekundarbereich II erfolgreich abschließen?

StatLink: http:/|dx.doi.org/10.1787/888932848191

Indikator $\mathrm{A} 3$

Wie viele Studierende werden ein Studium im Tertiärbereich abschließen?

StatLink: http:||dx.doi.org/10.1787/888932848343

Indikator $\mathrm{A}_{4}$

Wie hoch sind die Erfolgsquoten im

Tertiärbereich?

StatLink: http://dx.doi.org/10.1787/888932848476
Indikator $\mathrm{A}_{5}$

Wie beeinflusst der Bildungsstand die Erwerbsbeteiligung?

StatLink: http://dx.doi.org/10.1787/888932848533

Indikator $\mathrm{A} 6$

Welche Einkommenszuschläge lassen sich durch

Bildung erzielen?

StatLink: http://dx.doi.org/10.1787/888932848856

Indikator A7

Welche Anreize bestehen für Investitionen in Bildung?

StatLink: http://dx.doi.org/10.1787/888932849084

Indikator A8

Was sind die gesamtgesellschaftlichen Auswirkungen von Bildung?

StatLink: http://dx.doi.org/10.1787/888932849255 



\section{Über welche Bildungsabschlüsse verfügen Erwachsene?}

Der Anteil der Erwachsenen in den OECD-Ländern mit einem Abschluss im Tertiärbereich ist seit 2000 um fast ro Prozentpunkte gestiegen.

In den meisten OECD-Ländern ist der Anteil der Absolventen eines Studiengangs im Tertiärbereich unter den 25- bis 34-Jährigen am höchsten (im Durchschnitt 7 Prozentpunkte höher als in jeder anderen Altersgruppe).

Die geschlechtsspezifischen Unterschiede im Bildungsstand verringern sich nicht nur, in einigen Fällen kehren sie sich sogar um.

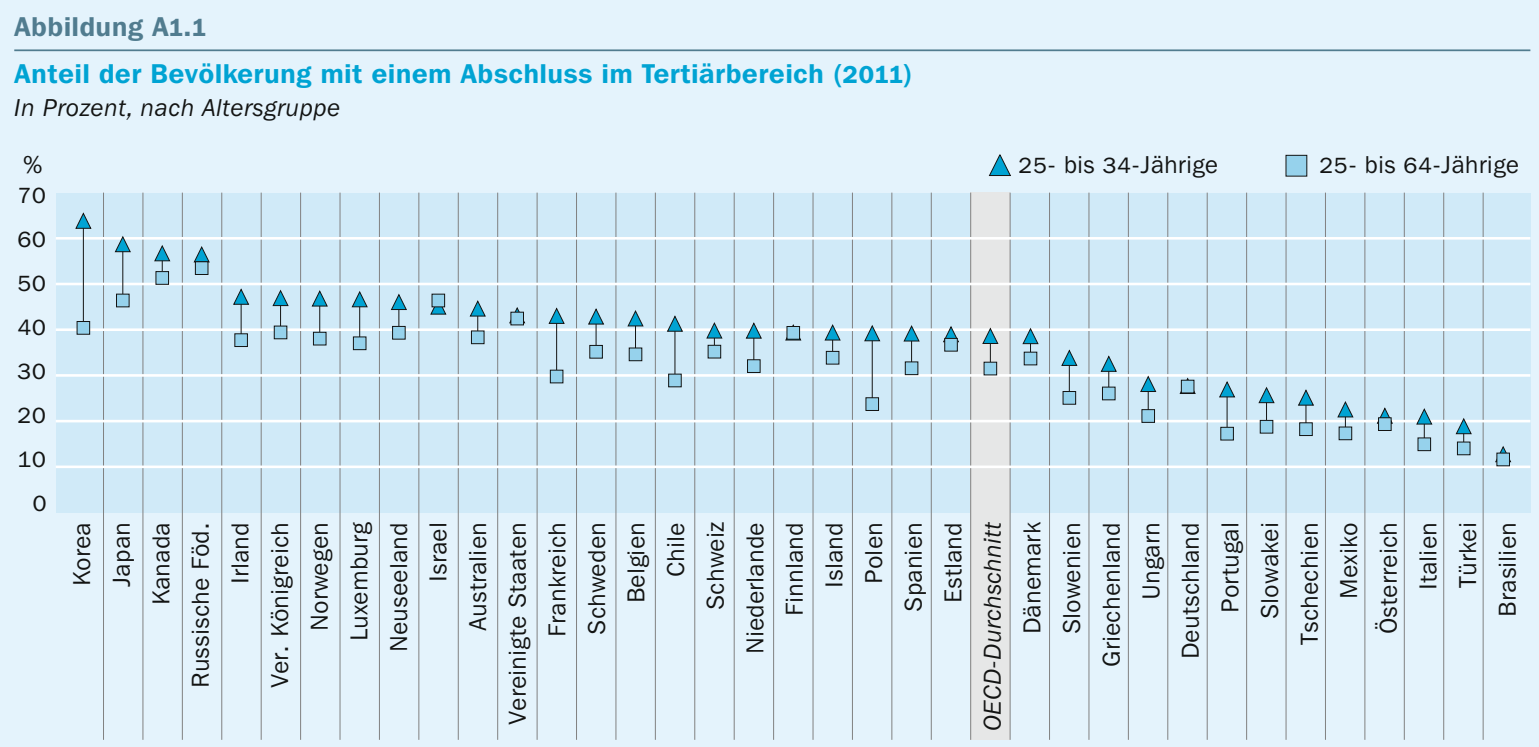

Anordnung der Länder in absteigender Reihenfolge des Anteils 25- bis 34-jähriger (in \%) mit einem Abschluss im Tertiärbereich.

Quelle: OECD. Tabelle A1.3a. Hinweise s. Anhang 3 unter www.oecd.org/edu/eag.htm. StatLink: http://dx.doi.org/10.1787/888932846215

\section{Kontext}

Der Bildungsstand wird häufig als indirekte Kennzahl für das „Humankapital“ und das Niveau der Kompetenzen des Einzelnen verwendet, das heißt für die in der Bevölkerung und Erwerbsbevölkerung zur Verfügung stehenden Kenntnisse und Fähigkeiten. Mit „Bildungsstand einer Bevölkerung“ wird der prozentuale Anteil einer Bevölkerung mit einem bestimmten Bildungsabschluss bezeichnet. Es besteht ein enger Zusammenhang zwischen einem höheren Bildungsstand und einer höheren Beschäftigungsquote, ein höherer Bildungsstand gilt als Tor zu besseren Beschäftigungsmöglichkeiten und Einkommenszuschlägen. Für den Einzelnen bestehen starke Anreize zur weiteren Bildungsteilnahme, und die Regierungen sind daran interessiert, durch Aus- und Weiterbildung die Fähigkeiten und Kenntnisse der Bevölkerung zu erweitern, insbesondere da sich die nationalen Volkswirtschaften immer mehr von einer auf Massenproduktion basierenden Wirtschaft zur wissensbasierten Wirtschaft entwickeln. 
In den vergangenen Jahrzehnten war in fast allen OECD-Ländern eine deutliche Steigerung des Bildungsstands der Bevölkerung zu beobachten. Die Zahl der Abschlüsse im Tertiärbereich hat deutlich zugenommen, und ein Abschluss im Sekundarbereich II (ISCED-Stufe 3) ist inzwischen in den meisten OECD-Ländern der am häufigsten von jungen Menschen erreichte Bildungsabschluss. In einigen Ländern hat die Politik inzwischen begonnen, die Entwicklung bestimmter Kompetenzen durch berufsbildende Bildungsgänge besser an die Bedürfnisse des Arbeitsmarktes anzupassen. Diese Ansätze scheinen in mehreren OECD-Ländern, in denen ein Abschluss in einem berufsbildenden Bildungsgang des Sekundarbereichs II der am häufigsten erzielte Abschluss bei Erwachsenen ist, einen deutlichen Einfluss auf den Bildungsstand gehabt zu haben.

Indikatoren dieser Ausgabe belegen, dass beim Bildungsstand, den Beschäftigungsquoten und den Einkommen weiterhin geschlechtsspezifische Unterschiede bestehen. In den OECD-Ländern ist der Anteil junger Frauen mit einem Abschluss im Sekundarbereich II und im Tertiärbereich höher als der junger Männer. Dennoch ist insgesamt der Anteil erwachsener Männer mit einem Abschluss im Sekundarbereich II höher als der erwachsener Frauen. Obwohl inzwischen ein größerer Anteil der Frauen als der Männer über einen Abschluss im Tertiärbereich verfügen, sind ihre Beschäftigungsquoten und Gehälter niedriger als die männlicher Absolventen des Tertiärbereichs (s. Indikatoren A5 und A6).

Die Beziehungen zwischen Bildung und der Nachfrage nach Kompetenzen werden in den Arbeitsmarktindikatoren zu Beschäftigung und Erwerbslosigkeit (s. Indikator A5), Einkommen (s. Indikator A6), Anreizen zur Investition in Bildung (s. Indikator A7) und dem Übergang von der Schule ins Erwerbsleben (s. Indikator $\mathrm{C}_{5}$ ) weiter gehend behandelt.

\section{Weitere wichtige Ergebnisse}

Der Anteil Erwachsener ohne einen Abschluss im Sekundarbereich II hat sich in den vergangenen ro Jahren um etwa ro Prozentpunkte verringert.

Obwohl die Abschlussquoten für den Tertiärbereich in den letzten Jahren gestiegen sind, erwerben weniger als 35 Prozent sowohl der Frauen als auch der Männer einen Abschluss im Tertiärbereich.

Bei den 30- bis 34-Jährigen verfügen mehr als 40 Prozent der Frauen über einen Abschluss im Tertiärbereich und übertreffen damit den Anteil der Männer mit einem entsprechenden Abschluss um etwa 8 Prozentpunkte.

\section{Entwicklungstendenzen}

Sowohl in den OECD-Ländern als auch in den G20-Ländern, die nicht der OECD angehören, sind die Abschlussquoten für den Tertiärbereich seit 2000 gestiegen, die Abschlussquoten im Sekundarbereich II und postsekundaren, nicht tertiären Bereich stabil geblieben und der Prozentsatz der Bevölkerung mit einer Ausbildung unterhalb des Sekundarbereichs II in den meisten OECD-Ländern zurückgegangen. Der Anteil der Erwachsenen ohne einen Abschluss im Sekundarbereich II sank zwischen 2000 
und 20II um fast ro Prozentpunkte, während der Anteil derjenigen mit einem Abschluss im Tertiärbereich ungefähr in gleichem Ausmaß gestiegen ist. Die Abschlussquoten unterscheiden sich jedoch je nach Altersgruppe sehr. Der Unterschied bei dem Anteil der Absolventen des Tertiärbereichs zwischen den 25- bis 34-Jährigen und den 55- bis 64-Jährigen reicht von mehr als 50 Prozentpunkten in Korea bis zu einer Umkehrung dieses Verhältnisses (d. h. weniger junge Erwachsene mit einem Abschluss im Tertiärbereich als ältere) in Israel.

\section{Hinweis}

In dieser Publikation wird in verschiedenen Indikatoren der Bildungsstand von Einzelnen, Gruppen und Ländern aufgezeigt. In Indikator AI ist der Bildungsstand der Bevölkerung, d.h. der prozentuale Anteil einer Bevölkerung, der einen bestimmten Bildungsbereich erfolgreich abgeschlossen hat, Gegenstand der Untersuchung. Die Abschlussquoten in Indikator $\mathrm{A}_{2}$ und $\mathrm{A} 3$ geben den voraussichtlichen prozentualen Anteil jüngerer Erwachsener an, die wahrscheinlich im Laufe ihres Lebens einen bestimmten Bildungsabschluss erwerben werden. Die Erfolgsquoten im Tertiärbereich in Indikator $\mathrm{A}_{4}$ beziehen sich auf den Anteil der Studierenden, die ein Studium aufnehmen und es innerhalb eines bestimmten Zeitraums erfolgreich abschließen.

\section{Analyse und Interpretationen}

\section{In den OECD-Ländern erreichte Bildungsabschlüsse}

Anteil der Bevölkerung mit einem Abschluss im Sekundarbereich II und Bedeutung der beruflichen Ausbildung

In den OCED-Ländern ist ein Abschluss im Sekundarbereich II (einschließlich postsekundaren, nicht tertiären Bereichs, jedoch ohne Kurzprogramme im Sekundarbereich II, d.h. ein Abschluss auf den ISCED-Stufen $3 \mathrm{~A}, 3_{3} \mathrm{~B},{ }_{3} \mathrm{C}$ lang und 4; weitere Informationen zur Definition der ISCED-Stufen finden sich in Hinweise für den Leser) eindeutig der von Erwachsenen (25- bis 64-Jährige) am häufigsten erreichte Bildungsstand. In den meisten OECD-Ländern verfügt mehr als ein Drittel der Bevölkerung über einen Abschluss im Sekundarbereich II als höchsten Bildungsabschluss, und in Deutschland, Estland, Japan, Österreich, Polen, Schweden, der Slowakei, Slowenien, Tschechien und Ungarn ist es sogar mehr als die Hälfte der Bevölkerung (Tab. Ar.4a).

Nur in Mexiko, Portugal und der Türkei ist dies für weniger als 20 Prozent der Bevölkerung der höchste erzielte Bildungsabschluss, und diese Länder sind, gemeinsam mit Italien und Spanien, die einzigen Länder, in denen der Anteil der Bevölkerung mit einer Ausbildung unterhalb des Sekundarbereichs II höher ist als der Anteil der Erwachsenen mit einem Abschluss im Sekundarbereich II oder Tertiärbereich (Tab. Ar.4a).

Abbildung Ar.2 zeigt, dass in vielen OECD-Ländern zwischen den Abschlussquoten von berufsbildenden und allgemeinbildenden Bildungsgängen im Sekundarbereich II erhebliche Unterschiede bestehen. In Deutschland, Österreich, Polen, der Slowakei, Slowenien und Tschechien verfügt mindestens die Hälfte der Bevölkerung über einen berufsbildenden Abschluss im Sekundarbereich II bzw. postsekundaren, nicht tertiä- 
Anteil der Bevölkerung (in \%), deren höchster Bildungsabschluss ein Abschluss im Sekundarbereich II bzW. postsekundaren, nicht tertiären Bereich (ISCED 3/4) ist (2011) ${ }^{1}$ Anteil der 25- bis 64-Jährigen (in \%) mit einem Abschluss der ISCED-Stufen 3 oder 4 als höchsten Bildungsabschluss und Ausrichtung des Bildungsgangs

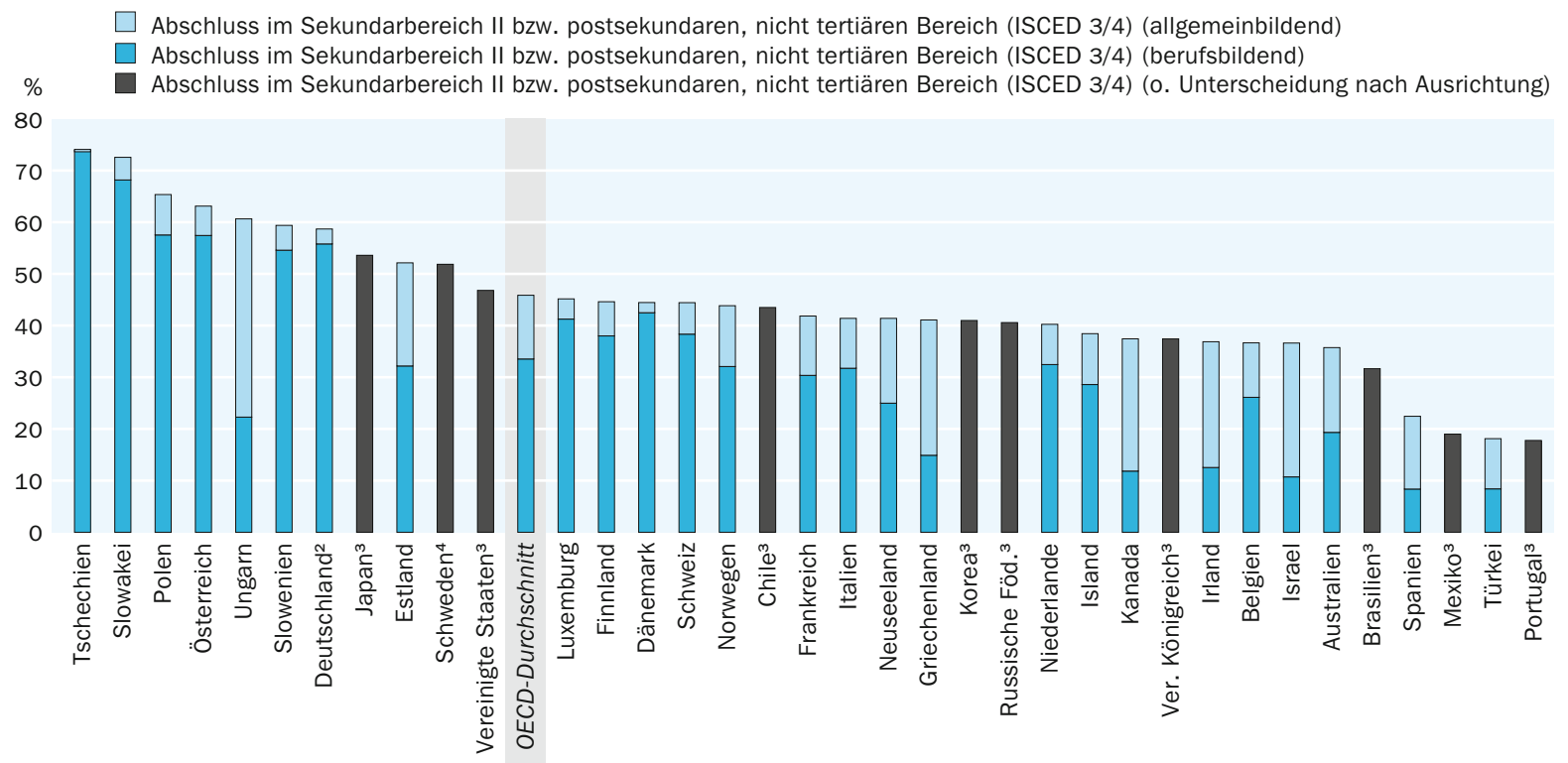

1. Ohne ISCED 3C kurze Bildungsgänge. 2. In Deutschland entspricht ein Abschluss auf ISCED-Stufe $4 A$ einem Abschluss sowohl eines allgemeinbildenden als auch eines berufsbildenden Bildungsgangs. Absolventen mit einem derartigen Abschluss wurden in dieser Abbildung den berufsbildenden Bildungsgängen zugeordnet. 3. Länder, für die keine Daten zur Ausrichtung des Bildungsgangs vorliegen. 4. Die Daten für Schweden enthalten rund 10 Prozent 25- bis 64-Jähriger mit einem Abschluss in einem Bildungsgang auf ISCED-Stufe 3 oder 4, der nicht nach seiner Ausrichtung zugeordnet werden kann.

Anordnung der Länder in absteigender Reihenfolge des Anteils 25- bis 64-Jähriger mit einem Abschluss im Sekundarbereich II bzw. postsekundaren, nicht tertiären Bereich (ISCED 3/4) unabhängig von der Ausrichtung des Bildungsgangs.

Quelle: OECD. Tabelle A1.5a. Hinweise s. Anhang 3 unter www.oecd.org/edu/eag.htm. StatLink: http://dx.doi.org/10.1787/888932846234

ren Bereich als höchsten Bildungsabschluss, allerdings besteht in diesen Ländern die Tendenz, die Ausbildung nach dem Erwerb einer Qualifikation im Sekundarbereich II zu beenden (Tab. Ar.5a).

Berufsbildende Ausbildungsgänge im Sekundarbereich II bieten die Möglichkeit, die für spezialisierte Berufe relevanten Kompetenzen, Kenntnisse und praktischen Erfahrungen zu erwerben, und bereiten junge Menschen auf den Eintritt in den Arbeitsmarkt vor (s. Kasten Ar.I mit weiteren Einzelheiten zu den Berufsbildungssystemen in Deutschland, Luxemburg, Österreich und der Schweiz). Es liegen jedoch nur wenige verlässliche Daten zu diesen Systemen vor, und internationale Vergleiche sind schwierig, insbesondere in Bezug auf den Tertiärbereich. Es bestehen nicht nur große Unterschiede zwischen den berufsbildenden Systemen der einzelnen Länder, sondern selbst wenn die berufsbildenden Ausbildungsgänge, wie in einigen Ländern der Fall, ein wichtiger Teil des Bildungssystems sind, ist doch ihr Prestige in der Regel deutlich geringer als das einer akademisch ausgerichteten Ausbildung (OECD, 2010 und 2013) (s. Tab. Ar.5a und Tab. Ar.5b im Internet).

\section{Anteil der Bevölkerung mit einem Abschluss im Tertiärbereich}

Im Verlauf der vergangenen Io Jahre ist der Anteil der Bevölkerung mit einem Abschluss im Tertiärbereich (einschließlich weiterführende forschungsorientierte Studiengänge, 


\section{Öffentlich-private Partnerschaften in berufsbildenden Ausbildungsgängen}

In einigen Ländern wie Deutschland, Luxemburg, Österreich und der Schweiz haben öffentlich-private Partnerschaften in der beruflichen Ausbildung eine lange Tradition und spielen bei der Vorbereitung der Schüler/Auszubildenden auf den Arbeitsmarkt eine wichtige Rolle. Ihre Bedeutung zeigt sich am hohen Anteil der Bevölkerung mit einem Abschluss im Sekundarbereich II, der Bildungsbeteiligung und den Erfolgsquoten in diesen Ländern (Tab. Ar.ra, Ar.5a und Indikatoren A2 und Cr).

Diese auch als „duale“ oder „kooperative“ Systeme der beruflichen Ausbildung bezeichneten Partnerschaften zeichnen sich durch folgende Merkmale aus:

- die Verbindung von betrieblicher und schulischer Ausbildung, um die Auszubildenden auf einen erfolgreichen Übergang in eine Vollzeitbeschäftigung vorzubereiten,

das hohe Maß an Engagement aufseiten der Arbeitgeber und anderer Sozialpartner,

die Möglichkeit für den Staat, die Ausbildungskosten mit dem privaten Sektor zu teilen,

- die Möglichkeit für Unternehmen, junge, einsatzfähige Arbeitskräfte zu erhalten und die Kosten für Stellenanzeigen, Einstellungsverfahren und Einarbeitung zu reduzieren, und

die Möglichkeit für Auszubildende, von hoch motivierenden Verdienst- und Lernsituationen zu profitieren, Verantwortung zu übernehmen und sich persönlich und beruflich zu entwickeln.

Zu den Stärken der dualen berufsbildenden Ausbildungsgänge gehört, dass mehrere Akteure, darunter Fachleute aus dem praktischen Bereich und von berufsbildenden Schulen, Arbeitgeber und Gewerkschaften, an der Entwicklung von Vorgaben für die berufliche Ausbildung und Lehrplänen beteiligt sind. Während der private Sektor in der Regel die Verantwortung für die praktische Ausbildung übernimmt, vermittelt die berufsbildende Schule das zur Ausübung eines Berufs erforderliche theoretische Wissen. Derartige Partnerschaften stellen sicher, dass sowohl die Bedürfnisse der Unternehmen als auch die der Beschäftigten erfüllt werden. Die verbindlichen Anforderungen der Ausbildungsvorgaben und der Lehrpläne garantieren einen nationalen Standard und gestatten den Unternehmen gleichzeitig, flexibel einen Ausbildungsplan mit den Auszubildenden zu vereinbaren. Es ist vor allem diesem Konzept zu verdanken, dass in diesen Ländern der Übergang von der Ausbildung in das erste Beschäftigungsverhältnis bemerkenswert reibungslos verläuft (Tab. $\mathrm{C}_{5} .2 \mathrm{a}$, Tab. $\mathrm{C}_{5} .2 \mathrm{~b}, \mathrm{C}_{5} .2 \mathrm{c}$ und $\mathrm{C}_{5} .2 \mathrm{~d}$ im Internet) und die Jugenderwerbslosenquote in allen diesen Ländern unter dem OECD-Durchschnitt liegt.

Dennoch sind Arbeitsmarktinitiativen und systematische Maßnahmen erforderlich, um die Auswirkungen von Konjunkturabschwächungen auszugleichen und spezifische Untergruppen, wie Migranten und Schüler mit einem besonderen pädagogischen Bedarf, zu unterstützen. In Österreich beispielsweise können Absolventen der Pflichtschulausbildung, die keinen Platz in einer Schule des Sekundarbereichs II 
oder in einem unternehmensbasierten Ausbildungsprogramm erhalten haben, einen Ausbildungsberuf in einer vom Arbeitsmarktservice (AMS) Österreich finanzierten überbetrieblichen Ausbildungsstätte erlernen.

Diese Beispiele zeigen, dass der Erwerb eines akademischen Grades nicht die einzige Möglichkeit ist, sich die für die Anforderungen des heutigen Arbeitsmarkts erforderlichen Kompetenzen anzueignen. Weiterbildungen für höhere Positionen bieten eine echte Alternative zu einem Hochschulabschluss und werden vom Einzelnen und von der Gesellschaft allgemein hoch geschätzt. In Deutschland und der Schweiz führen durch berufliche Weiterbildung und berufsbildende Schulen erworbene Qualifikationen zu anerkannten Berufsabschlüssen und Berufsbezeichnungen und bieten Aufstiegschancen ohne einen universitären Abschluss. Die berufliche Weiterbildung basiert auf einer Erstausbildung und führt zu Qualifikationen wie dem „Meister“, die als Äquivalent zu akademischen Abschlüssen gelten. Um die Gleichwertigkeit von allgemeinbildenden und berufsbildenden Bildungsgängen zu betonen, wurden für die Absolventen von berufsbildenden Bildungsgängen neue Zugangsmöglichkeiten zum Tertiärbereich eröffnet.

Trotz der Ähnlichkeiten zwischen den in Deutschland, Luxemburg, Österreich und der Schweiz bestehenden Systemen gibt es international gesehen große Unterschiede zwischen den berufsbildenden Ausbildungsgängen der einzelnen Länder. Die OECD hat mit der Studie Lernen für die Arbeitswelt (OECD, 2010) und dem Projekt Skills beyond School (OECD, 2013) umfassende Arbeiten zur Einschätzung der Herausforderungen an Berufsbildungssysteme in den OECD-Ländern durchgeführt.

d. h. der ISCED-Stufen 5 A, $5^{B}$ und 6) in den OECD-Ländern um fast ro Prozentpunkte gestiegen. Im Durchschnitt haben 33 Prozent der erwachsenen Frauen und 30 Prozent der erwachsenen Männer einen Abschluss im Tertiärbereich erworben (Tab. Ar.3b im Internet). In den meisten OECD-Ländern ist der Anteil der Absolventen eines Studiengangs im Tertiärbereich unter den jüngeren Erwachsenen durchschnittlich um 7 Prozentpunkte höher als unter allen Erwachsenen. In I5 Ländern liegt dieser Unterschied über dem OECD-Durchschnitt und beläuft sich in Chile, Frankreich, Japan, Korea und Polen auf mehr als ro Prozentpunkte (Abb. Ar.I).

Trotz dieser Steigerung liegen die Abschlussquoten im Tertiärbereich nur in Australien, Irland, Israel, Kanada, Neuseeland, Spanien und dem Vereinigten Königreich über den Abschlussquoten im Sekundarbereich II. In Korea ist der Anteil der Abschlüsse im Sekundarbereich II und im Tertiärbereich nahezu gleich. Spanien ist das einzige Land in dieser Gruppe, in dem ein höherer Anteil der Erwachsenen über eine Ausbildung unterhalb des Sekundarbereichs II verfügt als über einen Abschluss im Tertiärbereich (Tab. Ar.4a).

Es besteht ein wichtiger Unterschied zwischen einem Abschluss im Sekundarbereich II und im Tertiärbereich. Die Daten belegen, dass hohe Abschlussquoten im Sekundarbereich II nicht unbedingt hohe Abschlussquoten im Tertiärbereich bedeuten. Dies gilt insbesondere für Länder mit gut ausgebauten Berufsbildungssystemen im Sekundarbereich II oder dem postsekundaren, nicht tertiären Bereich (ISCED-Stufen 3 und 4). 
Ein Grund hierfür ist der enge Zusammenhang zwischen einem Abschluss im Sekundarbereich II und dem Arbeitsmarkt, eine Verbindung, die wahrscheinlich Einfluss darauf hat, ob sich der Einzelne dazu entscheidet, seine Ausbildung fortzusetzen. Dies kann auch auf Schwierigkeiten zurückzuführen sein, die bei einem Wechsel der Ausrichtung des Bildungsprogramms beim Übergang in den Tertiärbereich entstehen, die negativen Auswirkungen von Studiengebühren und entsprechenden Darlehen oder auch das Gefühl, dass eine über die Schulpflicht oder berufsbildende Ausbildung hinausgehende Ausbildung den Eintritt in den Arbeitsmarkt und die Erwerbstätigkeit verzögert.

\section{Entwicklung der in den OECD-Ländern erzielten Bildungsabschlüsse Entwicklung der erzielten Bildungsabschlüsse}

Heute nehmen mehr Menschen als je zuvor an Bildung teil. Die zwischen den Generationen bestehenden Unterschiede im Bildungsstand und die Zunahme von Abschlüssen im Tertiär- und Sekundarbereich spiegeln sich in der Entwicklung des Bildungsstands der Gesamtbevölkerung. In den meisten OECD-Ländern ist seit 2000 im Durchschnitt der Anteil der Menschen mit einer Ausbildung unterhalb des Sekundarbereichs II zurückgegangen und der mit einem Abschluss im Tertiärbereich gestiegen. Die Abschlussquoten im Sekundarbereich II und postsekundaren, nicht tertiären Bereich sind im gleichen Zeitraum in den meisten OECD-Ländern stabil geblieben. Australien, Irland, Japan, Kanada, Korea, Luxemburg, Polen, die Schweiz und das Vereinigte Königreich haben zwischen 2000 und 201 I eine Zunahme der Abschlussquoten für den Tertiärbereich um mehr als Io Prozentpunkte gemeldet.

Wie Abbildung AI.3 zeigt, verfügen die Länder im oberen rechten Quadranten nicht nur bereits über einen hohen Bevölkerungsanteil mit einem Abschluss im Tertiärbereich, auch der Unterschied zwischen den Generationen ist erheblich: Die Abschlussquoten bei den jüngeren Erwachsenen (25- bis 34-Jährige) sind höher als bei den älteren Erwachsenen (55- bis 64-Jährige). In Japan, Polen und insbesondere in Korea besteht zwischen den beiden Altersgruppen hinsichtlich des Anteils derjenigen mit einem Abschluss im Tertiärbereich ein Unterschied von mehr als 25 Prozentpunkten. Im Gegensatz dazu liegt der Unterschied zwischen diesen Altersgruppen in Brasilien, Estland, Finnland, Österreich, der Russischen Föderation und der Türkei bei weniger als Io Prozentpunkten. In Deutschland und den Vereinigten Staaten besteht bei den Abschlussquoten zwischen diesen beiden Altersgruppen ein Unterschied von etwas über einem Prozentpunkt, in Israel hingegen ist der Anteil älterer Erwachsener mit einem Abschluss im Tertiärbereich etwas höher als der jüngerer Erwachsener. Der untere linke Quadrant zeigt Länder, deren Abschlussquoten für den Tertiärbereich unter dem OECD-Durchschnitt liegen und in denen die Abschlussquoten von einer Generation zur nächsten nicht stark gestiegen sind (Abb. Ar.3).

In Australien, Belgien, Finnland, Griechenland, Irland, Island, Italien, Korea, Luxemburg, Neuseeland, Portugal, Spanien, Ungarn und dem Vereinigten Königreich ist zwischen 2000 und 2011 der Anteil der Erwachsenen, die nur über eine Ausbildung unterhalb des Sekundarbereichs II verfügen, um mehr als Io Prozentpunkte gesunken. Am anderen Ende der Skala ist in Dänemark und Norwegen der Anteil der Bevölkerung mit einer Ausbildung unterhalb des Sekundarbereichs II im gleichen Zeitraum um etwa 3 Prozentpunkte gestiegen (Tab. Ar.4a). 
Anteil der Bevölkerung mit einem Abschluss im Tertiärbereich (in \%) und Unterschied zwischen dem Bevölkerungsanteil 25- bis 34-Jähriger und 55- bis 64-Jähriger mit einem Abschluss im Tertiärbereich (2011)

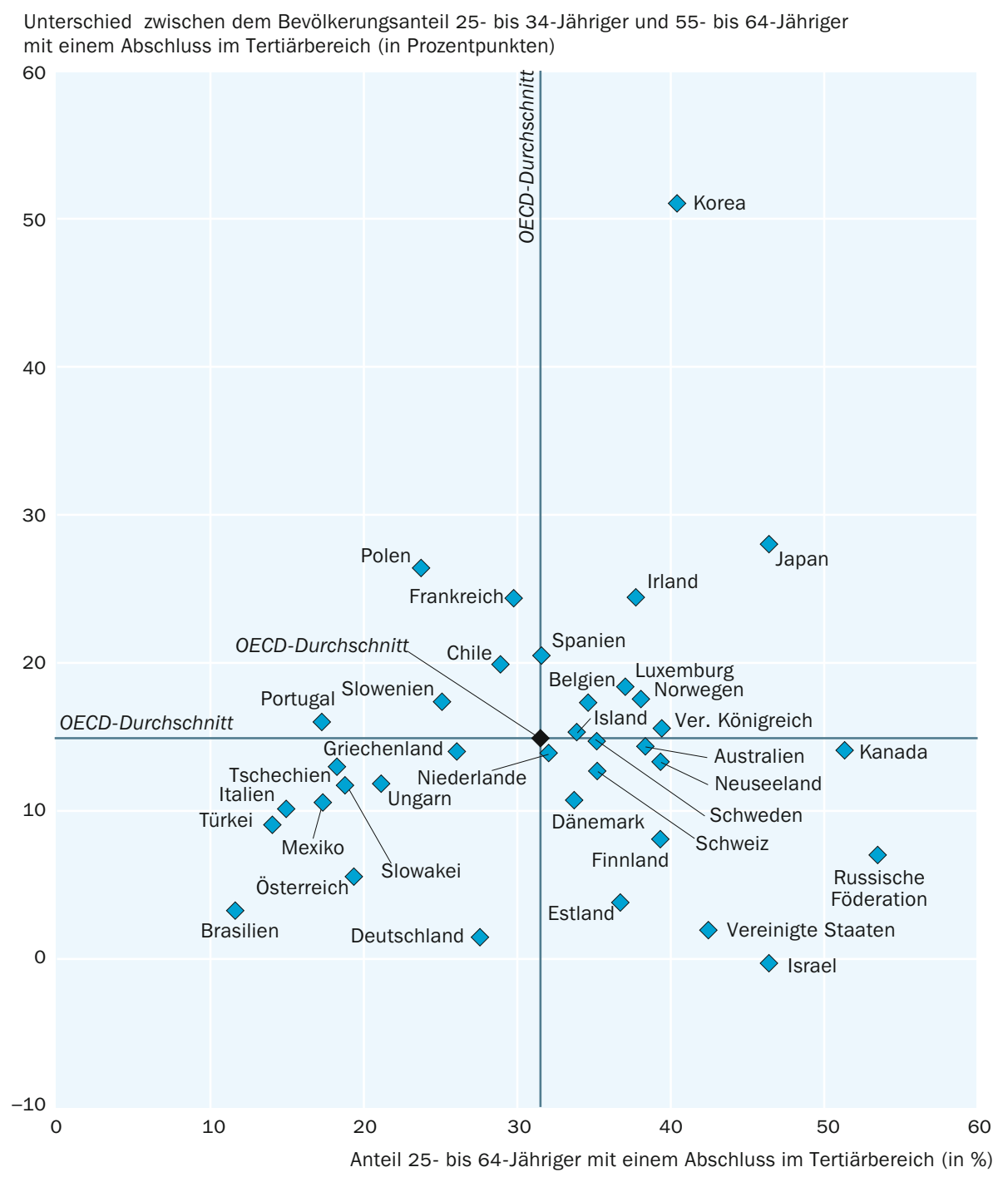

Quelle: OECD. Tabelle A1.3a. Hinweise s. Anhang 3 unter www.oecd.org/edu/eag.htm. StatLink: http://dx.doi.org/10.1787/888932846253

\section{Generationsspezifische Unterschiede bei Männern und Frauen}

In den meisten OECD-Ländern ist der Bildungsstand jüngerer Erwachsener (25- bis 34-Jährige) höher als der älterer Erwachsener (55- bis 64-Jährige). Im Durchschnitt verfügen 82 Prozent der jüngeren im Vergleich zu 64 Prozent der älteren Erwachsenen mindestens über einen Abschluss im Sekundarbereich II (Tab. AI.2a). Jüngere Erwachsene weisen außerdem um etwa I5 Prozentpunkte höhere Abschlussquoten für den Tertiärbereich auf als ältere Erwachsene. In einigen Ländern bestehen signifikante generationsspezifische Unterschiede. In Korea besteht zum Beispiel bei den Abschlussquoten für den Tertiärbereich zwischen diesen beiden Altersgruppen ein Unterschied von 5I Prozentpunkten. Belgien, Chile, Frankreich, Irland, Japan, Luxemburg, Norwegen, Polen, Portugal, Slowenien, Spanien und das Vereinigte Königreich weisen ebenfalls überdurchschnittlich hohe Unterschiede zwischen den beiden Altersgruppen auf. 

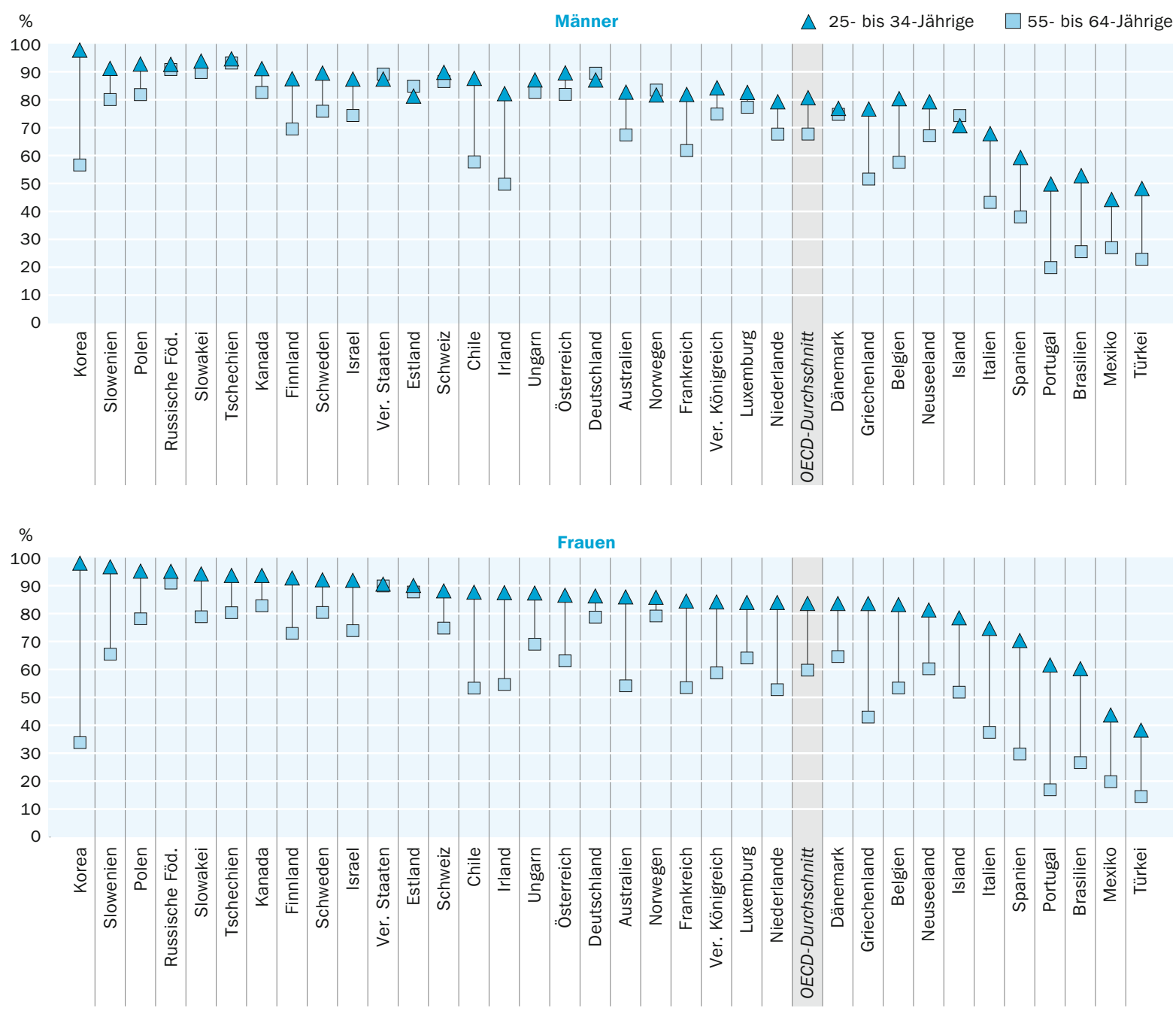

Anmerkung: Ohne ISCED 3 C kurze Bildungsgänge.

Anordnung der Länder in absteigender Reihenfolge des Anteils 25- bis 34-jähriger Frauen (in \%) mit mindestens einem Abschluss im Sekundarbereich II.

Quelle: OECD. Tabelle A1.2b im Internet. Hinweise s. Anhang 3 unter www.oecd.org/edu/eag.htm. StatLink: http://dx.doi.org/10.1787/888932846272

Im Gegensatz dazu sind die Unterschiede zwischen den Altersgruppen in Deutschland und den Vereinigten Staaten sehr gering, und in Israel ist der Anteil jüngerer Erwachsener mit einem Abschluss im Tertiärbereich etwas niedriger als der Anteil älterer Erwachsener mit diesem Bildungsstand (Tab. Ar.3a).

Abbildung Ar.4, die sich auf die Bevölkerung mit einem Abschluss mindestens im Sekundarbereich II konzentriert, d. h. diejenigen mit einem Abschluss im Sekundarbereich II oder postsekundaren, nicht tertiären Bereich oder im Tertiärbereich, zeigt, wie der Bildungsstand zwischen Männern und Frauen je nach Land und Generation variiert. Generationsspezifische Unterschiede sind insbesondere bei Frauen ausgeprägt. Im Durchschnitt besteht zwischen jüngeren und älteren Frauen ein Unterschied von 24 Prozentpunkten bei den Abschlussquoten im Sekundarbereich II und im Tertiär- 


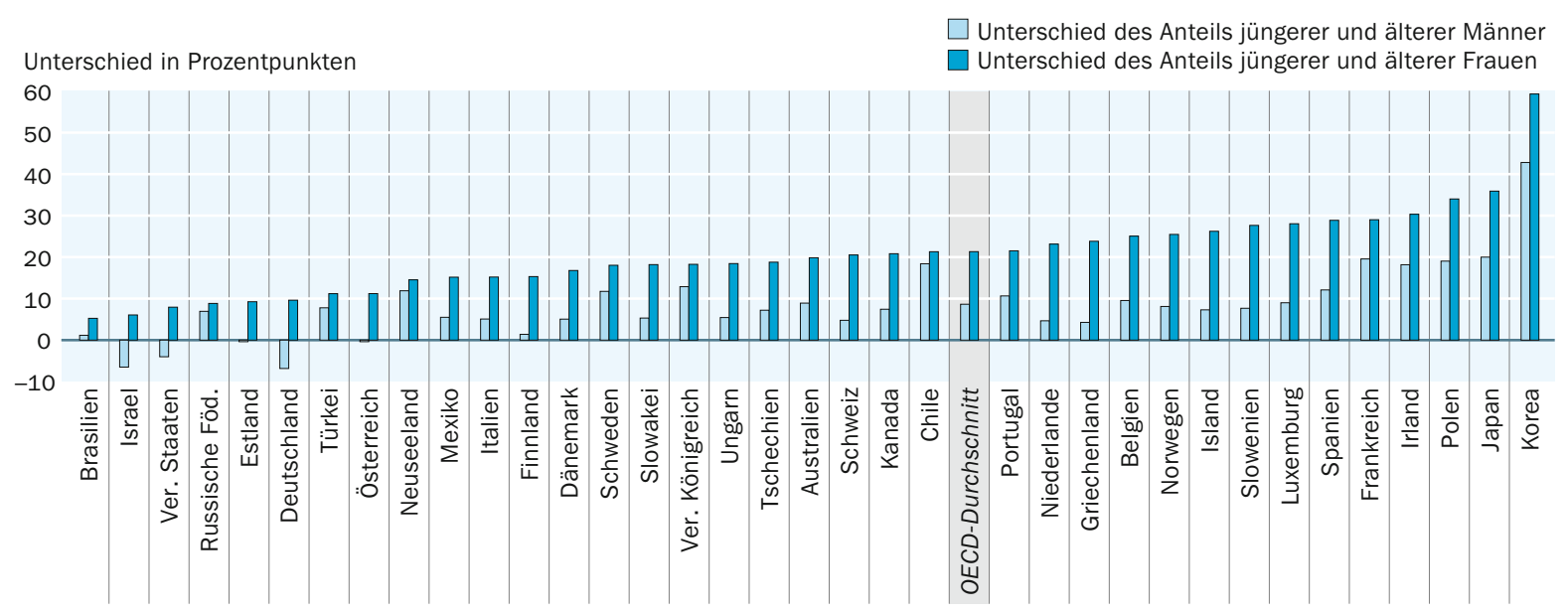

Anordnung der Länder in aufsteigender Reihenfolge des Unterschieds zwischen dem Anteil 25- bis 34-jähriger Frauen und dem Anteil 55- bis 64-jähriger Frauen mit einem Abschluss im Tertiärbereich.

Quelle: OECD. Tabelle A1.3b im Internet. Hinweise s. Anhang 3 unter www.oecd.org/edu/eag.htm. StatLink: http://dx.doi.org/10.1787/888932846291

bereich (84 Prozent gegenüber 6o Prozent). Dies lässt darauf schließen, dass in den meisten OECD-Ländern die Abschlussquoten im Sekundarbereich II und Tertiärbereich bei den Frauen der jüngeren Generationen stark gestiegen sind (Abb. AI.4 und Tab. Ar.3b im Internet).

Die generationsspezifischen Unterschiede bei den Abschlussquoten von Männern ähneln denen bei den Frauen, sind jedoch weniger ausgeprägt. In fast allen OECD-Ländern, mit Ausnahme von Deutschland, Estland, Island, Norwegen und den Vereinigten Staaten, ist der Anteil jüngerer Männer, die einen Abschluss mindestens im Sekundarbereich II erworben haben, gleich hoch oder höher als der Anteil älterer Männer mit dem gleichen Bildungsstand (Abb. Ar.4).

Im Laufe der Jahre haben sich auch die geschlechtsspezifischen Unterschiede im Bildungsstand verändert. Im Jahr 2000 war der Anteil der erwachsenen Männer mit einem Abschluss im Tertiärbereich höher als der der erwachsenen Frauen. Im Jahr 20II hatte sich die Situation umgekehrt: 33 Prozent der Frauen verfügten über einen Abschluss im Tertiärbereich im Vergleich zu 30 Prozent der Männer. Darüber hinaus liegen die Abschlussquoten im Sekundarbereich II und im Tertiärbereich bei jüngeren Frauen im Durchschnitt höher als bei Männern gleichen Alters. Im Durchschnitt verfügen 84 Prozent der jüngeren Frauen mindestens über einen Abschluss im Sekundarbereich II, bei den jüngeren Männern liegt dieser Prozentsatz bei 8r Prozent (Tab. Ar.2b und Ar.4b im Internet).

In den meisten OECD-Ländern ist die Wahrscheinlichkeit, dass Frauen über einen Abschluss im Tertiärbereich verfügen, höher als bei den Männern. In Australien, Irland, Israel, Kanada und Neuseeland ist der Anteil der Frauen mit einem Abschluss im Tertiärbereich höher als der Anteil von Männern oder Frauen mit einem anderen Abschluss. In Kanada weisen Frauen trotz hoher Abschlussquoten für den Tertiärbereich 
beider Geschlechter deutlich höhere Abschlussquoten als Männer auf (56 Prozent gegenüber 46 Prozent), und bei den jüngeren Erwachsenen besteht ein geschlechtsspezifischer Unterschied von I5 Prozentpunkten. Auch in Estland, Finnland, Island, Neuseeland, der Russischen Föderation, Schweden und Slowenien liegen die Abschlussquoten für den Tertiärbereich bei Frauen mindestens ro Prozentpunkte über denen der Männer.

Während jedoch im Durchschnitt der OECD-Länder die jüngeren Frauen fast Io Prozentpunkte höhere Abschlussquoten aufweisen als die jüngeren Männer, ist bei den älteren Erwachsenen (55- bis 64-Jährige) die Wahrscheinlichkeit, dass ein Mann über einen Abschluss im Tertiärbereich verfügt, höher als bei den Frauen (25 Prozent gegenüber 22 Prozent). Die Abschlussquoten für den Tertiärbereich bei jungen Frauen sind in Australien, Irland, Israel, Kanada, Neuseeland, Norwegen und Schweden stark gestiegen. In diesen Ländern verfügen mindestens 50 Prozent der jungen Frauen über einen Abschluss im Tertiärbereich im Vergleich zu weniger als 50 Prozent der jungen Männer (Tab. Ar.3b im Internet).

\section{Definitionen}

Altersgruppen: Erwachsene bezieht sich auf die Gruppe der 25- bis 64-Jährigen, jüngere Erwachsene bezieht sich auf 25- bis 34-Jährige, ältere Erwachsene bezieht sich auf 55- bis 64-Jährige.

Bildungsbereiche: unterhalb des Sekundarbereichs II umfasst die ISCED-Stufen o, I, 2 und ${ }_{3} \mathrm{C}$ kurz; Sekundarbereich II oder postsekundarer, nicht tertiärer Bereich umfasst die ISCED-Stufen $3 \mathrm{~A},{ }_{3} \mathrm{~B}$ und ${ }_{3} \mathrm{C}$ lang sowie 4 und Tertiärbereich die ISCED-Stufen $5 \mathrm{~A}, 5 \mathrm{~B}$ und 6 . Erläuterungen zu den einzelnen ISCED-Bereichen s. Hinweise für den Leser im vorderen Teil des Buches.

\section{Angewandte Methodik}

Die Daten zu Bevölkerung und Bildungsstand stammen für die meisten Länder aus Datenbanken der OECD und Eurostat, die aus nationalen Arbeitskräfteerhebungen zusammengetragen sind. Daten zum erzielten Bildungsstand für Argentinien, China, Indonesien, Saudi-Arabien und Südafrika stammen aus der Datenbank des Statistikinstituts der UNESCO zum Bildungsstand 25-Jähriger und Älterer (http:|/stats. uis.unesco. org/unesco/ReportFolders/ReportFolders. aspx [Zugriff am 22. Mai 2013]). Weitere Informationen s. Anhang 3 unter www.oecd.org/eduleag.htm.

Der Bildungsstand der Bevölkerung bezieht sich auf den Prozentsatz der Bevölkerung im Alter von 25 bis 64 Jahren, der einen bestimmten Bildungsbereich erfolgreich abgeschlossen hat.

Die meisten OECD-Länder ordnen Personen ohne einen Bildungsabschluss (d. h. Analphabeten oder Personen, deren Bildungsstand sich nicht in nationale Klassifizierungen einstufen lässt) der ISCED-Stufe o zu, daher sind die Durchschnittswerte für die 
ISCED-Stufen o/I (d. h. den Elementar- und Primarbereich) vermutlich hierdurch beeinflusst.

Die statistischen Daten für Israel wurden von den zuständigen israelischen Stellen bereitgestellt, die für sie verantwortlich zeichnen. Die Verwendung dieser Daten durch die OECD erfolgt unbeschadet des völkerrechtlichen Status der Golanhöhen, von OstJerusalem und der israelischen Siedlungen im Westjordanland.

\section{Weiterführende Informationen}

OECD (2010), Lernen für die Arbeitswelt, ISBN: 978-92-64-08783-5, www.oecd.org/berlin| publikationen/oecd-studiezurberufsbildunglernenfurdiearbeitswelt.htm.

OECD (2013), „Skills beyond School: the OECD Review of Post-Secondary Vocational Education and Training“, OECD Publishing, www.oecd.org/edu/skills-beyond-school/skills beyondschool.htm.

\section{Tabellen Indikator A1}

Tabelle Ar.Ia: Bildungsstand 25- bis 64-Jähriger (20II)

StatLink: http://dx.doi.org/10.1787/888932848001

WEB Table Ar.Ib: Educational attainment of 25-64 year-olds, by gender (Bildungsstand 25-bis 64-Jähriger, nach Geschlecht) (2011)

StatLink: http://dx.doi.org/10.1787/888932848020

Tabelle Ar.2a: Anteil der Bevölkerung mit mindestens einem Abschluss im Sekundarbereich II (in \%), nach Altersgruppe (20II)

StatLink: http://dx.doi.org/10.1787/888932848039

WEB Table AI.2b: Percentage of the population that has attained at least upper secondary education, by age group and gender (Anteil der Bevölkerung mit mindestens einem Abschluss im Sekundarbereich II [in \%], nach Altersgruppe und Geschlecht) (20II)

StatLink: http://dx.doi.org/10.1787/888932848058

Tabelle Ar.3a: Anteil der Bevölkerung mit einem Abschluss im Tertiärbereich (in \%), nach Art des Studiengangs und Altersgruppe (20II)

StatLink: http://dx.doi.org/10.1787/888932848077

WEB Table Ar.3b: Percentage of the population that has attained tertiary education, by type of programme, age group and gender (Anteil der Bevölkerung mit einem Abschluss im Tertiärbereich [in \%], nach Art des Studiengangs, Altersgruppe und Geschlecht) (20II)

StatLink: http://dx.doi.org/10.1787/888932848096 
Tabelle Ar.4a: Entwicklungstendenzen bei Bildungsabschlüssen, nach Altersgruppe, sowie durchschnittlicher jährlicher Anstieg (2000-20II)

StatLink: http:/|dx.doi.org/10.1787/888932848115

WEB Table Ar.4b: Trends in educational attainment, by gender and age group, and average annual growth rate (Entwicklungstendenzen bei Bildungsabschlüssen, nach Geschlecht und Altersgruppe sowie durchschnittlicher jährlicher Anstieg) (2000-20II)

StatLink: http://dx.doi.org/10.1787/888932848134

Tabelle Ar.5a: Bildungsstand von 25- bis 64-Jährigen, nach Ausrichtung des Bildungsgangs (berufsbildend oder allgemeinbildend) und Geschlecht (20II) StatLink: http://dx.doi.org/10.1787/888932848153

WEB Table AI.5b: Educational attainment by programme orientation, age group and gender (Bildungsstand von 25- bis 64-Jährigen, nach Ausrichtung des Bildungsgangs, Altersgruppe und Geschlecht) (20II)

StatLink: http://dx.doi.org/10.1787/888932848172 
Bildungsstand 25- bis 64-Jähriger (2011)

\begin{tabular}{|c|c|c|c|c|c|c|c|c|c|c|}
\hline & \multirow{2}{*}{$\begin{array}{c}\text { Elementar- } \\
\text { und Primar- } \\
\text { bereich }\end{array}$} & \multirow{2}{*}{$\begin{array}{c}\text { Sekundar- } \\
\text { bereich I }\end{array}$} & \multirow{2}{*}{$\begin{array}{c}\text { ISCED 3C } \\
\text { (kurz) }\end{array}$} & \multicolumn{2}{|c|}{ Sekundarbereich II } & \multirow{2}{*}{$\begin{array}{c}\text { Postsekun- } \\
\text { darer, nicht } \\
\text { tertiärer } \\
\text { Bereich }\end{array}$} & \multicolumn{3}{|c|}{ Tertiärbereich } & \multirow{2}{*}{$\begin{array}{c}\text { Alle } \\
\text { Bildungs- } \\
\text { bereiche } \\
\text { zusammen }\end{array}$} \\
\hline & & & & $\begin{array}{l}\text { ISCED 3C } \\
\text { (lang)/3B }\end{array}$ & ISCED $3 A$ & & $\begin{array}{c}\text { Tertiär- } \\
\text { bereich B }\end{array}$ & $\begin{array}{c}\text { Tertiär- } \\
\text { bereich A }\end{array}$ & $\begin{array}{l}\text { Weiter- } \\
\text { führende } \\
\text { forschungs- } \\
\text { orientierte } \\
\text { Studien- } \\
\text { gänge }\end{array}$ & \\
\hline & (1) & (2) & (3) & (4) & (5) & (6) & (7) & (8) & (9) & (10) \\
\hline \multicolumn{11}{|l|}{ OECD-Länder } \\
\hline Australien & 6 & 20 & $a$ & 15 & 16 & 4 & 10 & 27 & 1 & 100 \\
\hline Österreich & $x(2)$ & 16 & 1 & 47 & 6 & 10 & 7 & 12 & $x(8)$ & 100 \\
\hline Belgien & 12 & 16 & a & 10 & 24 & 3 & 18 & 16 & 1 & 100 \\
\hline Kanada & 3 & 8 & a & $x(5)$ & 26 & 12 & 25 & 27 & $x(8)$ & 100 \\
\hline Chile & 14 & 13 & a & $x(5)$ & 44 & a & 12 & 17 & $\mathrm{n}$ & 100 \\
\hline Tschechien & $\mathrm{n}$ & 7 & a & 39 & 35 & $x(5)$ & $x(8)$ & 18 & $x(8)$ & 100 \\
\hline Dänemark & 1 & 21 & 1 & 37 & 6 & $\mathrm{n}$ & 6 & 27 & 1 & 100 \\
\hline Estland & 1 & 10 & a & 14 & 31 & 7 & 12 & 24 & $\mathrm{n}$ & 100 \\
\hline Finnland & 6 & 10 & a & a & 44 & 1 & 14 & 24 & 1 & 100 \\
\hline Frankreich & 11 & 18 & a & 30 & 11 & $\mathrm{n}$ & 11 & 18 & 1 & 100 \\
\hline Deutschland & 3 & 10 & a & 48 & 3 & 8 & 11 & 15 & 1 & 100 \\
\hline Griechenland & 22 & 11 & $x(4)$ & 7 & 26 & 8 & 8 & 18 & $\mathrm{n}$ & 100 \\
\hline Ungarn & 1 & 17 & a & 29 & 29 & 2 & 1 & 20 & 1 & 100 \\
\hline Island & 27 & c & 2 & 18 & 13 & 6 & 4 & 29 & 1 & 100 \\
\hline Irland & 11 & 15 & 1 & $x(5)$ & 23 & 13 & 15 & 22 & 1 & 100 \\
\hline Israel & 10 & 7 & a & 9 & 28 & a & 15 & 30 & 1 & 100 \\
\hline Italien & 11 & 33 & $\mathrm{n}$ & 7 & 33 & 1 & $\mathrm{n}$ & 14 & $n$ & 100 \\
\hline Japan & $x(5)$ & $x(5)$ & $x(5)$ & $x(5)$ & 54 & a & 20 & 26 & $x(8)$ & 100 \\
\hline Korea & 8 & 10 & $a$ & $x(5)$ & 41 & a & 13 & 28 & $x(8)$ & 100 \\
\hline Luxemburg & 10 & 8 & 5 & 17 & 19 & 4 & 12 & 24 & 1 & 100 \\
\hline Mexiko & 41 & 23 & a & 6 & 13 & a & 1 & 16 & $x(8)$ & 100 \\
\hline Niederlande & 8 & 20 & $x(4)$ & 14 & 23 & 3 & 3 & 29 & $\mathrm{n}$ & 100 \\
\hline Neuseeland & $x(2)$ & 19 & 7 & 14 & 10 & 11 & 16 & 24 & $x(8)$ & 100 \\
\hline Norwegen & $\mathrm{n}$ & 18 & a & 28 & 12 & 4 & 2 & 35 & 1 & 100 \\
\hline Polen & $x(2)$ & 11 & a & 31 & 31 & 4 & $x(8)$ & 24 & $x(8)$ & 100 \\
\hline Portugal & 44 & 21 & $x(5)$ & $x(5)$ & 17 & $\mathrm{n}$ & $x(8)$ & 15 & 2 & 100 \\
\hline Slowakei & 1 & 8 & $x(4)$ & 34 & 39 & $x(5)$ & 1 & 17 & $n$ & 100 \\
\hline Slowenien & 1 & 14 & a & 26 & 33 & a & 11 & 12 & 2 & 100 \\
\hline Spanien & 18 & 28 & $a$ & 8 & 14 & $\mathrm{n}$ & 9 & 22 & 1 & 100 \\
\hline Schweden & 4 & 9 & a & $x(5)$ & 45 & 7 & 9 & 25 & 1 & 100 \\
\hline Schweiz & 3 & 9 & 2 & 40 & 5 & 6 & 11 & 22 & 3 & 100 \\
\hline Türkei & 57 & 11 & a & 8 & 10 & a & a & 14 & $x(8)$ & 100 \\
\hline Ver. Königreich & $n$ & 10 & 13 & 30 & 7 & $\mathrm{n}$ & 10 & 29 & 1 & 100 \\
\hline Vereinigte Staaten & 4 & 7 & $x(5)$ & $x(5)$ & 47 & $x(5)$ & 10 & 31 & 1 & 100 \\
\hline
\end{tabular}

\begin{tabular}{|c|c|c|c|c|c|c|c|c|c|c|}
\hline & \multicolumn{3}{|c|}{$\begin{array}{l}\text { Ausbildung unterhalb } \\
\text { Sekundarbereich II }\end{array}$} & \multicolumn{3}{|c|}{ Abschluss im Sekundarbereich II } & \multicolumn{3}{|c|}{ Abschluss im Tertiärbereich } & \\
\hline OECD-Durchschnitt & \multirow{2}{*}{\multicolumn{3}{|c|}{$\begin{array}{l}25 \\
24\end{array}$}} & \multirow{2}{*}{\multicolumn{3}{|c|}{$\begin{array}{l}44 \\
48\end{array}$}} & \multirow{2}{*}{\multicolumn{3}{|c|}{$\begin{array}{l}32 \\
29\end{array}$}} & \\
\hline EU21-Durchschnitt & & & & & & & & & & \\
\hline \multicolumn{11}{|l|}{ Sonst. G20-Länder } \\
\hline Argentinien $^{1}$ & 44 & 14 & a & 28 & $x(4)$ & a & $x(8)$ & 14 & $x(8)$ & 100 \\
\hline Brasilien & 41 & 15 & $x(5)$ & $x(5)$ & 32 & a & $x(8)$ & 12 & $x(8)$ & 100 \\
\hline China $^{2}$ & 35 & 43 & $\mathrm{~m}$ & $x(5)$ & 14 & 5 & $x(8)$ & 4 & $x(8)$ & 100 \\
\hline Indien & $\mathrm{m}$ & $\mathrm{m}$ & $\mathrm{m}$ & $\mathrm{m}$ & $\mathrm{m}$ & $\mathrm{m}$ & $\mathrm{m}$ & $\mathrm{m}$ & $\mathrm{m}$ & $\mathrm{m}$ \\
\hline Indonesien ${ }^{3}$ & 58 & 14 & a & 20 & $x(4)$ & a & $x(8)$ & 8 & $x(8)$ & 100 \\
\hline Russische Föd. & 1 & 5 & $x(4)$ & 19 & 21 & $x(4)$ & 26 & 27 & $\mathrm{n}$ & 100 \\
\hline Saudi-Arabien ${ }^{4}$ & 51 & 15 & a & 15 & $x(4)$ & 5 & $x(8)$ & 15 & $x(8)$ & 100 \\
\hline Südafrika & 27 & 14 & a & 46 & $x(4)$ & 7 & $x(8)$ & 6 & $x(8)$ & 100 \\
\hline G20-Durchschnitt & \multicolumn{3}{|c|}{36} & \multicolumn{3}{|c|}{34} & \multicolumn{3}{|c|}{25} & \\
\hline
\end{tabular}

Anmerkung: Aufgrund von Abweichungen in den Daten wurden der OECD- und der EU21-Durchschnitt nicht für jede einzelne Spalte berechnet. 1. Daten aus 2003. 2. Daten aus 2010. 3. Daten aus 2009. 4. Daten aus 2004.

Quelle: OECD. Arbeitskräfteerhebung des Netzwerks zu den Arbeitsmarktergebnissen sowie den wirtschaftlichen und sozialen Auswirkungen des Lernens (LSO) für die meisten Länder und Arbeitskräfteerhebung der EU (EU-LFS) für Dänemark, Finnland, Island, Irland, Luxemburg und Slowenien sowie Bildungsstand-Datenbank des Statistikinstituts des UNESCO für Argentinien, China, Indonesien, Saudi-Arabien und Südafrika. Hinweise s. Anhang 3 unter www.oecd.org/edu/eag.htm. StatLink: http://dx.doi.org/10.1787/888932848001

Erläuterung der Kennzeichnung fehlender Daten s. Hinweise für den Leser. 
Tabelle A1.2a

Anteil der Bevölkerung mit mindestens einem Abschluss im Sekundarbereich II (in \%), nach Altersgruppe (2011)

\begin{tabular}{|c|c|c|c|c|c|c|}
\hline & \multicolumn{6}{|c|}{ Altersgruppe } \\
\hline & $25-64$ & $30-34$ & $25-34$ & $35-44$ & $45-54$ & $55-64$ \\
\hline & (1) & (2) & (3) & (4) & (5) & (6) \\
\hline \multicolumn{7}{|l|}{ OECD-Länder } \\
\hline Australien & 74 & 84 & 84 & 78 & 69 & 61 \\
\hline Österreich & 82 & 88 & 88 & 86 & 82 & 72 \\
\hline Belgien & 71 & 82 & 82 & 79 & 68 & 56 \\
\hline Kanada & 89 & 93 & 92 & 92 & 88 & 83 \\
\hline Chile & 72 & $\mathrm{~m}$ & 88 & 77 & 67 & 56 \\
\hline Tschechien & 92 & 95 & 94 & 95 & 93 & 87 \\
\hline Dänemark & 77 & 82 & 80 & 82 & 76 & 70 \\
\hline Estland & 89 & 86 & 86 & 89 & 94 & 87 \\
\hline Finnland & 84 & 91 & 90 & 89 & 86 & 71 \\
\hline Frankreich & 72 & 83 & 83 & 78 & 68 & 58 \\
\hline Deutschland & 86 & 87 & 87 & 87 & 87 & 84 \\
\hline Griechenland & 67 & 78 & 80 & 74 & 64 & 47 \\
\hline Ungarn & 82 & 87 & 87 & 83 & 81 & 75 \\
\hline Island & 71 & 75 & 75 & 75 & 69 & 63 \\
\hline Irland & 73 & 86 & 85 & 80 & 68 & 52 \\
\hline Israel & 83 & 89 & 90 & 85 & 79 & 74 \\
\hline Italien & 56 & 69 & 71 & 60 & 52 & 40 \\
\hline Japan & $\mathrm{m}$ & $\mathrm{m}$ & $\mathrm{m}$ & $\mathrm{m}$ & $\mathrm{m}$ & $\mathrm{m}$ \\
\hline Korea & 81 & 98 & 98 & 96 & 75 & 45 \\
\hline Luxemburg & 77 & 82 & 83 & 78 & 75 & 71 \\
\hline Mexiko & 36 & 40 & 44 & 37 & 34 & 23 \\
\hline Niederlande & 72 & 82 & 82 & 77 & 71 & 60 \\
\hline Neuseeland & 74 & 81 & 80 & 78 & 73 & 64 \\
\hline Norwegen & 82 & 86 & 84 & 85 & 78 & 81 \\
\hline Polen & 89 & 94 & 94 & 92 & 90 & 80 \\
\hline Portugal & 35 & 52 & 56 & 39 & 24 & 18 \\
\hline Slowakei & 91 & 95 & 94 & 94 & 92 & 84 \\
\hline Slowenien & 84 & 94 & 94 & 87 & 83 & 73 \\
\hline Spanien & 54 & 66 & 65 & 61 & 50 & 34 \\
\hline Schweden & 87 & 91 & 91 & 91 & 87 & 78 \\
\hline Schweiz & 86 & 89 & 89 & 87 & 85 & 81 \\
\hline Türkei & 32 & 41 & 43 & 30 & 25 & 19 \\
\hline Vereinigtes Königreich & 77 & 84 & 84 & 80 & 75 & 67 \\
\hline Vereinigte Staaten & 89 & 89 & 89 & 89 & 89 & 90 \\
\hline OECD-Durchschnitt & 75 & 82 & 82 & 78 & 73 & 64 \\
\hline EU21-Durchschnitt & 76 & 84 & 84 & 80 & 75 & 65 \\
\hline \multicolumn{7}{|l|}{ Sonstige G20-Länder } \\
\hline Argentinien ${ }^{1}$ & 42 & $\mathrm{~m}$ & $\mathrm{~m}$ & $\mathrm{~m}$ & $\mathrm{~m}$ & $\mathrm{~m}$ \\
\hline Brasilien & 43 & 53 & 57 & 44 & 36 & 26 \\
\hline China $^{2}$ & 22 & $\mathrm{~m}$ & $\mathrm{~m}$ & $\mathrm{~m}$ & $\mathrm{~m}$ & $\mathrm{~m}$ \\
\hline Indien & $\mathrm{m}$ & $\mathrm{m}$ & $\mathrm{m}$ & $\mathrm{m}$ & $\mathrm{m}$ & $\mathrm{m}$ \\
\hline Indonesien ${ }^{3}$ & 28 & $\mathrm{~m}$ & $\mathrm{~m}$ & $\mathrm{~m}$ & $\mathrm{~m}$ & $\mathrm{~m}$ \\
\hline Russische Föderation & 94 & 93 & 94 & 95 & 95 & 91 \\
\hline Saudi-Arabien ${ }^{4}$ & 34 & $\mathrm{~m}$ & $\mathrm{~m}$ & $\mathrm{~m}$ & $\mathrm{~m}$ & $\mathrm{~m}$ \\
\hline Südafrika & 58 & $\mathrm{~m}$ & $\mathrm{~m}$ & $\mathrm{~m}$ & $\mathrm{~m}$ & $\mathrm{~m}$ \\
\hline G20-Durchschnitt & 60 & 76 & 77 & 72 & 66 & 57 \\
\hline
\end{tabular}

Anmerkung: ISCED 3c (kurz) Bildungsgänge sind in den Berechnungen nicht enthalten.

1. Daten aus 2003. 2. Daten aus 2010. 3. Daten aus 2009. 4. Daten aus 2004.

Quelle: OECD. Arbeitskräfteerhebung des Netzwerks zu den Arbeitsmarktergebnissen sowie den wirtschaftlichen und sozialen Auswirkungen des Lernens (LSO) für die meisten Länder und Arbeitskräfteerhebung der EU (EU-LFS) für Dänemark, Finnland, Island, Irland, Luxemburg und Slowenien sowie Bildungsstand-Datenbank des Statistikinstituts des UNESCO für Argentinien, China, Indonesien, Saudi-Arabien und Südafrika. Hinweise s. Anhang 3 unter www.oecd.org/edu/eag.htm. StatLink: http://dx.doi.org/10.1787/888932848039

Erläuterung der Kennzeichnung fehlender Daten s. Hinweise für den Leser. 
Tabelle A1.3a

Anteil der Bevölkerung mit einem Abschluss im Tertiärbereich (in \%), nach Art des Studiengangs und Altersgruppe (2011)

\begin{tabular}{|c|c|c|c|c|c|c|c|c|c|c|c|c|c|c|c|c|c|c|c|}
\hline & \multicolumn{6}{|c|}{ Abschluss im Tertiärbereich B } & \multicolumn{6}{|c|}{$\begin{array}{l}\text { Abschluss im Tertiärbereich A/ } \\
\text { einem weiterführenden forschungs- } \\
\text { orientierten Studiengang }\end{array}$} & \multicolumn{7}{|c|}{ Abschluss im Tertiärbereich insgesamt } \\
\hline & $\begin{array}{l}\stackrel{+}{0} \\
\vdots \\
\stackrel{1}{N}\end{array}$ & $\begin{array}{l}\text { d } \\
0 \\
0 \\
0\end{array}$ & $\begin{array}{l}\stackrel{+}{p} \\
\stackrel{1}{1} \\
\stackrel{N}{N}\end{array}$ & \begin{tabular}{l}
\multirow{J}{*}{} \\
$\vdots$ \\
0 \\
$m$
\end{tabular} & $\begin{array}{l}\stackrel{0}{b} \\
0 \\
b \\
g\end{array}$ & $\begin{array}{l}0 \\
0 \\
1 \\
1 \\
ٌ\end{array}$ & 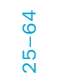 & $\begin{array}{l}\text { d } \\
\text { p. } \\
0 \\
0\end{array}$ & $\begin{array}{l}\stackrel{+}{\infty} \\
\stackrel{D}{W}\end{array}$ & \begin{tabular}{l}
\multirow{J}{*}{} \\
$\perp$ \\
$\stackrel{D}{m}$
\end{tabular} & 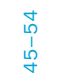 & $\begin{array}{l}\text { t } \\
0 \\
1 \\
ٌ\end{array}$ & $\begin{array}{l}\stackrel{+}{0} \\
\stackrel{1}{\omega} \\
\text { N }\end{array}$ & $\begin{array}{l}\text { d } \\
\text { D } \\
0\end{array}$ & $\begin{array}{l}\stackrel{+}{\infty} \\
\stackrel{1}{\omega}\end{array}$ & $\begin{array}{l}J \\
⿱ \\
D \\
ٍ \\
m\end{array}$ & 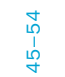 & $\begin{array}{l}\text { t } \\
\vdots \\
1 \\
\llcorner\end{array}$ & 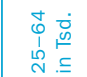 \\
\hline & (1) & (2) & (3) & (4) & (5) & (6) & (7) & (8) & (9) & (10) & (11) & (12) & (13) & (14) & (15) & (16) & (17) & (18) & (19) \\
\hline \multicolumn{20}{|l|}{ OECD-Länder } \\
\hline Australien & 10 & 10 & 10 & 11 & 12 & 9 & 28 & 35 & 35 & 30 & 24 & 21 & 38 & 45 & 45 & 41 & 35 & 30 & 4491 \\
\hline Österreich & 7 & 6 & 5 & 7 & 8 & 8 & 12 & 18 & 16 & 14 & 10 & 8 & 19 & 24 & 21 & 21 & 19 & 16 & 901 \\
\hline Belgien & 18 & 21 & 19 & 20 & 17 & 14 & 17 & 22 & 23 & 19 & 14 & 11 & 35 & 43 & 42 & 39 & 31 & 25 & 2041 \\
\hline Kanada & 25 & 27 & 26 & 26 & 25 & 21 & 27 & 31 & 31 & 32 & 23 & 22 & 51 & 58 & 57 & 58 & 48 & 43 & 9677 \\
\hline Chile & 12 & $\mathrm{~m}$ & 15 & 15 & 11 & 7 & 17 & $\mathrm{~m}$ & 27 & 15 & 12 & 15 & 29 & $\mathrm{~m}$ & 41 & 30 & 23 & 21 & 2490 \\
\hline Tschechien & $x(7)$ & $x(8)$ & $x(9)$ & $x(10)$ & $x(11)$ & $x(12)$ & 18 & 24 & 25 & 18 & 17 & 12 & 18 & 24 & 25 & 18 & 17 & 12 & 1111 \\
\hline Dänemark & 6 & 6 & 5 & 6 & 6 & 5 & 28 & 35 & 33 & 31 & 26 & 23 & 34 & 41 & 39 & 37 & 31 & 28 & 953 \\
\hline Estland & 12 & 13 & 12 & 12 & 13 & 11 & 25 & 28 & 27 & 23 & 24 & 24 & 37 & 40 & 39 & 35 & 37 & 35 & 267 \\
\hline Finnland & 14 & 3 & 2 & 17 & 22 & 17 & 25 & 43 & 38 & 30 & 19 & 15 & 39 & 46 & 39 & 47 & 41 & 31 & 1132 \\
\hline Frankreich & 11 & 17 & 16 & 14 & 9 & 7 & 18 & 27 & 27 & 21 & 13 & 12 & 30 & 43 & 43 & 36 & 22 & 19 & 9711 \\
\hline Deutschland & 11 & 10 & 9 & 11 & 12 & 11 & 16 & 21 & 18 & 18 & 15 & 15 & 28 & 31 & 28 & 29 & 27 & 26 & 12308 \\
\hline Griechenland & 8 & 9 & 12 & 9 & 6 & 3 & 18 & 20 & 21 & 19 & 18 & 15 & 26 & 29 & 33 & 28 & 24 & 19 & 1601 \\
\hline Ungarn & 1 & 1 & 2 & 1 & $\mathrm{n}$ & c & 20 & 27 & 27 & 21 & 18 & 16 & 21 & 28 & 28 & 21 & 18 & 16 & 1178 \\
\hline Island & 4 & c & 3 & 5 & 4 & 4 & 30 & 41 & 37 & 34 & 27 & 20 & 34 & 41 & 39 & 39 & 31 & 24 & 55 \\
\hline Irland & 15 & 18 & 16 & 18 & 13 & 10 & 23 & 32 & 31 & 26 & 18 & 13 & 38 & 49 & 47 & 43 & 31 & 23 & 904 \\
\hline Israel & 15 & 15 & 13 & 16 & 16 & 17 & 31 & 38 & 32 & 34 & 29 & 28 & 46 & 53 & 45 & 50 & 45 & 45 & 1673 \\
\hline Italien & n & $\mathrm{n}$ & $\mathrm{n}$ & $\mathrm{n}$ & $\mathrm{n}$ & $\mathrm{n}$ & 15 & 20 & 21 & 16 & 11 & 11 & 15 & 20 & 21 & 17 & 11 & 11 & 5019 \\
\hline Japan & 20 & $\mathrm{~m}$ & 24 & 25 & 20 & 12 & 26 & $\mathrm{~m}$ & 35 & 26 & 27 & 18 & 46 & $\mathrm{~m}$ & 59 & 51 & 47 & 31 & 29520 \\
\hline Korea & 13 & 24 & 25 & 15 & 6 & 2 & 28 & 40 & 39 & 35 & 22 & 11 & 40 & 64 & 64 & 49 & 28 & 13 & 11885 \\
\hline Luxemburg & 12 & 14 & 14 & 13 & 10 & 10 & 25 & 34 & 32 & 27 & 21 & 19 & 37 & 48 & 47 & 40 & 31 & 28 & 104 \\
\hline Mexiko & 1 & 1 & 1 & 1 & 1 & 1 & 16 & 19 & 21 & 14 & 15 & 11 & 17 & 20 & 23 & 15 & 16 & 12 & 9036 \\
\hline Niederlande & 3 & 3 & 2 & 3 & 3 & 2 & 30 & 38 & 38 & 31 & 27 & 24 & 32 & 41 & 40 & 34 & 29 & 26 & 2852 \\
\hline Neuseeland & 16 & 14 & 15 & 15 & 16 & 16 & 24 & 33 & 31 & 26 & 20 & 17 & 39 & 47 & 46 & 41 & 37 & 33 & 851 \\
\hline Norwegen & 2 & 2 & 1 & 2 & 3 & 3 & 36 & 48 & 46 & 39 & 31 & 26 & 38 & 50 & 47 & 42 & 34 & 29 & 973 \\
\hline Polen & $x(7)$ & $x(8)$ & $x(9)$ & $x(10)$ & $x(11)$ & $x(12)$ & 24 & 37 & 39 & 24 & 16 & 13 & 24 & 37 & 39 & 24 & 16 & 13 & 5150 \\
\hline Portugal & $x(7)$ & $x(8)$ & $x(9)$ & $x(10)$ & $x(11)$ & $x(12)$ & 17 & 26 & 27 & 19 & 11 & 11 & 17 & 26 & 27 & 19 & 11 & 11 & 1027 \\
\hline Slowakei & 1 & 1 & 1 & 1 & 1 & 1 & 17 & 22 & 24 & 16 & 15 & 13 & 19 & 23 & 26 & 17 & 16 & 14 & 595 \\
\hline Slowenien & 11 & 14 & 13 & 12 & 12 & 9 & 14 & 24 & 21 & 16 & 10 & 8 & 25 & 38 & 34 & 28 & 22 & 16 & 298 \\
\hline Spanien & 9 & 13 & 12 & 12 & 7 & 4 & 22 & 27 & 27 & 25 & 20 & 15 & 32 & 41 & 39 & 37 & 27 & 19 & 8350 \\
\hline Schweden & 9 & 8 & 9 & 9 & 9 & 10 & 26 & 40 & 34 & 31 & 21 & 18 & 35 & 48 & 43 & 39 & 31 & 28 & 1702 \\
\hline Schweiz & 11 & 11 & 9 & 12 & 12 & 9 & 25 & 32 & 30 & 28 & 22 & 18 & 35 & 44 & 40 & 39 & 33 & 27 & 1545 \\
\hline Türkei & $x(7)$ & $x(8)$ & $x(9)$ & $x(10)$ & $x(11)$ & $x(12)$ & 14 & 17 & 19 & 13 & 10 & 10 & 14 & 17 & 19 & 13 & 10 & 10 & 4709 \\
\hline Ver. Königreich & 10 & 8 & 8 & 11 & 12 & 9 & 30 & 40 & 39 & 32 & 24 & 22 & 39 & 48 & 47 & 43 & 36 & 31 & 12958 \\
\hline Vereinigte Staaten & 10 & 10 & 10 & 10 & 11 & 10 & 32 & 34 & 33 & 34 & 30 & 31 & 42 & 44 & 43 & 45 & 41 & 41 & 68921 \\
\hline OECD-Durchschnitt & 10 & 10 & 10 & 11 & 10 & 8 & 23 & 30 & 30 & 25 & 19 & 17 & 32 & 39 & 39 & 34 & 28 & 24 & \\
\hline OECD insg. (in Tsd.) & & & & & & & & & & & & & & & & & & & 215988 \\
\hline EU21-Durchschnitt & & & 9 & 10 & 9 & & 21 & 29 & 28 & 23 & 18 & 15 & 29 & 37 & 36 & 31 & 25 & 21 & \\
\hline
\end{tabular}

Sonst. G20-Länder

Argentinien ${ }^{1}$

Brasilien

China $^{2}$

Indien

Indonesien ${ }^{3}$

Russische Föd.

Saudi-Arabien ${ }^{4}$

Südafrika

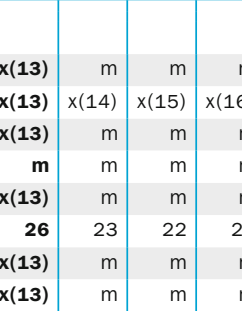

\begin{tabular}{r|r}
$m$ & \\
$m$ & $x(1$ \\
$m$ & \\
$m$ & \\
$m$ & \\
27 & \\
$m$ & \\
$m$ &
\end{tabular}

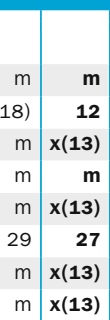

\begin{tabular}{r|r|r} 
& & \\
\hline$m$ & $m$ & $m$ \\
13 & 13 & 1 \\
$m$ & $m$ & $m$ \\
$m$ & $m$ & $m$ \\
$m$ & $m$ & $m$ \\
32 & 34 & 2 \\
$m$ & $m$ & $m$ \\
$m$ & $m$ & $m$
\end{tabular}
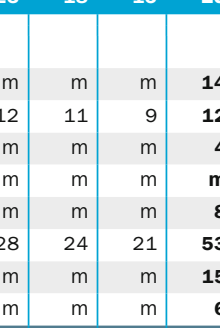

G20 insg. (in Tsd.)

1. Daten aus 2003. 2. Daten aus 2010. 3. Daten aus 2009. 4. Daten aus 2004.

Quelle: OECD. Arbeitskräfteerhebung des Netzwerks zu den Arbeitsmarktergebnissen sowie den wirtschaftlichen und sozialen Auswirkungen des Lernens (LSO) für die meisten Länder und Arbeitskräfteerhebung der EU (EU-LFS) für Dänemark, Finnland, Island, Irland, Luxemburg und Slowenien sowie Bildungsstand-Daten-

bank des Statistikinstituts des UNESCO für Argentinien, China, Indonesien, Saudi-Arabien und Südafrika. Hinweise s. Anhang 3 unter www.oecd.org/edu/eag.htm.

StatLink: http://dx.doi.org/10.1787/888932848077

Erläuterung der Kennzeichnung fehlender Daten s. Hinweise für den Leser. 
Entwicklungstendenzen bei Bildungsabschlüssen, nach Altersgruppe, sowie durchschnittlicher jährlicher Anstieg $(2000-2011)^{1}$

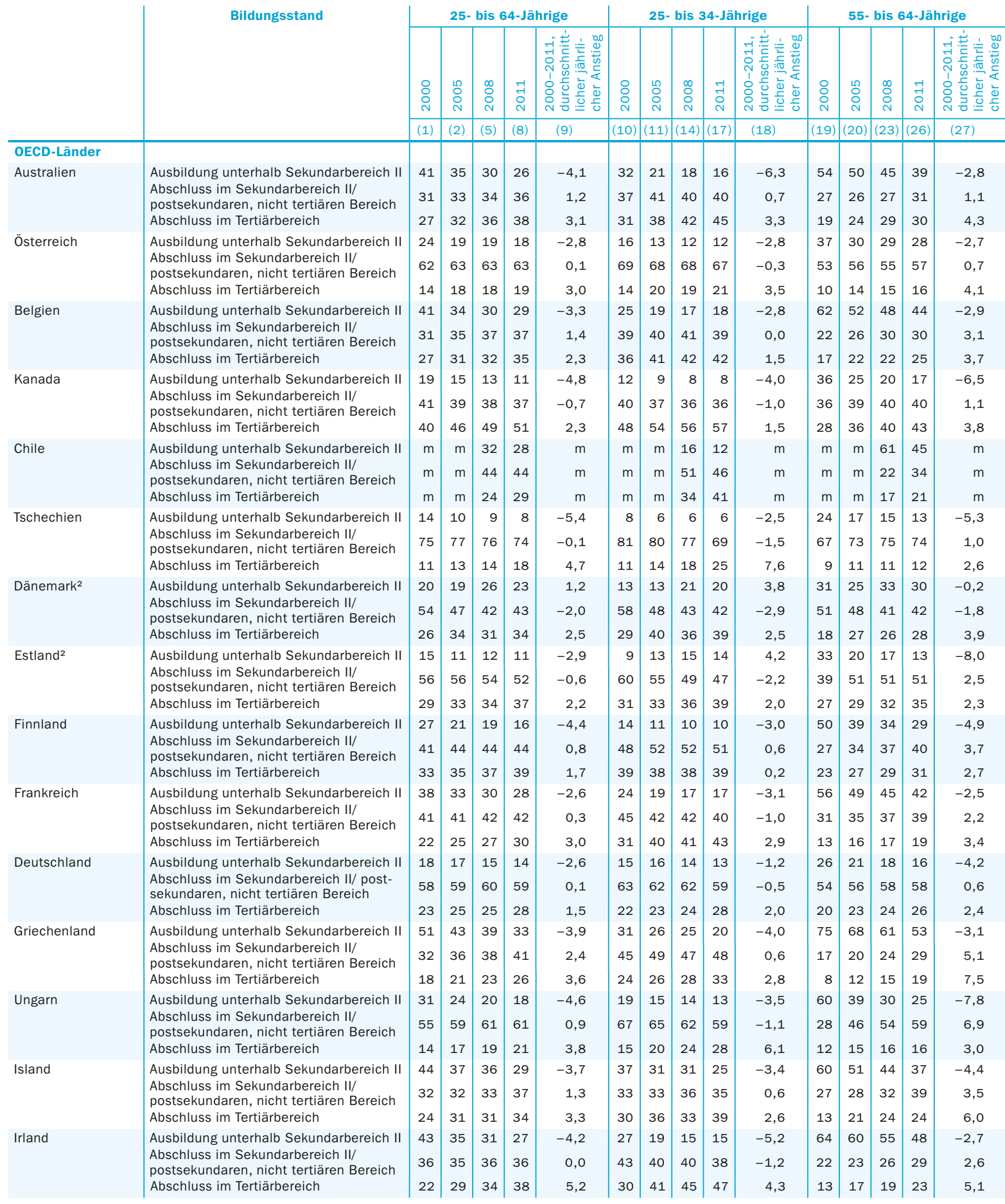

1. Die Daten zu den Jahren 2006, 2007, 2009 und 2010 stehen im Internet zur Verfügung (s. StatLink unten). 2. Die Zahlen für 2011 für Dänemark, Estland und die Niederlande in dieser Tabelle können von den Zahlen in den anderen Tabellen in Indikator A1 abweichen, da unterschiedliche Datenquellen zugrunde liegen. Die Zahlen in dieser Tabelle basieren für alle Jahre auf der EU-LFS. 3. Der durchschnittliche jährliche Anstieg in Norwegen wird ab 2005 berechnet, da die Zahlen für die Abschlussquoten der Jahre 2000 bis 2004 gemäß einer früheren Klassifizierung der Bildungsabschlüsse erstellt wurden und daher mit den Zahlen ab 2005 nicht vergleichbar sind.

Quellen: OECD. Arbeitskräfteerhebung des Netzwerks zu den Arbeitsmarktergebnissen sowie den wirtschaftlichen und sozialen Auswirkungen des Lernens (LSO) für die meisten Länder sowie Arbeitskräfteerhebung der EU (EU-LFS) für Dänemark, Estland, Finnland, Frankreich (nur für 2000), Island, Irland, Italien (nur für 2000), Luxemburg und Slowenien. Hinweise s. Anhang 3 unter www.oecd.org/edu/eag.htm. StatLink: http://dx.doi.org/10.1787/888932848115 Erläuterung der Kennzeichnung fehlender Daten s. Hinweise für den Leser. 
Tabelle A1.4a (Forts. 1)

Entwicklungstendenzen bei Bildungsabschlüssen, nach Altersgruppe, sowie durchschnittlicher jährlicher Anstieg (2000-2011)

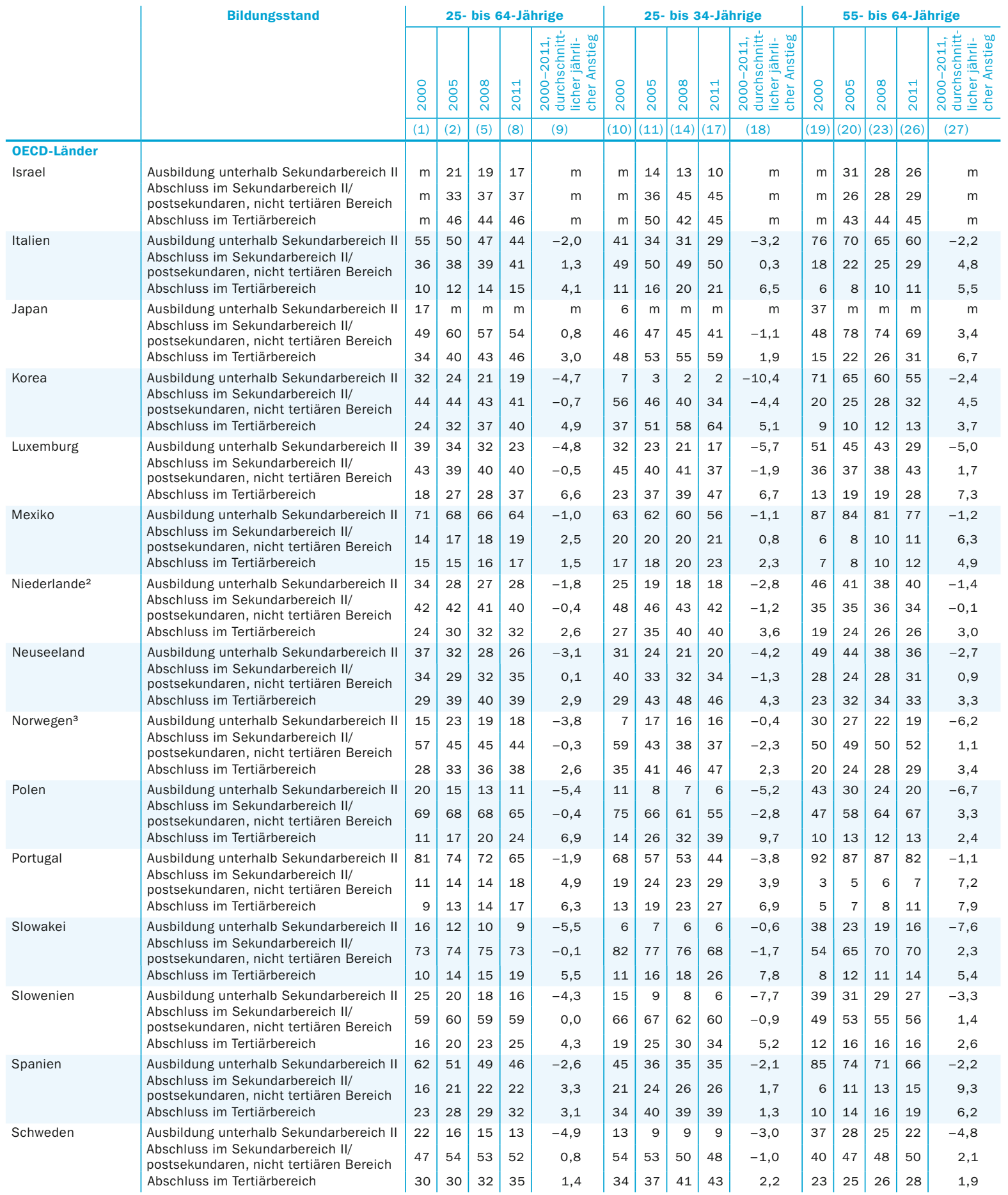

1. Die Daten zu den Jahren 2006, 2007, 2009 und 2010 stehen im Internet zur Verfügung (s. StatLink unten). 2. Die Zahlen für 2011 für Dänemark, Estland und die Niederlande in dieser Tabelle können von den Zahlen in den anderen Tabellen in Indikator A1 abweichen, da unterschiedliche Datenquellen zugrunde liegen. Die Zahlen in dieser Tabelle basieren für alle Jahre auf der EU-LFS. 3. Der durchschnittliche jährliche Anstieg in Norwegen wird ab 2005 berechnet, da die Zahlen für die Abschlussquoten der Jahre 2000 bis 2004 gemäß einer früheren Klassifizierung der Bildungsabschlüsse erstellt wurden und daher mit den Zahlen ab 2005 nicht vergleichbar sind.

Quellen: OECD. Arbeitskräfteerhebung des Netzwerks zu den Arbeitsmarktergebnissen sowie den wirtschaftlichen und sozialen Auswirkungen des Lernens (LSO) für die meisten Länder sowie Arbeitskräfteerhebung der EU (EU-LFS) für Dänemark, Estland, Finnland, Frankreich (nur für 2000), Island, Irland, Italien (nur für 2000), Luxemburg und Slowenien. Hinweise s. Anhang 3 unter www.oecd.org/edu/eag.htm. StatLink: http://dx.doi.org/10.1787/888932848115 Erläuterung der Kennzeichnung fehlender Daten s. Hinweise für den Leser. 
Tabelle A1.4a (Forts. 2)

Entwicklungstendenzen bei Bildungsabschlüssen, nach Altersgruppe, sowie durchschnittlicher jährlicher Anstieg (2000-2011)

\begin{tabular}{|c|c|c|c|c|c|c|c|c|c|c|c|c|c|c|c|c|}
\hline & \multirow[t]{3}{*}{ Bildungsstand } & \multicolumn{5}{|c|}{ 25- bis 64-Jährige } & \multicolumn{5}{|c|}{ 25- bis 34-Jährige } & \multicolumn{5}{|c|}{ 55- bis 64-Jährige } \\
\hline & & ㅇ & $\begin{array}{l}\text { Ln } \\
\circ \\
\stackrel{\text { N }}{ }\end{array}$ & $\begin{array}{l}\infty \\
\circ \\
\stackrel{0}{N}\end{array}$ & 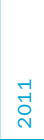 & 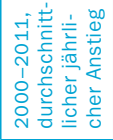 & $\begin{array}{l}\text { } \\
\text { ํ } \\
\text { ํ. }\end{array}$ & 응 & $\begin{array}{l}\infty \\
\stackrel{\circ}{\circ} \\
\text { ํ. }\end{array}$ & तે & 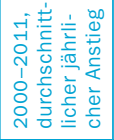 & $\begin{array}{l}\circ \\
\text { ㅇ } \\
\text { ํ. }\end{array}$ & $\begin{array}{l}\text { Ln } \\
\stackrel{\text { ㅇ }}{~}\end{array}$ & $\begin{array}{l}\infty \\
\stackrel{\circ}{\circ} \\
\text { ㄱ }\end{array}$ & 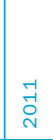 & 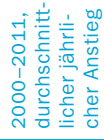 \\
\hline & & $(1)$ & $(2)$ & $(5)$ & $(8)$ & (9) & $(10)$ & (11) & $(14)$ & $(17)$ & $(18)$ & $(19)$ & $(20)$ & (23) & $(26)$ & $(27)$ \\
\hline \multicolumn{17}{|l|}{ OECD-Länder } \\
\hline \multirow[t]{3}{*}{ Schweiz } & Ausbildung unterhalb Sekundarbereich II & 16 & 15 & 13 & 14 & $-1,0$ & 10 & 10 & 10 & 11 & 0,6 & 26 & 21 & 17 & 19 & $-2,8$ \\
\hline & $\begin{array}{l}\text { Abschluss im Sekundarbereich II/ } \\
\text { postsekundaren, nicht tertiären Bereich }\end{array}$ & 60 & 56 & 53 & 50 & $-1,5$ & 64 & 59 & 52 & 49 & $-2,4$ & 55 & 57 & 55 & 54 & $-0,3$ \\
\hline & Abschluss im Tertiärbereich & 24 & 29 & 34 & 35 & 3,5 & 26 & 31 & 38 & 40 & 4,1 & 18 & 22 & 27 & 27 & 3,6 \\
\hline \multirow[t]{3}{*}{ Türkei } & Ausbildung unterhalb Sekundarbereich II & 77 & 72 & 70 & 68 & $-1,1$ & 72 & 63 & 60 & 57 & $-2,2$ & 87 & 84 & 81 & 81 & $-0,7$ \\
\hline & $\begin{array}{l}\text { Abschluss im Sekundarbereich II/ } \\
\text { postsekundaren, nicht tertiären Bereich }\end{array}$ & 15 & 18 & 18 & 18 & 1,8 & 19 & 24 & 25 & 25 & 2,4 & 7 & 8 & 9 & 10 & 3,2 \\
\hline & Abschluss im Tertiärbereich & 8 & 10 & 12 & 14 & 4,8 & 9 & 13 & 15 & 19 & 7,1 & 6 & 8 & 9 & 10 & 4,8 \\
\hline \multirow{3}{*}{$\begin{array}{l}\text { Vereinigtes } \\
\text { Königreich }\end{array}$} & Ausbildung unterhalb Sekundarbereich II & 37 & 33 & 28 & 23 & $-4,3$ & 33 & 27 & 20 & 16 & $-6,6$ & 45 & 40 & 38 & 33 & $-2,6$ \\
\hline & $\begin{array}{l}\text { Abschluss im Sekundarbereich II/ } \\
\text { postsekundaren, nicht tertiären Bereich }\end{array}$ & 37 & 37 & 36 & 37 & 0,1 & 38 & 38 & 37 & 37 & $-0,1$ & 37 & 36 & 34 & 35 & $-0,3$ \\
\hline & Abschluss im Tertiärbereich & 26 & 30 & 35 & 39 & 4,0 & 29 & 35 & 43 & 47 & 4,5 & 19 & 24 & 28 & 31 & 4,7 \\
\hline \multirow[t]{3}{*}{ Vereinigte Staaten } & Ausbildung unterhalb Sekundarbereich II & 13 & 12 & 11 & 11 & $-1,4$ & 12 & 13 & 12 & 11 & $-0,7$ & 18 & 14 & 11 & 10 & $-5,0$ \\
\hline & $\begin{array}{l}\text { Abschluss im Sekundarbereich II/ } \\
\text { postsekundaren, nicht tertiären Bereich }\end{array}$ & 51 & 49 & 48 & 47 & $-0,8$ & 50 & 47 & 47 & 46 & $-0,8$ & 52 & 49 & 49 & 48 & $-0,6$ \\
\hline & Abschluss im Tertiärbereich & 36 & 39 & 41 & 42 & 1,4 & 38 & 39 & 42 & 43 & 1,1 & 30 & 37 & 40 & 41 & 3,0 \\
\hline \multirow[t]{3}{*}{ OECD-Durchschnitt } & Ausbildung unterhalb Sekundarbereich II & 34 & 30 & 28 & 25 & $-2,7$ & 24 & 21 & 19 & 18 & $-2,8$ & 51 & 43 & 40 & 36 & $-3,0$ \\
\hline & $\begin{array}{l}\text { Abschluss im Sekundarbereich II/ } \\
\text { postsekundaren, nicht tertiären Bereich }\end{array}$ & 44 & 44 & 44 & 44 & 0,1 & 49 & 47 & 46 & 44 & $-1,0$ & 34 & 38 & 39 & 41 & 1,7 \\
\hline & Abschluss im Tertiärbereich & 22 & 27 & 29 & 32 & 3,3 & 26 & 33 & 35 & 39 & 3,5 & 15 & 20 & 22 & 24 & 4,2 \\
\hline \multirow{3}{*}{$\begin{array}{l}\text { OECD-Durchschnitt } \\
\text { für Länder mit ver- } \\
\text { fügbaren Daten für } \\
\text { alle Referenzjahre }\end{array}$} & Ausbildung unterhalb Sekundarbereich II & 35 & 30 & 28 & 25 & $-2,8$ & 25 & 21 & 20 & 18 & $-2,8$ & 51 & 44 & 40 & 36 & $-3,1$ \\
\hline & $\begin{array}{l}\text { Abschluss im Sekundarbereich II/ } \\
\text { postsekundaren, nicht tertiären Bereich }\end{array}$ & 4 & 14 & 44 & 44 & 0 & 49 & 47 & 46 & 44 & $-1,0$ & 34 & 37 & 39 & 41 & 1,8 \\
\hline & Abschluss im Tertiärbereich & 22 & 26 & 28 & 31 & 3,2 & 26 & 32 & 35 & 38 & 3,5 & 15 & 19 & 21 & 23 & 3,8 \\
\hline \multirow[t]{3}{*}{ EU21-Durchschnitt } & Ausbildung unterhalb Sekundarbereich II & 34 & 29 & 27 & 24 & $-3,2$ & 23 & 19 & 18 & 16 & $-3,2$ & 51 & 42 & 39 & 35 & $-3,4$ \\
\hline & $\begin{array}{l}\text { Abschluss im Sekundarbereich II/ } \\
\text { postsekundaren, nicht tertiären Bereich }\end{array}$ & 46 & 48 & 48 & 48 & 0,3 & 53 & 52 & 50 & 48 & $-0,9$ & 35 & 40 & 42 & 44 & 2,1 \\
\hline & Abschluss im Tertiärbereich & 20 & 24 & 26 & 29 & 3,4 & 24 & 29 & 32 & 36 & 3,8 & 14 & 18 & 19 & 21 & 3,8 \\
\hline
\end{tabular}

Sonst. G20-Länder

\begin{tabular}{|c|c|}
\hline Argentinien & $\begin{array}{l}\text { Ausbildung unterhalb Sekundarbereich II } \\
\text { Abschluss im Sekundarbereich II/ } \\
\text { postsekundaren, nicht tertiären Bereich } \\
\text { Abschluss im Tertiärbereich }\end{array}$ \\
\hline Brasilien & $\begin{array}{l}\text { Ausbildung unterhalb Sekundarbereich II } \\
\text { Abschluss im Sekundarbereich II/ } \\
\text { postsekundaren, nicht tertiären Bereich } \\
\text { Abschluss im Tertiärbereich }\end{array}$ \\
\hline China & $\begin{array}{l}\text { Ausbildung unterhalb Sekundarbereich II } \\
\text { Abschluss im Sekundarbereich II/ } \\
\text { postsekundaren, nicht tertiären Bereich } \\
\text { Abschluss im Tertiärbereich }\end{array}$ \\
\hline Indien & $\begin{array}{l}\text { Ausbildung unterhalb Sekundarbereich II } \\
\text { Abschluss im Sekundarbereich II/ } \\
\text { postsekundaren, nicht tertiären Bereich } \\
\text { Abschluss im Tertiärbereich }\end{array}$ \\
\hline Indonesien & $\begin{array}{l}\text { Ausbildung unterhalb Sekundarbereich II } \\
\text { Abschluss im Sekundarbereich II/ } \\
\text { postsekundaren, nicht tertiären Bereich } \\
\text { Abschluss im Tertiärbereich }\end{array}$ \\
\hline $\begin{array}{l}\text { Russische } \\
\text { Föderation }\end{array}$ & $\begin{array}{l}\text { Ausbildung unterhalb Sekundarbereich II } \\
\text { Abschluss im Sekundarbereich II/ } \\
\text { postsekundaren, nicht tertiären Bereich } \\
\text { Abschluss im Tertiärbereich }\end{array}$ \\
\hline Saudi-Arabien & $\begin{array}{l}\text { Ausbildung unterhalb Sekundarbereich II } \\
\text { Abschluss im Sekundarbereich II/ } \\
\text { postsekundaren, nicht tertiären Bereich } \\
\text { Abschluss im Tertiärbereich }\end{array}$ \\
\hline Südafrika & $\begin{array}{l}\text { Ausbildung unterhalb Sekundarbereich II } \\
\text { Abschluss im Sekundarbereich II/ } \\
\text { postsekundaren, nicht tertiären Bereich } \\
\text { Abschluss im Tertiärbereich }\end{array}$ \\
\hline
\end{tabular}

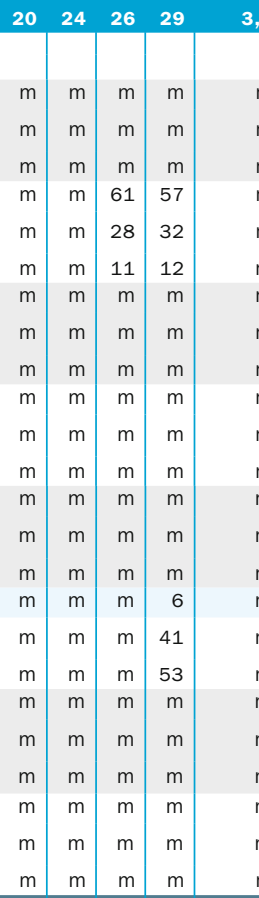

\begin{tabular}{|c|c|c|c|c|c|c|c|c|c|}
\hline $\mathrm{m}$ & $\mathrm{m}$ & $\mathrm{m}$ & $\mathrm{m}$ & $\mathrm{m}$ & $\mathrm{m}$ & $\mathrm{m}$ & $\mathrm{m}$ & $\mathrm{m}$ & $\mathrm{m}$ \\
\hline $\mathrm{m}$ & $\mathrm{m}$ & $\mathrm{m}$ & $\mathrm{m}$ & $\mathrm{m}$ & $\mathrm{m}$ & $\mathrm{m}$ & $\mathrm{m}$ & $\mathrm{m}$ & $\mathrm{m}$ \\
\hline $\mathrm{m}$ & $\mathrm{m}$ & $\mathrm{m}$ & $\mathrm{m}$ & $\mathrm{m}$ & $\mathrm{m}$ & $\mathrm{m}$ & $\mathrm{m}$ & $\mathrm{m}$ & $\mathrm{m}$ \\
\hline $\mathrm{m}$ & $\mathrm{m}$ & 50 & 43 & $\mathrm{~m}$ & $\mathrm{~m}$ & $\mathrm{~m}$ & 77 & 74 & $\mathrm{~m}$ \\
\hline $\mathrm{m}$ & $\mathrm{m}$ & 39 & 44 & $\mathrm{~m}$ & $\mathrm{~m}$ & $\mathrm{~m}$ & 14 & 17 & $\mathrm{~m}$ \\
\hline $\mathrm{m}$ & $\mathrm{m}$ & 11 & 13 & $\mathrm{~m}$ & $\mathrm{~m}$ & $\mathrm{~m}$ & 9 & 9 & $\mathrm{~m}$ \\
\hline $\mathrm{m}$ & $\mathrm{m}$ & $\mathrm{m}$ & $\mathrm{m}$ & $\mathrm{m}$ & $\mathrm{m}$ & $\mathrm{m}$ & $\mathrm{m}$ & $\mathrm{m}$ & $\mathrm{m}$ \\
\hline $\mathrm{m}$ & $\mathrm{m}$ & $\mathrm{m}$ & $\mathrm{m}$ & $\mathrm{m}$ & $\mathrm{m}$ & $\mathrm{m}$ & $\mathrm{m}$ & $\mathrm{m}$ & $\mathrm{m}$ \\
\hline $\mathrm{m}$ & $\mathrm{m}$ & $\mathrm{m}$ & $\mathrm{m}$ & $\mathrm{m}$ & $\mathrm{m}$ & $\mathrm{m}$ & $\mathrm{m}$ & $\mathrm{m}$ & $\mathrm{m}$ \\
\hline $\mathrm{m}$ & $\mathrm{m}$ & $\mathrm{m}$ & $\mathrm{m}$ & $\mathrm{m}$ & $\mathrm{m}$ & $\mathrm{m}$ & $\mathrm{m}$ & $\mathrm{m}$ & $\mathrm{m}$ \\
\hline $\mathrm{m}$ & $\mathrm{m}$ & $\mathrm{m}$ & $\mathrm{m}$ & $\mathrm{m}$ & $\mathrm{m}$ & $\mathrm{m}$ & $\mathrm{m}$ & $\mathrm{m}$ & $\mathrm{m}$ \\
\hline $\mathrm{m}$ & $\mathrm{m}$ & $\mathrm{m}$ & $\mathrm{m}$ & $\mathrm{m}$ & $\mathrm{m}$ & $\mathrm{m}$ & $\mathrm{m}$ & $\mathrm{m}$ & $\mathrm{m}$ \\
\hline $\mathrm{m}$ & $\mathrm{m}$ & $\mathrm{m}$ & $\mathrm{m}$ & $\mathrm{m}$ & $\mathrm{m}$ & $\mathrm{m}$ & $\mathrm{m}$ & $\mathrm{m}$ & $\mathrm{m}$ \\
\hline $\mathrm{m}$ & $\mathrm{m}$ & $\mathrm{m}$ & $\mathrm{m}$ & $\mathrm{m}$ & $\mathrm{m}$ & $\mathrm{m}$ & $\mathrm{m}$ & $\mathrm{m}$ & $\mathrm{m}$ \\
\hline $\mathrm{m}$ & $\mathrm{m}$ & $\mathrm{m}$ & $\mathrm{m}$ & $\mathrm{m}$ & $\mathrm{m}$ & $\mathrm{m}$ & $\mathrm{m}$ & $\mathrm{m}$ & $\mathrm{m}$ \\
\hline $\mathrm{m}$ & $\mathrm{m}$ & $\mathrm{m}$ & 6 & $\mathrm{~m}$ & $\mathrm{~m}$ & $\mathrm{~m}$ & $\mathrm{~m}$ & 9 & $\mathrm{~m}$ \\
\hline $\mathrm{m}$ & $\mathrm{m}$ & $\mathrm{m}$ & 38 & $\mathrm{~m}$ & $\mathrm{~m}$ & $\mathrm{~m}$ & $\mathrm{~m}$ & 42 & $\mathrm{~m}$ \\
\hline $\mathrm{m}$ & $\mathrm{m}$ & $\mathrm{m}$ & 56 & $\mathrm{~m}$ & $\mathrm{~m}$ & $\mathrm{~m}$ & $\mathrm{~m}$ & 49 & $\mathrm{~m}$ \\
\hline $\mathrm{m}$ & $\mathrm{m}$ & $\mathrm{m}$ & $\mathrm{m}$ & $\mathrm{m}$ & $\mathrm{m}$ & $\mathrm{m}$ & $\mathrm{m}$ & $\mathrm{m}$ & $\mathrm{m}$ \\
\hline $\mathrm{m}$ & $\mathrm{m}$ & $\mathrm{m}$ & $\mathrm{m}$ & $\mathrm{m}$ & $\mathrm{m}$ & $\mathrm{m}$ & $\mathrm{m}$ & $\mathrm{m}$ & $\mathrm{m}$ \\
\hline $\mathrm{m}$ & $\mathrm{m}$ & $\mathrm{m}$ & $\mathrm{m}$ & $\mathrm{m}$ & $\mathrm{m}$ & $\mathrm{m}$ & $\mathrm{m}$ & $\mathrm{m}$ & $\mathrm{m}$ \\
\hline $\mathrm{m}$ & $\mathrm{m}$ & $\mathrm{m}$ & $\mathrm{m}$ & $\mathrm{m}$ & $\mathrm{m}$ & $\mathrm{m}$ & $\mathrm{m}$ & $\mathrm{m}$ & $\mathrm{m}$ \\
\hline $\mathrm{m}$ & $\mathrm{m}$ & $\mathrm{m}$ & $\mathrm{m}$ & $\mathrm{m}$ & $\mathrm{m}$ & $\mathrm{m}$ & $\mathrm{m}$ & $\mathrm{m}$ & $\mathrm{m}$ \\
\hline $\mathrm{m}$ & $\mathrm{m}$ & $\mathrm{m}$ & $\mathrm{m}$ & $\mathrm{m}$ & $\mathrm{m}$ & $\mathrm{m}$ & $\mathrm{m}$ & $\mathrm{m}$ & $\mathrm{m}$ \\
\hline $\mathbf{m}$ & $\mathbf{m}$ & $\mathbf{m}$ & $\mathrm{m}$ & $\mathbf{m}$ & $\mathbf{m}$ & $\mathbf{m}$ & $\mathrm{m}$ & $\mathbf{m}$ & $\mathbf{m}$ \\
\hline
\end{tabular}

1. Die Daten zu den Jahren 2006, 2007, 2009 und 2010 stehen im Internet zur Verfügung (s. StatLink unten). 2. Die Zahlen für 2011 für Dänemark, Estland und die Niederlande in dieser Tabelle können von den Zahlen in den anderen Tabellen in Indikator A1 abweichen, da unterschiedliche Datenquellen zugrunde liegen. Die Zahlen in dieser Tabelle basieren für alle Jahre auf der EU-LFS. 3. Der durchschnittliche jährliche Anstieg in Norwegen wird ab 2005 berechnet, da die Zahlen für die Abschlussquoten der Jahre 2000 bis 2004 gemäß einer früheren Klassifizierung der Bildungsabschlüsse erstellt wurden und daher mit den Zahlen ab 2005 nicht vergleichbar sind.

Quellen: OECD. Arbeitskräfteerhebung des Netzwerks zu den Arbeitsmarktergebnissen sowie den wirtschaftlichen und sozialen Auswirkungen des Lernens (LSO) für die meisten Länder sowie Arbeitskräfteerhebung der EU (EU-LFS) für Dänemark, Estland, Finnland, Frankreich (nur für 2000), Island, Irland, Italien (nur für 2000), Luxemburg und Slowenien. Hinweise s. Anhang 3 unter www.oecd.org/edu/eag.htm. StatLink: http://dx.doi.org/10.1787/888932848115 Erläuterung der Kennzeichnung fehlender Daten s. Hinweise für den Leser. 
Bildungsstand von 25- bis 64-Jährigen, nach Ausrichtung des Bildungsgangs (berufsbildend oder allgemeinbildend) und Geschlecht (2011)

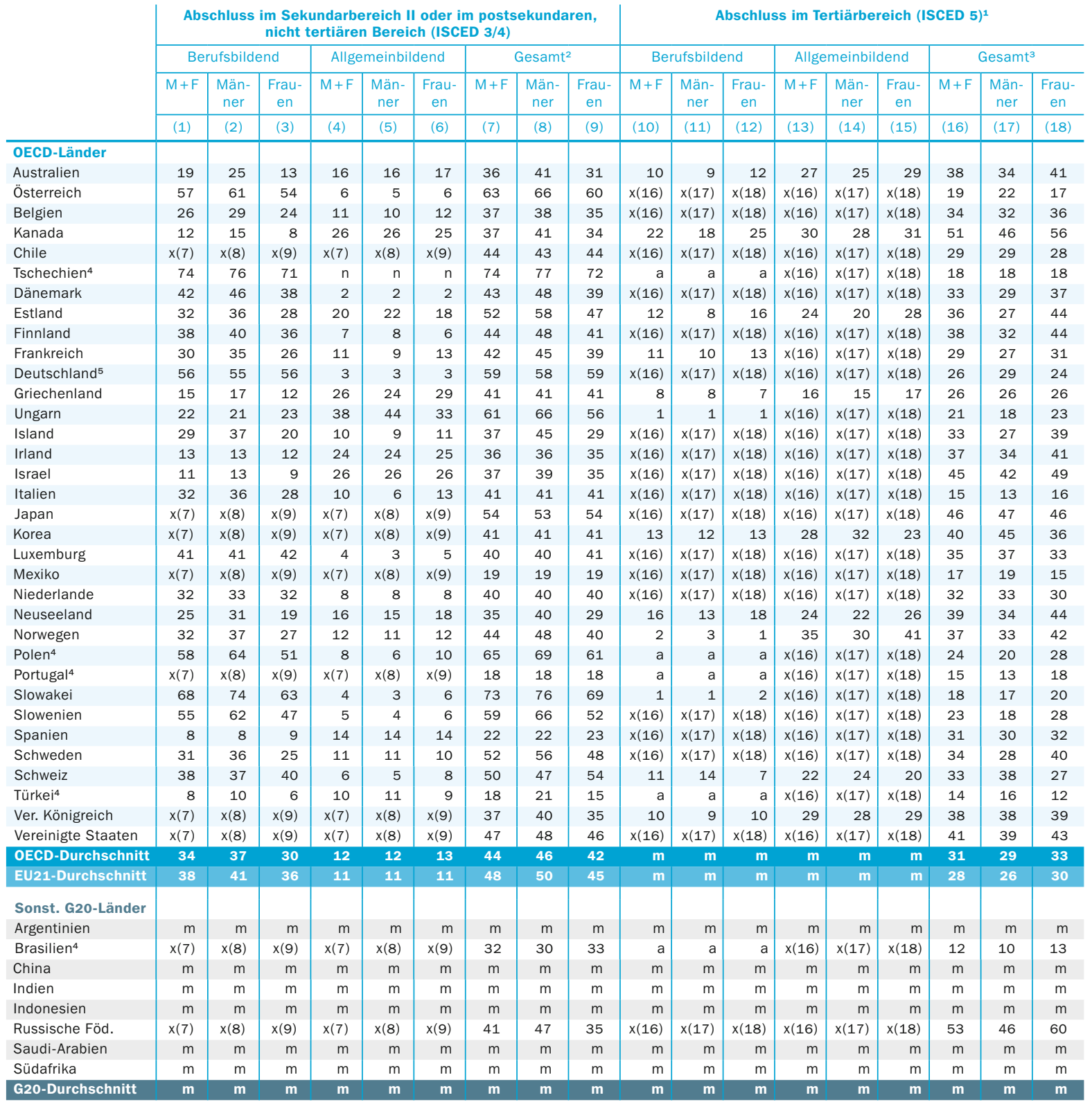

1. Diese Tabelle enthält für den Tertiärbereich nur Daten über Abschlüsse im Tertiärbereich A und B (ISCED 5A und 5B), da die meisten Daten zu ISCED 6 nicht nach allgmeinbildend/berufsbildend aufgegliedert werden können. 2. Die Zahlen stehen entweder für die kombinierten Anteile von Absolventen allgemeinbildender und berufsbildender Bildungsgänge oder die kombinierten Anteile von Absolventen beider Arten von Bildungsgängen und von Bildungsgängen, für die keine Ausrichtung angegeben ist, oder den Anteil von Absolventen von Bildungsgängen, für die keine Ausrichtung angegeben ist. Die Zahlen in diesen Spalten entsprechen denjenigen für Absolventen des Sekundarbereichs II oder des postsekundaren, nicht tertiären Bereichs in Tabelle A1.4a und Tabelle A1.4b im Internet.

3. Die Zahlen stehen entweder für die kombinierten Anteile von Absolventen allgemeinbildender und berufsbildender Bildungsgänge oder die kombinierten Anteile von Absolventen beider Arten von Bildungsgängen und von Bildungsgängen, für die keine Ausrichtung angegeben ist, oder den Anteil von Absolventen von Bildungsgängen, für die keine Ausrichtung angegeben ist. Die Zahlen in diesen Spalten haben keine genauen Entsprechungen in diesem Indikator. Tabelle A1.1a und Tabelle A1.1b im Internet enthalten getrennte Werte für die Abschlüsse auf den ISCED-Stufen 5A and 5B. 4. In Brasilien, Polen, Portugal, Tschechien und der Türkei enthalten die Zahlen für Bildungsgänge, bei denen keine Ausrichtung angegeben ist, nur Studiengänge der ISCED-Stufe 5A. 5. In Deutschland entspricht ein Abschluss auf ISCED-Stufe 4A einem Abschluss sowohl eines allgemeinbildenden als auch eines berufsbildenden Bildungsgangs. Absolventen mit einem derartigen Abschluss wurden in dieser Tabelle den berufsbildenden Bildungsgängen zugeordnet.

Quelle: OECD. Spezielle Datenerhebung zur beruflichen Ausbildung des Netzwerks zu den Arbeitsmarktergebnissen sowie den wirtschaftlichen und sozialen Auswirkungen des Lernens (LSO), Arbeitsgruppe Übergang vom Bildungssystem in den Arbeitsmarkt (Learning and Labour Transitions) für die meisten Länder sowie die Arbeitskräfteerhebung der EU (EU-LFS) und die Arbeitskräfteerhebung der EU mit Informationen zu den Fachrichtungen der entsprechenden Studiengänge (EULFS_VET) für Dänemark, Finnland, Irland, Island, Luxemburg und Slowenien. Hinweise s. Anhang 3 unter www.oecd.org/edu/eag.htm.

StatLink: http://dx.doi.org/10.1787/888932848153

Erläuterung der Kennzeichnung fehlender Daten s. Hinweise für den Leser. 


\section{Wie viele Schüler werden den Sekundar- bereich II erfolgreich abschließen?}

Ausgehend von den aktuellen Abschlussquoten wird geschätzt, dass im Durchschnitt 83 Prozent der gegenwärtig in den OECD-Ländern lebenden jungen Menschen im Laufe ihres Lebens einen Abschluss im Sekundarbereich II erwerben werden; in den G20-Ländern wird dies auf etwa 79 Prozent der jungen Menschen zutreffen.

Heute erlangen in fast allen OECD-Ländern eher junge Frauen als junge Männer einen Abschluss im Sekundarbereich II, eine Umkehr der früher üblichen Situation.

In Dänemark, Finnland, den Niederlanden und Norwegen sind rund to Prozent der Absolventen des Sekundarbereichs II mindestens 25 Jahre alt, während der entsprechende Anteil in Island und Portugal fast 20 Prozent bzw. 30 Prozent beträgt.

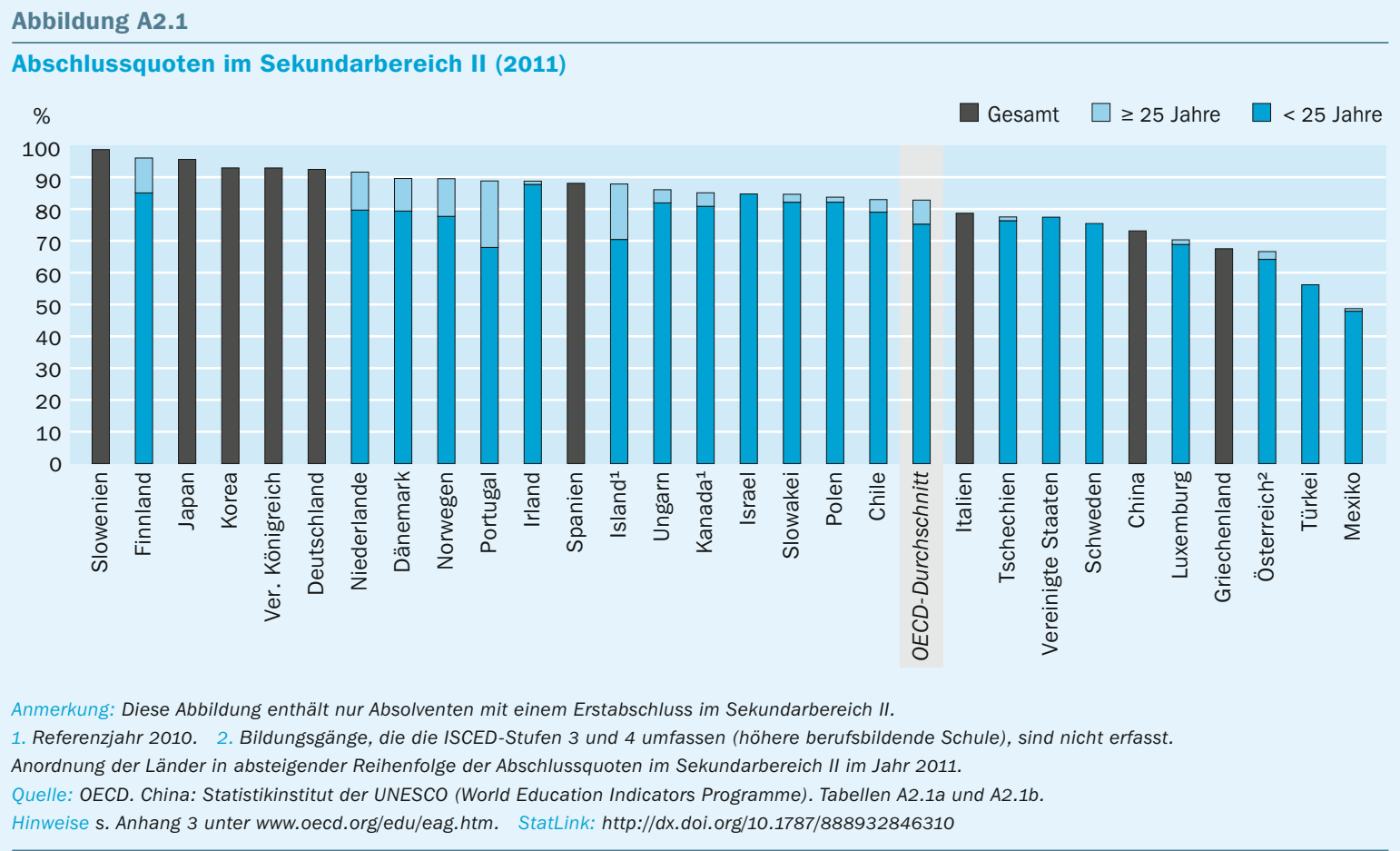

\section{Kontext}

Der Sekundarbereich II festigt durch allgemeinbildende oder berufsbildende Bildungsgänge das notwendige Wissen und die grundlegenden Fertigkeiten und Fähigkeiten der Schüler. Er soll sie auf den Eintritt in den Tertiärbereich oder den Arbeitsmarkt vorbereiten und darüber hinaus die Grundlage dafür legen, dass die Schüler zu engagierten Bürgern werden. In vielen Ländern ist dieser Bildungsbereich nicht Teil der Pflichtschulzeit und kann zwischen zwei und fünfJahre dauern. Von entscheidender Bedeutung jedoch ist, dass diese beiden Ausrichtungen der Bildungsgänge von 
gleicher Qualität sind und beide gewährleisten, dass den Schülern der entsprechende Übergang erfolgreich gelingt.

Ein Abschluss im Sekundarbereich II ist in allen Ländern immer wichtiger geworden, da die auf dem Arbeitsmarkt benötigten Kompetenzen in zunehmendem Ausmaß wissensbasiert sind und von den Beschäftigten mehr und mehr verlangt wird, sich den Unsicherheiten einer sich schnell wandelnden weltweiten Wirtschaft anzupassen. Abschlussquoten sind ein Hinweis darauf, inwieweit es den Bildungssystemen gelingt, die Schüler darauf vorzubereiten, den Mindestanforderungen des Arbeitsmarktes zu entsprechen, sie erfassen jedoch nicht die Qualität der Bildungsergebnisse.

\section{Weitere wichtige Ergebnisse}

- In 23 von 29 Ländern mit verfügbaren Daten liegen die Abschlussquoten für einen Erstabschluss im Sekundarbereich II bei mindestens 75 Prozent. In Dänemark, Deutschland, Finnland, Japan, Korea, den Niederlanden, Norwegen, Slowenien und dem Vereinigten Königreich liegen die Abschlussquoten bei mindestens 9o Prozent.

Im Durchschnitt der OECD-Länder erlangen Schüler ihren Erstabschluss im Sekundarbereich im Alter von 20 Jahren, wobei dieser Durchschnitt von I7 Jahren in Israel, der Türkei und den Vereinigten Staaten bis zu mindestens 22 Jahren in Finnland, Island, Norwegen und Portugal reicht.

Mehr junge Frauen als je zuvor erlangen einen Abschluss in einem berufsbildenden Bildungsgang. Ihre Abschlussquoten nähern sich inzwischen in diesen Bildungsgängen denen der jungen Männer an.

Der überwiegende Teil der Jungen in einem berufsbildenden Bildungsgang im Sekundarbereich II wählt eine Ausbildung in der Fachrichtung Ingenieurwissenschaften, Fertigung und Bauwesen, während sich Mädchen in diesen Bildungsgängen für andere Fachrichtungen, insbesondere Wirtschafts-, Rechts- und Sozialwissenschaften, Gesundheit und Soziales sowie Dienstleistungen, entscheiden.

\section{Entwicklungstendenzen}

Seit 1995 sind die Abschlussquoten im Sekundarbereich II im Durchschnitt der OECD-Länder mit vergleichbaren Daten um 8 Prozentpunkte gestiegen. Den stärksten Anstieg gab es in Mexiko, wo die jährliche Wachstumsrate zwischen 2000 und $201 \mathrm{I}$ bei 4 Prozent lag.

\section{Hinweise}

Abschlussquoten zeigen den geschätzten prozentualen Anteil einer spezifischen Altersgruppe, der im Laufe des Lebens einen Abschluss im Sekundarbereich II erwerben wird. Diese Schätzung basiert auf der Zahl der Absolventen im Jahr 20II sowie der Altersverteilung in dieser Gruppe. Die angegebenen Zahlen basieren sowohl auf einer bestimmten Population (der Altersgruppe) als auch auf den aktuellen Abschlussquoten, sie werden somit von jeder Änderung des Bildungssystems beeinflusst, wie beispielsweise der Einführung neuer Bildungsgänge und Änderungen der Dauer der 
Bildungsgänge. Abschlussquoten können sehr hoch sein und in einem Zeitraum, in dem unerwartet viele Personen in die Ausbildung zurückkehren, sogar mehr als roo Prozent betragen. Dies ist zum Beispiel in Portugal geschehen, als das Programm „Neue Chancen“ eingeführt wurde, um denjenigen, die die Schule ohne Abschluss im Sekundarbereich früh verlassen haben, eine zweite Chance zu geben.

In diesem Indikator bezieht sich die Angabe „Alter“ in der Regel auf das Alter von Schülern/Studierenden zu Beginn des Kalenderjahres, sie könnten jedoch schon ein Jahr älter als angegeben sein, wenn der Abschluss gegen Ende des Schuljahres erfolgt. Der 25. Geburtstag wird als die obere Altersgrenze für den Abschluss der Erstausbildung angesehen. 20II waren in den OECD-Ländern mehr als go Prozent der Absolventen mit einem Erstabschluss im Sekundarbereich II jünger als 25 Jahre. Absolventen dieses Bereichs, die bei Erreichen ihres Abschlusses 25 Jahre oder älter sind, besuchen in der Regel spezielle Bildungsgänge, z. B. des zweiten Bildungswegs.

\section{Analyse und Interpretationen}

\section{Abschlüsse im Sekundarbereich II \\ Überblick über die Abschlussquoten im Sekundarbereich II}

Seit 1995 sind die Abschlussquoten für einen Erstabschluss im Sekundarbereich II um rund 8 Prozentpunkte gestiegen. Aktuelle Schätzungen gehen davon aus, dass 83 Prozent der gegenwärtig in den OECD-Ländern lebenden jungen Menschen im Laufe ihres Lebens einen Abschluss im Sekundarbereich II erwerben werden (Tab. A2.Ia). Ein Abschluss im Sekundarbereich II wird häufig als Mindestvoraussetzung für einen erfolgreichen Einstieg in den Arbeitsmarkt erachtet. Die Kosten, die sowohl für den Einzelnen als auch für die Gesellschaft entstehen, wenn dieser Bildungsbereich nicht rechtzeitig abgeschlossen wird, können beträchtlich sein (s. Indikatoren A6 und A7).

Abschlussquoten bieten einen Hinweis darauf, ob bildungspolitische Initiativen tatsächlich dazu geführt haben, dass mehr Menschen einen Abschluss im Sekundarbereich II erwerben. Die großen Unterschiede zwischen den Abschlussquoten spiegeln die große Vielfalt der Bildungssysteme und -programme wider.

Es wird geschätzt, dass in Dänemark, Deutschland, Finnland, Japan, Korea, den Niederlanden, Norwegen, Slowenien und dem Vereinigten Königreich mehr als go Prozent der Menschen im Laufe ihres Lebens einen Abschluss im Sekundarbereich II erwerben werden, in Mexiko und der Türkei dagegen weniger als 6o Prozent (Tab. A2.ra). Dennoch weisen Mexiko, Portugal und die Türkei zusammen mit Spanien die höchsten durchschnittlichen jährlichen Wachstumsraten (von I995 bzW. 2000 bis 20II) bei den Abschlussquoten im Sekundarbereich II auf - deutlich oberhalb des OECD-Durchschnitts von o,6 Prozent. Die jährliche Wachstumsrate liegt in Spanien und der Türkei bei über 2 Prozent, in Mexiko und Portugal sogar bei über 3 Prozent (Tab. A2.2a).

Die berufliche Bildung ist in vielen OECD-Ländern ein wesentlicher Bestandteil der Ausbildung im Sekundarbereich (s. Indikator AI). Zwischen 2005 und 20II haben sich die Abschlussquoten für berufsvorbereitende und berufsbildende Bildungsgänge im 
Sekundarbereich II mit einem durchschnittlichen Anstieg von 2 Prozentpunkten ähnlich entwickelt wie die Abschlussquoten im Sekundarbereich II insgesamt. Zwischen den einzelnen Ländern bestehen jedoch deutliche Unterschiede bei diesen Entwicklungstendenzen. In Tschechien beispielsweise gingen die Abschlussquoten bei berufsbildenden Bildungsgängen in diesem Zeitraum um I5 Prozentpunkte zurück, während sie in Finnland um 2o Prozentpunkte stiegen (Tab. A2.2b im Internet).

Außerdem bedeuten diese Abschlussquoten nicht, dass alle Absolventen anschließend entweder ein Studium im Tertiärbereich aufnehmen oder direkt in den Arbeitsmarkt eintreten werden. Die Zahl der Absolventen, die weder in Beschäftigung noch in einer Form der Ausbildung sind, hat in allen OECD-Ländern sogar zugenommen. Daher ist es wichtig, die richtige Mischung an Bildungsangeboten bereitzustellen und sicherzustellen, dass sich den Schülern nach Erwerb eines Abschlusses ausreichend Perspektiven eröffnen.

\section{Abschlussquoten im Sekundarbereich II nach Alter}

Die Abschlussquoten unterscheiden sich auch hinsichtlich des Alters der Absolventen. Dies kann ein Hinweis darauf sein, ob es Möglichkeiten gibt, später im Leben einen Abschluss im Sekundarbereich II zu erwerben, und ob es Unterschiede beim typischen Abschlussalter bei allgemeinbildenden und berufsbildenden Bildungsgängen gibt.

Das durchschnittliche Alter eines Absolventen des Sekundarbereichs II (Erstabschluss) beträgt in den OECD-Ländern 20 Jahre, mehr als 90 Prozent der Absolventen mit einem Erstabschluss sind höchstens 25 Jahre alt. Das Alter, in dem ein Abschluss im Sekundarbereich II erworben wird, variiert zwischen den einzelnen Ländern, in einigen Fällen sogar erheblich. In Israel, der Türkei und den Vereinigten Staaten liegt das durchschnittliche Alter eines Erstabsolventen bei I7 Jahren - dem niedrigsten Alter in allen OECD-Ländern. Finnland, Island, Norwegen und Portugal liegen am anderen Ende der Bandbreite und weisen mit mindestens 22 Jahren das höchste durchschnittliche Alter auf (s. Tab. A2.ra und A2.Ib).

Unterschiede beim Alter der Absolventen lassen sich auch innerhalb einzelner Länder beobachten. Wie Abbildung A2.2 zeigt, bestehen innerhalb eines Landes deutliche Unterschiede zwischen dem Alter der Absolventen von allgemeinbildenden und berufsbildenden Bildungsgängen. Im Durchschnitt ist das Alter der Absolventen von berufsbildenden Bildungsgängen höher als das der Absolventen von allgemeinbildenden Bildungsgängen (22 Jahre gegenüber I9 Jahren). In Belgien, Brasilien, Dänemark, Finnland, Island, Irland, den Niederlanden und Norwegen liegt das durchschnittliche Alter der Absolventen von berufsbildenden Bildungsgängen bei mindestens 25 Jahren, in Australien sogar bei 30 Jahren (Abb. A2.2).

Das durchschnittliche Abschlussalter spiegelt auch spezielle nationale Gegebenheiten wider. In einigen Ländern können Schüler beispielsweise ohne nennenswerte Schwierigkeiten aus dem Bildungssystem aus- und zu einem späteren Zeitpunkt wieder eintreten. Daher sind die Abschlussquoten für Absolventen, die 25 Jahre oder älter sind, in Dänemark, Finnland, den Niederlanden und Norwegen relativ hoch - mindestens Io Prozent der Absolventen sind älter als 25 Jahre, während der entsprechende Anteil in Island und Portugal sogar fast 20 Prozent bzw. 30 Prozent beträgt. 


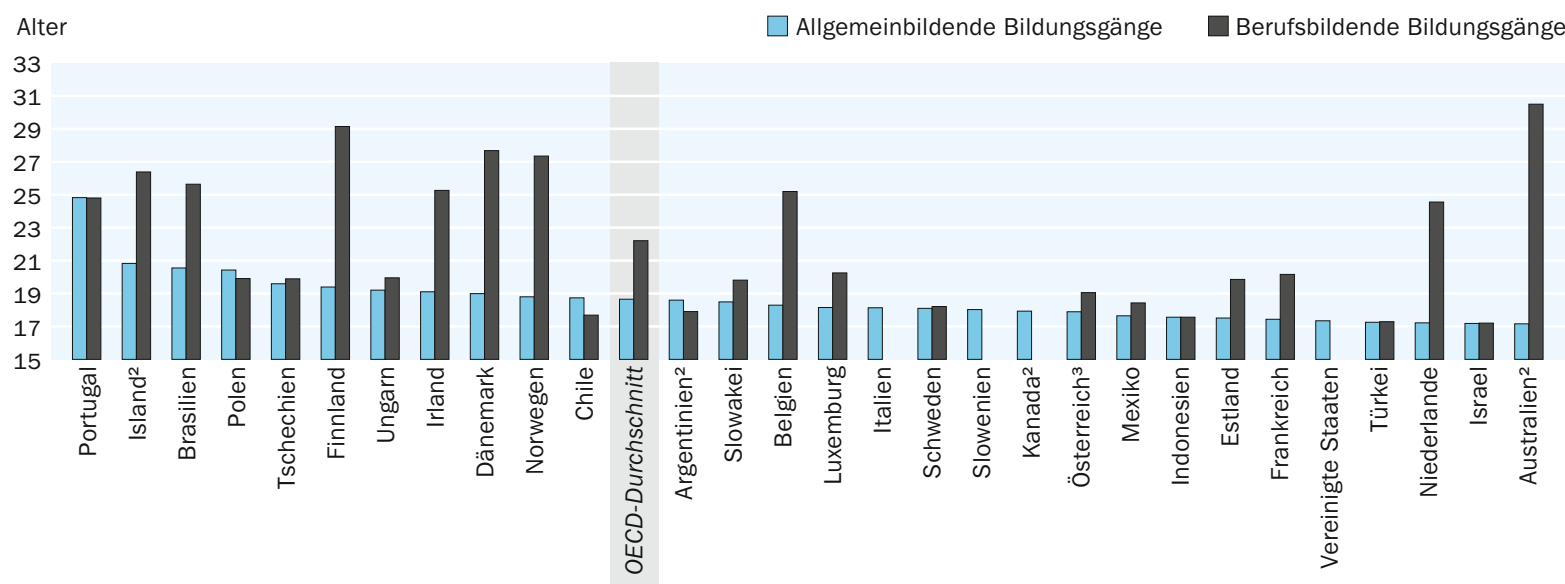

\footnotetext{
1. Das „durchschnittliche Abschlussalter“ bezieht sich in der Regel auf das Alter von Schülern zu Beginn des Kalenderjahres, sie könnten jedoch schon ein Jahr älter als angegeben sein, wenn der Abschluss gegen Ende des Schuljahres erfolgt. 2. Referenzjahr 2010. 3. Bildungsgänge, die die ISCED-Stufen 3 und 4 umfassen (höhere berufsbildende Schule), sind nicht erfasst.

Anordnung der Länder in absteigender Reihenfolge des durchschnittlichen Abschlussalters im Sekundarbereich II (allgemeinbildende Bildungsgänge) im Jahr 2011. Quelle: OECD. Argentinien, Indonesien: Statistikinstitut der UNESCO (World Education Indicators Programme). Tabelle A2.1a.

Hinweise s. Anhang 3 unter www.oecd.org/edu/eag.htm. StatLink: http://dx.doi.org/10.1787/888932846329
}

Die Tatsache, dass der Anteil der Absolventen, die jenseits des typischen Abschlussalters einen Abschluss erwerben, zwischen den Ländern und Bildungsgängen variiert, kann auch damit zusammenhängen, dass Abschlüsse über den sogenannten zweiten Bildungsweg erworben werden können. Diese Bildungsgänge verbessern die für den Arbeitsmarkt erforderlichen Kompetenzen. In Portugal wurde beispielsweise 2005 das Programm „Neue Chancen“ eingeführt, um denjenigen, die die Schule früh verlassen haben oder bei denen dieses Risiko bestand, eine zweite Chance zu geben und um diejenigen Arbeitnehmer zu unterstützen, die weitere Qualifikationen erwerben möchten. Als Folge dieses Programmes sind die Abschlussquoten zwischen 2008 und 2010 um mehr als 40 Prozentpunkte angestiegen. 20Io waren mehr als 40 Prozent der betreffenden Absolventen über 25 Jahre alt.

\section{Abschlussquoten im Sekundarbereich II nach Geschlecht}

In den meisten OECD-Ländern unterscheiden sich die Abschlussquoten für einen Erstabschluss im Sekundarbereich II auch erheblich je nach Geschlecht. Im Durchschnitt sind die Abschlussquoten für Frauen (mit 86 Prozent) höher als diejenigen der Männer (79 Prozent). In Griechenland, Island und Portugal liegen die Abschlussquoten für Frauen um mindestens I5 Prozentpunkte über denjenigen der Männer. Nur in Deutschland, Österreich und Tschechien ist der Anteil der männlichen Absolventen etwas gröBer als derjenige der Frauen (Tab. A2.ra).

Dieser Trend ist bei den unter 25-Jährigen noch ausgeprägter. Im Jahr 20II lagen im Durchschnitt aller OECD-Länder die Abschlussquoten im Sekundarbereich II bei 53 Prozent für die Frauen und 4I Prozent für die Männer. In Argentinien, Italien, Österreich, Polen, der Slowakei, Slowenien und Tschechien kommen auf zwei männliche Absolventen mindestens drei weibliche Absolventinnen (Tab. A2.Ib). 
Traditionell waren die Abschlussquoten der Männer in den berufsvorbereitenden und berufsbildenden Bildungsgängen höher als diejenigen der Frauen, und das ist auch heute noch der Fall. Im Durchschnitt liegen die Abschlussquoten in diesen Bildungsgängen für Männer um 4 Prozentpunkte über denen der Frauen (49 Prozent gegenüber 45 Prozent). In einigen Ländern lässt sich jedoch eine Veränderung dieser Entwicklung beobachten. In Australien, Belgien, Brasilien, Chile, China, Finnland, Irland, Island, den Niederlanden, Portugal und Spanien liegen die entsprechenden Abschlussquoten für Frauen über denjenigen der Männer.

Berufsbildende Bildungsgänge werden jedoch nicht in allen Ländern in gleichem Maße angeboten, daher variieren die Abschlussquoten zwischen den Ländern erheblich. In Finnland, den Niederlanden, Österreich, der Schweiz und Slowenien werden mehr als 70 Prozent der Abschlüsse in berufsvorbereitenden und berufsbildenden Bildungsgängen erlangt, in Argentinien, Brasilien, Estland, Indonesien, Japan, Kanada, Korea, Mexiko, der Türkei und Ungarn liegt ihr Anteil jedoch bei unter 30 Prozent (Tab. A2.ra).

\section{Abschlüsse im Sekundarbereich II nach Fachrichtungen}

Auch bei der Wahl der Fachrichtung zeigen sich geschlechtsspezifische Unterschiede, wenn junge Menschen einen berufsbildenden Bildungsgang wählen. Diese Unterschiede können den traditionellen Geschlechterrollen und Identitäten sowie der breiten Akzeptanz der mit den jeweiligen Fachrichtungen assoziierten kulturellen Werte zugeschrieben werden. Im Durchschnitt erwerben die meisten Absolventen von berufsbildenden Bildungsgängen des Sekundarbereichs II einen Abschluss in den Bereichen Ingenieurwissenschaften, Fertigung und Bauwesen (34 Prozent) (Tab. A2.3b im Internet). Die große Mehrheit der Absolventen dieses Bereichs sind jedoch Männer. Im Durchschnitt aller OECD-Länder sind 49 Prozent der Absolventen dieses Bereichs Männer, in Estland, Norwegen, Tschechien und Ungarn liegt ihr Anteil sogar bei über 70 Prozent. Mädchen finden sich dagegen eher bei den Absolventen der Sozial-, Rechtsund Wirtschaftswissenschaften (26 Prozent), Gesundheit und Soziales (I7 Prozent) und Dienstleistungen (I7 Prozent) (Tab. A2.3a).

Das Wissen um die Verteilung der Absolventen auf die verschiedenen Fachrichtungen kann den politischen Entscheidungsträgern dabei helfen sicherzustellen, dass die notwendigen qualifizierten Lehrkräfte in der Berufsbildung bereitstehen, um die Bedürfnisse sowohl der Schüler als auch der zukünftigen Arbeitgeber zu decken. Zu den Empfehlungen der OECD zu berufsbildenden Bildungsgängen im Sekundarbereich II gehört die Bereitstellung von Bildungsangeboten, die nicht nur den Vorlieben der Schüler und den Bedürfnissen der Arbeitgeber Rechnung tragen, sondern darüber hinaus die Schüler dabei unterstützen, die erforderlichen Rechen-, Lese- und Schreib- sowie allgemeine Kompetenzen zu erwerben, die für ein lebenslanges Lernen und das berufliche Fortkommen erforderlich sind (OECD, 2010).

\section{Abschlussquoten bei postsekundaren, nicht tertiären Bildungsgängen} In den OECD-Ländern werden ganz unterschiedliche Bildungsgänge im postsekundaren, nicht tertiären Bereich angeboten. Unter dem Gesichtspunkt internationaler Vergleichbarkeit liegen sie im Grenzbereich zwischen Sekundarbereich II und postsekundarem Bereich und können im spezifischen nationalen Zusammenhang möglicherweise eindeutig als zum Sekundarbereich II oder zum postsekundaren Bereich gehörig 


\section{Schwere Entscheidungen für Schüler im Sekundarbereich II}

Die Entscheidungen, die Schüler in diesem Bildungsbereich treffen, können sich langfristig auswirken, daher ist es wichtig, dass Bildungsgänge des Sekundarbereichs II zum einen den Bedürfnissen der Schüler und zum anderen den Anforderungen des Tertiärbereichs und des Arbeitsmarktes entsprechen. Wer das Bildungssystem ohne einen Abschluss im Sekundarbereich II verlässt, hat große Schwierigkeiten beim Eintritt in den Arbeitsmarkt und dem Verbleib dort, muss mit geringerem Einkommen und größerem Armutsrisiko rechnen und läuft eher Gefahr, eine ökonomische und soziale Last für die Gesellschaft zu werden (Le Métais, 2003; Levin, 2012; Lyche, 2010) (s. Indikatoren A5, A6 und A7).

Der Sekundarbereich II, ob allgemeinbildend oder berufsbildend, sollte darauf ausgelegt sein, den Schülern die Kompetenzen zu vermitteln, die es ihnen erlauben, in den Tertiärbereich und/oder den Arbeitsmarkt einzutreten. Gestaltet man die Systeme flexibler, um den Wechsel zwischen berufsbildenden und allgemeinbildenden Bildungsgängen zu ermöglichen, so kann man die Schüler erreichen, die vielleicht nicht auf andere Weise zu motivieren sind, einen Abschluss im Sekundarbereich II anzustreben. In zahlreichen OECD-Ländern besteht die Möglichkeit, zwischen den Bildungsgängen zu wechseln.

In den Niederlanden müssen sich Schüler beim Eintritt in den Sekundarbereich I für allgemeinbildende oder berufsbildende Bildungsgänge entscheiden. Der Sekundarbereich II ist jedoch so strukturiert, dass ein Wechsel zwischen den Bildungsgängen möglich ist und Schüler somit Bildungsgänge absolvieren können, die zum Tertiärbereich und/oder zum Eintritt in den Arbeitsmarkt führen.

In Finnland bietet der Sekundarbereich II den Schülern die Möglichkeit, zwischen allgemeinbildenden und berufsbildenden Bildungsgängen zu wechseln, und diese Flexibilität und Wahlmöglichkeit wird als ein den Schülern zustehendes Recht angesehen. In den meisten Fällen belegen Schüler Kurse in beiden Bildungsgängen, um ihre Bildungsziele zu erreichen (Sahlberg, 2006).

In Island können die Schüler dank eines Systems von Leistungspunkten (Credits) ganz einfach die Schule oder das Bildungsprogramm wechseln, da dieses System die Anerkennung von Credits erleichtert (Blondal et al., 20II).

In Deutschland und Frankreich können die Schüler im Sekundarbereich II zwar nicht von berufsbildenden Bildungsgängen in allgemeinbildende Bildungsgänge wechseln, sie können jedoch einen Abschluss erwerben, der den Zugang zum Tertiärbereich ermöglicht.

Dennoch ist es schwierig und unüblich, den Bildungsgang während des Sekundarbereichs II zu wechseln, außerdem können die genannten Möglichkeiten zu einer Verlängerung des Bildungsgangs führen, was einige Schüler davon abhalten könnte, einen Abschluss zu erwerben. Weiter gehende Untersuchungen und international vergleichbare Daten wären hilfreich, um zu verstehen, welche Systeme und Bil- 
dungsgänge am erfolgreichsten dazu beitragen, dass Schüler länger die Schule besuchen. Die OECD hat in jüngster Zeit Untersuchungen zum Sekundarbereich II durchgeführt, u.a. Completing the Foundation for Lifelong Learning: An OECD Survey of Upper Secondary Schools (OECD, 2004), Equity and Quality in Education: Supporting Disadvantaged Students and Schools (OECD, 2012) und das Arbeitspapier „Upper Secondary Practices and Challenges in OECD Countries and a Literature Review“ (Zapata, i.E.).

angesehen werden. Auch wenn der Inhalt dieser Bildungsgänge nicht wesentlich über den von Bildungsgängen des Sekundarbereichs II hinausgeht, erweitern diese postsekundaren, nicht tertiären Bildungsgänge doch die Kenntnisse derjenigen, die schon einen Abschluss im Sekundarbereich II erworben haben.

Die Teilnehmer der betreffenden Bildungsgänge sind in der Regel älter als diejenigen des Sekundarbereichs II. Diese Bildungsgänge bieten normalerweise Berufsbildungsabschlüsse an und umfassen u. a. die Erzieherausbildung in Österreich und die Berufsausbildung der Auszubildenden im dualen System in Deutschland, die bereits einen allgemeinbildenden Abschluss des Sekundarbereichs erlangt haben. Auch die Bildungsgänge der dualen Berufsausbildung, die nur für Schüler angeboten werden, die bereits einen Abschluss im Sekundarbereich II erzielt haben, werden bei diesen Bildungsgängen erfasst (Tab. A2.Ic im Internet).

Die Erstabschlussquoten bei postsekundaren, nicht tertiären Bildungsgängen sind niedrig im Vergleich zu denjenigen des Sekundarbereichs II. Im Durchschnitt haben 8 Prozent der Absolventen einen Abschluss in einem postsekundaren, nicht tertiären Bildungsgang, wobei der Anteil der Frauen mit 9 Prozent leicht über dem der Männer (8 Prozent) liegt. Die höchsten Abschlussquoten in diesen Bildungsgängen erreichen Neuseeland ( 33 Prozent), Österreich (25 Prozent) und Tschechien (27 Prozent), und in diesen drei Ländern liegen die Abschlussquoten der Frauen (mit 39 Prozent, 30 Prozent bzw. 30 Prozent) über denjenigen der Männer (27 Prozent, I9 Prozent bzw. 23 Prozent) (Tab. A2.Ic im Internet).

\section{Übergang nach dem Sekundarbereich II bzw. dem postsekundaren, nicht tertiären Bereich}

Der überwiegende Teil der Schüler erwirbt einen Abschluss in einem Bildungsgang des Sekundarbereichs II, der Zugang zu einer weiteren Ausbildung im Tertiärbereich gewähren soll (ISCED-Stufen $3 \mathrm{~A}$ und ${ }_{3} \mathrm{~B}$ ). Schüler aller Länder präferieren Bildungsgänge, die den direkten Zugang zum Tertiärbereich A (ISCED-Stufe $3 \mathrm{~A}$ ) ermöglichen, mit Ausnahme von Österreich, der Schweiz und Slowenien, wo die Bildungssysteme stärker auf berufsbildende Bildungsgänge ausgerichtet sind und daher mehr Schüler Bildungsgänge des Sekundarbereichs II absolvieren, die zu Studiengängen des Tertiärbereichs B führen. Im Jahr 20 I lag die Abschlussquote bei langen Bildungsgängen des Sekundarbereichs II (ISCED ${ }_{3} \mathrm{C}$ lang) im Durchschnitt der OECD-Länder bei I 8 Prozent (Tab. A2.Ia).

Abbildung A2.3 zeigt die Unterschiede zwischen den einzelnen Ländern auf, wenn man den Anteil der Schüler, die einen Abschluss erwerben, der den Zugang zum Tertiärbereich A ermöglicht (ISCED-Stufen 3A und 4A), mit dem Anteil der Schüler, die 
Zugang zum Tertiärbereich A für Absolventen des Sekundarbereichs II und des postsekundaren, nicht tertiären Bereichs, die jünger als 25 Jahre sind (2011)

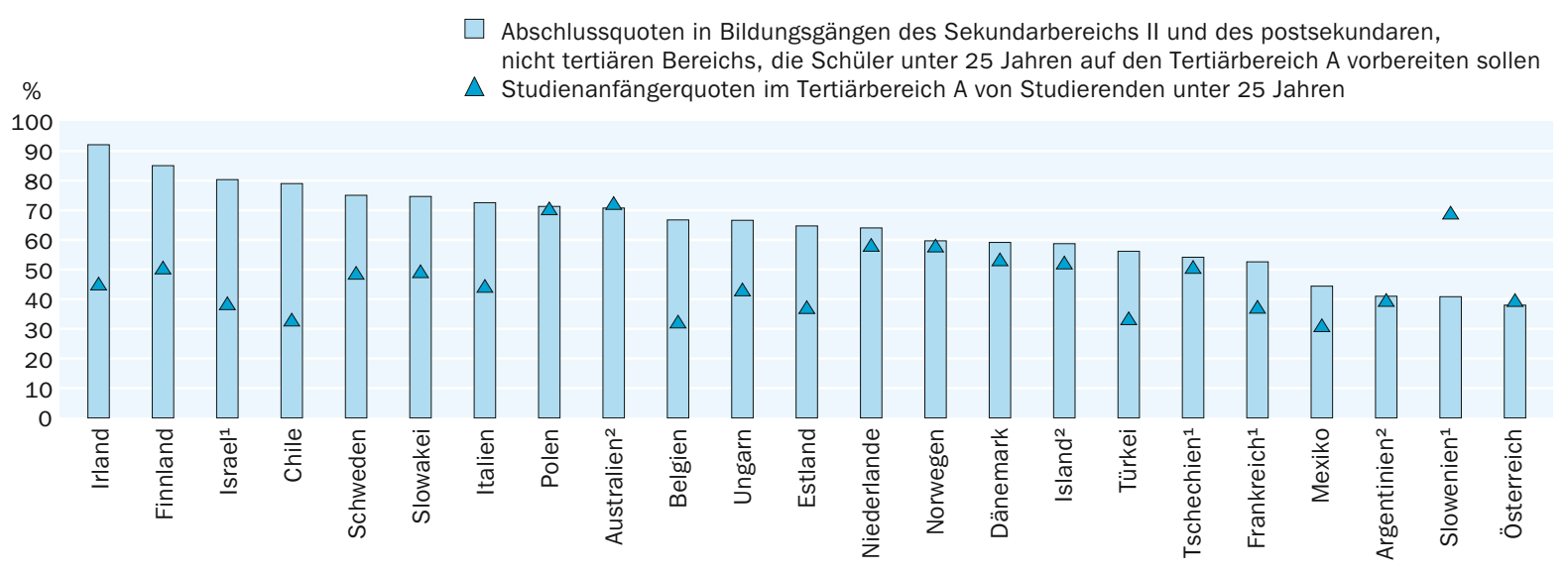

\footnotetext{
1. Angaben für Absolventen von Bildungsgängen des postsekundaren, nicht tertiären Bereichs liegen nicht vor. 2. Referenzjahr für Abschlussquoten 2010. Anordnung der Länder in absteigender Reihenfolge der Abschlussquoten im Jahr 2011 von Bildungsgängen im Sekundarbereich II, die Schüler unter 25 Jahren auf den Tertiärbereich A vorbereiten sollen.

Quelle: OECD. Argentinien: Statistikinstitut der UNESCO (World Education Indicators Programme). Tabelle A2.1b, Tabelle A2.1c im Internet und Tabelle C3.1b. Hinweise s. Anhang 3 unter www.oecd.org/edu/eag.htm. StatLink: http://dx.doi.org/10.1787/888932846348
}

tatsächlich vor ihrem 25. Geburtstag ein derartiges Studium aufnehmen, vergleicht. In Belgien, Chile, Finnland, Irland und Israel beträgt die Differenz zwischen diesen beiden Gruppen mindestens 30 Prozentpunkte. Das legt nahe, dass zahlreiche Schüler mit einem Abschluss, der ihnen den Zugang zu Studiengängen im Tertiärbereich A ermöglicht, kein derartiges Studium aufnehmen, wobei Bildungsgänge im Sekundarbereich II in Belgien und Israel Schüler jedoch auch auf Studiengänge im Tertiärbereich B vorbereiten.

In Finnland findet im Sekundarbereich II auch eine berufliche Ausbildung statt, sodass viele Absolventen nach dem Schulabschluss direkt in den Arbeitsmarkt eintreten, ohne ihre Ausbildung im Tertiärbereich fortzusetzen. An den finnischen Hochschulen gibt es auch ein Numerus-clausus-System, d. h., die Zahl der Studienplätze für Studienanfänger ist begrenzt. Daher müssen Absolventen des Sekundarbereichs II (allgemeinbildend) ihre Ausbildung eventuell für zwei bis drei Jahre unterbrechen, ehe sie einen Studienplatz an einer Universität oder polytechnischen Einrichtung bekommen. In Irland legt die Mehrheit der Schüler im Sekundarbereich die Prüfung für das Leaving Certificate (ISCED-Stufe $3 \mathrm{~A}$ ) ab. Obwohl dieser Bildungsgang den Übergang in den Tertiärbereich ermöglicht, beabsichtigen nicht alle Schüler, die die Prüfung ablegen, dies auch zu tun. Bis zum Einsetzen der globalen Wirtschaftskrise konnten Schulabgänger in Irland noch von einem nachfragestarken Arbeitsmarkt profitieren, was vielleicht auch eine solche Entscheidung beeinflusst haben mag.

Im Gegensatz hierzu liegen in Slowenien die Abschlussquoten im Sekundarbereich II und postsekundaren, nicht tertiären Bereich deutlich (mehr als 20 Prozentpunkte) unter den Studienanfängerquoten im Tertiärbereich A. Obwohl viele Schüler in Slowenien eher einen Abschluss im Sekundarbereich II erwerben, der den Zugang zum Ter- 
tiärbereich B eröffnet, entscheidet sich aber vielleicht später doch ein Teil von ihnen für ein Studium an einer Universität, was dort dank der sehr guten Übergangsmöglichkeiten zwischen diesen beiden Tertiärbereichen möglich ist.

\section{Definitionen}

Bei Absolventen im Referenzzeitraum kann es sich sowohl um Absolventen mit einem Erstabschluss als auch Absolventen, die einen zusätzlichen Abschluss erworben haben, handeln. Ein Absolvent mit Erstabschluss ist ein Schüler, der innerhalb des Referenzzeitraums in einem bestimmten Bildungsbereich zum ersten Mal einen Abschluss erworben hat. Wenn ein Schüler im Laufe der Jahre mehrere Abschlüsse erwirbt, so wird er oder sie zwar jedes Jahr als Absolvent gezählt, als Absolvent mit Erstabschluss jedoch nur einmal.

Netto-Abschlussquoten zeigen den geschätzten prozentualen Anteil einer Altersgruppe, der einen Abschluss im Sekundarbereich II erwirbt (ausgehend von den aktuellen Abschlussquoten).

\section{Angewandte Methodik}

Die Daten beziehen sich auf das Schuljahr 2009/2010 und beruhen auf der von der OECD im Jahre 2012 durchgeführten UOE-Datenerhebung zur Bildungsstatistik (weitere Informationen s. Anhang 3 unter www.oecd.org/edu/eag.htm).

Die Daten zur Entwicklung der Abschlussquoten im Sekundarbereich II basieren für die Jahre 1995 und 2000 bis 2004 auf einer im Januar 2007 durchgeführten speziellen Erhebung.

Außer es ist etwas anderes angegeben, wurden die Abschlussquoten als Netto-Abschlussquoten (d. h. die Summe der altersspezifischen Abschlussquoten) berechnet. Für diejenigen Länder, die keine derart ausführlichen Daten bereitstellen konnten, werden die Brutto-Abschlussquoten dargestellt. Zur Berechnung der Brutto-Abschlussquoten gab jedes Land das typische Abschlussalter an (s. Anhang I). Die Zahl der Absolventen wurde (ohne Berücksichtigung ihres jeweiligen Alters) durch die Bevölkerung im üblichen Abschlussalter geteilt. In vielen Ländern ist es jedoch schwierig, ein typisches Abschlussalter festzulegen, da die Altersspanne der Absolventen sehr groß ist.

Absolventen von Bildungsgängen der ISCED-Stufen $3 \mathrm{~A}, 3 \mathrm{~B}$ und ${ }_{3} \mathrm{C}$ (bzw. $4 \mathrm{~A}, 4 \mathrm{~B}, 4 \mathrm{C}$ ) werden nicht als Absolventen mit einem Erstabschluss gezählt. Daher können die Abschlussquoten auch nicht einfach aufaddiert werden, da einige Schüler in mehr als einem Bildungsgang im Sekundarbereich II einen Abschluss erlangen und somit doppelt gezählt würden. Das Gleiche gilt für Abschlussquoten nach Ausrichtung des Bildungsgangs, d.h. allgemeinbildend oder berufsbildend. Zudem ist das typische Abschlussalter für die unterschiedlichen Bildungsgänge nicht zwangsläufig gleich (s. Anhang I). Berufsvorbereitende und berufsbildende Bildungsgänge umfassen so- 
wohl schulische als auch kombinierte schulische und betriebliche Ausbildungen, die als Bestandteil des Bildungssystems gelten. Ausschließlich in Betrieben durchgeführte Ausbildungen und solche, die keiner formellen Aufsicht durch eine Bildungsbehörde unterstehen, bleiben unberücksichtigt.

Die statistischen Daten für Israel wurden von den zuständigen israelischen Stellen bereitgestellt, die für sie verantwortlich zeichnen. Die Verwendung dieser Daten durch die OECD erfolgt unbeschadet des völkerrechtlichen Status der Golanhöhen, von OstJerusalem und der israelischen Siedlungen im Westjordanland

\section{Weiterführende Informationen}

Blondal, K., J. Jonasson and A. Tannhauser (20II), „Dropout in a Small Society: Is the Icelandic Case Somehow Different?", in S. Lamb et al. (eds.), School Dropout and Completion: International Comparative Studies in Theory and Policy, Springer Science+Buisness Media B.V.

Le Métais, J. (2003), „International Developments in Upper Secondary Education: Context, Provision and Issues“, Research Report No. 2, INCA Thematic Study No. 8, National Council for Curriculum and Assessment, Dublin.

Levin, B. (2012), More High School Graduates: How Schools can Save Students from Dropping Out, Corwin: A Sage Company, United States of America.

Lyche, C. (2010), „Taking on the Completion Challenge: A Literature Review on Policies to Prevent Dropout and Early School Leaving“, OECD Education Working Papers, No. 53, OECD Publishing, http://dx.doi.org/10.1787/5km4m2t5gcmrren.

OECD (2004), Completing the Foundation for Lifelong Learning: An OECD Survey of Upper Secondary Schools, OECD Publishing, Paris, http://dx.doi.org/10.1787/978g264103733-en.

OECD (2010), Lernen für die Arbeitswelt, ISBN: 978-92-64-08783-5, www.oecd.org/berlin| publikationen/oecd-studiezurberufsbildunglernenfurdiearbeitswelt.htm.

OECD (2012), Equity and Quality in Education: Supporting Disadvantaged Students and Schools, OECD Publishing, http://dx.doi.org/10.1787/9789264130852-en.

Sahlberg, P. (2006), „Raising the Bar: How Finland Responds to the Twin Challenge of Secondary Education?", The World Bank, Washington, D. C., 7 December 2006.

Zapata, J. (2013 i. E.), „Upper Secondary Practices and Challenges in OECD Countries and a Literature Review“, OECD Working Papers, OECD Publishing. 


\section{Tabellen Indikator A2}

- Tabelle A2.Ia: Abschlussquoten im Sekundarbereich II und durchschnittliches Abschlussalter (20II)

StatLink: http:/|dx.doi.org/10.1787/888932848210

Tabelle A2.Ib: Abschlussquoten im Sekundarbereich II von Schülern, die jünger als 25 Jahre sind (20II)

StatLink: http://dx.doi.org/10.1787/888932848229

WEB Table A2.Ic: Post-secondary non-tertiary graduation rates (Abschlussquoten im postsekundaren, nicht tertiären Bereich) (20II)

StatLink: http://dx.doi.org/10.1787/888932848248

Tabelle A2.2a: Entwicklung der Abschlussquoten im Sekundarbereich II (Erstabschluss, I995-20II)

StatLink: http://dx.doi.org/10.1787/888932848267

WEB Table A2.2b: Trends in graduation rates (general and pre-vocational/vocational programmes) at upper secondary level (Entwicklung der Abschlussquoten im Sekundarbereich II [allgemeinbildend und berufsvorbereitend/berufsbildend]) (2005-20II)

StatLink: http://dx.doi.org/10.1787/888932848286

Tabelle A2.3a: Verteilung der Absolventen von berufsbildenden Bildungsgängen des Sekundarbereichs II, nach Fachrichtung und Geschlecht (20II)

StatLink: http://dx.doi.org/10.1787/888932848305

WEB Table A2.3b: Distribution of upper secondary vocational graduates, by field of education (Verteilung der Absolventen von berufsbildenden Bildungsgängen des Sekundarbereichs II, nach Fachrichtung) (20II)

StatLink: http://dx.doi.org/10.1787/888932848324 
Abschlussquoten im Sekundarbereich II und durchschnittliches Abschlussalter (2011)

Summe der Abschlussquoten der einzelnen Altersjahrgänge, nach Ausrichtung und Ziel des Bildungsgangs und Geschlecht

\begin{tabular}{|c|c|c|c|c|c|c|c|c|c|c|c|c|c|c|c|c|}
\hline & \multicolumn{4}{|c|}{$\begin{array}{c}\text { Gesamt } \\
\text { (Absolventen } \\
\text { mit Erstabschluss) }\end{array}$} & \multicolumn{4}{|c|}{$\begin{array}{l}\text { Allgemeinbildende } \\
\text { Bildungsgänge }\end{array}$} & \multicolumn{4}{|c|}{$\begin{array}{l}\text { Berufsvorbereitende/ } \\
\text { Berufsbildende Bildungsgänge }\end{array}$} & \multirow{2}{*}{$\begin{array}{c}\text { ISCED } \\
\mathbf{3 A}^{\mathbf{1}} \\
\mathrm{M}+\mathrm{F}\end{array}$} & \multirow{2}{*}{\begin{tabular}{c|}
$\begin{array}{c}\text { ISCED } \\
\mathbf{3 B}^{1}\end{array}$ \\
$\mathrm{M}+\mathrm{F}$
\end{tabular}} & \multirow{2}{*}{\begin{tabular}{|c|}
$\mid \begin{array}{c}\text { ISCED } \\
\mathbf{3 C} \\
\text { (Ilang) }^{1}\end{array}$ \\
$\mathrm{M}+\mathrm{F}$
\end{tabular}} & \multirow{2}{*}{$\begin{array}{c}\begin{array}{c}\text { ISCED } \\
\mathbf{3 C} \\
\text { (kurz) }^{1}\end{array} \\
\mathrm{M}+\mathrm{F}\end{array}$} \\
\hline & $M+F$ & Männer & Frauen & \begin{tabular}{|c|} 
Durch- \\
schnitt- \\
liches \\
Alter $^{2}$ \\
\end{tabular} & $M+F$ & Männer & \begin{tabular}{|l|} 
Frauen \\
\end{tabular} & \begin{tabular}{|c|} 
Durch- \\
schnitt- \\
liches \\
Alter $^{2}$ \\
\end{tabular} & $M+F$ & Männer & \begin{tabular}{|l|} 
Frauen \\
\end{tabular} & \begin{tabular}{|c|} 
Durch- \\
schnitt- \\
liches \\
Alter $^{2}$ \\
\end{tabular} & & & & \\
\hline & (1) & (2) & (3) & (4) & (5) & (6) & (7) & (8) & (9) & (10) & (11) & (12) & (13) & (17) & (21) & (25) \\
\hline \multicolumn{17}{|l|}{ OECD-Länder } \\
\hline Australien ${ }^{3}$ & m & $\mathrm{m}$ & $\mathrm{m}$ & $\mathrm{m}$ & 71 & 67 & 75 & 17 & 51 & 49 & 53 & 30 & 71 & a & 51 & a \\
\hline Österreich & 67 & 70 & 64 & 18 & 18 & 14 & 22 & 18 & 76 & 86 & 64 & 19 & 18 & 55 & 1 & 20 \\
\hline Belgien & m & $\mathrm{m}$ & $\mathrm{m}$ & $\mathrm{m}$ & 35 & 31 & 40 & 18 & 68 & 62 & 73 & 25 & 59 & a & 20 & 23 \\
\hline Kanada $^{3}$ & 85 & 82 & 88 & 19 & 82 & 78 & 86 & 18 & 4 & 4 & 3 & $\mathrm{~m}$ & 82 & a & 4 & a \\
\hline Chile & 83 & 80 & 86 & 18 & 53 & 50 & 56 & 19 & 30 & 29 & 31 & 18 & 83 & a & a & a \\
\hline Tschechien & 78 & 78 & 77 & 20 & 23 & 17 & 28 & 20 & 55 & 60 & 49 & 20 & 55 & $\mathrm{n}$ & 22 & a \\
\hline Dänemark & 90 & 85 & 94 & 21 & 60 & 52 & 68 & 19 & 46 & 46 & 46 & 28 & 60 & a & 46 & $\mathrm{n}$ \\
\hline Estland & m & $\mathrm{m}$ & $\mathrm{m}$ & $\mathrm{m}$ & 55 & 45 & 66 & 18 & 23 & 29 & 18 & 20 & 66 & 21 & 2 & a \\
\hline Finnland & 96 & 94 & 99 & 22 & 46 & 39 & 54 & 19 & 99 & 93 & 106 & 29 & 96 & a & a & a \\
\hline Frankreich & m & $\mathrm{m}$ & $\mathrm{m}$ & $\mathrm{m}$ & 52 & 46 & 59 & 17 & 69 & 70 & 68 & 20 & 53 & 19 & 4 & 46 \\
\hline Deutschland & 92 & 93 & 92 & $\mathrm{~m}$ & 46 & 41 & 51 & $\mathrm{~m}$ & 47 & 52 & 41 & $\mathrm{~m}$ & 46 & 46 & a & 1 \\
\hline Griechenland & 68 & 60 & 76 & $\mathrm{~m}$ & 68 & 60 & 76 & $\mathrm{~m}$ & 33 & 41 & 26 & $\mathrm{~m}$ & 68 & a & 33 & $x(21)$ \\
\hline Ungarn & 86 & 83 & 89 & 19 & 70 & 63 & 77 & 19 & 17 & 21 & 13 & 20 & 70 & a & 17 & $\mathbf{x}(21)$ \\
\hline Island ${ }^{3}$ & 88 & 76 & 101 & 23 & 69 & 58 & 81 & 21 & 54 & 53 & 55 & 26 & 65 & a & 37 & 18 \\
\hline Irland & 89 & 88 & 90 & 19 & 68 & 68 & 68 & 19 & 69 & 56 & 83 & 25 & 94 & a & 6 & 37 \\
\hline Israel & 85 & 79 & 91 & 17 & 54 & 48 & 59 & 17 & 33 & 35 & 32 & 17 & 80 & a & 7 & a \\
\hline Italien & 79 & 76 & 82 & $\mathrm{~m}$ & 36 & 26 & 47 & 18 & 62 & 69 & 55 & $\mathrm{~m}$ & 75 & 1 & a & 23 \\
\hline Japan & 96 & 95 & 96 & $\mathrm{~m}$ & 73 & 70 & 76 & $\mathrm{~m}$ & 23 & 25 & 20 & $\mathrm{~m}$ & 73 & 1 & 22 & $x(21)$ \\
\hline Korea & 93 & 92 & 93 & $\mathrm{~m}$ & 71 & 70 & 72 & $\mathrm{~m}$ & 22 & 22 & 21 & $\mathrm{~m}$ & 71 & a & 22 & a \\
\hline Luxemburg & 70 & 67 & 74 & 19 & 29 & 24 & 34 & 18 & 45 & 47 & 43 & 20 & 43 & 10 & 19 & 2 \\
\hline Mexiko & 49 & 45 & 52 & 18 & 45 & 42 & 48 & 18 & 4 & 4 & 4 & 18 & 45 & a & 4 & a \\
\hline Niederlande & 92 & 87 & 96 & 21 & 41 & 37 & 44 & 17 & 75 & 74 & 76 & 25 & 68 & a & 47 & a \\
\hline Neuseeland & m & $\mathrm{m}$ & $\mathrm{m}$ & $\mathrm{m}$ & $\mathbf{m}$ & $\mathrm{m}$ & $\mathrm{m}$ & $\mathrm{m}$ & $\mathrm{m}$ & $\mathrm{m}$ & $\mathrm{m}$ & $\mathrm{m}$ & $\mathbf{m}$ & m & $\mathbf{m}$ & $\mathbf{m}$ \\
\hline Norwegen & 90 & 85 & 95 & 22 & 61 & 50 & 72 & 19 & 35 & 43 & 27 & 27 & 61 & a & 35 & m \\
\hline Polen & 84 & 80 & 88 & 20 & 51 & 39 & 64 & 20 & 39 & 48 & 30 & 20 & 76 & a & 14 & a \\
\hline Portugal & 89 & 78 & 100 & 25 & 51 & 42 & 59 & 25 & 38 & 35 & 41 & 25 & $\mathbf{m}$ & m & m & m \\
\hline Slowakei & 85 & 82 & 87 & 19 & 26 & 20 & 31 & 18 & 66 & 70 & 62 & 20 & 76 & a & 15 & 1 \\
\hline Slowenien & 99 & 94 & 104 & $\mathrm{~m}$ & 37 & 30 & 46 & 18 & 75 & 81 & 68 & $\mathrm{~m}$ & 41 & 48 & 21 & 2 \\
\hline Spanien & 88 & 84 & 92 & $\mathrm{~m}$ & 51 & 44 & 58 & $\mathrm{~m}$ & 53 & 52 & 54 & $\mathrm{~m}$ & 51 & 20 & 9 & 23 \\
\hline Schweden & 75 & 73 & 78 & 18 & 32 & 26 & 37 & 18 & 44 & 47 & 41 & 18 & 75 & $\mathbf{n}$ & $\mathbf{n}$ & $\mathbf{n}$ \\
\hline Schweiz & m & $\mathrm{m}$ & $\mathrm{m}$ & $\mathrm{m}$ & 33 & 27 & 40 & $\mathrm{~m}$ & 73 & 78 & 69 & $\mathrm{~m}$ & 30 & 71 & 6 & $\mathbf{x}(21)$ \\
\hline Türkei & 56 & 56 & 56 & 17 & 31 & 29 & 33 & 17 & 25 & 27 & 23 & 17 & 56 & a & a & $\mathbf{m}$ \\
\hline Ver. Königreich & 93 & 91 & 95 & $\mathrm{~m}$ & m & $\mathrm{m}$ & $\mathrm{m}$ & $\mathrm{m}$ & m & $\mathrm{m}$ & $\mathrm{m}$ & $\mathrm{m}$ & m & m & 75 & 17 \\
\hline Vereinigte Staaten & 77 & 74 & 81 & 17 & $x(1)$ & $x(2)$ & $x(3)$ & $x(4)$ & $x(1)$ & $x(2)$ & $x(3)$ & $x(4)$ & $\mathbf{x}(\mathbf{1})$ & $\mathbf{x}(\mathbf{1})$ & $\mathbf{x}(\mathbf{1})$ & $\mathbf{x}(1)$ \\
\hline OECD-Durchschnitt & 83 & 79 & 86 & 20 & 50 & 44 & 56 & 19 & 47 & 49 & 45 & 22 & 64 & 10 & 18 & 9 \\
\hline EU21-Durchschnitt & 84 & 81 & 88 & 20 & 45 & 38 & 51 & 19 & 55 & 57 & 53 & 22 & 63 & 12 & 18 & 11 \\
\hline \multicolumn{17}{|l|}{ Sonst. G20-Länder } \\
\hline Argentinien ${ }^{3}$ & m & $\mathrm{m}$ & $\mathrm{m}$ & $\mathrm{m}$ & 36 & 29 & 44 & 19 & 7 & 8 & 5 & 18 & 43 & a & a & a \\
\hline Brasilien & m & $\mathrm{m}$ & $\mathrm{m}$ & $\mathrm{m}$ & 63 & 50 & 77 & 21 & 12 & 9 & 15 & 26 & 65 & 12 & a & a \\
\hline China & 73 & 72 & 74 & $\mathrm{~m}$ & 40 & 39 & 42 & $\mathrm{~m}$ & 53 & 52 & 53 & $\mathrm{~m}$ & 42 & $\mathbf{x}(\mathbf{1 3})$ & 31 & 20 \\
\hline Indien & m & $\mathrm{m}$ & $\mathrm{m}$ & $\mathrm{m}$ & m & $\mathrm{m}$ & $\mathrm{m}$ & $\mathrm{m}$ & m & $\mathrm{m}$ & $\mathrm{m}$ & $\mathrm{m}$ & m & m & m & m \\
\hline Indonesien & m & $\mathrm{m}$ & $\mathrm{m}$ & $\mathrm{m}$ & 34 & 31 & 37 & 18 & 22 & 25 & 18 & 18 & 34 & 22 & a & a \\
\hline Russische Föd. & $\mathbf{m}$ & $\mathrm{m}$ & $\mathrm{m}$ & $\mathrm{m}$ & 47 & $x(5)$ & $x(5)$ & $\mathrm{m}$ & 45 & 36 & 14 & $\mathrm{~m}$ & 47 & 19 & 22 & 4 \\
\hline Saudi-Arabien & m & $\mathrm{m}$ & $\mathrm{m}$ & m & m & $\mathrm{m}$ & $\mathrm{m}$ & $\mathrm{m}$ & m & $\mathrm{m}$ & $\mathrm{m}$ & $\mathrm{m}$ & m & m & m & m \\
\hline Südafrika & $\mathbf{m}$ & $\mathrm{m}$ & $\mathrm{m}$ & $\mathrm{m}$ & $\mathbf{m}$ & $\mathrm{m}$ & $\mathrm{m}$ & $\mathrm{m}$ & m & $\mathrm{m}$ & $\mathrm{m}$ & $\mathrm{m}$ & m & m & $\mathbf{m}$ & m \\
\hline G20-Durchschnitt & 79 & 78 & 81 & m & 52 & 47 & 58 & m & 32 & 32 & 28 & m & 57 & 9 & 16 & 9 \\
\hline
\end{tabular}

Anmerkung: Die Spalten für die separaten Abschlussquoten von Männern und Frauen sowie das durchschnittliche Abschlussalter im Sekundarbereich II nach Ausrichtung des Bildungsgangs, d.h. die Spalten (14) bis (16), (18) bis (20), (22) bis (24) und (26) bis (28), sind im Internet verfügbar (s. StatLink unten). Weiterführende Informationen zu den zur Berechnung der (Brutto-/Netto-)Abschlussquoten verwendeten Methoden und den entsprechenden typischen Altersjahrgängen s. Anhang 1. Unterschiede im Erhebungsbereich der Bevölkerungsdaten und der Absolventendaten bedeuten, dass die Abschlussquoten von Ländern mit einem Nettoabgang von Schülern (z. B. Luxemburg) wohl zu niedrig angesetzt und von Ländern mit einem Nettozugang von Schülern wohl zu hoch angesetzt sind.

1. ISCED 3A: Bildungsgänge sollen unmittelbaren Zugang zum Tertiärbereich A eröffnen.

ISCED 3B: Bildungsgänge sollen unmittelbaren Zugang zum Tertiärbereich B eröffnen.

ISCED $3 C$ (lang): Ähnlich lang wie typische $3 A$ - oder 3B-Bildungsgänge.

ISCED 3C (kurz): Kürzer als typische 3A- oder 3B-Bildungsgänge.

2. Das „durchschnittliche Abschlussalter“ bezieht sich auf das Alter von Schülern zu Beginn des Kalenderjahres, sie könnten jedoch schon ein Jahr älter als angegeben sein, wenn der Abschluss gegen Ende des Schuljahres erfolgt. 3. Referenzjahr 2010.

Quelle: OECD. Argentinien, China, Indonesien: Statistikinstitut der UNESCO (World Education Indicators Programme).

Hinweise s. Anhang 3 unter www.oecd.org/edu/eag.htm. StatLink: http://dx.doi.org/10.1787/888932848210

Erläuterung der Kennzeichnung fehlender Daten s. Hinweise für den Leser. 
Tabelle A2.1b

Abschlussquoten im Sekundarbereich II von Schülern, die jünger als 25 Jahre sind (2011)

Summe der Abschlussquoten der einzelnen Altersjahrgänge, nach Ausrichtung und Ziel des Bildungsgangs und Geschlecht

\begin{tabular}{|c|c|c|c|c|c|c|c|c|c|c|c|c|c|c|c|c|}
\hline & \multicolumn{4}{|c|}{$\begin{array}{c}\text { Gesamt } \\
\text { (Absolventen } \\
\text { mit Erstabschluss) }\end{array}$} & \multicolumn{4}{|c|}{$\begin{array}{l}\text { Allgemeinbildende } \\
\text { Bildungsgänge }\end{array}$} & \multicolumn{4}{|c|}{$\begin{array}{l}\text { Berufsvorbereitende/ } \\
\text { Berufsbildende Bildungsgänge }\end{array}$} & \multirow{2}{*}{$\begin{array}{c}\text { ISCED } \\
\mathbf{3 A}^{\mathbf{1}} \\
\\
\stackrel{4}{\perp}\end{array}$} & \multirow{2}{*}{$\begin{array}{c}\begin{array}{c}\text { ISCED } \\
\mathbf{3 B}^{1}\end{array} \\
\\
\stackrel{L}{+}\end{array}$} & \multirow{2}{*}{\begin{tabular}{|l}
$\begin{array}{c}\text { ISCED } \\
\text { 3C } \\
\text { (lang) }^{1}\end{array}$ \\
\\
\\
\\
\\
\end{tabular}} & \multirow{2}{*}{\begin{tabular}{c|c} 
& $\begin{array}{c}\text { ISCED } \\
\text { 3C } \\
\text { (kurz) }^{1}\end{array}$ \\
& \\
& \\
& \pm \\
\end{tabular}} \\
\hline & $\begin{array}{l}\frac{1}{+} \\
\sum^{2}\end{array}$ & 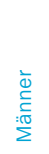 & 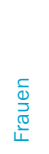 & 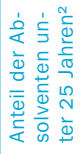 & $\frac{L}{+}$ & 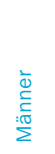 & $\frac{\sqrt{0}}{\stackrel{0}{\pi}}$ & 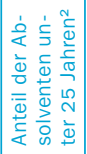 & $\begin{array}{l}\dot{L} \\
\stackrel{+}{\Sigma}\end{array}$ & 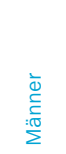 & $\underset{\substack{\mathbb{\omega} \\
\tilde{\omega}}}{\stackrel{c}{L}}$ & 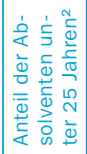 & & & & \\
\hline & (1) & (2) & (3) & (4) & (5) & (6) & (7) & (8) & (9) & (10) & (11) & (12) & (13) & (16) & (19) & (22) \\
\hline \multicolumn{17}{|l|}{ OECD-Länder } \\
\hline Australien ${ }^{3}$ & m & $\mathrm{m}$ & $\mathrm{m}$ & $\mathrm{m}$ & 71 & 67 & 75 & 100 & 24 & 25 & 22 & 47 & 71 & $\mathbf{a}$ & 24 & a \\
\hline Österreich & 64 & 67 & 61 & 96 & 18 & 14 & 22 & 99 & 69 & 80 & 58 & 90 & 18 & 50 & 1 & 18 \\
\hline Belgien & $\mathbf{m}$ & $\mathrm{m}$ & $\mathrm{m}$ & $\mathrm{m}$ & 35 & 31 & 40 & 100 & 50 & 49 & 50 & 71 & 59 & a & 20 & 4 \\
\hline Kanada $^{3}$ & 81 & 78 & 84 & 95 & 80 & 76 & 84 & 97 & 1 & 2 & 1 & 34 & 80 & $\mathbf{a}$ & 1 & a \\
\hline Chile & 79 & 77 & 82 & 96 & 49 & 47 & 51 & 94 & 30 & 29 & 30 & 99 & 79 & a & $\mathbf{a}$ & a \\
\hline Tschechien & 76 & 77 & 76 & 98 & 23 & 17 & 28 & 100 & 54 & 59 & 48 & 97 & 54 & $\mathrm{n}$ & 22 & a \\
\hline Dänemark & 79 & 77 & 82 & 89 & 58 & 50 & 67 & 98 & 27 & 32 & 22 & 57 & 58 & a & 27 & $\mathrm{n}$ \\
\hline Estland & m & $\mathrm{m}$ & $\mathrm{m}$ & $\mathrm{m}$ & 65 & 53 & 78 & 97 & 22 & 28 & 16 & 95 & 65 & 21 & 1 & a \\
\hline Finnland & 85 & 84 & 86 & 89 & 46 & 38 & 54 & 99 & 53 & 55 & 50 & 54 & 85 & a & a & a \\
\hline Frankreich & m & $\mathrm{m}$ & $\mathrm{m}$ & $\mathrm{m}$ & 53 & 46 & 60 & 100 & 62 & 66 & 58 & 89 & 53 & 19 & 3 & 40 \\
\hline Deutschland & $\mathbf{m}$ & $\mathrm{m}$ & $\mathrm{m}$ & $\mathrm{m}$ & m & $\mathrm{m}$ & $\mathrm{m}$ & $\mathrm{m}$ & m & $\mathrm{m}$ & $\mathrm{m}$ & $\mathrm{m}$ & $\mathbf{m}$ & m & a & $\mathbf{m}$ \\
\hline Griechenland & $\mathbf{m}$ & $\mathrm{m}$ & $\mathrm{m}$ & $\mathrm{m}$ & $\mathbf{m}$ & $\mathrm{m}$ & $\mathrm{m}$ & $\mathrm{m}$ & $\mathbf{m}$ & $\mathrm{m}$ & $\mathrm{m}$ & $\mathrm{m}$ & $\mathbf{m}$ & a & m & $\mathbf{m}$ \\
\hline Ungarn & 82 & 80 & 84 & 94 & 67 & 61 & 73 & 94 & 17 & 21 & 12 & 95 & 67 & a & 17 & $x(19)$ \\
\hline Island & 70 & 61 & 78 & 80 & 62 & 51 & 71 & 89 & 32 & 32 & 32 & 60 & 59 & $\mathbf{a}$ & 21 & 13 \\
\hline Irland & 88 & 87 & 89 & 99 & 66 & 66 & 66 & 96 & 51 & 45 & 58 & 69 & 92 & $\mathbf{a}$ & 6 & 19 \\
\hline Israel & 85 & 79 & 91 & 100 & 54 & 48 & 59 & 100 & 33 & 35 & 32 & 100 & 80 & $\mathbf{a}$ & 7 & a \\
\hline Italien & $\mathbf{m}$ & $\mathrm{m}$ & $\mathrm{m}$ & $\mathrm{m}$ & 36 & 26 & 47 & 100 & m & $\mathrm{m}$ & $\mathrm{m}$ & $\mathrm{m}$ & 73 & m & a & $\mathbf{m}$ \\
\hline Japan & $\mathbf{m}$ & $\mathrm{m}$ & $\mathrm{m}$ & $\mathrm{m}$ & $\mathbf{m}$ & $\mathrm{m}$ & $\mathrm{m}$ & $\mathrm{m}$ & $\mathbf{m}$ & $\mathrm{m}$ & $\mathrm{m}$ & $\mathrm{m}$ & $\mathbf{m}$ & $\mathbf{m}$ & m & $\mathbf{m}$ \\
\hline Korea & m & $\mathrm{m}$ & $\mathrm{m}$ & $\mathrm{m}$ & $\mathbf{m}$ & $\mathrm{m}$ & $\mathrm{m}$ & $\mathrm{m}$ & m & $\mathrm{m}$ & $\mathrm{m}$ & $\mathrm{m}$ & $\mathbf{m}$ & a & m & a \\
\hline Luxemburg & 69 & 66 & 72 & 97 & 29 & 24 & 34 & 100 & 43 & 45 & 41 & 95 & 43 & 9 & 18 & 2 \\
\hline Mexiko & 48 & 45 & 51 & 99 & 44 & 41 & 48 & 99 & 3 & 3 & 3 & 95 & 44 & a & 3 & a \\
\hline Niederlande & 80 & 76 & 83 & 86 & 41 & 37 & 44 & 100 & 57 & 58 & 57 & 76 & 64 & a & 34 & a \\
\hline Neuseeland & m & $\mathrm{m}$ & $\mathrm{m}$ & $\mathrm{m}$ & $\mathbf{m}$ & $\mathrm{m}$ & $\mathrm{m}$ & $\mathrm{m}$ & m & $\mathrm{m}$ & $\mathrm{m}$ & $\mathrm{m}$ & m & m & m & m \\
\hline Norwegen & 78 & 74 & 82 & 86 & 59 & 48 & 70 & 98 & 22 & 29 & 14 & 62 & 59 & a & 22 & $\mathbf{m}$ \\
\hline Polen & 82 & 79 & 86 & 98 & 47 & 35 & 59 & 90 & 39 & 47 & 30 & 99 & 71 & a & 14 & $\mathbf{a}$ \\
\hline Portugal & 68 & 60 & 76 & 70 & 39 & 32 & 47 & 70 & 29 & 29 & 29 & 69 & m & m & m & m \\
\hline Slowakei & 82 & 81 & 83 & 97 & 25 & 20 & 31 & 98 & 63 & 68 & 57 & 94 & 74 & $\mathbf{a}$ & 14 & $\mathrm{n}$ \\
\hline Slowenien & m & $\mathrm{m}$ & $\mathrm{m}$ & $\mathrm{m}$ & 37 & 29 & 45 & 100 & m & $\mathrm{m}$ & $\mathrm{m}$ & $\mathrm{m}$ & 41 & m & $\mathbf{m}$ & 2 \\
\hline Spanien & m & $\mathrm{m}$ & $\mathrm{m}$ & $\mathrm{m}$ & $\mathbf{m}$ & $\mathrm{m}$ & $\mathrm{m}$ & $\mathrm{m}$ & m & $\mathrm{m}$ & $\mathrm{m}$ & $\mathrm{m}$ & $\mathbf{m}$ & m & m & $\mathbf{m}$ \\
\hline Schweden & 75 & 73 & 78 & 100 & 32 & 26 & 37 & 100 & 44 & 47 & 41 & 100 & 75 & $\mathbf{m}$ & $\mathbf{n}$ & m \\
\hline Schweiz & $\mathbf{m}$ & $\mathrm{m}$ & $\mathrm{m}$ & $\mathrm{m}$ & $\mathbf{m}$ & $\mathrm{m}$ & $\mathrm{m}$ & $\mathrm{m}$ & $\mathbf{m}$ & $\mathrm{m}$ & $\mathrm{m}$ & $\mathrm{m}$ & $\mathbf{m}$ & $\mathbf{m}$ & $\mathbf{m}$ & $\mathbf{m}$ \\
\hline Türkei & 56 & 56 & 56 & 100 & 31 & 29 & 33 & 100 & 25 & 27 & 23 & 100 & 56 & a & a & $\mathbf{m}$ \\
\hline Ver. Königreich & $\mathbf{m}$ & $\mathrm{m}$ & $\mathrm{m}$ & $\mathrm{m}$ & $\mathbf{m}$ & $\mathrm{m}$ & $\mathrm{m}$ & $\mathrm{m}$ & $\mathbf{m}$ & $\mathrm{m}$ & $\mathrm{m}$ & $\mathrm{m}$ & $\mathbf{m}$ & m & m & $\mathbf{m}$ \\
\hline Vereinigte Staaten & 77 & 74 & 81 & 100 & $x(1)$ & $x(2)$ & $x(3)$ & $\mathrm{m}$ & $x(1)$ & $x(2)$ & $x(3)$ & $\mathrm{m}$ & $x(1)$ & $x(1)$ & $x(1)$ & $x(1)$ \\
\hline OECD-Durchschnitt & 75 & 72 & 78 & 93 & 47 & 41 & 53 & 97 & 37 & 40 & 34 & 80 & 63 & 4 & 11 & 5 \\
\hline EU21-Durchschnitt & 78 & 75 & 80 & 93 & 42 & 36 & 49 & 97 & 45 & 49 & 42 & 83 & 62 & 7 & 11 & 7 \\
\hline \multicolumn{17}{|l|}{ Sonst. G20-Länder } \\
\hline Argentinien ${ }^{3}$ & m & $\mathrm{m}$ & $\mathrm{m}$ & $\mathrm{m}$ & 34 & 27 & 42 & 95 & 7 & 8 & 5 & 98 & 41 & a & a & a \\
\hline Brasilien & m & $\mathrm{m}$ & $\mathrm{m}$ & $\mathrm{m}$ & 55 & 46 & 64 & 87 & 7 & 5 & 8 & 60 & 55 & 7 & $\mathbf{a}$ & a \\
\hline China & $\mathbf{m}$ & $\mathrm{m}$ & $\mathrm{m}$ & $\mathrm{m}$ & $\mathbf{m}$ & $\mathrm{m}$ & $\mathrm{m}$ & $\mathrm{m}$ & m & $\mathrm{m}$ & $\mathrm{m}$ & $\mathrm{m}$ & $\mathbf{m}$ & $\mathbf{m}$ & m & $\mathbf{m}$ \\
\hline Indien & $\mathbf{m}$ & $\mathrm{m}$ & $\mathrm{m}$ & $\mathrm{m}$ & $\mathbf{m}$ & $\mathrm{m}$ & $\mathrm{m}$ & $\mathrm{m}$ & $\mathbf{m}$ & $\mathrm{m}$ & $\mathrm{m}$ & $\mathrm{m}$ & m & m & m & $\mathbf{m}$ \\
\hline Indonesien & $\mathbf{m}$ & $\mathrm{m}$ & $\mathrm{m}$ & $\mathrm{m}$ & m & $\mathrm{m}$ & $\mathrm{m}$ & $\mathrm{m}$ & $\mathbf{m}$ & $\mathrm{m}$ & $\mathrm{m}$ & $\mathrm{m}$ & m & $\mathbf{m}$ & $\mathbf{m}$ & $\mathbf{m}$ \\
\hline Russische Föd. & $\mathbf{m}$ & $\mathrm{m}$ & $\mathrm{m}$ & $\mathrm{m}$ & $\mathbf{m}$ & $\mathrm{m}$ & $\mathrm{m}$ & $\mathrm{m}$ & $\mathbf{m}$ & $\mathrm{m}$ & $\mathrm{m}$ & $\mathrm{m}$ & $\mathbf{m}$ & $\mathbf{m}$ & $\mathbf{m}$ & $\mathbf{m}$ \\
\hline Saudi-Arabien & $\mathbf{m}$ & $\mathrm{m}$ & $\mathrm{m}$ & $\mathrm{m}$ & $\mathbf{m}$ & $\mathrm{m}$ & $\mathrm{m}$ & $\mathrm{m}$ & $\mathbf{m}$ & $\mathrm{m}$ & $\mathrm{m}$ & $\mathrm{m}$ & $\mathbf{m}$ & $\mathbf{m}$ & m & $\mathbf{m}$ \\
\hline Südafrika & m & $\mathrm{m}$ & $\mathrm{m}$ & $\mathrm{m}$ & m & $\mathrm{m}$ & $\mathrm{m}$ & $\mathrm{m}$ & m & $\mathrm{m}$ & $\mathrm{m}$ & $\mathrm{m}$ & m & m & m & m \\
\hline G20-Durchschnitt & $\mathbf{m}$ & m & m & m & $\mathbf{m}$ & m & m & $\mathbf{m}$ & m & $\mathbf{m}$ & $\mathbf{m}$ & m & $\mathbf{m}$ & $\mathbf{m}$ & $\mathbf{m}$ & $\mathbf{m}$ \\
\hline
\end{tabular}

Anmerkung: Die Spalten für die separaten Abschlussquoten von Männern und Frauen im Sekundarbereich II nach Ausrichtung des Studiengangs, d.h. die Spalten (14)/(15), (17)/(18), (20)/(21), (23)/(24), sind im Internet verfügbar (s. StatLink unten). Weiterführende Informationen zu den zur Berechnung der (Brutto-/Netto-) Abschlussquoten verwendeten Methoden und den entsprechenden typischen Altersjahrgängen s. Anhang 1. Unterschiede im Erhebungsbereich der Bevölkerungsdaten und der Absolventendaten bedeuten, dass die Abschlussquoten von Ländern mit einem Nettoabgang von Schülern (z. B. Luxemburg) wohl zu niedrig angesetzt und von Ländern mit einem Nettozugang von Schülern wohl zu hoch angesetzt sind.

1. ISCED 3A: Bildungsgänge sollen unmittelbaren Zugang zum Tertiärbereich A eröffnen.

ISCED 3B: Bildungsgänge sollen unmittelbaren Zugang zum Tertiärbereich B eröffnen.

ISCED 3C (lang): Ähnlich lang wie typische 3A- oder 3B-Bildungsgänge.

ISCED 3 C (kurz): Kürzer als typische $3 A$ - oder 3B-Bildungsgänge.

2. Anteil der Absolventen unter 25 Jahren an allen Absolventen. 3. Referenzjahr 2010.

Quelle: OECD. Argentinien: Statistikinstitut der UNESCO (World Education Indicators Programme). Hinweise s. Anhang 3 unter www.oecd.org/edu/eag.htm. StatLink: http://dx.doi.org/10.1787/888932848229

Erläuterung der Kennzeichnung fehlender Daten s. Hinweise für den Leser. 
Entwicklung der Abschlussquoten im Sekundarbereich II (Erstabschluss, 1995-2011)

\begin{tabular}{|c|c|c|c|c|c|c|c|c|c|c|c|c|c|c|}
\hline & 1995 & 2000 & 2001 & 2002 & 2003 & 2004 & 2005 & 2006 & 2007 & 2008 & 2009 & 2010 & 2011 & \begin{tabular}{|} 
Durchschnittl. \\
jährlicher \\
Anstieg \\
1995-2011
\end{tabular} \\
\hline \multicolumn{15}{|l|}{ OECD-Länder } \\
\hline Australien & $\mathrm{m}$ & $\mathrm{m}$ & $\mathrm{m}$ & $\mathrm{m}$ & $\mathrm{m}$ & $\mathrm{m}$ & $\mathrm{m}$ & $\mathrm{m}$ & $\mathrm{m}$ & $\mathrm{m}$ & $\mathrm{m}$ & $\mathrm{m}$ & m & $\mathrm{m}$ \\
\hline Österreich² & $\mathrm{m}$ & $\mathrm{m}$ & $\mathrm{m}$ & $\mathrm{m}$ & $\mathrm{m}$ & $\mathrm{m}$ & $\mathrm{m}$ & $\mathrm{m}$ & $\mathrm{m}$ & $\mathrm{m}$ & $\mathrm{m}$ & $\mathrm{m}$ & 67 & $\mathrm{~m}$ \\
\hline Belgien & $\mathrm{m}$ & $\mathrm{m}$ & $\mathrm{m}$ & $\mathrm{m}$ & $\mathrm{m}$ & $\mathrm{m}$ & $\mathrm{m}$ & $\mathrm{m}$ & $\mathrm{m}$ & $\mathrm{m}$ & $\mathrm{m}$ & $\mathrm{m}$ & m & $\mathrm{m}$ \\
\hline Kanada & $\mathrm{m}$ & $\mathrm{m}$ & 77 & 79 & 83 & 79 & 80 & 79 & 76 & 79 & 81 & 85 & m & $\mathrm{m}$ \\
\hline Chile & $\mathrm{m}$ & $\mathrm{m}$ & $\mathrm{m}$ & $\mathrm{m}$ & $\mathrm{m}$ & 79 & 85 & 82 & 82 & 83 & 85 & 83 & 83 & $\mathrm{~m}$ \\
\hline Tschechien & 78 & $\mathrm{~m}$ & 84 & 83 & 88 & 87 & 89 & 89 & 88 & 85 & 83 & 80 & 78 & $0,0 \%$ \\
\hline Dänemark & 83 & 95 & 95 & 94 & 88 & 88 & 82 & 84 & 85 & 83 & 85 & 86 & 90 & $0,5 \%$ \\
\hline Estland & $\mathrm{m}$ & $\mathrm{m}$ & $\mathrm{m}$ & $\mathrm{m}$ & $\mathrm{m}$ & $\mathrm{m}$ & $\mathrm{m}$ & $\mathrm{m}$ & $\mathrm{m}$ & $\mathrm{m}$ & $\mathrm{m}$ & $\mathrm{m}$ & m & $\mathrm{m}$ \\
\hline Finnland & 91 & 91 & 85 & 84 & 90 & 95 & 94 & 94 & 97 & 93 & 95 & 93 & 96 & $0,3 \%$ \\
\hline Frankreich & $\mathrm{m}$ & $\mathrm{m}$ & $\mathrm{m}$ & $\mathrm{m}$ & $\mathrm{m}$ & $\mathrm{m}$ & $\mathrm{m}$ & $\mathrm{m}$ & $\mathrm{m}$ & $\mathrm{m}$ & $\mathrm{m}$ & $\mathrm{m}$ & m & $\mathrm{m}$ \\
\hline Deutschland $^{3}$ & 100 & 92 & 92 & 94 & 97 & 99 & 99 & 100 & 100 & 97 & 84 & 87 & 92 & $\mathrm{~m}$ \\
\hline Griechenland & 80 & 54 & 76 & 85 & 96 & 93 & 100 & 98 & 96 & 91 & $\mathrm{~m}$ & $\mathrm{~m}$ & 68 & $-1,0 \%$ \\
\hline Ungarn & $\mathrm{m}$ & $\mathrm{m}$ & 83 & 82 & 87 & 86 & 84 & 87 & 84 & 78 & 86 & 86 & 86 & $\mathrm{~m}$ \\
\hline Island & 80 & 67 & 70 & 79 & 81 & 87 & 79 & 87 & 86 & 89 & 89 & 88 & m & $\mathrm{m}$ \\
\hline Irland & $\mathrm{m}$ & 74 & 77 & 78 & 91 & 92 & 91 & 87 & 90 & 88 & 91 & 94 & 89 & $1,6 \%$ \\
\hline Israel & $\mathrm{m}$ & $\mathrm{m}$ & $\mathrm{m}$ & 90 & 89 & 93 & 90 & 90 & 92 & 90 & 89 & 92 & 85 & $\mathrm{~m}$ \\
\hline Italien & $\mathrm{m}$ & 78 & 81 & 78 & $\mathrm{~m}$ & 82 & 85 & 86 & 84 & 86 & 81 & 83 & 79 & $0,1 \%$ \\
\hline Japan & 96 & 95 & 93 & 94 & 95 & 96 & 95 & 96 & 96 & 95 & 95 & 96 & 96 & $0,0 \%$ \\
\hline Korea & 88 & 96 & 100 & 99 & 92 & 94 & 94 & 93 & 91 & 93 & 89 & 94 & 93 & $0,4 \%$ \\
\hline Luxemburg & $\mathrm{m}$ & $\mathrm{m}$ & $\mathrm{m}$ & 69 & 71 & 69 & 75 & 71 & 75 & 73 & 69 & 70 & 70 & $\mathrm{~m}$ \\
\hline Mexiko & $\mathrm{m}$ & 33 & 34 & 35 & 37 & 39 & 40 & 42 & 43 & 44 & 45 & 47 & 49 & $3,6 \%$ \\
\hline Niederlande & $\mathrm{m}$ & $\mathrm{m}$ & $\mathrm{m}$ & $\mathrm{m}$ & $\mathrm{m}$ & $\mathrm{m}$ & $\mathrm{m}$ & $\mathrm{m}$ & $\mathrm{m}$ & $\mathrm{m}$ & $\mathrm{m}$ & $\mathrm{m}$ & 92 & $\mathrm{~m}$ \\
\hline Neuseeland & $\mathrm{m}$ & $\mathrm{m}$ & $\mathrm{m}$ & $\mathrm{m}$ & $\mathrm{m}$ & $\mathrm{m}$ & $\mathrm{m}$ & $\mathrm{m}$ & $\mathrm{m}$ & $\mathrm{m}$ & $\mathrm{m}$ & $\mathrm{m}$ & m & $\mathrm{m}$ \\
\hline Norwegen & 77 & 99 & 105 & 97 & 92 & 100 & 89 & 88 & 92 & 91 & 91 & 87 & 90 & $0,9 \%$ \\
\hline Polen & $\mathrm{m}$ & 90 & 93 & 91 & 86 & 79 & 85 & 81 & 84 & 83 & 85 & 84 & 84 & $-0,7 \%$ \\
\hline Portugal ${ }^{4}$ & 52 & 52 & 48 & 50 & 60 & 53 & 51 & 54 & 65 & 63 & 96 & 104 & 89 & $3,3 \%$ \\
\hline Slowakei & 85 & 87 & 72 & 60 & 56 & 83 & 85 & 86 & 86 & 82 & 82 & 86 & 85 & $0,0 \%$ \\
\hline Slowenien & $\mathrm{m}$ & $\mathrm{m}$ & $\mathrm{m}$ & $\mathrm{m}$ & $\mathrm{m}$ & $\mathrm{m}$ & 85 & 97 & 91 & 85 & 96 & 94 & 99 & $\mathrm{~m}$ \\
\hline Spanien & 62 & 60 & 66 & 66 & 67 & 66 & 72 & 72 & 74 & 73 & 74 & 80 & 88 & $2,2 \%$ \\
\hline Schweden & $\mathrm{m}$ & 75 & 71 & 72 & 76 & 78 & 76 & 75 & 74 & 74 & 74 & 75 & 75 & $0,1 \%$ \\
\hline Schweiz & 86 & 88 & 91 & 91 & 88 & 87 & 87 & 88 & 88 & 88 & 92 & 94 & m & $\mathrm{m}$ \\
\hline Türkei & 37 & 37 & 37 & 37 & 41 & 55 & 48 & 52 & 58 & 26 & 45 & 54 & 56 & $2,6 \%$ \\
\hline Vereinigtes Königreich & $\mathrm{m}$ & $\mathrm{m}$ & $\mathrm{m}$ & $\mathrm{m}$ & $\mathrm{m}$ & $\mathrm{m}$ & 86 & 88 & 89 & 91 & 92 & 93 & 93 & $\mathrm{~m}$ \\
\hline Vereinigte Staaten & 69 & 70 & 71 & 73 & 74 & 75 & 76 & 75 & 75 & 76 & 76 & 77 & 77 & $0,7 \%$ \\
\hline OECD-Durchschnitt & 78 & 76 & 77 & 78 & 79 & 81 & 82 & 82 & 83 & 81 & 83 & 84 & 83 & m \\
\hline $\begin{array}{l}\text { OECD-Ländermittel für } \\
\text { Länder mit Daten für } \\
1995,2000 \text { und } 2011\end{array}$ & 77 & 77 & & & & & & & & & & & 84 & $0,6 \%$ \\
\hline EU21-Durchschnitt & 79 & 77 & 79 & 77 & 79 & 78 & 81 & 82 & 84 & 84 & 85 & 85 & 83 & $\mathbf{m}$ \\
\hline
\end{tabular}

\begin{tabular}{|c|c|c|c|c|c|c|c|c|c|c|c|c|c|c|}
\hline EU21-Durchschnitt & 79 & 77 & 79 & 77 & 79 & 78 & 81 & 82 & 84 & 84 & 85 & 85 & 83 & m \\
\hline \multicolumn{15}{|l|}{ Sonstige G20-Länder } \\
\hline Argentinien & $\mathrm{m}$ & $\mathrm{m}$ & $\mathrm{m}$ & $\mathrm{m}$ & $\mathrm{m}$ & $\mathrm{m}$ & $\mathrm{m}$ & $\mathrm{m}$ & $\mathrm{m}$ & $\mathrm{m}$ & $\mathrm{m}$ & $\mathrm{m}$ & $\mathbf{m}$ & $\mathrm{m}$ \\
\hline Brasilien & $\mathrm{m}$ & $\mathrm{m}$ & $\mathrm{m}$ & $\mathrm{m}$ & $\mathrm{m}$ & $\mathrm{m}$ & $\mathrm{m}$ & $\mathrm{m}$ & $\mathrm{m}$ & $\mathrm{m}$ & $\mathrm{m}$ & $\mathrm{m}$ & m & $\mathrm{m}$ \\
\hline China & $\mathrm{m}$ & $\mathrm{m}$ & $\mathrm{m}$ & $\mathrm{m}$ & $\mathrm{m}$ & $\mathrm{m}$ & $\mathrm{m}$ & $\mathrm{m}$ & $\mathrm{m}$ & $\mathrm{m}$ & $\mathrm{m}$ & 69 & 73 & $\mathrm{~m}$ \\
\hline Indien & $\mathrm{m}$ & $\mathrm{m}$ & $\mathrm{m}$ & $\mathrm{m}$ & $\mathrm{m}$ & $\mathrm{m}$ & $\mathrm{m}$ & $\mathrm{m}$ & $\mathrm{m}$ & $\mathrm{m}$ & $\mathrm{m}$ & $\mathrm{m}$ & $\mathbf{m}$ & $\mathrm{m}$ \\
\hline Indonesien & $\mathrm{m}$ & $\mathrm{m}$ & $\mathrm{m}$ & $\mathrm{m}$ & $\mathrm{m}$ & $\mathrm{m}$ & $\mathrm{m}$ & $\mathrm{m}$ & $\mathrm{m}$ & $\mathrm{m}$ & $\mathrm{m}$ & $\mathrm{m}$ & $\mathbf{m}$ & $\mathrm{m}$ \\
\hline Russische Föderation & $\mathrm{m}$ & $\mathrm{m}$ & $\mathrm{m}$ & $\mathrm{m}$ & $\mathrm{m}$ & $\mathrm{m}$ & $\mathrm{m}$ & $\mathrm{m}$ & $\mathrm{m}$ & $\mathrm{m}$ & $\mathrm{m}$ & $\mathrm{m}$ & $\mathbf{m}$ & $\mathrm{m}$ \\
\hline Saudi-Arabien & $\mathrm{m}$ & $\mathrm{m}$ & $\mathrm{m}$ & $\mathrm{m}$ & $\mathrm{m}$ & $\mathrm{m}$ & $\mathrm{m}$ & $\mathrm{m}$ & $\mathrm{m}$ & $\mathrm{m}$ & $\mathrm{m}$ & $\mathrm{m}$ & $\mathbf{m}$ & $\mathrm{m}$ \\
\hline Südafrika & $\mathrm{m}$ & $\mathrm{m}$ & $\mathrm{m}$ & $\mathrm{m}$ & $\mathrm{m}$ & $\mathrm{m}$ & $\mathrm{m}$ & $\mathrm{m}$ & $\mathrm{m}$ & $\mathrm{m}$ & $\mathrm{m}$ & $\mathrm{m}$ & m & $\mathrm{m}$ \\
\hline G20-Durchschnitt & $\mathbf{m}$ & $\mathbf{m}$ & m & m & m & m & $\mathbf{m}$ & $m$ & m & m & m & 78 & 79 & m \\
\hline
\end{tabular}

Anmerkung: Bis 2004 wurden Abschlussquoten im Sekundarbereich II als Brutto-Abschlussquoten berechnet. Ab 2005 und für Länder mit verfügbaren Daten wurden die Abschlussquoten als Netto-Abschlussquoten (d.h. als Summe der altersspezifischen Abschlussquoten) berechnet. Weiterführende Informationen zu den zur Berechnung der (Brutto-/Netto-)Abschlussquoten verwendeten Methoden und den entsprechenden typischen Altersjahrgängen s. Anhang 1.

1. Für Länder, die keine Daten für 1995 angeben konnten, ist der durchschnittliche jährliche Anstieg für 2000-2011 kursiv angegeben. 2. Bildungsgänge, die die ISCED-Stufen 3 und 4 umfassen (höhere berufsbildende Schulen), sind nicht erfasst. 3. Unterbrechung der Zeitreihen zwischen 2008 und 2009 in Deutschland aufgrund einer teilweisen Neueinstufung berufsbildender Bildungsgänge in ISCED 2 und ISCED 5B und in Neuseeland aufgrund der zusätzlichen Berücksichtigung von ISCED-3C-Bildungsgängen (kurz). 4. Referenzjahr 1997 anstelle 1995.

Quelle: OECD. China: Statistikinstitut der UNESCO (World Education Indicators Programme). Hinweise s. Anhang 3 unter www. oecd.org/edu/eag.htm.

StatLink: http://dx.doi.org/10.1787/888932848267

Erläuterung der Kennzeichnung fehlender Daten s. Hinweise für den Leser. 
Tabelle A2.3a

Verteilung der Absolventen von berufsbildenden Bildungsgängen des Sekundarbereichs II, nach Fachrichtung und Geschlecht (2011)

\begin{tabular}{|c|c|c|c|c|c|c|c|c|c|c|c|c|c|c|c|c|c|c|}
\hline & \multicolumn{9}{|c|}{ Männer } & \multicolumn{9}{|c|}{ Frauen } \\
\hline & 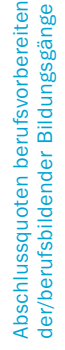 & 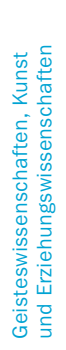 & 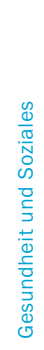 & 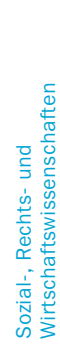 & 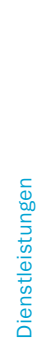 & 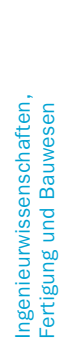 & 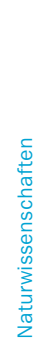 & 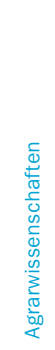 & 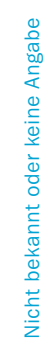 & 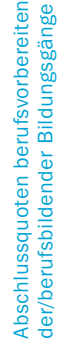 & 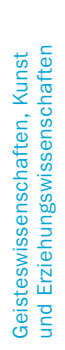 & 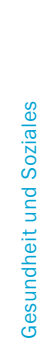 & 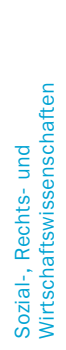 & 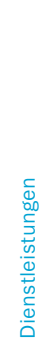 & 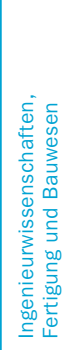 & 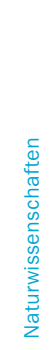 & 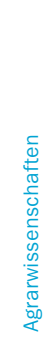 & 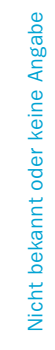 \\
\hline & (1) & (2) & (5) & (6) & (7) & (8) & (9) & (14) & (15) & (16) & (17) & (20) & (21) & (22) & (23) & (24) & (29) & (30) \\
\hline \multicolumn{19}{|l|}{ OECD-Länder } \\
\hline Australien ${ }^{1}$ & 49 & 2 & 5 & 13 & 12 & 59 & 2 & 5 & 2 & 53 & 6 & 36 & 29 & 17 & 4 & 1 & 2 & 5 \\
\hline Österreich ${ }^{2}$ & 86 & 1 & 2 & 10 & 8 & 45 & 2 & 8 & 24 & 64 & 2 & 10 & 34 & 16 & 6 & $\mathrm{n}$ & 8 & 24 \\
\hline Belgien & 62 & 15 & 6 & 11 & 7 & 33 & 3 & 2 & 24 & 73 & 23 & 23 & 12 & 13 & 2 & $\mathrm{n}$ & 1 & 25 \\
\hline Kanada $^{1}$ & 4 & $\mathrm{~m}$ & $\mathrm{~m}$ & $\mathrm{~m}$ & $\mathrm{~m}$ & $\mathrm{~m}$ & $\mathrm{~m}$ & $\mathrm{~m}$ & $\mathrm{~m}$ & 3 & $\mathrm{~m}$ & $\mathrm{~m}$ & $\mathrm{~m}$ & $\mathrm{~m}$ & $\mathrm{~m}$ & $\mathrm{~m}$ & $\mathrm{~m}$ & $\mathrm{~m}$ \\
\hline Chile & 29 & 1 & 2 & 24 & 7 & 58 & $\mathrm{n}$ & 7 & 1 & 31 & 13 & 7 & 48 & 16 & 11 & $\mathrm{n}$ & 4 & 1 \\
\hline Tschechien & 60 & 3 & 1 & 10 & 13 & 70 & $\mathrm{n}$ & 3 & $\mathrm{n}$ & 49 & 7 & 13 & 35 & 31 & 10 & $\mathrm{n}$ & 5 & $\mathrm{n}$ \\
\hline Dänemark & 46 & 3 & 6 & 13 & 12 & 58 & $\mathrm{n}$ & 8 & $\mathrm{n}$ & 46 & 1 & 50 & 29 & 10 & 6 & $\mathrm{n}$ & 4 & $\mathrm{n}$ \\
\hline Estland & 29 & 1 & $n$ & 2 & 9 & 75 & 7 & 6 & $\mathrm{n}$ & 18 & 6 & 2 & 17 & 38 & 26 & 4 & 7 & $\mathrm{n}$ \\
\hline Finnland & 93 & 4 & 5 & 10 & 16 & 57 & 4 & 4 & $\mathrm{n}$ & 106 & 8 & 31 & 21 & 25 & 10 & 1 & 5 & $n$ \\
\hline Frankreich & 70 & 2 & 3 & 15 & 12 & 63 & $\mathrm{n}$ & 6 & $\mathrm{n}$ & 68 & 2 & 29 & 34 & 26 & 6 & $\mathrm{n}$ & 2 & $\mathrm{n}$ \\
\hline Deutschland & 52 & 2 & 2 & 26 & 9 & 54 & 3 & 3 & $n$ & 41 & 3 & 16 & 53 & 19 & 7 & 1 & 1 & $n$ \\
\hline Griechenland & $\mathbf{m}$ & $\mathrm{m}$ & $\mathrm{m}$ & $\mathrm{m}$ & $\mathrm{m}$ & $\mathrm{m}$ & $\mathrm{m}$ & $\mathrm{m}$ & $\mathrm{m}$ & m & $\mathrm{m}$ & $\mathrm{m}$ & $\mathrm{m}$ & $\mathrm{m}$ & $\mathrm{m}$ & $\mathrm{m}$ & $\mathrm{m}$ & $\mathrm{m}$ \\
\hline Ungarn & 21 & 1 & 1 & 6 & 16 & 73 & $\mathrm{n}$ & 4 & $\mathrm{n}$ & 13 & 4 & 12 & 33 & 36 & 12 & $\mathrm{n}$ & 4 & $n$ \\
\hline Island ${ }^{1}$ & 53 & 11 & 1 & 12 & 13 & 59 & 1 & 2 & $\mathrm{n}$ & 55 & 26 & 19 & 20 & 24 & 6 & $\mathrm{n}$ & 4 & $\mathrm{n}$ \\
\hline Irland & 56 & $\mathrm{~m}$ & $\mathrm{~m}$ & $\mathrm{~m}$ & $\mathrm{~m}$ & $\mathrm{~m}$ & $\mathrm{~m}$ & $\mathrm{~m}$ & $\mathrm{~m}$ & 83 & $\mathrm{~m}$ & $\mathrm{~m}$ & $\mathrm{~m}$ & $\mathrm{~m}$ & $\mathrm{~m}$ & $\mathrm{~m}$ & $\mathrm{~m}$ & $\mathrm{~m}$ \\
\hline Israel & 35 & $\mathrm{~m}$ & $\mathrm{~m}$ & $\mathrm{~m}$ & $\mathrm{~m}$ & $\mathrm{~m}$ & $\mathrm{~m}$ & $\mathrm{~m}$ & $\mathrm{~m}$ & 32 & $\mathrm{~m}$ & $\mathrm{~m}$ & $\mathrm{~m}$ & $\mathrm{~m}$ & $\mathrm{~m}$ & $\mathrm{~m}$ & $\mathrm{~m}$ & $\mathrm{~m}$ \\
\hline Italien & 69 & $\mathrm{~m}$ & $\mathrm{~m}$ & $\mathrm{~m}$ & $\mathrm{~m}$ & $\mathrm{~m}$ & $\mathrm{~m}$ & $\mathrm{~m}$ & $\mathrm{~m}$ & 55 & $\mathrm{~m}$ & $\mathrm{~m}$ & $\mathrm{~m}$ & $\mathrm{~m}$ & $\mathrm{~m}$ & $\mathrm{~m}$ & $\mathrm{~m}$ & $\mathrm{~m}$ \\
\hline Japan & 25 & $n$ & 1 & 17 & 2 & 56 & $\mathrm{n}$ & 11 & 11 & 20 & $n$ & 10 & 40 & 13 & 8 & $\mathrm{n}$ & 12 & 17 \\
\hline Korea & 22 & 17 & $n$ & 7 & 3 & 60 & 11 & 2 & $\mathrm{n}$ & 21 & 32 & 1 & 24 & 5 & 23 & 13 & 2 & $\mathrm{n}$ \\
\hline Luxemburg & 47 & $\mathrm{~m}$ & $\mathrm{~m}$ & $\mathrm{~m}$ & $\mathrm{~m}$ & $\mathrm{~m}$ & $\mathrm{~m}$ & $\mathrm{~m}$ & $\mathrm{~m}$ & 43 & $\mathrm{~m}$ & $\mathrm{~m}$ & $\mathrm{~m}$ & $\mathrm{~m}$ & $\mathrm{~m}$ & $\mathrm{~m}$ & $\mathrm{~m}$ & $\mathrm{~m}$ \\
\hline Mexiko & 4 & $\mathrm{~m}$ & $\mathrm{~m}$ & $\mathrm{~m}$ & $\mathrm{~m}$ & $\mathrm{~m}$ & $\mathrm{~m}$ & $\mathrm{~m}$ & $\mathrm{~m}$ & 4 & $\mathrm{~m}$ & $\mathrm{~m}$ & $\mathrm{~m}$ & $\mathrm{~m}$ & $\mathrm{~m}$ & $\mathrm{~m}$ & $\mathrm{~m}$ & $\mathrm{~m}$ \\
\hline Niederlande & 74 & 4 & 6 & 18 & 23 & 37 & 7 & 5 & $n$ & 76 & 7 & 47 & 22 & 19 & 2 & $\mathrm{n}$ & 3 & $\mathrm{n}$ \\
\hline Neuseeland & $\mathbf{m}$ & $\mathrm{m}$ & $\mathrm{m}$ & $\mathrm{m}$ & $\mathrm{m}$ & $\mathrm{m}$ & $\mathrm{m}$ & $\mathrm{m}$ & $\mathrm{m}$ & $\mathbf{m}$ & $\mathrm{m}$ & $\mathrm{m}$ & $\mathrm{m}$ & $\mathrm{m}$ & $\mathrm{m}$ & $\mathrm{m}$ & $\mathrm{m}$ & $\mathrm{m}$ \\
\hline Norwegen & 43 & 1 & 4 & 2 & 14 & 74 & 3 & 3 & $\mathrm{n}$ & 27 & 5 & 48 & 13 & 23 & 9 & $\mathrm{n}$ & 3 & $n$ \\
\hline Polen & 48 & 1 & $\mathrm{n}$ & 7 & 13 & 63 & 11 & 5 & $\mathrm{n}$ & 30 & 3 & $\mathrm{n}$ & 34 & 47 & 11 & 2 & 4 & $\mathrm{n}$ \\
\hline Portugal & 35 & $\mathrm{~m}$ & $\mathrm{~m}$ & $\mathrm{~m}$ & $\mathrm{~m}$ & $\mathrm{~m}$ & $\mathrm{~m}$ & $\mathrm{~m}$ & $\mathrm{~m}$ & 41 & $\mathrm{~m}$ & $\mathrm{~m}$ & $\mathrm{~m}$ & $\mathrm{~m}$ & $\mathrm{~m}$ & $\mathrm{~m}$ & $\mathrm{~m}$ & $\mathrm{~m}$ \\
\hline Slowakei & 70 & 4 & 2 & 12 & 19 & 60 & $\mathrm{n}$ & 3 & $\mathrm{n}$ & 62 & 7 & 12 & 36 & 32 & 9 & $\mathrm{n}$ & 4 & $\mathrm{n}$ \\
\hline Slowenien & 81 & 3 & 5 & 14 & 11 & 55 & 7 & 5 & $\mathrm{n}$ & 68 & 14 & 21 & 37 & 16 & 7 & $\mathrm{n}$ & 6 & $\mathrm{n}$ \\
\hline Spanien & 52 & 16 & 4 & 11 & 12 & 45 & 8 & 4 & $n$ & 54 & 25 & 22 & 30 & 16 & 4 & 2 & 1 & $n$ \\
\hline Schweden & 47 & 12 & 5 & 5 & 9 & 66 & $\mathrm{n}$ & 3 & 1 & 41 & 34 & 22 & 11 & 14 & 10 & $\mathrm{n}$ & 8 & 1 \\
\hline Schweiz & 78 & 2 & 2 & 24 & 6 & 55 & 4 & 6 & $\mathrm{n}$ & 69 & 4 & 23 & 48 & 13 & 9 & $\mathrm{n}$ & 3 & $n$ \\
\hline Türkei & 27 & 1 & 2 & 12 & 4 & 55 & 13 & $\mathrm{n}$ & 14 & 23 & 5 & 25 & 17 & 8 & 13 & 11 & $\mathrm{n}$ & 20 \\
\hline Ver. Königreich & m & $\mathrm{m}$ & $\mathrm{m}$ & $\mathrm{m}$ & $\mathrm{m}$ & $\mathrm{m}$ & $\mathrm{m}$ & $\mathrm{m}$ & $\mathrm{m}$ & $\mathbf{m}$ & $\mathrm{m}$ & $\mathrm{m}$ & $\mathrm{m}$ & $\mathrm{m}$ & $\mathrm{m}$ & $\mathrm{m}$ & $\mathrm{m}$ & $\mathrm{m}$ \\
\hline Vereinigte Staaten & m & $\mathrm{m}$ & $\mathrm{m}$ & $\mathrm{m}$ & $\mathrm{m}$ & $\mathrm{m}$ & $\mathrm{m}$ & $\mathrm{m}$ & $\mathrm{m}$ & $\mathbf{m}$ & $\mathrm{m}$ & $\mathrm{m}$ & $\mathrm{m}$ & $\mathrm{m}$ & $\mathrm{m}$ & $\mathrm{m}$ & $\mathrm{m}$ & $\mathrm{m}$ \\
\hline OECD-Durchschnitt & 49 & 4 & 2 & 11 & 9 & 49 & 3 & 4 & 18 & 46 & 9 & 17 & 26 & 17 & 8 & 1 & 3 & 18 \\
\hline EU21-Ländermittel & 58 & 3 & 3 & 11 & 11 & 51 & 3 & 4 & 13 & 54 & 7 & 19 & 28 & 21 & 8 & 1 & 4 & 13 \\
\hline
\end{tabular}

\begin{tabular}{|c|c|c|c|c|c|c|c|c|c|c|c|c|c|c|c|c|c|c|}
\hline Sonst. G20-Länder & & & & & & & & & & & & & & & & & & \\
\hline Argentinien ${ }^{1}$ & 8 & 2 & $n$ & 13 & 1 & 65 & 8 & 7 & 5 & 5 & 6 & 1 & 31 & 2 & 38 & 12 & 9 & 2 \\
\hline Brasilien & 9 & $\mathrm{~m}$ & $\mathrm{~m}$ & $\mathrm{~m}$ & $\mathrm{~m}$ & $\mathrm{~m}$ & $\mathrm{~m}$ & $\mathrm{~m}$ & $\mathrm{~m}$ & 15 & $\mathrm{~m}$ & $\mathrm{~m}$ & $\mathrm{~m}$ & $\mathrm{~m}$ & $\mathrm{~m}$ & $\mathrm{~m}$ & $\mathrm{~m}$ & $\mathrm{~m}$ \\
\hline China & 52 & $\mathrm{~m}$ & $\mathrm{~m}$ & $\mathrm{~m}$ & $\mathrm{~m}$ & $\mathrm{~m}$ & $\mathrm{~m}$ & $\mathrm{~m}$ & $\mathrm{~m}$ & 53 & $\mathrm{~m}$ & $\mathrm{~m}$ & $\mathrm{~m}$ & $\mathrm{~m}$ & $\mathrm{~m}$ & $\mathrm{~m}$ & $\mathrm{~m}$ & $\mathrm{~m}$ \\
\hline Indien & m & $\mathrm{m}$ & $\mathrm{m}$ & $\mathrm{m}$ & $\mathrm{m}$ & $\mathrm{m}$ & $\mathrm{m}$ & $\mathrm{m}$ & $\mathrm{m}$ & $\mathbf{m}$ & $\mathrm{m}$ & $\mathrm{m}$ & $\mathrm{m}$ & $\mathrm{m}$ & $\mathrm{m}$ & $\mathrm{m}$ & $\mathrm{m}$ & $\mathrm{m}$ \\
\hline Indonesien & 25 & 2 & 2 & 49 & $n$ & 39 & $\mathrm{n}$ & $\mathrm{n}$ & 8 & 18 & 2 & 6 & 49 & $n$ & 29 & $n$ & 4 & 10 \\
\hline Russische Föd. & $\mathbf{m}$ & $\mathrm{m}$ & $\mathrm{m}$ & $\mathrm{m}$ & $\mathrm{m}$ & $\mathrm{m}$ & $\mathrm{m}$ & $\mathrm{m}$ & $\mathrm{m}$ & m & $\mathrm{m}$ & $\mathrm{m}$ & $\mathrm{m}$ & $\mathrm{m}$ & $\mathrm{m}$ & $\mathrm{m}$ & $\mathrm{m}$ & $\mathrm{m}$ \\
\hline Saudi-Arabien & m & $\mathrm{m}$ & $\mathrm{m}$ & $\mathrm{m}$ & $\mathrm{m}$ & $\mathrm{m}$ & $\mathrm{m}$ & $\mathrm{m}$ & $\mathrm{m}$ & $\mathbf{m}$ & $\mathrm{m}$ & $\mathrm{m}$ & $\mathrm{m}$ & $\mathrm{m}$ & $\mathrm{m}$ & $\mathrm{m}$ & $\mathrm{m}$ & $\mathrm{m}$ \\
\hline Südafrika & $\mathbf{m}$ & $\mathrm{m}$ & $\mathrm{m}$ & $\mathrm{m}$ & $\mathrm{m}$ & $\mathrm{m}$ & $\mathrm{m}$ & $\mathrm{m}$ & $\mathrm{m}$ & $\mathbf{m}$ & $\mathrm{m}$ & $\mathrm{m}$ & $\mathrm{m}$ & $\mathrm{m}$ & $\mathrm{m}$ & $\mathrm{m}$ & $\mathrm{m}$ & $\mathrm{m}$ \\
\hline G20-Durchschnitt & 32 & $\mathbf{m}$ & $\mathbf{m}$ & $\mathbf{m}$ & $\mathbf{m}$ & m & m & m & $\mathbf{m}$ & 29 & m & $\mathbf{m}$ & m & $\mathbf{m}$ & m & $\mathbf{m}$ & $\mathbf{m}$ & m \\
\hline
\end{tabular}

Anmerkung: Die Spalten mit den separaten Angaben zu „Geisteswissenschaften, Kunst und Erziehungswissenschaften“, d.h. die Spalten (3), (4), (18) und (19), sowie für "Naturwissenschaften“, d.h. die Spalten (10) bis (13), (25) bis (28), stehen im Internet zur Verfügung (s. StatLink unten).

1. Referenzjahr 2010. 2. Bildungsgänge, die die ISCED-Stufen 3 und 4 umfassen (höhere berufsbildende Schule), sind nicht erfasst.

Quelle: OECD. Argentinien, China, Indonesien: Statistikinstitut der UNESCO (World Education Indicators Programme).

Hinweise s. Anhang 3 unter www.oecd.org/edu/eag.htm. StatLink: http://dx.doi.org/10.1787/888932848305

Erläuterung der Kennzeichnung fehlender Daten s. Hinweise für den Leser. 


\section{Wie viele Studierende werden ein Studium im Tertiärbereich abschließen?}

Aufgrund der aktuellen Abschlussquoten wird davon ausgegangen, dass in den OECD-Ländern durchschnittlich 40 Prozent der jungen Erwachsenen von heute im Laufe ihres Lebens einen Abschluss im (weitgehend theoretisch orientierten) Tertiärbereich A erwerben werden.

Im Durchschnitt werden wahrscheinlich II Prozent der heutigen jungen Erwachsenen in den OECD-Ländern im Laufe ihres Lebens einen Abschluss im (weitgehend beruflich ausgerichteten) Tertiärbereich B erwerben.

Im Durchschnitt der OECD-Länder erwerben Studierende ihren ersten akademischen Abschluss im Alter von 27 Jahren, wobei dieser Durchschnitt von 24 Jahren in Indonesien und dem Vereinigten Königreich bis zu 29 Jahren oder mehr in Brasilien, Finnland, Island, Israel und Schweden reicht.

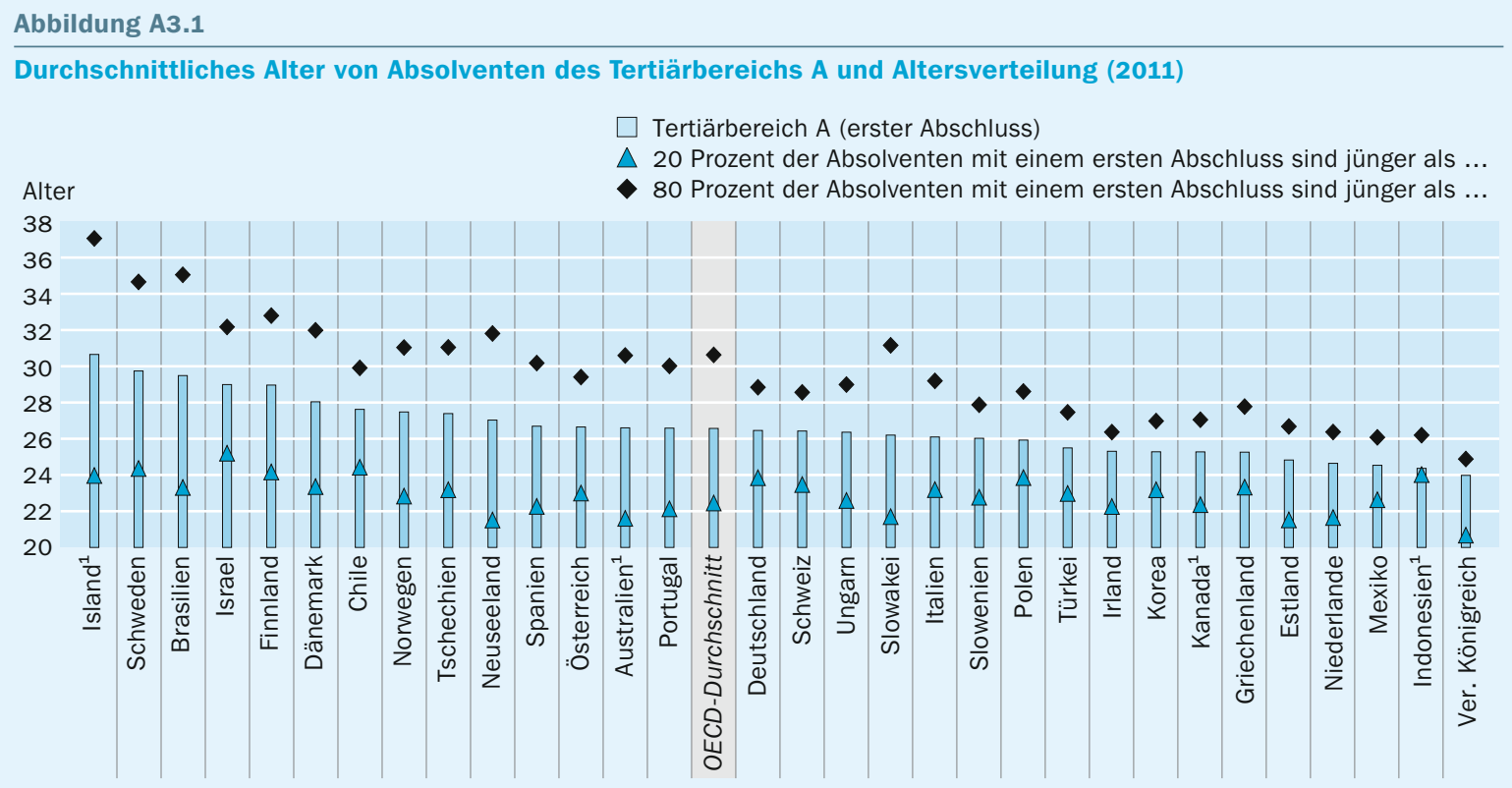

Anmerkung: Das „durchschnittliche Abschlussalter“ bezieht sich auf ein gewichtetes durchschnittliches Alter, in der Regel das Alter von Studierenden zu Beginn des Kalenderjahres. Sie könnten jedoch schon ein Jahr älter als angegeben sein, wenn der Abschluss gegen Ende des Studienjahres erfolgt. Zur Berechnung des durchschnittlichen Abschlussalters s. Anhang 3.

1. Referenzjahr 2010.

Anordnung der Länder in absteigender Reihenfolge des durchschnittlichen Alters von Absolventen des Tertiärbereichs A (erster Abschluss) im Jahr 2011. Quelle: OECD. Indonesien: Statistikinstitut der UNESCO (World Education Indicators Programme). Tabelle A3.1.

Hinweise s. Anhang 3 unter www.oecd.org/edu/eag.htm. StatLink: http://dx.doi.org/10.1787/888932846367

\section{Kontext}

Abschlussquoten im Tertiärbereich geben Aufschluss darüber, in welchem Ausmaß ein Land in der Lage ist, die Beschäftigten der Zukunft mit erweiterten, speziellen Kenntnissen und Fähigkeiten auszustatten. In den OECD-Ländern bestehen für den Einzelnen starke Anreize, u. a. in Form höherer Einkommen und besserer Beschäf- 
tigungsaussichten, einen Bildungsabschluss im Tertiärbereich zu erwerben (s. Indikatoren A5 und A6). Struktur und Umfang des Tertiärbereichs unterscheiden sich erheblich in den einzelnen Ländern, und die Abschlussquoten werden anscheinend davon beeinflusst, wie leicht der Zugang zu den Studiengängen ist, wie viel Flexibilität bei ihrem Abschluss gewährt wird und welche Nachfrage nach höherwertigen Kompetenzen auf dem Arbeitsmarkt besteht. Den Zugang zum Tertiärbereich zu erweitern und seine Qualität zu verbessern ist für wissensbasierte Volkswirtschaften von zentraler Bedeutung, aber angesichts knapper Budgets sind diese Ziele schwieriger denn je zu erreichen.

In den letzten Jahrzehnten wurde der Zugang zum Tertiärbereich deutlich erweitert, es entstanden neue Arten von Bildungseinrichtungen, zusätzliche und unterschiedliche Bildungsangebote sowie neue Formen der Vermittlung (OECD, 2008). Gleichzeitig wird die Gruppe der Studierenden zunehmend heterogener, da Gruppen, denen traditionell der Zugang zur Hochschulbildung verwehrt war, jetzt studieren, ältere Menschen danach streben, ihre Qualifikationen zu verbessern, um in einem zunehmend wettbewerbsorientierten Arbeitsmarkt zu bestehen, und schließlich Absolventen mit einem ersten Abschluss nach einem zweiten Abschluss streben.

\section{Weitere wichtige Ergebnisse}

Die Mehrheit der Absolventen der Tertiärbereiche A und B ist weiblich, dies gilt nicht für Promotionsstudiengänge. Aufgrund der aktuellen Abschlussquoten wird geschätzt, dass in den OECD-Ländern durchschnittlich 48 Prozent der jungen Frauen und 32 Prozent der jungen Männer von heute im Lauf ihres Lebens einen Abschluss im (weitgehend theoretisch orientierten) Tertiärbereich A erwerben werden.

Es wird davon ausgegangen, dass im Durchschnitt der OECD-Länder I,6 Prozent der jungen Erwachsenen einen weiterführenden forschungsorientierten Studiengang abschließen werden.

Internationale Studierende stellen in einer Reihe von Ländern, u. a. Australien, Neuseeland und dem Vereinigten Königreich, einen signifikanten Anteil der Absolventen des Tertiärbereichs.

\section{Entwicklungstendenzen}

Im Durchschnitt der OECD-Länder mit verfügbaren Daten sind die Abschlussquoten im Tertiärbereich A in den letzten I6 Jahren um 20 Prozentpunkte gestiegen, während die Abschlussquoten im Tertiärbereich B gleich geblieben sind. Promotionsstudiengänge stellen nur einen geringen Teil der Studiengänge im Tertiärbereich dar, aber die Abschlussquoten in diesem Bereich haben sich in den letzten I6 Jahren verdoppelt.

\section{Hinweise}

Abschlussquoten zeigen den geschätzten prozentualen Anteil einer Altersgruppe, der wahrscheinlich im Laufe des Lebens einen Abschluss erwerben wird. Diese Schätzung basiert auf der Zahl der Absolventen im Jahr 20II sowie der Altersverteilung in dieser 
Gruppe. Daher basieren die angegebenen Zahlen auf den aktuellen Abschlussquoten; sie werden somit von jeder Änderung des Bildungssystems beeinflusst, wie der Einführung neuer Studiengänge oder Änderungen der Dauer von Studiengängen, wie sie sich gerade durch die Umsetzung des Bologna-Prozesses ergeben.

Im vorliegenden Indikator wird der 30. Geburtstag als die Obergrenze für das typische Alter für einen Erstabschluss im Tertiärbereich A oder B angesehen. Die Obergrenze für das typische Alter von Absolventen eines weiterführenden forschungsorientierten Studiengangs liegt bei 35 Jahren.

In vielen Ländern wird klar zwischen erstem und zweitem akademischem Abschluss, d. h. dem Abschluss von Undergraduate- und Graduate-Studiengängen, unterschieden. In einigen Ländern wird jedoch ein Abschluss, der international mit dem Niveau eines Masterabschlusses vergleichbar ist, am Ende eines einzigen langen Studiengangs erworben. Zur genaueren Vergleichbarkeit beziehen sich die in diesem Indikator vorgestellten Daten, soweit nicht anders angegeben, auf Erstabschlüsse.

\section{Analyse und Interpretationen}

Aufgrund der Abschlussquoten von $201 \mathrm{I}$ wird davon ausgegangen, dass im Durchschnitt der 28 OECD-Länder, für die vergleichbare Daten zur Verfügung stehen, 40 Prozent der jungen Menschen im Laufe ihres Lebens einen Erstabschluss im Tertiärbereich A erwerben werden. Dieser Anteil reicht von weniger als 25 Prozent in Chile, Mexiko, Saudi-Arabien und der Türkei bis zu mindestens 50 Prozent in Australien, Dänemark, Island, Neuseeland, Polen und dem Vereinigten Königreich (Abb. A3.2).

Diese Studiengänge sind weitgehend theoretisch orientiert und sollen hinreichende Qualifikationen für den Zugang zu weiterführenden forschungsorientierten Studiengängen und Berufen mit hohen Qualifikationsanforderungen vermitteln. Sie werden normalerweise an Universitäten angeboten.

Aufgrund der Abschlussquoten von $201 \mathrm{I}$ wird davon ausgegangen, dass im Durchschnitt der OECD-Länder 39 Prozent der jungen Menschen einen ersten Abschluss im Tertiärbereich A (häufig als Bachelorabschluss bezeichnet) erwerben werden und I7 Prozent auch einen zweiten Abschluss (häufig als Masterabschluss bezeichnet). Für Studiengänge, die zu einem ersten Abschluss führen, liegt die Abschlussquote in Australien, Dänemark, Island, Neuseeland, Polen und der Russischen Föderation bei mindestens 50 Prozent, während es in Argentinien, Belgien, Chile, China, Estland, Griechenland, Indonesien, Mexiko, Saudi-Arabien, Südafrika und der Türkei höchstens 25 Prozent sind. Die niedrigen Abschlussquoten in Belgien und China werden durch höhere Abschlussquoten bei Studiengängen, die zu einem ersten Abschluss im Tertiärbereich B führen, kompensiert. In China werden etwa I6 Prozent der heute dort lebenden jungen Menschen im Laufe ihres Lebens einen Abschluss in einem zu einem ersten Abschluss führenden Studiengang im Tertiärbereich A erwerben und I9 Prozent in einem entsprechenden Studiengang im Tertiärbereich B. Die Abschlussquote bei Studiengängen, die zu einem zweiten Abschluss führen, liegt in Belgien, Polen, der 


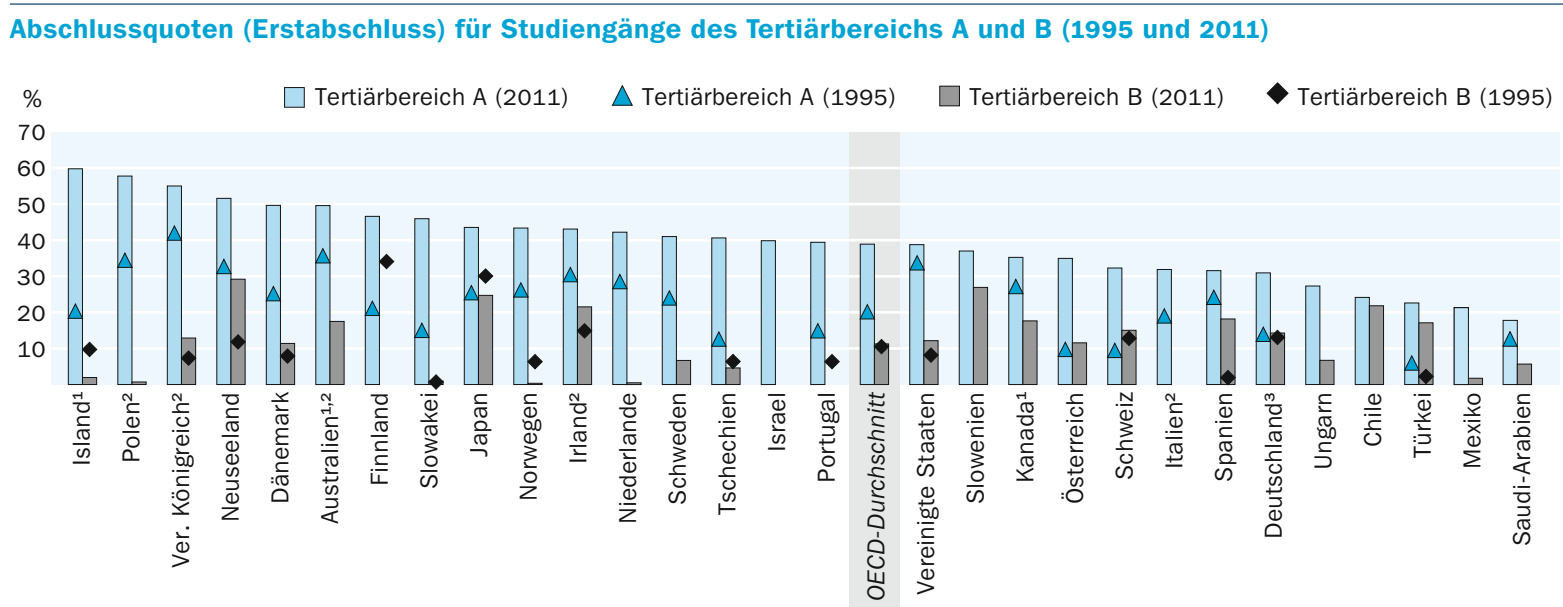

1. Referenzjahr 2010 anstelle 2011. 2. Referenzjahr 2000 anstelle 1995. 3. Unterbrechung der Zeitreihe zwischen 2008 und 2009 aufgrund einer teilweisen Neueinstufung berufsbildender Bildungsgänge in ISCED 2 und ISCED 5B.

Anordnung der Länder in absteigender Reihenfolge der Abschlussquoten (Erstabschluss) im Tertiärbereich A im Jahr 2011.

Quelle: OECD. Saudi-Arabien: Observatory on Higher Education. Tabelle A3.2a. Hinweise s. Anhang 3 unter www.oecd.org/edu/eag.htm.

StatLink: http://dx.doi.org/10.1787/888932846386

Slowakei, Tschechien und dem Vereinigten Königreich bei mindestens 25 Prozent. Mit der Umsetzung des Bologna-Prozesses hat die Zahl der Studiengänge im Tertiärbereich deutlich zugenommen (Tab. A3.Ia).

Der in den letzten Jahrzehnten schnell gestiegene Bedarf an Studiengängen des Tertiärbereichs A wurde auch durch kürzere, berufsorientierte Studiengänge, d. h. die Studiengänge im Tertiärbereich B, gedeckt. 20II lagen in den 26 OECD-Ländern mit vergleichbaren Daten die Abschlussquoten im Tertiärbereich B im Durchschnitt bei II Prozent; I3 Prozent der Frauen besaßen einen Abschluss in derartigen Studiengängen gegenüber ı Prozent der Männer. Vom Niveau her werden diese Studiengänge genauso wie die stärker theoretisch orientierten Studiengänge eingeordnet, sie sind jedoch häufig von kürzerer Dauer (in der Regel zwei bis drei Jahre). Sie sind im Allgemeinen nicht auf den Zugang zu einem weiterführenden universitären Abschluss orientiert, sondern sollen den Absolventen Kompetenzen vermitteln, die direkt auf dem Arbeitsmarkt verwendet werden können und die auch den Anforderungen des Arbeitsmarkts nach speziellen Kompetenzen entsprechen (Tab. A3.ra).

\section{Trenddaten}

In allen Ländern mit vergleichbaren Daten stiegen die Abschlussquoten im Tertiärbereich A zwischen 1995 und 20II. Der Anstieg war zwischen 1995 und 2005 besonders hoch und flachte danach wieder ab. In den letzten vier Jahren beliefen sich die Abschlussquoten im Tertiärbereich A unverändert auf rund 39 Prozent. Seit 1995 bzw. seit dem Jahr, für das erstmalig Daten vorliegen, sind die geschätzten Abschlussquoten im Tertiärbereich in Dänemark, Finnland, Österreich, Polen, Portugal, der Schweiz, der Slowakei und Tschechien um mindestens 20 Prozentpunkte gestiegen.

Aufgrund der fortschreitenden Harmonisierung der Hochschulbildung im Rahmen des Bologna-Prozesses und einer allgemeinen Abkehr von längeren Studiengängen zugunsten von Studiengängen mit einer Dauer von 3 Jahren ist in einigen Ländern ein 
Abschlussquoten im Tertiärbereich A mit und ohne internationale Studierende, nach Alter (2011)
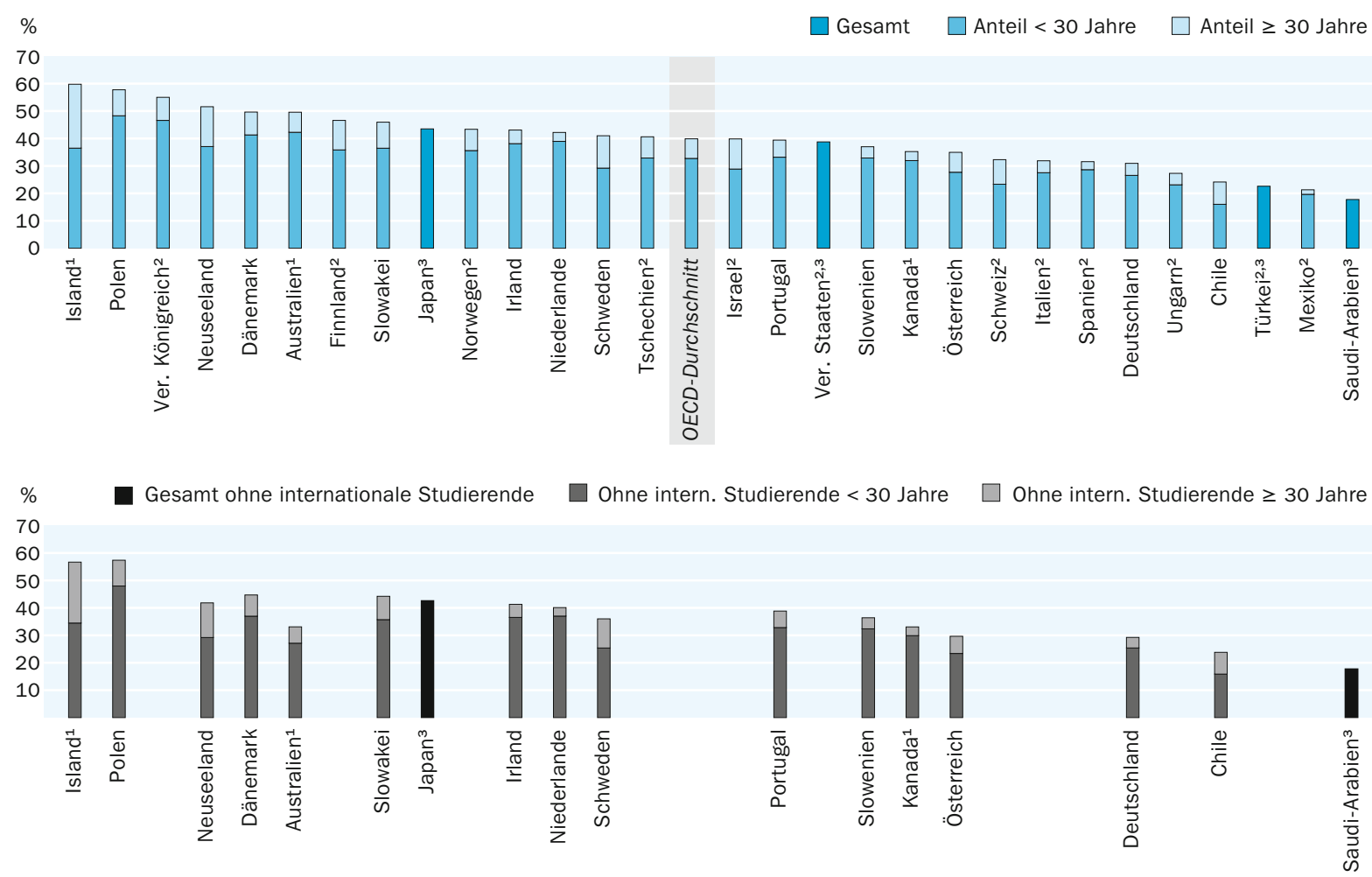

Anmerkung: Diese Abbildung enthält nur Absolventen des Tertiärbereichs A mit Erstabschluss.

1. Referenzjahr 2010. 2. Es liegen keine Abschlussquoten für internationale Studierende vor. 3. Es liegen keine nach Altersgruppe aufgeschlüsselten Abschlussquoten vor.

Anordnung der Länder in absteigender Reihenfolge der Gesamtabschlussquoten im Tertiärbereich A im Jahr 2011.

Quelle: OECD. Saudi-Arabien: Observatory of Higher Education. Tabellen A3.1a und A3.1b. Hinweise s. Anhang 3 unter www.oecd.org/edu/eag.htm.

StatLink: http://dx.doi.org/10.1787/888932846405

deutlicher Anstieg der Abschlussquoten zu beobachten gewesen. So kam es mit der Umsetzung der Bologna-Reformen beispielsweise in Tschechien zwischen 2004 und 2007 sowie in Finnland und der Slowakei zwischen 2007 und 2008 zu einem starken Anstieg der Abschlussquoten.

Im Tertiärbereich B gab es zwischen 1995 und $201 \mathrm{I}$ unterschiedliche Entwicklungen, auch wenn sich der OECD-Durchschnitt kaum verändert hat. In Spanien beispielsweise ist der starke Anstieg der Abschlussquoten im Tertiärbereich B auf die Einführung neuer, höherwertiger berufsbildender Ausbildungsgänge zurückzuführen. In Finnland hingegen laufen gegenwärtig die Studiengänge des Tertiärbereichs B aus, daher sind dort die Abschlussquoten für diese Studiengänge zugunsten stärker akademisch orientierter Studiengänge deutlich zurückgegangen (Abb. A3.2).

Geschlechtsspezifische Trenddaten zeigen, dass der Anstieg der Abschlussquoten im Tertiärbereich A bei den Frauen in einigen OECD-Ländern besonders stark war, insbesondere in der Slowakei, Slowenien und Tschechien, wo zwischen 2005 und $201 \mathrm{I}$ ein Anstieg von mindestens 25 Prozentpunkten zu beobachten war. Die Abschlussquoten der Männer in diesen Ländern stiegen zwar ebenfalls an, aber in weit geringerem Maße (Tab. A3.2b im Internet). 


\section{Abschlussquoten von Studierenden, die jünger als das typische Abschlussalter sind}

Im Durchschnitt der OECD-Länder erwerben Studierende ihren ersten Abschluss im Tertiärbereich im Alter von 27 Jahren, aber dieses Alter variiert sehr stark zwischen den einzelnen Ländern. Studierende in Indonesien und dem Vereinigten Königreich schließen ihr Studium im Durchschnitt vor ihrem 25. Geburtstag ab, in Brasilien, Finnland, Island, Israel und Schweden erwerben Studierende ihren ersten Abschluss im Tertiärbereich dagegen erst kurz nach dem 29. Geburtstag (Abb. A3.I).

Der Prozentsatz junger Menschen, die einen Abschluss im Tertiärbereich erwerben, und ihr Alter variieren je nach Land. In einigen Ländern ist ein großer Teil der Absolventen jenseits des typischen Abschlussalters. Altersunterschiede zwischen den Absolventen können mit strukturellen Faktoren, wie dem Abschluss des Sekundarbereichs II, der Dauer der Studiengänge oder einer eventuell bestehenden Wehrpflicht, zusammenhängen. Altersunterschiede zwischen den Absolventen können auch wirtschaftlichen Faktoren zuzuschreiben sein, wie dem Fehlen von Stipendien und der Flexibilität, Studium und Berufstätigkeit miteinander zu verbinden, oder bildungspolitischen Maßnahmen, die Erwachsene mit Berufserfahrung dazu ermutigen sollen, noch ein Studium im Tertiärbereich aufzunehmen und so vorhandene Kompetenzen zu vertiefen oder ganz neue Kompetenzen zu erlangen. Angesichts der aktuellen Weltwirtschaftslage haben sich junge Menschen auch dafür entschieden, ihre Ausbildung zu verlängern, anstatt den Eintritt in einen instabilen Arbeitsmarkt zu riskieren (s. Indikator $\mathrm{C}_{3}$ ). Die Tatsache, dass diese Männer und Frauen später ins Berufsleben eintreten, hat wirtschaftliche Konsequenzen, die bei bildungspolitischen Entscheidungen zu berücksichtigen sind. Hierzu zählen höhere Ausgaben pro Studierenden und entgangene Steuereinnahmen aufgrund des kürzeren Arbeitslebens der Betroffenen.

Es wird davon ausgegangen, dass weniger als ein Drittel der jungen Menschen den Abschluss im Tertiärbereich A vor Erreichen des 30. Lebensjahrs erwerben wird - wobei ihr Anteil von mehr als 40 Prozent in Australien, Dänemark, Polen und dem Vereinigten Königreich bis zu höchstens 20 Prozent in Chile und Mexiko reicht (Abb. A3.3).

\section{Abschlussquoten ohne internationale Studierende}

Bei „internationalen Studierenden“ handelt es sich um Studierende, die ausdrücklich zum Studium in ein anderes Land gekommen sind. Internationale Studierende haben aus verschiedenen Gründen einen wesentlichen Einfluss auf die geschätzten Abschlussquoten. Per Definition gelten sie als Absolventen mit einem Erstabschluss, unabhängig von ihren zuvor in anderen Ländern erworbenen Abschlüssen (d. h. ein internationaler Studierender, der ein zu einem zweiten Abschluss führendes Studium aufnimmt und abschließt, gilt als Absolvent mit einem Erstabschluss in dem Land seines Auslandsstudiums). Darüber hinaus kann durch sie die absolute Zahl der Absolventen unter der Bevölkerung steigen, da sie mit der Absicht zu studieren in das Land gekommen sind und nicht unbedingt, um dort zu arbeiten und auf Dauer zu bleiben. Die Abschlussquoten in Ländern mit einem großen Anteil internationaler Studierender wie Australien, Neuseeland und dem Vereinigten Königreich sind dadurch künstlich überhöht. Rechnet man zum Beispiel die internationalen Studierenden heraus, so fallen die Abschlussquoten (Erstabschluss) im Tertiärbereich A von Studierenden in Australien und Neuseeland um i6 bzw. Io Prozentpunkte geringer aus und die entsprechenden 
Abschlussquoten (Erstabschluss) im Tertiärbereich B in Neuseeland um 8 Prozentpunkte (Tab. A3.ra).

Der Beitrag internationaler Studierender zur Gesamtzahl der Absolventen ist auch bei Studiengängen, die zu einem ersten Abschluss im Tertiärbereich A führen (d.h. auf Ebene des Bachelors), signifikant. In Australien, Neuseeland, Österreich, der Schweiz und dem Vereinigten Königreich sind mindestens ro Prozent der Studierenden, die im Tertiärbereich einen ersten Abschluss erwerben, internationale Studierende. Der Beitrag internationaler Studierender zur Gesamtzahl der Absolventen ist bei den Studiengängen, die zu einem zweiten Abschluss führen, wie z. B. Masterstudiengängen, eher noch größer. Die entsprechenden Abschlussquoten in Australien und dem Vereinigten Königreich sinken um I3 bzw. I2 Prozent, wenn die internationalen Studierenden unberücksichtigt bleiben (Abb. A3.3).

\section{Abschlussquoten bei weiterführenden forschungsorientierten Studiengängen}

Bei Promovierten handelt es sich um Absolventen, die einen Abschluss auf der höchsten Ebene des formalen Bildungssystems erworben haben, zu ihnen gehören normalerweise auch Forscher, die einen Doktorgrad erworben haben. Aufgrund der Abschlussquoten von $201 \mathrm{I}$ wird davon ausgegangen, dass im Durchschnitt der OECD-Länder I,6 Prozent der jungen Menschen einen Abschluss in einem weiterführenden forschungsorientierten Studiengang erwerben werden, verglichen mit I, o Prozent im Jahr 2000. Zu den Ländern mit dem stärksten Anstieg der Abschlussquoten in weiterführenden forschungsorientierten Studiengängen gehören Dänemark, Irland, Neuseeland, die Slowakei und das Vereinigte Königreich, wo diese zwischen 2000 und 20 II um mindestens I Prozentpunkt angestiegen sind (Tab. A3.2c im Internet). In China lag die entsprechende Abschlussquote für 201 I mit 2,2 Prozent oberhalb des OECD-Durchschnitts (Tab. A3.ra).

Auf diesem Bildungsniveau weisen Frauen eine niedrigere Abschlussquote als Männer auf (I,5 Prozent gegenüber I,7 Prozent). Dies gilt für alle Länder mit Ausnahme von Argentinien, Estland, Finnland, Israel, Italien, Polen, Portugal, Saudi-Arabien, der Slowakei und den Vereinigten Staaten, wo der geschätzte Anteil der Frauen, die einen Abschluss in einem weiterführenden forschungsorientierten Studiengang erwerben, größer als derjenige der Männer ist (Tab. A3.Ia).

Einige Länder wollen internationale Studierende für Promotionsstudiengänge gewinnen. Die hohen Abschlussquoten, die in Finnland, Deutschland, Schweden und der Schweiz in diesem Bereich zu beobachten sind (mehr als 2,5 Prozent), sind teilweise auf den hohen Anteil internationaler Studierender bei den Promotionsstudiengängen zurückzuführen (Tab. A3.ra). Werden internationale Studierende bei der Berechnung nicht berücksichtigt, reduzieren sich die Abschlussquoten in ganz unterschiedlichem Ausmaß - von o,3 Prozentpunkten in Finnland bis zu I,6 Prozentpunkten in der Schweiz. Im Durchschnitt der OECD-Länder sind Absolventen von weiterführenden forschungsorientierten Studiengängen 35 Jahre alt, das durchschnittliche Abschlussalter reicht jedoch von 32 Jahren in Italien und den Niederlanden über 26 Jahre in Indonesien bis zu 38 Jahren oder mehr in Brasilien, Finnland, Korea, Neuseeland, Norwegen und Portugal (Tab. A3.ra). 
Geschlechtsspezifische Unterschiede bei der Wahl der Fachrichtung Die Verteilung der erworbenen Abschlüsse auf die einzelnen Fachrichtungen richtet sich nach deren relativer Beliebtheit bei den Studierenden, der relativen Anzahl der in den betreffenden Fachrichtungen an den Hochschulen und entsprechenden Einrichtungen angebotenen Stellen und der Struktur der für diese Studienfächer möglichen Abschlüsse in dem jeweiligen Land.

Frauen dominieren bei den Abschlüssen im erziehungswissenschaftlichen Bereich, sie stellen in diesen Studiengängen in allen Ländern mehr als 70 Prozent der Studierenden im Tertiärbereich A und in den weiterführenden forschungsorientierten Studiengängen, die einzigen Ausnahmen sind hier Japan (6o Prozent), Saudi-Arabien (66 Prozent) und die Türkei (57 Prozent). Auch im Bereich Gesundheit und Soziales handelt es sich bei dem überwiegenden Teil der Absolventen um Frauen, ihr Anteil an allen Abschlüssen betrug hier im Durchschnitt 75 Prozent (Tab. A3.3 im Internet).

Im Gegensatz dazu betrug der Anteil der Frauen bei den Absolventen in den Ingenieurwissenschaften, Fertigung und Bauwesen in allen Ländern mit Ausnahme von Argentinien, Estland, Island, Polen und Slowenien höchstens ein Drittel. Diese Situation hat sich seit 2000 nur geringfügig verändert, trotz zahlreicher Initiativen der OECD-Länder und der EU zur Verringerung geschlechtsspezifischer Unterschiede. So hat beispielsweise die Europäische Union 2000 das Ziel festgelegt, die Anzahl der Absolventen in Mathematik, Naturwissenschaften und Technik bis 2010 um mindestens I5 Prozent zu steigern sowie eine Verringerung des in diesen Studiengängen bestehenden Ungleichgewichts zwischen den Geschlechtern zu erreichen. Bislang wurden jedoch nur sehr geringe Fortschritte in dieser Hinsicht erzielt. Deutschland, die Schweiz, die Slowakei und Tschechien waren die einzigen vier Länder, in denen der Anteil der Frauen in den Naturwissenschaften zwischen 2000 und 201 I um mindestens Io Prozentpunkte gestiegen ist. Damit haben sich diese Länder in dieser Hinsicht dem OECD-Durchschnitt angenähert. In den OECD-Ländern ist der Anteil der Frauen in diesen Fachrichtungen geringfügig von 40 Prozent im Jahr 2000 auf 4I Prozent im Jahr 20II gestiegen - obwohl der Anteil der weiblichen Absolventen über alle Fachrichtungen hinweg in diesem Zeitraum von 54 Prozent auf 58 Prozent gestiegen ist. Der Anteil der Frauen in der Fachrichtung Ingenieurwissenschaften, Fertigung und Bauwesen ist ebenfalls niedrig, er ist jedoch in den letzten Io Jahren leicht von 23 auf 27 Prozent angestiegen (Tab. A3.3 im Internet).

\section{Definitionen}

Ein Studiengang im Tertiärbereich A, der zu einem ersten Abschluss führt, dauert kumuliert regulär mindestens drei Jahre (vollzeitäquivalent), z. B. beim Bachelorabschluss in vielen englischsprachigen Ländern, dem Diplom in vielen deutschsprachigen Ländern und der licence in vielen französischsprachigen Ländern.

Ein Erstabsolvent ist ein Studierender, der innerhalb des Referenzzeitraums zum ersten Mal in einem bestimmten Bildungsbereich - oder im Fall von ISCED 5 in einem Studiengang des Tertiärbereichs A oder B - einen Abschluss erwirbt. Wenn also ein Studierender im Laufe der Jahre mehrere Abschlüsse erwirbt, so wird er oder sie zwar jedes Jahr als Absolvent gezählt, als Erstabsolvent jedoch nur einmal. 
Studierende werden als internationale Studierende eingestuft, wenn sie aus ihrem Herkunftsland zwecks Studium in ein anderes Land gekommen sind. Per Definition gelten sie als Absolventen mit einem Erstabschluss, unabhängig von ihren früher in anderen Ländern erworbenen Abschlüssen.

Netto-Abschlussquoten zeigen den geschätzten prozentualen Anteil einer spezifischen Altersgruppe, der im Laufe des Lebens einen Abschluss im Tertiärbereich erwerben wird (ausgehend von den aktuellen Abschlussquoten).

Zu einem zweiten Abschluss führende und stärker theoretisch orientierte Studiengänge (z. B. beim Masterabschluss in vielen Ländern) werden getrennt von weiterführenden forschungsorientierten Studiengängen (ISCED 6) in den Tertiärbereich A eingeordnet.

Als Absolventen im Tertiärbereich gelten alle Studierenden, die einen Universitätsabschluss, Fachhochschulabschluss oder Abschluss in einem weiterführenden forschungsorientierten Studiengang auf Ebene der Promotion erwerben.

\section{Angewandte Methodik}

Die Daten beziehen sich auf das Studienjahr 20I0/20II und beruhen auf der von der OECD im Jahre 2012 durchgeführten UOE-Datenerhebung zur Bildungsstatistik (weitere Informationen s. Anhang 3 unter www.oecd.org/eduleag.htm).

Die Daten zu den Auswirkungen internationaler Studierender auf die Abschlussquoten im Tertiärbereich basieren auf einer im Dezember 2012 von der OECD durchgeführten speziellen Erhebung.

Die Daten zur Entwicklung der Abschlussquoten im Tertiärbereich für die Jahre 1995 und 2000 bis 2004 basieren auf einer speziellen Erhebung, die im Januar 2007 durchgeführt wurde.

Um einen von den unterschiedlichen nationalen Abschlussstrukturen unabhängigen Vergleich zu ermöglichen, werden die Abschlüsse in universitären Studiengängen entsprechend ihrer regulären Gesamtdauer untergliedert, mit anderen Worten entsprechend der (gesetzlich oder anders) festgelegten Zahl von Jahren, in denen ein Studiengang abgeschlossen werden kann. Abschlüsse, die nach kurzen Studiengängen mit einer Dauer von weniger als drei Jahren erworben werden, gelten hier nicht als gleichwertig mit einem Abschluss dieses Bildungsbereichs und werden somit bei diesem Indikator nicht berücksichtigt. $\mathrm{Zu}$ einem zweiten Abschluss führende Studiengänge werden nach der kumulierten Dauer der zum ersten und zum zweiten Abschluss führenden Studiengänge klassifiziert, wobei Absolventen, die bereits über einen ersten Abschluss verfügen, bei der Zählung der Absolventen mit einem Erstabschluss nicht berücksichtigt werden.

Außer es ist etwas anderes angegeben, wurden die Abschlussquoten als Netto-Abschlussquoten (d.h. als Summe der Abschlussquoten der einzelnen Altersjahrgänge) berechnet. Für diejenigen Länder, die keine detaillierten Daten bereitstellen konnten, 
werden die Brutto-Abschlussquoten dargestellt. Zur Berechnung der Brutto-Abschlussquoten gab jedes Land das typische Abschlussalter an (s. Anhang I). Die Zahl der Absolventen wurde (ohne Berücksichtigung ihres jeweiligen Alters) durch die Bevölkerung im üblichen Abschlussalter geteilt. In vielen Ländern ist es jedoch schwierig, ein typisches Abschlussalter anzugeben, weil die Altersverteilung der Absolventen sehr breit gestreut ist.

Die statistischen Daten für Israel wurden von den zuständigen israelischen Stellen bereitgestellt, die für sie verantwortlich zeichnen. Die Verwendung dieser Daten durch die OECD erfolgt unbeschadet des völkerrechtlichen Status der Golanhöhen, von OstJerusalem und der israelischen Siedlungen im Westjordanland.

\section{Weiterführende Informationen}

OECD (2008), Tertiary Education for the Knowledge Society: Volume 1 and Volume 2, OECD Publishing, http://dx.doi.org/10.1787/9789264046535-en.

\section{Tabellen Indikator A3}

Tabelle A3.Ia: Abschlussquoten und durchschnittliches Abschlussalter im Tertiärbereich (20II)

StatLink: http://dx.doi.org/10.1787/888932848362

Tabelle A3.Ib: Abschlussquoten im Tertiärbereich von Studierenden, die jünger als das typische Abschlussalter sind (20II)

StatLink: http:||dx.doi.org/10.1787/888932848381

Tabelle A3.2a: Entwicklung der Abschlussquoten im Tertiärbereich (I995-20II)

StatLink: http://dx.doi.org/10.1787/888932848400

WEB Table A3.2b: Trends in tertiary graduation rates, by gender (Entwicklung der Abschlussquoten im Tertiärbereich, nach Geschlecht) (2005-20II)

StatLink: http:|/dx.doi.org/10.1787/888932848419

WEB Table A3.2c: Trends in net graduation rates at advanced research level (Entwicklung der Netto-Abschlussquoten bei weiterführenden forschungsorientierten Studiengängen) (I995-20II)

StatLink: http://dx.doi.org/10.1787/888932848438

WEB Table A3.3: Percentage of tertiary qualifications awarded to women in tertiary-type A and advanced research programmes, by field of education (Prozentsatz der von Frauen erworbenen Abschlüsse im Tertiärbereich A und in weiterführenden forschungsorientierten Studiengängen, nach Fachrichtung) (2000, 20II) StatLink: http://dx.doi.org/10.1787/888932848457 
Abschlussquoten und durchschnittliches Abschlussalter im Tertiärbereich (2011)

Summe der Abschlussquoten der einzelnen Altersjahrgänge, nach Geschlecht und Art des Studiengangs

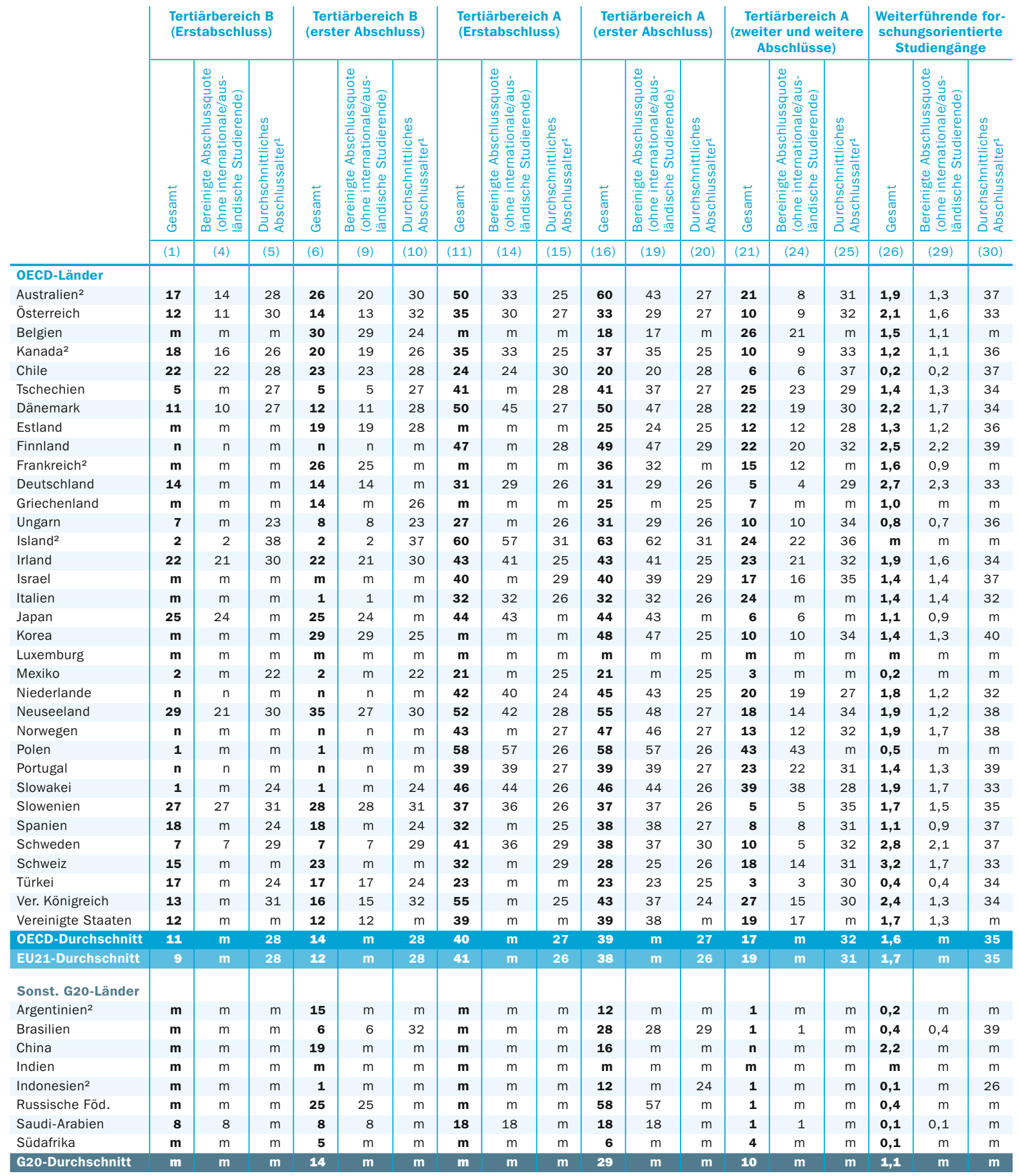

Anmerkung: Die Spalten mit den separaten Abschlussquoten für Männer und Frauen, d.h. die Spalten (2), (3), (7), (8), (12), (13), (17), (18), (22), (23), (27) und (28), stehen im Internet zur Verfügung (s. StatLink unten). Weiterführende Informationen zu den zur Berechnung der (Brutto-/Netto-)Abschlussquoten verwendeten Methoden und des entsprechenden typischen Abschlussalters s. Anhang 1. Unterschiede im Erhebungsbereich der Bevölkerungsdaten und der Absolventendaten bedeuten, dass die Abschlussquoten von Ländern mit einem Nettoabgang von Studierenden wohl zu niedrig angesetzt und von Ländern mit einem Nettozugang von Studierenden wohl zu hoch angesetzt sind. Bei den bereinigten Studienanfängerquoten in den Tabellen A3.1a und A3.1b ist dies weitgehend berücksichtigt. 1. Das „durchschnittliche Abschlussalter“ bezieht sich auf ein durchschnittliches gewichtetes Alter, in der Regel das Alter von Studierenden zu Beginn des Kalenderjahres, sie könnten jedoch schon ein Jahr älter als angegeben sein, wenn der Abschluss gegen Ende des Studienjahres erfolgt. 2. Referenzjahr 2010. Quelle: OECD. Argentinien, China, Indonesien: Statistikinstitut der UNESCO (World Education Indicators Programme). Saudi-Arabien: Observatory on Higher Education. Südafrika: Statistikinstitut der UNESCO. Hinweise s. Anhang 3 unter www.oecd.org/edu/eag.htm. StatLink: http://dx.doi.org/10.1787/888932848362 Erläuterung der Kennzeichnung fehlender Daten s. Hinweise für den Leser. 
Tabelle A3.1b

Abschlussquoten im Tertiärbereich von Studierenden, die jünger als das typische Abschlussalter sind (2011) Summe der Abschlussquoten der einzelnen Altersjahrgänge von bis zu 30-Jährigen im Tertiärbereich A oder B und von bis zu 35-Jährigen bei weiterführenden forschungsorientierten Studiengängen, nach Geschlecht und Art des Studiengangs

\begin{tabular}{|c|c|c|c|c|c|c|c|c|c|c|c|c|}
\hline & \multicolumn{2}{|c|}{$\begin{array}{l}\text { Tertiärbereich B } \\
\text { (Erstabschluss) }\end{array}$} & \multicolumn{2}{|c|}{$\begin{array}{c}\text { Tertiärbereich B } \\
\text { (erster Abschluss) }\end{array}$} & \multicolumn{2}{|c|}{$\begin{array}{l}\text { Tertiärbereich A } \\
\text { (Erstabschluss) }\end{array}$} & \multicolumn{2}{|c|}{$\begin{array}{c}\text { Teritärbereich A } \\
\text { (erster Abschluss) }\end{array}$} & \multicolumn{2}{|c|}{$\begin{array}{c}\text { Tertiärbereich A } \\
\text { (zweiter Abschluss) }\end{array}$} & \multicolumn{2}{|c|}{$\begin{array}{l}\text { Weiterführende for- } \\
\text { schungsorientierte } \\
\text { Studiengänge }\end{array}$} \\
\hline & $\begin{array}{l}\tilde{E} \\
\mathbb{W} \\
\mathbb{N} \\
\mathbb{\circlearrowleft}\end{array}$ & 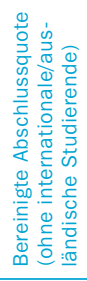 & $\begin{array}{l}\vec{E} \\
\mathbb{W} \\
\mathbb{N} \\
\mathbb{\circlearrowleft}\end{array}$ & 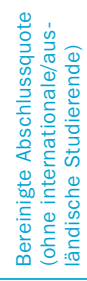 & $\begin{array}{l}\vec{E} \\
\mathbb{0} \\
\mathbb{0} \\
\mathbb{0}\end{array}$ & 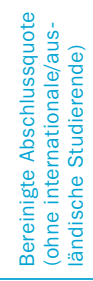 & 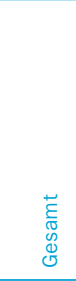 & 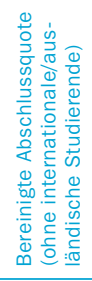 & 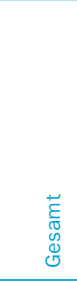 & 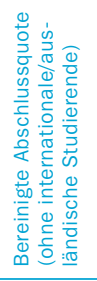 & 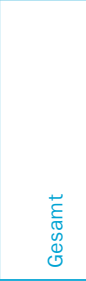 & 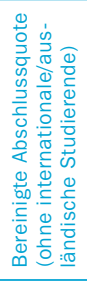 \\
\hline & (1) & (4) & (5) & (8) & (9) & (12) & (13) & (16) & (17) & (20) & (21) & (24) \\
\hline \multicolumn{13}{|l|}{ OECD-Länder } \\
\hline Australien ${ }^{1}$ & 11 & 8 & 14 & 9 & 42 & 27 & 48 & 33 & 13 & 3 & 1,0 & 0,7 \\
\hline Österreich & 7 & 7 & 8 & 8 & 28 & 23 & 27 & 24 & 6 & 5 & 1,6 & 1,2 \\
\hline Belgien & $\mathrm{m}$ & $\mathrm{m}$ & 27 & $\mathrm{~m}$ & $\mathrm{~m}$ & $\mathrm{~m}$ & $\mathrm{~m}$ & $\mathrm{~m}$ & $\mathrm{~m}$ & $\mathrm{~m}$ & $\mathrm{~m}$ & $\mathrm{~m}$ \\
\hline Kanada $^{1}$ & 14 & 13 & 16 & 15 & 32 & 30 & 33 & 31 & 5 & 5 & 0,8 & 0,6 \\
\hline Chile & 15 & 15 & 16 & 16 & 16 & 16 & 16 & 16 & 2 & 1 & 0,2 & $n$ \\
\hline Tschechien & 4 & $\mathrm{~m}$ & 4 & $\mathrm{~m}$ & 33 & $\mathrm{~m}$ & 33 & $\mathrm{~m}$ & 20 & $\mathrm{~m}$ & 0,7 & $\mathrm{~m}$ \\
\hline Dänemark & 9 & 8 & 10 & 8 & 41 & 37 & 39 & 37 & 16 & 14 & 1,5 & 1,1 \\
\hline Estland & $\mathrm{m}$ & $\mathrm{m}$ & 13 & $\mathrm{~m}$ & $\mathrm{~m}$ & $\mathrm{~m}$ & 21 & $\mathrm{~m}$ & 9 & $\mathrm{~m}$ & 0,8 & $\mathrm{~m}$ \\
\hline Finnland & $\mathrm{n}$ & $\mathrm{n}$ & $n$ & $\mathrm{n}$ & 36 & $\mathrm{~m}$ & 36 & 35 & 12 & 11 & 1,1 & 0,9 \\
\hline Frankreich ${ }^{1}$ & $\mathrm{~m}$ & $\mathrm{~m}$ & $\mathrm{~m}$ & $\mathrm{~m}$ & $\mathrm{~m}$ & $\mathrm{~m}$ & $\mathrm{~m}$ & $\mathrm{~m}$ & $\mathrm{~m}$ & $\mathrm{~m}$ & $\mathrm{~m}$ & $\mathrm{~m}$ \\
\hline Deutschland & $\mathrm{m}$ & $\mathrm{m}$ & $\mathrm{m}$ & $\mathrm{m}$ & 27 & 25 & 27 & 25 & 4 & 3 & 2,2 & 1,9 \\
\hline Griechenland & $\mathrm{m}$ & $\mathrm{m}$ & 13 & $\mathrm{~m}$ & $\mathrm{~m}$ & $\mathrm{~m}$ & 22 & $\mathrm{~m}$ & $\mathrm{~m}$ & $\mathrm{~m}$ & $\mathrm{~m}$ & $\mathrm{~m}$ \\
\hline Ungarn & 6 & $\mathrm{~m}$ & 7 & $\mathrm{~m}$ & 23 & $\mathrm{~m}$ & 26 & $\mathrm{~m}$ & 5 & $\mathrm{~m}$ & 0,5 & $\mathrm{~m}$ \\
\hline Island ${ }^{1}$ & $\mathrm{~m}$ & $\mathrm{~m}$ & $\mathrm{~m}$ & $\mathrm{~m}$ & 36 & 34 & 38 & 38 & 9 & 8 & 0,4 & $\mathrm{n}$ \\
\hline Irland & 14 & 13 & 14 & 13 & 38 & 37 & 38 & 36 & 13 & 12 & 1,3 & 1,1 \\
\hline Israel & $\mathrm{m}$ & $\mathrm{m}$ & $\mathrm{m}$ & $\mathrm{m}$ & 29 & $\mathrm{~m}$ & 29 & 29 & 5 & 5 & 0,7 & 0,7 \\
\hline Italien & $\mathrm{m}$ & $\mathrm{m}$ & $\mathrm{m}$ & $\mathrm{m}$ & 28 & $\mathrm{~m}$ & 28 & $\mathrm{~m}$ & $\mathrm{~m}$ & $\mathrm{~m}$ & 1,0 & $\mathrm{~m}$ \\
\hline Japan & $\mathrm{m}$ & $\mathrm{m}$ & $\mathrm{m}$ & $\mathrm{m}$ & $\mathrm{m}$ & $\mathrm{m}$ & $\mathrm{m}$ & $\mathrm{m}$ & $\mathrm{m}$ & $\mathrm{m}$ & $\mathrm{m}$ & $\mathrm{m}$ \\
\hline Korea & $\mathrm{m}$ & $\mathrm{m}$ & 25 & 25 & $\mathrm{~m}$ & $\mathrm{~m}$ & 46 & 45 & 5 & 5 & 0,5 & $\mathrm{n}$ \\
\hline Luxemburg & $\mathrm{m}$ & $\mathrm{m}$ & $\mathrm{m}$ & $\mathrm{m}$ & $\mathrm{m}$ & $\mathrm{m}$ & $\mathrm{m}$ & $\mathrm{m}$ & $\mathrm{m}$ & $\mathrm{m}$ & $\mathrm{m}$ & $\mathrm{m}$ \\
\hline Mexiko & 2 & $\mathrm{~m}$ & 2 & $\mathrm{~m}$ & 20 & $\mathrm{~m}$ & 20 & $\mathrm{~m}$ & $\mathrm{~m}$ & $\mathrm{~m}$ & $\mathrm{~m}$ & $\mathrm{~m}$ \\
\hline Niederlande & $\mathrm{n}$ & $\mathrm{n}$ & $\mathrm{n}$ & $\mathrm{m}$ & 39 & 37 & 41 & 39 & 17 & 16 & 1,6 & 1,1 \\
\hline Neuseeland & 18 & 11 & 21 & 14 & 37 & 29 & 42 & 35 & 9 & 6 & 0,9 & 0,5 \\
\hline Norwegen & $n$ & $\mathrm{~m}$ & $\mathrm{n}$ & $\mathrm{m}$ & 36 & $\mathrm{~m}$ & 38 & $\mathrm{~m}$ & 8 & $\mathrm{~m}$ & 1,0 & $\mathrm{~m}$ \\
\hline Polen & 1 & $\mathrm{~m}$ & 1 & $\mathrm{~m}$ & 48 & 48 & 48 & 48 & $\mathrm{~m}$ & $\mathrm{~m}$ & $\mathrm{~m}$ & $\mathrm{~m}$ \\
\hline Portugal & $\mathrm{n}$ & $\mathrm{n}$ & $\mathrm{n}$ & $\mathrm{n}$ & 33 & 33 & 33 & 33 & 15 & 14 & 0,7 & 0,6 \\
\hline Slowakei & 1 & $\mathrm{~m}$ & 1 & $\mathrm{~m}$ & 36 & 36 & 36 & 36 & 29 & 29 & 1,3 & 1,3 \\
\hline Slowenien & 16 & 16 & 16 & 16 & 33 & 32 & 33 & 32 & 2 & 2 & 1,2 & 1,1 \\
\hline Spanien & 16 & $\mathrm{~m}$ & 16 & $\mathrm{~m}$ & 29 & $\mathrm{~m}$ & 33 & $\mathrm{~m}$ & 6 & $\mathrm{~m}$ & 0,7 & $\mathrm{~m}$ \\
\hline Schweden & 4 & 4 & 5 & 5 & 29 & 25 & 26 & 25 & 6 & 2 & 1,6 & 1,1 \\
\hline Schweiz & $\mathrm{m}$ & $\mathrm{m}$ & $\mathrm{m}$ & $\mathrm{m}$ & 23 & $\mathrm{~m}$ & 24 & 22 & 11 & 8 & 2,6 & 1,3 \\
\hline Türkei & 15 & $\mathrm{~m}$ & 15 & $\mathrm{~m}$ & $\mathrm{~m}$ & $\mathrm{~m}$ & 20 & $\mathrm{~m}$ & 2 & $\mathrm{~m}$ & 0,3 & $\mathrm{~m}$ \\
\hline Ver. Königreich & 8 & $\mathrm{~m}$ & 9 & $\mathrm{~m}$ & 47 & $\mathrm{~m}$ & 38 & $\mathrm{~m}$ & 17 & $\mathrm{~m}$ & 1,7 & $\mathrm{~m}$ \\
\hline Vereinigte Staaten & $\mathrm{m}$ & $\mathrm{m}$ & $\mathrm{m}$ & $\mathrm{m}$ & $\mathrm{m}$ & $\mathrm{m}$ & $\mathrm{m}$ & $\mathrm{m}$ & $\mathrm{m}$ & $\mathrm{m}$ & $\mathrm{m}$ & $\mathrm{m}$ \\
\hline OECD-Durchschnitt & 8 & m & 10 & $\mathbf{m}$ & 33 & m & 32 & m & 10 & m & 1,1 & $\mathbf{m}$ \\
\hline EU21-Durchschnitt & 6 & m & 8 & m & 34 & m & 33 & m & 12 & m & 1,2 & m \\
\hline \multicolumn{13}{|l|}{ Sonst. G20-Länder } \\
\hline Argentinien $^{1}$ & $\mathrm{~m}$ & $\mathrm{~m}$ & $\mathrm{~m}$ & $\mathrm{~m}$ & $\mathrm{~m}$ & $\mathrm{~m}$ & $\mathrm{~m}$ & $\mathrm{~m}$ & $\mathrm{~m}$ & $\mathrm{~m}$ & $\mathrm{~m}$ & $\mathrm{~m}$ \\
\hline Brasilien & $\mathrm{m}$ & $\mathrm{m}$ & 3 & $\mathrm{~m}$ & $\mathrm{~m}$ & $\mathrm{~m}$ & 17 & $\mathrm{~m}$ & 1 & $\mathrm{~m}$ & 0,2 & $\mathrm{~m}$ \\
\hline China & $\mathrm{m}$ & $\mathrm{m}$ & $\mathrm{m}$ & $\mathrm{m}$ & $\mathrm{m}$ & $\mathrm{m}$ & $\mathrm{m}$ & $\mathrm{m}$ & $\mathrm{m}$ & $\mathrm{m}$ & $\mathrm{m}$ & $\mathrm{m}$ \\
\hline Indien & $\mathrm{m}$ & $\mathrm{m}$ & $\mathrm{m}$ & $\mathrm{m}$ & $\mathrm{m}$ & $\mathrm{m}$ & $\mathrm{m}$ & $\mathrm{m}$ & $\mathrm{m}$ & $\mathrm{m}$ & $\mathrm{m}$ & $\mathrm{m}$ \\
\hline Indonesien ${ }^{1}$ & $\mathrm{~m}$ & $\mathrm{~m}$ & 1 & $\mathrm{~m}$ & $\mathrm{~m}$ & $\mathrm{~m}$ & 12 & $\mathrm{~m}$ & 1 & $\mathrm{~m}$ & 0,1 & $\mathrm{~m}$ \\
\hline Russische Föd. & $\mathrm{m}$ & $\mathrm{m}$ & $\mathrm{m}$ & $\mathrm{m}$ & $\mathrm{m}$ & $\mathrm{m}$ & $\mathrm{m}$ & $\mathrm{m}$ & $\mathrm{m}$ & $\mathrm{m}$ & $\mathrm{m}$ & $\mathrm{m}$ \\
\hline Saudi-Arabien & $\mathrm{m}$ & $\mathrm{m}$ & $\mathrm{m}$ & $\mathrm{m}$ & $\mathrm{m}$ & $\mathrm{m}$ & $\mathrm{m}$ & $\mathrm{m}$ & $\mathrm{m}$ & $\mathrm{m}$ & $\mathrm{m}$ & $\mathrm{m}$ \\
\hline Südafrika & $\mathrm{m}$ & $\mathrm{m}$ & $\mathrm{m}$ & $\mathrm{m}$ & $\mathrm{m}$ & $\mathrm{m}$ & $\mathrm{m}$ & $\mathrm{m}$ & $\mathrm{m}$ & $\mathrm{m}$ & $\mathrm{m}$ & $\mathrm{m}$ \\
\hline G20-Durchschnitt & m & $\mathbf{m}$ & $\mathbf{m}$ & m & m & $\mathbf{m}$ & $\mathbf{m}$ & m & $\mathbf{m}$ & m & $\mathbf{m}$ & $\mathbf{m}$ \\
\hline
\end{tabular}

Anmerkung: Die Spalten mit den separaten Abschlussquoten für Männer und Frauen, d.h. die Spalten (2), (3), (6), (7), (10), (11), (14), (15), (18), (19), (22) und (23), stehen im Internet zur Verfügung (s. StatLink unten). Weiterführende Informationen zu den zur Berechnung der (Brutto-/Netto-)Abschlussquoten verwendeten Methoden und des entsprechenden typischen Abschlussalters s. Anhang 1. Unterschiede im Erhebungsbereich der Bevölkerungsdaten und der Absolventendaten bedeuten, dass die Abschlussquoten von Ländern mit einem Nettoabgang von Studierenden wohl zu niedrig angesetzt und von Ländern mit einem Nettozugang von Studierenden wohl zu hoch angesetzt sind. Bei den bereinigten Studienanfängerquoten in den Tabellen A3.1a und A3.1b ist dies weitgehend berücksichtigt. 1. Referenzjahr 2010

Quelle: OECD. Indonesien: Statistikinstitut der UNESCO (World Education Indicators Programme). Hinweise s. Anhang 3 unter www.oecd.org/edu/eag.htm. StatLink: http://dx.doi.org/10.1787/888932848381

Erläuterung der Kennzeichnung fehlender Daten s. Hinweise für den Leser. 
Entwicklung der Abschlussquoten im Tertiärbereich (1995-2011)

Summe der Abschlussquoten der einzelnen Altersjahrgänge, nach Art des Studiengangs

\begin{tabular}{|c|c|c|c|c|c|c|c|c|c|c|c|c|c|c|}
\hline & \multicolumn{7}{|c|}{ Tertiärbereich A (Erstabschluss) } & \multicolumn{7}{|c|}{ Tertiärbereich B (Erstabschluss) } \\
\hline & 1995 & 2000 & 2005 & 2008 & 2009 & 2010 & 2011 & 1995 & 2000 & 2005 & 2008 & 2009 & 2010 & 2011 \\
\hline & (1) & (2) & (7) & $(10)$ & (11) & (12) & $(13)$ & (14) & $(15)$ & $(20)$ & $(23)$ & $(24)$ & $(25)$ & $(26)$ \\
\hline \multicolumn{15}{|l|}{ OECD-Länder } \\
\hline Australien & $\mathrm{m}$ & 36 & 50 & 49 & 50 & 50 & m & $\mathrm{m}$ & $\mathrm{m}$ & $\mathrm{m}$ & 16 & 16 & 17 & $\mathbf{m}$ \\
\hline Österreich & 10 & 15 & 20 & 25 & 29 & 30 & 35 & $\mathrm{~m}$ & $\mathrm{~m}$ & 8 & 8 & 10 & 12 & 12 \\
\hline Belgien & $\mathrm{m}$ & $\mathrm{m}$ & $\mathrm{m}$ & $\mathrm{m}$ & $\mathrm{m}$ & $\mathrm{m}$ & m & $\mathrm{m}$ & $\mathrm{m}$ & $\mathrm{m}$ & $\mathrm{m}$ & $\mathrm{m}$ & $\mathrm{m}$ & m \\
\hline Kanada $^{1}$ & 27 & 27 & 29 & 37 & 36 & 35 & m & $\mathrm{m}$ & $\mathrm{m}$ & $\mathrm{m}$ & 29 & 29 & 18 & $\mathbf{m}$ \\
\hline Chile & $\mathrm{m}$ & $\mathrm{m}$ & $\mathrm{m}$ & $\mathrm{m}$ & $\mathrm{m}$ & $\mathrm{m}$ & 24 & $\mathrm{~m}$ & $\mathrm{~m}$ & $\mathrm{~m}$ & $\mathrm{~m}$ & $\mathrm{~m}$ & $\mathrm{~m}$ & 22 \\
\hline Tschechien & 13 & 14 & 23 & 36 & 38 & 38 & 41 & 6 & 5 & 6 & 5 & 4 & 5 & 5 \\
\hline Dänemark & 25 & 37 & 46 & 47 & 50 & 50 & 50 & 8 & 10 & 10 & 11 & 11 & 9 & 11 \\
\hline Estland & $\mathrm{m}$ & $\mathrm{m}$ & $\mathrm{m}$ & $\mathrm{m}$ & $\mathrm{m}$ & $\mathrm{m}$ & m & $\mathrm{m}$ & $\mathrm{m}$ & $\mathrm{m}$ & $\mathrm{m}$ & $\mathrm{m}$ & $\mathrm{m}$ & $\mathbf{m}$ \\
\hline Finnland & 21 & 40 & 47 & 63 & 44 & 49 & 47 & 34 & 7 & $n$ & $n$ & $n$ & $\mathrm{n}$ & $\mathbf{n}$ \\
\hline Frankreich & $\mathrm{m}$ & $\mathrm{m}$ & $\mathrm{m}$ & $\mathrm{m}$ & $\mathrm{m}$ & $\mathrm{m}$ & m & $\mathrm{m}$ & $\mathrm{m}$ & $\mathrm{m}$ & $\mathrm{m}$ & $\mathrm{m}$ & $\mathrm{m}$ & $\mathbf{m}$ \\
\hline Deutschland $^{1}$ & 14 & 18 & 20 & 25 & 28 & 30 & 31 & 13 & 11 & 11 & 10 & 14 & 14 & 14 \\
\hline Griechenland & 14 & 15 & 25 & $\mathrm{~m}$ & $\mathrm{~m}$ & $\mathrm{~m}$ & m & 5 & 6 & 11 & $\mathrm{~m}$ & $\mathrm{~m}$ & $\mathrm{~m}$ & $\mathbf{m}$ \\
\hline Ungarn & $\mathrm{m}$ & $\mathrm{m}$ & 33 & 30 & 31 & 31 & 27 & $\mathrm{~m}$ & $\mathrm{~m}$ & 4 & 4 & 5 & 6 & 7 \\
\hline Island & 20 & 33 & 56 & 57 & 51 & 60 & m & 10 & 5 & 4 & 4 & 2 & 2 & $\mathbf{m}$ \\
\hline Irland & $\mathrm{m}$ & 30 & 38 & 46 & 47 & 47 & 43 & $\mathrm{~m}$ & 15 & 24 & 26 & 26 & 26 & 22 \\
\hline Israel & $\mathrm{m}$ & $\mathrm{m}$ & 35 & 36 & 37 & 37 & 40 & $\mathrm{~m}$ & $\mathrm{~m}$ & $\mathrm{~m}$ & $\mathrm{~m}$ & $\mathrm{~m}$ & $\mathrm{~m}$ & m \\
\hline Italien & $\mathrm{m}$ & 19 & 41 & 33 & 33 & 32 & 32 & $\mathrm{~m}$ & $n$ & 1 & 1 & 1 & 1 & $\mathbf{m}$ \\
\hline Japan & 25 & 29 & 37 & 39 & 40 & 40 & 44 & 30 & 30 & 28 & 27 & 26 & 25 & 25 \\
\hline Korea & $\mathrm{m}$ & $\mathrm{m}$ & $\mathrm{m}$ & $\mathrm{m}$ & $\mathrm{m}$ & $\mathrm{m}$ & $\mathbf{m}$ & $\mathrm{m}$ & $\mathrm{m}$ & $\mathrm{m}$ & $\mathrm{m}$ & $\mathrm{m}$ & $\mathrm{m}$ & $\mathbf{m}$ \\
\hline Luxemburg & $\mathrm{m}$ & $\mathrm{m}$ & $\mathrm{m}$ & $\mathrm{m}$ & $\mathrm{m}$ & $\mathrm{m}$ & $\mathbf{m}$ & $\mathrm{m}$ & $\mathrm{m}$ & $\mathrm{m}$ & $\mathrm{m}$ & $\mathrm{m}$ & $\mathrm{m}$ & $\mathbf{m}$ \\
\hline Mexiko & $\mathrm{m}$ & $\mathrm{m}$ & 17 & 18 & 19 & 20 & 21 & $\mathrm{~m}$ & $\mathrm{~m}$ & 1 & 1 & 1 & 1 & 2 \\
\hline Niederlande & 29 & 35 & 42 & 41 & 42 & 42 & 42 & $\mathrm{~m}$ & $\mathrm{~m}$ & $n$ & $\mathrm{n}$ & $n$ & $\mathrm{n}$ & $\mathbf{n}$ \\
\hline Neuseeland & 33 & 50 & 51 & 48 & 50 & 47 & 52 & 12 & 17 & 21 & 21 & 24 & 26 & 29 \\
\hline Norwegen & 26 & 37 & 41 & 41 & 41 & 42 & 43 & 6 & 6 & 2 & 1 & $n$ & $\mathrm{n}$ & $\mathbf{n}$ \\
\hline Polen & $\mathrm{m}$ & 34 & 47 & 50 & 50 & 55 & 58 & $\mathrm{~m}$ & $\mathrm{~m}$ & $n$ & $\mathrm{n}$ & $n$ & 1 & 1 \\
\hline Portugal & 15 & 23 & 32 & 45 & 40 & 40 & 39 & 6 & 8 & 9 & 2 & 1 & $n$ & $\mathbf{n}$ \\
\hline Slowakei & 15 & $\mathrm{~m}$ & 30 & 58 & 62 & 49 & 46 & 1 & 2 & 2 & 1 & 1 & 1 & 1 \\
\hline Slowenien & $\mathrm{m}$ & $\mathrm{m}$ & 18 & 20 & 27 & 29 & 37 & $\mathrm{~m}$ & $\mathrm{~m}$ & 24 & 26 & 26 & 26 & 27 \\
\hline Spanien ${ }^{2}$ & 24 & 29 & 30 & 27 & 27 & 30 & 32 & 2 & 8 & 15 & 14 & 15 & 16 & 18 \\
\hline Schweden & 24 & 28 & 38 & 40 & 36 & 37 & 41 & $\mathrm{~m}$ & 4 & 5 & 6 & 6 & 6 & 7 \\
\hline Schweiz & 9 & 12 & 27 & 32 & 31 & 31 & 32 & 13 & 14 & 8 & 19 & 19 & 16 & 15 \\
\hline Türkei & 6 & 9 & 11 & 20 & 21 & 23 & 23 & 2 & $\mathrm{~m}$ & $\mathrm{~m}$ & 13 & 15 & 19 & 17 \\
\hline Vereinigtes Königreich & $\mathrm{m}$ & 42 & 47 & 48 & 48 & 51 & 55 & $\mathrm{~m}$ & 7 & 11 & 12 & 12 & 12 & 13 \\
\hline Vereinigte Staaten & 33 & 34 & 34 & 37 & 38 & 38 & 39 & 9 & 8 & 10 & 10 & 11 & 11 & 12 \\
\hline OECD-Durchschnitt & 20 & 28 & 34 & 39 & 39 & 39 & 39 & 11 & 9 & 9 & 11 & 11 & 10 & 11 \\
\hline $\begin{array}{l}\text { OECD-Ländermittel für } \\
\text { Länder mit Daten für } \\
1995,2000 \text { und } 2011\end{array}$ & 20 & 27 & & & & & 40 & 11 & 10 & & & & & 11 \\
\hline EU21-Durchschnitt & 18 & 27 & 34 & 40 & 39 & 40 & 41 & 9 & 7 & 8 & 8 & 8 & 8 & 9 \\
\hline
\end{tabular}

\begin{tabular}{|c|c|c|c|c|c|c|c|c|c|c|c|c|c|c|}
\hline Sonstige G20-Länder & & & & & & & & & & & & & & \\
\hline Argentinien & $\mathrm{m}$ & $\mathrm{m}$ & $\mathrm{m}$ & $\mathrm{m}$ & $\mathrm{m}$ & $\mathrm{m}$ & m & $\mathrm{m}$ & $\mathrm{m}$ & $\mathrm{m}$ & $\mathrm{m}$ & $\mathrm{m}$ & $\mathrm{m}$ & m \\
\hline Brasilien & $\mathrm{m}$ & 10 & $\mathrm{~m}$ & $\mathrm{~m}$ & $\mathrm{~m}$ & $\mathrm{~m}$ & m & $\mathrm{m}$ & $\mathrm{m}$ & $\mathrm{m}$ & $\mathrm{m}$ & $\mathrm{m}$ & $\mathrm{m}$ & m \\
\hline China & $\mathrm{m}$ & $\mathrm{m}$ & $\mathrm{m}$ & $\mathrm{m}$ & $\mathrm{m}$ & m & m & m & $\mathrm{m}$ & $\mathrm{m}$ & $\mathrm{m}$ & $\mathrm{m}$ & $\mathrm{m}$ & m \\
\hline Indien & $\mathrm{m}$ & $\mathrm{m}$ & $\mathrm{m}$ & $\mathrm{m}$ & $\mathrm{m}$ & $\mathrm{m}$ & m & $\mathrm{m}$ & $\mathrm{m}$ & $\mathrm{m}$ & $\mathrm{m}$ & $\mathrm{m}$ & $\mathrm{m}$ & m \\
\hline Indonesien & $\mathrm{m}$ & $\mathrm{m}$ & $\mathrm{m}$ & $\mathrm{m}$ & $\mathrm{m}$ & $m$ & m & $m$ & $\mathrm{~m}$ & $\mathrm{~m}$ & $m$ & $m$ & $m$ & m \\
\hline Russische Föderation & $\mathrm{m}$ & $\mathrm{m}$ & $\mathrm{m}$ & $\mathrm{m}$ & $\mathrm{m}$ & $\mathrm{m}$ & m & $\mathrm{m}$ & $\mathrm{m}$ & $\mathrm{m}$ & $\mathrm{m}$ & $\mathrm{m}$ & $m$ & m \\
\hline Saudi-Arabien & 11 & 13 & 18 & 21 & 19 & 20 & 18 & $\mathrm{n}$ & 3 & 5 & 6 & 6 & 8 & 8 \\
\hline Südafrika & $\mathrm{m}$ & $\mathrm{m}$ & $\mathrm{m}$ & $\mathrm{m}$ & $\mathrm{m}$ & $\mathrm{m}$ & m & $\mathrm{m}$ & $\mathrm{m}$ & $\mathrm{m}$ & $\mathrm{m}$ & $\mathrm{m}$ & $\mathrm{m}$ & m \\
\hline G20-Durchschnitt & m & m & $\mathbf{m}$ & $\mathbf{m}$ & $\mathbf{m}$ & $\mathbf{m}$ & $\mathbf{m}$ & m & m & m & m & m & $\mathbf{m}$ & m \\
\hline
\end{tabular}

Anmerkung: Die Angaben für die Jahre 2001, 2002, 2003, 2004, 2006 und 2007 sind im Internet verfügbar (s. StatLink unten). Bis zum Jahr 2004 wurden Abschlussquoten im Tertiärbereich $A$ und B auf Bruttobasis berechnet. Ab 2005 und für Länder mit verfügbaren Daten wurden die Abschlussquoten als Netto-Abschlussquoten (d.h. als Summe der Abschlussquoten der einzelnen Altersjahrgänge) berechnet. Weiterführende Informationen zu den zur Berechnung der (Brutto-/Netto-)Abschlussquoten verwendeten Methoden und des entsprechenden typischen Abschlussalters s. Anhang 1.

1. Unterbrechung der Zeitreihe zwischen 2008 und 2009 aufgrund einer teilweisen Neueinstufung berufsbildender Bildungsgänge in ISCED 2 und ISCED 5B.

2. Unterbrechung der Zeitreihe im Jahr 2008 aufgrund Veränderungen in der Methodik für ISCED 5A.

Quelle: OECD. Saudi-Arabien: Observatory on Higher Education. Hinweise s. Anhang 3 unter www. oecd.org/edu/eag.htm.

StatLink: http://dx.doi.org/10.1787/888932848400

Erläuterung der Kennzeichnung fehlender Daten s. Hinweise für den Leser. 



\section{Wie hoch sind die Erfolgsquoten im Tertiärbereich?}

Im Durchschnitt der OECD-Länder mit verfügbaren Daten erwerben rund 70 Prozent der Studierenden im Tertiärbereich A mindestens einen ersten Abschluss auf diesem Niveau.

Frauen, die sich in einem Studiengang des Tertiärbereichs A eingeschrieben haben, werden eher als Männer am Ende des Studiengangs auch einen Abschluss erlangen: Ihre Erfolgsquote liegt im Durchschnitt Io Prozentpunkte über derjenigen der Männer.

\section{Abbildung A4.1}

Anteil der Studierenden, die ein Studium im Tertiärbereich aufnehmen und mindestens einen ersten Abschluss in diesem Bildungsbereich erwerben, nach Geschlecht (2011)

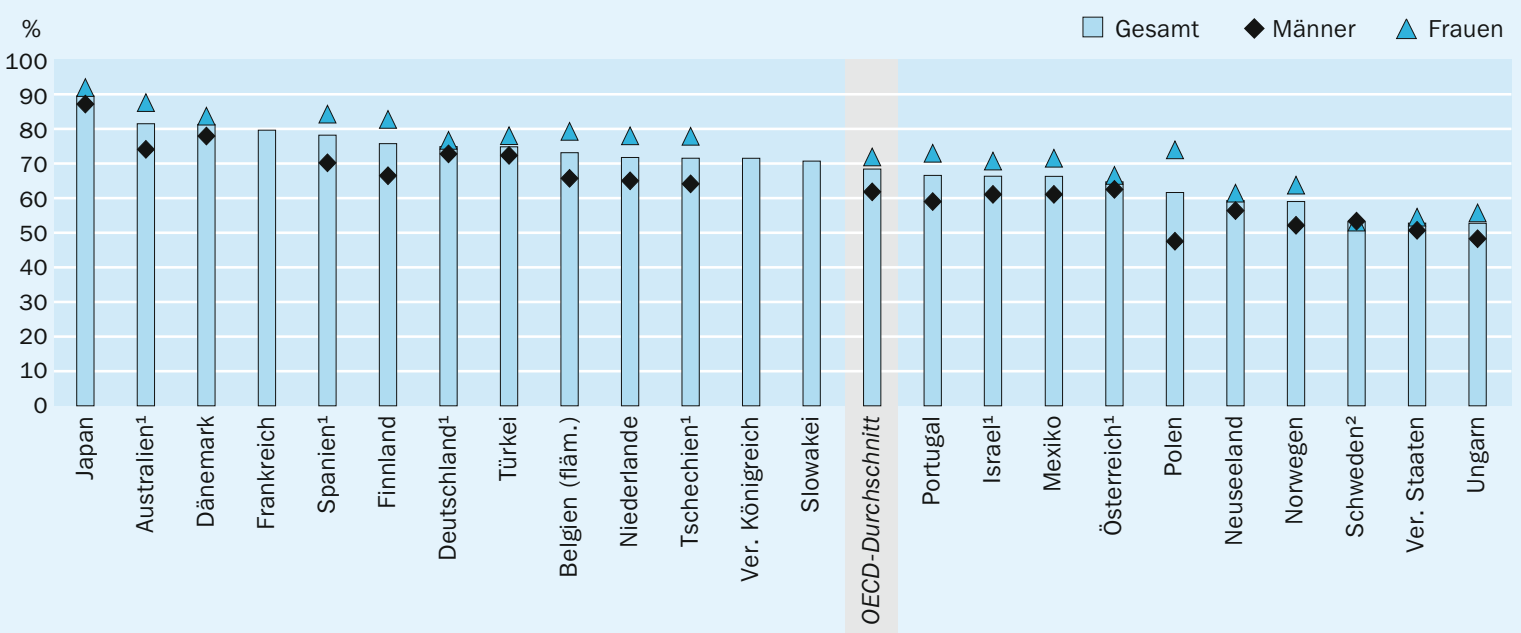

Anmerkung: Einige der Studierenden ohne Abschluss sind womöglich noch eingeschrieben oder haben ihr Studium nicht an der Einrichtung abgeschlossen, an der sie es begonnen haben, wie dies häufig in den Vereinigten Staaten der Fall ist. Einzelheiten zu den für die Berechnung der Erfolgsquoten verwendeten Methoden s. Tabelle A4.1.

1. Nur Tertiärbereich A. 2. Einschließlich Studierender, die einzelne Kurse belegen und womöglich gar nicht beabsichtigen, alle für einen Abschluss erforderlichen Kurse zu belegen.

Anordnung der Länder in absteigender Reihenfolge des Anteils der Studierenden, die im Tertiärbereich mindestens einen ersten Abschluss erwerben. Quelle: OECD. Tabelle A4.1. Hinweise s. Anhang 3 unter www.oecd.org/edu/eag.htm. StatLink: http://dx.doi.org/10.1787/888932846424

\section{Kontext}

Die Erfolgsquoten im Tertiärbereich können ein Hinweis auf die Effizienz des betreffenden Tertiärbereichs sein, denn sie zeigen auf, wie viele der Studierenden, die ein Studium im Tertiärbereich aufgenommen haben, dieses letztendlich auch erfolgreich abschließen. Niedrige Erfolgsquoten weisen jedoch nicht notwendigerweise auf Ineffizienz hin, denn Studierende können ihr Studium aus ganz unterschiedlichen Gründen abbrechen: Sie erkennen, dass sie das falsche Fachgebiet oder den falschen Studiengang gewählt haben; sie erbringen die von den Bildungseinrichtungen vorgegebenen Mindestleistungen nicht, was insbesondere bei einem relativ offenen Zugang 
zum Tertiärbereich vorkommt; oder es bieten sich bereits vor Abschluss des Studiums attraktive Beschäftigungsmöglichkeiten an. Studierende sind vielleicht der Ansicht, dass die angebotenen Studiengänge ihren Erwartungen bzw. den Arbeitsmarktanforderungen nicht entsprechen oder dass die Studiengänge länger dauern, als die Studierenden bereit sind, nicht auf dem Arbeitsmarkt aktiv zu sein. Niedrige Erfolgsquoten, d. h. hohe Studienabbruchquoten, können andererseits darauf hinweisen, dass das Bildungssystem den Bedürfnissen der Studierenden nicht gerecht wird.

\section{Weitere wichtige Ergebnisse}

In Neuseeland, Norwegen, Schweden, Ungarn und den Vereinigten Staaten schließen weniger als 6o Prozent der Studierenden, die ein Studium im Tertiärbereich aufnehmen, dieses mit einem ersten Abschluss auf diesem Niveau ab. In Australien, Dänemark, Finnland, Frankreich, Japan und Spanien hingegen sind es mehr als 75 Prozent.

Die Erfolgsquoten im Tertiärbereich B sind mit durchschnittlich 61 Prozent gegenüber denen des Tertiärbereichs A etwas niedriger, sie reichen von mindestens 75 Prozent in Deutschland, Japan und der Slowakei bis zu I8 Prozent in den Vereinigten Staaten.

Bei Vollzeitstudierenden ist die Wahrscheinlichkeit, dass sie ihr Studium erfolgreich abschließen, höher als bei Teilzeitstudierenden. Die größten Unterschiede zwischen Voll- und Teilzeitstudierenden bestehen in Neuseeland, wo im Tertiärbereich A die Erfolgsquoten für Vollzeitstudierende 34 Prozentpunkte über denjenigen der Teilzeitstudierenden liegen.

Studierende verlassen möglicherweise das Bildungssystem ohne Abschluss, weil sich ihnen in einigen Ländern bereits nach einem Studienjahr attraktive Beschäftigungsmöglichkeiten ergeben. In einigen Ländern haben manche ältere Studierende, die ein Studium im Tertiärbereich aufnehmen, gar nicht die Absicht, einen bestimmten Studiengang abzuschließen, sondern wollen vielmehr als Teil des lebenslangen Lernens nur einige Kurse belegen.

Es gibt keinen eindeutigen Zusammenhang zwischen der Höhe der von Bildungseinrichtungen des Tertiärbereichs A erhobenen Studiengebühren und den Erfolgsquoten. 


\section{Analyse und Interpretationen}

\section{Erfolgsquoten im Tertiärbereich}

Studierende „schließen ein Studium erfolgreich ab“, wenn sie einen Studiengang im Tertiärbereich A oder B beginnen und mit einem Abschluss eines der beiden Tertiärbereiche abschließen (auch wenn sie hierbei von Tertiärbereich A zu B oder umgekehrt wechseln). Im Durchschnitt der I8 OECD-Länder, für die Daten vorliegen, schließen etwa 32 Prozent der Studierenden keinen Studiengang des Tertiärbereichs erfolgreich $\mathrm{ab}$.

In Neuseeland, Norwegen, Schweden, den Vereinigten Staaten und Ungarn erwerben mehr als 40 Prozent der Studienanfänger im Tertiärbereich keinen Abschluss in diesem Bildungsbereich (Tertiärbereich A oder B), im Gegensatz zu den Studierenden in Dänemark, Finnland, Frankreich und Japan, wo dieser Anteil bei unter 25 Prozent liegt. In denjenigen Ländern, für die nur Daten zum Tertiärbereich A verfügbar sind, liegen die Abbruchquoten zwischen 18 Prozent in Australien und 35 Prozent in Österreich (Abb. A4.I).

Die Differenz zwischen dem Anteil an Arbeitsplätzen für Hochqualifizierte auf dem Arbeitsmarkt und dem Anteil der Absolventen des Tertiärbereichs (s. Indikator AI) deutet darauf hin, dass die meisten Länder davon profitieren würden, wenn ein größerer Teil der Studierenden das Studium erfolgreich abschließen würde. Eine Steigerung der Absolventenzahlen erfordert je nach Land unterschiedliche Strategien.

In den meisten Ländern schließen Vollzeitstudierende ihr Studium eher erfolgreich ab als Teilzeitstudierende. In einigen Ländern haben ältere Studierende jedoch gar nicht die Absicht, einen bestimmten Studiengang abzuschließen, sondern wollen vielmehr als Teil des lebenslangen Lernens einige Kurse belegen. Trotzdem werden diese Studierenden zusammen mit den eher traditionell Vollzeitstudierenden in der Kategorie Studienanfänger im Tertiärbereich erfasst. In Neuseeland zum Beispiel, wo ein Teilzeitstudium eher üblich ist - die Erfolgsquoten für Vollzeitstudierende im Tertiärbereich A liegen um 34 Prozentpunkte über denen der Teilzeitstudierenden -, wird geschätzt, dass etwa jeder fünfte Studierende alle belegten Module erfolgreich abschließt, aber nie die für eine formale Qualifikation erforderliche Gesamtzahl an Modulen belegt. Dadurch gerät eventuell die Erfolgsquote der eher dem traditionellen Modell des Vollzeitstudiums folgenden Studierenden im Tertiärbereich A in den Hintergrund, die 20 II bei 8I Prozent lag (Tab. A4.I und A4.2).

Frauen, die sich in einem Studiengang des Tertiärbereichs A eingeschrieben haben, werden eher als Männer am Ende des Studiengangs auch einen Abschluss erlangen: Ihre Erfolgsquote liegt Io Prozentpunkte über derjenigen der Männer. Nur in Deutschland, Österreich, Schweden und den Vereinigten Staaten beträgt die Differenz zwischen den Erfolgsquoten von Frauen und Männern weniger als 5 Prozentpunkte. In Finnland, Polen und Tschechien beträgt der geschlechtsspezifische Unterschied mehr als I5 Prozentpunkte zugunsten der Frauen (Abb. A4.I). 
Anteil der Studierenden, die ein Studium im Tertiärbereich A aufnehmen und mindesten einen ersten Abschluss in diesem Bildungsbereich erwerben, nach Vollzeit-/Teilzeitstudium (2011)

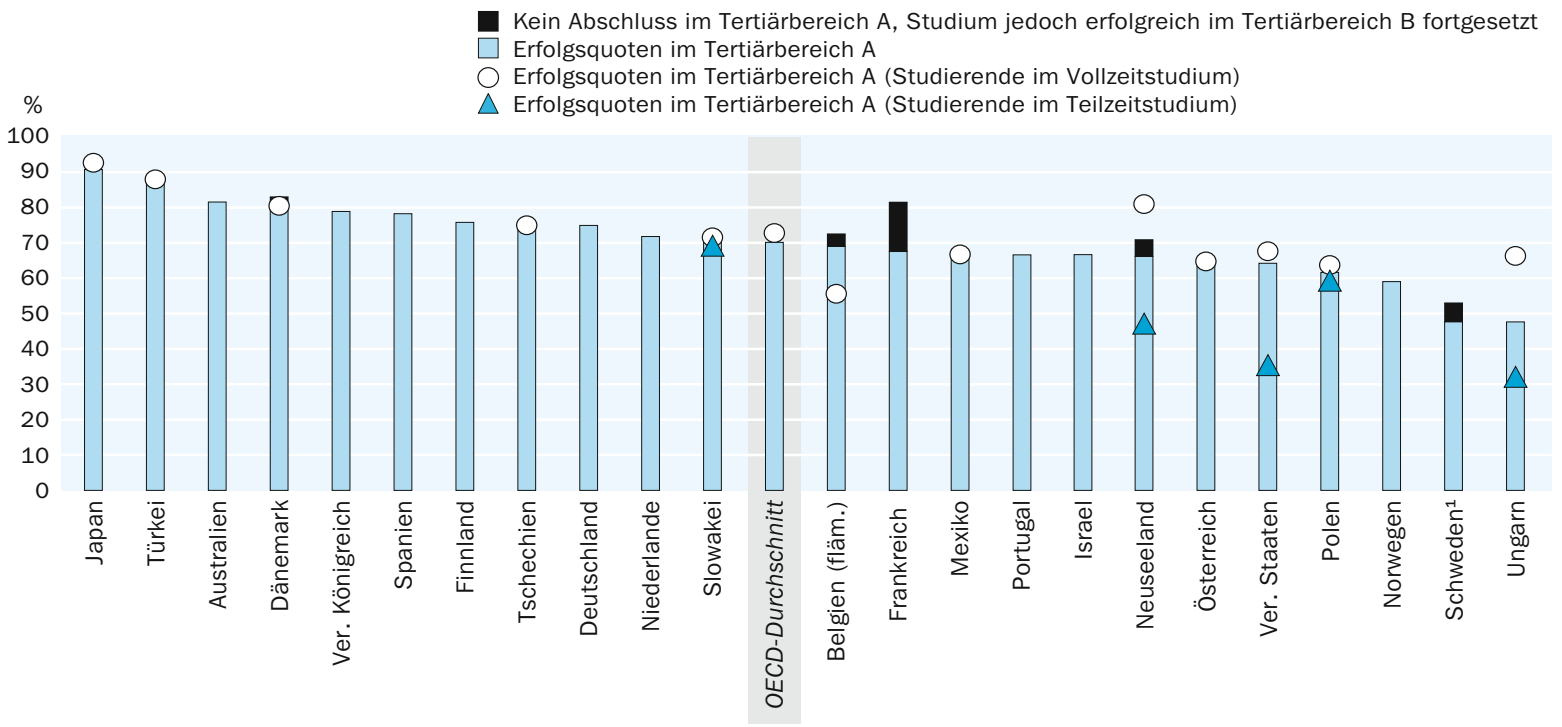

Anmerkung: Einige der Studierenden ohne Abschluss sind womöglich noch eingeschrieben oder haben ihr Studium nicht an der Einrichtung abgeschlossen, an der sie es begonnen haben, wie dies häufig in den Vereinigten Staaten der Fall ist. Einzelheiten zu den für die Berechnung der Erfolgsquoten verwendeten Methoden s. Tabelle A4.1.

1. Einschließlich Studierender, die einzelne Kurse belegen und womöglich gar nicht beabsichtigen, alle für einen Abschluss erforderlichen Kurse zu belegen. Anordnung der Länder in absteigender Reihenfolge des Anteils der Studierenden, die im Tertiärbereich A mindestens einen ersten Abschluss erwerben. Quelle: OECD. Tabellen A4.1 und A4.2. Hinweise s. Anhang 3 unter www.oecd.org/edu/eag.htm. StatLink: http://dx.doi.org/10.1787/888932846443

\section{Erfolgsquoten im Tertiärbereich A und B}

Im Durchschnitt der 23 OECD-Länder, für die Daten vorliegen, schließen etwa 30 Prozent der Studierenden des Tertiärbereichs A ihren Studiengang nicht erfolgreich ab. Die Erfolgsquoten sind jedoch in den einzelnen OECD-Ländern sehr unterschiedlich. In Norwegen, Schweden und Ungarn schließen weniger als 6o Prozent der Studierenden im Tertiärbereich A ihr Studium erfolgreich ab, im Gegensatz zu den Studierenden in Australien, Dänemark, Japan und der Türkei, wo dieser Anteil bei mindestens 80 Prozent liegt. Die Erfolgsquoten im Tertiärbereich B liegen mit durchschnittlich 6r Prozent etwas unterhalb denen des Tertiärbereichs A, und auch hier gibt es große Unterschiede zwischen den einzelnen Ländern. Die Erfolgsquoten im Tertiärbereich B reichen von mindestens 75 Prozent in Deutschland, Japan und der Slowakei bis zu nur I8 Prozent in den Vereinigten Staaten (Tab. A4.I).

Es gibt viele Diskussionen unter den Entscheidungsträgern in den OECD-Ländern, deren Bildungseinrichtungen niedrige Studiengebühren für Studiengänge im Tertiärbereich A verlangen, ob eine Anhebung der Studiengebühren zu einer Verbesserung der Erfolgsquoten führen würde. Aufgrund der Ergebnisse dieser Erörterungen haben die einzelnen Länder zum Teil ganz unterschiedliche Entscheidungen getroffen. So ist es den Universitäten in Italien aufgrund neuerer gesetzlicher Bestimmungen möglich, bei Überschreiten der regulären Studiendauer für ein Fach von den Studierenden höhere Studiengebühren zu verlangen. Ziel ist, die durchschnittliche Studiendauer im Tertiärbereich zu verkürzen. Einige OECD-Länder haben die Studiengebühren bereits angehoben (und erlassen sie einigen Studierenden bei guten Studienleistungen), um 
einen Anreiz für die Studierenden zu schaffen, das Studium schneller abzuschließen. Im Gegensatz hierzu sind einige Länder bei ihren niedrigen Studiengebühren geblieben, da die politischen Entscheidungsträger in diesen Ländern davon ausgehen, dass höhere Studiengebühren die Studiendauer verlängern könnten, wenn Studierende nebenbei arbeiten müssen, um die Studiengebühren zu bezahlen.

Diese unterschiedlichen Ansätze bei den Studiengebühren könnten der Grund dafür sein, dass sich nur eine schwache Korrelation zwischen den Erfolgsquoten im Tertiärbereich A und der Höhe der von den entsprechenden Bildungseinrichtungen des Tertiärbereichs A erhobenen Studiengebühren ergibt. So verlangen Australien, Japan, die Niederlande und das Vereinigte Königreich Studiengebühren von mehr als I.500 USDollar (s. Indikator B5) und haben Erfolgsquoten signifikant über dem OECD-Durchschnitt von 70 Prozent. Im Gegensatz dazu verzichten Dänemark und Finnland auf Studiengebühren und bieten in hohem Maße öffentliche Zuschüsse für Studierende, und auch sie haben Erfolgsquoten von mehr als 75 Prozent.

Dies ist keineswegs überraschend, denn alle Indikatoren zum Tertiärbereich und vor allem zu den Ertragsraten belegen, dass im Vergleich zu einem Abschluss im Sekundarbereich II ein Abschluss im Tertiärbereich A dem Einzelnen signifikante Vorteile im Hinblick auf das Einkommen (s. Indikator A6) und Beschäftigungsmöglichkeiten (s. Indikator A5) eröffnet. Dies kann ein ausreichend großer Anreiz für Studierende sein, ihr Studium unabhängig von der Höhe der Studiengebühren abzuschließen (s. Indikator A7).

\section{Folgen des Nichterlangens eines Abschlusses im Tertiärbereich A}

Die Aufnahme eines Studiums im Tertiärbereich A, ohne es erfolgreich abzuschließen, bedeutet dann nicht zwangsläufig ein Versagen, wenn es den Studierenden gelingt, ihr Studium im Tertiärbereich B erfolgreich fortzusetzen. Das Gleiche gilt natürlich auch umgekehrt. In Frankreich schließt ein signifikanter Teil der Studierenden das Studium im Tertiärbereich A nicht erfolgreich ab (I4 Prozent), sie setzen ihr Studium jedoch erfolgreich im Tertiärbereich B fort. Mit anderen Worten: In Frankreich werden von Ioo Studierenden, die ein Studium im Tertiärbereich A beginnen, 68 mindestens einen ersten Abschluss im Tertiärbereich A erwerben, I4 werden zu einem Studiengang im Tertiärbereich B wechseln, 4 werden im Bildungssystem verbleiben, und nur I4 werden das Studium ohne jeglichen Abschluss abbrechen. In Belgien (fläm.), Dänemark, Neuseeland und Schweden wechseln zwischen 3 und 5 Prozent der Studierenden, die keinen Abschluss im Tertiärbereich A erwerben, erfolgreich in den Tertiärbereich B. Diese Umorientierung gibt es auch bei Studierenden, die ursprünglich einen Studiengang im Tertiärbereich B aufgenommen haben: Studierende, die keinen Abschluss im Tertiärbereich B erwerben, wechseln in den Tertiärbereich A - in Dänemark 6 Prozent, in Neuseeland 7 Prozent und in Schweden 6 Prozent. Von diesen Ländern weist nur Neuseeland einen großen Anteil an Studierenden im Tertiärbereich B auf (s. Indikatoren $\mathrm{A}_{3}$ und $\mathrm{C}_{3}$ ).

Das Nichterreichen eines Abschlusses bedeutet nicht, dass die erworbenen Fähigkeiten und Kenntnisse verloren gehen oder auf dem Arbeitsmarkt nicht gewürdigt werden, eine Zeit lang im Arbeitsmarkt zu sein kann sich zudem positiv auf ein späteres Studium auswirken. In Schweden und den Vereinigten Staaten können Studierende den 


\section{Zusammenhang zwischen Studienanfängerquoten, Abschlussquoten und Erfolgsquoten}

Diese drei Indikatoren hängen eng zusammen und werden dazu verwendet, die wichtigsten Unterschiede zwischen den Tertiärbereichen in den einzelnen Ländern zu erklären und zu interpretieren. Die Veränderung einer dieser Faktoren kann sich auf die anderen beiden auswirken. Studienanfängerquoten und Abschlussquoten basieren auf der Gesamtbevölkerung, im Gegensatz zu Erfolgsquoten, die anhand der Studienanfänger der typischen Altersgruppe eines bestimmten Bildungsbereichs ermittelt werden.

Abbildung $A$

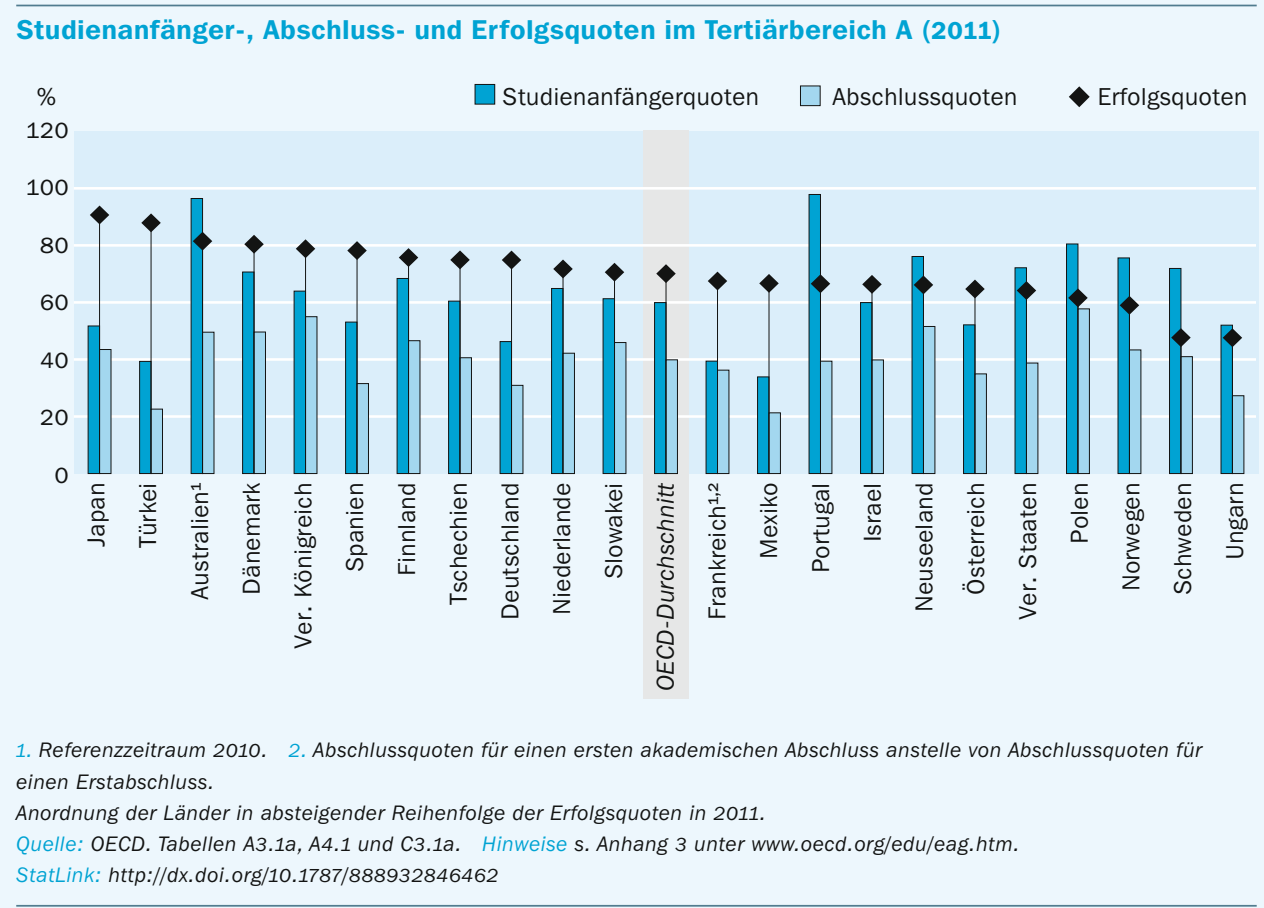

Die Definitionen der Studienanfängerquoten, der Abschlussquoten und der Erfolgsquoten (s. Abschnitt Definitionen) zeigen den Zusammenhang zwischen diesen Faktoren auf. Tatsächlich entsprechen die Erfolgsquoten nicht einfach der Division der Abschlussquoten durch die Studienanfängerquoten, eine signifikante Veränderung der Studienanfängerquoten oder der Erfolgsquoten wirkt sich jedoch definitiv auf die Abschlussquoten aus.

Ein signifikanter Anstieg/Rückgang der Erfolgsquoten im Tertiärbereich sollte sich unmittelbar auf die Abschlussquoten des Tertiärbereichs auswirken, sofern die Studienanfängerquoten im gleichen Zeitraum stabil bleiben. Dementsprechend kann sich ein signifikanter Anstieg/Rückgang der Studienanfängerquoten direkt auf die Abschlussquoten im Tertiärbereich auswirken, sofern die Erfolgsquoten im Tertiärbereich stabil bleiben. 
Wie bereits zuvor erwähnt, unterscheiden sich jedoch die Erfolgsquoten in den einzelnen OECD-Ländern sehr. Japan rangiert ganz oben mit einer Erfolgsquote von über 90 Prozent der Studierenden, die einen Studiengang im Tertiärbereich A erfolgreich abschließen, während in Schweden ungefähr jeder zweite Studierende den Tertiärbereich verlässt, ohne wenigstens einen ersten Abschluss zu erwerben.

In den Ländern mit niedrigen Erfolgsquoten (wobei zu berücksichtigen ist, dass es viele Gründe dafür geben mag, dass Studierende ihr Studium nicht erfolgreich abschließen) kompensieren hohe Studienanfängerquoten (wie in Neuseeland, Norwegen, Polen und Schweden) diesen Effekt und dienen dazu, die Absolventenzahlen im Vergleich zum OECD-Durchschnitt zu steigern und den Anforderungen des Arbeitsmarktes gerecht zu werden. Diese Länder haben sich dafür entschieden, allen potenziellen Studierenden, z.B. auch internationalen Studierenden oder älteren Studierenden, den Zugang zum Tertiärbereich zu erleichtern, was ihre Platzierung bei beiden Kennzahlen erklärt.

Gleichermaßen gleichen in Ländern mit einem begrenzten Zugang zu Studiengängen im Tertiärbereich wie Japan und der Türkei überdurchschnittlich hohe Erfolgsquoten die niedrigeren Studienanfängerquoten aus und steigern so die Abschlussquoten im Vergleich zum OECD-Durchschnitt (Abb. A).

Viele Länder haben noch erheblichen Spielraum, um ihre Abschlussquoten zu verbessern. In II der 23 Länder mit verfügbaren Daten zum Tertiärbereich A erwerben mehr als 30 Prozent der Studierenden keinen Abschluss in dem ursprünglich begonnenen Bildungsbereich. Blieben die Anfängerquoten in diesen Ländern stabil und/ oder stiegen die Erfolgsquoten auf die gleiche Höhe wie beispielsweise in Japan (rund go Prozent), würden die Abschlussquoten stark ansteigen (Abb. A).

Tertiärbereich A ohne einen Abschluss verlassen, einige Zeit arbeiten und ihr Studium zu einem späteren Zeitpunkt fortsetzen. Die vor Arbeitsaufnahme bereits abgeschlossenen Module werden später angerechnet. In Ländern mit einem modularen System wie Schweden erhalten Studierende für jeden abgeschlossenen Kurs Credits. Selbst wenn sie ausreichend Kurse für einen Abschluss belegt haben, beantragen sie eventuell keinen formalen Abschluss, da die Credits der einzelnen Kurse vieler Bildungsgänge auf dem Arbeitsmarkt als gleichwertig anerkannt werden.

Das Nichterlangen eines Abschlusses ist in den einzelnen Ländern in unterschiedlich starkem Maße ein bildungspolitisches Problem, und Erfolgsquoten sollten daher mit Vorsicht interpretiert werden. Es wird interessant sein zu sehen, ob sich zukünftige Veränderungen der Arbeitsmärkte auf die Anreize für den Einzelnen, ein Studium im Tertiärbereich abzuschließen, auswirken werden. 


\section{Definitionen}

Erfolgsquoten im Tertiärbereich werden definiert als Prozentsatz derjenigen Studienanfänger im jeweiligen Bildungsbereich, die diesen mindestens mit einem ersten $\mathrm{Ab}$ schluss beenden. Die Erfolgsquote basierend auf echten Kohortendaten wird berechnet als der Anteil der Absolventen (innerhalb von n Jahren) an einer gegebenen Studienanfängerkohorte (prospektiv). Die Erfolgsquote basierend auf Daten einer Querschnitterhebung wird berechnet als das Verhältnis der Zahl der Studierenden, die im Referenzjahr einen ersten Abschluss erwerben, zur Zahl der Studienanfänger im entsprechenden Bildungsbereich vor $n$ Jahren, wobei $n$ der Zahl an Jahren entspricht, die zum Erwerb des Abschlusses in einem Vollzeitstudium erforderlich sind.

Netto-Studienanfängerquoten zeigen den geschätzten prozentualen Anteil einer Altersgruppe, der im Laufe des Lebens zum ersten Mal in den Tertiärbereich eintreten wird. Netto-Studienanfängerquoten sind definiert als die Summe der Netto-Studienanfängerquoten für einzelne Altersjahrgänge. Die Gesamtnetto-Studienanfängerquote ist daher die Summe der prozentualen Anteile von Studienanfängern im Tertiärbereich A und B im Alter $i$ im Verhältnis zur Gesamtbevölkerung im Alter i für alle Altersgruppen. Da Daten für einzelne Altersjahrgänge nur für Altersjahrgänge von I5 bis 29 Jahren vorliegen, werden die Netto-Studienanfängerquoten für ältere Studierende anhand von Daten für Altersgruppen von jeweils fünfJahren geschätzt. Die Studienanfängerquoten sind daher ein Hinweis auf die Zugangsmöglichkeiten zum Tertiärbereich und die Wertschätzung einer Ausbildung im Tertiärbereich (s. Indikator $\mathrm{C}_{3}$ ).

Netto-Abschlussquoten zeigen den geschätzten prozentualen Anteil einer Altersgruppe, der einen Abschluss im Tertiärbereich erwerben wird, ausgehend von den aktuellen Abschlussquoten (s. Anhang I). Netto-Abschlussquoten werden in der gleichen Weise berechnet wie Studienanfängerquoten. Die Abschlussquoten im Tertiärbereich zeigen auf, in welchem Umfang die Bildungssysteme der einzelnen Länder Erwachsene mit höherwertigen Kenntnissen hervorbringen (s. Indikator A3).

Der nicht erfolgreiche Abschluss bezieht sich auf Studierende, die den jeweiligen Bildungsbereich ohne den Erwerb eines ersten Abschlusses verlassen. Als erster Abschluss im Tertiärbereich gilt unabhängig von der Studiendauer jeder Abschluss, der am Ende eines Studiengangs erworben wird, der nicht einen vorherigen erfolgreichen Abschluss im gleichen Bildungsbereich voraussetzt. In manchen Ländern ist die Unterscheidung zwischen Studienunterbrechung und nicht erfolgreichem Abschluss nur schwer möglich.

\section{Angewandte Methodik}

Daten zu den Erfolgsquoten wurden anhand einer speziellen Erhebung im Jahr 2012 ermittelt. In der Hälfte der in Tabelle A4.I aufgeführten Länder wird die Berechnung der Erfolgsquoten anhand einer Kohortenanalyse durchgeführt, die auf Paneldaten basiert, bei denen einzelne Studierende vom Studienanfang bis zum Abschluss des Studiengangs erfasst werden (echte Kohortenmethode). Die Schätzung für die anderen Länder geht von einem kontinuierlichen Fortschreiten der Studierenden im Tertiärbe- 
reich aus, da zwischen der Kohorte der Absolventen im Referenzjahr und der Kohorte der Studienanfänger $n$ Jahre zuvor Konsistenz erforderlich ist (Querschnittmethode). Diese Annahme könnte die Realität in den einzelnen Ländern jedoch zu stark vereinfachen (s. Anhang 3 unter www.oecd.org/edu/eag.htm).

Die statistischen Daten für Israel wurden von den zuständigen israelischen Stellen bereitgestellt, die für sie verantwortlich zeichnen. Die Verwendung dieser Daten durch die OECD erfolgt unbeschadet des völkerrechtlichen Status der Golanhöhen, von OstJerusalem und der israelischen Siedlungen im Westjordanland.

\section{Tabellen Indikator A4}

Tabelle A4.I: Erfolgsquoten im Tertiärbereich (20II)

StatLink: http://dx.doi.org/10.1787/888932848495

Tabelle A4.2: Erfolgsquoten im Tertiärbereich A, nach Vollzeit-/Teilzeitstudium (20II)

StatLink: http://dx.doi.org/10.1787/888932848514 
Tabelle A4.1

Erfolgsquoten im Tertiärbereich (2011)

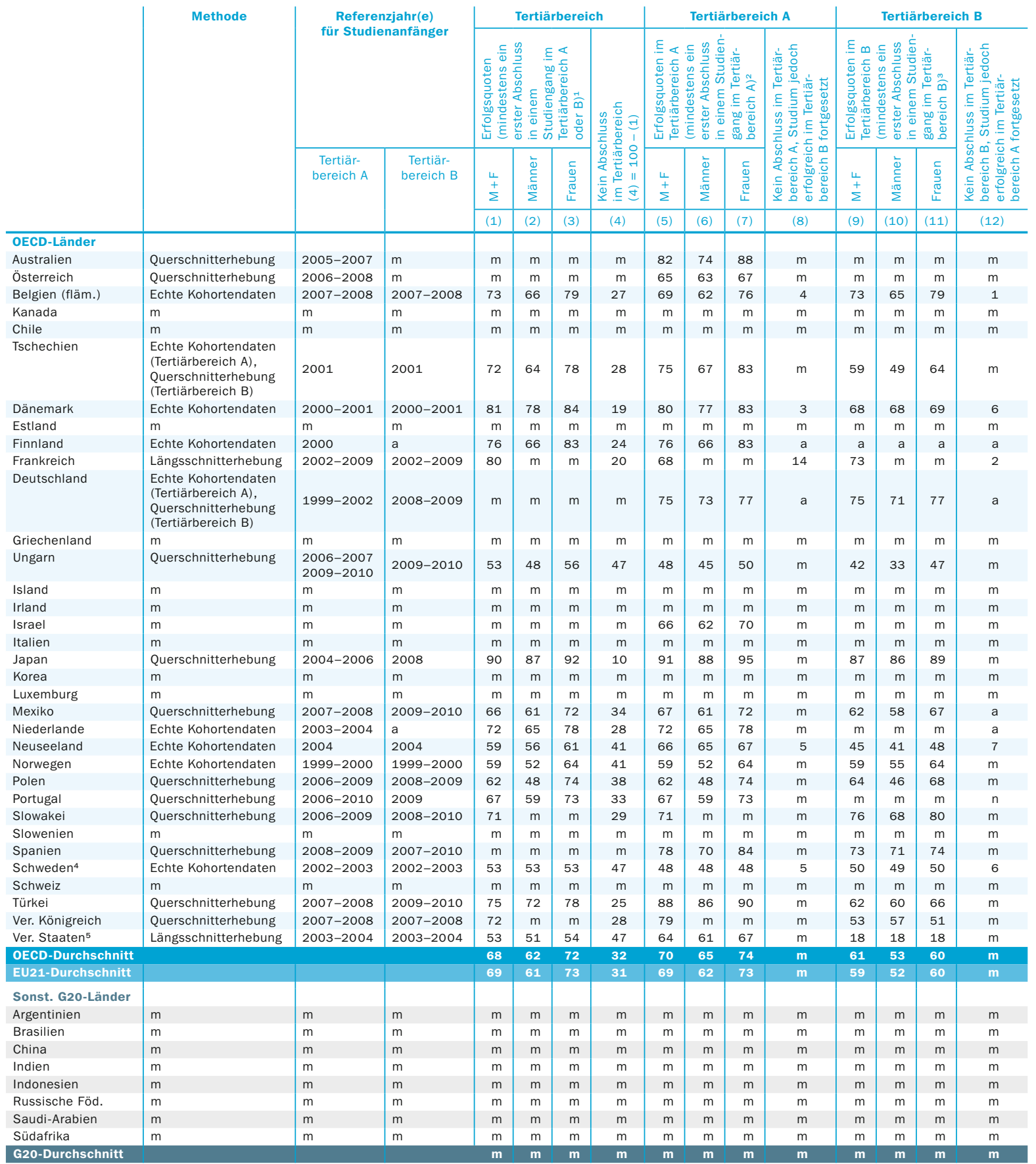

Anmerkung: Die Querschnitterhebung bezieht sich auf die Zahl der Absolventen dieser Studiengänge dividiert durch die Zahl der Studienanfänger dieser Studiengänge im Studienanfangsjahr. Die Querschnitterhebung bezieht sich auf die Zahl der Absolventen im Kalenderjahr 2011 und ist gemäß dem traditionellen OECD-Ansatz berechnet, der die unterschiedliche Dauer berücksichtigt. Echte Kohortendaten werden anhand einer Kohortenanalyse definiert und basieren auf Paneldaten. Daten beziehen sich auf Vollzeitstudierende und Teilzeitstudierende, wenn entsprechende Daten zur Verfügung stehen (Verfügbarkeit von Daten zu Teilzeitstudierenden s. Tabelle A4.2).

1. Die Erfolgsquoten im Tertiärbereich stellen den Anteil derjenigen dar, die ein Studium im Tertiärbereich A oder $B$ aufnehmen und mindestens einen ersten Abschluss in einem Studiengang des Tertiärbereichs A oder B erwerben. 2. Die Erfolgsquoten im Tertiärbereich A stellen den Anteil derjenigen dar, die ein Studium im Tertiärbereich A aufnehmen und mindestens einen ersten Abschluss in einem Studiengang des Tertiärbereichs A erwerben. 3. Die Erfolgsquoten im Tertiärbereich B stellen den Anteil derjenigen dar, die ein Studium im Tertiärbereich B aufnehmen und mindestens einen ersten Abschluss in einem Studiengang des Tertiärbereichs B erwerben. 4. Einschließlich Studierender, die einzelne Kurse belegen und womöglich gar nicht beabsichtigen, alle für einen Abschluss erforderlichen Kurse zu belegen. 5. Die Erfolgsquoten bei Studiengängen im Tertiärbereich A umfassen auch Studierende in einem 4-jährigen Studiengang, die an der Bildungseinrichtung, an dem sie ihr Studium aufnahmen, innerhalb von 6 Jahren einen Abschluss erwarben; die Erfolgsquoten im Tertiärbereich B umfassen auch Studierende aller 2-jährigen Studiengänge, die an der Bildungseinrichtung, an der sie ihr Studium aufnahmen, innerhalb von 3 Jahren einen Abschluss erwarben.

Quelle: OECD. Hinweise s. Anhang 3 unter www.oecd.org/edu/eag.htm. StatLink: http://dx.doi.org/10.1787/888932848495

Erläuterung der Kennzeichnung fehlender Daten s. Hinweise für den Leser. 
Erfolgsquoten im Tertiärbereich A, nach Vollzeit-/Teilzeitstudium (2011)

\begin{tabular}{|c|c|c|c|c|c|c|}
\hline & \multirow[t]{3}{*}{ Methode } & \multirow{3}{*}{\begin{tabular}{|c|}
$\begin{array}{c}\text { Referenzjahr(e) für } \\
\text { Studienanfänger }\end{array}$ \\
Tertiärbereich A \\
\end{tabular}} & \multicolumn{2}{|c|}{ Anteil der Studienanfänger ${ }^{1} \mathrm{im:}$} & \multicolumn{2}{|c|}{$\begin{array}{l}\text { Erfolgsquoten im Tertiärbereich A } \\
\text { (mindestens ein erster Abschluss in } \\
\text { einem Studiengang im Tertiärbereich A }\end{array}$} \\
\hline & & & Vollzeitstudium & Teilzeitstudium & Vollzeitstudium & Teilzeitstudium \\
\hline & & & (1) & (2) & (3) & (4) \\
\hline \multicolumn{7}{|l|}{ OECD-Länder } \\
\hline Australien & Querschnitterhebung & $2005-2007$ & $\mathrm{~m}$ & $\mathrm{~m}$ & $\mathrm{~m}$ & $\mathrm{~m}$ \\
\hline Österreich & Querschnitterhebung & $2006-2008$ & 100 & $\mathrm{~m}$ & 65 & $\mathrm{~m}$ \\
\hline Belgien (fläm.) & Echte Kohortendaten & $2007-2008$ & 89 & 11 & 56 & $\mathrm{~m}$ \\
\hline Kanada & $\mathrm{m}$ & $\mathrm{m}$ & $\mathrm{m}$ & $\mathrm{m}$ & $\mathrm{m}$ & $\mathrm{m}$ \\
\hline Chile & $\mathrm{m}$ & $\mathrm{m}$ & $\mathrm{m}$ & $\mathrm{m}$ & $\mathrm{m}$ & $\mathrm{m}$ \\
\hline Tschechien & Echte Kohortendaten & 2001 & 100 & $\mathrm{~m}$ & 75 & $\mathrm{~m}$ \\
\hline Dänemark & Echte Kohortendaten & $2000-2001$ & 100 & $\mathrm{~m}$ & 80 & $\mathrm{~m}$ \\
\hline Estland & $\mathrm{m}$ & $\mathrm{m}$ & $\mathrm{m}$ & $\mathrm{m}$ & $\mathrm{m}$ & $\mathrm{m}$ \\
\hline Finnland & Echte Kohortendaten & 2000 & $\mathrm{~m}$ & $\mathrm{~m}$ & $\mathrm{~m}$ & $\mathrm{~m}$ \\
\hline Frankreich & Längsschnitterhebung & 2002-2009 & $\mathrm{m}$ & $\mathrm{m}$ & $\mathrm{m}$ & $\mathrm{m}$ \\
\hline Deutschland & Echte Kohortendaten & $1999-2002$ & $\mathrm{~m}$ & $\mathrm{~m}$ & $\mathrm{~m}$ & $\mathrm{~m}$ \\
\hline Griechenland & $\mathrm{m}$ & $\mathrm{m}$ & $\mathrm{m}$ & $\mathrm{m}$ & $\mathrm{m}$ & $\mathrm{m}$ \\
\hline Ungarn & Querschnitterhebung & $\begin{array}{l}2006-2007 / \\
2009-2010\end{array}$ & 63 & 37 & 66 & 32 \\
\hline Island & $\mathrm{m}$ & $\mathrm{m}$ & $\mathrm{m}$ & $\mathrm{m}$ & $\mathrm{m}$ & $\mathrm{m}$ \\
\hline Irland & $\mathrm{m}$ & $\mathrm{m}$ & $\mathrm{m}$ & $\mathrm{m}$ & $\mathrm{m}$ & $\mathrm{m}$ \\
\hline Israel & $\mathrm{m}$ & $\mathrm{m}$ & $\mathrm{m}$ & $\mathrm{m}$ & $\mathrm{m}$ & $\mathrm{m}$ \\
\hline Italien & $\mathrm{m}$ & $\mathrm{m}$ & $\mathrm{m}$ & $\mathrm{m}$ & $\mathrm{m}$ & $\mathrm{m}$ \\
\hline Japan & Querschnitterhebung & $2004-2006$ & 98 & 2 & 93 & $\mathrm{~m}$ \\
\hline Korea & $\mathrm{m}$ & $\mathrm{m}$ & $\mathrm{m}$ & $\mathrm{m}$ & $\mathrm{m}$ & $\mathrm{m}$ \\
\hline Luxemburg & $\mathrm{m}$ & $\mathrm{m}$ & $\mathrm{m}$ & $\mathrm{m}$ & $\mathrm{m}$ & $\mathrm{m}$ \\
\hline Mexiko & Querschnitterhebung & $2007-2008$ & 100 & $\mathrm{~m}$ & 67 & $\mathrm{~m}$ \\
\hline Niederlande & Echte Kohortendaten & 2003-2004 & $\mathrm{m}$ & $\mathrm{m}$ & $\mathrm{m}$ & $\mathrm{m}$ \\
\hline Neuseeland & Echte Kohortendaten & 2004 & 56 & 44 & 81 & 47 \\
\hline Norwegen & Echte Kohortendaten & $1999-2000$ & $\mathrm{~m}$ & $\mathrm{~m}$ & $\mathrm{~m}$ & $\mathrm{~m}$ \\
\hline Polen & Querschnitterhebung & $2006-2009$ & 53 & 47 & 64 & 59 \\
\hline Portugal & Querschnitterhebung & $2006-2010$ & $\mathrm{~m}$ & $\mathrm{~m}$ & $\mathrm{~m}$ & $\mathrm{~m}$ \\
\hline Slowakei & Querschnitterhebung & $2006-2009$ & 62 & 38 & 72 & 69 \\
\hline Slowenien & $\mathrm{m}$ & $\mathrm{m}$ & $\mathrm{m}$ & $\mathrm{m}$ & $\mathrm{m}$ & $\mathrm{m}$ \\
\hline Spanien & Querschnitterhebung & $2008-2009$ & $\mathrm{~m}$ & $\mathrm{~m}$ & $\mathrm{~m}$ & $\mathrm{~m}$ \\
\hline Schweden & Echte Kohortendaten & $2002-2003$ & $\mathrm{~m}$ & $\mathrm{~m}$ & $\mathrm{~m}$ & $\mathrm{~m}$ \\
\hline Schweiz & $\mathrm{m}$ & $\mathrm{m}$ & $\mathrm{m}$ & $\mathrm{m}$ & $\mathrm{m}$ & $\mathrm{m}$ \\
\hline Türkei & Querschnitterhebung & $2007-2008$ & 100 & a & 88 & a \\
\hline Vereinigtes Königreich & Querschnitterhebung & $2007-2008$ & $\mathrm{~m}$ & $\mathrm{~m}$ & $\mathrm{~m}$ & $\mathrm{~m}$ \\
\hline Vereinigte Staaten ${ }^{2}$ & Längsschnitterhebung & $2003-2004$ & 81 & 19 & 68 & 35 \\
\hline \multicolumn{3}{|l|}{ OECD-Durchschnitt } & 83 & 25 & 73 & $\mathbf{m}$ \\
\hline EU21-Durchschnitt & & & 81 & 33 & 68 & $\mathrm{~m}$ \\
\hline \multicolumn{7}{|l|}{ Sonst. G20-Länder } \\
\hline Argentinien & $\mathrm{m}$ & $\mathrm{m}$ & $\mathrm{m}$ & $\mathrm{m}$ & $\mathrm{m}$ & $\mathrm{m}$ \\
\hline Brasilien & $\mathrm{m}$ & $\mathrm{m}$ & $\mathrm{m}$ & $\mathrm{m}$ & $\mathrm{m}$ & $\mathrm{m}$ \\
\hline China & $\mathrm{m}$ & $\mathrm{m}$ & $\mathrm{m}$ & $\mathrm{m}$ & $\mathrm{m}$ & $\mathrm{m}$ \\
\hline Indien & $\mathrm{m}$ & $\mathrm{m}$ & $\mathrm{m}$ & $\mathrm{m}$ & $\mathrm{m}$ & $\mathrm{m}$ \\
\hline Indonesien & $\mathrm{m}$ & $\mathrm{m}$ & $\mathrm{m}$ & $\mathrm{m}$ & $\mathrm{m}$ & $\mathrm{m}$ \\
\hline Russische Föderation & $\mathrm{m}$ & $\mathrm{m}$ & $\mathrm{m}$ & $\mathrm{m}$ & $\mathrm{m}$ & $\mathrm{m}$ \\
\hline Saudi-Arabien & $\mathrm{m}$ & $\mathrm{m}$ & $\mathrm{m}$ & $\mathrm{m}$ & $\mathrm{m}$ & $\mathrm{m}$ \\
\hline Südafrika & $\mathrm{m}$ & $\mathrm{m}$ & $\mathrm{m}$ & $\mathrm{m}$ & $\mathrm{m}$ & $\mathrm{m}$ \\
\hline G20-Durchschnitt & & & $\mathbf{m}$ & $\mathbf{m}$ & $\mathbf{m}$ & $\mathbf{m}$ \\
\hline
\end{tabular}

Anmerkung: Die Querschnitterhebung bezieht sich auf die Zahl der Absolventen im Kalenderjahr 2011 und ist gemäß dem traditionellen OECD-Ansatz berechnet, der die unterschiedliche Dauer berücksichtigt. Echte Kohortendaten werden anhand einer Kohortenanalyse definiert und basieren auf Paneldaten.

1. Basierend auf den Daten der OECD-Erhebung von 2012. 2. Einschließlich Studierender in einem 4-jährigen Studiengang, die an der Bildungseinrichtung, an der sie ihr Studium aufgenommen haben, innerhalb von 6 Jahren einen Abschluss erwarben.

Quelle: OECD. Hinweise s. Anhang 3 unter www.oecd.org/edu/eag.htm. StatLink: http://dx.doi.org/10.1787/888932848514

Erläuterung der Kennzeichnung fehlender Daten s. Hinweise für den Leser. 



\section{Wie beeinflusst der Bildungsstand die Erwerbsbeteiligung?}

In allen OECD-Ländern weisen die Absolventen des Tertiärbereichs die höchsten Beschäftigungsquoten auf, und bei ihnen ist auch die Wahrscheinlichkeit einer Vollzeitbeschäftigung am größten.

Für Personen ohne einen Abschluss im Sekundarbereich II sind die Erwerbslosenquoten fast dreimal so hoch (I3 Prozent im OECD-Durchschnitt) wie für Absolventen des Tertiärbereichs (5 Prozent).

Die Beschäftigungschancen für diejenigen, die zumindest den Sekundarbereich II abgeschlossen haben, sind günstiger als für diejenigen ohne einen solchen $\mathrm{Ab}$ schluss.

Unter den Absolventen des Tertiärbereichs sind die geschlechtsspezifischen Unterschiede am geringsten, am höchsten sind sie unter den Personen, die über eine Ausbildung unterhalb des Sekundarbereichs II verfügen.

Abbildung A5.1

Beschäftigungsquote 25- bis 64-Jähriger, nach Bildungsstand (2011)

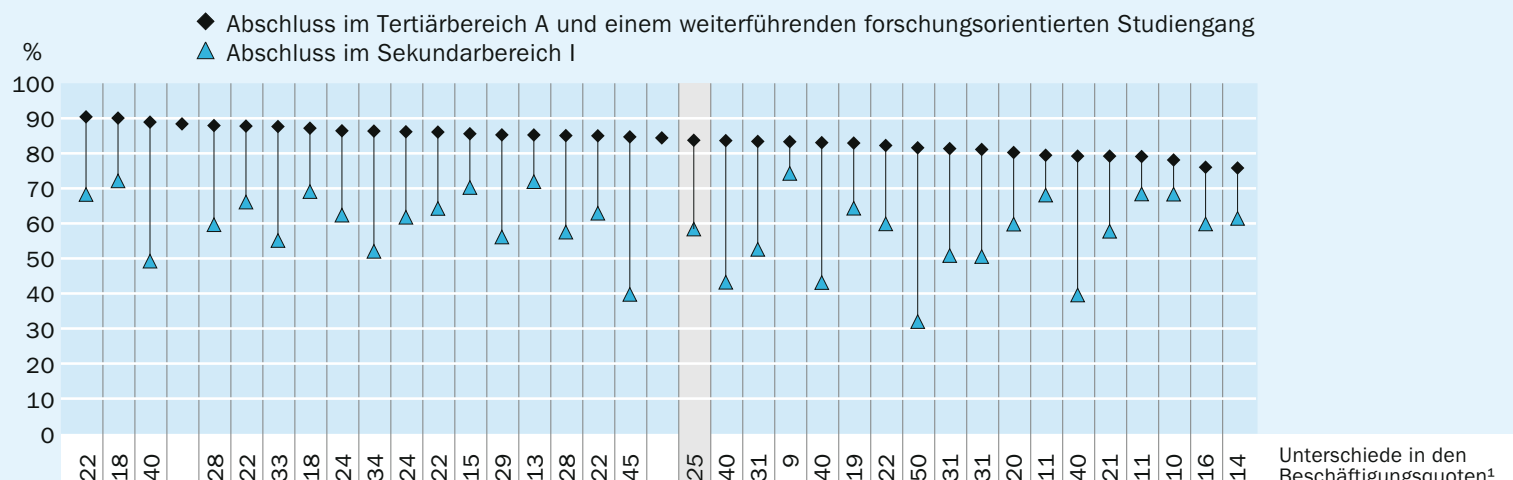

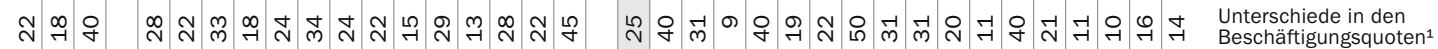

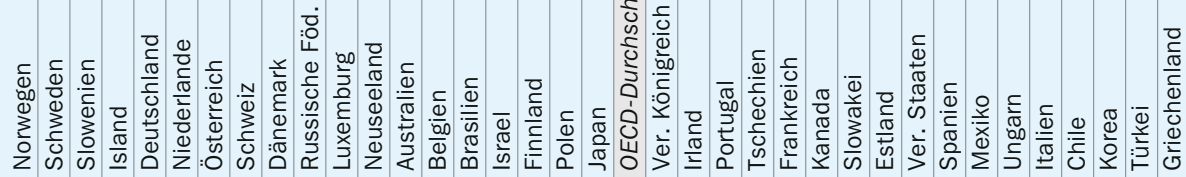

1. Unterschiede in den Beschäftigungsquoten (in Prozentpunkten) von Absolventen des Tertiärbereichs und Absolventen des Sekundarbereichs I. Anordnung der Länder in absteigender Reihenfolge der Beschäftigungsquote von 25- bis 64-jährigen Absolventen des Tertiärbereichs.

Quelle: OECD. Tabelle A5.1a. Hinweise s. Anhang 3 unter www.oecd.org/edu/eag.htm. StatLink: http://dx.doi.org/10.1787/888932846481

\section{Kontext}

Die Volkswirtschaften der OECD-Länder sind auf eine ausreichende Versorgung mit hoch qualifizierten Arbeitskräften angewiesen. Der Bildungsstand wird häufig als Kennzahl zur Bewertung des Humankapitals und der Fähigkeiten und Kenntnisse der Arbeitskräfte herangezogen. Der Indikator untersucht, wie gut die zur Verfügung 
stehenden Kompetenzen der Nachfrage entsprechen. So könnten beispielsweise hohe Erwerbslosenquoten auf ein Missverhältnis zwischen dem Bildungsstand der Bevölkerung und den Anforderungen des Arbeitsmarktes hindeuten.

In den meisten OECD-Ländern stiegen die Erwerbslosenquoten während der jüngsten Wirtschaftskrise sehr stark an und verharren seitdem auf diesem hohen Niveau. Am stärksten betroffen waren die Arbeitskräfte ohne einen Abschluss im Sekundarbereich II bzw. im postsekundaren, nicht tertiären Bereich: von 2008 bis 201 I stieg ihre Erwerbslosenquote von 8,8 Prozent auf I2,6 Prozent, d. h. um fast 4 Prozentpunkte (Tab. A5.4a). Aber schon vor der Krise hatte der schnelle technologische Fortschritt die Bedarfslage auf dem globalen Arbeitsmarkt verändert. Stark nachgefragt werden hoch qualifizierte Fachkräfte, während immer mehr Arbeitsplätze gering qualifizierter Beschäftigter der Automatisierung zum Opfer fallen.

Eine Langzeitbetrachtung der Daten zu Erwerbslosen- und Beschäftigungsquoten ist eine gute Grundlage zur Bewertung der langfristigen Entwicklungstendenzen und der unterschiedlichen Beschäftigungsrisiken für Männer und Frauen unterschiedlichen Alters und Bildungsstands. Diese Daten könnten den Regierungen helfen, die potenzielle Entwicklung der Volkswirtschaften in den nächsten Jahren besser abzuschätzen, was wiederum in die Gestaltung der Bildungspolitik einfließen könnte, um sicherzustellen, dass die heutigen Bildungsteilnehmer besser auf die Arbeitsplätze von morgen vorbereitet sind.

\section{Weitere wichtige Ergebnisse}

Die Wahrscheinlichkeit einer Vollzeitbeschäftigung steigt mit dem Bildungsstand. Rund 64 Prozent der Arbeitskräfte mit einer Ausbildung unterhalb des Sekundarbereichs II sind vollzeitbeschäftigt, 7I Prozent derjenigen mit einem Abschluss im Sekundarbereich II und 75 Prozent der Absolventen des Tertiärbereichs.

Bei Frauen ist die Wahrscheinlichkeit, Vollzeit zu arbeiten, geringer als bei Männern. Im OECD-Durchschnitt arbeiten 6o Prozent der beschäftigten Frauen Vollzeit, gegenüber 8o Prozent der Männer. Die Wahrscheinlichkeit einer Vollzeitbeschäftigung bei Frauen nimmt mit höherem Bildungsstand zu.

In den OECD-Ländern sind Arbeitskräfte mit einem Abschluss in einem berufsbildenden Ausbildungsgang im Sekundarbereich II mit höherer Wahrscheinlichkeit beschäftigt (76 Prozent) als die Absolventen von allgemeinbildenden Abschlüssen im Sekundarbereich II (70 Prozent). Auch ihre Erwerbslosenquote ist eher niedriger (7,4 Prozent) als die derjenigen mit einem allgemeinbildenden Abschluss im Sekundarbereich II (8,4 Prozent).

\section{Entwicklungstendenzen}

Während der letzten I5 Jahre waren in allen OECD-Ländern die Beschäftigungsquoten der Absolventen des Tertiärbereichs stets höher als die der Arbeitsmarktteilnehmer ohne einen Abschluss im Tertiärbereich. Umgekehrt übertrafen die Erwerbslosenquoten derjenigen mit einem niedrigeren Bildungsstand die Quoten der Absolventen des Tertiärbereichs. Durch die Wirtschaftskrise wurde die Kluft nur noch größer und traf die jungen Erwachsenen, die gerade erst in das Erwerbsleben eintraten, am här- 
testen. Mit wenigen Ausnahmen liegen die Erwerbslosenquoten junger Erwachsener überall höher als diejenigen der älteren Erwachsenen. Diese Feststellung gilt generell für jeden Bildungsstand, aber die Schere klafft bei denjenigen mit einer Ausbildung unterhalb des Sekundarbereichs II besonders weit auseinander.

Es scheint in allen OECD-Ländern so, als habe sich die Beschäftigungslage für Erwerbspersonen mit einer Ausbildung unterhalb des Sekundarbereichs II 20II leicht entspannt, allerdings wird man die Arbeitsmarktentwicklung in diesem Zeitraum erst dann richtig beurteilen können, wenn die Daten aus den letzten und künftigen Jahren vorliegen.

\section{Analyse und Interpretationen}

\section{Arbeitsmarktergebnisse nach Bildungsstand, Altersgruppe und Geschlecht Beschäftigungslage nach Bildungsstand \\ Ein Abschluss im Tertiärbereich verbessert die Beschäftigungschancen. Diese Feststel- lung gilt für alle OECD- und G20-Länder, für die Daten vorliegen. In den OECD-Län- dern sind über 80 Prozent der Absolventen des Tertiärbereichs beschäftigt, gegenüber 70 Prozent der Absolventen des Sekundarbereichs II und weniger als 6o Prozent der- jenigen mit einer Ausbildung unterhalb des Sekundarbereichs II (Tab. A5·3a).}

Abbildung A5.I verdeutlicht, dass die Unterschiede zwischen den Beschäftigungsquoten der Absolventen des Tertiärbereichs (Tertiärbereich A und weiterführende forschungsorientierte Studiengänge, ISCED-Stufen 5 A und 6) und denen der Absolventen des Sekundarbereichs I (ISCED-Stufe 2) in Polen, der Slowakei, Slowenien, Tschechien, Ungarn und dem Vereinigten Königreich mit mindestens 40 Prozentpunkten besonders groß sind. Am schwächsten fällt der Unterschied in Brasilien, Chile, Griechenland, Korea, Mexiko und Portugal aus, beträgt aber auch dort immerhin noch rund to bis I5 Prozentpunkte (Tab. A5.ra).

\section{Beschäftigungslage nach Altersgruppen}

Generell sind junge Erwachsene eher in Beschäftigung als ältere. Der Anteil der beschäftigten jungen Erwachsenen (25- bis 34-Jährige) mit einem Abschluss im Sekundarbereich II bzw. postsekundaren, nicht tertiären Bereich ist durchschnittlich mehr als 20 Prozentpunkte höher als der Anteil der beschäftigten älteren Erwachsenen (55bis 64-Jährige) mit dem gleichen Bildungsabschluss (76 Prozent gegenüber 54 Prozent). Rund 58 Prozent der jungen Erwachsenen mit einer Ausbildung unterhalb des Sekundarbereichs II sind beschäftigt, jedoch nur 4I Prozent der älteren Arbeitnehmer mit dem gleichen Bildungsstand, und bei den Absolventen des Tertiärbereichs sind es 82 Prozent der jüngeren Erwachsenen gegenüber 67 Prozent der älteren (Tab. A5·3a). Am stärksten ausgeprägt ist dieser Unterschied zwischen den Altersgruppen und den verschiedenen Bildungsständen in Luxemburg, Österreich, Slowenien und der Türkei. So sind beispielsweise 79 Prozent der jungen Erwachsenen mit einem Abschluss im Sekundarbereich II bzw. dem postsekundaren, nicht tertiären Bereich in Slowenien 
beschäftigt, jedoch nur 28 Prozent der älteren Arbeitnehmer mit dem gleichen Bildungsstand

\section{Beschäftigungslage nach Geschlecht}

Für jede Volkswirtschaft ist es - insbesondere bei drohender Überalterung - wichtig, alle vorhandenen Fähigkeiten und Kenntnisse für den Arbeitsmarkt nutzbar zu machen. Dennoch sind in allen OECD-Ländern und in allen Bildungsbereichen lediglich 65 Prozent der Frauen im Vergleich zu 8o Prozent der Männer beschäftigt. Der geschlechtsspezifische Unterschied bei den Beschäftigungsquoten ist unter den Personen mit dem niedrigsten Bildungsstand am größten: Zwischen Männern und Frauen mit einem Abschluss im Sekundarbereich I beträgt der Abstand rund 20 Prozentpunkte (69 Prozent bei den Männern gegenüber 48 Prozent bei den Frauen), bei den Absolventen des Sekundarbereichs II sind es I5 Prozentpunkte (8I Prozent für Männer und 64 Prozent für Frauen bei einem Abschluss der ISCED-Stufe ${ }_{3} \mathrm{C}$ [lang]/3B, 8o Prozent für Männer und $6_{5}$ Prozent für Frauen bei einem Abschluss der ISCED-Stufe $3 \mathrm{~A}$ ), aber weniger als Io Prozentpunkte zwischen den Männern und Frauen mit einem Abschluss im Tertiärbereich (86 Prozent für Männer und 77 Prozent für Frauen mit einem Abschluss im Tertiärbereich B, 88 Prozent für Männer und 79 Prozent für Frauen mit einem Abschluss auf ISCED-Stufe 5A/6). Obwohl der Unterschied zwischen den Beschäftigungsquoten von Männern und Frauen mit höherem Bildungsstand abnimmt, liegen die Quoten der Frauen mit einem Abschluss im Tertiärbereich im OECD-Durchschnitt doch immer noch deutlich unter denen der Männer - trotz der Tatsache, dass 20II der Anteil der Frauen mit einem Abschluss im Tertiärbereich in den OECD-Ländern etwas höher als der der Männer war (33 Prozent gegenüber 30 Prozent) (Tab. A5.Ib und Tab. Ar.Ib im Internet).

Der Unterschied zwischen den Beschäftigungsquoten von Männern und Frauen mit einem Abschluss im Tertiärbereich (Tertiärbereich A und weiterführende forschungsorientierte Studiengänge) ist in Japan, Korea, Mexiko, Tschechien und der Türkei mit mehr als 15 Prozentpunkten besonders groß. In Island, Norwegen, Portugal, Schweden und Slowenien beträgt der geschlechtsspezifische Unterschied zwischen den Beschäftigungsquoten weniger als 3 Prozentpunkte (Tab. A5.Ib).

\section{Erwerbslosigkeit nach Bildungsstand}

20 II waren in den OECD-Ländern durchschnittlich 7, I Prozent aller Erwachsenen erwerbslos. Die Erwerbslosenquote für alle Bildungsstände zusammengenommen war in Spanien mit 19,5 Prozent und Griechenland mit 16,o Prozent besonders hoch und belief sich in Estland, Irland, Portugal und der Slowakei auf mehr als io Prozent. In Korea, den Niederlanden und Norwegen lag die Erwerbslosenquote unter 3,5 Prozent (Tab. A5.2a).

Zwischen der Erwerbslosenquote und dem Bildungsstand besteht ein enger Zusammenhang. In den OECD-Ländern sind durchschnittlich I2,6 Prozent der Erwachsenen ohne einen Abschluss im Sekundarbereich II bzw. im postsekundaren, nicht tertiären Bildungsbereich erwerbslos im Vergleich zu 7,3 Prozent der Erwachsenen mit einem solchen Abschluss. Unter den Absolventen des Tertiärbereichs sind rund 4,8 Prozent erwerbslos. In einigen Ländern sind die Unterschiede zwischen den Erwerbslosenquoten je nach Bildungsstand besonders groß. So beträgt beispielsweise in Estland, Irland, 


\section{Unterschiede in den Erwerbslosenquoten nach Fachrichtung}

Die Indikatoren in Bildung auf einen Blick belegen, wie die Beschäftigungschancen mit dem Erwerb höherer Bildungsabschlüsse steigen. Für die Absolventen des Tertiärbereichs wurden in allen Ländern und im gesamten Zeitverlauf stets niedrigere Erwerbslosenquoten festgestellt. Zwar sind niedrigere Erwerbslosenquoten für Absolventen des Tertiärbereichs im Vergleich zu den Absolventen niedrigerer Bildungsbereiche ausführlich belegt, allerdings bedeutet das nicht, dass dieser Vorteil gleichermaßen für alle diese Absolventen bzw. durchgängig für alle Fachrichtungen des Tertiärbereichs gilt. In den Vereinigten Staaten und anderen Ländern hat man festgestellt, dass sich für die Arbeitsmarktergebnisse der Arbeitnehmer mit einem ersten Abschluss im Tertiärbereich A je nach Studiengang eine erhebliche Bandbreite ergibt. Die Einkommensdaten für 25- bis 29-Jährige in den Vereinigten Staaten zeigen zum Beispiel relative hohe Erwerbseinkommen für Absolventen der Fachrichtungen Ingenieurwesen und Informatik, jedoch relativ geringe Erwerbseinkommen für junge Absolventen der Erziehungs- oder Sozialwissenschaften. Andererseits ergab sich aus den US-amerikanischen Daten zur Erwerbslosigkeit auch keine durchgängig niedrige Erwerbslosenquote für bestimmte stark nachgefragte Fächer mit hohem Gehaltsniveau. So übertraf beispielsweise die Erwerbslosenquote der Absolventen der gut bezahlten Informatikfächer (5,3 Prozent) die der Absolventen der relativ gering honorierten Studiengänge für die Lehrerausbildung im Sekundarbereich (2,4 Prozent), dem Fach mit der absolut niedrigsten Erwerbslosenquote. Die Absolventen einiger Fachrichtungen erwarteten sowohl unterdurchschnittliche Bezahlung als auch überdurchschnittlich hohe Erwerbslosigkeit (bezogen auf Absolventen des Tertiärbereichs) (8,6 Prozent im Fach Geschichte und 7,8 Prozent für Philosophie und Religionswissenschaften). Die Absolventen anderer Studiengänge wiederum, wie Maschinenbau und Krankenpflege, hatten nach Abschluss des Studiums sowohl relativ hohe Gehälter als auch niedrige Erwerbslosenquoten (jeweils 3,I Prozent). Auch in anderen OECD-Ländern wurde eine relativ große Bandbreite an Erwerbslosenquoten je nach Fachrichtung festgestellt. Eine Untersuchung unter Absolventen des Tertiärbereichs des Jahres 2005 in Kanada ergab, dass die Erwerbslosenquoten im Jahr 2007 von Absolventen des Tertiärbereichs A von 3 Prozent bei Absolventen von Studiengängen in den Bereichen Agrarwissenschaften, Gesundheitswesen und Ingenieurwissenschaften bis zu 8 Prozent für die Absolventen von Studiengängen im Bereich Erziehungswissenschaften reichten. Diese Ergebnisse belegen, wie komplex und unterschiedlich die Ergebnisse für Absolventen von Studiengängen des Tertiärbereichs beim Eintritt in den Arbeitsmarkt sein können.

der Slowakei, Spanien, Tschechien und Ungarn der Unterschied zwischen der Erwerbslosenquote der Absolventen des Tertiärbereichs und denjenigen ohne einen Abschluss im Sekundarbereich II bzw. postsekundaren, nicht tertiären Bereich rund I5 Prozentpunkte und mehr. Der Abstand ist in Brasilien, Chile, Korea, Mexiko und der Türkei mit weniger als 2 Prozentpunkten am geringsten. In Chile, Korea und Mexiko haben Erwachsene ohne einen Abschluss im Sekundarbereich II bzw. im postsekundaren, nicht tertiären Bereich sogar eine noch etwas geringere Erwerbslosenquote als die Absolventen des Tertiärbereichs. Außerdem sind die Erwerbslosenquoten unter den 
Absolventen des Tertiärbereichs je nach Fachrichtung unterschiedlich (Kasten A5.I) und stehen nicht immer in Zusammenhang mit der Nachfrage auf den Arbeitsmärkten (Tab. A5.4a).

\section{Erwerbslosigkeit nach Altersgruppen}

Für alle Bildungsbereiche gilt, dass junge Erwachsene stärker von Erwerbslosigkeit betroffen sind als ältere. Im OECD-Durchschnitt sind 8,8 Prozent der älteren Erwachsenen mit einer Ausbildung unterhalb des Sekundarbereichs II erwerbslos gegenüber I8, I Prozent der jüngeren Erwachsenen mit vergleichbarem Bildungsstand. So sind auch 9, 5 Prozent der jungen Erwachsenen mit einem Abschluss im Sekundarbereich II bzw. postsekundaren, nicht tertiären Bereich erwerbslos im Vergleich zu 6,4 Prozent der älteren Erwachsenen mit ähnlichem Bildungsstand. Bei den Absolventen des Tertiärbereichs ist der Abstand zwischen den beiden Altersgruppen am geringsten: 6,8 Prozent der jungen Erwachsenen sind erwerbslos, bei den älteren Erwachsenen sind es 4,o Prozent. Dies unterstreicht die zunehmende Bedeutung des Erwerbs eines Abschlusses im Tertiärbereich. Die Tatsache, dass bei den jüngeren Erwachsenen sowohl die Erwerbslosenquoten als auch die Beschäftigungsquoten höher sind als bei den älteren Erwachsenen, hängt hauptsächlich mit der höheren Nichterwerbsquote bei den älteren Erwachsenen zusammen (Tab. A5.4a).

\section{Erwerbslosigkeit nach Geschlecht}

Im Durchschnitt sind die geschlechtsspezifischen Unterschiede bei den Erwerbslosenquoten weniger deutlich als bei den Beschäftigungsquoten. Unter den Erwachsenen mit einer Ausbildung unterhalb des Sekundarbereichs II sind die Erwerbslosenquoten für Frauen niedriger als für Männer (I2,2 Prozent gegenüber I2,9 Prozent). Unter den Erwachsenen, die einen Abschluss im Sekundarbereich II bzw. im postsekundaren, nicht tertiären Bereich erworben haben, sind die Erwerbslosenquoten für Frauen höher als für Männer (8,o Prozent gegenüber 6,9 Prozent). Dies trifft auch für die Absolventen des Tertiärbereichs zu, hier sind 4,5 Prozent der Männer und 5, I Prozent der Frauen erwerbslos (Tab. A5.4C und A5.4d im Internet).

Die geschlechtsspezifischen Unterschiede bei den Erwerbslosenquoten sind in Griechenland und der Türkei besonders groß. So waren beispielsweise in der Türkei Io,9 Prozent der Frauen mit einem Abschluss im Tertiärbereich (ISCED-Stufen 5A/6) erwerbslos, jedoch nur 5,9 Prozent der Männer mit diesem Bildungsstand. Noch ausgeprägter ist dieser Unterschied bei den Erwachsenen mit einem Abschluss im Sekundarbereich II: 18, 2 Prozent der Frauen mit einem Abschluss auf ISCED-Stufe 3 A waren erwerbslos gegenüber 7,2 Prozent der Männer (Tab. A5.2b).

\section{Auswirkungen der globalen Wirtschaftskrise auf die Arbeitsmarkt- ergebnisse}

\section{Entwicklung der Arbeitsmarktergebnisse zwischen 2008 und $201 \mathrm{I}$}

Während der Wirtschaftskrise stieg die Erwerbslosigkeit in fast allen OECD-Ländern. In Spanien und Griechenland stiegen die Erwerbslosenquoten am stärksten, aber auch in Estland, Irland, Portugal, der Slowakei, Slowenien, Ungarn und den Vereinigten Staaten stiegen die Erwerbslosenquoten für Absolventen aller Bildungsbereiche sehr stark an. Deutschland war das einzige Land, in dem die Erwerbslosenquoten für die Absolventen aller Bildungsbereiche zwischen 2008 und 201 I sanken. 
Abbildung A5.2

Erwerbslosenquoten 25- bis 64-Jähriger, nach Bildungsstand (2005, 2008 und 2011)

$$
\triangleright 2011 \mid 2008 \diamond 2005
$$

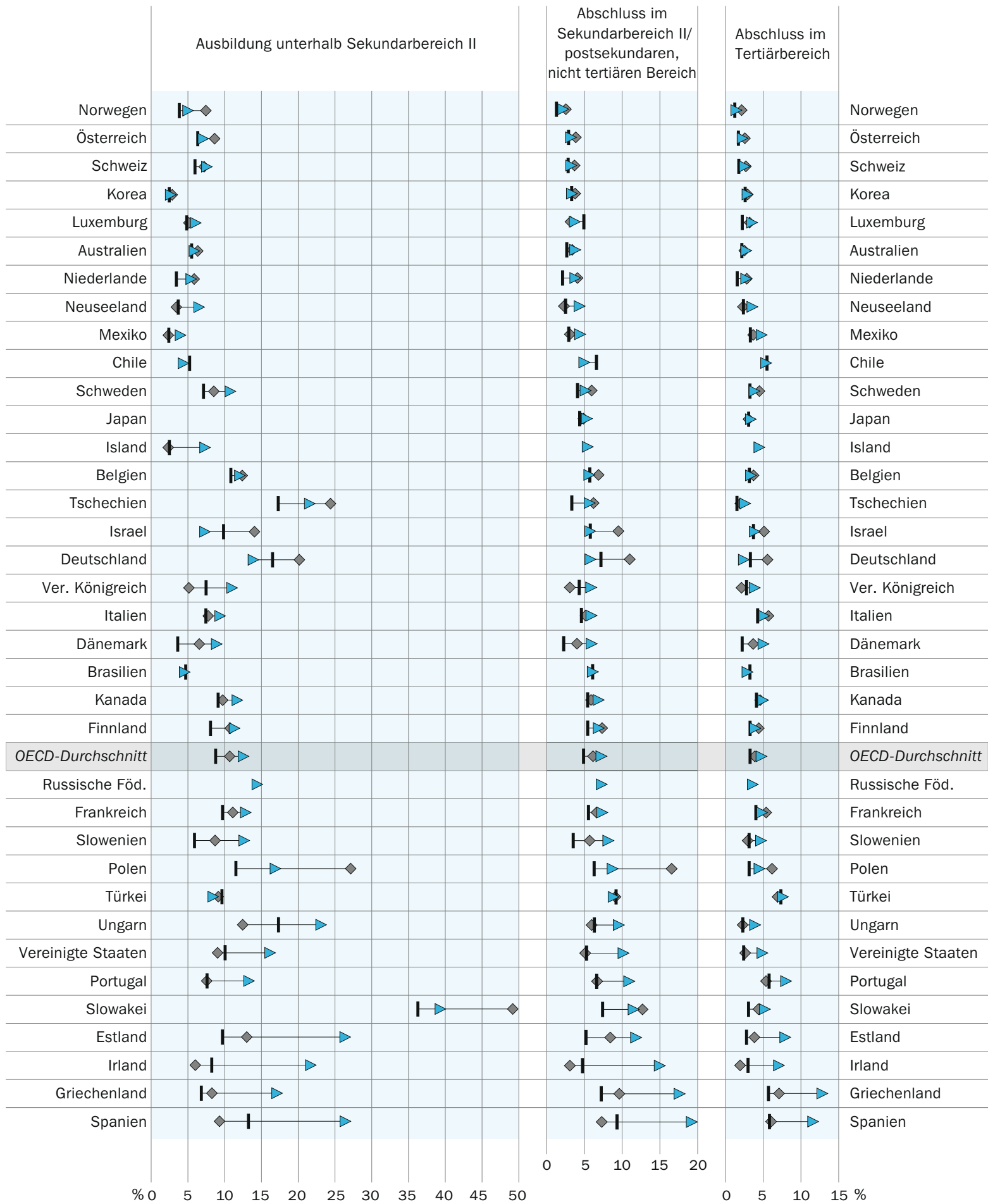

Anordnung der Länder in aufsteigender Reihenfolge der Erwerbslosenquoten von 25- bis 64-jährigen Absolventen des Sekundarbereichs II/postsekundaren, nicht tertiären Bereichs im Jahr 2011.

Quelle: OECD. Tabelle A5.4a. Hinweise s. Anhang 3 unter www.oecd.org/edu/eag.htm. StatLink: http://dx.doi.org/10.1787/888932846500 
Die waagerechten Linien in Abbildung A5.2 stellen die Entwicklung der Erwerbslosenquoten im Zeitverlauf dar. Die Abbildung zeigt, dass Personen ohne einen Abschluss im Sekundarbereich II am stärksten von Erwerbslosigkeit betroffen waren. Zwischen 2008 und 2011 stieg die Erwerbslosenquote von Erwachsenen ohne einen Abschluss im Sekundarbereich II von 8,8 Prozent auf I2,6 Prozent. Aber auch diejenigen, die einen Abschluss im Sekundarbereich II bzw. postsekundaren, nicht tertiären Bereich erworben hatten, waren betroffen: In dieser Gruppe erhöhte sich die Erwerbslosenquote im gesamten OECD-Raum von 4,9 Prozent in 2008 auf 7,3 Prozent in 20Ir. Nur in Belgien, Brasilien, Chile, Deutschland, Luxemburg und der Türkei blieben die Erwerbslosenquoten von 25- bis 64-Jährigen mit einem Abschluss im Sekundarbereich II oder im postsekundaren, nicht tertiären Bereich während dieses Zeitraum gleich bzw. sind gefallen. Im gleichen Zeitraum nahmen auch die Erwerbslosenquoten der Absolventen des Tertiärbereichs zu, wenngleich in geringerem Ausmaß: von 3,3 Prozent 2008 auf 4,8 Prozent im Jahr 20II. Ausnahmen waren Brasilien, Chile und Deutschland, hier sanken die Erwerbslosenquoten der Absolventen des Tertiärbereichs zwischen 2008 und $201 \mathrm{I}$ (Tab. A5.4a).

Bei den Erwachsenen ohne einen Abschluss im Sekundarbereich II stieg die Erwerbslosenquote für Männer von 2008 bis 201 I stärker (um 4, I Prozentpunkte, von 8,8 Prozent auf I2,9 Prozent) als für Frauen (um 2,7 Prozentpunkte, von 9,5 Prozent auf I2,2 Prozent). Auch Estland, Spanien, Tschechien, Ungarn und die Vereinigten Staaten meldeten einen deutlichen Anstieg der Erwerbslosenquoten unter denjenigen ohne einen Abschluss im Sekundarbereich II von 2008 auf 2009, und die Erwerbslosenquoten für diese Arbeitskräfte stiegen 20Io weiter an, jedoch in geringerem Ausmaß (Tab. A5.4b, A5.4c und A5.4d im Internet).

Junge Erwachsene ohne einen Abschluss im Sekundarbereich II hatten stärker unter der Krise zu leiden als ältere Erwachsene mit dem gleichen Bildungsstand. Im OECDDurchschnitt stieg die Erwerbslosenquote für die jüngere Kohorte zwischen 2008 und 20II um fast 5 Prozentpunkte (von I3,6 Prozent auf I8, I Prozent), gegenüber einem Anstieg um weniger als 3 Prozentpunkte für die ältere Gruppe (von 6,2 Prozent auf 8,8 Prozent). Auch die Zunahme der Erwerbslosenquoten für Absolventen des Sekundarbereichs II bzw. des postsekundaren, nicht tertiären Bereichs war im gleichen Zeitraum für die jüngere Kohorte stärker als für die ältere mit einem vergleichbaren Bildungsstand. Die Erwerbslosenquote der jüngeren Erwachsenen stieg von 6,4 Prozent auf 9,5 Prozent, die der älteren Erwachsenen von 4,2 Prozent auf 6,4 Prozent. Das Gleiche gilt für die Absolventen des Tertiärbereichs. Während die Erwerbslosenquote der 55- bis 64-Jährigen zwischen 2008 und 201 I um I Prozentpunkt von 2,9 Prozent auf 4 Prozent stieg, belief sich diese Steigerung bei den 25- bis 34-Jährigen auf mehr als 2 Prozentpunkte, von 4,6 Prozent auf 6,8 Prozent (Tab. A5.4a).

\section{Veränderungen von 2010 auf 2011}

Von 2010 auf 201 I beeinflusste die Wirtschaftskrise die Arbeitsmarktergebnisse in einigen Ländern weiterhin negativ, während in anderen Ländern die Erwerbslosenquoten langsam zurückgingen. Insbesondere für junge Erwachsene mit einer Ausbildung unterhalb des Sekundarbereichs II - die von der Krise am stärksten betroffen waren verringerte sich die Erwerbslosenquote im Durchschnitt aller OECD-Länder geringfügig von 19,0 Prozent in 2010 auf I8, I Prozent im Jahr 20II. Grund hierfür war ein 
Rückgang der Erwerbslosenquoten der jüngeren Männer um I,I Prozentpunkte von I9,o Prozent auf 17,9 Prozent, während es bei den jüngeren Frauen praktisch keine Veränderung gab, ihre Erwerbslosenquote veränderte sich um o, I Prozentpunkte von 2I, o Prozent auf 2I,I Prozent (Tab. A5.4b, A5.4c und A5.4d im Internet). Das Sinken der Erwerbslosenquoten der jüngeren Männer mit einer Ausbildung unterhalb des Sekundarbereichs II wurde von einem Anstieg ihrer Beschäftigungsquoten begleitet, so dass der Rückgang der Erwerbslosenquoten nicht allein darauf zurückzuführen ist, dass Personen den Arbeitsmarkt vollständig verlassen haben.

Die Erwerbslosenquote für Arbeitsmarktteilnehmer mit einer Ausbildung unterhalb des Sekundarbereichs II fiel von 2010 auf $201 \mathrm{I}$ in Deutschland, Israel, der Slowakei und der Türkei um mindestens I,5 Prozentpunkte. Im Gegensatz dazu stieg sie im gleichen Zeitraum in Griechenland (+ 5,2 Prozentpunkte) sowie in Irland, Luxemburg, Portugal, Slowenien und Spanien weiter (mindestens + I,5 Prozentpunkte) (Tab. A5.4b im Internet).

Auch bei den Absolventen des Sekundarbereichs II ließ sich von 2010 auf 20 II in allen OECD-Ländern ein leichter Rückgang der Erwerbslosenquote beobachten (von 7,6 Prozent auf 7,3 Prozent).

Während sich die Erwerbslosenquote der Absolventen des Tertiärbereichs insgesamt von 2010 auf $201 \mathrm{I}$ im Durchschnitt nicht veränderte (Anstieg um o, I Prozentpunkte von 4,7 Prozent auf 4,8 Prozent), fiel sie für die jungen männlichen Absolventen leicht (von 4,7 Prozent auf 4,5 Prozent), während sie für die Absolventinnen leicht stieg (von 4,9 Prozent auf 5, I Prozent). Gleichermaßen sank die Erwerbslosenquote der jüngeren Männer (von 6,9 Prozent auf 6,6 Prozent), während sie bei den jungen Frauen leicht zunahm (von 6,9 Prozent auf 7,3 Prozent). Die Erwerbslosenquote der älteren männlichen Absolventen des Tertiärbereichs ging leicht von 4,9 Prozent auf 4,5 Prozent zurück, während sie bei den älteren Absolventinnen nur minimal um o, I Prozentpunkte, von 3,5 Prozent in 2010 auf 3,4 Prozent in 20II, sank (Tab. A5.4b, A5.4c und A5.4d im Internet).

Erwerbsstatus nach berufs- und allgemeinbildenden Ausbildungsgängen Die Internationale Standardklassifikation des Bildungswesens (ISCED 97) definiert berufliche Ausbildung (Vocational Education and Training [VET]) als „Bildung, die den Teilnehmern in erster Linie praktische Fertigkeiten, Kenntnisse und ein umfassendes Verständnis vermittelt, die sie für die Arbeit in einem bestimmten Beruf oder Berufsfeld benötigen. Der erfolgreiche Abschluss eines solchen Bildungsganges führt zu einer für den Arbeitsmarkt relevanten beruflichen Qualifikation, die von den zuständigen Stellen in dem Land, in dem sie erworben wurde, anerkannt wird“ (UNESCO, I997).

Eine berufliche Ausbildung richtet sich zumeist an Absolventen mit einem Abschluss im Sekundarbereich II bzw. postsekundaren, nicht tertiären Bereich (ISCED-Stufen 3 und 4). In einigen Ländern wurde Absolventen von berufsbildenden Ausbildungsgängen durch Reformen der direkte Zugang zum Tertiärbereich erleichtert, in anderen werden berufliche Ausbildungsgänge auch im Tertiärbereich angeboten (ISCED-Stufe 5). Berufliche Ausbildungsgänge können auch eine Lehre oder duale Ausbildungsgänge umfassen, die dazu beitragen können, eine bessere Abstimmung zwischen dem Bedarf 
der Arbeitgeber an bestimmten Kompetenzen und den von den Arbeitnehmern auf dem Arbeitsmarkt angebotenen Kompetenzen zu schaffen (OECD, 2010). Diese Ausbildungsgänge werden häufig in enger Abstimmung mit den Arbeitgebern konzipiert, was die Einarbeitungszeit verkürzt und die unmittelbare und langfristige Produktivität von Neuanstellungen erhöht (s. Kasten AI.I). Untersuchungen haben gezeigt, dass berufsbildende Ausbildungsgänge gute Erträge für staatliche Investitionen erbringen können, und einige Länder mit gut ausgebauten Berufsbildungssystemen, wie Deutschland, waren bei der Bekämpfung der Jugenderwerbslosigkeit relativ erfolgreich (CEDEFOP, 20II). Ein möglicher Nachteil ist, dass die von den Ausbildungsteilnehmern in berufsbildenden Ausbildungsgängen erworbenen Kompetenzen auf sich schnell ändernden Arbeitsmärkten möglicherweise nur von begrenzter Relevanz sind. Da große Unterschiede zwischen den Berufsbildungssystemen in den einzelnen Ländern bestehen, ist die Vergleichbarkeit zwischen den Ländern hier etwas eingeschränkter als in anderen Bereichen der ISCED-Klassifikation. Daher gestaltet sich ein Vergleich der Teilnahme an beruflichen Ausbildungsgängen und der erzielten Ergebnisse in den einzelnen OECD-Ländern schwieriger.

Tabelle A5.5a gliedert die Arbeitsmarktergebnisse von berufsbildenden und allgemeinbildenden Bildungsgängen im Sekundarbereich II bzw. im postsekundaren, nicht tertiären Bereich (ISCED-Stufen 3/4) sowie im Tertiärbereich (ISCED-Stufe 5) auf. Daten zu berufsbildenden und allgemeinbildenden Bildungsgängen auf den ISCEDStufen 3/4 stehen aus 27 OECD-Ländern zur Verfügung, ähnliche Daten zu Studiengängen auf ISCED-Stufe 5 aus II Ländern.

In den OECD-Ländern, für die Daten vorliegen, sind 76 Prozent der Absolventen von berufsbildenden Ausbildungsgängen im Sekundarbereich II bzw. postsekundaren, nicht tertiären Bereich beschäftigt, damit liegt ihre Beschäftigungsquote 5 Prozentpunkte über der derjenigen, die als höchste Qualifikation einen Abschluss in einem allgemeinbildenden Ausbildungsgang im Sekundarbereich II erworben haben.

Die Erwerbslosenquoten der Absolventen von berufsbildenden Abschlüssen im Sekundarbereich II bzw. im postsekundaren, nicht tertiären Bereich sind niedriger: 7,4 Prozent gegenüber 8,4 Prozent für Erwachsene mit einem allgemeinbildenden Abschluss im Sekundarbereich II. In Dänemark, Island, Slowenien und Ungarn liegen die Erwerbslosenquoten für Erwachsene mit einem berufsbildenden Abschluss im Sekundarbereich II bzw. postsekundaren, nicht tertiären Bereich mindestens 3 Prozentpunkte unter denen der Absolventen von allgemeinbildenden Ausbildungsgängen im gleichen Bereich. Ein umgekehrtes Bild ergibt sich in fünf Ländern mit verfügbaren Daten - nämlich Frankreich, Griechenland, Irland, Neuseeland und Schweden (Abb. A5·3).

Die besseren Arbeitsmarktergebnisse Erwachsener, die als höchste Qualifikation einen berufsbildenden Abschluss im Sekundarbereich II erworben haben, im Vergleich zu Erwachsenen, die einen allgemeinbildenden Abschluss in diesem Bereich erwarben, könnten damit zusammenhängen, dass Erstere fachliche Kompetenzen erwerben, für die auf dem Arbeitsmarkt ein unmittelbarer Bedarf besteht. Ferner scheinen diese Erwachsenen frühere praktische Arbeitserfahrungen zu nutzen, um sich den ersten Arbeitsplatz zu sichern (CEDEFOP, 2012). Dagegen ist der direkte Bezug der in allgemeinbildenden Ausbildungsgängen des Sekundarbereichs II erworbenen Kompetenzen 
Erwerbslosenquoten 25- bis 64-jähriger Absolventen mit einem berufsbildenden und allgemeinbildenden Abschluss im Sekundarbereich II oder dem postsekundaren, nicht tertiären Bereich (2011)

20

18

16

14

12

10

8

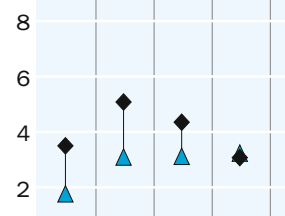

0

$\%$

20

18

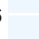

4

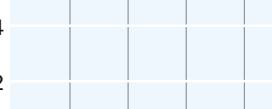

HII! $\triangle$ Berufsbildender Abschluss auf ISCED-Stufe 3/4

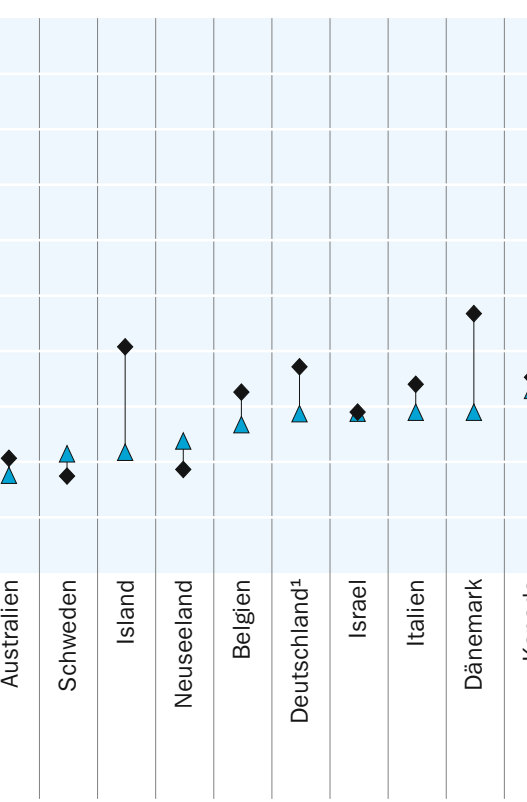

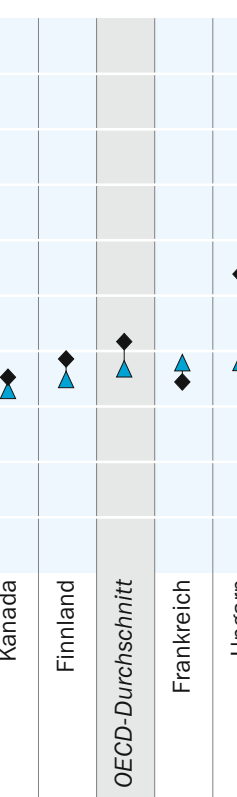

Allgemeinbildender Abschluss auf ISCED-Stufe 3/4

Anmerkung: Der Sekundarbereich II und der postsekundare, nicht tertiäre Bereich entsprechen den ISCED-Stufen 3 und 4. In dieser Abbildung sind nur Länder berücksichtigt, bei denen die Ausrichtung der Bildungsgänge angegeben wurde.

1. In Deutschland entspricht ein ISCED-4A-Abschluss einem Abschluss sowohl eines allgemeinbildenden als auch eines berufsbildenden Bildungsgangs. Absolventen mit einem derartigen Abschluss wurden in dieser Tabelle den berufsbildenden Bildungsgängen zugeordnet.

Anordnung der Länder in aufsteigender Reihenfolge der Erwerbslosenquote 25- bis 64-Jähriger mit einem berufsbildenden Abschluss auf ISCED-Stufe 3/4. Quelle: OECD. Tabelle A5.5a. Hinweise s. Anhang 3 unter www.oecd.org/edu/eag.htm. StatLink: http://dx.doi.org/10.1787/888932846519

zum Arbeitsmarkt meist weniger deutlich, da diese die Bildungsteilnehmer in der Regel darauf vorbereiten sollen, sich im Tertiärbereich dem Studium spezifischerer Fächer zu widmen. Daher könnte es für die Absolventen des allgemeinbildenden Sekundarbereichs II schwieriger sein, einen Arbeitsplatz zu finden, als für die mit einer berufsbildenden Ausbildung. Außerdem liegt der Anteil derjenigen, die nicht am Arbeitsmarkt teilnehmen, im Durchschnitt der OECD-Länder, für die vergleichbare Daten verfügbar sind, bei den Absolventen der berufsbildenden Ausbildungsgänge rund 5 Prozentpunkte unter dem derjenigen mit einem allgemeinbildenden Abschluss im Sekundarbereich II (Tab. A5.5a).

\section{Vollzeitbeschäftigte unter den Absolventen des Tertiärbereichs}

Mit dem Bildungsstand steigen nicht nur die Chancen auf eine Beschäftigung, sondern auch auf eine Vollzeitbeschäftigung. In den OECD-Ländern sind 7 1 Prozent der Erwerbspersonen unabhängig von ihrem Bildungsstand vollzeitbeschäftigt. Wobei einige aber nicht alle Länder hierbei Selbstständige ebenfalls berücksichtigen. Unter den beschäftigten Erwachsenen sind 7 1 Prozent der Absolventen des Sekundarbereichs II in Vollzeitbeschäftigung gegenüber 75 Prozent der Absolventen des Tertiärbereichs. Von den Beschäftigten ohne einen Abschluss im Sekundarbereich II arbeiten rund 64 Prozent Vollzeit (Tabelle A5.6). Die Definition von Vollzeitbeschäftigung unterscheidet sich zwischen den einzelnen Ländern: In einigen Ländern definieren die Befragten den Begriff selbst, in anderen gibt es offizielle Vorgaben hinsichtlich der Mindeststunden- 
Anteil der ganzjährig Vollzeitbeschäftigten unter den Absolventen des Tertiärbereichs mit Erwerbseinkommen, nach Geschlecht und Altersgruppe (2011)

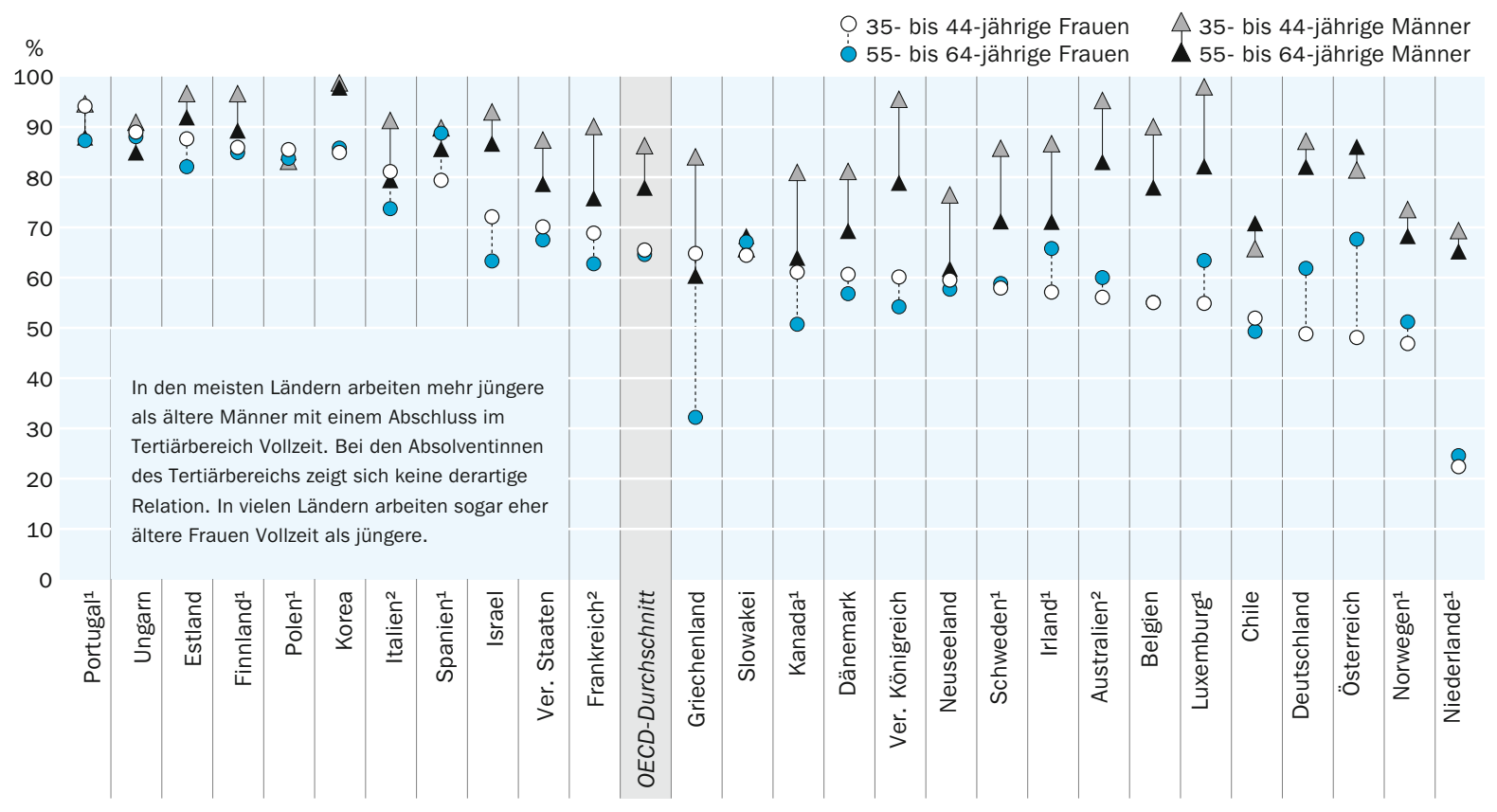

1. Referenzjahr 2010. 2. Referenzjahr 2009.

Anordnung der Länder in absteigender Reihenfolge des Anteils Vollzeitbeschäftigter 35- bis 44-jähriger Frauen.

Quelle: OECD. Tabelle A5.6. Hinweise s. Anhang 3 unter www.oecd.org/edu/eag.htm. StatLink: http://dx.doi.org/10.1787/888932846538

zahl. Diese Mindestanzahl an Stunden reicht von 30 Stunden pro Woche in Griechenland, Neuseeland und Tschechien bis zu 44 Stunden in Chile. Weitere Informationen zu den länderspezifischen Definitionen finden sich im Abschnitt Definitionen von Indikator A6 und in Anhang 3 unter www.oecd.orgleduleag.htm.

Abbildung A5.4 zeigt den Anteil der vollzeitbeschäftigten Erwerbspersonen an den Absolventen des Tertiärbereichs in den Altersgruppen der 35- bis 44-Jährigen und der 55- bis 64-Jährigen. Die Länge der schwarzen Linien verdeutlicht die Differenz zwischen den Anteilen der vollzeitbeschäftigten Männer in den beiden Altersgruppen, die Länge der gestrichelten Linien die Differenz zwischen den Anteilen der vollzeitbeschäftigten Frauen in den beiden Altersgruppen.

In fast allen OECD-Ländern ist der Anteil der 35- bis 44-jährigen Männer in Vollzeitbeschäftigung beträchtlich größer als der der 55- bis 64-Jährigen. Ein derartiges Muster lässt sich bei den Frauen nicht erkennen. In vielen Ländern übertrifft der Anteil der vollzeitbeschäftigten 55- bis 64-jährigen Frauen sogar den der 35-bis 44-Jährigen mit dem gleichen Bildungsstand. Diese Unterschiede sind wohl den unterschiedlichen Kinderbetreuungskonzepten in den einzelnen Ländern zuzuschreiben. Allerdings zeigt Abbildung A5.4 den Anteil der Vollzeitbeschäftigten an allen Erwerbspersonen, einschließlich Teilzeitbeschäftigten, somit sind Mütter, die vollständig aus dem Erwerbsleben ausgeschieden sind, gar nicht erfasst. Viele 35- bis 44-jährige Frauen haben kleine Kinder und arbeiten daher häufig Teilzeit. So ist zum Beispiel in Deutschland, Luxemburg und Österreich der Anteil der älteren Absolventinnen des Tertiärbereichs 
mit Vollzeitbeschäftigung höher als der der jüngeren. In anderen Ländern, wie beispielsweise in Frankreich, sind mehr jüngere Frauen vollzeitbeschäftigt als ältere. In den nordischen Ländern (Dänemark, Norwegen und Schweden) sowie in Belgien, Chile, den Niederlanden und Neuseeland besteht nur ein minimaler Unterschied zwischen der Vollzeitbeschäftigung älterer und jüngerer Frauen.

Dennoch liegt der Anteil der vollzeitbeschäftigten Absolventinnen des Tertiärbereichs in allen OECD-Ländern zusammengenommen deutlich unter dem der Männer mit dem gleichen Bildungsstand, obwohl in Estland, Finnland, Korea, Polen, Portugal und Ungarn über 80 Prozent der Absolventinnen und Absolventen des Tertiärbereichs beider Altersgruppen vollzeitbeschäftigt sind.

\section{Definitionen}

Unter Leitung der Internationalen Arbeitsorganisation (ILO) und ihrer Konferenzen der Arbeitsmarktstatistiker wurden Konzepte und Definitionen zur Erwerbsbeteiligung ausgearbeitet, die inzwischen als allgemein übliche Referenz verwendet werden (ILO, I982).

Die Erwerbsbevölkerung ist die Summe der Erwerbstätigen und der Erwerbslosen entsprechend der Definition der Arbeitskräfteerhebung.

Altersgruppen: Erwachsene bezieht sich auf die Gruppe der 25- bis 64-Jährigen, jüngere Erwachsene bezieht sich auf 25- bis 34-Jährige und ältere Erwachsene auf die 55- bis 64-Jährigen. Die Bevölkerung im erwerbsfähigen Alter umfasst die Gesamtbevölkerung im Alter von 25 bis 64 Jahren.

Beschäftigte werden definiert als diejenigen, die während der untersuchten Referenzwoche I. mindestens eine Stunde für ein Gehalt (Arbeitnehmer) oder für einen Gewinn (Selbstständige und unentgeltlich mithelfende Familienangehörige) arbeiten oder 2. einen Arbeitsplatz haben, aber vorübergehend nicht zur Arbeit gehen (aufgrund von Verletzung, Krankheit, Urlaub, Streik oder Aussperrung, Bildungs- oder Schulungsurlaub, Mutterschafts- oder Erziehungsurlaub usw.).

Die Beschäftigungsquote bezieht sich auf die Zahl der beschäftigten Personen in Relation zur Bevölkerung im erwerbsfähigen Alter, ausgedrückt in Prozent (die Zahl der Beschäftigten wird durch die Gesamtzahl aller Personen im erwerbsfähigen Alter dividiert). Die Beschäftigtenquoten nach Geschlecht, Alter, Bildungsstand, Art des Ausbildungsgangs und Altersgruppe werden jeweils innerhalb der entsprechenden Kategorie berechnet. So wird beispielsweise die Beschäftigungsquote der Frauen errechnet, indem man die Zahl der beschäftigten Frauen durch die Gesamtzahl der Frauen im erwerbsfähigen Alter teilt.

Vollzeitbeschäftigung bezieht sich auf Beschäftigte mit einer ganzjährigen Beschäftigung von mindestens 30 Wochenarbeitsstunden. Die Länge des Referenzzeitraums variiert zwischen einer Woche und einem Jahr. In einigen Ländern sind hierbei Selbstständige nicht berücksichtigt. Die landesspezifischen Definitionen von Vollzeitbeschäftigung 
sind im Abschnitt Definitionen im Indikator A6 sowie in Anhang 3 enthalten (www. oecd.org/edu/eag.htm).

Die Kategorie "Nicht im Arbeitsmarkt" umfasst diejenigen, die während der Erhebungswoche weder beschäftigt noch erwerbslos, d. h. diejenigen, die nicht arbeitssuchend sind. Die Zahl der Personen, die nicht im Arbeitsmarkt sind, errechnet sich durch den Abzug der Zahl der Erwerbstätigen von der Gesamtzahl der Personen im erwerbsfähigen Alter.

Die Nichterwerbsquote beschreibt den Anteil der Personen, die nicht im Arbeitsmarkt sind, an der Bevölkerung im erwerbsfähigen Alter, ausgedrückt in Prozent (d. h., die Zahl der nicht im Arbeitsmarkt befindlichen Personen wird durch die Zahl der Personen im erwerbsfähigen Alter dividiert). Die Nichterwerbsquoten nach Geschlecht, Alter, Bildungsstand, Art des Ausbildungsgangs und Altersgruppe werden jeweils innerhalb der entsprechenden Kategorie berechnet. So wird beispielsweise die Nichterwerbsquote unter den Absolventen des Tertiärbereichs berechnet, indem man die Zahl der nicht im Arbeitsmarkt befindlichen Absolventen des Tertiärbereichs durch die Gesamtzahl aller Absolventen des Tertiärbereichs im erwerbsfähigen Alter dividiert.

Bildungsbereiche: Eine Ausbildung unterhalb Sekundarbereich II entspricht Bildungsgängen auf den ISCED-Stufen o, I, 2 und ${ }_{3} \mathrm{C}$ (kurz). Sekundarbereich II bzw. postsekundarer, nicht tertiärer Bereich entspricht Bildungsgängen auf den ISCED-Stufen ${ }_{3} \mathrm{C}$ (lang), ${ }_{3} \mathrm{~B},{ }_{3} \mathrm{~A}$ und 4. Tertiärbereich entspricht Studiengängen auf den ISCED-Stufen ${ }_{5} B, 5 A$ und 6 . Erläuterungen zu allen ISCED-Bereichen s. Hinweise für den Leser im vorderen Teil des Buches.

Die Erwerbslosenquote bezieht sich auf die Zahl der Erwerbslosen in Relation zur Erwerbsbevölkerung, ausgedrückt in Prozent (d. h., die Zahl der Erwerbslosen wird durch die Summe der Beschäftigten und Erwerbslosen dividiert). Die Erwerbslosenquoten nach Geschlecht, Alter, Bildungsstand, Art des Ausbildungsgangs und Altersgruppe werden jeweils innerhalb der entsprechenden Kategorie berechnet. So wird beispielsweise die Erwerbslosenquote der Frauen berechnet, indem man die Zahl der erwerbslosen Frauen durch die Anzahl aller weiblichen Erwerbspersonen dividiert.

Erwerbslose werden definiert als Personen, die während der Erhebungswoche nicht erwerbstätig waren (d. h., die weder eine Arbeit hatten noch wenigstens eine Stunde oder mehr abhängig beschäftigt oder selbstständig tätig waren), aktiv Arbeit suchten (d. h., die in den vier Wochen vor der Erhebungswoche gezielte Schritte unternommen hatten, um eine bezahlte Arbeitsstelle zu finden bzw. sich selbstständig zu machen) und dem Arbeitsmarkt aktuell zur Verfügung stehen (d.h. spätestens zwei Wochen nach der Erhebungswoche eine entgeltliche abhängige oder selbstständige Tätigkeit aufnehmen konnten).

\section{Angewandte Methodik}

Die Daten zu Bevölkerung, Erwerbsstatus und Bildungsstand stammen aus Datenbanken der OECD und Eurostat, die aus nationalen Arbeitskräfteerhebungen zusammengetragen sind. Die Daten zu den Einkommen stammen aus einer speziellen Erhebung 
zu den Einkommen von ganzjährig Vollzeitbeschäftigten des OECD-Netzwerks zu den Arbeitsmarktergebnissen sowie den wirtschaftlichen und sozialen Auswirkungen des Lernens (LSO). Die länderspezifischen Definitionen von Vollzeitbeschäftigung sind im Abschnitt Definitionen im Indikator A6 sowie in Anhang 3 enthalten (www.oecd.org/edu) eag.htm).

Die statistischen Daten für Israel wurden von den zuständigen israelischen Stellen bereitgestellt, die für sie verantwortlich zeichnen. Die Verwendung dieser Daten durch die OECD erfolgt unbeschadet des völkerrechtlichen Status der Golanhöhen, von OstJerusalem und der israelischen Siedlungen im Westjordanland.

\section{Weiterführende Informationen}

European Centre for the Development of Vocational Training (CEDEFOP) (2011), The Benefits of Vocational Education and Training, Publications Office, Luxembourg.

European Centre for the Development of Vocational Training (CEDEFOP) (2012), From Education to Working Life: The Labour-Market Outcomes of Vocational Education and Training, Publications Office, Luxembourg.

International Labour Organization (ILO) (I982), „Resolution Concerning Statistics of the Economically Active Population, Employment, Unemployment and Underemployment", adopted by the Thirteenth International Conference of Labour Statisticians, October I982, Geneva.

OECD (2004), OECD Handbook for Internationally Comparative Education Statistics: Concepts, Standards, Definitions and Classifications, OECD Publishing, http://dx.doi.org/10.1787| 9789264104112-en.

OECD (2010), Lernen für die Arbeitswelt, ISBN: 978-92-64-08783-5, www.oecd.org/berlin/ publikationen/oecd-studiezurberufsbildunglernenfurdiearbeitswelt.htm.

UNESCO (1997): Internationale Standard-Klassifikation des Bildungswesens: ISCED I997 (International Standard Classification of Education ISCED I997, www. unesco.org/ education/information/nfsunesco/doc/isced_1997.htm.

\section{Tabellen Indikator A5}

Tabelle A5.ra: Beschäftigungsquoten 25-bis 64-Jähriger, nach Bildungsstand (20II) StatLink: http://dx.doi.org/10.1787/888932848552

Tabelle A5.Ib: Beschäftigungsquoten 25- bis 64-Jähriger, nach Bildungsstand und Geschlecht (20II) StatLink: http://dx.doi.org/10.1787/888932848571 
Tabelle A5.2a: Erwerbslosenquoten 25- bis 64-Jähriger, nach Bildungsstand (20II) StatLink: http://dx.doi.org/10.1787/888932848590

Tabelle A5.2b: Erwerbslosenquoten 25-bis 64-Jähriger, nach Bildungsstand und Geschlecht (20II)

StatLink: http://dx.doi.org/10.1787/888932848609

Tabelle A5.3a: Beschäftigungsquoten, nach Bildungsstand und Altersgruppe (2000, 2005, 2008 und 20II)

StatLink: http://dx.doi.org/10.1787/888932848628

WEB Table A5.3b: Trends in employment rates, by educational attainment and age group (Entwicklung der Beschäftigungsquoten, nach Bildungsstand und Altersgruppe) (2000, 2005-20II)

StatLink: http:||dx.doi.org/10.1787/888932848647

WEB Table A5.3c: Trends in employment rates among men, by educational attainment and age group (Entwicklung der Beschäftigungsquoten von Männern, nach Bildungsstand und Altersgruppe (2000, 2005-20II)

StatLink: http://dx.doi.org/10.1787/888932848666

WEB Table A5.3d: Trends in employment rates among women, by educational attainment and age group (Entwicklung der Beschäftigungsquoten von Frauen, nach Bildungsstand und Altersgruppe (2000, 2005-20II)

StatLink: http://dx.doi.org/10.1787/888932848685

Tabelle A5.4a: Erwerbslosenquoten, nach Bildungsstand und Altersgruppe (2000, 2005, 2008 und 20II)

StatLink: http:/|dx.doi.org/10.1787/888932848704

WEB Table A5.4b: Trends in unemployment rates, by educational attainment and age group (Entwicklung der Erwerbslosenquoten, nach Bildungsstand und Altersgruppe) (2000, 2005-20II)

StatLink: http://dx.doi.org/10.1787/888932848723

WEB Table A5.4c: Trends in unemployment rates among men, by educational attainment and age group (Entwicklung der Erwerbslosenquoten von Männern, nach Bildungsstand und Altersgruppe) (2000, 2005-20II)

StatLink: http://dx.doi.org/10.1787/888932848742

WEB Table A5.4d: Trends in unemployment rates among women, by educational attainment and age group (Entwicklung der Erwerbslosenquoten von Frauen, nach Bildungsstand und Altersgruppe) (2000, 2005-20II)

StatLink: http:||dx.doi.org/10.1787/888932848761 
Tabelle A5.5a: Erwerbsstatus 25- bis 64-Jähriger, nach Bildungsstand und Ausrichtung des Bildungsgangs (201I)

StatLink: http://dx.doi.org/10.1787/888932848780

WEB Table A5.5b: Labour market status among 25-64 year-olds, by educational attainment, programme orientation and gender (Erwerbsstatus 25- bis 64-Jähriger, nach Bildungsstand, Ausrichtung des Bildungsgangs und Geschlecht) (20II) StatLink: http://dx.doi.org/10.1787/888932848799

WEB Table A5.5c: Labour market status among 25-34 year-olds and 35-44 year-olds, educational attainment and programme orientation (Erwerbsstatus 25- bis 34-Jähriger und 35- bis 44-Jähriger, nach Bildungsstand und Ausrichtung des Bildungsgangs) (20II)

StatLink: http://dx.doi.org/10.1787/888932848818

Tabelle A5.6: Anteil der ganzjährig Vollzeitbeschäftigten an allen Personen mit Erwerbseinkommen, nach Bildungsstand und Altersgruppe (20II)

StatLink: http:|/dx.doi.org/10.1787/888932848837 
Tabelle A5.1a

Beschäftigungsquoten 25- bis 64- Jähriger, nach Bildungsstand (2011)

Zahl der 25- bis 64-jährigen Beschäftigten als Prozentsatz aller 25- bis 64-Jährigen

\begin{tabular}{|c|c|c|c|c|c|c|c|c|c|}
\hline & \multirow{2}{*}{$\begin{array}{l}\text { Ausbildung } \\
\text { im Elemen- } \\
\text { tar- und } \\
\text { Primar- } \\
\text { bereich }\end{array}$} & \multirow{2}{*}{$\left|\begin{array}{c}\text { Abschluss im } \\
\text { Sekundar- } \\
\text { bereich I }\end{array}\right|$} & \multirow[t]{2}{*}{$\begin{array}{c}\text { ISCED } 3 C \\
\text { (kurz) }\end{array}$} & \multicolumn{2}{|c|}{$\begin{array}{c}\text { Abschluss im } \\
\text { Sekundarbereich II }\end{array}$} & \multirow{2}{*}{\begin{tabular}{|c|} 
Abschluss im \\
postsekun- \\
daren, nicht \\
tertiären \\
Bereich
\end{tabular}} & \multicolumn{2}{|c|}{$\begin{array}{l}\text { Abschluss im } \\
\text { Tertiärbereich }\end{array}$} & \multirow{2}{*}{$\begin{array}{c}\text { Alle } \\
\text { Bildungs- } \\
\text { bereiche } \\
\text { zusammen }\end{array}$} \\
\hline & & & & $\begin{array}{l}\text { ISCED 3C } \\
\text { (lang)/3B }\end{array}$ & ISCED $3 A$ & & $\begin{array}{c}\text { Tertiär- } \\
\text { bereich B }\end{array}$ & $\begin{array}{c}\text { Tertiär- } \\
\text { bereich A/ } \\
\text { weiter- } \\
\text { führender } \\
\text { forschungs- } \\
\text { orientierter } \\
\text { Studiengang }\end{array}$ & \\
\hline & (1) & (2) & (3) & (4) & (5) & (6) & (7) & (8) & (9) \\
\hline \multicolumn{10}{|l|}{ OECD-Länder } \\
\hline Australien & 52 & 70 & a & 84 & 77 & 85 & 81 & 86 & 78 \\
\hline Österreich & $x(2)$ & 55 & 69 & 77 & 76 & 85 & 85 & 88 & 76 \\
\hline Belgien & 37 & 56 & $\mathrm{a}$ & 73 & 73 & 83 & 83 & 85 & 70 \\
\hline Kanada & 43 & 60 & a & $x(5)$ & 72 & 79 & 81 & 82 & 76 \\
\hline Chile & 59 & 68 & a & $x(5)$ & 73 & a & 80 & 79 & 72 \\
\hline Tschechien & c & 43 & a & 73 & 78 & $x(5)$ & $x(8)$ & 83 & 74 \\
\hline Dänemark & 45 & 62 & 74 & 80 & 76 & $\mathrm{c}$ & 82 & 86 & 78 \\
\hline Estland & $\mathrm{c}$ & 51 & a & 74 & 73 & 77 & 77 & 81 & 73 \\
\hline Finnland & 44 & 63 & a & a & 74 & 90 & 83 & 85 & 75 \\
\hline Frankreich & 41 & 64 & a & 73 & 75 & c & 85 & 83 & 72 \\
\hline Deutschland & 47 & 60 & a & 78 & 61 & 84 & 88 & 88 & 78 \\
\hline Griechenland & 48 & 61 & $x(4)$ & 70 & 60 & 66 & 72 & 76 & 63 \\
\hline Ungarn & 13 & 40 & a & 65 & 68 & 71 & 81 & 79 & 64 \\
\hline Island & 74 & $\mathrm{c}$ & 80 & 86 & 76 & 90 & 92 & 88 & 83 \\
\hline Irland & 35 & 53 & 61 & $x(5)$ & 65 & 64 & 77 & 83 & 66 \\
\hline Israel & 37 & 58 & $a$ & 76 & 69 & a & 78 & 85 & 72 \\
\hline Italien & 29 & 58 & 61 & 70 & 72 & 75 & 70 & 79 & 64 \\
\hline Japan & $x(5)$ & $x(5)$ & $x(5)$ & $x(5)$ & 73 & a & 73 & 84 & 76 \\
\hline Korea & 61 & 68 & a & $x(5)$ & 71 & a & 74 & 78 & 72 \\
\hline Luxemburg & 61 & 62 & 65 & 69 & 71 & 75 & 83 & 86 & 74 \\
\hline Mexiko & 59 & 68 & a & 66 & 73 & $a$ & 76 & 79 & 67 \\
\hline Niederlande & 52 & 66 & $x(4)$ & 76 & 82 & 81 & 80 & 88 & 77 \\
\hline Neuseeland & $x(2)$ & 64 & 79 & 78 & 81 & 88 & 82 & 86 & 79 \\
\hline Norwegen & $\mathrm{c}$ & 68 & a & 82 & 79 & 85 & 90 & 90 & 83 \\
\hline Polen & $x(2)$ & 40 & $a$ & 63 & 69 & 69 & $x(8)$ & 85 & 68 \\
\hline Portugal & 62 & 74 & $x(5)$ & $x(5)$ & 79 & 79 & $x(8)$ & 83 & 71 \\
\hline Slowakei & c & 32 & $x(4)$ & 66 & 74 & $x(5)$ & 81 & 82 & 69 \\
\hline Slowenien & 22 & 49 & $a$ & 67 & 73 & a & 83 & 89 & 71 \\
\hline Spanien & 40 & 60 & $a$ & 68 & 67 & c & 75 & 80 & 64 \\
\hline Schweden & 49 & 72 & $a$ & $x(5)$ & 83 & 84 & 85 & 90 & 83 \\
\hline Schweiz & 66 & 69 & 69 & 83 & 76 & 87 & 92 & 87 & 83 \\
\hline Türkei & 49 & 60 & $\mathrm{a}$ & 65 & 59 & a & $x(8)$ & 76 & 56 \\
\hline Vereinigtes Königreich & 21 & 43 & 66 & 78 & 78 & c & 82 & 84 & 75 \\
\hline Vereinigte Staaten & 52 & 51 & $x(5)$ & $x(5)$ & 67 & $x(5)$ & 76 & 81 & 71 \\
\hline OECD-Durchschnitt & 46 & 58 & m & 74 & 73 & 80 & 81 & 84 & 73 \\
\hline EU21-Durchschnitt & 40 & 55 & m & 72 & 73 & 77 & 81 & 84 & 72 \\
\hline \multicolumn{10}{|l|}{ Sonstige G20-Länder } \\
\hline Argentinien & $\mathrm{m}$ & $\mathrm{m}$ & $\mathrm{m}$ & $\mathrm{m}$ & $\mathrm{m}$ & $\mathrm{m}$ & $\mathrm{m}$ & $\mathrm{m}$ & $\mathrm{m}$ \\
\hline Brasilien & 65 & 72 & $x(5)$ & $x(5)$ & 70 & a & $x(8)$ & 85 & 70 \\
\hline China & $\mathrm{m}$ & $\mathrm{m}$ & $\mathrm{m}$ & $\mathrm{m}$ & $\mathrm{m}$ & $\mathrm{m}$ & $\mathrm{m}$ & $\mathrm{m}$ & $\mathrm{m}$ \\
\hline Indien & $\mathrm{m}$ & $\mathrm{m}$ & $\mathrm{m}$ & $\mathrm{m}$ & $\mathrm{m}$ & $\mathrm{m}$ & $\mathrm{m}$ & $\mathrm{m}$ & $\mathrm{m}$ \\
\hline Indonesien & $\mathrm{m}$ & $\mathrm{m}$ & $\mathrm{m}$ & $\mathrm{m}$ & $\mathrm{m}$ & $\mathrm{m}$ & $\mathrm{m}$ & $\mathrm{m}$ & $\mathrm{m}$ \\
\hline Russische Föderation & 27 & 52 & $x(4)$ & 78 & 68 & $x(4)$ & 79 & 86 & 77 \\
\hline Saudi-Arabien & $\mathrm{m}$ & $\mathrm{m}$ & $\mathrm{m}$ & $\mathrm{m}$ & $\mathrm{m}$ & $\mathrm{m}$ & $\mathrm{m}$ & $\mathrm{m}$ & $\mathrm{m}$ \\
\hline Südafrika & $\mathrm{m}$ & $\mathrm{m}$ & $\mathrm{m}$ & $\mathrm{m}$ & $\mathrm{m}$ & m & $\mathrm{m}$ & $\mathrm{m}$ & $\mathrm{m}$ \\
\hline G20-Durchschnitt & $\mathbf{m}$ & m & m & $\mathbf{m}$ & $\mathbf{m}$ & m & $\mathbf{m}$ & $\mathbf{m}$ & m \\
\hline
\end{tabular}

Quelle: OECD. Arbeitskräfteerhebung des Netzwerks zu den Arbeitsmarktergebnissen sowie den wirtschaftlichen und sozialen Auswirkungen des Lernens (LSO) für die meisten Länder sowie Arbeitskräfteerhebung der EU (EU-LFS) für Dänemark, Finnland, Island, Irland, Luxemburg und Slowenien.

Hinweise s. Anhang 3 unter www.oecd.org/edu/eag.htm. StatLink: http://dx.doi.org/10.1787/888932848552

Erläuterung der Kennzeichnung fehlender Daten s. Hinweise für den Leser. 
Beschäftigungsquoten 25- bis 64- Jähriger, nach Bildungsstand und Geschlecht (2011)

Zahl der 25- bis 64-jährigen Beschäftigten als Prozentsatz aller 25- bis 64-Jährigen

\begin{tabular}{|c|c|c|c|c|c|c|c|c|c|c|}
\hline & & \multirow{2}{*}{$\begin{array}{l}\text { Ausbildung } \\
\text { im Elemen- } \\
\text { tar- und } \\
\text { Primar- } \\
\text { bereich }\end{array}$} & \multirow{2}{*}{$\begin{array}{c}\text { Abschluss } \\
\text { im Sekun- } \\
\text { darbereich I }\end{array}$} & \multirow[t]{2}{*}{$\begin{array}{l}\text { ISCED 3C } \\
\text { (kurz) }\end{array}$} & \multicolumn{2}{|c|}{$\begin{array}{c}\text { Abschluss im } \\
\text { Sekundarbereich II }\end{array}$} & \multirow{2}{*}{$\begin{array}{c}\text { Abschluss } \\
\text { im postse- } \\
\text { kundaren, } \\
\text { nicht } \\
\text { tertiären } \\
\text { Bereich }\end{array}$} & \multicolumn{2}{|c|}{$\begin{array}{l}\text { Abschluss im } \\
\text { Tertiärbereich }\end{array}$} & \multirow{2}{*}{$\begin{array}{c}\text { Alle } \\
\text { Bildungs- } \\
\text { bereiche } \\
\text { zusammen }\end{array}$} \\
\hline & & & & & $\begin{array}{l}\text { ISCED 3C } \\
\text { (lang)/3B }\end{array}$ & ISCED $3 A$ & & $\begin{array}{c}\text { Tertiär- } \\
\text { bereich B }\end{array}$ & \begin{tabular}{|c|} 
Tertiär- \\
bereich A/ \\
weiter- \\
führender \\
forschungs- \\
orientierter \\
Studiengang
\end{tabular} & \\
\hline & & (1) & (2) & (3) & (4) & (5) & (6) & (7) & (8) & (9) \\
\hline \multicolumn{11}{|l|}{ OECD-Länder } \\
\hline Australien & $\begin{array}{l}\text { Männer } \\
\text { Frauen }\end{array}$ & $\begin{array}{l}67 \\
37\end{array}$ & $\begin{array}{l}80 \\
62\end{array}$ & $\begin{array}{l}a \\
a\end{array}$ & $\begin{array}{l}90 \\
70\end{array}$ & $\begin{array}{l}87 \\
68\end{array}$ & $\begin{array}{l}91 \\
79\end{array}$ & $\begin{array}{l}88 \\
75\end{array}$ & $\begin{array}{l}91 \\
81\end{array}$ & $\begin{array}{l}86 \\
70\end{array}$ \\
\hline Österreich & $\begin{array}{l}\text { Männer } \\
\text { Frauen }\end{array}$ & $\begin{array}{l}x(2) \\
x(2)\end{array}$ & $\begin{array}{l}65 \\
50\end{array}$ & $\begin{array}{l}80 \\
65\end{array}$ & $\begin{array}{l}81 \\
71\end{array}$ & $\begin{array}{l}80 \\
72\end{array}$ & $\begin{array}{l}87 \\
83\end{array}$ & $\begin{array}{l}88 \\
80\end{array}$ & $\begin{array}{l}91 \\
84\end{array}$ & $\begin{array}{l}82 \\
70\end{array}$ \\
\hline Belgien & $\begin{array}{l}\text { Männer } \\
\text { Frauen }\end{array}$ & $\begin{array}{l}46 \\
28\end{array}$ & $\begin{array}{l}66 \\
44\end{array}$ & $\begin{array}{l}a \\
a\end{array}$ & $\begin{array}{l}81 \\
65\end{array}$ & $\begin{array}{l}80 \\
66\end{array}$ & $\begin{array}{l}88 \\
77\end{array}$ & $\begin{array}{l}86 \\
81\end{array}$ & $\begin{array}{l}88 \\
83\end{array}$ & $\begin{array}{l}76 \\
64\end{array}$ \\
\hline Kanada & $\begin{array}{l}\text { Männer } \\
\text { Frauen }\end{array}$ & $\begin{array}{l}53 \\
31\end{array}$ & $\begin{array}{l}68 \\
50\end{array}$ & $\begin{array}{l}a \\
a\end{array}$ & $\begin{array}{l}x(5) \\
x(5)\end{array}$ & $\begin{array}{l}78 \\
67\end{array}$ & $\begin{array}{l}81 \\
73\end{array}$ & $\begin{array}{l}85 \\
78\end{array}$ & $\begin{array}{l}85 \\
80\end{array}$ & $\begin{array}{l}80 \\
72\end{array}$ \\
\hline Chile & $\begin{array}{l}\text { Männer } \\
\text { Frauen }\end{array}$ & $\begin{array}{l}79 \\
41\end{array}$ & $\begin{array}{l}88 \\
50\end{array}$ & $\begin{array}{l}a \\
a\end{array}$ & $\begin{array}{l}x(5) \\
x(5)\end{array}$ & $\begin{array}{l}89 \\
57\end{array}$ & $\begin{array}{l}a \\
a\end{array}$ & $\begin{array}{l}91 \\
71\end{array}$ & $\begin{array}{l}86 \\
71\end{array}$ & $\begin{array}{l}87 \\
58\end{array}$ \\
\hline Tschechien & $\begin{array}{l}\text { Männer } \\
\text { Frauen }\end{array}$ & $\begin{array}{l}\mathrm{c} \\
\mathrm{c}\end{array}$ & $\begin{array}{l}53 \\
38\end{array}$ & $\begin{array}{l}\mathrm{a} \\
\mathrm{a}\end{array}$ & $\begin{array}{l}81 \\
61\end{array}$ & $\begin{array}{l}88 \\
70\end{array}$ & $\begin{array}{l}x(5) \\
x(5)\end{array}$ & $\begin{array}{l}x(8) \\
x(8)\end{array}$ & $\begin{array}{l}92 \\
74\end{array}$ & $\begin{array}{l}83 \\
65\end{array}$ \\
\hline Dänemark & $\begin{array}{l}\text { Männer } \\
\text { Frauen }\end{array}$ & $\begin{array}{r}c \\
45\end{array}$ & $\begin{array}{l}70 \\
54\end{array}$ & $\begin{array}{l}76 \\
73\end{array}$ & $\begin{array}{l}82 \\
77\end{array}$ & $\begin{array}{l}79 \\
73\end{array}$ & $\begin{array}{l}\mathrm{c} \\
\mathrm{c}\end{array}$ & $\begin{array}{l}85 \\
79\end{array}$ & $\begin{array}{l}89 \\
85\end{array}$ & $\begin{array}{l}81 \\
74\end{array}$ \\
\hline Estland & $\begin{array}{l}\text { Männer } \\
\text { Frauen }\end{array}$ & $\begin{array}{l}\mathrm{c} \\
\mathrm{c}\end{array}$ & $\begin{array}{l}57 \\
43\end{array}$ & $\begin{array}{l}a \\
a\end{array}$ & $\begin{array}{l}77 \\
69\end{array}$ & $\begin{array}{l}78 \\
68\end{array}$ & $\begin{array}{l}82 \\
74\end{array}$ & $\begin{array}{l}82 \\
75\end{array}$ & $\begin{array}{l}86 \\
79\end{array}$ & $\begin{array}{l}76 \\
70\end{array}$ \\
\hline Finnland & $\begin{array}{l}\text { Männer } \\
\text { Frauen }\end{array}$ & $\begin{array}{l}48 \\
40\end{array}$ & $\begin{array}{l}69 \\
55\end{array}$ & $\begin{array}{l}\mathrm{a} \\
\mathrm{a}\end{array}$ & $\begin{array}{l}a \\
a\end{array}$ & $\begin{array}{l}77 \\
71\end{array}$ & $\begin{array}{l}92 \\
89\end{array}$ & $\begin{array}{l}83 \\
83\end{array}$ & $\begin{array}{l}89 \\
82\end{array}$ & $\begin{array}{l}77 \\
73\end{array}$ \\
\hline Frankreich & $\begin{array}{l}\text { Männer } \\
\text { Frauen }\end{array}$ & $\begin{array}{l}47 \\
36\end{array}$ & $\begin{array}{l}71 \\
58\end{array}$ & $\begin{array}{l}a \\
a\end{array}$ & $\begin{array}{l}78 \\
68\end{array}$ & $\begin{array}{l}80 \\
72\end{array}$ & $\begin{array}{l}\mathrm{c} \\
\mathrm{c}\end{array}$ & $\begin{array}{l}89 \\
83\end{array}$ & $\begin{array}{l}86 \\
80\end{array}$ & $\begin{array}{l}76 \\
67\end{array}$ \\
\hline Deutschland & $\begin{array}{l}\text { Männer } \\
\text { Frauen }\end{array}$ & $\begin{array}{l}59 \\
36\end{array}$ & $\begin{array}{l}69 \\
53\end{array}$ & $\begin{array}{l}a \\
a\end{array}$ & $\begin{array}{l}83 \\
73\end{array}$ & $\begin{array}{l}66 \\
55\end{array}$ & $\begin{array}{l}87 \\
81\end{array}$ & $\begin{array}{l}90 \\
85\end{array}$ & $\begin{array}{l}91 \\
84\end{array}$ & $\begin{array}{l}83 \\
72\end{array}$ \\
\hline Griechenland & $\begin{array}{l}\text { Männer } \\
\text { Frauen }\end{array}$ & $\begin{array}{l}63 \\
35\end{array}$ & $\begin{array}{l}75 \\
44\end{array}$ & $\begin{array}{l}x(4) \\
x(4)\end{array}$ & $\begin{array}{l}77 \\
48\end{array}$ & $\begin{array}{l}74 \\
48\end{array}$ & $\begin{array}{l}78 \\
55\end{array}$ & $\begin{array}{l}77 \\
67\end{array}$ & $\begin{array}{l}81 \\
71\end{array}$ & $\begin{array}{l}74 \\
51\end{array}$ \\
\hline Ungarn & $\begin{array}{l}\text { Männer } \\
\text { Frauen }\end{array}$ & $\begin{array}{l}18 \\
10\end{array}$ & $\begin{array}{l}49 \\
33\end{array}$ & $\begin{array}{l}a \\
a\end{array}$ & $\begin{array}{l}69 \\
57\end{array}$ & $\begin{array}{l}76 \\
62\end{array}$ & $\begin{array}{l}78 \\
65\end{array}$ & $\begin{array}{l}80 \\
82\end{array}$ & $\begin{array}{l}85 \\
75\end{array}$ & $\begin{array}{l}70 \\
58\end{array}$ \\
\hline Island & $\begin{array}{l}\text { Männer } \\
\text { Frauen }\end{array}$ & $\begin{array}{l}81 \\
68\end{array}$ & $\begin{array}{l}\mathrm{c} \\
\mathrm{c}\end{array}$ & $\begin{array}{r}c \\
73\end{array}$ & $\begin{array}{l}88 \\
84\end{array}$ & $\begin{array}{l}81 \\
72\end{array}$ & $\begin{array}{l}90 \\
89\end{array}$ & $\begin{array}{l}94 \\
91\end{array}$ & $\begin{array}{l}90 \\
87\end{array}$ & $\begin{array}{l}86 \\
79\end{array}$ \\
\hline Irland & $\begin{array}{l}\text { Männer } \\
\text { Frauen }\end{array}$ & $\begin{array}{l}42 \\
26\end{array}$ & $\begin{array}{l}62 \\
41\end{array}$ & $\begin{array}{l}67 \\
56\end{array}$ & $\begin{array}{l}x(5) \\
x(5)\end{array}$ & $\begin{array}{l}74 \\
58\end{array}$ & $\begin{array}{l}69 \\
59\end{array}$ & $\begin{array}{l}82 \\
73\end{array}$ & $\begin{array}{l}86 \\
81\end{array}$ & $\begin{array}{l}71 \\
61\end{array}$ \\
\hline Israel & $\begin{array}{l}\text { Männer } \\
\text { Frauen }\end{array}$ & $\begin{array}{l}54 \\
22\end{array}$ & $\begin{array}{l}67 \\
42\end{array}$ & $\begin{array}{l}\mathrm{a} \\
\mathrm{a}\end{array}$ & $\begin{array}{l}82 \\
68\end{array}$ & $\begin{array}{l}75 \\
64\end{array}$ & $\begin{array}{l}\mathrm{a} \\
\mathrm{a}\end{array}$ & $\begin{array}{l}83 \\
74\end{array}$ & $\begin{array}{l}88 \\
83\end{array}$ & $\begin{array}{l}78 \\
67\end{array}$ \\
\hline Italien & $\begin{array}{l}\text { Männer } \\
\text { Frauen }\end{array}$ & $\begin{array}{l}48 \\
16\end{array}$ & $\begin{array}{l}73 \\
40\end{array}$ & $\begin{array}{l}73 \\
55\end{array}$ & $\begin{array}{l}81 \\
59\end{array}$ & $\begin{array}{l}81 \\
63\end{array}$ & $\begin{array}{l}83 \\
70\end{array}$ & $\begin{array}{l}76 \\
66\end{array}$ & $\begin{array}{l}85 \\
75\end{array}$ & $\begin{array}{l}76 \\
52\end{array}$ \\
\hline Japan & $\begin{array}{l}\text { Männer } \\
\text { Frauen }\end{array}$ & $\begin{array}{l}x(5) \\
x(5)\end{array}$ & $\begin{array}{l}x(5) \\
x(5)\end{array}$ & $\begin{array}{l}x(5) \\
x(5)\end{array}$ & $\begin{array}{l}x(5) \\
x(5)\end{array}$ & $\begin{array}{l}85 \\
61\end{array}$ & $\begin{array}{l}a \\
a\end{array}$ & $\begin{array}{l}92 \\
66\end{array}$ & $\begin{array}{l}92 \\
68\end{array}$ & $\begin{array}{l}88 \\
63\end{array}$ \\
\hline Korea & $\begin{array}{l}\text { Männer } \\
\text { Frauen }\end{array}$ & $\begin{array}{l}72 \\
56\end{array}$ & $\begin{array}{l}81 \\
59\end{array}$ & $\begin{array}{l}a \\
a\end{array}$ & $\begin{array}{l}x(5) \\
x(5)\end{array}$ & $\begin{array}{l}84 \\
58\end{array}$ & $\begin{array}{l}a \\
a\end{array}$ & $\begin{array}{l}90 \\
58\end{array}$ & $\begin{array}{l}90 \\
62\end{array}$ & $\begin{array}{l}86 \\
59\end{array}$ \\
\hline Luxemburg & $\begin{array}{l}\text { Männer } \\
\text { Frauen }\end{array}$ & $\begin{array}{l}70 \\
53\end{array}$ & $\begin{array}{l}77 \\
49\end{array}$ & $\begin{array}{l}82 \\
51\end{array}$ & $\begin{array}{l}79 \\
56\end{array}$ & $\begin{array}{l}79 \\
65\end{array}$ & $\begin{array}{l}78 \\
70\end{array}$ & $\begin{array}{l}87 \\
79\end{array}$ & $\begin{array}{l}91 \\
80\end{array}$ & $\begin{array}{l}82 \\
65\end{array}$ \\
\hline Mexiko & $\begin{array}{l}\text { Männer } \\
\text { Frauen }\end{array}$ & $\begin{array}{l}85 \\
39\end{array}$ & $\begin{array}{l}91 \\
47\end{array}$ & $\begin{array}{l}a \\
a\end{array}$ & $\begin{array}{l}89 \\
57\end{array}$ & $\begin{array}{l}90 \\
54\end{array}$ & $\begin{array}{l}a \\
a\end{array}$ & $\begin{array}{l}85 \\
71\end{array}$ & $\begin{array}{l}87 \\
70\end{array}$ & $\begin{array}{l}88 \\
49\end{array}$ \\
\hline Niederlande & $\begin{array}{l}\text { Männer } \\
\text { Frauen }\end{array}$ & $\begin{array}{l}65 \\
40\end{array}$ & $\begin{array}{l}78 \\
55\end{array}$ & $\begin{array}{l}x(4) \\
x(4)\end{array}$ & $\begin{array}{l}82 \\
70\end{array}$ & $\begin{array}{l}87 \\
78\end{array}$ & $\begin{array}{l}84 \\
78\end{array}$ & $\begin{array}{l}85 \\
76\end{array}$ & $\begin{array}{l}90 \\
86\end{array}$ & $\begin{array}{l}84 \\
71\end{array}$ \\
\hline Neuseeland & $\begin{array}{l}\text { Männer } \\
\text { Frauen }\end{array}$ & $\begin{array}{l}x(2) \\
x(2)\end{array}$ & $\begin{array}{l}73 \\
56\end{array}$ & $\begin{array}{l}87 \\
73\end{array}$ & $\begin{array}{l}87 \\
71\end{array}$ & $\begin{array}{l}89 \\
74\end{array}$ & $\begin{array}{l}91 \\
76\end{array}$ & $\begin{array}{l}88 \\
78\end{array}$ & $\begin{array}{l}92 \\
82\end{array}$ & $\begin{array}{l}86 \\
73\end{array}$ \\
\hline Norwegen & $\begin{array}{l}\text { Männer } \\
\text { Frauen }\end{array}$ & $\begin{array}{l}\mathrm{c} \\
\mathrm{c}\end{array}$ & $\begin{array}{l}73 \\
63\end{array}$ & $\begin{array}{l}\mathrm{a} \\
\mathrm{a}\end{array}$ & $\begin{array}{l}86 \\
78\end{array}$ & $\begin{array}{l}83 \\
75\end{array}$ & $\begin{array}{l}88 \\
79\end{array}$ & $\begin{array}{l}91 \\
89\end{array}$ & $\begin{array}{l}92 \\
89\end{array}$ & $\begin{array}{l}85 \\
80\end{array}$ \\
\hline Polen & $\begin{array}{l}\text { Männer } \\
\text { Frauen }\end{array}$ & $\begin{array}{l}x(2) \\
x(2)\end{array}$ & $\begin{array}{l}49 \\
31\end{array}$ & $\begin{array}{l}a \\
a\end{array}$ & $\begin{array}{l}71 \\
50\end{array}$ & $\begin{array}{l}80 \\
59\end{array}$ & $\begin{array}{l}83 \\
64\end{array}$ & $\begin{array}{l}x(8) \\
x(8)\end{array}$ & $\begin{array}{l}89 \\
82\end{array}$ & $\begin{array}{l}75 \\
60\end{array}$ \\
\hline
\end{tabular}

Quelle: OECD. Arbeitskräfteerhebung des Netzwerks zu den Arbeitsmarktergebnissen sowie den wirtschaftlichen und sozialen Auswirkungen des Lernens (LSO) für die meisten Länder sowie Arbeitskräfteerhebung der EU (EU-LFS) für Dänemark, Finnland, Island, Irland, Luxemburg und Slowenien.

Hinweise s. Anhang 3 unter www.oecd.org/edu/eag.htm. StatLink: http://dx.doi.org/10.1787/888932848571

Erläuterung der Kennzeichnung fehlender Daten s. Hinweise für den Leser. 
Tabelle A5.1b (Forts.)

Beschäftigungsquoten 25- bis 64- Jähriger, nach Bildungsstand und Geschlecht (2011)

Zahl der 25- bis 64-jährigen Beschäftigten als Prozentsatz aller 25- bis 64-Jährigen

\begin{tabular}{|c|c|c|c|c|c|c|c|c|c|c|}
\hline & & \multirow{2}{*}{$\begin{array}{l}\text { Ausbildung } \\
\text { im Elemen- } \\
\text { tar- und } \\
\text { Primar- } \\
\text { bereich }\end{array}$} & \multirow{2}{*}{$\left|\begin{array}{c|}\text { Abschluss } \\
\text { im Sekun- } \\
\text { darbereich I }\end{array}\right|$} & \multirow[t]{2}{*}{$\begin{array}{c}\text { ISCED 3C } \\
\text { (kurz) }\end{array}$} & \multicolumn{2}{|c|}{$\begin{array}{c}\text { Abschluss im } \\
\text { Sekundarbereich II }\end{array}$} & \multirow{2}{*}{$\begin{array}{c}\text { Abschluss } \\
\text { im postse- } \\
\text { kundaren, } \\
\text { nicht } \\
\text { tertiären } \\
\text { Bereich }\end{array}$} & \multicolumn{2}{|c|}{$\begin{array}{l}\text { Abschluss im } \\
\text { Tertiärbereich }\end{array}$} & \multirow{2}{*}{$\begin{array}{c}\text { Alle } \\
\text { Bildungs- } \\
\text { bereiche } \\
\text { zusammen }\end{array}$} \\
\hline & & & & & $\begin{array}{l}\text { ISCED 3C } \\
\text { (lang)/3B }\end{array}$ & ISCED $3 A$ & & $\begin{array}{c}\text { Tertiär- } \\
\text { bereich B }\end{array}$ & \begin{tabular}{|c|} 
Tertiär- \\
bereich A/ \\
weiter- \\
führender \\
forschungs- \\
orientierter \\
Studiengang
\end{tabular} & \\
\hline & & (1) & (2) & (3) & (4) & (5) & (6) & (7) & (8) & (9) \\
\hline \multicolumn{11}{|l|}{ OECD-Länder } \\
\hline Portugal & $\begin{array}{l}\text { Männer } \\
\text { Frauen }\end{array}$ & $\begin{array}{l}69 \\
54\end{array}$ & $\begin{array}{l}80 \\
68\end{array}$ & $\begin{array}{l}x(5) \\
x(5)\end{array}$ & $\begin{array}{l}x(5) \\
x(5)\end{array}$ & $\begin{array}{l}81 \\
78\end{array}$ & $\begin{array}{l}86 \\
71\end{array}$ & $\begin{array}{l}x(8) \\
x(8)\end{array}$ & $\begin{array}{l}83 \\
83\end{array}$ & $\begin{array}{l}76 \\
67\end{array}$ \\
\hline Slowakei & $\begin{array}{l}\text { Männer } \\
\text { Frauen }\end{array}$ & $\begin{array}{l}\mathrm{C} \\
\mathrm{C}\end{array}$ & $\begin{array}{l}38 \\
28\end{array}$ & $\begin{array}{l}x(4) \\
x(4)\end{array}$ & $\begin{array}{l}73 \\
55\end{array}$ & $\begin{array}{l}83 \\
67\end{array}$ & $\begin{array}{l}x(5) \\
x(5)\end{array}$ & $\begin{array}{l}82 \\
81\end{array}$ & $\begin{array}{l}88 \\
77\end{array}$ & $\begin{array}{l}76 \\
61\end{array}$ \\
\hline Slowenien & $\begin{array}{l}\text { Männer } \\
\text { Frauen }\end{array}$ & $\begin{array}{l}27 \\
17\end{array}$ & $\begin{array}{l}59 \\
42\end{array}$ & $\begin{array}{l}\mathrm{a} \\
\mathrm{a}\end{array}$ & $\begin{array}{l}71 \\
60\end{array}$ & $\begin{array}{l}77 \\
69\end{array}$ & $\begin{array}{l}\mathrm{a} \\
\mathrm{a}\end{array}$ & $\begin{array}{l}84 \\
83\end{array}$ & $\begin{array}{l}90 \\
88\end{array}$ & $\begin{array}{l}74 \\
67\end{array}$ \\
\hline Spanien & $\begin{array}{l}\text { Männer } \\
\text { Frauen }\end{array}$ & $\begin{array}{l}49 \\
31\end{array}$ & $\begin{array}{l}69 \\
50\end{array}$ & $\begin{array}{l}\mathrm{a} \\
\mathrm{a}\end{array}$ & $\begin{array}{l}76 \\
60\end{array}$ & $\begin{array}{l}73 \\
61\end{array}$ & $\begin{array}{l}\mathrm{c} \\
\mathrm{c}\end{array}$ & $\begin{array}{l}80 \\
69\end{array}$ & $\begin{array}{l}83 \\
78\end{array}$ & $\begin{array}{l}71 \\
57\end{array}$ \\
\hline Schweden & $\begin{array}{l}\text { Männer } \\
\text { Frauen }\end{array}$ & $\begin{array}{l}61 \\
37\end{array}$ & $\begin{array}{l}79 \\
62\end{array}$ & $\begin{array}{l}\mathrm{a} \\
\mathrm{a}\end{array}$ & $\begin{array}{l}x(5) \\
x(5)\end{array}$ & $\begin{array}{l}87 \\
80\end{array}$ & $\begin{array}{l}87 \\
80\end{array}$ & $\begin{array}{l}86 \\
83\end{array}$ & $\begin{array}{l}91 \\
89\end{array}$ & $\begin{array}{l}86 \\
80\end{array}$ \\
\hline Schweiz & $\begin{array}{l}\text { Männer } \\
\text { Frauen }\end{array}$ & $\begin{array}{l}75 \\
58\end{array}$ & $\begin{array}{l}79 \\
62\end{array}$ & $\begin{array}{l}82 \\
66\end{array}$ & $\begin{array}{l}89 \\
77\end{array}$ & $\begin{array}{l}83 \\
72\end{array}$ & $\begin{array}{l}91 \\
83\end{array}$ & $\begin{array}{l}96 \\
86\end{array}$ & $\begin{array}{l}93 \\
80\end{array}$ & $\begin{array}{l}90 \\
76\end{array}$ \\
\hline Türkei & $\begin{array}{l}\text { Männer } \\
\text { Frauen }\end{array}$ & $\begin{array}{l}74 \\
26\end{array}$ & $\begin{array}{l}79 \\
23\end{array}$ & $\begin{array}{l}a \\
a\end{array}$ & $\begin{array}{l}83 \\
32\end{array}$ & $\begin{array}{l}80 \\
28\end{array}$ & $\begin{array}{l}a \\
a\end{array}$ & $\begin{array}{l}x(8) \\
x(8)\end{array}$ & $\begin{array}{l}84 \\
64\end{array}$ & $\begin{array}{l}78 \\
31\end{array}$ \\
\hline Vereinigtes Königreich & $\begin{array}{l}\text { Männer } \\
\text { Frauen }\end{array}$ & $\begin{array}{l}\mathrm{C} \\
\mathrm{C}\end{array}$ & $\begin{array}{l}55 \\
34\end{array}$ & $\begin{array}{l}75 \\
58\end{array}$ & $\begin{array}{l}83 \\
73\end{array}$ & $\begin{array}{l}82 \\
73\end{array}$ & $\begin{array}{l}\mathrm{C} \\
\mathrm{C}\end{array}$ & $\begin{array}{l}87 \\
77\end{array}$ & $\begin{array}{l}88 \\
79\end{array}$ & $\begin{array}{l}81 \\
69\end{array}$ \\
\hline Vereinigte Staaten & $\begin{array}{l}\text { Männer } \\
\text { Frauen }\end{array}$ & $\begin{array}{l}66 \\
37\end{array}$ & $\begin{array}{l}58 \\
41\end{array}$ & $\begin{array}{l}x(5) \\
x(5)\end{array}$ & $\begin{array}{l}x(5) \\
x(5)\end{array}$ & $\begin{array}{l}72 \\
62\end{array}$ & $\begin{array}{l}x(5) \\
x(5)\end{array}$ & $\begin{array}{l}79 \\
74\end{array}$ & $\begin{array}{l}86 \\
76\end{array}$ & $\begin{array}{l}76 \\
66\end{array}$ \\
\hline OECD-Durchschnitt & $\begin{array}{l}\text { Männer } \\
\text { Frauen }\end{array}$ & $\begin{array}{l}59 \\
37\end{array}$ & $\begin{array}{l}69 \\
48\end{array}$ & $\begin{array}{l}\mathbf{m} \\
\mathbf{m}\end{array}$ & $\begin{array}{l}81 \\
64\end{array}$ & $\begin{array}{l}80 \\
65\end{array}$ & $\begin{array}{l}85 \\
75\end{array}$ & $\begin{array}{l}86 \\
77\end{array}$ & $\begin{array}{l}88 \\
79\end{array}$ & $\begin{array}{l}80 \\
65\end{array}$ \\
\hline EU21-Durchschnitt & $\begin{array}{l}\text { Männer } \\
\text { Frauen }\end{array}$ & $\begin{array}{l}52 \\
35\end{array}$ & $\begin{array}{l}66 \\
47\end{array}$ & $\begin{array}{l}\mathrm{m} \\
\mathrm{m}\end{array}$ & $\begin{array}{l}79 \\
64\end{array}$ & $\begin{array}{l}79 \\
67\end{array}$ & $\begin{array}{l}84 \\
73\end{array}$ & $\begin{array}{l}84 \\
78\end{array}$ & $\begin{array}{l}88 \\
81\end{array}$ & $\begin{array}{l}78 \\
66\end{array}$ \\
\hline Sonstige G20-Länder & & & & & & & & & & \\
\hline Argentinien & & m & $\mathrm{m}$ & $\mathrm{m}$ & $\mathrm{m}$ & $\mathrm{m}$ & $\mathrm{m}$ & $\mathrm{m}$ & $\mathrm{m}$ & $\mathrm{m}$ \\
\hline Brasilien & $\begin{array}{l}\text { Männer } \\
\text { Frauen }\end{array}$ & $\begin{array}{l}83 \\
48\end{array}$ & $\begin{array}{l}87 \\
57\end{array}$ & $\begin{array}{l}x(5) \\
x(5)\end{array}$ & $\begin{array}{l}x(5) \\
x(5)\end{array}$ & $\begin{array}{l}89 \\
54\end{array}$ & $\begin{array}{l}a \\
a\end{array}$ & $\begin{array}{l}x(8) \\
x(8)\end{array}$ & $\begin{array}{l}92 \\
81\end{array}$ & $\begin{array}{l}86 \\
55\end{array}$ \\
\hline China & & $\mathrm{m}$ & $\mathrm{m}$ & $\mathrm{m}$ & $\mathrm{m}$ & $\mathrm{m}$ & $\mathrm{m}$ & $\mathrm{m}$ & $\mathrm{m}$ & $\mathrm{m}$ \\
\hline Indien & & $\mathrm{m}$ & $\mathrm{m}$ & $\mathrm{m}$ & $\mathrm{m}$ & $\mathrm{m}$ & $\mathrm{m}$ & $\mathrm{m}$ & $\mathrm{m}$ & $\mathrm{m}$ \\
\hline Indonesien & & $\mathrm{m}$ & $\mathrm{m}$ & $\mathrm{m}$ & $\mathrm{m}$ & $\mathrm{m}$ & $\mathrm{m}$ & $\mathrm{m}$ & $\mathrm{m}$ & $\mathrm{m}$ \\
\hline Russische Föderation & $\begin{array}{l}\text { Männer } \\
\text { Frauen }\end{array}$ & $\begin{array}{r}33 \\
\mathrm{c}\end{array}$ & $\begin{array}{l}60 \\
43\end{array}$ & $\begin{array}{l}x(4) \\
x(4)\end{array}$ & $\begin{array}{l}82 \\
71\end{array}$ & $\begin{array}{l}76 \\
60\end{array}$ & $\begin{array}{l}x(4) \\
x(4)\end{array}$ & $\begin{array}{l}86 \\
75\end{array}$ & $\begin{array}{l}90 \\
83\end{array}$ & $\begin{array}{l}82 \\
72\end{array}$ \\
\hline Saudi-Arabien & & $\mathrm{m}$ & $\mathrm{m}$ & $\mathrm{m}$ & $\mathrm{m}$ & $\mathrm{m}$ & $\mathrm{m}$ & $\mathrm{m}$ & $\mathrm{m}$ & $\mathrm{m}$ \\
\hline Südafrika & & $\mathrm{m}$ & $\mathrm{m}$ & $\mathrm{m}$ & $\mathrm{m}$ & $\mathrm{m}$ & $\mathrm{m}$ & $\mathrm{m}$ & $\mathrm{m}$ & $\mathrm{m}$ \\
\hline G20-Durchschnitt & Männer & $\mathbf{m}$ & m & m & $\mathbf{m}$ & $\mathbf{m}$ & $\mathbf{m}$ & m & $\mathbf{m}$ & $\mathbf{m}$ \\
\hline
\end{tabular}

Quelle: OECD. Arbeitskräfteerhebung des Netzwerks zu den Arbeitsmarktergebnissen sowie den wirtschaftlichen und sozialen Auswirkungen des Lernens (LSO) für die meisten Länder sowie Arbeitskräfteerhebung der EU (EU-LFS) für Dänemark, Finnland, Island, Irland, Luxemburg und Slowenien.

Hinweise s. Anhang 3 unter www.oecd.org/edu/eag.htm. StatLink: http://dx.doi.org/10.1787/888932848571

Erläuterung der Kennzeichnung fehlender Daten s. Hinweise für den Leser. 
Erwerbslosenquoten 25- bis 64- Jähriger, nach Bildungsstand (2011)

Zahl der 25- bis 64-jährigen Erwerbslosen als Prozentsatz aller 25- bis 64-jährigen Erwerbspersonen

\begin{tabular}{|c|c|c|c|c|c|c|c|c|c|}
\hline & \multirow{2}{*}{$\begin{array}{l}\text { Ausbildung } \\
\text { im Elemen- } \\
\text { tar- und } \\
\text { Primar- } \\
\text { bereich }\end{array}$} & \multirow{2}{*}{$\begin{array}{c}\text { Abschluss im } \\
\text { Sekundar- } \\
\text { bereich I }\end{array}$} & \multirow[t]{2}{*}{$\begin{array}{c}\text { ISCED 3C } \\
\text { (kurz) }\end{array}$} & \multicolumn{2}{|c|}{$\begin{array}{c}\text { Abschluss im } \\
\text { Sekundarbereich II }\end{array}$} & \multirow{2}{*}{\begin{tabular}{|} 
Abschluss im \\
postsekun- \\
daren, nicht \\
tertiären \\
Bereich
\end{tabular}} & \multicolumn{2}{|c|}{$\begin{array}{l}\text { Abschluss im } \\
\text { Tertiärbereich }\end{array}$} & \multirow{2}{*}{$\begin{array}{c}\text { Alle } \\
\text { Bildungs- } \\
\text { bereiche } \\
\text { zusammen }\end{array}$} \\
\hline & & & & $\begin{array}{r}\text { ISCED 3C } \\
\text { (lang)/3B }\end{array}$ & ISCED $3 \mathrm{~A}$ & & $\begin{array}{c}\text { Tertiär- } \\
\text { bereich } \mathrm{B}\end{array}$ & $\begin{array}{c}\text { Tertiär- } \\
\text { bereich A/ } \\
\text { weiter- } \\
\text { führender } \\
\text { forschungs- } \\
\text { orientierter } \\
\text { Studiengang }\end{array}$ & \\
\hline & (1) & (2) & (3) & (4) & (5) & (6) & (7) & (8) & (9) \\
\hline \multicolumn{10}{|l|}{ OECD-Länder } \\
\hline Australien & 8,2 & 5,3 & a & 3,3 & 4,1 & 4,3 & 3,1 & 2,7 & 3,8 \\
\hline Österreich & $x(2)$ & 7,6 & c & 3,3 & 4,4 & 2,3 & $1,1^{r}$ & 2,9 & 3,5 \\
\hline Belgien & 15,0 & 10,5 & a & 6,4 & 5,7 & $3,5^{r}$ & 2,8 & 4,0 & 6,1 \\
\hline Kanada & 14,6 & 10,9 & a & $x(5)$ & 7,1 & 6,6 & 5,3 & 4,7 & 6,3 \\
\hline Chile & 4,3 & 4,5 & a & $x(5)$ & 5,0 & a & 4,7 & 5,9 & 5,0 \\
\hline Tschechien & c & 21,4 & a & 7,1 & 4,2 & $x(8)$ & $x(8)$ & 2,6 & 5,9 \\
\hline Dänemark & c & 9,0 & c & 5,9 & 6,3 & c & 7,0 & 4,7 & 6,2 \\
\hline Estland & c & 25,5 & $a$ & 13,3 & 11,8 & 9,4 & 9,3 & 7,3 & 11,6 \\
\hline Finnland & 10,0 & 11,9 & a & a & 7,0 & c & 3,6 & 4,1 & 6,2 \\
\hline Frankreich & 14,1 & 12,4 & $a$ & 7,6 & 6,9 & 6,7 & 4,2 & 5,3 & 7,8 \\
\hline Deutschland & 17,8 & 12,9 & a & 6,1 & 7,4 & 3,9 & 2,3 & 2,6 & 5,7 \\
\hline Griechenland & 16,6 & 17,9 & $x(4)$ & 19,4 & 16,4 & 19,6 & 16,2 & 11,4 & 16,0 \\
\hline Ungarn & 50,0 & 22,1 & a & 11,5 & 7,7 & 8,8 & c & 3,8 & 9,9 \\
\hline Island & 7,8 & c & a & 4,7 & 7,6 & c & c & 4,9 & 5,6 \\
\hline Irland & 23,4 & 21,0 & $\mathrm{c}$ & $x(5)$ & 13,4 & 17,7 & 8,8 & 6,1 & 12,9 \\
\hline Israel & 8,0 & 6,7 & $a$ & 6,2 & 5,7 & $a$ & 4,3 & 3,7 & 5,0 \\
\hline Italien & 12,4 & 8,8 & 12,5 & 5,9 & 5,9 & 9,2 & 7,0 & 5,1 & 7,0 \\
\hline Japan & $x(5)$ & $x(5)$ & $x(5)$ & $x(5)$ & 5,3 & a & 3,9 & 3,0 & 4,4 \\
\hline Korea & 2,2 & 3,0 & a & $x(5)$ & 3,4 & a & 3,8 & 2,6 & 3,1 \\
\hline Luxemburg & $6,5^{r}$ & $6,3^{r}$ & c & $4,2^{r}$ & $3,7^{r}$ & c & $2,7^{r}$ & 3,9 & 4,1 \\
\hline Mexiko & 3,9 & 4,1 & a & 3,5 & 4,8 & a & 2,7 & 4,9 & 4,3 \\
\hline Niederlande & 5,0 & 4,2 & $x(4)$ & 4,3 & 3,0 & 0,0 & 0,0 & 2,7 & 3,2 \\
\hline Neuseeland & $x(2)$ & 7,5 & 4,2 & 6,1 & 3,4 & 3,3 & 4,9 & 2,7 & 4,5 \\
\hline Norwegen & c & 5,0 & $a$ & 1,7 & 3,5 & c & c & 1,5 & 2,3 \\
\hline Polen & $x(2)$ & 16,9 & $a$ & 10,0 & 7,7 & 8,0 & $x(8)$ & 4,5 & 8,1 \\
\hline Portugal & 13,0 & 13,9 & $x(5)$ & $x(5)$ & 10,9 & c & $x(8)$ & 8,0 & 11,8 \\
\hline Slowakei & 2,5 & 38,5 & $x(4)$ & 15,3 & 8,4 & $a$ & c & 5,2 & 11,8 \\
\hline Slowenien & 25,8 & 11,9 & a & 9,1 & 7,5 & a & 4,8 & 4,7 & 7,6 \\
\hline Spanien & 30,6 & 24,5 & $a$ & 19,2 & 19,3 & c & 14,6 & 10,4 & 19,5 \\
\hline Schweden & 18,7 & 8,2 & $a$ & $x(5)$ & 5,1 & 5,4 & 4,8 & 3,5 & 5,3 \\
\hline Schweiz & 8,2 & 7,5 & 7,0 & 3,2 & 4,9 & 2,6 & 1,7 & 3,0 & 3,5 \\
\hline Türkei & 8,1 & 9,8 & $a$ & 8,1 & 9,6 & $x(8)$ & $x(8)$ & 7,6 & 8,4 \\
\hline Vereinigtes Königreich & c & 14,6 & 9,0 & 6,2 & 4,6 & c & 3,7 & 3,9 & 6,0 \\
\hline Vereinigte Staaten & 13,2 & 17,9 & $x(5)$ & $x(5)$ & 10,2 & $x(5)$ & 6,5 & 4,4 & 8,3 \\
\hline OECD-Durchschnitt & 13,6 & 12,6 & m & $\mathbf{7 , 7}$ & 7,1 & 6,9 & 5,1 & 4,7 & 7,1 \\
\hline EU21-Durchschnitt & 17,4 & 15,2 & m & 9,1 & 8,0 & 7,9 & 5,8 & 5,1 & 8,4 \\
\hline \multicolumn{10}{|l|}{ Sonstige G20-Länder } \\
\hline Argentinien & $\mathrm{m}$ & $\mathrm{m}$ & $\mathrm{m}$ & $\mathrm{m}$ & $\mathrm{m}$ & $\mathrm{m}$ & $\mathrm{m}$ & $\mathrm{m}$ & $\mathrm{m}$ \\
\hline Brasilien & 4,2 & 5,5 & $x(5)$ & $\mathrm{m}$ & 6,1 & a & $x(8)$ & 2,9 & 4,8 \\
\hline China & $\mathrm{m}$ & $\mathrm{m}$ & $\mathrm{m}$ & $\mathrm{m}$ & $\mathrm{m}$ & $\mathrm{m}$ & $\mathrm{m}$ & $\mathrm{m}$ & $\mathrm{m}$ \\
\hline Indien & $\mathrm{m}$ & $\mathrm{m}$ & $\mathrm{m}$ & $\mathrm{m}$ & $\mathrm{m}$ & $\mathrm{m}$ & $\mathrm{m}$ & $\mathrm{m}$ & $\mathrm{m}$ \\
\hline Indonesien & $\mathrm{m}$ & $\mathrm{m}$ & $\mathrm{m}$ & $\mathrm{m}$ & $\mathrm{m}$ & $\mathrm{m}$ & $\mathrm{m}$ & $\mathrm{m}$ & $\mathrm{m}$ \\
\hline Russische Föderation & c & 14,0 & $x(4)$ & 6,1 & 8,5 & $x(4)$ & 4,4 & 2,9 & 5,5 \\
\hline Saudi-Arabien & $\mathrm{m}$ & $\mathrm{m}$ & $\mathrm{m}$ & $\mathrm{m}$ & $\mathrm{m}$ & $\mathrm{m}$ & $\mathrm{m}$ & $\mathrm{m}$ & $\mathrm{m}$ \\
\hline Südafrika & $\mathrm{m}$ & $\mathrm{m}$ & $\mathrm{m}$ & $\mathrm{m}$ & $\mathrm{m}$ & $\mathrm{m}$ & $\mathrm{m}$ & $\mathrm{m}$ & $\mathrm{m}$ \\
\hline G20-Durchschnitt & $\mathbf{m}$ & $\mathbf{m}$ & $\mathbf{m}$ & $\mathbf{m}$ & $\mathbf{m}$ & $\mathbf{m}$ & $\mathbf{m}$ & $\mathbf{m}$ & $\mathbf{m}$ \\
\hline
\end{tabular}

Quelle: OECD. Arbeitskräfteerhebung des Netzwerks zu den Arbeitsmarktergebnissen sowie den wirtschaftlichen und sozialen Auswirkungen des Lernens (LSO) für die meisten Länder sowie Arbeitskräfteerhebung der EU (EU-LFS) für Dänemark, Finnland, Island, Irland, Luxemburg und Slowenien. Hinweise s. Anhang 3 unter www.oecd.org/edu/eag.htm. StatLink: http://dx.doi.org/10.1787/888932848590 Erläuterung der Kennzeichnung fehlender Daten s. Hinweise für den Leser. 
Tabelle A5.2b

Erwerbslosenquoten 25- bis 64- Jähriger, nach Bildungsstand und Geschlecht (2011)

Zahl der 25- bis 64-jährigen Erwerbslosen als Prozentsatz aller 25- bis 64-jährigen Erwerbspersonen

\begin{tabular}{|c|c|c|c|c|c|c|c|c|c|c|}
\hline & & \multirow{2}{*}{$\begin{array}{l}\text { Ausbildung } \\
\text { im Elemen- } \\
\text { tar- und } \\
\text { Primar- } \\
\text { bereich }\end{array}$} & \multirow{2}{*}{$\begin{array}{c}\text { Abschluss } \\
\text { im Sekun- } \\
\text { darbereich I }\end{array}$} & \multirow[t]{2}{*}{$\begin{array}{c}\text { ISCED 3C } \\
\text { (kurz) }\end{array}$} & \multicolumn{2}{|c|}{$\begin{array}{c}\text { Abschluss im } \\
\text { Sekundarbereich II }\end{array}$} & \multirow{2}{*}{$\begin{array}{c}\text { Abschluss } \\
\text { im postse- } \\
\text { kundaren, } \\
\text { nicht } \\
\text { tertiären } \\
\text { Bereich }\end{array}$} & \multicolumn{2}{|c|}{$\begin{array}{l}\text { Abschluss im } \\
\text { Tertiärbereich }\end{array}$} & \multirow{2}{*}{$\begin{array}{c}\text { Alle } \\
\text { Bildungs- } \\
\text { bereiche } \\
\text { zusammen }\end{array}$} \\
\hline & & & & & $\begin{array}{l}\text { ISCED 3C } \\
\text { (lang)/3B }\end{array}$ & ISCED $3 A$ & & $\begin{array}{c}\text { Tertiär- } \\
\text { bereich B }\end{array}$ & \begin{tabular}{|c|} 
Tertiär- \\
bereich A/ \\
weiter- \\
führender \\
forschungs- \\
orientierter \\
Studiengang
\end{tabular} & \\
\hline & & (1) & (2) & (3) & (4) & (5) & (6) & (7) & (8) & (9) \\
\hline \multicolumn{11}{|l|}{ OECD-Länder } \\
\hline Australien & $\begin{array}{l}\text { Männer } \\
\text { Frauen }\end{array}$ & $\begin{array}{l}7,8 \\
9,0\end{array}$ & $\begin{array}{l}5,3 \\
5,3\end{array}$ & $\begin{array}{l}\mathrm{a} \\
\mathrm{a}\end{array}$ & $\begin{array}{l}2,3 \\
6,0\end{array}$ & $\begin{array}{l}3,9 \\
4,4\end{array}$ & $\begin{array}{r}3,9^{r} \\
4,6\end{array}$ & $\begin{array}{l}2,5 \\
3,6\end{array}$ & $\begin{array}{l}2,4 \\
2,9\end{array}$ & $\begin{array}{l}3,5 \\
4,2\end{array}$ \\
\hline Österreich & $\begin{array}{l}\text { Männer } \\
\text { Frauen }\end{array}$ & $\begin{array}{l}x(2) \\
x(2)\end{array}$ & $\begin{array}{l}8,8 \\
6,6\end{array}$ & $\begin{array}{l}\mathrm{c} \\
\mathrm{c}\end{array}$ & $\begin{array}{l}3,2 \\
3,4\end{array}$ & $\begin{array}{l}4,6^{r} \\
4,1^{r}\end{array}$ & $\begin{array}{l}2,4^{r} \\
2,3^{r}\end{array}$ & $\begin{array}{l}\mathrm{c} \\
\mathrm{c}\end{array}$ & $\begin{array}{l}2,5 \\
3,4\end{array}$ & $\begin{array}{l}3,5 \\
3,6\end{array}$ \\
\hline Belgien & $\begin{array}{l}\text { Männer } \\
\text { Frauen }\end{array}$ & $\begin{array}{l}16,2 \\
13,2\end{array}$ & $\begin{array}{r}9,8 \\
11,6\end{array}$ & $\begin{array}{l}\mathrm{a} \\
\mathrm{a}\end{array}$ & $\begin{array}{l}5,7 \\
7,2\end{array}$ & $\begin{array}{l}4,8 \\
6,8\end{array}$ & $\begin{array}{l}\mathrm{c} \\
\mathrm{c}\end{array}$ & $\begin{array}{l}3,2 \\
2,5\end{array}$ & $\begin{array}{l}3,7 \\
4,4\end{array}$ & $\begin{array}{l}6,1 \\
6,1\end{array}$ \\
\hline Kanada & $\begin{array}{l}\text { Männer } \\
\text { Frauen }\end{array}$ & $\begin{array}{l}13,5 \\
16,8\end{array}$ & $\begin{array}{l}10,5 \\
11,4\end{array}$ & $\begin{array}{l}a \\
a\end{array}$ & $\begin{array}{l}x(5) \\
x(5)\end{array}$ & $\begin{array}{l}7,3 \\
6,7\end{array}$ & $\begin{array}{l}6,8 \\
6,0\end{array}$ & $\begin{array}{l}5,1 \\
5,4\end{array}$ & $\begin{array}{l}4,8 \\
4,7\end{array}$ & $\begin{array}{l}6,5 \\
6,0\end{array}$ \\
\hline Chile & $\begin{array}{l}\text { Männer } \\
\text { Frauen }\end{array}$ & $\begin{array}{l}3,8 \\
5,2\end{array}$ & $\begin{array}{l}3,0 \\
6,8\end{array}$ & $\begin{array}{l}\mathrm{a} \\
\mathrm{a}\end{array}$ & $\begin{array}{l}x(5) \\
x(5)\end{array}$ & $\begin{array}{l}4,0 \\
6,4\end{array}$ & $\begin{array}{l}a \\
a\end{array}$ & $\begin{array}{l}3,8 \\
5,7\end{array}$ & $\begin{array}{l}5,2 \\
6,8\end{array}$ & $\begin{array}{l}4,0 \\
6,3\end{array}$ \\
\hline Tschechien & $\begin{array}{l}\text { Männer } \\
\text { Frauen }\end{array}$ & $\begin{array}{l}\mathrm{c} \\
\mathrm{c}\end{array}$ & $\begin{array}{l}23,5 \\
20,0\end{array}$ & $\begin{array}{l}a \\
a\end{array}$ & $\begin{array}{r}5,5 \\
10,2\end{array}$ & $\begin{array}{l}3,1 \\
5,1\end{array}$ & $\begin{array}{l}x(8) \\
x(8)\end{array}$ & $\begin{array}{l}x(8) \\
x(8)\end{array}$ & $\begin{array}{l}2,4 \\
2,9\end{array}$ & $\begin{array}{l}4,9 \\
7,3\end{array}$ \\
\hline Dänemark & $\begin{array}{l}\text { Männer } \\
\text { Frauen }\end{array}$ & $\begin{array}{l}\mathrm{c} \\
\mathrm{c}\end{array}$ & $\begin{array}{l}9,0 \\
9,0\end{array}$ & $\begin{array}{l}\mathrm{c} \\
\mathrm{c}\end{array}$ & $\begin{array}{l}6,0 \\
5,8\end{array}$ & $\begin{array}{l}5,8 \\
6,9\end{array}$ & $\begin{array}{l}\mathrm{n} \\
\mathrm{c}\end{array}$ & $\begin{array}{l}6,5 \\
7,6\end{array}$ & $\begin{array}{l}4,3 \\
5,0\end{array}$ & $\begin{array}{l}6,2 \\
6,2\end{array}$ \\
\hline Estland & $\begin{array}{l}\text { Männer } \\
\text { Frauen }\end{array}$ & $\begin{array}{l}\mathrm{c} \\
\mathrm{c}\end{array}$ & $\begin{array}{l}27,0 \\
22,7\end{array}$ & $\begin{array}{l}a \\
a\end{array}$ & $\begin{array}{l}11,6 \\
16,6\end{array}$ & $\begin{array}{l}11,4 \\
12,2\end{array}$ & $\begin{array}{c}9,7^{r} \\
9,2\end{array}$ & $\begin{array}{r}7,6^{r} \\
10,0\end{array}$ & $\begin{array}{l}6,6 \\
7,7\end{array}$ & $\begin{array}{l}12,0 \\
11,2\end{array}$ \\
\hline Finnland & $\begin{array}{l}\text { Männer } \\
\text { Frauen }\end{array}$ & $\begin{array}{r}9,9 \\
10,0\end{array}$ & $\begin{array}{l}11,9 \\
12,0\end{array}$ & $\begin{array}{l}\mathrm{a} \\
\mathrm{a}\end{array}$ & $\begin{array}{l}\mathrm{a} \\
\mathrm{a}\end{array}$ & $\begin{array}{l}7,4 \\
6,5\end{array}$ & $\begin{array}{l}\mathrm{c} \\
\mathrm{c}\end{array}$ & $\begin{array}{l}4,8 \\
2,9\end{array}$ & $\begin{array}{l}4,1 \\
4,2\end{array}$ & $\begin{array}{l}6,8 \\
5,5\end{array}$ \\
\hline Frankreich & $\begin{array}{l}\text { Männer } \\
\text { Frauen }\end{array}$ & $\begin{array}{l}14,4 \\
13,8\end{array}$ & $\begin{array}{l}11,7 \\
13,2\end{array}$ & $\begin{array}{l}a \\
a\end{array}$ & $\begin{array}{l}6,5 \\
9,1\end{array}$ & $\begin{array}{l}6,8 \\
6,9\end{array}$ & $\begin{array}{l}\mathrm{c} \\
\mathrm{c}\end{array}$ & $\begin{array}{l}4,3 \\
4,2\end{array}$ & $\begin{array}{l}4,9 \\
5,7\end{array}$ & $\begin{array}{l}7,4 \\
8,3\end{array}$ \\
\hline Deutschland & $\begin{array}{l}\text { Männer } \\
\text { Frauen }\end{array}$ & $\begin{array}{l}18,1 \\
17,4\end{array}$ & $\begin{array}{l}14,9 \\
11,0\end{array}$ & $\begin{array}{l}a \\
a\end{array}$ & $\begin{array}{l}6,4 \\
5,7\end{array}$ & $\begin{array}{l}7,3 \\
7,7\end{array}$ & $\begin{array}{l}4,4 \\
3,5\end{array}$ & $\begin{array}{l}2,1 \\
2,4\end{array}$ & $\begin{array}{l}2,4 \\
2,9\end{array}$ & $\begin{array}{l}5,9 \\
5,4\end{array}$ \\
\hline Griechenland & $\begin{array}{l}\text { Männer } \\
\text { Frauen }\end{array}$ & $\begin{array}{l}16,8 \\
16,4\end{array}$ & $\begin{array}{l}15,9 \\
22,0\end{array}$ & $\begin{array}{l}x(4) \\
x(4)\end{array}$ & $\begin{array}{l}15,3 \\
34,8\end{array}$ & $\begin{array}{l}13,0 \\
20,3\end{array}$ & $\begin{array}{l}14,5 \\
24,7\end{array}$ & $\begin{array}{l}12,9 \\
20,3\end{array}$ & $\begin{array}{r}8,9 \\
14,0\end{array}$ & $\begin{array}{l}13_{r} 7 \\
19,3\end{array}$ \\
\hline Ungarn & $\begin{array}{l}\text { Männer } \\
\text { Frauen }\end{array}$ & $\begin{array}{l}43,5 \\
56,0\end{array}$ & $\begin{array}{l}22,0 \\
22,2\end{array}$ & $\begin{array}{l}a \\
a\end{array}$ & $\begin{array}{l}11,2 \\
12,1\end{array}$ & $\begin{array}{l}6,8 \\
8,5\end{array}$ & $\begin{array}{r}7,1 \\
10,8\end{array}$ & $\begin{array}{l}\mathrm{c} \\
\mathrm{c}\end{array}$ & $\begin{array}{l}3,8 \\
3,9\end{array}$ & $\begin{array}{r}9,8 \\
10,0\end{array}$ \\
\hline Island & $\begin{array}{l}\text { Männer } \\
\text { Frauen }\end{array}$ & $\begin{array}{l}7,9 \\
7,6\end{array}$ & $\begin{array}{l}\mathrm{c} \\
\mathrm{c}\end{array}$ & $\begin{array}{l}\mathrm{c} \\
\mathrm{c}\end{array}$ & $\begin{array}{l}\mathrm{c} \\
\mathrm{c}\end{array}$ & $\begin{array}{l}\mathrm{c} \\
\mathrm{c}\end{array}$ & $\begin{array}{l}\mathrm{c} \\
\mathrm{c}\end{array}$ & $\begin{array}{l}\mathrm{c} \\
\mathrm{c}\end{array}$ & $\begin{array}{l}5,5 \\
4,5\end{array}$ & $\begin{array}{l}5,9 \\
5,3\end{array}$ \\
\hline Irland & $\begin{array}{l}\text { Männer } \\
\text { Frauen }\end{array}$ & $\begin{array}{l}27,2 \\
14,8\end{array}$ & $\begin{array}{l}24,2 \\
14,0\end{array}$ & $\begin{array}{r}23,6 \\
c\end{array}$ & $\begin{array}{l}x(5) \\
x(5)\end{array}$ & $\begin{array}{l}15,6 \\
10,6\end{array}$ & $\begin{array}{l}21,5 \\
12,2\end{array}$ & $\begin{array}{r}10,3 \\
7,5\end{array}$ & $\begin{array}{l}6,6 \\
5,6\end{array}$ & $\begin{array}{r}16,0 \\
9,2\end{array}$ \\
\hline Israel & $\begin{array}{l}\text { Männer } \\
\text { Frauen }\end{array}$ & $\begin{array}{l}8,7 \\
6,2\end{array}$ & $\begin{array}{l}7,1 \\
5,7\end{array}$ & $\begin{array}{l}\mathrm{a} \\
\mathrm{a}\end{array}$ & $\begin{array}{l}5,7 \\
7,0\end{array}$ & $\begin{array}{l}5,6 \\
5,7\end{array}$ & $\begin{array}{l}a \\
a\end{array}$ & $\begin{array}{l}3,8 \\
4,7\end{array}$ & $\begin{array}{l}3,5 \\
3,9\end{array}$ & $\begin{array}{l}5,0 \\
4,9\end{array}$ \\
\hline Italien & $\begin{array}{l}\text { Männer } \\
\text { Frauen }\end{array}$ & $\begin{array}{l}12,0 \\
13,3\end{array}$ & $\begin{array}{r}7,8 \\
10,9\end{array}$ & $\begin{array}{l}12,0 \\
12,9\end{array}$ & $\begin{array}{l}5,1 \\
7,0\end{array}$ & $\begin{array}{l}5,0 \\
7,1\end{array}$ & $\begin{array}{l}8,8 \\
9,4\end{array}$ & $\begin{array}{l}8,7 \\
5,5\end{array}$ & $\begin{array}{l}3,8 \\
6,3\end{array}$ & $\begin{array}{l}6,3 \\
8,1\end{array}$ \\
\hline Japan & $\begin{array}{l}\text { Männer } \\
\text { Frauen }\end{array}$ & $\begin{array}{l}x(5) \\
x(5)\end{array}$ & $\begin{array}{l}x(5) \\
x(5)\end{array}$ & $\begin{array}{l}x(5) \\
x(5)\end{array}$ & $\begin{array}{l}x(5) \\
x(5)\end{array}$ & $\begin{array}{l}5,8 \\
4,7\end{array}$ & $\begin{array}{l}a \\
a\end{array}$ & $\begin{array}{l}4,1 \\
3,8\end{array}$ & $\begin{array}{l}3,1 \\
2,9\end{array}$ & $\begin{array}{l}4,6 \\
4,1\end{array}$ \\
\hline Korea & $\begin{array}{l}\text { Männer } \\
\text { Frauen }\end{array}$ & $\begin{array}{l}3,2 \\
1,4\end{array}$ & $\begin{array}{l}3,9 \\
2,0\end{array}$ & $\begin{array}{l}a \\
a\end{array}$ & $\begin{array}{l}x(5) \\
x(5)\end{array}$ & $\begin{array}{l}3,7 \\
2,9\end{array}$ & $\begin{array}{l}a \\
a\end{array}$ & $\begin{array}{l}3,6 \\
4,0\end{array}$ & $\begin{array}{l}2,6 \\
2,5\end{array}$ & $\begin{array}{l}3,3 \\
2,7\end{array}$ \\
\hline Luxemburg & $\begin{array}{l}\text { Männer } \\
\text { Frauen }\end{array}$ & $\begin{array}{l}5,5 \\
7,6\end{array}$ & $\begin{array}{r}c \\
8,6\end{array}$ & $\begin{array}{l}c \\
c\end{array}$ & $\begin{array}{l}2,6^{r} \\
6,9^{r}\end{array}$ & $\begin{array}{l}3,8^{r} \\
3,6^{r}\end{array}$ & $\begin{array}{l}\mathrm{c} \\
\mathrm{c}\end{array}$ & $\begin{array}{r}c \\
3,5^{r}\end{array}$ & $\begin{array}{l}3,2 \\
5,0\end{array}$ & $\begin{array}{l}3,3 \\
5,2\end{array}$ \\
\hline Mexiko & $\begin{array}{l}\text { Männer } \\
\text { Frauen }\end{array}$ & $\begin{array}{l}4,4 \\
3,2\end{array}$ & $\begin{array}{l}3,9 \\
4,4\end{array}$ & $\begin{array}{l}a \\
a\end{array}$ & $\begin{array}{l}3,4 \\
3,6\end{array}$ & $\begin{array}{l}4,5 \\
5,3\end{array}$ & $\begin{array}{l}a \\
a\end{array}$ & $\begin{array}{l}4,0 \\
1,8\end{array}$ & $\begin{array}{l}4,8 \\
5,2\end{array}$ & $\begin{array}{l}4,3 \\
4,2\end{array}$ \\
\hline Niederlande & $\begin{array}{l}\text { Männer } \\
\text { Frauen }\end{array}$ & $\begin{array}{l}6,6 \\
2,6\end{array}$ & $\begin{array}{l}3,9 \\
4,5\end{array}$ & $\begin{array}{l}x(4) \\
x(4)\end{array}$ & $\begin{array}{l}4,5 \\
4,0\end{array}$ & $\begin{array}{l}3,3 \\
2,7\end{array}$ & $\begin{array}{l}\mathrm{c} \\
\mathrm{c}\end{array}$ & $\begin{array}{l}\mathrm{c} \\
\mathrm{c}\end{array}$ & $\begin{array}{l}2,9 \\
2,5\end{array}$ & $\begin{array}{l}3,5 \\
3,0\end{array}$ \\
\hline Neuseeland & $\begin{array}{l}\text { Männer } \\
\text { Frauen }\end{array}$ & $\begin{array}{l}x(2) \\
x(2)\end{array}$ & $\begin{array}{l}7,3 \\
7,6\end{array}$ & $\begin{array}{l}3,5 \\
4,9\end{array}$ & $\begin{array}{l}5,4 \\
6,7\end{array}$ & $\begin{array}{l}3,2 \\
3,6\end{array}$ & $\begin{array}{l}3,0 \\
4,7\end{array}$ & $\begin{array}{l}4,2 \\
5,4\end{array}$ & $\begin{array}{l}2,4 \\
3,0\end{array}$ & $\begin{array}{l}4,1 \\
5,0\end{array}$ \\
\hline Norwegen & $\begin{array}{l}\text { Männer } \\
\text { Frauen }\end{array}$ & $\begin{array}{l}\mathrm{C} \\
\mathrm{C}\end{array}$ & $\begin{array}{l}5,5 \\
4,4\end{array}$ & $\begin{array}{l}a \\
a\end{array}$ & $\begin{array}{r}1,7 \\
\mathrm{C}\end{array}$ & $\begin{array}{l}\mathrm{c} \\
\mathrm{C}\end{array}$ & $\begin{array}{l}\mathrm{c} \\
\mathrm{c}\end{array}$ & $\begin{array}{l}\mathrm{c} \\
\mathrm{c}\end{array}$ & $\begin{array}{l}1,5 \\
1,5\end{array}$ & $\begin{array}{l}2,5 \\
2,2\end{array}$ \\
\hline Polen & $\begin{array}{l}\text { Männer } \\
\text { Frauen }\end{array}$ & $\begin{array}{l}x(2) \\
x(2)\end{array}$ & $\begin{array}{l}16,3 \\
17,8\end{array}$ & $\begin{array}{l}a \\
a\end{array}$ & $\begin{array}{r}9,0 \\
12,1\end{array}$ & $\begin{array}{l}6,3 \\
9,3\end{array}$ & $\begin{array}{c}5,4^{r} \\
9,2\end{array}$ & $\begin{array}{l}x(8) \\
x(8)\end{array}$ & $\begin{array}{l}3,9 \\
5,0\end{array}$ & $\begin{array}{l}7,5 \\
8,8\end{array}$ \\
\hline
\end{tabular}

Quelle: OECD. Arbeitskräfteerhebung des Netzwerks zu den Arbeitsmarktergebnissen sowie den wirtschaftlichen und sozialen Auswirkungen des Lernens (LSO) für die meisten Länder sowie Arbeitskräfteerhebung der EU (EU-LFS) für Dänemark, Finnland, Island, Irland, Luxemburg und Slowenien.

Hinweise s. Anhang 3 unter www.oecd.org/edu/eag.htm. StatLink: http://dx.doi.org/10.1787/888932848609

Erläuterung der Kennzeichnung fehlender Daten s. Hinweise für den Leser. 
Tabelle A5.2b (Forts.)

Erwerbslosenquoten 25- bis 64- Jähriger, nach Bildungsstand und Geschlecht (2011)

Zahl der 25- bis 64-jährigen Erwerbslosen als Prozentsatz aller 25- bis 64-jährigen Erwerbspersonen

\begin{tabular}{|c|c|c|c|c|c|c|c|c|c|c|}
\hline & & \multirow{2}{*}{$\begin{array}{l}\text { Ausbildung } \\
\text { im Elemen- } \\
\text { tar- und } \\
\text { Primar- } \\
\text { bereich }\end{array}$} & \multirow{2}{*}{$\begin{array}{c}\text { Abschluss } \\
\text { im Sekun- } \\
\text { darbereich I }\end{array}$} & \multirow[t]{2}{*}{$\begin{array}{c}\text { ISCED 3C } \\
\text { (kurz) }\end{array}$} & \multicolumn{2}{|c|}{$\begin{array}{c}\text { Abschluss im } \\
\text { Sekundarbereich II }\end{array}$} & \multirow{2}{*}{$\begin{array}{c}\text { Abschluss } \\
\text { im postse- } \\
\text { kundaren, } \\
\text { nicht } \\
\text { tertiären } \\
\text { Bereich }\end{array}$} & \multicolumn{2}{|c|}{$\begin{array}{l}\text { Abschluss im } \\
\text { Tertiärbereich }\end{array}$} & \multirow{2}{*}{$\begin{array}{c}\text { Alle } \\
\text { Bildungs- } \\
\text { bereiche } \\
\text { zusammen }\end{array}$} \\
\hline & & & & & $\begin{array}{l}\text { ISCED 3C } \\
\text { (lang)/3B }\end{array}$ & ISCED $3 \mathrm{~A}$ & & $\begin{array}{c}\text { Tertiär- } \\
\text { bereich B }\end{array}$ & \begin{tabular}{|c|} 
Tertiär- \\
bereich A/ \\
weiter- \\
führender \\
forschungs- \\
orientierter \\
Studiengang
\end{tabular} & \\
\hline & & (1) & (2) & (3) & (4) & (5) & (6) & (7) & (8) & (9) \\
\hline \multicolumn{11}{|l|}{ OECD-Länder } \\
\hline Portugal & $\begin{array}{l}\text { Männer } \\
\text { Frauen }\end{array}$ & $\begin{array}{l}13,3 \\
12,6\end{array}$ & $\begin{array}{l}11,9 \\
16,2\end{array}$ & $\begin{array}{l}x(5) \\
x(5)\end{array}$ & $\begin{array}{l}x(5) \\
x(5)\end{array}$ & $\begin{array}{l}10,1 \\
11,6\end{array}$ & $\begin{array}{l}\mathrm{c} \\
\mathrm{c}\end{array}$ & $\begin{array}{l}x(8) \\
x(8)\end{array}$ & $\begin{array}{l}9,1 \\
7,3\end{array}$ & $\begin{array}{l}11,7 \\
11,9\end{array}$ \\
\hline Slowakei & $\begin{array}{l}\text { Männer } \\
\text { Frauen }\end{array}$ & $\begin{array}{l}\mathrm{c} \\
\mathrm{c}\end{array}$ & $\begin{array}{l}42,9 \\
34,4\end{array}$ & $\begin{array}{l}x(4) \\
x(4)\end{array}$ & $\begin{array}{l}13,9 \\
17,8\end{array}$ & $\begin{array}{l}8,0 \\
8,9\end{array}$ & $\begin{array}{l}a \\
a\end{array}$ & $\begin{array}{l}\mathrm{C} \\
\mathrm{C}\end{array}$ & $\begin{array}{l}4,6 \\
5,8\end{array}$ & $\begin{array}{l}11,5 \\
12,1\end{array}$ \\
\hline Slowenien & $\begin{array}{l}\text { Männer } \\
\text { Frauen }\end{array}$ & $\begin{array}{r}28,0^{r} \\
c\end{array}$ & $\begin{array}{l}12,6 \\
11,1\end{array}$ & $\begin{array}{l}a \\
a\end{array}$ & $\begin{array}{r}8,2 \\
11,0\end{array}$ & $\begin{array}{l}7,1 \\
7,9\end{array}$ & $\begin{array}{l}a \\
a\end{array}$ & $\begin{array}{l}5,7^{r} \\
4,1^{r}\end{array}$ & $\begin{array}{l}4,1 \\
5,0\end{array}$ & $\begin{array}{l}7,6 \\
7,6\end{array}$ \\
\hline Spanien & $\begin{array}{l}\text { Männer } \\
\text { Frauen }\end{array}$ & $\begin{array}{l}30,7 \\
30,4\end{array}$ & $\begin{array}{l}23,1 \\
26,5\end{array}$ & $\begin{array}{l}\mathrm{a} \\
\mathrm{a}\end{array}$ & $\begin{array}{l}17,1 \\
21,6\end{array}$ & $\begin{array}{l}17,9 \\
20,9\end{array}$ & $\begin{array}{l}\mathrm{c} \\
\mathrm{c}\end{array}$ & $\begin{array}{l}12,5 \\
17,5\end{array}$ & $\begin{array}{r}9,7 \\
11,0\end{array}$ & $\begin{array}{l}18,9 \\
20,1\end{array}$ \\
\hline Schweden & $\begin{array}{l}\text { Männer } \\
\text { Frauen }\end{array}$ & $\begin{array}{l}15,9 \\
23,0\end{array}$ & $\begin{array}{l}7,3 \\
9,7\end{array}$ & $\begin{array}{l}\mathrm{a} \\
\mathrm{a}\end{array}$ & $\begin{array}{l}x(5) \\
x(5)\end{array}$ & $\begin{array}{l}5,0 \\
5,3\end{array}$ & $\begin{array}{l}4,8 \\
6,3\end{array}$ & $\begin{array}{l}5,6 \\
4,2\end{array}$ & $\begin{array}{l}3,7 \\
3,4\end{array}$ & $\begin{array}{l}5,3 \\
5,3\end{array}$ \\
\hline Schweiz & $\begin{array}{l}\text { Männer } \\
\text { Frauen }\end{array}$ & $\begin{array}{l}7,3^{r} \\
9,0\end{array}$ & $\begin{array}{l}7,1 \\
7,9\end{array}$ & $\begin{array}{l}9,3^{r} \\
6,1^{r}\end{array}$ & $\begin{array}{l}3,3 \\
3,0\end{array}$ & $\begin{array}{r}2,1^{r} \\
3,2\end{array}$ & $\begin{array}{l}1,3^{r} \\
2,6^{r}\end{array}$ & $\begin{array}{l}2,5^{r} \\
3,7^{r}\end{array}$ & $\begin{array}{l}2,5 \\
3,7\end{array}$ & $\begin{array}{l}3,2 \\
3,9\end{array}$ \\
\hline Türkei & $\begin{array}{l}\text { Männer } \\
\text { Frauen }\end{array}$ & $\begin{array}{l}8,6 \\
6,8\end{array}$ & $\begin{array}{r}8,9 \\
15,7\end{array}$ & $\begin{array}{l}a \\
a\end{array}$ & $\begin{array}{r}6,1 \\
16,3\end{array}$ & $\begin{array}{r}7,2 \\
18,2\end{array}$ & $\begin{array}{l}x(8) \\
x(8)\end{array}$ & $\begin{array}{l}x(8) \\
x(8)\end{array}$ & $\begin{array}{r}5,9 \\
10,9\end{array}$ & $\begin{array}{r}7,8 \\
10,0\end{array}$ \\
\hline Vereinigtes Königreich & $\begin{array}{l}\text { Männer } \\
\text { Frauen }\end{array}$ & $\begin{array}{l}\mathrm{C} \\
\mathrm{C}\end{array}$ & $\begin{array}{l}15,1 \\
13,9\end{array}$ & $\begin{array}{r}10,4 \\
7,5\end{array}$ & $\begin{array}{l}6,1 \\
6,3\end{array}$ & $\begin{array}{l}4,5 \\
4,7\end{array}$ & $\begin{array}{l}\mathrm{c} \\
\mathrm{c}\end{array}$ & $\begin{array}{l}4,3 \\
3,2\end{array}$ & $\begin{array}{l}3,9 \\
4,0\end{array}$ & $\begin{array}{l}6,2 \\
5,7\end{array}$ \\
\hline Vereinigte Staaten & $\begin{array}{l}\text { Männer } \\
\text { Frauen }\end{array}$ & $\begin{array}{l}12,6 \\
14,2\end{array}$ & $\begin{array}{l}19,1 \\
15,7\end{array}$ & $\begin{array}{l}x(5) \\
x(5)\end{array}$ & $\begin{array}{l}x(5) \\
x(5)\end{array}$ & $\begin{array}{r}11,3 \\
8,8\end{array}$ & $\begin{array}{l}x(5) \\
x(5)\end{array}$ & $\begin{array}{l}6,9 \\
6,1\end{array}$ & $\begin{array}{l}4,6 \\
4,3\end{array}$ & $\begin{array}{l}9,2 \\
7,2\end{array}$ \\
\hline OECD-Durchschnitt & $\begin{array}{l}\text { Männer } \\
\text { Frauen }\end{array}$ & $\begin{array}{l}14,0 \\
13,5\end{array}$ & $\begin{array}{l}13,0 \\
12,6\end{array}$ & $\begin{array}{l}\mathrm{m} \\
\mathrm{m}\end{array}$ & $\begin{array}{r}6,9 \\
10,2\end{array}$ & $\begin{array}{l}6,8 \\
7,7\end{array}$ & $\begin{array}{l}6,7 \\
8,1\end{array}$ & $\begin{array}{l}5,6 \\
5,8\end{array}$ & $\begin{array}{l}4,3 \\
5,0\end{array}$ & $\begin{array}{l}7,0 \\
7,2\end{array}$ \\
\hline EU21-Durchschnitt & $\begin{array}{l}\text { Männer } \\
\text { Frauen }\end{array}$ & $\begin{array}{l}17,7 \\
17,2\end{array}$ & $\begin{array}{l}15,6 \\
14,8\end{array}$ & $\begin{array}{l}\mathrm{m} \\
\mathrm{m}\end{array}$ & $\begin{array}{r}7,9 \\
10,8\end{array}$ & $\begin{array}{l}7,3 \\
8,2\end{array}$ & $\begin{array}{l}7,3 \\
9,0\end{array}$ & $\begin{array}{l}6,5 \\
6,6\end{array}$ & $\begin{array}{l}4,6 \\
5,4\end{array}$ & $\begin{array}{l}8,1 \\
8,4\end{array}$ \\
\hline Sonstige G20-Länder & & & & & & & & & & \\
\hline Argentinien & & $\mathrm{m}$ & $\mathrm{m}$ & $\mathrm{m}$ & $\mathrm{m}$ & $\mathrm{m}$ & $\mathrm{m}$ & $\mathrm{m}$ & $\mathrm{m}$ & $\mathrm{m}$ \\
\hline Brasilien & $\begin{array}{l}\text { Männer } \\
\text { Frauen }\end{array}$ & $\begin{array}{l}3,0 \\
6,1\end{array}$ & $\begin{array}{l}3,6 \\
8,1\end{array}$ & $\begin{array}{l}x(5) \\
x(5)\end{array}$ & $\begin{array}{l}x(5) \\
x(5)\end{array}$ & $\begin{array}{l}3,5 \\
9,6\end{array}$ & $\begin{array}{l}a \\
a\end{array}$ & $\begin{array}{l}x(8) \\
x(8)\end{array}$ & $\begin{array}{l}2,0 \\
3,7\end{array}$ & $\begin{array}{l}3,1 \\
7,1\end{array}$ \\
\hline China & & $m$ & $\mathrm{~m}$ & $\mathrm{~m}$ & $\mathrm{~m}$ & $\mathrm{~m}$ & $\mathrm{~m}$ & $\mathrm{~m}$ & $\mathrm{~m}$ & $\mathrm{~m}$ \\
\hline Indien & & $\mathrm{m}$ & $\mathrm{m}$ & $\mathrm{m}$ & $\mathrm{m}$ & $\mathrm{m}$ & $\mathrm{m}$ & $\mathrm{m}$ & $\mathrm{m}$ & $\mathrm{m}$ \\
\hline Indonesien & & $m$ & $\mathrm{~m}$ & $\mathrm{~m}$ & $\mathrm{~m}$ & $\mathrm{~m}$ & $\mathrm{~m}$ & $\mathrm{~m}$ & $\mathrm{~m}$ & $\mathrm{~m}$ \\
\hline Russische Föderation & $\begin{array}{l}\text { Männer } \\
\text { Frauen }\end{array}$ & $\begin{array}{l}\mathrm{C} \\
\mathrm{c}\end{array}$ & $\begin{array}{l}14,4 \\
13,4\end{array}$ & $\begin{array}{l}x(4) \\
x(4)\end{array}$ & $\begin{array}{l}6,1 \\
6,2\end{array}$ & $\begin{array}{l}8,4 \\
8,6\end{array}$ & $\begin{array}{l}x(4) \\
x(4)\end{array}$ & $\begin{array}{l}4,5 \\
4,3\end{array}$ & $\begin{array}{l}3,1 \\
2,8\end{array}$ & $\begin{array}{l}5,9 \\
5,2\end{array}$ \\
\hline Saudi-Arabien & & $\mathrm{m}$ & $\mathrm{m}$ & $\mathrm{m}$ & $\mathrm{m}$ & $\mathrm{m}$ & $\mathrm{m}$ & $\mathrm{m}$ & $\mathrm{m}$ & $\mathrm{m}$ \\
\hline Südafrika & & $\mathrm{m}$ & $\mathrm{m}$ & $\mathrm{m}$ & $\mathrm{m}$ & $\mathrm{m}$ & $\mathrm{m}$ & $\mathrm{m}$ & $\mathrm{m}$ & $\mathrm{m}$ \\
\hline G20-Durchschnitt & Männer & m & m & $\mathbf{m}$ & m & $\mathbf{m}$ & m & m & m & $\mathbf{m}$ \\
\hline
\end{tabular}

Quelle: OECD. Arbeitskräfteerhebung des Netzwerks zu den Arbeitsmarktergebnissen sowie den wirtschaftlichen und sozialen Auswirkungen des Lernens (LSO) für die meisten Länder sowie Arbeitskräfteerhebung der EU (EU-LFS) für Dänemark, Finnland, Island, Irland, Luxemburg und Slowenien.

Hinweise s. Anhang 3 unter www.oecd.org/edu/eag.htm. StatLink: http://dx.doi.org/10.1787/888932848609

Erläuterung der Kennzeichnung fehlender Daten s. Hinweise für den Leser. 
Beschäftigungsquoten, nach Bildungsstand und Altersgruppe (2000, 2005, 2008 und 2011)

Zahl der 25- bis 64-jährigen/25- bis 34-jährigen/55- bis 64-jährigen Beschäftigten als Prozentsatz aller 25- bis 64-Jährigen/

25- bis 34-Jährigen/55- bis 64-Jährigen

Bildungsstand

\begin{tabular}{|l|l|l|} 
25- bis 64-Jährige & 25- bis 34-Jährige & 55- bis 64-Jährige
\end{tabular}

\begin{tabular}{|c|c|c|c|c|c|c|c|c|c|c|c|c|c|c|c|c|}
\hline & \multirow[t]{3}{*}{ Bildungsstand } & \multicolumn{5}{|c|}{ 25- bis 64-Jährige } & \multicolumn{5}{|c|}{ 25- bis 34-Jährige } & \multicolumn{5}{|c|}{ 55- bis 64-Jährige } \\
\hline & & $\begin{array}{l}\stackrel{\text { }}{\circ} \\
\text { ㄱ. }\end{array}$ & $\begin{array}{l}\text { Ln } \\
\stackrel{\circ}{\text { N }}\end{array}$ & $\begin{array}{l}\infty \\
\stackrel{0}{\circ} \\
\text { N }\end{array}$ & $\begin{array}{l}-1 \\
\stackrel{\sim}{N}\end{array}$ & 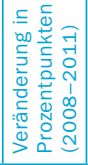 & $\begin{array}{l}\text { ¿ } \\
\text { ㄱ }\end{array}$ & $\begin{array}{l}\text { LO } \\
\stackrel{\circ}{ } \\
\text { N }\end{array}$ & $\begin{array}{l}\infty \\
\stackrel{0}{0} \\
\text { N }\end{array}$ & $\begin{array}{l}\stackrel{-}{-1} \\
\stackrel{N}{N}\end{array}$ & 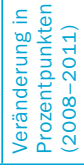 & $\begin{array}{l}\text { ঃ } \\
\text { ㄱ. }\end{array}$ & $\begin{array}{l}\stackrel{\text { O }}{\circ} \\
\stackrel{\circ}{N}\end{array}$ & $\begin{array}{l}\infty \\
\stackrel{\bigcirc}{\circ} \\
\text { N }\end{array}$ & $\begin{array}{l}\text { ㄱ. } \\
\text { 오 }\end{array}$ & 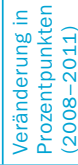 \\
\hline & & (1) & (2) & (3) & (4) & (5) & (6) & (7) & (8) & (9) & (10) & (11) & (12) & (13) & (14) & (15) \\
\hline OECD-Länder & & & & & & & & & & & & & & & & \\
\hline Australien & $\begin{array}{l}\text { Ausbildung unterhalb Sekundarbereich II } \\
\text { Abschluss im Sekundarbereich II/ } \\
\text { postsekundaren, nicht tertiären Bereich } \\
\text { Abschluss im Tertiärbereich }\end{array}$ & $\begin{array}{l}61 \\
77 \\
83\end{array}$ & $\begin{array}{l}63 \\
80 \\
84\end{array}$ & $\begin{array}{l}62 \\
81 \\
83\end{array}$ & $\begin{array}{l}66 \\
81 \\
84\end{array}$ & $\begin{array}{r}4,3 \\
-0,1 \\
1,0\end{array}$ & $\begin{array}{l}64 \\
80 \\
84\end{array}$ & $\begin{array}{l}64 \\
81 \\
85\end{array}$ & $\begin{array}{l}64 \\
82 \\
86\end{array}$ & $\begin{array}{l}65 \\
82 \\
85\end{array}$ & $\begin{array}{r}0,8 \\
-0,6 \\
-0,9\end{array}$ & $\begin{array}{l}39 \\
53 \\
65\end{array}$ & $\begin{array}{l}46 \\
62 \\
69\end{array}$ & $\begin{array}{l}41 \\
64 \\
67\end{array}$ & $\begin{array}{l}55 \\
71 \\
74\end{array}$ & $\begin{array}{r}14,1 \\
6,6 \\
6,7\end{array}$ \\
\hline Österreich & $\begin{array}{l}\text { Ausbildung unterhalb Sekundarbereich II } \\
\text { Abschluss im Sekundarbereich II/ } \\
\text { postsekundaren, nicht tertiären Bereich } \\
\text { Abschluss im Tertiärbereich }\end{array}$ & $\begin{array}{l}54 \\
75 \\
87\end{array}$ & $\begin{array}{l}53 \\
74 \\
85\end{array}$ & $\begin{array}{l}57 \\
78 \\
86\end{array}$ & $\begin{array}{l}56 \\
78 \\
87\end{array}$ & $\begin{array}{r}-0,8 \\
-0,2 \\
0,1\end{array}$ & $\begin{array}{l}70 \\
84 \\
92\end{array}$ & $\begin{array}{l}61 \\
84 \\
87\end{array}$ & $\begin{array}{l}62 \\
85 \\
90\end{array}$ & $\begin{array}{l}64 \\
85 \\
88\end{array}$ & $\begin{array}{r}2,0 \\
0,0 \\
-1,8\end{array}$ & $\begin{array}{l}19 \\
29 \\
59\end{array}$ & $\begin{array}{l}24 \\
31 \\
54\end{array}$ & $\begin{array}{l}31 \\
41 \\
61\end{array}$ & $\begin{array}{l}30 \\
41 \\
64\end{array}$ & $\begin{array}{r}-0,8 \\
-0,1 \\
3,2\end{array}$ \\
\hline Belgien & $\begin{array}{l}\text { Ausbildung unterhalb Sekundarbereich II } \\
\text { Abschluss im Sekundarbereich II/ } \\
\text { postsekundaren, nicht tertiären Bereich } \\
\text { Abschluss im Tertiärbereich }\end{array}$ & $\begin{array}{l}51 \\
75 \\
85\end{array}$ & $\begin{array}{l}49 \\
74 \\
84\end{array}$ & $\begin{array}{l}49 \\
75 \\
85\end{array}$ & $\begin{array}{l}48 \\
74 \\
84\end{array}$ & $\begin{array}{l}-1,7 \\
-0,7 \\
-0,5\end{array}$ & $\begin{array}{l}64 \\
84 \\
92\end{array}$ & $\begin{array}{l}57 \\
81 \\
90\end{array}$ & $\begin{array}{l}59 \\
83 \\
91\end{array}$ & $\begin{array}{l}55 \\
79 \\
89\end{array}$ & $\begin{array}{l}-4,5 \\
-3,4 \\
-1,9\end{array}$ & $\begin{array}{l}19 \\
31 \\
46\end{array}$ & $\begin{array}{l}21 \\
38 \\
49\end{array}$ & $\begin{array}{l}24 \\
39 \\
52\end{array}$ & $\begin{array}{l}27 \\
42 \\
56\end{array}$ & $\begin{array}{l}3,3 \\
3,2 \\
3,3\end{array}$ \\
\hline Kanada & $\begin{array}{l}\text { Ausbildung unterhalb Sekundarbereich II } \\
\text { Abschluss im Sekundarbereich II/ } \\
\text { postsekundaren, nicht tertiären Bereich } \\
\text { Abschluss im Tertiärbereich }\end{array}$ & $\begin{array}{l}55 \\
76 \\
83\end{array}$ & $\begin{array}{l}56 \\
76 \\
82\end{array}$ & $\begin{array}{l}58 \\
76 \\
83\end{array}$ & $\begin{array}{l}55 \\
74 \\
82\end{array}$ & $\begin{array}{l}-2,7 \\
-2,2 \\
-0,9\end{array}$ & $\begin{array}{l}60 \\
79 \\
86\end{array}$ & $\begin{array}{l}62 \\
80 \\
85\end{array}$ & $\begin{array}{l}61 \\
80 \\
85\end{array}$ & $\begin{array}{l}59 \\
78 \\
84\end{array}$ & $\begin{array}{l}-1,7 \\
-2,7 \\
-1,5\end{array}$ & $\begin{array}{l}37 \\
52 \\
57\end{array}$ & $\begin{array}{l}41 \\
57 \\
62\end{array}$ & $\begin{array}{l}44 \\
58 \\
64\end{array}$ & $\begin{array}{l}43 \\
59 \\
65\end{array}$ & $\begin{array}{r}-1,2 \\
0,7 \\
1,1\end{array}$ \\
\hline Chile & $\begin{array}{l}\text { Ausbildung unterhalb Sekundarbereich II } \\
\text { Abschluss im Sekundarbereich II/ } \\
\text { postsekundaren, nicht tertiären Bereich } \\
\text { Abschluss im Tertiärbereich }\end{array}$ & $\begin{array}{l}\mathrm{m} \\
\mathrm{m} \\
\mathrm{m}\end{array}$ & $\begin{array}{l}\mathrm{m} \\
\mathrm{m} \\
\mathrm{m}\end{array}$ & $\begin{array}{l}59 \\
70 \\
79\end{array}$ & $\begin{array}{l}63 \\
73 \\
79\end{array}$ & $\begin{array}{r}4,5 \\
2,7 \\
-0,1\end{array}$ & $\begin{array}{l}\mathrm{m} \\
\mathrm{m} \\
\mathrm{m}\end{array}$ & $\begin{array}{l}\mathrm{m} \\
\mathrm{m} \\
\mathrm{m}\end{array}$ & $\begin{array}{l}59 \\
71 \\
75\end{array}$ & $\begin{array}{l}62 \\
75 \\
76\end{array}$ & $\begin{array}{l}3,4 \\
4,4 \\
1,6\end{array}$ & $\begin{array}{l}\mathrm{m} \\
\mathrm{m}\end{array}$ & $\begin{array}{l}\mathrm{m} \\
\mathrm{m} \\
\mathrm{m}\end{array}$ & $\begin{array}{l}51 \\
59 \\
76\end{array}$ & $\begin{array}{l}55 \\
61 \\
70\end{array}$ & $\begin{array}{r}3,8 \\
2,5 \\
-5,7\end{array}$ \\
\hline Tschechien & $\begin{array}{l}\text { Ausbildung unterhalb Sekundarbereich II } \\
\text { Abschluss im Sekundarbereich II/ } \\
\text { postsekundaren, nicht tertiären Bereich } \\
\text { Abschluss im Tertiärbereich }\end{array}$ & $\begin{array}{l}47 \\
76 \\
87\end{array}$ & $\begin{array}{l}41 \\
75 \\
86\end{array}$ & $\begin{array}{l}47 \\
77 \\
85\end{array}$ & $\begin{array}{l}42 \\
75 \\
83\end{array}$ & $\begin{array}{l}-4,3 \\
-1,3 \\
-2,0\end{array}$ & $\begin{array}{l}51 \\
77 \\
83\end{array}$ & $\begin{array}{l}43 \\
78 \\
81\end{array}$ & $\begin{array}{l}50 \\
79 \\
79\end{array}$ & $\begin{array}{l}46 \\
78 \\
76\end{array}$ & $\begin{array}{l}-3,5 \\
-0,7 \\
-3,5\end{array}$ & $\begin{array}{l}17 \\
39 \\
66\end{array}$ & $\begin{array}{l}20 \\
47 \\
69\end{array}$ & $\begin{array}{l}28 \\
48 \\
73\end{array}$ & $\begin{array}{l}25 \\
48 \\
73\end{array}$ & $\begin{array}{l}-2,3 \\
-0,4 \\
-0,5\end{array}$ \\
\hline Dänemark ${ }^{1}$ & $\begin{array}{l}\text { Ausbildung unterhalb Sekundarbereich II } \\
\text { Abschluss im Sekundarbereich II/ } \\
\text { postsekundaren, nicht tertiären Bereich } \\
\text { Abschluss im Tertiärbereich }\end{array}$ & $\begin{array}{l}62 \\
81 \\
88\end{array}$ & $\begin{array}{l}62 \\
80 \\
86\end{array}$ & $\begin{array}{l}68 \\
83 \\
88\end{array}$ & $\begin{array}{l}63 \\
79 \\
86\end{array}$ & $\begin{array}{l}-5,7 \\
-3,7 \\
-2,7\end{array}$ & $\begin{array}{l}70 \\
85 \\
88\end{array}$ & $\begin{array}{l}64 \\
83 \\
87\end{array}$ & $\begin{array}{l}75 \\
88 \\
90\end{array}$ & $\begin{array}{l}62 \\
80 \\
85\end{array}$ & $\begin{array}{r}-13,8 \\
-7,7 \\
-4,9\end{array}$ & $\begin{array}{l}41 \\
57 \\
73\end{array}$ & $\begin{array}{l}42 \\
61 \\
73\end{array}$ & $\begin{array}{l}45 \\
61 \\
73\end{array}$ & $\begin{array}{l}47 \\
61 \\
72\end{array}$ & $\begin{array}{r}2,7 \\
0,1 \\
-1,3\end{array}$ \\
\hline Estland $^{1}$ & $\begin{array}{l}\text { Ausbildung unterhalb Sekundarbereich II } \\
\text { Abschluss im Sekundarbereich II/ } \\
\text { postsekundaren, nicht tertiären Bereich } \\
\text { Abschluss im Tertiärbereich }\end{array}$ & $\begin{array}{l}42 \\
70 \\
83\end{array}$ & $\begin{array}{l}50 \\
74 \\
84\end{array}$ & $\begin{array}{l}58 \\
80 \\
86\end{array}$ & $\begin{array}{l}48 \\
74 \\
80\end{array}$ & $\begin{array}{r}-10,0 \\
-5,7 \\
-5,8\end{array}$ & $\begin{array}{l}53 \\
74 \\
85\end{array}$ & $\begin{array}{l}60 \\
77 \\
84\end{array}$ & $\begin{array}{l}72 \\
84 \\
82\end{array}$ & $\begin{array}{l}58 \\
76 \\
79\end{array}$ & $\begin{array}{r}-13,3 \\
-8,1 \\
-3,2\end{array}$ & $\begin{array}{l}24 \\
46 \\
62\end{array}$ & $\begin{array}{l}36 \\
53 \\
74\end{array}$ & $\begin{array}{l}38 \\
61 \\
78\end{array}$ & $\begin{array}{l}31 \\
57 \\
67\end{array}$ & $\begin{array}{r}-7,9 \\
-3,8 \\
-10,6\end{array}$ \\
\hline Finnland & $\begin{array}{l}\text { Ausbildung unterhalb Sekundarbereich II } \\
\text { Abschluss im Sekundarbereich II/ } \\
\text { postsekundaren, nicht tertiären Bereich } \\
\text { Abschluss im Tertiärbereich }\end{array}$ & $\begin{array}{l}60 \\
75 \\
84\end{array}$ & $\begin{array}{l}58 \\
75 \\
84\end{array}$ & $\begin{array}{l}59 \\
77 \\
86\end{array}$ & $\begin{array}{l}56 \\
75 \\
84\end{array}$ & $\begin{array}{l}-3,7 \\
-2,5 \\
-1,3\end{array}$ & $\begin{array}{l}69 \\
76 \\
84\end{array}$ & $\begin{array}{l}63 \\
77 \\
86\end{array}$ & $\begin{array}{l}69 \\
79 \\
87\end{array}$ & $\begin{array}{l}56 \\
78 \\
83\end{array}$ & $\begin{array}{r}-12,6 \\
-1,6 \\
-4,0\end{array}$ & $\begin{array}{l}33 \\
42 \\
60\end{array}$ & $\begin{array}{l}43 \\
53 \\
66\end{array}$ & $\begin{array}{l}45 \\
57 \\
70\end{array}$ & $\begin{array}{l}44 \\
56 \\
70\end{array}$ & $\begin{array}{r}-1,1 \\
-0,7 \\
0,4\end{array}$ \\
\hline Frankreich & $\begin{array}{l}\text { Ausbildung unterhalb Sekundarbereich II } \\
\text { Abschluss im Sekundarbereich II/ } \\
\text { postsekundaren, nicht tertiären Bereich } \\
\text { Abschluss im Tertiärbereich }\end{array}$ & $\begin{array}{l}56 \\
75 \\
83\end{array}$ & $\begin{array}{l}59 \\
76 \\
83\end{array}$ & $\begin{array}{l}57 \\
76 \\
85\end{array}$ & $\begin{array}{l}56 \\
74 \\
84\end{array}$ & $\begin{array}{l}-1,7 \\
-2,1 \\
-0,7\end{array}$ & $\begin{array}{l}61 \\
80 \\
85\end{array}$ & $\begin{array}{l}63 \\
80 \\
86\end{array}$ & $\begin{array}{l}62 \\
82 \\
89\end{array}$ & $\begin{array}{l}56 \\
78 \\
87\end{array}$ & $\begin{array}{l}-5,9 \\
-3,8 \\
-1,9\end{array}$ & $\begin{array}{l}24 \\
31 \\
50\end{array}$ & $\begin{array}{l}32 \\
40 \\
56\end{array}$ & $\begin{array}{l}30 \\
39 \\
57\end{array}$ & $\begin{array}{l}34 \\
42 \\
57\end{array}$ & $\begin{array}{l}3,8 \\
3,2 \\
0,0\end{array}$ \\
\hline Deutschland & $\begin{array}{l}\text { Ausbildung unterhalb Sekundarbereich II } \\
\text { Abschluss im Sekundarbereich II/ } \\
\text { postsekundaren, nicht tertiären Bereich } \\
\text { Abschluss im Tertiärbereich }\end{array}$ & $\begin{array}{l}51 \\
70 \\
83\end{array}$ & $\begin{array}{l}52 \\
71 \\
83\end{array}$ & $\begin{array}{l}55 \\
75 \\
86\end{array}$ & $\begin{array}{l}57 \\
78 \\
88\end{array}$ & $\begin{array}{l}1,3 \\
2,3 \\
2,0\end{array}$ & $\begin{array}{l}60 \\
79 \\
89\end{array}$ & $\begin{array}{l}52 \\
74 \\
85\end{array}$ & $\begin{array}{l}55 \\
78 \\
88\end{array}$ & $\begin{array}{l}56 \\
80 \\
89\end{array}$ & $\begin{array}{l}0,8 \\
2,7 \\
1,3\end{array}$ & $\begin{array}{l}26 \\
37 \\
58\end{array}$ & $\begin{array}{l}32 \\
43 \\
63\end{array}$ & $\begin{array}{l}38 \\
52 \\
69\end{array}$ & $\begin{array}{l}42 \\
58 \\
75\end{array}$ & $\begin{array}{l}3,9 \\
5,7 \\
6,2\end{array}$ \\
\hline Griechenland & $\begin{array}{l}\text { Ausbildung unterhalb Sekundarbereich II } \\
\text { Abschluss im Sekundarbereich II/ } \\
\text { postsekundaren, nicht tertiären Bereich } \\
\text { Abschluss im Tertiärbereich }\end{array}$ & $\begin{array}{l}58 \\
65 \\
81\end{array}$ & $\begin{array}{l}59 \\
69 \\
82\end{array}$ & $\begin{array}{l}60 \\
70 \\
83\end{array}$ & $\begin{array}{l}53 \\
63 \\
75\end{array}$ & $\begin{array}{l}-7,7 \\
-7,2 \\
-7,8\end{array}$ & $\begin{array}{l}67 \\
69 \\
79\end{array}$ & $\begin{array}{l}72 \\
73 \\
79\end{array}$ & $\begin{array}{l}72 \\
75 \\
80\end{array}$ & $\begin{array}{l}57 \\
65 \\
69\end{array}$ & $\begin{array}{l}-14,4 \\
-10,2 \\
-11,3\end{array}$ & $\begin{array}{l}39 \\
31 \\
50\end{array}$ & $\begin{array}{l}39 \\
38 \\
59\end{array}$ & $\begin{array}{l}40 \\
38 \\
60\end{array}$ & $\begin{array}{l}37 \\
36 \\
52\end{array}$ & $\begin{array}{l}-3,2 \\
-2,5 \\
-7,7\end{array}$ \\
\hline Ungarn & $\begin{array}{l}\text { Ausbildung unterhalb Sekundarbereich II } \\
\text { Abschluss im Sekundarbereich II/ } \\
\text { postsekundaren, nicht tertiären Bereich } \\
\text { Abschluss im Tertiärbereich }\end{array}$ & $\begin{array}{l}36 \\
72 \\
82\end{array}$ & $\begin{array}{l}38 \\
70 \\
83\end{array}$ & $\begin{array}{l}39 \\
69 \\
80\end{array}$ & $\begin{array}{l}38 \\
66 \\
79\end{array}$ & $\begin{array}{l}-0,9 \\
-2,4 \\
-0,6\end{array}$ & $\begin{array}{l}50 \\
75 \\
83\end{array}$ & $\begin{array}{l}49 \\
75 \\
83\end{array}$ & $\begin{array}{l}47 \\
75 \\
82\end{array}$ & $\begin{array}{l}41 \\
72 \\
80\end{array}$ & $\begin{array}{l}-5,7 \\
-2,8 \\
-2,8\end{array}$ & $\begin{array}{l}12 \\
29 \\
52\end{array}$ & $\begin{array}{l}16 \\
39 \\
60\end{array}$ & $\begin{array}{l}17 \\
34 \\
49\end{array}$ & $\begin{array}{l}21 \\
36 \\
56\end{array}$ & $\begin{array}{l}4,3 \\
2,3 \\
6,7\end{array}$ \\
\hline Island & $\begin{array}{l}\text { Ausbildung unterhalb Sekundarbereich II } \\
\text { Abschluss im Sekundarbereich II/ } \\
\text { postsekundaren, nicht tertiären Bereich } \\
\text { Abschluss im Tertiärbereich }\end{array}$ & $\begin{array}{l}89 \\
89 \\
97\end{array}$ & $\begin{array}{l}83 \\
88 \\
92\end{array}$ & $\begin{array}{l}83 \\
86 \\
91\end{array}$ & $\begin{array}{l}74 \\
83 \\
89\end{array}$ & $\begin{array}{l}-8,7 \\
-2,9 \\
-2,2\end{array}$ & $\begin{array}{l}89 \\
82 \\
96\end{array}$ & $\begin{array}{l}81 \\
81 \\
92\end{array}$ & $\begin{array}{l}83 \\
80 \\
89\end{array}$ & $\begin{array}{l}72 \\
74 \\
85\end{array}$ & $\begin{array}{r}-10,5 \\
-6,1 \\
-3,4\end{array}$ & $\begin{array}{l}83 \\
89 \\
92\end{array}$ & $\begin{array}{l}82 \\
86 \\
89\end{array}$ & $\begin{array}{l}79 \\
84 \\
89\end{array}$ & $\begin{array}{l}71 \\
84 \\
85\end{array}$ & $\begin{array}{l}-8,5 \\
-0,5 \\
-3,8\end{array}$ \\
\hline
\end{tabular}

1. Die Zahlen für 2011 für Dänemark, Estland und die Niederlande in dieser Tabelle können von den Zahlen in anderen Tabellen in Indikator A5 abweichen, da unterschiedliche Datenquellen zugrunde liegen. Die Zahlen in dieser Tabelle basieren für alle Jahre auf der EU-LFS. 2. Die Zahlen für 2000 sind nicht mit den Zahlen in den Folgejahren vergleichbar, da 2000 noch die frühere Klassifizierung des Bildungsstands verwendet wurde.

Quelle: OECD. Arbeitskräfteerhebung des Netzwerks zu den Arbeitsmarktergebnissen sowie den wirtschaftlichen und sozialen Auswirkungen des Lernens (LSO) für die meisten Länder sowie Arbeitskräfteerhebung der EU (EU-LFS) für Dänemark, Estland, Finnland, Frankreich (nur für 2000), Island, Irland, Italien (nur für 2000), Luxemburg, die Niederlande und Slowenien. Hinweise s. Anhang 3 unter www.oecd.org/edu/eag.htm.

StatLink: http://dx.doi.org/10.1787/888932848628

Erläuterung der Kennzeichnung fehlender Daten s. Hinweise für den Leser. 
Beschäftigungsquoten, nach Bildungsstand und Altersgruppe (2000, 2005, 2008 und 2011)

Zahl der 25- bis 64-jährigen/25- bis 34-jährigen/55- bis 64-jährigen Beschäftigten als Prozentsatz aller 25- bis 64-Jährigen/ 25- bis 34-Jährigen/55- bis 64-Jährigen

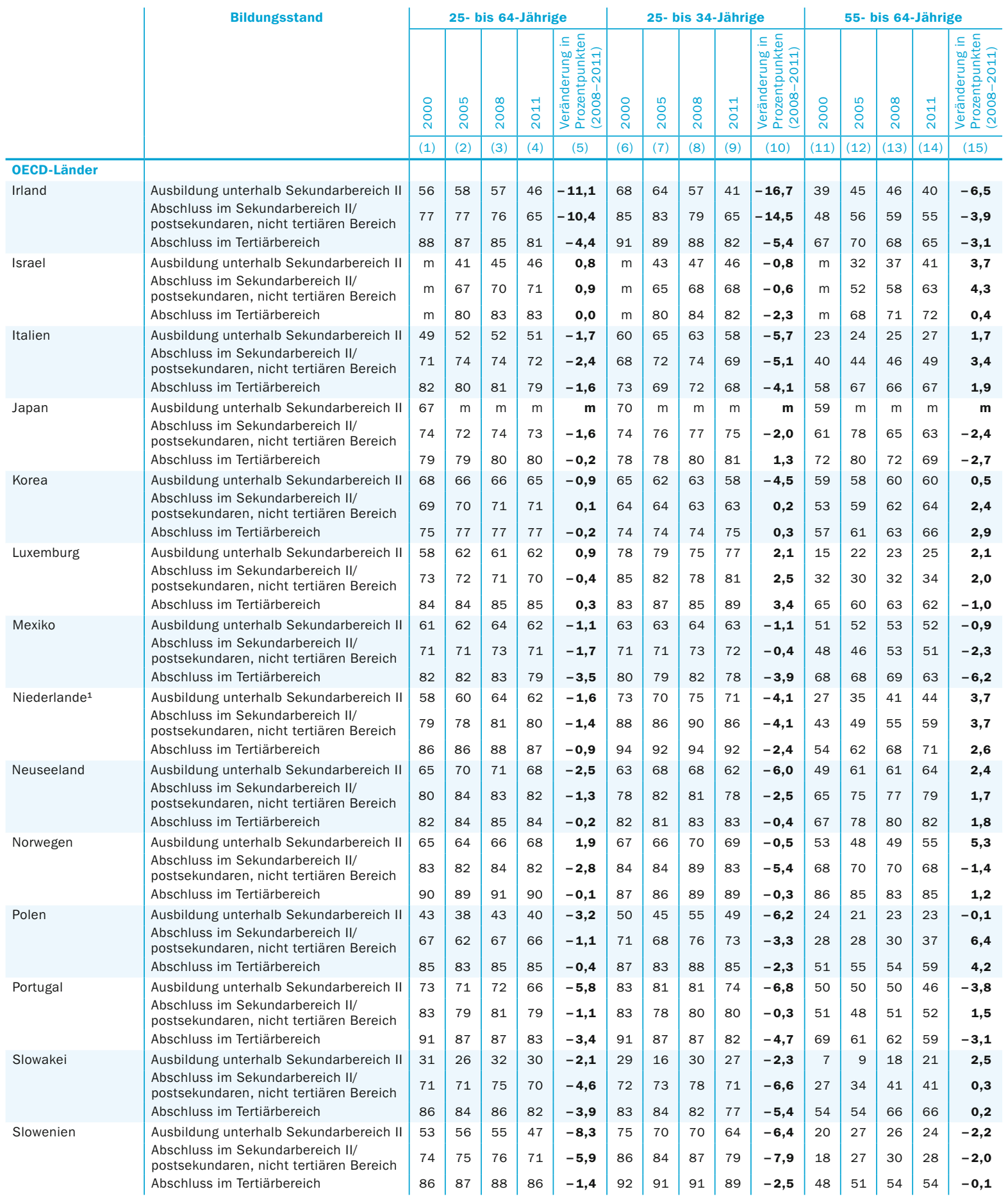

1. Die Zahlen für 2011 für Dänemark, Estland und die Niederlande in dieser Tabelle können von den Zahlen in anderen Tabellen in Indikator A5 abweichen, da unterschiedliche Datenquellen zugrunde liegen. Die Zahlen in dieser Tabelle basieren für alle Jahre auf der EU-LFS. 2. Die Zahlen für 2000 sind nicht mit den Zahlen in den Folgejahren vergleichbar, da 2000 noch die frühere Klassifizierung des Bildungsstands verwendet wurde.

Quelle: OECD. Arbeitskräfteerhebung des Netzwerks zu den Arbeitsmarktergebnissen sowie den wirtschaftlichen und sozialen Auswirkungen des Lernens (LSO) für die meisten Länder sowie Arbeitskräfteerhebung der EU (EU-LFS) für Dänemark, Estland, Finnland, Frankreich (nur für 2000), Island, Irland, Italien (nur für 2000), Luxemburg, die Niederlande und Slowenien. Hinweise s. Anhang 3 unter www.oecd.org/edu/eag.htm.

StatLink: http://dx.doi.org/10.1787/888932848628

Erläuterung der Kennzeichnung fehlender Daten s. Hinweise für den Leser. 
Tabelle A5.3a (Forts. 2)

Beschäftigungsquoten, nach Bildungsstand und Altersgruppe (2000, 2005, 2008 und 2011)

Zahl der 25- bis 64-jährigen/25- bis 34-jährigen/55- bis 64-jährigen Beschäftigten als Prozentsatz aller 25- bis 64-Jährigen/ 25- bis 34-Jährigen/55- bis 64-Jährigen

\begin{tabular}{|c|c|c|c|c|c|c|c|c|c|c|c|c|c|c|c|c|}
\hline & \multirow[t]{3}{*}{ Bildungsstand } & \multicolumn{5}{|c|}{ 25- bis 64-Jährige } & \multicolumn{5}{|c|}{ 25- bis 34-Jährige } & \multicolumn{5}{|c|}{ 55- bis 64-Jährige } \\
\hline & & 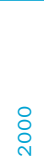 & 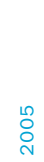 & $\stackrel{\infty}{\circ}$ & ते & 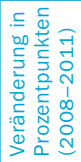 & 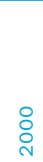 & 芩 & $\stackrel{N}{N}^{\infty}$ & 궁 & 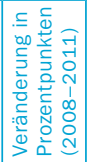 & 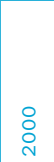 & 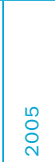 & $\stackrel{\infty}{\circ}$ & $\stackrel{\text { I }}{\stackrel{n}{2}}$ & 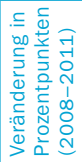 \\
\hline & & (1) & (2) & (3) & (4) & (5) & (6) & (7) & (8) & (9) & (10) & (11) & (12) & (13) & (14) & (15) \\
\hline \multicolumn{17}{|l|}{ OECD-Länder } \\
\hline \multirow[t]{3}{*}{ Spanien } & Ausbildung unterhalb Sekundarbereich II & 54 & 59 & 59 & 52 & $-7,0$ & 65 & 71 & 69 & 57 & $-11,7$ & 33 & 38 & 39 & 37 & $-2,2$ \\
\hline & $\begin{array}{l}\text { Abschluss im Sekundarbereich II/ } \\
\text { postsekundaren, nicht tertiären Bereich }\end{array}$ & 72 & 75 & 75 & 67 & $-7,7$ & 73 & 77 & 78 & 66 & $-11,2$ & 51 & 51 & 53 & 52 & $-1,5$ \\
\hline & Abschluss im Tertiärbereich & 80 & 82 & 84 & 79 & $-4,8$ & 75 & 81 & 84 & 76 & $-7,2$ & 64 & 65 & 67 & 64 & $-2,6$ \\
\hline \multirow[t]{3}{*}{ Schweden } & Ausbildung unterhalb Sekundarbereich II & 68 & 66 & 66 & 65 & $-1,0$ & 67 & 65 & 65 & 60 & $-4,8$ & 56 & 59 & 60 & 61 & 1,2 \\
\hline & $\begin{array}{l}\text { Abschluss im Sekundarbereich II/ } \\
\text { postsekundaren, nicht tertiären Bereich }\end{array}$ & 82 & 81 & 83 & 84 & 0,3 & 83 & 81 & 84 & 83 & $-1,3$ & 66 & 69 & 70 & 72 & 2,3 \\
\hline & Abschluss im Tertiärbereich & 87 & 87 & 89 & 89 & $-0,5$ & 82 & 84 & 88 & 86 & $-1,8$ & 79 & 83 & 82 & 82 & 0,5 \\
\hline \multirow[t]{3}{*}{ Schweiz } & Ausbildung unterhalb Sekundarbereich II & 64 & 65 & 68 & 68 & 0,8 & 68 & 68 & 71 & 70 & $-0,6$ & 47 & 51 & 53 & 54 & 1,3 \\
\hline & $\begin{array}{l}\text { Abschiuss im Sekundarberelch II/ } \\
\text { postsekundaren, nicht tertiären Bereich }\end{array}$ & 81 & 80 & 82 & 83 & 0,5 & 84 & 83 & 85 & 86 & 1,2 & 66 & 65 & 68 & 69 & 1,5 \\
\hline & Abschluss im Tertiärbereich & 90 & 90 & 90 & 89 & $-1,7$ & 91 & 91 & 92 & 88 & $-4,2$ & 78 & 79 & 80 & 82 & 1,7 \\
\hline \multirow[t]{3}{*}{ Türkei } & Ausbildung unterhalb Sekundarbereich II & 53 & 47 & 47 & 51 & 4,0 & 55 & 49 & 49 & 53 & 4,1 & 38 & 30 & 29 & 33 & 3,7 \\
\hline & $\begin{array}{l}\text { Abschluss im Sekundarbereich II/ } \\
\text { postsekundaren, nicht tertiären Bereich }\end{array}$ & 64 & 62 & 61 & 62 & 1,0 & 67 & 64 & 65 & 66 & 0,5 & 20 & 24 & 21 & 27 & 6,0 \\
\hline & Abschluss im Tertiärbereich & 78 & 75 & 75 & 76 & 1,5 & 83 & 79 & 79 & 77 & $-1,6$ & 37 & 34 & 36 & 40 & 3,7 \\
\hline \multirow{3}{*}{$\begin{array}{l}\text { Vereinigtes } \\
\text { Königreich }\end{array}$} & Ausbildung unterhalb Sekundarbereich II & 65 & 65 & 59 & 56 & $-3,3$ & 66 & 64 & 60 & 56 & $-4,4$ & 51 & 56 & 45 & 42 & $-3,2$ \\
\hline & $\begin{array}{l}\text { Abschluss im Sekundarbereich II/ } \\
\text { postsekundaren, nicht tertiären Bereich }\end{array}$ & 81 & 82 & 80 & 78 & $-1,9$ & 83 & 81 & 81 & 78 & $-3,2$ & 65 & 69 & 65 & 64 & $-1,2$ \\
\hline & Abschluss im Tertiärbereich & 88 & 88 & 85 & 83 & $-1,8$ & 91 & 90 & 88 & 86 & $-2,2$ & 67 & 72 & 67 & 64 & $-3,0$ \\
\hline \multirow[t]{3}{*}{ Vereinigte Staaten } & Ausbildung unterhalb Sekundarbereich II & 58 & 57 & 56 & 51 & $-5,1$ & 64 & 62 & 60 & 54 & $-6,2$ & 40 & 39 & 41 & 39 & $-1,6$ \\
\hline & $\begin{array}{l}\text { Abschluss im Sekundarbereich II/ } \\
\text { postsekundaren, nicht tertiären Bereich }\end{array}$ & 77 & 73 & 73 & 67 & $-5,7$ & 80 & 74 & 75 & 67 & $-7,1$ & 58 & 58 & 60 & 56 & $-3,4$ \\
\hline & Abschluss im Tertiärbereich & 85 & 82 & 83 & 80 & $-3,2$ & 87 & 83 & 86 & 82 & $-3,5$ & 70 & 72 & 73 & 70 & $-2,8$ \\
\hline \multirow[t]{3}{*}{ OECD-Durchschnitt } & Ausbildung unterhalb Sekundarbereich II & 57 & 57 & 58 & 55 & $-2,6$ & 64 & 61 & 63 & 58 & $-4,9$ & 36 & 38 & 40 & 41 & 4,5 \\
\hline & $\begin{array}{l}\text { Abschluss im Sekundarbereich II/ } \\
\text { postsekundaren, nicht tertiären Bereich }\end{array}$ & 75 & 75 & 76 & 74 & $-2,2$ & 78 & 77 & 79 & 76 & $-3,3$ & 46 & 51 & 53 & 54 & 3,1 \\
\hline & Abschluss im Tertiärbereich & 85 & 84 & 84 & 83 & $-1,5$ & 85 & 84 & 85 & 82 & $-2,6$ & 63 & 66 & 67 & 67 & 2,2 \\
\hline \multirow{3}{*}{$\begin{array}{l}\text { OECD-Durchschnitt } \\
\text { für Länder mit } \\
\text { Daten für alle } \\
\text { Referenzjahre }\end{array}$} & Ausbildung unterhalb Sekundarbereich II & 57 & 57 & 58 & 56 & & 64 & 62 & 64 & 58 & & 35 & 39 & 40 & 40 & \\
\hline & $\begin{array}{l}\text { Abschluss im Sekundarbereich II/ } \\
\text { postsekundaren, nicht tertiären Bereich }\end{array}$ & 75 & 75 & 76 & 74 & & 78 & 78 & 80 & 76 & & 46 & 50 & 52 & 53 & \\
\hline & Abschluss im Tertiärbereich & 85 & 84 & 85 & 83 & & 86 & 85 & 85 & 83 & & 62 & 65 & 67 & 67 & \\
\hline \multirow[t]{3}{*}{ EU21-Durchschnitt } & Ausbildung unterhalb Sekundarbereich II & 53 & 54 & 56 & 52 & $-3,8$ & 63 & 61 & 63 & 56 & $-6,6$ & 29 & 33 & 35 & 35 & 6,8 \\
\hline & $\begin{array}{l}\text { Abschluss im Sekundarbereich II/ } \\
\text { postsekundaren, nicht tertiären Bereich }\end{array}$ & 74 & 74 & 76 & 73 & $-2,9$ & 79 & 78 & 81 & 76 & $-4,3$ & 40 & 45 & 48 & 49 & 4,4 \\
\hline & Abschluss im Tertiärbereich & 85 & 85 & 85 & 83 & $-2,0$ & 86 & 85 & 86 & 83 & $-3,3$ & 60 & 63 & 65 & 65 & 2,9 \\
\hline \multicolumn{17}{|l|}{ Sonst. G20-Länder } \\
\hline Argentinien & & $\mathrm{m}$ & $\mathrm{m}$ & $\mathrm{m}$ & $\mathrm{m}$ & m & $\mathrm{m}$ & $\mathrm{m}$ & $\mathrm{m}$ & $\mathrm{m}$ & m & $\mathrm{m}$ & $\mathrm{m}$ & $\mathrm{m}$ & $\mathrm{m}$ & m \\
\hline \multirow[t]{3}{*}{ Brasilien } & Ausbildung unterhalb Sekundarbereich II & $\mathrm{m}$ & $\mathrm{m}$ & 69 & 67 & $-2,3$ & $\mathrm{~m}$ & $\mathrm{~m}$ & 73 & 71 & $-2,0$ & $\mathrm{~m}$ & $\mathrm{~m}$ & 54 & 51 & $-3,1$ \\
\hline & $\begin{array}{l}\text { Abschluss im Sekundarbereich II/ } \\
\text { postsekundaren, nicht tertiären Bereich }\end{array}$ & $\mathrm{m}$ & $\mathrm{m}$ & 78 & 70 & $-7,6$ & $\mathrm{~m}$ & $\mathrm{~m}$ & 80 & 64 & $-16,0$ & $\mathrm{~m}$ & $\mathrm{~m}$ & 54 & 53 & $-0,9$ \\
\hline & Abschluss im Tertiärbereich & $\mathrm{m}$ & $\mathrm{m}$ & 86 & 85 & $-0,7$ & $\mathrm{~m}$ & $\mathrm{~m}$ & 89 & 88 & $-1,1$ & $\mathrm{~m}$ & $\mathrm{~m}$ & 65 & 65 & $-0,5$ \\
\hline China & & $\mathrm{m}$ & $\mathrm{m}$ & $\mathrm{m}$ & $\mathrm{m}$ & m & $\mathrm{m}$ & $\mathrm{m}$ & $\mathrm{m}$ & $\mathrm{m}$ & m & $\mathrm{m}$ & $\mathrm{m}$ & $\mathrm{m}$ & $\mathrm{m}$ & m \\
\hline Indien & & $\mathrm{m}$ & $\mathrm{m}$ & $\mathrm{m}$ & $\mathrm{m}$ & m & $\mathrm{m}$ & $\mathrm{m}$ & $\mathrm{m}$ & $\mathrm{m}$ & m & $\mathrm{m}$ & $\mathrm{m}$ & $\mathrm{m}$ & $\mathrm{m}$ & m \\
\hline Indonesien & & $\mathrm{m}$ & $\mathrm{m}$ & $\mathrm{m}$ & $\mathrm{m}$ & m & $\mathrm{m}$ & $\mathrm{m}$ & $\mathrm{m}$ & $\mathrm{m}$ & m & $\mathrm{m}$ & $\mathrm{m}$ & $\mathrm{m}$ & $\mathrm{m}$ & $\mathbf{m}$ \\
\hline \multirow{3}{*}{$\begin{array}{l}\text { Russische } \\
\text { Föderation }\end{array}$} & Ausbildung unterhalb Sekundarbereich II & $\mathrm{m}$ & m & m & 49 & m & m & $\mathrm{m}$ & $\mathrm{m}$ & 57 & m & $\mathrm{m}$ & $\mathrm{m}$ & $\mathrm{m}$ & 28 & m \\
\hline & $\begin{array}{l}\text { Abschluss im Sekundarbereich II/ } \\
\text { postsekundaren, nicht tertiären Bereich }\end{array}$ & $\mathrm{m}$ & $\mathrm{m}$ & $\mathrm{m}$ & 73 & m & $\mathrm{m}$ & $\mathrm{m}$ & $\mathrm{m}$ & 79 & m & $\mathrm{m}$ & $\mathrm{m}$ & $\mathrm{m}$ & 44 & m \\
\hline & Abschluss im Tertiärbereich & $\mathrm{m}$ & $\mathrm{m}$ & $\mathrm{m}$ & 83 & m & $\mathrm{m}$ & $\mathrm{m}$ & $\mathrm{m}$ & 88 & m & $\mathrm{m}$ & $\mathrm{m}$ & $\mathrm{m}$ & 54 & $\mathbf{m}$ \\
\hline Saudi-Arabien & & $\mathrm{m}$ & $\mathrm{m}$ & $\mathrm{m}$ & $\mathrm{m}$ & m & $\mathrm{m}$ & $\mathrm{m}$ & $\mathrm{m}$ & $\mathrm{m}$ & m & $\mathrm{m}$ & $\mathrm{m}$ & $\mathrm{m}$ & $\mathrm{m}$ & $\mathbf{m}$ \\
\hline Südafrika & & $\mathrm{m}$ & $\mathrm{m}$ & $\mathrm{m}$ & $\mathrm{m}$ & m & $\mathrm{m}$ & $\mathrm{m}$ & $\mathrm{m}$ & $\mathrm{m}$ & m & $\mathrm{m}$ & $\mathrm{m}$ & $\mathrm{m}$ & $\mathrm{m}$ & m \\
\hline \multicolumn{2}{|l|}{ G20-Durchschnitt } & m & m & $\mathbf{m}$ & m & m & m & m & m & m & m & m & $\mathbf{m}$ & m & m & m \\
\hline
\end{tabular}

1. Die Zahlen für 2011 für Dänemark, Estland und die Niederlande in dieser Tabelle können von den Zahlen in anderen Tabellen in Indikator A5 abweichen, da unterschiedliche Datenquellen zugrunde liegen. Die Zahlen in dieser Tabelle basieren für alle Jahre auf der EU-LFS. 2. Die Zahlen für 200o sind nicht mit den Zahlen in den Folgejahren vergleichbar, da 2000 noch die frühere Klassifizierung des Bildungsstands verwendet wurde.

Quelle: OECD. Arbeitskräfteerhebung des Netzwerks zu den Arbeitsmarktergebnissen sowie den wirtschaftlichen und sozialen Auswirkungen des Lernens (LSO) für die meisten Länder sowie Arbeitskräfteerhebung der EU (EU-LFS) für Dänemark, Estland, Finnland, Frankreich (nur für 2000), Island, Irland, Italien (nur für 2000), Luxemburg, die Niederlande und Slowenien. Hinweise s. Anhang 3 unter www.oecd.org/edu/eag.htm.

StatLink: http://dx.doi.org/10.1787/888932848628

Erläuterung der Kennzeichnung fehlender Daten s. Hinweise für den Leser. 
Erwerbslosenquoten, nach Bildungsstand und Altersgruppe (2000, 2005, 2008 und 2011)

Zahl der 25- bis 64-jährigen/25- bis 34-jährigen/55- bis 64-jährigen Erwerbslosen als Prozentsatz aller 25- bis 64-jährigen/ 25- bis 34-jährigen/55- bis 64-jährigen Erwerbspersonen

\begin{tabular}{|c|c|c|c|c|c|c|c|c|c|c|c|c|c|c|c|c|}
\hline & \multirow[t]{3}{*}{ Bildungsstand } & \multicolumn{5}{|c|}{ 25- bis 64-Jährige } & \multicolumn{5}{|c|}{ 25- bis 34-Jährige } & \multicolumn{5}{|c|}{ 55- bis 64-Jährige } \\
\hline & & $\stackrel{4}{\circ}$ & $\stackrel{\circ}{\circ}$ & $\stackrel{\infty}{\stackrel{\infty}{N}}$ & กี & 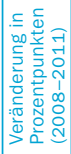 & 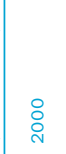 & 兽 & $\stackrel{\infty}{\circ}$ & $\stackrel{\text { กे }}{7}$ & 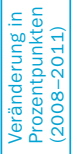 & $\stackrel{\text { i }}{\circ}$ & 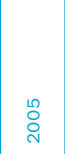 & 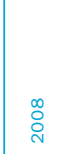 & กิ & 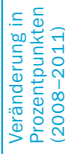 \\
\hline & & (1) & $(2)$ & (3) & (4) & (5) & (6) & (7) & (8) & (9) & $(10)$ & (11) & $(12)$ & (13) & (14) & (15) \\
\hline \multicolumn{17}{|l|}{ OECD-Länder } \\
\hline \multirow[t]{3}{*}{ Australien } & ich II & 7,5 & 6,3 & 5,5 & 5,9 & 0,4 & 11,4 & 12,3 & 8,5 & 9,5 & 1,0 & 4,9 & 3,7 & 3,2 & 3,6 &, 5 \\
\hline & $\begin{array}{l}\text { Abschluss im Sekundarbereich II/ } \\
\text { postsekundaren, nicht tertiären Bereich }\end{array}$ & 4,5 & 3,4 & 2,7 & 3,8 & 1,1 & 5,3 & 4,0 & 3,3 & 4,1 & 0,7 & 4,1 & 3,4 & 2,5 & 3,2 & 0,7 \\
\hline & Abschluss im Tertiärbereich & 3,6 & 2,5 & 2,2 & 2,8 & 0,6 & 3,8 & 2,8 & 2,2 & 3,4 & 1,2 & $3,5^{r}$ & $2,6 r$ & $2,1^{r}$ & 2,6 & 8 \\
\hline \multirow[t]{3}{*}{ Österreich } & Ausbildung unterhalb Sekundarbereich II & 6,2 & 8,6 & 6,3 & 7,1 & 0,8 & 8,1 & 14,9 & 13,4 & 10,1 & $-3,3$ & c & c & c & $4,7 r$ & \\
\hline & $\begin{array}{l}\text { Abschluss im Sekundarbereich II/ } \\
\text { postsekundaren, nicht tertiären Bereich }\end{array}$ & 2,9 & 3,9 & 2,9 & 3,2 & 0,3 & 2,7 & 4,5 & 3,4 & 4,2 & 0,7 & 6,0 & 3,8 & $2,4 r$ & 3,5 & ,0 \\
\hline & Abschluss im Tertiärbereich & 1,5 & 2,6 & 1,7 & 2,3 & 0,6 & c & 3,9 & $2,1^{r}$ & 3,3 & 1,2 & c & c & c & c & $\mathbf{m}$ \\
\hline \multirow[t]{3}{*}{ Belgien } & Ausbildung unterhalb Sekundarbereich II & 9,8 & 12,4 & 10,8 & 12,1 & 1,2 & 17,5 & 23,0 & 20,0 & 21,4 & 1,4 & $3,8^{r}$ & $6,1^{r}$ & $6,2^{r}$ & 6,3 & ,2 \\
\hline & $\begin{array}{l}\text { Abschluss im Sekundarbereich II/ } \\
\text { postsekundaren, nicht tertiären Bereich }\end{array}$ & 5,3 & 6,9 & 5,7 & 5,7 & $-0,1$ & 6,7 & 9,4 & 8,1 & 9,0 & 0,9 & $3,5^{r}$ & $4,1^{r}$ & 3,9 r & $3,6^{r}$ & $-0,3$ \\
\hline & Abschluss im Tertiärbereich & 2,7 & 3,7 & 3,2 & 3,4 & 0,2 & 3,3 & 4,9 & 4,3 & 4,4 & 0,1 & c & c & c & c & \\
\hline \multirow[t]{3}{*}{ Kanada } & kundarbereich II & 10,2 & 9,7 & 9,1 & 11,7 & 2,6 & 15,0 & 13,3 & 12,9 & 15,5 & 2,6 & 7,2 & 7,9 & 7,2 & 11,0 & 8 \\
\hline & $\begin{array}{l}\text { im Sekundarbereic } \\
\text { daren, nicht tertiär }\end{array}$ & 5,9 & 5,9 & 5,4 & 6,9 & 1,5 & 6,8 & 6,7 & 6,2 & 8,1 & 2,0 & 5,5 & 5,3 & 5,8 & 6,8 & 0,9 \\
\hline & Abschluss im Tertiärbereich & 4,1 & 4,6 & 4,1 & 5,0 & 0,9 & 4,5 & 5,2 & 4,3 & 5,4 & 1,1 & 4,0 & 4,2 & 4,4 & 5,4 & ,9 \\
\hline \multirow[t]{3}{*}{ Chile } & Ausbildung unterhalb Sekun & $\mathrm{m}$ & $\mathrm{m}$ & 5,2 & 4,4 & $-0,8$ & $\mathrm{~m}$ & $\mathrm{~m}$ & 9,6 & 6,0 & $-3,6$ & $\mathrm{~m}$ & $\mathrm{~m}$ & 3,4 & 3,6 & 2 \\
\hline & $\begin{array}{l}\text { Abschlc } \\
\text { postsel }\end{array}$ & $\mathrm{m}$ & $\mathrm{m}$ & 6,6 & 5,0 & $-1,6$ & $\mathrm{~m}$ & $\mathrm{~m}$ & 9,4 & 7,0 & $-2,4$ & $\mathrm{~m}$ & $\mathrm{~m}$ & 5,2 & 4,0 & $-1,1$ \\
\hline & Abschluss im Tertiärbereich & $\mathrm{m}$ & $\mathrm{m}$ & 5,5 & 5,4 & $-0,1$ & $\mathrm{~m}$ & $\mathrm{~m}$ & 8,7 & 8,2 & $-0,6$ & $\mathrm{~m}$ & $\mathrm{~m}$ & 2,6 & 2,6 & 0,0 \\
\hline \multirow[t]{3}{*}{ Tschechien } & Ausbildung unterhalb Sekundarbereich II & 19,3 & 24,4 & 17,3 & 21,6 & 4,3 & 28,3 & 35,5 & 23,9 & 29,9 & 6,0 & 8,1 & 13,7 & 10,6 & 13,6 & 3,0 \\
\hline & $\begin{array}{l}\text { Absch } \\
\text { postse }\end{array}$ & 6,7 & 6,2 & 3,3 & 5,7 & 2,4 & 8,7 & 7,0 & 3,7 & 6,5 & 2,8 & 5,3 & 4,9 & 3,6 & 5,8 & $\mathbf{2 , 2}$ \\
\hline & Abschl & ,5 & 2,0 & 1,5 & 2,6 & 1,1 & 3,4 & 2,4 & 2,5 & 3,6 & 1,1 & 2,2 & 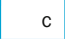 & - & 2,4 & \\
\hline \multirow[t]{3}{*}{ Dänemark ${ }^{1}$} & ereich II & 6,3 & 6,5 & 3,6 & 8,9 & 5,3 & 10,6 & 9,7 & 6,2 & 15,0 & 8,9 & $3,1^{r}$ & 6,5 & 3,3 & 6,7 & 3,5 \\
\hline & $\begin{array}{l}\text { Abschl } \\
\text { postse }\end{array}$ & 3,9 & 4,0 & 2,3 & 6,0 & $3, \mathbf{7}$ & 3,9 & 4,3 & 2,6 & 9,0 & 6,4 & 4,9 & 5,7 & 2,6 & 6,6 & 4,0 \\
\hline & Abschluss im Tertiärbereich & 2,6 & 3,7 & 2,2 & 5,0 & 2,8 & 4,2 & 5,0 & 3,1 & 7,4 & 4,3 & $2,9^{r}$ & 3,6 & $2,0 \mathrm{r}$ & 3,7 & 1,7 \\
\hline \multirow[t]{3}{*}{ Estland $^{1}$} & Ausbilc & 21,8 & 13,0 & 9,7 & 26,4 & 16,7 & 29,0 & 17,0 & 9,1 & 26,8 & 17,6 & 23,4 & c & c & $16,9^{r}$ & \\
\hline & ereich & 14,5 & 8,4 & 5,2 & 11,9 & 6,6 & 15,4 & 7,2 & 5,0 & 13,3 & 8,3 & 3,9 & 5,9 & $4,3 r$ & 10,9 & 6,7 \\
\hline & ssch & 4,6 & 3,8 & 2,8 & 7,9 & 5,1 & 4,1 & $3,1^{r}$ & $2,6^{r}$ & 7,6 & 5,0 & 3,7 & $\mathrm{c}$ & c & 11,4 & \\
\hline \multirow[t]{3}{*}{ Finnland } & darbereich II & 11,9 & 10,7 & 8,1 & 11,3 & 3,3 & 16,4 & 17,4 & 11,5 & 18,1 & 6,6 & 11,5 & 9,0 & 7,2 & 8,6 & ,4 \\
\hline & & 8 & 7,4 & 5,4 & 6,9 & 1,5 & 10,4 & 8,0 & 6,5 & 7,6 & 1,2 & 9,7 & 7,0 & 5,7 & 7,5 & 18 \\
\hline & Abschluss im Tertiärbereich & 4,9 & 4,4 & 3,3 & 4,0 & 0,7 & 6,7 & 4,8 & 3,7 & 5,3 & 1,6 & 6,5 & 4,6 & 3,6 & 4,0 & 4 \\
\hline \multirow[t]{3}{*}{ Frankreich } & Ausbildung unterhalb Sekundarbereich II & 13,8 & 11,1 & 9,7 & 12,9 & 3,2 & 21,7 & 18,8 & 16,9 & 23,3 & 6,4 & 8,5 & 6,3 & 5,8 & 8,7 & 2,9 \\
\hline & Absch & 8, & 6,6 & 5,5 & 7,4 & 1,8 & 10,3 & 9,3 & 8,3 & 11,4 & 3,1 & 7,7 & 4,6 & 4,2 & 6,0 & 1,8 \\
\hline & Abschli & 5,1 & 5,4 & 4,0 & 4,9 & 0,8 & 6,6 & 6,4 & 4,5 & 6,1 & 1,6 & 4,3 & 4,3 & 3,5 & 4,3 & 0,8 \\
\hline \multirow[t]{3}{*}{ Deutschland } & Indarbereich II & 13,7 & 20,2 & 16,5 & 13,9 & $-2,6$ & 14,6 & 25,6 & 21,6 & 19,6 & $-2,1$ & 15,8 & 18,3 & 14,7 & 11,8 & $-3,0$ \\
\hline & $\begin{array}{l}\text { Abschly } \\
\text { postsek }\end{array}$ & & 11,0 & 7,2 & 5,8 & $-1,4$ & 6,2 & 10,9 & 7,3 & 6,1 & $-1,2$ & 13,7 & 13,9 & 8,9 & 7,1 & 1,7 \\
\hline & Abschluss im Tertiärbereich & 4,0 & 5,6 & 3,3 & 2,4 & $-0,9$ & 2,7 & 5,9 & 3,6 & 2,7 & $-0,9$ & 7,5 & 7,8 & 4,9 & 3,4 & $-1,5$ \\
\hline \multirow[t]{3}{*}{ Griechenland } & Ausbildung unterhalb Sekundarbereich II & 8,2 & 8,3 & 6,8 & 17,1 & 10,3 & 14,0 & 11,1 & 10,0 & 25,1 & 15,0 & 4,0 & 4,5 & 4,0 & 9,7 & 5,6 \\
\hline & $\begin{array}{l}\text { Abschlu } \\
\text { postsek }\end{array}$ & 1 & 9,6 & 7,2 & 17,6 & 10,4 & 15,6 & 13,1 & 10,4 & 23,4 & 13,0 & 5,0 & c & c & 10,4 & \\
\hline & Absch & 7,5 & 7,1 & 5,7 & 12,8 & 7,1 & 13,7 & 13,3 & 12,0 & 25,6 & 13,6 & c & c & c & c & m \\
\hline Ungarn & Ausbildung unterhalb Sekundarbereich II & 9,9 & 12,4 & 17,3 & 23,1 & 5,8 & 14,1 & 16,7 & 22,4 & 28,5 & 6,2 & 3,9 & 6,4 & 10,4 & 16,2 & 5,8 \\
\hline & $\begin{array}{l}\text { Sekundarbereich II/ } \\
\text { ren, nicht tertiären Bereich }\end{array}$ & & 6,0 & 6,3 & 9,6 & 3,2 & 6,8 & 7,3 & 7,7 & 10,9 & 3,2 & 3,6 & 4,0 & 5,1 & 8,7 & ,6 \\
\hline & Abschluss im Tertiärbereich & 1,3 & 2,3 & 2,3 & 3,9 & 1,6 & 1,6 & 3,1 & 3,2 & 5,4 & 2,2 & c & c & c & 3,7 & in \\
\hline Island & Ausbildung unterhalb Sekundarbereich II & 2,0 & 2,3 & 2,5 & 7,3 & 4,8 & c & c & c & 11,6 & $\mathbf{m}$ & c & c & c & c & $\mathrm{m}$ \\
\hline & $\begin{array}{l}\text { Abschluss im Sekundarbereich II/ } \\
\text { postsekundaren, nicht tertiären Bereich }\end{array}$ & & 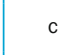 & c & 5,4 & $\mathbf{m}$ & $c$ & c & . & 9,1 & $\mathbf{m}$ & c & c & c & c & \\
\hline & Abschluss im Tertiärbereich & c & c & ${ }^{c}$ & 4,5 & m & c & c & c & c & m & $\mathrm{n}$ & $\mathrm{c}$ & C & c & \\
\hline
\end{tabular}

1. Die Zahlen für 2011 für Dänemark, Estland und die Niederlande in dieser Tabelle können von den Zahlen in anderen Tabellen in Indikator A5 abweichen, da unterschiedliche Datenquellen zugrunde liegen. Die Zahlen in dieser Tabelle basieren für alle Jahre auf der EU-LFS. 2. Die Zahlen für 2000 sind nicht mit den Zahlen in den Folgejahren vergleichbar, da 2000 noch die frühere Klassifizierung des Bildungsstands verwendet wurde.

Quelle: OECD. Arbeitskräfteerhebung des Netzwerks zu den Arbeitsmarktergebnissen sowie den wirtschaftlichen und sozialen Auswirkungen des Lernens (LSO) für die meisten Länder sowie Arbeitskräfteerhebung der EU (EU-LFS) für Dänemark, Estland, Finnland, Frankreich (nur für 2000), Island, Irland, Italien (nur für 2000), Luxemburg, die Niederlande und Slowenien. Hinweise s. Anhang 3 unter www.oecd.org/edu/eag.htm. StatLink: http://dx.doi.org/10.1787/888932848704 Erläuterung der Kennzeichnung fehlender Daten s. Hinweise für den Leser. 
Tabelle A5.4a (Forts. 1)

Erwerbslosenquoten, nach Bildungsstand und Altersgruppe (2000, 2005, 2008 und 2011)

Zahl der 25- bis 64-jährigen/25- bis 34-jährigen/55- bis 64-jährigen Erwerbslosen als Prozentsatz aller 25- bis 64-jährigen/ 25- bis 34-jährigen/55- bis 64-jährigen Erwerbspersonen

\begin{tabular}{|c|c|c|c|c|c|c|c|c|c|c|c|c|c|c|c|c|}
\hline & \multirow[t]{3}{*}{ Bildungsstand } & \multicolumn{5}{|c|}{ 25- bis 64-Jährige } & \multicolumn{5}{|c|}{ 25- bis 34-Jährige } & \multicolumn{5}{|c|}{ 55- bis 64-Jährige } \\
\hline & & $\begin{array}{l}\circ \\
\text { ¿ }\end{array}$ & $\begin{array}{l}\stackrel{\text { L }}{\circ} \\
\stackrel{\sim}{N}\end{array}$ & $\begin{array}{l}\infty \\
\stackrel{D}{ } \\
\stackrel{i}{ }\end{array}$ & 공 & 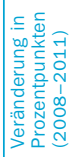 & : & : & 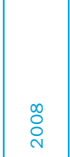 & 곰 & 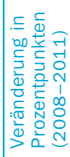 & : & ஜ̊ & 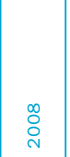 & ) & 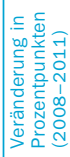 \\
\hline & & (1) & (2) & (3) & (4) & (5) & (6) & (7) & (8) & (9) & (10) & (11) & (12) & (13) & (14) & (15) \\
\hline \multicolumn{17}{|l|}{ OECD-Länder } \\
\hline Irland & $\begin{array}{l}\text { Ausbildung unterhalb Sekundarbereich II } \\
\text { Abschluss im Sekundarbereich II/ } \\
\text { postsekundaren, nicht tertiären Bereich } \\
\text { Abschluss im Tertiärbereich }\end{array}$ & $\begin{array}{l}7,1 \\
2,6 \\
1,6\end{array}$ & $\begin{array}{l}6,0 \\
3,1 \\
2,0\end{array}$ & $\begin{array}{l}8,2 \\
4,8 \\
3,0\end{array}$ & $\begin{array}{r}21,7 \\
15,0 \\
7,1\end{array}$ & $\begin{array}{r}13,5 \\
10,2 \\
4,1\end{array}$ & $\begin{array}{l}9,8 \\
2,7 \\
2,0\end{array}$ & $\begin{array}{r}10,4 \\
3,7 \\
2,4\end{array}$ & $\begin{array}{r}15,5 \\
6,4 \\
3,5\end{array}$ & $\begin{array}{r}37,0 \\
20,6 \\
8,7\end{array}$ & $\begin{array}{r}21,5 \\
14,2 \\
5,2\end{array}$ & $\begin{array}{r}3,0 \\
\mathrm{C} \\
\mathrm{C}\end{array}$ & $\begin{array}{r}3,1 \\
c \\
c\end{array}$ & $\begin{array}{r}4,1 \\
\mathrm{C} \\
\mathrm{C}\end{array}$ & $\begin{array}{r}12,4 \\
9,6 \\
5,4\end{array}$ & $\begin{array}{r}8,3 \\
m \\
m\end{array}$ \\
\hline Israel & $\begin{array}{l}\text { Ausbildung unterhalb Sekundarbereich II } \\
\text { Abschluss im Sekundarbereich II/ } \\
\text { postsekundaren, nicht tertiären Bereich } \\
\text { Abschluss im Tertiärbereich }\end{array}$ & $\begin{array}{l}\mathrm{m} \\
\mathrm{m} \\
\mathrm{m}\end{array}$ & $\begin{array}{r}14,0 \\
9,5 \\
5,1\end{array}$ & $\begin{array}{l}9,8 \\
5,8 \\
3,7\end{array}$ & $\begin{array}{l}7,3 \\
5,8 \\
3,9\end{array}$ & $\begin{array}{r}-2,5 \\
0,0 \\
0,2\end{array}$ & $\begin{array}{l}\mathrm{m} \\
\mathrm{m} \\
\mathrm{m}\end{array}$ & $\begin{array}{r}14,2 \\
10,9 \\
5,7\end{array}$ & $\begin{array}{r}10,9 \\
6,8 \\
4,1\end{array}$ & $\begin{array}{r}10,1 \\
7,7 \\
5,1\end{array}$ & $\begin{array}{r}-0,9 \\
0,9 \\
0,9\end{array}$ & $\begin{array}{l}\mathrm{m} \\
\mathrm{m} \\
\mathrm{m}\end{array}$ & $\begin{array}{r}10,3 \\
10,0 \\
5,1\end{array}$ & $\begin{array}{l}8,3 \\
4,0 \\
3,4\end{array}$ & $\begin{array}{l}5,9 \\
4,3 \\
3,6\end{array}$ & $\begin{array}{r}-2,5 \\
0,3 \\
0,3\end{array}$ \\
\hline Italien & $\begin{array}{l}\text { Ausbildung unterhalb Sekundarbereich II } \\
\text { Abschluss im Sekundarbereich II/ } \\
\text { postsekundaren, nicht tertiären Bereich } \\
\text { Abschluss im Tertiärbereich }\end{array}$ & $\begin{array}{l}9,8 \\
7,4 \\
5,9\end{array}$ & $\begin{array}{l}7,8 \\
5,2 \\
5,7\end{array}$ & $\begin{array}{l}7,4 \\
4,6 \\
4,3\end{array}$ & $\begin{array}{l}9,4 \\
6,0 \\
5,2\end{array}$ & $\begin{array}{l}1,9 \\
1,3 \\
0,9\end{array}$ & $\begin{array}{l}15,1 \\
12,3 \\
15,5\end{array}$ & $\begin{array}{r}11,8 \\
8,1 \\
13,8\end{array}$ & $\begin{array}{r}11,3 \\
7,2 \\
9,4\end{array}$ & $\begin{array}{l}14,8 \\
10,2 \\
11,5\end{array}$ & $\begin{array}{l}3,6 \\
2,9 \\
2,1\end{array}$ & $\begin{array}{l}5,8 \\
1,8 \\
0,7\end{array}$ & $\begin{array}{l}4,8 \\
2,4 \\
1,0\end{array}$ & $\begin{array}{l}4,9 \\
1,8 \\
0,6\end{array}$ & $\begin{array}{l}6,3 \\
2,5 \\
1,1\end{array}$ & $\begin{array}{l}1,3 \\
0,7 \\
0,5\end{array}$ \\
\hline Japan & $\begin{array}{l}\text { Ausbildung unterhalb Sekundarbereich II } \\
\text { Abschluss im Sekundarbereich II/ } \\
\text { postsekundaren, nicht tertiären Bereich } \\
\text { Abschluss im Tertiärbereich }\end{array}$ & $\begin{array}{l}6,6 \\
5,0 \\
3,1\end{array}$ & $\begin{array}{r}m \\
5,4 \\
2,7\end{array}$ & $\begin{array}{r}m \\
4,7 \\
2,8\end{array}$ & $\begin{array}{r}m \\
5,3 \\
3,4\end{array}$ & $\begin{array}{r}m \\
0,7 \\
0,5\end{array}$ & $\begin{array}{l}9,6 \\
6,6 \\
4,4\end{array}$ & $\begin{array}{r}m \\
7,0 \\
4,6\end{array}$ & $\begin{array}{r}m \\
6,3 \\
4,2\end{array}$ & $\begin{array}{r}m \\
7,5 \\
4,5\end{array}$ & $\begin{array}{r}m \\
1,2 \\
0,2\end{array}$ & $\begin{array}{l}6,5 \\
5,5 \\
4,8\end{array}$ & $\begin{array}{r}m \\
4,5 \\
2,4\end{array}$ & $\begin{array}{r}m \\
3,8 \\
2,9\end{array}$ & $\begin{array}{r}m \\
5,5 \\
3,9\end{array}$ & $\begin{array}{r}m \\
1,7 \\
1,0\end{array}$ \\
\hline Korea & $\begin{array}{l}\text { Ausbildung unterhalb Sekundarbereich II } \\
\text { Abschluss im Sekundarbereich II/ } \\
\text { postsekundaren, nicht tertiären Bereich } \\
\text { Abschluss im Tertiärbereich }\end{array}$ & $\begin{array}{l}3,7 \\
4,1 \\
3,6\end{array}$ & $\begin{array}{l}2,9 \\
3,8 \\
2,9\end{array}$ & $\begin{array}{l}2,5 \\
3,3 \\
2,6\end{array}$ & $\begin{array}{l}2,7 \\
3,4 \\
2,9\end{array}$ & $\begin{array}{l}0,2 \\
0,0 \\
0,3\end{array}$ & $\begin{array}{l}7,3 \\
5,0 \\
4,6\end{array}$ & $\begin{array}{l}8,1 \\
5,7 \\
4,2\end{array}$ & $\begin{array}{l}8,6 \\
5,9 \\
4,0\end{array}$ & $\begin{array}{l}7,0 \\
6,2 \\
4,6\end{array}$ & $\begin{array}{r}-1,6 \\
0,3 \\
0,6\end{array}$ & $\begin{array}{l}2,7 \\
3,7 \\
3,1\end{array}$ & $\begin{array}{l}2,3 \\
3,3 \\
1,8\end{array}$ & $\begin{array}{l}2,0 \\
1,9 \\
1,8\end{array}$ & $\begin{array}{l}2,5 \\
2,9 \\
1,4\end{array}$ & $\begin{array}{r}0,4 \\
1,0 \\
-0,3\end{array}$ \\
\hline Luxemburg & $\begin{array}{l}\text { Ausbildung unterhalb Sekundarbereich II } \\
\text { Abschluss im Sekundarbereich II/ } \\
\text { postsekundaren, nicht tertiären Bereich } \\
\text { Abschluss im Tertiärbereich }\end{array}$ & $\begin{array}{r}3,1 \\
1,6^{r} \\
C\end{array}$ & $\begin{array}{l}5,1 \\
3,2 \\
3,2\end{array}$ & $\begin{array}{r}4,8 \\
4,9 \\
2,2^{r}\end{array}$ & $\begin{array}{l}6,1 \\
3,7 \\
3,5\end{array}$ & $\begin{array}{r}1,2 \\
-1,2 \\
1,3\end{array}$ & $\begin{array}{r}5,4 r \\
2,2 r \\
c\end{array}$ & $\begin{array}{l}8,1 \mathrm{r} \\
4,0 \mathrm{r} \\
2,7 \mathrm{r}\end{array}$ & $\begin{array}{l}8,4 r \\
8,2 \\
2,4 r\end{array}$ & $\begin{array}{l}7,4 \mathrm{r} \\
4,5 \mathrm{r} \\
4,3 \mathrm{r}\end{array}$ & $\begin{array}{r}-1,0 \\
-3,7 \\
1,9\end{array}$ & $\begin{array}{l}\mathrm{c} \\
\mathrm{c} \\
\mathrm{c}\end{array}$ & $\begin{array}{l}\mathrm{c} \\
\mathrm{c} \\
\mathrm{c}\end{array}$ & $\begin{array}{l}\mathrm{c} \\
\mathrm{c} \\
\mathrm{c}\end{array}$ & $\begin{array}{l}\mathrm{c} \\
\mathrm{c} \\
\mathrm{c}\end{array}$ & $\begin{array}{l}\mathbf{m} \\
\mathbf{m} \\
\mathbf{m}\end{array}$ \\
\hline Mexiko & $\begin{array}{l}\text { Ausbildung unterhalb Sekundarbereich II } \\
\text { Abschluss im Sekundarbereich II/ } \\
\text { postsekundaren, nicht tertiären Bereich } \\
\text { Abschluss im Tertiärbereich }\end{array}$ & $\begin{array}{l}1,5 \\
2,2 \\
2,4\end{array}$ & $\begin{array}{l}2,3 \\
3,1 \\
3,7\end{array}$ & $\begin{array}{l}2,4 \\
2,9 \\
3,3\end{array}$ & $\begin{array}{l}4,0 \\
4,4 \\
4,8\end{array}$ & $\begin{array}{l}1,6 \\
1,5 \\
1,5\end{array}$ & $\begin{array}{l}1,8 \\
2,5 \\
3,5\end{array}$ & $\begin{array}{l}2,8 \\
4,1 \\
5,5\end{array}$ & $\begin{array}{l}3,1 \\
4,4 \\
5,1\end{array}$ & $\begin{array}{l}5,4 \\
5,8 \\
7,2\end{array}$ & $\begin{array}{l}2,3 \\
1,4 \\
2,1\end{array}$ & $\begin{array}{l}1,2 \\
2,6 \\
2,1\end{array}$ & $\begin{array}{l}1,9 \\
2,4 \\
3,1\end{array}$ & $\begin{array}{l}1,9 \\
0,9 \\
2,3\end{array}$ & $\begin{array}{l}2,9 \\
3,4 \\
3,1\end{array}$ & $\begin{array}{l}1,0 \\
2,5 \\
0,7\end{array}$ \\
\hline Niederlande $^{1}$ & $\begin{array}{l}\text { Ausbildung unterhalb Sekundarbereich II } \\
\text { Abschluss im Sekundarbereich II/ } \\
\text { postsekundaren, nicht tertiären Bereich } \\
\text { Abschluss im Tertiärbereich }\end{array}$ & $\begin{array}{l}3,4 \\
1,9 \\
1,7\end{array}$ & $\begin{array}{l}5,8 \\
4,1 \\
2,8\end{array}$ & $\begin{array}{l}3,4 \\
2,1 \\
1,6\end{array}$ & $\begin{array}{l}5,4 \\
3,8 \\
2,8\end{array}$ & $\begin{array}{l}2,0 \\
1,7 \\
1,2\end{array}$ & $\begin{array}{l}4,5 \\
1,6 \\
1,5\end{array}$ & $\begin{array}{l}8,7 \\
3,9 \\
2,6\end{array}$ & $\begin{array}{l}4,5 \\
1,9 \\
1,2\end{array}$ & $\begin{array}{l}8,1 \\
4,2 \\
2,6\end{array}$ & $\begin{array}{l}3,5 \\
2,3 \\
1,4\end{array}$ & $\begin{array}{l}1,8 \\
1,9 \\
1,9\end{array}$ & $\begin{array}{l}4,5 \\
4,6 \\
3,1\end{array}$ & $\begin{array}{l}3,6 \\
3,5 \\
2,6\end{array}$ & $\begin{array}{l}4,2 \\
4,6 \\
3,6\end{array}$ & $\begin{array}{l}0,6 \\
1,2 \\
1,0\end{array}$ \\
\hline Neuseeland & $\begin{array}{l}\text { Ausbildung unterhalb Sekundarbereich II } \\
\text { Abschluss im Sekundarbereich II/ } \\
\text { postsekundaren, nicht tertiären Bereich } \\
\text { Abschluss im Tertiärbereich }\end{array}$ & $\begin{array}{l}6,6 \\
3,9 \\
3,3\end{array}$ & $\begin{array}{l}3,4 \\
2,3 \\
2,3\end{array}$ & $\begin{array}{l}3,7 \\
2,5 \\
2,4\end{array}$ & $\begin{array}{l}6,5 \\
4,4 \\
3,6\end{array}$ & $\begin{array}{l}2,8 \\
1,9 \\
1,2\end{array}$ & $\begin{array}{l}9,0 \\
4,7 \\
3,6\end{array}$ & $\begin{array}{l}5,5 \\
3,0 \\
3,3\end{array}$ & $\begin{array}{l}6,6 \\
3,9 \\
3,4\end{array}$ & $\begin{array}{r}10,4 \\
5,8 \\
4,5\end{array}$ & $\begin{array}{l}3,7 \\
1,9 \\
1,1\end{array}$ & $\begin{array}{l}5,4 \\
3,8 \\
3,9\end{array}$ & $\begin{array}{l}1,8 \\
1,7 \\
1,9\end{array}$ & $\begin{array}{l}2,1 \\
1,8 \\
2,0\end{array}$ & $\begin{array}{l}3,9 \\
3,3 \\
2,8\end{array}$ & $\begin{array}{l}1,8 \\
1,5 \\
0,8\end{array}$ \\
\hline Norwegen ${ }^{2}$ & $\begin{array}{l}\text { Ausbildung unterhalb Sekundarbereich II } \\
\text { Abschluss im Sekundarbereich II/ } \\
\text { postsekundaren, nicht tertiären Bereich } \\
\text { Abschluss im Tertiärbereich }\end{array}$ & $\begin{array}{l}2,2 \\
2,6 \\
1,9\end{array}$ & $\begin{array}{l}7,4 \\
2,6 \\
2,1\end{array}$ & $\begin{array}{l}3,8 \\
1,3 \\
1,2\end{array}$ & $\begin{array}{l}5,0 \\
2,2 \\
1,5\end{array}$ & $\begin{array}{l}1,2 \\
0,9 \\
0,2\end{array}$ & $\begin{array}{r}c \\
3,7 \\
2,7\end{array}$ & $\begin{array}{r}14,4 \\
4,1 \\
3,1\end{array}$ & $\begin{array}{r}c \\
c \\
2,2\end{array}$ & $\begin{array}{l}9,2 \\
3,7 \\
2,4\end{array}$ & $\begin{array}{r}m \\
m \\
0,2\end{array}$ & $\begin{array}{l}\mathrm{c} \\
\mathrm{c} \\
\mathrm{c}\end{array}$ & $\begin{array}{l}c \\
c \\
c\end{array}$ & $\begin{array}{l}\mathrm{c} \\
\mathrm{c} \\
\mathrm{c}\end{array}$ & $\begin{array}{l}\mathrm{c} \\
\mathrm{c} \\
\mathrm{c}\end{array}$ & $\begin{array}{l}\mathbf{m} \\
\mathbf{m} \\
\mathbf{m}\end{array}$ \\
\hline Polen & $\begin{array}{l}\text { Ausbildung unterhalb Sekundarbereich II } \\
\text { Abschluss im Sekundarbereich II/ } \\
\text { postsekundaren, nicht tertiären Bereich } \\
\text { Abschluss im Tertiärbereich }\end{array}$ & $\begin{array}{r}20,6 \\
13,9 \\
4,3\end{array}$ & $\begin{array}{r}27,1 \\
16,6 \\
6,2\end{array}$ & $\begin{array}{r}11,5 \\
6,3 \\
3,1\end{array}$ & $\begin{array}{r}16,9 \\
8,8 \\
4,5\end{array}$ & $\begin{array}{l}5,4 \\
2,5 \\
1,4\end{array}$ & $\begin{array}{r}32,4 \\
16,8 \\
7,4\end{array}$ & $\begin{array}{r}38,3 \\
19,9 \\
9,8\end{array}$ & $\begin{array}{r}15,4 \\
7,4 \\
5,2\end{array}$ & $\begin{array}{r}22,4 \\
11,5 \\
7,0\end{array}$ & $\begin{array}{l}7,0 \\
4,2 \\
1,8\end{array}$ & $\begin{array}{r}7,7 \\
11,6 \\
6,7\end{array}$ & $\begin{array}{c}13,6 \\
13,0 \\
4,5 r\end{array}$ & $\begin{array}{r}7,1 \\
6,0 \\
C\end{array}$ & $\begin{array}{r}11,3 \\
7,4 \\
2,1 \\
r\end{array}$ & $\begin{array}{r}4,1 \\
1,5 \\
\mathrm{~m}\end{array}$ \\
\hline Portugal & $\begin{array}{l}\text { Ausbildung unterhalb Sekundarbereich II } \\
\text { Abschluss im Sekundarbereich II/ } \\
\text { postsekundaren, nicht tertiären Bereich } \\
\text { Abschluss im Tertiärbereich }\end{array}$ & $\begin{array}{l}3,6 \\
3,5 \\
2,7\end{array}$ & $\begin{array}{l}7,5 \\
6,7 \\
5,4\end{array}$ & $\begin{array}{l}7,6 \\
6,6 \\
5,8\end{array}$ & $\begin{array}{r}13,3 \\
10,9 \\
8,0\end{array}$ & $\begin{array}{l}5,7 \\
4,3 \\
2,2\end{array}$ & $\begin{array}{l}4,2 \\
3,5 \\
4,3\end{array}$ & $\begin{array}{l}9,0 \\
8,3 \\
9,2\end{array}$ & $\begin{array}{l}9,2 \\
7,5 \\
9,0\end{array}$ & $\begin{array}{l}16,1 \\
12,2 \\
12,7\end{array}$ & $\begin{array}{l}6,9 \\
4,7 \\
3,7\end{array}$ & $\begin{array}{r}3,3 \\
\mathrm{C} \\
\mathrm{C}\end{array}$ & $\begin{array}{r}6,4 \\
c \\
c\end{array}$ & $\begin{array}{r}7,1 \\
\mathrm{C} \\
\mathrm{c}\end{array}$ & $\begin{array}{r}11,7 \\
9,7 \\
6,2\end{array}$ & $\begin{array}{r}4,6 \\
m \\
m\end{array}$ \\
\hline Slowakei & $\begin{array}{l}\text { Ausbildung unterhalb Sekundarbereich II } \\
\text { Abschluss im Sekundarbereich II/ } \\
\text { postsekundaren, nicht tertiären Bereich } \\
\text { Abschluss im Tertiärbereich }\end{array}$ & $\begin{array}{r}36,3 \\
14,3 \\
4,6\end{array}$ & $\begin{array}{r}49,2 \\
12,7 \\
4,4\end{array}$ & $\begin{array}{r}36,3 \\
7,4 \\
3,1\end{array}$ & $\begin{array}{r}39,3 \\
11,5 \\
5,2\end{array}$ & $\begin{array}{l}3,1 \\
4,1 \\
2,2\end{array}$ & $\begin{array}{r}55,7 \\
17,7 \\
7,0\end{array}$ & $\begin{array}{r}73,8 \\
13,8 \\
5,3\end{array}$ & $\begin{array}{r}51,4 \\
8,8 \\
4,7\end{array}$ & $\begin{array}{r}54,1 \\
14,8 \\
8,3\end{array}$ & $\begin{array}{l}2,6 \\
6,0 \\
3,5\end{array}$ & $\begin{array}{r}30,6 \\
10,1 \\
C\end{array}$ & $\begin{array}{r}36,5 \\
11,6 \\
7,7\end{array}$ & $\begin{array}{r}18,9 \\
5,7 \\
\mathrm{C}\end{array}$ & $\begin{array}{r}21,9 \\
10,5 \\
C\end{array}$ & $\begin{array}{r}3,0 \\
4,9 \\
m\end{array}$ \\
\hline Slowenien & $\begin{array}{l}\text { Ausbildung unterhalb Sekundarbereich II } \\
\text { Abschluss im Sekundarbereich II/ } \\
\text { postsekundaren, nicht tertiären Bereich } \\
\text { Abschluss im Tertiärbereich }\end{array}$ & $\begin{array}{l}9,8 \\
5,7 \\
2,1\end{array}$ & $\begin{array}{l}8,7 \\
5,7 \\
3,0\end{array}$ & $\begin{array}{l}5,9 \\
3,5 \\
3,1\end{array}$ & $\begin{array}{r}12,7 \\
8,2 \\
4,7\end{array}$ & $\begin{array}{l}6,8 \\
4,7 \\
1,6\end{array}$ & $\begin{array}{r}11,3 \\
5,8 \\
3,8\end{array}$ & $\begin{array}{c}16,1 \mathrm{r} \\
6,7 \\
5,1 \mathrm{r}\end{array}$ & $\begin{array}{r}10,1 \mathrm{r} \\
4,2 \\
5,6\end{array}$ & $\begin{array}{r}18,3 r \\
11,7 \\
7,4\end{array}$ & $\begin{array}{l}8,3 \\
7,5 \\
1,7\end{array}$ & $\begin{array}{r}c \\
10,9 \\
C\end{array}$ & $\begin{array}{r}2,9 r \\
6,3 r \\
c\end{array}$ & $\begin{array}{l}4,4 \mathrm{r} \\
4,6 \mathrm{r} \\
2,7 \mathrm{r}\end{array}$ & $\begin{array}{l}5,3 \mathrm{r} \\
7,2 \mathrm{r} \\
5,2^{\mathrm{r}}\end{array}$ & $\begin{array}{l}0,9 \\
2,6 \\
2,6\end{array}$ \\
\hline
\end{tabular}

1. Die Zahlen für 2011 für Dänemark, Estland und die Niederlande in dieser Tabelle können von den Zahlen in anderen Tabellen in Indikator A5 abweichen, da unterschiedliche Datenquellen zugrunde liegen. Die Zahlen in dieser Tabelle basieren für alle Jahre auf der EU-LFS. 2. Die Zahlen für 2000 sind nicht mit den Zahlen in den Folgejahren vergleichbar, da 2000 noch die frühere Klassifizierung des Bildungsstands verwendet wurde.

Quelle: OECD. Arbeitskräfteerhebung des Netzwerks zu den Arbeitsmarktergebnissen sowie den wirtschaftlichen und sozialen Auswirkungen des Lernens (LSO) für die meisten Länder sowie Arbeitskräfteerhebung der EU (EU-LFS) für Dänemark, Estland, Finnland, Frankreich (nur für 2000), Island, Irland, Italien (nur für 2000), Luxemburg, die Niederlande und Slowenien. Hinweise s. Anhang 3 unter www.oecd.org/edu/eag.htm. StatLink: http://dx.doi.org/10.1787/888932848704 Erläuterung der Kennzeichnung fehlender Daten s. Hinweise für den Leser. 
Erwerbslosenquoten, nach Bildungsstand und Altersgruppe (2000, 2005, 2008 und 2011)

Zahl der 25- bis 64-jährigen/25- bis 34-jährigen/55- bis 64-jährigen Erwerbslosen als Prozentsatz aller 25- bis 64-jährigen/

25- bis 34-jährigen/55- bis 64-jährigen Erwerbspersonen

\begin{tabular}{|c|c|c|c|c|c|c|c|c|c|c|c|c|c|c|c|c|}
\hline & \multirow[t]{3}{*}{ Bildungsstand } & \multicolumn{5}{|c|}{ 25- bis 64-Jährige } & \multicolumn{5}{|c|}{ 25- bis 34-Jährige } & \multicolumn{5}{|c|}{ 55- bis 64 -Jährige } \\
\hline & & : & 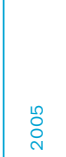 & $\stackrel{\infty}{\stackrel{2}{\circ}}$ & $\stackrel{\text { in }}{\rightarrow}$ & 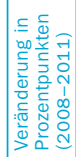 & $\stackrel{-}{\circ}$ & $\stackrel{n}{\circ}$ & $\stackrel{\infty}{\stackrel{2}{2}}$ & $\stackrel{4}{-1}$ & 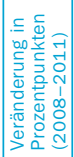 & : & $\stackrel{n}{\circ}$ & $\stackrel{\infty}{\stackrel{\sim}{\circ}}$ & $\stackrel{\text { ㄱ. }}{\rightarrow}$ & 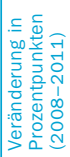 \\
\hline & & (1) & (2) & (3) & (4) & (5) & (6) & (7) & (8) & (9) & (10) & (11) & (12) & (13) & (14) & (15) \\
\hline \multicolumn{17}{|l|}{ OECD-Länder } \\
\hline \multirow[t]{3}{*}{ Spanien } & Ausbildung unterhalb Sekundarbereich II & 13,7 & 9,3 & 13,2 & 26,4 & 13,2 & 17,8 & 11,4 & 17,4 & 33,4 & 16,0 & 10,8 & 6,9 & 9,1 & 18,7 & 9,6 \\
\hline & $\begin{array}{l}\text { Abschluss im Sekundarbereich II/ } \\
\text { postsekundaren, nicht tertiären Bereich }\end{array}$ & 10,9 & 7,3 & 9,3 & 19,2 & 9,9 & 12,9 & 9,0 & 11,2 & 24,0 & 12,8 & 6,4 & 6,6 & 6,3 & 13,5 & 7,2 \\
\hline & Abschluss im Tertiärbereich & 9,5 & 6,1 & 5,8 & 11,6 & 5,8 & 14,5 & 8,5 & 8,0 & 16,2 & 8,2 & 4,1 & 3,5 & 3,0 & 7,1 & 4,1 \\
\hline \multirow[t]{3}{*}{ Schweden } & Ausbildung unterhalb Sekundarbereich II & 8,0 & 8,5 & 7,1 & 10,8 & 3,7 & 13,1 & 17,8 & 14,7 & 20,1 & 5,4 & 8,1 & 5,2 & 4,0 & 6,4 & 2,4 \\
\hline & $\begin{array}{l}\text { Abschluss im Sekundarbereich II/ } \\
\text { postsekundaren, nicht tertiären Bereich }\end{array}$ & 5,3 & 6,0 & 4,1 & 5,2 & 1,1 & 5,6 & 8,5 & 5,4 & 7,0 & 1,5 & 6,6 & 5,4 & 4,2 & 5,2 & 1,1 \\
\hline & Abschluss im Tertiärbereich & 3,0 & 4,5 & 3,3 & 3,8 & 0,6 & 3,2 & 7,1 & 4,2 & 5,1 & 0,8 & 2,9 & 2,3 & 3,0 & 2,8 & $-0,2$ \\
\hline \multirow[t]{3}{*}{ Schweiz } & Ausbildung unterhalb Sekundarbereich II & 4,8 & 7,2 & 6,0 & 7,6 & 1,6 & c & 11,8 & 8,9 & 13,3 & 4,5 & $7,0 \mathrm{r}$ & 6,0 & c & $6,0 \mathrm{r}$ & m \\
\hline & $\begin{array}{l}\text { Abschluss im Sekundarbereich II/ } \\
\text { postsekundaren, nicht tertiären Bereich }\end{array}$ & 2,2 & 3,7 & 2,9 & 3,3 & 0,4 & 2,8 & 4,7 & 3,1 & 3,8 & 0,6 & $1,8^{r}$ & 3,7 & 3,1 & 3,1 & 0,0 \\
\hline & Abschluss im Tertiärbereich & 1,4 & 2,7 & 1,8 & 2,6 & 0,8 & c & 3,4 & 2,0 & 3,3 & 1,3 & c & c & c & $2,1^{r}$ & m \\
\hline \multirow[t]{3}{*}{ Türkei } & Ausbildung unterhalb Sekundarbereich II & 4,6 & 9,1 & 9,6 & 8,4 & $-1,2$ & 5,7 & 11,3 & 12,1 & 10,4 & $-1,7$ & 2,4 & 4,2 & 5,3 & 5,3 & 0,0 \\
\hline & $\begin{array}{l}\text { Abschluss im Sekundarbereich II/ } \\
\text { postsekundaren, nicht tertiären Bereich }\end{array}$ & 5,5 & 9,1 & 9,2 & 8,9 & $-0,3$ & 7,1 & 11,9 & 11,1 & 10,1 & $-1,0$ & $\mathrm{n}$ & 4,5 & 7,6 & 8,1 & 0,5 \\
\hline & Abschluss im Tertiärbereich & 3,9 & 6,9 & 7,3 & 7,6 & 0,3 & 6,5 & 10,9 & 10,8 & 11,4 & 0,6 & 3,3 & 4,3 & 4,4 & 3,9 & $-0,5$ \\
\hline \multirow{3}{*}{$\begin{array}{l}\text { Vereinigtes } \\
\text { Königreich }\end{array}$} & Ausbildung unterhalb Sekundarbereich II & 6,6 & 5,1 & 7,5 & 11,0 & 3,5 & 9,1 & 7,8 & 12,0 & 18,9 & 6,9 & 5,6 & 3,2 & 4,3 & 7,4 & 3,1 \\
\hline & $\begin{array}{l}\text { Abschluss im Sekundarbereich II/ } \\
\text { postsekundaren, nicht tertiären Bereich }\end{array}$ & 4,0 & 3,1 & 4,3 & 5,9 & 1,6 & 4,7 & 4,2 & 5,9 & 8,2 & 2,3 & 4,0 & 2,4 & 3,9 & 4,9 & 1,0 \\
\hline & Abschluss im Tertiärbereich & 2,1 & 2,1 & 2,8 & 3,9 & 1,1 & 2,0 & 2,4 & 3,2 & 4,7 & 1,5 & 3,7 & 2,8 & 3,2 & 3,9 & 0,7 \\
\hline \multirow{3}{*}{$\begin{array}{l}\text { Vereinigte } \\
\text { Staaten }\end{array}$} & Ausbildung unterhalb Sekundarbereich II & 7,9 & 9,0 & 10,1 & 16,2 & 6,1 & 10,3 & 11,7 & 14,2 & 19,7 & 5,5 & 5,2 & 7,5 & 5,6 & 10,0 & 4,3 \\
\hline & $\begin{array}{l}\text { Abschluss im Sekundarbereich II/ } \\
\text { postsekundaren, nicht tertiären Bereich }\end{array}$ & 3,6 & 5,1 & 5,3 & 10,2 & 4,9 & 4,4 & 6,9 & 7,4 & 13,3 & 5,9 & 3,1 & 4,2 & 3,7 & 8,0 & 4,3 \\
\hline & Abschluss im Tertiärbereich & 1,8 & 2,6 & 2,4 & 4,9 & 2,5 & 2,0 & 3,0 & 2,6 & 5,0 & 2,4 & c & 2,3 & 2,5 & 5,4 & 2,9 \\
\hline \multirow{3}{*}{$\begin{array}{l}\text { OECD- } \\
\text { Durchschnitt }\end{array}$} & Ausbildung unterhalb Sekundarbereich II & 9,4 & 10,7 & 8,8 & 12,6 & 3,8 & 14,6 & 16,4 & 13,6 & 18,1 & 4,5 & 7,5 & 9,4 & 6,2 & 8,8 & 2,5 \\
\hline & $\begin{array}{l}\text { Abschluss im Sekundarbereich II/ } \\
\text { postsekundaren, nicht tertiären Bereich }\end{array}$ & 6,0 & 6,2 & 4,9 & 7,3 & 2,4 & 7,1 & 7,5 & 6,4 & 9,5 & 3,1 & 5,4 & 6,0 & 4,2 & 6,4 & 2,2 \\
\hline & Abschluss im Tertiärbereich & 3,4 & 3,9 & 3,3 & 4,8 & 1,5 & 5,1 & 5,4 & 4,6 & 6,8 & 2,2 & 3,6 & 3,4 & 2,9 & 4,0 & 1,1 \\
\hline \multirow{3}{*}{$\begin{array}{l}\text { OECD-Durch- } \\
\text { schnitt für } \\
\text { Länder mit } \\
\text { Daten für alle } \\
\text { Referenzjahre }\end{array}$} & Ausbildung unterhalb Sekundarbereich II & 9,5 & 10,6 & 8,8 & 13,0 & & 14,7 & 16,5 & 13,8 & 18,7 & & 7,5 & 7,4 & 6,3 & 9,1 & \\
\hline & $\begin{array}{l}\text { Abschluss im Sekundarbereich III } \\
\text { postsekundaren, nicht tertiären Bereich }\end{array}$ & 6,0 & 6,1 & 4,8 & 7,4 & & 7,2 & 7,4 & 6,3 & 9,7 & & 5,4 & 5,4 & 4,2 & 6,6 & \\
\hline & Abschluss im Tertiärbereich & 3,4 & 3,9 & 3,2 & 4,8 & & 5,1 & 5,4 & 4,5 & 6,9 & & 3,5 & 3,6 & 2,9 & 4,0 & \\
\hline \multirow{3}{*}{$\begin{array}{l}\text { EU21- } \\
\text { Durchschnitt }\end{array}$} & Ausbildung unterhalb Sekundarbereich II & 11,6 & 12,8 & 10,4 & 15,6 & 5,1 & 16,8 & 19,2 & 15,5 & 22,3 & 6,8 & 8,8 & 11,6 & 7,2 & 10,4 & 3,2 \\
\hline & $\begin{array}{l}\text { Abschluss im Sekundarbereich II/ } \\
\text { postsekundaren, nicht tertiären Bereich }\end{array}$ & 6,9 & 6,8 & 5,2 & 8,5 & 3,3 & 8,2 & 8,1 & 6,5 & 11,0 & 4,4 & 6,5 & 6,9 & 4,5 & 7,3 & 2,8 \\
\hline & Abschluss im Tertiärbereich & 3,7 & 4,1 & 3,2 & 5,2 & 2,0 & 5,7 & 5,8 & 4,7 & 7,6 & 2,9 & 3,9 & 3,7 & 2,9 & 4,4 & 1,5 \\
\hline \multicolumn{17}{|l|}{$\begin{array}{l}\text { Sonstige } \\
\text { G20-Länder }\end{array}$} \\
\hline Argentinien & & $\mathrm{m}$ & $\mathrm{m}$ & $\mathrm{m}$ & $\mathrm{m}$ & $\mathbf{m}$ & $\mathrm{m}$ & $\mathrm{m}$ & $\mathrm{m}$ & $\mathrm{m}$ & m & $\mathrm{m}$ & $\mathrm{m}$ & $\mathrm{m}$ & $\mathrm{m}$ & m \\
\hline \multirow[t]{3}{*}{ Brasilien } & Ausbildung unterhalb Sekundarbereich II & $\mathrm{m}$ & $\mathrm{m}$ & 4,7 & 4,6 & $-0,1$ & $\mathrm{~m}$ & $\mathrm{~m}$ & 7,0 & 7,2 & 0,1 & $\mathrm{~m}$ & $\mathrm{~m}$ & 2,4 & 2,4 & 0,0 \\
\hline & $\begin{array}{l}\text { Abschluss im Sekundarbereich II/ } \\
\text { postsekundaren, nicht tertiären Bereich }\end{array}$ & $\mathrm{m}$ & $\mathrm{m}$ & 6,1 & 6,1 & 0,0 & $\mathrm{~m}$ & $\mathrm{~m}$ & 8,2 & 9,0 & 0,8 & $\mathrm{~m}$ & $\mathrm{~m}$ & 3,0 & 2,5 & $-0,4$ \\
\hline & Abschluss im Tertiärbereich & $\mathrm{m}$ & $\mathrm{m}$ & 3,3 & 2,9 & $-0,3$ & $\mathrm{~m}$ & $\mathrm{~m}$ & 5,1 & 4,3 & $-0,8$ & $\mathrm{~m}$ & $\mathrm{~m}$ & 1,9 & 1,7 & $-0,2$ \\
\hline China & & $\mathrm{m}$ & $\mathrm{m}$ & $\mathrm{m}$ & $\mathrm{m}$ & m & $\mathrm{m}$ & $\mathrm{m}$ & $\mathrm{m}$ & $\mathrm{m}$ & m & $\mathrm{m}$ & $\mathrm{m}$ & $\mathrm{m}$ & $\mathrm{m}$ & m \\
\hline Indien & & $\mathrm{m}$ & $\mathrm{m}$ & $\mathrm{m}$ & $\mathrm{m}$ & $\mathbf{m}$ & $\mathrm{m}$ & $\mathrm{m}$ & $\mathrm{m}$ & $\mathrm{m}$ & $\mathbf{m}$ & $\mathrm{m}$ & $\mathrm{m}$ & $\mathrm{m}$ & $\mathrm{m}$ & m \\
\hline Indonesien & & $\mathrm{m}$ & $\mathrm{m}$ & $\mathrm{m}$ & $\mathrm{m}$ & $\mathbf{m}$ & $\mathrm{m}$ & $\mathrm{m}$ & $\mathrm{m}$ & $\mathrm{m}$ & $\mathbf{m}$ & $\mathrm{m}$ & $\mathrm{m}$ & $\mathrm{m}$ & $\mathrm{m}$ & m \\
\hline \multirow{3}{*}{$\begin{array}{l}\text { Russische } \\
\text { Föderation }\end{array}$} & Ausbildung unterhalb Sekundarbereich II & $\mathrm{m}$ & $\mathrm{m}$ & $\mathrm{m}$ & 14,4 & $\mathbf{m}$ & $\mathrm{m}$ & $\mathrm{m}$ & $\mathrm{m}$ & 17,9 & $\mathbf{m}$ & $\mathrm{m}$ & $\mathrm{m}$ & $\mathrm{m}$ & c & m \\
\hline & $\begin{array}{l}\text { Abschluss im Sekundarbereich II/ } \\
\text { postsekundaren, nicht tertiären Bereich }\end{array}$ & $\mathrm{m}$ & $\mathrm{m}$ & $\mathrm{m}$ & 7,3 & $\mathbf{m}$ & $\mathrm{m}$ & $\mathrm{m}$ & $\mathrm{m}$ & 8,7 & $\mathbf{m}$ & $\mathrm{m}$ & $\mathrm{m}$ & $\mathrm{m}$ & 5,5 & $\mathbf{m}$ \\
\hline & Abschluss im Tertiärbereich & $\mathrm{m}$ & $\mathrm{m}$ & $\mathrm{m}$ & 3,6 & $\mathbf{m}$ & $\mathrm{m}$ & $\mathrm{m}$ & $\mathrm{m}$ & 4,5 & $\mathbf{m}$ & $\mathrm{m}$ & $\mathrm{m}$ & $\mathrm{m}$ & 3,4 & m \\
\hline Saudi-Arabien & & $\mathrm{m}$ & $\mathrm{m}$ & $\mathrm{m}$ & $\mathrm{m}$ & m & $\mathrm{m}$ & $\mathrm{m}$ & $\mathrm{m}$ & $\mathrm{m}$ & m & $\mathrm{m}$ & $\mathrm{m}$ & $\mathrm{m}$ & $\mathrm{m}$ & m \\
\hline Südafrika & & $\mathrm{m}$ & $\mathrm{m}$ & $\mathrm{m}$ & $\mathrm{m}$ & $\mathbf{m}$ & $\mathrm{m}$ & $\mathrm{m}$ & $\mathrm{m}$ & $\mathrm{m}$ & m & $\mathrm{m}$ & $\mathrm{m}$ & $\mathrm{m}$ & $\mathrm{m}$ & m \\
\hline $\begin{array}{l}\text { G20-Durch- } \\
\text { schnitt }\end{array}$ & & $\mathrm{n}$ & $\mathbf{m}$ & $\mathbf{m}$ & $\mathbf{m}$ & m & $\mathbf{m}$ & $\mathbf{m}$ & $\mathbf{m}$ & $\mathbf{m}$ & $\mathbf{m}$ & m & m & $\mathbf{m}$ & m & $n$ \\
\hline
\end{tabular}

1. Die Zahlen für 2011 für Dänemark, Estland und die Niederlande in dieser Tabelle können von den Zahlen in anderen Tabellen in Indikator A5 abweichen, da unterschiedliche Datenquellen zugrunde liegen. Die Zahlen in dieser Tabelle basieren für alle Jahre auf der EU-LFS. 2. Die Zahlen für 200o sind nicht mit den Zahlen in den Folgejahren vergleichbar, da 2000 noch die frühere Klassifizierung des Bildungsstands verwendet wurde.

Quelle: OECD. Arbeitskräfteerhebung des Netzwerks zu den Arbeitsmarktergebnissen sowie den wirtschaftlichen und sozialen Auswirkungen des Lernens (LSO) für die meisten Länder sowie Arbeitskräfteerhebung der EU (EU-LFS) für Dänemark, Estland, Finnland, Frankreich (nur für 2000), Island, Irland, Italien (nur für 2000), Luxemburg, die Niederlande und Slowenien. Hinweise s. Anhang 3 unter www.oecd.org/edu/eag.htm. StatLink: http://dx.doi.org/10.1787/888932848704 Erläuterung der Kennzeichnung fehlender Daten s. Hinweise für den Leser. 
Tabelle A5.5a

Erwerbsstatus 25- bis 64-Jähriger, nach Bildungsstand und Ausrichtung des Bildungsgangs (2011)

\begin{tabular}{|c|c|c|c|c|c|c|c|c|c|c|c|c|c|c|c|c|c|c|}
\hline & \multicolumn{6}{|c|}{ Beschäftigungsquote (in \%) } & \multicolumn{6}{|c|}{ Erwerbslosenquote (in \%) } & \multicolumn{6}{|c|}{ Nichterwerbsquote (in \%) } \\
\hline & \multicolumn{2}{|c|}{ Berufsbildend } & \multicolumn{2}{|c|}{$\begin{array}{l}\text { Allgemein- } \\
\text { bildend }\end{array}$} & \multicolumn{2}{|c|}{ Gesamt $^{1}$} & \multicolumn{2}{|c|}{ Berufsbildend } & \multicolumn{2}{|c|}{$\begin{array}{l}\text { Allgemein- } \\
\text { bildend }\end{array}$} & \multicolumn{2}{|c|}{ Gesamt $^{1}$} & \multicolumn{2}{|c|}{ Berufsbildend } & \multicolumn{2}{|c|}{$\begin{array}{l}\text { Allgemein- } \\
\text { bildend }\end{array}$} & \multicolumn{2}{|c|}{ Gesamt $^{1}$} \\
\hline & $\begin{array}{c}\text { ISCED } \\
3 / 4\end{array}$ & $\begin{array}{c}\text { ISCED } \\
5^{2}\end{array}$ & $\begin{array}{c}\text { ISCED } \\
3 / 4\end{array}$ & $\begin{array}{c}\text { ISCED } \\
5^{2}\end{array}$ & $\begin{array}{c}\text { ISCED } \\
3 / 4\end{array}$ & $\begin{array}{c}\text { ISCED } \\
5^{2}\end{array}$ & $\begin{array}{c}\text { ISCED } \\
3 / 4\end{array}$ & $\begin{array}{c}\text { ISCED } \\
5^{2}\end{array}$ & $\begin{array}{c}\text { ISCED } \\
3 / 4\end{array}$ & \begin{tabular}{|c|} 
ISCED \\
$5^{2}$
\end{tabular} & $\begin{array}{c}\text { ISCED } \\
3 / 4\end{array}$ & $\begin{array}{c}\text { ISCED } \\
5^{2}\end{array}$ & $\begin{array}{c}\text { ISCED } \\
3 / 4\end{array}$ & $\begin{array}{c}\text { ISCED } \\
5^{2}\end{array} \mid$ & \begin{tabular}{|c|} 
ISCED \\
$3 / 4$
\end{tabular} & $\begin{array}{c}\text { ISCED } \\
5^{2}\end{array}$ & $\begin{array}{c}\text { ISCED } \\
3 / 4\end{array}$ & $\begin{array}{c}\text { ISCED } \\
5^{2}\end{array}$ \\
\hline & (1) & $(2)$ & (3) & (4) & (5) & (6) & (7) & (8) & (9) & (10) & (11) & $(12)$ & (13) & (14) & (15) & $(16)$ & (17) & (18) \\
\hline \multicolumn{19}{|l|}{ OECD-Länder } \\
\hline Australien & 84 & 81 & 77 & 85 & 81 & 84 & 3,5 & 3,1 & 4,1 & 2,7 & 3,8 & 2,8 & 13 & 17 & 20 & 12 & 16 & 13 \\
\hline Österreich & 78 & $x(6)$ & 76 & $x(6)$ & 78 & 87 & 3,1 & $x(12)$ & 4,4 & $x(12)$ & 3,2 & 2,3 & 19 & $x(18)$ & 21 & $x(18)$ & 20 & 11 \\
\hline Belgien & 76 & $x(6)$ & 69 & $x(6)$ & 74 & 84 & 5,3 & $x(12)$ & 6,5 & $x(12)$ & 5,7 & 3,3 & 20 & $x(18)$ & 26 & $x(18)$ & 22 & 13 \\
\hline Kanada & 79 & 81 & 72 & 82 & 74 & 82 & 6,6 & 5,4 & 7,1 & 4,7 & 6,9 & 5,0 & 16 & 14 & 22 & 14 & 20 & 14 \\
\hline Chile & $x(5)$ & $x(6)$ & $x(5)$ & $x(6)$ & 73 & 79 & $x(11)$ & $x(12)$ & $x(11)$ & $x(12)$ & 5,0 & 5,4 & $x(17)$ & $x(18)$ & $x(17)$ & $x(18)$ & 23 & 16 \\
\hline Tschechien $^{3}$ & 75 & $x(6)$ & 72 & $x(6)$ & 75 & 83 & 5,7 & $x(12)$ & C & $x(12)$ & 5,7 & 2,6 & 20 & $x(18)$ & $\mathrm{c}$ & $x(18)$ & 20 & 15 \\
\hline Dänemark & 79 & $x(6)$ & 65 & $x(6)$ & 79 & 86 & 5,8 & $x(12)$ & 9,4 & $x(12)$ & 6,0 & 5,1 & 16 & $x(18)$ & 28 & $x(18)$ & 16 & 10 \\
\hline Estland & 75 & 77 & 72 & 81 & 74 & 80 & 11,5 & 9,3 & 12,4 & 7,4 & 11,9 & 8,0 & 15 & 15 & 17 & 12 & 16 & 13 \\
\hline Finnland & 74 & $x(6)$ & 73 & $x(6)$ & 75 & 84 & 7,0 & $x(12)$ & 7,7 & $x(12)$ & 6,9 & 4,0 & 20 & $x(18)$ & 20 & $x(18)$ & 20 & 12 \\
\hline Frankreich & 73 & $x(6)$ & 75 & $x(6)$ & 74 & 84 & 7,6 & $x(12)$ & 6,9 & $x(12)$ & 7,4 & 4,9 & 21 & $x(18)$ & 20 & $x(18)$ & 20 & 12 \\
\hline Deutschland ${ }^{4}$ & 78 & 88 & 61 & 87 & 78 & 88 & 5,7 & $x(12)$ & 7,4 & $x(12)$ & 5,8 & 2,5 & 17 & $x(18)$ & 34 & $x(18)$ & 18 & 10 \\
\hline Griechenland & 68 & 72 & 60 & 75 & 63 & 75 & 19,5 & 16,2 & 16,4 & 11,6 & 17,6 & 13,0 & 16 & 14 & 29 & 16 & 24 & 14 \\
\hline Ungarn & 70 & $x(6)$ & 64 & $x(6)$ & 66 & 79 & 7,6 & $x(12)$ & 10,8 & $x(12)$ & 9,6 & 3,9 & 24 & $x(18)$ & 28 & $x(18)$ & 27 & 18 \\
\hline Island & 86 & $x(6)$ & 74 & $x(6)$ & 83 & 89 & 4,4 & $x(12)$ & 8,2 & $x(12)$ & 5,4 & 5,0 & 10 & $x(18)$ & 19 & $x(18)$ & 12 & 7 \\
\hline Irland & 65 & $x(6)$ & 65 & $x(6)$ & 65 & 81 & 17,7 & $x(12)$ & 13,8 & $x(12)$ & 15,0 & 7,2 & 21 & $x(18)$ & 24 & $x(18)$ & 23 & 13 \\
\hline Israel & 78 & $x(6)$ & 68 & $x(6)$ & 71 & 83 & 5,8 & $x(12)$ & 5,8 & $x(12)$ & 5,8 & 3,9 & 18 & $x(18)$ & 28 & $x(18)$ & 25 & 14 \\
\hline Italien & 74 & $x(6)$ & 64 & $x(6)$ & 72 & 79 & 5,8 & $x(12)$ & 6,8 & $x(12)$ & 6,0 & 5,2 & 21 & $x(18)$ & 31 & $x(18)$ & 24 & 17 \\
\hline Japan & $x(5)$ & $x(6)$ & $x(5)$ & $x(6)$ & 73 & 79 & $x(11)$ & $x(12)$ & $x(11)$ & $x(12)$ & 5,3 & 3,5 & $x(17)$ & $x(18)$ & $x(17)$ & $x(18)$ & 23 & 18 \\
\hline Korea & $x(5)$ & 74 & $x(5)$ & 78 & 71 & 77 & $x(11)$ & 3,8 & $x(11)$ & 2,6 & 3,4 & 2,9 & $\mathrm{x}(17)$ & 23 & $x(17)$ & 20 & 27 & 21 \\
\hline Luxemburg & 70 & $x(6)$ & 63 & $x(6)$ & 70 & 85 & 4,0 & $x(12)$ & $c$ & $x(12)$ & 3,7 & 3,6 & 27 & $x(18)$ & 34 & $x(18)$ & 27 & 12 \\
\hline Mexiko & $x(5)$ & $x(6)$ & $x(5)$ & $x(6)$ & 71 & 79 & $x(11)$ & $x(12)$ & $x(11)$ & $x(12)$ & 4,4 & 4,8 & $x(17)$ & $x(18)$ & $x(17)$ & $x(18)$ & 26 & 17 \\
\hline Niederlande & 81 & $x(6)$ & 77 & $x(6)$ & 80 & 87 & 3,2 & $x(12)$ & 3,1 & $x(12)$ & 3,8 & 2,6 & 17 & $x(18)$ & 20 & $x(18)$ & 17 & 10 \\
\hline Neuseeland & 83 & 82 & 80 & 86 & 82 & 84 & 4,8 & 4,9 & 3,7 & 2,7 & 4,4 & 3,6 & 13 & 14 & 17 & 11 & 14 & 13 \\
\hline Norwegen & 83 & 90 & 79 & 90 & 82 & 90 & 1,8 & c & 3,5 & 1,6 & 2,2 & 1,6 & 16 & 9 & 18 & 8 & 16 & 8 \\
\hline Polen ${ }^{3}$ & 66 & $x(6)$ & 62 & $x(6)$ & 66 & 85 & 8,6 & $x(12)$ & 9,9 & $x(12)$ & 8,8 & 4,5 & 27 & $x(18)$ & 31 & $x(18)$ & 28 & 11 \\
\hline Portugal $^{3}$ & $x(5)$ & $x(6)$ & $x(5)$ & $x(6)$ & 79 & 83 & $x(11)$ & $x(12)$ & $x(11)$ & $x(12)$ & 10,9 & 8,3 & $x(17)$ & $x(18)$ & $x(17)$ & $x(18)$ & 11 & 9 \\
\hline Slowakei & 71 & $x(6)$ & 66 & $x(6)$ & 70 & 82 & 11,5 & c & 11,9 & $x(12)$ & 11,5 & 5,2 & 20 & $x(18)$ & 25 & $x(18)$ & 21 & 14 \\
\hline Slowenien & 71 & $x(6)$ & 66 & $x(6)$ & 71 & 86 & 7,8 & $x(12)$ & 12,7 & $x(12)$ & 8,2 & 5,0 & 23 & $x(18)$ & 24 & $x(18)$ & 23 & 10 \\
\hline Spanien & 68 & $x(6)$ & 67 & $x(6)$ & 67 & 79 & 19,2 & $x(12)$ & 19,3 & $x(12)$ & 19,2 & 11,8 & 16 & $x(18)$ & 17 & $x(18)$ & 16 & 11 \\
\hline Schweden & 85 & $x(6)$ & 88 & $x(6)$ & 84 & 89 & 4,3 & $x(12)$ & 3,5 & $x(12)$ & 5,2 & 3,9 & 11 & $x(18)$ & 9 & $x(18)$ & 12 & 8 \\
\hline Schweiz & 83 & 92 & 77 & 87 & 83 & 89 & 3,1 & 1,7 & 5,1 & 3,1 & 3,3 & 2,7 & 15 & 6 & 19 & 11 & 15 & 9 \\
\hline Türkei $^{3}$ & 65 & $x(6)$ & 59 & $x(6)$ & 62 & 76 & 8,1 & $x(12)$ & 9,6 & $x(12)$ & 8,9 & 7,6 & 29 & $x(18)$ & 35 & $x(18)$ & 32 & 18 \\
\hline Ver. Königreich & $x(5)$ & 82 & $x(5)$ & 83 & 78 & 83 & $x(11)$ & 3,7 & $x(11)$ & 4,0 & 5,9 & 3,9 & $x(17)$ & 15 & $x(17)$ & 13 & 17 & 14 \\
\hline Vereinigte Staaten & $x(5)$ & 77 & $x(5)$ & 80 & 67 & 80 & $x(11)$ & 6,3 & $x(11)$ & 4,8 & 10,2 & 5,0 & $x(17)$ & 18 & $x(17)$ & 16 & 25 & 16 \\
\hline OECD-Durchschnitt & 76 & m & 70 & m & 74 & 83 & 7,4 & m & 8,4 & m & 7,3 & 4,8 & 18 & m & 24 & m & 20 & 13 \\
\hline EU21-Durchschnitt & 76 & m & 70 & m & 74 & 83 & 8,1 & $\mathrm{~m}$ & 9,1 & $\mathrm{~m}$ & 8,2 & 5,3 & 17 & m & 23 & m & 19 & 12 \\
\hline \multicolumn{19}{|l|}{ Sonst. G20-Länder } \\
\hline Argentinien & $\mathrm{m}$ & $\mathrm{m}$ & $\mathrm{m}$ & $\mathrm{m}$ & $\mathrm{m}$ & $\mathrm{m}$ & $\mathrm{m}$ & $\mathrm{m}$ & $\mathrm{m}$ & $\mathrm{m}$ & $\mathrm{m}$ & $\mathrm{m}$ & $\mathrm{m}$ & $\mathrm{m}$ & $\mathrm{m}$ & $\mathrm{m}$ & $\mathrm{m}$ & $\mathrm{m}$ \\
\hline Brasilien $^{3}$ & $x(5)$ & $x(6)$ & $x(5)$ & $x(6)$ & 70 & 85 & $x(11)$ & $x(12)$ & $x(11)$ & $x(12)$ & 6,1 & 2,9 & $x(17)$ & $x(18)$ & $x(17)$ & $x(18)$ & 25 & 12 \\
\hline China & $\mathrm{m}$ & $\mathrm{m}$ & $\mathrm{m}$ & $\mathrm{m}$ & $\mathrm{m}$ & $\mathrm{m}$ & $\mathrm{m}$ & $\mathrm{m}$ & $\mathrm{m}$ & $\mathrm{m}$ & $\mathrm{m}$ & $\mathrm{m}$ & $\mathrm{m}$ & $\mathrm{m}$ & $\mathrm{m}$ & $\mathrm{m}$ & $\mathrm{m}$ & $\mathrm{m}$ \\
\hline Indien & $\mathrm{m}$ & $\mathrm{m}$ & $\mathrm{m}$ & $\mathrm{m}$ & $\mathrm{m}$ & $\mathrm{m}$ & $\mathrm{m}$ & $\mathrm{m}$ & $\mathrm{m}$ & $\mathrm{m}$ & $\mathrm{m}$ & $\mathrm{m}$ & $\mathrm{m}$ & $\mathrm{m}$ & $\mathrm{m}$ & $\mathrm{m}$ & $\mathrm{m}$ & $\mathrm{m}$ \\
\hline Indonesien & $\mathrm{m}$ & $\mathrm{m}$ & $\mathrm{m}$ & $\mathrm{m}$ & $\mathrm{m}$ & $\mathrm{m}$ & $\mathrm{m}$ & $\mathrm{m}$ & $\mathrm{m}$ & $\mathrm{m}$ & $\mathrm{m}$ & $\mathrm{m}$ & $\mathrm{m}$ & $\mathrm{m}$ & $\mathrm{m}$ & $\mathrm{m}$ & $\mathrm{m}$ & $\mathrm{m}$ \\
\hline Russische Föd. & $x(5)$ & $x(6)$ & $x(5)$ & $x(6)$ & 73 & 83 & $x(11)$ & $x(12)$ & $x(11)$ & $x(12)$ & 7,3 & 3,6 & $x(17)$ & $x(18)$ & $x(17)$ & $x(18)$ & 21 & 14 \\
\hline Saudi-Arabien & $\mathrm{m}$ & $\mathrm{m}$ & $\mathrm{m}$ & $\mathrm{m}$ & $\mathrm{m}$ & $\mathrm{m}$ & $\mathrm{m}$ & $\mathrm{m}$ & $\mathrm{m}$ & $\mathrm{m}$ & $\mathrm{m}$ & $\mathrm{m}$ & $\mathrm{m}$ & $\mathrm{m}$ & $\mathrm{m}$ & $\mathrm{m}$ & $\mathrm{m}$ & $\mathrm{m}$ \\
\hline Südafrika & $\mathrm{m}$ & $\mathrm{m}$ & $\mathrm{m}$ & $\mathrm{m}$ & $\mathrm{m}$ & $\mathrm{m}$ & $\mathrm{m}$ & $\mathrm{m}$ & $\mathrm{m}$ & $\mathrm{m}$ & $\mathrm{m}$ & $\mathrm{m}$ & $\mathrm{m}$ & $\mathrm{m}$ & $\mathrm{m}$ & $\mathrm{m}$ & $\mathrm{m}$ & $\mathrm{m}$ \\
\hline G20-Durchschnitt & $\mathbf{m}$ & $\mathbf{m}$ & $\mathbf{m}$ & m & $\mathbf{m}$ & $\mathbf{m}$ & m & $\mathbf{m}$ & $\mathbf{m}$ & $\mathbf{m}$ & $\mathbf{m}$ & m & $\mathbf{m}$ & m & m & m & m & m \\
\hline
\end{tabular}

1. "Gesamt" bezieht sich auf die gewichteten Durchschnitte der Beschäftigungs-, Erwerbslosen- und Nichterwerbsquoten von Personen mit einem Abschluss der ISCED-Stufe 3/4 und der ISCED-Stufe 5A/5B. 2. Diese Tabelle enthält für den Tertiärbereich nur Daten über Abschlüsse im Tertiärbereich A und B (ISCED 5A und $5 B$ ), da die meisten Daten zu ISCED 6 nicht nach allgemeinbildend/berufsbildend aufgegliedert werden können. 3. Zahlen beziehen sich nur auf ISCEDStufe 5A, ISCED-Stufe 5B findet keine Anwendung. 4. In Deutschland entspricht ein Abschluss auf ISCED-Stufe 4A einem Abschluss sowohl eines allgemeinbildenden als auch eines berufsbildenden Bildungsgangs. Absolventen mit einem derartigen Abschluss wurden in dieser Tabelle den berufsbildenden Bildungsgängen zugeordnet.

Quelle: OECD. Spezielle Datenerhebung des Netzwerks zu den Arbeitsmarktergebnissen sowie den wirtschaftlichen und sozialen Auswirkungen des Lernens (LSO), Arbeitsgruppe Übergang vom Bildungssystem in den Arbeitsmarkt (Learning and Labour Transitions [LLT]) für die meisten Länder sowie die Arbeitskräfteerhebung der EU (EU-LFS) und die Arbeitskräfteerhebung (LSF) der EU mit Informationen zu den Fachrichtungen der entsprechenden Studiengänge (EULFS_VET) für Dänemark, Estland, Finnland, Irland, Island, Luxemburg und Slowenien. Hinweise s. Anhang 3 unter www.oecd.org/edu/eag.htm.

StatLink: http://dx.doi.org/10.1787/888932848780

Erläuterung der Kennzeichnung fehlender Daten s. Hinweise für den Leser. 
Tabelle A5.6

Anteil der ganzjährig Vollzeitbeschäftigten an allen Personen mit Erwerbseinkommen, nach Bildungsstand und Altersgruppe (2011) ${ }^{1}$

Erläuterung der Tabelle: In Australien arbeiten 89 Prozent der 25- bis 64-jährigen Männer mit einer Ausbildung unterhalb des Sekundarbereichs, die über ein

Erwerbseinkommen verfügen, vollzeit. Bei den 25- bis 64-jährigen Frauen sind es 47 Prozent.

\begin{tabular}{|c|c|c|c|c|c|c|c|c|c|c|c|c|c|c|}
\hline & & & \multicolumn{3}{|c|}{$\begin{array}{l}\text { Ausbildung unterhalb } \\
\text { Sekundarbereich II }\end{array}$} & \multicolumn{3}{|c|}{$\begin{array}{l}\text { Abschluss im Sekundar- } \\
\text { bereich II/postsekundaren, } \\
\text { nicht tertiären Bereich }\end{array}$} & \multicolumn{3}{|c|}{ Abschluss im Tertiärbereich } & \multicolumn{3}{|c|}{$\begin{array}{l}\text { Alle Bildungsbereiche } \\
\text { zusammen }\end{array}$} \\
\hline & & & $25-64$ & $35-44$ & $55-64$ & $25-64$ & $35-44$ & $55-64$ & $25-64$ & $35-44$ & $55-64$ & $25-64$ & $35-44$ & $55-64$ \\
\hline & & & (1) & (2) & (3) & (4) & (5) & (6) & (7) & (8) & (9) & (10) & (11) & (12) \\
\hline \multicolumn{15}{|l|}{ OECD-Länder } \\
\hline \multirow[t]{3}{*}{ Australien } & 2009 & Männer & 89 & 94 & 79 & 91 & 93 & 85 & 92 & 95 & 83 & 91 & 94 & 83 \\
\hline & & Frauen & 47 & 43 & 42 & 53 & 51 & 52 & 65 & 56 & 60 & 57 & 52 & 51 \\
\hline & & $M+F$ & 69 & 69 & 61 & 77 & 77 & 74 & 77 & 75 & 72 & 75 & 75 & 69 \\
\hline \multirow[t]{3}{*}{ Österreich } & 2011 & Männer & 63 & 64 & 68 & 76 & 77 & 81 & 80 & 81 & 86 & 76 & 77 & 80 \\
\hline & & Frauen & 37 & 38 & 38 & 41 & 34 & 48 & 55 & 48 & 68 & 43 & 37 & 49 \\
\hline & & $M+F$ & 48 & 49 & 51 & 60 & 56 & 69 & 69 & 66 & 79 & 60 & 57 & 68 \\
\hline \multirow[t]{3}{*}{ Belgien } & 2011 & Männer & 77 & 100 & 69 & 64 & 64 & 60 & 86 & 90 & 78 & 83 & 88 & 73 \\
\hline & & Frauen & 32 & c & c & 57 & 55 & 55 & 58 & 55 & 55 & 49 & 45 & 46 \\
\hline & & $M+F$ & 59 & 66 & 55 & 65 & 65 & 60 & 72 & 72 & 69 & 67 & 68 & 62 \\
\hline \multirow[t]{3}{*}{ Kanada } & 2010 & Männer & 70 & 73 & 65 & 73 & 75 & 67 & 74 & 81 & 64 & 73 & 77 & 65 \\
\hline & & Frauen & 52 & 56 & 49 & 54 & 57 & 54 & 59 & 61 & 51 & 57 & 59 & 52 \\
\hline & & $M+F$ & 63 & 66 & 58 & 64 & 67 & 61 & 66 & 71 & 58 & 65 & 69 & 59 \\
\hline \multirow[t]{3}{*}{ Chile } & 2011 & Männer & 55 & 52 & 60 & 64 & 69 & 70 & 65 & 66 & 71 & 61 & 62 & 65 \\
\hline & & Frauen & 38 & 34 & 43 & 51 & 49 & 53 & 53 & 52 & 49 & 47 & 45 & 48 \\
\hline & & $M+F$ & 49 & 46 & 55 & 58 & 60 & 63 & 59 & 59 & 62 & 55 & 55 & 59 \\
\hline Tschechien & & & m & $\mathrm{m}$ & $\mathrm{m}$ & m & $\mathrm{m}$ & $\mathrm{m}$ & $\mathbf{m}$ & $\mathrm{m}$ & $\mathrm{m}$ & m & $\mathrm{m}$ & $\mathrm{m}$ \\
\hline \multirow[t]{3}{*}{ Dänemark } & 2011 & Männer & 50 & 50 & 50 & 59 & 62 & 55 & 74 & 81 & 69 & 61 & 66 & 58 \\
\hline & & Frauen & 44 & 42 & 44 & 51 & 53 & 46 & 58 & 61 & 57 & 52 & 55 & 49 \\
\hline & & $M+F$ & 47 & 47 & 47 & 55 & 58 & 51 & 65 & 70 & 63 & 57 & 61 & 54 \\
\hline \multirow[t]{3}{*}{ Estland } & 2011 & Männer & 94 & 97 & 80 & 98 & 100 & 95 & 95 & 97 & 92 & 97 & 98 & 92 \\
\hline & & Frauen & 83 & 74 & 82 & 88 & 88 & 84 & 87 & 88 & 82 & 87 & 87 & 83 \\
\hline & & $M+F$ & 90 & 88 & 80 & 93 & 94 & 89 & 90 & 91 & 85 & 92 & 92 & 87 \\
\hline \multirow[t]{3}{*}{ Finnland } & 2010 & Männer & 92 & 94 & 89 & 93 & 95 & 90 & 95 & 97 & 89 & 94 & 96 & 90 \\
\hline & & Frauen & 79 & 80 & 77 & 82 & 83 & 80 & 88 & 86 & 85 & 85 & 85 & 81 \\
\hline & & $M+F$ & 86 & 89 & 82 & 88 & 90 & 84 & 91 & 90 & 87 & 89 & 90 & 85 \\
\hline Frankreich & 2009 & Männer & 73 & 76 & 61 & 80 & 86 & 61 & 87 & 90 & 76 & 80 & 85 & 65 \\
\hline & & Frauen & 50 & 55 & 45 & 61 & 63 & 59 & 70 & 69 & 63 & 62 & 64 & 54 \\
\hline & & $M+F$ & 62 & 66 & 52 & 72 & 75 & 60 & 78 & 79 & 70 & 72 & 75 & 59 \\
\hline Deutschland & 2011 & Männer & 85 & 90 & 88 & 82 & 85 & 81 & 83 & 87 & 82 & 82 & 86 & 82 \\
\hline & & Frauen & 43 & 36 & 36 & 45 & 39 & 41 & 56 & 49 & 62 & 48 & 42 & 46 \\
\hline & & $M+F$ & 64 & 60 & 59 & 63 & 62 & 61 & 71 & 70 & 74 & 66 & 65 & 65 \\
\hline Griechenland & 2011 & Männer & 54 & 64 & 40 & 67 & 78 & 37 & 73 & 84 & 60 & 65 & 76 & 44 \\
\hline & & Frauen & 25 & 31 & 16 & 36 & 41 & 19 & 62 & 65 & 32 & 40 & 46 & 20 \\
\hline & & $M+F$ & 39 & 49 & 26 & 52 & 59 & 28 & 67 & 74 & 49 & 53 & 61 & 31 \\
\hline Ungarn & 2011 & Männer & 76 & 78 & 74 & 85 & 87 & 82 & 89 & 91 & 85 & 85 & 87 & 81 \\
\hline & & Frauen & 74 & 76 & 68 & 82 & 83 & 79 & 89 & 89 & 88 & 83 & 84 & 79 \\
\hline & & $M+F$ & 75 & 77 & 70 & 84 & 85 & 81 & 89 & 90 & 87 & 84 & 85 & 80 \\
\hline Island & & & $\mathbf{m}$ & $\mathrm{m}$ & $\mathrm{m}$ & $\mathbf{m}$ & $\mathrm{m}$ & $\mathrm{m}$ & $\mathbf{m}$ & $\mathrm{m}$ & $\mathrm{m}$ & $\mathbf{m}$ & $\mathrm{m}$ & $\mathrm{m}$ \\
\hline Irland & 2010 & Männer & 63 & 69 & 56 & 69 & 74 & 56 & 82 & 87 & 71 & 72 & 77 & 60 \\
\hline & & Frauen & 25 & 21 & 16 & 46 & 49 & 47 & 61 & 57 & 66 & 50 & 48 & 45 \\
\hline & & $M+F$ & 49 & 51 & 45 & 58 & 61 & 51 & 71 & 73 & 69 & 62 & 64 & 54 \\
\hline Israel & 2011 & Männer & 89 & 90 & 87 & 92 & 93 & 87 & 88 & 93 & 87 & 90 & 93 & 87 \\
\hline & & Frauen & 55 & 64 & 40 & 68 & 70 & 59 & 69 & 72 & 63 & 68 & 71 & 60 \\
\hline & & $M+F$ & 78 & 84 & 69 & 82 & 83 & 74 & 78 & 83 & 76 & 79 & 83 & 75 \\
\hline Italien & 2009 & Männer & 80 & 82 & 71 & 86 & 90 & 78 & 87 & 91 & 79 & 84 & 86 & 75 \\
\hline & & Frauen & 55 & 56 & 54 & 66 & 64 & 67 & 78 & 81 & 74 & 65 & 65 & 62 \\
\hline & & $M+F$ & 71 & 73 & 65 & 77 & 78 & 74 & 82 & 86 & 77 & 76 & 77 & 70 \\
\hline Japan & & & $\mathbf{m}$ & $\mathrm{m}$ & $\mathrm{m}$ & $\mathbf{m}$ & $\mathrm{m}$ & $\mathrm{m}$ & $\mathbf{m}$ & $\mathrm{m}$ & $\mathrm{m}$ & $\mathbf{m}$ & $\mathrm{m}$ & $\mathrm{m}$ \\
\hline Korea & 2011 & Männer & 92 & 93 & 90 & 97 & 98 & 96 & 98 & 99 & 98 & 97 & 98 & 94 \\
\hline & & Frauen & 81 & 81 & 76 & 85 & 86 & 82 & 90 & 85 & 86 & 86 & 85 & 79 \\
\hline & & $M+F$ & 86 & 87 & 83 & 92 & 92 & 91 & 95 & 94 & 95 & 93 & 93 & 88 \\
\hline Luxemburg & 2010 & Männer & 88 & 91 & 80 & 91 & 93 & 75 & 91 & 98 & 82 & 90 & 94 & 79 \\
\hline & & Frauen & 43 & 50 & 27 & 53 & 46 & 41 & 65 & 55 & 63 & 54 & 51 & 40 \\
\hline & & $M+F$ & 67 & 71 & 54 & 76 & 75 & 64 & 78 & 76 & 76 & 74 & 74 & 64 \\
\hline
\end{tabular}

Anmerkung: Die Länge des Referenzzeitraums variiert zwischen 1 Woche und 1 Jahr. In einigen Ländern ohne Selbstständige.

1. Vollzeitbeschäftigung bezieht sich auf Beschäftigte mit einer ganzjährigen Beschäftigung von mindestens 30 Wochenarbeitsstunden. Einzelheiten s. Indikator A6 und Anhang 3.

Quelle: OECD. Spezielle Datenerhebung zu Einkommen von ganzjährig Vollzeitbeschäftigten des Netzwerks zu den Arbeitmarktergebnissen sowie den wirtschaftlichen und sozialen Auswirkungen des Lernens (LSO), Arbeitsgruppe Wirtschaftliche Ergebnisse von Bildung (Economic Outcomes).

Hinweise s. Anhang 3 unter www.oecd.org/edu/eag.htm. StatLink: http://dx.doi.org/10.1787/888932848837

Erläuterung der Kennzeichnung fehlender Daten s. Hinweise für den Leser. 
Tabelle A5.6 (Forts.)

Anteil der ganzjährig Vollzeitbeschäftigten an allen Personen mit Erwerbseinkommen, nach Bildungsstand und Altersgruppe (2011) ${ }^{1}$

Erläuterung der Tabelle: In Australien arbeiten 89 Prozent der 25- bis 64-jährigen Männer mit einer Ausbildung unterhalb des Sekundarbereichs, die über ein Erwerbseinkommen verfügen, vollzeit. Bei den 25- bis 64-jährigen Frauen sind es 47 Prozent.

\begin{tabular}{|c|c|c|c|c|c|c|c|c|c|c|c|c|c|c|}
\hline & & & \multicolumn{3}{|c|}{$\begin{array}{l}\text { Ausbildung unterhalb } \\
\text { Sekundarbereich II }\end{array}$} & \multicolumn{3}{|c|}{$\begin{array}{l}\text { Abschluss im Sekundar- } \\
\text { bereich II/postsekundaren, } \\
\text { nicht tertiären Bereich }\end{array}$} & \multicolumn{3}{|c|}{ Abschluss im Tertiärbereich } & \multicolumn{3}{|c|}{$\begin{array}{c}\text { Alle Bildungsbereiche } \\
\text { zusammen }\end{array}$} \\
\hline & & & $25-64$ & $35-44$ & $55-64$ & $25-64$ & $35-44$ & $55-64$ & $25-64$ & $35-44$ & $55-64$ & $25-64$ & $35-44$ & $55-64$ \\
\hline & & & (1) & $(2)$ & (3) & $(4)$ & (5) & (6) & (7) & (8) & (9) & (10) & (11) & (12) \\
\hline \multicolumn{15}{|l|}{ OECD-Länder } \\
\hline Mexiko & & & m & $\mathrm{m}$ & $\mathrm{m}$ & m & $\mathrm{m}$ & $\mathrm{m}$ & m & $\mathrm{m}$ & $\mathrm{m}$ & m & $\mathrm{m}$ & $\mathrm{m}$ \\
\hline \multirow[t]{3}{*}{ Niederlande } & 2010 & Männer & 71 & 72 & 70 & 70 & 73 & 69 & 68 & 69 & 65 & 70 & 71 & 68 \\
\hline & & Frauen & 15 & 14 & 11 & 19 & 15 & 17 & 29 & 22 & 25 & 22 & 17 & 17 \\
\hline & & $M+F$ & 46 & 46 & 42 & 45 & 43 & 48 & 49 & 46 & 50 & 47 & 45 & 47 \\
\hline \multirow[t]{3}{*}{ Neuseeland } & 2011 & Männer & 73 & 78 & 63 & 72 & 73 & 64 & 74 & 76 & 62 & 73 & 75 & 63 \\
\hline & & Frauen & 59 & 57 & 54 & 55 & 52 & 48 & 64 & 60 & 58 & 60 & 57 & 54 \\
\hline & & $M+F$ & 66 & 68 & 58 & 66 & 65 & 58 & 69 & 68 & 60 & 67 & 67 & 59 \\
\hline \multirow[t]{3}{*}{ Norwegen } & 2010 & Männer & 51 & 54 & 48 & 65 & 69 & 59 & 69 & 74 & 68 & 63 & 67 & 60 \\
\hline & & Frauen & 28 & 28 & 25 & 36 & 37 & 34 & 46 & 47 & 51 & 39 & 40 & 38 \\
\hline & & $M+F$ & 41 & 42 & 37 & 53 & 55 & 47 & 57 & 59 & 60 & 52 & 54 & 49 \\
\hline \multirow[t]{3}{*}{ Polen } & 2010 & Männer & 85 & 87 & 86 & 88 & 90 & 86 & 82 & 83 & 85 & 86 & 88 & 86 \\
\hline & & Frauen & 79 & 78 & 77 & 85 & 86 & 84 & 82 & 85 & 84 & 84 & 85 & 83 \\
\hline & & $M+F$ & 82 & 83 & 83 & 87 & 88 & 85 & 82 & 85 & 84 & 85 & 86 & 85 \\
\hline \multirow[t]{3}{*}{ Portugal } & 2010 & Männer & 98 & 98 & 98 & 96 & 98 & 96 & 93 & 95 & 88 & 97 & 98 & 97 \\
\hline & & Frauen & 90 & 91 & 85 & 94 & 95 & 93 & 93 & 94 & 87 & 92 & 93 & 86 \\
\hline & & $M+F$ & 95 & 95 & 93 & 95 & 96 & 95 & 93 & 94 & 88 & 95 & 95 & 93 \\
\hline \multirow[t]{3}{*}{ Slowakei } & 2011 & Männer & 50 & 49 & 55 & 63 & 65 & 62 & 65 & 66 & 68 & 61 & 63 & 62 \\
\hline & & Frauen & 47 & 42 & 49 & 57 & 58 & 60 & 62 & 64 & 67 & 57 & 58 & 59 \\
\hline & & $M+F$ & 48 & 45 & 51 & 60 & 61 & 61 & 63 & 65 & 68 & 59 & 61 & 60 \\
\hline Slowenien & & & m & $\mathrm{m}$ & $\mathrm{m}$ & $\mathbf{m}$ & $\mathrm{m}$ & $\mathrm{m}$ & $\mathbf{m}$ & $\mathrm{m}$ & $\mathrm{m}$ & m & $\mathrm{m}$ & $\mathrm{m}$ \\
\hline \multirow[t]{3}{*}{ Spanien } & 2010 & Männer & 78 & 78 & 82 & 85 & 86 & 92 & 86 & 90 & 86 & 83 & 84 & 85 \\
\hline & & Frauen & 55 & 45 & 62 & 68 & 69 & 82 & 78 & 79 & 89 & 68 & 67 & 74 \\
\hline & & $M+F$ & 70 & 66 & 74 & 78 & 79 & 88 & 82 & 85 & 87 & 76 & 77 & 80 \\
\hline \multirow[t]{3}{*}{ Schweden } & 2010 & Männer & 74 & 77 & 69 & 79 & 84 & 63 & 79 & 86 & 71 & 78 & 84 & 67 \\
\hline & & Frauen & 37 & 46 & 30 & 48 & 49 & 43 & 60 & 58 & 59 & 52 & 53 & 47 \\
\hline & & $M+F$ & 60 & 65 & 55 & 65 & 69 & 53 & 68 & 70 & 64 & 66 & 69 & 57 \\
\hline Schweiz & & & m & $\mathrm{m}$ & $\mathrm{m}$ & m & $\mathrm{m}$ & $\mathrm{m}$ & m & $\mathrm{m}$ & $\mathrm{m}$ & m & $\mathrm{m}$ & $\mathrm{m}$ \\
\hline Türkei & & & m & $\mathrm{m}$ & $\mathrm{m}$ & $\mathbf{m}$ & $\mathrm{m}$ & $\mathrm{m}$ & m & $\mathrm{m}$ & $\mathrm{m}$ & m & $\mathrm{m}$ & $\mathrm{m}$ \\
\hline \multirow{3}{*}{$\begin{array}{l}\text { Vereinigtes } \\
\text { Königreich }\end{array}$} & 2011 & Männer & 85 & 84 & 83 & 93 & 95 & 85 & 92 & 95 & 79 & 92 & 94 & 83 \\
\hline & & Frauen & 44 & 43 & 40 & 54 & 51 & 49 & 66 & 60 & 54 & 59 & 55 & 49 \\
\hline & & $M+F$ & 67 & 69 & 61 & 75 & 74 & 69 & 79 & 79 & 68 & 76 & 76 & 68 \\
\hline \multirow{3}{*}{$\begin{array}{l}\text { Vereinigte } \\
\text { Staaten }\end{array}$} & 2011 & Männer & 66 & 68 & 67 & 76 & 78 & 76 & 83 & 87 & 79 & 78 & 81 & 77 \\
\hline & & Frauen & 51 & 53 & 53 & 65 & 66 & 64 & 70 & 70 & 68 & 66 & 67 & 65 \\
\hline & & $M+F$ & 61 & 63 & 61 & 71 & 73 & 70 & 77 & 79 & 73 & 73 & 75 & 71 \\
\hline OECD-Durch- & & Männer & 75 & 78 & 71 & 80 & 83 & 74 & 83 & 86 & 78 & 80 & 83 & 75 \\
\hline schnitt & & Frauen & 51 & 51 & 48 & 59 & 59 & 57 & 67 & 66 & 65 & 60 & 60 & 56 \\
\hline & & $M+F$ & 64 & 66 & 60 & 71 & 72 & 67 & 75 & 76 & 72 & 71 & 72 & 66 \\
\hline EU21- & & Männer & 76 & 79 & 72 & 80 & 83 & 74 & 83 & 87 & 79 & 81 & 84 & 75 \\
\hline Durchschnitt & & Frauen & 50 & 51. & 48 & 60 & 59 & 57 & 68 & 67 & 66 & 61 & 60 & 56 \\
\hline & & $M+F$ & 65 & 66 & 60 & 71 & 72 & 67 & 76 & 77 & 73 & 71 & 73 & 67 \\
\hline $\begin{array}{l}\text { Sonstige } \\
\text { G20-Länder }\end{array}$ & & & & & & & & & & & & & & \\
\hline Argentinien & & & m & $\mathrm{m}$ & $\mathrm{m}$ & m & $\mathrm{m}$ & $\mathrm{m}$ & m & $\mathrm{m}$ & $\mathrm{m}$ & m & $\mathrm{m}$ & $\mathrm{m}$ \\
\hline Brasilien & & & m & $\mathrm{m}$ & $\mathrm{m}$ & m & $\mathrm{m}$ & $\mathrm{m}$ & m & $\mathrm{m}$ & $\mathrm{m}$ & m & $\mathrm{m}$ & $\mathrm{m}$ \\
\hline China & & & m & $\mathrm{m}$ & $\mathrm{m}$ & m & $\mathrm{m}$ & $\mathrm{m}$ & $\mathbf{m}$ & $\mathrm{m}$ & $\mathrm{m}$ & $\mathbf{m}$ & $\mathrm{m}$ & $\mathrm{m}$ \\
\hline Indien & & & m & $\mathrm{m}$ & $\mathrm{m}$ & $\mathbf{m}$ & $\mathrm{m}$ & $\mathrm{m}$ & m & $\mathrm{m}$ & $\mathrm{m}$ & m & $\mathrm{m}$ & $\mathrm{m}$ \\
\hline Indonesien & & & m & $\mathrm{m}$ & $\mathrm{m}$ & m & $\mathrm{m}$ & $\mathrm{m}$ & m & $\mathrm{m}$ & $\mathrm{m}$ & m & $\mathrm{m}$ & $\mathrm{m}$ \\
\hline Russische Föd. & & & m & $\mathrm{m}$ & $\mathrm{m}$ & m & $\mathrm{m}$ & $\mathrm{m}$ & m & $\mathrm{m}$ & $\mathrm{m}$ & m & $\mathrm{m}$ & $\mathrm{m}$ \\
\hline Saudi-Arabien & & & m & $\mathrm{m}$ & $\mathrm{m}$ & m & $\mathrm{m}$ & $\mathrm{m}$ & m & $\mathrm{m}$ & $\mathrm{m}$ & m & $\mathrm{m}$ & $\mathrm{m}$ \\
\hline Südafrika & & & m & $\mathrm{m}$ & $\mathrm{m}$ & m & $\mathrm{m}$ & $\mathrm{m}$ & m & $\mathrm{m}$ & $\mathrm{m}$ & m & $\mathrm{m}$ & $\mathrm{m}$ \\
\hline $\begin{array}{l}\text { G20-Durch- } \\
\text { schnitt }\end{array}$ & & & m & m & m & $\mathbf{m}$ & $\mathbf{m}$ & $\mathbf{m}$ & m & m & $\mathbf{m}$ & m & m & $\mathbf{m}$ \\
\hline
\end{tabular}

Anmerkung: Die Länge des Referenzzeitraums variiert zwischen 1 Woche und 1 Jahr. In einigen Ländern ohne Selbstständige.

1. Vollzeitbeschäftigung bezieht sich auf Beschäftigte mit einer ganzjährigen Beschäftigung von mindestens 30 Wochenarbeitsstunden. Einzelheiten s. Indikator A6 und Anhang 3.

Quelle: OECD. Spezielle Datenerhebung zu Einkommen von ganzjährig Vollzeitbeschäftigten des Netzwerks zu den Arbeitmarktergebnissen sowie den wirtschaftlichen und sozialen Auswirkungen des Lernens (LSO), Arbeitsgruppe Wirtschaftliche Ergebnisse von Bildung (Economic Outcomes).

Hinweise s. Anhang 3 unter www.oecd.org/edu/eag.htm. StatLink: http://dx.doi.org/10.1787/888932848837

Erläuterung der Kennzeichnung fehlender Daten s. Hinweise für den Leser. 


\section{Welche Einkommenszuschläge lassen sich durch Bildung erzielen?}

In allen OECD-Ländern verdienen Erwachsene mit einem Abschluss im Tertiärbereich mehr als Absolventen des Sekundarbereichs II oder des postsekundaren, nicht tertiären Bereichs, die wiederum mehr verdienen als Erwachsene mit einer Ausbildung unterhalb des Sekundarbereichs II.

In Brasilien, Griechenland und den Vereinigten Staaten verdienen Personen mit einer Ausbildung unterhalb des Sekundarbereichs II im Allgemeinen höchstens ${ }_{6}$ Prozent dessen, was Personen mit einem Abschluss im Sekundarbereich II oder im postsekundaren, nicht tertiären Bereich verdienen.

Im Durchschnitt der OECD-Länder nehmen die Einkommensunterschiede zwischen jüngeren und älteren Erwerbstätigen mit dem Bildungsstand zu, wovon ältere Erwerbstätige mit einem höheren Bildungsstand profitieren. Der Einkommenszuschlag 55- bis 64-Jähriger mit einem Abschluss im Tertiärbereich ist im Allgemeinen höher als der aller Altersgruppen mit einem Abschluss im Tertiärbereich zusammen: Die Einkommensunterschiede nehmen im Durchschnitt um I6 Prozentpunkte zu.

Die geschlechtsspezifischen Einkommensunterschiede bleiben unabhängig vom Bildungsstand bestehen. In den OECD-Ländern findet sich der größte Einkommensunterschied zwischen Männern und Frauen bei Absolventen des Tertiärbereichs.

In vielen Ländern verfügen mehr als die Hälfte der I5- bis 24-jährigen Schüler/Studierenden über ein Erwerbseinkommen. In Belgien, Chile, Estland, Israel, Italien, der Schweiz und Spanien sind es jedoch weniger als 20 Prozent. 


\section{Kontext}

Höhere Kompetenzen führen in der Regel zu besseren Beschäftigungschancen (s. Indikator A5) und höheren Einkommen. Für alle OECD-Länder mit verfügbaren Daten gilt in der Tat, je höher der Bildungsstand, desto höher das relative Einkommen.

Die Chance auf ein höheres Einkommen und Steigerungen dieses Einkommens im Verlaufe der Zeit zusammen mit weiteren gesellschaftlichen Vorteilen stellen für den Einzelnen einen Anreiz dar, auf einen höheren Bildungsstand hinzuarbeiten. In den meisten OECD- und G20-Ländern galt dies selbst 20II, als die Auswirkungen der globalen Wirtschaftskrise noch weithin spürbar waren und obwohl der wirtschaftliche Vorteil je nach gewähltem Studienfach variiert (Carnevale, 2012 und Kasten A6.I). Während die relativen Einkommen von Personen mit einem höheren Bildungsstand tendenziell mit zunehmendem Alter steigen, sinken die relativen Einkommen von Personen mit einer Ausbildung unterhalb des Sekundarbereichs II tendenziell mit zunehmendem Alter.

Die Entscheidung des Einzelnen, auf einen höheren Bildungs- oder Ausbildungsstand hinzuarbeiten, kann durch viele Faktoren beeinflusst werden. In manchen Ländern kann sie mit den Kosten für Bildung und Ausbildung zusammenhängen, besonders nach Ende der Schulpflicht. Diese Kosten beinhalten auch die Auswirkungen eines zeitlich aufgeschobenen Eintritts in den Arbeitsmarkt einschließlich der entgangenen potenziellen Einkünfte (s. Indikator A7).

Die länderspezifischen Unterschiede bei den relativen Einkommen spiegeln verschiedene Einflussfaktoren wider, u. a. auf dem Arbeitsmarkt geforderte Kompetenzen, die Gesetzgebung zu den Mindestlöhnen, die Stärke der Gewerkschaften, die mehr oder weniger flächendeckende Geltung von Tarifverträgen, das Angebot an Arbeitskräften 
mit einem bestimmten Bildungsstand und die relative Verbreitung von saisonaler und Teilzeitbeschäftigung.

\section{Weitere wichtige Ergebnisse}

In Belgien, Finnland, Neuseeland, Österreich, Slowenien und Spanien erzielen Absolventinnen des Tertiärbereichs mindestens rund 75 Prozent der Gehälter von Männern mit einem Abschluss im Tertiärbereich, während sie in Brasilien, Chile und Estland höchstens ${ }_{5}$ Prozent der Einkommen von Männern mit gleichem Bildungsstand erreichen.

Mit zunehmendem Alter ist der Einkommensunterschied für Frauen mit einem Abschluss im Sekundarbereich II oder im postsekundaren, nicht tertiären Bereich gegenüber gleichaltrigen Männern mit einem vergleichbaren Bildungsstand geringer. Diese Frauen können davon ausgehen, im Alter von 55 bis 64 Jahren 79 Prozent des Einkommens der Männer zu verdienen.

In allen Ländern haben Erwerbstätige mit einer Ausbildung unterhalb des Sekundarbereichs II während ihres gesamten Erwerbslebens große Einkommensnachteile. Im Durchschnitt der OECD-Länder gelingt es nur 3 Prozent derjenigen mit einer Ausbildung unterhalb des Sekundarbereichs II, das Doppelte des nationalen Medians der Einkommen zu verdienen.

Im Durchschnitt haben 67 Prozent aller 25- bis 29-jährigen Studierenden ein Erwerbseinkommen, obwohl 78 Prozent aller 25- bis 29-Jährigen (also sowohl Studierende als auch nicht in der Ausbildung befindliche Personen) ein derartiges Einkommen haben. Von den 25- bis 29-Jährigen haben 85 Prozent der Männer, die sich nicht in Ausbildung befinden, ein Erwerbseinkommen im Vergleich zu 76 Prozent der Frauen.

\section{Entwicklungstendenzen}

In allen OECD-Ländern verdienen Erwachsene mit einem Abschluss im Tertiärbereich deutlich mehr als Erwachsene mit einer Ausbildung unterhalb des Sekundarbereichs II. Zwischen 2000 und 201 I sind nur in einigen wenigen Ländern, für die Informationen für beide Jahre vorliegen (Deutschland, die Schweiz und Ungarn), die Einkommen von Erwachsenen mit einer Ausbildung unterhalb des Sekundarbereichs II im Vergleich zu den Einkommen von Erwachsenen mit einem Abschluss im Sekundarbereich II oder dem postsekundaren, nicht tertiären Bereich in begrenztem Umfang gestiegen.

Andererseits sind in den meisten OECD-Ländern, u.a. Belgien, Deutschland, der Schweiz, Ungarn und den Vereinigten Staaten die Einkommen von Erwerbstätigen mit einem Abschluss im Tertiärbereich in Relation zu den Einkommen von Erwerbstätigen mit einem Abschluss im Sekundarbereich II oder dem postsekundaren, nicht tertiären Bereich während des gleichen Zeitraums gestiegen.

Diese Unterschiede deuten darauf hin, dass die Nachfrage nach speziellen Kompetenzen, die auf dem neuesten Stand sind, in diesen zehn Jahren gestiegen sein könnte - und dass sich Personen mit weniger speziellen Kompetenzen heute in einer schwächeren Position befinden. 


\section{Analyse und Interpretationen}

\section{Bildungsstand und relative Einkommen}

Je höher der Bildungsstand, desto höher sind die relativen Einkommen. Ein Abschluss im Sekundarbereich II scheint der Schlüssel zu den höchsten Einkommenssteigerungen zu sein. Die Einkommensunterschiede zwischen Absolventen des Tertiärbereichs und Absolventen des Sekundarbereichs II sind im Allgemeinen ausgeprägter als die Einkommensunterschiede zwischen Absolventen des Sekundarbereichs II und Personen ohne einen Abschluss des Sekundarbereichs II. Da die privaten Investitionskosten für Bildung oberhalb des Sekundarbereichs II in den meisten Ländern deutlich höher sind, stellt u.a. ein hoher Einkommenszuschlag sicher, dass genügend Menschen bereit sind, Zeit und Geld in eine weitere Ausbildung zu investieren.

In allen OECD-Ländern verdienen Erwachsene mit einem Abschluss im Tertiärbereich mehr als Erwachsene mit einem Abschuss im Sekundarbereich II oder postsekundaren, nicht tertiären Bereich, die wiederum mehr verdienen als Erwachsene mit einer Ausbildung unterhalb des Sekundarbereichs II. Ein Abschluss des Sekundarbereichs II stellt in vielen Ländern den Bildungsstand dar, ab dem eine weitere Ausbildung hohe relative Einkommen impliziert. So könnte man den Sekundarbereich II als die Bezugsgröße sehen, anhand derer das Einkommen in Relation zum Bildungsstand gemessen werden kann.

In allen Ländern verdienen Erwachsene mit einem Abschluss im Tertiärbereich mehr als mit einem niedrigeren Bildungsabschluss. Die relativen Einkommen von Erwachsenen, die den Tertiärbereich absolviert haben, belaufen sich durchschnittlich auf mehr das I,5-Fache derjenigen mit einem Abschluss im Sekundarbereich II oder postsekundaren, nicht tertiären Bereich und in Brasilien, Chile und Ungarn auf mehr als das Doppelte der Einkommen von Erwachsenen mit diesem niedrigeren Bildungsabschluss (Tab. A6.I).

Die Unterschiede zwischen Erwachsenen mit einer Ausbildung unterhalb des Sekundarbereichs II und denjenigen mit einem Abschluss im Sekundarbereich II oder postsekundaren, nicht tertiären Bereich variieren. In Belgien, Deutschland, Estland und Irland sind die Unterschiede relativ gering: In der Gruppe mit den niedrigeren Bildungsabschlüssen liegen die Einkommen bei mehr als 85 Prozent der Einkommen der Gruppe mit den höheren Bildungsabschlüssen. In Brasilien, Griechenland und den Vereinigten Staaten verdienen diejenigen mit einer Ausbildung unterhalb des Sekundarbereichs II im Allgemeinen weniger als 65 Prozent dessen, was Absolventen des Sekundarbereichs II oder des postsekundaren, nicht tertiären Bildungsbereichs verdienen (Abb. A6.I).

\section{Relative Einkommen nach Geschlecht und Alter}

In den OECD-Ländern wirkt sich der Bildungsstand in unterschiedlichem Ausmaß auf die relativen Einkommen aus. So beläuft sich beispielsweise das relative Einkommen für einen Mann mit einem Abschluss im Tertiärbereich A bzw. einem weiterführenden forschungsorientierten Studiengang im Vergleich zu einem Mann mit einem Abschluss im Sekundarbereich II bzw. postsekundaren, nicht tertiären Bereich in Brasilien, Chile, 
Irland, Slowenien und Ungarn auf mehr als Ioo Prozent. Das gilt auch für Frauen mit dem gleichen Bildungsstand in Brasilien, Chile, Griechenland und Irland (Tab. A6.I).

Sowohl Männer als auch Frauen mit einem Abschluss im Tertiärbereich B haben ein höheres Einkommen als Personen mit einem Abschluss im Sekundarbereich II oder im postsekundaren, nicht tertiären Bereich. In den OECD-Ländern verdienen Männer mit dem höheren Bildungsstand durchschnittlich 26 Prozent mehr als Männer mit dem niedrigeren Bildungsstand (in Portugal und Slowenien mehr als 6o Prozent), während Frauen mit dem höheren Bildungsstand 32 Prozent mehr als Frauen mit dem niedrigeren Bildungsstand verdienen (in Chile und Griechenland mehr als 6o Prozent).

Im Durchschnitt liegt das Einkommen von Männern mit einer Ausbildung unterhalb des Sekundarbereichs II bei 77 Prozent des Einkommens von Männern mit einem Abschluss

Abbildung A6.2

Relative Einkommen 25- bis 64-jähriger Erwerbstätiger, nach Bildungsstand und Geschlecht (2011) Abschluss im Sekundarbereich II oder postsekundaren, nicht tertiären Bereich $=100$
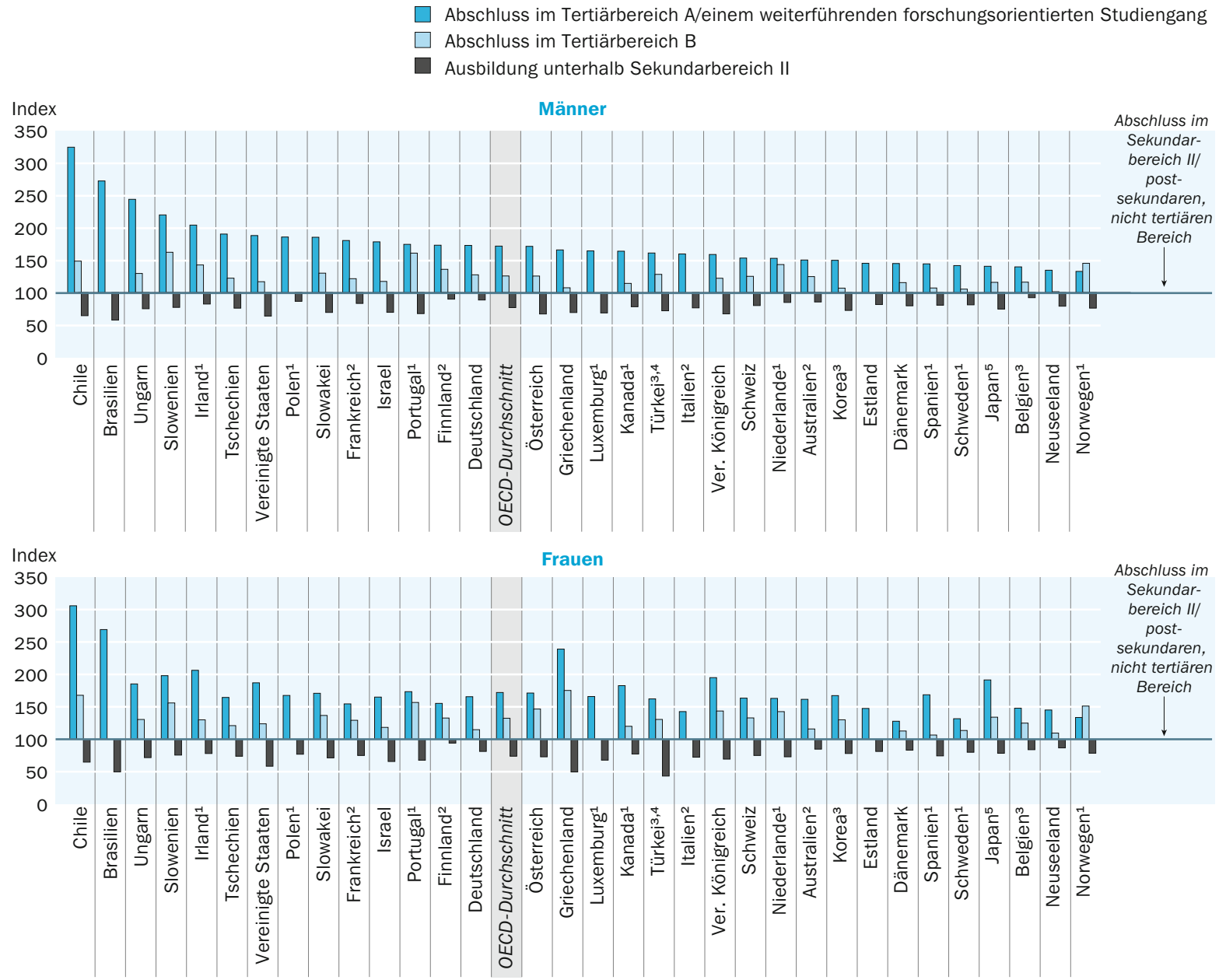

1. Referenzjahr 2010. 3. Referenzjahr 2009. 2. Einkommen nach Abzug der Einkommensteuer. 4. Referenzjahr 2005. 5. Referenzjahr 2007. Anordnung der Länder in absteigender Reihenfolge der relativen Einkommen von 25- bis 64-jährigen Männern mit einem Abschluss im Tertiärbereich A (einschließlich weiterführender forschungsorientierter Studiengänge).

Quelle: OECD. Tabelle A6.1. Hinweise s. Anhang 3 unter www.oecd.org/edu/eag.htm. StatLink: http://dx.doi.org/10.1787/888932846576 
Abbildung A6.3

Unterschiede zwischen älteren und allen Erwerbstätigen bei den relativen Einkommen, nach Bildungsstand (2011) Unterschiede beim Einkommen in Relation zu Einkommen mit einem Abschluss im Sekundarbereich II/postsekundaren, nicht tertiären Bereich (in Prozentpunkten)

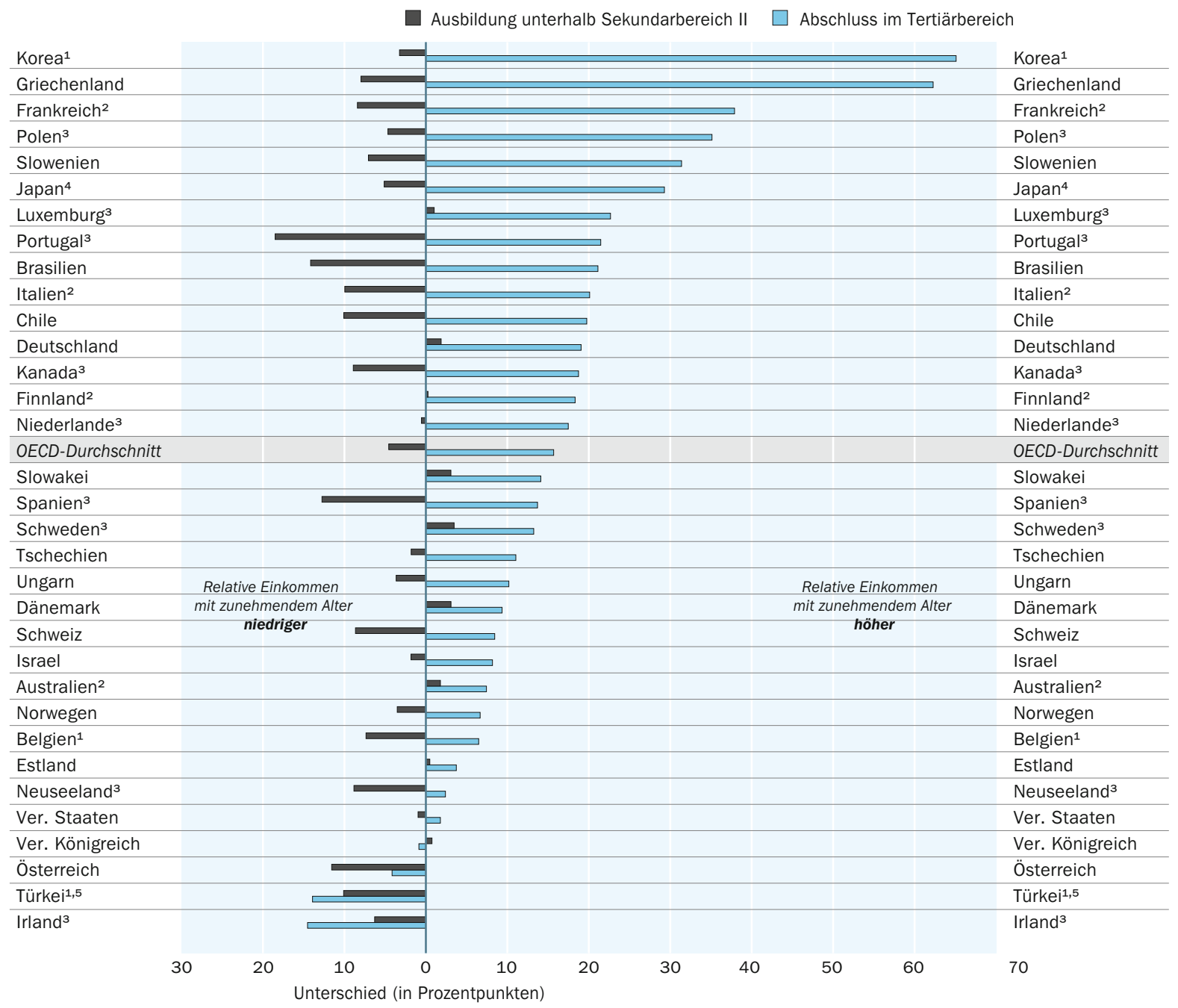

1. Einkommen nach Abzug der Einkommensteuer. 2. Referenzjahr 2009. 3. Referenzjahr 2010. 4. Referenzjahr 2007. 5. Referenzjahr 2005. Anordnung der Länder in absteigender Reihenfolge des Unterschieds in den relativen Einkommen von 55- bis 64-Jährigen und der Gesamtbevölkerung (25- bis 64-Jährige) mit einem Abschluss im Tertiärbereich.

Quelle: OECD. Tabelle A6.1. Hinweise s. Anhang 3 unter www.oecd.org/edu/eag.htm. StatLink: http://dx.doi.org/10.1787/888932846595

im Sekundarbereich II bzw. dem postsekundaren, nicht tertiären Bereich. Dabei reicht die Bandbreite von weniger als 6o Prozent in Brasilien bis zu mindestens go Prozent in Belgien und Finnland. Das Einkommen von Frauen mit dem niedrigeren Bildungsstand beträgt durchschnittlich 74 Prozent des Einkommens von Frauen mit dem höheren Bildungsstand, wobei die Bandbreite von höchstens 50 Prozent in Brasilien, Griechenland und der Türkei bis zu mehr als go Prozent in Finnland reicht (Abb. A6.2).

Ein höherer Bildungsstand wird mit höheren Einkommen während des gesamten Erwerbslebens assoziiert. Im Durchschnitt der OECD-Länder steigen die Einkommen mit einem höheren Bildungsstand, wobei dieser Anstieg für ältere Erwerbstätige besonders groß ist. Personen mit einem höheren Bildungsstand haben eine größere Wahrschein- 
lichkeit, einen Arbeitsplatz zu finden und auch zu behalten, und damit auch größere Chancen, Berufserfahrung zu gewinnen.

In allen Ländern mit Ausnahme von Irland, Österreich, der Türkei und dem Vereinigten Königreich erzielen 55- bis 64-jährige Absolventen des Tertiärbereichs höhere relative Einkommen als alle Absolventen des Tertiärbereichs im erwerbsfähigen Alter ( 25 bis 64 Jahre) zusammen. Der Unterschied zwischen den beiden Gruppen beläuft sich im Durchschnitt auf fast I6 Prozentpunkte. In allen Ländern mit Ausnahme von Australien, Dänemark, Deutschland, Estland, Finnland, Luxemburg, Norwegen, Schweden, der Slowakei und dem Vereinigten Königreich vergrößern sich für diejenigen mit einer Ausbildung unterhalb des Sekundarbereichs II die Nachteile bei den relativen Einkommen mit zunehmendem Alter. Dieser zunehmende Nachteil ist nicht so ausgeprägt wie der Anstieg des Einkommensvorteils für Absolventen des Tertiärbereichs, was darauf hindeutet, dass ein Abschluss im Tertiärbereich der entscheidende Faktor für ein höheres Einkommen mit zunehmendem Alter ist (Tab. A6.I).

In Abbildung A6.3 wird von dem Unterschied der Einkommen der älteren Erwerbstätigen der Unterschied der relativen Einkommen der 25- bis 64-jährigen Erwerbstätigen abgezogen. In beiden Fällen handelt es sich um Unterschiede in Relation zu den Einkommen von gleichaltrigen Erwerbstätigen mit einem Abschluss im Sekundarbereich II bzw. postsekundaren, nicht tertiären Bereich. Das Ergebnis ist der Unterschied der relativen Einkommen zwischen den zwei Altersgruppen, angegeben in Prozentpunkten. Nimmt man beispielsweise den OECD-Durchschnitt, so beläuft sich der Unterschied der relativen Einkommen zwischen allen Erwachsenen mit einer Ausbildung unterhalb des Sekundarbereichs II und allen Erwachsenen mit einem Abschluss im Sekundarbereich II oder dem postsekundaren, nicht tertiären Bereich im Durchschnitt auf 24 Prozent, was bedeutet dass die erstere Gruppe 24 Prozent weniger verdient als die Erwachsenen mit einem Abschluss im Sekundarbereich II oder dem postsekundaren, nicht tertiären Bereich. Ältere Erwachsene mit einer Ausbildung unterhalb des Sekundarbereichs verdienen im Durchschnitt 28 Prozent weniger als gleichaltrige Erwachsene mit einem Abschluss des Sekundarbereichs II oder des postsekundaren, nicht tertiären Bereichs. Der Unterschied zwischen diesen beiden Altersgruppen bei den relativen Einkommen beläuft sich auf rund 5 Prozentpunkte (wie in der Abbildung dargestellt). Für Beschäftigte mit einem Abschluss im Tertiärbereich wird der Unterschied zwischen den beiden Altersgruppen bei den relativen Einkommen auf die gleiche Art und Weise berechnet: Bei ihnen beläuft er sich im Durchschnitt auf rund I6 Prozentpunkte.

In den OECD-Ländern ergibt sich bei einem Vergleich der relativen Einkommen zwischen älteren und jüngeren Beschäftigten in der Gruppe der Erwerbstätigen mit einer Ausbildung unterhalb des Sekundarbereichs II ein Vorteil zugunsten der jüngeren Erwerbstätigen. Ältere Beschäftigte mit diesem Bildungsstand verdienen 8 Prozentpunkte weniger als jüngere Beschäftigte (Tab. A6.I).

Im Durchschnitt liegen die Einkommen von 25- bis 34-Jährigen mit einer Ausbildung unterhalb des Sekundarbereichs II bei 8o Prozent der gleichen Altersgruppe mit einem Abschluss des Sekundarbereichs II. Die Einkommen von 55- bis 64-Jährigen mit einer Ausbildung unterhalb des Sekundarbereichs II dagegen liegen bei 72 Prozent der Ein- 
kommen der gleichen Altersgruppe mit einem Abschluss des Sekundarbereichs II. Die Unterschiede sind bei Frauen größer (76 Prozent bzw. 68 Prozent) und bei Männern geringer (8o Prozent bzw. 75 Prozent) (Tab. A6.I).

In allen Ländern mit Ausnahme von Australien, Dänemark, Deutschland, Estland, Finnland, Irland, Norwegen, Schweden und der Slowakei vergrößern sich für diejenigen mit einer Ausbildung unterhalb des Sekundarbereichs II die Einkommensnachteile mit zunehmendem Alter. Folglich bedeutet ein Abschluss im Tertiärbereich in den meisten Ländern nicht nur bessere Chancen auf Beschäftigung im Alter, sondern auch eine $\mathrm{Zu}$ nahme der Einkommens- und Produktivitätsvorteile während des gesamten Erwerbslebens. In den meisten OECD-Ländern ist deshalb für Erwachsene mit einem Abschluss im Tertiärbereich die Wahrscheinlichkeit am höchsten, einen Arbeitsplatz zu finden, ihn zu behalten und während des Erwerbslebens das Einkommen zu steigern (Tab. A6.I).

\section{Entwicklung der relativen Einkommen nach Bildungsstand}

Zwischen 2000 und 2011 sanken die relativen Einkommen von Erwerbstätigen mit einer Ausbildung unterhalb des Sekundarbereichs II mit nur wenigen Ausnahmen in den meisten OECD-Ländern. In Deutschland, der Schweiz und Ungarn stiegen die relativen Einkommen derjenigen mit einer Ausbildung unterhalb des Sekundarbereichs II während dieser Jahre. Außerdem stiegen seit 2000 auch in Belgien die relativen Einkommen von Frauen mit einer Ausbildung unterhalb des Sekundarbereichs II. Die relativen Einkommen von Männern mit diesem Bildungsstand stiegen während dieses Zeitraums nur in Deutschland und der Schweiz (Tab. A6.2a, A6.2b und A6.2c).

In den meisten Ländern sind die relativen Einkommen von Beschäftigten mit einem Abschluss im Tertiärbereich zwischen 2000 und 201 I gestiegen. Trotzdem scheinen sie in einigen Ländern nicht unerheblichen Schwankungen unterlegen zu sein. Während in Belgien, Deutschland, der Schweiz, Ungarn und den Vereinigten Staaten die verfügbaren Daten Schwankungen hin zu einem gewissen Anstieg zeigen, scheint es bei den relativen Einkommen der Beschäftigten mit einem Abschluss im Tertiärbereich in Neuseeland und dem Vereinigten Königreich gegenüber dem Jahr 2000 eher zu einer Senkung gekommen zu sein (Tab. A6.2a).

Die Daten zu den Entwicklungen der Einkommen sind jeweils relativ zu den Veränderungen der Einkommen von Beschäftigten mit einem Abschluss im Sekundarbereich II oder dem postsekundaren, nicht tertiären Bereich. Daher ist es schwierig, die durchschnittliche Entwicklung der relativen Einkommen der Beschäftigten mit unterschiedlichem Bildungsstand über die Jahre hinweg zu beurteilen (weitere Informationen s. Abschnitt Angewandte Methodik).

\section{Bildungsstand und geschlechtsspezifische Unterschiede bei den Einkommen}

Die geschlechtsspezifischen Einkommensunterschiede bleiben unabhängig vom Bildungsstand bestehen. Die zur Verfügung stehenden Daten zeigen, dass der größte Einkommensunterschied zwischen Männern und Frauen bei Absolventen des Tertiärbereichs besteht. Nur in Belgien, Finnland, Neuseeland, Österreich, Slowenien und Spanien erzielen die Absolventinnen des Tertiärbereichs mindestens 75 Prozent der Einkommen der Männer. In Brasilien, Chile und Estland erreichen Absolventinnen des 
Tertiärbereichs höchstens 65 Prozent der Einkommen von Männern mit gleichem Bildungsstand (Tab. A6.3a).

Im Durchschnitt haben nur Absolventinnen des Sekundarbereichs II oder des postsekundaren, nicht tertiären Bildungsbereichs in Relation zu den Männern mit zunehmendem Alter Einkommenssteigerungen. Frauen mit einem Abschluss im Tertiärbereich sowie Frauen mit einer Ausbildung unterhalb des Sekundarbereichs haben mit zunehmendem Alter keine Einkommenssteigerungen im Verhältnis zu den Einkommen der Männer. 55- bis 64-jährige Absolventinnen des Tertiärbereichs können damit rechnen, 72 Prozent des Einkommens von Männern in der gleichen Altersgruppe und mit dem gleichen Bildungsstand zu verdienen, wohingegen Frauen in dieser Altersgruppe mit einer Ausbildung unterhalb des Sekundarbereichs II 74 Prozent der Einkommen von Männern in der gleichen Altersgruppe und mit dem gleichen Bildungsstand erreichen können (Tab. A6.3a).

\section{Einkommensverteilung innerhalb des jeweiligen Bildungsstands}

Da dieser Indikator die Erwerbseinkommen aller Erwerbstätigen enthält (außer in Tab. A6.3a, in der nur die Einkommen von ganzjährig Vollzeitbeschäftigten erfasst sind), wirkt sich die Zahl der geleisteten Arbeitsstunden auf das Einkommen generell und insbesondere auf die Einkommensverteilung aus. Anhand der Daten zur Einkommensverteilung innerhalb von Gruppen mit unterschiedlichem Bildungsstand lässt sich ersehen, wie eng die Einkommen um den Median für das jeweilige Land verteilt sind. Dies zeigt nicht nur, in welchem Ausmaß die gleiche Einkommenshöhe erzielt wird, sondern weist auch auf die mit einer Investition in Bildung verbundenen Risiken hin (da das Risiko normalerweise anhand der Unterschiede hinsichtlich der Einkommenshöhe gemessen wird).

Die Tabellen A6.4a, A6.4b und A6.4c (im Internet) sowie Abbildung A6.4 zeigen die Einkommensverteilung von Beschäftigten nach Bildungsstand. Aus den Tabellen geht die Einkommensverteilung für Erwachsene insgesamt sowie getrennt für Männer und Frauen hervor. Für Erwerbstätige mit einem Erwerbseinkommen sind fünf Einkommenskategorien von „Hälfte oder weniger als die Hälfte des Medians“ bis „Mehr als das Doppelte des Medians“ angegeben. In einer separaten Spalte ist der Anteil der Personen ohne Erwerbseinkommen aufgeführt.

In Abbildung A6.4 werden die Ergebnisse für Personen mit einer Ausbildung unterhalb des Sekundarbereichs II und für die Absolventen des Tertiärbereichs A bzw. weiterführender forschungsorientierter Studiengänge gegenübergestellt, indem der Anteil der Erwerbstätigen, deren Einkommen in die Kategorie „Hälfte oder weniger als die Hälfte des Medians" fällt, mit dem Anteil der Erwerbstätigen verglichen wird, deren Einkommen „Mehr als das Doppelte des Medians“ beträgt. Wie erwartet ergibt sich zwischen diesen beiden Qualifikationsniveaus ein großer Unterschied: Im Durchschnitt haben die Absolventen des Tertiärbereichs wesentlich größere Chancen, das Doppelte des Medians zu verdienen, und gleichzeitig ist die Wahrscheinlichkeit, dass sie in der niedrigsten Einkommenskategorie sind, wesentlich geringer als für diejenigen mit einer Ausbildung unterhalb des Sekundarbereichs II. 
Abbildung A6.4

Unterschiede in der Verteilung der relativen Einkommen bei 25- bis 64-jährigen Erwerbstätigen, nach Bildungsstand (2011) Anteil der 25- bis 64-jährigen Bevölkerung in der Einkommenskategorie „Hälfte oder weniger als die Hälfte des Medians“ und Anteil der Bevölkerung in der Einkommenskategorie „Mehr als das Doppelte des Medians“ für Erwerbstätige mit einer Ausbildung unterhalb des Sekundarbereichs II und Erwerbstätige mit einem Abschluss im Tertiärbereich A oder eines weiterführenden forschungsorientierten Studiengangs

Ausbildung unterhalb Sekundarbereich II

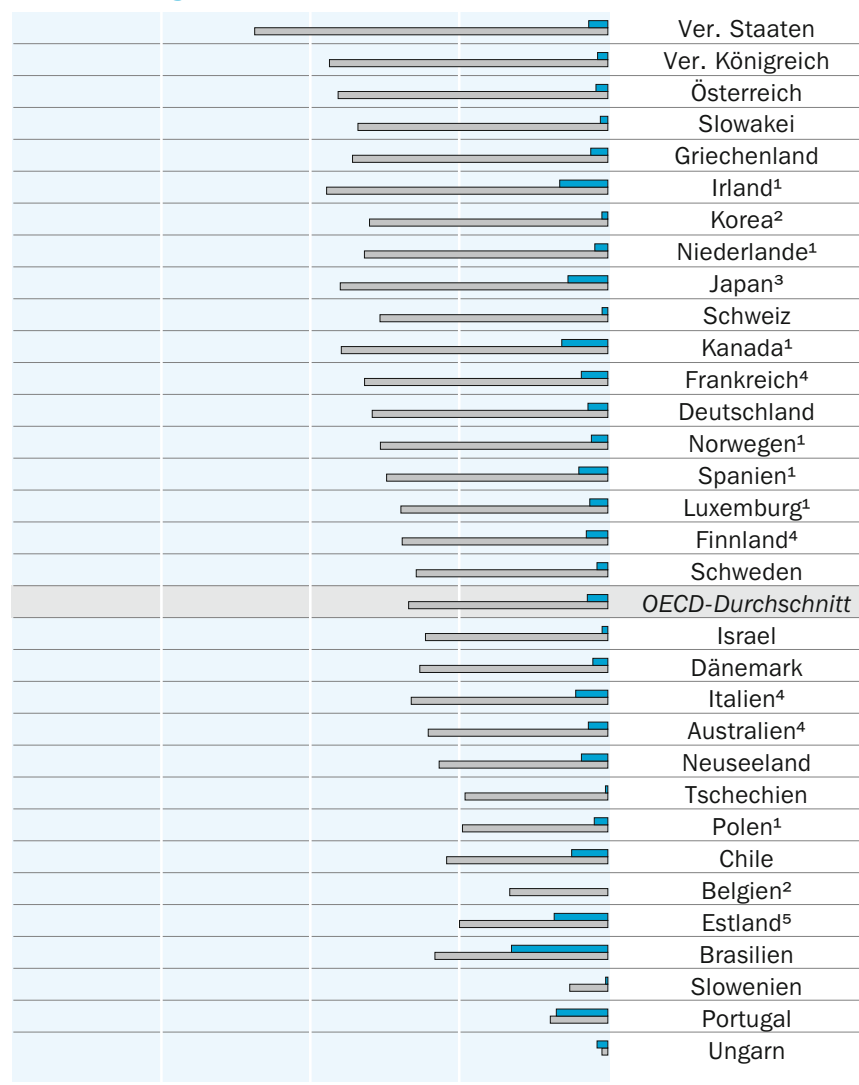

Abschluss im Tertiärbereich A/ einem weiterführenden forschungsorientierten Studiengang

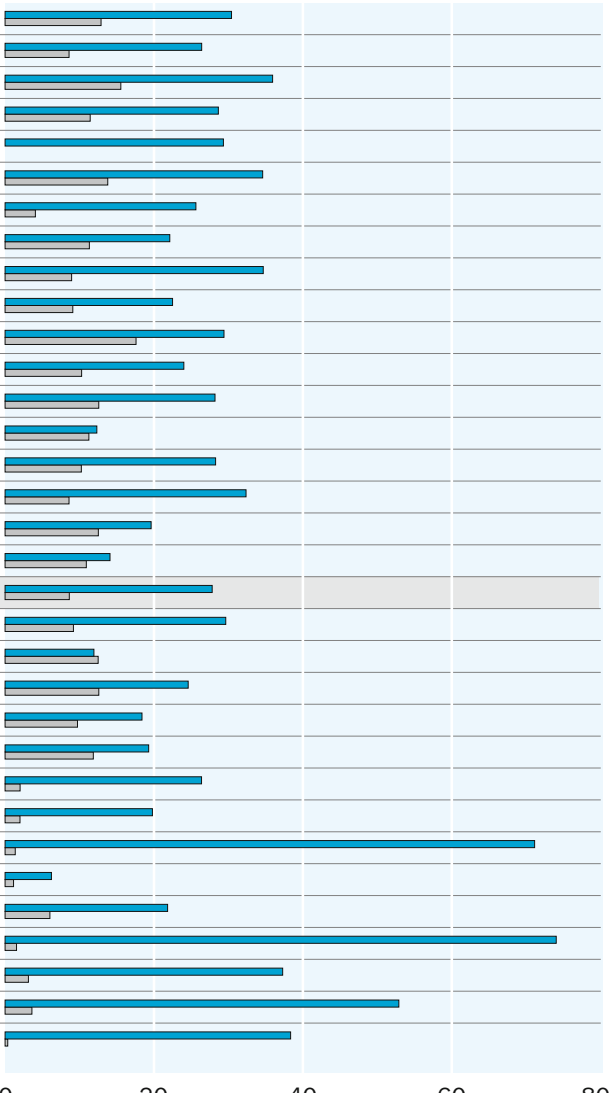

1. Referenzjahr 2010. 2. Einkommen nach Abzug der Einkommensteuer. 3. Referenzjahr 2007. 4. Referenzjahr 2009. 5. Gesamter Tertiärbereich einschließlich weiterführender forschungsorientierter Studiengänge.

Anordnung der Länder in absteigender Reihenfolge des Unterschieds zwischen dem Anteil der 25- bis 64-jährigen Bevölkerung in der Einkommenskategorie „Hälfte oder weniger als die Hälfte des Medians“ und dem Anteil der Bevölkerung in der Einkommenskategorie „Mehr als das Doppelte des Medians“ bei einer Ausbildung unterhalb des Sekundarbereichs II.

Quelle: OECD. Tabelle C6.4a im Internet. Hinweise s. Anhang 3 unter www.oecd.org/edu/eag.htm. StatLink: http://dx.doi.org/10.1787/888932846614

Es gibt jedoch einige bemerkenswerte Unterschiede in der Situation von Absolventen des Tertiärbereichs in den einzelnen Ländern. In Brasilien, Chile und Portugal verdienen mindestens 50 Prozent derjenigen, die den Tertiärbereich A oder weiterführende forschungsorientierte Studiengänge abgeschlossen haben, das Doppelte des Medians, in Kanada und Österreich fallen mehr als 15 Prozent der Gruppe mit einem derartigen Abschluss in die niedrigste Einkommenskategorie (Hälfte oder weniger als die Hälfte des Medians), und in Dänemark und Norwegen sind Personen mit einer solchen Qualifikation gleich häufig in der niedrigsten und der höchsten Einkommenskategorie anzutreffen (Abb. A6.4). 


\section{Unterschied der Einkommenszuschläge nach Studienfächern}

Die Einkommensindikatoren in Bildung auf einen Blick dokumentieren deutlich die im Zusammenhang mit einem höheren Abschluss verbundenen Einkommenszuschläge. Höhere Durchschnittseinkommen für Absolventen des Tertiärbereichs wurden durchgängig sowohl in allen Ländern als auch im Zeitverlauf beobachtet. Die Einkommenszuschläge wurden zwar für den Tertiärbereich insgesamt dokumentiert, das bedeutet jedoch nicht, dass alle diese Einkommenszuschläge erhalten haben oder dass diese Vorteile durchgängig bei allen Tertiärbereichen oder bei allen Studiengängen im Tertiärbereich zu beobachten sind. So lag beispielsweise 20 II in den Vereinigten Staaten das durchschnittliche Jahresgehalt von 25- bis 29-jährigen Absolventen des Tertiärbereichs A (erster Abschluss) bei 44.800 US-Dollar. Das durchschnittliche Jahresgehalt reichte dabei jedoch von 34.750 US-Dollar für Studierende mit einem Abschluss im Studiengang Soziale Arbeit bis zu 75.700 USDollar für Studierende mit einem Abschluss in Informationstechnologie. $\mathrm{Zu}$ den Studiengängen mit relativ niedrigen Einkommen zählten u.a. Theologie und Religionswissenschaften (35.530 US-Dollar), Bildende Künste (35.60o US-Dollar) und Lehrerausbildung für den Primarbereich (37.500 US-Dollar). Andere Studiengänge mit durchschnittlichen Jahreseinkommen von mehr als 60.00o US-Dollar sind u.a. andere Ingenieurfachrichtungen, Informatik und Informationstechnologie sowie Managementinformationssysteme und Statistik.

Tendenziell konnte ein Zusammenhang der bestbezahlten Bereiche mit Studienfächern mit einem hohen Anteil von männlichen Studierenden hergestellt werden und für die schlechter bezahlten Bereiche ein Zusammenhang mit Studienfächern mit einem hohen Anteil von weiblichen Studierenden, doch es gab auch Ausnahmen. Die Einkommen in Pflegeberufen, in denen Frauen überwiegen, waren mit 53.650 USDollar bei Absolventen des Tertiärbereichs weit überdurchschnittlich. Auch in anderen Ländern wurden große Einkommensunterschiede je nach Studienfach beobachtet, obwohl bislang keine internationalen Vergleichsdaten zu den Einkommen nach Studienfach vorliegen. In Kanada war 2007 der Gehaltsmedian für Absolventen des Tertiärbereichs A, die 2005 ihr Studium abgeschlossen hatten, bei Absolventen mit einem Abschluss in Ingenieurwissenschaften rund 64 Prozent höher als die Gehälter für Absolventen mit den Hauptfächern Bildende Künste oder Darstellende Künste. In Schweden lag 2010 das Durchschnittsgehalt für 25- bis 29-Jährige mit einem Abschluss in Ingenieurwissenschaften 90 Prozent höher als das Durchschnittsgehalt von Absolventen mit den Hauptfächern Kunst oder Geisteswissenschaften. Ein Jahr nach dem Abschluss eines Studiengangs im Tertiärbereich A im Jahr 2010 lag der Gehaltsmedian für Absolventen mit Hauptfach Gesundheitswesen 58 Prozent höher als der Gehaltsmedian für Absolventen des Bereichs Bildende Kunst. Zur gleichen Zeit lagen die Gehälter von Absolventen des Hauptfachs Ingenieurwissenschaften 45 Prozent höher als die Gehälter von Absolventen des Hauptfachs Kreative Künste. Die durchschnittlichen Einkommenszuschläge in Bildung auf einen Blick spiegeln die Grundstrukturen der Volkswirtschaften wider, aber das tatsächliche Einkommen des Einzelnen wird durch das jeweilige Wissen, die Fähigkeiten und Kenntnisse und die Erfahrung beeinflusst. Daten aus der in Kürze erscheinenden OECDErhebung „Survey of Adult Skills“, hervorgegangen aus dem „Programme for the 
International Assessment of Adult Competencies (PIAAC)“, werden ein tiefer gehendes Verständnis, wie sich diese Faktoren in den verschiedenen OECD-Ländern auf die Einkommen auswirken, ermöglichen.

In allen Ländern haben Personen, die während des gesamten Erwerbslebens nur über niedrige Qualifikationen verfügen (Ausbildung unterhalb des Sekundarbereichs II), große Einkommensnachteile. Im Durchschnitt der OECD-Länder verdienen nur 3 Prozent derjenigen mit einer Ausbildung unterhalb des Sekundarbereichs II das Doppelte des Medians. Auch wenn ihr Anteil in Brasilien, Estland, Irland, Japan, Kanada und Portugal mehr als 5 Prozent beträgt, übersteigt ihr Anteil doch nur in Brasilien ro Prozent. Im Durchschnitt verdienen über 28 Prozent der Erwerbstätigen mit einer Ausbildung unterhalb des Sekundarbereichs II weniger als die Hälfte des nationalen Medians. In Griechenland verdienen 64 Prozent der Beschäftigten mit einer solchen Ausbildung weniger als die Hälfte des nationalen Medians (Abb. A6.4).

\section{Einkommen von Studierenden}

In den OECD-Ländern verfügen 53 Prozent der I5- bis 24-Jährigen über ein Erwerbseinkommen. In dieser Altersgruppe hat die Mehrheit der Nichtschüler/Nichtstudierenden (7o Prozent) ein Erwerbseinkommen, wohingegen dies auf weniger als die Hälfte der Schüler/Studierenden (42 Prozent) zutrifft. Neue Daten zu den Einkommen von Schülern und Studierenden zeigen, dass weibliche Schülerinnen/Studierende (d. h. Frauen, die sich gleichzeitig in Ausbildung und Beschäftigung befinden) in diesem Alter mit einer höheren Wahrscheinlichkeit einer Erwerbstätigkeit nachgehen als ihre männlichen Altersgenossen. Der Anteil der Schülerinnen und weiblichen Studierenden mit einem Erwerbseinkommen ist um 3 Prozentpunkte höher als der der männlichen Schüler und Studierenden (43 Prozent verglichen mit 40 Prozent). Im Gegensatz dazu ist der Anteil der I5- bis 24-jährigen männlichen Nichtschüler/Nichtstudierenden mit einem Erwerbseinkommen um 4 Prozentpunkte höher als der Anteil der weiblichen Nichtschüler/Nichtstudierenden (72 Prozent im Vergleich zu 68 Prozent) (Tab. A6.5b).

Die Einkommen von 15- bis 24-jährigen Schülern/Studierenden sind im Allgemeinen niedriger als die Einkommen von allen Nichtschüler/Nichtstudierenden, unabhängigvon ihrem Bildungsstand, mit Ausnahme von Chile (sowohl von Männern als auch Männern und Frauen zusammen), von Frauen in Estland und von Männern in Israel (Tab. A6.5a).

Schüler/Studierende haben normalerweise geringere Erwerbseinkommen als Nichtschüler/Nichtstudierende gleichen Alters und mit dem gleichen Bildungsstand. Dies gilt insbesondere in Ländern, wo ein großer Teil der Schüler/Studierenden über Erwerbseinkommen verfügt, wie in Dänemark, Frankreich, Kanada, Korea, Norwegen, Österreich und Schweden. Dies deutet darauf hin, dass Schüler/Studierende hauptsächlich Teilzeit und während der Ferien arbeiten, möglicherweise auch in Jobs, die nicht ihrem Bildungsstand entsprechen. Es ist zu berücksichtigen, dass in Ländern mit einem langen Referenzzeitraum für die Einkommensdaten (z. B. einem Kalenderjahr) es häufiger der Fall sein kann, dass die Erwerbseinkommen der Schüler/Studierenden Einkommen während der Ferien beinhalten (Tab. A6.5a und A6.5b). 
Im Durchschnitt erhalten Studierende mit einem Abschluss im Tertiärbereich die höchsten Erwerbseinkommen aller Schüler/Studierenden. Gleichermaßen erzielen Schüler/Studierende mit einem Abschluss im Sekundarbereich II oder postsekundaren, nicht tertiären Bereich höhere Erwerbseinkommen als Schüler mit einer Ausbildung unterhalb des Sekundarbereichs II. Aber die Tendenz lässt sich nicht in allen Ländern so beobachten. Nur in Australien, Belgien, Estland, Frankreich, Israel, Neuseeland, dem Vereinigten Königreich und den Vereinigten Staaten steigen die relativen Einkommen von I5- bis 24-jährigen Schülern/Studierenden mit zunehmendem Bildungsstand und verfügen Studierende mit einem Abschluss im Tertiärbereich über die höchsten Einkommen (Tab. A6.5a).

Die Einkommensverteilung istjedoch keinesfalls homogen. In Australien, Deutschland, Finnland, Frankreich, Italien, Kanada, Korea, Neuseeland, Norwegen, der Schweiz und den Vereinigten Staaten verdienen Schüler/Studierende unabhängig vom Bildungsstand zwischen 40 Prozent und 50 Prozent dessen, was erwerbstätige Nichtschüler/Nichtstudierende verdienen. In Belgien, Brasilien, Chile, Estland, Israel und dem Vereinigten Königreich verdienen manche Schüler/Studierende 8o Prozent dessen, was erwerbstätige Nichtschüler/Nichtstudierende gleichen Alters verdienen, und in Brasilien, Chile und Estland verdienen sie sogar mehr als Nichtschüler/Nichtstudierende (Tab. A6.5a).

In vielen Ländern verfügt mehr als die Hälfte der 15- bis 24-jährigen Schüler/Studierenden über ein Erwerbseinkommen. Unter den Ländern, wo dies nicht der Fall ist, haben in Belgien, Chile, Estland, Israel, Italien, der Schweiz und Spanien jedoch höchstens 20 Prozent der I5- bis 24-jährigen Schüler/Studierenden überhaupt ein solches Einkommen (Tab. A6.5b). Trotzdem muss man berücksichtigen, dass in einigen Ländern, z. B. der Schweiz, ein Teil der Schüler im Sekundarbereich II aufgrund eines Ausbildungsvertrags mit einem Betrieb über Einkommen verfügt, dies ist jedoch in den Berechnungen nicht berücksichtigt.

Diese Ergebnisse unterstützen die weitverbreitete Ansicht, dass eine Fortsetzung der Ausbildung über die Schulpflicht hinaus neben möglichen Studiengebühren und Darlehensrückzahlungen auch entgangenes Einkommen während der Ausbildung (selbst bei gleichzeitiger Erwerbstätigkeit) mit sich bringt, was Einzelne davon abhalten könnte, einen höheren Bildungsstand anzustreben.

\section{Definitionen}

Altersgruppen: Erwachsene bezieht sich auf die Gruppe der 25- bis 64-Jährigen, jüngere Erwachsene bezieht sich auf 25 - bis 34 -Jährige, ältere Erwachsene bezieht sich auf 55 - bis 64-Jährige. Die Bevölkerung im erwerbsfähigen Alter umfasst die Gesamtbevölkerung im Alter von 25 bis 64 Jahren.

Zur Definition von Vollzeiteinkommen sollten die Länder angeben, ob sie einen selbst definierten Vollzeitstatus oder eine bestimmte Anzahl für in der Regel geleistete Arbeitsstunden pro Woche anwenden. Belgien, Frankreich, Italien, Luxemburg, Portugal, Schweden, Spanien und das Vereinigte Königreich verwendeten einen selbst definierten Vollzeitstatus; die übrigen Länder definierten den Vollzeitstatus über die 
Arbeitsstunden pro Woche. In Chile lag die Grenze bei 44/45 Wochenstunden, in der Slowakei bei 37 Wochenstunden, in Slowenien und Ungarn bei 36 Wochenstunden, in Australien, Deutschland, Estland, Israel, Kanada, Korea, Norwegen und den Vereinigten Staaten bei 35 Wochenstunden und in Griechenland, Neuseeland und Tschechien bei 30 Wochenstunden. Die übrigen teilnehmenden Länder gaben keine reguläre Mindestwochenarbeitszeit für den Vollzeitstatus an.

Für einige Länder stammen die Daten zu Einkommen von ganzjähriger Vollzeitbeschäftigten aus der europäischen Gemeinschaftsstatistik über Einkommen und Lebensbedingungen (EU-SILC), die einen eigenen Ansatz zur Definition des Vollzeitstatus verwendet.

Auch die Länge des Referenzzeitraums für die Einkommen unterschied sich. Australien, Neuseeland und das Vereinigte Königreich berichteten die wöchentlichen Einkommen, Belgien, Brasilien, Chile, Estland, Finnland, Israel (3 Monate), Korea, Portugal und die Schweiz die Monatseinkommen, und alle anderen Länder Jahreseinkommen. Frankreich gab bis einschließlich 2007 monatliche Einkommen an, ab 2008 dann Jahreseinkommen.

Bildungsbereiche: Eine Ausbildung unterhalb Sekundarbereich II entspricht Bildungsgängen auf den ISCED-Stufen o, I, 2 und ${ }_{3} \mathrm{C}$ (kurz). Sekundarbereich II bzw. postsekundarer, nicht tertiärer Bereich entspricht Bildungsgängen auf den ISCED-Stufen ${ }_{3} \mathrm{C}$ (lang), ${ }_{3} \mathrm{~B},{ }_{3} \mathrm{~A}$ und 4. Tertiärbereich entspricht Studiengängen auf den ISCED-Stufen ${ }_{5} B,{ }_{5} A$ und 6. Erläuterungen zu den einzelnen ISCED-Bereichen s. Hinweise für den Leser im vorderen Teil des Buches.

\section{Angewandte Methodik}

Der Indikator basiert auf zwei verschiedenen Datenerhebungen. Zum einen auf der regulären Datenerhebung zu den Erwerbseinkommen aller Personen während des Erhebungszeitraums, einschließlich Teilzeit- oder saisonaler Beschäftigung. Diese Datenbank enthält zum ersten Mal Daten zu den Einkommen von Schülern/Studierenden im Vergleich zu Nichtschülern/Nichtstudierenden. Die zweite Datenerhebung erfolgte zu den Einkommen von ganzjährig Vollzeitbeschäftigten.

Die Daten in den Tabellen A6.3a (geschlechtsspezifische Unterschiede bei Einkommen aus Vollzeitbeschäftigung) und A5.6 (Unterschiede bei Einkommen aus Vollzeitbeschäftigung nach Bildungsstand) stammen aus der Erhebung zu den Einkommen ganzjährig Vollzeitbeschäftigter. Allen anderen Tabellen in diesem Indikator liegt die reguläre Datenerhebung zugrunde.

Bei den Einkommensdaten in den Tabellen A6.I und A6.2, Tabelle A6.4 im Internet und Tabelle A6.5a (reguläre Einkommenserhebung) handelt es sich je nach Land um Jahres-, Monats- oder Wocheneinkommen (s. Länge des Referenzzeitraums oben im Abschnitt Definitionen). Die Einkommen sind vor Abzug der Einkommensteuer angegeben, außer für Belgien, Korea und die Türkei, dort handelt es sich Einkommen nach Abzug der Einkommensteuer. Für Portugal, Slowenien, Tschechien und Ungarn ent- 
halten die regulären Zahlen keine Einkommensdaten für Teilzeitbeschäftigte; in Portugal, Tschechien und Ungarn enthalten die Daten keine Einkommen, die nur während eines Teils des Jahres erwirtschaftet wurden.

Da sich die Einkommensdaten für die einzelnen Länder in mehrfacher Hinsicht unterscheiden, sollten die Ergebnisse mit Vorsicht interpretiert werden. So beeinflussen beispielsweise bei Ländern, die Daten von Jahreseinkommen vorgelegt haben, Unterschiede in der Häufigkeit von saisonal beschränkten Beschäftigungsverhältnissen bei Personen mit unterschiedlichem Bildungsstand das relative Einkommen, was sich in den Daten der Länder, die wöchentliche oder monatliche Gehaltsangaben vorgelegt haben, nicht in gleichem Maße niederschlägt. Außerdem ist zu berücksichtigen, dass sich die verfügbaren Daten in den Tabellen A6.2a, A6.2b und A6.2c auf relative Einkommen beziehen und daher bei der Interpretation der Entwicklung der relativen Einkommen von Erwerbstätigen mit unterschiedlichem Bildungsstand mit Vorsicht zu interpretieren sind. Schließlich könnten in den Tabellen A6.5a und A6.5 b Unterschiede zwischen den einzelnen Ländern auf Unterschiede bei den Datenquellen und in der Länge des Referenzzeitraums zurückzuführen sein. Weitere Einzelheiten s. Anhang 3 unter www.oecd.orgleduleag.htm.

Die statistischen Daten für Israel wurden von den zuständigen israelischen Stellen bereitgestellt, die für sie verantwortlich zeichnen. Die Verwendung dieser Daten durch die OECD erfolgt unbeschadet des völkerrechtlichen Status der Golanhöhen, von OstJerusalem und der israelischen Siedlungen im Westjordanland.

\section{Weiterführende Informationen}

Carnevale, A. (2012), Hard Times: College Majors, Unemployment and Earnings: Not All College Degrees Are Created Equal, Center on Education and the Workforce, Washington, D. C.

\section{Tabellen Indikator A6}

Tabelle A6.I: Relative Einkommen 25- bis 64-Jähriger mit Erwerbseinkommen, nach Bildungsstand, Geschlecht und Altersgruppe (20II)

StatLink: http://dx.doi.org/10.1787/888932848875

Tabelle A6.2a: Entwicklung der relativen Einkommen 25- bis 64-Jähriger mit

Erwerbseinkommen, nach Bildungsstand (2000-20II)

StatLink: http://dx.doi.org/10.1787/888932848894

Tabelle A6.2b: Entwicklung der relativen Einkommen 25- bis 64-jähriger Männer mit Erwerbseinkommen, nach Bildungsstand (2000-20II)

StatLink: http://dx.doi.org/10.1787/888932848913

Tabelle A6.2c: Entwicklung der relativen Einkommen 25- bis 64-jähriger Frauen mit Erwerbseinkommen, nach Bildungsstand (2000-20II)

StatLink: http:||dx.doi.org/10.1787/888932848932 
Tabelle A6.3a: Einkommensunterschiede zwischen Frauen und Männern, nach Bildungsstand und Altersgruppe (20II)

StatLink: http://dx.doi.org/10.1787/888932848951

Tabelle A6.3b: Entwicklung der Einkommensunterschiede zwischen 25- und 64-jährigen Frauen und Männern, nach Bildungsstand (2000-20II)

StatLink: http://dx.doi.org/10.1787/888932848970

WEB Table A6.4a: Distribution of 25-64 year-olds, by educational attainment and level of earnings relative to median earnings (Verteilung 25-bis 64-Jähriger nach Bildungsstand und Höhe der Einkommen in Relation zum Median) (20II)

StatLink: http:|/dx.doi.org/10.1787/888932848989

WEB Table A6.4b: Distribution of 25-64 year-old men, by educational attainment and level of earnings relative to median earnings (Verteilung 25-bis 64 -jähriger Männer nach Bildungsstand und Höhe der Einkommen in Relation zum Median) (20II)

StatLink: http:|/dx.doi.org/10.1787/888932849008

WEB Table A6.4c: Distribution of 25-64 year-old women, by educational attainment and level of earnings relative to median earnings (Verteilung 25- bis 64 -jähriger Frauen nach Bildungsstand und Höhe der Einkommen in Relation zum Median) (20II)

StatLink: http://dx.doi.org/10.1787/888932849027

Tabelle A6.5a: Relative Einkommen von I5- bis 24-jährigen Schülern und Studierenden, nach Bildungsstand und Geschlecht (20II)

StatLink: http://dx.doi.org/10.1787/888932849046

Tabelle A6.5b: Anteil junger Erwachsener mit Erwerbseinkommen an allen jungen Erwachsenen, nach Geschlecht, Altersgruppe und Ausbildungsstatus (20II)

StatLink: http:|/dx.doi.org/10.1787/888932849065 
Relative Einkommen 25- bis 64-Jähriger mit Erwerbseinkommen, nach Bildungsstand, Geschlecht und Altersgruppe (2011) Abschluss im Sekundarbereich II oder postsekundaren, nicht tertiären Bereich $=100$

\begin{tabular}{|c|c|c|c|c|c|c|c|c|c|c|c|c|c|c|c|c|c|}
\hline & & & \multicolumn{3}{|c|}{\begin{tabular}{|} 
Ausbildung unterhalb \\
Sekundarbereich II
\end{tabular}} & \multicolumn{3}{|c|}{$\begin{array}{l}\text { Abschluss im } \\
\text { postsekundaren, } \\
\text { nicht tertiären } \\
\text { Bereich }\end{array}$} & \multicolumn{3}{|c|}{$\begin{array}{l}\text { Abschluss im } \\
\text { Tertiärbereich B }\end{array}$} & \multicolumn{3}{|c|}{\begin{tabular}{|c} 
Abschluss im Tertiär- \\
bereich $\mathrm{A} / \mathrm{einem}$ \\
weiterführenden \\
forschungsorientier- \\
ten Studiengang
\end{tabular}} & \multicolumn{3}{|c|}{$\begin{array}{l}\text { Tertiärbereich } \\
\text { insgesamt }\end{array}$} \\
\hline & & & $25-64$ & $25-34$ & $55-64$ & $25-64$ & $25-34$ & $55-64$ & $25-64$ & $25-34$ & $55-64$ & $25-64$ & $25-34$ & $55-64$ & $25-64$ & $25-34$ & $55-64$ \\
\hline & & & (1) & (2) & (3) & (4) & (5) & (6) & (7) & (8) & (9) & (10) & (11) & (12) & (13) & (14) & (15) \\
\hline \multicolumn{18}{|l|}{ OECD-Länder } \\
\hline \multirow[t]{3}{*}{ Australien } & 2009 & Männer & 85 & 78 & 88 & 103 & 110 & 100 & 125 & 100 & 131 & 151 & 122 & 163 & 144 & 117 & 155 \\
\hline & & Frauen & 85 & 75 & 88 & 95 & 107 & 94 & 116 & 105 & 118 & 162 & 151 & 169 & 148 & 141 & 150 \\
\hline & & $M+F$ & 81 & 77 & 82 & 93 & 103 & 95 & 111 & 96 & 113 & 145 & 126 & 157 & 135 & 119 & 143 \\
\hline \multirow[t]{3}{*}{ Österreich } & 2011 & Männer & 67 & 76 & 59 & 133 & 115 & 183 & 126 & 125 & 114 & 172 & 145 & 175 & 154 & 139 & 151 \\
\hline & & Frauen & 73 & 67 & 59 & 124 & 120 & 143 & 147 & 108 & 154 & 171 & 167 & 178 & 163 & 153 & 167 \\
\hline & & $M+F$ & 66 & 73 & 54 & 123 & 113 & 164 & 135 & 119 & 124 & 171 & 149 & 176 & 158 & 141 & 154 \\
\hline \multirow[t]{3}{*}{ Belgien $^{1}$} & 2011 & Männer & 92 & 93 & 87 & 97 & 101 & 94 & 116 & 112 & 116 & 140 & 129 & 145 & 129 & 122 & 133 \\
\hline & & Frauen & 84 & 88 & 77 & 95 & 103 & 83 & 125 & 123 & 125 & 148 & 141 & 156 & 134 & 132 & 137 \\
\hline & & $M+F$ & 91 & 92 & 83 & 96 & 101 & 89 & 116 & 113 & 118 & 143 & 132 & 153 & 129 & 123 & 135 \\
\hline Kanada & 2010 & Männer & 78 & 90 & 69 & 108 & 113 & 100 & 114 & 113 & 123 & 165 & 126 & 195 & 140 & 120 & 164 \\
\hline & & Frauen & 77 & 104 & 70 & 105 & 117 & 95 & 120 & 126 & 115 & 183 & 184 & 178 & 151 & 160 & 143 \\
\hline & & $M+F$ & 80 & 97 & 71 & 109 & 113 & 101 & 111 & 110 & 117 & 166 & 136 & 197 & 139 & 124 & 158 \\
\hline Chile & 2011 & Männer & 64 & 69 & 58 & a & a & a & 149 & 134 & 145 & 325 & 267 & 343 & 271 & 229 & 300 \\
\hline & & Frauen & 65 & 70 & 48 & a & a & a & 168 & 141 & 147 & 306 & 275 & 274 & 262 & 241 & 239 \\
\hline & & $M+F$ & 66 & 70 & 56 & a & a & a & 151 & 133 & 143 & 309 & 261 & 323 & 260 & 227 & 279 \\
\hline Tschechien & 2011 & Männer & 76 & 78 & 77 & $\mathrm{~m}$ & $\mathrm{~m}$ & $\mathrm{~m}$ & 122 & 121 & 127 & 191 & 162 & 195 & 187 & 158 & 193 \\
\hline & & Frauen & 74 & 76 & 70 & $\mathrm{~m}$ & $\mathrm{~m}$ & $\mathrm{~m}$ & 121 & 118 & 117 & 164 & 150 & 176 & 160 & 144 & 172 \\
\hline & & $M+F$ & 73 & 78 & 71 & $\mathrm{~m}$ & $\mathrm{~m}$ & $\mathrm{~m}$ & 117 & 114 & 118 & 181 & 154 & 190 & 176 & 149 & 187 \\
\hline Dänemark & 2011 & Männer & 79 & 76 & 85 & 68 & 44 & 101 & 115 & 115 & 113 & 146 & 113 & 161 & 138 & 113 & 151 \\
\hline & & Frauen & 83 & 76 & 87 & 42 & 44 & 66 & 113 & 120 & 107 & 128 & 123 & 134 & 126 & 123 & 130 \\
\hline & & $M+F$ & 81 & 78 & 84 & 62 & 45 & 108 & 115 & 116 & 110 & 130 & 111 & 143 & 128 & 112 & 137 \\
\hline Estland & 2011 & Männer & 81 & 78 & 85 & $\mathrm{~m}$ & $m$ & $\mathrm{~m}$ & $\mathrm{~m}$ & $\mathrm{~m}$ & $\mathrm{~m}$ & 146 & 112 & 151 & 146 & 112 & 151 \\
\hline & & Frauen & 81 & 78 & 76 & $\mathrm{~m}$ & $m$ & $\mathrm{~m}$ & $\mathrm{~m}$ & $\mathrm{~m}$ & $\mathrm{~m}$ & 148 & 136 & 142 & 148 & 136 & 142 \\
\hline & & $M+F$ & 87 & 83 & 88 & $\mathrm{~m}$ & $\mathrm{~m}$ & $\mathrm{~m}$ & $\mathrm{~m}$ & $\mathrm{~m}$ & $\mathrm{~m}$ & 135 & 112 & 139 & 135 & 112 & 139 \\
\hline Finnland & 2009 & Männer & 90 & 89 & 92 & $\mathrm{~m}$ & $m$ & $m$ & 136 & 132 & 135 & 174 & 138 & 211 & 162 & 137 & 179 \\
\hline & & Frauen & 94 & 89 & 93 & $\mathrm{~m}$ & $\mathrm{~m}$ & $\mathrm{~m}$ & 133 & 128 & 126 & 155 & 142 & 191 & 146 & 141 & 154 \\
\hline & & $M+F$ & 93 & 92 & 93 & $\mathrm{~m}$ & $\mathrm{~m}$ & $\mathrm{~m}$ & 128 & 120 & 128 & 161 & 130 & 206 & 149 & 129 & 167 \\
\hline Frankreich & 2009 & Männer & 83 & 84 & 79 & $\mathrm{~m}$ & $\mathrm{~m}$ & $\mathrm{~m}$ & 121 & 117 & 149 & 181 & 150 & 240 & 157 & 135 & 215 \\
\hline & & Frauen & 75 & 74 & 62 & $\mathrm{~m}$ & $\mathrm{~m}$ & $\mathrm{~m}$ & 129 & 135 & 111 & 155 & 150 & 164 & 145 & 145 & 147 \\
\hline & & $M+F$ & 79 & 80 & 70 & $\mathrm{~m}$ & $\mathrm{~m}$ & $\mathrm{~m}$ & 122 & 121 & 130 & 163 & 142 & 208 & 147 & 134 & 185 \\
\hline Deutschland & 2011 & Männer & 88 & 76 & 94 & 121 & 130 & 114 & 127 & 128 & 117 & 173 & 136 & 187 & 161 & 135 & 169 \\
\hline & & Frauen & 81 & 74 & 84 & 121 & 121 & 113 & 115 & 119 & 108 & 166 & 151 & 200 & 155 & 145 & 183 \\
\hline & & $M+F$ & 86 & 78 & 88 & 116 & 117 & 111 & 132 & 121 & 126 & 174 & 142 & 200 & 164 & 139 & 183 \\
\hline Griechenland & 2011 & Männer & 69 & 93 & 62 & 98 & 102 & 87 & 107 & 109 & 99 & 167 & 142 & 224 & 151 & 131 & 200 \\
\hline & & Frauen & 50 & 62 & 43 & 118 & 116 & 155 & 175 & 174 & 79 & 239 & 193 & 323 & 222 & 187 & 260 \\
\hline & & $M+F$ & 61 & 86 & 53 & 102 & 104 & 104 & 126 & 132 & 96 & 186 & 157 & 271 & 170 & 149 & 233 \\
\hline Ungarn & 2011 & Männer & 75 & 76 & 76 & 123 & 117 & 126 & 130 & 127 & 133 & 245 & 203 & 248 & 243 & 202 & 247 \\
\hline & & Frauen & 72 & 75 & 65 & 114 & 108 & 115 & 130 & 132 & 138 & 185 & 170 & 194 & 185 & 170 & 193 \\
\hline & & $M+F$ & 73 & 76 & 69 & 118 & 112 & 120 & 127 & 127 & 135 & 208 & 182 & 218 & 207 & 182 & 217 \\
\hline Island & & & $\mathrm{m}$ & $\mathrm{m}$ & $\mathrm{m}$ & $\mathrm{m}$ & $\mathrm{m}$ & $\mathrm{m}$ & $\mathrm{m}$ & $\mathrm{m}$ & $\mathrm{m}$ & $\mathrm{m}$ & $\mathrm{m}$ & $\mathrm{m}$ & $\mathrm{m}$ & $\mathrm{m}$ & $\mathrm{m}$ \\
\hline Irland & 2010 & Männer & 82 & 77 & 70 & 86 & 99 & 76 & 143 & 119 & 152 & 205 & 208 & 162 & 180 & 177 & 158 \\
\hline & & Frauen & 78 & 77 & 68 & 99 & 90 & 102 & 130 & 162 & 141 & 206 & 252 & 165 & 178 & 223 & 155 \\
\hline & & $M+F$ & 85 & 74 & 79 & 90 & 95 & 86 & 135 & 125 & 147 & 200 & 205 & 169 & 175 & 179 & 161 \\
\hline Israel & 2011 & Männer & 69 & 72 & 70 & 106 & 110 & 92 & 117 & 108 & 123 & 179 & 151 & 192 & 159 & 139 & 166 \\
\hline & & Frauen & 66 & 73 & 59 & 125 & 161 & 110 & 118 & 106 & 131 & 165 & 143 & 167 & 151 & 134 & 153 \\
\hline & & $M+F$ & 72 & 75 & 70 & 110 & 127 & 95 & 115 & 104 & 124 & 167 & 141 & 180 & 151 & 132 & 159 \\
\hline Italien & 2009 & Männer & 76 & 90 & 68 & $\mathrm{~m}$ & $\mathrm{~m}$ & $\mathrm{~m}$ & $\mathrm{~m}$ & $\mathrm{~m}$ & $\mathrm{~m}$ & 160 & 120 & 183 & 160 & 120 & 183 \\
\hline & & Frauen & 72 & 80 & 67 & $m$ & $m$ & $\mathrm{~m}$ & $\mathrm{~m}$ & $\mathrm{~m}$ & $\mathrm{~m}$ & 143 & 136 & 151 & 143 & 136 & 151 \\
\hline & & $M+F$ & 77 & 91 & 68 & $\mathrm{~m}$ & $\mathrm{~m}$ & $\mathrm{~m}$ & $\mathrm{~m}$ & $\mathrm{~m}$ & $\mathrm{~m}$ & 148 & 122 & 168 & 148 & 122 & 168 \\
\hline Japan & 2007 & Männer & 74 & 88 & 71 & $\mathrm{~m}$ & $\mathrm{~m}$ & $\mathrm{~m}$ & 116 & 111 & 126 & 141 & 126 & 157 & 139 & 125 & 154 \\
\hline & & Frauen & 78 & 73 & 77 & $\mathrm{~m}$ & $\mathrm{~m}$ & $\mathrm{~m}$ & 134 & 134 & 146 & 191 & 171 & 225 & 161 & 155 & 178 \\
\hline & & $M+F$ & 80 & 90 & 74 & $\mathrm{~m}$ & $\mathrm{~m}$ & $\mathrm{~m}$ & 90 & 96 & 106 & 168 & 139 & 197 & 148 & 129 & 178 \\
\hline Korea $^{1}$ & 2011 & Männer & 72 & 84 & 73 & $\mathrm{~m}$ & $\mathrm{~m}$ & $\mathrm{~m}$ & 107 & 106 & 134 & 151 & 129 & 207 & 137 & 120 & 195 \\
\hline & & Frauen & 78 & 84 & 78 & $\mathrm{~m}$ & $\mathrm{~m}$ & $\mathrm{~m}$ & 130 & 120 & 227 & 167 & 143 & 237 & 153 & 133 & 235 \\
\hline & & $M+F$ & 71 & 85 & 67 & $\mathrm{~m}$ & $\mathrm{~m}$ & $\mathrm{~m}$ & 116 & 110 & 154 & 164 & 132 & 225 & 147 & 123 & 212 \\
\hline Luxemburg & 2010 & Männer & 68 & 68 & 83 & 105 & 99 & 74 & $\mathrm{~m}$ & $\mathrm{~m}$ & $\mathrm{~m}$ & 165 & 143 & 188 & 165 & 143 & 188 \\
\hline & & Frauen & 68 & 61 & 49 & 113 & 61 & 91 & $\mathrm{~m}$ & $\mathrm{~m}$ & $\mathrm{~m}$ & 166 & 167 & 150 & 166 & 167 & 150 \\
\hline & & $M+F$ & 66 & 67 & 66 & 119 & 109 & 80 & $\mathrm{~m}$ & $\mathrm{~m}$ & $\mathrm{~m}$ & 159 & 151 & 177 & 159 & 151 & 177 \\
\hline Mexiko & & & $\mathrm{m}$ & $\mathrm{m}$ & $\mathrm{m}$ & $\mathrm{m}$ & $\mathrm{m}$ & $\mathrm{m}$ & $\mathrm{m}$ & $\mathrm{m}$ & $\mathrm{m}$ & $\mathrm{m}$ & $\mathrm{m}$ & $\mathrm{m}$ & $\mathrm{m}$ & $\mathrm{m}$ & $\mathrm{m}$ \\
\hline
\end{tabular}

1. Einkommen nach Abzug der Einkommensteuer.

Quelle: OECD. Spezielle Datenerhebung zu Einkommen des Netzwerks zu den Arbeitsmarktergebnissen sowie den wirtschaftlichen und sozialen Auswirkungen des Lernens (LSO). Hinweise s. Anhang 3 unter www.oecd.org/edu/eag.htm. StatLink: http://dx.doi.org/10.1787/888932848875

Erläuterung der Kennzeichnung fehlender Daten s. Hinweise für den Leser. 
Tabelle A6.1 (Forts.)

Relative Einkommen 25- bis 64-Jähriger mit Erwerbseinkommen, nach Bildungsstand, Geschlecht und Altersgruppe (2011) Abschluss im Sekundarbereich II oder postsekundaren, nicht tertiären Bereich $=100$

\begin{tabular}{|c|c|c|c|c|c|c|c|c|c|c|c|c|c|c|c|c|c|}
\hline & & & \multicolumn{3}{|c|}{\begin{tabular}{|c} 
Ausbildung unterhalb \\
Sekundarbereich II
\end{tabular}} & \multicolumn{3}{|c|}{$\begin{array}{l}\text { Abschluss im } \\
\text { postsekundaren, } \\
\text { nicht tertiären } \\
\text { Bereich }\end{array}$} & \multicolumn{3}{|c|}{$\begin{array}{l}\text { Abschluss im } \\
\text { Tertiärbereich B }\end{array}$} & \multicolumn{3}{|c|}{\begin{tabular}{|c|} 
Abschluss im Tertiär- \\
bereich A/einem \\
weiterführenden \\
forschungsorientier- \\
ten Studiengang
\end{tabular}} & \multicolumn{3}{|c|}{$\begin{array}{c}\text { Tertiärbereich } \\
\text { insgesamt }\end{array}$} \\
\hline & & & $25-64$ & $25-34$ & $55-64$ & $25-64$ & $25-34$ & $55-64$ & $25-64$ & $25-34$ & $55-64$ & $25-64$ & $25-34$ & $55-64$ & $25-64$ & $25-34$ & $55-64$ \\
\hline & & & (1) & (2) & (3) & (4) & (5) & (6) & (7) & (8) & (9) & (10) & (11) & (12) & (13) & (14) & (15) \\
\hline \multicolumn{18}{|l|}{ OECD-Länder } \\
\hline Niederlande & 2010 & $\begin{array}{l}\text { Männer } \\
\text { Frauen } \\
M+F\end{array}$ & $\begin{array}{l}85 \\
73 \\
83\end{array}$ & $\begin{array}{l}90 \\
77 \\
90\end{array}$ & $\begin{array}{l}82 \\
68 \\
74\end{array}$ & $\begin{array}{l}\mathrm{m} \\
\mathrm{m} \\
\mathrm{m}\end{array}$ & $\begin{array}{l}\mathrm{m} \\
\mathrm{m} \\
\mathrm{m}\end{array}$ & $\begin{array}{l}\mathrm{m} \\
\mathrm{m} \\
\mathrm{m}\end{array}$ & $\begin{array}{l}143 \\
143 \\
145\end{array}$ & $\begin{array}{l}133 \\
138 \\
134\end{array}$ & $\begin{array}{l}139 \\
129 \\
145\end{array}$ & $\begin{array}{l}154 \\
163 \\
157\end{array}$ & $\begin{array}{l}134 \\
148 \\
137\end{array}$ & $\begin{array}{l}155 \\
164 \\
160\end{array}$ & $\begin{array}{l}153 \\
162 \\
156\end{array}$ & $\begin{array}{l}134 \\
148 \\
137\end{array}$ & $\begin{array}{l}154 \\
162 \\
159\end{array}$ \\
\hline Neuseeland & 2011 & $\begin{array}{l}\text { Männer } \\
\text { Frauen } \\
M+F\end{array}$ & $\begin{array}{l}79 \\
87 \\
79\end{array}$ & $\begin{array}{l}85 \\
88 \\
87\end{array}$ & $\begin{array}{l}77 \\
85 \\
76\end{array}$ & $\begin{array}{r}101 \\
88 \\
110\end{array}$ & $\begin{array}{l}102 \\
102 \\
112\end{array}$ & $\begin{array}{r}99 \\
73 \\
107\end{array}$ & $\begin{array}{r}101 \\
110 \\
97\end{array}$ & $\begin{array}{r}90 \\
111 \\
94\end{array}$ & $\begin{array}{r}99 \\
120 \\
97\end{array}$ & $\begin{array}{l}135 \\
145 \\
132\end{array}$ & $\begin{array}{l}115 \\
146 \\
120\end{array}$ & $\begin{array}{l}153 \\
164 \\
149\end{array}$ & $\begin{array}{l}123 \\
131 \\
118\end{array}$ & $\begin{array}{l}106 \\
136 \\
112\end{array}$ & $\begin{array}{l}133 \\
140 \\
125\end{array}$ \\
\hline Norwegen & 2010 & $\begin{array}{l}\text { Männer } \\
\text { Frauen } \\
M+F\end{array}$ & $\begin{array}{l}76 \\
78 \\
76\end{array}$ & $\begin{array}{l}73 \\
75 \\
73\end{array}$ & $\begin{array}{l}77 \\
79 \\
77\end{array}$ & $\begin{array}{l}121 \\
116 \\
125\end{array}$ & $\begin{array}{l}119 \\
108 \\
123\end{array}$ & $\begin{array}{l}127 \\
125 \\
133\end{array}$ & $\begin{array}{l}145 \\
151 \\
152\end{array}$ & $\begin{array}{l}136 \\
149 \\
133\end{array}$ & $\begin{array}{l}146 \\
150 \\
165\end{array}$ & $\begin{array}{l}133 \\
134 \\
127\end{array}$ & $\begin{array}{l}106 \\
127 \\
107\end{array}$ & $\begin{array}{l}154 \\
148 \\
149\end{array}$ & $\begin{array}{l}134 \\
134 \\
128\end{array}$ & $\begin{array}{l}107 \\
128 \\
107\end{array}$ & $\begin{array}{l}153 \\
148 \\
151\end{array}$ \\
\hline Polen & 2010 & $\begin{array}{l}\text { Männer } \\
\text { Frauen } \\
M+F\end{array}$ & $\begin{array}{l}86 \\
77 \\
83\end{array}$ & $\begin{array}{l}85 \\
87 \\
87\end{array}$ & $\begin{array}{l}84 \\
66 \\
78\end{array}$ & $\begin{array}{l}110 \\
118 \\
109\end{array}$ & $\begin{array}{l}106 \\
110 \\
102\end{array}$ & $\begin{array}{l}113 \\
118 \\
114\end{array}$ & $\begin{array}{l}\mathrm{m} \\
\mathrm{m} \\
\mathrm{m}\end{array}$ & $\begin{array}{l}\mathrm{m} \\
\mathrm{m} \\
\mathrm{m}\end{array}$ & $\begin{array}{l}\mathrm{m} \\
\mathrm{m} \\
\mathrm{m}\end{array}$ & $\begin{array}{l}186 \\
168 \\
169\end{array}$ & $\begin{array}{l}160 \\
155 \\
148\end{array}$ & $\begin{array}{l}223 \\
182 \\
204\end{array}$ & $\begin{array}{l}186 \\
168 \\
169\end{array}$ & $\begin{array}{l}160 \\
155 \\
148\end{array}$ & $\begin{array}{l}223 \\
182 \\
204\end{array}$ \\
\hline Portugal & 2010 & $\begin{array}{l}\text { Männer } \\
\text { Frauen } \\
M+F\end{array}$ & $\begin{array}{l}67 \\
68 \\
69\end{array}$ & $\begin{array}{l}79 \\
78 \\
81\end{array}$ & $\begin{array}{l}52 \\
51 \\
51\end{array}$ & $\begin{array}{r}98 \\
112 \\
104\end{array}$ & $\begin{array}{l}102 \\
116 \\
108\end{array}$ & $\begin{array}{r}87 \\
118 \\
96\end{array}$ & $\begin{array}{l}161 \\
157 \\
159\end{array}$ & $\begin{array}{l}143 \\
146 \\
144\end{array}$ & $\begin{array}{l}150 \\
155 \\
154\end{array}$ & $\begin{array}{l}175 \\
173 \\
171\end{array}$ & $\begin{array}{l}158 \\
167 \\
159\end{array}$ & $\begin{array}{l}193 \\
199 \\
201\end{array}$ & $\begin{array}{l}173 \\
171 \\
170\end{array}$ & $\begin{array}{l}156 \\
165 \\
158\end{array}$ & $\begin{array}{l}184 \\
188 \\
191\end{array}$ \\
\hline Slowakei & 2011 & $\begin{array}{l}\text { Männer } \\
\text { Frauen } \\
M+F\end{array}$ & $\begin{array}{l}69 \\
71 \\
67\end{array}$ & $\begin{array}{l}60 \\
69 \\
63\end{array}$ & $\begin{array}{l}79 \\
69 \\
70\end{array}$ & $\begin{array}{l}\mathrm{m} \\
\mathrm{m} \\
\mathrm{m}\end{array}$ & $\begin{array}{l}\mathrm{m} \\
\mathrm{m} \\
\mathrm{m}\end{array}$ & $\begin{array}{l}\mathrm{m} \\
\mathrm{m} \\
\mathrm{m}\end{array}$ & $\begin{array}{l}130 \\
137 \\
123\end{array}$ & $\begin{array}{l}121 \\
130 \\
116\end{array}$ & $\begin{array}{l}153 \\
138 \\
135\end{array}$ & $\begin{array}{l}186 \\
171 \\
177\end{array}$ & $\begin{array}{l}155 \\
154 \\
148\end{array}$ & $\begin{array}{l}198 \\
183 \\
192\end{array}$ & $\begin{array}{l}185 \\
169 \\
175\end{array}$ & $\begin{array}{l}154 \\
153 \\
147\end{array}$ & $\begin{array}{l}197 \\
179 \\
189\end{array}$ \\
\hline Slowenien & 2011 & $\begin{array}{l}\text { Männer } \\
\text { Frauen } \\
M+F\end{array}$ & $\begin{array}{l}77 \\
76 \\
76\end{array}$ & $\begin{array}{l}79 \\
83 \\
83\end{array}$ & $\begin{array}{l}73 \\
62 \\
69\end{array}$ & $\begin{array}{l}\mathrm{m} \\
\mathrm{m} \\
\mathrm{m}\end{array}$ & $\begin{array}{l}\mathrm{m} \\
\mathrm{m} \\
\mathrm{m}\end{array}$ & $\begin{array}{l}\mathrm{m} \\
\mathrm{m} \\
\mathrm{m}\end{array}$ & $\begin{array}{l}162 \\
156 \\
155\end{array}$ & $\begin{array}{l}143 \\
132 \\
130\end{array}$ & $\begin{array}{l}175 \\
161 \\
167\end{array}$ & $\begin{array}{l}220 \\
198 \\
203\end{array}$ & $\begin{array}{l}165 \\
160 \\
151\end{array}$ & $\begin{array}{l}250 \\
234 \\
243\end{array}$ & $\begin{array}{l}197 \\
180 \\
183\end{array}$ & $\begin{array}{l}156 \\
150 \\
143\end{array}$ & $\begin{array}{l}226 \\
202 \\
215\end{array}$ \\
\hline Spanien & 2010 & $\begin{array}{l}\text { Männer } \\
\text { Frauen } \\
M+F\end{array}$ & $\begin{array}{l}80 \\
74 \\
80\end{array}$ & $\begin{array}{l}93 \\
90 \\
94\end{array}$ & $\begin{array}{l}70 \\
60 \\
68\end{array}$ & $\begin{array}{l}\mathrm{C} \\
\mathrm{C} \\
\mathrm{C}\end{array}$ & $\begin{array}{l}\mathrm{C} \\
\mathrm{C} \\
\mathrm{C}\end{array}$ & $\begin{array}{l}\mathrm{C} \\
\mathrm{C} \\
\mathrm{C}\end{array}$ & $\begin{array}{l}107 \\
107 \\
108\end{array}$ & $\begin{array}{l}116 \\
119 \\
117\end{array}$ & $\begin{array}{r}98 \\
98 \\
102\end{array}$ & $\begin{array}{l}145 \\
169 \\
150\end{array}$ & $\begin{array}{l}128 \\
157 \\
136\end{array}$ & $\begin{array}{l}155 \\
182 \\
162\end{array}$ & $\begin{array}{l}133 \\
157 \\
140\end{array}$ & $\begin{array}{l}124 \\
149 \\
131\end{array}$ & $\begin{array}{l}144 \\
174 \\
154\end{array}$ \\
\hline Schweden & 2010 & $\begin{array}{l}\text { Männer } \\
\text { Frauen } \\
M+F\end{array}$ & $\begin{array}{l}81 \\
80 \\
82\end{array}$ & $\begin{array}{l}79 \\
75 \\
78\end{array}$ & $\begin{array}{l}83 \\
84 \\
85\end{array}$ & $\begin{array}{l}122 \\
108 \\
120\end{array}$ & $\begin{array}{l}79 \\
85 \\
80\end{array}$ & $\begin{array}{l}127 \\
125 \\
133\end{array}$ & $\begin{array}{l}105 \\
114 \\
105\end{array}$ & $\begin{array}{l}96 \\
95 \\
94\end{array}$ & $\begin{array}{l}111 \\
121 \\
111\end{array}$ & $\begin{array}{l}142 \\
132 \\
133\end{array}$ & $\begin{array}{l}118 \\
130 \\
118\end{array}$ & $\begin{array}{l}159 \\
148 \\
152\end{array}$ & $\begin{array}{l}133 \\
127 \\
125\end{array}$ & $\begin{array}{l}113 \\
124 \\
113\end{array}$ & $\begin{array}{l}147 \\
138 \\
139\end{array}$ \\
\hline Schweiz & 2011 & $\begin{array}{l}\text { Männer } \\
\text { Frauen } \\
M+F\end{array}$ & $\begin{array}{l}80 \\
75 \\
76\end{array}$ & $\begin{array}{l}86 \\
72 \\
80\end{array}$ & $\begin{array}{l}75 \\
68 \\
68\end{array}$ & $\begin{array}{r}99 \\
116 \\
105\end{array}$ & $\begin{array}{l}102 \\
110 \\
104\end{array}$ & $\begin{array}{l}104 \\
116 \\
110\end{array}$ & $\begin{array}{l}125 \\
133 \\
138\end{array}$ & $\begin{array}{l}124 \\
129 \\
128\end{array}$ & $\begin{array}{l}122 \\
134 \\
138\end{array}$ & $\begin{array}{l}154 \\
163 \\
163\end{array}$ & $\begin{array}{l}132 \\
145 \\
137\end{array}$ & $\begin{array}{l}167 \\
164 \\
178\end{array}$ & $\begin{array}{l}144 \\
155 \\
155\end{array}$ & $\begin{array}{l}130 \\
142 \\
135\end{array}$ & $\begin{array}{l}150 \\
155 \\
164\end{array}$ \\
\hline Türkei $^{1}$ & 2005 & $\begin{array}{l}\text { Männer } \\
\text { Frauen } \\
M+F\end{array}$ & $\begin{array}{l}72 \\
43 \\
69\end{array}$ & $\begin{array}{l}77 \\
37 \\
70\end{array}$ & $\begin{array}{l}60 \\
49 \\
59\end{array}$ & $\begin{array}{l}m \\
m \\
m\end{array}$ & $\begin{array}{l}\mathrm{m} \\
\mathrm{m} \\
\mathrm{m}\end{array}$ & $\begin{array}{l}\mathrm{m} \\
\mathrm{m} \\
\mathrm{m}\end{array}$ & $\begin{array}{l}128 \\
131 \\
125\end{array}$ & $\begin{array}{r}154 \\
93 \\
131\end{array}$ & $\begin{array}{r}121 \\
m \\
128\end{array}$ & $\begin{array}{l}162 \\
162 \\
157\end{array}$ & $\begin{array}{l}178 \\
150 \\
166\end{array}$ & $\begin{array}{l}133 \\
307 \\
138\end{array}$ & $\begin{array}{l}153 \\
154 \\
149\end{array}$ & $\begin{array}{l}171 \\
133 \\
156\end{array}$ & $\begin{array}{l}129 \\
307 \\
135\end{array}$ \\
\hline $\begin{array}{l}\text { Vereinigtes } \\
\text { Königreich }\end{array}$ & 2011 & $\begin{array}{l}\text { Männer } \\
\text { Frauen } \\
M+F\end{array}$ & $\begin{array}{l}67 \\
69 \\
69\end{array}$ & $\begin{array}{l}63 \\
78 \\
70\end{array}$ & $\begin{array}{l}75 \\
69 \\
69\end{array}$ & $\begin{array}{l}\mathrm{m} \\
\mathrm{m} \\
\mathrm{m}\end{array}$ & $\begin{array}{l}\mathrm{m} \\
\mathrm{m} \\
\mathrm{m}\end{array}$ & $\begin{array}{l}\mathrm{m} \\
\mathrm{m} \\
\mathrm{m}\end{array}$ & $\begin{array}{l}122 \\
144 \\
125\end{array}$ & $\begin{array}{l}100 \\
134 \\
106\end{array}$ & $\begin{array}{l}135 \\
160 \\
138\end{array}$ & $\begin{array}{l}160 \\
195 \\
168\end{array}$ & $\begin{array}{l}146 \\
189 \\
153\end{array}$ & $\begin{array}{l}159 \\
182 \\
164\end{array}$ & $\begin{array}{l}151 \\
182 \\
157\end{array}$ & $\begin{array}{l}138 \\
180 \\
145\end{array}$ & $\begin{array}{l}152 \\
175 \\
156\end{array}$ \\
\hline $\begin{array}{l}\text { Vereinigte } \\
\text { Staaten }\end{array}$ & 2011 & $\begin{array}{l}\text { Männer } \\
\text { Frauen } \\
M+F\end{array}$ & $\begin{array}{l}64 \\
58 \\
64\end{array}$ & $\begin{array}{l}69 \\
61 \\
69\end{array}$ & $\begin{array}{l}66 \\
55 \\
63\end{array}$ & $\begin{array}{l}\mathrm{m} \\
\mathrm{m} \\
\mathrm{m}\end{array}$ & $\begin{array}{l}\mathrm{m} \\
\mathrm{m} \\
\mathrm{m}\end{array}$ & $\begin{array}{l}\mathrm{m} \\
\mathrm{m} \\
\mathrm{m}\end{array}$ & $\begin{array}{l}117 \\
124 \\
116\end{array}$ & $\begin{array}{l}125 \\
143 \\
128\end{array}$ & $\begin{array}{l}109 \\
122 \\
111\end{array}$ & $\begin{array}{l}189 \\
187 \\
184\end{array}$ & $\begin{array}{l}168 \\
188 \\
169\end{array}$ & $\begin{array}{l}181 \\
192 \\
186\end{array}$ & $\begin{array}{l}182 \\
181 \\
177\end{array}$ & $\begin{array}{l}164 \\
184 \\
165\end{array}$ & $\begin{array}{l}175 \\
184 \\
179\end{array}$ \\
\hline $\begin{array}{l}\text { OECD- } \\
\text { Durchschnitt }\end{array}$ & & Männer & 77 & 80 & 75 & 106 & 103 & 106 & 126 & 120 & 128 & 172 & 146 & 188 & 162 & 140 & 176 \\
\hline Durchschnitt & & $\begin{array}{l}\text { Frauen } \\
M+F\end{array}$ & $\begin{array}{l}74 \\
76\end{array}$ & $\begin{array}{l}76 \\
80\end{array}$ & $\begin{array}{l}68 \\
72\end{array}$ & $\begin{array}{l}107 \\
106\end{array}$ & $\begin{array}{l}105 \\
104\end{array}$ & $\begin{array}{l}108 \\
109\end{array}$ & $\begin{array}{l}132 \\
125\end{array}$ & $\begin{array}{l}127 \\
118\end{array}$ & $\begin{array}{l}132 \\
128\end{array}$ & $\begin{array}{l}172 \\
168\end{array}$ & $\begin{array}{l}161 \\
146\end{array}$ & $\begin{array}{l}188 \\
187\end{array}$ & $\begin{array}{l}161 \\
157\end{array}$ & $\begin{array}{l}154 \\
140\end{array}$ & $\begin{array}{l}174 \\
173\end{array}$ \\
\hline $\begin{array}{l}\text { EU21- } \\
\text { Durchschnitt }\end{array}$ & & $\begin{array}{l}\text { Männer } \\
\text { Frauen } \\
\text { M+F }\end{array}$ & $\begin{array}{l}78 \\
75 \\
77\end{array}$ & $\begin{array}{l}80 \\
77 \\
81\end{array}$ & $\begin{array}{l}77 \\
68 \\
73\end{array}$ & $\begin{array}{l}106 \\
106 \\
105\end{array}$ & $\begin{array}{l}99 \\
98 \\
99\end{array}$ & $\begin{array}{l}107 \\
112 \\
110\end{array}$ & $\begin{array}{l}128 \\
134 \\
128 \\
\end{array}$ & $\begin{array}{l}121 \\
130 \\
121 \\
\end{array}$ & $\begin{array}{l}130 \\
127 \\
129\end{array}$ & $\begin{array}{l}173 \\
169 \\
166\end{array}$ & \begin{tabular}{|l|l|}
146 \\
159 \\
145
\end{tabular} & $\begin{array}{l}189 \\
181 \\
186\end{array}$ & $\begin{array}{l}164 \\
161 \\
158\end{array}$ & \begin{tabular}{c|c|}
141 \\
154 \\
140
\end{tabular} & \begin{tabular}{|l|l|}
178 \\
169 \\
174
\end{tabular} \\
\hline Sonst. G20-Län & & & & & & & & & & & & & & & & & \\
\hline Argentinien & & Männer & $\mathrm{m}$ & $\mathrm{m}$ & $\mathrm{m}$ & $\mathrm{m}$ & $\mathrm{m}$ & $\mathrm{m}$ & $\mathrm{m}$ & $\mathrm{m}$ & $\mathrm{m}$ & $\mathrm{m}$ & $\mathrm{m}$ & $\mathrm{m}$ & $\mathrm{m}$ & $\mathrm{m}$ & $\mathrm{m}$ \\
\hline Brasilien & 2011 & $\begin{array}{l}\text { Männer } \\
\text { Frauen } \\
M+F\end{array}$ & $\begin{array}{l}57 \\
50 \\
58\end{array}$ & $\begin{array}{l}61 \\
48 \\
61\end{array}$ & $\begin{array}{l}44 \\
37 \\
44\end{array}$ & $\begin{array}{l}\mathrm{m} \\
\mathrm{m} \\
\mathrm{m}\end{array}$ & $\begin{array}{l}\mathrm{m} \\
\mathrm{m} \\
\mathrm{m}\end{array}$ & $\begin{array}{l}\mathrm{m} \\
\mathrm{m} \\
\mathrm{m}\end{array}$ & $\begin{array}{l}\mathrm{m} \\
\mathrm{m} \\
\mathrm{m}\end{array}$ & $\begin{array}{l}\mathrm{m} \\
\mathrm{m} \\
\mathrm{m}\end{array}$ & $\begin{array}{l}\mathrm{m} \\
\mathrm{m} \\
\mathrm{m}\end{array}$ & $\begin{array}{l}273 \\
269 \\
257\end{array}$ & $\begin{array}{l}241 \\
266 \\
240\end{array}$ & $\begin{array}{l}286 \\
281 \\
278\end{array}$ & $\begin{array}{l}273 \\
269 \\
257\end{array}$ & $\begin{array}{l}241 \\
266 \\
240\end{array}$ & $\begin{array}{l}286 \\
281 \\
278\end{array}$ \\
\hline China & & Männer & $\mathrm{m}$ & $\mathrm{m}$ & $\mathrm{m}$ & $\mathrm{m}$ & $\mathrm{m}$ & $\mathrm{m}$ & $\mathrm{m}$ & $\mathrm{m}$ & $\mathrm{m}$ & $\mathrm{m}$ & $\mathrm{m}$ & $\mathrm{m}$ & $\mathrm{m}$ & $m$ & $\mathrm{~m}$ \\
\hline Indien & & Männer & $\mathrm{m}$ & $\mathrm{m}$ & $\mathrm{m}$ & $\mathrm{m}$ & $\mathrm{m}$ & $\mathrm{m}$ & $\mathrm{m}$ & $\mathrm{m}$ & $\mathrm{m}$ & $\mathrm{m}$ & $\mathrm{m}$ & $\mathrm{m}$ & $\mathrm{m}$ & $\mathrm{m}$ & $\mathrm{m}$ \\
\hline Indonesien & & Männer & $m$ & $\mathrm{~m}$ & $\mathrm{~m}$ & $\mathrm{~m}$ & $\mathrm{~m}$ & $\mathrm{~m}$ & $\mathrm{~m}$ & $\mathrm{~m}$ & $\mathrm{~m}$ & $\mathrm{~m}$ & $\mathrm{~m}$ & $\mathrm{~m}$ & $\mathrm{~m}$ & $\mathrm{~m}$ & $m$ \\
\hline Russische Föd. & & Männer & $\mathrm{m}$ & $\mathrm{m}$ & $\mathrm{m}$ & $\mathrm{m}$ & $\mathrm{m}$ & $\mathrm{m}$ & $\mathrm{m}$ & $\mathrm{m}$ & $\mathrm{m}$ & $\mathrm{m}$ & $\mathrm{m}$ & $\mathrm{m}$ & $\mathrm{m}$ & $\mathrm{m}$ & $\mathrm{m}$ \\
\hline Saudi-Arabien & & Männer & $\mathrm{m}$ & $\mathrm{m}$ & $\mathrm{m}$ & $\mathrm{m}$ & $\mathrm{m}$ & $\mathrm{m}$ & $\mathrm{m}$ & $\mathrm{m}$ & $\mathrm{m}$ & $\mathrm{m}$ & $\mathrm{m}$ & $\mathrm{m}$ & $\mathrm{m}$ & $\mathrm{m}$ & $\mathrm{m}$ \\
\hline Südafrika & & Männer & $\mathrm{m}$ & $\mathrm{m}$ & $\mathrm{m}$ & $\mathrm{m}$ & $\mathrm{m}$ & $\mathrm{m}$ & $\mathrm{m}$ & $\mathrm{m}$ & $\mathrm{m}$ & $\mathrm{m}$ & $\mathrm{m}$ & $\mathrm{m}$ & $\mathrm{m}$ & $\mathrm{m}$ & $\mathrm{m}$ \\
\hline G20-Durchschn & & & $\mathbf{m}$ & m & m & $\mathbf{m}$ & m & m & m & m & m & m & m & m & $\mathbf{m}$ & m & m \\
\hline
\end{tabular}

1. Einkommen nach Abzug der Einkommensteuer.

Quelle: OECD. Spezielle Datenerhebung zu Einkommen des Netzwerks zu den Arbeitsmarktergebnissen sowie den wirtschaftlichen und sozialen Auswirkungen des Lernens (LSO). Hinweise s. Anhang 3 unter www.oecd.org/edu/eag.htm. StatLink: http://dx.doi.org/10.1787/888932848875

Erläuterung der Kennzeichnung fehlender Daten s. Hinweise für den Leser. 
Entwicklung der relativen Einkommen 25- bis 64-Jähriger mit Erwerbseinkommen, nach Bildungsstand (2000-2011) Abschluss im Sekundarbereich II oder postsekundaren, nicht tertiären Bereich $=100$

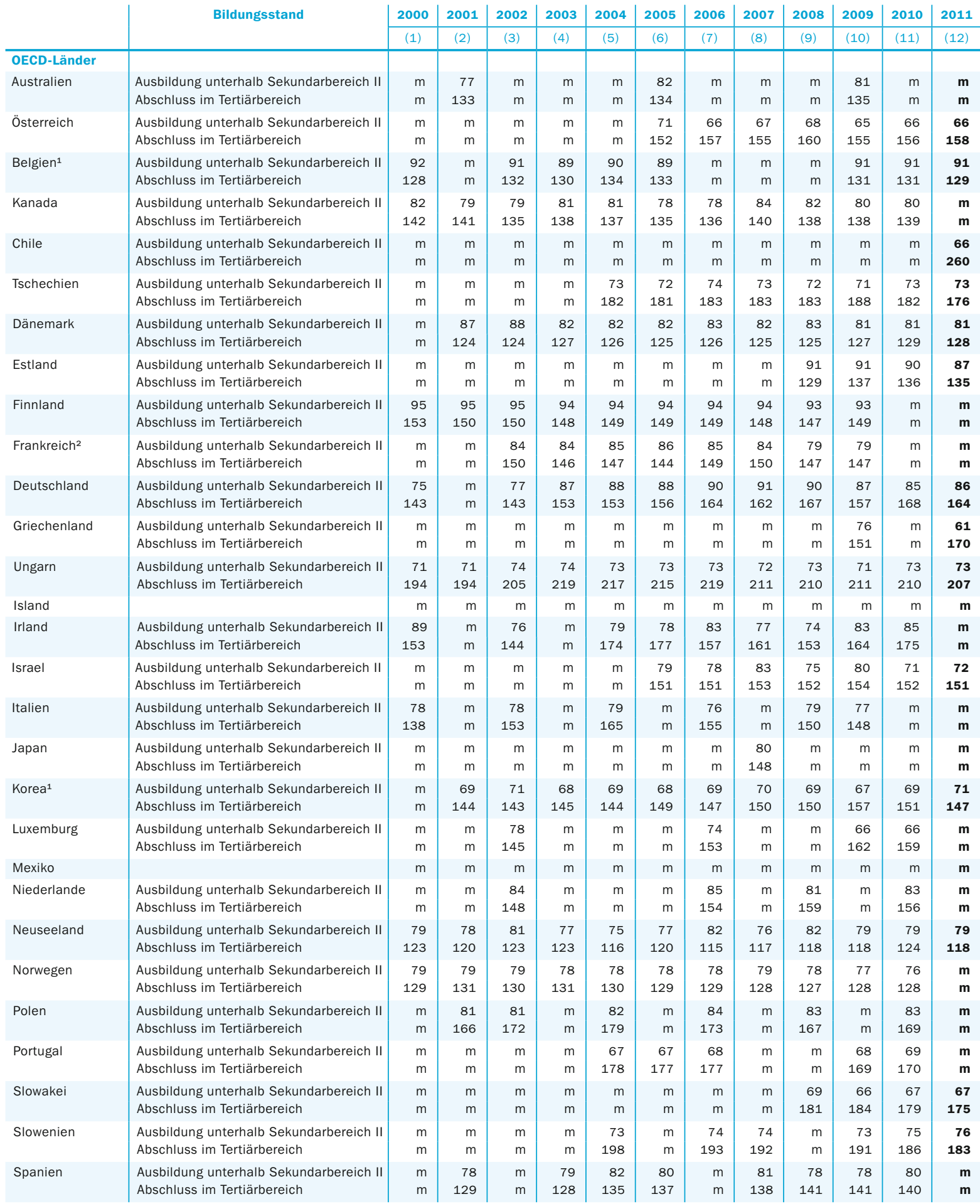

1. Einkommen nach Abzug der Einkommensteuer. 2. Unterbrechung der Zeitreihe zwischen 2007 und 2008 aufgrund eines Wechsels der Datenquelle.

3. Die Zahlen des OECD-Durchschnitts können nicht über die Jahre verglichen werden, da sich die Zahl der Länder, aus denen dieser Durchschnitt errechnet wird, jedes Jahr geändert hat.

Quelle: OECD. Spezielle Datenerhebung zu Einkommen des Netzwerks zu den Arbeitsmarktergebnissen sowie den wirtschaftlichen und sozialen Auswirkungen des Lernens (LSO). Hinweise s. Anhang 3 unter www.oecd.org/edu/eag.htm. StatLink: http://dx.doi.org/10.1787/888932848894

Erläuterung der Kennzeichnung fehlender Daten s. Hinweise für den Leser. 
Tabelle A6.2a (Forts.)

Entwicklung der relativen Einkommen 25- bis 64-Jähriger mit Erwerbseinkommen, nach Bildungsstand (2000-2011)

Abschluss im Sekundarbereich II oder postsekundaren, nicht tertiären Bereich $=100$

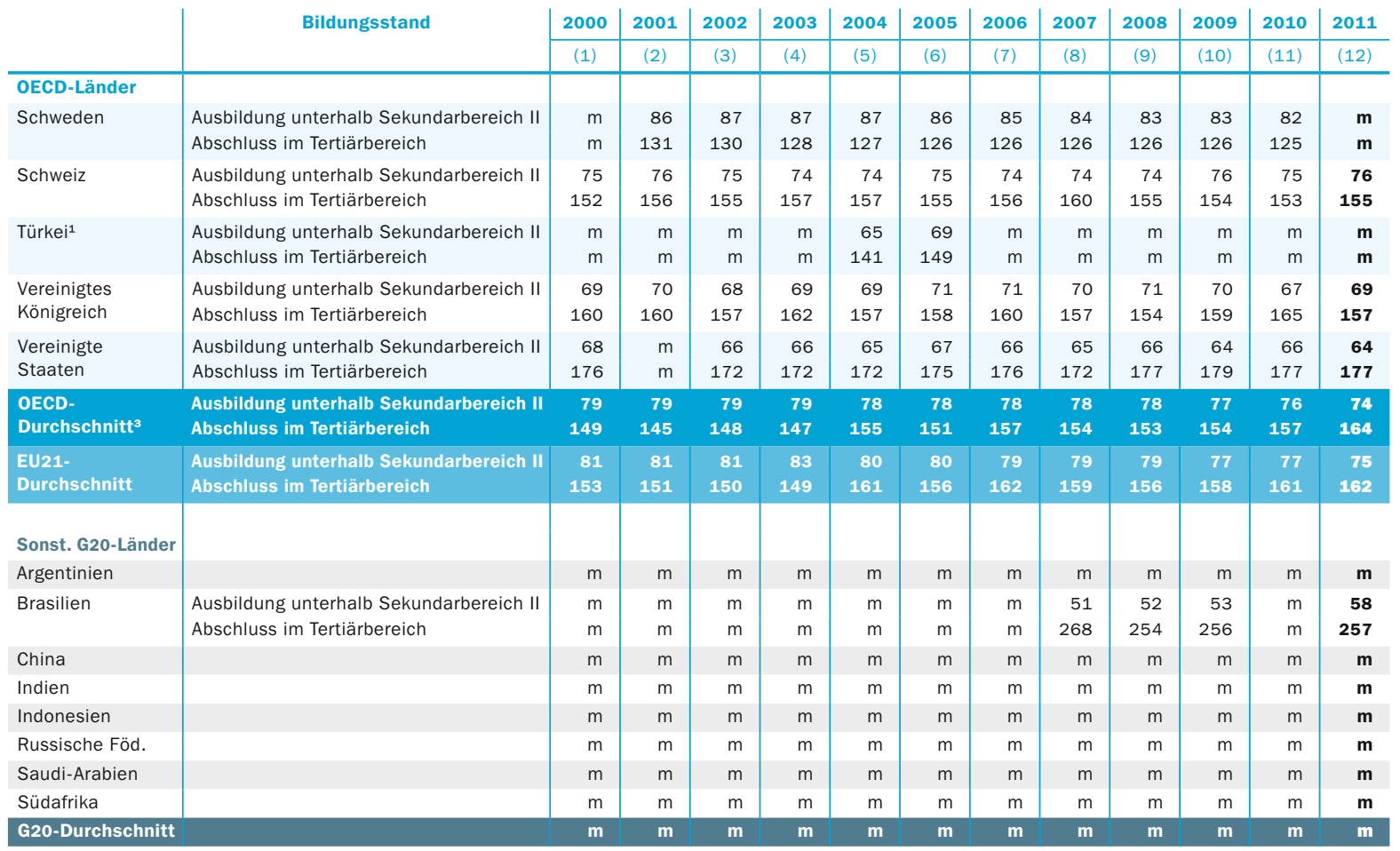

1. Einkommen nach Abzug der Einkommensteuer. 2. Unterbrechung der Zeitreihe zwischen 2007 und 2008 aufgrund eines Wechsels der Datenquelle.

3. Die Zahlen des OECD-Durchschnitts können nicht über die Jahre verglichen werden, da sich die Zahl der Länder, aus denen dieser Durchschnitt errechnet wird, jedes Jahr geändert hat.

Quelle: OECD. Spezielle Datenerhebung zu Einkommen des Netzwerks zu den Arbeitsmarktergebnissen sowie den wirtschaftlichen und sozialen Auswirkungen des Lernens (LSO). Hinweise s. Anhang 3 unter www.oecd.org/edu/eag.htm. StatLink: http://dx.doi.org/10.1787/888932848894

Erläuterung der Kennzeichnung fehlender Daten s. Hinweise für den Leser. 
Entwicklung der relativen Einkommen 25- bis 64-jähriger Männer mit Erwerbseinkommen, nach Bildungsstand (2000-2011) Abschluss im Sekundarbereich II oder postsekundaren, nicht tertiären Bereich $=100$

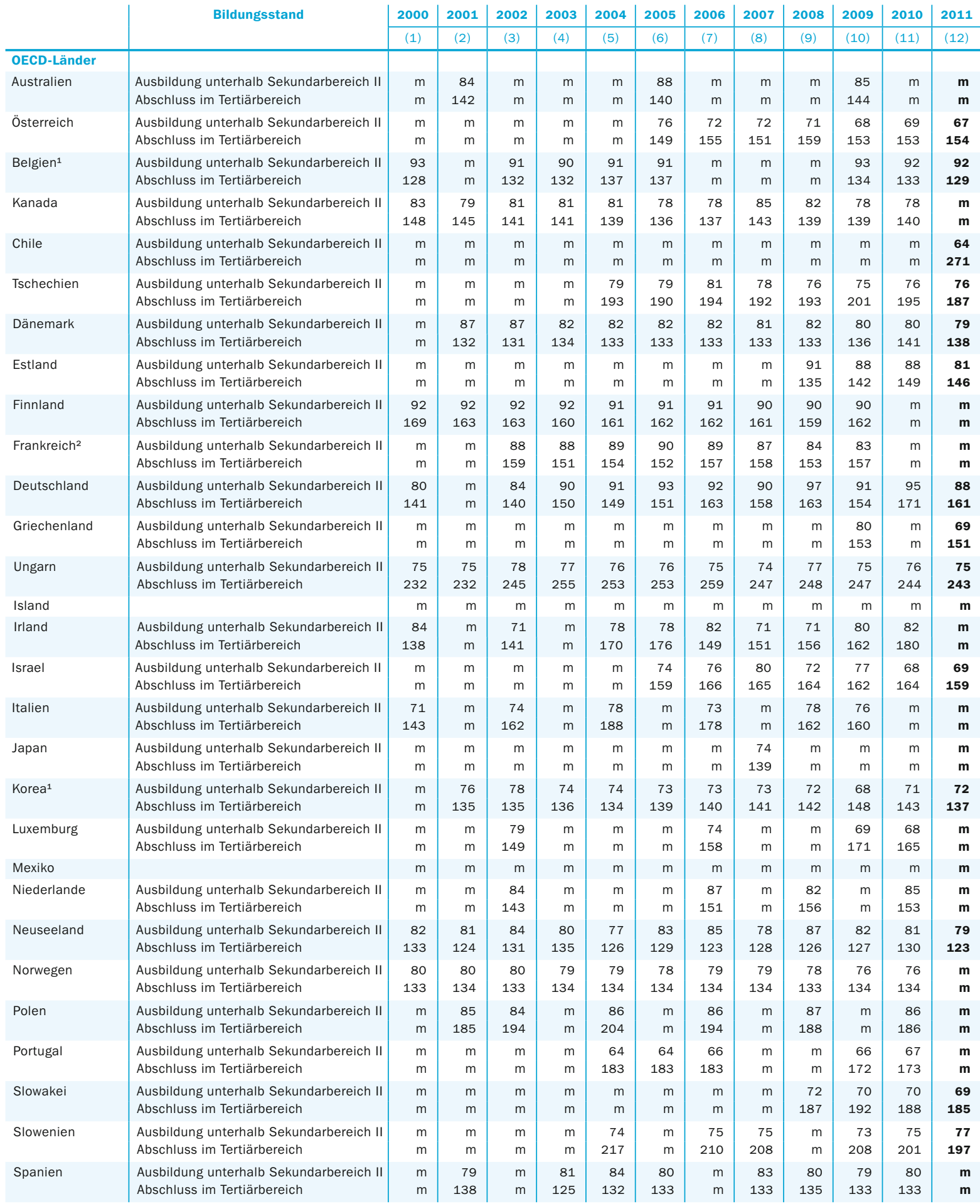

1. Einkommen nach Abzug der Einkommensteuer. 2. Unterbrechung der Zeitreihe zwischen 2007 und 2008 aufgrund eines Wechsels der Datenquelle.

3. Die Zahlen des OECD-Durchschnitts können nicht über die Jahre verglichen werden, da sich die Zahl der Länder, aus denen dieser Durchschnitt errechnet wird, jedes Jahr geändert hat.

Quelle: OECD. Spezielle Datenerhebung zu Einkommen des Netzwerks zu den Arbeitsmarktergebnissen sowie den wirtschaftlichen und sozialen Auswirkungen des Lernens (LSO). Hinweise s. Anhang 3 unter www.oecd.org/edu/eag.htm. StatLink: http://dx.doi.org/10.1787/888932848913

Erläuterung der Kennzeichnung fehlender Daten s. Hinweise für den Leser. 
Tabelle A6.2b (Forts.)

Entwicklung der relativen Einkommen 25- bis 64-jähriger Männer mit Erwerbseinkommen, nach Bildungsstand (2000-2011) Abschluss im Sekundarbereich II oder postsekundaren, nicht tertiären Bereich $=100$

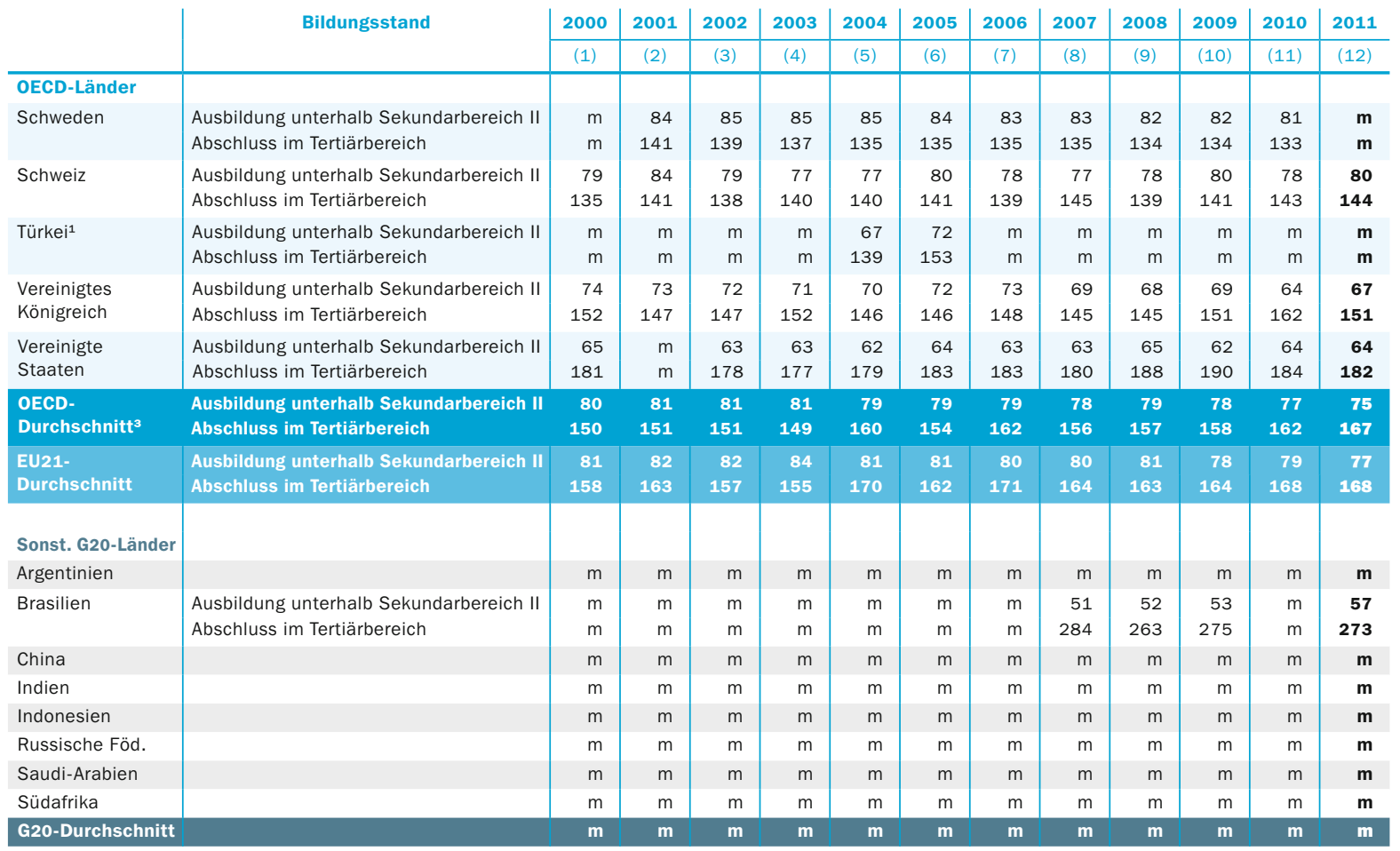

1. Einkommen nach Abzug der Einkommensteuer. 2. Unterbrechung der Zeitreihe zwischen 2007 und 2008 aufgrund eines Wechsels der Datenquelle.

3. Die Zahlen des OECD-Durchschnitts können nicht über die Jahre verglichen werden, da sich die Zahl der Länder, aus denen dieser Durchschnitt errechnet wird, jedes Jahr geändert hat.

Quelle: OECD. Spezielle Datenerhebung zu Einkommen des Netzwerks zu den Arbeitsmarktergebnissen sowie den wirtschaftlichen und sozialen Auswirkungen des Lernens (LSO). Hinweise s. Anhang 3 unter www.oecd.org/edu/eag.htm. StatLink: http://dx.doi.org/10.1787/888932848913

Erläuterung der Kennzeichnung fehlender Daten s. Hinweise für den Leser. 
Entwicklung der relativen Einkommen 25- bis 64-jähriger Frauen mit Erwerbseinkommen, nach Bildungsstand (2000-2011) Abschluss im Sekundarbereich II oder postsekundaren, nicht tertiären Bereich $=100$

\begin{tabular}{|c|c|c|c|c|c|c|c|c|c|c|c|c|c|}
\hline & \multirow{2}{*}{ Bildungsstand } & 2000 & 2001 & 2002 & 2003 & 2004 & 2005 & 2006 & 2007 & 2008 & 2009 & 2010 & 2011 \\
\hline & & (1) & (2) & (3) & (4) & (5) & (6) & (7) & (8) & (9) & $(10)$ & (11) & $(12)$ \\
\hline OECD-Länder & & & & & & & & & & & & & \\
\hline Australien & $\begin{array}{l}\text { Ausbildung unterhalb Sekundarbereich II } \\
\text { Abschluss im Tertiärbereich }\end{array}$ & $\begin{array}{l}\mathrm{m} \\
\mathrm{m}\end{array}$ & $\begin{array}{r}84 \\
146\end{array}$ & $\begin{array}{l}\mathrm{m} \\
\mathrm{m}\end{array}$ & $\begin{array}{l}\mathrm{m} \\
\mathrm{m}\end{array}$ & $\begin{array}{l}\mathrm{m} \\
\mathrm{m}\end{array}$ & $\begin{array}{r}88 \\
147\end{array}$ & $\begin{array}{l}\mathrm{m} \\
\mathrm{m}\end{array}$ & $\begin{array}{l}\mathrm{m} \\
\mathrm{m}\end{array}$ & $\begin{array}{l}m \\
m\end{array}$ & $\begin{array}{r}85 \\
148\end{array}$ & $\begin{array}{l}\mathrm{m} \\
\mathrm{m}\end{array}$ & $\begin{array}{l}\mathbf{m} \\
\mathbf{m}\end{array}$ \\
\hline Österreich & $\begin{array}{l}\text { Ausbildung unterhalb Sekundarbereich II } \\
\text { Abschluss im Tertiärbereich }\end{array}$ & $\begin{array}{l}\mathrm{m} \\
\mathrm{m}\end{array}$ & $\begin{array}{l}\mathrm{m} \\
\mathrm{m}\end{array}$ & $\begin{array}{l}\mathrm{m} \\
\mathrm{m}\end{array}$ & $\begin{array}{l}\mathrm{m} \\
\mathrm{m}\end{array}$ & $\begin{array}{l}\mathrm{m} \\
\mathrm{m}\end{array}$ & $\begin{array}{r}74 \\
156\end{array}$ & $\begin{array}{r}71 \\
158\end{array}$ & $\begin{array}{r}73 \\
160\end{array}$ & $\begin{array}{r}74 \\
159\end{array}$ & $\begin{array}{r}70 \\
158\end{array}$ & $\begin{array}{r}71 \\
162\end{array}$ & $\begin{array}{r}73 \\
163\end{array}$ \\
\hline Belgien $^{1}$ & $\begin{array}{l}\text { Ausbildung unterhalb Sekundarbereich II } \\
\text { Abschluss im Tertiärbereich }\end{array}$ & $\begin{array}{r}82 \\
132\end{array}$ & $\begin{array}{l}\mathrm{m} \\
\mathrm{m}\end{array}$ & $\begin{array}{r}83 \\
139\end{array}$ & $\begin{array}{r}81 \\
132\end{array}$ & $\begin{array}{r}82 \\
137\end{array}$ & $\begin{array}{r}81 \\
134\end{array}$ & $\begin{array}{l}m \\
m\end{array}$ & $\begin{array}{l}m \\
m\end{array}$ & $\begin{array}{l}m \\
m\end{array}$ & $\begin{array}{r}84 \\
135\end{array}$ & $\begin{array}{r}86 \\
136\end{array}$ & $\begin{array}{r}84 \\
134\end{array}$ \\
\hline Kanada & $\begin{array}{l}\text { Ausbildung unterhalb Sekundarbereich II } \\
\text { Abschluss im Tertiärbereich }\end{array}$ & $\begin{array}{r}72 \\
140\end{array}$ & $\begin{array}{r}70 \\
146\end{array}$ & $\begin{array}{r}67 \\
134\end{array}$ & $\begin{array}{r}73 \\
144\end{array}$ & $\begin{array}{r}70 \\
140\end{array}$ & $\begin{array}{r}70 \\
140\end{array}$ & $\begin{array}{r}68 \\
141\end{array}$ & $\begin{array}{r}72 \\
144\end{array}$ & $\begin{array}{r}73 \\
146\end{array}$ & $\begin{array}{r}77 \\
150\end{array}$ & $\begin{array}{r}77 \\
151\end{array}$ & $\begin{array}{l}\mathbf{m} \\
\mathbf{m}\end{array}$ \\
\hline Chile & $\begin{array}{l}\text { Ausbildung unterhalb Sekundarbereich II } \\
\text { Abschluss im Tertiärbereich }\end{array}$ & $\begin{array}{l}\mathrm{m} \\
\mathrm{m}\end{array}$ & $\mathrm{m}$ & $\mathrm{m}$ & $\begin{array}{l}m \\
m\end{array}$ & $\begin{array}{l}m \\
m\end{array}$ & $\mathrm{~m}$ & $\begin{array}{l}\mathrm{m} \\
\mathrm{m}\end{array}$ & $\begin{array}{l}m \\
m\end{array}$ & $\mathrm{~m}$ & $\begin{array}{l}m \\
m\end{array}$ & $\begin{array}{l}m \\
m\end{array}$ & $\begin{array}{r}65 \\
262\end{array}$ \\
\hline Tschechien & $\begin{array}{l}\text { Ausbildung unterhalb Sekundarbereich II } \\
\text { Abschluss im Tertiärbereich }\end{array}$ & $\begin{array}{l}\mathrm{m} \\
\mathrm{m}\end{array}$ & $\begin{array}{l}\mathrm{m} \\
\mathrm{m}\end{array}$ & $\begin{array}{l}\mathrm{m} \\
\mathrm{m}\end{array}$ & $\begin{array}{l}\mathrm{m} \\
\mathrm{m}\end{array}$ & $\begin{array}{r}73 \\
160\end{array}$ & $\begin{array}{r}72 \\
161\end{array}$ & $\begin{array}{r}73 \\
163\end{array}$ & $\begin{array}{r}74 \\
165\end{array}$ & $\begin{array}{r}73 \\
164\end{array}$ & $\begin{array}{r}72 \\
166\end{array}$ & $\begin{array}{r}74 \\
163\end{array}$ & $\begin{array}{r}74 \\
160\end{array}$ \\
\hline Dänemark & $\begin{array}{l}\text { Ausbildung unterhalb Sekundarbereich II } \\
\text { Abschluss im Tertiärbereich }\end{array}$ & $\begin{array}{l}\mathrm{m} \\
\mathrm{m}\end{array}$ & $\begin{array}{r}90 \\
124\end{array}$ & $\begin{array}{r}90 \\
123\end{array}$ & $\begin{array}{r}85 \\
127\end{array}$ & $\begin{array}{r}85 \\
126\end{array}$ & $\begin{array}{r}84 \\
126\end{array}$ & $\begin{array}{r}84 \\
125\end{array}$ & $\begin{array}{r}83 \\
124\end{array}$ & $\begin{array}{r}84 \\
123\end{array}$ & $\begin{array}{r}83 \\
125\end{array}$ & $\begin{array}{r}83 \\
126\end{array}$ & $\begin{array}{r}83 \\
126\end{array}$ \\
\hline Estland & $\begin{array}{l}\text { Ausbildung unterhalb Sekundarbereich II } \\
\text { Abschluss im Tertiärbereich }\end{array}$ & $\begin{array}{l}\mathrm{m} \\
\mathrm{m}\end{array}$ & $\begin{array}{l}\mathrm{m} \\
\mathrm{m}\end{array}$ & $\mathrm{m}$ & $\begin{array}{l}\mathrm{m} \\
\mathrm{m}\end{array}$ & $\begin{array}{l}\mathrm{m} \\
\mathrm{m}\end{array}$ & $\begin{array}{l}m \\
m\end{array}$ & $\mathrm{~m}$ & $\begin{array}{l}\mathrm{m} \\
\mathrm{m}\end{array}$ & $\begin{array}{r}82 \\
146\end{array}$ & $\begin{array}{r}86 \\
162\end{array}$ & $\begin{array}{r}87 \\
154\end{array}$ & $\begin{array}{r}81 \\
148\end{array}$ \\
\hline Finnland & $\begin{array}{l}\text { Ausbildung unterhalb Sekundarbereich II } \\
\text { Abschluss im Tertiärbereich }\end{array}$ & $\begin{array}{r}99 \\
146\end{array}$ & $\begin{array}{r}98 \\
146\end{array}$ & $\begin{array}{r}98 \\
146\end{array}$ & $\begin{array}{r}97 \\
146\end{array}$ & $\begin{array}{r}97 \\
146\end{array}$ & $\begin{array}{r}98 \\
145\end{array}$ & $\begin{array}{r}97 \\
146\end{array}$ & $\begin{array}{r}96 \\
146\end{array}$ & $\begin{array}{r}95 \\
145\end{array}$ & $\begin{array}{r}94 \\
146\end{array}$ & $\begin{array}{l}m \\
m\end{array}$ & $\begin{array}{l}\mathbf{m} \\
\mathbf{m}\end{array}$ \\
\hline Frankreich ${ }^{2}$ & $\begin{array}{l}\text { Ausbildung unterhalb Sekundarbereich II } \\
\text { Abschluss im Tertiärbereich }\end{array}$ & $\begin{array}{l}\mathrm{m} \\
\mathrm{m}\end{array}$ & $\begin{array}{l}m \\
m\end{array}$ & $\begin{array}{r}81 \\
146\end{array}$ & $\begin{array}{r}81 \\
146\end{array}$ & $\begin{array}{r}82 \\
145\end{array}$ & $\begin{array}{r}81 \\
142\end{array}$ & $\begin{array}{r}82 \\
146\end{array}$ & $\begin{array}{r}82 \\
147\end{array}$ & $\begin{array}{r}75 \\
151\end{array}$ & $\begin{array}{r}75 \\
145\end{array}$ & $\begin{array}{l}\mathrm{m} \\
\mathrm{m}\end{array}$ & $\begin{array}{l}\mathbf{m} \\
\mathbf{m}\end{array}$ \\
\hline Deutschland & $\begin{array}{l}\text { Ausbildung unterhalb Sekundarbereich II } \\
\text { Abschluss im Tertiärbereich }\end{array}$ & $\begin{array}{r}72 \\
137\end{array}$ & $\begin{array}{l}m \\
m\end{array}$ & $\begin{array}{r}73 \\
137\end{array}$ & $\begin{array}{r}81 \\
145\end{array}$ & $\begin{array}{r}81 \\
148\end{array}$ & $\begin{array}{r}77 \\
151\end{array}$ & $\begin{array}{r}83 \\
153\end{array}$ & $\begin{array}{r}84 \\
159\end{array}$ & $\begin{array}{r}80 \\
158\end{array}$ & $\begin{array}{r}79 \\
154\end{array}$ & $\begin{array}{r}74 \\
153\end{array}$ & $\begin{array}{r}81 \\
155\end{array}$ \\
\hline Griechenland & $\begin{array}{l}\text { Ausbildung unterhalb Sekundarbereich II } \\
\text { Abschluss im Tertiärbereich }\end{array}$ & $\begin{array}{l}\mathrm{m} \\
\mathrm{m}\end{array}$ & $\begin{array}{l}\mathrm{m} \\
\mathrm{m}\end{array}$ & $\begin{array}{l}\mathrm{m} \\
\mathrm{m}\end{array}$ & $\mathrm{m}$ & $\begin{array}{l}m \\
m\end{array}$ & $\begin{array}{l}m \\
m\end{array}$ & $\begin{array}{l}m \\
m\end{array}$ & $\begin{array}{l}\mathrm{m} \\
\mathrm{m}\end{array}$ & $\begin{array}{l}\mathrm{m} \\
\mathrm{m}\end{array}$ & $\begin{array}{r}65 \\
163\end{array}$ & $\begin{array}{l}m \\
m\end{array}$ & $\begin{array}{r}50 \\
222\end{array}$ \\
\hline Ungarn & $\begin{array}{l}\text { Ausbildung unterhalb Sekundarbereich II } \\
\text { Abschluss im Tertiärbereich }\end{array}$ & $\begin{array}{r}71 \\
164\end{array}$ & $\begin{array}{r}71 \\
164\end{array}$ & $\begin{array}{r}71 \\
176\end{array}$ & $\begin{array}{r}72 \\
192\end{array}$ & $\begin{array}{r}71 \\
190\end{array}$ & $\begin{array}{r}72 \\
188\end{array}$ & $\begin{array}{r}72 \\
189\end{array}$ & $\begin{array}{r}71 \\
185\end{array}$ & $\begin{array}{r}71 \\
183\end{array}$ & $\begin{array}{r}68 \\
185\end{array}$ & $\begin{array}{r}71 \\
187\end{array}$ & $\begin{array}{r}72 \\
185\end{array}$ \\
\hline Island & & $\mathrm{m}$ & $\mathrm{m}$ & $\mathrm{m}$ & $\mathrm{m}$ & $\mathrm{m}$ & $\mathrm{m}$ & $\mathrm{m}$ & $\mathrm{m}$ & $\mathrm{m}$ & $\mathrm{m}$ & $\mathrm{m}$ & m \\
\hline Irland & $\begin{array}{l}\text { Ausbildung unterhalb Sekundarbereich II } \\
\text { Abschluss im Tertiärbereich }\end{array}$ & $\begin{array}{r}65 \\
163\end{array}$ & $\begin{array}{l}\mathrm{m} \\
\mathrm{m}\end{array}$ & $\begin{array}{r}60 \\
153\end{array}$ & $\begin{array}{l}m \\
m\end{array}$ & $\begin{array}{r}63 \\
171\end{array}$ & $\begin{array}{r}61 \\
172\end{array}$ & $\begin{array}{r}63 \\
180\end{array}$ & $\begin{array}{r}67 \\
185\end{array}$ & $\begin{array}{r}65 \\
162\end{array}$ & $\begin{array}{r}73 \\
171\end{array}$ & $\begin{array}{r}78 \\
178\end{array}$ & $\begin{array}{l}\mathbf{m} \\
\mathbf{m}\end{array}$ \\
\hline Israel & $\begin{array}{l}\text { Ausbildung unterhalb Sekundarbereich II } \\
\text { Abschluss im Tertiärbereich }\end{array}$ & $\begin{array}{l}m \\
m\end{array}$ & $\begin{array}{l}\mathrm{m} \\
\mathrm{m}\end{array}$ & $\begin{array}{l}\mathrm{m} \\
\mathrm{m}\end{array}$ & $\begin{array}{l}m \\
m\end{array}$ & $\begin{array}{l}\mathrm{m} \\
\mathrm{m}\end{array}$ & $\begin{array}{r}72 \\
157\end{array}$ & $\begin{array}{r}67 \\
150\end{array}$ & $\begin{array}{r}67 \\
155\end{array}$ & $\begin{array}{r}67 \\
153\end{array}$ & $\begin{array}{r}70 \\
159\end{array}$ & $\begin{array}{r}63 \\
150\end{array}$ & $\begin{array}{r}66 \\
151\end{array}$ \\
\hline Italien & $\begin{array}{l}\text { Ausbildung unterhalb Sekundarbereich II } \\
\text { Abschluss im Tertiärbereich }\end{array}$ & $\begin{array}{r}84 \\
137\end{array}$ & $\begin{array}{l}m \\
m\end{array}$ & $\begin{array}{r}78 \\
147\end{array}$ & $\begin{array}{l}m \\
m\end{array}$ & $\begin{array}{r}73 \\
138\end{array}$ & $\begin{array}{l}m \\
m\end{array}$ & $\begin{array}{r}74 \\
143\end{array}$ & $\begin{array}{l}m \\
m\end{array}$ & $\begin{array}{r}70 \\
142\end{array}$ & $\begin{array}{r}72 \\
143\end{array}$ & $\begin{array}{l}m \\
m\end{array}$ & $\begin{array}{l}\mathbf{m} \\
\mathbf{m}\end{array}$ \\
\hline Japan & $\begin{array}{l}\text { Ausbildung unterhalb Sekundarbereich II } \\
\text { Abschluss im Tertiärbereich }\end{array}$ & $\begin{array}{l}\mathrm{m} \\
\mathrm{m}\end{array}$ & $\begin{array}{l}\mathrm{m} \\
\mathrm{m}\end{array}$ & $\mathrm{m}$ & $\mathrm{m}$ & $\begin{array}{l}\mathrm{m} \\
\mathrm{m}\end{array}$ & $\begin{array}{l}m \\
m\end{array}$ & $\begin{array}{l}\mathrm{m} \\
\mathrm{m}\end{array}$ & $\begin{array}{r}78 \\
161\end{array}$ & $\begin{array}{l}\mathrm{m} \\
\mathrm{m}\end{array}$ & $\begin{array}{l}\mathrm{m} \\
\mathrm{m}\end{array}$ & $\begin{array}{l}\mathrm{m} \\
\mathrm{m}\end{array}$ & $\begin{array}{l}\mathbf{m} \\
\mathbf{m}\end{array}$ \\
\hline Korea $^{1}$ & $\begin{array}{l}\text { Ausbildung unterhalb Sekundarbereich II } \\
\text { Abschluss im Tertiärbereich }\end{array}$ & $\begin{array}{l}\mathrm{m} \\
\mathrm{m}\end{array}$ & $\begin{array}{r}76 \\
158\end{array}$ & $\begin{array}{r}76 \\
151\end{array}$ & $\begin{array}{r}75 \\
157\end{array}$ & $\begin{array}{r}77 \\
158\end{array}$ & $\begin{array}{r}76 \\
160\end{array}$ & $\begin{array}{r}76 \\
156\end{array}$ & $\begin{array}{r}75 \\
155\end{array}$ & $\begin{array}{r}75 \\
154\end{array}$ & $\begin{array}{r}77 \\
160\end{array}$ & $\begin{array}{r}77 \\
155\end{array}$ & $\begin{array}{r}78 \\
153\end{array}$ \\
\hline Luxemburg & $\begin{array}{l}\text { Ausbildung unterhalb Sekundarbereich II } \\
\text { Abschluss im Tertiärbereich }\end{array}$ & $\begin{array}{l}m \\
m\end{array}$ & $\begin{array}{l}\mathrm{m} \\
\mathrm{m}\end{array}$ & $\begin{array}{r}74 \\
131\end{array}$ & $\begin{array}{l}m \\
m\end{array}$ & $\begin{array}{l}\mathrm{m} \\
\mathrm{m}\end{array}$ & $\begin{array}{l}\mathrm{m} \\
\mathrm{m}\end{array}$ & $\begin{array}{r}73 \\
134\end{array}$ & $\begin{array}{l}\mathrm{m} \\
\mathrm{m}\end{array}$ & $\begin{array}{l}m \\
m\end{array}$ & $\begin{array}{r}65 \\
160\end{array}$ & $\begin{array}{r}68 \\
166\end{array}$ & $\begin{array}{l}\mathbf{m} \\
\mathbf{m}\end{array}$ \\
\hline Mexiko & & $\mathrm{m}$ & $\mathrm{m}$ & $m$ & $\mathrm{~m}$ & $\mathrm{~m}$ & $\mathrm{~m}$ & $\mathrm{~m}$ & $m$ & $m$ & $\mathrm{~m}$ & $\mathrm{~m}$ & m \\
\hline Niederlande & $\begin{array}{l}\text { Ausbildung unterhalb Sekundarbereich II } \\
\text { Abschluss im Tertiärbereich }\end{array}$ & $\begin{array}{l}\mathrm{m} \\
\mathrm{m}\end{array}$ & $\begin{array}{l}m \\
m\end{array}$ & $\begin{array}{r}72 \\
155\end{array}$ & $\begin{array}{l}m \\
m\end{array}$ & $\begin{array}{l}m \\
m\end{array}$ & $\begin{array}{l}\mathrm{m} \\
\mathrm{m}\end{array}$ & $\begin{array}{r}75 \\
159\end{array}$ & $\begin{array}{l}\mathrm{m} \\
\mathrm{m}\end{array}$ & $\begin{array}{r}73 \\
162\end{array}$ & $\begin{array}{l}m \\
m\end{array}$ & $\begin{array}{r}73 \\
162\end{array}$ & $\begin{array}{l}\mathbf{m} \\
\mathbf{m}\end{array}$ \\
\hline Neuseeland & $\begin{array}{l}\text { Ausbildung unterhalb Sekundarbereich II } \\
\text { Abschluss im Tertiärbereich }\end{array}$ & $\begin{array}{r}86 \\
126\end{array}$ & $\begin{array}{r}82 \\
130\end{array}$ & $\begin{array}{r}86 \\
131\end{array}$ & $\begin{array}{r}84 \\
127\end{array}$ & $\begin{array}{r}83 \\
123\end{array}$ & $\begin{array}{r}79 \\
123\end{array}$ & $\begin{array}{r}89 \\
122\end{array}$ & $\begin{array}{r}85 \\
126\end{array}$ & $\begin{array}{r}83 \\
125\end{array}$ & $\begin{array}{r}82 \\
123\end{array}$ & $\begin{array}{r}85 \\
135\end{array}$ & $\begin{array}{r}87 \\
131\end{array}$ \\
\hline Norwegen & $\begin{array}{l}\text { Ausbildung unterhalb Sekundarbereich II } \\
\text { Abschluss im Tertiärbereich }\end{array}$ & $\begin{array}{r}81 \\
132\end{array}$ & $\begin{array}{r}81 \\
135\end{array}$ & $\begin{array}{r}81 \\
135\end{array}$ & $\begin{array}{r}81 \\
137\end{array}$ & $\begin{array}{r}81 \\
136\end{array}$ & $\begin{array}{r}81 \\
135\end{array}$ & $\begin{array}{r}81 \\
134\end{array}$ & $\begin{array}{r}81 \\
134\end{array}$ & $\begin{array}{r}80 \\
133\end{array}$ & $\begin{array}{r}80 \\
135\end{array}$ & $\begin{array}{r}78 \\
134\end{array}$ & $\begin{array}{l}\mathbf{m} \\
\mathbf{m}\end{array}$ \\
\hline Polen & $\begin{array}{l}\text { Ausbildung unterhalb Sekundarbereich II } \\
\text { Abschluss im Tertiärbereich }\end{array}$ & $\begin{array}{l}\mathrm{m} \\
\mathrm{m}\end{array}$ & $\begin{array}{r}74 \\
155\end{array}$ & $\begin{array}{r}73 \\
159\end{array}$ & $\begin{array}{l}m \\
m\end{array}$ & $\begin{array}{r}74 \\
166\end{array}$ & $\begin{array}{l}\mathrm{m} \\
\mathrm{m}\end{array}$ & $\begin{array}{r}76 \\
165\end{array}$ & $\begin{array}{l}m \\
m\end{array}$ & $\begin{array}{r}75 \\
161\end{array}$ & $\mathrm{~m}$ & $\begin{array}{r}77 \\
168\end{array}$ & $\begin{array}{l}\mathbf{m} \\
\mathbf{m}\end{array}$ \\
\hline Portugal & $\begin{array}{l}\text { Ausbildung unterhalb Sekundarbereich II } \\
\text { Abschluss im Tertiärbereich }\end{array}$ & $\begin{array}{l}\mathrm{m} \\
\mathrm{m}\end{array}$ & $\begin{array}{l}m \\
m\end{array}$ & $\begin{array}{l}m \\
m\end{array}$ & $\begin{array}{l}m \\
m\end{array}$ & $\begin{array}{r}66 \\
173\end{array}$ & $\begin{array}{r}66 \\
173\end{array}$ & $\begin{array}{r}67 \\
173\end{array}$ & $\begin{array}{l}m \\
m\end{array}$ & $\begin{array}{l}m \\
m\end{array}$ & $\begin{array}{r}67 \\
171\end{array}$ & $\begin{array}{r}68 \\
171\end{array}$ & $\begin{array}{l}\mathbf{m} \\
\mathbf{m}\end{array}$ \\
\hline Slowakei & $\begin{array}{l}\text { Ausbildung unterhalb Sekundarbereich II } \\
\text { Abschluss im Tertiärbereich }\end{array}$ & $\begin{array}{l}m \\
m\end{array}$ & $\begin{array}{l}m \\
m\end{array}$ & $\begin{array}{l}\mathrm{m} \\
\mathrm{m}\end{array}$ & $\begin{array}{l}m \\
m\end{array}$ & $\begin{array}{l}m \\
m\end{array}$ & $\begin{array}{l}m \\
m\end{array}$ & $\begin{array}{l}m \\
m\end{array}$ & $\begin{array}{l}\mathrm{m} \\
\mathrm{m}\end{array}$ & $\begin{array}{r}72 \\
176\end{array}$ & $\begin{array}{r}70 \\
177\end{array}$ & $\begin{array}{r}71 \\
172\end{array}$ & $\begin{array}{r}71 \\
169\end{array}$ \\
\hline Slowenien & $\begin{array}{l}\text { Ausbildung unterhalb Sekundarbereich II } \\
\text { Abschluss im Tertiärbereich }\end{array}$ & $\begin{array}{l}\mathrm{m} \\
\mathrm{m}\end{array}$ & $\begin{array}{l}\mathrm{m} \\
\mathrm{m}\end{array}$ & $\begin{array}{l}\mathrm{m} \\
\mathrm{m}\end{array}$ & $\begin{array}{l}\mathrm{m} \\
\mathrm{m}\end{array}$ & $\begin{array}{r}71 \\
190\end{array}$ & $\begin{array}{l}m \\
m\end{array}$ & $\begin{array}{r}72 \\
188\end{array}$ & $\begin{array}{r}72 \\
187\end{array}$ & $\begin{array}{l}\mathrm{m} \\
\mathrm{m}\end{array}$ & $\begin{array}{r}72 \\
185\end{array}$ & $\begin{array}{r}74 \\
181\end{array}$ & $\begin{array}{r}76 \\
180\end{array}$ \\
\hline Spanien & $\begin{array}{l}\text { Ausbildung unterhalb Sekundarbereich II } \\
\text { Abschluss im Tertiärbereich }\end{array}$ & $\begin{array}{l}\mathrm{m} \\
\mathrm{m}\end{array}$ & $\begin{array}{r}64 \\
125\end{array}$ & $\begin{array}{l}\mathrm{m} \\
\mathrm{m}\end{array}$ & $\begin{array}{r}69 \\
143\end{array}$ & $\begin{array}{r}71 \\
150\end{array}$ & $\begin{array}{r}73 \\
155\end{array}$ & $\begin{array}{l}\mathrm{m} \\
\mathrm{m}\end{array}$ & $\begin{array}{r}70 \\
149\end{array}$ & $\begin{array}{r}69 \\
156\end{array}$ & $\begin{array}{r}71 \\
159\end{array}$ & $\begin{array}{r}74 \\
157\end{array}$ & $\begin{array}{l}\mathbf{m} \\
\mathbf{m}\end{array}$ \\
\hline
\end{tabular}

1. Einkommen nach Abzug der Einkommensteuer. 2. Unterbrechung der Zeitreihe zwischen 2007 und 2008 aufgrund eines Wechsels der Datenquelle.

3. Die Zahlen des OECD-Durchschnitts können nicht über die Jahre verglichen werden, da sich die Zahl der Länder, aus denen dieser Durchschnitt errechnet wird, jedes Jahr geändert hat.

Quelle: OECD. Spezielle Datenerhebung zu Einkommen des Netzwerks zu den Arbeitsmarktergebnissen sowie den wirtschaftlichen und sozialen Auswirkungen des Lernens (LSO). Hinweise s. Anhang 3 unter www.oecd.org/edu/eag.htm. StatLink: http://dx.doi.org/10.1787/888932848932

Erläuterung der Kennzeichnung fehlender Daten s. Hinweise für den Leser. 
Tabelle A6.2c (Forts.)

Entwicklung der relativen Einkommen 25- bis 64-jähriger Frauen mit Erwerbseinkommen, nach Bildungsstand (2000-2011) Abschluss im Sekundarbereich II oder postsekundaren, nicht tertiären Bereich $=100$

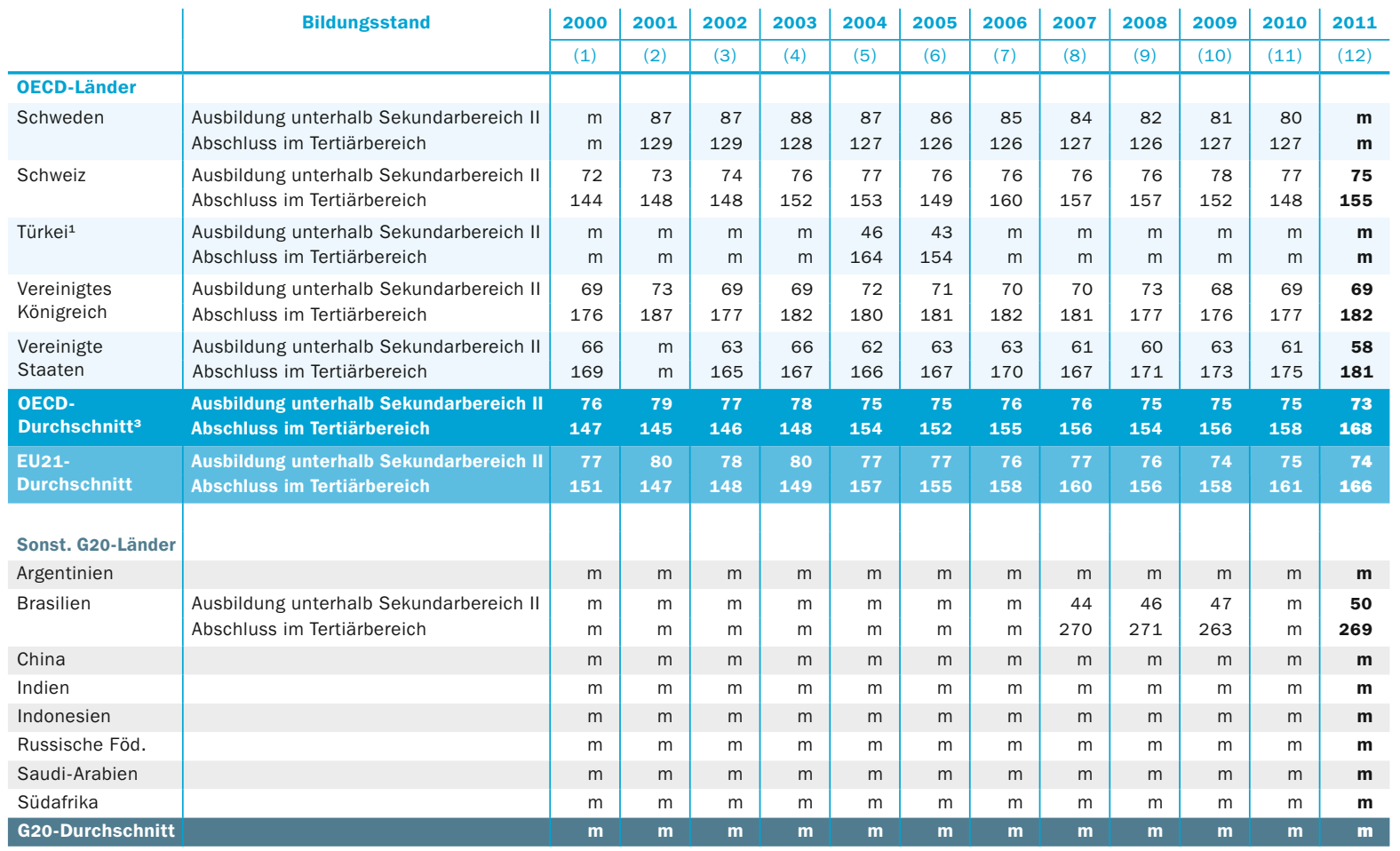

1. Einkommen nach Abzug der Einkommensteuer. 2. Unterbrechung der Zeitreihe zwischen 2007 und 2008 aufgrund eines Wechsels der Datenquelle.

3. Die Zahlen des OECD-Durchschnitts können nicht über die Jahre verglichen werden, da sich die Zahl der Länder, aus denen dieser Durchschnitt errechnet wird, jedes Jahr geändert hat.

Quelle: OECD. Spezielle Datenerhebung zu Einkommen des Netzwerks zu den Arbeitsmarktergebnissen sowie den wirtschaftlichen und sozialen Auswirkungen des Lernens (LSO). Hinweise s. Anhang 3 unter www.oecd.org/edu/eag.htm. StatLink: http://dx.doi.org/10.1787/888932848932

Erläuterung der Kennzeichnung fehlender Daten s. Hinweise für den Leser. 
Einkommensunterschiede zwischen Frauen und Männern, nach Bildungsstand und Altersgruppe (2011)

Durchschnittliche Jahreseinkommen von ganzjährig vollzeitbeschäftigten Frauen als Prozentsatz derjenigen von Männern

\begin{tabular}{|c|c|c|c|c|c|c|c|c|c|c|c|c|c|}
\hline & \multirow[t]{3}{*}{ Jahr } & \multicolumn{3}{|c|}{$\begin{array}{l}\text { Ausbildung unterhalb } \\
\text { Sekundarbereich II }\end{array}$} & \multicolumn{3}{|c|}{$\begin{array}{l}\text { Abschluss im Sekundar- } \\
\text { bereich II/postsekundaren, } \\
\text { nicht tertiären Bereich }\end{array}$} & \multicolumn{3}{|c|}{ Abschluss im Tertiärbereich } & \multicolumn{3}{|c|}{$\begin{array}{c}\text { Alle Bildungsbereiche } \\
\text { zusammen }\end{array}$} \\
\hline & & $25-64$ & $35-44$ & $55-64$ & $25-64$ & $35-44$ & $55-64$ & $25-64$ & $35-44$ & $55-64$ & $25-64$ & $35-44$ & $55-64$ \\
\hline & & (1) & (2) & (3) & (4) & (5) & (6) & (7) & (8) & (9) & (10) & (11) & (12) \\
\hline \multicolumn{14}{|l|}{ OECD-Länder } \\
\hline Australien & 2009 & 76 & 76 & 83 & 73 & 68 & 75 & 72 & 70 & 73 & 77 & 74 & 80 \\
\hline Österreich & 2011 & 81 & 77 & 86 & 77 & 75 & 83 & 75 & 74 & 79 & 76 & 74 & 81 \\
\hline Belgien & 2011 & 80 & $\mathrm{~m}$ & $\mathrm{~m}$ & 86 & 78 & 95 & 86 & 86 & 81 & 92 & 91 & 86 \\
\hline Kanada & 2010 & 72 & 79 & 71 & 73 & 76 & 73 & 72 & 72 & 59 & 75 & 76 & 65 \\
\hline Chile & 2011 & 76 & 79 & 70 & 69 & 68 & 71 & 62 & 70 & 53 & 77 & 82 & 66 \\
\hline Tschechien & 2011 & 79 & 78 & 80 & 80 & 74 & 87 & 70 & 64 & 85 & 75 & 68 & 80 \\
\hline Dänemark & 2011 & 82 & 80 & 82 & 80 & 78 & 83 & 74 & 75 & 73 & 79 & 79 & 79 \\
\hline Estland & 2011 & 63 & 57 & 64 & 65 & 62 & 77 & 65 & 55 & 73 & 71 & 65 & 80 \\
\hline Finnland & 2010 & 79 & 76 & 79 & 78 & 76 & 79 & 75 & 74 & 74 & 80 & 78 & 77 \\
\hline Frankreich & 2009 & 75 & 70 & 80 & 81 & 75 & 95 & 73 & 75 & 68 & 79 & 77 & 79 \\
\hline Deutschland & 2011 & 73 & 74 & 74 & 80 & 86 & 77 & 69 & 76 & 68 & 74 & 79 & 72 \\
\hline Griechenland & 2011 & 61 & 62 & 59 & 74 & 70 & 58 & 74 & 74 & 87 & 76 & 75 & 67 \\
\hline Ungarn & 2011 & 82 & 82 & 80 & 87 & 83 & 96 & 66 & 57 & 73 & 83 & 77 & 86 \\
\hline Island & & $\mathrm{m}$ & $\mathrm{m}$ & $\mathrm{m}$ & $\mathrm{m}$ & $\mathrm{m}$ & $\mathrm{m}$ & $\mathrm{m}$ & $\mathrm{m}$ & $\mathrm{m}$ & $\mathrm{m}$ & $\mathrm{m}$ & $\mathrm{m}$ \\
\hline Irland & 2010 & 87 & 82 & 87 & 79 & 87 & 78 & 73 & 75 & 58 & 84 & 82 & 78 \\
\hline Israel & 2011 & 75 & 67 & 66 & 75 & 78 & 72 & 68 & 70 & 63 & 74 & 76 & 69 \\
\hline Italien & 2009 & 80 & 78 & 86 & 80 & 80 & 81 & 66 & 75 & 60 & 82 & 85 & 80 \\
\hline Japan & & $\mathrm{m}$ & $\mathrm{m}$ & $\mathrm{m}$ & $\mathrm{m}$ & $\mathrm{m}$ & $\mathrm{m}$ & $\mathrm{m}$ & $\mathrm{m}$ & $\mathrm{m}$ & $\mathrm{m}$ & $\mathrm{m}$ & $\mathrm{m}$ \\
\hline Korea $^{1}$ & 2011 & 66 & 72 & 65 & 62 & 61 & 62 & 68 & 68 & 75 & 63 & 61 & 54 \\
\hline Luxemburg & 2010 & 80 & 78 & 56 & 74 & 81 & 80 & 73 & 81 & 64 & 80 & 84 & 69 \\
\hline Mexiko & & $\mathrm{m}$ & $\mathrm{m}$ & $\mathrm{m}$ & $\mathrm{m}$ & $\mathrm{m}$ & $\mathrm{m}$ & $\mathrm{m}$ & $\mathrm{m}$ & $\mathrm{m}$ & $\mathrm{m}$ & $\mathrm{m}$ & $\mathrm{m}$ \\
\hline Niederlande & 2010 & 77 & 79 & 76 & 79 & 85 & 79 & 74 & 83 & 74 & 82 & 88 & 80 \\
\hline Neuseeland & 2011 & 81 & 86 & 83 & 78 & 79 & 74 & 78 & 76 & 74 & 80 & 80 & 78 \\
\hline Norwegen & 2010 & 82 & 80 & 82 & 78 & 78 & 78 & 74 & 75 & 73 & 80 & 81 & 78 \\
\hline Polen & 2010 & 71 & 66 & 73 & 80 & 73 & 94 & 71 & 66 & 76 & 84 & 80 & 90 \\
\hline Portugal & 2010 & 75 & 75 & 74 & 72 & 72 & 70 & 69 & 74 & 69 & 79 & 80 & 69 \\
\hline Slowakei & 2011 & 72 & 72 & 72 & 74 & 70 & 82 & 66 & 58 & 74 & 73 & 67 & 78 \\
\hline Slowenien & 2011 & 85 & 84 & 83 & 86 & 83 & 99 & 79 & 79 & 89 & 92 & 91 & 103 \\
\hline Spanien & 2010 & 76 & 85 & 71 & 79 & 77 & 74 & 88 & 89 & 85 & 90 & 94 & 84 \\
\hline Schweden & 2010 & 84 & 90 & 86 & 83 & 85 & 79 & 74 & 68 & 77 & 82 & 80 & 86 \\
\hline Schweiz & & $\mathrm{m}$ & $\mathrm{m}$ & $\mathrm{m}$ & $\mathrm{m}$ & $\mathrm{m}$ & $\mathrm{m}$ & $\mathrm{m}$ & $\mathrm{m}$ & $\mathrm{m}$ & $\mathrm{m}$ & $\mathrm{m}$ & $\mathrm{m}$ \\
\hline Türkei & & $\mathrm{m}$ & $\mathrm{m}$ & $\mathrm{m}$ & $\mathrm{m}$ & $\mathrm{m}$ & $\mathrm{m}$ & $\mathrm{m}$ & $\mathrm{m}$ & $\mathrm{m}$ & $\mathrm{m}$ & $\mathrm{m}$ & $\mathrm{m}$ \\
\hline Vereinigtes Königreich & 2011 & 66 & 69 & 63 & 61 & 61 & 63 & 68 & 67 & 68 & 69 & 68 & 68 \\
\hline Vereinigte Staaten & 2011 & 67 & 69 & 54 & 70 & 69 & 67 & 69 & 71 & 67 & 72 & 74 & 67 \\
\hline OECD-Durchschnitt & & 76 & 76 & 74 & 77 & 76 & 79 & 72 & 72 & 72 & 79 & 78 & 77 \\
\hline EU21-Durchschnitt & & 77 & 76 & 76 & 78 & 78 & 82 & 73 & 73 & 74 & 80 & 79 & 80 \\
\hline \multicolumn{14}{|l|}{ Sonstige G20-Länder } \\
\hline Argentinien & & $\mathrm{m}$ & $\mathrm{m}$ & $\mathrm{m}$ & $\mathrm{m}$ & $\mathrm{m}$ & $\mathrm{m}$ & $\mathrm{m}$ & $\mathrm{m}$ & $\mathrm{m}$ & $\mathrm{m}$ & $\mathrm{m}$ & $\mathrm{m}$ \\
\hline Brasilien & 2011 & 65 & 66 & 60 & 63 & 64 & 61 & 61 & 59 & 60 & 77 & 76 & 73 \\
\hline China & & $\mathrm{m}$ & $\mathrm{m}$ & $\mathrm{m}$ & $\mathrm{m}$ & $\mathrm{m}$ & $\mathrm{m}$ & $\mathrm{m}$ & $\mathrm{m}$ & $\mathrm{m}$ & $\mathrm{m}$ & $\mathrm{m}$ & $\mathrm{m}$ \\
\hline Indien & & $\mathrm{m}$ & $\mathrm{m}$ & $\mathrm{m}$ & $\mathrm{m}$ & $\mathrm{m}$ & $\mathrm{m}$ & $\mathrm{m}$ & $\mathrm{m}$ & $\mathrm{m}$ & $\mathrm{m}$ & $\mathrm{m}$ & $\mathrm{m}$ \\
\hline Indonesien & & $\mathrm{m}$ & $\mathrm{m}$ & $\mathrm{m}$ & $\mathrm{m}$ & $\mathrm{m}$ & $\mathrm{m}$ & $\mathrm{m}$ & $\mathrm{m}$ & $\mathrm{m}$ & $\mathrm{m}$ & $\mathrm{m}$ & $\mathrm{m}$ \\
\hline Russische Föderation & & $\mathrm{m}$ & $\mathrm{m}$ & $\mathrm{m}$ & $\mathrm{m}$ & $\mathrm{m}$ & $\mathrm{m}$ & $\mathrm{m}$ & $\mathrm{m}$ & $\mathrm{m}$ & $\mathrm{m}$ & $\mathrm{m}$ & $\mathrm{m}$ \\
\hline Saudi-Arabien & & $\mathrm{m}$ & $\mathrm{m}$ & $\mathrm{m}$ & $\mathrm{m}$ & $\mathrm{m}$ & $\mathrm{m}$ & $\mathrm{m}$ & $\mathrm{m}$ & $\mathrm{m}$ & $\mathrm{m}$ & $\mathrm{m}$ & $\mathrm{m}$ \\
\hline Südafrika & & $\mathrm{m}$ & $\mathrm{m}$ & $\mathrm{m}$ & $\mathrm{m}$ & $\mathrm{m}$ & $\mathrm{m}$ & $\mathrm{m}$ & $\mathrm{m}$ & $\mathrm{m}$ & $\mathrm{m}$ & $\mathrm{m}$ & $\mathrm{m}$ \\
\hline G20-Durchschnitt & & m & $\mathbf{m}$ & $\mathbf{m}$ & $\mathbf{m}$ & $\mathbf{m}$ & $\mathbf{m}$ & m & $\mathbf{m}$ & $\mathbf{m}$ & $\mathbf{m}$ & $\mathbf{m}$ & $\mathbf{m}$ \\
\hline
\end{tabular}

1. Einkommen nach Abzug der Einkommensteuer.

Quelle: OECD. Spezielle Datenerhebung zu den Einkommen von ganzjährig Vollzeitbeschäftigten des Netzwerks zu den Arbeitsmarktergebnissen sowie den wirtschaftlichen und sozialen Auswirkungen des Lernens (LSO), Arbeitsgruppe Wirtschaftliche Ergebnisse von Bildung (Economic Outcomes).

Hinweise s. Anhang 3 unter www.oecd.org/edu/eag.htm. StatLink: http://dx.doi.org/10.1787/888932848951

Erläuterung der Kennzeichnung fehlender Daten s. Hinweise für den Leser. 
Entwicklung der Einkommensunterschiede zwischen 25- und 64-jährigen Frauen und Männern, nach Bildungsstand (2000-2011)

Durchschnittliche Jahreseinkommen von ganzjährig vollzeitbeschäftigten Frauen als Prozentsatz derjenigen von Männern

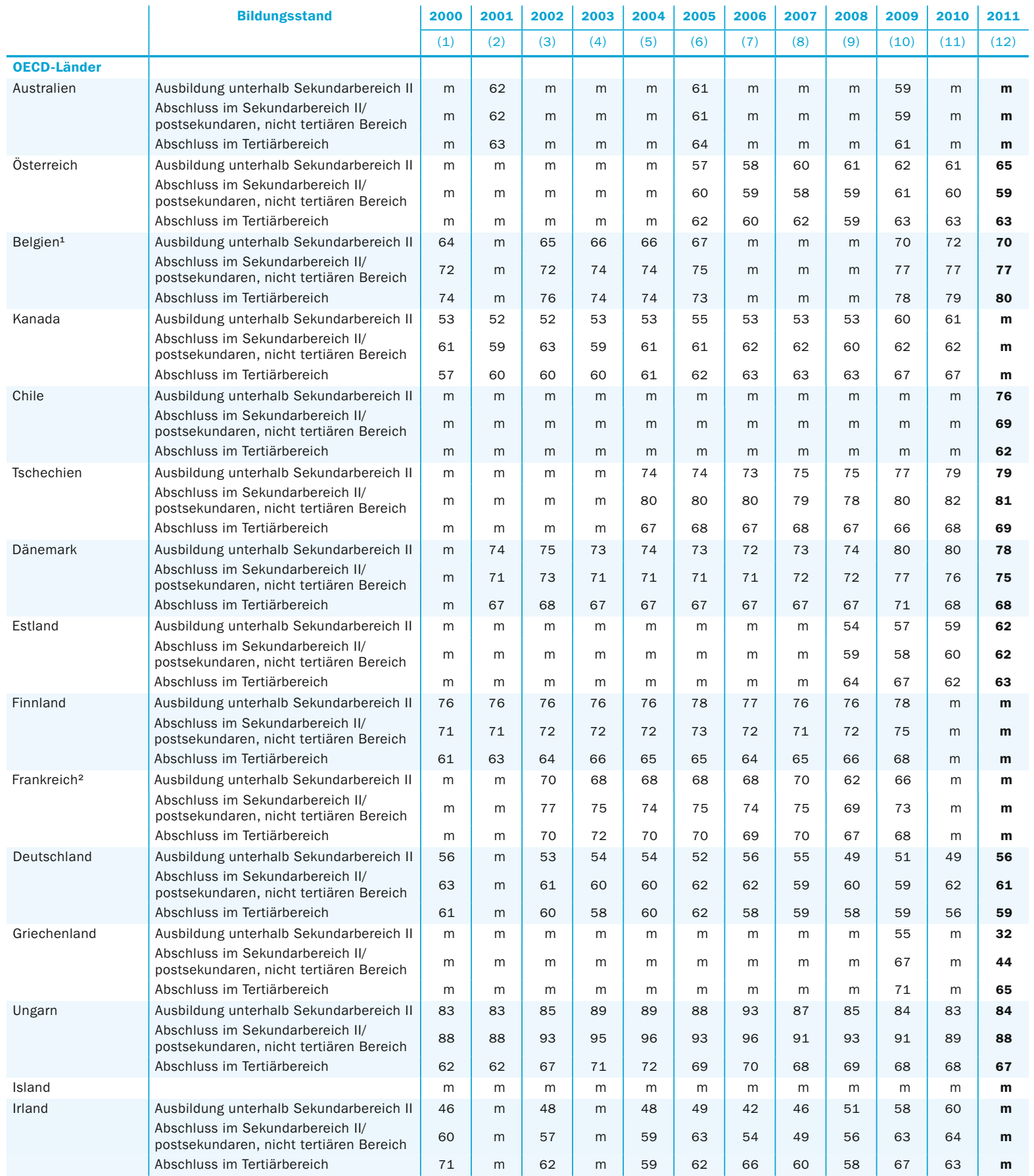

1. Einkommen nach Abzug der Einkommensteuer. 2. Unterbrechung der Zeitreihe zwischen 2007 und 2008 aufgrund eines Wechsels der Datenquelle.

3. Die Zahlen des OECD-Durchschnitts können nicht über die Jahre verglichen werden, da sich die Zahl der Länder, aus denen dieser Durchschnitt errechnet wird, jedes Jahr geändert hat.

Quelle: OECD. Spezielle Datenerhebung zu den Einkommen von ganzjährig Vollzeitbeschäftigten des Netzwerks zu den Arbeitsmarktergebnissen sowie den wirtschaftlichen und sozialen Auswirkungen des Lernens (LSO), Arbeitsgruppe Wirtschaftliche Ergebnisse von Bildung (Economic Outcomes).

Hinweise s. Anhang 3 unter www.oecd.org/edu/eag.htm. StatLink: http://dx.doi.org/10.1787/888932848970

Erläuterung der Kennzeichnung fehlender Daten s. Hinweise für den Leser. 
Tabelle A6.3b (Forts. 1)

Entwicklung der Einkommensunterschiede zwischen 25- und 64-jährigen Frauen und Männern, nach Bildungsstand (2000-2011)

Durchschnittliche Jahreseinkommen von ganzjährig vollzeitbeschäftigten Frauen als Prozentsatz derjenigen von Männern

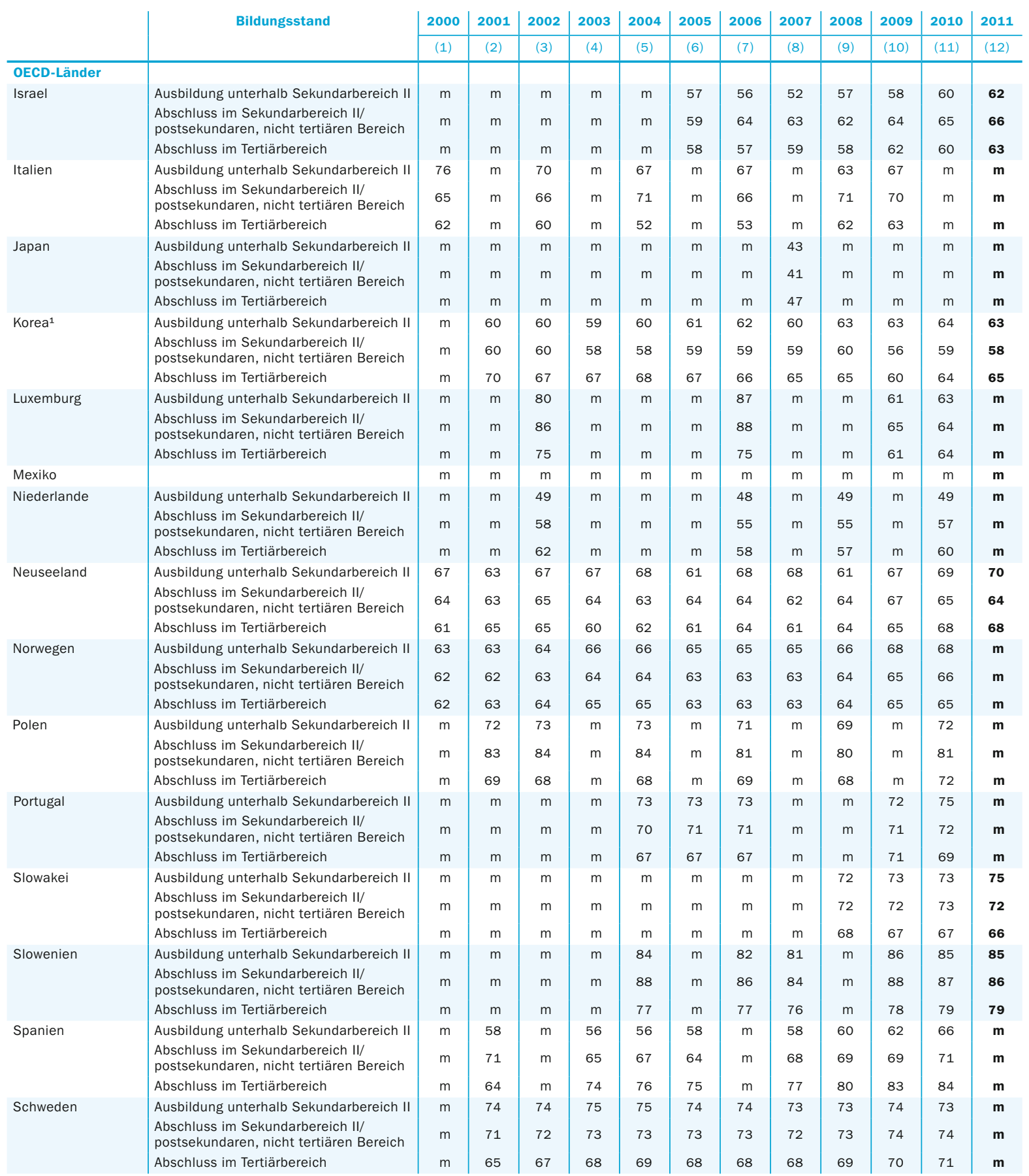

1. Einkommen nach Abzug der Einkommensteuer. 2. Unterbrechung der Zeitreihe zwischen 2007 und 2008 aufgrund eines Wechsels der Datenquelle.

3. Die Zahlen des OECD-Durchschnitts können nicht über die Jahre verglichen werden, da sich die Zahl der Länder, aus denen dieser Durchschnitt errechnet wird, jedes Jahr geändert hat.

Quelle: OECD. Spezielle Datenerhebung zu den Einkommen von ganzjährig Vollzeitbeschäftigten des Netzwerks zu den Arbeitsmarktergebnissen sowie den wirtschaftlichen und sozialen Auswirkungen des Lernens (LSO), Arbeitsgruppe Wirtschaftliche Ergebnisse von Bildung (Economic Outcomes).

Hinweise s. Anhang 3 unter www.oecd.org/edu/eag.htm. StatLink: http://dx.doi.org/10.1787/888932848970

Erläuterung der Kennzeichnung fehlender Daten s. Hinweise für den Leser. 
Tabelle A6.3b (Forts. 2)

Entwicklung der Einkommensunterschiede zwischen 25- und 64-jährigen Frauen und Männern, nach Bildungsstand (2000-2011)

Durchschnittliche Jahreseinkommen von ganzjährig vollzeitbeschäftigten Frauen als Prozentsatz derjenigen von Männern

\begin{tabular}{|c|c|c|c|c|c|c|c|c|c|c|c|c|c|}
\hline & \multirow{2}{*}{ Bildungsstand } & 2000 & 2001 & 2002 & 2003 & 2004 & 2005 & 2006 & 2007 & 2008 & 2009 & 2010 & 2011 \\
\hline & & (1) & (2) & (3) & (4) & (5) & (6) & (7) & (8) & (9) & (10) & $(11)$ & (12) \\
\hline \multicolumn{14}{|l|}{ OECD-Länder } \\
\hline \multirow[t]{3}{*}{ Schweiz } & Ausbildung unterhalb Sekundarbereich II & 53 & 51 & 53 & 55 & 55 & 54 & 55 & 56 & 53 & 56 & 58 & 55 \\
\hline & $\begin{array}{l}\text { Abschluss im Sekundarbereich II/ } \\
\text { postsekundaren, nicht tertiären Bereich }\end{array}$ & 58 & 58 & 56 & 56 & 56 & 57 & 56 & 57 & 55 & 57 & 59 & 58 \\
\hline & Abschluss im Tertiärbereich & 62 & 61 & 60 & 61 & 61 & 60 & 65 & 61 & 62 & 62 & 61 & 63 \\
\hline \multirow[t]{3}{*}{ 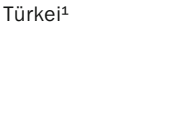 } & Ausbildung unterhalb Sekundarbereich II & $\mathrm{m}$ & $\mathrm{m}$ & m & $\mathrm{m}$ & 52 & 47 & $\mathrm{~m}$ & $\mathrm{~m}$ & $\mathrm{~m}$ & $\mathrm{~m}$ & $\mathrm{~m}$ & $\mathbf{m}$ \\
\hline & $\begin{array}{l}\text { Abschluss im Sekundarbereich II/ } \\
\text { postsekundaren, nicht tertiären Bereich }\end{array}$ & $\mathrm{m}$ & $\mathrm{m}$ & $\mathrm{m}$ & $\mathrm{m}$ & 75 & 78 & $\mathrm{~m}$ & $\mathrm{~m}$ & $\mathrm{~m}$ & $\mathrm{~m}$ & $\mathrm{~m}$ & $\mathbf{m}$ \\
\hline & Abschluss im Tertiärbereich & $\mathrm{m}$ & $\mathrm{m}$ & $\mathrm{m}$ & $\mathrm{m}$ & 89 & 78 & $\mathrm{~m}$ & $\mathrm{~m}$ & $\mathrm{~m}$ & $\mathrm{~m}$ & $\mathrm{~m}$ & m \\
\hline \multirow{3}{*}{$\begin{array}{l}\text { Vereinigtes } \\
\text { Königreich }\end{array}$} & Ausbildung unterhalb Sekundarbereich II & 50 & 52 & 53 & 53 & 55 & 55 & 53 & 56 & 59 & 57 & 70 & 50 \\
\hline & $\begin{array}{l}\text { Abschluss im Sekundarbereich II/ } \\
\text { postsekundaren, nicht tertiären Bereich }\end{array}$ & 54 & 52 & 55 & 55 & 54 & 56 & 56 & 55 & 55 & 58 & 65 & 48 \\
\hline & Abschluss im Tertiärbereich & 63 & 66 & 67 & 66 & 66 & 69 & 69 & 69 & 68 & 68 & 71 & 58 \\
\hline \multirow[t]{3}{*}{ Vereinigte Staaten } & Ausbildung unterhalb Sekundarbereich II & 60 & $\mathrm{~m}$ & 63 & 67 & 63 & 63 & 65 & 64 & 60 & 69 & 63 & 58 \\
\hline & $\begin{array}{l}\text { Abschluss im Sekundarbereich II/ } \\
\text { postsekundaren, nicht tertiären Bereich }\end{array}$ & 60 & $\mathrm{~m}$ & 63 & 64 & 63 & 65 & 65 & 66 & 65 & 68 & 66 & 64 \\
\hline & Abschluss im Tertiärbereich & 56 & $\mathrm{~m}$ & 58 & 61 & 59 & 59 & 60 & 61 & 59 & 62 & 63 & 63 \\
\hline \multirow{3}{*}{$\begin{array}{l}\text { OECD- } \\
\text { Durchschnitt }\end{array}$} & Ausbildung unterhalb Sekundarbereich II & 62 & 65 & 65 & 65 & 66 & 63 & 66 & 64 & 63 & 66 & 67 & 66 \\
\hline & $\begin{array}{l}\text { Abschluss im Sekundarbereich II/ } \\
\text { postsekundaren, nicht tertiären Bereich }\end{array}$ & 65 & 67 & 68 & 67 & 70 & 67 & 69 & 65 & 66 & 68 & 69 & 67 \\
\hline & Abschluss im Tertiärbereich & 63 & 65 & 65 & 66 & 67 & 66 & 65 & 64 & 64 & 67 & 67 & 66 \\
\hline \multirow{3}{*}{$\begin{array}{l}\text { EU21- } \\
\text { Durchschnitt }\end{array}$} & Ausbildung unterhalb Sekundarbereich II & 65 & 70 & 67 & 68 & 69 & 67 & 68 & 67 & 64 & 68 & 69 & 67 \\
\hline & $\begin{array}{l}\text { Abschluss im Sekundarbereich II/ } \\
\text { postsekundaren, nicht tertiären Bereich }\end{array}$ & 68 & 72 & 71 & 71 & 73 & 70 & 72 & 70 & 68 & 71 & 71 & 69 \\
\hline & Abschluss im Tertiärbereich & 65 & 65 & 67 & 69 & 67 & 68 & 66 & 67 & 65 & 69 & 68 & 67 \\
\hline \multicolumn{14}{|l|}{ Sonst. G20-Länder } \\
\hline Argentinien & & $\mathrm{m}$ & $\mathrm{m}$ & $\mathrm{m}$ & m & $\mathrm{m}$ & $\mathrm{m}$ & $\mathrm{m}$ & $\mathrm{m}$ & $\mathrm{m}$ & $\mathrm{m}$ & $\mathrm{m}$ & m \\
\hline \multirow[t]{3}{*}{ Brasilien } & Ausbildung unterhalb Sekundarbereich II & m & $\mathrm{m}$ & $\mathrm{m}$ & $\mathrm{m}$ & $\mathrm{m}$ & $\mathrm{m}$ & $\mathrm{m}$ & 49 & 49 & 50 & $\mathrm{~m}$ & 51 \\
\hline & $\begin{array}{l}\text { Abschluss im Sekundarbereich II/ } \\
\text { postsekundaren, nicht tertiären Bereich }\end{array}$ & $\mathrm{m}$ & $\mathrm{m}$ & $\mathrm{m}$ & $\mathrm{m}$ & $\mathrm{m}$ & $\mathrm{m}$ & $\mathrm{m}$ & 58 & 56 & 57 & $\mathrm{~m}$ & 59 \\
\hline & Abschluss im Tertiärbereich & $\mathrm{m}$ & $\mathrm{m}$ & $\mathrm{m}$ & $\mathrm{m}$ & $\mathrm{m}$ & $\mathrm{m}$ & $\mathrm{m}$ & 55 & 57 & 55 & $\mathrm{~m}$ & 58 \\
\hline China & & $\mathrm{m}$ & $\mathrm{m}$ & $\mathrm{m}$ & $\mathrm{m}$ & $\mathrm{m}$ & $\mathrm{m}$ & $\mathrm{m}$ & $\mathrm{m}$ & $\mathrm{m}$ & $\mathrm{m}$ & $\mathrm{m}$ & m \\
\hline Indien & & $\mathrm{m}$ & $\mathrm{m}$ & $\mathrm{m}$ & $\mathrm{m}$ & $\mathrm{m}$ & $\mathrm{m}$ & $\mathrm{m}$ & $\mathrm{m}$ & $\mathrm{m}$ & $\mathrm{m}$ & $\mathrm{m}$ & $\mathbf{m}$ \\
\hline Indonesien & & $\mathrm{m}$ & $\mathrm{m}$ & $\mathrm{m}$ & $\mathrm{m}$ & $\mathrm{m}$ & $\mathrm{m}$ & $\mathrm{m}$ & $\mathrm{m}$ & $\mathrm{m}$ & $\mathrm{m}$ & $\mathrm{m}$ & $\mathbf{m}$ \\
\hline Russische Föd. & & $\mathrm{m}$ & $\mathrm{m}$ & $\mathrm{m}$ & $\mathrm{m}$ & $\mathrm{m}$ & $\mathrm{m}$ & $\mathrm{m}$ & $\mathrm{m}$ & $\mathrm{m}$ & $\mathrm{m}$ & $\mathrm{m}$ & $\mathbf{m}$ \\
\hline Saudi-Arabien & & $\mathrm{m}$ & $\mathrm{m}$ & $\mathrm{m}$ & $\mathrm{m}$ & $\mathrm{m}$ & $\mathrm{m}$ & $\mathrm{m}$ & $\mathrm{m}$ & $\mathrm{m}$ & $\mathrm{m}$ & $\mathrm{m}$ & m \\
\hline Südafrika & & $\mathrm{m}$ & $\mathrm{m}$ & $\mathrm{m}$ & $\mathrm{m}$ & $\mathrm{m}$ & $\mathrm{m}$ & $\mathrm{m}$ & $\mathrm{m}$ & $\mathrm{m}$ & $\mathrm{m}$ & $\mathrm{m}$ & $\mathbf{m}$ \\
\hline G20-Durchschnitt & & $\mathbf{m}$ & m & $\mathbf{m}$ & $\mathbf{m}$ & $\mathbf{m}$ & m & $\mathbf{m}$ & m & $\mathbf{m}$ & $\mathbf{m}$ & m & $\mathbf{m}$ \\
\hline
\end{tabular}

1. Einkommen nach Abzug der Einkommensteuer. 2. Unterbrechung der Zeitreihe zwischen 2007 und 2008 aufgrund eines Wechsels der Datenquelle.

3. Die Zahlen des OECD-Durchschnitts können nicht über die Jahre verglichen werden, da sich die Zahl der Länder, aus denen dieser Durchschnitt errechnet wird, jedes Jahr geändert hat.

Quelle: OECD. Spezielle Datenerhebung zu den Einkommen von ganzjährig Vollzeitbeschäftigten des Netzwerks zu den Arbeitsmarktergebnissen sowie den wirtschaftlichen und sozialen Auswirkungen des Lernens (LSO), Arbeitsgruppe Wirtschaftliche Ergebnisse von Bildung (Economic Outcomes).

Hinweise s. Anhang 3 unter www.oecd.org/edu/eag.htm. StatLink: http://dx.doi.org/10.1787/888932848970

Erläuterung der Kennzeichnung fehlender Daten s. Hinweise für den Leser. 
Relative Einkommen von 15- bis 24-jährigen Schülern und Studierenden, nach Bildungsstand und Geschlecht (2011) Im Vergleich zu 15- bis 24-Jährigen, die sich nicht in Ausbildung befinden (Nichtschüler/Nichtstudierende, die Erwerbseinkommen beziehen $=100$ )

\begin{tabular}{|c|c|c|c|c|c|c|}
\hline & & & $\begin{array}{l}\text { Ausbildung unterhalb } \\
\text { Sekundarbereich II }\end{array}$ & \begin{tabular}{|} 
Abschluss im Sekundarbe- \\
reich II/postsekundaren, \\
nicht tertiären Bereich
\end{tabular} & $\begin{array}{l}\text { Abschluss im } \\
\text { Tertiärbereich }\end{array}$ & $\begin{array}{c}\text { Alle Bildungsbereiche } \\
\text { zusammen }\end{array}$ \\
\hline & & & (1) & (2) & (3) & (4) \\
\hline OECD-Länder & & & & & & \\
\hline Australien & 2009 & Männer & 36 & 56 & 67 & 48 \\
\hline & & Frauen & 24 & 53 & 68 & 44 \\
\hline & & $M+F$ & 31 & 54 & 69 & 46 \\
\hline Österreich & 2011 & Männer & 54 & 37 & 20 & 36 \\
\hline & & Frauen & 49 & 30 & 46 & 30 \\
\hline & & $M+F$ & 51 & 32 & 36 & 33 \\
\hline Belgien & 2010 & Männer & 56 & 78 & 79 & 70 \\
\hline & & Frauen & 57 & 63 & 83 & 64 \\
\hline & & $M+F$ & 54 & 67 & 82 & 66 \\
\hline Kanada & 2010 & Männer & 33 & 48 & 48 & 42 \\
\hline & & Frauen & 45 & 54 & 43 & 42 \\
\hline & & $M+F$ & 36 & 49 & 45 & 42 \\
\hline Chile & 2011 & Männer & 123 & 120 & c & 116 \\
\hline & & Frauen & 78 & 92 & c & 76 \\
\hline & & $M+F$ & 112 & 111 & c & 102 \\
\hline Tschechien & & & $\mathrm{m}$ & $\mathrm{m}$ & $\mathrm{m}$ & $\mathrm{m}$ \\
\hline Dänemark & 2011 & Männer & 43 & 43 & 43 & 37 \\
\hline & & Frauen & 43 & 54 & 43 & 41 \\
\hline & & $M+F$ & 42 & 47 & 43 & 38 \\
\hline Estland & 2011 & Männer & 66 & 75 & c & 79 \\
\hline & & Frauen & 38 & 121 & 130 & 109 \\
\hline & & $M+F$ & 51 & 94 & 109 & 90 \\
\hline Finnland & 2009 & Männer & 32 & 55 & 65 & 41 \\
\hline & & Frauen & 47 & 57 & 51 & 45 \\
\hline & & $M+F$ & 36 & 55 & 53 & 42 \\
\hline Frankreich & 2009 & Männer & 46 & 39 & 40 & 40 \\
\hline & & Frauen & 47 & 48 & 53 & 50 \\
\hline & & $M+F$ & 23 & 42 & 47 & 44 \\
\hline Deutschland & 2011 & Männer & 35 & 50 & c & 43 \\
\hline & & Frauen & 57 & 43 & c & 44 \\
\hline & & $\mathrm{M}+\mathrm{F}$ & 41 & 46 & c & 43 \\
\hline Griechenland & 2011 & Männer & c & 9 & $\mathrm{n}$ & 7 \\
\hline & & Frauen & c & 14 & c & 18 \\
\hline & & $M+F$ & c & 12 & $\mathrm{c}$ & 13 \\
\hline Ungarn & & & $\mathrm{m}$ & $\mathrm{m}$ & $\mathrm{m}$ & $\mathrm{m}$ \\
\hline Island & & & $\mathrm{m}$ & $\mathrm{m}$ & $\mathrm{m}$ & $\mathrm{m}$ \\
\hline Irland & & & $\mathrm{m}$ & $\mathrm{m}$ & $\mathrm{m}$ & $\mathrm{m}$ \\
\hline Israel & 2011 & Männer & c & 46 & 90 & 102 \\
\hline & & Frauen & c & 51 & 70 & 92 \\
\hline & & $M+F$ & c & 47 & 77 & 93 \\
\hline Italien & 2009 & Männer & 28 & 50 & c & 44 \\
\hline & & Frauen & 43 & 52 & c & 58 \\
\hline & & $M+F$ & 33 & 50 & c & 49 \\
\hline Japan & & & $\mathrm{m}$ & $\mathrm{m}$ & $\mathrm{m}$ & $\mathrm{m}$ \\
\hline Korea & 2011 & Männer & 39 & 50 & 49 & 50 \\
\hline & & Frauen & 60 & 49 & 48 & 48 \\
\hline & & $M+F$ & 47 & 49 & 48 & 48 \\
\hline Luxemburg & & & $\mathrm{m}$ & $\mathrm{m}$ & $\mathrm{m}$ & $\mathrm{m}$ \\
\hline Mexiko & & & $\mathrm{m}$ & $\mathrm{m}$ & $\mathrm{m}$ & $\mathrm{m}$ \\
\hline Niederlande & & & $\mathrm{m}$ & $\mathrm{m}$ & $\mathrm{m}$ & $\mathrm{m}$ \\
\hline Neuseeland & 2011 & Männer & 49 & 52 & 64 & 52 \\
\hline & & Frauen & 27 & 42 & 55 & 40 \\
\hline & & $M+F$ & 38 & 46 & 59 & 45 \\
\hline Norwegen & 2010 & Männer & 38 & 39 & 38 & 39 \\
\hline & & Frauen & 34 & 46 & 40 & 43 \\
\hline & & $M+F$ & 36 & 40 & 39 & 40 \\
\hline
\end{tabular}

1. Für einige Länder in dieser Tabelle beziehen sich die Angaben auf 16- bis 24-Jährige.

Quelle: OECD. Spezielle Datenerhebung zu Einkommen des Netzwerks zu den Arbeitsmarktergebnissen sowie den wirtschaftlichen und sozialen Auswirkungen des Lernens (LSO). Hinweise s. Anhang 3 unter www.oecd.org/edu/eag.htm. StatLink: http://dx.doi.org/10.1787/888932849046 Erläuterung der Kennzeichnung fehlender Daten s. Hinweise für den Leser. 
Tabelle A6.5a (Forts.)

Relative Einkommen von 15- bis 24-jährigen Schülern und Studierenden, nach Bildungsstand und Geschlecht (2011) ${ }^{1}$ Im Vergleich zu 15- bis 24-Jährigen, die sich nicht in Ausbildung befinden (Nichtschüler/Nichtstudierende, die Erwerbseinkommen beziehen $=100$ )

\begin{tabular}{|c|c|c|c|c|c|c|}
\hline & & & $\begin{array}{l}\text { Ausbildung unterhalb } \\
\text { Sekundarbereich II }\end{array}$ & $\begin{array}{c}\text { Abschluss im Sekundarbe- } \\
\text { reich II/postsekundaren, } \\
\text { nicht tertiären Bereich }\end{array}$ & $\begin{array}{l}\text { Abschluss im } \\
\text { Tertiärbereich }\end{array}$ & $\begin{array}{l}\text { Alle Bildungsbereiche } \\
\text { zusammen }\end{array}$ \\
\hline & & & (1) & (2) & (3) & (4) \\
\hline OECD-Länder & & & & & & \\
\hline Polen & & & $\mathrm{m}$ & $\mathrm{m}$ & $\mathrm{m}$ & $\mathrm{m}$ \\
\hline Portugal & & & $\mathrm{m}$ & $\mathrm{m}$ & $\mathrm{m}$ & $\mathrm{m}$ \\
\hline Slowakei & & & $\mathrm{m}$ & $\mathrm{m}$ & $\mathrm{m}$ & $\mathrm{m}$ \\
\hline Slowenien & & & $\mathrm{m}$ & $\mathrm{m}$ & $\mathrm{m}$ & $\mathrm{m}$ \\
\hline Spanien & 2010 & Männer & 59 & 55 & 54 & 59 \\
\hline & & Frauen & 38 & 49 & 56 & 52 \\
\hline & & $M+F$ & 50 & 48 & 56 & 54 \\
\hline Schweden & 2009 & Männer & 11 & 46 & 30 & 24 \\
\hline & & Frauen & 12 & 58 & 44 & 34 \\
\hline & & $M+F$ & 11 & 50 & 38 & 28 \\
\hline Schweiz & 2011 & Männer & 38 & 58 & 38 & 52 \\
\hline & & Frauen & 42 & 47 & 43 & 43 \\
\hline & & $M+F$ & 38 & 51 & 41 & 46 \\
\hline Türkei & & & $\mathrm{m}$ & $\mathrm{m}$ & $\mathrm{m}$ & $\mathrm{m}$ \\
\hline Vereinigtes Königreich & 2011 & Männer & 45 & 51 & 97 & 58 \\
\hline & & Frauen & 34 & 50 & 68 & 51 \\
\hline & & $M+F$ & 40 & 49 & 82 & 53 \\
\hline Vereinigte Staaten & 2011 & Männer & 27 & 54 & 60 & 46 \\
\hline & & Frauen & 42 & 66 & 78 & 55 \\
\hline & & $M+F$ & 31 & 58 & 69 & 49 \\
\hline OECD-Durchschnitt & & Männer & 46 & 56 & 59 & 53 \\
\hline & & Frauen & 45 & 57 & 62 & 53 \\
\hline & & $\mathbf{M}+\mathbf{F}$ & 43 & 55 & 61 & 52 \\
\hline EU21-Durchschnitt & & Männer & 43 & 49 & 53 & 45 \\
\hline & & Frauen & 42 & 53 & 64 & 50 \\
\hline & & $M+F$ & 39 & 49 & 61 & 46 \\
\hline Sonstige G20-Länder & & & & & & \\
\hline Argentinien & & & $\mathrm{m}$ & $\mathrm{m}$ & $\mathrm{m}$ & $\mathrm{m}$ \\
\hline Brasilien & 2011 & Männer & 58 & 120 & 119 & 72 \\
\hline & & Frauen & 74 & 118 & 92 & 84 \\
\hline & & $M+F$ & 60 & 116 & 106 & 76 \\
\hline China & & & $\mathrm{m}$ & $\mathrm{m}$ & $\mathrm{m}$ & $\mathrm{m}$ \\
\hline Indien & & & $\mathrm{m}$ & $\mathrm{m}$ & $\mathrm{m}$ & $\mathrm{m}$ \\
\hline Indonesien & & & $\mathrm{m}$ & $\mathrm{m}$ & $\mathrm{m}$ & $\mathrm{m}$ \\
\hline Russische Föderation & & & $\mathrm{m}$ & $\mathrm{m}$ & $\mathrm{m}$ & $\mathrm{m}$ \\
\hline Saudi-Arabien & & & $\mathrm{m}$ & $\mathrm{m}$ & $\mathrm{m}$ & $\mathrm{m}$ \\
\hline Südafrika & & & $\mathrm{m}$ & $\mathrm{m}$ & $\mathrm{m}$ & $\mathrm{m}$ \\
\hline G20-Durchschnitt & & & m & m & m & m \\
\hline
\end{tabular}

1. Für einige Länder in dieser Tabelle beziehen sich die Angaben auf 16- bis 24-Jährige.

Quelle: OECD. Spezielle Datenerhebung zu Einkommen des Netzwerks zu den Arbeitsmarktergebnissen sowie den wirtschaftlichen und sozialen Auswirkungen des Lernens (LSO). Hinweise s. Anhang 3 unter www.oecd.org/edu/eag.htm. StatLink: http://dx.doi.org/10.1787/888932849046

Erläuterung der Kennzeichnung fehlender Daten s. Hinweise für den Leser. 
Anteil junger Erwachsener mit Erwerbseinkommen an allen jungen Erwachsenen, nach Geschlecht, Altersgruppe und Ausbildungsstatus (2011)

Erläuterung der Tabelle: In Australien beziehen 68 Prozent aller 15- bis 24-jährigen Nichtschüler/Nichtstudierenden Erwerbseinkommen und 52 Prozent aller 15- bis 24-jährigen Schüler/Studierenden. $58 \%$ aller 15- bis 24-Jährigen beziehen ein Erwerbseinkommen.

\begin{tabular}{|c|c|c|c|c|c|c|c|c|}
\hline \multirow{4}{*}{$\begin{array}{l}\text { OECD-Länder } \\
\end{array}$} & & & \multicolumn{3}{|c|}{ 15- bis 24-Jährige ${ }^{1}$} & \multicolumn{3}{|c|}{ 25- bis 29-Jährige } \\
\hline & & & \multirow{2}{*}{$\begin{array}{c}\begin{array}{c}\text { Nichtschüler/- } \\
\text { Nichtstudierende }\end{array} \\
\text { (1) }\end{array}$} & \multirow{2}{*}{$\begin{array}{c}\begin{array}{c}\text { Schüler/ } \\
\text { Studierende }\end{array} \\
(2)\end{array}$} & \multirow{2}{*}{$\begin{array}{c}\text { Gesamt } \\
(3)\end{array}$} & \multirow{2}{*}{$\begin{array}{c}\begin{array}{c}\text { Nichtschüler/- } \\
\text { Nichtstudierende }\end{array} \\
(4)\end{array}$} & \multirow{2}{*}{$\begin{array}{c}\begin{array}{c}\text { Schüler/ } \\
\text { Studierende }\end{array} \\
\text { (5) }\end{array}$} & \multirow{2}{*}{$\begin{array}{c}\text { Gesam } \\
(6)\end{array}$} \\
\hline & & & & & & & & \\
\hline & & & & & & & & \\
\hline \multirow[t]{3}{*}{ Australien } & 2009 & Männer & 68 & 51 & 57 & 81 & 80 & 81 \\
\hline & & Frauen & 68 & 53 & 59 & 69 & 71 & 69 \\
\hline & & $M+F$ & 68 & 52 & 58 & 75 & 75 & 75 \\
\hline \multirow[t]{3}{*}{ Österreich } & 2011 & Männer & 87 & 68 & 76 & 96 & 80 & 93 \\
\hline & & Frauen & 85 & 63 & 71 & 85 & 76 & 84 \\
\hline & & $M+F$ & 86 & 65 & 74 & 91 & 78 & 89 \\
\hline \multirow[t]{3}{*}{ Belgien } & 2010 & Männer & 62 & 6 & 26 & 76 & 33 & 73 \\
\hline & & Frauen & 57 & 7 & 23 & 71 & 34 & 69 \\
\hline & & $M+F$ & 60 & 6 & 24 & 73 & 41 & 71 \\
\hline \multirow[t]{3}{*}{ Kanada } & 2010 & Männer & 85 & 61 & 71 & 90 & 75 & 88 \\
\hline & & Frauen & 80 & 69 & 73 & 86 & 80 & 85 \\
\hline & & $M+F$ & 83 & 65 & 72 & 88 & 78 & 87 \\
\hline \multirow[t]{3}{*}{ Chile } & 2011 & Männer & 63 & 12 & 34 & 85 & 44 & 79 \\
\hline & & Frauen & 37 & 8 & 21 & 56 & 46 & 54 \\
\hline & & $M+F$ & 50 & 10 & 27 & 70 & 45 & 66 \\
\hline Tschechien & & & $\mathrm{m}$ & $\mathrm{m}$ & $\mathrm{m}$ & $\mathrm{m}$ & $\mathrm{m}$ & $\mathrm{m}$ \\
\hline \multirow[t]{3}{*}{ Dänemark } & 2011 & Männer & 74 & 69 & 71 & 85 & 83 & 85 \\
\hline & & Frauen & 70 & 75 & 73 & 80 & 83 & 81 \\
\hline & & $M+F$ & 73 & 72 & 72 & 83 & 83 & 83 \\
\hline \multirow[t]{3}{*}{ Estland } & 2011 & Männer & 47 & 8 & 23 & 59 & 42 & 56 \\
\hline & & Frauen & 47 & 13 & 23 & 51 & 52 & 51 \\
\hline & & $M+F$ & 47 & 11 & 23 & 55 & 47 & 53 \\
\hline Finnland & & & $\mathrm{m}$ & $\mathrm{m}$ & $\mathrm{m}$ & $\mathrm{m}$ & $\mathrm{m}$ & $\mathrm{m}$ \\
\hline Frankreich & 2009 & Männer & 85 & 34 & 58 & 95 & 93 & 95 \\
\hline & & Frauen & 81 & 36 & 54 & 86 & 78 & 85 \\
\hline & & $M+F$ & 84 & 35 & 56 & 90 & 84 & 90 \\
\hline Deutschland & 2011 & Männer & 59 & 35 & 43 & 81 & 44 & 71 \\
\hline & & Frauen & 61 & 32 & 41 & 74 & 49 & 69 \\
\hline & & $M+F$ & 60 & 33 & 42 & 77 & 46 & 70 \\
\hline Griechenland & 2011 & Männer & 61 & 51 & 55 & 76 & 58 & 73 \\
\hline & & Frauen & 62 & 52 & 55 & 70 & 66 & 69 \\
\hline & & $M+F$ & 62 & 51 & 55 & 73 & 62 & 71 \\
\hline Ungarn & & & $\mathrm{m}$ & $\mathrm{m}$ & $\mathrm{m}$ & $\mathrm{m}$ & $\mathrm{m}$ & $\mathrm{m}$ \\
\hline Island & & & $\mathrm{m}$ & $\mathrm{m}$ & $\mathrm{m}$ & $\mathrm{m}$ & $\mathrm{m}$ & $\mathrm{m}$ \\
\hline Irland & & & $\mathrm{m}$ & $\mathrm{m}$ & $\mathrm{m}$ & $\mathrm{m}$ & $\mathrm{m}$ & $\mathrm{m}$ \\
\hline Israel & 2011 & Männer & 65 & 14 & 43 & 77 & 66 & 74 \\
\hline & & Frauen & 58 & 20 & 39 & 71 & 74 & 71 \\
\hline & & $M+F$ & 61 & 18 & 41 & 74 & 70 & 73 \\
\hline Italien & 2009 & Männer & 66 & 13 & 36 & 88 & 41 & 82 \\
\hline & & Frauen & 54 & 12 & 27 & 72 & 49 & 69 \\
\hline & & $M+F$ & 61 & 13 & 31 & 80 & 46 & 75 \\
\hline Japan & & & $\mathrm{m}$ & $\mathrm{m}$ & $\mathrm{m}$ & $\mathrm{m}$ & $\mathrm{m}$ & $\mathrm{m}$ \\
\hline Korea & 2011 & Männer & 93 & 91 & 92 & 90 & 96 & 90 \\
\hline & & Frauen & 97 & 86 & 94 & 94 & 95 & 94 \\
\hline & & $M+F$ & 96 & 88 & 93 & 92 & 95 & 92 \\
\hline Luxemburg & & & $\mathrm{m}$ & $\mathrm{m}$ & $\mathrm{m}$ & $\mathrm{m}$ & $\mathrm{m}$ & $\mathrm{m}$ \\
\hline Mexiko & & & $m$ & $\mathrm{~m}$ & $\mathrm{~m}$ & $\mathrm{~m}$ & $\mathrm{~m}$ & $m$ \\
\hline Niederlande & & & $\mathrm{m}$ & $\mathrm{m}$ & $\mathrm{m}$ & $\mathrm{m}$ & $\mathrm{m}$ & $\mathrm{m}$ \\
\hline Neuseeland & 2011 & Männer & 73 & 32 & 49 & 88 & 53 & 83 \\
\hline & & Frauen & 62 & 37 & 47 & 66 & 64 & 66 \\
\hline & & $M+F$ & 68 & 35 & 48 & 77 & 59 & 74 \\
\hline Norwegen & 2010 & Männer & 79 & 73 & 76 & 92 & 91 & 92 \\
\hline & & Frauen & 77 & 80 & 79 & 89 & 91 & 89 \\
\hline & & $M+F$ & 78 & 77 & 77 & 91 & 91 & 91 \\
\hline
\end{tabular}

1. Für einige Länder in dieser Tabelle beziehen sich die Angaben auf 16- bis 24-Jährige.

Quelle: OECD. Spezielle Datenerhebung zu Einkommen des Netzwerks zu den Arbeitsmarktergebnissen sowie den wirtschaftlichen und sozialen Auswirkungen des Lernens (LSO). Hinweise s. Anhang 3 unter www.oecd.org/edu/eag.htm. StatLink: http://dx.doi.org/10.1787/888932849065 Erläuterung der Kennzeichnung fehlender Daten s. Hinweise für den Leser. 
Tabelle A6.5b (Forts.)

Anteil junger Erwachsener mit Erwerbseinkommen an allen jungen Erwachsenen, nach Geschlecht, Altersgruppe und Ausbildungsstatus (2011)

Erläuterung der Tabelle: In Australien beziehen 68 Prozent aller 15- bis 24-jährigen Nichtschüler/Nichtstudierenden Erwerbseinkommen und 52 Prozent aller 15- bis 24-jährigen Schüler/Studierenden. $58 \%$ aller 15- bis 24-Jährigen beziehen ein Erwerbseinkommen.

\begin{tabular}{|c|c|c|c|c|c|c|c|c|}
\hline & & & \multicolumn{3}{|c|}{ 15- bis 24 -Jährige ${ }^{1}$} & \multicolumn{3}{|c|}{ 25- bis 29-Jährige } \\
\hline & & & $\begin{array}{l}\text { Nichtschüler/- } \\
\text { Nichtstudierende }\end{array}$ & $\begin{array}{c}\text { Schüler/ } \\
\text { Studierende }\end{array}$ & Gesamt & $\begin{array}{l}\text { Nichtschüler/- } \\
\text { Nichtstudierende }\end{array}$ & $\begin{array}{c}\text { Schüler/ } \\
\text { Studierende }\end{array}$ & Gesamt \\
\hline & & & (1) & (2) & (3) & (4) & (5) & (6) \\
\hline \multicolumn{9}{|l|}{ OECD-Länder } \\
\hline Polen & & & $\mathrm{m}$ & $\mathrm{m}$ & $\mathrm{m}$ & $\mathrm{m}$ & $\mathrm{m}$ & $\mathrm{m}$ \\
\hline Portugal & & & $\mathrm{m}$ & $\mathrm{m}$ & $\mathrm{m}$ & $\mathrm{m}$ & $\mathrm{m}$ & $\mathrm{m}$ \\
\hline Slowakei & & & $\mathrm{m}$ & $\mathrm{m}$ & $\mathrm{m}$ & $\mathrm{m}$ & $\mathrm{m}$ & $\mathrm{m}$ \\
\hline Slowenien & & & $\mathrm{m}$ & $\mathrm{m}$ & $\mathrm{m}$ & $\mathrm{m}$ & $\mathrm{m}$ & $\mathrm{m}$ \\
\hline \multirow[t]{3}{*}{ Spanien } & 2010 & Männer & 60 & 10 & 30 & 79 & 46 & 72 \\
\hline & & Frauen & 57 & 14 & 29 & 74 & 47 & 69 \\
\hline & & $M+F$ & 58 & 12 & 29 & 76 & 47 & 71 \\
\hline \multirow[t]{3}{*}{ Schweden } & 2009 & Männer & 100 & 100 & 100 & 100 & 100 & 100 \\
\hline & & Frauen & 100 & 100 & 100 & 99 & 100 & 99 \\
\hline & & $M+F$ & 100 & 100 & 100 & 99 & 100 & 99 \\
\hline \multirow[t]{3}{*}{ Schweiz } & 2011 & Männer & 72 & 12 & 35 & 85 & 66 & 81 \\
\hline & & Frauen & 75 & 19 & 38 & 78 & 63 & 76 \\
\hline & & $M+F$ & 73 & 16 & 36 & 82 & 65 & 79 \\
\hline Türkei & & & $\mathrm{m}$ & $\mathrm{m}$ & $\mathrm{m}$ & $\mathrm{m}$ & $\mathrm{m}$ & $\mathrm{m}$ \\
\hline \multirow{3}{*}{$\begin{array}{l}\text { Vereinigtes } \\
\text { Königreich }\end{array}$} & 2011 & Männer & 67 & 29 & 51 & 85 & 64 & 83 \\
\hline & & Frauen & 63 & 35 & 50 & 72 & 63 & 71 \\
\hline & & $M+F$ & 65 & 32 & 50 & 79 & 64 & 77 \\
\hline \multirow[t]{3}{*}{ Vereinigte Staaten } & 2011 & Männer & 75 & 37 & 52 & $\mathrm{~m}$ & $\mathrm{~m}$ & $\mathrm{~m}$ \\
\hline & & Frauen & 69 & 42 & 52 & $\mathrm{~m}$ & $\mathrm{~m}$ & $\mathrm{~m}$ \\
\hline & & $M+F$ & 72 & 40 & 52 & $\mathrm{~m}$ & $\mathrm{~m}$ & $\mathrm{~m}$ \\
\hline \multirow[t]{3}{*}{ OECD-Durchschnitt } & & Männer & 72 & 40 & 54 & 85 & 67 & 82 \\
\hline & & Frauen & 67 & 42 & 52 & 75 & 67 & 74 \\
\hline & & $\mathbf{M}+\mathbf{F}$ & 70 & 41 & 53 & 80 & 67 & 78 \\
\hline \multirow[t]{3}{*}{ EU21-Durchschnitt } & & Männer & 70 & 38 & 52 & 84 & 62 & 80 \\
\hline & & Frauen & 67 & 40 & 50 & 76 & 63 & 74 \\
\hline & & $M+F$ & 69 & 39 & 51 & 80 & 63 & 77 \\
\hline \multicolumn{9}{|l|}{ Sonst. G20-Länder } \\
\hline Argentinien & & & $\mathrm{m}$ & $\mathrm{m}$ & $\mathrm{m}$ & $\mathrm{m}$ & $\mathrm{m}$ & $\mathrm{m}$ \\
\hline \multirow[t]{3}{*}{ Brasilien } & 2011 & Männer & 76 & 38 & 59 & 88 & 76 & 87 \\
\hline & & Frauen & 51 & 28 & 40 & 62 & 67 & 63 \\
\hline & & $M+F$ & 64 & 33 & 49 & 75 & 71 & 75 \\
\hline China & & & $\mathrm{m}$ & $\mathrm{m}$ & $\mathrm{m}$ & $\mathrm{m}$ & $\mathrm{m}$ & $\mathrm{m}$ \\
\hline Indien & & & $\mathrm{m}$ & $\mathrm{m}$ & $\mathrm{m}$ & $\mathrm{m}$ & $\mathrm{m}$ & $\mathrm{m}$ \\
\hline Indonesien & & & $\mathrm{m}$ & $\mathrm{m}$ & $\mathrm{m}$ & $\mathrm{m}$ & $\mathrm{m}$ & $\mathrm{m}$ \\
\hline Russische Föd. & & & $\mathrm{m}$ & $\mathrm{m}$ & $\mathrm{m}$ & $\mathrm{m}$ & $\mathrm{m}$ & $\mathrm{m}$ \\
\hline Saudi-Arabien & & & $\mathrm{m}$ & $\mathrm{m}$ & $\mathrm{m}$ & $\mathrm{m}$ & $\mathrm{m}$ & $\mathrm{m}$ \\
\hline Südafrika & & & $\mathrm{m}$ & $\mathrm{m}$ & $\mathrm{m}$ & $\mathrm{m}$ & $\mathrm{m}$ & $\mathrm{m}$ \\
\hline G20-Durchschnitt & & & $\mathbf{m}$ & m & m & m & m & $\mathbf{m}$ \\
\hline
\end{tabular}

1. Für einige Länder in dieser Tabelle beziehen sich die Angaben auf 16- bis 24-Jährige.

Quelle: OECD. Spezielle Datenerhebung zu Einkommen des Netzwerks zu den Arbeitsmarktergebnissen sowie den wirtschaftlichen und sozialen Auswirkungen des Lernens (LSO). Hinweise s. Anhang 3 unter www.oecd.org/edu/eag.htm. StatLink: http://dx.doi.org/10.1787/888932849065

Erläuterung der Kennzeichnung fehlender Daten s. Hinweise für den Leser. 


\section{Welche Anreize bestehen für Investitionen in Bildung?}

Die privaten Erträge für einen Abschluss im Tertiärbereich sind beträchtlich.

Ein höherer Bildungsstand zahlt sich nicht nur für den Einzelnen aus, sondern auch für den Staat, dem höhere Steuereinnahmen und Sozialversicherungsbeiträge zufließen.

Der staatliche Nettoertrag aus einer Bildungsinvestition im Tertiärbereich bei einem Mann beläuft sich in den OECD-Ländern auf über Ioo.ooo US-Dollar - fast das Dreifache der staatlichen Investitionssumme für diese Ausbildung. Bei einer Frau wird mit rund 60.000 US-Dollar fast das Doppelte der staatlichen Investitionssumme als staatlicher Nettoertrag erreicht.

Abbildung A7.1

Staatlicher und privater Nettoertrag bei einem Mann, der einen Abschluss im Tertiärbereich erwirbt (2009) Im Vergleich zu den Erträgen bei einem Abschluss im Sekundarbereich II/postsekundaren, nicht tertiären Bereich

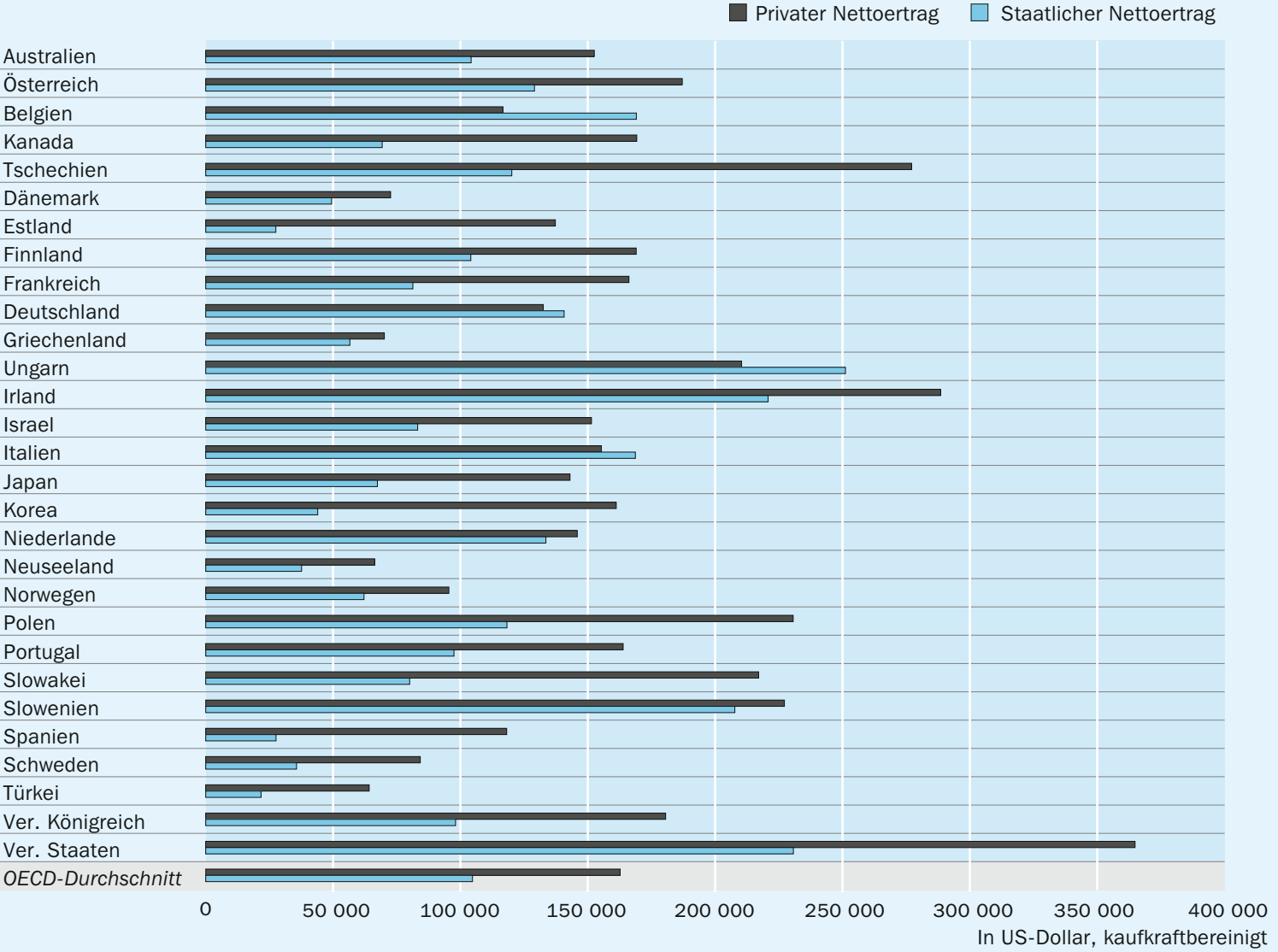

Anmerkung: Referenzjahr für die Türkei ist 2005, für Japan 2007, für Italien, die Niederlande und Polen 2008, für alle anderen Länder 2009. CashflowBestandteile sind mit einem Zinssatz von 3 Prozent abgezinst. 


\section{Kontext}

Der Erwerb eines höheren Bildungsabschlusses ist sowohl für den Einzelnen als auch die Gesellschaft als Ganzes von Vorteil, nicht nur finanziell, sondern auch wegen des Wohlergehens, das damit einhergeht. Für den Einzelnen verbessert ein höherer Bildungsstand die Beschäftigungschancen und mindert das Risiko der Erwerbslosigkeit. Die besseren Arbeitsmarktchancen (s. Indikator A5) und die Aussichten auf ein höheres Erwerbseinkommen (s. Indikator A6) sind ein starker Anreiz für den Einzelnen, in Bildung zu investieren und im Hinblick auf zukünftige Erträge Konsum- und Einkommensverzicht in der Gegenwart zu leisten. Die Gesellschaft ihrerseits gewinnt durch geringere öffentliche Ausgaben für Sozialleistungen und höhere Steuereinnahmen, wenn diese Bildungsteilnehmer dann in den Arbeitsmarkt eintreten.

Für politische Entscheidungsträger ist es von entscheidender Bedeutung, genau zu verstehen, welche wirtschaftlichen Anreize den Einzelnen zu einer Bildungsinvestition motivieren. So kann der starke Anstieg der Arbeitsmarktnachfrage nach höher qualifizierten Arbeitskräften die Einkommen und die Erträge erheblich steigern, bevor sich das Angebot entsprechend anpasst. Dies signalisiert einen Bedarf an weiteren Bildungsinvestitionen. In Ländern mit rigidem Arbeitsrecht und starren Strukturen, die Entgeltunterschiede eher generell einschränken, wird ein solches Signal schwächer ausfallen.

Die Erträge genau zu kennen ist auch für die Entwicklung von politischen Maßnahmen für den Zugang zu Bildung, die Besteuerung und die Weiterbildungskosten für den Einzelnen wichtig. Daher sollte die Ausgewogenheit von privaten und staatlichen Erträgen zusammen mit den Informationen aus den anderen hier behandelten Indikatoren betrachtet werden. Um zu entscheiden, welches der optimale Betrag ist, den der Staat in die Bildung investieren sollte, genügt nicht allein die Betrachtung der staatlichen Ertragsrate (Kasten A7.I). Wenn die privaten und die staatlichen Ertragsraten zu stark auseinanderklaffen, könnte das einerseits auf verzerrende steuerliche Bestimmungen oder andererseits auf eine unverhältnismäßig starke Subventionierung des Bildungswesens hindeuten.

In Ländern mit lang dauernden Studiengängen im Tertiärbereich und relativ hohen Einkommen mit einem Abschluss im Sekundarbereich II bzw. dem postsekundaren, nicht tertiären Bereich sind die Auswirkungen des entgangenen Einkommens recht hoch (s. Indikator BI). Wie stark der Effekt tatsächlich ist, hängt auch vom zu erwartenden Entgeltniveau und der Beschäftigungswahrscheinlichkeit ab. Mit zunehmender Verschlechterung der Arbeitsmarktlage für junge Erwachsene (s. Indikator $\mathrm{C}_{5}$ ) sinken die Investitionskosten. Da Besserqualifizierte bei schlechter Konjunktur auf dem Arbeitsmarkt tendenziell besser dastehen (s. Indikator A5), wird die Nutzenseite sowohl für den Einzelnen als auch die Gesellschaft durch die größeren Einkommensunterschiede noch weiter aufgewertet. In künftigen Ausgaben von Bildung auf einen Blick werden die Daten aus 2010 und 20II, als die Auswirkungen der weltweiten Wirtschaftskrise am größten waren, wahrscheinlich einen noch stärkeren Anreiz für eine Bildungsinvestition sowohl von privater als auch von staatlicher Seite aufzeigen. 


\section{Weitere wichtige Ergebnisse}

Die Bruttoeinkommensvorteile aus einem Abschluss im Tertiärbereich gegenüber einem $\mathrm{Ab}$ schluss im Sekundarbereich II bzw. im postsekundaren, nicht tertiären Bereich belaufen sich im OECD-Durchschnitt für Männer auf 330.000 US-Dollar und für Frauen auf 240.000 US-Dollar.

Der Bruttoeinkommensvorteil für Absolventen des Sekundarbereichs II bzw. des postsekundaren, nicht tertiären Bereichs gegenüber Erwerbspersonen ohne diesen Abschluss ist in Norwegen, Österreich und den Vereinigten Staaten besonders ausgeprägt und beläuft sich auf mindestens 250.000 US-Dollar für einen Mann und I50.00o US-Dollar für eine Frau.

- Im Durchschnitt der 28 OECD-Länder mit verfügbaren Daten liegt der staatliche Ertrag (der Kapitalwert) bei einem Mann, der den Sekundarbereich II bzw. den postsekundaren, nicht tertiären Bereich abgeschlossen hat, um rund 38.000 US-Dollar höher als für einen Mann ohne einen solchen Abschluss. Bei einer Frau beträgt der staatliche Ertrag 22.000 US-Dollar.

Mit wenigen Ausnahmen ist der private Nettoertrag einer Investition in einen Abschluss im Tertiärbereich größer als der in einen Abschluss im Sekundarbereich II oder im postsekundaren, nicht tertiären Bereich. Nur in Dänemark und Schweden erzielen sowohl Männer als auch Frauen mit einem Abschluss im Sekundarbereich II oder im postsekundaren, nicht tertiären Bereich höhere Erträge. In Norwegen und Korea sind die Erträge für einen Abschluss im Sekundarbereich II bzw. im postsekundaren, nicht tertiären Bereich für Männer höher als für einen Abschluss im Tertiärbereich, in Neuseeland gilt dies für Frauen.

Im Durchschnitt der OECD-Länder bringt ein Bildungsteilnehmer rund 55.000 US-Dollar für einen Abschluss im Tertiärbereich auf. In Japan, den Niederlanden, dem Vereinigten Königreich und den Vereinigten Staaten sind es im Durchschnitt unter Berücksichtigung der direkten und indirekten Kosten mehr als I00.00o US-Dollar.

\section{Analyse und Interpretationen}

\section{Finanzielle Erträge aus Bildungsinvestitionen}

In diesem Indikator werden die Kosten und der Nutzen von Bildung und die Anreize für eine Investition in Bildung untersucht. Es wird der wirtschaftliche Nutzen der Bildung für den Einzelnen mittels einer Schätzung des Einkommenszuschlags für einen höheren Bildungsstand unter Berücksichtigung der direkten und indirekten Kosten und des Nutzens des Erwerbs eines solchen Bildungsabschlusses bewertet. Zur Nutzenseite gehören nicht nur höhere Einkommen im Vergleich zu den Absolventen niedrigerer Bildungsabschlüsse, sondern auch die Beschäftigungswahrscheinlichkeit, als geldwerter Vorteil mittels der als „Effekt der Erwerbslosigkeit“ bezeichneten Variablen ausgedrückt.

$\mathrm{Zu}$ den Kosten gehören zum einen die direkten Kosten, insbesondere Schul-/Studiengebühren und zum anderen indirekte Kosten wie höhere Einkommensteuern und Sozialversicherungsbeiträge sowie Einkommensausfälle durch den verspäteten 
Eintritt in den Arbeitsmarkt und weniger Anspruch auf soziale Transferleistungen, wie Wohngeld, Familienbeihilfen oder ergänzende Sozialhilfeleistungen. Ferner werden Sozialversicherungsbeiträge und Einkommensteuern als Prozentsatz des Einkommens berechnet und sind für die Bessergebildeten meist höher, da sie eher zu den Besserverdienern gehören.

Der wirtschaftliche Nutzen und die Kosten eines Abschlusses im Tertiärbereich werden mit denen eines Abschlusses im Sekundarbereich II bzw. im postsekundaren, nicht tertiären Bereich verglichen. Der Bezugspunkt für den Sekundarbereich II bzw. den postsekundaren, nicht tertiären Bereich ist eine Ausbildung unterhalb des Sekundarbereichs II. Bei den Berechnungen werden jeweils die Ergebnisse für Frauen untereinander und die für Männer untereinander verglichen. Die Berechnungen werden getrennt für Männer und Frauen durchgeführt, und es wird kein Durschnitt berechnet, um den geschlechtsspezifischen Einkommensunterschieden und Erwerbslosenquoten Rechnung zu tragen.

Die Darstellung von Kosten und Nutzen der Bildung und den Anreizen für eine Investition in Bildung ist ein recht komplexes Unterfangen, das gewisse methodische und analytische Überlegungen voraussetzt. Eine Bildungsinvestition, sowohl seitens des Einzelnen als auch seitens des Staates, umfasst ein komplexes Zusammenspiel von Faktoren und Wirkungen, die weit über die hier berücksichtigten Aspekte hinausgehen. Zum besseren Verständnis der getroffenen Aussagen sollte daher der vorliegende Indikator im Zusammenhang mit anderen in dieser Publikation (und in Bildung aufeinen Blick 2012) behandelten Indikatoren interpretiert werden. Die Grenzen der Berechnungen sowie die zugrundeliegenden Konzepte und Annahmen werden im Abschnitt Angewandte Methodik am Ende dieses Indikators erläutert.

\section{Anreize zur Investition in Bildung für den Einzelnen}

Sekundarbereich II bzw. postsekundarer, nicht tertiärer Bereich

In den OECD-Ländern kann ein Mann, der in einen Abschluss des Sekundarbereichs II bzw. des postsekundaren, nicht tertiären Bereichs investiert, damit rechnen, in seinem Erwerbsleben netto rund I00.000 US-Dollar mehr zu verdienen als ein Mann ohne einen solchen Abschluss. Dieser Betrag variiert jedoch erheblich zwischen den einzelnen Ländern: In Korea, Norwegen, Österreich und den Vereinigten Staaten generiert ein Abschluss dieses Bildungsbereichs im Laufe des Berufslebens mindestens 200.00 USDollar zusätzlich (Tab. A7.ra).

Der Nutzen für den Einzelnen ergibt sich im Allgemeinen aus dem Bruttoerwerbseinkommen und dem geringeren Risiko der Erwerbslosigkeit. In den meisten Ländern haben Männer mit einem Abschluss im Sekundarbereich II bzw. postsekundaren, nicht tertiären Bereich einen deutlichen Einkommensvorteil gegenüber geringer Qualifizierten. Auch das geringere Risiko der Erwerbslosigkeit kann einen großen Wert darstellen. Die besseren Beschäftigungsaussichten von Männern mit einem Abschluss in diesem Bereich werden in Deutschland, der Slowakei und Tschechien mit mindestens 85.000 US-Dollar bewertet (Tab. A7.ra).

Als Kosten der Bildung gelten sämtliche Faktoren wie direkte Kosten, entgangenes Einkommen, der Einkommensteuereffekt, die Effekte sozialer Transferleistungen und 
Abbildung A7.2

Private Kosten und privater Nutzen eines Abschlusses im Sekundarbereich II bzw. im postsekundaren, nicht tertiären Bereich für Männer und Frauen

Im Vergleich zu den Erträgen einer Ausbildung unterhalb des Sekundarbereichs II

Direkte Kosten

$\square$ Entgangenes Einkommen

$\square$ Effekt Einkommensteuer

$\square$ Effekt Sozialversicherungsbeiträge

Effekt Transferleistunge

$\square$ Effekt Bruttoeinkommensvorteile

Effekt Erwerbslosigkeit

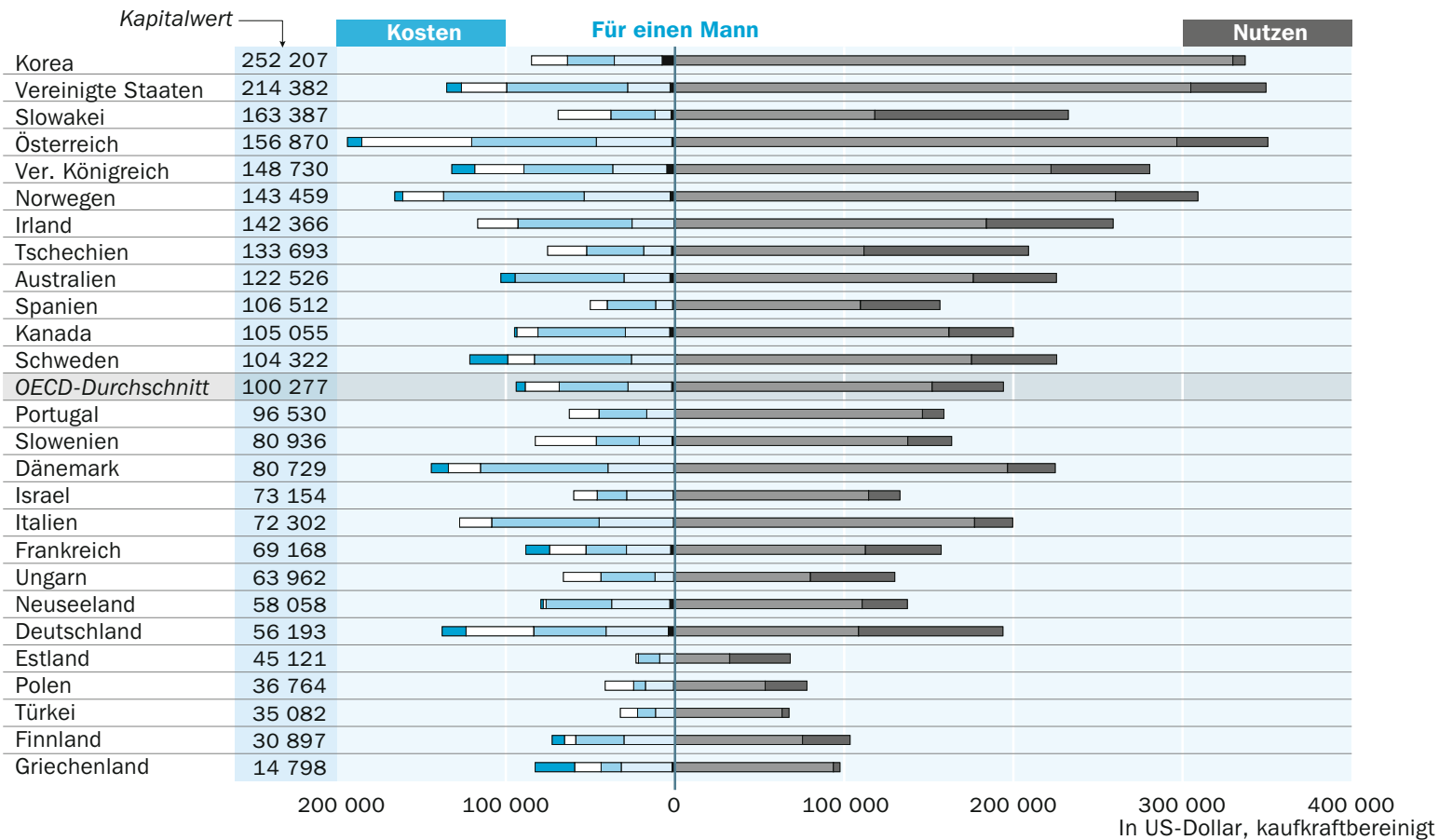

Kapitalwert

\begin{tabular}{l|r} 
Vereinigte Staaten & 141680 \\
\hline Slowakei & 137078 \\
\hline Irland & 118058 \\
\hline Spanien & 112703 \\
\hline Tschechien & 108418 \\
\hline Osterreich & 93226 \\
\hline Portugal & 76019 \\
\hline Italien & 74010 \\
\hline Ungarn & 73554 \\
\hline Korea & 71432 \\
\hline OECD-Durchschnitt & 69124 \\
\hline Schweden & 68678 \\
\hline Israel & 68602 \\
\hline Slowenien & 64352 \\
\hline Australien & 60094 \\
\hline Dänemark & 59882 \\
\hline Ver. Königreich & 59818 \\
\hline Griechenland & 53481 \\
\hline Neuseeland & 51151 \\
\hline Kanada & 47643 \\
\hline Polen & 47335 \\
\hline Norwegen & 46450 \\
\hline Frankreich & 44992 \\
\hline Estland & 43139 \\
\hline Türkei & 33223 \\
\hline Deutschland & 26191 \\
\hline Finnland & 16009 \\
\hline
\end{tabular}

\section{Kosten}

Für eine Frau

In US-Dollar, kaufkraftbereinigt

200000

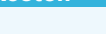

Nutzen

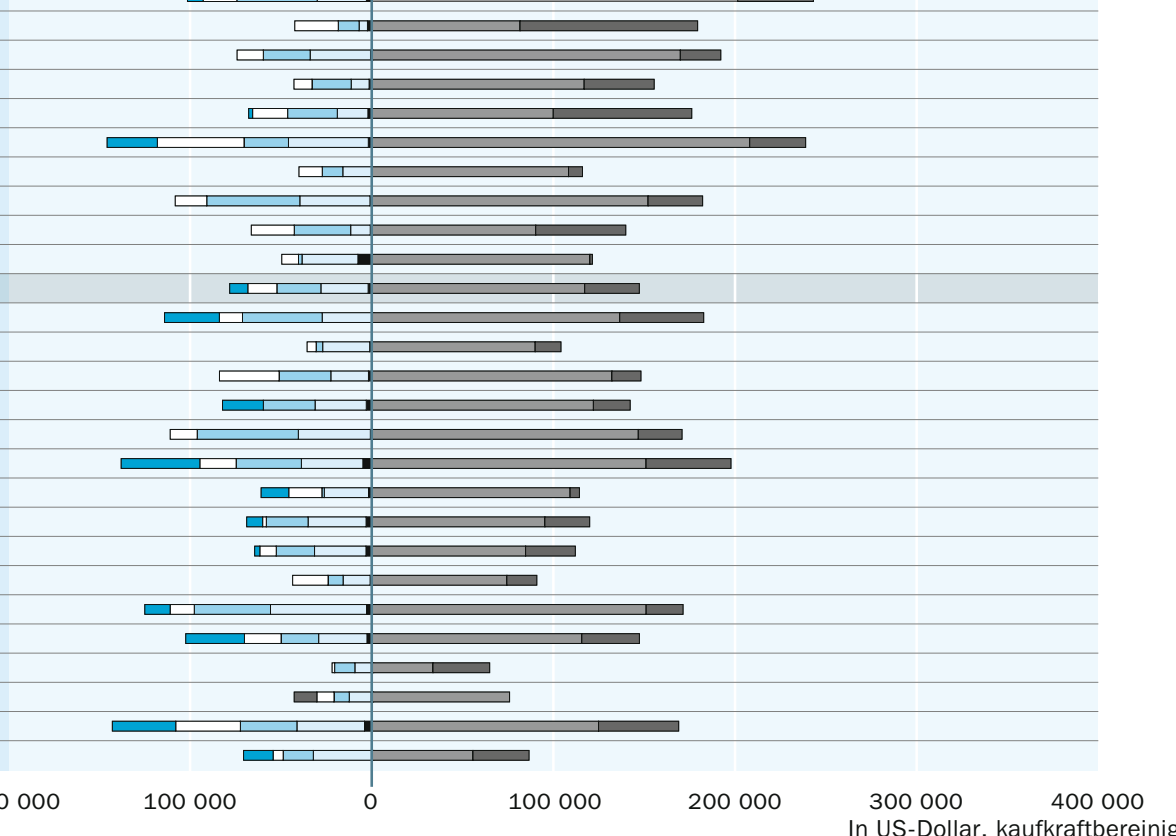

Anmerkung: Referenzjahr für die Türkei ist 2005, für Italien und Polen 2008, für alle anderen Länder 2009. Cashflow-Bestandteile sind mit einem Zinssatz von 3 Prozent abgezinst.

Anordnung der Länder in absteigender Reihenfolge des privaten Kapitalwerts.

Quelle: OECD. Tabellen A7.1a und A7.1b. Hinweise s. Anhang 3 unter www.oecd.org/edu/eag.htm. StatLink: http://dx.doi.org/10.1787/888932846652 
der Sozialversicherungsbeiträge (s. Abschnitt Definitionen). Die Daten für einen Mann, der einen Abschluss im Sekundarbereich II bzw. im postsekundaren, nicht tertiären Bereich erwirbt, zeigen, dass zu den Ländern mit relativ starken Einkommensteuereffekten (schätzungsweise über 65.00o US-Dollar) Dänemark, Irland, Norwegen, Österreich und die Vereinigten Staaten gehören. In Estland, Griechenland, Israel, Polen und der Türkei sind die Einkommensteuereffekte geringer (geschätzt weniger als 20.000 US-Dollar). Die höchsten Sozialversicherungsbeiträge müssen in Deutschland, Irland, Norwegen, Österreich, der Slowakei, Slowenien, dem Vereinigten Königreich und den Vereinigten Staaten abgeführt werden (geschätzt mehr als 23.00o US-Dollar). In Dänemark, Deutschland, Frankreich, Griechenland, Schweden und dem Vereinigten Königreich summieren sich die indirekten Kosten durch geringere Ansprüche auf Sozialleistungen auf über Io.00o US-Dollar (Tab. A7.Ia).

Die direkten Investitionskosten, die einer Frau für den Erwerb eines Abschlusses im Sekundarbereich II bzw. postsekundaren, nicht tertiären Bereich entstehen, sind meist zu vernachlässigen, der Investitionsaufwand besteht im Wesentlichen aus dem entgangenen Einkommen. Die Höhe des entgangenen Einkommens ist in den einzelnen Ländern sehr unterschiedlich, je nach Länge der Ausbildung, Einkommensniveau und den Einkommensunterschieden zwischen den Absolventen des Sekundarbereichs II bzw. postsekundaren, nicht tertiären Bereichs und denjenigen mit einem niedrigeren Bildungsabschluss (Tab. A7.Ib).

Gute Arbeitsmarktchancen sowohl für männlich als auch weibliche Jugendliche ohne einen Abschluss im Sekundarbereich II bzw. postsekundaren, nicht tertiären Bereich erhöhen die Kosten für weitere Investitionen in einen höheren Bildungsabschluss, Gleiches gilt für geringere Einkommensunterschiede und eine längere Ausbildungsdauer im Sekundarbereich II oder den postsekundaren, nicht tertiären Bildungsgängen. In Estland, der Slowakei, Spanien, der Türkei und Ungarn beläuft sich das entgangene Einkommen schätzungsweise auf weniger als I3.000 US-Dollar für den Einzelnen (Männer und Frauen), während es in Dänemark, Deutschland, Italien, Norwegen und Österreich mehr als 36.000 US-Dollar sind (Tab. A7.Ia und A7.rb).

Männer erzielen meist höhere finanzielle Erträge aus einem Abschluss im Sekundarbereich II bzw. postsekundaren, nicht tertiären Bereich als Frauen. Ausnahmen bilden hier Griechenland, Italien, Polen, Spanien und Ungarn. In diesen Ländern ist der private Kapitalwert für einen Abschluss im Sekundarbereich II bzw. postsekundaren, nicht tertiären Bereich für Frauen höher als für Männer. Im Durchschnitt der OECDLänder liegt der Nettoertrag für Frauen im Laufe ihres Erwerbslebens bei 69.000 USDollar, rund 30.000 US-Dollar weniger als für Männer. Der geschlechtsspezifische Unterschied bei den privaten Nettoerträgen ist in Korea, Norwegen, Österreich, dem Vereinigten Königreich und den Vereinigten Staaten besonders ausgeprägt. Das größte Gefälle besteht in Korea, wo ein Mann beim Erwerb eines Abschlusses im Sekundarbereich II bzw. postsekundaren, nicht tertiären Bereich einen Bruttoeinkommensvorteil von rund 250.000 US-Dollar erreicht, eine Frau jedoch lediglich von 71.000 US-Dollar. Im Wesentlichen ergibt sich dieser Abstand aus den Unterschieden bei den sozialen Transferleistungen und den Kosten der Erwerbslosigkeit für das jeweilige Geschlecht (Abb. A7.2). 


\begin{abstract}
Abschluss im Tertiärbereich
Im Allgemeinen können die Absolventen des Tertiärbereichs mit den höchsten Nettoerträgen rechnen. Im Durchschnitt der OECD-Länder erwirtschaften die Absolventen des Tertiärbereichs rund 6o Prozent mehr als die Absolventen des Sekundarbereichs II bzw. postsekundaren, nicht tertiären Bereichs. Von einigen wenigen Ausnahmen abgesehen führt eine Investition in einen Abschluss im Tertiärbereich zu einem höheren privaten Nettoertrag als die Investition in einen Abschluss im Sekundarbereich II bzw. postsekundaren, nicht tertiären Bereich.
\end{abstract}

Der Nettoertrag einer Bildungsinvestition im Tertiärbereich ist für Männer in der Regel höher als für Frauen. Nur in Portugal sind die durchschnittlichen Erträge für Männer und Frauen fast gleich. In Griechenland, Spanien und der Türkei erzielen die Frauen höhere Erträge (Tab. A7.3a und A7.3b).

Der Bruttoeinkommensvorteil aus einem Abschluss im Tertiärbereich stellt für Frauen und Männer einen beachtlichen Wert dar: durchschnittlich 330.000 US-Dollar für Männer und 240.000 US-Dollar für Frauen, allerdings bestehen zwischen den einzelnen Ländern auch signifikante Unterschiede.

Polen, Slowenien, Tschechien und Ungarn gehören zu den Ländern mit Einkommenszuschlägen über dem OECD-Durchschnitt, obwohl dort die Gesamtkosten und das Einkommensniveau im Vergleich zu anderen OECD-Ländern relativ niedrig sind. Eine mögliche Erklärung könnte der relativ niedrige Anteil von Absolventen des Tertiärbereichs in der Bevölkerung im erwerbsfähigen Alter sein, was wiederum auf ein knappes Angebot an Hochschulabsolventen hindeutet. Dies könnte im Laufe der Jahre zu einer Steigerung der Einkommen und der Entgeltunterschiede zwischen Absolventen des Tertiärbereichs und der Bildungsbereiche darunter geführt haben.

Im Durchschnitt der OECD-Länder wirkt sich der Effekt der Erwerbslosenunterstützung gegenüber einem Abschluss im Sekundarbereich II bzw. postsekundaren, nicht tertiären Bereich weniger deutlich aus als der Einkommensunterschied, wesentlich stärker wirken sich dagegen die Effekte von Steuern, Sozialversicherungsbeiträgen und sozialen Transferleistungen sowie die direkten Kosten aus. Insbesondere für einen Abschluss im Tertiärbereich ist ein längerer Verbleib im Bildungssystem erforderlich, wodurch den Absolventen Einkommen in erheblichem Umfang entgeht (entgangenes Einkommen), das sie bei einem früheren Eintritt in den Arbeitsmarkt hätten verdienen können.

Der private Investitionsaufwand für einen Abschluss im Tertiärbereich ist in einigen Ländern sehr hoch. Im Durchschnitt aller OECD-Länder bringt ein Bildungsteilnehmer rund 55.000 US-Dollar für einen Abschluss im Tertiärbereich auf. Unter Einbeziehung der direkten und indirekten Kosten investieren Bildungsteilnehmer beiderlei Geschlechts in den Niederlanden, dem Vereinigten Königreich und den Vereinigten Staaten durchschnittlich mehr als I00.000 US-Dollar in den Erwerb eines Abschlusses im Tertiärbereich. Im OECD-Durchschnitt machen die direkten Kosten wie Studiengebühren ungefähr ein Fünftel der privaten Gesamtinvestition für einen Abschluss im Tertiärbereich aus (geschätzte II.00o US-Dollar pro Person, unabhängig vom Geschlecht) (Tab. A7.3a und A7.3b). 
Schwache Arbeitsmarkterträge können zum Beispiel durch die Senkung der privaten Kosten für den Besuch des Tertiärbereichs verbessert werden. Eine Reihe von Ländern subventionieren die direkten Bildungskosten nicht nur, sondern gewähren auch Studiendarlehen oder Zuschüsse, um den Tertiärbereich attraktiver und leichter zugänglich zu machen. Anders als Darlehen sind Studienzuschüsse Transferleistungen in Form von Geld, Sach- oder Dienstleistungen, die nicht zurückgezahlt werden müssen. Im vorliegenden Indikator werden lediglich die Studienzuschüsse, nicht jedoch die Darlehen berücksichtigt.

Zuschüsse sind insbesondere in Dänemark von großer Bedeutung, da sie dort (mit geschätzten 25.00o US-Dollar) mehr als 40 Prozent der Gesamtkosten einer Ausbildung im Tertiärbereich abdecken. In Finnland, den Niederlanden, Österreich und Schweden werden die Zuschüsse auf mehr als 8.00o US-Dollar, d. h. rund 15 Prozent der Gesamtkosten, beziffert (Tab. A7.3a und A7.3b).

Aus den Daten geht jedoch hervor, dass es in den Ländern mit den höchsten direkten Kosten für die Teilnahme am Tertiärbereich, insbesondere in Australien, Japan, Korea, dem Vereinigten Königreich und den Vereinigten Staaten, keine oder nur sehr geringe Studienzuschüsse gibt. In Australien, dem Vereinigten Königreich und den Vereinigten Staaten tragen Zuschüsse weniger als 2 Prozent zu den direkten Kosten für einen Abschluss im Tertiärbereich bei. Dagegen bieten viele Länder, u. a. auch diejenigen mit niedrigen Zuschüssen, Studiendarlehen an, die nach dem Abschluss zurückgezahlt werden müssen. Die Konditionen für diese Darlehen, insbesondere ab wann die Tilgung beginnen muss (z. B. sobald das Einkommen eine bestimmte Höhe erreicht oder direkt nach dem Abschluss etc.) sowie die Zinssätze, unterscheiden sich stark von Land zu Land. Bei den meisten Studiendarlehen hängen jedoch der zu tilgende Betrag und die Tilgungsrate vom tatsächlichen Einkommen nach dem Abschluss ab. Die Möglichkeit, ein Studiendarlehen aufzunehmen, kann Bildungsteilnehmer, insbesondere aus sozioökonomisch benachteiligten Bevölkerungsschichten, ermutigen, einen Abschluss anzustreben. Da die Darlehen jedoch nach Abschluss des Studiums zurückgezahlt werden müssen - und somit von den Einkommensvorteilen abzuziehen sind -, mindern sie den finanziellen Nutzen der Bildung.

\section{Staatliche Ertragsraten von Bildungsinvestitionen}

\section{Abschluss im Sekundarbereich II bzw. postsekundaren, nicht tertiären Bereich}

Wie schon oben ausgeführt, führt ein höherer Bildungsstand tendenziell im Durchschnitt zu einem höheren Einkommensniveau (s. Indikator A6). Daher generieren Bildungsinvestitionen staatliche Erträge in Form von Mehreinnahmen bei den Einkommensteuern und Sozialversicherungsbeiträgen und Minderausgaben in Form von geringeren sozialstaatlichen Transferleistungen. In den meisten Ländern sind die staatlichen Erträge bei der Investition in einen Abschluss im Sekundarbereich II bzw. im postsekundaren, nicht tertiären Bereich von männlichen und weiblichen Bildungsteilnehmern positiv. Im Durchschnitt aller OECD-Länder generiert ein Abschluss in diesem Bildungsbereich einen staatlichen Nettoertrag von 38.000 US-Dollar bei einem Mann und von 22.000 US-Dollar bei einer Frau (Tab. A7.2a und A7.2b).

Im Durchschnitt ist der staatliche Nutzen doppelt so hoch wie der staatliche Gesamtaufwand für eine Ausbildung im Sekundarbereich II bzw. postsekundaren, nicht 
tertiären Bereich, sowohl bei Frauen als auch bei Männern. Im Vereinigten Königreich ist der staatliche Nutzen fast sechsmal höher als der staatliche Aufwand bei einem Mann mit diesem Bildungsstand, bei Frauen ist es sogar das 8-Fache (Tab. A7.2a und A7.2b).

\section{Abschluss im Tertiärbereich}

Im Durchschnitt der OECD-Länder sind die staatlichen Investitionen für einen Bildungsabschluss im Tertiärbereich pro Absolvent 39.000 US-Dollar höher als für einen Abschluss im Sekundarbereich II bzw. postsekundaren, nicht tertiären Bereich (unter Berücksichtigung des direkten staatlichen Aufwands und der indirekten Kosten). Der staatliche Aufwand für einen Absolventen im Tertiärbereich ist in Dänemark, Deutschland, den Niederlanden, Norwegen, Österreich und Schweden am höchsten (über 60.00o US-Dollar mehr als für einen Absolventen im Sekundarbereich II) (Abb. A7·3).

In den meisten Ländern sind die staatlichen Erträge für einen Abschluss im Tertiärbereich wesentlich höher als für einen Abschluss im Sekundarbereich II bzw. postsekundaren, nicht tertiären Bildungsbereich. Grund hierfür sind die durch das bessere Einkommensniveau der Absolventen des Tertiärbereichs veranlassten höheren Steuereinnahmen und Sozialversicherungsbeitragszahlungen. Im Durchschnitt der OECDLänder beläuft sich der staatliche Nettoertrag aus einer Investition in einen Abschluss im Tertiärbereich bei einem Mann auf mehr als Ioo.00o US-Dollar und bei einer Frau auf mehr als 57.000 US-Dollar. Unter Berücksichtigung der direkten Kosten, des entgangenen Einkommens und der öffentlichen Zuschüsse übertrifft der staatliche Nutzen bei einem männlichen Absolventen des Tertiärbereichs die staatlichen Kosten um das Vierfache, bei einer Absolventin um das Doppelte (Tab. A7.4a und A7.4b).

Die unterschiedlichen Erträge sowohl auf privater als auch auf staatlicher Seite werden weitgehend durch die unterschiedlichen Einkommen bestimmt. Wenn die Einkommensunterschiede geringer sind, ist auch der wirtschaftliche Ertrag eines Abschlusses im Tertiärbereich geringer. Dies gilt insbesondere in Dänemark, Neuseeland, Norwegen und Schweden. In den nordischen Ländern werden die Effekte dieser geringen Einkommensdifferenzen im Allgemeinen dadurch aufgewogen, dass die Ausbildung im Tertiärbereich fast kostenlos angeboten wird und großzügige Studienbeihilfen gewährt werden (s. Indikator B5).

Aufgrund der erheblichen Unterschiede bei den Einkommenszuschlägen in den einzelnen OECD-Ländern ergeben sich auch Unterschiede bei den Steuer- und anderen staatlichen Einnahmen in einer Art und Weise, die nicht ganz den allgemeinen Erwartungen entspricht. Wegen des geringen Einkommenszuschlags in den nordischen Ländern erreichen die durchschnittlichen Einkommen von Absolventen des Tertiärbereichs normalerweise nicht den Bereich mit hohen Grenzsteuersätzen. Der Staat profitiert in den Ländern bei den Steuern und Sozialabgaben von Hochschulabsolventen am stärksten, in denen die Einkommensunterschiede groß sind bzw. in denen das durchschnittliche Einkommensniveau einem hohen Einkommensteuersatz unterliegt. In Deutschland, Irland, Italien, den Niederlanden, Österreich, Polen, Slowenien, Ungarn und den Vereinigten Staaten zahlen Absolventen des Tertiärbereichs erheblich mehr Steuern und Sozialabgaben. Der Einkommenszuschlag liegt in jedem dieser Länder über dem OECD-Durchschnitt, und daher sind auch die abgeführten Sozialabgaben höher. 
Abbildung A7.3

Staatliche Kosten und staatlicher Nutzen bei einem Mann, der einen Abschluss im Tertiärbereich erwirbt (2009) Im Vergleich zu den Erträgen eines Abschlusses im Sekundarbereich II bzw. postsekundaren, nicht tertiären Bereich

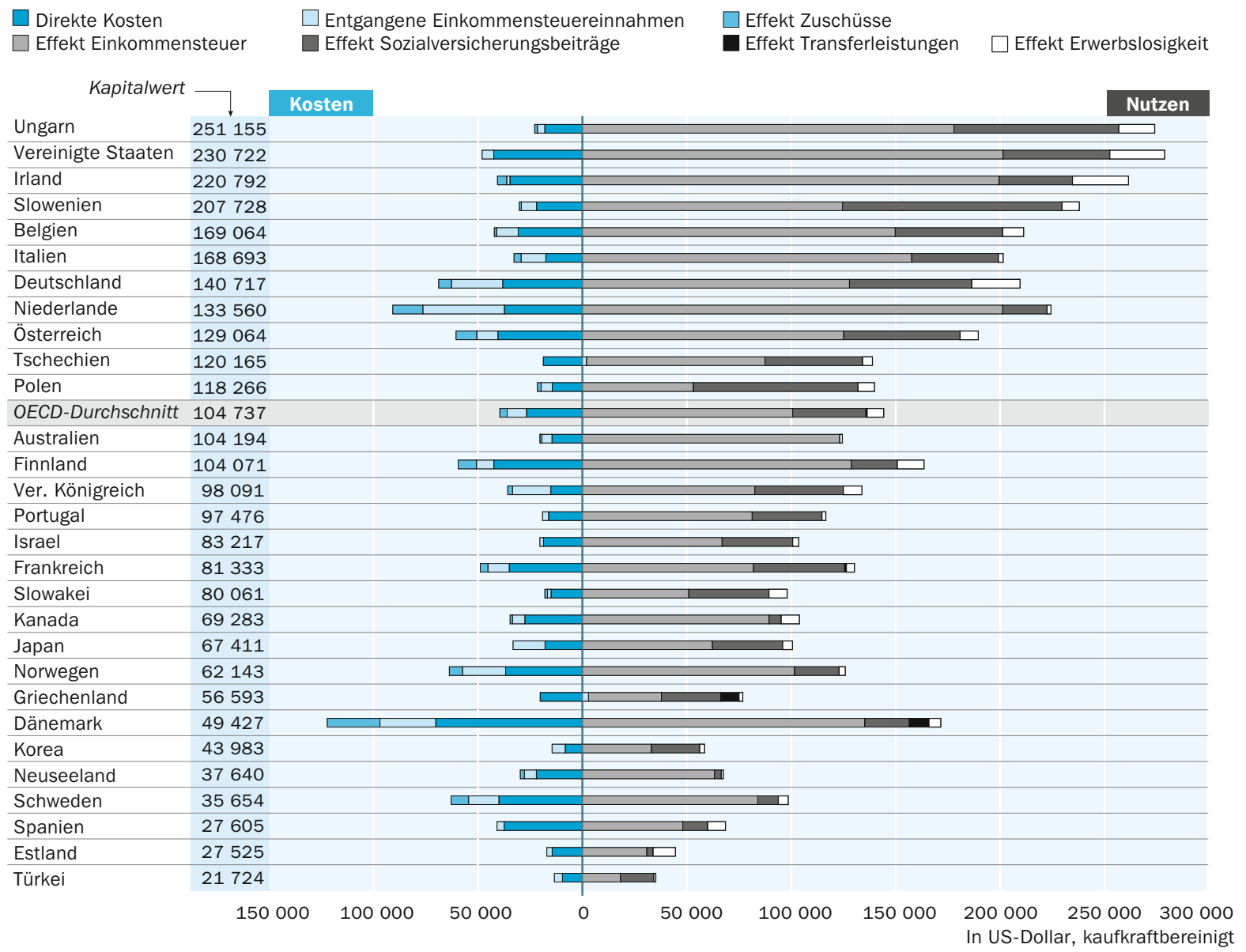

Anmerkung: Referenzjahr für die Türkei ist 2005, für Japan 2007, für Italien, die Niederlande und Polen 2008, für alle anderen Länder 2009. Cashflow-Bestandteile sind mit einem Zinssatz von 3 Prozent abgezinst.

Anordnung der Länder in absteigender Reihenfolge des staatlichen Kapitalwerts.

Quelle: OECD. Tabelle A7.4a. Hinweise s. Anhang 3 unter www.oecd.org/edu/eag.htm. StatLink: http://dx.doi.org/10.1787/888932846671

In einigen Ländern gibt es steuerpolitische Maßnahmen zur effektiven Senkung der tatsächlich abgeführten privaten Einkommensteuern, insbesondere in den oberen Einkommensklassen. Zur Förderung des Eigenheimbesitzes haben viele OECD-Länder Steuererleichterungen für Hypothekenzinsen eingeführt. Derartige Vergünstigungen kommen hauptsächlich den Absolventen des Tertiärbereichs und den Zahlern hoher Grenzsteuersätze zugute. Besonders hohe Steuererleichterungen für ein Eigenheim werden in Dänemark, Finnland, Griechenland, den Niederlanden, Norwegen, Schweden, Tschechien und den Vereinigten Staaten gewährt (s. Andrews et al., 20II).

\section{Die Verteilung der Bildungskosten zwischen dem staatlichen und dem privaten Sektor}

Die direkten Kosten der Bildung werden größtenteils vom staatlichen Sektor getragen. Im Durchschnitt aller OECD-Länder tragen die Bildungsteilnehmer rund 30 Prozent der gesamten direkten privaten und staatlichen Investitionskosten für die Bildung im 
Abbildung A7.4

Staatliche gegenüber privaten Kosten für einen Abschluss im Tertiärbereich bei einer Frau (2009) Im Vergleich zu den Erträgen eines Abschlusses im Sekundarbereich II bzw. postsekundaren, nicht tertiären Bereich

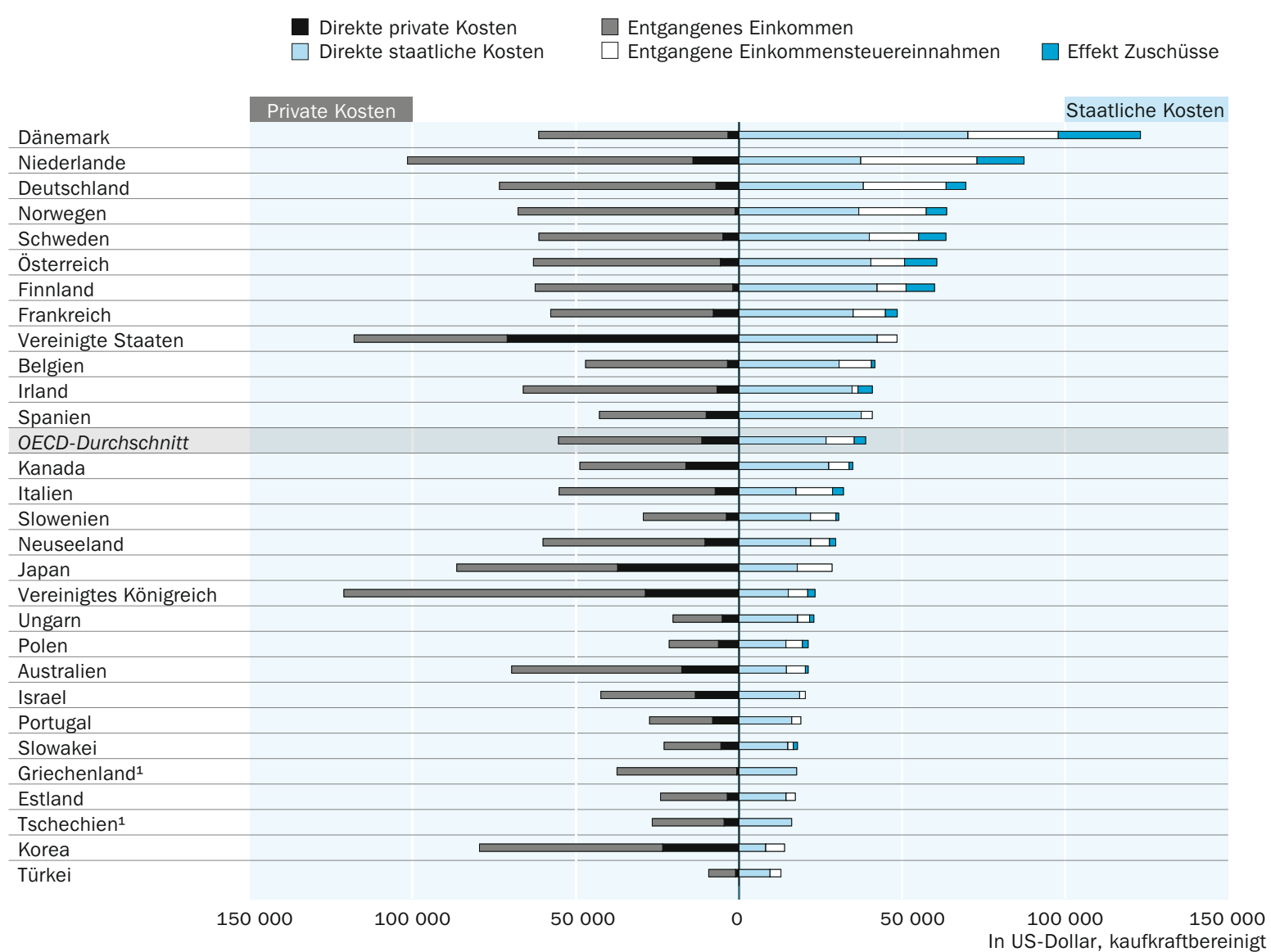

Anmerkung: Referenzjahr für die Türkei ist 2005. Referenzjahr für Japan ist 2007. Referenzjahr für Italien, Niederlande und Polen ist 2008. Referenzjahr für alle anderen Länder ist 2009. Cashflow-Bestandteile sind mit einem Zinssatz von 3 Prozent abgezinst.

1. Bei Tschechien und Griechenland beziehen sich die direkten staatlichen Kosten auf die staatlichen Gesamtkosten.

Anordnung der Länder in absteigender Reihenfolge der staatlichen Gesamtkosten.

Quelle: OECD. Tabellen A7.3b und A7.4b. Hinweise s. Anhang 3 unter www.oecd.org/edu/eag.htm StatLink: http://dx.doi.org/10.1787/888932846690

Tertiärbereich. Nur in wenigen Ländern, insbesondere in Australien, Japan, Korea, dem Vereinigten Königreich und den Vereinigten Staaten, machen die direkten privaten Kosten wie Studiengebühren über die Hälfte der gesamten direkten öffentlichen und privaten Kosten für eine Ausbildung im Tertiärbereich aus. Einige Länder gewähren den Bildungsteilnehmern Studienzuschüsse und Darlehen zur Erleichterung der finanziellen Belastung, die der angestrebte Erwerb eines Abschlusses im Tertiärbereich mit sich bringt. Die Studienzuschüsse werden nach verschiedenen Kriterien gewährt, z. B. herausragenden Leistungen oder der sozioökonomischen Herkunft, um auch junge Menschen aus Familien mit einem niedrigen Einkommen zu einer Fortsetzung ihrer Ausbildung zu ermutigen. Besonders hohe Zuschüsse werden in den nordischen Ländern wie Dänemark (25.200 US-Dollar), Finnland (8.700 US-Dollar) und Schweden (8.300 US-Dollar) gewährt, ferner auch in den Niederlanden (I4.400 US-Dollar) und in Österreich (9.900 US-Dollar). Interessanterweise scheint keine Beziehung zwischen den direkten Kosten und den Studienzuschüssen zu bestehen. Die Länder mit den 


\section{Was bedeuten private und öffentliche Erträge aus Bildung}

Die privaten Erträge aus Bildung sind für den Einzelnen ein wesentlicher Anreiz zur Investition in Bildung über die Schulpflicht hinaus. In diesem Kasten wird der Begriff „Ertrag“ immer im Sinne einer Ertragsrate verwendet. Bei der Ertragsrate wird der Ertrag, also das entsprechende Einkommen, als Prozentsatz der Investition ausgedrückt. Ein hoher privater Ertrag wirkt für den Einzelnen als starke Motivation, in (Weiter-)Bildung über die Schulpflicht hinaus zu investieren. In modernen Gesellschaften ist auch der Staat am Nutzen und den Kosten der Bildung beteiligt. Normalerweise besteuert er einen Teil des privaten Zusatzeinkommens, trägt aber auch einen Teil der Kosten, somit lassen sich staatliche Erträge für weiter gehende Bildungsinvestitionen errechnen. Wie auch bei den privaten Erträgen bestehen diese aus dem Überschuss der durch höhere Bildungsabschlüsse veranlassten staatlichen Einnahmen über die dem Staat durch diese Bildungsteilnahme entstehenden Kosten. Jedoch können die staatlichen Erträge nicht direkt als Orientierung für politische Entscheidungen über Bildungsinvestitionen herangezogen werden, wie dies im privaten Bereich mit den privaten Erträgen geschehen kann. Für die Politik ergeben sich nützliche Einsichten erst durch den Vergleich von staatlichen und privaten Erträgen. Genauer gesagt können anhand dieses Vergleichs staatlicherseits die geeigneten Finanzierungskonzepte für eine Bildungsteilnahme über die Schulpflicht hinaus entwickelt werden.

Die Humankapitaltheorie sieht den Einzelnen, nicht den Staat als denjenigen, der in Bildung investiert. Denn schließlich entscheidet jeder Einzelne für sich persönlich, ob er seine Ausbildung fortsetzen will oder nicht. Diese Entscheidung wird in dem Bewusstsein getroffen, dass die Investition von Zeit in weiterführende Bildung das Entgelt pro Zeiteinheit erhöhen wird. Da aber die Dauer des Erwerbslebens begrenzt ist bzw. das Ruhestandsalter festliegt, verkürzt sich bei längerer Bildungsdauer die zur Teilnahme am Arbeitsmarkt noch zur Verfügung stehende Zeit. Die Humankapitaltheorie besagt, dass der Einzelne - unter der Annahme vollkommener Märkte und rational handelnder Einzelner - ohne staatliches Eingreifen genau die Bildungsdauer auswählen wird, mit der er sein Einkommen während seiner Lebensdauer maximieren kann. Wenn zum Beispiel durch technischen Wandel der private Ertrag für das Humankapital angehoben wird, werden die privaten Akteure - so das Modell - mehr Zeit in Bildung investieren, als sie ansonsten investiert hätten. Durch steigende private Erträge werden die Marktteilnehmer direkt veranlasst, die Nutzung der zur Verfügung stehenden Zeit zu überdenken, um ihr Lebenseinkommen zu maximieren.

Bringt man nun den Staat mit in das Modell ein, so würde er idealerweise die eigenen Entscheidungen der Privatpersonen in dieser hypothetischen Welt nicht beeinflussen. Daraus folgt, dass der Steuersatz für Mehreinkommen aufgrund eines höheren Bildungsstandes (höheres Entgelt) genau dem Satz entsprechen sollte, mit dem der Staat die Bildungskosten subventioniert. Mit anderen Worten, die staatliche Politik sollte neutral sein (Netherlands Bureau of Economic Policy Analysis, 2012). Progressive Besteuerung und Kapitalertragssteuern führen zu komplexeren Effekten, aber der Grundsatz der Neutralität gilt weiterhin (Lans Bovenberg und Jacobs, 2005). 
Daher sind die staatlichen Erträge mit großer Vorsicht zu bewerten. Die Effizienz staatlicher Bemühungen bei der Finanzierung weiterführender Bildung lässt sich durch einen Vergleich der staatlichen mit den privaten Erträgen beurteilen. Übersteigen die staatlichen Erträge die privaten, wird das Mehreinkommen, das sich aus dem höheren Bildungsstand ergibt, stärker besteuert, als die Bildung staatlich subventioniert wird. Dies wird den Einzelnen von Bildungsinvestitionen abhalten und zu einem - sowohl für den Einzelnen als auch für den Staat - suboptimalen Lebensarbeitseinkommen führen. Das Umgekehrte gilt, wenn die staatlichen Erträge unter den privaten liegen. In diesem Fall investiert der Staat zu viel in die Bildung und veranlasst Einzelne dazu, zu viel in Bildung zu investieren, was auch das Niveau des Lebensarbeitseinkommens unter das maximal erzielbare drückt. Die optimale staatliche Politik bedeutet gleich hohe staatliche und private Erträge, was wiederum nur ein anderer Ausdruck des Neutralitätsgrundsatzes ist.

Allerdings gilt dieser Grundsatz nur, wenn auch die beiden anderen Annahmen gelten: dass es einen vollkommenen Markt gibt und dass die Einzelnen rational handeln. Sollten diese beiden Annahmen nicht mehr gelten, kann es für den Staat durchaus Veranlassung geben, vom Neutralitätsgrundsatz abzuweichen.

Zunächst einmal kann Bildung möglicherweise eine Reihe externer Effekte haben. Außer dem Einkommen für den Einzelnen könnte eine Bildungsinvestition auch Vor- bzw. Nachteile für andere mit sich bringen, die der Investierende nicht internalisieren kann und die dann den Markt verzerren. Der Nutzen für die Gesellschaft als Ganzes könnte größer oder geringer sein als der Nutzen für den Einzelnen. $\mathrm{Zu}$ den positiven externen Effekten zählen u. a. die Wissensverbreitung, staatsbürgerliches und gesellschaftliches Wohlergehen und eine geringere Verbrechensrate. Es können sich jedoch auch negative externe Effekte ergeben. In der Literatur gibt es Hinweise darauf, dass der gesellschaftliche Nutzen den privaten Nutzen übersteigt und somit per Saldo die externen Effekte positiv sind (Netherlands Bureau of Economic Policy Analysis, 2012). Mittels staatlicher Beihilfen kann es dem Einzelnen ermöglicht werden, diesen externen Nutzen zu internalisieren.

Zum Zweiten ist eine weitere Bildungsinvestition eine rationale, langfristige Entscheidung, die impliziert, dass die mehr oder weniger bekannten unmittelbar anfallenden Bildungskosten gegen nicht sichere Vorteile in der Zukunft abgewogen werden. In der Literatur finden sich Hinweise darauf, dass der Einzelne dazu neigt, Vorteile in der Zukunft zu niedrig einzuschätzen (s. beispielsweise Laibson, 1997) bzw. hoch risikoscheu zu sein. In derartigen Fällen kann es sein, dass der Einzelne zu wenig in Bildung investiert. Hier können staatliche Subventionen korrigierend auf das Verhalten des Einzelnen wirken. Wenn die externen Effekte insgesamt positiv sind, die Entscheidungen des Einzelnen aber eher zu suboptimalen Bildungsinvestitionen führen, weil sie durch persönliche Einstellungen beeinflusst werden, sind staatliche Subventionen der Bildungsinvestition gefragt, die den Grenzsteuersatz auf Erwerbseinkommen übersteigen. Dies führt zu einer staatlichen Ertragsrate, die unter der privaten liegt. Doch es sei noch einmal betont, die staatliche Ertragsrate kann nicht allein als Anreiz für höhere staatliche Investitionen in Bildung herangezogen werden. 
Was bedeutet das für die praktische Politik? Tatsächlich ist es äußerst schwierig, die staatlichen und die privaten Erträge richtig und vollständig abzuschätzen. Daher sind die in Bildung auf einen Blick veröffentlichten Zahlen mit Vorsicht zu interpretieren. Zeigen sich jedoch deutliche Diskrepanzen zwischen den privaten und staatlichen Erträgen, ist eine weitere Analyse angebracht, um zu prüfen, ob nicht etwa das Steuersystem oder die Subventionsvergabe zu starken Verzerrungen führen. Ferner können die staatlichen und privaten Erträge nur als Hinweise auf die optimale Finanzierungsmethode für Bildungsangebote nach der Schulpflicht gelten, d. h., um festzustellen, wie Kosten und Nutzen zwischen dem Staat und dem Einzelnen aufgeteilt werden könnten. Bildungspolitik umfasst jedoch noch wesentlich mehr.

höheren Studienzuschüssen sind nicht diejenigen mit den höchsten direkten privaten Kosten. Umgekehrt gewährt unter den fünf Ländern mit den höchsten direkten Kosten nur das Vereinigte Königreich Studienbeihilfen in nennenswerter Höhe (2.200 USDollar) (Abb. A7.4).

\section{Definitionen}

Direkte Kosten stehen für die Ausgaben, die jährlich für Bildungsteilnehmer mit Mitteln aus allen Quellen (öffentliche, private Haushalte und andere private Einheiten) getätigt werden. Sie stehen im Verhältnis zur Länge der Ausbildungsdauer.

Die Höhe des entgangenen Einkommens während der Dauer der Ausbildung/des Studiums hängt hauptsächlich vom Einkommensniveau ab, das jemand, der nicht in Ausbildung ist, zu erwarten hätte, sowie von der Ausbildungsdauer. Das entgangene Einkommen eines Bildungsteilnehmers ist der Nettobetrag nach Steuern, Sozialversicherungsbeiträgen und sozialen Transferleistungen.

Entgangene Einkommensteuern umfassen die Steuern, Sozialversicherungsbeiträge und sozialen Transferleistungen, die die Staatskasse nicht vereinnahmt.

Die Einkommensvorteile (brutto) sind eine Schätzung des Erwerbseinkommens, das der Einzelne nach dem Ausbildungsabschluss auf dem Arbeitsmarkt erzielen kann.

Der Einkommensteuereffekt ist der Betrag, der dem staatlichen Sektor schätzungsweise durch die Steuern zufließt. In der Regel ist dies die Hauptquelle der staatlichen Erträge aus den getätigten Bildungsinvestitionen. Aufgrund der Steuerprogression ist der Effekt bei den Absolventen des Tertiärbereichs ausgeprägter.

Die Ertragsrate gibt an, bei welchem realen Zinssatz die Investition die Gewinnschwelle erreicht.

Der Kapitalwert steht für den Unterschied zwischen dem abgezinsten Nutzen und den abgezinsten Investitionskosten und bildet den Mehrwert ab, den die Bildung über den realen Zinssatz von 3 Prozent hinaus erwirtschaftet, der für derartige Kapitalflüsse angesetzt wird. 
Der Effekt der Sozialversicherungsbeiträge bei den vorliegenden Berechnungen umfasst nur die vom Arbeitnehmer geleisteten Beiträge, die Arbeitgeberbeiträge bleiben unberücksichtigt, denn diese sind eine weitere Quelle staatlicher Erträge. In den meisten OECDLändern zahlen die Arbeitnehmer pauschale Sozialversicherungsbeiträge, daher sind die Unterschiede zwischen den Bildungsbereichen geringer und proportional zum Einkommensniveau.

Der Effekt der Transferleistungen betrifft die sozialen Transferleistungen für ein bestimmtes Einkommensniveau.

Der Effekt der Erwerbslosigkeit wird anhand des Einkommensniveaus für die verschiedenen Bildungsbereiche im Laufe des Erwerbslebens in geldwerte Vorteile umgerechnet.

\section{Angewandte Methodik}

Dieser Indikator baut auf Informationen auf, die in anderen Kapiteln von Bildung auf einen Blick 2012 dargestellt wurden, mit einer Ausnahme: Zur Berechnung der staatlichen Erträge und der Untersuchung des Nettovorteils für den Einzelnen wurden Daten aus der OECD-Datenbank „Taxing Wages“ herangezogen. Als Einkommensdaten werden die Angaben aus den Erhebungen des Netzwerks zu den Arbeitsmarktergebnissen sowie den wirtschaftlichen und sozialen Auswirkungen des Lernens (LSO) verwendet (in Bildung auf einen Blick 2012 sind diese als relative Einkommen in Indikator A8 dargestellt). Die Angaben zu den direkten Kosten der Bildung wurden den Indikatoren BI und B 3 entnommen. Die Daten zur Beschäftigungswahrscheinlichkeit (Erwerbslosenquote für die verschiedenen Bildungsbereiche und Altersgruppen) sind Indikator A7 entnommen. Die Mindestlöhne werden als Näherungswert für das potenzielle Entgelt eines Bildungsteilnehmers verwendet, das er verdienen könnte, wenn er sich nicht in Ausbildung befände, um das entgangene Einkommen eines Absolventen des Sekundarbereichs II bzw. postsekundaren, nicht tertiären Bereichs zu berechnen.

In diesem Indikator werden die Erträge aus Bildung mittels des Kapitalwerts der Investition (net present value - NPV) berechnet. Hierbei werden Kosten und Nutzen während des gesamten Lebens auf den Zeitpunkt zurückgerechnet, an dem mit der Investition begonnen wurde. Dies geschieht, indem alle Mittelflüsse mit einem bestimmten Zinssatz (dem Abzinsungssatz) auf den Investitionsbeginn abgezinst werden. Die Festlegung des Zinssatzes ist recht schwierig, da er nicht nur den gesamten Zeithorizont der Investitionsdauer erfassen sollte, sondern auch die Kreditkosten bzw. das empfundene Investitionsrisiko. Zur Vereinfachung und leichteren Interpretation der Ergebnisse wird der gleiche Abzinsungssatz für alle OECD-Länder angewendet.

Um einen angemessenen Abzinsungssatz zu bestimmen, wurden langfristige Staatsanleihen als Bezugspunkt gewählt. 2009 betrug der durchschnittliche langfristige Zinssatz in den OECD-Ländern ca. 4,4 Prozent (OECD-Finanzdatenbank [OECD, 2013]). Unter der Annahme, dass die nationalen Zentralbanken die erwartete Inflation bei maximal 2 Prozent pro Jahr halten konnten, bedeutet dies einen Realzinssatz zwischen 2 Prozent und 3 Prozent. Der hier verwendete reale Abzinsungssatz von 3 Prozent spiegelt die Tatsache wider, dass die Berechnungen zu konstanten Preisen durchge- 
führt wurden. Die Veränderung des Abzinsungssatzes hat wesentliche Auswirkungen auf den Kapitalwert von Bildungsinvestitionen.

Die Abzinsung von Kosten und Nutzen mittels dieses Zinssatzes auf den Gegenwartsoder Barwert macht den wirtschaftlichen Nutzen der Gesamtinvestition und die Höhe seiner einzelnen Bestandteile über die Zeit und alle Länder vergleichbar. Durch Verwendung der gleichen Betrachtungsgröße können auch einzelne Bestandteile in den einzelnen Bildungsbereichen oder zwischen privater und staatlicher Seite hinzugezählt oder abgezogen werden, um die Wechselwirkungen einzelner Faktoren zu untersuchen.

Die Berechnungen nach der Kapitalwertmethode basieren auf dem gleichen Prinzip wie die Berechnungen der Ertragsrate nach der internen Zinsfußmethode (internal rate of return - IRR), der wesentliche Unterschied zwischen beiden Methoden liegt in der Festlegung des Zinssatzes. Bei den Berechnungen im Rahmen der internen Zinsfußmethode wird der Zinssatz so weit angehoben, bis sich der wirtschaftliche Nutzen und die Investitionskosten die Waage halten. Dies ergibt den Zinssatz, bei dem die Investition die Gewinnschwelle erreicht.

Bei der Berechnung des Kapitalwerts beinhaltet der private Investitionsaufwand das entgangene Nettoeinkommen, bereinigt um die Beschäftigungswahrscheinlichkeit (Erwerbslosenquote) und den direkten privaten Aufwand für die Bildungsteilnahme. Beide Investitionsflüsse berücksichtigen die Dauer der Bildungsteilnahme. Auf der Nutzenseite gehen die altersabhängigen Einkommensprofile in die Berechnung der Einkommensunterschiede zwischen den verschiedenen Absolventengruppen ein. Aus diesen Unterschieden bei den Bruttoeinkommen ergeben sich nach Bereinigung um die Unterschiede bei den Einkommensteuern, Sozialabgaben und Transferleistungen (u. a. Wohngeld und einkommensabhängige Sozialleistungen) die Nettoeinkommensunterschiede. Ferner wird der Cashflow um die Beschäftigungswahrscheinlichkeit (Erwerbslosenquote) bereinigt. Die Berechnungen werden getrennt für Männer und Frauen durchgeführt, um den geschlechtsspezifischen Einkommensunterschieden und Erwerbslosenquoten Rechnung zu tragen.

Zur Berechnung des Kapitalwerts einer staatlichen Investition gehen in den staatlichen Aufwand die entgangenen staatlichen Einnahmen während der Ausbildung (Einkommensteuern und Sozialabgaben) ein sowie die staatlichen Ausgaben (unter Berücksichtigung der Ausbildungsdauer). In einigen Ländern sind die Steuerausfälle gering, da junge Menschen weniger verdienen. Die Kosten der Bildung bestehen für den staatlichen Sektor aus den direkten Bildungsausgaben (wie dem direkten Aufwand für Gehälter der Lehrkräfte, den Bau von Schulgebäuden, dem Kauf von Schulbüchern usw.) sowie aus den öffentlich-privaten Transferleistungen (wie Stipendien und Studienbeihilfen an private Haushalte und andere Zuschüsse für Ausbildungsangebote am Arbeitsplatz an andere private Einheiten). Auf der Nutzenseite stehen für den öffentlichen Sektor die Mehreinnahmen von Steuern und Sozialabgaben aus höheren Einkommen sowie Einsparungen bei den Transferzahlungen, d. h. bei Wohngeld und Sozialleistungen, die der Staat oberhalb eines bestimmten Einkommensniveaus nicht mehr aufbringen muss. 
Für die hier vorgenommenen Ermittlungen der finanziellen Erträge sind einige generelle konzeptionelle Einschränkungen zu berücksichtigen, z. B.:

- Für die Berechnung des Gesamteinkommens während des Erwerbslebens wird beispielsweise für alle Länder einheitlich das Alter von 64 Jahren als Obergrenze angesetzt. Das Ruhestandsalter variiert jedoch stark von Land zu Land. Einige Jahre aktiver Arbeitsmarktteilnahme mehr oder weniger können für den Einzelnen und den Staat einen großen Unterschied bei dem Ertrag aus seiner Bildung bedeuten. Damit sind die Ertragsraten in den Ländern, in denen das Ruhestandsalter deutlich von der Altersgrenze 64 Jahre abweicht, mit großer Wahrscheinlichkeit entweder zu hoch oder zu niedrig angesetzt.

- Da das Einkommen üblicherweise mit dem Bildungsstand steigt, konsumieren Bessergebildete normalerweise auch mehr Waren und Dienstleistungen und zahlen so zusätzlich Mehrwertsteuer auf ihren Konsum. Daher sind in diesem Indikator die staatlichen Ertragsraten wohl zu niedrig angesetzt.

- Besserverdienende zahlen tendenziell auch mehr für ihre Altersvorsorge ein und verfügen somit auch nach dem Ausscheiden aus dem Erwerbsleben noch über weitere Einkommensvorteile, die in den Berechnungen in diesem Indikator unberücksichtigt bleiben. Bessergebildete haben außerdem tendenziell eine höhere Lebenserwartung, was zusätzliche staatliche Kosten mit sich bringt, die hier ebenfalls unberücksichtigt bleiben.

Viele Staaten gewähren Bildungsteilnehmern Darlehen zu geringen Zinssätzen. Darlehen können einen starken Anreiz für den Einzelnen zur Fortsetzung der Bildungsteilnahme darstellen, deren Kosten hierdurch gesenkt werden. Allerdings müssen Darlehen später zurückgezahlt werden und vermindern daher auch den finanziellen Nutzen der Bildungsteilnahme. Solche Zuschüsse können den Ertrag aus Bildung für den Einzelnen häufig erheblich beeinflussen, sie werden jedoch in diesem Indikator nicht berücksichtigt.

Bei den direkten Kosten handelt es sich vorrangig um die Schul-/Studiengebühren, aber auch um die Kosten für Lernmaterialien oder die Lebenshaltungskosten, die durch den Wohnungswechsel an einen Ort veranlasst werden, an dem ein bestimmtes Bildungsangebot wahrgenommen wird. Sie werden hier nicht berücksichtigt.

Die angegebenen Daten stellen rein rechnerische Werte dar. Zweifellos unterscheiden sich diese Ergebnisse von ökonometrischen Schätzungen, die eher die gleichen Daten auf der Mikroebene (z. B. Daten aus Haushalts- oder Einzelerhebungen) anwenden würden und nicht das lebenslange Einkommen errechnet auf Basis von Durchschnittseinkommen.

Bei der Interpretation der entgangenen Einkommen bei einem Abschluss im Sekundarbereich II bzw. postsekundaren, nicht tertiären Bereich ist Vorsicht angebracht, da die Mindestlöhne als Näherungswert verwendet werden.

Vor diesem Hintergrund sollten die Zahlen zu den Bildungserträgen in den einzelnen Ländern mit Vorsicht interpretiert werden.

Der hier gewählte Ansatz schätzt das künftige Einkommen von Personen mit unterschiedlichem Bildungsstand auf Grundlage der Erkenntnisse über die aktuellen Unterschiede bei den durchschnittlichen Bruttoeinkommen nach Bildungsstand und Alter. Die Beziehungen zwischen den unterschiedlichen Abschlüssen und Einkommen müssen in der Zukunft jedoch nicht unbedingt die gleichen sein wie in der Gegenwart, 
denn der technologische, wirtschaftliche und soziale Wandel können das mit einem bestimmten Bildungsstand assoziierte Einkommensniveau verändern.

In den Unterschieden bei den Erträgen zwischen den einzelnen Ländern kommen zum Teil auch unterschiedliche institutionelle und vom Markt unabhängige, einkommenswirksame Bedingungen zum Tragen, wie institutionelle Bedingungen, die die Flexibilität der relativen Einkommen einschränken.

Die Beurteilung des Nutzens berücksichtigt auch den Beitrag von Bildung zu einer höheren Beschäftigungswahrscheinlichkeit, wenn eine Beschäftigung angestrebt wird. Das macht die Ergebnisse jedoch auch abhängig von der konjunkturellen Phase, in der die Daten erhoben wurden. Da Besserausgebildete normalerweise auch in schwierigeren ökonomischen Zeiten eher im Arbeitsmarkt verbleiben, steigt im Allgemeinen der Wert des erworbenen Bildungsstandes in Zeiten schwachen wirtschaftlichen Wachstums.

Ferner erfordern die Berechnungen eine Reihe restriktiver Annahmen zur Wahrung der internationalen Vergleichbarkeit. Zur Berechnung der Bildungsinvestition wurde das entgangene Einkommen auf der Höhe des gesetzlichen Mindestlohnes bzw. einer Entsprechung hierfür für die Länder, in denen die Einkommensdaten auch Teilzeitarbeitsverhältnisse enthalten, standardisiert. Wenn kein nationaler Mindestlohn verfügbar war, wurde eine Einkommensstufe aus den Tarifverträgen gewählt. Durch diese Annahme wird versucht, die angegebenen sehr niedrigen Einkommen für I5bis 24-Jährige auszugleichen, die in früheren Ausgaben von Bildung auf einen Blick zu außergewöhnlich hohen Schätzwerten führten. Bei Japan, den Niederlanden, Portugal, Tschechien, Ungarn und dem Vereinigten Königreich werden die tatsächlichen Einkommen zur Berechnung der entgangenen Einkommen verwendet, da dort in den Erhebungen zu den Einkommensdaten keine Teilzeitbeschäftigungen enthalten sind.

Kosten und Nutzen eines Abschlusses im Sekundarbereich II oder im postsekundaren, nicht tertiären Bereich lassen sich für Belgien und die Niederlande nicht berechnen, da der Besuch des Sekundarbereiches II bzw. postsekundaren, nicht tertiären Bereichs in diesen Ländern Pflicht ist. Im Falle einer verpflichtenden Bildungsteilnahme kann die Methodik dieses Indikators, die den Investitionsansatz verfolgt, nicht konsequent angewendet werden. Der Investitionsansatz unterstellt, dass eine Investitionsentscheidung über den Erwerb eines Abschlusses auf einem bestimmten Niveau getroffen wird, um in den Genuss des damit verbundenen Nutzens zu gelangen. In den Ländern, in denen die Teilnahme an einem bestimmten Bildungsbereich Pflicht ist, steht eine solche Entscheidung nicht an, und daher greift diese Methodik in diesen Fällen nicht.

Weitere Einzelheiten zur angewandten Methodik s. OECD, 20II sowie Anhang 3 unter www.oecd.org/edu/eag.htm.

Die statistischen Daten für Israel wurden von den zuständigen israelischen Stellen bereitgestellt, die für sie verantwortlich zeichnen. Die Verwendung dieser Daten durch die OECD erfolgt unbeschadet des völkerrechtlichen Status der Golanhöhen, von OstJerusalem und der israelischen Siedlungen im Westjordanland. 


\section{Weiterführende Informationen}

Andrews, D., A. Caldera Sánches and A. Johansson (20II), „Housing Markets and Structural Policies in OECD Countries“, OECD Economics Department Working Papers, No. 836, OECD Publishing, http://dx.doi.org/10.1787/5kgk8t2kguf3-en.

Laibson, D. (I997), „Golden Eggs and Hyperbolic Discounting“, Quarterly Journal of Economics, May, pp. 443-477.

Lans Bovenberg, A. and B. Jacobs (2005), „Redistribution and Education Subsidies are Siamese Twins“, Journal of Public Economics, Vol. 89 (II-I2), pp. 2005-2035.

Netherlands Bureau of Economic Policy Analysis (2012), „Increases of Private Contribution to Higher Education“, The Hague.

OECD (20II), „A User's Guide to Indicator A9: Incentives to Invest in Education“ (im Internet unter www.oecd.org/eduleag2011).

OECD (2013), „Exchange Rates (USD monthly averages)“, Monthly Monetary and Financial Statistics (MEI) (Datenbank), http://stats.oecd.org/Index.aspx?QueryId=16g (Zugriff am I3. Mai 2013).

\section{Tabellen Indikator A7}

Tabelle A7.Ia: Private Kosten und privater Nutzen für einen Mann, der einen Abschluss im Sekundarbereich II bzw. postsekundaren, nicht tertiären Bereich erwirbt (2009)

StatLink: http://dx.doi.org/10.1787/888932849103

Tabelle A7.Ib: Private Kosten und privater Nutzen für eine Frau, die einen Abschluss im Sekundarbereich II bzw. postsekundaren, nicht tertiären Bereich erwirbt (2009)

StatLink: http://dx.doi.org/10.1787/888932849122

Tabelle A7.2a: Staatliche Kosten und staatlicher Nutzen bei einem Mann, der einen Abschluss im Sekundarbereich II bzw. postsekundaren, nicht tertiären Bereich erwirbt (2009)

StatLink: http:/|dx.doi.org/10.1787/888932849141

Tabelle A7.2b: Staatliche Kosten und staatlicher Nutzen bei einer Frau, die einen Abschluss im Sekundarbereich II bzw. postsekundaren, nicht tertiären Bereich erwirbt (2009) StatLink: http://dx.doi.org/10.1787/888932849160

Tabelle A7.3a: Private Kosten und privater Nutzen für einen Mann, der einen Abschluss im Tertiärbereich erwirbt (2009) StatLink: http://dx.doi.org/10.1787/888932849179 
Tabelle A7.3b: Private Kosten und privater Nutzen für eine Frau, die einen Abschluss im Tertiärbereich erwirbt (2009)

StatLink: http:/|dx.doi.org/10.1787/888932849198

Tabelle A7.4a: Staatliche Kosten und staatlicher Nutzen bei einem Mann, der einen Abschluss im Tertiärbereich erwirbt (2009)

StatLink: http:/|dx.doi.org/10.1787/888932849217

Tabelle A7.4b: Staatliche Kosten und staatlicher Nutzen bei einer Frau, die einen Abschluss im Tertiärbereich erwirbt (2009)

StatLink: http:||dx.doi.org/10.1787/888932849236 
Private Kosten und privater Nutzen für einen Mann, der einen Abschluss im Sekundarbereich II bzw. postsekundaren, nicht tertiären Bereich erwirbt (2009)

Im Vergleich zu einem Mann, der einen Abschluss im Sekundarbereich I erwirbt (in US-Dollar, kaufkraftbereinigt mittels KKP für das BIP)

\begin{tabular}{|c|c|c|c|c|c|c|c|c|c|c|c|c|}
\hline & Jahr & $\begin{array}{l}\text { Direkte } \\
\text { Kosten }\end{array}$ & $\begin{array}{l}\text { Entgan- } \\
\text { genes } \\
\text { Einkom- } \\
\text { men }\end{array}$ & $\begin{array}{l}\text { Gesamt- } \\
\text { kosten }\end{array}$ & $\begin{array}{c}\text { Einkom- } \\
\text { mens- } \\
\text { vorteile } \\
\text { (brutto) }\end{array}$ & $\begin{array}{c}\text { Effekt } \\
\text { Einkom- } \\
\text { men- } \\
\text { steuer }\end{array}$ & \begin{tabular}{|c|} 
Effekt So- \\
zialversi- \\
cherungs- \\
beiträge
\end{tabular} & $\begin{array}{c}\text { Effekt } \\
\text { Transfer- } \\
\text { leistun- } \\
\text { gen }\end{array}$ & $\begin{array}{l}\text { Effekt } \\
\text { Erwerbs- } \\
\text { losigkeit }\end{array}$ & $\begin{array}{l}\text { Gesamt- } \\
\text { nutzen }\end{array}$ & $\begin{array}{l}\text { Kapital- } \\
\text { wert }\end{array}$ & $\begin{array}{c}\text { Ertrags- } \\
\text { rate }\end{array}$ \\
\hline & & (1) & (2) & (3) & (4) & (5) & (6) & (7) & (8) & (9) & (10) & (11) \\
\hline \multicolumn{13}{|l|}{ OECD-Länder } \\
\hline Australien & 2009 & -3019 & -27156 & -30175 & 176400 & -64407 & 0 & -8303 & 49011 & 152701 & 122526 & $19,9 \%$ \\
\hline Österreich & 2009 & -1890 & -44642 & -46532 & 296619 & -73664 & -64903 & -8442 & 53792 & 203402 & 156870 & $13,1 \%$ \\
\hline Belgien $^{1}$ & & $\mathrm{~m}$ & $\mathrm{~m}$ & m & $\mathrm{m}$ & $\mathrm{m}$ & $\mathrm{m}$ & $\mathrm{m}$ & $\mathrm{m}$ & m & m & $\mathrm{m}$ \\
\hline Kanada & 2009 & -3176 & -26160 & -29336 & 161993 & -51689 & -12759 & -1050 & 37895 & 134391 & 105055 & $13,9 \%$ \\
\hline Chile & & $\mathrm{m}$ & $\mathrm{m}$ & m & $\mathrm{m}$ & $\mathrm{m}$ & $\mathrm{m}$ & $\mathrm{m}$ & $\mathrm{m}$ & m & m & $\mathrm{m}$ \\
\hline Tschechien & 2009 & -2116 & -16417 & -18533 & 111711 & -33748 & -22963 & 0 & 97226 & 152226 & 133693 & $23,8 \%$ \\
\hline Dänemark & 2009 & -767 & -38878 & -39645 & 196594 & -75388 & -18916 & -10020 & 28105 & 120374 & 80729 & $11,8 \%$ \\
\hline Estland & 2009 & -252 & -8833 & -9085 & 32324 & -12566 & -1362 & 0 & 35810 & 54206 & 45121 & $16,9 \%$ \\
\hline Finnland & 2009 & -178 & -30022 & -30201 & 75381 & -28532 & -6632 & -7202 & 28082 & 61097 & 30897 & $7,8 \%$ \\
\hline Frankreich & 2009 & -2632 & -26088 & -28720 & 112593 & -23972 & -21496 & -13971 & 44735 & 97888 & 69168 & $10,9 \%$ \\
\hline Deutschland & 2009 & -3973 & -36807 & -40779 & 108511 & -42779 & -39984 & -14061 & 85286 & 96973 & 56193 & $8,2 \%$ \\
\hline Griechenland & 2009 & -1780 & -30044 & -31824 & 93624 & -11870 & -15658 & -23320 & 3845 & 46622 & 14798 & $4,1 \%$ \\
\hline Ungarn & 2009 & -823 & -11014 & -11837 & 80092 & -31994 & -22087 & 0 & 49789 & 75800 & 63962 & $19,4 \%$ \\
\hline Island & & $\mathrm{m}$ & $\mathrm{m}$ & m & $\mathrm{m}$ & $\mathrm{m}$ & $\mathrm{m}$ & $\mathrm{m}$ & $\mathrm{m}$ & m & $\mathbf{m}$ & $\mathrm{m}$ \\
\hline Irland & 2009 & -688 & -24715 & -25403 & 184104 & -67498 & -23665 & 0 & 74829 & 167770 & 142366 & $20,4 \%$ \\
\hline Israel & 2009 & -1120 & -27472 & -28592 & 114461 & -17425 & -13778 & 0 & 18488 & 101746 & 73154 & $10,1 \%$ \\
\hline Italien & 2008 & -986 & -43886 & -44872 & 177073 & -63514 & -18903 & 0 & 22519 & 117174 & 72302 & $8,1 \%$ \\
\hline$J^{\prime a p a n}{ }^{2}$ & & $\mathrm{~m}$ & $\mathrm{~m}$ & m & $\mathrm{m}$ & $\mathrm{m}$ & $\mathrm{m}$ & $\mathrm{m}$ & $\mathrm{m}$ & m & $\mathbf{m}$ & $\mathrm{m}$ \\
\hline Korea & 2009 & -7620 & -28267 & -35888 & 329758 & -27699 & -21179 & 0 & 7215 & 288094 & 252207 & $12,6 \%$ \\
\hline Luxemburg & & $\mathrm{m}$ & $\mathrm{m}$ & $\mathbf{m}$ & $\mathrm{m}$ & $\mathrm{m}$ & $\mathrm{m}$ & $\mathrm{m}$ & $\mathrm{m}$ & m & $\mathbf{m}$ & $\mathrm{m}$ \\
\hline Mexiko & & $\mathrm{m}$ & $\mathrm{m}$ & m & $\mathrm{m}$ & $\mathrm{m}$ & $\mathrm{m}$ & $\mathrm{m}$ & $\mathrm{m}$ & m & $\mathbf{m}$ & $\mathrm{m}$ \\
\hline Niederlande $^{1}$ & & $\mathrm{~m}$ & $\mathrm{~m}$ & $\mathbf{m}$ & $\mathrm{m}$ & $\mathrm{m}$ & $\mathrm{m}$ & $\mathrm{m}$ & $\mathrm{m}$ & m & $\mathbf{m}$ & $\mathrm{m}$ \\
\hline Neuseeland & 2009 & -3128 & -34334 & -37462 & 110659 & -38760 & -2339 & -711 & 26671 & 95519 & 58058 & $8,1 \%$ \\
\hline Norwegen & 2009 & -2859 & -50874 & -53734 & 260393 & -83124 & -24042 & -4703 & 48669 & 197192 & 143459 & $13,2 \%$ \\
\hline Polen & 2008 & -916 & -16602 & -17518 & 53311 & -6965 & -16753 & 0 & 24689 & 54282 & 36764 & $10,3 \%$ \\
\hline Portugal & 2009 & 0 & -16727 & -16727 & 146280 & -28260 & -17439 & 0 & 12676 & 113256 & 96530 & $12,2 \%$ \\
\hline Slowakei & 2009 & -2358 & -9468 & -11826 & 118139 & -26127 & -31086 & 0 & 114287 & 175214 & 163387 & $34,6 \%$ \\
\hline Slowenien & 2009 & -1803 & -19322 & -21125 & 137605 & -25432 & -35986 & 0 & 25875 & 102061 & 80936 & $15,9 \%$ \\
\hline Spanien & 2009 & -1464 & -10001 & -11465 & 109692 & -28649 & -9921 & 0 & 46855 & 117977 & 106512 & $21,2 \%$ \\
\hline Schweden & 2009 & -21 & -25769 & -25790 & 175330 & -57342 & -15777 & -22368 & 50269 & 130112 & 104322 & $16,3 \%$ \\
\hline Schweiz & & $\mathrm{m}$ & $\mathrm{m}$ & m & $\mathrm{m}$ & $\mathrm{m}$ & $\mathrm{m}$ & $\mathrm{m}$ & $\mathrm{m}$ & m & m & $\mathrm{m}$ \\
\hline Türkei & 2005 & -336 & -11218 & -11554 & 63318 & -10584 & -10115 & 0 & 4017 & 46637 & 35082 & $9,5 \%$ \\
\hline Ver. Königreich & 2009 & -4880 & -31944 & -36824 & 222261 & -52477 & -29089 & -13494 & 58353 & 185553 & 148730 & $13,9 \%$ \\
\hline Vereinigte Staaten & 2009 & -2930 & -25106 & -28036 & 304861 & -71514 & -26707 & -8675 & 44454 & 242418 & 214382 & $20,6 \%$ \\
\hline \multicolumn{2}{|l|}{ OECD-Durchschnitt } & -1989 & -25837 & -27826 & 152042 & -40615 & -20136 & -5243 & 42055 & 128103 & 100277 & $14,5 \%$ \\
\hline EU21-Durchschnitt & & -1529 & -24510 & -26039 & 135069 & -38376 & -22923 & -6271 & 47612 & 115110 & 89071 & $14,9 \%$ \\
\hline
\end{tabular}

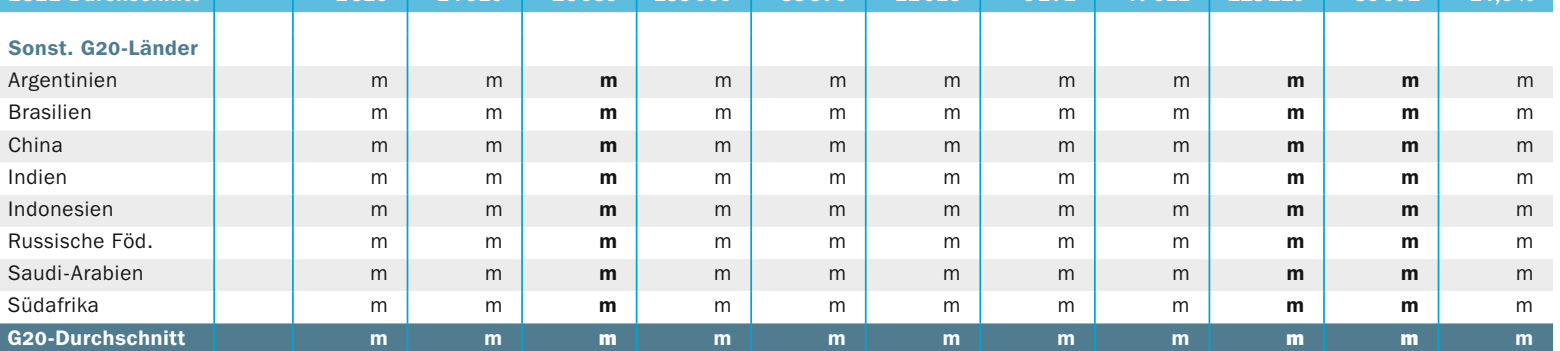

Anmerkung: Die Zahlen basieren auf dem Unterschied zwischen Männern, die einen Abschluss im Sekundarbereich II/postsekundaren, nicht tertiären Bereich erworben haben, und Männern, die keinen derartigen Abschluss erworben haben.

1. Für Belgien und die Niederlande keine Datenangabe in der Tabelle, da der Sekundarbereich Il dort Pflicht ist. 2. Für Japan keine Datenangabe in der Tabelle, da keine nach Abschluss im Sekundarbereich I und Sekundarbereich II aufgegliederten Daten vorlagen.

Quelle: OECD. Bildung auf einen Blick 2012. Hinweise s. Anhang 3 unter www.oecd.org/edu/eag.htm. StatLink: http://dx.doi.org/10.1787/888932849103 Erläuterung der Kennzeichnung fehlender Daten s. Hinweise für den Leser. 
Tabelle A7.1b

Private Kosten und privater Nutzen für eine Frau, die einen Abschluss im Sekundarbereich II bzw. postsekundaren, nicht tertiären Bereich erwirbt (2009)

Im Vergleich zu einer Frau, die einen Abschluss im Sekundarbereich I erwirbt (in US-Dollar, kaufkraftbereinigt mittels KKP für das BIP)

\begin{tabular}{|c|c|c|c|c|c|c|c|c|c|c|c|c|}
\hline & Jahr & $\begin{array}{l}\text { Direkte } \\
\text { Kosten }\end{array}$ & $\begin{array}{c}\text { Entgan- } \\
\text { genes } \\
\text { Einkom- } \\
\text { men }\end{array}$ & $\begin{array}{l}\text { Gesamt- } \\
\text { kosten }\end{array}$ & $\begin{array}{c}\text { Einkom- } \\
\text { mens- } \\
\text { vorteile } \\
\text { (brutto) }\end{array}$ & $\begin{array}{l}\text { Effekt } \\
\text { Einkom- } \\
\text { men- } \\
\text { steuer }\end{array}$ & \begin{tabular}{|c|} 
Effekt So- \\
zialversi- \\
cherungs- \\
beiträge
\end{tabular} & \begin{tabular}{|c|} 
Effekt \\
Transfer- \\
leistun- \\
gen
\end{tabular} & $\begin{array}{c}\text { Effekt } \\
\text { Erwerbs- } \\
\text { losigkeit }\end{array}$ & $\begin{array}{l}\text { Gesamt- } \\
\text { nutzen }\end{array}$ & $\begin{array}{c}\text { Kapital- } \\
\text { wert }\end{array}$ & $\begin{array}{l}\text { Ertrags- } \\
\text { rate }\end{array}$ \\
\hline & & (1) & (2) & (3) & (4) & (5) & (6) & (7) & (8) & (9) & (10) & (11) \\
\hline \multicolumn{13}{|l|}{ OECD-Länder } \\
\hline Australien & 2009 & -3019 & -28198 & -31217 & 122044 & -28457 & 0 & -22467 & 20190 & 91311 & 60094 & $12,7 \%$ \\
\hline Österreich & 2009 & -1890 & -43950 & -45840 & 208105 & -24496 & -47697 & -27606 & 30761 & 139066 & 93226 & $10,6 \%$ \\
\hline Belgien $^{1}$ & & $\mathrm{~m}$ & $\mathrm{~m}$ & m & $\mathrm{m}$ & $\mathrm{m}$ & $\mathrm{m}$ & $\mathrm{m}$ & $\mathrm{m}$ & m & m & $\mathrm{m}$ \\
\hline Kanada & 2009 & -3176 & -28317 & -31493 & 84708 & -21088 & -9042 & -2803 & 27362 & 79136 & 47643 & $7,4 \%$ \\
\hline Chile & & $\mathrm{m}$ & $\mathrm{m}$ & $\mathbf{m}$ & $\mathrm{m}$ & $\mathrm{m}$ & $\mathrm{m}$ & $\mathrm{m}$ & $\mathrm{m}$ & m & m & $\mathrm{m}$ \\
\hline Tschechien & 2009 & -2116 & -16853 & -18969 & 99967 & -27339 & -19280 & -2144 & 76183 & 127387 & 108418 & $20,7 \%$ \\
\hline Dänemark & 2009 & -767 & -39659 & -40426 & 146775 & -55677 & -14804 & 0 & 24014 & 100308 & 59882 & $9,9 \%$ \\
\hline Estland & 2009 & -252 & -9051 & -9303 & 33745 & -11179 & -1290 & 0 & 31166 & 52442 & 43139 & $25,9 \%$ \\
\hline Finnland & 2009 & -178 & -31990 & -32168 & 55774 & -16608 & -5546 & -16226 & 30783 & 48177 & 16009 & $5,5 \%$ \\
\hline Frankreich & 2009 & -2632 & -26610 & -29242 & 115681 & -20689 & -20151 & -32278 & 31671 & 74234 & 44992 & $7,8 \%$ \\
\hline Deutschland & 2009 & -3973 & -37238 & -41210 & 124880 & -31103 & -35604 & -34860 & 44088 & 67401 & 26191 & $5,9 \%$ \\
\hline Griechenland & 2009 & -1780 & -24381 & -26160 & 109244 & -1304 & -18230 & -15164 & 5096 & 79641 & 53481 & $7,8 \%$ \\
\hline Ungarn & 2009 & -823 & -10788 & -11611 & 90284 & -31059 & -23601 & 0 & 49541 & 85165 & 73554 & $21,9 \%$ \\
\hline Island & & $\mathrm{m}$ & $\mathrm{m}$ & $\mathbf{m}$ & $\mathrm{m}$ & $\mathrm{m}$ & $\mathrm{m}$ & $\mathrm{m}$ & $\mathrm{m}$ & $\mathbf{m}$ & $\mathbf{m}$ & $\mathrm{m}$ \\
\hline Irland & 2009 & -688 & -33235 & -33923 & 169908 & -25758 & -14394 & 0 & 22225 & 151980 & 118058 & $21,3 \%$ \\
\hline Israel & 2009 & -1120 & -25901 & -27021 & 90011 & -3606 & -4902 & 0 & 14120 & 95623 & 68602 & $10,3 \%$ \\
\hline Italien & 2008 & -986 & -38624 & -39610 & 152167 & -51238 & -17293 & 0 & 29983 & 113620 & 74010 & $8,4 \%$ \\
\hline$J a p a n^{2}$ & & $\mathrm{~m}$ & $\mathrm{~m}$ & m & $\mathrm{m}$ & $\mathrm{m}$ & $\mathrm{m}$ & $\mathrm{m}$ & $\mathrm{m}$ & m & m & $\mathrm{m}$ \\
\hline Korea & 2009 & -7620 & -30787 & -38407 & 120130 & -1914 & -9164 & 0 & 787 & 109839 & 71432 & $10,8 \%$ \\
\hline Luxemburg & & $\mathrm{m}$ & $\mathrm{m}$ & $\mathbf{m}$ & $\mathrm{m}$ & $\mathrm{m}$ & $\mathrm{m}$ & $\mathrm{m}$ & $\mathrm{m}$ & $\mathbf{m}$ & $\mathbf{m}$ & $\mathrm{m}$ \\
\hline Mexiko & & $\mathrm{m}$ & $\mathrm{m}$ & m & $\mathrm{m}$ & $\mathrm{m}$ & $\mathrm{m}$ & $\mathrm{m}$ & $\mathrm{m}$ & $\mathbf{m}$ & $\mathbf{m}$ & $\mathrm{m}$ \\
\hline Niederlande $^{1}$ & & $\mathrm{~m}$ & $\mathrm{~m}$ & m & $\mathrm{m}$ & $\mathrm{m}$ & $\mathrm{m}$ & $\mathrm{m}$ & $\mathrm{m}$ & $\mathbf{m}$ & $\mathbf{m}$ & $\mathrm{m}$ \\
\hline Neuseeland & 2009 & -3128 & -31941 & -35069 & 95339 & -22970 & -2033 & -8738 & 24622 & 86220 & 51151 & $9,2 \%$ \\
\hline Norwegen & 2009 & -2859 & -52871 & -55731 & 151109 & -41979 & -13303 & -13885 & 20239 & 102181 & 46450 & $6,4 \%$ \\
\hline Polen & 2008 & -916 & -14879 & -15794 & 74416 & -8271 & -19448 & 0 & 16433 & 63130 & 47335 & $10,5 \%$ \\
\hline Portugal & 2009 & 0 & -15946 & -15946 & 108338 & -11302 & -12754 & 0 & 7683 & 91965 & 76019 & $12,1 \%$ \\
\hline Slowakei & 2009 & -2358 & -4617 & -6975 & 81677 & -11451 & -23898 & 0 & 97725 & 144054 & 137078 & $48,4 \%$ \\
\hline Slowenien & 2009 & -1803 & -20740 & -22543 & 132244 & -28476 & -32797 & 0 & 15924 & 86895 & 64352 & $10,5 \%$ \\
\hline Spanien & 2009 & -1464 & -9868 & -11332 & 116983 & -21569 & -9851 & 0 & 38471 & 124035 & 112703 & $24,9 \%$ \\
\hline Schweden & 2009 & -21 & -27283 & -27304 & 136537 & -43847 & -12740 & -30163 & 46195 & 95982 & 68678 & $11,0 \%$ \\
\hline Schweiz & & $\mathrm{m}$ & $\mathrm{m}$ & m & $\mathrm{m}$ & $\mathrm{m}$ & $\mathrm{m}$ & $\mathrm{m}$ & $\mathrm{m}$ & m & m & $\mathrm{m}$ \\
\hline Türkei & 2005 & -336 & -12058 & -12394 & 75879 & -8395 & -9432 & 0 & -12434 & 45618 & 33223 & $9,2 \%$ \\
\hline Ver. Königreich & 2009 & -4880 & -33859 & -38739 & 151062 & -35926 & -19985 & -43256 & 46662 & 98557 & 59818 & $9,3 \%$ \\
\hline Vereinigte Staaten & 2009 & -2930 & -27153 & -30083 & 201542 & -44205 & -18597 & -8544 & 41567 & 171763 & 141680 & $16,5 \%$ \\
\hline \multicolumn{2}{|l|}{ OECD-Durchschnitt } & -1989 & -26031 & -28020 & 117252 & -24227 & -15994 & -9928 & 30041 & 97143 & 69124 & $13,7 \%$ \\
\hline EU21-Durchschnitt & & -1529 & -24420 & -25950 & 117099 & -25405 & -19409 & -11205 & 35811 & 96891 & 70941 & $15,1 \%$ \\
\hline
\end{tabular}

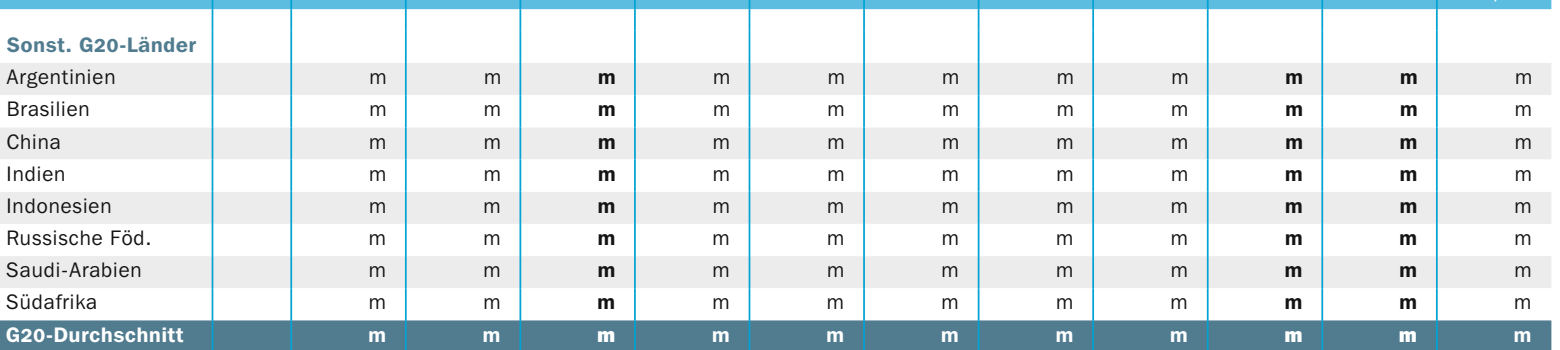

Anmerkung: Die Zahlen basieren auf dem Unterschied zwischen Frauen, die einen Abschluss im Sekundarbereich II/postsekundaren, nicht tertiären Bereich erworben haben, und Frauen, die keinen derartigen Abschluss erworben haben.

1. Für Belgien und die Niederlande keine Datenangabe in der Tabelle, da der Sekundarbereich Il dort Pflicht ist. 2. Für Japan keine Datenangabe in der Tabelle, da keine nach Abschluss im Sekundarbereich I und Sekundarbereich II aufgegliederten Daten vorlagen.

Quelle: OECD. Bildung auf einen Blick 2012. Hinweise s. Anhang 3 unter www.oecd.org/edu/eag.htm. StatLink: http://dx.doi.org/10.1787/888932849122 Erläuterung der Kennzeichnung fehlender Daten s. Hinweise für den Leser. 
Staatliche Kosten und staatlicher Nutzen bei einem Mann, der einen Abschluss im Sekundarbereich II bzw. postsekundaren, nicht tertiären Bereich erwirbt (2009)

Im Vergleich zu einem Mann, der einen Abschluss im Sekundarbereich I erwirbt (in US-Dollar, kaufkraftbereinigt mittels KKP für das BIP)

\begin{tabular}{|c|c|c|c|c|c|c|c|c|c|c|c|}
\hline & Jahr & $\begin{array}{l}\text { Direkte } \\
\text { Kosten }\end{array}$ & \begin{tabular}{|c|} 
Entgan- \\
gene \\
Einkom- \\
mensteuer
\end{tabular} & $\begin{array}{l}\text { Gesamt- } \\
\text { kosten }\end{array}$ & $\left|\begin{array}{c}\text { Effekt } \\
\text { Einkom- } \\
\text { mensteuer }\end{array}\right|$ & $\begin{array}{c}\text { Effekt } \\
\text { Sozial- } \\
\text { versiche- } \\
\text { rungs- } \\
\text { beiträge }\end{array}$ & $\begin{array}{c}\text { Effekt } \\
\text { Transfer- } \\
\text { leistungen }\end{array}$ & $\begin{array}{l}\text { Effekt } \\
\text { Erwerbs- } \\
\text { losigkeit }\end{array}$ & $\begin{array}{l}\text { Gesamt- } \\
\text { nutzen }\end{array}$ & $\begin{array}{c}\text { Kapital- } \\
\text { wert }\end{array}$ & $\begin{array}{l}\text { Ertrags- } \\
\text { rate }\end{array}$ \\
\hline & & (1) & (2) & (3) & (4) & (5) & (6) & (7) & (8) & (9) & (10) \\
\hline \multicolumn{12}{|l|}{ OECD-Länder } \\
\hline Australien & 2009 & -15955 & -3020 & -18975 & 55053 & 0 & 8303 & 9355 & 72710 & 53735 & $17,1 \%$ \\
\hline Österreich & 2009 & -42552 & -8054 & -50606 & 67624 & 55258 & 8442 & 15685 & 147010 & 96404 & $9,2 \%$ \\
\hline Belgien $^{1}$ & & $\mathrm{~m}$ & $\mathrm{~m}$ & $\mathbf{m}$ & $\mathrm{m}$ & $\mathrm{m}$ & $\mathrm{m}$ & $\mathrm{m}$ & $\mathbf{m}$ & m & $\mathrm{m}$ \\
\hline Kanada & 2009 & -26071 & -5023 & -31094 & 45151 & 10200 & 1050 & 9097 & 65497 & 34403 & $6,7 \%$ \\
\hline Chile & & $\mathrm{m}$ & $\mathrm{m}$ & m & $\mathrm{m}$ & $\mathrm{m}$ & $\mathrm{m}$ & $\mathrm{m}$ & $\mathbf{m}$ & m & $\mathrm{m}$ \\
\hline Tschechien & 2009 & -21277 & 1458 & -19819 & 22510 & 12319 & 0 & 21883 & 56711 & 36892 & $10,2 \%$ \\
\hline Dänemark & 2009 & -30337 & -18553 & -48890 & 67718 & 15671 & 10020 & 10915 & 104324 & 55434 & $7,7 \%$ \\
\hline Estland & 2009 & -18857 & -1210 & -20066 & 6687 & 650 & 0 & 6592 & 13928 & -6138 & $1,5 \%$ \\
\hline Finnland & 2009 & -21711 & -4391 & -26103 & 23424 & 4855 & 7202 & 6884 & 42366 & 16263 & $6,5 \%$ \\
\hline Frankreich & 2009 & -31556 & -5171 & -36727 & 19109 & 15422 & 13971 & 10937 & 59440 & 22713 & $6,4 \%$ \\
\hline Deutschland & 2009 & -27953 & -14083 & -42036 & 29047 & 22523 & 14061 & 31192 & 96824 & 54788 & $9,4 \%$ \\
\hline Griechenland & 2009 & -22045 & 2032 & -20013 & 11723 & 15045 & 23320 & 760 & 50848 & 30835 & $6,0 \%$ \\
\hline Ungarn & 2009 & -14716 & -2674 & -17391 & 24747 & 13668 & 0 & 15666 & 54081 & 36690 & $10,0 \%$ \\
\hline Island & & $\mathrm{m}$ & $\mathrm{m}$ & $\mathbf{m}$ & $\mathrm{m}$ & $\mathrm{m}$ & $\mathrm{m}$ & $\mathrm{m}$ & $\mathbf{m}$ & $\mathbf{m}$ & $\mathrm{m}$ \\
\hline Irland & 2009 & -29498 & -763 & -30261 & 59215 & 19169 & 0 & 12780 & 91164 & 60903 & $8,1 \%$ \\
\hline Israel & 2009 & -15405 & -1650 & -17055 & 16363 & 12601 & 0 & 2240 & 31204 & 14148 & $5,5 \%$ \\
\hline Italien & 2008 & -32919 & -10264 & -43183 & 59003 & 16776 & 0 & 6638 & 82418 & 39235 & $6,0 \%$ \\
\hline$J{ }^{2}$ & & $\mathrm{~m}$ & $\mathrm{~m}$ & m & $\mathrm{m}$ & $\mathrm{m}$ & $\mathrm{m}$ & $\mathrm{m}$ & $\mathbf{m}$ & m & $\mathrm{m}$ \\
\hline Korea & 2009 & -24344 & -2983 & -27327 & 27524 & 20643 & 0 & 711 & 48878 & 21551 & $4,8 \%$ \\
\hline Luxemburg & & $\mathrm{m}$ & $\mathrm{m}$ & $\mathbf{m}$ & $\mathrm{m}$ & $\mathrm{m}$ & $\mathrm{m}$ & $\mathrm{m}$ & $\mathbf{m}$ & m & $\mathrm{m}$ \\
\hline Mexiko & & $\mathrm{m}$ & $\mathrm{m}$ & $\mathbf{m}$ & $\mathrm{m}$ & $\mathrm{m}$ & $\mathrm{m}$ & $\mathrm{m}$ & $\mathbf{m}$ & m & $\mathrm{m}$ \\
\hline Niederlande $^{1}$ & & $\mathrm{~m}$ & $\mathrm{~m}$ & m & $\mathrm{m}$ & $\mathrm{m}$ & $\mathrm{m}$ & $\mathrm{m}$ & m & m & $\mathrm{m}$ \\
\hline Neuseeland & 2009 & -21397 & -3991 & -25388 & 33911 & 1888 & 711 & 5299 & 41810 & 16422 & $5,3 \%$ \\
\hline Norwegen & 2009 & -36851 & -15816 & -52667 & 73644 & 20269 & 4703 & 13253 & 111869 & 59202 & $8,0 \%$ \\
\hline Polen & 2008 & -16232 & -5565 & -21797 & 5188 & 11477 & 0 & 7053 & 23718 & 1921 & $3,4 \%$ \\
\hline Portugal & 2009 & -20476 & -2386 & -22862 & 27209 & 16054 & 0 & 2436 & 45699 & 22837 & $5,5 \%$ \\
\hline Slowakei & 2009 & -13158 & -910 & -14068 & 18167 & 15854 & 0 & 23191 & 57212 & 43145 & $13,4 \%$ \\
\hline Slowenien & 2009 & -18800 & -5902 & -24702 & 23126 & 30304 & 0 & 7989 & 61419 & 36716 & $8,9 \%$ \\
\hline Spanien & 2009 & -19800 & -1030 & -20830 & 24782 & 6967 & 0 & 6822 & 38570 & 17739 & $5,5 \%$ \\
\hline Schweden & 2009 & -28557 & -6913 & -35470 & 46699 & 12285 & 22368 & 14135 & 95487 & 60018 & $14,8 \%$ \\
\hline Schweiz & & $\mathrm{m}$ & $\mathrm{m}$ & $\mathbf{m}$ & m & $\mathrm{m}$ & $\mathrm{m}$ & $\mathrm{m}$ & $\mathbf{m}$ & m & $\mathrm{m}$ \\
\hline Türkei & 2005 & -4776 & -4551 & -9327 & 9997 & 9514 & 0 & 1188 & 20699 & 11371 & $6,4 \%$ \\
\hline Ver. Königreich & 2009 & -17187 & 2307 & -14881 & 44425 & 24434 & 13494 & 12707 & 95060 & 80179 & $21,2 \%$ \\
\hline Vereinigte Staaten & 2009 & -33481 & -3231 & -36713 & 65191 & 23333 & 8675 & 9698 & 106897 & 70185 & $10,0 \%$ \\
\hline \multicolumn{2}{|l|}{ OECD-Durchschnitt } & -23304 & -4705 & -28010 & 34894 & 15661 & 5243 & 10196 & 65994 & 37984 & $8,4 \%$ \\
\hline EU21-Durchschnitt & & -23757 & -4560 & -28317 & 32245 & 17152 & 6271 & 11904 & 67571 & 39254 & $8,5 \%$ \\
\hline
\end{tabular}

\begin{tabular}{|c|c|c|c|c|c|c|c|c|c|c|}
\hline Sonst. G20-Länder & & & & & & & & & & \\
\hline Argentinien & $\mathrm{m}$ & $\mathrm{m}$ & m & $\mathrm{m}$ & $\mathrm{m}$ & $\mathrm{m}$ & $\mathrm{m}$ & m & m & $\mathrm{m}$ \\
\hline Brasilien & $\mathrm{m}$ & $\mathrm{m}$ & $\mathbf{m}$ & $\mathrm{m}$ & $\mathrm{m}$ & $\mathrm{m}$ & $\mathrm{m}$ & $\mathbf{m}$ & $\mathbf{m}$ & $\mathrm{m}$ \\
\hline China & $\mathrm{m}$ & $\mathrm{m}$ & $\mathbf{m}$ & $\mathrm{m}$ & $\mathrm{m}$ & $\mathrm{m}$ & $\mathrm{m}$ & $\mathbf{m}$ & $\mathbf{m}$ & $\mathrm{m}$ \\
\hline Indien & $\mathrm{m}$ & $\mathrm{m}$ & $\mathbf{m}$ & $\mathrm{m}$ & $\mathrm{m}$ & $\mathrm{m}$ & $\mathrm{m}$ & $\mathbf{m}$ & $\mathbf{m}$ & $\mathrm{m}$ \\
\hline Indonesien & $\mathrm{m}$ & $\mathrm{m}$ & m & $\mathrm{m}$ & $\mathrm{m}$ & $\mathrm{m}$ & $\mathrm{m}$ & m & m & $\mathrm{m}$ \\
\hline Russische Föd. & $\mathrm{m}$ & $\mathrm{m}$ & $\mathbf{m}$ & $\mathrm{m}$ & $\mathrm{m}$ & $\mathrm{m}$ & $\mathrm{m}$ & $\mathbf{m}$ & $\mathbf{m}$ & $\mathrm{m}$ \\
\hline Saudi-Arabien & $\mathrm{m}$ & $\mathrm{m}$ & $\mathbf{m}$ & $\mathrm{m}$ & $\mathrm{m}$ & $\mathrm{m}$ & $\mathrm{m}$ & $\mathbf{m}$ & $\mathbf{m}$ & $\mathrm{m}$ \\
\hline Südafrika & $\mathrm{m}$ & $\mathrm{m}$ & m & $\mathrm{m}$ & $\mathrm{m}$ & $\mathrm{m}$ & $\mathrm{m}$ & m & m & $\mathrm{m}$ \\
\hline G20-Durchschnitt & $\mathbf{m}$ & $\mathbf{m}$ & $\mathbf{m}$ & m & $\mathbf{m}$ & $\mathbf{m}$ & $\mathbf{m}$ & $\mathbf{m}$ & $\mathbf{m}$ & $\mathbf{m}$ \\
\hline
\end{tabular}

Anmerkung: Die Zahlen basieren auf dem Unterschied zwischen Männern, die einen Abschluss im Sekundarbereich II/postsekundaren, nicht tertiären Bereich erworben haben, und Männern, die keinen derartigen Abschluss erworben haben.

1. Für Belgien und die Niederlande keine Datenangabe in der Tabelle, da der Sekundarbereich Il dort Pflicht ist. 2. Für Japan keine Datenangabe in der Tabelle, da keine nach Abschluss im Sekundarbereich I und Sekundarbereich II aufgegliederten Daten vorlagen.

Quelle: OECD. Bildung auf einen Blick 2012. Hinweise s. Anhang 3 unter www.oecd.org/edu/eag.htm. StatLink: http://dx.doi.org/10.1787/888932849141 Erläuterung der Kennzeichnung fehlender Daten s. Hinweise für den Leser. 
Tabelle A7.2b

Staatliche Kosten und staatlicher Nutzen bei einer Frau, die einen Abschluss im Sekundarbereich II bzw. postsekundaren, nicht tertiären Bereich erwirbt (2009)

Im Vergleich zu einer Frau, die einen Abschluss im Sekundarbereich I erwirbt (in US-Dollar, kaufkraftbereinigt mittels KKP für das BIP)

\begin{tabular}{|c|c|c|c|c|c|c|c|c|c|c|c|}
\hline & Jahr & $\begin{array}{l}\text { Direkte } \\
\text { Kosten }\end{array}$ & \begin{tabular}{|c|} 
Entgan- \\
gene \\
Einkom- \\
mensteuer
\end{tabular} & $\begin{array}{l}\text { Gesamt- } \\
\text { kosten }\end{array}$ & $\begin{array}{c}\text { Effekt } \\
\text { Einkom- } \\
\text { mensteuer }\end{array}$ & $\begin{array}{c}\text { Effekt } \\
\text { Sozial- } \\
\text { versiche- } \\
\text { rungs- } \\
\text { beiträge }\end{array}$ & $\begin{array}{c}\text { Effekt } \\
\text { Transfer- } \\
\text { leistungen }\end{array}$ & $\begin{array}{l}\text { Effekt } \\
\text { Erwerbs- } \\
\text { losigkeit }\end{array}$ & $\begin{array}{l}\text { Gesamt- } \\
\text { nutzen }\end{array}$ & $\begin{array}{c}\text { Kapital- } \\
\text { wert }\end{array}$ & $\begin{array}{l}\text { Ertrags- } \\
\text { rate }\end{array}$ \\
\hline & & (1) & (2) & (3) & (4) & (5) & (6) & (7) & (8) & (9) & (10) \\
\hline \multicolumn{12}{|l|}{ OECD-Länder } \\
\hline Australien & 2009 & -15955 & -3136 & -19091 & 26218 & 0 & 22467 & 2239 & 50924 & 31833 & $18,4 \%$ \\
\hline Österreich & 2009 & -42552 & -7929 & -50481 & 23951 & 42287 & 27606 & 5954 & 99799 & 49318 & $7,8 \%$ \\
\hline Belgien $^{1}$ & & $\mathrm{~m}$ & $\mathrm{~m}$ & $\mathbf{m}$ & $\mathrm{m}$ & $\mathrm{m}$ & $\mathrm{m}$ & $m$ & m & m & $\mathrm{m}$ \\
\hline Kanada & 2009 & -26071 & -5437 & -31508 & 17830 & 7276 & 2803 & 5025 & 32934 & 1425 & $3,2 \%$ \\
\hline Chile & & $\mathrm{m}$ & $\mathrm{m}$ & $\mathbf{m}$ & $\mathrm{m}$ & $\mathrm{m}$ & $\mathrm{m}$ & $\mathrm{m}$ & $\mathbf{m}$ & m & $\mathrm{m}$ \\
\hline Tschechien & 2009 & -21277 & 1497 & -19781 & 20002 & 10946 & 2144 & 15671 & 48763 & 28983 & $8,8 \%$ \\
\hline Dänemark & 2009 & -30337 & -18925 & -49263 & 49790 & 11689 & 0 & 9001 & 70481 & 21218 & $5,3 \%$ \\
\hline Estland & 2009 & -18857 & -1240 & -20096 & 6916 & 672 & 0 & 4880 & 12469 & -7628 & $0,6 \%$ \\
\hline Finnland & 2009 & -21711 & -4679 & -26390 & 12075 & 3607 & 16226 & 6472 & 38380 & 11989 & $6,6 \%$ \\
\hline Frankreich & 2009 & -31556 & -5275 & -36831 & 17923 & 15865 & 32278 & 7052 & 73117 & 36287 & $6,7 \%$ \\
\hline Deutschland & 2009 & -27953 & -14248 & -42201 & 27294 & 26613 & 34860 & 12800 & 101567 & 59366 & $10,9 \%$ \\
\hline Griechenland & 2009 & -22045 & 1649 & -20396 & 1347 & 17423 & 15164 & 764 & 34699 & 14303 & $4,8 \%$ \\
\hline Ungarn & 2009 & -14716 & -2620 & -17336 & 24816 & 15247 & 0 & 14598 & 54660 & 37324 & $10,4 \%$ \\
\hline Island & & $\mathrm{m}$ & $\mathrm{m}$ & $\mathbf{m}$ & $\mathrm{m}$ & $\mathrm{m}$ & $\mathrm{m}$ & $\mathrm{m}$ & $\mathbf{m}$ & m & $\mathrm{m}$ \\
\hline Irland & 2009 & -29498 & -1027 & -30524 & 24738 & 13916 & 0 & 1498 & 40152 & 9628 & $4,2 \%$ \\
\hline Israel & 2009 & -15405 & -1556 & -16961 & 3499 & 4383 & 0 & 626 & 8508 & -8453 & $0,7 \%$ \\
\hline Italien & 2008 & -32919 & -9033 & -41952 & 47153 & 14467 & 0 & 6910 & 68530 & 26578 & $5,2 \%$ \\
\hline Japan $^{2}$ & & $\mathrm{~m}$ & $\mathrm{~m}$ & $\mathbf{m}$ & $\mathrm{m}$ & $\mathrm{m}$ & $\mathrm{m}$ & $\mathrm{m}$ & $\mathbf{m}$ & m & $\mathrm{m}$ \\
\hline Korea & 2009 & -24344 & -3145 & -27488 & 1904 & 9104 & 0 & 70 & 11078 & -16410 & $-1,3 \%$ \\
\hline Luxemburg & & $\mathrm{m}$ & $\mathrm{m}$ & $\mathbf{m}$ & $\mathrm{m}$ & $\mathrm{m}$ & $\mathrm{m}$ & $\mathrm{m}$ & $\mathbf{m}$ & m & $\mathrm{m}$ \\
\hline Mexiko & & $\mathrm{m}$ & $\mathrm{m}$ & $\mathbf{m}$ & $m$ & $\mathrm{~m}$ & $\mathrm{~m}$ & $\mathrm{~m}$ & $\mathbf{m}$ & m & $\mathrm{m}$ \\
\hline Niederlande ${ }^{1}$ & & $\mathrm{~m}$ & $\mathrm{~m}$ & $\mathbf{m}$ & $\mathrm{m}$ & $\mathrm{m}$ & $\mathrm{m}$ & $\mathrm{m}$ & $\mathbf{m}$ & $\mathbf{m}$ & $\mathrm{m}$ \\
\hline Neuseeland & 2009 & -21397 & -3713 & -25110 & 19183 & 1618 & 8738 & 4202 & 33740 & 8631 & $4,8 \%$ \\
\hline Norwegen & 2009 & -36851 & -16437 & -53288 & 39007 & 11741 & 13885 & 4534 & 69166 & 15879 & $4,8 \%$ \\
\hline Polen & 2008 & -16232 & -4987 & -21219 & 7206 & 15942 & 0 & 4571 & 27719 & 6500 & $4,2 \%$ \\
\hline Portugal & 2009 & -20476 & -2275 & -22751 & 11178 & 11919 & 0 & 958 & 24055 & 1304 & $3,2 \%$ \\
\hline Slowakei & 2009 & -13158 & -444 & -13601 & 8542 & 10905 & 0 & 15902 & 35349 & 21747 & $9,1 \%$ \\
\hline Slowenien & 2009 & -18800 & -6335 & -25135 & 27178 & 29297 & 0 & 4798 & 61272 & 36137 & $7,8 \%$ \\
\hline Spanien & 2009 & -19800 & -1016 & -20817 & 20119 & 7434 & 0 & 3866 & 31420 & 10603 & $4,5 \%$ \\
\hline Schweden & 2009 & -28557 & -7319 & -35876 & 34935 & 9544 & 30163 & 12109 & 86750 & 50875 & $13,4 \%$ \\
\hline Schweiz & & $\mathrm{m}$ & $\mathrm{m}$ & $\mathbf{m}$ & $\mathrm{m}$ & $\mathrm{m}$ & $\mathrm{m}$ & $\mathrm{m}$ & $\mathbf{m}$ & m & $\mathrm{m}$ \\
\hline Türkei & 2005 & -4776 & -4892 & -9668 & 10025 & 11264 & 0 & -3463 & 17827 & 8159 & $5,8 \%$ \\
\hline Ver. Königreich & 2009 & -17187 & 4881 & -12306 & 30198 & 16609 & 43256 & 9105 & 99167 & 86861 & $20,9 \%$ \\
\hline Vereinigte Staaten & 2009 & -33481 & -3495 & -36976 & 39703 & 15443 & 8544 & 7657 & 71346 & 34370 & $6,9 \%$ \\
\hline OECD-Durchschnitt & & -23304 & -4659 & -27963 & 21259 & 12893 & 9928 & 6069 & 50149 & 22186 & $6,8 \%$ \\
\hline EU21-Durchschnitt & & -23757 & -4407 & -28164 & 21965 & 15243 & 11205 & 7606 & 56019 & 27855 & $7,5 \%$ \\
\hline \multicolumn{12}{|l|}{ Sonst. G20-Länder } \\
\hline Argentinien & & $\mathrm{m}$ & $\mathrm{m}$ & m & $\mathrm{m}$ & $\mathrm{m}$ & $\mathrm{m}$ & $\mathrm{m}$ & m & m & $\mathrm{m}$ \\
\hline Brasilien & & $\mathrm{m}$ & $\mathrm{m}$ & $\mathbf{m}$ & $\mathrm{m}$ & $\mathrm{m}$ & $\mathrm{m}$ & $\mathrm{m}$ & $\mathbf{m}$ & $\mathbf{m}$ & $\mathrm{m}$ \\
\hline China & & $\mathrm{m}$ & $\mathrm{m}$ & m & $\mathrm{m}$ & $\mathrm{m}$ & $\mathrm{m}$ & $\mathrm{m}$ & m & m & $\mathrm{m}$ \\
\hline Indien & & $\mathrm{m}$ & $\mathrm{m}$ & $\mathbf{m}$ & $\mathrm{m}$ & $\mathrm{m}$ & $\mathrm{m}$ & $\mathrm{m}$ & $\mathbf{m}$ & $\mathbf{m}$ & $\mathrm{m}$ \\
\hline Indonesien & & $\mathrm{m}$ & $\mathrm{m}$ & m & $\mathrm{m}$ & $\mathrm{m}$ & $\mathrm{m}$ & $\mathrm{m}$ & m & m & $\mathrm{m}$ \\
\hline Russische Föd. & & $\mathrm{m}$ & $\mathrm{m}$ & m & $\mathrm{m}$ & $\mathrm{m}$ & $\mathrm{m}$ & $\mathrm{m}$ & $\mathbf{m}$ & m & $\mathrm{m}$ \\
\hline Saudi-Arabien & & $\mathrm{m}$ & $\mathrm{m}$ & m & $\mathrm{m}$ & $\mathrm{m}$ & $\mathrm{m}$ & $\mathrm{m}$ & m & m & $\mathrm{m}$ \\
\hline Südafrika & & $\mathrm{m}$ & $\mathrm{m}$ & $\mathbf{m}$ & $\mathrm{m}$ & $\mathrm{m}$ & $\mathrm{m}$ & $\mathrm{m}$ & $\mathbf{m}$ & $\mathbf{m}$ & $\mathrm{m}$ \\
\hline G20-Durchschnitt & & $\mathbf{m}$ & $\mathbf{m}$ & m & m & $\mathbf{m}$ & m & m & m & $\mathbf{m}$ & $\mathbf{m}$ \\
\hline
\end{tabular}

Anmerkung: Die Zahlen basieren auf dem Unterschied zwischen Frauen, die einen Abschluss im Sekundarbereich II/postsekundaren, nicht tertiären Bereich erworben haben, und Frauen, die keinen derartigen Abschluss erworben haben.

1. Für Belgien und die Niederlande keine Datenangabe in der Tabelle, da der Sekundarbereich Il dort Pflicht ist. 2. Für Japan keine Datenangabe in der Tabelle, da keine nach Abschluss im Sekundarbereich I und Sekundarbereich II aufgegliederten Daten vorlagen.

Quelle: OECD. Bildung auf einen Blick 2012. Hinweise s. Anhang 3 unter www.oecd.org/edu/eag.htm. StatLink: http://dx.doi.org/10.1787/888932849160 Erläuterung der Kennzeichnung fehlender Daten s. Hinweise für den Leser. 
Private Kosten und privater Nutzen für einen Mann, der einen Abschluss im Tertiärbereich erwirbt (2009) Im Vergleich zu einem Mann, der einen Abschluss im Sekundarbereich II/postsekundaren, nicht tertiären Bereich erwirbt (in US-Dollar, kaufkraftbereinigt mittels KKP für das BIP)

\begin{tabular}{|c|c|c|c|c|c|c|c|c|c|c|c|c|c|}
\hline & Jahr & $\begin{array}{l}\text { Direkte } \\
\text { Kosten }\end{array}$ & $\begin{array}{l}\text { Entgan- } \\
\text { genes } \\
\text { Einkom- } \\
\text { men }\end{array}$ & $\begin{array}{c}\text { Gesamt- } \\
\text { kosten }\end{array}$ & $\begin{array}{l}\text { Einkom- } \\
\text { mens- } \\
\text { vorteile } \\
\text { (brutto) }\end{array}$ & \begin{tabular}{|c} 
Effekt \\
Einkom- \\
men- \\
steuer
\end{tabular} & $\begin{array}{c}\text { Effekt } \\
\text { Sozial- } \\
\text { versiche- } \\
\text { rungs- } \\
\text { beiträge }\end{array}$ & \begin{tabular}{|c} 
Effekt \\
Transfer- \\
leistun- \\
gen
\end{tabular} & \begin{tabular}{|c|} 
Effekt \\
Erwerbs- \\
losigkeit
\end{tabular} & $\mid \begin{array}{c}\text { Zu- } \\
\text { schüsse }\end{array}$ & \begin{tabular}{|c|} 
Gesamt- \\
nutzen
\end{tabular} & $\begin{array}{c}\text { Kapital- } \\
\text { wert }\end{array} \mid$ & $\begin{array}{c}\text { Ertrags- } \\
\text { rate }\end{array}$ \\
\hline & & (1) & (2) & (3) & (4) & (5) & (6) & (7) & (8) & (9) & (10) & (11) & (12) \\
\hline \multicolumn{14}{|l|}{ OECD-Länder } \\
\hline Australien & 2009 & -17528 & -50814 & -68342 & 339977 & -124441 & 0 & 0 & 5363 & 7 & 220906 & 152564 & $9,0 \%$ \\
\hline Österreich & 2009 & -5689 & -56184 & -61872 & 404385 & -129756 & -59771 & 0 & 24265 & 9852 & 248975 & 187103 & $11,7 \%$ \\
\hline Belgien & 2009 & -3514 & -45409 & -48922 & 352354 & -156492 & -54714 & 0 & 23422 & 1047 & 165617 & 116694 & $10,4 \%$ \\
\hline Kanada & 2009 & -16282 & -30684 & -46966 & 287032 & -96213 & -7645 & 0 & 31906 & 1103 & 216183 & 169217 & $12,3 \%$ \\
\hline Chile & & $\mathrm{m}$ & $\mathrm{m}$ & $\mathbf{m}$ & $\mathrm{m}$ & $\mathrm{m}$ & $\mathrm{m}$ & $\mathrm{m}$ & $\mathrm{m}$ & $\mathrm{m}$ & $\mathbf{m}$ & $\mathbf{m}$ & $\mathrm{m}$ \\
\hline Tschechien & 2009 & -4692 & -23017 & -27709 & 424850 & -88209 & -48588 & 0 & 16814 & 0 & 304867 & 277158 & $20,1 \%$ \\
\hline Dänemark & 2009 & -3365 & -55899 & -59263 & 266180 & -139677 & -22432 & -9435 & 12030 & 25189 & 131855 & 72592 & $8,5 \%$ \\
\hline Estland & 2009 & -3583 & -18346 & -21929 & 150074 & -40454 & -4070 & 0 & 53647 & 0 & 159197 & 137268 & $22,0 \%$ \\
\hline Finnland & 2009 & -1873 & -56911 & -58784 & 343119 & -138956 & -24568 & 0 & 39479 & 8730 & 227803 & 169020 & $11,9 \%$ \\
\hline Frankreich & 2009 & -7868 & -51472 & -59340 & 338590 & -83938 & -45390 & -880 & 13494 & 3620 & 225495 & 166155 & $10,1 \%$ \\
\hline Deutschland & 2009 & -7061 & -64242 & -71304 & 353025 & -140458 & -69031 & 0 & 54278 & 6021 & 203835 & 132531 & $9,2 \%$ \\
\hline Griechenland & 2009 & -690 & -43715 & -44405 & 182193 & -35679 & -29437 & -8700 & 6156 & 0 & 114533 & 70128 & $7,5 \%$ \\
\hline Ungarn & 2009 & -5131 & -14443 & -19575 & 464922 & -188649 & -85331 & 0 & 37732 & 1283 & 229956 & 210381 & $25,6 \%$ \\
\hline Island & & $\mathrm{m}$ & $\mathrm{m}$ & $\mathbf{m}$ & $\mathrm{m}$ & $\mathrm{m}$ & $\mathrm{m}$ & $\mathrm{m}$ & $\mathrm{m}$ & $\mathrm{m}$ & $\mathbf{m}$ & $\mathbf{m}$ & $\mathrm{m}$ \\
\hline Irland & 2009 & -6716 & -50436 & -57152 & 512095 & -219981 & -41438 & 0 & 90659 & 4361 & 345695 & 288543 & $19,8 \%$ \\
\hline Israel & 2009 & -13394 & -28223 & -41617 & 281602 & -68554 & -34985 & 0 & 14996 & 0 & 193060 & 151443 & $11,4 \%$ \\
\hline Italien & 2008 & -7285 & -50608 & -57893 & 408011 & -159562 & -41835 & 0 & 3295 & Зззо & 213239 & 155346 & $8,1 \%$ \\
\hline Japan & 2007 & -37215 & -66750 & -103965 & 326614 & -64523 & -36039 & 0 & 20931 & 0 & 246983 & 143018 & $7,4 \%$ \\
\hline Korea & 2009 & -23378 & -54050 & -77428 & 280071 & -34128 & -24344 & 0 & 17002 & 0 & 238601 & 161173 & $16,0 \%$ \\
\hline Luxemburg & & $\mathrm{m}$ & $\mathrm{m}$ & $\mathbf{m}$ & $\mathrm{m}$ & $\mathrm{m}$ & $\mathrm{m}$ & $\mathrm{m}$ & $\mathrm{m}$ & $\mathrm{m}$ & m & $\mathbf{m}$ & $\mathrm{m}$ \\
\hline Mexiko & & $\mathrm{m}$ & $\mathrm{m}$ & $\mathbf{m}$ & $\mathrm{m}$ & $\mathrm{m}$ & $\mathrm{m}$ & $\mathrm{m}$ & $\mathrm{m}$ & $\mathrm{m}$ & m & $\mathbf{m}$ & $\mathrm{m}$ \\
\hline Niederlande & 2008 & -14113 & -90118 & -104231 & 455296 & -202175 & -22153 & 0 & 4778 & 14371 & 250117 & 145886 & $7,9 \%$ \\
\hline Neuseeland & 2009 & -10414 & -49605 & -60019 & 188649 & -64074 & -3261 & 0 & 3169 & 1891 & 126375 & 66357 & $6,7 \%$ \\
\hline Norwegen & 2009 & -1180 & -66506 & -67686 & 273737 & -103788 & -22034 & 0 & 9009 & 6226 & 163151 & 95465 & $6,7 \%$ \\
\hline Polen & 2008 & -6291 & -15995 & -22287 & 367019 & -55868 & -83937 & 0 & 23960 & 1742 & 252917 & 230630 & $23,4 \%$ \\
\hline Portugal & 2009 & -8085 & -19784 & -27869 & 304147 & -82653 & -33871 & 0 & 4128 & 0 & 191751 & 163882 & $14,9 \%$ \\
\hline Slowakei & 2009 & -5543 & -17281 & -22823 & 302035 & -55140 & -42864 & 0 & 34628 & 1250 & 239909 & 217086 & $21,5 \%$ \\
\hline Slowenien & 2009 & -3858 & -25921 & -29779 & 475118 & -128427 & -109421 & 0 & 19474 & 226 & 256970 & 227191 & $18,2 \%$ \\
\hline Spanien & 2009 & -10051 & -32644 & -42695 & 188318 & -53898 & -14573 & 0 & 41006 & 0 & 160853 & 118157 & $10,2 \%$ \\
\hline Schweden & 2009 & -4913 & -54097 & -59010 & 219203 & -87765 & -10739 & 0 & 14209 & 8341 & 143249 & 84239 & $7,6 \%$ \\
\hline Schweiz & & $\mathrm{m}$ & $\mathrm{m}$ & $\mathbf{m}$ & $\mathrm{m}$ & $\mathrm{m}$ & $\mathrm{m}$ & $\mathrm{m}$ & $\mathrm{m}$ & $\mathrm{m}$ & m & $\mathbf{m}$ & $\mathrm{m}$ \\
\hline Türkei & 2005 & -1061 & -9402 & -10463 & 106985 & -18682 & -16424 & 0 & 2761 & 0 & 74640 & 64177 & $19,3 \%$ \\
\hline Ver. Königreich & 2009 & -28704 & -91976 & -120679 & 398503 & -88234 & -45568 & 0 & 34295 & 2244 & 301240 & 180560 & $8,2 \%$ \\
\hline Vereinigte Staaten & 2009 & -71053 & -43069 & -114122 & 667905 & -220754 & -57941 & 0 & 89759 & 0 & 478969 & 364847 & $12,3 \%$ \\
\hline OECD-Durchschnitt & & -11398 & -44055 & -55453 & 333173 & -105901 & -37669 & -656 & 25746 & 3477 & 218170 & 162718 & $13,0 \%$ \\
\hline EU21-Durchschnitt & & -6951 & -43925 & -50876 & 345472 & -113798 & -44487 & -951 & 27587 & 4580 & 218404 & 167528 & $13,8 \%$ \\
\hline \multicolumn{14}{|l|}{ Sonst. G20-Länder } \\
\hline Argentinien & & $\mathrm{m}$ & $\mathrm{m}$ & $\mathbf{m}$ & $\mathrm{m}$ & $\mathrm{m}$ & $\mathrm{m}$ & $\mathrm{m}$ & $\mathrm{m}$ & $\mathrm{m}$ & m & $\mathbf{m}$ & $\mathrm{m}$ \\
\hline Brasilien & & $\mathrm{m}$ & $\mathrm{m}$ & $\mathbf{m}$ & $\mathrm{m}$ & $\mathrm{m}$ & $\mathrm{m}$ & $\mathrm{m}$ & $\mathrm{m}$ & $\mathrm{m}$ & m & $\mathbf{m}$ & $\mathrm{m}$ \\
\hline China & & $\mathrm{m}$ & $\mathrm{m}$ & $\mathbf{m}$ & $\mathrm{m}$ & $\mathrm{m}$ & $\mathrm{m}$ & $\mathrm{m}$ & $\mathrm{m}$ & $\mathrm{m}$ & m & m & $\mathrm{m}$ \\
\hline Indien & & $\mathrm{m}$ & $\mathrm{m}$ & $\mathbf{m}$ & $\mathrm{m}$ & $\mathrm{m}$ & $\mathrm{m}$ & $\mathrm{m}$ & $\mathrm{m}$ & $\mathrm{m}$ & m & $\mathbf{m}$ & $\mathrm{m}$ \\
\hline Indonesien & & $\mathrm{m}$ & $\mathrm{m}$ & $\mathbf{m}$ & $\mathrm{m}$ & $\mathrm{m}$ & $\mathrm{m}$ & $\mathrm{m}$ & $\mathrm{m}$ & $\mathrm{m}$ & m & $\mathbf{m}$ & $\mathrm{m}$ \\
\hline Russische Föd. & & $\mathrm{m}$ & $\mathrm{m}$ & $\mathbf{m}$ & $\mathrm{m}$ & $\mathrm{m}$ & $\mathrm{m}$ & $\mathrm{m}$ & $\mathrm{m}$ & $\mathrm{m}$ & $\mathbf{m}$ & $\mathbf{m}$ & $\mathrm{m}$ \\
\hline Saudi-Arabien & & $\mathrm{m}$ & $\mathrm{m}$ & $\mathbf{m}$ & $\mathrm{m}$ & $\mathrm{m}$ & $\mathrm{m}$ & $\mathrm{m}$ & $\mathrm{m}$ & $\mathrm{m}$ & m & $\mathbf{m}$ & $\mathrm{m}$ \\
\hline Südafrika & & $\mathrm{m}$ & $\mathrm{m}$ & $\mathbf{m}$ & $\mathrm{m}$ & $\mathrm{m}$ & $\mathrm{m}$ & $\mathrm{m}$ & $\mathrm{m}$ & $\mathrm{m}$ & m & $\mathbf{m}$ & $\mathrm{m}$ \\
\hline G20-Durchschnitt & & m & $\mathbf{m}$ & $\mathbf{m}$ & $\mathbf{m}$ & m & m & $\mathbf{m}$ & m & m & $\mathbf{m}$ & m & $\mathbf{m}$ \\
\hline
\end{tabular}

Anmerkung: Die Zahlen basieren auf dem Unterschied zwischen Männern, die einen Abschluss im Tertiärbereich erworben haben, und Männern, die einen Abschluss im Sekundarbereich II/postsekundaren, nicht tertiären Bereich erworben haben.

Quelle: OECD. Bildung auf einen Blick 2012. Hinweise s. Anhang 3 unter www.oecd.org/edu/eag.htm. StatLink: http://dx.doi.org/10.1787/888932849179 Erläuterung der Kennzeichnung fehlender Daten s. Hinweise für den Leser. 
Tabelle A7.3b

Private Kosten und privater Nutzen für eine Frau, die einen Abschluss im Tertiärbereich erwirbt (2009) Im Vergleich zu einer Frau, die einen Abschluss im Sekundarbereich II/postsekundaren, nicht tertiären Bereich erwirbt (in US-Dollar, kaufkraftbereinigt mittels KKP für das BIP)

\begin{tabular}{|c|c|c|c|c|c|c|c|c|c|c|c|c|c|}
\hline & Jahr & $\begin{array}{l}\text { Direkte } \\
\text { Kosten }\end{array}$ & $\begin{array}{c}\text { Entgan- } \\
\text { genes } \\
\text { Einkom- } \\
\text { men }\end{array}$ & $\begin{array}{c}\text { Gesamt- } \\
\text { kosten }\end{array}$ & $\begin{array}{l}\text { Einkom- } \\
\text { mens- } \\
\text { vorteile } \\
\text { (brutto) }\end{array}$ & $\begin{array}{c}\text { Effekt } \\
\text { Einkom- } \\
\text { men- } \\
\text { steuer }\end{array}$ & $\begin{array}{c}\text { Effekt } \\
\text { Sozial- } \\
\text { versiche- } \\
\text { rungs- } \\
\text { beiträge }\end{array}$ & $\begin{array}{c}\text { Effekt } \\
\text { Transfer- } \\
\text { leistun- } \\
\text { gen }\end{array}$ & \begin{tabular}{|c|} 
Effekt \\
Erwerbs- \\
losigkeit
\end{tabular} & $\begin{array}{c}\text { Zu- } \\
\text { schüsse }\end{array}$ & $\begin{array}{c}\text { Gesamt- } \\
\text { nutzen }\end{array}$ & $\begin{array}{c}\text { Kapital- } \\
\text { wert }\end{array}$ & $\begin{array}{l}\text { Ertrags- } \\
\text { rate }\end{array}$ \\
\hline & & (1) & (2) & (3) & (4) & (5) & (6) & (7) & (8) & (9) & (10) & (11) & (12) \\
\hline \multicolumn{14}{|l|}{ OECD-Länder } \\
\hline Australien & 2009 & -17528 & -52120 & -69648 & 253308 & -91641 & 0 & 0 & 13021 & 7 & 174695 & 105046 & $8,8 \%$ \\
\hline Österreich & 2009 & -5689 & -57294 & -62983 & 318996 & -87509 & -57683 & 0 & 4947 & 9852 & 188603 & 125620 & $9,1 \%$ \\
\hline Belgien & 2009 & -3514 & -43468 & -46981 & 305193 & -121702 & -72732 & 0 & 32859 & 1047 & 144665 & 97683 & $11,0 \%$ \\
\hline Kanada & 2009 & -16282 & -32449 & -48731 & 249037 & -68337 & -20011 & 0 & 17718 & 1103 & 179511 & 130780 & $12,2 \%$ \\
\hline Chile & & $\mathrm{m}$ & $\mathrm{m}$ & m & $\mathrm{m}$ & $\mathrm{m}$ & $\mathrm{m}$ & $\mathrm{m}$ & $\mathrm{m}$ & $\mathrm{m}$ & m & m & $\mathrm{m}$ \\
\hline Tschechien & 2009 & -4556 & -22004 & -26560 & 234992 & -51432 & -29160 & 0 & 30543 & & 184943 & 158383 & $17,8 \%$ \\
\hline Dänemark & 2009 & -3365 & -57986 & -61351 & 166763 & -60038 & -14206 & -8679 & 7527 & 25189 & 116556 & 55205 & $8,5 \%$ \\
\hline Estland & 2009 & -3583 & -20438 & -24021 & 131866 & -31316 & -3140 & 0 & 24987 & 0 & 122398 & 98377 & $18,5 \%$ \\
\hline Finnland & 2009 & -1873 & -60589 & -62461 & 211875 & -72749 & -15039 & -4079 & 21742 & 8730 & 150480 & 88019 & $8,8 \%$ \\
\hline Frankreich & 2009 & -7868 & -49824 & -57692 & 212928 & -43190 & -32362 & -8444 & 23641 & 3620 & 156192 & 98499 & $8,9 \%$ \\
\hline Deutschland & 2009 & -7061 & -66325 & -73387 & 244493 & -73871 & -55471 & -123 & 24260 & 6021 & 145309 & 71922 & $6,8 \%$ \\
\hline Griechenland & 2009 & -690 & -36674 & -37363 & 186037 & -21786 & -33976 & -29066 & 26865 & & 128074 & 90710 & $9,6 \%$ \\
\hline Ungarn & 2009 & -5131 & -15047 & -20178 & 251870 & -108574 & -47547 & 0 & 27402 & 1283 & 124433 & 104255 & $17,6 \%$ \\
\hline Island & & $\mathrm{m}$ & $\mathrm{m}$ & m & $\mathrm{m}$ & $\mathrm{m}$ & $\mathrm{m}$ & $\mathrm{m}$ & $\mathrm{m}$ & $\mathrm{m}$ & m & $\mathbf{m}$ & $\mathrm{m}$ \\
\hline Irland & 2009 & -6716 & -59372 & -66088 & 391860 & -116093 & -51190 & 0 & 23110 & 4361 & 252048 & 185960 & $14,2 \%$ \\
\hline Israel & 2009 & -13394 & -28918 & -42312 & 181036 & -27193 & -20924 & 0 & 14996 & & 147914 & 105602 & $10,2 \%$ \\
\hline Italien & 2008 & -7285 & -47826 & -55111 & 223811 & -79954 & -21986 & 0 & 7563 & зззо & 132764 & 77652 & $6,9 \%$ \\
\hline Japan & 2007 & -37215 & -49265 & -86481 & 231306 & -20848 & -29117 & 0 & 9951 & & 191293 & 104812 & $7,8 \%$ \\
\hline Korea & 2009 & -23378 & -56149 & -79527 & 255083 & -9753 & -19619 & 0 & 4347 & & 230058 & 150531 & $8,6 \%$ \\
\hline Luxemburg & & $\mathrm{m}$ & $\mathrm{m}$ & m & $\mathrm{m}$ & $\mathrm{m}$ & $\mathrm{m}$ & $\mathrm{m}$ & $\mathrm{m}$ & $\mathrm{m}$ & m & m & $\mathrm{m}$ \\
\hline Mexiko & & $\mathrm{m}$ & $\mathrm{m}$ & m & $\mathrm{m}$ & $\mathrm{m}$ & $\mathrm{m}$ & $\mathrm{m}$ & $\mathrm{m}$ & $\mathrm{m}$ & $\mathbf{m}$ & m & $\mathrm{m}$ \\
\hline Niederlande & 2008 & -14113 & -87458 & -101571 & 339338 & -129641 & -30381 & 0 & 9467 & 14371 & 203152 & 101581 & $7,0 \%$ \\
\hline Neuseeland & 2009 & -10414 & -49614 & -60027 & 133789 & -31532 & -2328 & -2623 & 3114 & 1891 & 102311 & 42283 & $6,9 \%$ \\
\hline Norwegen & 2009 & -1180 & -66522 & -67702 & 224711 & -63163 & -17633 & 0 & 319 & 6226 & 150459 & 82758 & $7,7 \%$ \\
\hline Polen & 2008 & -6291 & -15058 & -21350 & 215086 & -24687 & -52035 & 0 & 27164 & 1742 & 167270 & 145920 & $19,9 \%$ \\
\hline Portugal & 2009 & -8085 & -19280 & -27365 & 259278 & -60491 & -31347 & 0 & 25663 & & 193104 & 165739 & $16,2 \%$ \\
\hline Slowakei & 2009 & -5543 & -17363 & -22906 & 190019 & -34361 & -29863 & 0 & 33017 & 1250 & 160062 & 137156 & $18,5 \%$ \\
\hline Slowenien & 2009 & -3858 & -25447 & -29305 & 358406 & -87540 & -84889 & 0 & 26254 & 226 & 212456 & 183151 & $17,3 \%$ \\
\hline Spanien & 2009 & -10051 & -32691 & -42743 & 240593 & -64677 & -18000 & 0 & 43061 & & 200976 & 158234 & $12,1 \%$ \\
\hline Schweden & 2009 & -4913 & -56388 & -61301 & 141448 & -42879 & -11081 & -10 & 16338 & 8341 & 112156 & 50855 & $6,5 \%$ \\
\hline Schweiz & & $\mathrm{m}$ & $\mathrm{m}$ & m & $\mathrm{m}$ & $\mathrm{m}$ & $\mathrm{m}$ & $\mathrm{m}$ & $\mathrm{m}$ & $\mathrm{m}$ & $\mathbf{m}$ & m & $\mathrm{m}$ \\
\hline Türkei & 2005 & -1061 & -8185 & -9246 & 116530 & -21267 & -19627 & 0 & 14075 & & 89711 & 80466 & $19,2 \%$ \\
\hline Ver. Königreich & 2009 & -28704 & -92382 & -121086 & 355479 & -74244 & -40895 & -1548 & 21048 & 2244 & 262084 & 140998 & $7,5 \%$ \\
\hline Vereinigte Staaten & 2009 & -71053 & -46918 & $\mid-117971$ & 405817 & $\mid-102914$ & -33654 & 0 & 34571 & & 303819 & 185848 & $9,1 \%$ \\
\hline \multicolumn{2}{|l|}{ OECD-Durchschnitt } & -11393 & -43898 & -55291 & 242446 & -62875 & -30893 & -1882 & 19640 & 5042 & 169914 & 114622 & $11,5 \%$ \\
\hline EU21-Durchschnitt & & -6944 & -44146 & -51090 & 249017 & -69337 & -36649 & -2598 & 22873 & 5725 & 167886 & 116796 & $12,1 \%$ \\
\hline \multicolumn{14}{|l|}{ Sonst. G20-Länder } \\
\hline Argentinien & & $\mathrm{m}$ & $\mathrm{m}$ & $\mathbf{m}$ & $\mathrm{m}$ & $\mathrm{m}$ & $\mathrm{m}$ & $\mathrm{m}$ & $\mathrm{m}$ & $\mathrm{m}$ & $\mathbf{m}$ & $\mathbf{m}$ & $\mathrm{m}$ \\
\hline Brasilien & & $\mathrm{m}$ & $\mathrm{m}$ & m & $\mathrm{m}$ & $\mathrm{m}$ & $\mathrm{m}$ & $\mathrm{m}$ & $\mathrm{m}$ & $\mathrm{m}$ & $\mathbf{m}$ & m & $\mathrm{m}$ \\
\hline China & & $\mathrm{m}$ & $\mathrm{m}$ & m & $\mathrm{m}$ & $\mathrm{m}$ & $\mathrm{m}$ & $\mathrm{m}$ & $\mathrm{m}$ & $\mathrm{m}$ & $\mathbf{m}$ & m & $\mathrm{m}$ \\
\hline Indien & & $\mathrm{m}$ & $\mathrm{m}$ & m & $\mathrm{m}$ & $\mathrm{m}$ & $\mathrm{m}$ & $\mathrm{m}$ & $\mathrm{m}$ & $\mathrm{m}$ & $\mathbf{m}$ & m & $\mathrm{m}$ \\
\hline Indonesien & & $\mathrm{m}$ & $\mathrm{m}$ & m & $\mathrm{m}$ & $\mathrm{m}$ & $\mathrm{m}$ & $\mathrm{m}$ & $\mathrm{m}$ & $\mathrm{m}$ & $\mathbf{m}$ & m & $\mathrm{m}$ \\
\hline Russische Föd. & & $\mathrm{m}$ & $\mathrm{m}$ & m & $\mathrm{m}$ & $\mathrm{m}$ & $\mathrm{m}$ & $\mathrm{m}$ & $\mathrm{m}$ & $\mathrm{m}$ & $\mathbf{m}$ & m & $\mathrm{m}$ \\
\hline Saudi-Arabien & & $\mathrm{m}$ & $\mathrm{m}$ & m & $\mathrm{m}$ & $\mathrm{m}$ & $\mathrm{m}$ & $\mathrm{m}$ & $\mathrm{m}$ & $\mathrm{m}$ & m & m & $\mathrm{m}$ \\
\hline Südafrika & & $\mathrm{m}$ & $\mathrm{m}$ & m & $\mathrm{m}$ & $\mathrm{m}$ & $\mathrm{m}$ & $\mathrm{m}$ & $\mathrm{m}$ & $\mathrm{m}$ & $\mathbf{m}$ & $\mathbf{m}$ & $\mathrm{m}$ \\
\hline G20-Durchschnit & & m & $\mathbf{m}$ & $\mathbf{m}$ & m & m & m & $\mathbf{m}$ & $\mathbf{m}$ & $\mathbf{m}$ & $\mathbf{m}$ & $\mathbf{m}$ & \\
\hline
\end{tabular}

Anmerkung: Die Zahlen basieren auf dem Unterschied zwischen Frauen, die einen Abschluss im Tertiärbereich erworben haben, und Frauen, die einen Abschluss im Sekundarbereich II/postsekundaren, nicht tertiären Bereich erworben haben.

Quelle: OECD. Bildung auf einen Blick 2012. Hinweise s. Anhang 3 unter www.oecd.org/edu/eag.htm. StatLink: http://dx.doi.org/10.1787/888932849198 Erläuterung der Kennzeichnung fehlender Daten s. Hinweise für den Leser. 
Staatliche Kosten und staatlicher Nutzen bei einem Mann, der einen Abschluss im Tertiärbereich erwirbt (2009) Im Vergleich zu einem Mann, der einen Abschluss im Sekundarbereich II/postsekundaren, nicht tertiären Bereich erwirbt (in US-Dollar, kaufkraftbereinigt mittels KKP für das BIP)

\begin{tabular}{|c|c|c|c|c|c|c|c|c|c|c|c|c|}
\hline & Jahr & $\begin{array}{l}\text { Direkte } \\
\text { Kosten }\end{array}$ & $\begin{array}{c}\text { Entgan- } \\
\text { gene Ein- } \\
\text { kommen- } \\
\text { steuer }\end{array}$ & $\begin{array}{c}\text { Zu- } \\
\text { schüsse }\end{array}$ & \begin{tabular}{|c} 
Gesamt- \\
kosten
\end{tabular} & $\begin{array}{c}\text { Effekt } \\
\text { Einkom- } \\
\text { men- } \\
\text { steuer }\end{array}$ & $\begin{array}{c}\text { Effekt } \\
\text { Sozial- } \\
\text { versiche- } \\
\text { rungs- } \\
\text { beiträge }\end{array}$ & \begin{tabular}{|c|} 
Effekt \\
Transfer- \\
leistun- \\
gen
\end{tabular} & \begin{tabular}{|c|} 
Effekt \\
Erwerbs- \\
losigkeit
\end{tabular} & $\begin{array}{l}\text { Gesamt- } \\
\text { nutzen }\end{array}$ & $\begin{array}{c}\text { Kapital- } \\
\text { wert }\end{array}$ & $\begin{array}{c}\text { Ertrags- } \\
\text { rate }\end{array}$ \\
\hline & & (1) & (2) & (3) & (4) & (5) & (6) & (7) & (8) & (9) & (10) & (11) \\
\hline \multicolumn{13}{|l|}{ OECD-Länder } \\
\hline Australien & 2009 & -14588 & -5652 & -7 & -20247 & 123233 & 0 & 0 & 1208 & 124441 & 104194 & $13,1 \%$ \\
\hline Österreich & 2009 & -40474 & -10137 & -9852 & -60463 & 125114 & 55730 & 0 & 8682 & 189527 & 129064 & $9,3 \%$ \\
\hline Belgien & 2009 & -30735 & -10360 & -1047 & -42142 & 149793 & 51455 & 0 & 9957 & 211206 & 169064 & $13,3 \%$ \\
\hline Kanada & 2009 & -27580 & -5892 & -1103 & -34575 & 89400 & 5792 & 0 & 8666 & 103858 & 69283 & $8,8 \%$ \\
\hline Chile & & $\mathrm{m}$ & $\mathrm{m}$ & $\mathrm{m}$ & & $\mathrm{m}$ & $\mathrm{m}$ & $\mathrm{m}$ & $\mathrm{m}$ & $\mathbf{m}$ & $\mathbf{m}$ & $\mathrm{m}$ \\
\hline Tschechien & 2009 & -18675 & 2044 & 0 & -16631 & 85412 & 46743 & 0 & 4642 & 136796 & 120165 & $17,2 \%$ \\
\hline Dänemark & 2009 & -70252 & -26675 & -25189 & -122116 & 135256 & 21252 & 9435 & 5601 & 171544 & 49427 & $4,5 \%$ \\
\hline Estland & 2009 & -14486 & -2513 & 0 & -16999 & 30876 & 3001 & 0 & 10647 & 44524 & 27525 & $10,2 \%$ \\
\hline Finnland & 2009 & -42400 & -8324 & -8730 & -59454 & 128733 & 22053 & 0 & 12738 & 163525 & 104071 & $8,3 \%$ \\
\hline Frankreich & 2009 & -35052 & -10203 & -3620 & -48875 & 81969 & 43570 & 880 & 3789 & 130208 & 81333 & $7,5 \%$ \\
\hline Deutschland & 2009 & -38170 & -24581 & -6021 & -68772 & 127860 & 58572 & 0 & 23056 & 209489 & 140717 & $9,1 \%$ \\
\hline Griechenland & 2009 & -20179 & 2956 & 0 & -17223 & 34885 & 28464 & 8700 & 1766 & 73816 & 56593 & $11,6 \%$ \\
\hline Ungarn & 2009 & -18036 & -3507 & -1283 & -22826 & 177893 & 78934 & 0 & 17153 & 273981 & 251155 & $25,4 \%$ \\
\hline Island & & $\mathrm{m}$ & $\mathrm{m}$ & $\mathrm{m}$ & & $\mathrm{m}$ & $\mathrm{m}$ & $\mathrm{m}$ & $\mathrm{m}$ & $\mathbf{m}$ & $\mathbf{m}$ & $\mathrm{m}$ \\
\hline Irland & 2009 & -34708 & -1558 & -4361 & -40627 & 199558 & 35080 & 0 & 26781 & 261419 & 220792 & $17,0 \%$ \\
\hline Israel & 2009 & -18626 & -1695 & 0 & -20321 & 66889 & 33788 & 0 & 2861 & 103538 & 83217 & $11,3 \%$ \\
\hline Italien & 2008 & -17538 & -11836 & -3330 & -32704 & 157696 & 41484 & 0 & 2217 & 201397 & 168693 & $10,1 \%$ \\
\hline Japan & 2007 & -17897 & -15254 & 0 & -33151 & 62285 & 33612 & 0 & 4665 & 100562 & 67411 & $8,4 \%$ \\
\hline Korea & 2009 & -8250 & -6238 & 0 & -14488 & 33093 & 23097 & 0 & 2281 & 58472 & 43983 & $17,4 \%$ \\
\hline Luxemburg & & $\mathrm{m}$ & $\mathrm{m}$ & $\mathrm{m}$ & & $\mathrm{m}$ & $\mathrm{m}$ & $\mathrm{m}$ & $\mathrm{m}$ & $\mathbf{m}$ & $\mathbf{m}$ & $\mathrm{m}$ \\
\hline Mexiko & & $\mathrm{m}$ & $\mathrm{m}$ & $\mathrm{m}$ & & $\mathrm{m}$ & $\mathrm{m}$ & $\mathrm{m}$ & $\mathrm{m}$ & $\mathbf{m}$ & $\mathbf{m}$ & $\mathrm{m}$ \\
\hline Niederlande & 2008 & -37382 & -39015 & -14371 & -90768 & 201244 & 21220 & 0 & 1863 & 224327 & 133560 & $7,4 \%$ \\
\hline Neuseeland & 2009 & -22037 & -5766 & -1891 & -29694 & 63286 & 3207 & 0 & 842 & 67334 & 37640 & $6,9 \%$ \\
\hline Norwegen & 2009 & -36777 & -20675 & -6226 & -63679 & 101586 & 21334 & 0 & 2902 & 125821 & 62143 & $5,7 \%$ \\
\hline Polen & 2008 & -14435 & -5361 & -1742 & -21539 & 53177 & 78804 & 0 & 7824 & 139805 & 118266 & $15,0 \%$ \\
\hline Portugal & 2009 & -16226 & -2822 & 0 & -19048 & 81284 & 33419 & 0 & 1821 & 116524 & 97476 & $12,4 \%$ \\
\hline Slowakei & 2009 & -15033 & -1660 & -1250 & -17943 & 50956 & 38359 & 0 & 8689 & 98004 & 80061 & $14,2 \%$ \\
\hline Slowenien & 2009 & -21977 & -7917 & -226 & -30120 & 124522 & 105125 & 0 & 8201 & 237848 & 207728 & $15,8 \%$ \\
\hline Spanien & 2009 & -37506 & -3361 & 0 & -40867 & 48062 & 11981 & 0 & 8429 & 68472 & 27605 & $5,3 \%$ \\
\hline Schweden & 2009 & -39997 & -14512 & -8341 & -62850 & 83967 & 9847 & 0 & 4690 & 98504 & 35654 & $4,9 \%$ \\
\hline Schweiz & & $\mathrm{m}$ & $\mathrm{m}$ & $\mathrm{m}$ & & $\mathrm{m}$ & $\mathrm{m}$ & $\mathrm{m}$ & $\mathrm{m}$ & $\mathbf{m}$ & $\mathbf{m}$ & $\mathrm{m}$ \\
\hline Türkei & 2005 & -9567 & -3814 & 0 & -13381 & 18209 & 16010 & 0 & 886 & 35106 & 21724 & $9,3 \%$ \\
\hline Ver. Königreich & 2009 & -15151 & -18315 & -2244 & -35710 & 82547 & 42425 & 0 & 8830 & 133802 & 98091 & $11,1 \%$ \\
\hline Vereinigte Staaten & 2009 & -42430 & -5543 & 0 & -47973 & 201429 & 51098 & 0 & 26168 & 278695 & 230722 & $14,1 \%$ \\
\hline OECD-Durchschnitt & & -26764 & -9248 & -3477 & -39489 & 100697 & 35016 & 656 & 7857 & 144226 & 104737 & $11,2 \%$ \\
\hline EU21-Durchschnitt & & -28921 & -9883 & -4580 & -43384 & 108040 & 41376 & 951 & 8869 & 159236 & 115852 & $11,5 \%$ \\
\hline \multicolumn{13}{|l|}{ Sonst. G20-Länder } \\
\hline Argentinien & & $\mathrm{m}$ & $\mathrm{m}$ & $\mathrm{m}$ & m & $\mathrm{m}$ & $\mathrm{m}$ & $\mathrm{m}$ & $\mathrm{m}$ & m & m & $\mathrm{m}$ \\
\hline Brasilien & & $\mathrm{m}$ & $\mathrm{m}$ & $\mathrm{m}$ & $\mathbf{m}$ & $\mathrm{m}$ & $\mathrm{m}$ & $\mathrm{m}$ & $\mathrm{m}$ & $\mathbf{m}$ & $\mathbf{m}$ & $\mathrm{m}$ \\
\hline China & & $\mathrm{m}$ & $\mathrm{m}$ & $\mathrm{m}$ & $\mathbf{m}$ & $\mathrm{m}$ & $\mathrm{m}$ & $\mathrm{m}$ & $\mathrm{m}$ & $\mathbf{m}$ & $\mathbf{m}$ & $\mathrm{m}$ \\
\hline Indien & & $\mathrm{m}$ & $\mathrm{m}$ & $\mathrm{m}$ & m & $\mathrm{m}$ & $\mathrm{m}$ & m & $\mathrm{m}$ & m & m & $\mathrm{m}$ \\
\hline Indonesien & & $\mathrm{m}$ & $\mathrm{m}$ & $\mathrm{m}$ & m & $\mathrm{m}$ & $\mathrm{m}$ & $\mathrm{m}$ & $\mathrm{m}$ & m & m & $\mathrm{m}$ \\
\hline Russische Föd. & & $\mathrm{m}$ & $\mathrm{m}$ & $\mathrm{m}$ & $\mathbf{m}$ & $\mathrm{m}$ & $\mathrm{m}$ & $\mathrm{m}$ & $\mathrm{m}$ & $\mathbf{m}$ & $\mathbf{m}$ & $\mathrm{m}$ \\
\hline Saudi-Arabien & & $\mathrm{m}$ & $\mathrm{m}$ & $\mathrm{m}$ & m & $\mathrm{m}$ & $\mathrm{m}$ & $\mathrm{m}$ & $\mathrm{m}$ & $\mathbf{m}$ & $\mathbf{m}$ & $\mathrm{m}$ \\
\hline Südafrika & & $\mathrm{m}$ & $\mathrm{m}$ & $\mathrm{m}$ & m & $\mathrm{m}$ & $\mathrm{m}$ & $\mathrm{m}$ & $\mathrm{m}$ & m & $\mathbf{m}$ & $\mathrm{m}$ \\
\hline G20-Durchschnitt & & m & $\mathbf{m}$ & $\mathbf{m}$ & m & m & m & m & m & $\mathbf{m}$ & m & m \\
\hline
\end{tabular}

Anmerkung: Die Zahlen basieren auf dem Unterschied zwischen Männern, die einen Abschluss im Tertiärbereich erworben haben, und Männern, die einen Abschluss im Sekundarbereich II/postsekundaren, nicht tertiären Bereich erworben haben.

Quelle: OECD. Bildung auf einen Blick 2012. Hinweise s. Anhang 3 unter www.oecd.org/edu/eag.htm. StatLink: http://dx.doi.org/10.1787/888932849217 Erläuterung der Kennzeichnung fehlender Daten s. Hinweise für den Leser. 
Tabelle A7.4b

Staatliche Kosten und staatlicher Nutzen bei einer Frau, die einen Abschluss im Tertiärbereich erwirbt (2009) Im Vergleich zu einer Frau, die einen Abschluss im Sekundarbereich II/postsekundaren, nicht tertiären Bereich erwirbt

(in US-Dollar, kaufkraftbereinigt mittels KKP für das BIP)

\begin{tabular}{|c|c|c|c|c|c|c|c|c|c|c|c|c|}
\hline & Jahr & $\begin{array}{l}\text { Direkte } \\
\text { Kosten }\end{array}$ & $\begin{array}{l}\text { Entgan- } \\
\text { gene Ein- } \\
\text { kommen- } \\
\text { steuer }\end{array}$ & $\begin{array}{c}\text { Zu- } \\
\text { schüsse }\end{array}$ & $\begin{array}{l}\text { Gesamt- } \\
\text { kosten }\end{array}$ & $\begin{array}{c}\text { Effekt } \\
\text { Einkom- } \\
\text { men- } \\
\text { steuer }\end{array}$ & \begin{tabular}{c|} 
Effekt \\
Sozial- \\
versiche- \\
rungs- \\
beiträge
\end{tabular} & \begin{tabular}{c|} 
Effekt \\
Transfer- \\
leistun- \\
gen
\end{tabular} & $\begin{array}{c}\text { Effekt } \\
\text { Erwerbs- } \\
\text { losigkeit }\end{array}$ & $\begin{array}{c}\text { Gesamt- } \\
\text { nutzen }\end{array}$ & $\begin{array}{c}\text { Kapital- } \\
\text { wert }\end{array}$ & $\begin{array}{l}\text { Ertrags- } \\
\text { rate }\end{array}$ \\
\hline & & (1) & (2) & (3) & (4) & (5) & (6) & (7) & (8) & (9) & (10) & (11) \\
\hline \multicolumn{13}{|l|}{ OECD-Länder } \\
\hline Australien & 2009 & -14588 & -5797 & -7 & -20392 & 89111 & 0 & 0 & 2530 & 91641 & 71249 & $13,7 \%$ \\
\hline Österreich & 2009 & -40474 & -10337 & -9852 & -60663 & 86600 & 56802 & 0 & 1790 & 145192 & 84529 & $7,1 \%$ \\
\hline Belgien & 2009 & -30735 & -9917 & -1047 & -41699 & 113699 & 68183 & 0 & 12552 & 194434 & 152735 & $15,7 \%$ \\
\hline Kanada & 2009 & -27580 & -6231 & -1103 & -34914 & 65263 & 18759 & 0 & 4325 & 88347 & 53433 & $8,5 \%$ \\
\hline Chile & & $m$ & $\mathrm{~m}$ & $\mathrm{~m}$ & & $\mathrm{~m}$ & $\mathrm{~m}$ & $\mathrm{~m}$ & $\mathrm{~m}$ & $\mathbf{m}$ & $\mathbf{m}$ & $\mathrm{m}$ \\
\hline Tschechien & 2009 & -18131 & 1954 & 0 & -16177 & 47167 & 25813 & 0 & 7612 & 80592 & 64415 & $14,1 \%$ \\
\hline Dänemark & 2009 & -70252 & -27671 & -25189 & -123112 & 57873 & 13394 & 8679 & 2976 & 82923 & -40189 & $1,2 \%$ \\
\hline Estland & 2009 & -14486 & -2799 & 0 & -17285 & 27197 & 2643 & 0 & 4616 & 34456 & 17170 & $8,0 \%$ \\
\hline Finnland & 2009 & -42400 & -8862 & -8730 & -59992 & 68219 & 13657 & 4079 & 5912 & 91868 & 31876 & $5,2 \%$ \\
\hline Frankreich & 2009 & -35052 & -9877 & -3620 & -48548 & 40275 & 29147 & 8444 & 6130 & 83996 & 35448 & $6,2 \%$ \\
\hline Deutschland & 2009 & -38170 & -25378 & -6021 & -69569 & 69954 & 50504 & 123 & 8884 & 129465 & 59896 & $6,1 \%$ \\
\hline Griechenland & 2009 & -20179 & 2480 & 0 & -17699 & 20386 & 29703 & 29066 & 5673 & 84828 & 67129 & $11,7 \%$ \\
\hline Ungarn & 2009 & -18036 & -3654 & -1283 & -22972 & 101528 & 42906 & 0 & 11687 & 156121 & 133149 & $18,2 \%$ \\
\hline Island & & $\mathrm{m}$ & $\mathrm{m}$ & $\mathrm{m}$ & & $\mathrm{m}$ & $\mathrm{m}$ & $\mathrm{m}$ & $\mathrm{m}$ & $\mathbf{m}$ & $\mathbf{m}$ & $\mathrm{m}$ \\
\hline Irland & 2009 & -34708 & -1834 & -4361 & -40903 & 112479 & 49498 & 0 & 5306 & 167283 & 126380 & $13,7 \%$ \\
\hline Israel & 2009 & -18626 & -1737 & 0 & -20363 & 26284 & 19949 & 0 & 1883 & 48117 & 27754 & $7,1 \%$ \\
\hline Italien & 2008 & -17538 & -11185 & -3330 & -32053 & 77919 & 21270 & 0 & 2750 & 101940 & 69886 & $8,0 \%$ \\
\hline Japan & 2007 & -17897 & -10654 & 0 & -28551 & 20218 & 27924 & 0 & 1822 & 49965 & 21414 & $6,2 \%$ \\
\hline Korea & 2009 & -8250 & -5734 & 0 & -13984 & 9689 & 19291 & 0 & 393 & 29372 & 15388 & $6,5 \%$ \\
\hline Luxemburg & & $\mathrm{m}$ & $\mathrm{m}$ & $\mathrm{m}$ & & $\mathrm{m}$ & $\mathrm{m}$ & $\mathrm{m}$ & $\mathrm{m}$ & $\mathbf{m}$ & $\mathbf{m}$ & $\mathrm{m}$ \\
\hline Mexiko & & $\mathrm{m}$ & $\mathrm{m}$ & $\mathrm{m}$ & & $\mathrm{m}$ & $\mathrm{m}$ & $\mathrm{m}$ & $\mathrm{m}$ & m & m & $\mathrm{m}$ \\
\hline Niederlande & 2008 & -37382 & -35640 & -14371 & -87392 & 128001 & 28440 & 0 & 3582 & 160023 & 72630 & $6,2 \%$ \\
\hline Neuseeland & 2009 & -22037 & -5767 & -1891 & -29695 & 30974 & 2276 & 2623 & 611 & 36484 & 6788 & $4,4 \%$ \\
\hline Norwegen & 2009 & -36777 & -20680 & -6226 & -63684 & 63118 & 17608 & 0 & 70 & 80796 & 17112 & $4,2 \%$ \\
\hline Polen & 2008 & -14435 & -5047 & -1742 & -21225 & 22460 & 46221 & 0 & 8041 & 76723 & 55498 & $10,9 \%$ \\
\hline Portugal & 2009 & -16226 & -2750 & 0 & -18976 & 56926 & 28536 & 0 & 6375 & 91837 & 72861 & $11,1 \%$ \\
\hline Slowakei & 2009 & -15033 & -1668 & -1250 & -17951 & 31258 & 25456 & 0 & 7510 & 64223 & 46272 & $11,2 \%$ \\
\hline Slowenien & 2009 & -21977 & -7773 & -226 & -29975 & 83288 & 79108 & 0 & 10033 & 172429 & 142454 & $13,0 \%$ \\
\hline Spanien & 2009 & -37506 & -3366 & 0 & -40872 & 59154 & 15280 & 0 & 8243 & 82677 & 41805 & $6,5 \%$ \\
\hline Schweden & 2009 & -39997 & -15126 & -8341 & -63464 & 39273 & 9944 & 10 & 4743 & 53970 & -9494 & $2,3 \%$ \\
\hline Schweiz & & $\mathrm{m}$ & $\mathrm{m}$ & $\mathrm{m}$ & & $\mathrm{m}$ & $\mathrm{m}$ & $\mathrm{m}$ & $\mathrm{m}$ & m & $\mathbf{m}$ & $\mathrm{m}$ \\
\hline Türkei & 2005 & -9567 & -3320 & 0 & -12887 & 19194 & 17528 & 0 & 4171 & 40894 & 28006 & $9,1 \%$ \\
\hline Ver. Königreich & 2009 & -15151 & -5958 & -2244 & -23353 & 71002 & 39051 & 1548 & 5086 & 116686 & 93333 & $14,8 \%$ \\
\hline Vereinigte Staaten & 2009 & -42430 & -6038 & 0 & -48468 & 97093 & 31023 & 0 & 8452 & 136568 & 88100 & $9,5 \%$ \\
\hline \multicolumn{2}{|l|}{ OECD-Durchschnitt } & -26746 & -8633 & -3477 & -38856 & 59848 & 28618 & 1882 & 5302 & 95650 & 56794 & $9,0 \%$ \\
\hline EU21-Durchschnitt & & -28893 & -9220 & -4580 & -42694 & 65733 & 33778 & 2598 & 6475 & 108583 & 65889 & $9,6 \%$ \\
\hline
\end{tabular}

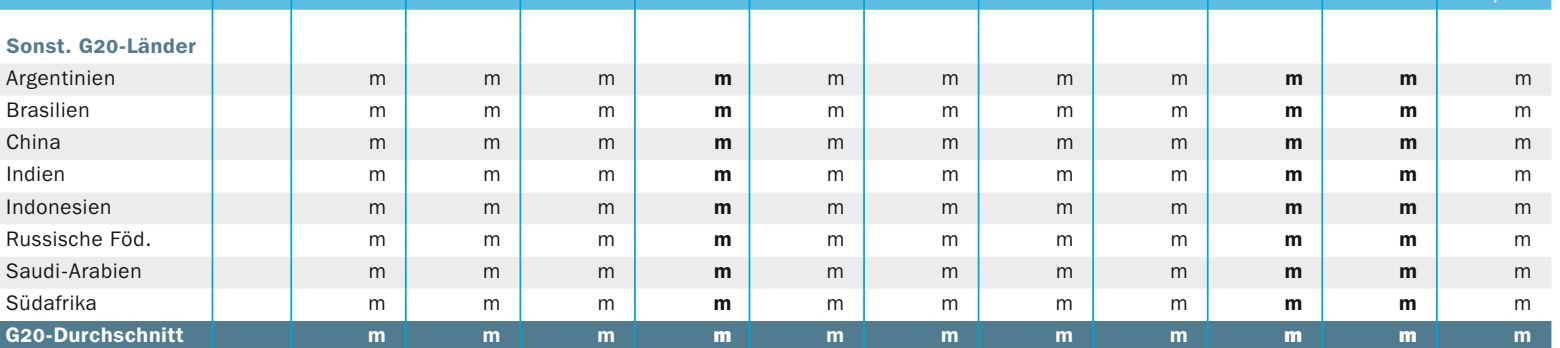

Anmerkung: Die Zahlen basieren auf dem Unterschied zwischen Frauen, die einen Abschluss im Tertiärbereich erworben haben, und Frauen, die einen Abschluss im Sekundarbereich II/postsekundaren, nicht tertiären Bereich erworben haben.

Quelle: OECD. Bildung auf einen Blick 2012. Hinweise s. Anhang 3 unter www.oecd.org/edu/eag.htm. StatLink: http://dx.doi.org/10.1787/888932849236 Erläuterung der Kennzeichnung fehlender Daten s. Hinweise für den Leser. 


\section{Was sind die gesamtgesellschaftlichen Auswirkungen von Bildung?}

In Durchschnitt von 24 OECD-Ländern ist die Wahrscheinlichkeit, dass Erwachsene mit einem Abschluss im Tertiärbereich fettleibig sind, halb so groß wie die von Personen, die über eine Ausbildung unterhalb des Sekundarbereichs II verfügen.

In 23 OECD-Ländern ist bei Absolventen des Tertiärbereichs die Wahrscheinlichkeit zu rauchen im Durchschnitt 6 Prozentpunkte niedriger als bei Erwachsenen, die über eine Ausbildung unterhalb des Sekundarbereichs II verfügen.

Abbildung A8.1

Anteil der Erwachsenen, die fettleibig sind, nach Bildungsstand (2011)

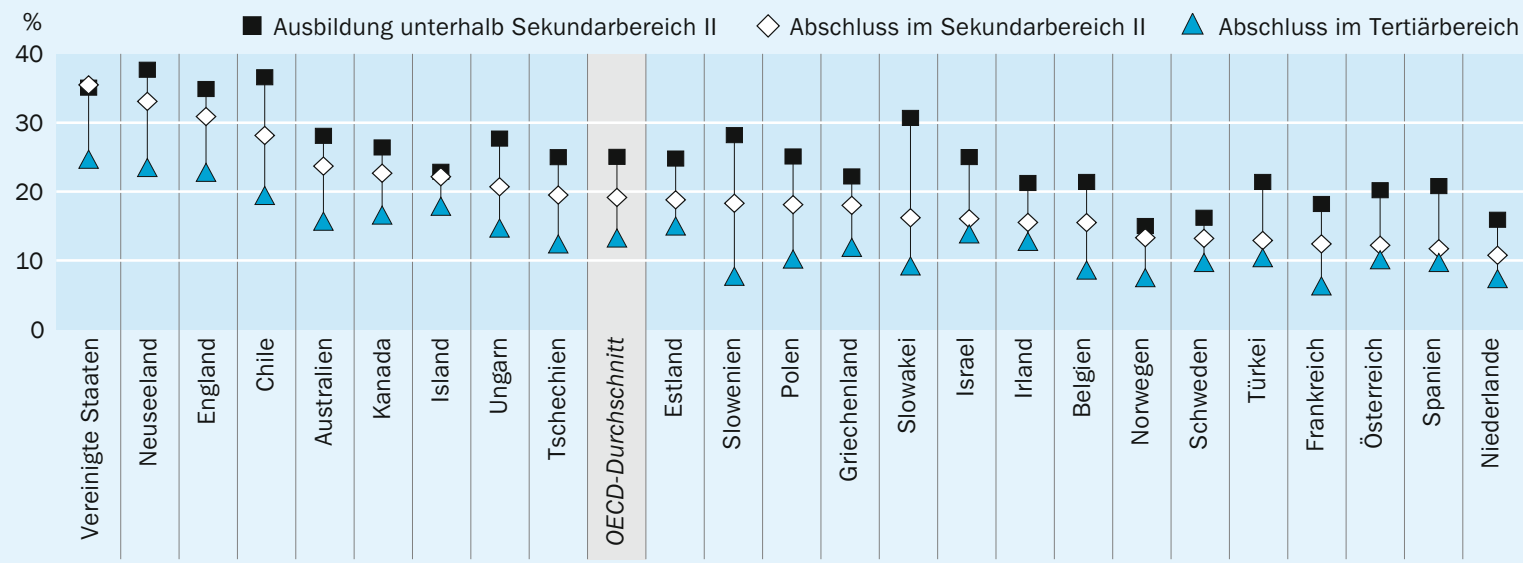

Anmerkung: Als fettleibig gelten Personen mit einem Body-Mass-Index (BMI) von 30 und darüber. Die verwendeten Erhebungsfragen s. Anhang 3. Referenzjahr für die Daten ist 2011, außer für Australien 2010, Belgien 2008, Chile 2009/2010, England 2010, Estland 2006, Frankreich 2008, Griechenland 2009, Irland 2007, Island 2007, Israel 2010, Niederlande 2008, Norwegen 2008, Österreich 2006, Polen 2009, Slowakei 2009, Slowenien 2007, Spanien 2009, Tschechien 2008, Türkei 2008, Ungarn 2009.

Anordnung der Länder in absteigender Reihenfolge des Anteils 25- bis 64-jähriger Erwachsener, die einen BMI von 30 und darüber angeben, an allen Erwachsenen mit einem Abschluss im Sekundarbereich II.

Quelle: OECD. Tabelle A8.1. Hinweise s. Anhang 3 unter www.oecd.org/edu/eag.htm. StatLink: http://dx.doi.org/10.1787/888932846709

\section{Kontext}

Trotz des schnellen Anstiegs der Lebenserwartung während der letzten Jahrzehnte bleibt die Gesundheit ein wichtiges politisches Anliegen in den OECD-Ländern. Die Art der Gesundheitsprobleme hat sich stark verändert, schwerwiegende chronische Erkrankungen, wie Diabetes und schwere Depressionen, haben stark zugenommen, gleichzeitig haben sich gesundheitsrelevante Verhaltensweisen in den Bereichen Ernährung, Sport und Alkoholkonsum verschlechtert. Darüber hinaus gibt es Besorgnis über die ausgeprägten Unterschiede beim Gesundheitszustand, da sich bestimmte demografische und sozioökonomische Gruppen in einem signifikant schlechteren Gesundheitszustand befinden (WHO, 2008). Insgesamt sind 2010 in den OECDLändern die Ausgaben im Gesundheitsbereich auf 9,5 Prozent des BIP gestiegen, von 3,9 Prozent bei Gründung der OECD im Jahr 196r. Es ist davon auszugehen, dass sie 
aufgrund der alternden Bevölkerung in den OECD-Ländern auch weiter steigen werden (OECD, 20II).

Bildung kann sich auf das Vorkommen von Fettleibigkeit und Rauchen auswirken, da Kindheit und Jugend eine wichtige Zeit für die Entwicklung eines gesundheitsbewussten Verhaltens sind (OECD, 20I0). In der diesjährigen Ausgabe von Bildung auf einen Blick werden zwei Gesundheitsindikatoren, Fettleibigkeit und Rauchen, und ihr Zusammenhang mit dem Bildungsstand untersucht.

\section{Weitere wichtige Ergebnisse}

Bei Erwachsenen mit einem höheren Bildungsstand ist die Wahrscheinlichkeit von Fettleibigkeit und täglichem Rauchen niedriger. Die Reduzierung der Fettleibigkeitsquoten bei steigendem Bildungsstand ist bei Frauen wesentlich höher, ebenso auch in Ländern mit einem im Durchschnitt hohen Anteil fettleibiger Personen. Die Verringerung der Raucherquoten nach Bildungsstand ist bei Männern wesentlich höher als bei Frauen. Diese Verringerung ist außerdem in den mitteleuropäischen und überwiegend englischsprachigen Ländern höher als in anderen OECD-Ländern.

Die Beziehung zwischen Bildungsstand und Gesundheitsindikatoren (Fettleibigkeit und tägliches Rauchen) bleibt auch nach Berücksichtigung von geschlechts-, alters- und einkommensspezifischen Unterschieden stark. 


\section{Analyse und Interpretationen}

\section{Fettleibigkeit}

Fettleibigkeit hat laut der WHO inzwischen epidemische Ausmaße erreicht (WHO, 2008). Sie wird mit schwerwiegenden chronischen Erkrankungen, Behinderungen, einer geringeren Lebensqualität und einer kürzeren Lebenserwartung in Verbindung gebracht. Außerdem beeinflusst sie die psychische Gesundheit und sozialen Kontakte des Einzelnen und wird mit negativen Auswirkungen auf die Bildungsergebnisse in Verbindung gebracht (OECD, 2010). Die zunehmende Fettleibigkeit betrifft alle Bevölkerungsgruppen, allerdings deuten die Forschungsergebnisse darauf hin, dass Fettleibigkeit bei Angehörigen benachteiligter sozioökonomischer Gruppen, insbesondere bei Frauen, tendenziell häufiger vorzukommen scheint.

Im Durchschnitt der 24 OECD-Länder mit verfügbaren Daten sind etwa I9 Prozent der Erwachsenen fettleibig (Tab. A8.I). Fettleibigkeit tritt besonders häufig bei Personen mit einer Ausbildung unterhalb des Sekundarbereichs II auf (25 Prozent) und relativ selten bei Personen mit einem Abschluss im Tertiärbereich (I3 Prozent). Die mit einer höheren Bildung in Verbindung gebrachte inkrementelle Verbesserung im Bereich Gesundheit (in diesem Fall I2 Prozentpunkte) wird im Allgemeinen als Bildungsgradient bezeichnet. Der Bildungsgradient für Fettleibigkeit verläuft bei Frauen besonders steil: ein Unterschied von 16 Prozentpunkten, verglichen mit einem Unterschied von 7 Prozentpunkten bei Männern.

Einige Länder, in denen Fettleibigkeit häufig auftritt - Chile, Neuseeland und die Vereinigten Staaten -, weisen einen besonders steilen Bildungsgradienten von durchschnittlich I4 Prozentpunkten auf. Der Bildungsgradient beträgt in den Ländern mit einem weniger häufigen Auftreten von Fettleibigkeit (den Niederlanden, Norwegen und Schweden) im Durchschnitt 8 Prozentpunkte (Tab. A8.I).

Wird die zwischen Bildungsstand und Fettleibigkeit bestehende Beziehung vor allem durch Alter oder Geschlecht bestimmt? Es kann beispielsweise sein, dass bei jüngeren Altersgruppen (oder Frauen) eine geringere Wahrscheinlichkeit der Fettleibigkeit besteht und dass sie auch über höhere Bildungsabschlüsse als die älteren Altersgruppen (oder Männer) verfügen. Tabelle A8.3 enthält regressionsbasierte Schätzungen, die diese Unterschiede berücksichtigen. Sie deuten darauf hin, dass die Beziehung zwischen Bildungsstand und Fettleibigkeit auch nach Berücksichtigung von Geschlecht und Alter ausgeprägt bleibt.

\section{Rauchen}

Im Durchschnitt ist der Anteil der Raucher in der Bevölkerung in den letzten ro Jahren um 20 Prozent zurückgegangen, mit einem stärkeren Rückgang bei den Frauen (OECD, 20II). Dennoch ist Rauchen immer noch für etwa ro Prozent der Todesfälle bei Erwachsenen verantwortlich und die wichtigste Ursache für Kreislauf- und Krebserkrankungen (OECD 20II). In allen OECD-Ländern mit Ausnahme von Schweden rauchen mehr Männer als Frauen. Dieser geschlechtsspezifische Unterschied ist in China, Indonesien, Japan, Korea, der Russischen Föderation und der Türkei besonders hoch. Für Personen mit einem sozioökonomisch ungünstigen Hintergrund wird ein höherer Anteil an Rauchern und intensiveres Rauchen gemeldet. 
Anteil der Erwachsenen, die rauchen, nach Bildungsstand (2011)

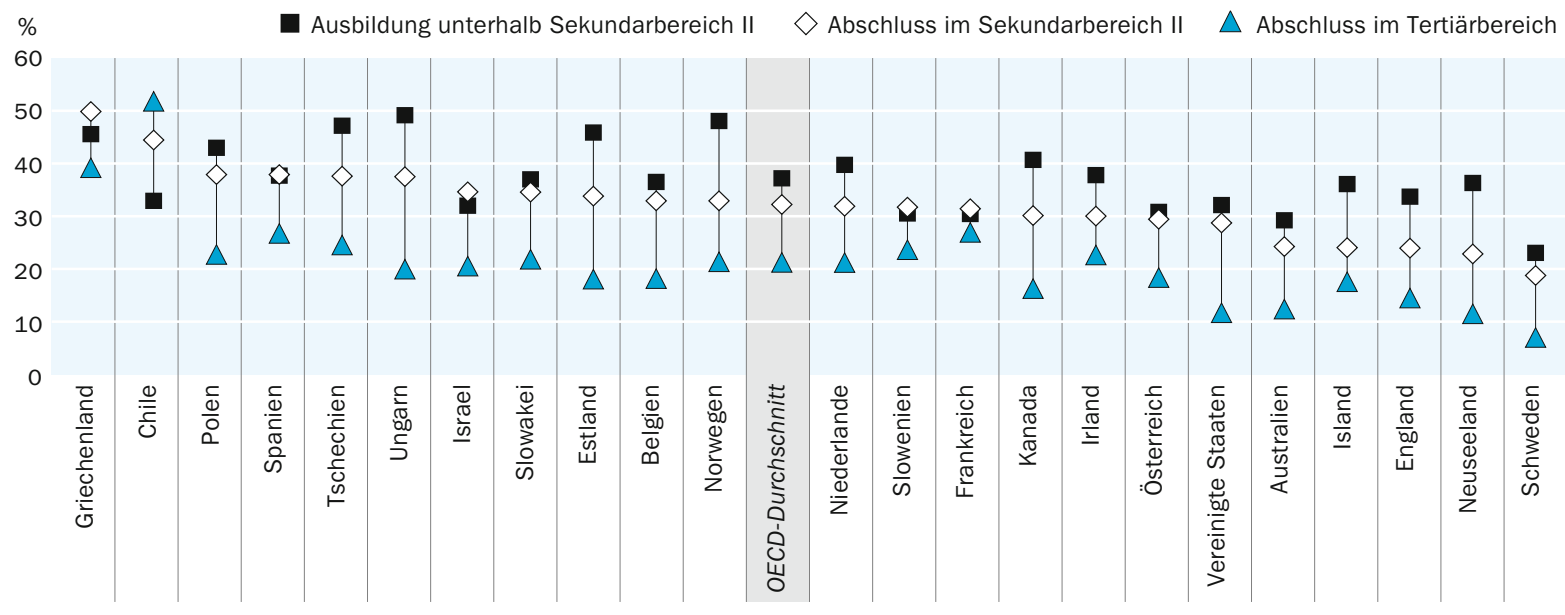

Anmerkung: Personen, die rauchen, werden definiert als Personen, die gegenwärtig rauchen bzw. Tabakprodukte konsumieren. Die verwendeten Erhebungsfragen s. Anhang 3. Referenzjahr für die Daten ist 2011, außer für Australien 2010, Belgien 2008, Chile 2009/2010, England 2010, Estland 2006, Frankreich 2008, Griechenland 2009, Irland 2007, Island 2007, Israel 2010, Niederlande 2008, Norwegen 2008, Österreich 2006, Polen 2009, Slowakei 2009, Slowenien 2007, Spanien 2009, Tschechien 2008, Ungarn 2009.

Anordnung der Länder in absteigender Reihenfolge des Anteils 25- bis 64-jähriger Erwachsener, die angeben regelmäßig zu rauchen, an allen Erwachsenen mit einem Abschluss im Sekundarbereich II.

Quelle: OECD. Tabelle A8.2. Hinweise s. Anhang 3 unter oecd.org/edu/eag.htm. StatLink: http://dx.doi.org/10.1787/888932846728

In den in diesem Zusammenhang erfassten 23 OECD-Ländern rauchen 30 Prozent der Erwachsenen täglich (Tab. A8.2). Der Anteil der Personen, die täglich rauchen, ist bei Personen mit einer Ausbildung unterhalb des Sekundarbereichs II besonders hoch (37 Prozent) und bei Personen mit einem Abschluss im Tertiärbereich niedrig (2I Prozent). Der Bildungsgradient ist bei Männern besonders hoch, mit einem Unterschied von 20 Prozentpunkten bei der Häufigkeit des täglichen Rauchens. Bei Frauen beträgt dieser Bildungsgradient nur I3 Prozentpunkte (Tab. A8.2).

Bestimmte mitteleuropäische Länder, insbesondere Estland, Polen, Tschechien und Ungarn, die vorwiegend englischsprachigen Länder, d. h. Australien, Kanada, Neuseeland und die Vereinigten Staaten sowie Norwegen weisen besonders hohe Bildungsgradienten auf. In all diesen Ländern ist die Wahrscheinlichkeit, dass Erwachsene mit mindestens einem Abschluss im Tertiärbereich derzeit rauchen, halb so hoch wie bei Personen mit einer Ausbildung unterhalb des Sekundarbereichs II (Tab. A8.2).

Der Zusammenhang zwischen Bildungsstand und täglichem Rauchen wird im Allgemeinen nicht von individuellen geschlechts- und altersspezifischen Unterschieden beeinflusst. Regressionsbasierte Schätzungen, die diese Unterschiede berücksichtigen, deuten darauf hin, dass die Beziehung zwischen Bildungsstand und täglichem Rauchen auch nach der Berücksichtigung von Geschlecht und Alter im Allgemeinen ausgeprägt bleibt (Tab. A8.4).

\section{Auswirkungen des Bildungsstands auf das Einkommen}

Bildung kann dadurch direkte Auswirkungen auf gesundheitsrelevante Verhaltensweisen und Ergebnisse haben, dass der Einzelne durch Bildung lernen kann, sich für einen gesünderen Lebensstil zu entscheiden und gesundheitsschädliche Verhaltensweisen 
zu vermeiden. Bildung kann die Gesundheit auch indirekt beeinflussen, da bei Personen mit einem höheren Bildungsstand die Wahrscheinlichkeit höher ist, dass sie mehr Geld verdienen und sich eine bessere Gesundheitsversorgung und Lebensweise leisten können. Um diese indirekten Auswirkungen zu betrachten, enthalten die Tabellen A8.3 und A8.4 regressionsbasierte Schätzungen, die die Auswirkungen des Einkommens berücksichtigen. Die Ergebnisse belegen, dass der Einfluss des Bildungsstands auch nach Berücksichtigung der Auswirkungen des Einkommens hoch bleibt. Dies lässt vermuten, dass Bildung durch eine Verbesserung der Kompetenzen und Gewohnheiten Einfluss auf die Gesundheit haben kann, wobei andere mit der Wahl der (Aus-)Bildung zusammenhängende Faktoren oder die Auswirkungen bestimmter Qualifikationen auf die Lebensentwürfe durchaus ebenfalls eine Rolle spielen können.

\section{Definitionen}

Dieser Abschnitt beschreibt den Bildungsstand und gesundheitsbezogene Variablen. Eine detaillierte Beschreibung der Variablen einschließlich der in jeder Erhebung verwendeten Fragen findet sich in Anhang 3 unter www.oecd.orgleduleag.htm.

Die Bildungsstandvariablen in den einzelnen Datenquellen wurden auf der Grundlage des ISCED-97-Klassifizierungssystems einer von drei Kategorien des Bildungsstands zugeordnet (Ausbildung unterhalb des Sekundarbereichs II, Abschluss im Sekundarbereich II und Abschluss im Tertiärbereich). Bildungsbereiche: Unterhalb des Sekundarbereichs II umfasst die ISCED-Stufen $0, \mathrm{I}, 2$ und ${ }_{3} \mathrm{C}$ (kurz); Sekundarbereich II oder postsekundarer, nicht tertiärer Bereich umfasst die ISCED-Stufen $3 \mathrm{~A},{ }_{3} \mathrm{~B}$ und ${ }_{3} \mathrm{C}$ (lang) sowie 4 und Tertiärbereich die ISCED-Stufen $5 \mathrm{~A}, 5^{\mathrm{B}}$ und 6 . Erläuterungen zu den einzelnen ISCED-Bereichen s. Hinweise für den Leser im vorderen Teil des Buches.

Fettleibigkeit und Übergewicht werden als ein zu hohes Gewicht definiert, das aufgrund des hohen Anteils an Körperfett ein Gesundheitsrisiko darstellt. Die am häufigsten verwendete Methode basiert auf dem Body-Mass-Index (BMI), bei dem es sich um eine einzelne Zahl handelt, die das Gewicht des Einzelnen im Verhältnis zu seiner Größe (Gewicht/Größe ${ }^{2}$, Gewicht in Kilogramm und Größe in Meter) bewertet. Auf der Grundlage der WHO-Klassifizierung werden Erwachsene mit einem BMI von 25 bis 30 als übergewichtig definiert und Erwachsene mit einem BMI von 30 und darüber als fettleibig. Diese Klassifizierung mag nicht für alle ethnischen Gruppen geeignet sein, da bei vielen Gruppen entsprechende Risikostufen bei einem niedrigeren oder höheren BMI bestehen. Die Schwellenwerte für Erwachsene sind nicht geeignet, um Übergewicht und Fettleibigkeit bei Kindern zu messen (OCED, 20II).

Tägliches Rauchen bedeutet, dass eine Person derzeit täglich raucht oder Tabak auf andere Weise konsumiert. Die internationale Vergleichbarkeit ist aufgrund der fehlenden Standardisierung der Messung von Rauchgewohnheiten in Fragebogenerhebungen zur Gesundheit in den einzelnen OECD-Ländern nur eingeschränkt gegeben. In einigen nordischen Ländern gibt es eine signifikante Zahl von Nutzern von Snus (nitrosaminarmen rauchlosen Tabak). In der Fachliteratur wird geschätzt, dass Snus die Gesundheitsrisiken der Nutzer im Vergleich zur Zigarette um 9o Prozent senkt. Aufgrund einer teilweisen Substituierbarkeit (d. h., dass einige Zigarettenraucher statt Zigaretten Snus 
verwenden), hat Snus positive Auswirkungen auf die öffentliche Gesundheit (SCENIHR, 2008). Daher sind in Norwegen und Schweden Nutzer von Snus, die nicht gleichzeitig Raucher sind, nicht in diesen Indikator einbezogen.

\section{Angewandte Methodik}

Angesichts der potenziell signifikanten Unterschiede zwischen den einzelnen Ländern bei den Standards zur Messung von Fettleibigkeit und Rauchen sollten diese Indikatoren mit Vorsicht interpretiert werden (für Einzelheiten siehe Anhang 3 unter www.oecd. org/edu/eag.htm). Der Schwerpunkt sollte auf eher bildungsabhängigen Unterschieden bei den gesundheitsrelevanten Verhaltensweisen und Ergebnissen innerhalb eines Landes liegen und nicht auf Vergleichen zwischen einzelnen Ländern.

Dieser Indikator basiert auf gemeinsamen Entwicklungsarbeiten des INES-Netzwerks zu den Arbeitsmarktergebnissen sowie den wirtschaftlichen und sozialen Auswirkungen des Lernens (LSO) und dem OECD-Zentrum für Forschung und Innovation im Bildungswesen (CERI). Der konzeptuelle Rahmen für diese Indikatoren basiert auf den Arbeiten des CERI-Projekts „Social Outcomes of Learning“ (OECD, 2007; OECD, 20Io), die empirischen Untersuchungsstrategien wurden vom INES/LSO-Netzwerk entwickelt. Nähere Angaben zur Berechnung der Indikatoren siehe Anhang 3 unter www. oecd.org/eduleag.htm.

Die diesjährige Ausgabe von Bildung auf einen Blick enthält neue Indikatoren, die vor allem unter Verwendung der Mikrodaten aus der Europäischen Gesundheitsbefragung (European Health Interview Survey) (Eurostat) berechnet wurden, die eine vereinheitlichte und relativ gut vergleichbare Datenquelle in den europäischen Ländern darstellt. Zur Berechnung von Indikatoren aus außereuropäischen Ländern wurden verschiedene Erhebungen verwendet, unter anderem: in Australien der Australian Institute of Health and Welfare's National Drug Strategy Household Survey 2010 des Australian Data Archive; in Kanada der Community Health Survey 2010; in Chile die Nationale Gesundheitsbefragung (Encuesta Nacional de Salud - ENS) 2009/2010; in England der Health Survey 2010; in Island der Questioner Survey, Health and Wellbeing of Icelanders 2007; in Irland der Survey of Lifestyle and Attitudes to Nutrition 2007; in Israel die Sozialerhebung aus dem Jahr 2010; in Neuseeland der Health Survey 20Ir/2012; in den Niederlanden die Fragebogenerhebung Gesundheit (Teil der Ständigen Erhebung zu den Lebensbedingungen - POLS) 2008; in Norwegen die nationale Gesundheitsbefragung 2008; in Schweden die Erhebungen zu den Lebensbedingungen von Statistics Sweden 20II; und in den Vereinigten Staaten der National Health Interview Survey 20II. Hierbei ist zu berücksichtigen, dass die Daten aller Länder auf im Rahmen von Erhebungen gemachten Selbstangaben beruhen, wodurch nicht unbedingt die wirkliche Prävalenz von Fettleibigkeit und Rauchen erfasst wird.

Die Erhebungen wurden auf der Grundlage folgender Faktoren gewählt:

Altersbegrenzung: Verwendet wurden Erhebungen mit Erwachsenen im Alter von 25 bis 64 Jahren. 
Vergleichbarkeit der Variablen für den Bildungsstand: Im Allgemeinen wurden Mikrodaten verwendet, bei denen die Verteilung des Bildungsstands höchstens um Io Prozentpunkte von den Verteilungen abweicht, die für vergleichbare Jahre in Bildung aufeinen Blick veröffentlicht wurden.

Vergleichbarkeit der Variablen für die Gesundheit: Die Auswahl der Erhebungen basierte auf der Vergleichbarkeit der Variablen, die die Identifizierung von Fettleibigkeit und täglichem Rauchen ermöglichen.

Länderabdeckung: Ein ganz wesentliches Ziel ist es, Erhebungen auszuwählen, die es erlauben, Ergebnisse aus vielen OECD-Ländern vorzustellen. Aus diesem Grund wurde die Erhebung European Health Interview Survey ausgewählt, die die Erwachsenenbevölkerung einer großen Zahl der Mitgliedstaaten der Europäischen Union sowie anderer Staaten abdeckt.

Stichprobenumfang: Verwendet wurden Erhebungen mit mindestens rund I.00o Fällen pro Land, um zu verlässlichen Schätzungen zu gelangen. Die meisten Erhebungen in diesem Bereich weisen einen relativ großen Stichprobenumfang auf.

Zur Berechnung inkrementeller Differenzen (in Prozentpunkten) wurden länderspezifische Regressionsmodelle genutzt, um jede dichotome Ergebnisvariable (z. B. hohe gegenüber niedriger Inzidenz von Fettleibigkeit) aus dem Bildungsstand des Einzelnen vorherzusagen, mit und ohne Kontrollvariable für Alter, Geschlecht und Familieneinkommen. In vorläufigen Analysen wurden sowohl das Probitmodell als auch die Methode der kleinsten Quadrate (ordinary least squares - OLS) verwendet, in beiden Fällen ergaben sich sehr ähnliche Schätzungen der inkrementellen Differenzen. In der abschließenden Analyse wurde zur Erzeugung der inkrementellen Differenzen OLS verwendet, da die mit diesem Verfahren ermittelten Koeffizienten leichter zu interpretieren sind (Tab. A8.3 und A8.4).

Die statistischen Daten für Israel wurden von den zuständigen israelischen Stellen bereitgestellt, die für sie verantwortlich zeichnen. Die Verwendung dieser Daten durch die OECD erfolgt unbeschadet des völkerrechtlichen Status der Golanhöhen, von OstJerusalem und der israelischen Siedlungen im Westjordanland.

\section{Weiterführende Informationen}

Eurostat (2010), Statistical Database, http://epp.eurostat.ec.europa.eu/portal/page/portal/ population/data/database.

OECD (2007), Understanding the Social Outcomes of Learning, OECD Publishing, http://dx. doi.org/10.1787/9789264034181-en.

OECD (2010), Improving Health and Social Cohesion through Education, Educational Research and Innovation, OECD Publishing, http://dx.doi.org/10.1787/20769679. 
OECD (20II), Health at a Glance: OECD Indicators, OECD Publishing, http:/|dx.doi. org/10.1787/health_glance-2011-en.

Scientific Committee on Emerging and Newly Identified Health Risks (SCENIHR) (2008), Health Effects of Smokeless Tobacco Products, European Commission, February.

World Health Organization (WHO) (2008), Closing the Gap in a Generation, WHO, Geneva.

\section{Tabellen Indikator A8}

Tabelle A8.I: Anteil der Erwachsenen, die fettleibig sind, nach Bildungsstand und Geschlecht (20II)

StatLink: http://dx.doi.org/10.1787/888932849274

Tabelle A8.2: Anteil der Erwachsenen, die rauchen, nach Bildungsstand und Geschlecht (20II)

StatLink: http:/|dx.doi.org/10.1787/888932849293

Tabelle A8.3: Unterschied bei der „Wahrscheinlichkeit, fettleibig zu sein“ (in Prozentpunkten), der mit einem höheren Bildungsstand zusammenhängt (20II) StatLink: http:/|dx.doi.org/10.1787/888932849312

Tabelle A8.4: Unterschied bei der „Wahrscheinlichkeit zu rauchen“ (in Prozentpunkten), der mit einem höheren Bildungsstand zusammenhängt (20II) StatLink: http:/|dx.doi.org/10.1787/888932849331 
Anteil der Erwachsenen, die fettleibig sind, nach Bildungsstand und Geschlecht (2011) In Prozent der 25- bis 64-Jährigen

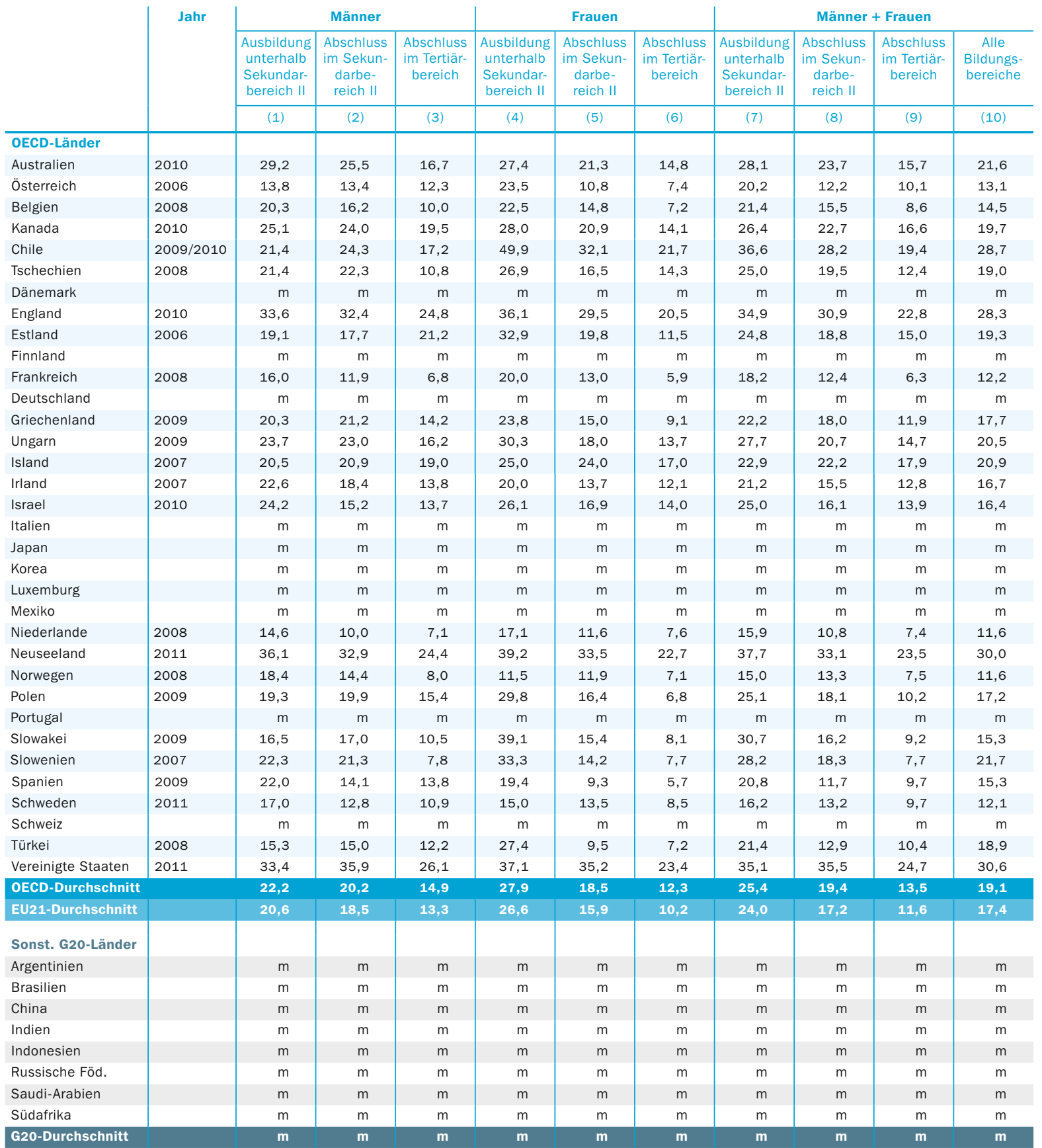

Anmerkung: Als fettleibig gelten Personen mit einem Body-Mass-Index (BMI) von 30 und darüber (verwendete Erhebungsfragen s. Anhang 3).

Quelle: Europäische Gesundheitsbefragung (European Health Interview Survey EHIS) für Belgien, Estland, Frankreich, Griechenland, Österreich, Polen, Slowakei, Slowenien, Spanien, Tschechien, die Türkei und Ungarn. National Drug Strategy Household Survey für Australien. Canadian Community Health Survey für Kanada. Nationale Gesundheitsbefragung für Chile. Health Survey für England. Fragebogenerhebung Health and Wellbeing of Icelanders für Island. Survey of Lifestyle and Attitudes to Nutrition für Irland. Sozialerhebung für Israel. Fragebogenerhebung Gesundheit für die Niederlande. New Zealand Health Survey für Neuseeland. Norwegische Gesundheitsbefragung für Norwegen. Erhebungen zu den Lebensbedingungen für Schweden. National Health Interview Survey für die Vereinigten Staaten. Hinweise s. Anhang 3 unter www.oecd.org/edu/eag/htm. StatLink: http://dx.doi.org/10.1787/888932849274 Erläuterung der Kennzeichnung fehlender Daten s. Hinweise für den Leser. 
Tabelle A8.2

Anteil der Erwachsenen, die rauchen, nach Bildungsstand und Geschlecht (2011)

In Prozent der 25- bis 64-Jährigen

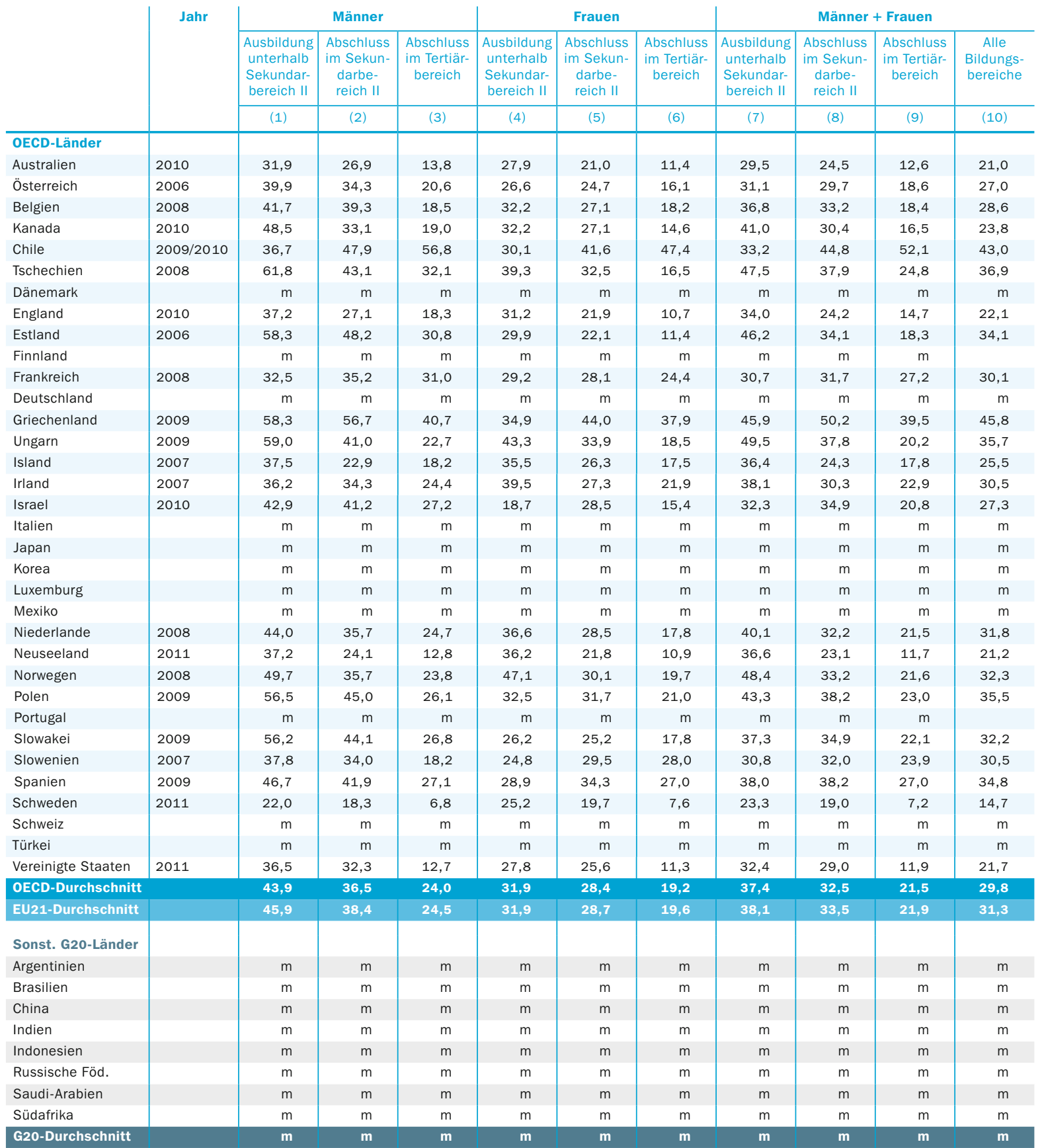

Anmerkung: Personen, die rauchen, werden definiert als Personen, die gegenwärtig rauchen bzw. Tabakprodukte konsumieren (verwendete Erhebungsfragen s. Anhang 3).

Quelle: Europäische Gesundheitsbefragung (European Health Interview Survey EHIS) für Belgien, Estland, Frankreich, Griechenland, Österreich, Polen, Slowakei, Slowenien, Spanien, Tschechien, die Türkei und Ungarn. National Drug Strategy Household Survey für Australien. Canadian Community Health Survey für Kanada. Nationale Gesundheitsbefragung für Chile. Health Survey für England. Fragebogenerhebung Health and Wellbeing of Icelanders für Island. Survey of Lifestyle and Attitudes to Nutrition für Irland. Sozialerhebung für Israel. Fragebogenerhebung Gesundheit für die Niederlande. New Zealand Health Survey für Neuseeland. Norwegische Gesundheitsbefragung für Norwegen. Erhebungen zu den Lebensbedingungen für Schweden. National Health Interview Survey für die Vereinigten Staaten. Hinweise s. Anhang 3 unter www.oecd.org/edu/eag.htm. StatLink: http://dx.doi.org/10.1787/888932849293

Erläuterung der Kennzeichnung fehlender Daten s. Hinweise für den Leser. 
Tabelle A8.3

Unterschied bei der „Wahrscheinlichkeit, fettleibig zu sein“ (in Prozentpunkten), der mit einem höheren Bildungsstand zusammenhängt (2011)

In Prozent der 25- bis 64-Jährigen, nach Bildungsstand

\begin{tabular}{|c|c|c|c|c|c|c|c|c|}
\hline & \multirow[t]{3}{*}{ Jahr } & \multirow{2}{*}{$\begin{array}{c}\text { Anteil fettlei- } \\
\text { biger Erwach- } \\
\text { sener (in \%) } \\
\text { an Personen } \\
\text { mit einem } \\
\text { Abschluss im } \\
\text { Sekundar- } \\
\text { bereich II }\end{array}$} & \multicolumn{3}{|c|}{$\begin{array}{c}\text { Unterschied im Ergebnis zwischen Ausbildung } \\
\text { unterhalb des Sekundarbereichs II } \\
\text { und Abschluss im Sekundarbereich II }\end{array}$} & \multicolumn{3}{|c|}{$\begin{array}{c}\text { Unterschied im Ergebnis zwischen Abschluss } \\
\text { im Sekundarbereich II } \\
\text { und Abschluss im Tertiärbereich }\end{array}$} \\
\hline & & & $\begin{array}{c}\text { Ohne } \\
\text { Kontrollvariable }\end{array}$ & $\begin{array}{c}\text { Kontrollvariable } \\
\text { Alter, } \\
\text { Geschlecht }\end{array}$ & $\begin{array}{l}\text { Kontrollvariable } \\
\text { Alter, } \\
\text { Geschlecht, } \\
\text { Einkommen }\end{array}$ & $\begin{array}{c}\text { Ohne } \\
\text { Kontrollvariable }\end{array}$ & $\begin{array}{l}\text { Kontrollvariable } \\
\text { Alter, } \\
\text { Geschlecht }\end{array}$ & $\begin{array}{l}\text { Kontrollvariable } \\
\text { Alter, } \\
\text { Geschlecht, } \\
\text { Einkommen }\end{array}$ \\
\hline & & (1) & (2) & (3) & (4) & (5) & (6) & $(7)$ \\
\hline \multicolumn{9}{|l|}{ OECD-Länder } \\
\hline Australien & 2010 & 23,7 & $-4,4$ & $-3,1$ & $-2,9$ & $-8,0$ & $-7,5$ & $-7,4$ \\
\hline Österreich & 2006 & 12,2 & $-8,0$ & $-6,6$ & $-6,4$ & $-2,1$ & $-2,2$ & $-1,6$ \\
\hline Belgien & 2008 & 15,5 & $-5,9$ & $-4,0$ & $-3,9$ & $-6,9$ & $-6,7$ & $-6,5$ \\
\hline Kanada & 2010 & 22,7 & $-3,7$ & $-3,4$ & $-3,3$ & $-6,1$ & $-5,3$ & $-5,4$ \\
\hline Chile & $2009 / 2010$ & 28,2 & 8,5 & 5,0 & 5,5 & $-8,7$ & $-7,1$ & $-6,5$ \\
\hline Tschechien & 2008 & 19,5 & $-5,5$ & $-3,5$ & $-2,3$ & $-7,1$ & $-5,4$ & $-4,4$ \\
\hline Dänemark & & $\mathrm{m}$ & $\mathrm{m}$ & $\mathrm{m}$ & $\mathrm{m}$ & $\mathrm{m}$ & $\mathrm{m}$ & $\mathrm{m}$ \\
\hline England & 2010 & 30,9 & $-4,0$ & $-2,1$ & $-1,1$ & $-8,1$ & $-7,7$ & $-6,3$ \\
\hline Estland & 2006 & 18,8 & $-6,0$ & $-5,1$ & $-5,6$ & $-3,8$ & $-1,8$ & $-1,7$ \\
\hline Finnland & & $\mathrm{m}$ & $\mathrm{m}$ & $\mathrm{m}$ & $\mathrm{m}$ & $\mathrm{m}$ & $\mathrm{m}$ & $\mathrm{m}$ \\
\hline Frankreich & 2008 & 12,4 & $-5,8$ & $-4,7$ & $-4,7$ & $-6,1$ & $-5,6$ & $-5,6$ \\
\hline Deutschland & & $\mathrm{m}$ & $\mathrm{m}$ & $\mathrm{m}$ & $\mathrm{m}$ & $\mathrm{m}$ & $\mathrm{m}$ & $\mathrm{m}$ \\
\hline Griechenland & 2009 & 18,0 & $-4,2$ & $-0,0$ & $-0,1$ & $-6,1$ & $-6,9$ & $-6,9$ \\
\hline Ungarn & 2009 & 20,7 & $-7,0$ & $-5,7$ & $-6,0$ & $-6,0$ & $-4,2$ & $-3,2$ \\
\hline Island & 2007 & 22,2 & $-0,7$ & $-0,2$ & $-0,1$ & $-4,3$ & $-4,2$ & $-2,9$ \\
\hline Irland & 2007 & 15,5 & $-5,7$ & $-4,6$ & $-4,4$ & $-2,8$ & $-2,2$ & $-2,2$ \\
\hline Israel & 2010 & 16,1 & $-9,0$ & $-5,9$ & $-6,0$ & $-2,2$ & $-4,0$ & $-3,9$ \\
\hline Italien & & $\mathrm{m}$ & $\mathrm{m}$ & $\mathrm{m}$ & $\mathrm{m}$ & $\mathrm{m}$ & $\mathrm{m}$ & $\mathrm{m}$ \\
\hline Japan & & $m$ & $\mathrm{~m}$ & $\mathrm{~m}$ & $\mathrm{~m}$ & $\mathrm{~m}$ & $\mathrm{~m}$ & $\mathrm{~m}$ \\
\hline Korea & & $\mathrm{m}$ & $\mathrm{m}$ & $\mathrm{m}$ & $\mathrm{m}$ & $\mathrm{m}$ & $\mathrm{m}$ & $\mathrm{m}$ \\
\hline Luxemburg & & $\mathrm{m}$ & $\mathrm{m}$ & $\mathrm{m}$ & $\mathrm{m}$ & $\mathrm{m}$ & $\mathrm{m}$ & $\mathrm{m}$ \\
\hline Mexiko & & $\mathrm{m}$ & $\mathrm{m}$ & $\mathrm{m}$ & $\mathrm{m}$ & $\mathrm{m}$ & $\mathrm{m}$ & $\mathrm{m}$ \\
\hline Niederlande & 2008 & 10,8 & $\mathrm{~m}$ & $\mathrm{~m}$ & $\mathrm{~m}$ & $m$ & $\mathrm{~m}$ & $\mathrm{~m}$ \\
\hline Neuseeland & 2011 & $\mathrm{~m}$ & $m$ & $\mathrm{~m}$ & $\mathrm{~m}$ & $\mathrm{~m}$ & $\mathrm{~m}$ & $\mathrm{~m}$ \\
\hline Norwegen & 2008 & 33,1 & $-1,7$ & $-1,7$ & $-1,2$ & $-5,8$ & $-5,6$ & $-5,2$ \\
\hline Polen & 2009 & 18,1 & $-7,0$ & $-3,7$ & $-4,1$ & $-7,9$ & $-4,8$ & $-5,3$ \\
\hline Portugal & & $\mathrm{m}$ & $\mathrm{m}$ & $\mathrm{m}$ & $\mathrm{m}$ & $\mathrm{m}$ & $\mathrm{m}$ & $\mathrm{m}$ \\
\hline Slowakei & 2009 & 16,2 & $-14,5$ & $-10,1$ & $-9,7$ & $-7,0$ & $-5,1$ & $-5,1$ \\
\hline Slowenien & 2007 & 18,3 & $-9,9$ & $-7,1$ & $-6,2$ & $-10,6$ & $-9,2$ & $-6,9$ \\
\hline Spanien & 2009 & 11,7 & $-9,0$ & $-7,7$ & $-7,0$ & $-2,0$ & $-1,5$ & $-0,4$ \\
\hline Schweden & 2011 & 13,2 & $\mathrm{~m}$ & $\mathrm{~m}$ & $\mathrm{~m}$ & $\mathrm{~m}$ & $\mathrm{~m}$ & $\mathrm{~m}$ \\
\hline Schweiz & & $\mathrm{m}$ & $\mathrm{m}$ & $\mathrm{m}$ & $\mathrm{m}$ & $\mathrm{m}$ & $\mathrm{m}$ & $\mathrm{m}$ \\
\hline Türkei & 2008 & 12,9 & $-8,5$ & $-4,1$ & $-4,8$ & $-2,4$ & $-2,9$ & $-3,6$ \\
\hline Vereinigte Staaten & 2011 & 35,5 & 0,4 & 0,4 & 2,2 & $-10,8$ & $-10,7$ & $-8,3$ \\
\hline \multicolumn{2}{|l|}{ OECD-Durchschnitt } & 18,4 & $-5,4$ & $-3,8$ & $-3,5$ & $-6,0$ & $-5,3$ & $-4,8$ \\
\hline EU21-Durchschnitt & & 17,2 & $-7,3$ & $-5,2$ & $-4,9$ & $-5,9$ & $-4,9$ & $-4,4$ \\
\hline \multicolumn{9}{|l|}{ Sonst. G20-Länder } \\
\hline Argentinien & & $\mathrm{m}$ & $\mathrm{m}$ & $\mathrm{m}$ & $\mathrm{m}$ & $\mathrm{m}$ & $\mathrm{m}$ & $\mathrm{m}$ \\
\hline Brasilien & & $\mathrm{m}$ & $\mathrm{m}$ & $\mathrm{m}$ & $\mathrm{m}$ & $\mathrm{m}$ & $\mathrm{m}$ & $\mathrm{m}$ \\
\hline China & & $\mathrm{m}$ & $\mathrm{m}$ & $\mathrm{m}$ & $\mathrm{m}$ & $\mathrm{m}$ & $\mathrm{m}$ & $\mathrm{m}$ \\
\hline Indien & & $\mathrm{m}$ & $\mathrm{m}$ & $\mathrm{m}$ & $\mathrm{m}$ & $\mathrm{m}$ & $\mathrm{m}$ & $\mathrm{m}$ \\
\hline Indonesien & & $\mathrm{m}$ & $m$ & $\mathrm{~m}$ & $m$ & $\mathrm{~m}$ & $\mathrm{~m}$ & $\mathrm{~m}$ \\
\hline Russische Föd. & & $\mathrm{m}$ & $\mathrm{m}$ & $\mathrm{m}$ & $\mathrm{m}$ & $\mathrm{m}$ & $\mathrm{m}$ & $\mathrm{m}$ \\
\hline Saudi-Arabien & & $\mathrm{m}$ & $\mathrm{m}$ & $\mathrm{m}$ & $\mathrm{m}$ & $\mathrm{m}$ & $\mathrm{m}$ & $\mathrm{m}$ \\
\hline Südafrika & & $\mathrm{m}$ & $\mathrm{m}$ & $\mathrm{m}$ & $\mathrm{m}$ & $\mathrm{m}$ & $\mathrm{m}$ & $\mathrm{m}$ \\
\hline G20-Durchschnitt & & m & m & $\mathbf{m}$ & m & m & $\mathbf{m}$ & $\mathbf{m}$ \\
\hline
\end{tabular}

Anmerkung: Als fettleibig gelten Personen mit einem Body-Mass-Index (BMI) von 30 und darüber (verwendete Erhebungsfragen s. Anhang 3). Abgesehen von Spalte (1) basieren die Berechnungen auf Regressionen der kleinsten Quadrate (ordinary least squares - OLS) bei 25-bis 64-jährigen Erwachsenen. Fett gedruckte Werte sind statistisch signifikant und bei 5 Prozent ungleich 0. Nicht lineare Modelle (Probitmodelle) ergeben ähnliche Ergebnisse.

Quelle: Europäische Gesundheitsbefragung (European Health Interview Survey EHIS) für Belgien, Estland, Frankreich, Griechenland, Österreich, Polen, Slowakei, Slowenien, Spanien, Tschechien, die Türkei und Ungarn. National Drug Strategy Household Survey für Australien. Canadian Community Health Survey für Kanada. Nationale Gesundheitsbefragung für Chile. Health Survey für England. Fragebogenerhebung Health and Wellbeing of Icelanders für Island. Survey of Lifestyle and Attitudes to Nutrition für Irland. Sozialerhebung für Israel. Fragebogenerhebung Gesundheit für die Niederlande. New Zealand Health Survey für Neuseeland. Norwegische Gesundheitsbefragung für Norwegen. Erhebungen zu den Lebensbedingungen für Schweden. National Health Interview Survey für die Vereinigten Staaten. Hinweise s. Anhang 3 unter www.oecd.org/edu/eag.htm. StatLink: http://dx.doi.org/10.1787/888932849312 Erläuterung der Kennzeichnung fehlender Daten s. Hinweise für den Leser. 
Tabelle A8.4

Unterschied bei der „Wahrscheinlichkeit zu rauchen“ (in Prozentpunkten), der mit einem höheren Bildungsstand zusammenhängt (2011)

In Prozent der 25- bis 64-Jährigen, nach Bildungsstand

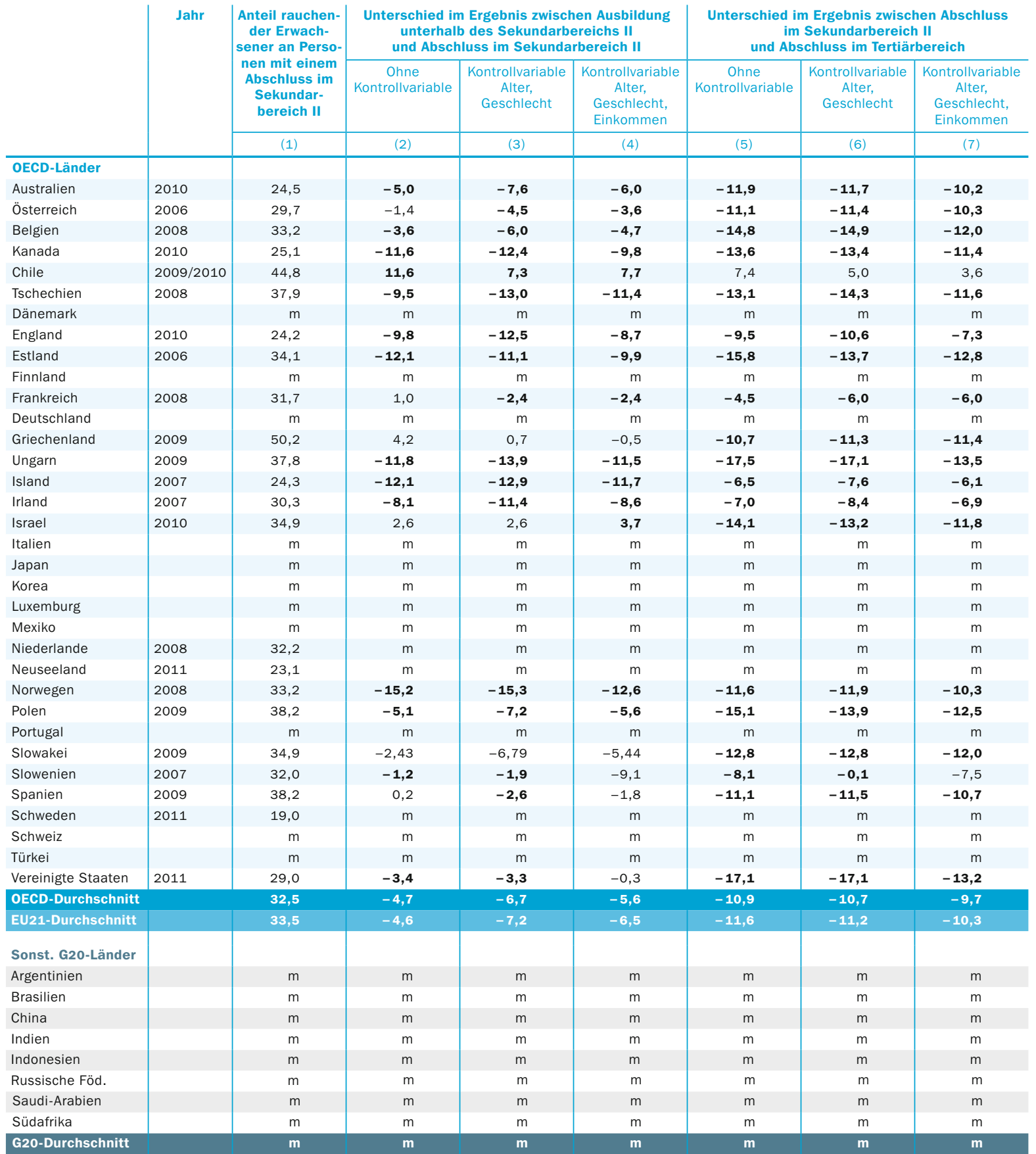

Anmerkung: Raucher sind definiert als Personen, die gegenwärtig rauchen oder andere Tabakprodukte konsumieren (verwendete Erhebungsfragen s. Anhang 3). Abgesehen von Spalte (1) basieren die Berechnungen auf Regressionen der kleinsten Quadrate (ordinary least squares - OLS) bei 25- bis 64-jährigen Erwachsenen. Fett gedruckte Werte sind statistisch signifikant und bei 5 Prozent ungleich 0. Nicht lineare Modelle (Probitmodelle) ergeben ähnliche Ergebnisse.

Quelle: Europäische Gesundheitsbefragung (European Health Interview Survey EHIS) für Belgien, Estland, Frankreich, Griechenland, Österreich, Polen, Slowakei, Slowenien, Spanien, Tschechien, die Türkei und Ungarn. National Drug Strategy Household Survey für Australien. Canadian Community Health Survey für Kanada. Nationale Gesundheitsbefragung für Chile. Health Survey für England. Fragebogenerhebung Health and Wellbeing of Icelanders für Island. Survey of Lifestyle and Attitudes to Nutrition für Irland. Sozialerhebung für Israel. Fragebogenerhebung Gesundheit für die Niederlande. New Zealand Health Survey für Neuseeland. Norwegische Gesundheitsbefragung für Norwegen. Erhebungen zu den Lebensbedingungen für Schweden. National Health Interview Survey für die Vereinigten Staaten. Hinweise s. Anhang 3 unter www.oecd.org/edu/eag.htm. StatLink: http://dx.doi.org/10.1787/888932849331 Erläuterung der Kennzeichnung fehlender Daten s. Hinweise für den Leser. 


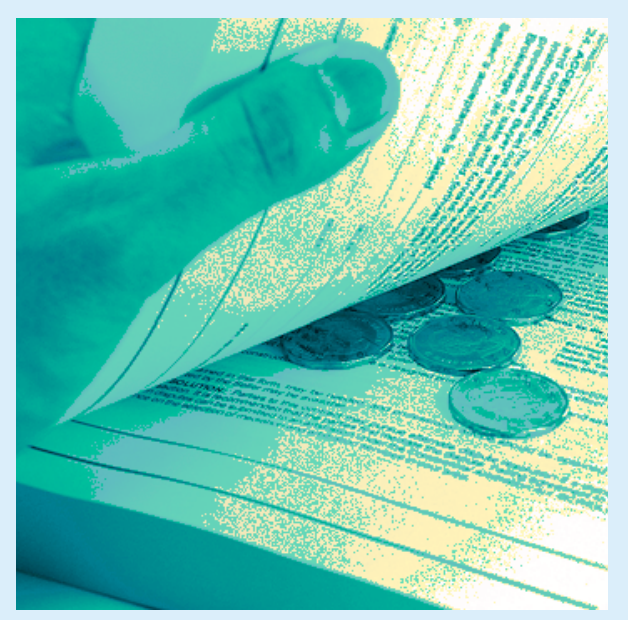

\section{Die in Bildung investierten Finanz- und Humanressourcen}

Indikator $\mathrm{BI}$

Wie hoch sind die Ausgaben pro Schüler/

Studierenden?

StatLink: http://dx.doi.org/10.1787/888932849350

Indikator B2

Welcher Teil des Bruttoinlandsprodukts wird für Bildung ausgegeben?

StatLink:http:||dx.doi.org/10.1787/888932849559

Indikator $\mathrm{B}_{3}$

Wie groß ist der Anteil der öffentlichen und der privaten Ausgaben im Bildungswesen?

StatLink: http:||dx.doi.org/10.1787/888932849673

Indikator $\mathrm{B} 4$

Wie hoch sind die öffentlichen Gesamtausgaben für Bildung?

StatLink: http://dx.doi.org/10.1787/888932849787
Indikator $\mathrm{B}_{5}$

Wie hoch sind die Studiengebühren und welche öffentlichen Unterstützungsleistungen erhalten Studierende?

StatLink: http://dx.doi.org/10.1787/888932849901

WEB Indikator B6

Wofür werden Finanzmittel im Bereich der Bildung ausgegeben?

StatLink: http:/|dx.doi.org/10.1787/888932850015

Indikator $\mathrm{B}_{7}$

Welche Faktoren beeinflussen die Höhe der Bildungsausgaben?

StatLink: http://dx.doi.org/10.1787/888932850072 


\section{Klassifizierung der Bildungsausgaben}

In diesem Kapitel werden die Bildungsausgaben anhand von drei Dimensionen klassifiziert:

Die erste Dimension ist im nachstehenden Diagramm durch die horizontale Achse dargestellt und bezieht sich auf den Ort, an dem Ausgaben anfallen. Die eine Komponente dieser Dimension sind Ausgaben in den Schulen und Hochschulen sowie in den Bildungsministerien und anderen Einrichtungen, die direkt an der Bereitstellung und Unterstützung von Bildung beteiligt sind. Ausgaben für Bildung außerhalb von Bildungseinrichtungen sind eine weitere Komponente.

Die zweite Dimension ist im nachstehenden Diagramm durch die vertikale Achse dargestellt und kennzeichnet die für Bildungszwecke erworbenen Sach- und Dienstleistungen. Nicht alle Ausgaben für Bildungseinrichtungen sind als unmittelbare Ausgaben für Bildung oder Unterricht einzustufen. In vielen OECD-Ländern bieten die Bildungseinrichtungen zusätzlich zum Unterricht auch noch verschiedene zusätzliche Dienstleistungen zur Unterstützung der Schüler/Studierenden und ihrer Familien an, wie z. B. Mahlzeiten, Transport, Unterbringung etc. Im Tertiärbereich können die Ausgaben für Forschung und Entwicklung einen nicht unerheblichen Anteil darstellen. Nicht alle Ausgaben für Sach- und Dienstleistungen im Bildungsbereich finden in Bildungseinrichtungen statt. So können beispielsweise Familien die erforderlichen Schulbücher und Unterrichtsmaterialien selbst kaufen oder ihren Kindern Privatunterricht erteilen lassen.

Die dritte Dimension - im nachstehenden Diagramm durch die farbliche Kennzeichnung dargestellt - nimmt eine Einteilung der Mittel nach ihrer Herkunft vor. $\mathrm{Zu}$ diesen Quellen zählen die öffentliche Hand und internationale Organisationen (hellgrau) sowie die privaten Haushalte und andere private Einheiten (hellblau). Wo private Bildungsausgaben durch öffentliche Mittel subventioniert werden, ist dies im Diagramm graublau gekennzeichnet.

Ausgaben für eigentliche Bildungsdienstleistungen

Ausgaben für Forschung und Entwicklung

Ausgaben für nicht unterrichtsbezogene Dienstleistungen im Bildungsbereich
Ausgaben für Bildungseinrichtungen

(z. B. Schulen, Hochschulen, Einrichtungen der Bildungsverwaltung und soziale Dienste für Schüler/Studierende)
Bildungsausgaben außerhalb von Bildungseinrichtungen (z.B. der private Erwerb von Gütern und Dienstleistungen für Bildungszwecke, inkl. Privatunterricht)

z. B. öffentliche Ausgaben für Bildungsangebote in Bildungseinrichtungen

z. B. subventionierte private Ausgaben für Unterrichtszwecke in Bildungseinrichtungen

z.B. private Ausgaben für Schul- bzw. Studiengebühren

z.B. öffentliche Ausgaben für Forschung an Hochschulen

z. B. Mittel der Privatwirtschaft für Forschung und Entwicklung an Bildungseinrichtungen

z.B. öffentliche Ausgaben für zusätzliche Dienstleistungen wie Mahlzeiten, Transport zur Schule, Unterbringung auf dem Campus

z.B. subventionierte private Ausgaben für Bücher

z.B. private Ausgaben für Bücher und anderes Unterrichtsmaterial oder Privatunterricht
z.B. subventionierte private Ausgaben für den Lebensunterhalt der Schüler/Studierenden bzw. reduzierte Tarife im ÖPNV

z. B. private Ausgaben für den Lebensunterhalt der Schüler/ Studierenden bzw. reduzierte Tarife im ÖPNV 


\section{Erfasste Daten}

Indikator B1, B2, B3 und B6

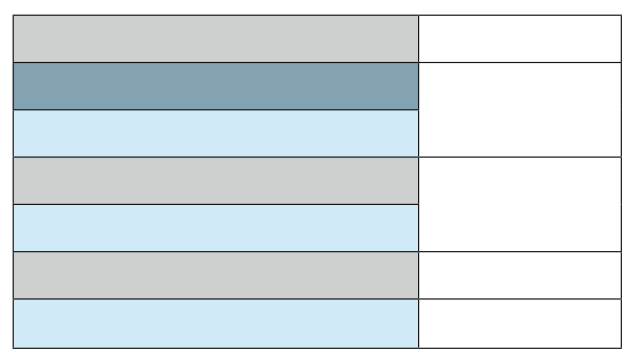

Indikator B4 und B5

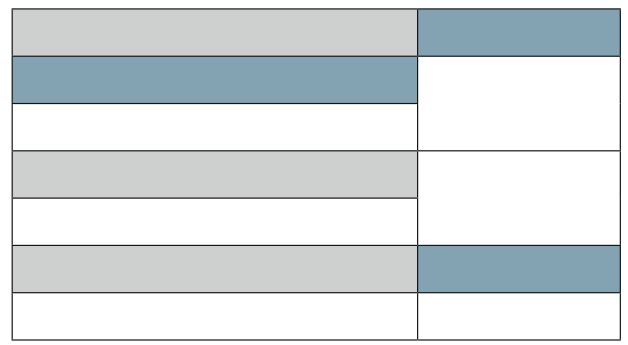





\section{Wie hoch sind die Ausgaben pro Schüler/ Studierenden?}

Die OECD-Länder geben vom Primar- bis zum Tertiärbereich jährlich im Durchschnitt 9.3I3 US-Dollar pro Schüler/Studierenden aus: 7.974 US-Dollar pro Schüler im Primarbereich, 9.0I4 US-Dollar pro Schüler im Sekundarbereich und I3.528 USDollar pro Studierenden im Tertiärbereich.

Im Primar- und Sekundarbereich entfallen 94 Prozent der Gesamtausgaben pro Schüler auf die Ausgaben für eigentliche Bildungsdienstleistungen. Größere Unterschiede treten im Tertiärbereich auf, u. a. weil dort die Ausgaben für Forschung und Entwicklung (F\&E) im Durchschnitt 3I Prozent der Gesamtausgaben pro Studierenden ausmachen.

Zwischen 2005 und 2010 stiegen die Ausgaben in Bildungseinrichtungen des Primar-, Sekundar- und postsekundaren, nicht tertiären Bereichs pro Schüler im Durchschnitt der OECD-Länder um I7 Prozentpunkte. Von 2009 auf 2010 jedoch sanken als Folge der Wirtschaftskrise die Bildungsausgaben in rund einem Drittel der OECD-Länder.

Abbildung B1.1

Jährliche Ausgaben von Bildungseinrichtungen pro Schüler/Studierenden, nach Leistungsbereich (2010) In US-Dollar, kaufkraftbereinigt, basierend auf Vollzeitäquivalenten, für Primar- bis Tertiärbereich

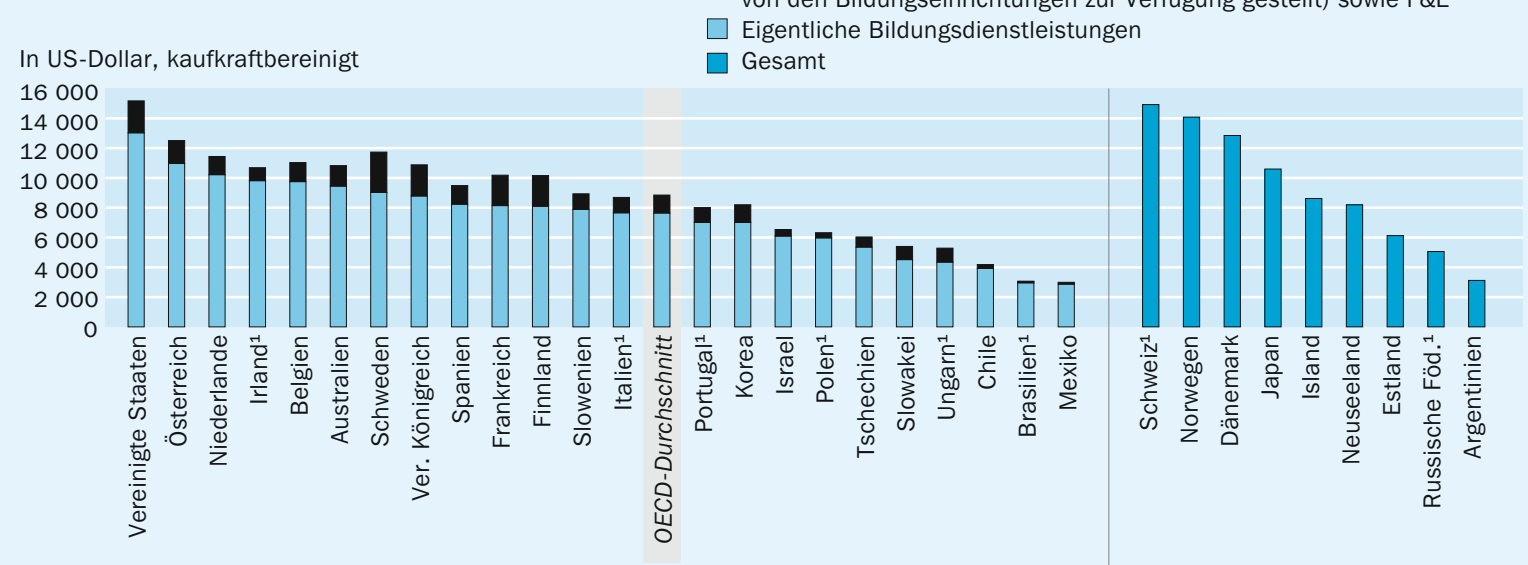

1. Nur öffentliche Bildungseinrichtungen.

Anordnung der Länder in absteigender Reihenfolge der Ausgaben von Bildungseinrichtungen pro Schüler/Studierenden für eigentliche Bildungsdienstleistungen. Quelle: OECD. Argentinien, Indonesien: Statistikinstitut der UNESCO (World Education Indicators Programme). Tabelle B1.2.

Hinweise s. Anhang 3 unter www.oecd.org/edu/eag.htm. StatLink: http://dx.doi.org/10.1787/888932846747

Erläuterung der Abbildung: Die Ausgaben von Bildungseinrichtungen pro Schüler/Studierenden können als Kennzahl für die Kosten pro Schüler/Studierenden im jeweiligen formalen Bildungssystem dienen. Die Abbildung zeigt die jährlichen (mit Mitteln aus öffentlichen und privaten Quellen finanzierten) Ausgaben pro Schüler/Studierenden von Bildungseinrichtungen in US-Dollar, kaufkraftbereinigt, basierend auf Vollzeitäquivalenten. Hierbei wird nach Art der erbrachten Leistung unterschieden: eigentliche Bildungsaufgaben, zusätzliche Dienstleistungen sowie Forschung und Entwicklung. Die Ausgaben für eigentliche Bildungsdienstleistungen umfassen alle Ausgaben, die direkt mit Unterricht und Bildung an Bildungseinrichtungen in Zusammenhang stehen. Dies umfasst alle Ausgaben für Lehrkräfte, Schulgebäude, Unterrichtsmaterial, Bücher und die Verwaltung. 


\section{Kontext}

Zwischen der Nachfrage nach hochwertiger Bildung, die sich in höheren Kosten pro Schüler/Studierenden niederschlagen kann, und dem Bedarf an öffentlichen Ausgaben für andere Bereiche sowie der Gesamtbelastung für den Steuerzahler muss ein ausgewogenes Verhältnis gefunden werden. Die Politik muss auch die Notwendigkeit, die Qualität des Bildungsangebots zu verbessern, mit dem Wunsch, den Zugang zur Bildung, insbesondere im Tertiärbereich, zu erweitern, in Einklang bringen. Eine vergleichende Übersicht der Entwicklung der Ausgaben von Bildungseinrichtungen pro Schüler/Studierenden zeigt, dass in vielen OECD-Ländern mit dem Anstieg der Schüler-/Studierendenzahlen keine entsprechende Steigerung der dem Bildungsbereich zur Verfügung stehenden Mittel einhergegangen ist. Außerdem legen einige OECD-Länder besonderen Wert auf eine hohe Bildungsbeteiligung im Tertiärbereich, während andere stärker in eine möglichst umfassende Bildungsbeteiligung schon kleiner Kinder im Alter von drei oder vier Jahren investieren. Finanzkrisen können sich sowohl auf die Höhe der Bildungsinvestitionen als auch auf die Zahl der Schüler/ Studierenden auswirken. Die aktuelle globale Wirtschaftskrise wird wahrscheinlich zu Änderungen bei der Höhe der Ausgaben pro Schüler/Studierenden geführt haben. Das volle Ausmaß der Auswirkungen ist jedoch anhand der verfügbaren Daten noch nicht erkennbar, da die Krise erst Ende 2008 einsetzte.

Die Ausgaben von Bildungseinrichtungen pro Schüler/Studierenden werden in hohem Maße beeinflusst von den Gehältern der Lehrkräfte (s. Indikatoren B6 und D3), den Ruhestandsregelungen, den Unterrichtsstunden der Schüler sowie den von den Lehrkräften zu unterrichtenden Stunden (s. Indikator B7), den Kosten von Lehrmaterialien und -einrichtungen, der Ausrichtung der angebotenen Bildungs- bzw. Studiengänge (z. B. allgemeinbildend oder berufsbildend) und der Zahl der Schüler/ Studierenden in einem Bildungssystem (s. Indikator CI). Maßnahmen zur Anwerbung neuer Lehrkräfte, zur Verringerung der durchschnittlichen Klassengröße oder zur Änderung der Zusammensetzung der Beschäftigten im Bildungswesen (s. Indikator D2) haben im Lauf der Zeit ebenfalls zu Veränderungen bei den Ausgaben von Bildungseinrichtungen pro Schüler/Studierenden geführt. Außerdem können sich auch Ausgaben für zusätzliche Dienstleistungen sowie für Forschung und Entwicklung auf die Höhe der Ausgaben pro Schüler/Studierenden auswirken.

\section{Weitere wichtige Ergebnisse}

In den Io Ländern mit den höchsten Ausgaben von Bildungseinrichtungen pro Schüler im Sekundarbereich sind hohe Gehälter der Lehrkräfte sowie eine niedrige SchülerLehrkräfte-Relation häufig die wesentlichen Faktoren für die Höhe der Ausgaben.

Im Primar- und Sekundarbereich gibt es eine eindeutig positive Korrelation zwischen den Ausgaben von Bildungseinrichtungen pro Schüler und dem BIP pro Kopf. Im Tertiärbereich ist diese schwächer ausgeprägt, da in diesem Bereich größere Unterschiede bei den Finanzierungsmechanismen und der Bildungsbeteiligung bestehen.

Werden nicht unterrichtsbezogene Tätigkeiten (Forschung und Entwicklung sowie zusätzliche Dienstleistungen, z. B. soziale Dienstleistungen für Schüler/Studierende) nicht berücksichtigt, geben die OECD-Länder pro Schüler/Studierenden durchschnittlich vom Primar- bis zum Tertiär- 
bereich 7.637 US-Dollar pro Jahr aus. Dieser niedrigere Wert im Vergleich mit den durchschnittlichen Gesamtausgaben ergibt sich hauptsächlich aus den wesentlich niedrigeren Ausgaben pro Studierenden im Tertiärbereich (8.889 US-Dollar), wenn nicht unterrichtsbezogene Tätigkeiten nicht berücksichtigt werden.

Im Durchschnitt sind die Bildungsausgaben der OECD-Länder pro Studierenden im Tertiärbereich fast doppelt so hoch wie im Primarbereich. Im Tertiärbereich können jedoch Leistungen im Zusammenhang mit Forschung und Entwicklung bzw. zusätzliche Dienstleistungen einen wesentlichen Teil der Kosten ausmachen. Ohne diese beiden Leistungsbereiche sind die Ausgaben pro Studierenden für eigentliche Bildungsdienstleistungen im Tertiärbereich immer noch um durchschnittlich Io Prozent höher als im Primar-, Sekundar- und postsekundaren, nicht tertiären Bereich.

Die Schülern im Sekundarbereich angebotenen Ausrichtungen von Bildungsgängen beeinflussen das Ausgabenniveau pro Schüler/Studierenden in den meisten Ländern. Die I7 OECDLänder, aus denen separate Daten zu den Ausgaben für allgemeinbildende und berufsbildende Bildungsgänge im Sekundarbereich II vorliegen, geben durchschnittlich 706 US-Dollar mehr pro Bildungsteilnehmer in berufsbildenden Bildungsgängen aus als für diejenigen in allgemeinbildenden Bildungsgängen.

\section{Entwicklungstendenzen}

In allen Ländern mit verfügbaren Daten stiegen die Ausgaben von Bildungseinrichtungen pro Schüler im Primar-, Sekundar- und postsekundaren, nicht tertiären Bereich zwischen 1995 und 2010 im Durchschnitt um mehr als 6r Prozent, während die Schülerzahlen in diesem Zeitraum in den meisten Ländern relativ gleich blieben.

Zwischen 2005 und 2010 gingen die Ausgaben im Tertiärbereich pro Studierenden in 8 der 3I Länder mit verfügbaren Daten zurück, da die Bildungsausgaben nicht mit den steigenden Studierendenzahlen Schritt hielten. Obwohl sich die Zahl der Studierenden in Island, Israel, Österreich, dem Vereinigten Königreich und den Vereinigten Staaten zwischen 2005 und 2010 deutlich erhöhte, stiegen die Bildungsausgaben nicht in demselben Ausmaß. Daher verringerten sich in diesen Ländern die Ausgaben pro Studierenden. Dies war auch in Neuseeland, der Schweiz und der Russischen Föderation der Fall, wo die öffentlichen Ausgaben pro Studierenden (es lagen keine Daten zu den privaten Aufwendungen vor) in diesem Zeitraum zurückgingen. 


\section{Analyse und Interpretationen}

\section{Ausgaben von Bildungseinrichtungen pro Schüler/Studierenden}

Die Ausgaben pro Schüler/Studierenden vom Primar- bis zum Tertiärbereich reichten 2010 von höchstens 4.000 US-Dollar pro Schüler/Studierenden in Argentinien, Brasilien und Mexiko über mehr als Io.0oo US-Dollar pro Schüler/Studierenden in Australien, Belgien, Dänemark, Finnland, Frankreich, Irland, Japan, den Niederlanden, Norwegen, Österreich, Schweden, der Schweiz und dem Vereinigten Königreich bis zu mehr als 15.000 US-Dollar in den Vereinigten Staaten. In 9 der 32 Länder mit verfügbaren Daten lagen die Ausgaben pro Schüler/Studierenden vom Primar-bis zum Tertiärbereich zwischen I0.00o US-Dollar und weniger als I2.000 US-Dollar (Abb. BI.I und Tab. Bi.ra).

Die einzelnen Länder verteilen ihre Ressourcen nach unterschiedlichen Prioritäten (s. Indikator B7). So gehören beispielsweise unter den zehn Ländern mit den höchsten Ausgaben der Bildungseinrichtungen pro Schüler im Sekundarbereich Belgien, Dänemark, Irland, Luxemburg, die Niederlande, die Schweiz und die Vereinigten Staaten zu den Ländern mit den höchsten Gehältern von Lehrkräften nach ıo Jahren Berufserfahrung im Sekundarbereich I und II (s. Indikator D3), und Belgien, Dänemark, Norwegen und Österreich haben mit die niedrigste Schüler-Lehrkräfte-Relation im Sekundarbereich (s. Indikator D2).

Aber auch wenn die Gesamtausgaben pro Schüler/Studierenden vom Primar- bis zum Tertiärbereich in einigen OECD-Ländern ähnlich hoch sind, sind die Unterschiede bei der Verteilung der Mittel auf die einzelnen Bildungsbereiche beträchtlich. Die Ausgaben von Bildungseinrichtungen pro Schüler/Studierenden in einem typischen OECDLand (ausgedrückt durch das arithmetische Mittel aller OECD-Länder) belaufen sich auf 7.974 US-Dollar im Primarbereich, 9.0I4 US-Dollar im Sekundarbereich und I3.528 US-Dollar im Tertiärbereich (Tab. BI.ra und Abb. BI.2). Die durchschnittlichen Ausgaben pro Studierenden im Tertiärbereich werden sehr stark durch das hohe Ausgabenniveau (mehr als 20.000 US-Dollar) in einigen wenigen OECD-Ländern, vor allem Kanada, der Schweiz und den Vereinigten Staaten, beeinflusst.

Hinter diesen Durchschnittswerten verbergen sich sehr unterschiedlich hohe Ausgaben von Bildungseinrichtungen pro Schüler/Studierenden, die sich im Primarbereich um den Faktor II und im Sekundarbereich um den Faktor 7 unterscheiden. Im Primarbereich reichen die Ausgaben von höchstens 2.400 US-Dollar pro Schüler in Mexiko und der Türkei bis zu 2I.240 US-Dollar in Luxemburg, im Sekundarbereich von höchstens 2.60o US-Dollar in Brasilien und der Türkei bis zu 17.633 US-Dollar in Luxemburg (Tab. Br.ra und Abb. Br.2).

Diese Vergleiche beruhen auf kaufkraftbereinigten Zahlen, die mittels Kaufkraftparitäten für das BIP und nicht mittels Devisenmarktkurs berechnet wurden. Damit entsprechen sie dem Betrag in Landeswährung, der erforderlich wäre, um dieselben Waren und Dienstleistungen eines Warenkorbs in einem bestimmten Land zu erhalten wie mit dem angegebenen Betrag in US-Dollar in den Vereinigten Staaten. 
Abbildung B1.2

Jährliche Ausgaben von Bildungseinrichtungen pro Schüler/Studierenden für alle Leistungsbereiche, nach Bildungsbereich (2010)

In US-Dollar, kaufkraftbereinigt, basierend auf Vollzeitäquivalenten

In US-Dollar, kaufkraftbereinigt

Primarbereich

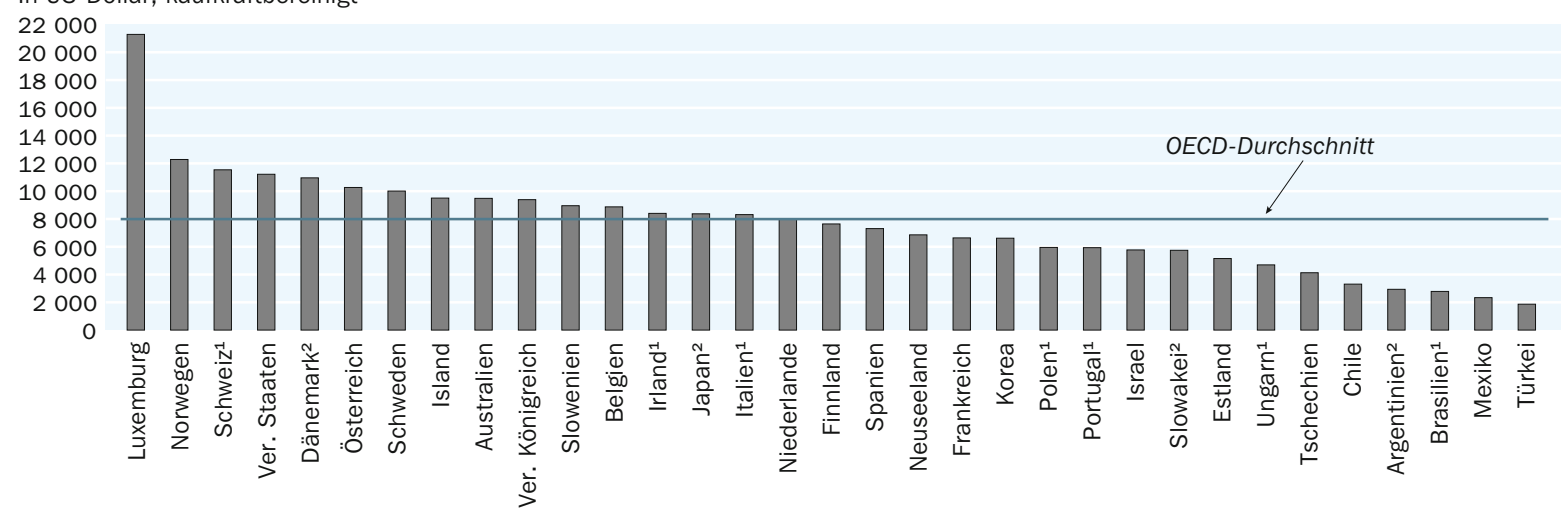

Sekundarbereich

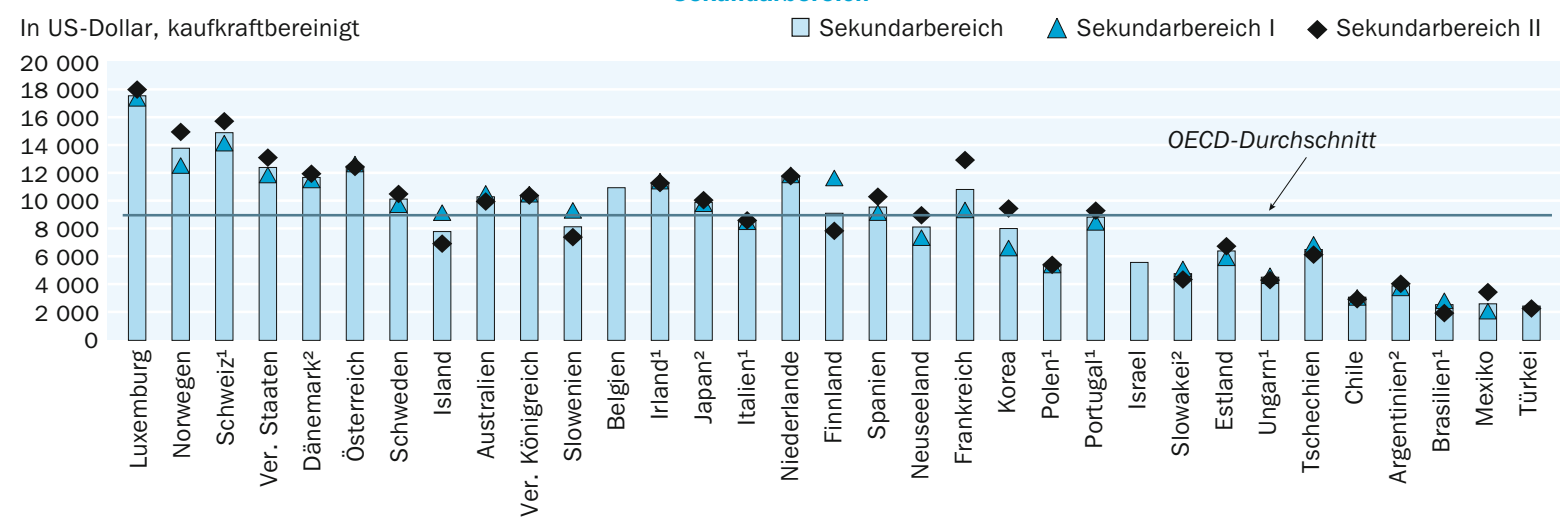

Tertiärbereich

In US-Dollar, kaufkraftbereinigt

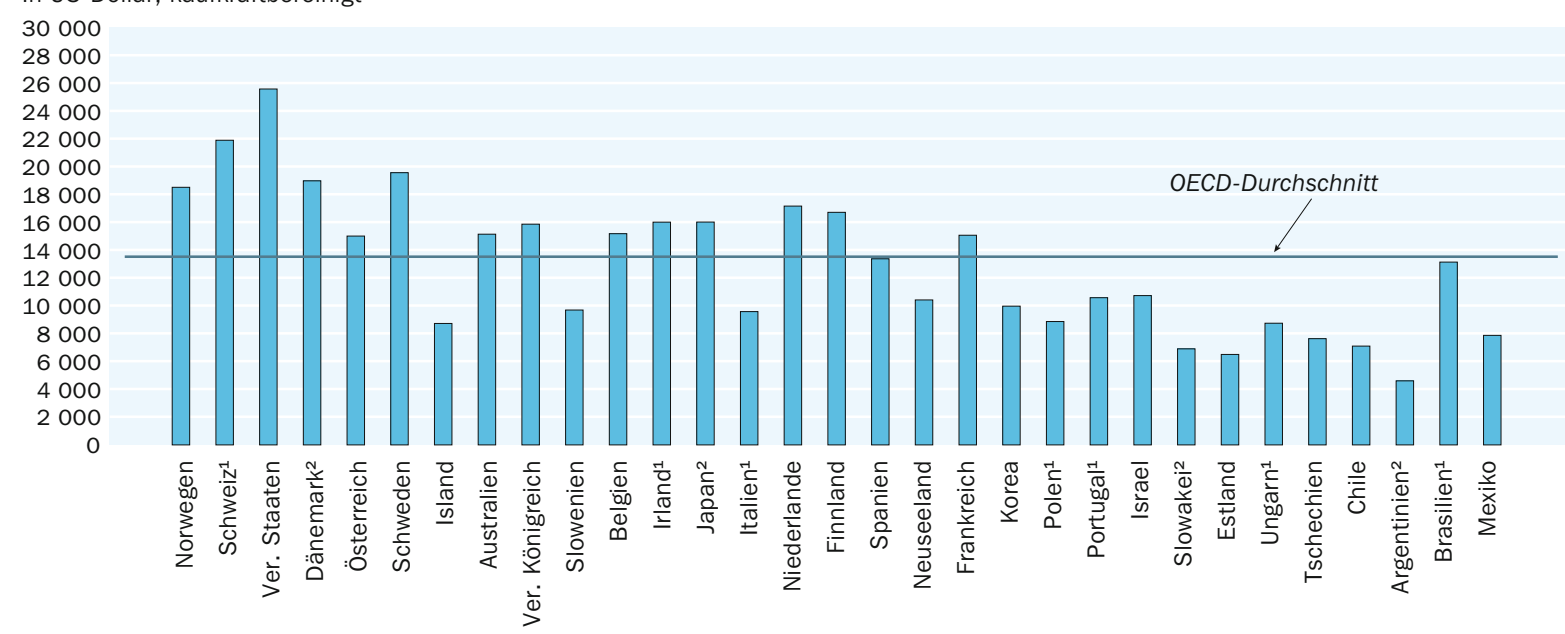

1. Nur öffentliche Bildungseinrichtungen (Kanada: nur im Tertiärbereich, Italien: außer im Tertiärbereich). 2. Einige Bildungsbereiche sind in anderen Bildungsbereichen enthalten. Einzelheiten s. Erläuterung von „x“ in Hinweise für den Leser.

Anordnung der Länder in absteigender Reihenfolge der Ausgaben von Bildungseinrichtungen pro Schüler im Primarbereich.

Quelle: OECD. Argentinien: Statistikinstitut der UNESCO (World Education Indicators Programme). Tabelle B1.1a.

Hinweise s. Anhang 3 unter www.oecd.org/edu/eag.htm. StatLink: http://dx.doi.org/10.1787/888932846766 


\section{Ausgaben pro Schüler/Studierenden für eigentliche Bildungs- dienstleistungen}

Im Durchschnitt aller OECD-Länder machen die Ausgaben für eigentliche Bildungsdienstleistungen vom Primar- bis zum Tertiärbereich 82 Prozent der Gesamtausgaben pro Schüler/Studierenden aus, in Brasilien, Mexiko und Polen sogar mehr als 94 Prozent. In 4 der 23 Länder mit verfügbaren Daten (Finnland, Frankreich, Schweden und dem Vereinigten Königreich) entfallen weniger als 8o Prozent der Gesamtausgaben pro Schüler/Studierenden auf eigentliche Bildungsdienstleistungen. Die jährlichen Ausgaben für Forschung und Entwicklung sowie zusätzliche Dienstleistungen beeinflussen die Rangfolge der Länder, wenn alle Leistungsbereiche zusammen betrachtet werden. Hinter diesen Durchschnittswerten verbergen sich jedoch große Unterschiede zwischen den einzelnen Bildungsbereichen (Tab. Br.2).

Im Primar- und Sekundarbereich spielen die Ausgaben für eigentliche Bildungsdienstleistungen die wichtigste Rolle bei den Bildungsausgaben. Im Durchschnitt der OECD-Länder, für die Daten vorliegen, betreffen 94 Prozent der Gesamtausgaben der Bildungseinrichtungen (bzw. 8.oor US-Dollar) pro Schüler im Primar-, Sekundar- und postsekundaren, nicht tertiären Bereich eigentliche Bildungsdienstleistungen. In 9 der 22 Länder mit verfügbaren Daten entfallen auf zusätzliche Dienstleistungen der Bildungseinrichtungen weniger als 5 Prozent der Gesamtausgaben pro Schüler. Andererseits liegt dieser Anteil in Finnland, Frankreich, Korea, Schweden, der Slowakei, Ungarn und dem Vereinigten Königreich bei mehr als ıo Prozent (Tab. BI.2).

Größere Unterschiede ergeben sich im Tertiärbereich, was unter anderem darauf zurückzuführen ist, dass Ausgaben für Forschung und Entwicklung hier einen wesentlichen Teil der Bildungsausgaben ausmachen können. Die OECD-Länder, in denen Forschung und Entwicklung hauptsächlich in Bildungseinrichtungen des Tertiärbereichs stattfinden (z. B. Portugal, Schweden und die Schweiz), haben in der Regel höhere Ausgaben für Bildungseinrichtungen pro Studierenden als Länder, in denen ein Großteil der Forschungs- und Entwicklungsaktivitäten in anderen öffentlichen Einrichtungen oder in Unternehmen angesiedelt ist.

Ohne die Ausgaben für Forschung und Entwicklung sowie zusätzliche Dienstleistungen (nicht unterrichtsbezogene Dienstleistungen wie zum Beispiel soziale Dienstleistungen für Studierende) belaufen sich die Ausgaben für die eigentlichen Bildungsdienstleistungen an Bildungseinrichtungen des Tertiärbereichs im Durchschnitt auf 8.889 US-Dollar pro Studierenden. Sie reichen von höchstens 5.000 US-Dollar in Argentinien, Estland und der Slowakei bis zu mehr als I0.000 US-Dollar in Brasilien, Irland, Kanada, den Niederlanden, Norwegen und Österreich und mehr als I9.000 USDollar in den Vereinigten Staaten (Tab. BI.2).

Im Durchschnitt der OECD-Länder machen die Ausgaben für Forschung und Entwicklung (F\&E) sowie zusätzliche Dienstleistungen im Tertiärbereich 3I Prozent bzw. 4 Prozent der Gesamtausgaben von Bildungseinrichtungen im Tertiärbereich pro Studierenden aus. In 6 der 28 OECD-Länder, für die Daten zu den Ausgaben für Forschung und Entwicklung sowie für zusätzliche Dienstleistungen getrennt von den Gesamtausgaben vorliegen (Australien, Finnland, Norwegen, Portugal, Schweden, die Schweiz), entfallen mindestens 40 Prozent der Gesamtausgaben von Bildungseinrichtungen 
pro Studierenden auf F\&E und zusätzliche Dienstleistungen im Tertiärbereich. Dies kann erhebliche Beträge ergeben: In Finnland, Kanada, den Niederlanden, Norwegen, Schweden und der Schweiz belaufen sich die Ausgaben für F\&E sowie für zusätzliche Dienstleistungen auf mehr als 6.00o US-Dollar pro Studierenden (Tab. BI.2).

\section{Ausgaben von Bildungseinrichtungen pro Schüler/Studierenden in den verschiedenen Bildungsbereichen}

In fast allen Ländern steigen die Ausgaben von Bildungseinrichtungen pro Schüler/ Studierenden mit der Höhe des Bildungsbereichs, das Ausmaß der Steigerung variiert jedoch erheblich zwischen den einzelnen Ländern (Tab. Br.Ia und Abb. BI.3). Die Ausgaben im Sekundarbereich sind im Durchschnitt io Prozent höher als im Primarbereich. In Frankreich, Portugal und Tschechien sind es sogar mehr als 50 Prozent mehr, dies ist vor allem auf die im Sekundar- gegenüber dem Primarbereich höhere Zahl der Unterrichtsstunden für Schüler bei einer gleichzeitig signifikant niedrigeren Zahl der von Lehrkräften zu erteilenden Unterrichtszeitstunden im Vergleich zum OECD-Durchschnitt zurückzuführen. In diesen Ländern sind auch die Gehälter der Lehrkräfte im Primarbereich im Vergleich zu denen im Sekundarbereich I niedriger (s. Indikatoren $\mathrm{B}_{7}$, Dr und $\mathrm{D}_{4}$ ).

In den OECD-Ländern werden im Durchschnitt von den Bildungseinrichtungen im Tertiärbereich pro Studierenden I,7-mal mehr Mittel ausgegeben als von den Bildungseinrichtungen pro Schüler im Primarbereich; es gibt jedoch große Unterschiede in den

\section{Abbildung B1.3}

Ausgaben von Bildungseinrichtungen pro Schüler/Studierenden in den einzelnen Bildungsbereichen im Vergleich zum Primarbereich, für alle Leistungsbereiche (2010)

Primarbereich $=100$

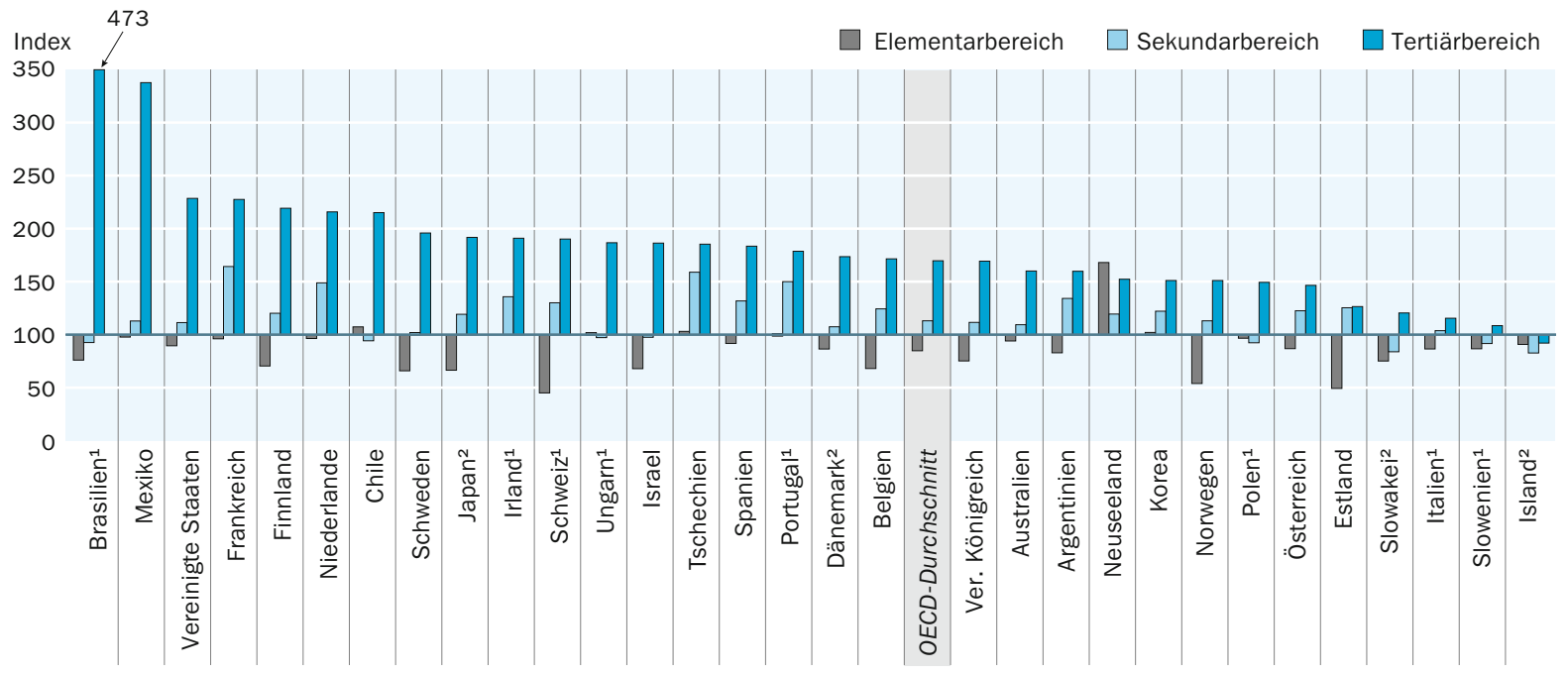

Anmerkung: Ein Index von 300 für den Tertiärbereich bedeutet, dass die Ausgaben von Bildungseinrichtungen pro Studierenden im Tertiärbereich dreimal so hoch sind wie die Ausgaben von Bildungseinrichtungen pro Schüler im Primarbereich. Ein Index vom 50 für den Elementarbereich bedeutet, dass die Ausgaben von Bildungseinrichtungen pro Kind im Elementarbereich halb so hoch sind wie die Ausgaben von Bildungseinrichtungen pro Schüler im Primarbereich.

1. Nur öffentliche Bildungseinrichtungen. 2. Einige Bildungsbereiche sind in anderen Bildungsbereichen enthalten. Einzelheiten s. Erläuterung von " $x^{“}$ in Hinweise für den Leser.

Anordnung der Länder in absteigender Reihenfolge der Ausgaben von Bildungseinrichtungen pro Studierenden im Tertiärbereich in Relation zum Primarbereich. Quelle: OECD. Argentinien: Statistikinstitut der UNESCO (World Education Indicators Programme). Tabelle B1.1a.

Hinweise s. Anhang 3 unter www.oecd.org/edu/eag.htm. StatLink: http://dx.doi.org/10.1787/888932846785 
Ausgabenstrukturen, hauptsächlich aufgrund der Tatsache, dass sich der bildungspolitische Rahmen im Tertiärbereich stärker unterscheidet (s. Indikator B5). So wenden Estland, Island, Italien, Österreich, Polen, die Slowakei und Slowenien beispielsweise für einen Studierenden im Tertiärbereich weniger als das I,5-Fache an Mitteln als für einen Schüler im Primarbereich auf, Brasilien und Mexiko jedoch mindestens rund das 3-Fache (Tab. Br.ra und Abb. Br.3).

\section{Unterschiede in den Bildungsausgaben pro Schüler/Studierenden zwischen allgemein- und berufsbildenden Bildungsgängen}

Die 17 OECD-Länder mit verfügbaren Daten geben durchschnittlich 706 US-Dollar mehr pro Bildungsteilnehmer in berufsbildenden Bildungsgängen des Sekundarbereichs II aus als für Teilnehmer an allgemeinbildenden Bildungsgängen. Die Länder mit einer hohen Beteiligung an dualen Berufsbildungssystemen im Sekundarbereich II (z. B. Frankreich, Finnland, Luxemburg, die Niederlande, Österreich, die Schweiz und Ungarn) weisen in der Regel auch die größten Unterschiede bei den Ausgaben pro Bildungsteilnehmer zwischen allgemeinbildenden und berufsbildenden Bildungsgängen auf (im Vergleich zum OECD-Durchschnitt). So wendet Finnland beispielsweise I.422 US-Dollar mehr für einen Schüler in einem berufsbildenden Bildungsgang des Sekundarbereichs II auf als in einem allgemeinbildenden Bildungsgang, in Luxemburg sind es 3.664 US-Dollar mehr, in den Niederlanden 2.628 US-Dollar, in Neuseeland I.559 US-Dollar und in der Schweiz 4.495 US-Dollar mehr. Frankreich, die Slowakei und Tschechien geben ebenfalls mehr für einen Teilnehmer an berufsbildenden Bildungsgängen aus als für einen Teilnehmer an allgemeinbildenden Bildungsgängen (8or US-Dollar, I.234 US-Dollar bzw. I.I82 US-Dollar mehr), auch wenn die Unterschiede hier kleiner sind. Ausnahmen sind hier Österreich mit ungefähr gleich hohen Ausgaben pro Schüler in beiden Arten von Bildungsgängen und Ungarn, wo die Ausgaben pro Schüler in einem allgemeinbildenden Bildungsgang die Ausgaben pro Schüler in einem dualen Ausbildungsgang geringfügig übersteigen. Die geringen Unterschiede in Frankreich, Österreich und Ungarn lassen sich zum Teil aus den zu niedrig angesetzten Ausgaben privater Unternehmen im Rahmen dualer Ausbildungsgänge erklären (Kasten B3.I in Bildung auf einen Blick 2011, Tab. Br.6 und Tab. Cr.3 in Indikator C).

\section{Ausgaben von Bildungseinrichtungen pro Studierenden während der durchschnittlichen Dauer der Studiengänge im Tertiärbereich}

Angesichts der Tatsache, dass sowohl die Dauer von Studiengängen im Tertiärbereich als auch die Intensität der Teilnahme als Vollzeit- oder Teilzeitstudierender zwischen den einzelnen Ländern variieren, geben die Unterschiede zwischen den einzelnen Ländern bei den jährlichen Ausgaben pro Studierenden für Bildungsdienstleistungen (Abb. BI.2) nicht unbedingt die Unterschiede in den Gesamtkosten für die Ausbildung eines typischen Studierenden im Tertiärbereich wider. Beispielsweise können vergleichsweise niedrige jährliche Ausgaben von Bildungseinrichtungen pro Studierenden zu vergleichsweise hohen Gesamtkosten im Tertiärbereich führen, wenn die übliche Dauer der Studiengänge im Tertiärbereich lang ist. Abbildung BI.4 gibt einen Überblick über die durchschnittlichen Ausgaben pro Studierenden im Laufe des gesamten Studiums. Die Zahlen beziehen sich auf alle Studierenden, für die Ausgaben anfallen, unabhängig davon, ob sie einen Abschluss erwerben oder nicht. Obwohl die Berechnungen auf einer Reihe vereinfachter Annahmen beruhen und daher mit Vorsicht zu interpretieren sind (s. Anhang 3 unter www.oecd.org/eduleag.htm), gibt es einige bemer- 
Abbildung B1.4

Kumulierte Ausgaben von Bildungseinrichtungen pro Studierenden während der durchschnittlichen Dauer von Studiengängen im Tertiärbereich (2010)

Jährliche Ausgaben von Bildungseinrichtungen pro Studierenden multipliziert mit der durchschnittlichen Dauer von Studiengängen im Tertiärbereich, in US-Dollar (kaufkraftbereinigt)

In US-Dollar, kaufkraftbereinigt

120000

100000

80000

60000

40000

20000

0

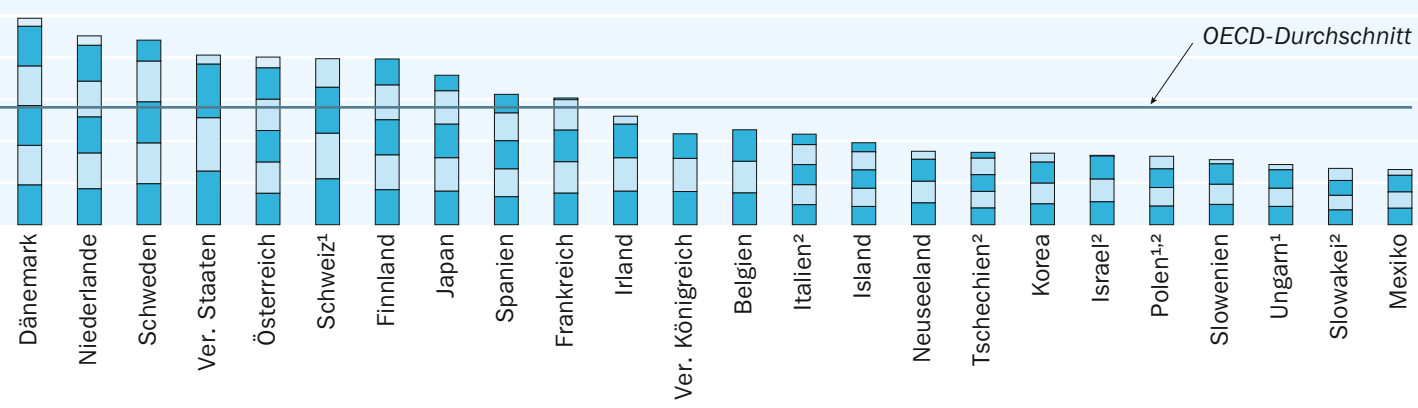

Anmerkung: Jeder Abschnitt eines Balkens steht für die jährlichen Ausgaben von Bildungseinrichtungen pro Studierenden. Die Zahl der Abschnitte steht für die Zahl an Jahren, die ein Studierender im Durchschnitt im Tertiärbereich verbringt.

1. Nur öffentliche Bildungseinrichtungen. 2. Nur Tertiärbereich A und weiterführende forschungsorientierte Studiengänge.

Anordnung der Länder in absteigender Reihenfolge der Gesamtausgaben von Bildungseinrichtungen pro Studierenden während der durchschnittlichen Dauer von Studiengängen im Tertiärbereich.

Quelle: OECD. Tabelle B1.3a. Hinweise s. Anhang 3 unter www.oecd.org/edu/eag.htm. StatLink: http://dx.doi.org/10.1787/888932846804

kenswerte Unterschiede in der Rangfolge der Länder, je nachdem ob sie auf den jährlichen oder kumulierten Ausgaben basieren.

So sind beispielsweise die jährlichen Bildungsausgaben pro Studierenden im Tertiärbereich in Japan ungefähr genauso hoch wie in Irland (I6.0I5 US-Dollar bzw. I6.008 USDollar) (Tab. Br.ra). Jedoch ist die durchschnittliche Studiendauer in Japan über ein Jahr länger als in Irland (4,5 gegenüber 3,2 Jahren). Daher sind in Irland die kumulierten Ausgaben für jeden Studierenden im Tertiärbereich fast 20.000 US-Dollar niedriger als in Japan (5I.865 US-Dollar gegenüber 7I.44I US-Dollar) (Abb. BI.4 und Tab. BI.3a).

Die Gesamtkosten eines Studiengangs im Tertiärbereich A sind in der Schweiz (mit I27.904 US-Dollar) mehr als doppelt so hoch wie in fast zwei Drittel der Länder mit Ausnahme von Finnland, Frankreich, Japan, den Niederlanden, Österreich, Schweden und Spanien (Tab. Br.3a). Diese Zahlen müssen natürlich im Zusammenhang mit den Unterschieden in den nationalen Abschlussstrukturen sowie möglichen Unterschieden im akademischen Niveau der Hochschulabschlüsse gesehen werden. Die (kürzeren und beruflich ausgerichteten) Studiengänge im Tertiärbereich B sind in der Regel kostengünstiger als Studiengänge des Tertiärbereichs A, hauptsächlich aufgrund der kürzeren Dauer.

\section{Ausgaben von Bildungseinrichtungen pro Schüler/Studierenden im Verhältnis zum BIP pro Kopf}

Da in den meisten OECD-Ländern in den unteren Bildungsbereichen eine fast vollständige Bildungsbeteiligung gegeben ist (und dort in der Regel Schulpflicht besteht), können die Ausgaben von Bildungseinrichtungen pro Schüler im Verhältnis zum BIP pro Kopf in diesen Bildungsbereichen auch als die Ressourcen ausgelegt werden, die für junge Menschen im schulpflichtigen Alter in Relation zur Finanzkraft eines Landes 
ausgegeben werden. In den höheren Bildungsbereichen sind die aus dieser Kenngröße abzuleitenden Schlussfolgerungen aufgrund der sehr unterschiedlichen Bildungsbeteiligung in den einzelnen Ländern weniger eindeutig. So können beispielsweise OECD-Länder im Tertiärbereich bei dieser Kennzahl einen vorderen Rang belegen, wenn ein großer Anteil ihres BIP für eine relativ geringe Zahl von Studierenden aufgewendet wird.

In den OECD-Ländern belaufen sich die Ausgaben von Bildungseinrichtungen pro Schüler im Primarbereich auf durchschnittlich 23 Prozent des BIP pro Kopf, pro Schüler im Sekundarbereich auf 26 Prozent und pro Studierenden im Tertiärbereich auf 4I Prozent. Insgesamt belaufen sich die Ausgaben pro Schüler/Studierenden vom Primar- bis zum Tertiärbereich in den OECD-Ländern auf durchschnittlich 28 Prozent des BIP pro Kopf (Tab. BI.4). Länder mit einem niedrigen Ausgabenniveau können dennoch eine Höhe der Ausgaben im Verhältnis zum BIP pro Kopf aufweisen, die ähnlich hoch ist wie in Ländern mit einem hohen Ausgabenniveau pro Schüler/Studierenden. So werden beispielsweise in Korea und Portugal, wo sowohl die Ausgaben von Bildungseinrichtungen pro Schüler im Sekundarbereich als auch das BIP pro Kopf unter dem OECD-Durchschnitt liegen, im Verhältnis zum BIP pro Kopf mehr Mittel pro Schüler aufgewendet als im OECD-Durchschnitt.

Das Verhältnis zwischen BIP pro Kopf und Ausgaben von Bildungseinrichtungen pro Schüler/Studierenden ist nicht eindeutig. Jedoch gibt es sowohl im Primar- als auch im Sekundarbereich eine eindeutig positive Korrelation zwischen den Ausgaben von Bildungseinrichtungen pro Schüler und dem BIP pro Kopf - ärmere Länder geben in der Regel weniger pro Schüler aus als reichere. Obwohl in diesen Bildungsbereichen die Korrelation im Allgemeinen positiv ist, gibt es selbst zwischen Ländern mit ähnlichem BIP pro Kopf Unterschiede, insbesondere in den Ländern, in denen das BIP pro Kopf mehr als 30.000 US-Dollar beträgt. Israel und Slowenien sind beispielsweise Länder mit einem ähnlich hohen BIP pro Kopf (s. Tab. X2.I in Anhang 2), geben aber im Primar- und Sekundarbereich völlig unterschiedliche Anteile ihres BIP pro Kopf aus. In Israel liegt dieser Anteil im Primarbereich bei 22 Prozent und im Sekundarbereich bei 2I Prozent (und somit unter dem OECD-Durchschnitt von 23 Prozent bzw. 26 Prozent), während sich die entsprechenden Anteile in Slowenien auf 34 Prozent bzw. 3 I Prozent belaufen und somit zu den höchsten Werten überhaupt gehören (Tab. BI.4 und Abb. Br.5).

Bei den Ausgaben im Tertiärbereich sind die Unterschiede größer, und auch das Verhältnis zwischen dem relativen Wohlstand eines Landes und dem Ausgabenniveau unterscheidet sich. Kanada, Mexiko, Schweden und die Vereinigten Staaten geben pro Studierenden im Tertiärbereich mehr als 49 Prozent ihres BIP pro Kopf aus, einige der größten Anteile nach Brasilien (Tab. Br.4 und Abb. Br.5). Brasilien wendet den Gegenwert von ${ }_{05}$ Prozent des BIP pro Kopf für jeden Studierenden im Tertiärbereich auf, hierbei ist jedoch zu berücksichtigen, dass nur 4 Prozent der Schüler/Studierenden aller Bildungsbereiche im Tertiärbereich eingeschrieben sind (Tab. Br.7 im Internet). 


\section{Abbildung B1.5}

Jährliche Ausgaben von Bildungseinrichtungen pro Schüler/Studierenden im Verhältnis zum BIP pro Kopf (2010) In US-Dollar, kaufkraftbereinigt, nach Bildungsbereich

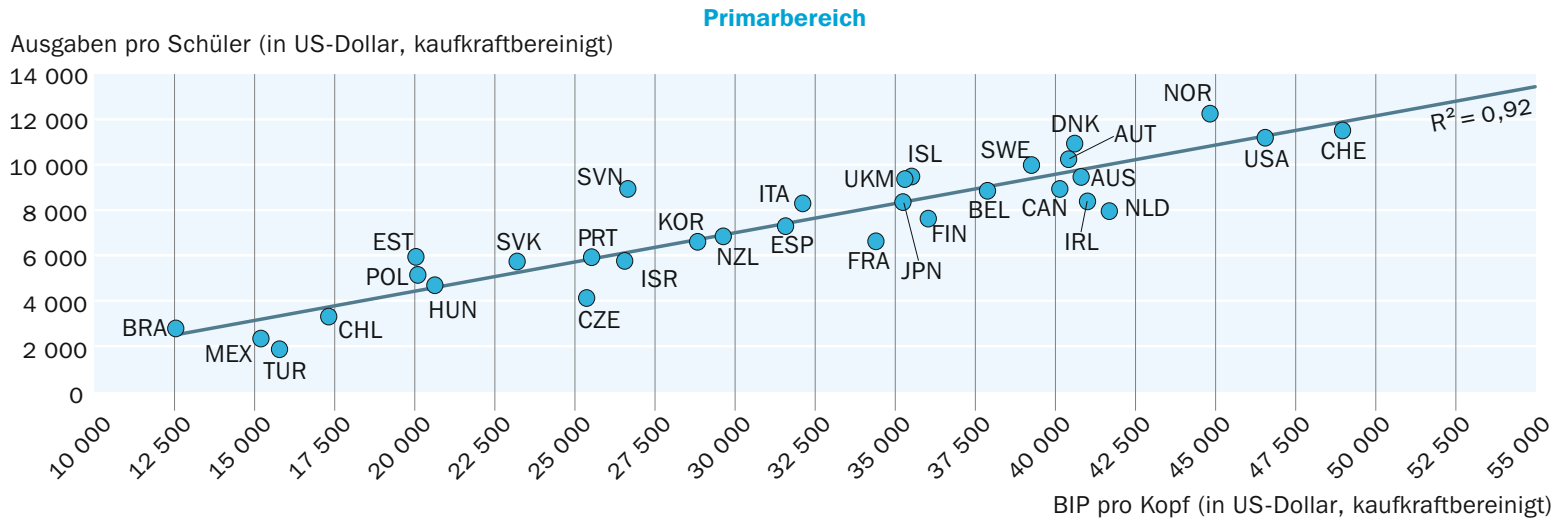

Ausgaben pro Schüler (in US-Dollar, kaufkraftbereinigt)

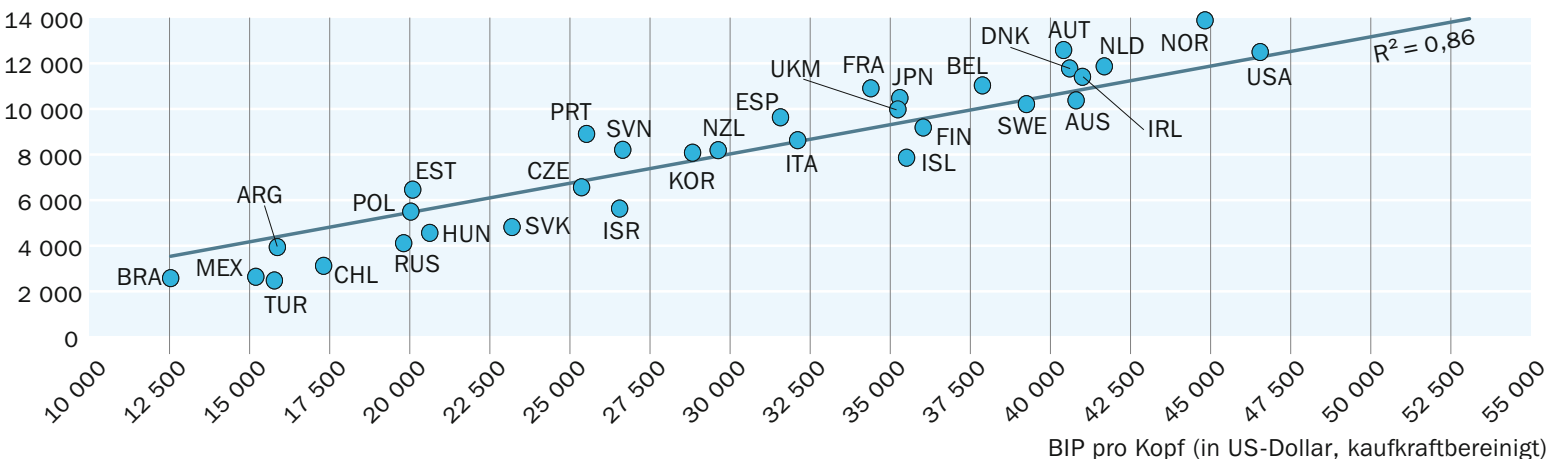

Ausgaben pro Studierenden (in US-Dollar, kaufkraftbereinigt)

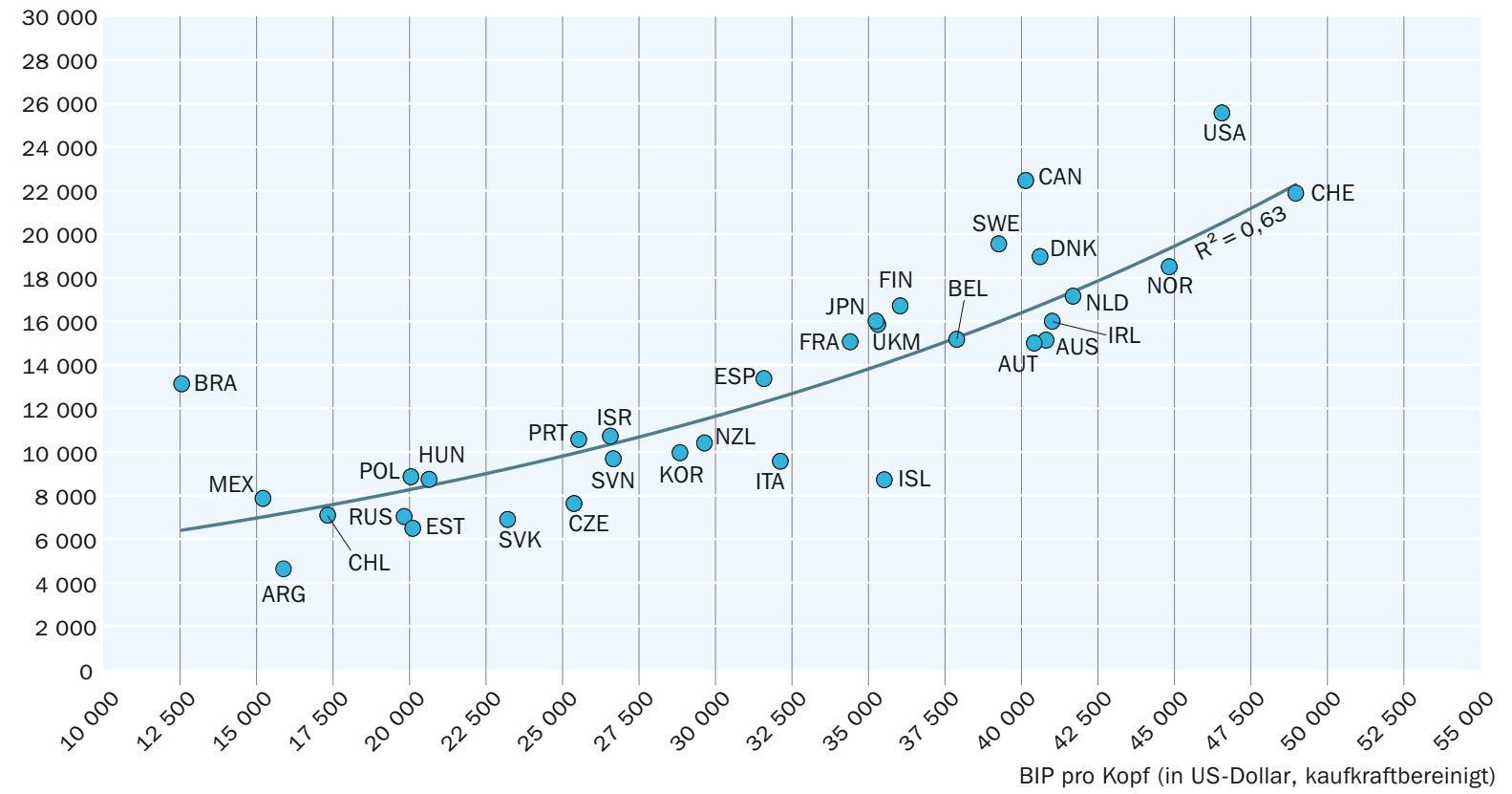




\section{Veränderungen der Ausgaben von Bildungseinrichtungen pro Schüler/} Studierenden zwischen 1995 und 2010

Veränderungen bei den Ausgaben von Bildungseinrichtungen spiegeln hauptsächlich Veränderungen in der Zahl junger Menschen im schulpflichtigen Alter sowie bei den Gehältern der Lehrkräfte wider. Diese steigen tendenziell im Laufe der Zeit real: Die Gehälter der Lehrkräfte (der Hauptkostenfaktor) sind in den meisten Ländern in den letzten Io Jahren gestiegen (s. Indikator $\mathrm{D}_{3}$ ). Die Zahl junger Menschen im üblichen Schulalter beeinflusst sowohl die Zahl der Schüler/Studierenden als auch den organisatorischen Aufwand und den Umfang der Mittel, die ein Land in sein Bildungssystem investieren muss. Je größer diese Bevölkerungsgruppe ist, desto höher ist die potenzielle Nachfrage nach Bildungsdienstleistungen.

In allen Ländern stiegen die Ausgaben von Bildungseinrichtungen pro Schüler im Primar-, Sekundar- und postsekundaren, nicht tertiären Bereich zwischen 1995 und 2010 im Durchschnitt um 6r Prozent, während die Schülerzahlen in diesen Bildungsbereichen in diesem Zeitraum relativ stabil blieben. Der Anstieg war in den Zeiträumen 2000 bis 2005 und 2005 bis 2010 in etwa gleich hoch, was zeigt, dass sich die globale Wirtschaftskrise in der Mehrzahl der Länder noch nicht auf die Bildungsausgaben ausgewirkt hatte. Diese Entwicklung könnte sich jedoch in Zukunft umkehren, denn wie Tabelle B2.5 und Kasten B2.I zeigen, sanken in einem Drittel der Länder die Bildungshaushalte von 2009 auf 2010.

Zwischen 2005 und 2010 stiegen in 23 der 33 Länder mit verfügbaren Daten die Ausgaben von Bildungseinrichtungen pro Schüler im Primar-, Sekundar- und postsekundaren, nicht tertiären Bereich um mindestens ro Prozent. In Brasilien, Polen und der Slowakei belief sich der Anstieg auf mehr als 50 Prozent. In Dänemark, Frankreich und Mexiko hingegen nahmen diese Ausgaben zwischen 2005 und 2010 um höchstens 5 Prozent zu. Nur in Island, Italien und Ungarn war zwischen 2005 und 2010 ein Rückgang bei den Ausgaben für Schüler im Primar-, Sekundar- und postsekundaren, nicht tertiären Bereich festzustellen (Tab. Bi.5a und Abb. Bı.6).

Sinkende Schülerzahlen sind (mit Ausnahme Ungarns) offensichtlich nicht der ausschlaggebende Faktor für die Veränderungen bei den Ausgaben in diesen Bildungsbereichen gewesen. In Brasilien, Chile, Estland, Korea, Polen, der Russischen Föderation, der Slowakei und Tschechien ging vielmehr zwischen 2005 und 2010 ein Rückgang der Schülerzahlen von mehr als 5 Prozent mit einer deutlichen Steigerung (um mehr als 5 Prozent) der Ausgaben von Bildungseinrichtungen pro Schüler einher. In Luxemburg, Schweden und Slowenien ging ein ähnlicher Rückgang der Schülerzahlen im Primar-, Sekundar- und postsekundaren, nicht tertiären Bereich mit einem nur leichten Anstieg der Ausgaben in diesen Bildungsbereichen einher (Abb. Br.6).

Im Tertiärbereich ergibt sich ein anderes Bild. In einigen Fällen sanken die Ausgaben pro Studierenden zwischen 1995 und 2010, da die Bildungsausgaben hinter den steigenden Studierendenzahlen zurückblieben. Im Zeitraum von 1995 bis 2000 blieben die Ausgaben von Bildungseinrichtungen pro Studierenden im Tertiärbereich im Durchschnitt der OECD-Länder gleich, stiegen dann aber zwischen 2000 und 2005 sowie zwischen 2005 und 2010 an. Zwischen 2005 und 2010 stiegen in Estland, Korea und Polen die Ausgaben pro Studierenden um mindestens 30 Prozent. 


\section{Abbildung B1.6}

Veränderung der Ausgaben von Bildungseinrichtungen pro Schüler/Studierenden, nach Bildungsbereich (2005, 2010) Index der Veränderung zwischen 2005 und 2010 (2005 = 100, zu konstanten Preisen von 2010)

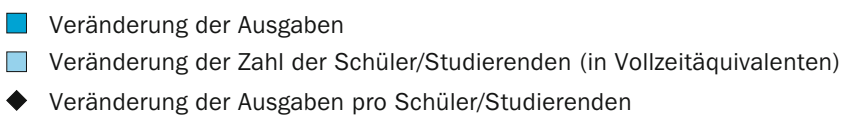

Primar-, Sekundar- und postsekundarer, nicht tertiärer Bereich
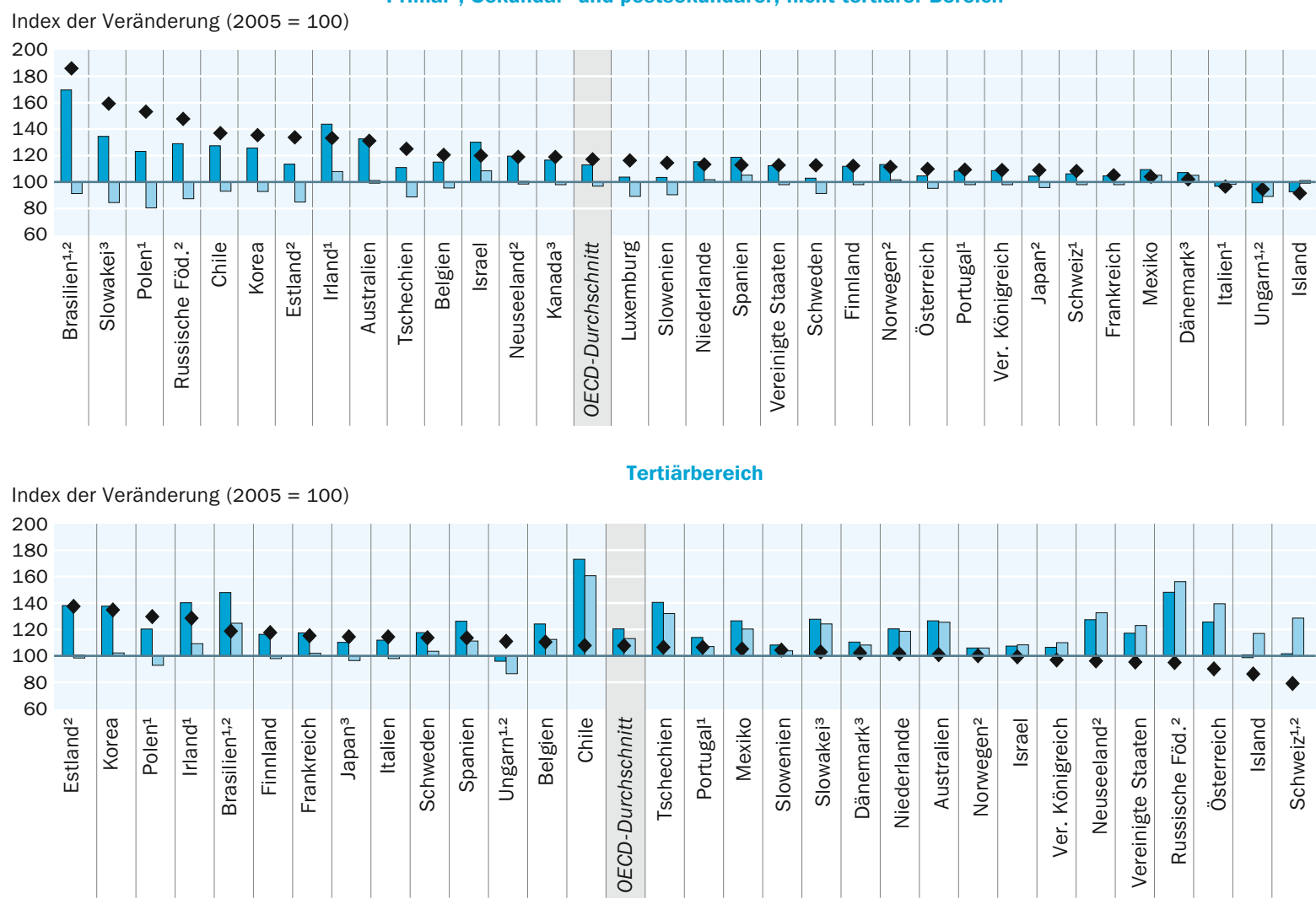

1. Nur öffentliche Bildungseinrichtungen. 2. Nur öffentliche Ausgaben. 3. Einige Bildungsbereiche sind in anderen Bildungsbereichen enthalten. Einzelheiten s. Erläuterung von „x“ in Hinweise für den Leser.

Anordnung der Länder in absteigender Reihenfolge der Veränderung der Ausgaben von Bildungseinrichtungen pro Schüler/Studierenden.

Quelle: OECD. Tabellen B1.5a und B1.5b. Hinweise s. Anhang 3 unter www.oecd.org/edu/eag.htm. StatLink: http://dx.doi.org/10.1787/888932846842

Im Gegensatz dazu sanken zwischen 2005 und 2010 unter den 3I Ländern mit verfügbaren Daten die Ausgaben pro Studierenden im Tertiärbereich in Island, Israel, Österreich, dem Vereinigten Königreich und den Vereinigten Staaten. Dies war auch in Neuseeland und der Schweiz der Fall, wo die öffentlichen Ausgaben pro Studierenden (es lagen keine Daten zu den privaten Aufwendungen vor) in diesem Zeitraum zurückgingen. In all diesen Ländern ist dieser Rückgang größtenteils auf einen schnellen Anstieg der Studierendenzahlen im Tertiärbereich um mindestens 8 Prozent zurückzuführen (Tab. BI.5 und Abb. Br.6). 


\section{Definitionen}

Zusätzliche Dienstleistungen sind Dienstleistungen, die von den Bildungseinrichtungen neben dem eigentlichen Bildungsauftrag erbracht werden. Soziale Dienstleistungen für Schüler/Studierende stellen den wichtigsten Bereich zusätzlicher Dienstleistungen dar. Im Primar-, Sekundar- und postsekundaren, nicht tertiären Bereich umfassen die sozialen Dienstleistungen die Bereitstellung von Mahlzeiten, die Gesundheitsdienste der Schulen sowie Schultransporte. Im Tertiärbereich zählen u. a. Wohnheime, Mensen und Gesundheitsdienste dazu.

Eigentliche Bildungsdienstleistungen stehen in direktem Zusammenhang mit Unterricht und Bildung an Bildungseinrichtungen. Hierzu gehören die Vergütungen der Lehrkräfte, der Bau und die Instandhaltung von Schulgebäuden, Unterrichtsmaterial, Bücher und die Verwaltung der Schulen.

Forschung und Entwicklung (F\&E) umfasst Forschung an Hochschulen und anderen Bildungseinrichtungen des Tertiärbereichs, unabhängig davon, ob diese aus dem allgemeinen Etat der Einrichtungen, über separate Zuschüsse oder über Verträge mit öffentlichen oder privaten Geldgebern finanziert werden.

\section{Angewandte Methodik}

Die Daten beziehen sich auf das Haushaltsjahr 2010 und beruhen auf der von der OECD im Jahre 2012 durchgeführten UOE-Datenerhebung zur Bildungsstatistik (weitere Informationen s. Anhang 3 unter www.oecd.orgleduleag.htm).

Tabelle BI.5 zeigt die Veränderungen der Ausgaben von Bildungseinrichtungen pro Schüler/Studierenden zwischen den Haushaltsjahren 1995, 2000, 2005 und 2010. Die OECD-Länder wurden gebeten, die Daten für 1995, 2000 und 2005 entsprechend den Definitionen und dem Erhebungsbereich der UOE-Datenerhebung von $2012 \mathrm{zu}$ erfassen. Alle Daten zu den Ausgaben sowie die Angaben zum BIP der Jahre I995, 2000 und 2005 wurden mittels des BIP-Preisdeflators an das Preisniveau von 2010 angepasst.

Dieser Indikator gibt Auskunft über die direkten öffentlichen und privaten Ausgaben von Bildungseinrichtungen im Verhältnis zur Zahl der Schüler bzw. Studierenden (in Vollzeitäquivalenten) an diesen Einrichtungen. Im Interesse einer besseren internationalen Vergleichbarkeit sind öffentliche Zuwendungen zum Lebensunterhalt der Schüler/Studierenden außerhalb von Bildungseinrichtungen nicht enthalten.

Die Ausgaben für eigentliche Bildungsdienstleistungen werden als der Restbetrag sämtlicher Ausgaben ermittelt, d. h., sie ergeben sich aus den Gesamtausgaben für Bildungseinrichtungen abzüglich der Ausgaben für F\&E und zusätzliche Dienstleistungen. Ausgaben für Forschung und Entwicklung werden anhand der Angaben der forschenden Institutionen und nicht der betreffenden Geldgeber entsprechend klassifiziert. 
Die Ausgaben von Bildungseinrichtungen pro Schüler/Studierenden in einem bestimmten Bildungsbereich werden mittels Division der Gesamtausgaben von Bildungseinrichtungen in diesem Bereich durch die entsprechende Schüler-/Studierendenzahl (in Vollzeitäquivalenten) ermittelt. Dabei wurden nur jene Bildungseinrichtungen und Bildungsgänge berücksichtigt, für die sowohl Daten über die Zahl der Schüler/Studierenden als auch Zahlen über die Ausgaben vorlagen. Die Ausgaben in Landeswährung werden in US-Dollar umgerechnet, indem der betreffende Betrag in Landeswährung durch den Kaufkraftparitätsindex (KKP-Index) für das BIP geteilt wird. Dieser Umrechnungskurs wird verwendet, weil der Devisenmarktkurs von einer Vielzahl von Faktoren beeinflusst wird (Zinsen, Handelspolitik, Konjunkturerwartungen etc.), die wenig mit der aktuellen relativen inländischen Kaufkraft in den einzelnen OECD-Ländern zu tun haben (weitere Informationen s. Anhang 2).

Für einige Länder sind keine Zahlen zu den Ausgaben für Schüler/Studierende an privaten Bildungseinrichtungen verfügbar, für andere Länder sind die Angaben zu unabhängigen privaten Bildungseinrichtungen nicht vollständig. In diesen Fällen wurden nur die Ausgaben für öffentliche sowie staatlich subventionierte private Einrichtungen berücksichtigt.

Die Ausgaben von Bildungseinrichtungen pro Schüler/Studierenden im Verhältnis zum BIP pro Kopf werden berechnet, indem die Ausgaben von Bildungseinrichtungen pro Schüler/ Studierenden in Landeswährung als prozentualer Anteil des ebenfalls in Landeswährung ausgedrückten BIP pro Kopf angegeben werden. Wenn die Referenzzeiträume für Daten zu den Bildungsausgaben und für das BIP unterschiedlich sind, werden unter Verwendung der für das betreffende OECD-Land geltenden Inflationsraten die Ausgabendaten auf den Bezugszeitraum der BIP-Daten umgerechnet (s. Anhang 2).

Die kumulierten Ausgaben während der durchschnittlichen Dauer der Studiengänge im Tertiärbereich (Tab. BI.3a) werden durch Multiplikation der aktuellen jährlichen Ausgaben mit der typischen Dauer der betreffenden Studiengänge berechnet. Die Vorgehensweise zur Ermittlung der typischen Durchschnittsdauer von Studiengängen im Tertiärbereich ist (auf Englisch) in Anhang 3 unter www.oecd.org/eduleag. htm beschrieben. Die Studiendauer im Tertiärbereich wird anhand von Daten ermittelt, die aus einer 2012 in den OECD-Ländern durchgeführten Erhebung stammen.

Vollzeitäquivalente Schüler/Studierende: Die Erstellung einer Rangfolge der OECD-Länder nach den jährlichen Ausgaben von Bildungseinrichtungen pro Schüler/Studierenden wird durch unterschiedliche Definitionen der einzelnen Länder für Vollzeit-, Teilzeitund vollzeitäquivalente Bildungsteilnahme erschwert. In einigen OECD-Ländern gelten alle Bildungsteilnehmer im Tertiärbereich als Vollzeitstudierende, während in anderen Ländern die Beteiligung aufgrund der innerhalb einer vorgegebenen Referenzzeit für die erfolgreiche Absolvierung bestimmter Module erworbenen Credits (Leistungspunkte) beurteilt wird. Bei OECD-Ländern, die genaue Angaben über Teilzeitstudierende machen können, werden sich höhere Ausgaben der Bildungseinrichtungen pro vollzeitäquivalenten Studierenden ergeben als bei denjenigen OECD-Ländern, die nicht zwischen den verschiedenen Teilnahmemöglichkeiten differenzieren können. 
Die statistischen Daten für Israel wurden von den zuständigen israelischen Stellen bereitgestellt, die für sie verantwortlich zeichnen. Die Verwendung dieser Daten durch die OECD erfolgt unbeschadet des völkerrechtlichen Status der Golanhöhen, von OstJerusalem und der israelischen Siedlungen im Westjordanland.

\section{Tabellen Indikator B1}

Tabelle Bı.ıa: Jährliche Ausgaben von Bildungseinrichtungen pro Schüler/ Studierenden für alle Leistungsbereiche (2010) StatLink: http://dx.doi.org/10.1787/888932849369

WEB Table Ar.b: Annual expenditure per student by educational institutions for core services (Jährliche Ausgaben von Bildungseinrichtungen pro Schüler/ Studierenden für eigentliche Bildungsdienstleistungen) (2010) StatLink: http://dx.doi.org/10.1787/888932849388

Tabelle BI.2: Jährliche Ausgaben von Bildungseinrichtungen pro Schüler/Studierenden für eigentliche Bildungsdienstleistungen, zusätzliche Dienstleistungen und F\&E (2010)

StatLink: http://dx.doi.org/10.1787/888932849407

Tabelle Br.3a: Kumulierte Ausgaben von Bildungseinrichtungen pro Studierenden für alle Leistungsbereiche während der durchschnittlichen Dauer von Studiengängen im Tertiärbereich (2010)

StatLink: http://dx.doi.org/10.1787/888932849426

WEB Table Ar.3b: Cumulative expenditure per student by educational institutions for all services over the theoretical duration of primary and secondary studies (Kumulierte Ausgaben von Bildungseinrichtungen pro Schüler für alle Leistungsbereiche während der regulären Ausbildungsdauer im Primar- und Sekundarbereich) (2010)

StatLink: http://dx.doi.org/10.1787/888932849445

Tabelle BI.4: Jährliche Ausgaben von Bildungseinrichtungen pro Schüler/Studierenden für alle Leistungsbereiche im Verhältnis zum BIP pro Kopf (2010) StatLink: http://dx.doi.org/10.1787/888932849464

Tabelle BI.5a: Veränderung der Ausgaben von Bildungseinrichtungen pro Schüler im Primar-, Sekundar- und postsekundaren, nicht tertiären Bildungsbereich für alle Leistungsbereiche aufgrund verschiedener Faktoren (I995, 2000, 2005, 2010) StatLink: http://dx.doi.org/10.1787/888932849483

Tabelle BI.5b: Veränderung der Ausgaben von Bildungseinrichtungen pro Studierenden im Tertiärbereich für alle Leistungsbereiche aufgrund verschiedener Faktoren (I995, 2000, 2005, 2010)

StatLink: http://dx.doi.org/10.1787/888932849502 
Tabelle Br.6: Jährliche Ausgaben von Bildungseinrichtungen pro Schüler im Sekundarbereich für alle Leistungsbereiche, nach Art des Bildungsgangs (2010) StatLink: http://dx.doi.org/10.1787/888932849521

WEB Table Cr.7: Distribution of expenditure (as a percentage) by educational institutions compared to the number of students enrolled at each level of education (Anteil der Ausgaben von Bildungseinrichtungen [in \%] im Vergleich zur Zahl der Schüler/Studierenden pro Bildungsbereich) (2010)

StatLink: http://dx.doi.org/10.1787/888932849540 
Tabelle B1.1a

Jährliche Ausgaben von Bildungseinrichtungen pro Schüler/Studierenden für alle Leistungsbereiche (2010) In US-Dollar, kaufkraftbereinigt mittels KKP für das BIP, nach Bildungsbereich, basierend auf Vollzeitäquivalenten

\begin{tabular}{|c|c|c|c|c|c|c|c|c|c|c|c|}
\hline & \multirow{2}{*}{\begin{tabular}{|c|} 
Elemen- \\
tarbereich \\
(für \\
3-Jährige \\
und \\
Ältere)
\end{tabular}} & \multirow[t]{2}{*}{$\begin{array}{l}\text { Primar- } \\
\text { bereich }\end{array}$} & \multicolumn{3}{|c|}{ Sekundarbereich } & \multirow{2}{*}{$\begin{array}{c}\text { Postse- } \\
\text { kundarer, } \\
\text { nicht } \\
\text { tertiärer } \\
\text { Bereich }\end{array}$} & \multicolumn{3}{|c|}{$\begin{array}{c}\text { Tertiärbereich } \\
\text { (einschl. F\&E-Aktivitäten) }\end{array}$} & \multirow{2}{*}{\begin{tabular}{|c|} 
Tertiär- \\
bereich \\
insgesamt \\
ohne \\
F\&E-Akti- \\
vitäten
\end{tabular}} & \multirow{2}{*}{$\begin{array}{c}\text { Primar- bis } \\
\text { Tertiär- } \\
\text { bereich } \\
\text { (einschl. } \\
\text { F\&E-Akti- } \\
\text { vitäten) }\end{array}$} \\
\hline & & & $\begin{array}{c}\text { Sekundar- } \\
\text { bereich I }\end{array}$ & $\begin{array}{l}\text { Sekundar- } \\
\text { bereich II }\end{array}$ & $\begin{array}{l}\text { Sekundar- } \\
\text { bereich } \\
\text { insgesamt }\end{array}$ & & $\begin{array}{c}\text { Tertiär- } \\
\text { bereich B }\end{array}$ & \begin{tabular}{|c|} 
Tertiär- \\
bereich A \\
und wei- \\
terführende \\
forschungs- \\
orientierte \\
Studien- \\
gänge
\end{tabular} & $\begin{array}{c}\text { Tertiär- } \\
\text { bereich } \\
\text { insgesamt }\end{array}$ & & \\
\hline & (1) & (2) & (3) & (4) & (5) & (6) & (7) & (8) & (9) & (10) & (11) \\
\hline \multicolumn{12}{|l|}{ OECD-Länder } \\
\hline Australien & 8899 & 9463 & 10595 & 9966 & 10350 & 7124 & 8829 & 16502 & 15142 & 9379 & 10825 \\
\hline Österreich & 8893 & 10244 & 12711 & 12390 & 12551 & 5418 & 6491 & 15101 & 15007 & 10488 & 12507 \\
\hline Belgien & 6024 & 8852 & $x(5)$ & $x(5)$ & 11004 & $x(5)$ & $x(9)$ & $x(9)$ & 15179 & 9645 & 11028 \\
\hline Kanada $^{1,2}$ & $x(2)$ & 8933 & $x(2)$ & 11317 & $\mathrm{~m}$ & $\mathrm{~m}$ & 14461 & 27123 & 22475 & 16300 & m \\
\hline Chile $^{3}$ & 3544 & з301 & 3092 & 3119 & 3110 & a & 4028 & 9580 & 7101 & 6829 & 4183 \\
\hline Tschechien & 4247 & 4120 & 6919 & 6244 & 6546 & 1920 & 3275 & 7970 & 7635 & 6244 & 6037 \\
\hline Dänemark & 9454 & 10935 & 11561 & 11914 & 11747 & $x(4,9)$ & $x(9)$ & $x(9)$ & 18977 & $\mathrm{~m}$ & 12848 \\
\hline Estland & 2533 & 5140 & 5948 & 6834 & 6444 & 7923 & 7361 & 6080 & 6501 & 3909 & 6126 \\
\hline Finnland & 5372 & 7624 & 11705 & 7912 & 9162 & $x(5)$ & $\mathrm{n}$ & 16714 & 16714 & 9802 & 10157 \\
\hline Frankreich & 6362 & 6622 & 9399 & 12874 & 10877 & $\mathrm{~m}$ & 12283 & 15997 & 15067 & 10309 & 10182 \\
\hline Deutschland & $\mathrm{m}$ & $\mathrm{m}$ & $\mathrm{m}$ & $\mathrm{m}$ & $\mathrm{m}$ & $\mathrm{m}$ & $\mathrm{m}$ & $\mathrm{m}$ & $\mathrm{m}$ & $\mathrm{m}$ & m \\
\hline Griechenland & $\mathrm{m}$ & $\mathrm{m}$ & $\mathrm{m}$ & $\mathrm{m}$ & $\mathrm{m}$ & $\mathrm{m}$ & $\mathrm{m}$ & $\mathrm{m}$ & $\mathrm{m}$ & $\mathrm{m}$ & m \\
\hline Ungarn² & 4773 & 4684 & 4657 & 4459 & 4553 & 3360 & 4463 & 9071 & 8745 & 6824 & 5285 \\
\hline Island & 8606 & 9482 & 9204 & 7014 & 7841 & $x(5)$ & $x(9)$ & $\mathrm{x}(9)$ & 8728 & $\mathrm{~m}$ & 8619 \\
\hline Irland $^{2}$ & $\mathrm{~m}$ & 8384 & 11477 & 11265 & 11380 & 10394 & $x(9)$ & $x(9)$ & 16008 & 11512 & 10685 \\
\hline Israel & 3910 & 5758 & $x(5)$ & $x(5)$ & 5616 & 5096 & 9748 & 10945 & 10730 & $\mathrm{~m}$ & 6537 \\
\hline Italien ${ }^{2}$ & 7177 & 8296 & 8548 & 8646 & 8607 & $\mathrm{~m}$ & 10674 & 9576 & 9580 & 6266 & 8690 \\
\hline Japan & 5550 & 8353 & 9847 & 10064 & 9957 & $x(4,9)$ & 10239 & 17544 & 16015 & $\mathrm{~m}$ & 10596 \\
\hline Korea & 6739 & 6601 & 6652 & 9477 & 8060 & a & 5713 & 11271 & 9972 & 8226 & 8198 \\
\hline Luxemburg & 20958 & 21240 & 17449 & 17813 & 17633 & $\mathrm{~m}$ & $\mathrm{~m}$ & $\mathrm{~m}$ & $\mathrm{~m}$ & $\mathrm{~m}$ & m \\
\hline Mexiko & 2280 & 2331 & 2102 & 3617 & 2632 & a & $x(9)$ & $x(9)$ & 7872 & 6611 & 2993 \\
\hline Niederlande & 7664 & 7954 & 11925 & 11750 & 11838 & 11145 & 9873 & 17172 & 17161 & 10818 & 11439 \\
\hline Neuseeland & 11495 & 6842 & 7400 & 9007 & 8170 & 9440 & 8491 & 10923 & 10418 & 8816 & 8192 \\
\hline Norwegen & 6610 & 12255 & 12603 & 14845 & 13852 & $x(5)$ & $x(9)$ & $x(9)$ & 18512 & 10933 & 14081 \\
\hline Polen ${ }^{2}$ & 5737 & 5937 & 5428 & 5530 & 5483 & 7020 & 6432 & 8892 & 8866 & 7281 & 6321 \\
\hline Portugal ${ }^{2}$ & 5977 & 5922 & 8504 & 9327 & 8882 & $\mathrm{~m}$ & $x(9)$ & $x(9)$ & 10578 & 5843 & 8009 \\
\hline Slowakei & 4306 & 5732 & 5147 & 4501 & 4806 & $x(4)$ & $x(4)$ & 6904 & 6904 & 5831 & 5400 \\
\hline Slowenien & 7744 & 8935 & 9368 & 7472 & 8187 & $x(4)$ & $\mathrm{x}(9)$ & $x(9)$ & 9693 & 7719 & 8933 \\
\hline Spanien & 6685 & 7291 & 9208 & 10306 & 9608 & a & 10384 & 14072 & 13373 & 9494 & 9484 \\
\hline Schweden & 6582 & 9987 & 9776 & 10497 & 10185 & 6176 & 6387 & 20750 & 19562 & 9143 & 11734 \\
\hline Schweiz ${ }^{2}$ & 5186 & 11513 & 14216 & 15595 & 14972 & $x(4)$ & 5021 & 23457 & 21893 & 9620 & 14922 \\
\hline Türkei & 2490 & 1860 & a & 2470 & 2470 & a & $\mathrm{m}$ & $\mathrm{m}$ & $\mathrm{m}$ & $\mathrm{m}$ & m \\
\hline Ver. Königreich & 7047 & 9369 & 10533 & 10388 & 10452 & a & $x(9)$ & $x(9)$ & 15862 & 10546 & 10878 \\
\hline Vereinigte Staaten & 10020 & 11193 & 11920 & 13045 & 12464 & $\mathrm{~m}$ & $x(9)$ & $x(9)$ & 25576 & 22744 & 15171 \\
\hline OECD-Durchschnitt & 6762 & 7974 & 8893 & 9322 & 9014 & 4413 & $\sim$ & $\sim$ & 13528 & 9274 & 9313 \\
\hline OECD insgesamt & 6569 & 7126 & $\sim$ & $\sim$ & 8973 & $\sim$ & $\sim$ & $\sim$ & 17665 & 14624 & 10416 \\
\hline EU21-Durchschnitt & 7085 & 8277 & 9459 & 9451 & 9471 & 5336 & $\sim$ & $\sim$ & 12856 & 8334 & 9208 \\
\hline \multicolumn{12}{|l|}{ Sonst. G20-Länder } \\
\hline Argentinien ${ }^{2}$ & 2427 & 2929 & 3779 & 4202 & 3930 & a & 2932 & 5539 & 4680 & $\mathrm{~m}$ & 3628 \\
\hline Brasilien $^{2}$ & 2111 & 2778 & 2849 & 2148 & 2571 & a & $x(9)$ & $x(9)$ & 13137 & 12381 & 3067 \\
\hline China & $\mathrm{m}$ & $\mathrm{m}$ & $\mathrm{m}$ & $\mathrm{m}$ & $\mathrm{m}$ & $\mathrm{m}$ & $\mathrm{m}$ & $\mathrm{m}$ & $\mathrm{m}$ & $\mathrm{m}$ & m \\
\hline Indien & $\mathrm{m}$ & $\mathrm{m}$ & $\mathrm{m}$ & $\mathrm{m}$ & $\mathrm{m}$ & $\mathrm{m}$ & $\mathrm{m}$ & $\mathrm{m}$ & $\mathrm{m}$ & $\mathrm{m}$ & m \\
\hline Indonesien & $\mathrm{m}$ & $\mathrm{m}$ & $\mathrm{m}$ & $\mathrm{m}$ & $\mathrm{m}$ & $\mathrm{m}$ & $\mathrm{m}$ & $\mathrm{m}$ & $\mathrm{m}$ & $\mathrm{m}$ & m \\
\hline Russische Föd. ${ }^{2}$ & $\mathrm{~m}$ & $x(5)$ & $x(5)$ & $x(5)$ & 4100 & $x(5)$ & 4509 & 7622 & 7039 & 6612 & 5058 \\
\hline Saudi-Arabien & $\mathrm{m}$ & $\mathrm{m}$ & $\mathrm{m}$ & $m$ & $\mathrm{~m}$ & $\mathrm{~m}$ & $\mathrm{~m}$ & $\mathrm{~m}$ & $\mathrm{~m}$ & $\mathrm{~m}$ & m \\
\hline Südafrika & $\mathrm{m}$ & $\mathrm{m}$ & $\mathrm{m}$ & $\mathrm{m}$ & $\mathrm{m}$ & $\mathrm{m}$ & $\mathrm{m}$ & $\mathrm{m}$ & $\mathrm{m}$ & $\mathrm{m}$ & m \\
\hline G20-Durchschnitt & $\mathbf{m}$ & $\mathbf{m}$ & m & m & $\mathbf{m}$ & $\mathbf{m}$ & m & $\mathbf{m}$ & $\mathbf{m}$ & $\mathbf{m}$ & $\mathbf{m}$ \\
\hline
\end{tabular}

1. Referenzjahr 2009. 2. Nur öffentliche Bildungseinrichtungen (Kanada: nur im Tertiärbereich, Italien und Russische Föderation: außer im Tertiärbereich). 3. Referenzjahr 2011.

Quelle: OECD. Argentinien: Statistikinstitut der UNESCO (World Education Indicators Programme). Hinweise s. Anhang 3 unter www.oecd.org/edu/eag.htm. StatLink: http://dx.doi.org/10.1787/888932849369

Erläuterung der Kennzeichnung fehlender Daten s. Hinweise für den Leser. 
Tabelle B1.2

Jährliche Ausgaben von Bildungseinrichtungen pro Schüler/Studierenden für eigentliche Bildungsdienstleistungen, zusätzliche Dienstleistungen und F\&E (2010)

In US-Dollar, kaufkraftbereinigt mittels KKP für das BIP, nach Bildungsbereich und Leistungsbereich, basierend auf Vollzeitäquivalenten

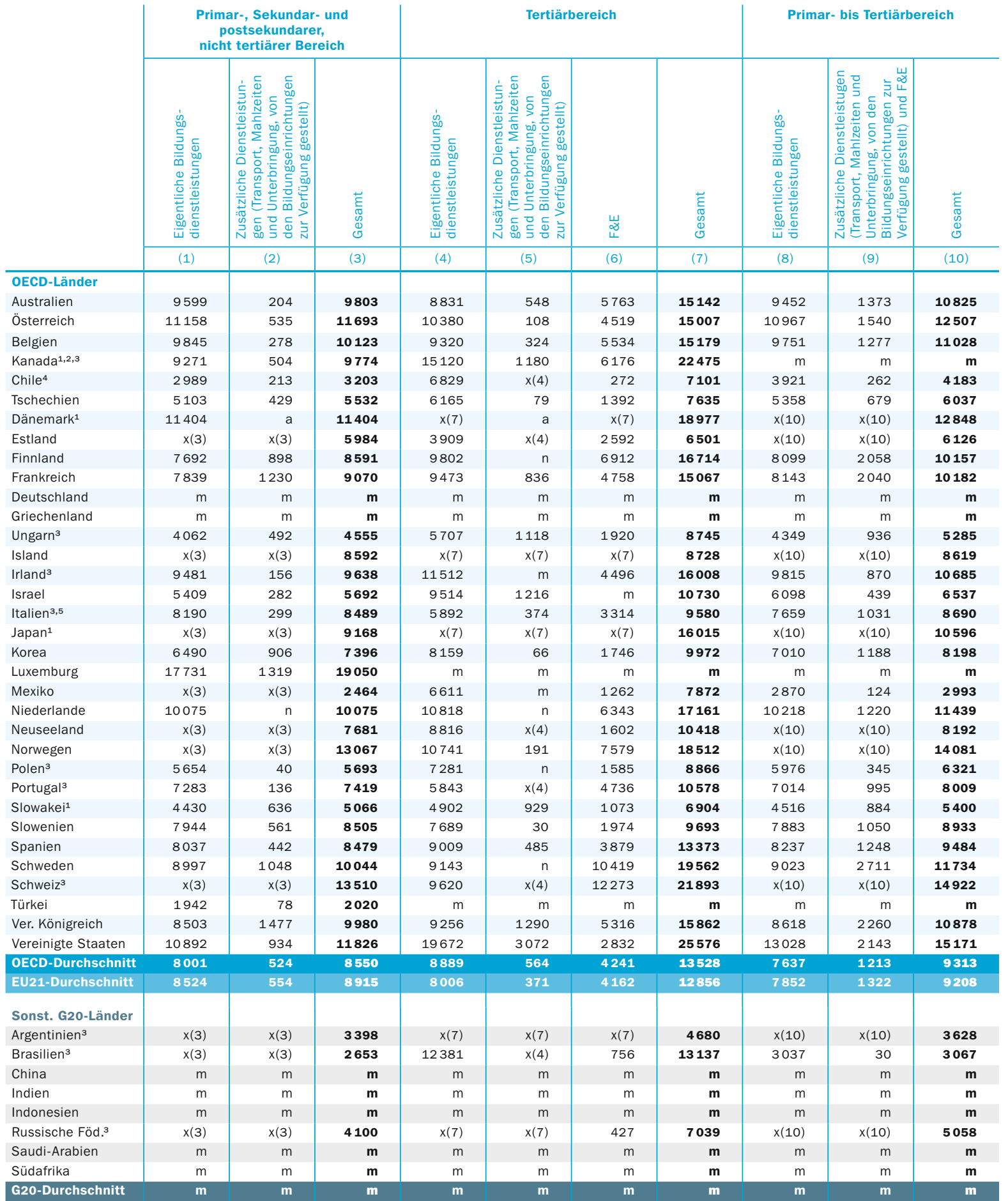

1. Einige Bildungsbereiche sind in anderen Bildungsbereichen enthalten. Einzelheiten s. Erläuterung von „x“ in Hinweise für den Leser. 2. Referenzjahr 2009.

3. Nur öffentliche Bildungseinrichtungen (Kanada: nur im Tertiärbereich, Italien: außer im Tertiärbereich). 4. Referenzjahr 2011.5 . Ohne postsekundaren, nicht tertiären Bereich.

Quelle: OECD. Argentinien: Statistikinstitut der UNESCO (World Education Indicators Programme). Hinweise s. Anhang 3 unter www.oecd.org/edu/eag.htm. StatLink: http://dx.doi.org/10.1787/888932849407

Erläuterung der Kennzeichnung fehlender Daten s. Hinweise für den Leser. 
Tabelle B1.3a

Kumulierte Ausgaben von Bildungseinrichtungen pro Studierenden für alle Leistungsbereiche während der durchschnittlichen Dauer von Studiengängen im Tertiärbereich (2010)

In US-Dollar, kaufkraftbereinigt mittels KKP für das BIP, nach Art des Studiengangs

\begin{tabular}{|c|c|c|c|c|c|c|c|}
\hline & \multirow[t]{3}{*}{ Methode $^{1}$} & \multicolumn{3}{|c|}{$\begin{array}{l}\text { Durchschnittliche Dauer von Studiengängen } \\
\text { im Tertiärbereich } 2010 \text { (in Jahren) }\end{array}$} & \multicolumn{3}{|c|}{$\begin{array}{l}\text { Kumulierte Ausgaben pro Studierenden während } \\
\text { der durchschnittlichen Dauer von Studiengängen } \\
\text { im Tertiärbereich (in US-Dollar) }\end{array}$} \\
\hline & & Tertiärbereich B & \begin{tabular}{|c|} 
Tertiärbereich A \\
und weiterführende \\
forschungsorien- \\
tierte Studiengänge
\end{tabular} & $\begin{array}{l}\text { Tertiärbereich } \\
\text { insgesamt }\end{array}$ & Tertiärbereich B & $\begin{array}{l}\text { Tertiärbereich A } \\
\text { und weiterführende } \\
\text { forschungsorien- } \\
\text { tierte Studiengänge }\end{array}$ & $\begin{array}{c}\text { Tertiärbereich } \\
\text { insgesamt }\end{array}$ \\
\hline & & (1) & (2) & (3) & (4) & (5) & (6) \\
\hline \multicolumn{8}{|l|}{ OECD-Länder } \\
\hline Australien & & $\mathrm{m}$ & $\mathrm{m}$ & m & $\mathrm{m}$ & $\mathrm{m}$ & m \\
\hline Österreich & NF & 2,34 & 6,10 & 5,34 & 15189 & 92119 & 80138 \\
\hline Belgien $^{2}$ & VM & 2,41 & 3,67 & 2,99 & $x(6)$ & $x(6)$ & 45384 \\
\hline Kanada & & $\mathrm{m}$ & $\mathrm{m}$ & m & $\mathrm{m}$ & $\mathrm{m}$ & m \\
\hline Chile & & $\mathrm{m}$ & $\mathrm{m}$ & m & $\mathrm{m}$ & $\mathrm{m}$ & m \\
\hline Tschechien ${ }^{3}$ & VM & 2,36 & 4,34 & 4,10 & $\mathrm{~m}$ & 34591 & m \\
\hline Dänemark & NF & 2,74 & 5,49 & 5,20 & $x(6)$ & $x(6)$ & 98680 \\
\hline Estland & VM & 3,29 & 4,97 & 4,42 & 24222 & 30202 & 28762 \\
\hline Finnland & VM & $a$ & 4,74 & 4,74 & a & 79224 & 79224 \\
\hline Frankreich $^{3}$ & VM & 3,00 & 4,74 & 4,02 & 36849 & 75827 & 60570 \\
\hline Deutschland & VM & 2,41 & 4,95 & 4,19 & $\mathrm{~m}$ & $\mathrm{~m}$ & m \\
\hline Griechenland & & $\mathrm{m}$ & $\mathrm{m}$ & m & $\mathrm{m}$ & $\mathrm{m}$ & m \\
\hline Ungarn ${ }^{4}$ & $\mathrm{NF}$ & 1,85 & 3,71 & 3,29 & 8275 & 33665 & 28764 \\
\hline Island & VM & $x(3)$ & $x(3)$ & 4,49 & $x(6)$ & $x(6)$ & 39188 \\
\hline Irland ${ }^{4}$ & VM & 2,21 & 4,02 & 3,24 & $x(6)$ & $x(6)$ & 51865 \\
\hline Israel & VM & $\mathrm{m}$ & 3,03 & m & $\mathrm{m}$ & 33163 & m \\
\hline Italien & $\mathrm{NF}$ & $\mathrm{m}$ & 4,52 & m & $\mathrm{m}$ & 43283 & m \\
\hline Japan & VM & 2,09 & 4,63 & 4,46 & 21433 & 81269 & 71441 \\
\hline Korea & VM & 2,07 & 4,22 & 3,43 & 11826 & 47564 & 34202 \\
\hline Luxemburg & & $\mathrm{m}$ & $\mathrm{m}$ & m & $\mathrm{m}$ & $\mathrm{m}$ & $\mathbf{m}$ \\
\hline Mexiko & NF & 1,72 & 3,49 & 3,35 & $x(6)$ & $x(6)$ & 26373 \\
\hline Niederlande & VM & $\mathrm{m}$ & 5,26 & 5,26 & $\mathrm{~m}$ & 90322 & 90269 \\
\hline Neuseeland & VM & 1,93 & 4,06 & 3,37 & 16417 & 44293 & 35102 \\
\hline Norwegen & & $\mathrm{m}$ & $\mathrm{m}$ & m & $\mathrm{m}$ & $\mathrm{m}$ & m \\
\hline Polen ${ }^{4}$ & VM & $\mathrm{m}$ & 3,68 & $\mathbf{m}$ & $\mathrm{m}$ & 32721 & m \\
\hline Portugal & & $\mathrm{m}$ & $\mathrm{m}$ & m & $\mathrm{m}$ & $\mathrm{m}$ & m \\
\hline Slowakei & $\mathrm{NF}$ & 2,47 & 3,90 & 3,82 & $\mathrm{~m}$ & 26924 & m \\
\hline Slowenien & $\mathrm{NF}$ & 2,63 & 3,64 & 3,21 & $x(6)$ & $x(6)$ & 31097 \\
\hline Spanien & VM & 2,15 & 5,54 & 4,66 & 22327 & 77961 & 62319 \\
\hline Schweden & VM & 2,44 & 4,70 & 4,51 & 15566 & 97526 & 88225 \\
\hline Schweiz ${ }^{4}$ & VM & 2,19 & 5,45 & 3,62 & 10979 & 127904 & 79346 \\
\hline Türkei & VM & 1,94 & 2,73 & 2,65 & $x(6)$ & $x(6)$ & m \\
\hline Ver. Königreich ${ }^{3}$ & VM & $x(3)$ & $x(3)$ & 2,74 & $x(6)$ & $x(6)$ & 43463 \\
\hline Vereinigte Staaten & $\mathrm{NF}$ & $x(3)$ & $x(3)$ & 3,17 & $x(6)$ & $x(6)$ & 81076 \\
\hline \multicolumn{2}{|l|}{ OECD insgesamt } & 2,21 & 4,40 & 3,93 & $\sim$ & $\sim$ & 57774 \\
\hline EU21-Durchschnitt & & 2,31 & 4,59 & 4,11 & $\sim$ & $\sim$ & 60674 \\
\hline \multicolumn{8}{|l|}{ Sonst. G20-Länder } \\
\hline Argentinien & & $\mathrm{m}$ & $\mathrm{m}$ & m & $\mathrm{m}$ & $\mathrm{m}$ & m \\
\hline Brasilien & & $\mathrm{m}$ & $\mathrm{m}$ & m & $\mathrm{m}$ & $\mathrm{m}$ & m \\
\hline China & & $\mathrm{m}$ & $\mathrm{m}$ & m & $\mathrm{m}$ & $\mathrm{m}$ & m \\
\hline Indien & & $\mathrm{m}$ & $\mathrm{m}$ & m & $\mathrm{m}$ & $\mathrm{m}$ & m \\
\hline Indonesien & & $\mathrm{m}$ & $\mathrm{m}$ & m & $\mathrm{m}$ & $\mathrm{m}$ & m \\
\hline Russische Föd. & & $\mathrm{m}$ & $\mathrm{m}$ & m & $\mathrm{m}$ & $\mathrm{m}$ & m \\
\hline Saudi-Arabien & & $\mathrm{m}$ & $\mathrm{m}$ & m & $\mathrm{m}$ & $\mathrm{m}$ & m \\
\hline Südafrika & & $\mathrm{m}$ & $\mathrm{m}$ & m & $\mathrm{m}$ & $\mathrm{m}$ & m \\
\hline G20-Durchschnitt & & $\mathbf{m}$ & m & m & $\mathbf{m}$ & $\mathbf{m}$ & m \\
\hline
\end{tabular}

1. Zur Ermittlung der Dauer von Studiengängen im Tertiärbereich wurde entweder die Verkettungsmethode (VM) oder eine Näherungsformel (NF) verwendet.

2. Referenzjahr 2008. 3. Die durchschnittliche Dauer von Studiengängen im Tertiärbereich wurde auf Grundlage nationaler Daten geschätzt. 4. Nur öffentliche Bildungseinrichtungen.

Quelle: OECD. Hinweise s. Anhang 3 unter www.oecd.org/edu/eag.htm. StatLink: http://dx.doi.org/10.1787/888932849426

Erläuterung der Kennzeichnung fehlender Daten s. Hinweise für den Leser. 
Tabelle B1.4

Jährliche Ausgaben von Bildungseinrichtungen pro Schüler/Studierenden für alle Leistungsbereiche im Verhältnis zum BIP pro Kopf (2010)

Nach Bildungsbereich, basierend auf Vollzeitäquivalenten

\begin{tabular}{|c|c|c|c|c|c|c|c|c|c|c|c|}
\hline & \multirow{2}{*}{ 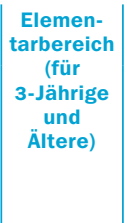 } & \multirow[t]{2}{*}{$\begin{array}{l}\text { Primar- } \\
\text { bereich }\end{array}$} & \multicolumn{3}{|c|}{ Sekundarbereich } & \multirow{2}{*}{$\begin{array}{l}\text { Post- } \\
\text { sekunda- } \\
\text { rer, nicht } \\
\text { tertiärer } \\
\text { Bereich }\end{array}$} & \multicolumn{3}{|c|}{$\begin{array}{c}\text { Tertiärbereich } \\
\text { (einschl. F\&E-Aktivitäten) }\end{array}$} & \multirow{2}{*}{\begin{tabular}{|c|} 
Tertiär- \\
bereich \\
insgesamt \\
ohne F\&E- \\
Aktivitäten
\end{tabular}} & \multirow{2}{*}{\begin{tabular}{|c} 
Primar- bis \\
Tertiär- \\
bereich \\
(einschl. \\
F\&E-Akti- \\
vitäten)
\end{tabular}} \\
\hline & & & $\begin{array}{c}\text { Sekundar- } \\
\text { bereich I }\end{array}$ & $\begin{array}{l}\text { Sekundar- } \\
\text { bereich II }\end{array}$ & $\begin{array}{c}\text { Sekundar- } \\
\text { bereich } \\
\text { insgesamt }\end{array}$ & & $\begin{array}{c}\text { Tertiär- } \\
\text { bereich B }\end{array}$ & \begin{tabular}{|c|} 
Tertiärbe- \\
reich A und \\
weiterfüh- \\
rende For- \\
schungs- \\
programme
\end{tabular} & $\begin{array}{c}\text { Tertiär- } \\
\text { bereich } \\
\text { insgesamt }\end{array}$ & & \\
\hline & (1) & (2) & (3) & (4) & (5) & (6) & (7) & (8) & (9) & (10) & (11) \\
\hline \multicolumn{12}{|l|}{ OECD-Länder } \\
\hline Australien & 22 & 23 & 26 & 24 & 25 & 17 & 22 & 40 & 37 & 23 & 27 \\
\hline Österreich & 22 & 25 & 31 & 31 & 31 & 13 & 16 & 37 & 37 & 26 & 31 \\
\hline Belgien & 16 & 23 & $x(5)$ & $x(5)$ & 29 & $x(5)$ & $x(9)$ & $x(9)$ & 40 & 25 & 29 \\
\hline Kanada $^{1,2}$ & $x(2)$ & 22 & $x(2)$ & 28 & $\mathrm{~m}$ & $\mathrm{~m}$ & 36 & 68 & 56 & 41 & m \\
\hline Chile $^{3}$ & 20 & 19 & 18 & 18 & 18 & a & 23 & 55 & 41 & 39 & 24 \\
\hline Tschechien & 17 & 16 & 27 & 25 & 26 & 8 & 13 & 31 & 30 & 25 & 24 \\
\hline Dänemark & 23 & 27 & 28 & 29 & 29 & $x(4,9)$ & $x(9)$ & $x(9)$ & 47 & $\mathrm{~m}$ & 32 \\
\hline Estland & 13 & 26 & 30 & 34 & 32 & 39 & 37 & 30 & 32 & 19 & 30 \\
\hline Finnland & 15 & 21 & 32 & 22 & 25 & $x(5)$ & $n$ & 46 & 46 & 27 & 28 \\
\hline Frankreich & 18 & 19 & 27 & 37 & 32 & $\mathrm{~m}$ & 36 & 47 & 44 & 30 & 30 \\
\hline Deutschland & $\mathrm{m}$ & $\mathrm{m}$ & $\mathrm{m}$ & $\mathrm{m}$ & $\mathrm{m}$ & $\mathrm{m}$ & $\mathrm{m}$ & $\mathrm{m}$ & $\mathrm{m}$ & $\mathrm{m}$ & m \\
\hline Griechenland & $\mathrm{m}$ & $\mathrm{m}$ & $\mathrm{m}$ & $\mathrm{m}$ & $\mathrm{m}$ & $\mathrm{m}$ & $\mathrm{m}$ & $\mathrm{m}$ & $\mathrm{m}$ & $\mathrm{m}$ & m \\
\hline Ungarn² & 23 & 23 & 23 & 22 & 22 & 16 & 22 & 44 & 42 & 33 & 26 \\
\hline Island & 24 & 27 & 26 & 20 & 22 & $x(5)$ & $x(9)$ & $x(9)$ & 25 & $\mathrm{~m}$ & 24 \\
\hline Irland ${ }^{2}$ & $\mathrm{~m}$ & 20 & 28 & 27 & 28 & 25 & $x(9)$ & $x(9)$ & 39 & 28 & 26 \\
\hline Israel & 15 & 22 & $x(5)$ & $x(5)$ & 21 & 19 & 37 & 41 & 40 & $\mathrm{~m}$ & 25 \\
\hline Italien² & 22 & 26 & 27 & 27 & 27 & $\mathrm{~m}$ & 33 & 30 & 30 & 20 & 27 \\
\hline Japan & 16 & 24 & 28 & 29 & 28 & $x(4,9)$ & 29 & 50 & 45 & $\mathrm{~m}$ & 30 \\
\hline Korea & 23 & 23 & 23 & 33 & 28 & a & 20 & 39 & 35 & 29 & 28 \\
\hline Luxemburg & 25 & 25 & 21 & 21 & 21 & $\mathrm{~m}$ & $\mathrm{~m}$ & $\mathrm{~m}$ & $\mathrm{~m}$ & $\mathrm{~m}$ & m \\
\hline Mexiko & 15 & 15 & 14 & 24 & 17 & $a$ & $x(9)$ & $x(9)$ & 52 & 44 & 20 \\
\hline Niederlande & 18 & 19 & 29 & 28 & 28 & 27 & 24 & 41 & 41 & 26 & 27 \\
\hline Neuseeland & 39 & 23 & 25 & 30 & 28 & 32 & 29 & 37 & 35 & 30 & 28 \\
\hline Norwegen & 15 & 27 & 28 & 33 & 31 & $x(5)$ & $x(9)$ & $x(9)$ & 41 & 24 & 31 \\
\hline Polen² & 29 & 30 & 27 & 28 & 27 & 35 & 32 & 44 & 44 & 36 & 32 \\
\hline Portugal $^{2}$ & 23 & 23 & 33 & 37 & 35 & $\mathrm{~m}$ & $x(9)$ & $x(9)$ & 41 & 23 & 31 \\
\hline Slowakei & 19 & 25 & 22 & 19 & 21 & $x(4)$ & $x(4)$ & 30 & 30 & 25 & 23 \\
\hline Slowenien & 29 & 34 & 35 & 28 & 31 & $x(4)$ & $x(9)$ & $x(9)$ & 36 & 29 & 34 \\
\hline Spanien & 21 & 23 & 29 & 33 & 30 & a & 33 & 45 & 42 & 30 & 30 \\
\hline Schweden & 17 & 25 & 25 & 27 & 26 & 16 & 16 & 53 & 50 & 23 & 30 \\
\hline Schweiz ${ }^{2}$ & 11 & 24 & 29 & 32 & 31 & $x(4)$ & 10 & 48 & 45 & 20 & 30 \\
\hline Türkei & 16 & 12 & a & 16 & 16 & a & $\mathrm{m}$ & $\mathrm{m}$ & $\mathrm{m}$ & $\mathrm{m}$ & m \\
\hline Ver. Königreich & 20 & 27 & 30 & 29 & 30 & a & $x(9)$ & $x(9)$ & 45 & 30 & 31 \\
\hline Vereinigte Staaten & 22 & 24 & 26 & 28 & 27 & $\mathrm{~m}$ & $x(9)$ & $x(9)$ & 55 & 49 & 33 \\
\hline OECD-Durchschnitt & 20 & 23 & 26 & 27 & 26 & 15 & 25 & 43 & 41 & 29 & 28 \\
\hline EU21-Durchschnitt & 20 & 23 & 25 & 27 & 26 & 12 & 24 & 41 & 39 & 29 & 28 \\
\hline \multicolumn{12}{|l|}{ Sonst. G20-Länder } \\
\hline Argentinien ${ }^{2}$ & 15 & 18 & 24 & 26 & 25 & a & 18 & 35 & 29 & $\mathrm{~m}$ & 23 \\
\hline Brasilien² & 17 & 22 & 23 & 17 & 21 & a & $x(9)$ & $x(9)$ & 105 & 99 & 24 \\
\hline China & $\mathrm{m}$ & $\mathrm{m}$ & $\mathrm{m}$ & $\mathrm{m}$ & $\mathrm{m}$ & $\mathrm{m}$ & $\mathrm{m}$ & $\mathrm{m}$ & $\mathrm{m}$ & $\mathrm{m}$ & m \\
\hline Indien & $\mathrm{m}$ & $\mathrm{m}$ & $\mathrm{m}$ & $\mathrm{m}$ & $\mathrm{m}$ & $\mathrm{m}$ & $\mathrm{m}$ & $\mathrm{m}$ & $\mathrm{m}$ & $\mathrm{m}$ & m \\
\hline Indonesien & $\mathrm{m}$ & $\mathrm{m}$ & $\mathrm{m}$ & $\mathrm{m}$ & $\mathrm{m}$ & $\mathrm{m}$ & $\mathrm{m}$ & $\mathrm{m}$ & $\mathrm{m}$ & $\mathrm{m}$ & m \\
\hline Russische Föd. ${ }^{2}$ & $\mathrm{~m}$ & $x(5)$ & $x(5)$ & $x(5)$ & 21 & a & 23 & 38 & 36 & 33 & 26 \\
\hline Saudi-Arabien & $\mathrm{m}$ & $\mathrm{m}$ & $\mathrm{m}$ & $\mathrm{m}$ & $\mathrm{m}$ & $\mathrm{m}$ & $\mathrm{m}$ & $\mathrm{m}$ & $\mathrm{m}$ & $\mathrm{m}$ & m \\
\hline Südafrika & $\mathrm{m}$ & $\mathrm{m}$ & $\mathrm{m}$ & $\mathrm{m}$ & $\mathrm{m}$ & $\mathrm{m}$ & $\mathrm{m}$ & $\mathrm{m}$ & $\mathrm{m}$ & $\mathrm{m}$ & m \\
\hline G20-Durchschnitt & m & $\mathbf{m}$ & m & $\mathbf{m}$ & m & $\mathbf{m}$ & m & $\mathbf{m}$ & m & $\mathbf{m}$ & $\mathbf{m}$ \\
\hline
\end{tabular}

1. Referenzjahr 2009. 2. Nur öffentliche Bildungseinrichtungen (Kanada: nur im Tertiärbereich, Italien und Russische Föderation: außer im Tertiärbereich).

3. Referenzjahr 2011.

Quelle: OECD. Argentinien: Statistikinstitut der UNESCO (World Education Indicators Programme). Hinweise s. Anhang 3 unter www.oecd.org/edu/eag.htm. StatLink: http://dx.doi.org/10.1787/888932849464

Erläuterung der Kennzeichnung fehlender Daten s. Hinweise für den Leser. 
Veränderung der Ausgaben von Bildungseinrichtungen pro Schüler im Primar-, Sekundar- und postsekundaren, nicht tertiären Bereich für alle Leistungsbereiche aufgrund verschiedener Faktoren (1995, 2000, 2005, 2010) Index der Veränderung (BIP-Deflator $2005=100$, zu konstanten Preisen)

\begin{tabular}{|c|c|c|c|c|c|c|c|c|c|}
\hline & \multicolumn{9}{|c|}{ Primar-, Sekundar- und postsekundarer, nicht tertiärer Bereich } \\
\hline & \multicolumn{3}{|c|}{$\begin{array}{l}\text { Veränderung der Ausgaben } \\
\qquad(2005=100)\end{array}$} & \multicolumn{3}{|c|}{$\begin{array}{l}\text { Veränderung der Zahl der Schüler } \\
\qquad(2005=100)\end{array}$} & \multicolumn{3}{|c|}{$\begin{array}{l}\text { Veränderung der Ausgaben pro Schüler } \\
\qquad(2005=100)\end{array}$} \\
\hline & 1995 & 2000 & 2010 & 1995 & 2000 & 2010 & 1995 & 2000 & 2010 \\
\hline \multicolumn{10}{|l|}{ OECD-Länder } \\
\hline Australien & 63 & 82 & 133 & 87 & 93 & 101 & 73 & 88 & 131 \\
\hline Österreich & 90 & 97 & 105 & $\mathrm{~m}$ & 101 & 95 & m & 95 & 110 \\
\hline Belgien & $\mathrm{m}$ & 94 & 115 & $\mathrm{~m}$ & 91 & 95 & m & 103 & 121 \\
\hline Kanada $^{1,2}$ & 91 & 86 & 117 & $\mathrm{~m}$ & 99 & 98 & $\mathbf{m}$ & 87 & 119 \\
\hline Chile $^{3}$ & $\mathrm{~m}$ & $\mathrm{~m}$ & 127 & $\mathrm{~m}$ & $\mathrm{~m}$ & 93 & $\mathbf{m}$ & $\mathbf{m}$ & 137 \\
\hline Tschechien & 86 & 76 & 111 & 115 & 107 & 89 & 75 & 71 & 125 \\
\hline Dänemark ${ }^{1}$ & 72 & 86 & 107 & 91 & 95 & 105 & 79 & 91 & 102 \\
\hline Estland $^{4}$ & 62 & 80 & 114 & 117 & 121 & 85 & 53 & 66 & 134 \\
\hline Finnland & 72 & 81 & 112 & 88 & 95 & 100 & 81 & 85 & 112 \\
\hline Frankreich & 90 & 100 & 105 & $\mathrm{~m}$ & 102 & 100 & m & 98 & 105 \\
\hline Deutschland & 94 & 100 & $\mathrm{~m}$ & 99 & 102 & $\mathrm{~m}$ & 95 & 97 & m \\
\hline Griechenland $^{1}$ & 50 & 78 & $\mathrm{~m}$ & 107 & 101 & $\mathrm{~m}$ & 46 & 77 & m \\
\hline Ungarn ${ }^{4,5}$ & 69 & 69 & 84 & 113 & 108 & 89 & 61 & 64 & 95 \\
\hline Island & $\mathrm{m}$ & 72 & 93 & 93 & 94 & 101 & $\mathbf{m}$ & 77 & 91 \\
\hline Irland ${ }^{5}$ & 54 & 67 & 144 & 102 & 97 & 108 & 53 & 69 & 133 \\
\hline Israel & 79 & 95 & 130 & 84 & 94 & 108 & 94 & 101 & 120 \\
\hline Italien ${ }^{5,6}$ & 97 & 96 & 97 & 101 & 99 & 100 & 96 & 97 & 97 \\
\hline$J^{J a p a n^{1}}$ & 97 & 99 & 104 & 124 & 109 & 96 & 78 & 90 & 109 \\
\hline Korea & $\mathrm{m}$ & 69 & 126 & 110 & 102 & 93 & $\mathbf{m}$ & 68 & 135 \\
\hline Luxemburg ${ }^{4,5,7}$ & $\mathrm{~m}$ & $\mathrm{~m}$ & 104 & $\mathrm{~m}$ & $\mathrm{~m}$ & 89 & $\mathbf{m}$ & $\mathbf{m}$ & 116 \\
\hline Mexiko & 65 & 80 & 109 & 88 & 95 & 105 & 74 & 85 & 104 \\
\hline Niederlande & 69 & 84 & 115 & 94 & 97 & 102 & 73 & 87 & 113 \\
\hline Neuseeland ${ }^{4}$ & 65 & 92 & 120 & $\mathrm{~m}$ & $\mathrm{~m}$ & 100 & $\mathbf{m}$ & $\mathbf{m}$ & 119 \\
\hline Norwegen ${ }^{4}$ & 72 & 87 & 113 & 84 & 95 & 102 & 86 & 92 & 111 \\
\hline Polen 5 & 63 & 89 & 123 & 125 & 114 & 80 & 50 & 78 & 153 \\
\hline Portugal ${ }^{5}$ & 74 & 98 & 108 & 117 & 111 & 99 & 63 & 88 & 109 \\
\hline Slowakei ${ }^{1}$ & 71 & 73 & 135 & 114 & 108 & 84 & 62 & 68 & 159 \\
\hline Slowenien & $\mathrm{m}$ & $\mathrm{m}$ & 103 & $\mathrm{~m}$ & $\mathrm{~m}$ & 90 & $\mathbf{m}$ & $\mathbf{m}$ & 115 \\
\hline Spanien & 92 & 93 & 119 & 127 & 107 & 105 & 73 & 87 & 113 \\
\hline Schweden & 71 & 88 & 103 & 85 & 98 & 91 & 84 & 90 & 113 \\
\hline Schweiz ${ }^{5}$ & 76 & 88 & 106 & 93 & 98 & 98 & 81 & 89 & 108 \\
\hline Türkei ${ }^{4,5}$ & $\mathrm{~m}$ & $\mathrm{~m}$ & $\mathrm{~m}$ & $\mathrm{~m}$ & $\mathrm{~m}$ & $\mathrm{~m}$ & $\mathbf{m}$ & $\mathbf{m}$ & $\mathbf{m}$ \\
\hline Vereinigtes Königreich & 61 & 70 & 109 & 98 & 113 & 100 & 62 & 62 & 109 \\
\hline Vereinigte Staaten & 69 & 86 & 112 & 93 & 98 & 100 & 74 & 89 & 113 \\
\hline OECD-Durchschnitt & 75 & 85 & 113 & 102 & 101 & 97 & 73 & 84 & 117 \\
\hline EU21-Durchschnitt & 74 & 85 & 111 & 106 & 104 & 95 & 69 & 83 & 118 \\
\hline \multicolumn{10}{|l|}{ Sonstige G20-Länder } \\
\hline Argentinien & $\mathrm{m}$ & $\mathrm{m}$ & $\mathrm{m}$ & $\mathrm{m}$ & $\mathrm{m}$ & $\mathrm{m}$ & m & $\mathbf{m}$ & m \\
\hline Brasilien $^{4,5}$ & 58 & 66 & 170 & 84 & 98 & 91 & 69 & 67 & 186 \\
\hline China & $\mathrm{m}$ & $\mathrm{m}$ & $\mathrm{m}$ & $\mathrm{m}$ & $\mathrm{m}$ & $\mathrm{m}$ & m & m & m \\
\hline Indien & $\mathrm{m}$ & $\mathrm{m}$ & $\mathrm{m}$ & $\mathrm{m}$ & $\mathrm{m}$ & $\mathrm{m}$ & m & m & m \\
\hline Indonesien & $\mathrm{m}$ & $\mathrm{m}$ & $\mathrm{m}$ & $\mathrm{m}$ & $\mathrm{m}$ & $\mathrm{m}$ & m & $\mathbf{m}$ & m \\
\hline Russische Föderation ${ }^{4}$ & $\mathrm{~m}$ & 66 & 129 & $\mathrm{~m}$ & $\mathrm{~m}$ & 87 & m & $\mathbf{m}$ & 148 \\
\hline Saudi-Arabien & $\mathrm{m}$ & $\mathrm{m}$ & $\mathrm{m}$ & m & $\mathrm{m}$ & $\mathrm{m}$ & m & $\mathbf{m}$ & m \\
\hline Südafrika & $\mathrm{m}$ & $\mathrm{m}$ & $\mathrm{m}$ & $\mathrm{m}$ & $\mathrm{m}$ & $\mathrm{m}$ & m & $\mathbf{m}$ & m \\
\hline G20-Durchschnitt & $\mathbf{m}$ & $\mathbf{m}$ & $\mathbf{m}$ & $\mathbf{m}$ & $\mathbf{m}$ & m & $\mathbf{m}$ & $\mathbf{m}$ & m \\
\hline
\end{tabular}

1. Einige Bildungsbereiche sind in anderen Bildungsbereichen enthalten. Einzelheiten s. Erläuterung von „x“ in Hinweise für den Leser. 2. Referenzjahr 2009 anstelle 2010. 3. Referenzjahr 2011 anstelle 2010, Referenzjahr 2006 anstelle 2005. 4. Nur öffentliche Ausgaben. 5. Nur öffentliche Bildungseinrichtungen. 6. Ohne postsekundaren, nicht tertiären Bereich. 7. Einschließlich Elementarbereich.

Quelle: OECD. Hinweise s. Anhang 3 unter www.oecd.org/edu/eag.htm. StatLink: http://dx.doi.org/10.1787/888932849483

Erläuterung der Kennzeichnung fehlender Daten s. Hinweise für den Leser. 
Tabelle B1.5b

Veränderung der Ausgaben von Bildungseinrichtungen pro Studierenden im Tertiärbereich für alle Leistungsbereiche aufgrund verschiedener Faktoren $(1995,2000,2005,2010)$

Index der Veränderung (BIP-Deflator $2005=100$, zu konstanten Preisen)

\begin{tabular}{|c|c|c|c|c|c|c|c|c|c|}
\hline & \multicolumn{9}{|c|}{ Tertiärbereich } \\
\hline & \multicolumn{3}{|c|}{$\begin{array}{l}\text { Veränderung der Ausgaben } \\
\qquad(2005=100)\end{array}$} & \multicolumn{3}{|c|}{$\begin{array}{l}\text { Veränderung der Zahl der Studierenden } \\
\qquad(2005=100)\end{array}$} & \multicolumn{3}{|c|}{$\begin{array}{l}\text { Veränderung der Ausgaben } \\
\text { pro Studierenden } \\
(2005=100)\end{array}$} \\
\hline & 1995 & 2000 & 2010 & 1995 & 2000 & 2010 & 1995 & 2000 & 2010 \\
\hline \multicolumn{10}{|l|}{ OECD-Länder } \\
\hline Australien & 74 & 83 & 126 & 73 & $\mathrm{~m}$ & 125 & 103 & $\mathbf{m}$ & 101 \\
\hline Österreich & 72 & 75 & 126 & 93 & 103 & 139 & 77 & 73 & 90 \\
\hline Belgien & $\mathrm{m}$ & 98 & 124 & $\mathrm{~m}$ & 94 & 112 & m & 104 & 110 \\
\hline $\operatorname{Kanada}^{1,2,3}$ & 64 & 86 & 117 & $\mathrm{~m}$ & $\mathrm{~m}$ & $\mathrm{~m}$ & $\mathbf{m}$ & $\mathbf{m}$ & m \\
\hline Chile $^{4}$ & $\mathrm{~m}$ & $\mathrm{~m}$ & 173 & $\mathrm{~m}$ & $\mathrm{~m}$ & 161 & $\mathbf{m}$ & m & 108 \\
\hline Tschechien & 64 & 65 & 140 & 46 & 72 & 132 & 139 & 90 & 106 \\
\hline Dänemark ${ }^{1}$ & 78 & 86 & 110 & 94 & 98 & 108 & 83 & 88 & 102 \\
\hline Estland $^{5}$ & 64 & 92 & 138 & 51 & 85 & 100 & 124 & 108 & 137 \\
\hline Finnland & 77 & 86 & 116 & 85 & 95 & 99 & 91 & 91 & 118 \\
\hline Frankreich & 85 & 93 & 117 & $\mathrm{~m}$ & 95 & 102 & m & 98 & 115 \\
\hline Deutschland & 89 & 94 & $\mathrm{~m}$ & 96 & 93 & $\mathrm{~m}$ & 92 & 101 & m \\
\hline Griechenland $^{1}$ & 28 & 42 & $\mathrm{~m}$ & 46 & 68 & $\mathrm{~m}$ & 61 & 63 & m \\
\hline Ungarn 3,5 & 64 & 81 & 96 & 38 & 66 & 86 & 167 & 122 & 111 \\
\hline Island & $\mathrm{m}$ & 69 & 101 & 53 & 68 & 117 & m & 103 & 86 \\
\hline Irland ${ }^{3}$ & 55 & 100 & 140 & 72 & 85 & 109 & 76 & 117 & 128 \\
\hline Israel & 64 & 90 & 107 & 59 & 82 & 108 & 107 & 110 & 99 \\
\hline Italien & 73 & 93 & 112 & 89 & 90 & 98 & 82 & 103 & 114 \\
\hline $\operatorname{Japan}^{1}$ & 82 & 94 & 110 & 98 & 99 & 96 & 84 & 95 & 114 \\
\hline Korea & $\mathrm{m}$ & 79 & 138 & 63 & 93 & 102 & m & 84 & 135 \\
\hline Luxemburg & $\mathrm{m}$ & $\mathrm{m}$ & $\mathrm{m}$ & $\mathrm{m}$ & $\mathrm{m}$ & $\mathrm{m}$ & m & m & m \\
\hline Mexiko & 57 & 73 & 126 & 64 & 83 & 120 & 89 & 88 & 105 \\
\hline Niederlande & 80 & 84 & 120 & 82 & 85 & 119 & 97 & 98 & 102 \\
\hline Neuseeland 5 & 87 & 84 & 127 & $\mathrm{~m}$ & $\mathrm{~m}$ & 133 & m & $\mathbf{m}$ & 96 \\
\hline Norwegen ${ }^{5}$ & 78 & 83 & 106 & 88 & 88 & 106 & 88 & 95 & 100 \\
\hline Polen $^{3}$ & 34 & 57 & 120 & 44 & 80 & 93 & 77 & 72 & 130 \\
\hline Portugal $^{3}$ & 51 & 70 & 114 & 69 & 90 & 107 & 74 & 78 & 106 \\
\hline Slowakei ${ }^{1}$ & 54 & 67 & 128 & 51 & 71 & 124 & 106 & 94 & 103 \\
\hline Slowenien & $\mathrm{m}$ & $\mathrm{m}$ & 108 & $\mathrm{~m}$ & $\mathrm{~m}$ & 104 & m & $\mathbf{m}$ & 104 \\
\hline Spanien & 63 & 88 & 126 & 108 & 107 & 111 & 59 & 82 & 113 \\
\hline Schweden & 70 & 86 & 117 & 68 & 82 & 103 & 102 & 105 & 114 \\
\hline Schweiz $z^{3,5}$ & 69 & 77 & 101 & 75 & 79 & 128 & 92 & 98 & 79 \\
\hline Türkei & $\mathrm{m}$ & $\mathrm{m}$ & $\mathrm{m}$ & $\mathrm{m}$ & $\mathrm{m}$ & $\mathrm{m}$ & m & m & m \\
\hline Vereinigtes Königreich & 64 & 66 & 106 & 83 & 93 & 110 & 77 & 70 & 97 \\
\hline Vereinigte Staaten & 65 & 78 & 117 & 81 & 89 & 123 & 80 & 88 & 95 \\
\hline OECD-Durchschnitt & 67 & 81 & 120 & 72 & 86 & 113 & 93 & 93 & 108 \\
\hline EU21-Durchschnitt & 65 & 80 & 120 & 72 & 87 & 109 & 93 & 92 & 111 \\
\hline \multicolumn{10}{|l|}{ Sonstige G20-Länder } \\
\hline Argentinien & $\mathrm{m}$ & $\mathrm{m}$ & $\mathrm{m}$ & $\mathrm{m}$ & $\mathrm{m}$ & $\mathrm{m}$ & $\mathbf{m}$ & $\mathbf{m}$ & m \\
\hline Brasilien $^{3,5}$ & 66 & 79 & 148 & 56 & 70 & 125 & 118 & 112 & 119 \\
\hline China & $\mathrm{m}$ & $\mathrm{m}$ & $\mathrm{m}$ & $\mathrm{m}$ & $\mathrm{m}$ & $\mathrm{m}$ & m & m & m \\
\hline Indien & $\mathrm{m}$ & $\mathrm{m}$ & $\mathrm{m}$ & $\mathrm{m}$ & $\mathrm{m}$ & $\mathrm{m}$ & m & $\mathbf{m}$ & m \\
\hline Indonesien & $\mathrm{m}$ & $\mathrm{m}$ & $\mathrm{m}$ & $\mathrm{m}$ & $\mathrm{m}$ & $\mathrm{m}$ & m & m & m \\
\hline Russische Föderation ${ }^{5}$ & $\mathrm{~m}$ & 44 & 148 & $\mathrm{~m}$ & $\mathrm{~m}$ & 156 & m & m & 95 \\
\hline Saudi-Arabien & $\mathrm{m}$ & $\mathrm{m}$ & $\mathrm{m}$ & $\mathrm{m}$ & $\mathrm{m}$ & $\mathrm{m}$ & m & $\mathbf{m}$ & m \\
\hline Südafrika & $\mathrm{m}$ & $\mathrm{m}$ & $\mathrm{m}$ & $\mathrm{m}$ & $\mathrm{m}$ & $\mathrm{m}$ & $\mathbf{m}$ & $\mathbf{m}$ & m \\
\hline G20-Durchschnitt & m & m & m & $\mathbf{m}$ & $\mathbf{m}$ & m & $\mathbf{m}$ & m & m \\
\hline
\end{tabular}

1. Einige Bildungsbereiche sind in anderen Bildungsbereichen enthalten. Einzelheiten s. Erläuterung von „x“ in Hinweise für den Leser. 2. Referenzjahr 2009 anstelle 2010. 3. Nur öffentliche Bildungseinrichtungen. 4. Referenzjahr 2011 anstelle 2010, Referenzjahr 2006 anstelle $2005 . \quad 5$. Nur öffentliche Ausgaben. Quelle: OECD. Hinweise s. Anhang 3 unter www.oecd.org/edu/eag.htm. StatLink: http://dx.doi.org/10.1787/888932849502 Erläuterung der Kennzeichnung fehlender Daten s. Hinweise für den Leser. 
Tabelle B1.6

Jährliche Ausgaben von Bildungseinrichtungen pro Schüler im Sekundarbereich für alle Leistungsbereiche, nach Art des Bildungsgangs (2010)

In US-Dollar, kaufkraftbereinigt mittels KKP für das BIP, nach Bildungsbereich (basierend auf Vollzeitäquivalenten)

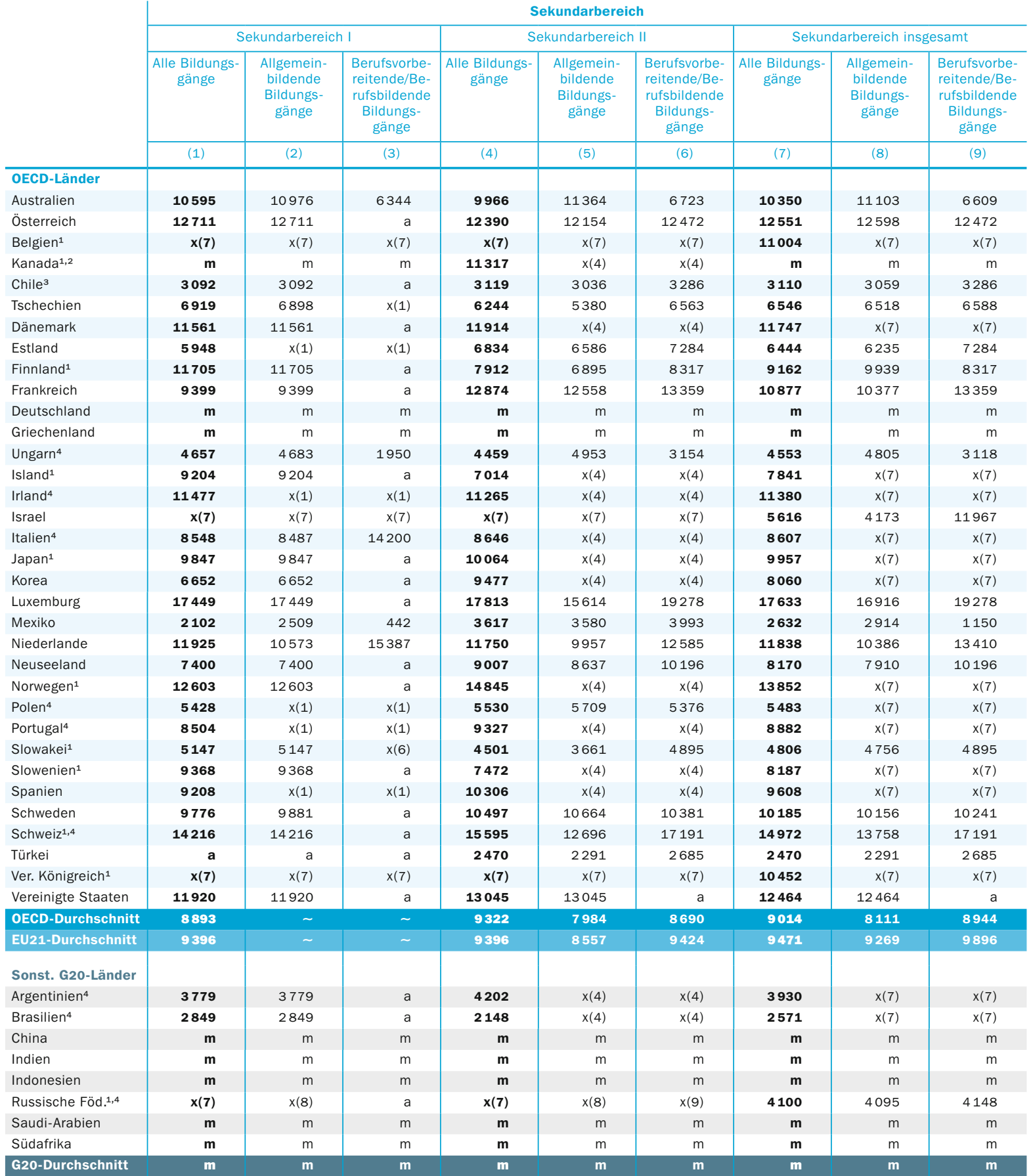

1. Einige Bildungsbereiche sind in anderen Bildungsbereichen enthalten. Einzelheiten s. Erläuterung von „x“ in Hinweise für den Leser. 2. Referenzjahr 2009.

3. Referenzjahr 2011. 4. Nur öffentliche Bildungseinrichtungen.

Quelle: OECD. Argentinien: Statistikinstitut der UNESCO (World Education Indicators Programme). Hinweise s. Anhang 3 unter www.oecd.org/edu/eag.htm.

StatLink: http://dx.doi.org/10.1787/888932849521

Erläuterung der Kennzeichnung fehlender Daten s. Hinweise für den Leser. 


\section{Welcher Teil des Bruttoinlandsprodukts wird für Bildung ausgegeben?}

20 Io gaben die OECD-Länder im Durchschnitt 6,3 Prozent ihres BIP für Bildungseinrichtungen aus. In Dänemark, Island, Israel, Korea, Neuseeland, Norwegen und den Vereinigten Staaten waren es mehr als 7 Prozent.

Zwischen 2000 und 2010 stiegen in fast allen Ländern mit verfügbaren Daten die Gesamtausgaben für alle Bildungsbereiche zusammen stärker als das Bruttoinlandsprodukt.

Zwar stieg das BIP von 2009 auf 2010 in den meisten Ländern (real), doch die öffentlichen Ausgaben für Bildungseinrichtungen fielen in diesem Zeitraum in einem Drittel der OECD-Länder, wahrscheinlich aufgrund der fiskalischen Konsolidierungsmaßnahmen.

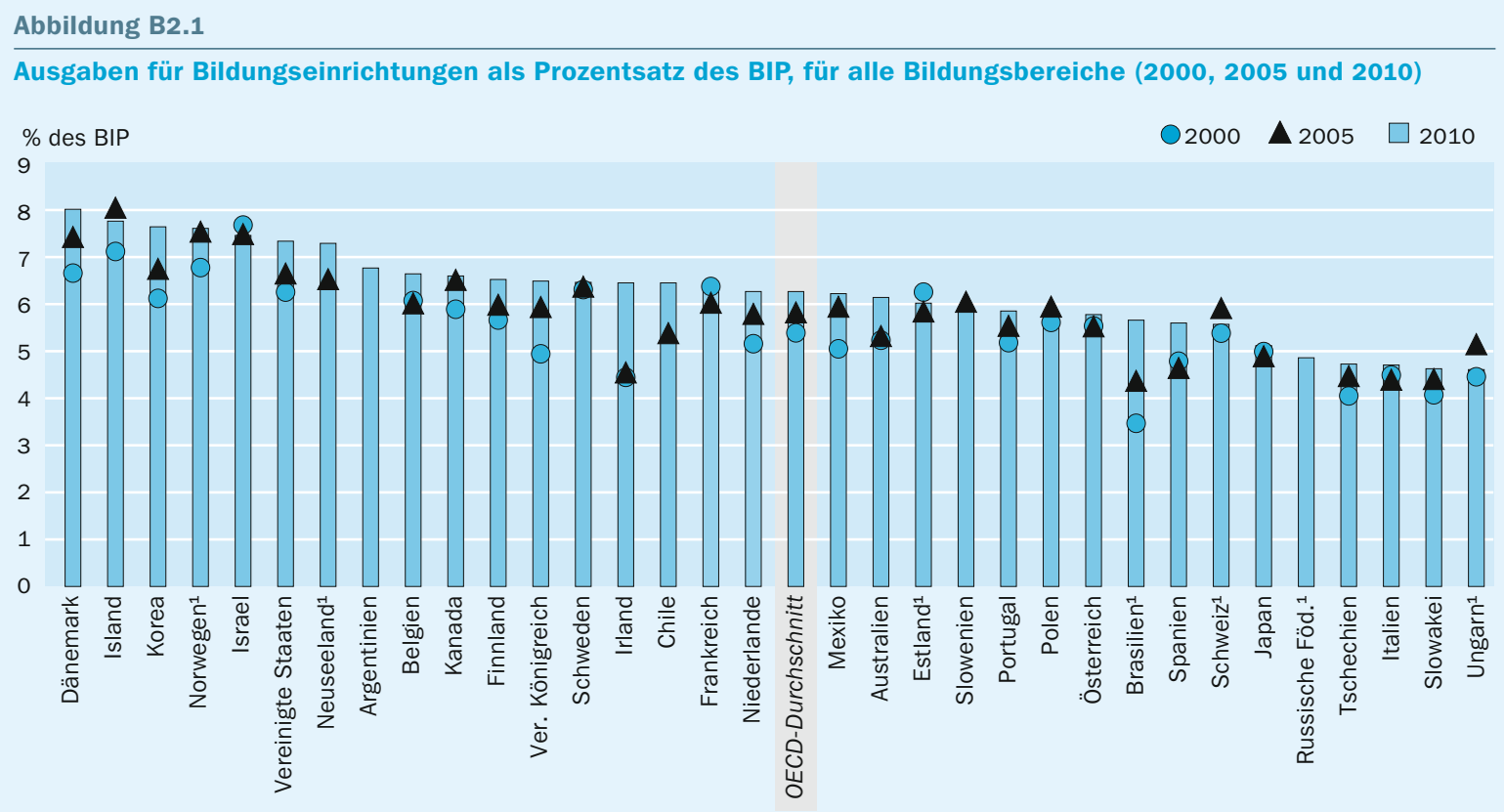

1. Nur öffentliche Ausgaben (Schweiz: nur im Tertiärbereich; Norwegen: nur im Primar-, Sekundar- und postsekundaren, nicht tertiären Bereich; Estland, Neuseeland und die Russische Föderation: nur 2000).

Anordnung der Länder in absteigender Reihenfolge der mit Mitteln aus öffentlichen und privaten Quellen finanzierten Ausgaben für Bildungseinrichtungen im Jahr 2010.

Quelle: OECD. Argentinien: Statistikinstitut der UNESCO (World Education Indicators Programme). Tabelle B2.1.

Hinweise s. Anhang 3 unter www.oecd.org/edu/eag.htm. StatLink: http://dx.doi.org/10.1787/888932846880

Erläuterung der Abbildung: Die Abbildung zeigt die Ausgaben für Bildung als den 2000, 2005 und 2010 in Bildungseinrichtungen investierten Anteil des jeweiligen Volkseinkommens. Es werden die mit Mitteln sowohl aus privaten als auch öffentlichen Quellen finanzierten direkten und indirekten Ausgaben für Bildungseinrichtungen aufgezeigt. 


\section{Kontext}

Dieser Indikator zeigt die Ausgaben für Bildungseinrichtungen der einzelnen Länder in Relation zum jeweiligen nationalen Wohlstand auf. Der nationale Wohlstand wird basierend auf dem Bruttoinlandsprodukt (BIP) geschätzt, die Bildungsausgaben umfassen dabei die Ausgaben der öffentlichen Haushalte, von Unternehmen, einzelnen Schülern/Studierenden und ihren Familien.

Ausgaben für Bildungseinrichtungen stellen eine Investition dar, die unter anderem dazu beitragen soll, das Wirtschaftswachstum zu stärken, die Produktivität zu steigern, die persönliche und gesellschaftliche Entwicklung zu fördern sowie soziale Ungleichheiten zu verringern. Welcher Anteil des BIP für das Bildungswesen bereitgestellt wird, hängt von den unterschiedlichen Präferenzen verschiedener öffentlicher und privater Akteure ab. Die Mittel für Bildung stammen jedoch hauptsächlich aus den öffentlichen Haushalten, daher stehen diese Ausgaben ständig auf dem Prüfstand. Während einer Finanzkrise können selbst zentrale staatliche Aufgaben wie das Bildungswesen von Haushaltskürzungen betroffen sein.

Die Höhe der Ausgaben eines Landes für Bildungseinrichtungen wird bestimmt durch die Zahl der jungen Menschen im Schulalter, der Bildungsbeteiligung, den Gehältern der Lehrkräfte sowie der Unterrichtsorganisation und der Art und Weise der Vermittlung von Lerninhalten. Im Primar- und Sekundarbereich I (d. h. grob bei den 5- bis I4-Jährigen) liegt die Bildungsbeteiligung in den OECD-Ländern bei nahezu ıoo Prozent, und Veränderungen bei der Zahl der Schüler hängen eng mit der demografischen Entwicklung zusammen. Im Sekundarbereich II und dem Tertiärbereich ist dies jedoch weniger der Fall, da Teile der entsprechenden Altersgruppen das Bildungssystem bereits verlassen haben (s. Indikator CI).

\section{Weitere wichtige Ergebnisse}

Auf den Elementarbereich entfallen im Durchschnitt der OECD-Länder fast 10 Prozent der Ausgaben für Bildungseinrichtungen bzw. o,6 Prozent des BIP. Es bestehen jedoch große Unterschiede zwischen den einzelnen Ländern. So liegen beispielsweise die Ausgaben für den Elementarbereich in Australien und der Türkei bei unter o, 2 Prozent des BIP, in Dänemark und Island dagegen bei mindestens rund I Prozent.

Auf den Primar-, Sekundar- und postsekundaren, nicht tertiären Bereich entfallen im Durchschnitt der OECD-Länder fast zwei Drittel der Gesamtausgaben für Bildungseinrichtungen bzw. 3,9 Prozent des Bruttoinlandsprodukts. Neuseeland und Norwegen geben mehr als 5 Prozent des BIP für diese Bildungsbereiche aus, während es in Japan, der Russischen Föderation, Tschechien, der Türkei und Ungarn höchstens 3 Prozent sind.

Aufden Tertiärbereich entfällt im Durchschnitt der OECD-Länder ein Viertel der Ausgaben für Bildungseinrichtungen bzw. I,6 Prozent des BIP. Chile, Kanada, Korea und die Vereinigten Staaten investieren zwischen 2,4 Prozent und 2,8 Prozent ihres BIP in Bildungseinrichtungen des Tertiärbereichs.

Die privaten Ausgaben für Bildungseinrichtungen als Prozentsatz des BIP sind im Tertiärbereich am höchsten. In Chile, Korea und den Vereinigten Staaten belaufen sie sich auf I,7 Prozent bis I,9 Prozent des BIP. 


\section{Entwicklungstendenzen}

Die öffentlichen Ausgaben für Bildung (alle Bildungsbereiche zusammen) stiegen in den OECD-Ländern zwischen 2008 und 2010 durchschnittlich um 5 Prozent. Dennoch verlangsamte sich der jährliche Anstieg der öffentlichen Ausgaben für Bildungseinrichtungen während dieses Zeitraums im Durchschnitt der OECD-Länder von 4 Prozent von 2008 auf 2009 auf I Prozent von 2009 auf 2010.

Mehr als ein Drittel der Länder mit verfügbaren Daten berichtete eine Verlangsamung des jährlichen Anstiegs der öffentlichen Ausgaben für Bildungseinrichtungen zwischen 2008 und 20I0: Irland, Neuseeland, Norwegen, Österreich, Portugal, Spanien und die Vereinigten Staaten berichteten eine Zunahme von 2008 auf 2009 und dann eine Abnahme von 2009 auf 2010, während Estland, Island, Italien und Ungarn sowohl von 2008 auf 2009 als auch von 2009 auf 2010 eine Abnahme berichteten.

\section{Analyse und Interpretationen}

\section{Gesamtausgaben im Verhältnis zum BIP}

In allen OECD- und G20-Ländern mit verfügbaren Daten wird ein bedeutender Teil des BIP für Bildungseinrichtungen ausgegeben. 2010 gaben die OECD-Länder im Durchschnitt 6,3 Prozent ihres BIP für Bildungseinrichtungen aus. Berücksichtigt man öffentliche und private Quellen, so gaben die OECD-Länder insgesamt 6,5 Prozent der Gesamtsumme ihrer Bruttoinlandsprodukte für Bildungseinrichtungen aus.

Die Ausgaben für Bildungseinrichtungen (alle Bildungsbereiche zusammen) als Prozentsatz des BIP lagen in fast der Hälfte der OECD- und G20-Länder bei über 6 Prozent und in den folgenden sieben Ländern sogar bei über 7 Prozent: Dänemark (7,9 Prozent), Island (7,7 Prozent), Israel (7,4 Prozent), Korea (7,6 Prozent), Neuseeland (7,3 Prozent), Norwegen (7,6 Prozent) und den Vereinigten Staaten (7,3 Prozent). Am anderen Ende des Spektrums gaben fünf Länder weniger als 5 Prozent ihres BIP für Bildungseinrichtungen aus, nämlich Italien (4,7 Prozent), die Russische Föderation (4,9 Prozent), die Slowakei (4,6 Prozent), Tschechien (4,7 Prozent) und Ungarn (4,6 Prozent).

\section{Ausgaben für Bildungseinrichtungen aufgegliedert nach Bildungs- bereichen}

Fast zwei Drittel der Bildungsausgaben aller OECD-Länder entfallen im Durchschnitt auf den Primar-, Sekundar- und postsekundaren, nicht tertiären Bereich, ein Viertel auf den Tertiärbereich und fast ein Zehntel auf den Elementarbereich. Im Durchschnitt aller OECD-Länder fließen 42 Prozent der Bildungsausgaben in den Primar- und Sekundarbereich I. Die Ausgaben für Bildungseinrichtungen sind abhängig vom Alter der Bevölkerung. Länder mit überdurchschnittlich hohen Ausgaben für Bildungseinrichtungen als Prozentsatz des BIP sind in der Regel Länder mit einem überdurchschnittlich hohen Anteil der Bevölkerung in dem für den Primar- und Sekundarbereich I typischen Alter (Tab. B2.2 und Indikator CI). 
Ausgaben für Bildungseinrichtungen als Prozentsatz des BIP (2010)

Finanziert mit Mitteln aus öffentlichen und privaten Quellen, nach Bildungsbereich und Herkunft der Mittel
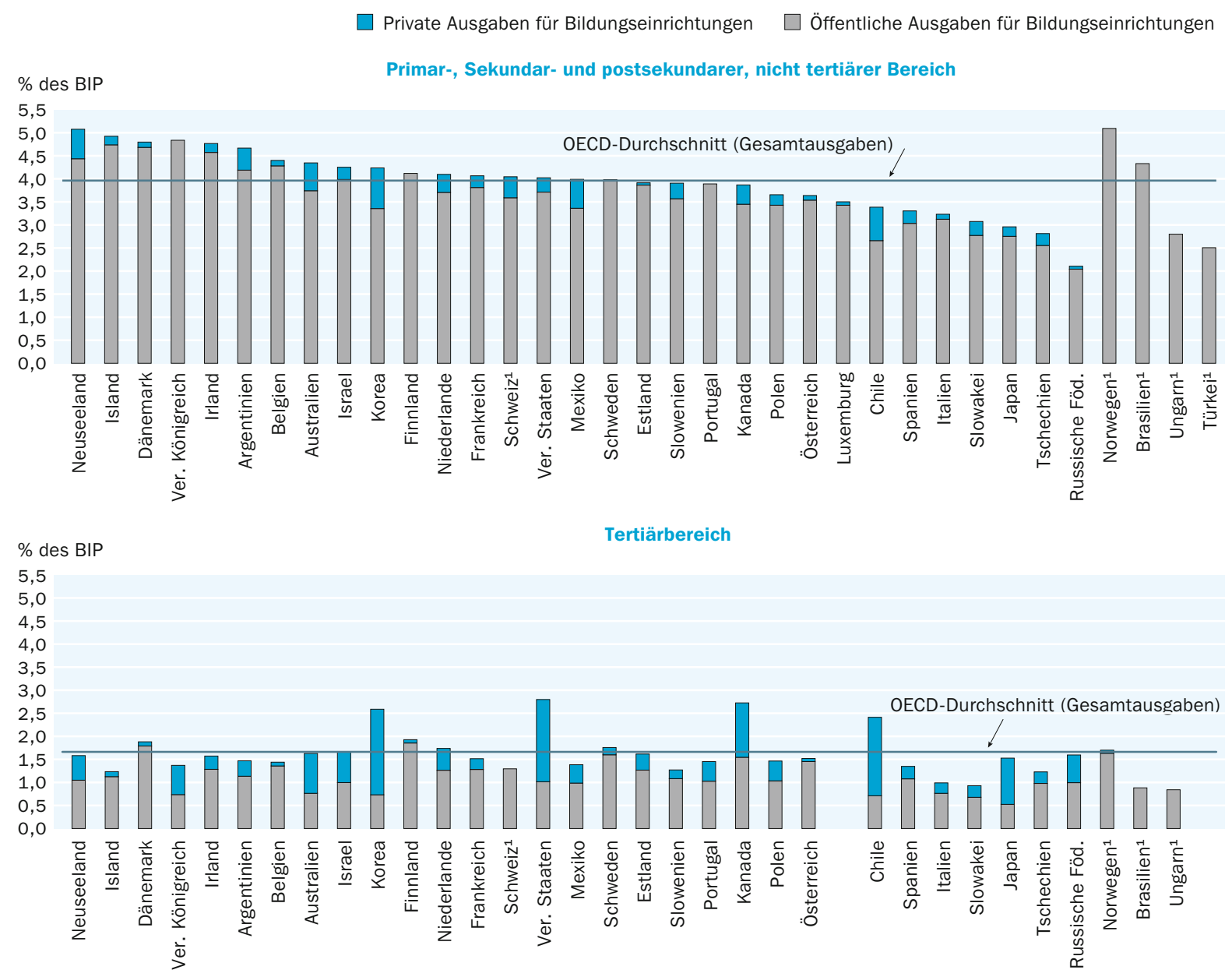

1. Nur öffentliche Ausgaben (Schweiz: nur im Tertiärbereich; Norwegen: nur im Primar-, Sekundar- und postsekundaren, nicht tertiären Bereich). Anordnung der Länder in absteigender Reihenfolge der mit Mitteln aus öffentlichen und privaten Quellen finanzierten Ausgaben für Bildungseinrichtungen im Primar-, Sekundar- und postsekundaren, nicht tertiären Bereich.

Quelle: OECD. Argentinien: Statistikinstitut der UNESCO (World Education Indicators Programme). Tabelle B2.3.

Hinweise s. Anhang 3 unter www.oecd.org/edu/eag.htm. StatLink: http://dx.doi.org/10.1787/888932846899

In allen OECD- und G20-Ländern mit verfügbaren Daten entfällt der größte Teil der insgesamt für Bildungseinrichtungen aufgewendeten Mittel auf den Primar-, Sekundar- und postsekundaren, nicht tertiären Bereich (verglichen mit den auf den Elementar- und den Tertiärbereich entfallenden Mitteln). Dieser Anteil liegt in den meisten Ländern bei über 6o Prozent, eine Ausnahme bilden nur folgende acht Länder: Chile (53 Prozent), Israel (57 Prozent), Japan (58 Prozent), Kanada (59 Prozent), Korea (56 Prozent), die Russische Föderation (43 Prozent), Spanien (59 Prozent) und die Vereinigten Staaten (55 Prozent). Für den Primar-, Sekundar- und postsekundaren, nicht tertiären Bereich reichen die Ausgaben als Prozentsatz des BIP von höchstens 3 Prozent in Japan (3,0 Prozent), der Russischen Föderation (2, I Prozent), Tschechien (2,8 Prozent), der Türkei (2,5 Prozent) und Ungarn (2,8 Prozent) bis zu mehr als 5 Prozent in Neuseeland (5, I Prozent) und Norwegen (5,I Prozent). 
Für den Primar- und Sekundarbereich I belaufen sich die Ausgaben als Prozentsatz des BIP in allen Ländern auf mehr als I, 6 Prozent und auf mindestens 3 Prozent in Australien (3,4 Prozent), Brasilien (3,5 Prozent), Dänemark (3,4 Prozent), Irland (3,5 Prozent), Island (3,6 Prozent), Mexiko (3,I Prozent), Neuseeland (3,2 Prozent), Norwegen (3,5 Prozent), dem Vereinigten Königreich (3,2 Prozent) und den Vereinigten Staaten (3,0 Prozent).

Mit Ausnahme von Dänemark und Island geben alle Länder weniger als I Prozent des BIP für den Elementarbereich aus. Die Daten zum Elementarbereich sind jedoch mit Vorsicht zu betrachten, weil zwischen den Ländern große Unterschiede bei der Bildungsbeteiligung, dem Eintrittsalter in den Elementarbereich und der Erfassung privat finanzierter Bildungseinrichtungen im Elementarbereich bestehen (s. Indikator CI).

In mehr als der Hälfte der Länder machen die Ausgaben für den Tertiärbereich mehr als I, 5 Prozent des BIP aus, in Kanada (mit 2,7 Prozent), Korea (mit 2,6 Prozent) und den Vereinigten Staaten (mit 2,8 Prozent) belaufen sie sich sogar auf mehr als 2,5 Prozent. Drei Länder wenden weniger als I Prozent des BIP für den Tertiärbereich auf Brasilien ( 0,9 Prozent), die Slowakei ( 0,9 Prozent) und Ungarn (o,8 Prozent) (Tab. B2.2 und Abb. B2.2).

\section{Veränderungen der Gesamtausgaben für Bildungseinrichtungen zwischen 2000 und 2010}

Die Anstieg der Schüler-/Studierendenzahlen im Sekundarbereich II und Tertiärbereich zwischen 2000 und 2010 ging in den meisten Ländern mit einem Anstieg der finanziellen Ausgaben für diese Bereiche einher.

Im Zeitraum 2000 bis 2010 stiegen in den Ländern mit vergleichbaren Daten sowohl die Ausgaben für Bildungseinrichtungen (alle Bildungsbereiche zusammen) als auch das BIP (s. Tab. X2.3). In Estland, Frankreich und Israel stiegen die Bildungsausgaben langsamer als das BIP, sodass die Ausgaben als Prozentsatz des BIP um bis zu o, 2 Prozentpunkte sanken. In allen anderen Ländern mit vergleichbaren Daten stiegen dagegen die öffentlichen Ausgaben für Bildungseinrichtungen (alle Bildungsbereiche zusammen) stärker als das BIP, was zu einem Anstieg der Ausgaben für Bildungseinrichtungen als Prozentsatz des BIP führte (Abb. B2.I). Einen Anstieg von über I Prozentpunkt hatten Brasilien (von 3,5 Prozent auf 5,6 Prozent), Dänemark (von 6,6 Prozent auf 7,9 Prozent), Irland (von 4,4 Prozent auf 6,4 Prozent), Korea (von 6, I Prozent auf 7,6 Prozent), Mexiko (von 5, o Prozent auf 6,2 Prozent), die Niederlande (von 5, I Prozent auf 6,3 Prozent), die Russische Föderation (von 2,9 Prozent auf 4,9 Prozent), das Vereinigte Königreich (von 4,9 Prozent auf 6,5 Prozent) und die Vereinigten Staaten (von 6,2 Prozent auf 7,3 Prozent) (Tab. B2.I).

Die Ausgaben für den Primar-, Sekundar- und den postsekundaren, nicht tertiären Bereich zusammen und den Tertiärbereich veränderten sich in etwa gleicher Weise.

\section{Die Auswirkungen der Finanzkrise auf die öffentlichen Ausgaben für Bildungseinrichtungen zwischen 2008 und 2010}

Die im Jahr 2008 einsetzende globale Wirtschaftskrise hatte und hat noch immer sehr negative Auswirkungen auf die unterschiedlichen Bereiche der Wirtschaft. Auf der 


\section{Finanzierung der Bildung in Europa: Die Auswirkungen der Wirtschaftskrise (Eurydice-Bericht)}

\section{Veränderungen der Bildungshaushalte von 2010 bis 2012}

Eurydice trug Informationen über die von den Mitgliedstaaten der Europäischen Union in den Jahren 20I0, $201 \mathrm{I}$ und 2012 verabschiedeten Bildungshaushalte zusammen, um ein Gesamtbild der jüngsten Veränderungen in der Bildungsfinanzierung zu erhalten. Hierbei ist zu berücksichtigen, dass diese Daten mit Vorsicht interpretiert werden sollten, da sie aufHaushaltsdaten beruhen und nicht auf den tatsächlichen Ausgaben wie ansonsten in diesem Kapitel B. Diese Daten untermauerten jedoch die in Tabelle B2.5 beobachteten Tendenzen und zeigen tendenziell, dass die 2010 in einem Drittel der Länder beobachteten Kürzungen in den nächsten zwei Jahren auch in weiteren OECD-Ländern zu beobachten sein werden.

Die Auswirkungen der Finanzkrise auf die Bildungshaushalte zeigen sich hauptsächlich in den OECD-Ländern, die 2010 und 201 I generell unter einem beträchtlichen Haushaltsdefizit litten (Frankreich, Griechenland, Irland, Island, Polen, Portugal, die Slowakei, Slowenien, Spanien und das Vereinigte Königreich). 20II waren Frankreich und Slowenien die Ausnahme, in diesen Ländern blieben die Bildungshaushalte stabil.

2011 und/oder 2012 wurden insgesamt in 5 OECD-Ländern/Regionen, für die Daten vorliegen, Kürzungen der Bildungshaushalte vorgenommen. In Griechenland, Italien, Portugal, Ungarn und dem Vereinigten Königreich (Wales) wurden Kürzungen um mehr als 5 Prozent vorgenommen, während diese in Belgien (frz.), Estland, Frankreich, Irland, Polen, der Slowakei, Slowenien, Spanien, Tschechien und dem Vereinigten Königreich zwischen I Prozent und 5 Prozent betrugen. Dennoch erhöhten sieben Länder/Regionen ihre Bildungshaushalte $201 \mathrm{I}$ und/oder 2012 real um I Prozent bis 5 Prozent (Belgien [frz.], Finnland, Island, Irland, Österreich, die Slowakei und Schweden), auch wenn in vielen dieser Länder in einem der Zeiträume Kürzungen vorgenommen wurden. In Belgien (dtsch.), Luxemburg und der Türkei gab es einen Anstieg von real mehr als 5 Prozent.

Quelle: Eurydice (2012), http://eacea.ec.europa.eu/education/eurydice/documents/thematic_ reports/147EN.pdf.

Basis von Daten für die Jahre 2009 und 20 ro allein ist eine Bewertung der umfassenden Auswirkungen dieser Krise auf die Bildungseinrichtungen verfrüht, die Auswirkungen auf die Wirtschaft insgesamt lassen sich jedoch bereits jetzt beobachten. Kasten B2.I bietet detaillierte Informationen über die Auswirkungen der Krise auf die Bildungshaushalte.

Zwischen 2008 und 2010 stieg das BIP (zu konstanten Preisen) nur in 9 der 30 Länder mit verfügbaren Daten und nur in sieben Ländern um mehr als I Prozent - in Australien, Israel, Korea, Neuseeland, Polen, Schweden und der Schweiz. 
Mehr als zwei Drittel der Bildungsausgaben in den meisten Ländern stammen aus öffentlichen Quellen. Wie wirkte sich der Rückgang des BIP-Wachstums auf die öffentlichen Bildungsausgaben aus? Erste verfügbare Zahlen zeigen, dass der Bildungssektor von den Haushaltskürzungen am Anfang kaum berührt war.

Da in den meisten Ländern der öffentliche Haushalt verabschiedet wird, lange bevor die Mittel tatsächlich fließen, wirken sich aktuelle Entwicklungen nur in gewissem Umfang unmittelbar auf die Bildungsfinanzierung aus. Außerdem versuchen die meisten Staaten, den Bildungsbereich vor starken Einschnitten bei den öffentlichen Investitionen zu schützen.

Von den 30 Ländern mit verfügbaren Daten für den Zeitraum 2008 bis 2010 kürzten nur fünf Länder die öffentlichen Ausgaben für Bildungseinrichtungen real: Estland (um ro Prozent), Island (um I2 Prozent), Italien (um 7 Prozent), Ungarn (um ro Prozent) und die Vereinigten Staaten (um r Prozent). Dies führte nur in Island, Italien und Ungarn zu einer Senkung der Ausgaben für Bildungseinrichtungen als Prozentsatz des BIP, da die Ausgabensenkung höher war als der Rückgang des BIP. In Estland und den Vereinigten Staaten entsprach der Rückgang des BIP den geringeren öffentlichen Bildungsausgaben oder war höher, sodass die öffentlichen Ausgaben für Bildungseinrichtungen als Prozentsatz des BIP konstant blieben (Vereinigte Staaten) oder leicht stiegen (Estland) (Abb. B2.3).

In anderen Ländern ergibt sich ein anderes Bild. Während die öffentlichen Ausgaben für Bildungseinrichtungen stiegen, sank in den meisten dieser Länder das BIP. Daher sank der für Bildung bereitgestellte Anteil des BIP zwischen 2008 und 2010 weiter, mit Ausnahme von Polen, wo auch das BIP stieg, und zwar schneller als die öffentlichen Ausgaben für Bildungseinrichtungen, was zu einer Senkung der öffentlichen Ausgaben für Bildungseinrichtungen als Prozentsatz des BIP führte.

Werden die Veränderungen von 2008 auf 2009 und von 2009 auf 2010 getrennt analysiert, ist das Ergebnis jedoch weniger positiv. In den meisten der 30 Länder mit verfügbaren Daten nahm das BIP von 2008 auf 2009 ab (mit Ausnahme von Australien, Israel, Korea, Neuseeland und Polen). Während in Griechenland, Irland, Island, Luxemburg und Spanien das BIP von 2009 auf 2010 weiter abnahm, stieg es in den anderen Ländern und deutete zumindest auf eine teilweise Erholung in diesen Ländern in diesem Zeitraum hin.

Derweil stiegen die öffentlichen Ausgaben für Bildungseinrichtungen in den OECDLändern von 2008 auf 2009 um durchschnittlich 4 Prozent und in Australien, Neuseeland und Portugal sogar um mehr als Io Prozent. Im gleichen Zeitraum berichteten jedoch sieben Länder Kürzungen der öffentlichen Ausgaben für Bildungseinrichtungen, von ihnen berichteten Estland, Island, Italien und Ungarn Kürzungen von mehr als 4 Prozent.

Zwar stieg das BIP von 2009 auf 2010 in den meisten Ländern, doch die öffentlichen Ausgaben für Bildungseinrichtungen fielen in diesem Zeitraum in einem Drittel der OECD-Länder. Während also von 2009 auf 2010 die öffentlichen Ausgaben weiter sanken (in Estland um 4,8 Prozent, in Island um 8,4 Prozent, in Italien um 3,3 Prozent und in Ungarn um 3,4 Prozent), wurden in den meisten anderen OECD-Ländern erst 


\section{Abbildung B2.3}

Auswirkungen der Wirtschaftskrise auf die öffentlichen Bildungsausgaben

Index der Veränderung der öffentlichen Ausgaben für Bildungseinrichtungen als Prozentsatz des BIP zwischen 2008 und 2010, für alle

Bildungsbereiche $(2008=100$, zu konstanten Preisen des Jahres 2010)
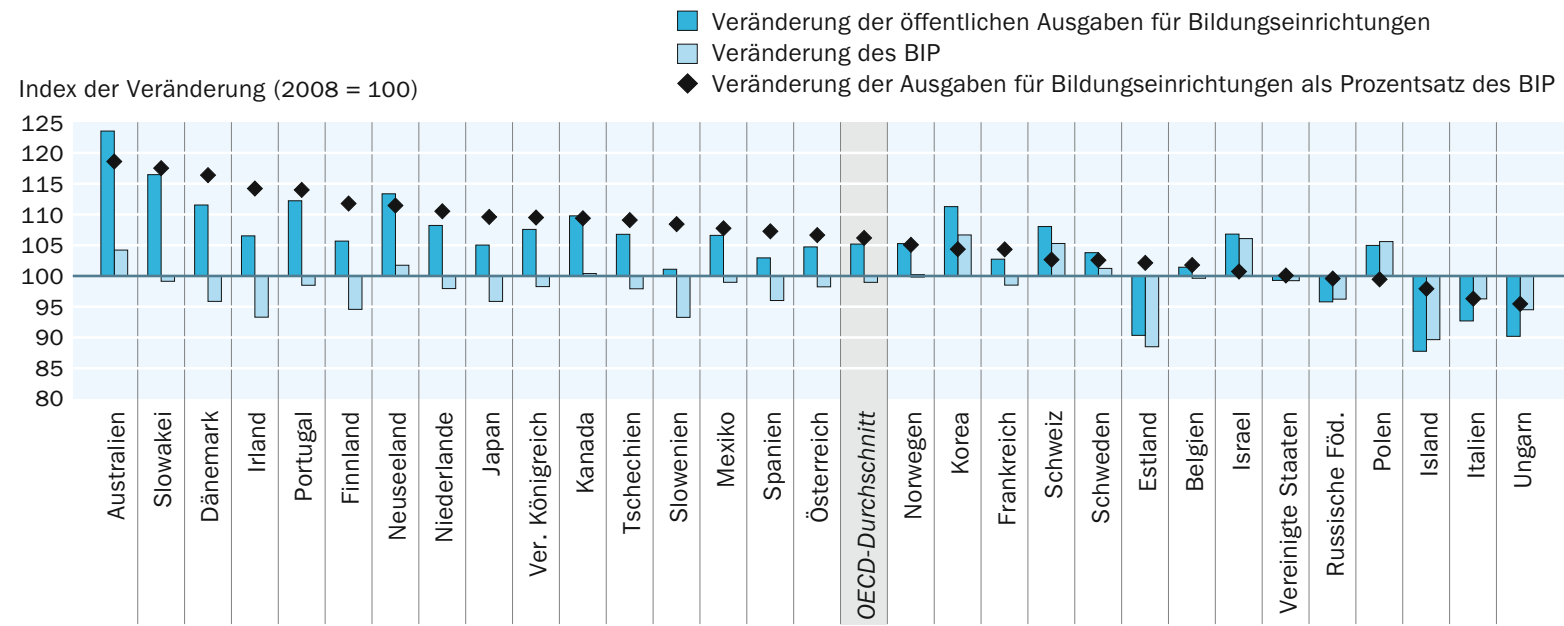

Index der Veränderung der Ausgaben für Bildungseinrichtungen

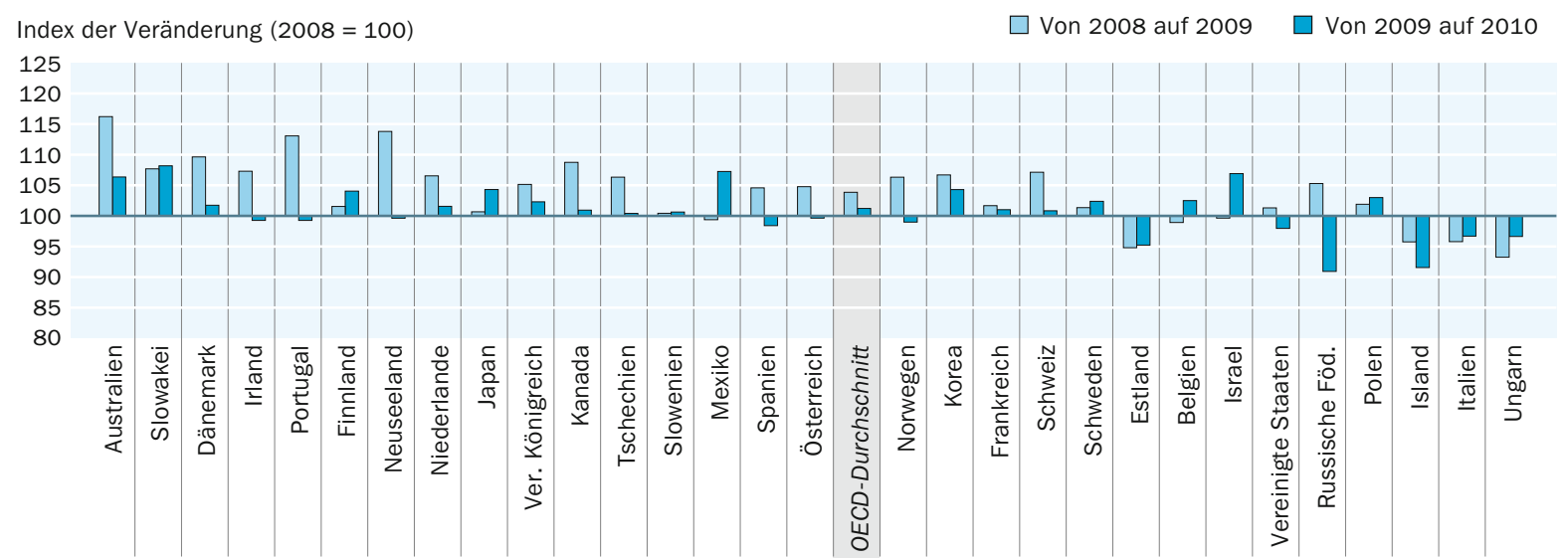

Index der Veränderung des BIP

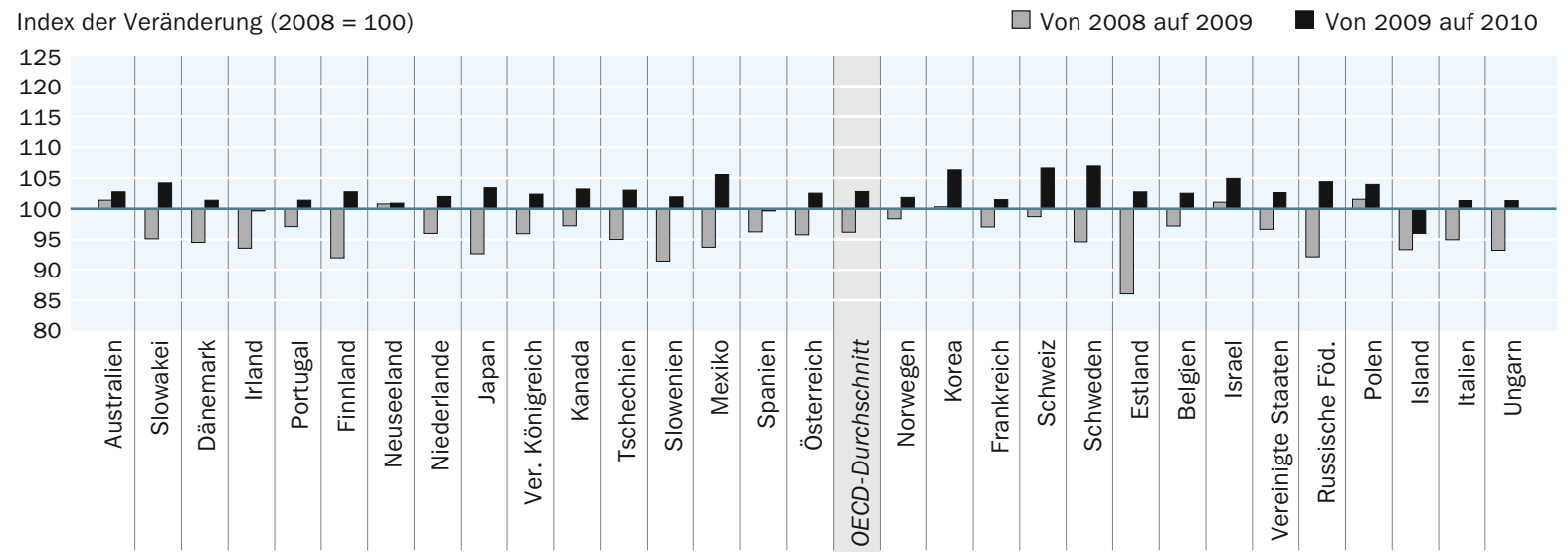

Anordnung der Länder in absteigender Reihenfolge der Veränderung der Ausgaben für Bildungseinrichtungen als Prozentsatz des BIP. Quelle: OECD. Tabelle B2.5. Hinweise s. Anhang 3 unter www.oecd.org/edu/eag.htm. StatLink: http://dx.doi.org/10.1787/888932846918 
in diesem Zeitraum die ersten Auswirkungen der Finanzkrise auf die Bildungshaushalte spürbar. Von 2009 auf 2010 sanken die öffentlichen Ausgaben für Bildungseinrichtungen in Irland, Neuseeland, Norwegen, Österreich, Portugal, Spanien und den Vereinigten Staaten um höchstens 2 Prozent. Norwegen erhöhte 2009 im Rahmen seiner Bemühungen, den Auswirkungen der Krise entgegenzuwirken, die Ausgaben für Bildungseinrichtungen erheblich, setzte diese Bemühungen jedoch 2010 nicht fort. Im Durchschnitt der OECD-Länder stiegen die öffentlichen Ausgaben für Bildungseinrichtungen von 2009 auf 2010 nur um I Prozent.

\section{Ausgaben für Unterricht, Forschung und Entwicklung sowie zusätzliche Dienstleistungen}

Im Durchschnitt der OECD-Länder entfallen rund 89 Prozent aller Ausgaben für den Primar-, Sekundar- und postsekundaren, nicht tertiären Bereich zusammen auf eigentliche Bildungsdienstleistungen. Dieser Anteil ist im Tertiärbereich deutlich geringer (im Durchschnitt der OECD 7I Prozent), da dort andere Leistungen, insbesondere im Zusammenhang mit Forschung und Entwicklung (F\&E), einen wesentlichen Teil der Bildungsausgaben ausmachen können.

Im Tertiärbereich reichen die Ausgaben für Forschung und Entwicklung (F\&E) als Prozentsatz des BIP von weniger als 0,2 Prozent in Brasilien (0,05 Prozent), Chile (0,I4 Prozent), der Slowakei (0,I4 Prozent) und Ungarn (0,I8 Prozent) bis zu mehr als o,6 Prozent in Australien ( 0,62 Prozent), Estland ( 0,64 Prozent), Finnland (o,8o Prozent), Kanada (o,68 Prozent), den Niederlanden (o,64 Prozent), Norwegen (o,7o Prozent), Schweden (0,94 Prozent) und der Schweiz (o,69 Prozent). Diese Unterschiede erklären einen Teil der Unterschiede zwischen den einzelnen Ländern bei den Gesamtbildungsausgaben pro Studierenden im Tertiärbereich (Tab. B2.4 und Abb. B2.4). So deuten zum Beispiel hohe F\&E-Ausgaben in den oben angeführten Ländern darauf hin, dass die Ausgaben für Bildungseinrichtungen pro Studierendem in diesen Ländern nach einer Bereinigung um den F\&E-Anteil wesentlich niedriger wären (s. Tab. BI.2).

In vielen OECD-Ländern bieten Schulen und Hochschulen soziale Dienste für Schüler und Studierende ebenso wie in einigen Fällen auch Dienstleistungen für die Allgemeinheit an. Die Finanzierung dieser zusätzlichen Dienstleistungen erfolgt durch öffentliche Mittel und Gebühren, die von den Schülern/Studierenden und ihren Familien erhoben werden. Die Ausgaben für zusätzliche Dienstleistungen im Primar-, Sekundar- und postsekundaren, nicht tertiären Bereich zusammen als Prozentsatz des BIP liegen im Durchschnitt der OECD-Länder bei ungefähr 0,25 Prozent (Tab. B2.4). Dieser Anteil übersteigt 0,40 Prozent in Finnland ( 0,43 Prozent), Frankreich $(0,55$ Prozent), Korea (o,46 Prozent), Schweden (o,42 Prozent) und dem Vereinigten Königreich (o,7I Prozent).

Im Tertiärbereich werden diese zusätzlichen Dienstleistungen häufiger als in jedem anderen Bildungsbereich durch die privaten Nutzer bezahlt. Im Durchschnitt der OECDLänder belaufen sich die Ausgaben für zusätzliche Dienstleistungen im Tertiärbereich auf o,o6 Prozent des BIP. In einigen Ländern liegt dieser Anteil bei über o, I Prozent: Israel (0,I9 Prozent), in Kanada (0,13 Prozent), der Slowakei (0,13 Prozent), Ungarn (o,II Prozent), dem Vereinigten Königreich (o,II Prozent) und den Vereinigten Staaten (o,34 Prozent). 
Ausgaben für eigentliche Bildungsdienstleistungen, Forschung und Entwicklung (F\&E) sowie zusätzliche

Dienstleistungen als Prozentsatz des BIP, Tertiärbereich (2010)

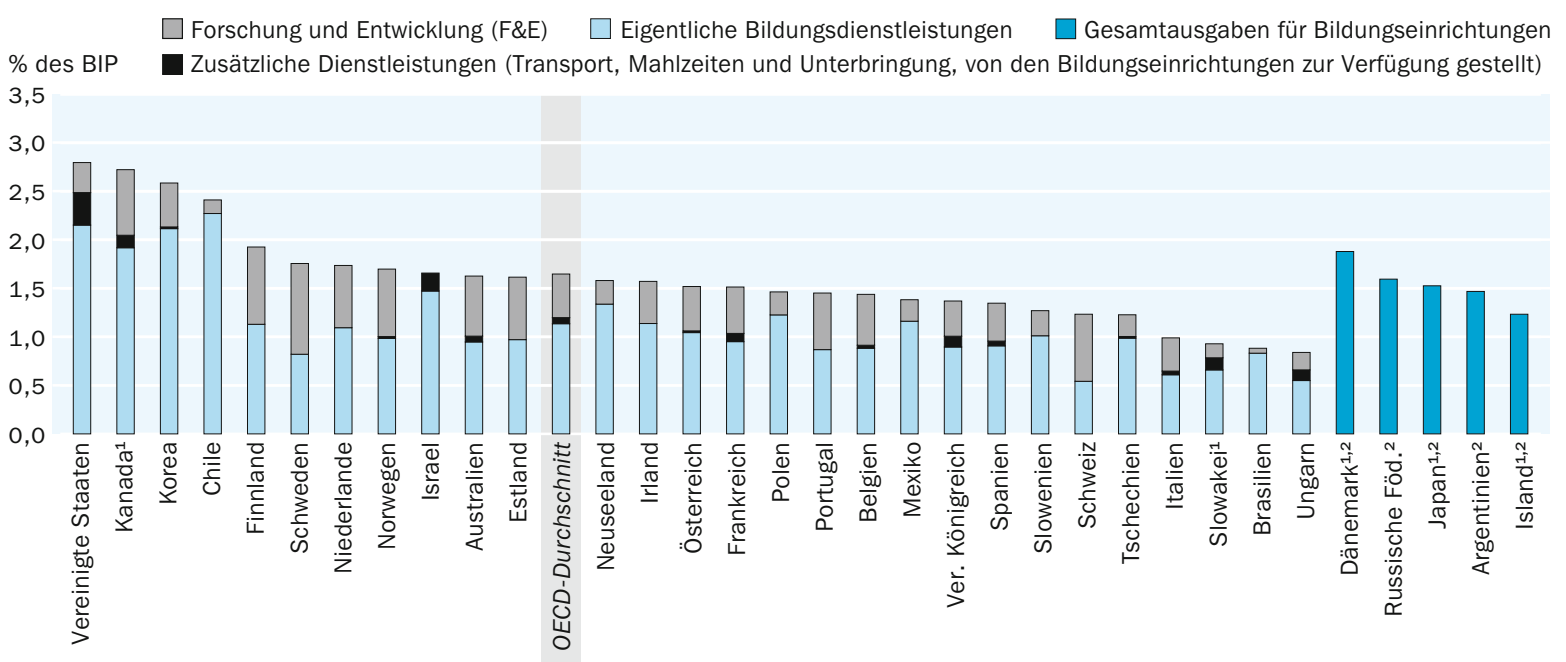

1. Einige Bildungsbereiche sind in anderen Bildungsbereichen enthalten. Einzelheiten s. Erläuterung von „x“ in Hinweise für den Leser. 2. Gesamtausgaben im Tertiärbereich einschließlich Ausgaben für Forschung und Entwicklung (F\&E).

Anordnung der Länder in absteigender Reihenfolge der Gesamtausgaben für Bildungseinrichtungen im Tertiärbereich.

Quelle: OECD. Argentinien: Statistikinstitut der UNESCO (World Education Indicators Programme). Hinweise s. Anhang 3 unter www.oecd.org/edu/eag.htm.

StatLink: $h$ ttp://dx.doi.org/10.1787/888932846937

\section{Ausgaben für Bildungseinrichtungen nach Herkunft der Mittel}

Bildung wird mit Mitteln sowohl aus öffentlichen als auch privaten Quellen finanziert. Höhere Ausgaben für Bildungseinrichtungen infolge höherer Schüler-/Studierendenzahlen und aufgrund anderer Faktoren bedeuten eine größere finanzielle Belastung für die Gesellschaft insgesamt, wobei diese Belastung jedoch nicht nur die öffentliche Hand betrifft. Im Durchschnitt stammen von den 6,5 Prozent der Gesamtsumme der Bruttoinlandsprodukte in der OECD, die für Bildung bereitgestellt werden, drei Viertel der Ausgaben für alle Bildungsbereiche zusammen (5,o Prozent) aus öffentlichen Quellen (Tab. B2.3). Sie sind in allen Ländern die wichtigste Finanzierungsquelle und stellen zwischen mindestens 6o Prozent (Chile) bis zu fast 98 Prozent (Finnland und Schweden) aller für Bildung bereitgestellten Mittel dar. Die Aufschlüsselung der Bildungsausgaben nach Herkunft der Mittel und Bildungsbereichen macht jedoch größere Unterschiede zwischen den einzelnen Ländern deutlich (s. Indikator B3).

\section{Definitionen}

Zusätzliche Dienstleistungen sind Dienstleistungen, die von den Bildungseinrichtungen neben dem eigentlichen Bildungsauftrag erbracht werden. Soziale Dienstleistungen für Schüler/Studierende stellen den wichtigsten Bereich zusätzlicher Dienstleistungen dar. Im Primar-, Sekundar- und postsekundaren, nicht tertiären Bereich umfassen die sozialen Dienstleistungen die Bereitstellung von Mahlzeiten, die Gesundheitsdienste der Schulen sowie Schultransporte. Im Tertiärbereich sind es u. a. Wohnheime, Mensen und Gesundheitsdienste. 
Eigentliche Bildungsdienstleistungen umfassen alle Dienstleistungen, die direkt mit dem Unterricht an Bildungseinrichtungen in Zusammenhang stehen, einschließlich den Lehrkräften, dem Bau und der Instandhaltung von Schulgebäuden, dem Unterrichtsmaterial, Büchern und der Verwaltung der Schulen.

Ausgaben für Forschung und Entwicklung (F\&E) beinhalten sämtliche Ausgaben für Forschung an Hochschulen und anderen Bildungseinrichtungen des Tertiärbereichs, unabhängig davon, ob diese aus dem allgemeinen Etat der Einrichtungen, über separate Zuschüsse oder über Verträge mit öffentlichen oder privaten Geldgebern finanziert werden. Ausgaben für Forschung und Entwicklung werden anhand der Angaben der forschenden Institutionen und nicht der betreffenden Geldgeber klassifiziert.

Private Zahlungen für Unterrichtsleistungen/Bildungsgüter außerhalb von Bildungseinrichtungen umfassen alle Bildungsgüter und Dienstleistungen, die außerhalb von Bildungseinrichtungen erworben werden. So können beispielsweise Familien Schulbücher und Unterrichtsmaterialien selbst kaufen oder ihren Kindern Privatunterricht erteilen lassen.

\section{Angewandte Methodik}

Die Daten beziehen sich auf das Haushaltsjahr 2010 und beruhen auf der von der OECD im Jahre 2012 durchgeführten UOE-Datenerhebung zur Bildungsstatistik (weitere Informationen s. Anhang 3 unter www.oecd.org/eduleag.htm).

Die statistischen Daten für Israel wurden von den zuständigen israelischen Stellen bereitgestellt, die für sie verantwortlich zeichnen. Die Verwendung dieser Daten durch die OECD erfolgt unbeschadet des völkerrechtlichen Status der Golanhöhen, von OstJerusalem und der israelischen Siedlungen im Westjordanland.

\section{Weiterführende Informationen}

OECD (20II), Bildung auf einen Blick 2011 - OECD-Indikatoren, W. Bertelsmann Verlag, Bielefeld.

\section{Tabellen Indikator B2}

Tabelle B2.I: Ausgaben für Bildungseinrichtungen als Prozentsatz des BIP, nach Bildungsbereich (I995, 2000, 2005, 2010) StatLink: http://dx.doi.org/10.1787/888932849578

Tabelle B2.2: Ausgaben für Bildungseinrichtungen als Prozentsatz des BIP, nach Bildungsbereich (2010)

StatLink: http://dx.doi.org/10.1787/888932849597 
Tabelle B2.3: Ausgaben für Bildungseinrichtungen als Prozentsatz des BIP, nach Herkunft der Mittel und Bildungsbereich (2010)

StatLink: http://dx.doi.org/10.1787/888932849616

Tabelle B2.4: Ausgaben für Bildungseinrichtungen als Prozentsatz des BIP, nach Leistungsbereich (2010)

StatLink: http:/|dx.doi.org/10.1787/888932849635

- Tabelle B2.5: Veränderung der öffentlichen Ausgaben für Bildungseinrichtungen als Prozentsatz des BIP (2008, 2009, 2010)

StatLink:http:||dx.doi.org/10.1787/888932849654 
Tabelle B2.1

Ausgaben für Bildungseinrichtungen als Prozentsatz des BIP, nach Bildungsbereich (1995, 2000, 2005, 2010) Finanziert mit Mitteln aus öffentlichen und privaten Quellen, nach Jahr

\begin{tabular}{|c|c|c|c|c|c|c|c|c|c|c|c|c|}
\hline & \multicolumn{4}{|c|}{$\begin{array}{l}\text { Primar-, Sekundar- und postsekundarer, } \\
\text { nicht tertiärer Bereich }\end{array}$} & \multicolumn{4}{|c|}{ Tertiärbereich } & \multicolumn{4}{|c|}{ Alle Bildungsbereiche zusammen } \\
\hline & 1995 & 2000 & 2005 & 2010 & 1995 & 2000 & 2005 & 2010 & 1995 & 2000 & 2005 & 2010 \\
\hline & (1) & (2) & (3) & (4) & (5) & (6) & (7) & (8) & (9) & (10) & (11) & (12) \\
\hline \multicolumn{13}{|l|}{ OECD-Länder } \\
\hline Australien & 3,4 & 3,6 & 3,7 & 4,3 & 1,6 & 1,4 & 1,5 & 1,6 & 5,0 & 5,2 & 5,3 & 6,1 \\
\hline Österreich & 4,2 & 3,9 & 3,7 & 3,6 & 1,2 & 1,1 & 1,3 & 1,5 & 6,1 & 5,5 & $\mathbf{5 , 5}$ & 5,8 \\
\hline Belgien & $\mathrm{m}$ & 4,1 & 4,1 & 4,4 & $\mathrm{~m}$ & 1,3 & 1,2 & 1,4 & m & 6,1 & 6,0 & 6,6 \\
\hline Kanada $^{1,2}$ & 4,3 & 3,3 & 3,7 & 3,9 & 2,1 & 2,3 & 2,7 & 2,7 & 6,7 & 5,9 & 6,5 & 6,6 \\
\hline Chile $^{3}$ & $\mathrm{~m}$ & $\mathrm{~m}$ & 3,2 & 3,4 & $\mathrm{~m}$ & $\mathrm{~m}$ & 1,7 & 2,4 & m & $\mathbf{m}$ & 5,4 & 6,4 \\
\hline Tschechien & 3,3 & 2,7 & 2,9 & 2,8 & 0,9 & 0,8 & 1,0 & 1,2 & 4,8 & 4,0 & 4,5 & 4,7 \\
\hline Dänemark ${ }^{2}$ & 4,0 & 4,1 & 4,5 & 4,8 & 1,6 & 1,6 & 1,7 & 1,9 & 6,2 & 6,6 & 7,4 & 8,0 \\
\hline Estland ${ }^{4}$ & 4,9 & 4,5 & 4,0 & 3,9 & 1,1 & 1,2 & 1,3 & 1,6 & 6,7 & 6,2 & 5,8 & 6,0 \\
\hline Finnland & 4,0 & 3,6 & 3,9 & 4,1 & 1,9 & 1,7 & 1,7 & 1,9 & 6,3 & 5,6 & 6,0 & 6,5 \\
\hline Frankreich & 4,5 & 4,3 & 4,0 & 4,1 & 1,4 & 1,3 & 1,3 & 1,5 & 6,6 & 6,4 & 6,0 & 6,3 \\
\hline Deutschland & 3,4 & 3,3 & 3,2 & $\mathrm{~m}$ & 1,1 & 1,1 & 1,1 & $\mathrm{~m}$ & 5,1 & 4,9 & 5,0 & $\mathbf{m}$ \\
\hline Griechenland $^{2}$ & 2,0 & 2,7 & 2,8 & $\mathrm{~m}$ & 0,6 & 0,8 & 1,5 & $\mathrm{~m}$ & 2,7 & 3,6 & 4,3 & $\mathbf{m}$ \\
\hline Ungarn ${ }^{4}$ & 3,2 & 2,8 & 3,3 & 2,8 & 0,8 & 0,9 & 0,9 & 0,8 & 4,8 & 4,4 & 5,1 & 4,6 \\
\hline Island & $\mathrm{m}$ & 4,8 & 5,4 & 4,9 & $\mathrm{~m}$ & 1,1 & 1,2 & 1,2 & $\mathbf{m}$ & 7,1 & 8,0 & 7,7 \\
\hline Irland & 3,8 & 2,9 & 3,4 & 4,8 & 1,3 & 1,5 & 1,1 & 1,6 & 5,2 & 4,4 & 4,5 & 6,4 \\
\hline Israel & 4,6 & 4,3 & 4,1 & 4,3 & 1,7 & 1,9 & 1,9 & 1,7 & 7,8 & 7,7 & 7,5 & 7,4 \\
\hline Italien & 3,5 & 3,1 & 3,1 & 3,2 & 0,7 & 0,9 & 0,9 & 1,0 & 4,6 & 4,5 & 4,4 & 4,7 \\
\hline$J^{\prime} a p a n^{2}$ & 3,1 & 3,0 & 2,9 & 3,0 & 1,3 & 1,4 & 1,4 & 1,5 & 4,9 & 5,0 & 4,9 & 5,1 \\
\hline Korea & $\mathrm{m}$ & 3,5 & 4,1 & 4,2 & $\mathrm{~m}$ & 2,2 & 2,3 & 2,6 & m & 6,1 & 6,7 & 7,6 \\
\hline Luxemburg & $\mathrm{m}$ & $\mathrm{m}$ & 3,7 & 3,5 & $\mathrm{~m}$ & $\mathrm{~m}$ & $\mathrm{~m}$ & $\mathrm{~m}$ & m & $\mathbf{m}$ & $\mathbf{m}$ & $\mathbf{m}$ \\
\hline Mexiko & 3,7 & 3,5 & 4,0 & 4,0 & 1,0 & 1,0 & 1,2 & 1,4 & 5,1 & 5,0 & 5,9 & 6,2 \\
\hline Niederlande & 3,4 & 3,4 & 3,8 & 4,1 & 1,6 & 1,4 & 1,5 & 1,7 & 5,4 & 5,1 & 5,8 & 6,3 \\
\hline Neuseeland ${ }^{4}$ & $\mathrm{~m}$ & $\mathrm{~m}$ & 4,6 & 5,1 & $\mathrm{~m}$ & $\mathrm{~m}$ & 1,5 & 1,6 & m & m & 6,5 & 7,3 \\
\hline Norwegen ${ }^{4}$ & 5,0 & 5,0 & 5,1 & 5,1 & 1,9 & 1,6 & 1,7 & 1,7 & 6,9 & 6,8 & 7,5 & 7,6 \\
\hline Polen & 3,6 & 3,9 & 3,7 & 3,7 & 0,8 & 1,1 & 1,6 & 1,5 & 5,2 & 5,6 & 5,9 & 5,8 \\
\hline Portugal & 3,5 & 3,7 & 3,7 & 3,9 & 0,9 & 1,0 & 1,3 & 1,5 & 4,9 & 5,2 & 5,5 & 5,8 \\
\hline Slowakei² & 3,1 & 2,7 & 2,9 & 3,1 & 0,7 & 0,8 & 0,9 & 0,9 & 4,6 & 4,1 & 4,4 & 4,6 \\
\hline Slowenien & $\mathrm{m}$ & $\mathrm{m}$ & 4,1 & 3,9 & $\mathrm{~m}$ & $\mathrm{~m}$ & 1,3 & 1,3 & m & m & 6,0 & 5,9 \\
\hline Spanien & 3,8 & 3,2 & 2,9 & 3,3 & 1,0 & 1,1 & 1,1 & 1,3 & 5,3 & 4,8 & 4,6 & 5,6 \\
\hline Schweden & 4,1 & 4,2 & 4,2 & 4,0 & 1,5 & 1,6 & 1,6 & 1,8 & 6,0 & 6,3 & 6,4 & 6,5 \\
\hline Schweiz ${ }^{4}$ & 3,8 & 4,0 & 4,2 & 4,0 & 1,1 & 1,1 & 1,4 & 1,3 & 5,2 & 5,4 & 5,9 & 5,6 \\
\hline Türkei ${ }^{4}$ & 1,2 & 1,8 & $\mathrm{~m}$ & 2,5 & 0,5 & 0,8 & $\mathrm{~m}$ & $\mathrm{~m}$ & 1,7 & 2,5 & m & m \\
\hline Vereinigtes Königreich & 3,6 & 3,6 & 4,4 & 4,8 & 1,1 & 1,0 & 1,3 & 1,4 & 5,2 & 4,9 & 5,9 & 6,5 \\
\hline Vereinigte Staaten & 3,6 & 3,7 & 3,8 & 4,0 & 2,2 & 2,2 & 2,4 & 2,8 & 6,2 & 6,2 & 6,6 & 7,3 \\
\hline OECD-Durchschnitt & 3,6 & 3,6 & 3,8 & 3,9 & 1,2 & 1,3 & 1,5 & 1,6 & 5,4 & 5,4 & 5,8 & 6,3 \\
\hline OECD insgesamt & 3,6 & 3,5 & 3,7 & 3,8 & 1,6 & 1,6 & 1,8 & 2,1 & 5,6 & 5,6 & 6,0 & 6,5 \\
\hline EU21-Durchschnitt & 3,7 & 3,5 & 3,6 & 3,8 & 1,1 & 1,1 & 1,3 & 1,4 & 5,3 & 5,2 & 5,5 & 5,9 \\
\hline $\begin{array}{l}\text { OECD-Ländermittel } \\
\text { für Länder mit Daten } \\
\text { für 1995, } 2000,2005 \\
\text { und } 2010 \text { (25 Länder) }\end{array}$ & 3,8 & 3,6 & 3,7 & 3,9 & 1,3 & 1,3 & 1,5 & 1,6 & 5,7 & 5,5 & 5,7 & 6,1 \\
\hline \multicolumn{13}{|l|}{ Sonstige G20-Länder } \\
\hline Argentinien & $\mathrm{m}$ & $\mathrm{m}$ & $\mathrm{m}$ & 4,7 & $\mathrm{~m}$ & $\mathrm{~m}$ & $\mathrm{~m}$ & 1,5 & m & m & m & 6,8 \\
\hline Brasilien ${ }^{4}$ & 2,6 & 2,4 & 3,2 & 4,3 & 0,7 & 0,7 & 0,8 & 0,9 & 3,7 & 3,5 & 4,4 & 5,6 \\
\hline China & $\mathrm{m}$ & $\mathrm{m}$ & $\mathrm{m}$ & $\mathrm{m}$ & $\mathrm{m}$ & $\mathrm{m}$ & $\mathrm{m}$ & $\mathrm{m}$ & m & m & m & m \\
\hline Indien & $\mathrm{m}$ & $\mathrm{m}$ & $\mathrm{m}$ & $\mathrm{m}$ & $\mathrm{m}$ & $\mathrm{m}$ & $\mathrm{m}$ & $\mathrm{m}$ & m & $\mathbf{m}$ & m & m \\
\hline Indonesien & $\mathrm{m}$ & $\mathrm{m}$ & $\mathrm{m}$ & $\mathrm{m}$ & $\mathrm{m}$ & $\mathrm{m}$ & $\mathrm{m}$ & $\mathrm{m}$ & m & m & m & m \\
\hline Russische Föderation ${ }^{4}$ & $\mathrm{~m}$ & 1,7 & 1,5 & 2,1 & $\mathrm{~m}$ & 0,5 & 0,6 & 1,6 & m & 2,9 & 2,9 & 4,9 \\
\hline Saudi-Arabien & $\mathrm{m}$ & $\mathrm{m}$ & $\mathrm{m}$ & $\mathrm{m}$ & $\mathrm{m}$ & $\mathrm{m}$ & $\mathrm{m}$ & $\mathrm{m}$ & m & m & m & m \\
\hline Südafrika & $\mathrm{m}$ & $\mathrm{m}$ & $\mathrm{m}$ & $\mathrm{m}$ & $\mathrm{m}$ & $\mathrm{m}$ & $\mathrm{m}$ & $\mathrm{m}$ & m & m & m & m \\
\hline G20-Durchschnitt & $\mathbf{m}$ & $\mathbf{m}$ & m & m & m & $\mathbf{m}$ & $\mathbf{m}$ & m & m & $\mathbf{m}$ & m & m \\
\hline
\end{tabular}

1. Referenzjahr 2009 anstelle 2010. 2. Einige Bildungsbereiche sind in anderen Bildungsbereichen enthalten. Einzelheiten s. Erläuterung von „ $x^{\prime \prime}$ in Hinweise für den Leser. 3. Referenzjahr 2011 anstelle 2010, Referenzjahr 2006 anstelle 2005. 4. Nur öffentliche Ausgaben (Schweiz: nur im Tertiärbereich; Norwegen: nur im Primar-, Sekundar- und postsekundaren, nicht tertiären Bereich; Estland, Neuseeland und die Russische Föderation: nur Daten für 1995 und 2000 verfügbar). Quelle: OECD. Argentinien: Statistikinstitut der UNESCO (World Education Indicators Programme). Hinweise s. Anhang 3 unter www.oecd.org/edu/eag.htm. StatLink: http://dx.doi.org/10.1787/888932849578

Erläuterung der Kennzeichnung fehlender Daten s. Hinweise für den Leser. 
Tabelle B2.2

Ausgaben für Bildungseinrichtungen als Prozentsatz des BIP, nach Bildungsbereich (2010)

Finanziert mit Mitteln aus öffentlichen und privaten Quellen ${ }^{1}$

\begin{tabular}{|c|c|c|c|c|c|c|c|c|c|}
\hline & \multirow{2}{*}{$\begin{array}{l}\text { Elemen- } \\
\text { tarbereich } \\
\text { (3-Jährige } \\
\text { und Ältere) }\end{array}$} & \multicolumn{4}{|c|}{$\begin{array}{c}\text { Primar-, Sekundar- und postsekundarer, } \\
\text { nicht tertiärer Bereich }\end{array}$} & \multicolumn{3}{|c|}{ Tertiärbereich } & \multirow{2}{*}{$\begin{array}{c}\text { Alle } \\
\text { Bildungs- } \\
\text { bereiche } \\
\text { zusammen } \\
\text { (einschl. } \\
\text { nicht zuge- } \\
\text { ordneter } \\
\text { Bildungs- } \\
\text { gänge) }\end{array}$} \\
\hline & & \begin{tabular}{c|} 
Primar-, \\
Sekundar- \\
und post- \\
sekundarer, \\
nicht tertiärer \\
Bereich \\
insgesamt
\end{tabular} & $\begin{array}{c}\text { Primar- und } \\
\text { Sekundar- } \\
\text { bereich I }\end{array}$ & $\begin{array}{l}\text { Sekundar- } \\
\text { bereich II }\end{array}$ & \begin{tabular}{|c|} 
Post- \\
sekundarer, \\
nicht tertiärer \\
Bereich
\end{tabular} & $\begin{array}{c}\text { Tertiär- } \\
\text { bereich } \\
\text { insgesamt }\end{array}$ & $\begin{array}{c}\text { Tertiär- } \\
\text { bereich B }\end{array}$ & \begin{tabular}{|c|} 
Tertiär- \\
bereich A \\
und weiter- \\
führende \\
forschungs- \\
orientierte \\
Studiengänge
\end{tabular} & \\
\hline & (1) & (2) & (3) & (4) & (5) & (6) & (7) & (8) & (9) \\
\hline \multicolumn{10}{|l|}{ OECD-Länder } \\
\hline Australien & 0,1 & 4,3 & 3,4 & 0,8 & 0,1 & 1,6 & 0,2 & 1,5 & 6,1 \\
\hline Österreich & 0,6 & 3,6 & 2,3 & 1,3 & $\mathrm{n}$ & 1,5 & $\mathrm{n}$ & 1,5 & 5,8 \\
\hline Belgien ${ }^{2}$ & 0,6 & 4,4 & 1,6 & 2,8 & $x(4)$ & 1,4 & $x(6)$ & $x(6)$ & 6,6 \\
\hline Kanada $^{3}$ & $x(3)$ & 3,9 & 2,3 & 1,6 & $x(7)$ & 2,7 & 0,9 & 1,8 & 6,6 \\
\hline Chile $^{4}$ & 0,6 & 3,4 & 2,2 & 1,2 & a & 2,4 & 0,6 & 1,8 & 6,4 \\
\hline Tschechien & 0,5 & 2,8 & 1,7 & 1,1 & $\mathrm{n}$ & 1,2 & $\mathrm{n}$ & 1,2 & 4,7 \\
\hline Dänemark & 1,1 & 4,8 & 3,4 & 1,4 & $x(4,6)$ & 1,9 & $x(6)$ & $x(6)$ & 8,0 \\
\hline Estland & 0,5 & 3,9 & 2,3 & 1,3 & 0,3 & 1,6 & 0,6 & 1,0 & 6,0 \\
\hline Finnland & 0,4 & 4,1 & 2,5 & 1,6 & $x(4)$ & 1,9 & $\mathrm{n}$ & 1,9 & 6,5 \\
\hline Frankreich & 0,7 & 4,1 & 2,6 & 1,4 & $\mathrm{n}$ & 1,5 & 0,3 & 1,2 & 6,3 \\
\hline Deutschland & $\mathrm{m}$ & $\mathrm{m}$ & $\mathrm{m}$ & $\mathrm{m}$ & $\mathrm{m}$ & $\mathrm{m}$ & $\mathrm{m}$ & $\mathrm{m}$ & m \\
\hline Griechenland & $\mathrm{m}$ & $\mathrm{m}$ & $\mathrm{m}$ & $\mathrm{m}$ & $\mathrm{m}$ & $\mathrm{m}$ & $\mathrm{m}$ & $\mathrm{m}$ & m \\
\hline Ungarn 5 & 0,7 & 2,8 & 1,7 & 1,0 & 0,1 & 0,8 & $\mathrm{n}$ & 0,8 & 4,6 \\
\hline Island & 1,0 & 4,9 & 3,6 & 1,4 & $x(4)$ & 1,2 & $x(6)$ & 1,2 & 7,7 \\
\hline Irland & $x(9)$ & 4,8 & 3,5 & 1,0 & 0,3 & 1,6 & $x(6)$ & $x(6)$ & 6,4 \\
\hline Israel & 0,8 & 4,3 & 2,5 & 1,8 & $\mathrm{n}$ & 1,7 & 0,3 & 1,4 & 7,4 \\
\hline Italien & 0,5 & 3,2 & 1,9 & 1,2 & 0,1 & 1,0 & $\mathrm{n}$ & 1,0 & 4,7 \\
\hline Japan & 0,2 & 3,0 & 2,1 & 0,8 & $x(4,6)$ & 1,5 & 0,2 & 1,3 & 5,1 \\
\hline Korea & 0,3 & 4,2 & 2,8 & 1,5 & a & 2,6 & 0,3 & 2,3 & 7,6 \\
\hline Luxemburg & 0,8 & 3,5 & 2,6 & 0,9 & $\mathrm{n}$ & $\mathrm{m}$ & $\mathrm{m}$ & $\mathrm{m}$ & m \\
\hline Mexiko & 0,6 & 4,0 & 3,1 & 0,9 & a & 1,4 & $x(6)$ & $x(6)$ & 6,2 \\
\hline Niederlande & 0,4 & 4,1 & 2,8 & 1,3 & $\mathrm{n}$ & 1,7 & $\mathrm{n}$ & 1,7 & 6,3 \\
\hline Neuseeland & 0,6 & 5,1 & 3,2 & 1,6 & 0,2 & 1,6 & 0,3 & 1,3 & 7,3 \\
\hline Norwegen 5 & 0,5 & 5,1 & 3,5 & 1,6 & $x(4)$ & 1,7 & $x(6)$ & $x(6)$ & 7,6 \\
\hline Polen & 0,7 & 3,7 & 2,6 & 1,1 & $\mathrm{n}$ & 1,5 & $\mathrm{n}$ & 1,5 & 5,8 \\
\hline Portugal & 0,4 & 3,9 & 2,7 & 1,2 & $\mathrm{~m}$ & 1,5 & $x(6)$ & $x(6)$ & 5,8 \\
\hline Slowakei & 0,5 & 3,1 & 2,0 & 1,0 & $x(4)$ & 0,9 & $x(4)$ & 0,9 & 4,6 \\
\hline Slowenien & 0,7 & 3,9 & 2,7 & 1,2 & $x(4)$ & 1,3 & $x(6)$ & $x(6)$ & 5,9 \\
\hline Spanien & 0,9 & 3,3 & 2,5 & 0,8 & a & 1,3 & 0,2 & 1,1 & 5,6 \\
\hline Schweden & 0,7 & 4,0 & 2,6 & 1,3 & $\mathrm{n}$ & 1,8 & $x(6)$ & $x(6)$ & 6,5 \\
\hline Schweiz ${ }^{5}$ & 0,2 & 4,0 & 2,6 & 1,5 & $x(4)$ & 1,3 & $\mathrm{n}$ & 1,3 & 5,6 \\
\hline Türkei ${ }^{5}$ & $\mathrm{n}$ & 2,5 & 1,7 & 0,8 & a & $\mathrm{m}$ & $\mathrm{m}$ & $\mathrm{m}$ & m \\
\hline Vereinigtes Königreich & 0,3 & 4,8 & 3,2 & 1,6 & a & 1,4 & $x(6)$ & $x(6)$ & 6,5 \\
\hline Vereinigte Staaten & 0,5 & 4,0 & 3,0 & 1,1 & $\mathrm{~m}$ & 2,8 & $x(6)$ & $x(6)$ & 7,3 \\
\hline OECD-Durchschnitt & 0,6 & 3,9 & 2,6 & 1,3 & $\mathbf{n}$ & 1,6 & 0,2 & 1,4 & 6,3 \\
\hline OECD insgesamt & 0,5 & 3,8 & 2,7 & 1,1 & $\mathrm{n}$ & 2,1 & 0,2 & 1,4 & 6,5 \\
\hline EU21-Durchschnitt & 0,6 & 3,8 & 2,5 & 1,3 & n & 1,4 & 0,1 & 1,3 & 5,9 \\
\hline \multicolumn{10}{|l|}{ Sonstige G20-Länder } \\
\hline Argentinien & 0,6 & 4,7 & 3,6 & 1,0 & a & 1,5 & 0,4 & 1,0 & 6,8 \\
\hline Brasilien $^{5}$ & 0,4 & 4,3 & 3,5 & 0,8 & a & 0,9 & $x(6)$ & $x(6)$ & 5,6 \\
\hline China & $\mathrm{m}$ & $\mathrm{m}$ & $\mathrm{m}$ & $\mathrm{m}$ & $\mathrm{m}$ & $\mathrm{m}$ & $\mathrm{m}$ & $\mathrm{m}$ & m \\
\hline Indien & $\mathrm{m}$ & $\mathrm{m}$ & $\mathrm{m}$ & $\mathrm{m}$ & $\mathrm{m}$ & $\mathrm{m}$ & $\mathrm{m}$ & $\mathrm{m}$ & m \\
\hline Indonesien & $\mathrm{m}$ & $\mathrm{m}$ & $\mathrm{m}$ & $\mathrm{m}$ & a & $\mathrm{m}$ & $x(6)$ & $x(6)$ & m \\
\hline Russische Föderation & 0,8 & 2,1 & $x(2)$ & $x(2)$ & $x(2)$ & 1,6 & 0,2 & 1,4 & 4,9 \\
\hline Saudi-Arabien & $\mathrm{m}$ & $\mathrm{m}$ & $\mathrm{m}$ & $\mathrm{m}$ & $\mathrm{m}$ & $\mathrm{m}$ & $\mathrm{m}$ & $\mathrm{m}$ & m \\
\hline Südafrika & $\mathrm{m}$ & $\mathrm{m}$ & $\mathrm{m}$ & $\mathrm{m}$ & $\mathrm{m}$ & $\mathrm{m}$ & $\mathrm{m}$ & $\mathrm{m}$ & m \\
\hline G20-Durchschnitt & m & m & m & m & m & m & m & m & m \\
\hline
\end{tabular}

1. Einschließlich Mitteln aus internationalen Quellen. 2. Spalte (3) bezieht sich nur auf den Primarbereich und Spalte (4) auf den gesamten Sekundarbereich.

3. Referenzjahr 2009. 4. Referenzjahr 2011. 5. Nur öffentliche Ausgaben (Schweiz: nur im Tertiärbereich; Norwegen: nur im Primar-, Sekundar- und postsekundaren, nicht tertiären Bereich).

Quelle: OECD. Argentinien: Statistikinstitut der UNESCO (World Education Indicators Programme). Hinweise s. Anhang 3 unter www.oecd.org/edu/eag.htm.

StatLink: http://dx.doi.org/10.1787/888932849597

Erläuterung der Kennzeichnung fehlender Daten s. Hinweise für den Leser. 
Tabelle B2.3

Ausgaben für Bildungseinrichtungen als Prozentsatz des BIP, nach Herkunft der Mittel und Bildungsbereich (2010) Finanziert mit Mitteln aus öffentlichen und privaten Quellen

\begin{tabular}{|c|c|c|c|c|c|c|c|c|c|c|c|c|}
\hline & \multicolumn{3}{|c|}{ Elementarbereich } & \multicolumn{3}{|c|}{$\begin{array}{c}\text { Primar-, Sekundar- und } \\
\text { postsekundarer, } \\
\text { nicht tertiärer Bereich }\end{array}$} & \multicolumn{3}{|c|}{ Tertiärbereich } & \multicolumn{3}{|c|}{$\begin{array}{c}\text { Alle Bildungsbereiche } \\
\text { zusammen }\end{array}$} \\
\hline & $\begin{array}{c}\text { Öffent- } \\
\text { lich }^{1}\end{array}$ & Privat $^{2}$ & Gesamt & $\begin{array}{l}\text { Öffent- } \\
\text { lich }^{1}\end{array}$ & Privat $^{2}$ & Gesamt & $\begin{array}{l}\text { Öffent- } \\
\text { lich }^{1}\end{array}$ & Privat $^{2}$ & Gesamt & $\begin{array}{l}\text { Öffent- } \\
\text { lich }^{1}\end{array}$ & Privat $^{2}$ & Gesamt \\
\hline & (1) & (2) & (3) & (4) & (5) & (6) & (7) & (8) & $(9)$ & (10) & (11) & (12) \\
\hline \multicolumn{13}{|l|}{ OECD-Länder } \\
\hline Australien & 0,06 & 0,05 & 0,11 & 3,7 & 0,6 & 4,3 & 0,8 & 0,9 & 1,6 & 4,6 & 1,5 & 6,1 \\
\hline Österreich & 0,60 & $\mathrm{n}$ & 0,61 & 3,5 & 0,1 & 3,6 & 1,5 & 0,1 & 1,5 & 5,6 & 0,2 & 5,8 \\
\hline Belgien & 0,62 & 0,02 & 0,64 & 4,3 & 0,1 & 4,4 & 1,4 & 0,1 & 1,4 & 6,4 & 0,2 & 6,6 \\
\hline$K^{K a n a d a}{ }^{3,4}$ & $x(4)$ & $x(5)$ & $x(6)$ & 3,4 & 0,4 & 3,9 & 1,5 & 1,2 & 2,7 & 5,0 & 1,6 & 6,6 \\
\hline Chile $^{5}$ & 0,53 & 0,11 & 0,64 & 2,7 & 0,7 & 3,4 & 0,7 & 1,7 & 2,4 & 3,9 & 2,5 & 6,4 \\
\hline Tschechien & 0,47 & 0,04 & 0,51 & 2,6 & 0,3 & 2,8 & 1,0 & 0,2 & 1,2 & 4,1 & 0,6 & 4,7 \\
\hline Dänemark ${ }^{4}$ & 0,93 & 0,14 & 1,08 & 4,7 & 0,1 & 4,8 & 1,8 & 0,1 & 1,9 & 7,6 & 0,4 & 8,0 \\
\hline Estland & 0,45 & 0,01 & 0,45 & 3,9 & 0,1 & 3,9 & 1,3 & 0,3 & 1,6 & 5,6 & 0,4 & 6,0 \\
\hline Finnland & 0,40 & 0,04 & 0,44 & 4,1 & $\mathrm{n}$ & 4,1 & 1,9 & 0,1 & 1,9 & 6,4 & 0,1 & 6,5 \\
\hline Frankreich & 0,68 & 0,05 & 0,72 & 3,8 & 0,3 & 4,1 & 1,3 & 0,2 & 1,5 & 5,8 & 0,5 & 6,3 \\
\hline Deutschland & $\mathrm{m}$ & $\mathrm{m}$ & m & $\mathrm{m}$ & $\mathrm{m}$ & $\mathbf{m}$ & $\mathrm{m}$ & $\mathrm{m}$ & m & $\mathrm{m}$ & $\mathrm{m}$ & m \\
\hline Griechenland & $\mathrm{m}$ & $\mathrm{m}$ & m & $\mathrm{m}$ & $\mathrm{m}$ & m & $\mathrm{m}$ & $\mathrm{m}$ & m & $\mathrm{m}$ & $\mathrm{m}$ & m \\
\hline Ungarn & 0,70 & $\mathrm{~m}$ & m & 2,8 & $\mathrm{~m}$ & m & 0,8 & $\mathrm{~m}$ & m & 4,6 & $\mathrm{~m}$ & m \\
\hline Island & 0,73 & 0,23 & 0,96 & 4,7 & 0,2 & 4,9 & 1,1 & 0,1 & 1,2 & 7,0 & 0,7 & 7,7 \\
\hline Irland & $\mathrm{m}$ & $\mathrm{m}$ & $\mathbf{m}$ & 4,6 & 0,2 & 4,8 & 1,3 & 0,3 & 1,6 & 6,0 & 0,5 & 6,4 \\
\hline Israel & 0,66 & 0,18 & 0,84 & 4,0 & 0,3 & 4,3 & 1,0 & 0,7 & 1,7 & 5,9 & 1,5 & 7,4 \\
\hline Italien & 0,44 & 0,04 & 0,47 & 3,1 & 0,1 & 3,2 & 0,8 & 0,2 & 1,0 & 4,3 & 0,4 & 4,7 \\
\hline Japan $^{4}$ & 0,10 & 0,12 & 0,22 & 2,8 & 0,2 & 3,0 & 0,5 & 1,0 & 1,5 & 3,6 & 1,5 & 5,1 \\
\hline Korea & 0,15 & 0,12 & 0,27 & 3,4 & 0,9 & 4,2 & 0,7 & 1,9 & 2,6 & 4,8 & 2,8 & 7,6 \\
\hline Luxemburg & 0,75 & 0,01 & 0,76 & 3,4 & 0,1 & 3,5 & $\mathrm{~m}$ & $\mathrm{~m}$ & m & $\mathrm{m}$ & $\mathrm{m}$ & m \\
\hline Mexiko & 0,54 & 0,10 & 0,64 & 3,4 & 0,6 & 4,0 & 1,0 & 0,4 & 1,4 & 5,1 & 1,1 & 6,2 \\
\hline Niederlande & 0,41 & 0,01 & 0,42 & 3,7 & 0,4 & 4,1 & 1,3 & 0,5 & 1,7 & 5,4 & 0,9 & 6,3 \\
\hline Neuseeland & 0,53 & 0,09 & 0,62 & 4,4 & 0,6 & 5,1 & 1,0 & 0,5 & 1,6 & 6,0 & 1,3 & 7,3 \\
\hline Norwegen & 0,43 & 0,08 & 0,51 & 5,1 & $\mathrm{~m}$ & m & 1,6 & 0,1 & 1,7 & 7,5 & $\mathrm{~m}$ & m \\
\hline Polen & 0,52 & 0,14 & 0,66 & 3,4 & 0,2 & 3,7 & 1,0 & 0,4 & 1,5 & 5,0 & 0,8 & 5,8 \\
\hline Portugal & 0,41 & $\mathrm{n}$ & 0,41 & 3,9 & $n$ & 3,9 & 1,0 & 0,4 & 1,5 & 5,4 & 0,4 & 5,8 \\
\hline Slowakei ${ }^{4}$ & 0,40 & 0,08 & 0,48 & 2,8 & 0,3 & 3,1 & 0,7 & 0,3 & 0,9 & 4,0 & 0,6 & 4,6 \\
\hline Slowenien & 0,58 & 0,15 & 0,74 & 3,6 & 0,3 & 3,9 & 1,1 & 0,2 & 1,3 & 5,2 & 0,7 & 5,9 \\
\hline Spanien & 0,69 & 0,25 & 0,94 & 3,0 & 0,3 & 3,3 & 1,1 & 0,3 & 1,3 & 4,8 & 0,8 & 5,6 \\
\hline Schweden & 0,71 & $\mathrm{n}$ & 0,71 & 4,0 & $\mathrm{n}$ & 4,0 & 1,6 & 0,2 & 1,8 & 6,3 & 0,2 & 6,5 \\
\hline Schweiz & 0,19 & $\mathrm{~m}$ & m & 3,6 & 0,5 & 4,0 & 1,3 & $\mathrm{~m}$ & $\mathbf{m}$ & 5,2 & $\mathrm{~m}$ & m \\
\hline Türkei & 0,04 & $\mathrm{~m}$ & $\mathbf{m}$ & 2,5 & $\mathrm{~m}$ & m & $\mathrm{m}$ & $\mathrm{m}$ & $\mathbf{m}$ & $\mathrm{m}$ & $\mathrm{m}$ & m \\
\hline Vereinigtes Königreich & 0,32 & $\mathrm{n}$ & 0,32 & 4,8 & $\mathrm{n}$ & 4,8 & 0,7 & 0,6 & 1,4 & 5,9 & 0,6 & 6,5 \\
\hline Vereinigte Staaten & 0,36 & 0,15 & 0,50 & 3,7 & 0,3 & 4,0 & 1,0 & 1,8 & 2,8 & 5,1 & 2,2 & 7,3 \\
\hline OECD-Durchschnitt & 0,47 & 0,08 & 0,58 & 3,7 & 0,3 & 4,0 & 1,1 & 0,5 & 1,7 & 5,4 & 0,9 & 6,3 \\
\hline OECD insgesamt & 0,37 & 0,11 & 0,49 & 3,5 & 0,3 & 3,9 & 1,0 & 1,1 & 2,1 & 5,0 & 1,5 & 6,5 \\
\hline EU21-Durchschnitt & 0,56 & 0,06 & 0,61 & 3,7 & 0,2 & 3,9 & 1,2 & 0,3 & 1,5 & 5,5 & 0,5 & 6,0 \\
\hline \multicolumn{13}{|l|}{ Sonstige G20-Länder } \\
\hline Argentinien & 0,43 & 0,19 & 0,62 & 4,2 & 0,5 & 4,7 & 1,1 & 0,3 & 1,5 & 5,8 & 1,0 & 6,8 \\
\hline Brasilien & 0,44 & $\mathrm{~m}$ & m & 4,3 & $\mathrm{~m}$ & m & 0,9 & $\mathrm{~m}$ & m & 5,6 & $\mathrm{~m}$ & m \\
\hline China & $\mathrm{m}$ & $\mathrm{m}$ & m & $m$ & $\mathrm{~m}$ & m & $\mathrm{m}$ & $\mathrm{m}$ & m & $\mathrm{m}$ & $\mathrm{m}$ & m \\
\hline Indien & $\mathrm{m}$ & $\mathrm{m}$ & m & $\mathrm{m}$ & $\mathrm{m}$ & m & $\mathrm{m}$ & $\mathrm{m}$ & m & $\mathrm{m}$ & $\mathrm{m}$ & m \\
\hline Indonesien & $\mathrm{m}$ & $\mathrm{m}$ & m & $\mathrm{m}$ & $\mathrm{m}$ & m & $\mathrm{m}$ & $\mathrm{m}$ & m & $\mathrm{m}$ & $\mathrm{m}$ & m \\
\hline Russische Föderation & 0,71 & 0,10 & 0,81 & 2,0 & 0,1 & 2,1 & 1,0 & 0,6 & 1,6 & 4,1 & 0,8 & 4,9 \\
\hline Saudi-Arabien & $\mathrm{m}$ & $\mathrm{m}$ & m & $\mathrm{m}$ & $\mathrm{m}$ & m & $\mathrm{m}$ & $\mathrm{m}$ & m & $\mathrm{m}$ & $\mathrm{m}$ & m \\
\hline Südafrika & $\mathrm{m}$ & $\mathrm{m}$ & m & $\mathrm{m}$ & $\mathrm{m}$ & m & $\mathrm{m}$ & $\mathrm{m}$ & m & $\mathrm{m}$ & $\mathrm{m}$ & m \\
\hline G20-Durchschnitt & m & m & $\mathbf{m}$ & m & $\mathbf{m}$ & m & $\mathbf{m}$ & m & m & m & m & $m$ \\
\hline
\end{tabular}

1. Einschließlich öffentlicher Subventionen an private Haushalte, die Bildungseinrichtungen zuzurechnen sind, sowie direkter mit Mitteln aus internationalen Quellen finanzierter Ausgaben für Bildungseinrichtungen. 2. Ohne öffentliche Subventionen, die Bildungseinrichtungen zuzurechnen sind.

3. Referenzjahr 2009. 4. Einige Bildungsbereiche sind in anderen Bildungsbereichen enthalten. Einzelheiten s. Erläuterung von „X“ in Hinweise für den Leser. 5. Referenzjahr 2011.

Quelle: OECD. Argentinien: Statistikinstitut der UNESCO (World Education Indicators Programme). Hinweise s. Anhang 3 unter www.oecd.org/edu/eag.htm. StatLink: http://dx.doi.org/10.1787/888932849616

Erläuterung der Kennzeichnung fehlender Daten s. Hinweise für den Leser. 
Tabelle B2.4

Ausgaben für Bildungseinrichtungen als Prozentsatz des BIP, nach Leistungsbereich (2010)

Ausgaben für Unterricht, Forschung und Entwicklung und zusätzliche Dienstleistungen in Bildungseinrichtungen sowie private Ausgaben für außerhalb von Bildungseinrichtungen erworbene Bildungsgüter

\begin{tabular}{|c|c|c|c|c|c|c|c|c|c|}
\hline & \multicolumn{4}{|c|}{$\begin{array}{l}\text { Primar-, Sekundar- und } \\
\text { postsekundarer, nicht tertiärer Bereich }\end{array}$} & \multicolumn{5}{|c|}{ Tertiärbereich } \\
\hline & \multicolumn{3}{|c|}{ Ausgaben für Bildungseinrichtungen } & \multirow[b]{2}{*}{\begin{tabular}{|c|} 
Private \\
Zahlungen für \\
Unterrichts- \\
leistungen/ \\
Bildungsgüter \\
außerhalb \\
von Bildungs- \\
einrichtungen
\end{tabular}} & \multicolumn{4}{|c|}{ Ausgaben für Bildungseinrichtungen } & \multirow[b]{2}{*}{\begin{tabular}{|c|} 
Private \\
Zahlungen für \\
Unterrichts- \\
leistungen/ \\
Bildungsgüter \\
außerhalb \\
von Bildungs- \\
einrichtungen
\end{tabular}} \\
\hline & $\begin{array}{l}\text { Eigentliche } \\
\text { Bildungs- } \\
\text { dienstleis- } \\
\text { tungen }\end{array}$ & \begin{tabular}{|c|} 
Zusätzliche \\
Dienst- \\
leistungen \\
(Transport, \\
Mahlzeiten \\
und Unter- \\
bringung, von \\
den Bildungs- \\
einrichtungen \\
zur Verfügung \\
gestellt) \\
\end{tabular} & Gesamt & & $\begin{array}{l}\text { Eigentliche } \\
\text { Bildungs- } \\
\text { dienstleis- } \\
\text { tungen }\end{array}$ & \begin{tabular}{|c|} 
Zusätzliche \\
Dienst- \\
leistungen \\
(Transport, \\
Mahlzeiten \\
und Unter- \\
bringung, von \\
den Bildungs- \\
einrichtungen \\
zur Verfügung \\
gestellt) \\
\end{tabular} & $\begin{array}{l}\text { Forschung } \\
\text { und Entwick- } \\
\text { lung (F\&E) } \\
\text { in tertiären } \\
\text { Bildungsein- } \\
\text { richtungen }\end{array}$ & Gesamt & \\
\hline & (1) & (2) & (3) & (4) & (5) & (6) & (7) & (8) & (9) \\
\hline \multicolumn{10}{|l|}{ OECD-Länder } \\
\hline Australien & 4,26 & 0,09 & 4,35 & 0,09 & 0,95 & 0,06 & 0,62 & 1,63 & 0,13 \\
\hline Österreich & 3,47 & 0,17 & 3,64 & $\mathrm{~m}$ & 1,05 & 0,01 & 0,46 & 1,52 & $\mathrm{~m}$ \\
\hline Belgien & 4,28 & 0,12 & 4,40 & 0,15 & 0,88 & 0,03 & 0,52 & 1,44 & 0,22 \\
\hline$K^{2}$ anada $a^{1,2,3}$ & 3,66 & 0,20 & 3,86 & $\mathrm{~m}$ & 1,92 & 0,13 & 0,68 & 2,72 & 0,12 \\
\hline Chile $^{4}$ & 3,16 & 0,23 & 3,39 & $\mathrm{~m}$ & 2,27 & $x(5)$ & 0,14 & 2,41 & $\mathrm{~m}$ \\
\hline Tschechien & 2,60 & 0,22 & 2,81 & 0,05 & 0,99 & 0,01 & 0,22 & 1,23 & 0,03 \\
\hline Dänemark ${ }^{2}$ & $x(3)$ & $x(3)$ & 4,80 & $\mathrm{~m}$ & $x(8)$ & a & $x(8)$ & 1,88 & $\mathrm{~m}$ \\
\hline Estland & $x(3)$ & $x(3)$ & 3,91 & $\mathrm{~m}$ & 0,97 & $x(5)$ & 0,64 & 1,62 & $\mathrm{~m}$ \\
\hline Finnland & 3,71 & 0,43 & 4,15 & $\mathrm{~m}$ & 1,13 & a & 0,80 & 1,93 & $\mathrm{~m}$ \\
\hline Frankreich & 3,52 & 0,55 & 4,07 & 0,17 & 0,95 & 0,08 & 0,48 & 1,51 & 0,07 \\
\hline Deutschland & $\mathrm{m}$ & $\mathrm{m}$ & m & $\mathrm{m}$ & $\mathrm{m}$ & $\mathrm{m}$ & $\mathrm{m}$ & m & $\mathrm{m}$ \\
\hline Griechenland & $\mathrm{m}$ & $\mathrm{m}$ & m & $\mathrm{m}$ & $\mathrm{m}$ & $\mathrm{m}$ & $\mathrm{m}$ & m & $\mathrm{m}$ \\
\hline Ungarn ${ }^{3}$ & 2,50 & 0,30 & 2,80 & $\mathrm{~m}$ & 0,55 & 0,11 & 0,18 & 0,84 & $\mathrm{~m}$ \\
\hline Island & $x(3)$ & $x(3)$ & 4,92 & $\mathrm{n}$ & $x(8)$ & $x(8)$ & $x(8)$ & 1,23 & $\mathrm{n}$ \\
\hline Irland ${ }^{3}$ & 4,69 & 0,08 & 4,77 & 0,03 & 1,14 & $\mathrm{~m}$ & 0,43 & 1,57 & $\mathrm{~m}$ \\
\hline Israel & 4,05 & 0,21 & 4,26 & 0,29 & 1,47 & 0,19 & $\mathrm{~m}$ & 1,66 & $\mathrm{n}$ \\
\hline Italien ${ }^{3}$ & 3,12 & 0,11 & 3,23 & 0,41 & 0,61 & 0,04 & 0,34 & 0,99 & 0,14 \\
\hline$J^{\prime a p a n}{ }^{2}$ & $x(3)$ & $x(3)$ & 2,96 & 0,79 & $x(8)$ & $x(8)$ & $x(8)$ & 1,53 & 0,04 \\
\hline Korea & 3,77 & 0,46 & 4,24 & $\mathrm{~m}$ & 2,12 & 0,02 & 0,45 & 2,59 & $\mathrm{~m}$ \\
\hline Luxemburg & 3,26 & 0,24 & 3,50 & 0,06 & $\mathrm{~m}$ & $\mathrm{~m}$ & $\mathrm{~m}$ & m & $\mathrm{m}$ \\
\hline Mexiko & $x(3)$ & $x(3)$ & 3,99 & 0,19 & 1,16 & $\mathrm{~m}$ & 0,22 & 1,38 & 0,05 \\
\hline Niederlande & 4,10 & $\mathrm{n}$ & 4,10 & 0,15 & 1,09 & $\mathrm{n}$ & 0,64 & 1,74 & 0,07 \\
\hline Neuseeland & $x(3)$ & $x(3)$ & 5,08 & 0,03 & 1,34 & $x(8)$ & 0,24 & 1,58 & $\mathrm{~m}$ \\
\hline Norwegen & $x(3)$ & $x(3)$ & 5,09 & $\mathrm{~m}$ & 0,99 & 0,02 & 0,70 & 1,70 & $\mathrm{~m}$ \\
\hline Polen $^{3}$ & 3,63 & 0,03 & 3,66 & 0,22 & 1,23 & $\mathrm{n}$ & 0,24 & 1,46 & 0,04 \\
\hline Portugal $^{3}$ & 3,83 & 0,07 & 3,89 & 0,11 & 0,87 & $x(8)$ & 0,58 & 1,45 & $\mathrm{~m}$ \\
\hline Slowakei ${ }^{2}$ & 2,69 & 0,39 & 3,08 & 0,32 & 0,66 & 0,13 & 0,14 & 0,93 & 0,20 \\
\hline Slowenien & 3,65 & 0,26 & 3,91 & $\mathrm{m}$ & 1,01 & $\mathrm{n}$ & 0,26 & 1,27 & $\mathrm{~m}$ \\
\hline Spanien & 3,13 & 0,17 & 3,30 & $\mathrm{~m}$ & 0,91 & 0,05 & 0,39 & 1,35 & $\mathrm{~m}$ \\
\hline Schweden & 3,57 & 0,42 & 3,98 & $\mathrm{~m}$ & 0,82 & a & 0,94 & 1,76 & $\mathrm{~m}$ \\
\hline Schweiz ${ }^{3}$ & $x(3)$ & $x(3)$ & 4,05 & $\mathrm{~m}$ & 0,54 & $x(8)$ & 0,69 & 1,23 & $\mathrm{~m}$ \\
\hline Türkei & 2,41 & 0,10 & 2,51 & $\mathrm{~m}$ & $x(8)$ & $x(8)$ & $\mathrm{m}$ & $\mathbf{m}$ & $\mathrm{m}$ \\
\hline Vereinigtes Königreich & 4,08 & 0,71 & 4,78 & $\mathrm{~m}$ & 0,80 & 0,11 & 0,46 & 1,37 & 0,11 \\
\hline Vereinigte Staaten & 3,71 & 0,32 & 4,02 & a & 2,15 & 0,34 & 0,31 & 2,80 & a \\
\hline OECD-Durchschnitt & 3,53 & 0,24 & 3,92 & 0,18 & 1,13 & 0,06 & 0,45 & 1,61 & 0,08 \\
\hline EU21-Durchschnitt & 3,52 & 0,25 & $\mathbf{3 , 8 3}$ & 0,17 & 0,92 & 0,04 & 0,45 & 1,44 & 0,11 \\
\hline \multicolumn{10}{|l|}{ Sonstige G20-Länder } \\
\hline Argentinien & $x(3)$ & $x(3)$ & 4,67 & $\mathrm{~m}$ & $x(8)$ & $x(8)$ & $x(8)$ & 1,47 & $\mathrm{~m}$ \\
\hline Brasilien $^{3}$ & $x(3)$ & $x(3)$ & 4,33 & $\mathrm{~m}$ & 0,83 & $x(5)$ & 0,05 & 0,88 & $\mathrm{~m}$ \\
\hline China & $\mathrm{m}$ & $\mathrm{m}$ & m & $\mathrm{m}$ & $\mathrm{m}$ & $\mathrm{m}$ & $\mathrm{m}$ & $\mathbf{m}$ & $\mathrm{m}$ \\
\hline Indien & $\mathrm{m}$ & $\mathrm{m}$ & $\mathbf{m}$ & $\mathrm{m}$ & $\mathrm{m}$ & $\mathrm{m}$ & $\mathrm{m}$ & $\mathbf{m}$ & $\mathrm{m}$ \\
\hline Indonesien & $\mathrm{m}$ & $\mathrm{m}$ & m & $\mathrm{m}$ & $\mathrm{m}$ & $\mathrm{m}$ & $\mathrm{m}$ & $\mathbf{m}$ & $\mathrm{m}$ \\
\hline Russische Föderation & $x(3)$ & $x(3)$ & 2,11 & $\mathrm{~m}$ & $x(8)$ & $x(8)$ & $x(8)$ & 1,60 & $\mathrm{~m}$ \\
\hline Saudi-Arabien & $\mathrm{m}$ & $\mathrm{m}$ & $\mathbf{m}$ & $\mathrm{m}$ & $\mathrm{m}$ & $\mathrm{m}$ & $\mathrm{m}$ & $\mathbf{m}$ & $\mathrm{m}$ \\
\hline Südafrika & $\mathrm{m}$ & $\mathrm{m}$ & m & $\mathrm{m}$ & $\mathrm{m}$ & $\mathrm{m}$ & $\mathrm{m}$ & $\mathbf{m}$ & $\mathrm{m}$ \\
\hline G20-Durchschnitt & m & m & $\mathbf{m}$ & m & $\mathbf{m}$ & $\mathbf{m}$ & $\mathbf{m}$ & $\mathbf{m}$ & $\mathbf{m}$ \\
\hline
\end{tabular}

1. Referenzjahr 2009. 2. Einige Bildungsbereiche sind in anderen Bildungsbereichen enthalten. Einzelheiten s. Erläuterung von „ $x^{\prime \prime}$ in Hinweise für den Leser.

3. Nur öffentliche Ausgaben (Kanada: nur im Tertiärbereich, Italien: außer im Tertiärbereich). 4. Referenzjahr 2011.

Quelle: OECD. Argentinien: Statistikinstitut der UNESCO (World Education Indicators Programme). Hinweise s. Anhang 3 unter www.oecd.org/edu/eag.htm.

StatLink: http://dx.doi.org/10.1787/888932849635

Erläuterung der Kennzeichnung fehlender Daten s. Hinweise für den Leser. 
Tabelle B2.5

Veränderung der öffentlichen Ausgaben für Bildungseinrichtungen als Prozentsatz des BIP $(2008,2009,2010)$ Index der Veränderung der öffentlichen Ausgaben für Bildungseinrichtungen als Prozentsatz des BIP zwischen 2008 und 2010, für alle Bildungsbereiche (zu konstanten Preisen des Jahres 2010)

\begin{tabular}{|c|c|c|c|c|c|c|c|c|c|}
\hline & \multicolumn{3}{|c|}{$\begin{array}{l}\text { Veränderung der öffentlichen }{ }^{1} \\
\text { Ausgaben für Bildungseinrichtungen } \\
\text { für alle Bildungsbereiche zusammen }\end{array}$} & \multicolumn{3}{|c|}{ Veränderung des BIP } & \multicolumn{3}{|c|}{$\begin{array}{l}\text { Veränderung der Ausgaben } \\
\text { für Bildungseinrichtungen } \\
\text { als Prozentsatz des BIP }\end{array}$} \\
\hline & $\begin{array}{c}\text { Von } 2008 \\
\text { auf } 2009 \\
(2008=100)\end{array}$ & $\begin{array}{c}\text { Von } 2009 \\
\text { auf } 2010 \\
(2009=100)\end{array}$ & $\begin{array}{c}\text { Zwischen } \\
2008 \\
\text { und } 2010 \\
(2008=100)\end{array}$ & $\begin{array}{c}\text { Von } 2008 \\
\text { auf } 2009 \\
(2008=100)\end{array}$ & $\begin{array}{c}\text { Von } 2009 \\
\text { auf } 2010 \\
(2009=100)\end{array}$ & $\begin{array}{c}\text { Zwischen } \\
2008 \\
\text { und } 2010 \\
(2008=100)\end{array}$ & $\begin{array}{c}\text { Von } 2008 \\
\text { auf } 2009 \\
(2008=100)\end{array}$ & $\begin{array}{l}\text { Von } 2009 \\
\text { auf } 2010 \\
(2009=100)\end{array}$ & $\begin{array}{c}\text { Zwischen } \\
2008 \\
\text { und } 2010 \\
(2008=100)\end{array}$ \\
\hline & (1) & (2) & (3) & (4) & (5) & (6) & (7) & (8) & (9) \\
\hline \multicolumn{10}{|l|}{ OECD-Länder } \\
\hline Australien & 116 & 106 & 124 & 101 & 103 & 104 & 115 & 104 & 119 \\
\hline Österreich & 105 & 100 & 105 & 96 & 103 & 98 & 109 & 97 & 107 \\
\hline Belgien & 99 & 102 & 101 & 97 & 103 & 100 & 102 & 100 & 102 \\
\hline Kanada & 109 & 101 & 110 & 97 & 103 & 100 & 112 & 98 & 109 \\
\hline Chile & $\mathrm{m}$ & $\mathrm{m}$ & m & $\mathrm{m}$ & $\mathrm{m}$ & m & $\mathrm{m}$ & $\mathrm{m}$ & m \\
\hline Tschechien & 106 & 100 & 107 & 95 & 103 & 98 & 112 & 97 & 109 \\
\hline Dänemark & 110 & 102 & 112 & 95 & 101 & 96 & 116 & 100 & 116 \\
\hline Estland & 95 & 95 & 90 & 86 & 103 & 88 & 110 & 93 & 102 \\
\hline Finnland & 102 & 104 & 106 & 92 & 103 & 95 & 110 & 101 & 112 \\
\hline Frankreich & 102 & 101 & 103 & 97 & 101 & 98 & 105 & 100 & 104 \\
\hline Deutschland & 104 & $\mathrm{~m}$ & m & 95 & 104 & 99 & 110 & $\mathrm{~m}$ & m \\
\hline Griechenland & $\mathrm{m}$ & $\mathrm{m}$ & m & 97 & 95 & 92 & $\mathrm{~m}$ & $\mathrm{~m}$ & m \\
\hline Ungarn & 93 & 97 & 90 & 93 & 101 & 94 & 100 & 95 & 95 \\
\hline Island & 96 & 92 & 88 & 93 & 96 & 90 & 103 & 95 & 98 \\
\hline Irland & 107 & 99 & 107 & 94 & 100 & 93 & 115 & 100 & 114 \\
\hline Israel & 100 & 107 & 107 & 101 & 105 & 106 & 99 & 102 & 101 \\
\hline Italien & 96 & 97 & 93 & 95 & 101 & 96 & 101 & 95 & 96 \\
\hline Japan & 101 & 104 & 105 & 93 & 103 & 96 & 109 & 101 & 110 \\
\hline Korea & 107 & 104 & 111 & 100 & 106 & 107 & 106 & 98 & 104 \\
\hline Luxemburg & $\mathrm{m}$ & $\mathrm{m}$ & $\mathbf{m}$ & 94 & 99 & 94 & $\mathrm{~m}$ & $\mathrm{~m}$ & $\mathbf{m}$ \\
\hline Mexiko & 99 & 107 & 107 & 94 & 106 & 99 & 106 & 102 & 108 \\
\hline Niederlande & 107 & 102 & 108 & 96 & 102 & 98 & 111 & 100 & 111 \\
\hline Neuseeland & 114 & 100 & 113 & 101 & 101 & 102 & 113 & 99 & 111 \\
\hline Norwegen & 106 & 99 & 105 & 98 & 102 & 100 & 108 & 97 & 105 \\
\hline Polen & 102 & 103 & 105 & 102 & 104 & 106 & 100 & 99 & 99 \\
\hline Portugal & 113 & 99 & 112 & 97 & 101 & 98 & 116 & 98 & 114 \\
\hline Slowakei & 108 & 108 & 116 & 95 & 104 & 99 & 113 & 104 & 118 \\
\hline Slowenien & 100 & 101 & 101 & 91 & 102 & 93 & 110 & 99 & 108 \\
\hline Spanien & 105 & 98 & 103 & 96 & 100 & 96 & 109 & 99 & 107 \\
\hline Schweden & 101 & 102 & 104 & 95 & 107 & 101 & 107 & 96 & 103 \\
\hline Schweiz & 107 & 101 & 108 & 99 & 107 & 105 & 109 & 95 & 103 \\
\hline Türkei & $\mathrm{m}$ & $\mathrm{m}$ & m & 95 & 109 & 104 & $\mathrm{~m}$ & $\mathrm{~m}$ & m \\
\hline Vereinigtes Königreich & 105 & 102 & 108 & 96 & 102 & 98 & 110 & 100 & 110 \\
\hline Vereinigte Staaten & 101 & 98 & 99 & 97 & 103 & 99 & 105 & 95 & 100 \\
\hline OECD-Durchschnitt & 104 & 101 & 105 & 96 & 103 & 98 & 108 & 99 & 107 \\
\hline EU21-Durchschnitt & 103 & 101 & 104 & 95 & 102 & 97 & 109 & 98 & 107 \\
\hline \multicolumn{10}{|l|}{ Sonstige G20-Länder } \\
\hline Argentinien & $\mathrm{m}$ & $\mathrm{m}$ & m & $\mathrm{m}$ & $\mathrm{m}$ & m & $\mathrm{m}$ & $\mathrm{m}$ & $\mathbf{m}$ \\
\hline Brasilien & 102 & 111 & 113 & $\mathrm{~m}$ & $\mathrm{~m}$ & m & $\mathrm{m}$ & $\mathrm{m}$ & m \\
\hline China & $\mathrm{m}$ & $\mathrm{m}$ & m & $\mathrm{m}$ & $\mathrm{m}$ & m & $\mathrm{m}$ & $\mathrm{m}$ & m \\
\hline Indien & $\mathrm{m}$ & $\mathrm{m}$ & m & $\mathrm{m}$ & $\mathrm{m}$ & m & $\mathrm{m}$ & $\mathrm{m}$ & m \\
\hline Indonesien & $\mathrm{m}$ & $\mathrm{m}$ & $\mathbf{m}$ & $\mathrm{m}$ & $\mathrm{m}$ & m & $\mathrm{m}$ & $\mathrm{m}$ & $\mathbf{m}$ \\
\hline Russische Föderation & 105 & 91 & 96 & 92 & 104 & 96 & 114 & 87 & 100 \\
\hline Saudi-Arabien & $\mathrm{m}$ & $\mathrm{m}$ & m & $\mathrm{m}$ & $\mathrm{m}$ & m & $\mathrm{m}$ & $\mathrm{m}$ & m \\
\hline Südafrika & $\mathrm{m}$ & $\mathrm{m}$ & m & $\mathrm{m}$ & $\mathrm{m}$ & m & $\mathrm{m}$ & $\mathrm{m}$ & m \\
\hline G20-Durchschnitt & m & $\mathbf{m}$ & $\mathbf{m}$ & m & m & m & $\mathbf{m}$ & m & $m$ \\
\hline
\end{tabular}

1. Ohne öffentliche Subventionen, die Bildungseinrichtungen zuzurechnen sind.

Quelle: OECD. Hinweise s. Anhang 3 unter www.oecd.org/edu/eag.htm. StatLink: http://dx.doi.org/10.1787/888932849654

Erläuterung der Kennzeichnung fehlender Daten s. Hinweise für den Leser. 



\section{Wie groß ist der Anteil der öffentlichen und der privaten Ausgaben im Bildungswesen?}

Im Durchschnitt aller OECD-Länder stammen 84 Prozent aller Mittel für Bildungseinrichtungen aus öffentlichen Quellen.

Durchschnittlich stammen rund 92 Prozent der Mittel für Bildungseinrichtungen im Primar-, Sekundar- und postsekundaren, nicht tertiären Bereich in den OECDLändern aus öffentlichen Quellen, und nur in Chile, Korea und dem Vereinigten Königreich liegt dieser Anteil unter 8o Prozent.

Die Bildungseinrichtungen des Tertiärbereichs und in geringerem Ausmaß die des Elementarbereichs werden am stärksten aus privaten Mitteln finanziert: mit 32 Prozent bzw. I8 Prozent. In allen Ländern mit vergleichbaren Daten stieg zwischen 2000 und 2010 der Anteil der öffentlichen Ausgaben für Bildungseinrichtungen in allen Bildungsbereichen zusammen. Da jedoch immer mehr private Haushalte einen Teil der Bildungskosten übernehmen, nahm die private Finanzierung in mehr als drei Viertel der Länder sogar noch stärker zu.

\section{Abbildung B3.1}

Anteil der privaten Ausgaben für Bildungseinrichtungen (2010)

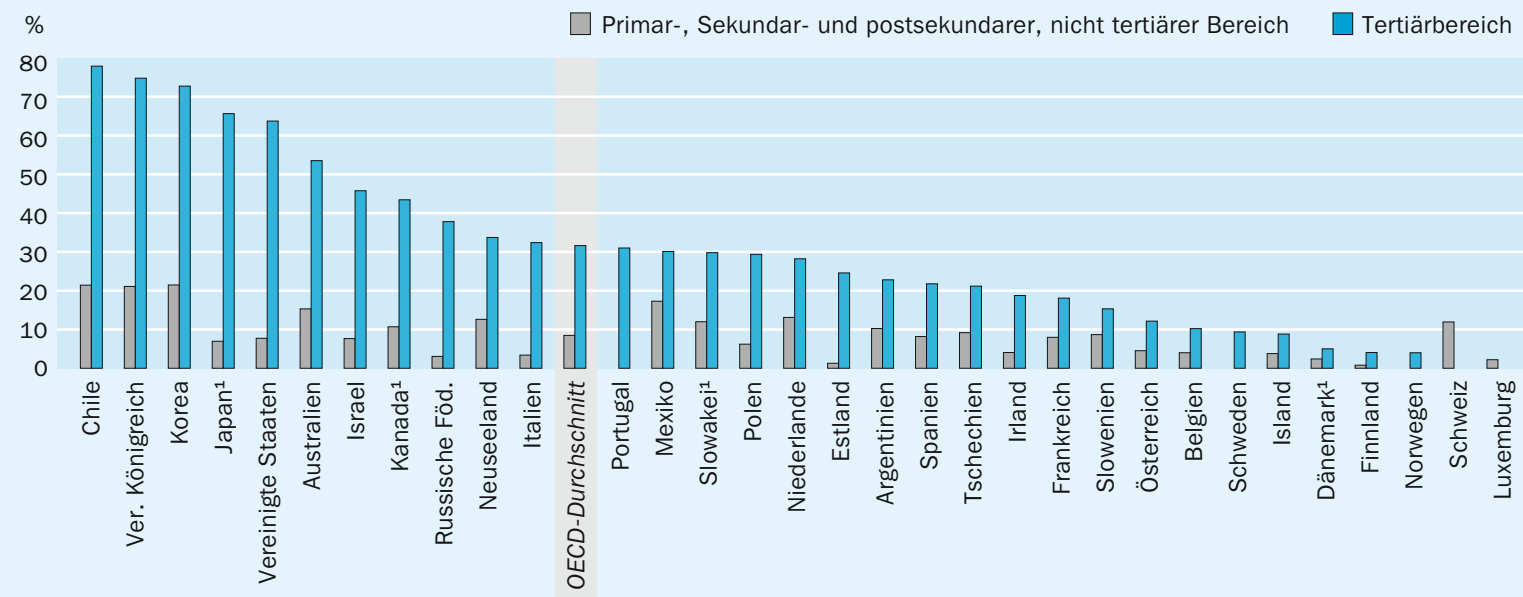

1. Einige Bildungsbereiche sind in anderen Bildungsbereichen enthalten. Einzelheiten s. Erläuterung von „ $x$ “ in Hinweise für den Leser. Anordnung der Länder in absteigender Reihenfolge des Anteils privater Ausgaben für Bildungseinrichtungen im Tertiärbereich. Quelle: OECD. Argentinien: Statistikinstitut der UNESCO (World Education Indicators Programme). Tabellen B3.2a und B3.2b. Hinweise s. Anhang 3 unter www.oecd.org/edu/eag.htm. StatLink: http://dx.doi.org/10.1787/888932846956

Erläuterung der Abbildung: Die Abbildung zeigt die privaten Ausgaben für Bildungseinrichtungen als Prozentsatz der Gesamtausgaben für Bildungseinrichtungen. Darin enthalten sind sämtliche Beträge, die über private Quellen an Bildungseinrichtungen fließen, einschließlich staatlich subventionierter Zahlungen privater Haushalte, von privaten Haushalten bezahlter Schul-/Studiengebühren sowie anderer privater Ausgaben (z. B. für Internatsunterbringung), die den Bildungseinrichtungen zukommen. 


\section{Kontext}

Heute nehmen mehr Menschen an einer größeren Vielfalt von Bildungsgängen als je zuvor teil, die von immer mehr Anbietern angeboten werden. Deshalb wird die Antwort auf die Frage, wer das Streben des Einzelnen nach besserer Bildung unterstützen soll, der Staat oder die Bildungsteilnehmer selbst, immer wichtiger. In der gegenwärtigen wirtschaftlichen Situation haben viele Länder Schwierigkeiten, die nötigen Mittel für eine alleinige Finanzierung der gestiegenen Nachfrage nach Bildung durch die öffentliche Hand aufzubringen. Zudem fordern manche Politiker, dass diejenigen, die am stärksten von Bildung profitieren, nämlich diejenigen, die Bildungsangebote wahrnehmen, auch zumindest einen Teil der Kosten tragen sollten. Zwar stellt die Finanzierung durch öffentliche Mittel noch immer einen sehr großen Teil der Bildungsfinanzierung dar, aber private Mittel rücken zunehmend in den Vordergrund.

In vielen OECD-Ländern ist das Verhältnis von öffentlichen und privaten Mitteln bei der Bildungsfinanzierung ein wichtiges politisches Thema, insbesondere in Bezug auf den Elementar- und Tertiärbereich, wo eine vollständige oder fast vollständige Finanzierung durch öffentliche Mittel weniger üblich ist. In diesen Bildungsbereichen stammt die private Finanzierung vor allem von den privaten Haushalten, was Befürchtungen hinsichtlich der Chancengleichheit beim Zugang zu Bildung aufwirft. Diese Debatte wird besonders im Hinblick auf die Finanzierung des Tertiärbereichs intensiv geführt. Einige Akteure haben Bedenken, dass sich das Verhältnis zwischen öffentlicher und privater Finanzierung so stark verschieben könnte, dass dadurch potenzielle Studierende von der Aufnahme eines Studiums im Tertiärbereich abgehalten werden. Andere meinen, die Länder sollten die öffentlichen Unterstützungsleistungen für Studierende signifikant erhöhen, während sich wiederum andere dafür einsetzen, dass mehr Mittel von privaten Unternehmen zur Finanzierung des Tertiärbereichs genutzt werden. Im Gegensatz dazu gilt der Besuch des Primar-, Sekundar- und postsekundaren, nicht tertiären Bildungsbereichs, für den größtenteils Schulpflicht besteht, normalerweise als öffentliches Gut, und er wird daher hauptsächlich von der öffentlichen Hand finanziert.

\section{Weitere wichtige Ergebnisse}

Mit öffentlichen Mitteln werden hauptsächlich staatliche Bildungseinrichtungen finanziert, aber auch private Bildungseinrichtungen, jedoch in unterschiedlichem Ausmaß. Im Durchschnitt aller OECD-Länder sind für alle Bildungsbereiche zusammen die öffentlichen Ausgaben für öffentliche Bildungseinrichtungen pro Schüler/Studierenden mehr als doppelt so hoch wie die öffentlichen Ausgaben für private Bildungseinrichtungen. Das Verhältnis reicht jedoch von weniger als dem Doppelten im Primar-, Sekundar- und postsekundaren, nicht tertiären Bereich (Faktor I,7) sowie dem Elementarbereich (Faktor I,8) bis zum Dreifachen (Faktor 3,0) im Tertiärbereich.

Die Länder mit den niedrigsten öffentlichen Ausgaben pro Studierenden an öffentlichen und privaten Bildungseinrichtungen des Tertiärbereichs haben auch die geringste Anzahl an Studierenden an öffentlichen Bildungseinrichtungen im Tertiärbereich, mit Ausnahme von Polen.

In den meisten Ländern mit verfügbaren Daten wird der größte Teil der privaten Ausgaben für den Tertiärbereich von den privaten Haushalten getragen. Ausnahmen sind hier Belgien, 
Kanada, Österreich, Schweden, die Slowakei und Tschechien, wo die Ausgaben anderer privater Einheiten (z. B. privater Unternehmen und gemeinnütziger Organisationen) höher als die Ausgaben privater Haushalte sind, hauptsächlich weil die hier von den Bildungseinrichtungen des Tertiärbereichs erhobenen Studiengebühren niedrig oder vernachlässigbar sind (mit Ausnahme Kanadas).

\section{Entwicklungstendenzen}

Zwischen 1995 und 2010 ging im Durchschnitt der OECD-Länder, für die Trenddaten für alle Jahre verfügbar sind, der Anteil der öffentlichen Finanzierung von Bildungseinrichtungen im Tertiärbereich von 77 Prozent im Jahr 1995 auf 76 Prozent im Jahr 2000, 7I Prozent im Jahr 2005 und dann auf 68 Prozent im Jahr 2010 zurück (Tab. B3.3). Diese Entwicklung wurde hauptsächlich durch die nicht europäischen Länder beeinflusst, in denen die Studiengebühren im Allgemeinen höher sind und Unternehmen durch die Gewährung von Zuschüssen stärker in die Finanzierung von Bildungseinrichtungen des Tertiärbereichs eingebunden sind.

Zwischen 2000 und 2010 ließ sich in mehr als drei Viertel der Länder (20 von 24 Ländern) mit vergleichbaren Daten eine Steigerung des Anteils der privaten Finanzierung im Tertiärbereich beobachten. Im Durchschnitt stieg dieser Anteil um 7 Prozentpunkte und in Italien, Mexiko, Portugal, der Slowakei und dem Vereinigten Königreich um mehr als 9 Prozentpunkte (Tab. B3.2b). Auch im Primar-, Sekundar- und postsekundaren, nicht tertiären Bereich sowie in allen Bildungsbereichen zusammen stieg im Durchschnitt der OECD-Länder der Anteil der privaten Finanzierung, am stärksten in der Slowakei und dem Vereinigten Königreich (Tab. B3.2a).

\section{Analyse und Interpretationen}

Die Anteile öffentlicher und privater Ausgaben für Bildungseinrichtungen In den OECD-Ländern werden Bildungseinrichtungen immer noch überwiegend aus öffentlichen Mitteln finanziert, obwohl es im Tertiärbereich einen erheblichen und zunehmenden Anteil privater Finanzierung gibt. Im Durchschnitt aller OECD-Länder stammen 84 Prozent aller Mittel für Bildungseinrichtungen direkt aus öffentlichen Quellen, I6 Prozent aus privaten Quellen (Tab. B3.I).

Der Anteil der öffentlichen und der privaten Finanzierung variiert jedoch erheblich zwischen den einzelnen Ländern. Bei einem Vergleich der Ausgaben über alle Bildungsbereiche hinweg liegt der Anteil der privaten Finanzierung in Israel, Kanada und Mexiko bei mehr als I9 Prozent, in Australien, Japan, dem Vereinigten Königreich und den Vereinigten Staaten bei mehr als 25 Prozent und in Chile und Korea bei mehr als 35 Prozent. Im Gegensatz hierzu werden in Finnland und Schweden weniger als 3 Prozent der Ausgaben für Bildungseinrichtungen aus privaten Mitteln finanziert (2,4 Prozent bzw. 2,5 Prozent) (Tab. B3.I). 
Nimmt man alle Bildungsbereiche zusammen, sind die privaten Ausgaben für Bildung zwischen 2000 und 2010 gestiegen, und in den meisten Ländern stiegen auch die privaten Ausgaben als Prozentsatz der Gesamtausgaben für Bildungseinrichtungen. Hierdurch verringerte sich der Anteil öffentlicher Mittel für Bildungseinrichtungen in Italien, Kanada, Mexiko und Portugal um mindestens 4 Prozentpunkte und in der Slowakei und dem Vereinigten Königreich um mehr als Io Prozentpunkte. Dieser Rückgang ist hauptsächlich auf einen signifikanten Anstieg der privaten Ausgaben im gleichen Zeitraum zurückzuführen. In Portugal und dem Vereinigten Königreich beispielsweise stiegen die von Bildungseinrichtungen des Tertiärbereichs erhobenen Studiengebühren beträchtlich (Tab. B3.I).

Der Rückgang des Anteils der öffentlichen Ausgaben an den Gesamtausgaben für Bildungseinrichtungen (und daraus resultierende Erhöhungen des Anteils der privaten Ausgaben) wurde jedoch im Allgemeinen nicht durch eine (reale) Kürzung der öffentlichen Ausgaben für Bildungseinrichtungen begleitet (Tab. B3.I). Tatsächlich war sogar in vielen OECD-Ländern mit dem höchsten Anstieg der privaten Finanzierung auch der höchste Anstieg der öffentlichen Finanzierung zu beobachten. Dies deutet darauf hin, dass eine verstärkte private Finanzierung tendenziell die öffentlichen Mittel nicht ersetzt, sondern eher ergänzt. Der Anteil der privaten Ausgaben für Bildungseinrichtungen variiert jedoch je nach Land und Bildungsbereich.

\section{Die Anteile öffentlicher und privater Ausgaben für Bildungseinrichtungen} im Primar-, Sekundar- und postsekundaren, nicht tertiären Bereich

Die öffentlichen Haushalte sind in allen Ländern im Primar-, Sekundar- und postsekundaren, nicht tertiären Bildungsbereich die wichtigste Finanzquelle. Mit Ausnahme von Australien, Chile, Kanada, Korea, Mexiko, Neuseeland, den Niederlanden, der Schweiz, der Slowakei und dem Vereinigten Königreich stammen weniger als ıo Prozent der Mittel für diese Bildungsbereiche aus privaten Quellen (Tab. B3.2a und Abb. B3.2). In den meisten Ländern wird in diesen Bereichen der größte Teil der privaten Ausgaben von den privaten Haushalten getätigt und betrifft hauptsächlich Schul-/Studiengebühren. In den Niederlanden und der Schweiz hingegen machen Beiträge privater Unternehmen zur dualen Berufsausbildung den Großteil der privaten Ausgaben im Sekundarbereich II und im postsekundaren, nicht tertiären Bereich aus (s. Kasten B3.I in Bildung auf einen Blick 2011).

Zwischen 2000 und 2010 ging in mehr als zwei Drittel der Länder (I7 von 25 Ländern) mit vergleichbaren Daten der Anteil der öffentlichen Finanzierung im Primar-, Sekundar- und postsekundaren, nicht tertiären Bereich zurück. Jedoch stieg der entsprechende private Anteil nur in vier dieser Länder um mindestens 3 Prozentpunkte - in Kanada von 7,6 auf Io,7 Prozent, in Mexiko von I3,9 auf 17,3 Prozent, in der Slowakei von 2,4 auf I2,O Prozent und im Vereinigten Königreich von II,3 auf 2I,3 Prozent. In den anderen Ländern betrug die Verlagerung in die entgegengesetzte Richtung, also hin zur öffentlichen Finanzierung, zwischen 2000 und 2010 nur in Japan mehr als 3 Prozentpunkte (von Io, 2 Prozent auf 7 Prozent). Trotz dieser Unterschiede stiegen die öffentlichen Ausgaben für Bildungseinrichtungen im Primar-, Sekundar- und postsekundaren, nicht tertiären Bereich zwischen 2000 und 2010 in allen Ländern mit vergleichbaren Daten (Tab. B3.2a). 
Anteile öffentlicher und privater Ausgaben für Bildungseinrichtungen (2010)

Nach Bildungsbereich

Alle privaten Quellen, einschließlich Subventionen, die aus öffentlichen Quellen finanzierten Zahlungen an Bildungseinrichtungen zuzurechnen sind

$\square$ Ausgaben anderer privater Einheiten

$\square$ Ausgaben privater Haushalte

$\square$ Öffentliche Ausgaben für Bildungseinrichtungen
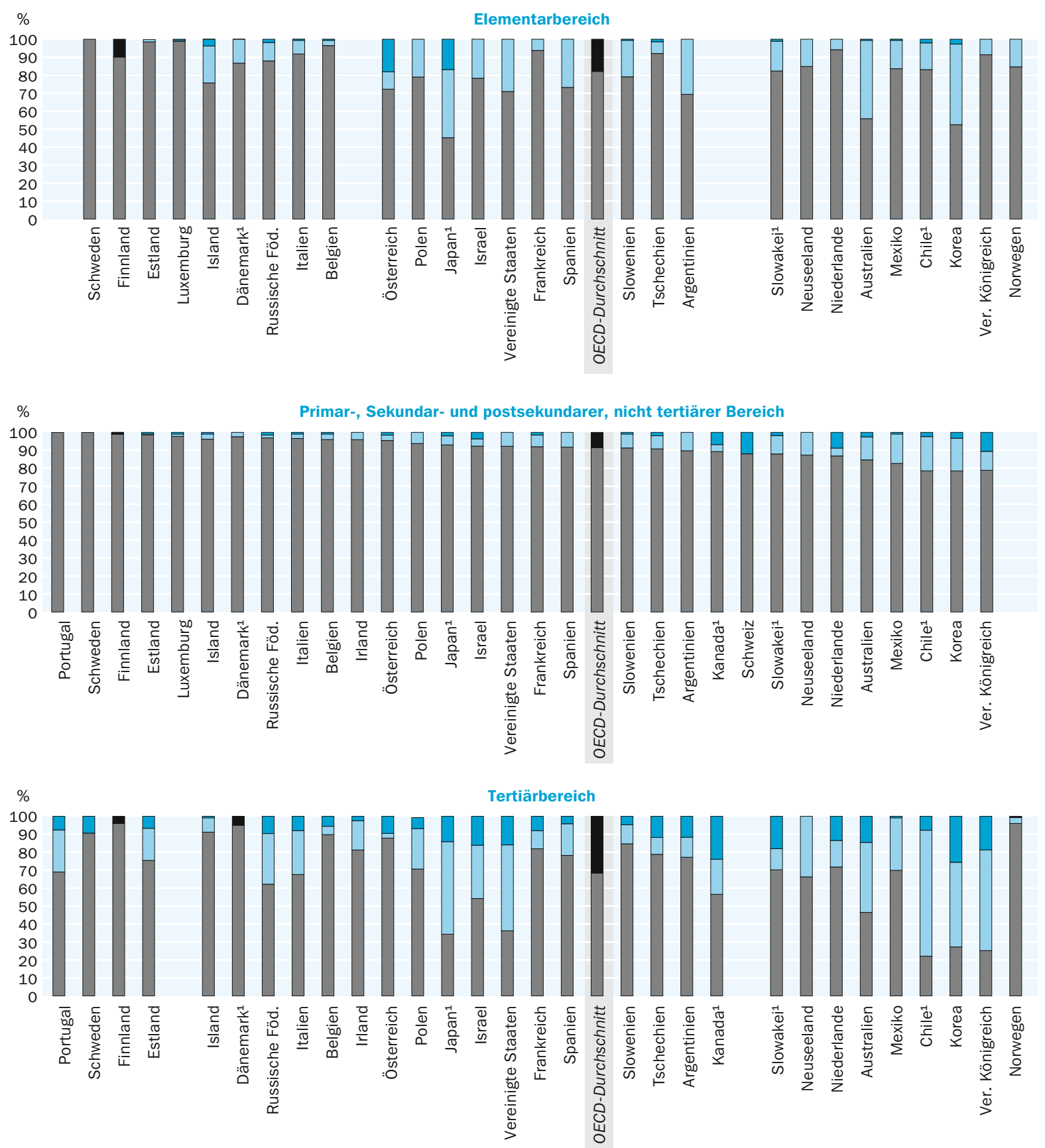

1. Einige Bildungsbereiche sind in anderen Bildungsbereichen enthalten. Einzelheiten s. Erläuterung von „X“ in Hinweise für den Leser.

Anordnung der Länder in absteigender Reihenfolge des Anteils der öffentlichen Ausgaben für Bildungseinrichtungen im Primar, Sekundar- und postsekundaren, nicht tertiären Bereich.

Quelle: OECD. Argentinien: Statistikinstitut der UNESCO (World Education Indicators Programme). Tabellen B3.2a und B3.2b.

Hinweise s. Anhang 3 unter www.oecd.org/edu/eag.htm. StatLink: http://dx.doi.org/10.1787/888932846975 


\section{Die Anteile öffentlicher und privater Ausgaben für Bildungs- einrichtungen im Tertiärbereich}

Im Tertiärbereich deuten die hohen privaten Erträge (s. Indikator A7) darauf hin, dass eine stärkere Beteiligung des Einzelnen und anderer privater Einheiten an den Kosten der (Aus-)Bildung gerechtfertigt sein könnte, solange gewährleistet wird, dass Studierenden unabhängig von ihren wirtschaftlichen Verhältnissen Finanzierungsmöglichkeiten zur Verfügung stehen (s. Indikator B5). In allen Ländern ist der Anteil privater Mittel an der Bildungsfinanzierung im Tertiärbereich weitaus höher (durchschnittlich 32 Prozent der Gesamtausgaben) als im Primar-, Sekundar- und postsekundaren, nicht tertiären Bereich (Tab. B3.2a und B3.2b).

Der Anteil der Ausgaben für Bildungseinrichtungen im Tertiärbereich, der von Einzelnen, Unternehmen und anderen privaten Einheiten getragen wird, einschließlich staatlich subventionierter privater Zahlungen, reicht von höchstens 5 Prozent in Dänemark, Finnland und Norwegen (wo die von den Bildungseinrichtungen im Tertiärbereich erhobenen Studiengebühren niedrig oder vernachlässigbar sind) über mehr als 40 Prozent in Australien, Israel, Japan, Kanada und den Vereinigten Staaten bis zu mehr als 7o Prozent in Chile, Korea und dem Vereinigten Königreich (Abb. B3.2 und Tab. B3.2b). Von diesen Ländern sind in Korea und dem Vereinigten Königreich die meisten Studierenden an privaten Bildungseinrichtungen eingeschrieben (rund 8o Prozent an privaten Hochschulen in Korea, Ioo Prozent an staatlich subventionierten privaten Einrichtungen im Vereinigten Königreich), und die Bildungseinrichtungen finanzieren sich hauptsächlich über die Studiengebühren (zu mehr als 70 Prozent in Korea und mehr als 50 Prozent im Vereinigten Königreich).

Die Beiträge anderer privater Einheiten als der privaten Haushalte zur Finanzierung von Bildungseinrichtungen sind im Durchschnitt aller OECD-Länder im Tertiärbereich höher als in anderen Bildungsbereichen. In Australien, Israel, Japan, Kanada, Korea, den Niederlanden, Österreich, Schweden, der Slowakei, Tschechien, dem Vereinigten Königreich und den Vereinigten Staaten werden mindestens 9 Prozent der Ausgaben für Bildungseinrichtungen im Tertiärbereich von anderen privaten Einheiten als den privaten Haushalten aufgebracht. In Schweden fließen diese Beiträge größtenteils in die finanzielle Förderung von Forschung und Entwicklung.

In vielen OECD-Ländern spiegelt die wachsende Teilnahme an Studiengängen im Tertiärbereich (s. Indikator $\mathrm{Cr}$ ) eine starke individuelle und gesellschaftliche Nachfrage wider. Höhere Studierendenzahlen gingen Hand in Hand mit einer Erhöhung der Investitionen, sowohl mit Mitteln aus öffentlichen als auch aus privaten Quellen, und führten zu einer Verschiebung des Verhältnisses von öffentlicher und privater Finanzierung. Im Durchschnitt der OECD-Länder, für die Trenddaten für alle Referenzjahre verfügbar sind, ging der Anteil der öffentlichen Finanzierung von Bildungseinrichtungen im Tertiärbereich leicht von 77 Prozent im Jahr 1995 auf 76 Prozent im Jahr 2000 und dann stärker auf 7I Prozent im Jahr 2005 und 68 Prozent im Jahr 2010 zurück. Diese Entwicklung ist hauptsächlich in den nicht europäischen Ländern zu beobachten, in denen die Studiengebühren im Allgemeinen höher sind und Unternehmen größtenteils durch die Gewährung von Zuschüssen an Bildungseinrichtungen des Tertiärbereichs stärker in deren Finanzierung eingebunden sind (Tab. B3.3, Abb. B3.3 und Indikator B5). 


\section{Abbildung B3.3}

Anteil der privaten Ausgaben für Bildungseinrichtungen im Tertiärbereich (2000, 2005 und 2010) und Veränderung des Anteils der privaten Ausgaben zwischen 2000 und 2010 (in Prozentpunkten)
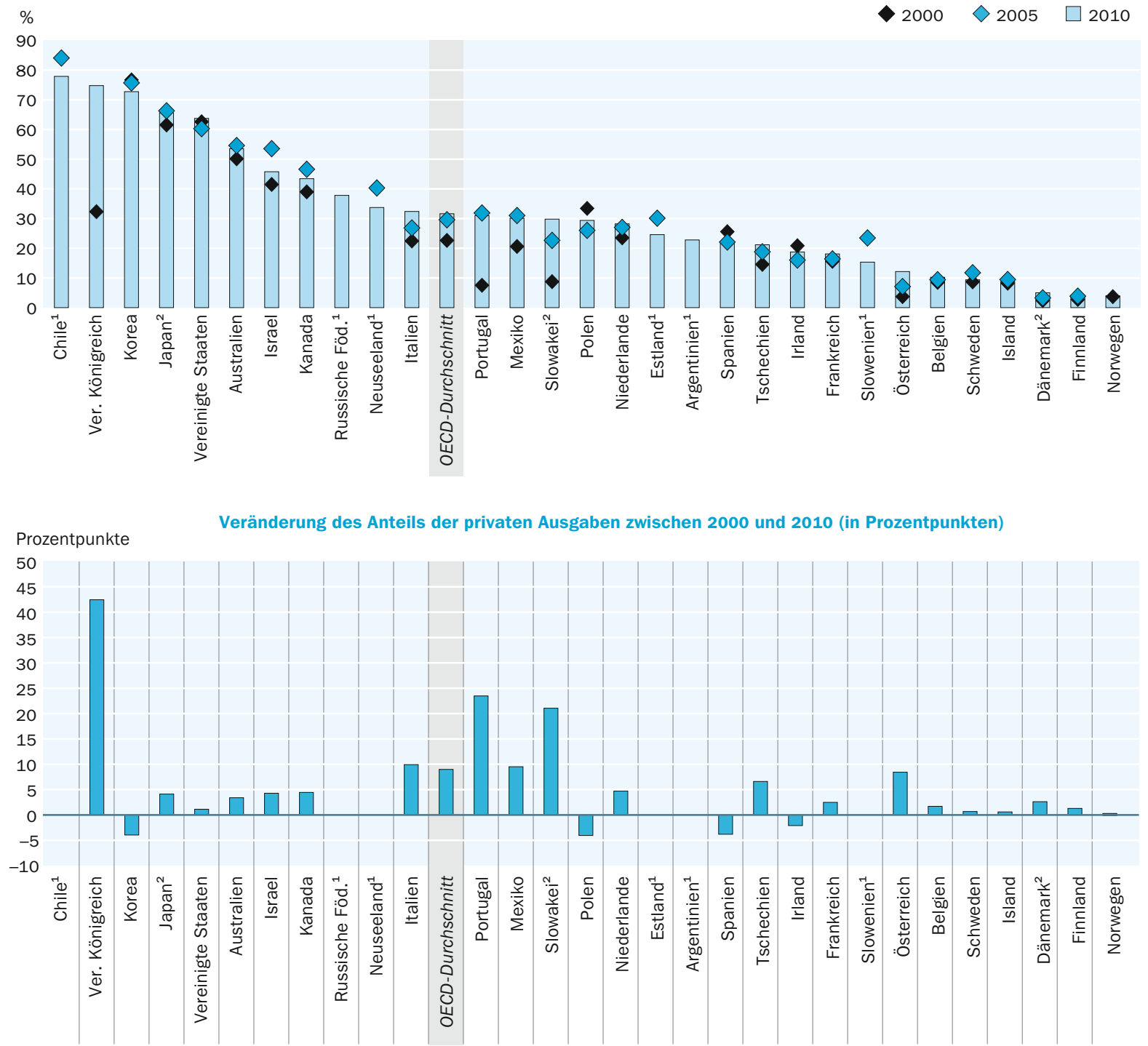

1. Die Veränderung zwischen 2000 und 2010 konnte nicht berechnet werden, da kein Wert für 2000 vorliegt. 2. Einige Bildungsbereiche sind in anderen Bildungsbereichen enthalten. Einzelheiten s. Erläuterung von „x“ in Hinweise für den Leser.

Anordnung der Länder in absteigender Reihenfolge des Anteils der privaten Ausgaben für Bildungseinrichtungen im Jahr 2010.

Quelle: OECD. Argentinien: Statistikinstitut der UNESCO (World Education Indicators Programme). Tabelle B3.3.

Hinweise s. Anhang 3 unter www.oecd.org/edu/eag.htm. StatLink: http://dx.doi.org/10.1787/888932846994

In 20 der 24 Länder mit vergleichbaren Daten für 2000 und 2010 stieg der Anteil der privaten Finanzierung im Tertiärbereich. Gleichermaßen stieg in II der 20 Länder mit vergleichbaren Daten für 1995 und 2010 der Anteil der privaten Bildungsausgaben im Tertiärbereich während dieses Zeitraums um mindestens 3 Prozentpunkte. Dieser Anstieg betrug in Australien, Italien, Portugal und der Slowakei mehr als Io Prozentpunkte und im Vereinigten Königreich mehr als 50 Prozentpunkte. In Australien ist dieser Anstieg hauptsächlich auf Änderungen des 1997 eingeführten Higher Education Contribution Scheme/Higher Education Loan Programme (HECS/HELP) zurückzuführen. Im Vereinigten Königreich ist dieser sehr starke Anstieg das Ergebnis schrittweiser 
Erhöhungen der Studiengebühren im Verlauf des letzten Jahrzehnts (weitere Informationen s. Indikator B5 und Anhang 3).

Nur in Irland und Tschechien - und in geringerem Ausmaß in Norwegen und Spanien - kam es zwischen 1995 und 2010 zu einem signifikanten Rückgang des Anteils der privaten Ausgaben für Bildungseinrichtungen im Tertiärbereich (Tab. B3.3 und Abb. B3.3). In Irland wurden die Studiengebühren in Studiengängen, die zu einem ersten Abschluss im Tertiärbereich führen, während des letzten Jahrzehnts schrittweise abgeschafft, was zu einem Rückgang der privaten Ausgaben in diesem Bereich führte.

Die privaten Ausgaben für Bildungseinrichtungen stiegen zwischen 2000 und $2010 \mathrm{im}$ Allgemeinen stärker als die öffentlichen Ausgaben. Dennoch stiegen auch die öffentlichen Ausgaben im Tertiärbereich in allen Ländern mit verfügbaren Vergleichsdaten für 2000 und 2010, und zwar unabhängig von den Veränderungen bei den privaten Ausgaben (Tab. B3.2b). 5 der 9 Länder, in denen die privaten Ausgaben während dieses Zeitraums am stärksten anstiegen (Mexiko, Österreich, Polen, die Slowakei und Tschechien), gehören auch zu den ıo Ländern, in denen die öffentlichen Ausgaben am stärksten anstiegen (Tab. B3.2b).

\section{Öffentliche Ausgaben für Bildungseinrichtungen pro Schüler/ Studierenden nach Art der Bildungseinrichtung}

Die Höhe der öffentlichen Ausgaben zeigt teilweise den Stellenwert, den einzelne Länder der Bildung einräumen (s. Indikatoren B2 und B4). Öffentliche Mittel fließen selbstverständlich in erster Linie in öffentliche Bildungseinrichtungen, aber in einigen Fällen fließt auch ein signifikanter Anteil der öffentlichen Mittel in private Bildungseinrichtungen.

Tabelle B3.4 zeigt die öffentlichen Mittel für Bildungseinrichtungen im Verhältnis zur Größe des jeweiligen Bildungssystems, mit dem Schwerpunkt auf den öffentlichen Ausgaben pro Schüler/Studierenden für öffentliche und private Bildungseinrichtungen (private Mittel werden in Tabelle B3.4 nicht berücksichtigt, obwohl sie in einigen Ländern einen signifikanten Anteil der Finanzmittel für Bildungseinrichtungen, besonders im Tertiärbereich, darstellen). Dies kann somit als ergänzende Information zu den öffentlichen Ausgaben im Verhältnis zum BIP betrachtet werden (s. Indikator B2).

Im Durchschnitt aller OECD-Länder sind für alle Bildungsbereiche zusammen die öffentlichen Ausgaben für öffentliche Bildungseinrichtungen pro Schüler/Studierenden fast doppelt so hoch wie die öffentlichen Ausgaben für private Bildungseinrichtungen pro Schüler/Studierenden (8.382 US-Dollar gegenüber 4.435 US-Dollar). Die Unterschiede variieren jedoch in den einzelnen Bildungsbereichen. Im Elementarbereich sind die öffentlichen Ausgaben für öffentliche Bildungseinrichtungen pro Kind rund doppelt so hoch wie für private Bildungseinrichtungen (6.275 US-Dollar gegenüber 3.494 US-Dollar). Das gilt auch für den Primar-, Sekundar- und postsekundaren, nicht tertiären Bereich (8.4I2 US-Dollar gegenüber 5.029 US-Dollar). Im Tertiärbereich sind die öffentlichen Ausgaben pro Studierenden für öffentliche Bildungseinrichtungen dreimal so hoch wie für private Bildungseinrichtungen (II.382 US-Dollar gegenüber 3.826 US-Dollar). 
Im Elementarbereich liegen in den OECD-Ländern die öffentlichen Ausgaben pro Kind sowohl für öffentliche als auch für private Bildungseinrichtungen bei durchschnittlich 5.643 US-Dollar, reichen jedoch von I.906 US-Dollar in Mexiko bis zu mehr als 20.000 US-Dollar in Luxemburg. Die öffentlichen Ausgaben pro Kind sind in der Regel bei öffentlichen Bildungseinrichtungen höher als bei privaten Bildungseinrichtungen, aber in der Regel besuchen weniger Kinder private Bildungseinrichtungen. So sind beispielsweise in Mexiko und den Niederlanden die öffentlichen Ausgaben pro Kind für private Bildungseinrichtungen verschwindend niedrig, und ein verhältnismäßig kleiner Teil der Kinder besucht private Bildungseinrichtungen. Im Gegensatz dazu besuchen fast alle Kinder in Neuseeland private Einrichtungen, und die öffentlichen Ausgaben pro Kind in privaten Einrichtungen liegen über dem Durchschnitt ( 9.892 USDollar) (Tab. B3.4 und C2.2).

Im Primar-, Sekundar- und postsekundaren, nicht tertiären Bereich (den Bereichen mit dem höchsten Anteil öffentlicher Mittel bei der Finanzierung, Tab. B3.2a) liegen die öffentlichen Ausgaben pro Schüler sowohl für öffentliche als auch private Bildungseinrichtungen im Durchschnitt der OECD-Länder bei 7.705 US-Dollar, variieren aber von 2.019 US-Dollar in der Türkei bis zu mehr als I0.000 US-Dollar in Dänemark, Luxemburg, Norwegen, Österreich, Schweden und den Vereinigten Staaten. Die meisten Schüler in diesen Bereichen besuchen öffentliche Bildungseinrichtungen, und die öffentlichen Ausgaben pro Schüler sind in der Regel für öffentliche Bildungseinrichtungen höher als für private Bildungseinrichtungen, mit Ausnahme von Finnland, Island, Israel, Norwegen und der Türkei. In diesen fünf OECD-Ländern besuchen zwi-

Abbildung B3.4

Jährliche öffentliche Ausgaben für Bildungseinrichtungen pro Studierenden im Tertiärbereich, nach Art der Bildungseinrichtung (2010)

In US-Dollar, kaufkraftbereinigt

$\square$ Öffentliche Bildungseinrichtungen $\square$ Private Bildungseinrichtungen 25000

20000

15000

10000

5000

0
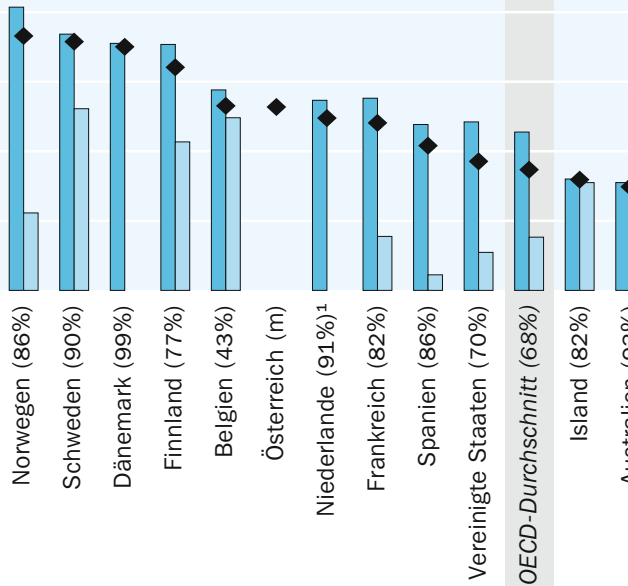
schen 7 Prozent und 25 Prozent der Schüler private Bildungseinrichtungen. In Mexiko und den Niederlanden sind die öffentlichen Ausgaben für private Bildungseinrichtungen pro Schüler niedrig oder zu vernachlässigen, da der private Bildungssektor nur schwach ausgeprägt ist und keine oder nur sehr geringe öffentliche Finanzmittel erhält (Tab. CI.4).

Im Tertiärbereich belaufen sich die öffentlichen Mittel pro Studierenden sowohl für öffentliche als auch private Bildungseinrichtungen im Durchschnitt der OECD-Länder auf 8.676 US-Dollar, variieren aber von rund I.500 US-Dollar in Chile bis zu mehr als I7.000 US-Dollar in Dänemark, Norwegen und Schweden, drei Länder, in denen die Höhe privater Ausgaben in diesem Bildungsbereich niedrig oder zu vernachlässigen ist. In allen Ländern mit verfügbaren Daten sind die öffentlichen Ausgaben pro Studierenden für öffentliche Bildungseinrichtungen höher als für private (Tab. B3.4 und Abb. B3.4).

In diesem Bereich ist die Zuteilung öffentlicher Mittel an öffentliche und private Bildungseinrichtungen in den einzelnen Ländern unterschiedlich. In Dänemark und den Niederlanden besuchen mindestens 90 Prozent der Studierenden öffentliche Bildungseinrichtungen, und der größte Teil der öffentlichen Mittel fließt in diese Einrichtungen. Die öffentlichen Ausgaben pro Studierenden für öffentliche Bildungseinrichtungen liegen über dem OECD-Durchschnitt, und die öffentlichen Ausgaben pro Studierenden für private Bildungseinrichtungen sind zu vernachlässigen. In diesen Ländern ergänzen die privaten Mittel die öffentlichen in ganz unterschiedlichem Ausmaß: In Dänemark liegt der Anteil privater Ausgaben an den Ausgaben für öffentliche und private Bildungseinrichtungen bei unter 5 Prozent, in den Niederlanden bei mehr als 28 Prozent (Abb. B3.4 und Tab. B3.2b).

In Belgien, Estland, Finnland, Island, Schweden und Ungarn fließen öffentliche Mittel sowohl in öffentliche als auch private Bildungseinrichtungen, und die öffentlichen Ausgaben pro Studierenden für private Bildungseinrichtungen belaufen sich auf mindestens 59 Prozent (und bis zu fast Ioo Prozent) der öffentlichen Ausgaben pro Studierenden für öffentliche Bildungseinrichtungen (Tab. B3.4). Allerdings ist die Bildungsbeteiligung in diesen Ländern sehr unterschiedlich. In Finnland, Island, Schweden und Ungarn besuchen mindestens 8o Prozent der Studierenden öffentliche Bildungseinrichtungen, während Studierende in Estland und Belgien hauptsächlich staatlich subventionierte private Bildungseinrichtungen besuchen. In all diesen Ländern liegt der Anteil der privaten Ausgaben für Bildungseinrichtungen im Tertiärbereich unter dem OECD-Durchschnitt. In den übrigen Ländern fließen öffentliche Mittel hauptsächlich in öffentliche Bildungseinrichtungen (Abb. B3.4 und Tab. B3.4).

\section{Definitionen}

Andere private Einheiten umfasst private Unternehmen und gemeinnützige Organisationen, wie beispielsweise kirchliche Organisationen, Wohltätigkeitseinrichtungen, Unternehmerverbände und Arbeitnehmervereinigungen. 
$\mathrm{Zu}$ den privaten Ausgaben zählen alle direkten Ausgaben für Bildungseinrichtungen, unabhängig davon, ob diese teilweise durch öffentliche Mittel subventioniert werden oder nicht. Ausgaben von privaten Unternehmen für den betrieblichen Teil der dualen Ausbildung von Auszubildenden und Schülern gelten ebenfalls als Ausgaben anderer privater Einheiten. Die in den privaten Mitteln enthaltenen öffentlichen Subventionen an die privaten Haushalte werden getrennt ausgewiesen.

Die Anteile der öffentlichen und der privaten Ausgaben für Bildungseinrichtungen sind angegeben in Prozent der gesamten Bildungsausgaben, die im öffentlichen und privaten Sektor entstehen bzw. anfallen.

Die öffentlichen Ausgaben beziehen sich auf alle Schüler/Studierenden in öffentlichen und privaten Bildungseinrichtungen, unabhängig davon, ob diese Einrichtungen öffentliche Mittel erhalten oder nicht.

\section{Angewandte Methodik}

Die Daten beziehen sich auf das Haushaltsjahr 2010 und beruhen auf der von der OECD im Jahre 2012 durchgeführten UOE-Datenerhebung zur Bildungsstatistik (weitere Informationen s. Anhang 3 unter www.oecd.org/eduleag.htm).

Nicht alle Ausgaben für bildungsbezogene Sach- und Dienstleistungen fallen in Bildungseinrichtungen an. Familien erwerben beispielsweise Schul-/Lehrbücher oder Unterrichtsmaterial im Handel oder finanzieren Nachhilfestunden für ihre Kinder außerhalb von Bildungseinrichtungen. Im Tertiärbereich können auch die Kosten für den Lebensunterhalt sowie entgangene Einkommen einen signifikanten Anteil der Bildungskosten ausmachen. Diese außerhalb von Bildungseinrichtungen anfallenden Ausgaben sind, selbst wenn sie öffentlich subventioniert werden, bei diesem Indikator nicht berücksichtigt. Öffentliche Subventionen für Bildungsausgaben außerhalb von Bildungseinrichtungen werden in den Indikatoren $\mathrm{B}_{4}$ und $\mathrm{B}_{5}$ behandelt.

Ein Teil der Haushaltsmittel von Bildungseinrichtungen bezieht sich auf zusätzliche Dienstleistungen für Schüler/Studierende, u. a. soziale Dienste für Schüler/Studierende (Unterkunft, Verpflegung und Transport). Die Kosten für diese Leistungen werden teilweise über Beiträge der Schüler/Studierenden gedeckt und in diesem Indikator mit erfasst.

Die Daten für die Ausgaben der Jahre 1995 und 2000 wurden im Rahmen einer 2012 aktualisierten speziellen Erhebung ermittelt, in der die Ausgaben für 1995 und 2000 entsprechend den Definitionen und den Methoden der aktuellen UOE-Datenerhebung angepasst wurden.

Die statistischen Daten für Israel wurden von den zuständigen israelischen Stellen bereitgestellt, die für sie verantwortlich zeichnen. Die Verwendung dieser Daten durch die OECD erfolgt unbeschadet des völkerrechtlichen Status der Golanhöhen, von OstJerusalem und der israelischen Siedlungen im Westjordanland. 


\section{Tabellen Indikator B3}

Tabelle B3.I: Relative Anteile öffentlicher und privater Ausgaben für Bildungseinrichtungen aller Bildungsbereiche $(2000,2010)$

StatLink: http:/|dx.doi.org/10.1787/888932849692

Tabelle B3.2a: Relative Anteile öffentlicher und privater Ausgaben für Bildungseinrichtungen, nach Bildungsbereich (2000, 2010)

StatLink: http://dx.doi.org/10.1787/888932849711

Tabelle B3.2b: Relative Anteile öffentlicher und privater Ausgaben für Bildungseinrichtungen im Tertiärbereich (2000, 2010)

StatLink: http://dx.doi.org/10.1787/888932849730

Tabelle B3.3: Entwicklung der relativen Anteile öffentlicher Ausgaben für Bildungseinrichtungen im Tertiärbereich und Index der Veränderung dieser Ausgaben zwischen 1995 und 2010

StatLink: http://dx.doi.org/10.1787/888932849749

Tabelle B3.4: Jährliche öffentliche Ausgaben für Bildungseinrichtungen pro Schüler/Studierenden, nach Art der Bildungseinrichtung (2010)

StatLink: http:||dx.doi.org/10.1787/888932849768 
Tabelle B3.1

Relative Anteile öffentlicher und privater Ausgaben für Bildungseinrichtungen aller Bildungsbereiche (2000, 2010) Aufteilung der Mittel für Bildungseinrichtungen aus öffentlichen und privaten Quellen nach Transferzahlungen aus öffentlichen Quellen, nach Jahr

\begin{tabular}{|c|c|c|c|c|c|c|c|c|c|}
\hline & \multicolumn{5}{|c|}{2010} & \multicolumn{2}{|c|}{2000} & \multicolumn{2}{|c|}{$\begin{array}{l}\text { Index der Veränderung der } \\
\text { Ausgaben für Bildungsein- } \\
\text { richtungen zwischen } 2000 \\
\text { und } 2010(2000=100, \\
\text { zu konstanten Preisen })\end{array}$} \\
\hline & \multirow{2}{*}{$\begin{array}{c}\text { Aus } \\
\text { öffentlichen } \\
\text { Quellen }\end{array}$} & \multicolumn{3}{|c|}{ Aus privaten Quellen } & \multirow{2}{*}{$\begin{array}{l}\text { Aus privaten } \\
\text { Quellen: } \\
\text { hiervon sub- } \\
\text { ventioniert }\end{array}$} & \multirow{2}{*}{$\begin{array}{c}\text { Aus } \\
\text { öffentlichen } \\
\text { Quellen }\end{array}$} & \multirow{2}{*}{$\begin{array}{c}\text { Alle } \\
\text { privaten } \\
\text { Quellen }^{1}\end{array}$} & \multirow{2}{*}{$\begin{array}{c}\text { Aus } \\
\text { öffentlichen } \\
\text { Quellen }\end{array}$} & \multirow{2}{*}{$\begin{array}{c}\text { Alle } \\
\text { privaten } \\
\text { Quellen }^{1}\end{array}$} \\
\hline & & $\begin{array}{l}\text { Ausgaben } \\
\text { privater } \\
\text { Haushalte }\end{array}$ & $\begin{array}{c}\text { Ausgaben an- } \\
\text { derer privater } \\
\text { Einheiten }\end{array}$ & $\begin{array}{c}\text { Alle } \\
\text { privaten } \\
\text { Quellen }^{1}\end{array}$ & & & & & \\
\hline & (1) & (2) & (3) & (4) & (5) & (6) & (7) & (8) & (9) \\
\hline \multicolumn{10}{|l|}{ OECD-Länder } \\
\hline Australien & 74,1 & 20,2 & 5,7 & 25,9 & 1,1 & 74,1 & 25,9 & 159 & 159 \\
\hline Österreich & 91,0 & 3,6 & 5,4 & 9,0 & 6,0 & 94,0 & 6,0 & 118 & 183 \\
\hline Belgien & 94,8 & 3,9 & 1,3 & 5,2 & 1,9 & 94,3 & 5,7 & 126 & 114 \\
\hline Kanada ${ }^{2}$ & 75,8 & 10,3 & 13,9 & 24,2 & 0,5 & 79,9 & 20,1 & 124 & 158 \\
\hline Chile $^{3}$ & 57,9 & 37,8 & 4,4 & 42,1 & 2,7 & $\mathrm{~m}$ & $\mathrm{~m}$ & $\mathrm{~m}$ & $\mathrm{~m}$ \\
\hline Tschechien & 87,7 & 7,9 & 4,3 & 12,3 & $\mathrm{n}$ & 89,9 & 10,1 & 158 & 198 \\
\hline Dänemark & 94,5 & 4,4 & $\mathrm{~m}$ & 5,5 & $\mathrm{~m}$ & 96,0 & 4,0 & 125 & 174 \\
\hline Estland & 93,0 & 5,2 & 1,8 & 7,0 & $\mathrm{~m}$ & $\mathrm{~m}$ & $\mathrm{~m}$ & 143 & $\mathrm{~m}$ \\
\hline Finnland & 97,6 & $x(4)$ & $x(4)$ & 2,4 & $\mathrm{n}$ & 98,0 & 2,0 & 136 & 159 \\
\hline Frankreich & 89,8 & 7,3 & 2,9 & 10,2 & $\mathrm{~m}$ & 91,2 & 8,8 & 109 & 128 \\
\hline Deutschland & $\mathbf{m}$ & $\mathrm{m}$ & $\mathrm{m}$ & $\mathbf{m}$ & $\mathrm{m}$ & 86,1 & 13,9 & $\mathrm{~m}$ & $\mathrm{~m}$ \\
\hline Griechenland & $\mathbf{m}$ & $\mathrm{m}$ & $\mathrm{m}$ & $\mathbf{m}$ & $\mathrm{m}$ & 93,8 & 6,2 & $\mathrm{~m}$ & $\mathrm{~m}$ \\
\hline Ungarn & $\mathbf{m}$ & $\mathrm{m}$ & $\mathrm{m}$ & $\mathbf{m}$ & $\mathrm{m}$ & $\mathrm{m}$ & $\mathrm{m}$ & 126 & $\mathrm{~m}$ \\
\hline Island & 90,4 & 8,4 & 1,3 & 9,6 & a & 90,0 & 10,0 & 136 & 131 \\
\hline Irland & 92,5 & 6,9 & 0,6 & 7,5 & $\mathrm{n}$ & 90,5 & 9,5 & 194 & 151 \\
\hline Israel & 77,6 & 15,4 & 7,0 & 22,4 & 2,1 & 79,8 & 20,2 & 130 & 148 \\
\hline Italien & 90,1 & 8,1 & 1,8 & 9,9 & 1,9 & 94,3 & 5,7 & 100 & 184 \\
\hline Japan & 70,2 & 20,4 & 9,4 & 29,8 & $\mathrm{~m}$ & 71,0 & 29,0 & 109 & 113 \\
\hline Korea & 61,6 & 27,7 & 10,8 & 38,4 & 1,2 & 59,2 & 40,8 & 195 & 177 \\
\hline Luxemburg & $\mathbf{m}$ & $\mathrm{m}$ & $\mathrm{m}$ & $\mathbf{m}$ & $\mathrm{m}$ & $\mathrm{m}$ & $\mathrm{m}$ & $\mathrm{m}$ & $\mathrm{m}$ \\
\hline Mexiko & 80,5 & 19,3 & 0,2 & 19,5 & 1,3 & 85,3 & 14,7 & 139 & 196 \\
\hline Niederlande & 83,3 & 7,3 & 9,4 & 16,7 & 2,6 & 84,1 & 15,9 & 137 & 146 \\
\hline Neuseeland & 82,6 & 17,4 & $x(2)$ & 17,4 & $\mathrm{~m}$ & $\mathrm{~m}$ & $\mathrm{~m}$ & 138 & $\mathrm{~m}$ \\
\hline Norwegen & $\mathbf{m}$ & $\mathrm{m}$ & $\mathrm{m}$ & $\mathbf{m}$ & $\mathrm{m}$ & 95,0 & 5,0 & 142 & $\mathrm{~m}$ \\
\hline Polen & 86,2 & $x(4)$ & $x(4)$ & 13,8 & $\mathrm{~m}$ & 89,0 & 11,0 & 147 & 190 \\
\hline Portugal & 92,6 & 5,6 & 1,8 & 7,4 & $\mathrm{~m}$ & 98,6 & 1,4 & 112 & 615 \\
\hline Slowakei & 84,2 & 10,9 & 4,9 & 15,8 & 2,0 & 96,4 & 3,6 & 159 & 790 \\
\hline Slowenien & 88,4 & 10,2 & 1,4 & 11,6 & $\mathrm{n}$ & $\mathrm{m}$ & $\mathrm{m}$ & $\mathrm{m}$ & $\mathrm{m}$ \\
\hline Spanien & 85,4 & 13,6 & 1,0 & 14,6 & 0,4 & 87,4 & 12,6 & 140 & 167 \\
\hline Schweden & 97,5 & $\mathrm{n}$ & 2,5 & 2,5 & a & 97,0 & 3,0 & 127 & 104 \\
\hline Schweiz & $\mathbf{m}$ & $\mathrm{m}$ & $\mathrm{m}$ & $\mathbf{m}$ & $\mathrm{m}$ & 91,8 & 8,2 & 122 & $\mathrm{~m}$ \\
\hline Türkei & $\mathbf{m}$ & $\mathrm{m}$ & $\mathrm{m}$ & $\mathbf{m}$ & $\mathrm{m}$ & 98,6 & 1,4 & $\mathrm{~m}$ & $\mathrm{~m}$ \\
\hline Vereinigtes Königreich & 68,6 & 19,7 & 11,7 & 31,4 & 22,4 & 85,2 & 14,8 & 120 & 317 \\
\hline Vereinigte Staaten & 69,4 & 24,5 & 6,1 & 30,6 & $\mathrm{~m}$ & 72,0 & 28,0 & 131 & 148 \\
\hline OECD-Durchschnitt & 83,6 & $\sim$ & $\sim$ & 16,4 & 2,4 & 87,9 & 12,1 & 136 & 211 \\
\hline EU21-Durchschnitt & 89,3 & $\sim$ & $\sim$ & 10,7 & 3,1 & 92,1 & 7,9 & 134 & 241 \\
\hline \multicolumn{10}{|l|}{ Sonstige G20-Länder } \\
\hline Argentinien & 85,2 & 12,3 & 2,5 & 14,8 & $n$ & $\mathrm{~m}$ & $\mathrm{~m}$ & $\mathrm{~m}$ & $\mathrm{~m}$ \\
\hline Brasilien & $\mathbf{m}$ & $\mathrm{m}$ & $\mathrm{m}$ & $\mathbf{m}$ & $\mathrm{m}$ & $\mathrm{m}$ & $\mathrm{m}$ & 239 & $\mathrm{~m}$ \\
\hline China & $\mathbf{m}$ & $\mathrm{m}$ & $\mathrm{m}$ & $\mathbf{m}$ & $\mathrm{m}$ & $\mathrm{m}$ & $\mathrm{m}$ & $\mathrm{m}$ & $\mathrm{m}$ \\
\hline Indien & $\mathbf{m}$ & $\mathrm{m}$ & $\mathrm{m}$ & $\mathbf{m}$ & $\mathrm{m}$ & $\mathrm{m}$ & $\mathrm{m}$ & $\mathrm{m}$ & $\mathrm{m}$ \\
\hline Indonesien & $\mathbf{m}$ & $\mathrm{m}$ & $\mathrm{m}$ & $\mathbf{m}$ & $\mathrm{m}$ & $\mathrm{m}$ & $\mathrm{m}$ & $\mathrm{m}$ & $\mathrm{m}$ \\
\hline Russische Föderation & 84,2 & 11,6 & 4,1 & 15,8 & $a$ & $\mathrm{~m}$ & $\mathrm{~m}$ & 222 & $\mathrm{~m}$ \\
\hline Saudi-Arabien & $\mathbf{m}$ & $\mathrm{m}$ & $\mathrm{m}$ & $\mathbf{m}$ & $\mathrm{m}$ & $\mathrm{m}$ & $\mathrm{m}$ & $\mathrm{m}$ & $\mathrm{m}$ \\
\hline Südafrika & $\mathbf{m}$ & $\mathrm{m}$ & $\mathrm{m}$ & m & $\mathrm{m}$ & $\mathrm{m}$ & $\mathrm{m}$ & $\mathrm{m}$ & $\mathrm{m}$ \\
\hline G20-Durchschnitt & $\mathbf{m}$ & $\mathbf{m}$ & $\mathbf{m}$ & $\mathbf{m}$ & $\mathbf{m}$ & $\mathbf{m}$ & $\mathbf{m}$ & $\mathbf{m}$ & $\mathbf{m}$ \\
\hline
\end{tabular}

1. Einschließlich Subventionen, die mit Mitteln aus öffentlichen Quellen finanzierten Zahlungen an Bildungseinrichtungen zuzurechnen sind.

2. Referenzjahr 2009 anstelle 2010. 3. Referenzjahr 2011 anstelle 2010.

Quelle: OECD. Argentinien: Statistikinstitut der UNESCO (World Education Indicators Programme). Hinweise s. Anhang 3 unter www.oecd.org/edu/eag.htm.

StatLink: http://dx.doi.org/10.1787/888932849692

Erläuterung der Kennzeichnung fehlender Daten s. Hinweise für den Leser. 
Relative Anteile öffentlicher und privater Ausgaben für Bildungseinrichtungen, nach Bildungsbereich (2000, 2010) Aufteilung der Mittel für Bildungseinrichtungen aus öffentlichen und privaten Quellen nach Transferzahlungen aus öffentlichen Quellen (in \%), nach Jahr

\begin{tabular}{|c|c|c|c|c|c|c|c|c|c|c|c|c|c|c|}
\hline & \multirow{2}{*}{\multicolumn{5}{|c|}{$\begin{array}{c}\begin{array}{c}\text { Elementarbereich } \\
\text { (für 3-Jährige und Ältere) }\end{array} \\
2010\end{array}$}} & \multicolumn{9}{|c|}{$\begin{array}{l}\text { Primar-, Sekundar- und } \\
\text { postsekundarer, nicht tertiärer Bereich }\end{array}$} \\
\hline & & & & & & & & 2010 & & & & & \begin{tabular}{|l} 
Index der V \\
Ausgaben $\mathrm{f}$ \\
richtungen \\
und 2010 \\
zu konsta
\end{tabular} & $\begin{array}{l}\text { lerung der } \\
\text { dungsein- } \\
\text { hen } 2000 \\
0=100, \\
\text { Preisen) }\end{array}$ \\
\hline & \multirow[b]{2}{*}{ 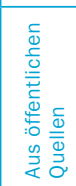 } & \multicolumn{3}{|c|}{ Aus privaten Quellen } & \multirow[b]{2}{*}{ 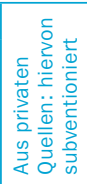 } & \multirow[b]{2}{*}{ 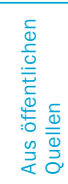 } & \multicolumn{3}{|c|}{ Aus privaten Quellen } & \multirow[b]{2}{*}{ 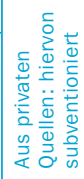 } & \multirow[b]{2}{*}{ 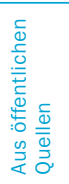 } & \multirow[b]{2}{*}{ 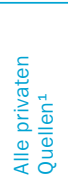 } & \multirow[b]{2}{*}{ 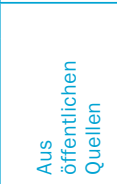 } & \multirow[b]{2}{*}{ 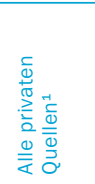 } \\
\hline & & 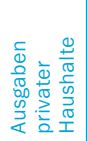 & 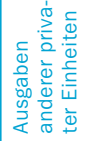 & 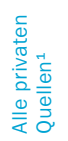 & & & 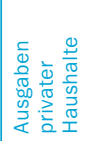 & 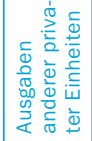 & 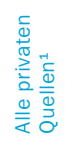 & & & & & \\
\hline & (1) & (2) & (3) & (4) & (5) & (6) & (7) & (8) & (9) & (10) & (11) & (12) & (13) & (14) \\
\hline \multicolumn{15}{|l|}{ OECD-Länder } \\
\hline Australien & 55,8 & 43,9 & 0,3 & 44,2 & 0,9 & 84,7 & 12,8 & 2,5 & 15,3 & 1,4 & 83,7 & 16,3 & 164 & 152 \\
\hline Österreich & 72,2 & 9,7 & 18,1 & 27,8 & 27,0 & 95,5 & 3,0 & 1,5 & 4,5 & 1,7 & 95,8 & 4,2 & 108 & 117 \\
\hline Belgien & 96,4 & 3,5 & 0,1 & 3,6 & 0,8 & 96,0 & 3,8 & 0,2 & 4,0 & 1,3 & 94,7 & 5,3 & 124 & 93 \\
\hline Kanada ${ }^{2,3}$ & $x(6)$ & $x(7)$ & $x(8)$ & $x(9)$ & $x(6)$ & 89,3 & 3,9 & 6,8 & 10,7 & $x(6)$ & 92,4 & 7,6 & 131 & 191 \\
\hline Chile $^{4}$ & 83,1 & 14,8 & 2,1 & 16,9 & $\mathrm{n}$ & 78,6 & 19,1 & 2,4 & 21,4 & a & $\mathrm{m}$ & $\mathrm{m}$ & $\mathrm{m}$ & $\mathrm{m}$ \\
\hline Tschechien & 92,0 & 6,5 & 1,4 & 8,0 & $n$ & 90,8 & 7,3 & 1,9 & 9,2 & $\mathrm{n}$ & 91,7 & 8,3 & 144 & 161 \\
\hline Dänemark ${ }^{3}$ & 86,7 & 13,3 & $n$ & 13,3 & $\mathrm{~m}$ & 97,6 & 2,4 & $\mathrm{n}$ & 2,4 & $n$ & 97,8 & 2,2 & 124 & 138 \\
\hline Estland & 98,5 & 1,3 & $\mathrm{n}$ & 1,5 & $\mathrm{~m}$ & 98,7 & 1,0 & 0,3 & 1,3 & $\mathrm{~m}$ & $\mathrm{~m}$ & $\mathrm{~m}$ & 142 & $\mathrm{~m}$ \\
\hline Finnland & 90,1 & $x(4)$ & $x(4)$ & 9,9 & $\mathrm{n}$ & 99,2 & $x(9)$ & $x(9)$ & 0,8 & $\mathrm{n}$ & 99,3 & 0,7 & 137 & 162 \\
\hline Frankreich & 93,7 & 6,2 & $\mathrm{n}$ & 6,3 & $\mathrm{~m}$ & 92,0 & 6,5 & 1,5 & 8,0 & $\mathrm{~m}$ & 92,6 & 7,4 & 104 & 113 \\
\hline Deutschland & m & $\mathrm{m}$ & $\mathrm{m}$ & $\mathbf{m}$ & $\mathrm{m}$ & $\mathbf{m}$ & $\mathrm{m}$ & $\mathrm{m}$ & m & $\mathrm{m}$ & 87,1 & 12,9 & $\mathrm{~m}$ & $\mathrm{~m}$ \\
\hline Griechenland & $x(6)$ & $x(7)$ & $x(8)$ & $x(9)$ & $\mathrm{m}$ & $\mathbf{m}$ & $\mathrm{m}$ & $\mathrm{n}$ & m & $\mathrm{m}$ & 91,7 & 8,3 & $\mathrm{~m}$ & $\mathrm{~m}$ \\
\hline Ungarn & m & $\mathrm{m}$ & $\mathrm{m}$ & m & $\mathrm{m}$ & $\mathbf{m}$ & $\mathrm{m}$ & $\mathrm{m}$ & m & $\mathrm{n}$ & $\mathrm{m}$ & $\mathrm{m}$ & 123 & $\mathrm{~m}$ \\
\hline Island & 75,7 & 20,5 & 3,8 & 24,3 & a & 96,2 & 3,5 & 0,2 & 3,8 & a & 96,4 & 3,6 & 128 & 134 \\
\hline Irland & m & $\mathrm{m}$ & $\mathrm{m}$ & $\mathbf{m}$ & $\mathrm{m}$ & 95,9 & 4,1 & $\mathrm{~m}$ & 4,1 & $\mathrm{n}$ & 96,0 & 4,0 & 213 & 216 \\
\hline Israel & 78,3 & 21,7 & $\mathrm{n}$ & 21,7 & 0,1 & 92,4 & 4,0 & 3,6 & 7,6 & 1,2 & 94,1 & 5,9 & 135 & 179 \\
\hline Italien & 91,8 & 8,1 & 0,1 & 8,2 & $n$ & 96,6 & 3,2 & 0,1 & 3,4 & $n$ & 97,8 & 2,2 & 104 & 162 \\
\hline $\operatorname{Japan}^{3}$ & 45,2 & 37,9 & 16,9 & 54,8 & $\mathrm{~m}$ & 93,0 & 5,0 & 2,0 & 7,0 & $\mathrm{~m}$ & 89,8 & 10,2 & 110 & 72 \\
\hline Korea & 52,5 & 44,8 & 2,7 & 47,5 & 2,6 & 78,5 & 18,2 & 3,2 & 21,5 & 0,7 & 80,8 & 19,2 & 177 & 204 \\
\hline Luxemburg & 98,8 & 1,0 & 0,2 & 1,2 & $\mathrm{n}$ & 97,8 & 1,9 & 0,3 & 2,2 & $\mathrm{~m}$ & $\mathrm{~m}$ & $\mathrm{~m}$ & $\mathrm{~m}$ & $\mathrm{~m}$ \\
\hline Mexiko & 83,6 & 16,3 & 0,1 & 16,4 & 0,2 & 82,7 & 17,2 & 0,1 & 17,3 & 1,5 & 86,1 & 13,9 & 131 & 170 \\
\hline Niederlande & 94,2 & 5,8 & a & 5,8 & 3,1 & 86,9 & 4,4 & 8,7 & 13,1 & 3,5 & 85,7 & 14,3 & 139 & 126 \\
\hline Neuseeland & 84,8 & 15,2 & $x(2)$ & 15,2 & $\mathrm{~m}$ & 87,4 & 12,6 & $x(7)$ & 12,6 & $\mathrm{~m}$ & $\mathrm{~m}$ & $\mathrm{~m}$ & 130 & $\mathrm{~m}$ \\
\hline Norwegen & 84,6 & 15,4 & $\mathrm{~m}$ & 15,4 & $\mathrm{n}$ & $\mathbf{m}$ & $\mathrm{m}$ & $\mathrm{m}$ & m & $\mathrm{m}$ & 99,0 & 1,0 & 130 & $\mathrm{~m}$ \\
\hline Polen & 79,0 & 21,0 & $\mathrm{~m}$ & 21,0 & $n$ & 93,8 & 6,2 & $\mathrm{~m}$ & 6,2 & $\mathrm{~m}$ & 95,4 & 4,6 & 135 & 188 \\
\hline Portugal & m & $\mathrm{m}$ & $\mathrm{m}$ & $\mathbf{m}$ & $\mathrm{m}$ & 100,0 & $\mathrm{n}$ & $\mathrm{m}$ & $\mathrm{n}$ & $\mathrm{m}$ & 99,9 & 0,1 & 111 & 88 \\
\hline Slowakei ${ }^{3}$ & 82,3 & 16,6 & 1,1 & 17,7 & 0,5 & 88,0 & 10,2 & 1,8 & 12,0 & 2,2 & 97,6 & 2,4 & 165 & 924 \\
\hline Slowenien & 79,1 & 20,8 & 0,1 & 20,9 & $\mathrm{n}$ & 91,3 & 8,1 & 0,6 & 8,7 & $\mathrm{n}$ & $\mathrm{m}$ & $\mathrm{m}$ & $\mathrm{m}$ & $\mathrm{m}$ \\
\hline Spanien & 73,2 & 26,8 & $\mathrm{~m}$ & 26,8 & $\mathrm{n}$ & 91,8 & 8,2 & $\mathrm{~m}$ & 8,2 & a & 93,0 & 7,0 & 126 & 149 \\
\hline Schweden & 100,0 & $\mathrm{n}$ & $\mathrm{n}$ & $\mathbf{n}$ & $\mathrm{n}$ & 99,9 & $\mathrm{n}$ & a & $\mathbf{n}$ & $\mathrm{n}$ & 99,9 & 0,1 & 117 & 63 \\
\hline Schweiz & m & $\mathrm{m}$ & $\mathrm{m}$ & $\mathbf{m}$ & $\mathrm{m}$ & 88,1 & $\mathrm{n}$ & 11,9 & 11,9 & 0,7 & 88,9 & 11,1 & 120 & 130 \\
\hline Türkei & m & $\mathrm{m}$ & $\mathrm{m}$ & $\mathbf{m}$ & $\mathrm{m}$ & $\mathbf{m}$ & $\mathrm{m}$ & $\mathrm{m}$ & m & m & $\mathrm{m}$ & $\mathrm{m}$ & $\mathrm{m}$ & $\mathrm{m}$ \\
\hline Ver. Königreich & 91,4 & 8,6 & $n$ & 8,6 & 8,4 & 78,9 & 10,5 & 10,6 & 21,1 & 22,2 & 88,7 & 11,3 & 137 & 289 \\
\hline Vereinigte Staaten & 70,9 & 29,1 & a & 29,1 & a & 92,3 & 7,7 & $\mathrm{~m}$ & 7,7 & a & 91,7 & 8,3 & 131 & 118 \\
\hline OECD-Durchschnitt & 82,1 & $\sim$ & $\sim$ & 17,9 & 2,1 & 91,5 & $\sim$ & $\sim$ & 8,5 & 1,7 & 92,9 & 7,1 & 134 & 181 \\
\hline EU21-Durchschnitt & 88,7 & $\sim$ & $\sim$ & 11,3 & 2,2 & 93,9 & $\sim$ & $\sim$ & 6,1 & 0,7 & 94,4 & 5,6 & 136 & 198 \\
\hline \multicolumn{15}{|l|}{ Sonst. G20-Länder } \\
\hline Argentinien & 69,3 & 30,7 & $\mathrm{n}$ & 30,7 & $\mathrm{~m}$ & 89,8 & 10,2 & a & 10,2 & $\mathrm{~m}$ & $\mathrm{~m}$ & $\mathrm{~m}$ & $\mathrm{~m}$ & $\mathrm{~m}$ \\
\hline Brasilien & m & $\mathrm{m}$ & $\mathrm{m}$ & m & $\mathrm{m}$ & $\mathbf{m}$ & $\mathrm{m}$ & $\mathrm{m}$ & m & $\mathrm{m}$ & $\mathrm{m}$ & $\mathrm{m}$ & 259 & $\mathrm{~m}$ \\
\hline China & m & $\mathrm{m}$ & $\mathrm{m}$ & $\mathbf{m}$ & $\mathrm{m}$ & $\mathbf{m}$ & $\mathrm{m}$ & $\mathrm{m}$ & m & $\mathrm{m}$ & $\mathrm{m}$ & $\mathrm{m}$ & $\mathrm{m}$ & $\mathrm{m}$ \\
\hline Indien & m & $\mathrm{m}$ & $\mathrm{m}$ & m & $\mathrm{m}$ & m & $\mathrm{m}$ & $\mathrm{m}$ & m & $\mathrm{m}$ & $\mathrm{m}$ & $\mathrm{m}$ & $\mathrm{m}$ & $\mathrm{m}$ \\
\hline Indonesien & m & $\mathrm{m}$ & $\mathrm{m}$ & $\mathbf{m}$ & $\mathrm{m}$ & $\mathbf{m}$ & $\mathrm{m}$ & $\mathrm{m}$ & m & $\mathrm{m}$ & $\mathrm{m}$ & $\mathrm{m}$ & $\mathrm{m}$ & $\mathrm{m}$ \\
\hline Russische Föd. & 87,9 & 10,2 & 1,9 & 12,1 & a & 96,9 & 1,5 & 1,5 & 3,1 & a & $\mathrm{m}$ & $\mathrm{m}$ & 196 & $\mathrm{~m}$ \\
\hline Saudi-Arabien & m & $\mathrm{m}$ & $\mathrm{m}$ & $\mathbf{m}$ & $\mathrm{m}$ & $\mathbf{m}$ & $\mathrm{m}$ & $\mathrm{m}$ & m & m & $\mathrm{m}$ & $\mathrm{m}$ & $\mathrm{m}$ & $\mathrm{m}$ \\
\hline Südafrika & m & $\mathrm{m}$ & $\mathrm{m}$ & $\mathbf{m}$ & $\mathrm{m}$ & $\mathbf{m}$ & m & $\mathrm{m}$ & m & m & $\mathrm{m}$ & $\mathrm{m}$ & $\mathrm{m}$ & $\mathrm{m}$ \\
\hline G20-Durchschnitt & m & m & m & $\mathbf{m}$ & $\mathbf{m}$ & m & m & $\mathbf{m}$ & $\mathbf{m}$ & m & m & $\mathbf{m}$ & m & m \\
\hline
\end{tabular}

1. Einschließlich Subventionen, die mit Mitteln aus öffentlichen Quellen finanzierten Zahlungen an Bildungseinrichtungen zuzurechnen sind. Um private Mittel ohne Subventionen zu berechnen, sind von den privaten Mitteln in Spalte (4) bzw. (9) die öffentlichen Subventionen in Spalte (5) bzw. (10) abzuziehen. Um die gesamten öffentlichen Mittel einschließlich öffentlicher Subventionen zu berechnen, sind den direkten öffentlichen Mitteln in Spalte (1) bzw. (6) die öffentlichen Subventionen in Spalte (5) bzw. (10) hinzuzurechnen. 2. Referenzjahr 2009 anstelle 2010. 3. Einige Bildungsbereiche sind in anderen Bildungsbereichen enthalten. Einzelheiten s. Erläuterung von „, $x^{\prime}$ in Hinweise für den Leser. 4. Referenzjahr 2011 anstelle 2010.

Quelle: OECD. Argentinien: Statistikinstitut der UNESCO (World Education Indicators Programme). Hinweise s. Anhang 3 unter www.oecd.org/edu/eag.htm. StatLink: http://dx.doi.org/10.1787/888932849711

Erläuterung der Kennzeichnung fehlender Daten s. Hinweise für den Leser. 
Relative Anteile öffentlicher und privater Ausgaben für Bildungseinrichtungen im Tertiärbereich $(2000,2010)$ Aufteilung der Mittel für Bildungseinrichtungen aus öffentlichen und privaten Quellen nach Transferzahlungen aus öffentlichen Quellen (in \%), nach Jahr

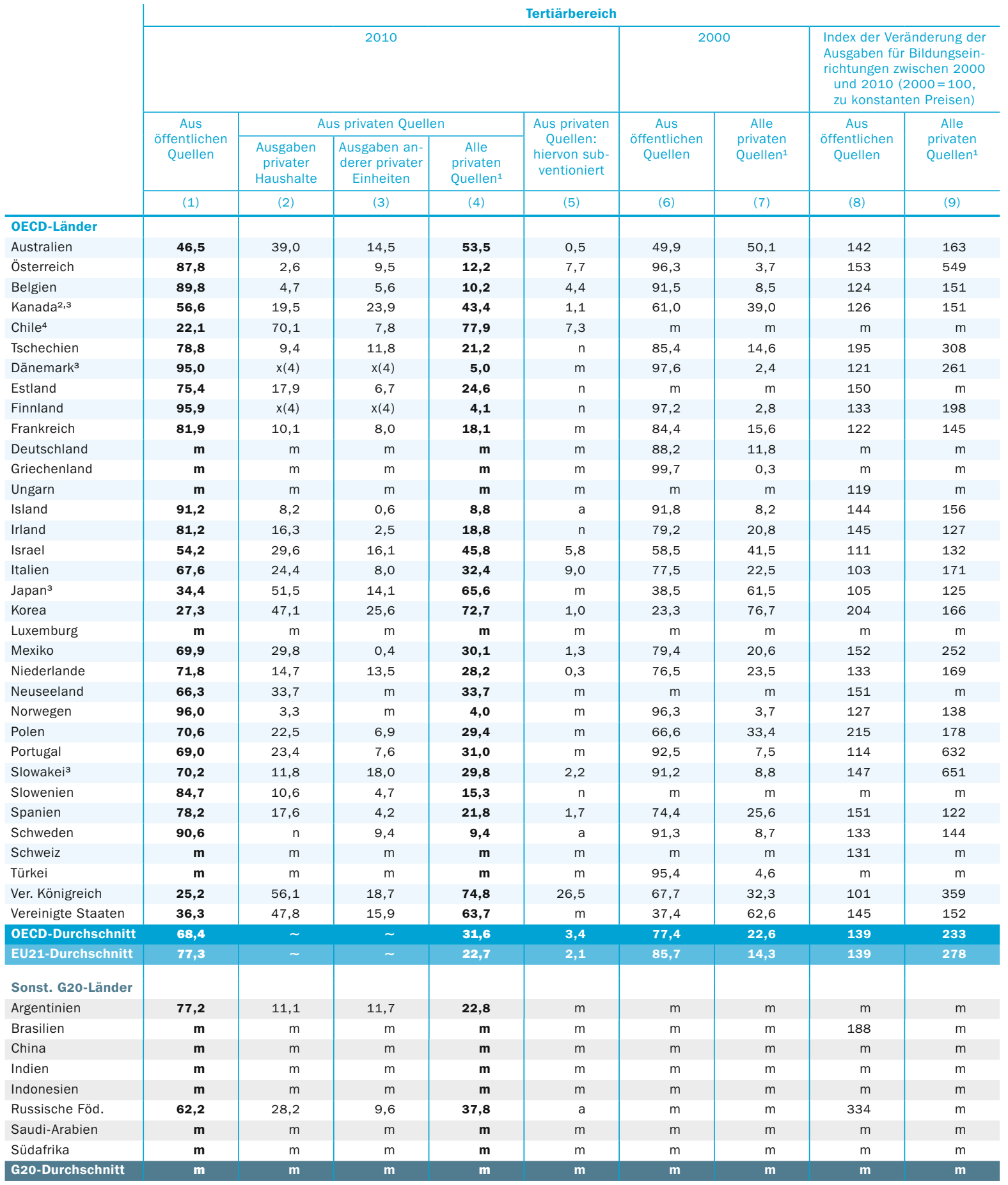

1. Einschließlich Subventionen, die mit Mitteln aus öffentlichen Quellen finanzierten Zahlungen an Bildungseinrichtungen zuzurechnen sind. Um private Mittel ohne Subventionen zu berechnen, sind von den privaten Mitteln in Spalte (4) die öffentlichen Subventionen in Spalte (5) abzuziehen. Um die gesamten öffentlichen Mittel einschließlich öffentlicher Subventionen zu berechnen, sind den direkten öffentlichen Mitteln in Spalte (1) die öffentlichen Subventionen in Spalte (5) hinzuzurechnen. 2. Referenzjahr 2009 anstelle 2010. 3. Einige Bildungsbereiche sind in anderen Bildungsbereichen enthalten. Einzelheiten s. Erläuterung von „X“ in Hinweise für den Leser. 4. Referenzjahr 2011 anstelle 2010.

Quelle: OECD. Argentinien: Statistikinstitut der UNESCO (World Education Indicators Programme). Hinweise s. Anhang 3 unter www.oecd.org/edu/eag.htm. StatLink: $h$ ttp://dx.doi.org/10.1787/888932849730

Erläuterung der Kennzeichnung fehlender Daten s. Hinweise für den Leser. 
Tabelle B3.3

Entwicklung der relativen Anteile öffentlicher Ausgaben ${ }^{1}$ für Bildungseinrichtungen im Tertiärbereich und Index der Veränderung dieser Ausgaben zwischen 1995 und 2010 $2000=100$

\begin{tabular}{|c|c|c|c|c|c|c|c|c|c|c|c|c|}
\hline & \multicolumn{6}{|c|}{$\begin{array}{l}\text { Anteil der öffentlichen Ausgaben für Bildungseinrichtungen } \\
\text { im Tertiärbereich (in \%) }\end{array}$} & \multicolumn{6}{|c|}{$\begin{array}{l}\text { Index der Veränderung der öffentlichen Ausgaben für Bildungs- } \\
\text { einrichtungen im Tertiärbereich zwischen } 1995 \text { und } 2010 \\
(2000=100, \text { zu konstanten Preisen })\end{array}$} \\
\hline & 1995 & 2000 & 2005 & 2008 & 2009 & 2010 & 1995 & 2000 & 2005 & 2008 & 2009 & 2010 \\
\hline & (1) & (2) & (3) & (4) & (5) & (6) & (7) & (8) & (9) & (10) & (11) & (12) \\
\hline \multicolumn{13}{|l|}{ OECD-Länder } \\
\hline Australien & 64,6 & 49,9 & 45,4 & 44,9 & 45,4 & 46,5 & 116 & 100 & 110 & 121 & 134 & 142 \\
\hline Österreich & 96,1 & 96,3 & 92,9 & 84,7 & 87,7 & 87,8 & 96 & 100 & 129 & 131 & 142 & 153 \\
\hline Belgien & $\mathrm{m}$ & 91,5 & 90,6 & 89,8 & 89,7 & 89,8 & $\mathrm{~m}$ & 100 & 101 & 118 & 123 & 124 \\
\hline Kanada ${ }^{2,3}$ & 56,6 & 61,0 & 53,4 & 58,7 & 62,9 & 56,6 & 69 & 100 & 108 & 121 & 130 & 126 \\
\hline Chile $^{4}$ & $\mathrm{~m}$ & $\mathrm{~m}$ & 15,9 & 14,6 & 23,4 & 22,1 & $\mathrm{~m}$ & $\mathrm{~m}$ & $\mathrm{~m}$ & $\mathrm{~m}$ & $\mathrm{~m}$ & $\mathrm{~m}$ \\
\hline Tschechien & 71,5 & 85,4 & 81,2 & 79,1 & 79,9 & 78,8 & 84 & 100 & 148 & 190 & 202 & 195 \\
\hline Dänemark ${ }^{2}$ & 99,4 & 97,6 & 96,7 & 95,5 & 95,4 & 95,0 & 93 & 100 & 115 & 114 & 121 & 121 \\
\hline Estland & $\mathrm{m}$ & $\mathrm{m}$ & 69,9 & 78,8 & 80,2 & 75,4 & 69 & 100 & 109 & 149 & 164 & 150 \\
\hline Finnland & 97,8 & 97,2 & 96,1 & 95,4 & 95,8 & 95,9 & 90 & 100 & 115 & 122 & 127 & 133 \\
\hline Frankreich & 85,3 & 84,4 & 83,6 & 81,7 & 83,1 & 81,9 & 93 & 100 & 106 & 116 & 121 & 122 \\
\hline Deutschland & 89,2 & 88,2 & 85,3 & 85,4 & 84,4 & $\mathrm{~m}$ & 96 & 100 & 102 & 118 & 120 & $\mathrm{~m}$ \\
\hline Griechenland ${ }^{2}$ & $\mathrm{~m}$ & 99,7 & 96,7 & $\mathrm{~m}$ & $\mathrm{~m}$ & $\mathrm{~m}$ & 63 & 100 & 229 & $\mathrm{~m}$ & $\mathrm{~m}$ & $\mathrm{~m}$ \\
\hline Ungarn & $\mathrm{m}$ & $\mathrm{m}$ & 78,5 & $\mathrm{~m}$ & $\mathrm{~m}$ & $\mathrm{~m}$ & $\mathrm{~m}$ & $\mathrm{~m}$ & $\mathrm{~m}$ & $\mathrm{~m}$ & $\mathrm{~m}$ & $\mathrm{~m}$ \\
\hline Island ${ }^{2}$ & $\mathrm{~m}$ & 91,8 & 90,5 & 92,2 & 92,0 & 91,2 & $\mathrm{~m}$ & 100 & 142 & 165 & 159 & 144 \\
\hline Irland & 69,7 & 79,2 & 84,0 & 82,6 & 83,8 & 81,2 & 48 & 100 & 106 & 143 & 156 & 145 \\
\hline Israel & 62,5 & 58,5 & 46,5 & 51,3 & 58,2 & 54,2 & 75 & 100 & 89 & 97 & 109 & 111 \\
\hline Italien & 82,9 & 77,5 & 73,2 & 70,7 & 68,6 & 67,6 & 85 & 100 & 101 & 110 & 104 & 103 \\
\hline$J^{\prime} a n^{2}$ & 35,1 & 38,5 & 33,7 & 33,3 & 35,3 & 34,4 & 80 & 100 & 94 & 101 & 106 & 105 \\
\hline Korea & $\mathrm{m}$ & 23,3 & 24,3 & 22,3 & 26,1 & 27,3 & $\mathrm{~m}$ & 100 & 132 & 155 & 183 & 204 \\
\hline Luxemburg & $\mathrm{m}$ & $\mathrm{m}$ & $\mathrm{m}$ & $\mathrm{m}$ & $\mathrm{m}$ & $\mathrm{m}$ & $\mathrm{m}$ & $\mathrm{m}$ & $\mathrm{m}$ & $\mathrm{m}$ & $\mathrm{m}$ & $\mathrm{m}$ \\
\hline Mexiko & 77,4 & 79,4 & 69,0 & 70,1 & 68,7 & 69,9 & 75 & 100 & 119 & 136 & 146 & 152 \\
\hline Niederlande & 79,4 & 76,5 & 73,0 & 71,5 & 71,1 & 71,8 & 99 & 100 & 113 & 121 & 127 & 133 \\
\hline Neuseeland & $\mathrm{m}$ & $\mathrm{m}$ & 59,7 & 70,4 & 67,9 & 66,3 & 103 & 100 & 119 & 158 & 157 & 151 \\
\hline Norwegen & 93,7 & 96,3 & $\mathrm{~m}$ & 96,9 & 96,1 & 96,0 & 93 & 100 & 120 & 122 & 128 & 127 \\
\hline Polen & $\mathrm{m}$ & 66,6 & 74,0 & 69,6 & 69,7 & 70,6 & 89 & 100 & 193 & 202 & 211 & 215 \\
\hline Portugal & 96,5 & 92,5 & 68,1 & 62,1 & 70,9 & 69,0 & 77 & 100 & 102 & 99 & 109 & 114 \\
\hline Slowakei² & 95,4 & 91,2 & 77,3 & 73,1 & 70,0 & 70,2 & 86 & 100 & 127 & 145 & 139 & 147 \\
\hline Slowenien & $\mathrm{m}$ & $\mathrm{m}$ & 76,5 & 83,8 & 85,1 & 84,7 & $\mathrm{~m}$ & $\mathrm{~m}$ & $\mathrm{~m}$ & $\mathrm{~m}$ & $\mathrm{~m}$ & $\mathrm{~m}$ \\
\hline Spanien & 74,4 & 74,4 & 77,9 & 78,9 & 79,1 & 78,2 & 72 & 100 & 119 & 143 & 149 & 151 \\
\hline Schweden & 93,6 & 91,3 & 88,2 & 89,1 & 89,8 & 90,6 & 84 & 100 & 111 & 117 & 125 & 133 \\
\hline Schweiz & $\mathrm{m}$ & $\mathrm{m}$ & $\mathrm{m}$ & $\mathrm{m}$ & $\mathrm{m}$ & $\mathrm{m}$ & 90 & 100 & 129 & 117 & 128 & 131 \\
\hline Türkei & 96,3 & 95,4 & $\mathrm{~m}$ & $\mathrm{~m}$ & $\mathrm{~m}$ & $\mathrm{~m}$ & 55 & 100 & $\mathrm{~m}$ & $\mathrm{~m}$ & $\mathrm{~m}$ & $\mathrm{~m}$ \\
\hline Ver. Königreich & 80,0 & 67,7 & $\mathrm{~m}$ & 45,7 & 42,2 & 25,2 & 115 & 100 & $\mathrm{~m}$ & 114 & 117 & 101 \\
\hline Vereinigte Staaten & 38,6 & 37,4 & 39,7 & 39,1 & 37,8 & 36,3 & 85 & 100 & 135 & 148 & 150 & 145 \\
\hline OECD-Durchschnitt & 78,9 & $\mathbf{7 7 , 4}$ & 70,4 & 69,4 & 70,4 & 68,4 & 84 & 100 & 122 & 132 & 139 & 140 \\
\hline $\begin{array}{l}\text { OECD-Durchschnitt } \\
\text { für Länder mit ver- } \\
\text { fügbaren Daten für } \\
\text { alle Referenzjahre }\end{array}$ & 76,7 & 75,6 & 70,9 & 68,8 & 69,8 & 68,0 & 84 & 100 & 114 & 126 & 133 & 135 \\
\hline EU21-Durchschnitt & 86,3 & 85,5 & 81,5 & $\mathbf{7 7 , 7}$ & 78,3 & 76,4 & 84 & 100 & 116 & 129 & 135 & 138 \\
\hline \multicolumn{13}{|l|}{ Sonst. G20-Länder } \\
\hline Argentinien & $\mathrm{m}$ & $\mathrm{m}$ & $\mathrm{m}$ & $\mathrm{m}$ & $\mathrm{m}$ & $\mathrm{m}$ & $\mathrm{m}$ & $\mathrm{m}$ & $\mathrm{m}$ & $\mathrm{m}$ & $\mathrm{m}$ & $\mathrm{m}$ \\
\hline Brasilien & $\mathrm{m}$ & $\mathrm{m}$ & $\mathrm{m}$ & $\mathrm{m}$ & $\mathrm{m}$ & $\mathrm{m}$ & 84 & 100 & 127 & 159 & 162 & 188 \\
\hline China & $\mathrm{m}$ & $\mathrm{m}$ & $\mathrm{m}$ & $\mathrm{m}$ & $\mathrm{m}$ & $\mathrm{m}$ & $\mathrm{m}$ & $\mathrm{m}$ & $\mathrm{m}$ & $\mathrm{m}$ & $\mathrm{m}$ & $\mathrm{m}$ \\
\hline Indien & $\mathrm{m}$ & $\mathrm{m}$ & $\mathrm{m}$ & $\mathrm{m}$ & $\mathrm{m}$ & $\mathrm{m}$ & $\mathrm{m}$ & $\mathrm{m}$ & $\mathrm{m}$ & $\mathrm{m}$ & $\mathrm{m}$ & $\mathrm{m}$ \\
\hline Indonesien & $\mathrm{m}$ & $\mathrm{m}$ & $\mathrm{m}$ & $\mathrm{m}$ & $\mathrm{m}$ & $\mathrm{m}$ & $\mathrm{m}$ & $\mathrm{m}$ & $\mathrm{m}$ & $\mathrm{m}$ & $\mathrm{m}$ & $\mathrm{m}$ \\
\hline Russische Föd. & $\mathrm{m}$ & $\mathrm{m}$ & $\mathrm{m}$ & $\mathrm{m}$ & $\mathrm{m}$ & 62,2 & $\mathrm{~m}$ & 100 & 226 & 333 & 379 & 334 \\
\hline Saudi-Arabien & $\mathrm{m}$ & $\mathrm{m}$ & $\mathrm{m}$ & $\mathrm{m}$ & $\mathrm{m}$ & $\mathrm{m}$ & $\mathrm{m}$ & $\mathrm{m}$ & $\mathrm{m}$ & $\mathrm{m}$ & $\mathrm{m}$ & $\mathrm{m}$ \\
\hline Südafrika & $\mathrm{m}$ & $\mathrm{m}$ & $\mathrm{m}$ & $\mathrm{m}$ & $\mathrm{m}$ & $\mathrm{m}$ & $\mathrm{m}$ & $\mathrm{m}$ & $\mathrm{m}$ & $\mathrm{m}$ & $\mathrm{m}$ & $\mathrm{m}$ \\
\hline G20-Durchschnitt & m & m & m & $\mathbf{m}$ & $\mathbf{m}$ & $\mathbf{m}$ & $\mathbf{m}$ & $\mathbf{m}$ & $\mathbf{m}$ & $\mathbf{m}$ & m & m \\
\hline
\end{tabular}

1. Öffentliche Ausgaben und Gesamtausgaben für Bildungseinrichtungen ohne Mittel aus internationalen Quellen. 2. Einige Bildungsbereiche sind in anderen Bildungsbereichen enthalten. Einzelheiten s. Erläuterung von „X“ in Hinweise für den Leser. 3. Referenzjahr 2009 anstelle 2010.4 . Referenzjahr 2011 anstelle 2010.

Quelle: OECD. Hinweise s. Anhang 3 unter www.oecd.org/edu/eag.htm. StatLink: http://dx.doi.org/10.1787/888932849749

Erläuterung der Kennzeichnung fehlender Daten s. Hinweise für den Leser. 
Tabelle B3.4

Jährliche öffentliche Ausgaben für Bildungseinrichtungen pro Schüler/Studierenden, nach Art der Bildungseinrichtung (2010)

In US-Dollar, kaufkraftbereinigt mittels KKP für das BIP, nach Bildungsbereich und Art der Bildungseinrichtung

\begin{tabular}{|c|c|c|c|c|c|c|c|c|c|c|c|c|c|}
\hline & \multicolumn{3}{|c|}{ Elementarbereich } & \multicolumn{3}{|c|}{$\begin{array}{c}\text { Primar-, Sekundar- und } \\
\text { postsekundarer, } \\
\text { nicht tertiärer Bereich }\end{array}$} & \multicolumn{4}{|c|}{ Tertiärbereich } & \multicolumn{3}{|c|}{$\begin{array}{c}\text { Alle Bildungsbereiche } \\
\text { zusammen }\end{array}$} \\
\hline & $\begin{array}{l}\text { Öffent- } \\
\text { liche } \\
\text { Bildungs- } \\
\text { einrich- } \\
\text { tungen }\end{array}$ & $\begin{array}{l}\text { Private } \\
\text { Bildungs- } \\
\text { einrich- } \\
\text { tungen }\end{array}$ & $\begin{array}{c}\text { Insge- } \\
\text { samt: } \\
\text { öffent- } \\
\text { liche und } \\
\text { private }\end{array}$ & $\begin{array}{l}\text { Öffent- } \\
\text { liche } \\
\text { Bildungs- } \\
\text { einrich- } \\
\text { tungen }\end{array}$ & \begin{tabular}{|c|} 
Private \\
Bildungs- \\
einrich- \\
tungen
\end{tabular} & $\begin{array}{c}\text { Insge- } \\
\text { samt: } \\
\text { offent- } \\
\text { liche und } \\
\text { private }\end{array}$ & $\begin{array}{l}\text { Öffent- } \\
\text { liche } \\
\text { Bildungs- } \\
\text { einrich- } \\
\text { tungen }\end{array}$ & $\begin{array}{l}\text { Private } \\
\text { Bildungs- } \\
\text { einrich- } \\
\text { tungen }\end{array}$ & $\begin{array}{l}\text { Insge- } \\
\text { samt: } \\
\text { öffent- } \\
\text { liche und } \\
\text { private }\end{array}$ & $\begin{array}{l}\text { Hiervon: } \\
\text { F\&E- } \\
\text { Tätig- } \\
\text { keiten }\end{array}$ & $\begin{array}{c}\text { Öffent- } \\
\text { liche } \\
\text { Bildungs- } \\
\text { einrich- } \\
\text { tungen }\end{array}$ & $\begin{array}{l}\text { Private } \\
\text { Bildungs- } \\
\text { einrich- } \\
\text { tungen }\end{array}$ & $\begin{array}{c}\text { Insge- } \\
\text { samt: } \\
\text { offent- } \\
\text { liche und } \\
\text { private }\end{array}$ \\
\hline & (1) & (2) & (3) & (4) & (5) & (6) & (7) & (8) & (9) & (10) & (11) & (12) & (13) \\
\hline \multicolumn{14}{|l|}{ OECD-Länder } \\
\hline Australien & $x(3)$ & $x(3)$ & 4965 & 9036 & 7648 & 8581 & 7749 & 3368 & 7445 & 5290 & $x(13)$ & $x(13)$ & 8366 \\
\hline Österreich & $x(3)$ & $x(3)$ & 6423 & $x(6)$ & $x(6)$ & 11164 & $\mathrm{x}(9)$ & $\mathrm{x}(9)$ & 13184 & 4519 & $x(13)$ & $x(13)$ & 10915 \\
\hline Belgien & 6336 & 5337 & 5809 & 10723 & 9025 & 9715 & 14411 & 12411 & 13266 & 4369 & 10953 & 9020 & 9833 \\
\hline Kanada $^{1}$ & $x(4)$ & $\mathrm{m}$ & $\mathbf{m}$ & 9213 & $\mathrm{~m}$ & $\mathbf{m}$ & 13974 & $\mathrm{~m}$ & $\mathbf{m}$ & $\mathrm{m}$ & 10305 & $\mathrm{~m}$ & m \\
\hline Chile $^{2}$ & 3495 & 2636 & 2944 & 3626 & 1737 & 2517 & 4248 & 968 & 1502 & 232 & 3676 & 1617 & 2339 \\
\hline Tschechien & 3928 & 2764 & 3909 & 5160 & 3284 & 5024 & 6766 & 401 & 5784 & 1252 & 5453 & 2161 & 5187 \\
\hline Dänemark & 8272 & 5846 & 8197 & 11847 & 6347 & 11130 & 17757 & a & 17510 & $x(9)$ & 12443 & 6176 & 11834 \\
\hline Estland & 2505 & 2006 & 2492 & 5963 & 4212 & 5895 & 10815 & 3021 & 4310 & 2056 & 5517 & 3129 & 4992 \\
\hline Finnland & 4949 & 3698 & 4839 & 8425 & 9568 & 8522 & 17680 & 10675 & 16036 & 5663 & 9346 & 9405 & 9352 \\
\hline Frankreich & 6430 & 2677 & 5965 & 9105 & 5455 & 8383 & 13814 & 3880 & 12041 & 4481 & 9339 & 4893 & 8530 \\
\hline Deutschland & $\mathrm{m}$ & $\mathrm{m}$ & $\mathbf{m}$ & $\mathrm{m}$ & $\mathrm{m}$ & $\mathbf{m}$ & $m$ & $\mathrm{~m}$ & m & $\mathrm{m}$ & $\mathrm{m}$ & $\mathrm{m}$ & m \\
\hline Griechenland & $\mathrm{m}$ & $\mathrm{m}$ & $\mathbf{m}$ & $\mathrm{m}$ & $\mathrm{m}$ & $\mathbf{m}$ & $\mathrm{m}$ & $\mathrm{m}$ & m & $\mathrm{m}$ & $\mathrm{m}$ & $\mathrm{m}$ & $\mathbf{m}$ \\
\hline Ungarn & $x(3)$ & $x(3)$ & 4366 & $x(6)$ & $x(6)$ & 4202 & 6144 & 4281 & 5849 & 1265 & 4801 & 4316 & 4738 \\
\hline Island & 6853 & 3971 & 6514 & 8228 & 8523 & 8242 & 8005 & 7747 & 7958 & $x(9)$ & 8579 & 7345 & 8478 \\
\hline Irland & $\mathrm{m}$ & $\mathrm{m}$ & 6121 & 9311 & $\mathrm{~m}$ & $\mathbf{m}$ & 12928 & $\mathrm{~m}$ & m & 3737 & 9906 & $\mathrm{~m}$ & $\mathbf{m}$ \\
\hline Israel & 3716 & 2096 & 3208 & 5185 & 5248 & 5200 & 21982 & 5746 & 5897 & $\mathrm{~m}$ & 5273 & 4741 & 5076 \\
\hline Italien ${ }^{3}$ & 6887 & 777 & 4997 & 8247 & 1014 & 7686 & 6847 & 2075 & 6424 & 3053 & 7835 & 1063 & 7061 \\
\hline Japan & $x(3)$ & $x(3)$ & 2806 & $x(6)$ & $x(6)$ & 8643 & $x(9)$ & $x(9)$ & 6249 & $x(9)$ & $x(13)$ & $x(13)$ & 8120 \\
\hline Korea & 8383 & 2223 & 3671 & 6758 & 5445 & 6523 & 9556 & 1459 & 3058 & 1223 & 8158 & 2744 & 6034 \\
\hline Luxemburg & 21935 & 5470 & 20530 & 19964 & 6542 & 18089 & $\mathrm{~m}$ & $\mathrm{~m}$ & $\mathbf{m}$ & $\mathrm{m}$ & $\mathrm{m}$ & $\mathrm{m}$ & $\mathbf{m}$ \\
\hline Mexiko & 2217 & 8 & 1906 & 2278 & 10 & 2038 & 8097 & a & 5502 & 1262 & 2762 & 8 & 2408 \\
\hline Niederlande ${ }^{4}$ & 7196 & 3554 & 7073 & 8825 & $n$ & 8622 & 13665 & $\mathrm{n}$ & 12385 & 4969 & 9452 & 326 & 9121 \\
\hline Neuseeland & 2213 & 9892 & 9752 & 7066 & 2238 & 6712 & 7524 & 1837 & 6905 & 1602 & 7142 & 5626 & 6936 \\
\hline Norwegen & 5903 & 5220 & 5594 & 13066 & 13088 & 13067 & 20360 & 5569 & 18289 & 6801 & 13791 & 10592 & 13414 \\
\hline Polen & $x(3)$ & $x(3)$ & 3906 & $x(6)$ & $x(6)$ & 4993 & $x(9)$ & $x(9)$ & 4742 & 917 & $x(13)$ & $x(13)$ & 4801 \\
\hline Portugal & 5977 & $\mathrm{~m}$ & $\mathbf{m}$ & 7415 & $\mathrm{~m}$ & $\mathbf{m}$ & 8197 & 1056 & 6553 & 3552 & 7574 & $\mathrm{~m}$ & $\mathbf{m}$ \\
\hline Slowakei & 3577 & 2682 & 3545 & 4493 & 4088 & 4458 & 4751 & $\mathrm{~m}$ & 4751 & 1032 & 4585 & 3989 & 4545 \\
\hline Slowenien & 6196 & 1933 & 6084 & 7766 & 5455 & 7736 & 7699 & 2769 & 7212 & 1520 & 7543 & 3399 & 7407 \\
\hline Spanien & 7293 & 2050 & 5421 & 9559 & 3675 & 7742 & 11925 & 1118 & 10403 & 2820 & 9608 & 3066 & 7704 \\
\hline Schweden & 6651 & 6225 & 6582 & 10071 & 9868 & 10044 & 18421 & 13060 & 17879 & 8070 & 10720 & 9404 & 10547 \\
\hline Schweiz & 5186 & $\mathrm{~m}$ & $\mathbf{m}$ & 11726 & $\mathrm{~m}$ & m & 21893 & $\mathrm{~m}$ & m & $\mathrm{m}$ & 12808 & $\mathrm{~m}$ & $\mathbf{m}$ \\
\hline Türkei & 2467 & 2597 & 2490 & 2008 & 2413 & 2019 & $\mathrm{~m}$ & $\mathrm{~m}$ & $\mathbf{m}$ & $\mathrm{m}$ & $\mathrm{m}$ & $\mathrm{m}$ & $\mathbf{m}$ \\
\hline Ver. Königreich & 6979 & 4867 & 6438 & 8623 & 4885 & 7875 & $a$ & 3834 & 3834 & 3537 & 8488 & 4416 & 7196 \\
\hline Vereinigte Staaten & 11326 & 1845 & 7105 & 11859 & 923 & 10912 & 12112 & 2732 & 9275 & $x(9)$ & 11870 & 1871 & 10172 \\
\hline OECD-Durchschnitt & 6275 & 3494 & 5643 & 8412 & 5029 & 7705 & 11382 & 3826 & 8676 & 3184 & 8382 & 4435 & 7504 \\
\hline EU21-Durchschnitt & 7007 & 3563 & 6261 & 9094 & 5244 & 8311 & 10739 & 4184 & 9539 & 3342 & 8348 & 4507 & 7735 \\
\hline \multicolumn{14}{|l|}{ Sonst. G20-Länder } \\
\hline Argentinien & 2427 & $\mathrm{~m}$ & $\mathbf{m}$ & 3398 & $\mathrm{~m}$ & m & 4680 & $\mathrm{~m}$ & m & $\mathrm{m}$ & 3500 & $\mathrm{~m}$ & m \\
\hline Brasilien & 2111 & $\mathrm{~m}$ & $\mathbf{m}$ & 2653 & $\mathrm{~m}$ & $\mathbf{m}$ & 13137 & $\mathrm{~m}$ & $\mathbf{m}$ & 756 & 2964 & $\mathrm{~m}$ & $\mathbf{m}$ \\
\hline China & $\mathrm{m}$ & $\mathrm{m}$ & m & $\mathrm{m}$ & $\mathrm{m}$ & m & $m$ & $m$ & m & $\mathrm{m}$ & $\mathrm{m}$ & $m$ & m \\
\hline Indien & $\mathrm{m}$ & $\mathrm{m}$ & $\mathbf{m}$ & $\mathrm{m}$ & $\mathrm{m}$ & $\mathbf{m}$ & $\mathrm{m}$ & $\mathrm{m}$ & $\mathbf{m}$ & $\mathrm{m}$ & $\mathrm{m}$ & $\mathrm{m}$ & $\mathbf{m}$ \\
\hline Indonesien & $\mathrm{m}$ & $\mathrm{m}$ & $\mathbf{m}$ & $\mathrm{m}$ & $\mathrm{m}$ & $\mathbf{m}$ & $\mathrm{m}$ & $\mathrm{m}$ & m & $\mathrm{m}$ & $\mathrm{m}$ & $\mathrm{m}$ & $\mathbf{m}$ \\
\hline Russische Föd. & $\mathrm{m}$ & $\mathrm{m}$ & $\mathbf{m}$ & 3978 & $\mathrm{~m}$ & $\mathbf{m}$ & 4980 & $\mathrm{~m}$ & $\mathbf{m}$ & $\mathrm{m}$ & $\mathrm{m}$ & $\mathrm{m}$ & m \\
\hline Saudi-Arabien² & $\mathrm{m}$ & $\mathrm{m}$ & m & $\mathrm{m}$ & $\mathrm{m}$ & m & & $\mathrm{m}$ & m & $\mathrm{m}$ & $m$ & $\mathrm{~m}$ & m \\
\hline Südafrika & $\mathrm{m}$ & $\mathrm{m}$ & $\mathbf{m}$ & $\mathrm{m}$ & $\mathrm{m}$ & $\mathbf{m}$ & $\mathrm{m}$ & $\mathrm{m}$ & $\mathbf{m}$ & $\mathrm{m}$ & $\mathrm{m}$ & $\mathrm{m}$ & $\mathbf{m}$ \\
\hline G20-Durchschnitt & m & $\mathbf{m}$ & $\mathbf{m}$ & m & $\mathbf{m}$ & $\mathbf{m}$ & m & $\mathbf{m}$ & $\mathbf{m}$ & $\mathbf{m}$ & $\mathbf{m}$ & $\mathbf{m}$ & m \\
\hline
\end{tabular}

1. Referenzjahr 2009. 2. Referenzjahr 2011. 3. Ohne postsekundaren, nicht tertiären Bereich. 4. Staatlich subventionierte private Bildungseinrichtungen sind in den öffentlichen Bildungseinrichtungen enthalten.

Quelle: OECD. Argentinien: Statistikinstitut der UNESCO (World Education Indicators Programme). Hinweise s. Anhang 3 unter www.oecd.org/edu/eag.htm. StatLink: http://dx.doi.org/10.1787/888932849768

Erläuterung der Kennzeichnung fehlender Daten s. Hinweise für den Leser. 



\section{Wie hoch sind die öffentlichen Gesamt- ausgaben für Bildung?}

Die OECD-Länder wenden im Durchschnitt I3 Prozent ihrer öffentlichen Gesamtausgaben für Bildung auf, dies reicht jedoch von weniger als ro Prozent in Irland, Italien, Japan, Tschechien und Ungarn bis zu mehr als 20 Prozent in Mexiko und Neuseeland.

Zwischen 1995 und 2005 stieg der Anteil der öffentlichen Mittel, die in den Bildungsbereich flossen, in den meisten Ländern mit vergleichbaren Daten für beide Jahre. Nur in Frankreich, Israel, Japan, Kanada, Neuseeland und Portugal ergab sich ein anderes Bild.

Zwischen 2005 und 2010 nahm der Anteil der öffentlichen Bildungsausgaben an den öffentlichen Gesamtausgaben in rund zwei Drittel der Länder ab, da sich die öffentlichen Bildungsausgaben und die öffentlichen Gesamtausgaben nicht im gleichen Ausmaß veränderten.

Zwischen 2008 und 2010 lässt sich zwar keine eindeutige globale Entwicklungstendenz des Anteils der öffentlichen Ausgaben für Bildung erkennen, aber in I4 der 30 Länder mit verfügbaren Daten stiegen in diesem Zeitraum die öffentlichen Ausgaben für Bildung schneller als die öffentlichen Ausgaben für alle sonstigen Leistungsbereiche.

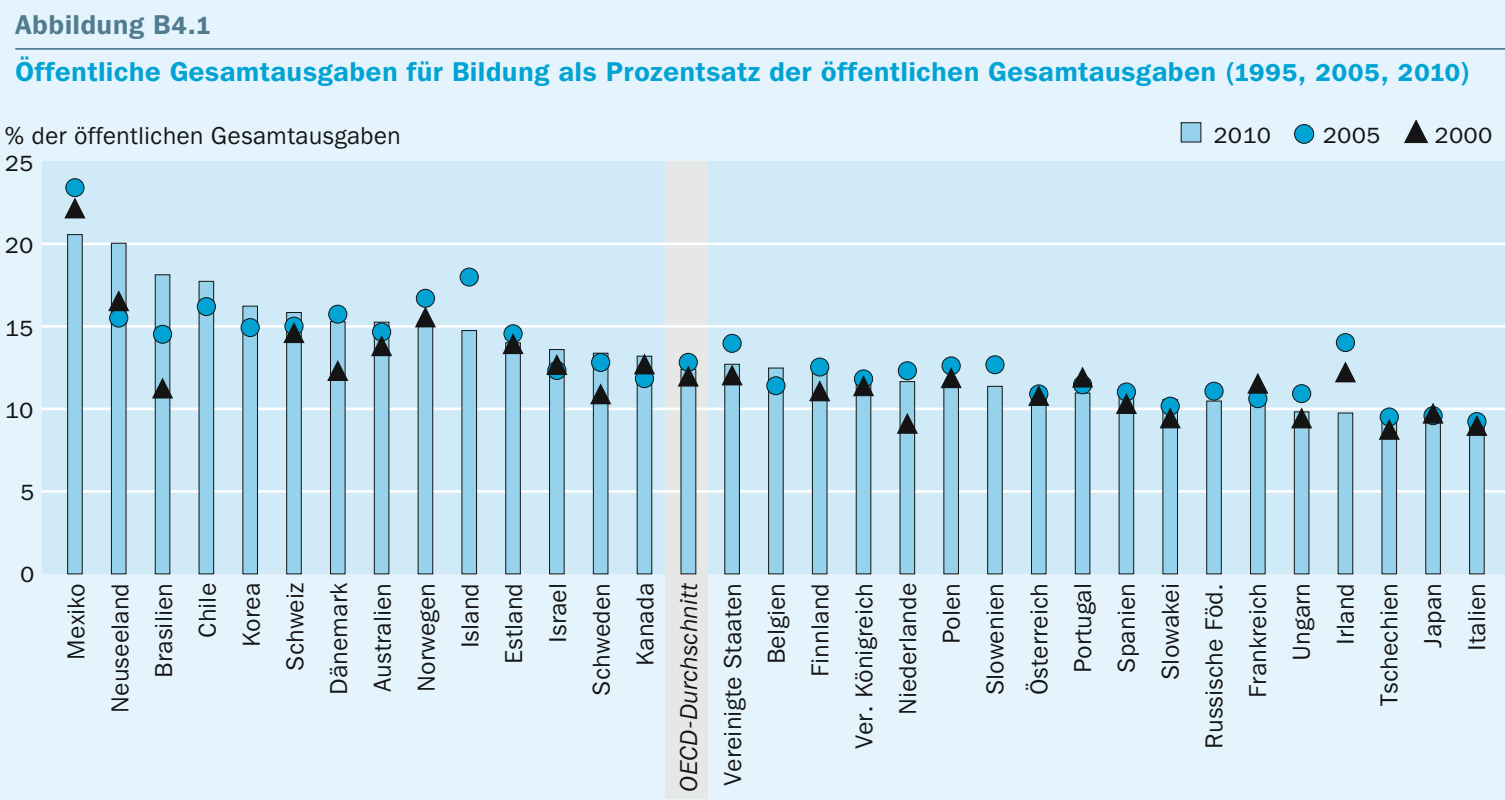

Anordnung der Länder in absteigender Reihenfolge der öffentlichen Gesamtausgaben für Bildung in allen Bildungsbereichen zusammen als Prozentsatz der öffentlichen Gesamtausgaben im Jahr 2010.

Quelle: OECD. Tabelle B4.2. Hinweise s. Anhang 3 unter www.oecd.org/edu/eag.htm. StatLink: http://dx.doi.org/10.1787/888932847032 


\section{Kontext}

Die Entscheidungen der Länder über die Zuweisung von Haushaltsmitteln auf die unterschiedlichen Sektoren, wie z. B. Bildung, Gesundheit, soziale Sicherheit oder Verteidigung, hängen nicht nur von den jeweiligen Prioritäten ab, sondern auch davon, ob die Märkte allein diese Dienstleistungen - insbesondere im Tertiärbereich angemessen erbringen können. Die Märkte werden möglicherweise versagen, wenn der öffentliche Nutzen größer als der private Nutzen ist. Staatliche Mittel können beispielsweise dazu beitragen, mehr Mitgliedern der Gesellschaft Zugang zu Bildung zu verschaffen. Die Wirtschaftskrise belastete die öffentlichen Haushalte jedoch so stark, dass möglicherweise weniger öffentliche Mittel für Bildung bereitgestellt werden. Dies kann wiederum den Zugang zu Bildung oder die Ergebnisse und die Qualität von Bildung beeinflussen. Andererseits könnte die Nachfrage von Erwerbslosen nach Bildung und Ausbildung steigen, wodurch höhere Bildungsausgaben notwendig werden. Doch höhere Ausgaben bedeuten nicht notwendigerweise bessere Ergebnisse oder eine höhere Qualität der Ausbildung. Außerdem werden Ausgaben durch viele Faktoren beeinflusst (s. Indikator B7), die bei einem Vergleich der einzelnen Länder zu berücksichtigen sind.

Dieser Indikator stellt die öffentlichen Gesamtausgaben für Bildung dar, und zwar sowohl im Verhältnis zu den öffentlichen Gesamtausgaben eines Landes als auch im Verhältnis zum jeweiligen Bruttoinlandsprodukt, um die relative Größe des jeweiligen öffentlichen Haushalts zu berücksichtigen. Darüber hinaus enthält er Informationen über die verschiedenen öffentlichen Finanzierungsquellen für das Bildungswesen (zentrale, regionale und lokale staatliche Ebenen) und Transferzahlungen zwischen den verschiedenen staatlichen Ebenen.

\section{Weitere wichtige Ergebnisse}

In den meisten OECD-Ländern sind die öffentlichen Bildungsausgaben für den Primar-, Sekundar- und postsekundaren, nicht tertiären Bereich mehr als doppelt so hoch wie für den Tertiärbereich.

Im Primar-, Sekundar- und postsekundaren, nicht tertiären Bereich erfolgt die öffentliche Finanzierung dezentraler als im Tertiärbereich. Im Durchschnitt stammen in den OECDLändern mehr als 50 Prozent der originären öffentlichen Mittel für diese Bildungsbereiche von der zentralen staatlichen Ebene.

Rund 87 Prozent der öffentlichen Mittel für den Tertiärbereich stammen von der zentralen staatlichen Ebene (vor Berücksichtigung von Transfers öffentlicher Mittel von der zentralen staatlichen Ebene an regionale und lokale staatliche Ebenen).

Im Primar-, Sekundar- und postsekundaren, nicht tertiären Bildungsbereich hatte allein Neuseeland eine vollkommen zentralisierte Finanzierung durch öffentliche Mittel, während der Tertiärbereich in neun Ländern (Chile, Estland, Irland, Island, Neuseeland, den Niederlanden, Norwegen, der Slowakei und Ungarn) vollständig zentral finanziert wird. 


\section{Entwicklungstendenzen}

Zwischen 1995 und 2010 stieg der für Bildung (alle Bildungsbereiche zusammen) verwendete Anteil der öffentlichen Gesamtausgaben in zwei Drittel der Länder mit verfügbaren Daten leicht an. Aber während des Zeitraums von 2005 bis 2010 gingen die öffentlichen Ausgaben für Bildung als Prozentsatz der öffentlichen Gesamtausgaben in knapp zwei Drittel der Länder mit verfügbaren Daten zurück. Dieser Rückgang war in Irland, Island, Mexiko, Norwegen, Polen, Slowenien, Ungarn und den Vereinigten Staaten (mit mindestens I Prozentpunkt) besonders ausgeprägt (Tab. B4.2).

Ähnliche Veränderungen waren zwischen 1995 und 20 Io bei den öffentlichen Ausgaben für Bildung als Prozentsatz des BIP zu beobachten, und auch hier verlief die Entwicklung während des Zeitraums 2005 bis 2010 ganz anders. Während der Anteil der öffentlichen Ausgaben für Bildung in den meisten Ländern von 2005 bis 2010 rückläufig war, stiegen die Bildungsausgaben als Prozentsatz des BIP während dieses Zeitraums in fast allen Ländern. Im Durchschnitt stiegen sie in den OECD-Ländern mit verfügbaren Daten zu beiden Jahren um fast o,4 Prozentpunkte - das Ergebnis eines Anstiegs der öffentlichen Ausgaben bei gleichzeitigem Rückgang des BIP (s. Indikator B2).

Zwischen 2008 und 2010 stiegen in allen Ländern mit Ausnahme von Estland, Island, Italien und Ungarn sowohl die Ausgaben für Bildung als auch die öffentlichen Gesamtausgaben für alle Leistungsbereiche. In 16 von 30 Ländern stiegen dabei die öffentlichen Ausgaben für alle Leistungsbereiche schneller als die öffentlichen Ausgaben für Bildung (Tab. B4.2).

\section{Analyse und Interpretationen}

\section{Gesamtvolumen der in Bildung investierten öffentlichen Mittel}

2010 wendeten die OECD-Länder für die öffentlichen Gesamtausgaben für Bildung im Durchschnitt I3, o Prozent ihrer öffentlichen Gesamtausgaben für alle Leistungsbereiche auf, wobei die Bandbreite von höchstens Io Prozent in Irland (9,7 Prozent), Italien (8,9 Prozent), Japan (9,3 Prozent), Tschechien ( 9,7 Prozent) und Ungarn ( 9,8 Prozent) bis zu mindestens 20 Prozent in Mexiko (20,6 Prozent) und Neuseeland (20,0 Prozent) reichte (Abb. B4.I und Tab. B4.I).

In den meisten Ländern werden rund zwei Drittel der öffentlichen Gesamtausgaben für Bildung (als Prozentsatz der öffentlichen Gesamtausgaben) für den Primar-, Sekundar- und postsekundaren, nicht tertiären Bereich aufgewendet. Dies erklärt sich hauptsächlich durch die fast universelle Bildungsbeteiligung in diesen Bildungsbereichen (s. Indikator CI) und die demografische Bevölkerungsstruktur.

Die öffentlichen Ausgaben für den Tertiärbereich belaufen sich im Durchschnitt der OECD-Länder auf weniger als ein Viertel (23,5 Prozent) der öffentlichen Gesamtausgaben für Bildung. In den OECD- und sonstigen G20-Ländern reicht dieser Anteil von 
weniger als 16 Prozent in Korea ( ${ }_{5}, 8$ Prozent) bis zu mehr als 30 Prozent in Kanada $(35,4$ Prozent) und Finnland (31,8 Prozent).

Bei der Betrachtung der öffentlichen Bildungsausgaben als Teil der öffentlichen Gesamtausgaben ist die relative Größe der öffentlichen Haushalte zu berücksichtigen. Die Ergebnisse verändern sich, wenn man die öffentlichen Gesamtausgaben für Bildung für alle Bildungsbereiche zusammen als Prozentsatz des BIP betrachtet und diese mit den öffentlichen Gesamtausgaben für Bildung als Prozentsatz der öffentlichen Gesamtausgaben vergleicht. Unter den OECD-Ländern zählten 20 Io Chile (mit 4, I Prozent), Italien (mit 4,5 Prozent), Japan (mit 3,8 Prozent), die Slowakei (mit 4,2 Prozent) und Tschechien (mit 4,2 Prozent) zu den Ländern mit den niedrigsten öffentlichen Ausgaben für Bildung im Verhältnis zum BIP, ebenso wie das G20-Land Russische Föderation (mit 4,I Prozent). Am anderen Ende des Spektrums wendeten nur Dänemark und Norwegen mehr als 8 Prozent des BIP für Bildung auf (jeweils 8,8 Prozent), wesentlich mehr als der OECD-Durchschnitt von 5,8 Prozent (Tab. B4.I).

Entgegen den Erwartungen liegen die Länder mit den höchsten öffentlichen Gesamtausgaben für Bildung als Prozentsatz der öffentlichen Gesamtausgaben im Jahr 2010 Brasilien, Korea, Neuseeland und die Schweiz (Abb. B4.I) - ganz hinten bezüglich der öffentlichen Gesamtausgaben als Prozentsatz des BIP (Abb. B4.2). Dänemark und Island sind hier die Ausnahmen, da sie bei beiden Kennzahlen hohe Werte aufweisen (Abb. B4.2).

Bei der Betrachtung der öffentlichen Gesamtausgaben für alle Leistungsbereiche (z. B. Gesundheit, soziale Sicherheit, Umwelt) und nicht allein der öffentlichen Bildungsausgaben als Prozentsatz des BIP variieren die Zahlen erheblich zwischen den einzelnen Ländern. Mehr als ein Drittel der Länder gab für 2010 an, dass die öffentlichen Gesamtausgaben für alle Leistungsbereiche als Prozentsatz des BIP mehr als 50 Prozent

Abbildung B4.2

Öffentliche Gesamtausgaben für alle Leistungsbereiche als Prozentsatz des BIP $(2000,2010)$

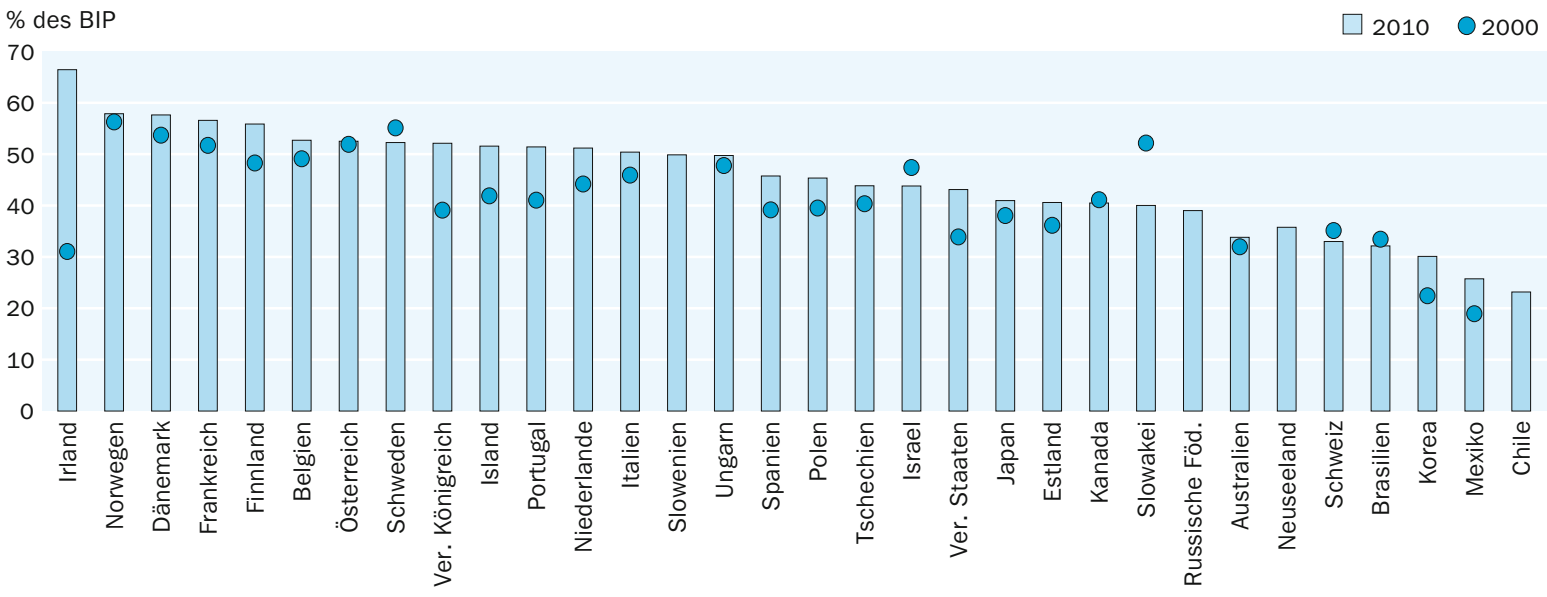

Anmerkung: Diese Abbildung zeigt die öffentlichen Gesamtausgaben für alle Leistungsbereiche und nicht nur die öffentlichen Ausgaben für Bildung. Anordnung der Länder in absteigender Reihenfolge der öffentlichen Gesamtausgaben als Prozentsatz des BIP im Jahr 2010.

Quelle: OECD. Anhang 2. Hinweise s. Anhang 3 unter www.oecd.org/edu/eag.htm. StatLink: http://dx.doi.org/10.1787/888932847051 
ausmachten, und in fünf der Länder waren es mehr als 55 Prozent $(57,6$ Prozent in Dänemark, 55,8 Prozent in Finnland, 56,5 Prozent in Frankreich, 66,4 Prozent in Irland und 57,8 Prozent in Norwegen). In Mexiko, am anderen Ende der Skala, beliefen sich die öffentlichen Gesamtausgaben auf 25,7 Prozent des BIP (Abb. B4.2 und Anhang 2).

\section{Veränderungen der öffentlichen Gesamtausgaben für Bildung als} Prozentsatz der öffentlichen Gesamtausgaben zwischen 1995 und 2010 Zwischen 1995 und 2005 wurde ein signifikanter Anstieg beobachtet ...

Im Verlauf der Io Jahre von 1995 bis 2005 stiegen die öffentlichen Bildungsausgaben (für alle Bildungsbereiche zusammen) als Prozentsatz der öffentlichen Gesamtausgaben in 20 der 26 OECD-Länder mit verfügbaren Daten sowohl für I995 als auch 2005 (durchschnittlich um o,8 Prozentpunkte in diesen 26 Ländern). Nur in Frankreich, Israel, Japan, Kanada, Neuseeland und Portugal ergab sich ein anderes Bild.

Zwischen 1995 und 2005 entwickelten sich die beiden Kennzahlen öffentliche Bildungsausgaben als Prozentsatz des BIP und öffentliche Bildungsausgaben als Prozentsatz der öffentlichen Gesamtausgaben unterschiedlich. Im Durchschnitt sanken die öffentlichen Ausgaben für Bildung als Prozentsatz des BIP zwischen 1995 und 2005 um o, I Prozentpunkte, wohingegen die öffentlichen Ausgaben für Bildung als Prozentsatz der öffentlichen Gesamtausgaben im gleichen Zeitraum um o,8 Prozentpunkte stiegen. In Brasilien, Dänemark, Griechenland, Mexiko und den Vereinigten Staaten stiegen die öffentlichen Bildungsausgaben als Prozentsatz des BIP um mehr als 0, 5 Prozentpunkte, während sie in Estland, Frankreich, Israel, Kanada, Österreich und der Slowakei um mehr als 0,5 Prozentpunkte sanken (Tab. B4.2).

... dem jedoch ab 2005 infolge der Finanzkrise des Jahres 2008 ein Rückgang folgte Die Ausgaben änderten sich zwischen 2005 und 2010 sehr. Während dieser 6 Jahre gingen die öffentlichen Bildungsausgaben als Prozentsatz der öffentlichen Gesamtausgaben in knapp zwei Drittel der Länder (in I9 von 32 Ländern) im Durchschnitt um 0,4 Prozentpunkte zurück (von I2,8 Prozent in 2005 auf I2,4 Prozent in 2010). Die größten Veränderungen gab es in Irland ( 4,2 Prozentpunkte), Island $(-3,3$ Prozentpunkte) und Mexiko (-2,9 Prozentpunkte). Auch in Norwegen, Polen, Slowenien, Ungarn und den Vereinigten Staaten gab es signifikante Veränderungen (mindestens - I Prozentpunkt). Ausnahmen waren hier Israel, Kanada und Neuseeland, wo es zwischen 1995 und 2005 zu einer Verringerung der Bildungsausgaben als Prozentsatz der öffentlichen Gesamtausgaben kam, der ein Anstieg der Ausgaben zwischen 2005 und 2010 folgte.

Bei einem Vergleich von 2010 mit 2005 ergibt sich ein anderes Bild, weil sich Auswirkungen der Finanzkrise auch auf das BIP bemerkbar machten. Daher stiegen die Bildungsausgaben als Prozentsatz des BIP in allen Ländern (mit Ausnahme von Norwegen, Polen, der Schweiz und Ungarn) zwischen diesen beiden Jahren bzw. blieben gleich. Im OECD-Durchschnitt für Länder mit verfügbaren Daten für alle Jahre belief sich der Anstieg auf 0,3 Prozentpunkte (Tab. B4.2 und Kasten B2.I in Indikator B2). 
Erste Auswirkungen der Finanzkrise: In mehr als der Hälfte der Länder stiegen die öffentlichen Ausgaben für Bildung langsamer als die öffentlichen Ausgaben für alle Leistungsbereiche

Die zwischen 2008 und 2010 beobachteten Veränderungen gehen wahrscheinlich auf die ersten Auswirkungen der globalen Wirtschaftskrise, die 2008 begann, zurück. Die Krise belastete die öffentlichen Haushalte insgesamt und erforderte von den Regierungen eine Priorisierung bei den Mittelzuweisungen für Bildung und andere wichtige öffentliche Sektoren, wie z. B. Gesundheit oder soziale Sicherheit (Tab. B4.2 und Abb. B4.3).

Im Zeitraum 2008 bis 2010 lassen sich im Gegensatz zum Zeitraum I995 bis 2005 keine klaren globalen Entwicklungstendenzen bei den öffentlichen Ausgaben für Bildung als Prozentsatz der öffentlichen Gesamtausgaben beobachten.

Gleichwohl stiegen in 26 von 30 Ländern zwischen 2008 und 2010 sowohl die öffentlichen Ausgaben für Bildung als auch die öffentlichen Ausgaben für alle Leistungsbereiche. In I6 dieser 30 Länder stiegen dabei die öffentlichen Ausgaben für alle Leistungsbereiche schneller als die öffentlichen Ausgaben für Bildung (Tab. B4.2 und Abb. B4.3). Die Unterschiede waren in Brasilien, Irland, Mexiko, Norwegen und den Vereinigten Staaten am größten. In Irland ist der Rückgang der öffentlichen Bildungsausgaben als Prozentsatz der öffentlichen Gesamtausgaben für alle Leistungsbereiche zwischen 2008 und 2010 um 27 Prozent größtenteils auf die sehr hohen Kapitaltransfers an irische Banken im Jahr 2010 zurückzuführen, die sich sehr stark auf die Nettokreditvergabe des Staates auswirkten.

In den I4 anderen Ländern stiegen die öffentlichen Bildungsausgaben schneller als die öffentlichen Ausgaben für alle Leistungsbereiche. Der Anstieg der öffentlichen Gesamtausgaben für alle Leistungsbereiche variierte zwischen I Prozent in Israel und der Schweiz und I4 Prozent in der Slowakei. In Australien belief sich der Anstieg für alle Leistungsbereiche zusammen auf 8 Prozent, während die Bildungsausgaben um 23 Prozent stiegen.

Nur in Estland, Island, Italien und Ungarn sanken die öffentlichen Ausgaben für alle Leistungsbereiche zwischen 2008 und 2010. In Island, wo die öffentlichen Gesamtausgaben für alle Leistungsbereiche um ganze 20 Prozent abnahmen, sanken die öffentlichen Bildungsausgaben zwar auch, jedoch weniger stark. In den anderen drei Ländern sanken die öffentlichen Ausgaben für Bildung stärker als die öffentlichen Gesamtausgaben (Tab. B4.2 und Abb. B4.3).

\section{Herkunft der öffentlichen Mittel, die in Bildung investiert werden}

Alle staatlichen Quellen für Mittel für Bildungsausgaben (außer den internationalen Quellen) sind einer der folgenden drei staatlichen Ebenen zugeordnet: der zentralen, der regionalen und der lokalen staatlichen Ebene. In einigen Ländern wird Bildung zentral finanziert, während in anderen die Finanzierung nach Transferzahlungen zwischen den verschiedenen staatlichen Ebenen sehr dezentral erfolgen kann.

In den letzten Jahren wurden viele Schulen zu autonomeren und dezentraleren Einrichtungen, die außerdem Schülern, Eltern und der Allgemeinheit gegenüber stärker re- 


\section{Abbildung B4.3}

Index der Veränderung der öffentlichen Gesamtausgaben für Bildung als Prozentsatz der öffentlichen Gesamtausgaben für alle Bildungsbereiche zusammen zwischen 2008 und 2010

(2008=100, zu konstanten Preisen von 2010)

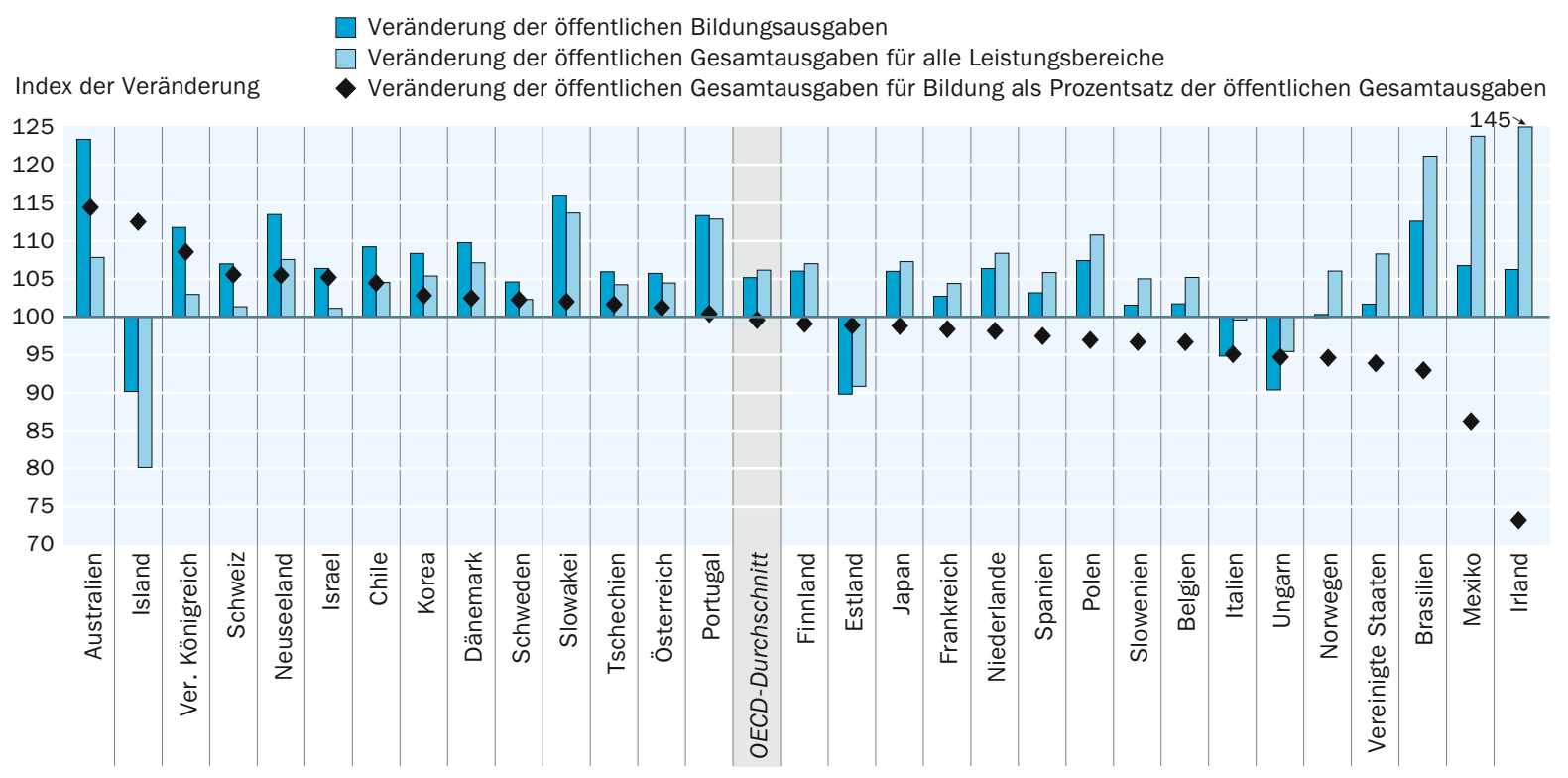

chenschaftspflichtig in Bezug auf die erzielten Ergebnisse geworden sind. Die Ergebnisse der Schulleistungsstudie PISA deuten darauf hin, dass - wenn Autonomie und Rechenschaftspflichten intelligent kombiniert werden - sie tendenziell mit besseren Leistungen der Schüler einhergehen.

Die Finanzierung mittels öffentlicher Mittel ist im Tertiärbereich stärker zentralisiert als in den anderen Bildungsbereichen. 20I0 stammten in den OECD-Ländern im Durchschnitt 53,8 Prozent der öffentlichen Mittel für den Primar-, Sekundar- und postsekundaren, nicht tertiären Bereich zusammen (vor Transferzahlungen) aus dem zentralen staatlichen Haushalt, verglichen mit 86,8 Prozent für den Tertiärbereich (Tab. B4.3 und Tab. B4.4 im Internet).

Der Anteil der originären Mittel von der zentralen staatlichen Ebene für den Primar-, Sekundar- und postsekundaren, nicht tertiären Bereich zusammen unterschied sich stark von Land zu Land. Vier Länder gaben einen Anteil von weniger als io Prozent an Kanada (3,7 Prozent), Norwegen (9,5 Prozent), Polen (4,4 Prozent) und die Schweiz (3,2 Prozent). In Kanada spielt die zentrale staatliche Ebene im Primar- und Sekundarbereich keine Rolle, die Finanzierung dieser Bildungsbereiche wird von den Provinzen bzw. Territorien zur Verfügung gestellt.

Am anderen Ende des Spektrums stammten in Irland, Neuseeland und der Türkei die öffentlichen Mittel fast ausschließlich von der zentralen staatlichen Ebene, ebenso wie mehr als 90 Prozent der originären öffentlichen Mittel in Chile (9I,9 Prozent), Israel (9I,2 Prozent) und den Niederlanden (90,3 Prozent). Berücksichtigt man jedoch die 
Abbildung B4.4

Originäre Herkunft der öffentlichen Mittel für Bildung im Primar-, Sekundar- und postsekundaren, nicht tertiären Bildungsbereich, nach staatlicher Ebene (2010)

In Prozentpunkten

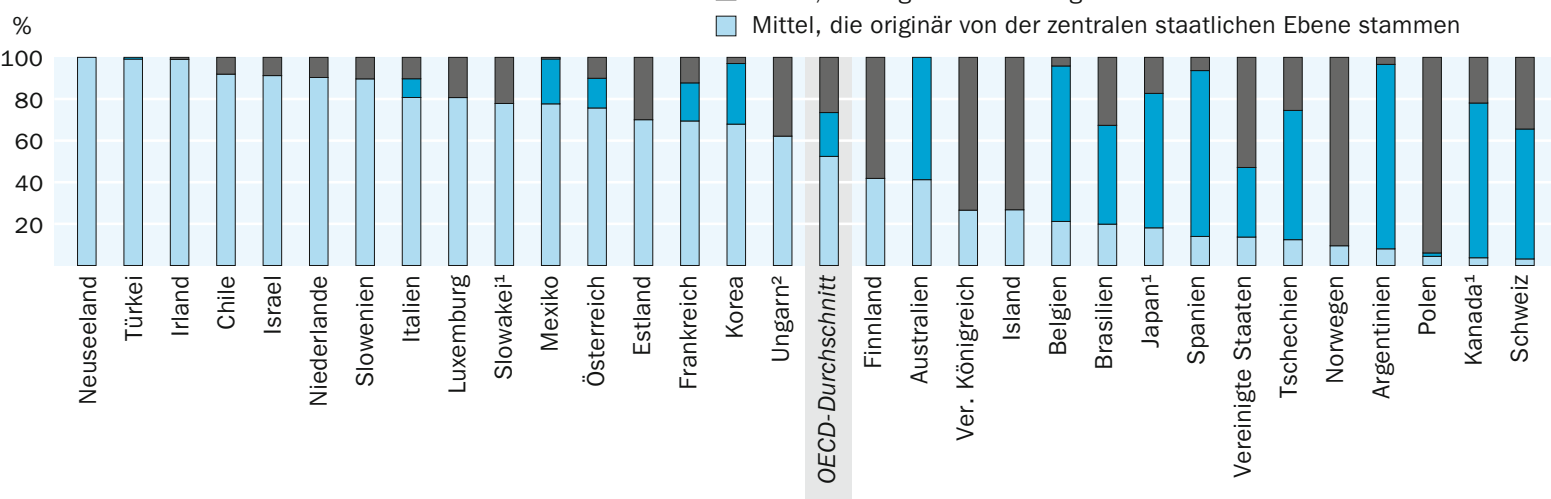

Veränderung des Anteils der Mittel für Bildung im Primar-, Sekundar- und postsekundaren, nicht tertiären Bildungsbereich, die von den unterschiedlichen staatlichen Ebenen stammen,

aufgegliedert nach den originären und letztendlichen Erwerbern von Bildungsressourcen (2010)
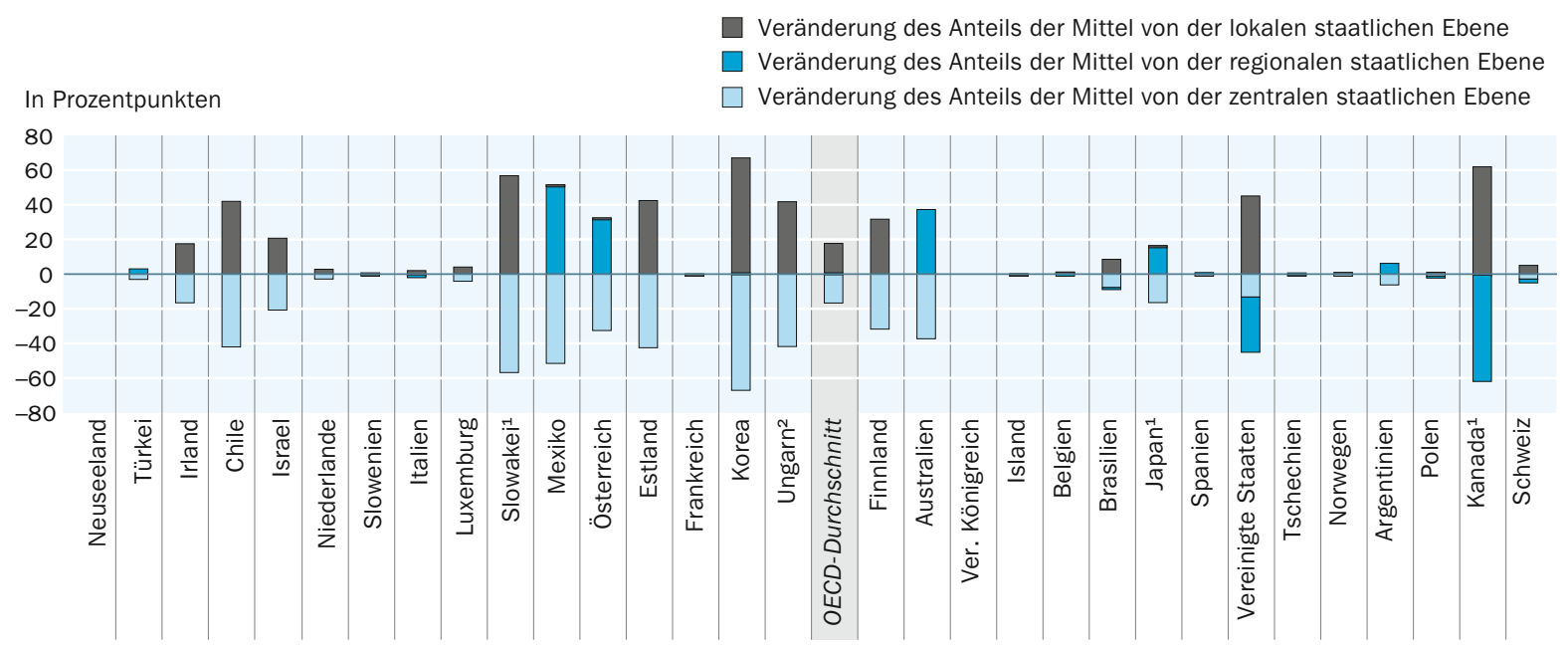

1. Einige Bildungsbereiche sind in anderen Bildungsbereichen enthalten. Einzelheiten s. Erläuterung von „x in Hinweise für den Leser. 2. Mittel von der lokalen staatlichen Ebene enthalten Mittel von der regionalen staatlichen Ebene.

Anordnung der Länder in absteigender Reihenfolge des Anteils der Mittel, die originär von der zentralen staatlichen Ebene stammen.

Quelle: OECD. Argentinien, Indonesien: Statistikinstitut der UNESCO (World Education Indicators Programm). Tabelle B4.3.

Hinweise s. Anhang 3 www.unter www.oecd.org/edu/eag.htm. StatLink: http://dx.doi.org/10.1787/888932847089

Transferzahlungen zwischen den einzelnen staatlichen Ebenen, ergibt sich ein stark verändertes Bild. Nach diesen Transferzahlungen stammten in Kanada (mit 3,I Prozent), Polen (3,3 Prozent) und der Schweiz (0,3 Prozent) weniger als 5 Prozent der öffentlichen Mittel aus zentralen staatlichen Quellen, dies galt jedoch auch für Australien (3,9 Prozent), Japan ( 1,7 Prozent), Korea (o,9 Prozent) und die Vereinigten Staaten ( 0,5 Prozent). Nur in Neuseeland erfolgt die Finanzierung (selbst nach Berücksichtigung der Transferzahlungen) ausschließlich zentral (Abb. B4.4 und Tab. B4.3).

Die Transferzahlungen von der zentralen staatlichen Ebene an regionale und lokale staatliche Ebenen im Primar-, Sekundar- und postsekundaren, nicht tertiären Bildungs- 
bereich zusammen sind im Durchschnitt der OECD-Länder höher als im Tertiärbereich, was die Dezentralisierung auch auf diese Bildungsbereiche ausdehnt. Im Primar-, Sekundar- und postsekundaren, nicht tertiären Bereich zusammen stammen im Durchschnitt der OECD-Länder 44,2 Prozent der öffentlichen Mittel nach Transferzahlungen von der lokalen staatlichen Ebene, verglichen mit 27,2 Prozent vor derartigen Transferzahlungen. Im Tertiärbereich stammen im Durchschnitt der OECD-Länder weniger als 3 Prozent der öffentlichen Mittel von der lokalen staatlichen Ebene, und zwar sowohl vor als auch nach Transferzahlungen (Tab. B4.3 und Tab. B4.4 im Internet).

Im Primar-, Sekundar- und postsekundaren, nicht tertiären Bereich zusammen gibt es zwischen den einzelnen Ländern große Unterschiede beim Umfang der Transferzahlungen von Mitteln der zentralen staatlichen Ebene an nachgeordnete staatliche Ebenen. Der Unterschied nach Transferzahlungen von der zentralen staatlichen Ebene an nachgeordnete staatliche Ebenen beträgt in Chile, Estland, Korea, Mexiko, der Slowakei und Ungarn mehr als 40 Prozentpunkte. In Australien, Kanada, Mexiko und den Vereinigten Staaten beläuft sich die Differenz nach Transferzahlungen öffentlicher Mittel von der regionalen staatlichen Eben auf die lokale staatliche Ebene auf mehr als 30 Prozentpunkte (Abb. B4.4).

Im Tertiärbereich ist der Anteil der öffentlichen Mittel von der zentralen staatlichen Ebene relativ hoch, und zwar sowohl vor als auch nach Transferzahlungen zwischen den verschiedenen staatlichen Ebenen. Am niedrigsten ist der Anteil der öffentlichen Mittel von der zentralen staatlichen Ebene in Belgien (26,6 Prozent vor und 25,3 Prozent nach Transferzahlungen) und Spanien (I6,o Prozent vor und I5,8 Prozent nach Transferzahlungen). Demgegenüber liegt dieser Anteil in Io Ländern sowohl vor als auch nach Transferzahlungen bei fast roo Prozent: Chile, Estland, Island, Neuseeland, den Niederlanden, Norwegen, Portugal, der Slowakei, Ungarn und dem Vereinigten Königreich (Tab. B4.4 im Internet).

\section{Definitionen}

Öffentliche Bildungsausgaben beinhalten die Ausgaben für Bildungseinrichtungen sowie Unterstützungsleistungen für den Lebensunterhalt von Schülern/Studierenden und für andere private Ausgaben außerhalb von Bildungseinrichtungen. Darin enthalten sind die Ausgaben sämtlicher öffentlicher Einrichtungen einschließlich anderer Ministerien neben dem Bildungsministerium sowie die Ausgaben der lokalen und regionalen Verwaltungen und anderer öffentlicher Stellen. Hinsichtlich der Verwendung öffentlicher Mittel für Bildung gibt es Unterschiede zwischen den einzelnen OECD-Ländern. Öffentliche Mittel können direkt an Bildungseinrichtungen fließen oder über staatliche Programme oder die privaten Haushalte in die Bildungseinrichtungen gelenkt werden. Sie können auch auf den Erwerb von Bildungsdienstleistungen beschränkt sein oder als Unterstützung zur Bestreitung der Lebenshaltungskosten von Schülern/Studierenden gewährt werden.

Alle staatlichen Quellen für Mittel für Bildungsausgaben (außer den internationalen Quellen) können einer der folgenden drei Ebenen zugeordnet werden: zentrale (nationale) staatliche Ebene, regionale staatliche Ebene (Provinz, Bundesstaat, Bundesland 
etc.), lokale staatliche Ebene (Stadt, Gemeinde, Distrikt etc.). Die Begriffe „regional“ und „lokal“ beziehen sich auf staatliche Stellen, deren Zuständigkeit sich auf bestimmte geografische Untereinheiten eines Landes beschränkt. Sie beziehen sich nicht auf staatliche Stellen, deren Befugnisse nicht geografisch determiniert sind, sondern die für bestimmte Dienstleistungen, Funktionen oder Gruppen von Schülern/Studierenden zuständig sind.

Öffentliche Gesamtausgaben beinhalten die nicht rückzahlbaren laufenden und investiven Ausgaben aller staatlichen Verwaltungseinheiten auf zentraler, regionaler und lokaler staatlicher Ebene. Darin sind die direkten öffentlichen Finanzmittel für Bildungseinrichtungen ebenso enthalten wie die öffentlichen Unterstützungsleistungen für private Haushalte (z. B. in Form von Stipendien und Studiendarlehen für Studiengebühren und die Lebenshaltungskosten von Studierenden) und andere private Einheiten für Bildungszwecke (z. B. Subventionen für Unternehmen oder Arbeitnehmerorganisationen, die Ausbildungsgänge im Rahmen der dualen Berufsausbildung durchführen).

\section{Angewandte Methodik}

Die Daten beziehen sich auf das Haushaltsjahr 2010 und beruhen auf der von der OECD im Jahre 2012 durchgeführten UOE-Datenerhebung zur Bildungsstatistik (weitere Informationen s. Anhang 3 unter www.oecd.org/eduleag.htm).

Die Zahlen für die öffentlichen Gesamtausgaben stammen aus der OECD-Datenbank der volkswirtschaftlichen Gesamtrechnungen (s. Anhang 2) und beruhen auf dem System of National Accounts 1993.

Bildungsausgaben werden ausgedrückt als Prozentsatz der öffentlichen Gesamtausgaben eines Landes und als Prozentsatz des BIP.

Ausgaben für den Schuldendienst (z. B. Zinszahlungen) sind zwar bei den öffentlichen Gesamtausgaben erfasst, nicht aber bei den öffentlichen Bildungsausgaben. Grund hierfür ist, dass einige Länder nicht zwischen den Zinszahlungen für den Bereich Bildung und denen für andere Bereiche differenzieren können. Das bedeutet, dass die öffentlichen Ausgaben für Bildung als Prozentsatz der öffentlichen Gesamtausgaben in denjenigen Ländern zu niedrig geschätzt sein können, in denen Zinszahlungen einen großen Teil der öffentlichen Gesamtausgaben für alle Leistungsbereiche ausmachen.

Die statistischen Daten für Israel wurden von den zuständigen israelischen Stellen bereitgestellt, die für sie verantwortlich zeichnen. Die Verwendung dieser Daten durch die OECD erfolgt unbeschadet des völkerrechtlichen Status der Golanhöhen, von OstJerusalem und der israelischen Siedlungen im Westjordanland. 


\section{Tabellen Indikator B4}

Tabelle B4.I: Öffentliche Gesamtausgaben für Bildung (2010)

StatLink: http://dx.doi.org/10.1787/888932849806

Tabelle B4.2: Öffentliche Gesamtausgaben für Bildung (1995, 2000, 2005 und 2010)

StatLink: http://dx.doi.org/10.1787/888932849825

Tabelle B4.3: Herkunft der Mittel für öffentliche Bildungsausgaben im Primar-, Sekundar- und postsekundaren, nicht tertiären Bereich, nach staatlicher Ebene (2010)

StatLink: http:||dx.doi.org/10.1787/888932849844

WEB Table B4.4: Sources of public educational funds, before and after transfers, by level of government for tertiary education (Herkunft der Mittel für öffentliche Bildungsausgaben für den Tertiärbereich, vor und nach Transferzahlungen, nach staatlicher Ebene) (2010)

StatLink: http://dx.doi.org/10.1787/888932849863

WEB Table B4.5: Distribution of total public expenditure on education (Öffentliche Gesamtausgaben für Bildung) (2010)

StatLink: http://dx.doi.org/10.1787/888932849882 
Tabelle B4.1

Öffentliche Gesamtausgaben für Bildung (2010)

Direkte öffentliche Ausgaben für Bildungseinrichtungen plus öffentliche Subventionen an private Haushalte ${ }^{1}$ und andere private Einheiten als Prozentsatz der öffentlichen Gesamtausgaben und als Prozentsatz des BIP, nach Bildungsbereich

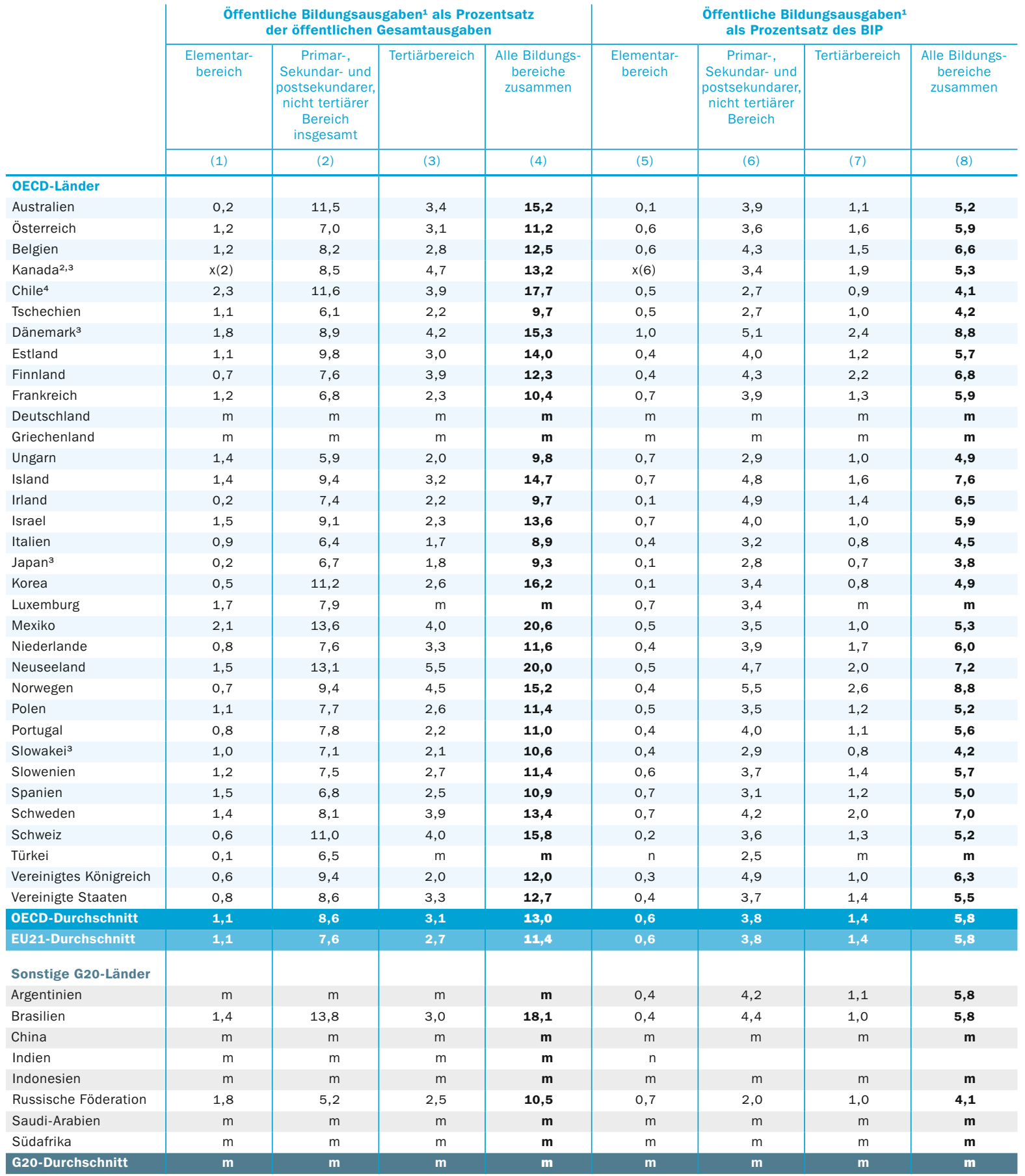

1. In dieser Tabelle enthaltene öffentliche Ausgaben beinhalten öffentliche Subventionen an private Haushalte für den Lebensunterhalt (Stipendien und Studienbeihilfen für Schüler bzw. Studierende/private Haushalte und Studiendarlehen), die nicht für Bildungseinrichtungen ausgegeben werden. Daher übersteigen die in dieser Tabelle angegebenen Zahlen die für öffentliche Ausgaben für Bildungseinrichtungen in Tabelle B2.4. 2. Referenzjahr 2009 anstelle $2010 . \quad 3$. Einige Bildungsbereiche sind in anderen Bildungsbereichen enthalten. Einzelheiten s. Erläuterung von „x“ in Hinweise für den Leser. 4. Referenzjahr 2011 anstelle 2010. Quelle: OECD. Argentinien: Statistikinstitut der UNESCO (World Education Indicators Programme). Hinweise s. Anhang 3 unter www.oecd.org/edu/eag.htm. StatLink: http://dx.doi.org/10.1787/888932849806

Erläuterung der Kennzeichnung fehlender Daten s. Hinweise für den Leser. 
Öffentliche Gesamtausgaben für Bildung (1995, 2000, 2005 und 2010)

Direkte öffentliche Ausgaben für Bildungseinrichtungen plus öffentliche Subventionen an private Haushalte ${ }^{1}$ und andere private Einheiten als Prozentsatz der öffentlichen Gesamtausgaben und als Prozentsatz des BIP, für alle Bildungsbereiche zusammen, nach Jahr

\begin{tabular}{|c|c|c|c|c|c|c|c|c|c|c|c|}
\hline & \multicolumn{4}{|c|}{$\begin{array}{l}\text { Öffentliche Bildungsausgaben }{ }^{1} \\
\text { als Prozentsatz der öffentlichen } \\
\text { Gesamtausgaben }\end{array}$} & \multicolumn{4}{|c|}{$\begin{array}{l}\text { Öffentliche Bildungsausgaben }{ }^{1} \\
\text { als Prozentsatz des BIP }\end{array}$} & \multicolumn{3}{|c|}{$\begin{array}{l}\text { Index der Veränderung zwischen } 2008 \text { und } 2010 \\
(2008=100, \text { zu konstanten Preisen })\end{array}$} \\
\hline & 1995 & 2000 & 2005 & 2010 & 1995 & 2000 & 2005 & 2010 & $\begin{array}{l}\text { Öffentliche } \\
\text { Bildungs- } \\
\text { ausgaben }\end{array}$ & $\begin{array}{c}\text { Öffentliche } \\
\text { Gesamtausgaben } \\
\text { für alle Leistungs- } \\
\text { bereiche }\end{array}$ & \begin{tabular}{|c} 
Öffentliche \\
Gesamtausgaben \\
für Bildung als \\
Prozentsatz der \\
offentlichen \\
Gesamtausgaben
\end{tabular} \\
\hline & (1) & (2) & (3) & (4) & (5) & (6) & (7) & (8) & (9) & (10) & (11) \\
\hline \multicolumn{12}{|l|}{ OECD-Länder } \\
\hline Australien & 13,8 & 14,3 & 14,6 & 15,2 & 4,8 & 4,6 & 4,5 & 5,2 & 123 & 108 & 114 \\
\hline Österreich & 10,8 & 10,7 & 10,9 & 11,2 & 6,1 & 5,6 & 5,4 & 5,9 & 106 & 104 & 101 \\
\hline Belgien & $\mathrm{m}$ & 12,0 & 11,4 & 12,5 & $\mathrm{~m}$ & 5,9 & 5,9 & 6,6 & 102 & 105 & 97 \\
\hline Kanada ${ }^{2,3}$ & 12,7 & 12,4 & 11,8 & 13,2 & 6,2 & 5,1 & 5,1 & 5,3 & $\mathrm{~m}$ & $\mathrm{~m}$ & $\mathrm{~m}$ \\
\hline Chile $^{4}$ & $\mathrm{~m}$ & $\mathrm{~m}$ & 16,2 & 17,7 & $\mathrm{~m}$ & $\mathrm{~m}$ & 3,0 & 4,1 & 109 & 105 & 104 \\
\hline Tschechien & 8,7 & 9,5 & 9,5 & 9,7 & 4,5 & 3,8 & 4,1 & 4,2 & 106 & 104 & 102 \\
\hline Dänemark ${ }^{3}$ & 12,3 & 15,4 & 15,7 & 15,3 & 7,3 & 8,3 & 8,3 & 8,8 & 110 & 107 & 102 \\
\hline Estland & 13,9 & 14,8 & 14,5 & 14,0 & 5,8 & 5,4 & 4,9 & 5,7 & 90 & 91 & 99 \\
\hline Finnland & 11,1 & 12,5 & 12,5 & 12,3 & 6,8 & 6,0 & 6,3 & 6,8 & 106 & 107 & 99 \\
\hline Frankreich & 11,5 & 11,6 & 10,6 & 10,4 & 6,3 & 6,0 & 5,7 & 5,9 & 103 & 104 & 98 \\
\hline Deutschland & 8,6 & 10,2 & 10,1 & $\mathrm{~m}$ & 4,7 & 4,6 & 4,8 & $\mathrm{~m}$ & $\mathrm{~m}$ & 107 & $\mathrm{~m}$ \\
\hline Griechenland & 5,6 & 7,3 & $\mathrm{~m}$ & $\mathrm{~m}$ & 2,6 & 3,4 & 4,1 & $\mathrm{~m}$ & $\mathrm{~m}$ & 94 & $\mathrm{~m}$ \\
\hline Ungarn & 9,4 & 10,4 & 10,9 & 9,8 & 5,3 & 5,0 & 5,5 & 4,9 & 90 & 95 & 95 \\
\hline Island & $\mathrm{m}$ & 15,9 & 18,0 & 14,7 & $\mathrm{~m}$ & 6,7 & 7,6 & 7,6 & 90 & 80 & 113 \\
\hline Irland & 12,2 & 13,7 & 14,0 & 9,7 & 5,0 & 4,2 & 4,7 & 6,5 & 106 & 145 & 73 \\
\hline Israel & 12,7 & 13,4 & 12,3 & 13,6 & 6,5 & 6,3 & 5,6 & 5,9 & 106 & 101 & 105 \\
\hline Italien & 9,0 & 9,8 & 9,2 & 8,9 & 4,7 & 4,5 & 4,4 & 4,5 & 95 & 100 & 95 \\
\hline$J_{a p a n^{3}}$ & 9,7 & 9,5 & 9,6 & 9,3 & 3,5 & 3,6 & 3,5 & 3,8 & 106 & 107 & 99 \\
\hline Korea & $\mathrm{m}$ & 16,6 & 14,9 & 16,2 & $\mathrm{~m}$ & 3,7 & 4,0 & 4,9 & 108 & 105 & 103 \\
\hline Luxemburg & $\mathrm{m}$ & $\mathrm{m}$ & $\mathrm{m}$ & $\mathrm{m}$ & $\mathrm{m}$ & $\mathrm{m}$ & $\mathrm{m}$ & $\mathrm{m}$ & $\mathrm{m}$ & 108 & $\mathrm{~m}$ \\
\hline Mexiko & 22,2 & 23,4 & 23,4 & 20,6 & 4,2 & 4,4 & 5,0 & 5,3 & 107 & 124 & 86 \\
\hline Niederlande & 9,1 & 11,2 & 12,3 & 11,6 & 5,1 & 5,0 & 5,5 & 6,0 & 106 & 108 & 98 \\
\hline Neuseeland & 16,5 & $\mathrm{~m}$ & 15,5 & 20,0 & 5,6 & 6,7 & 6,0 & 7,2 & 113 & 108 & 105 \\
\hline Norwegen & 15,6 & 14,0 & 16,7 & 15,2 & 9,3 & 7,8 & 9,3 & 8,8 & 100 & 106 & 95 \\
\hline Polen & 11,9 & 12,7 & 12,6 & 11,4 & 5,2 & 5,0 & 5,5 & 5,2 & 107 & 111 & 97 \\
\hline Portugal & 11,9 & 12,7 & 11,4 & 11,0 & 4,9 & 5,2 & 5,2 & 5,6 & 113 & 113 & 100 \\
\hline Slowakei ${ }^{3}$ & 9,4 & 7,5 & 10,1 & 10,6 & 4,6 & 3,9 & 3,8 & 4,2 & 116 & 114 & 102 \\
\hline Slowenien & $\mathrm{m}$ & $\mathrm{m}$ & 12,6 & 11,4 & $\mathrm{~m}$ & $\mathrm{~m}$ & 5,7 & 5,7 & 102 & 105 & 97 \\
\hline Spanien & 10,3 & 10,9 & 11,0 & 10,9 & 4,6 & 4,3 & 4,2 & 5,0 & 103 & 106 & 97 \\
\hline Schweden & 10,9 & 13,0 & 12,8 & 13,4 & 7,1 & 7,2 & 6,9 & 7,0 & 105 & 102 & 102 \\
\hline Schweiz & 14,6 & 14,4 & 15,0 & 15,8 & 5,3 & 5,1 & 5,5 & 5,2 & 107 & 101 & 106 \\
\hline Türkei & $\mathrm{m}$ & $\mathrm{m}$ & $\mathrm{m}$ & $\mathrm{m}$ & $\mathrm{m}$ & $\mathrm{m}$ & $\mathrm{m}$ & $\mathrm{m}$ & $\mathrm{m}$ & 116 & $\mathrm{~m}$ \\
\hline Ver. Königreich & 11,4 & 11,0 & 11,8 & 12,0 & 5,0 & 4,3 & 5,2 & 6,3 & 112 & 103 & 109 \\
\hline Vereinigte Staaten & 12,0 & 13,8 & 13,9 & 12,7 & 4,5 & 4,7 & 5,1 & 5,5 & 102 & 108 & 94 \\
\hline OECD-Durchschnitt & 11,8 & 12,6 & 13,1 & 13,0 & 5,4 & 5,2 & 5,3 & 5,8 & 105 & 106 & 100 \\
\hline EU21-Durchschnitt & 10,4 & 11,4 & 11,8 & 11,4 & 5,3 & 5,1 & 5,3 & 5,8 & 104 & 106 & 98 \\
\hline $\begin{array}{l}\text { OECD-Durchschnitt } \\
\text { (Länder mit ver- } \\
\text { fügbaren Daten für } \\
\text { alle Jahre }\end{array}$ & 12,0 & 12,6 & 12,8 & 12,4 & 5,5 & 5,2 & 5,4 & 5,7 & & & \\
\hline
\end{tabular}

\begin{tabular}{|c|c|c|c|c|c|c|c|c|c|c|c|}
\hline \multicolumn{12}{|l|}{ Sonst. G20-Länder } \\
\hline Argentinien & $\mathrm{m}$ & $\mathrm{m}$ & $\mathrm{m}$ & $\mathrm{m}$ & $\mathrm{m}$ & $\mathrm{m}$ & $\mathrm{m}$ & 5,8 & $\mathrm{~m}$ & $\mathrm{~m}$ & $\mathrm{~m}$ \\
\hline Brasilien & 11,2 & 10,5 & 14,5 & 18,1 & 3,9 & 3,5 & 4,5 & 5,8 & 113 & 121 & 93 \\
\hline China & $\mathrm{m}$ & $\mathrm{m}$ & $\mathrm{m}$ & $\mathrm{m}$ & $\mathrm{m}$ & $\mathrm{m}$ & $\mathrm{m}$ & $\mathrm{m}$ & $\mathrm{m}$ & $\mathrm{m}$ & $\mathrm{m}$ \\
\hline Indien & $\mathrm{m}$ & $\mathrm{m}$ & $\mathrm{m}$ & $\mathrm{m}$ & $\mathrm{m}$ & $\mathrm{m}$ & $\mathrm{m}$ & & $\mathrm{m}$ & $\mathrm{m}$ & $\mathrm{m}$ \\
\hline Indonesien & $\mathrm{m}$ & $\mathrm{m}$ & $\mathrm{m}$ & $\mathrm{m}$ & $\mathrm{m}$ & $\mathrm{m}$ & $\mathrm{m}$ & $\mathrm{m}$ & $\mathrm{m}$ & $\mathrm{m}$ & $\mathrm{m}$ \\
\hline Russische Föd. & $m$ & 10,6 & 11,0 & 10,5 & $\mathrm{~m}$ & $\mathrm{~m}$ & $\mathrm{~m}$ & 4,1 & $\mathrm{~m}$ & $\mathrm{~m}$ & $\mathrm{~m}$ \\
\hline Saudi-Arabien & $\mathrm{m}$ & $\mathrm{m}$ & $\mathrm{m}$ & $\mathrm{m}$ & $\mathrm{m}$ & $\mathrm{m}$ & $\mathrm{m}$ & $\mathrm{m}$ & $\mathrm{m}$ & $\mathrm{m}$ & $\mathrm{m}$ \\
\hline Südafrika & $\mathrm{m}$ & $\mathrm{m}$ & $\mathrm{m}$ & $\mathrm{m}$ & $\mathrm{m}$ & $\mathrm{m}$ & $\mathrm{m}$ & $\mathrm{m}$ & $\mathrm{m}$ & $\mathrm{m}$ & $\mathrm{m}$ \\
\hline G20-Durchschnitt & $\mathbf{m}$ & $\mathbf{m}$ & $\mathbf{m}$ & m & $\mathbf{m}$ & $\mathbf{m}$ & $\mathbf{m}$ & $\mathbf{m}$ & $\mathbf{m}$ & $\mathbf{m}$ & $\mathbf{m}$ \\
\hline
\end{tabular}

1. In dieser Tabelle enthaltene öffentliche Ausgaben beinhalten öffentliche Subventionen an private Haushalte für den Lebensunterhalt (Stipendien und Studienbeihilfen für Schüler bzw. Studierende/private Haushalte und Studiendarlehen), die nicht für Bildungseinrichtungen ausgegeben werden. Daher übersteigen die in dieser Tabelle angegebenen Zahlen die für öffentliche Ausgaben für Bildungseinrichtungen in Tabelle B2.4. 2. Referenzjahr 2009 anstelle 2010. 3. Einige Bildungsbereiche sind in anderen Bildungsbereichen enthalten. Einzelheiten s. Erläuterung von „x“ in Hinweise für den Leser. 4 . Referenzjahr 2011 anstelle 2010. Daten beziehen sich auf 2009-2011 anstelle 2008-2010.

Quelle: OECD. Argentinien: Statistikinstitut der UNESCO (World Education Indicators Programme). Hinweise s. Anhang 3 unter www.oecd.org/edu/eag.htm. StatLink: http://dx.doi.org/10.1787/888932849825

Erläuterung der Kennzeichnung fehlender Daten s. Hinweise für den Leser. 
Tabelle B4.3

Herkunft der Mittel für öffentliche Bildungsausgaben im Primar-, Sekundar- und postsekundaren, nicht tertiären Bereich, nach staatlicher Ebene (2010)

\begin{tabular}{|c|c|c|c|c|c|c|c|c|}
\hline & \multicolumn{4}{|c|}{$\begin{array}{l}\text { Originäre Herkunft der Mittel (vor Transferzahlungen } \\
\text { zwischen den verschiedenen staatlichen Ebenen) }\end{array}$} & \multicolumn{4}{|c|}{$\begin{array}{l}\text { Letztendliche Herkunft der Mittel (nach Transferzahlungen } \\
\text { zwischen den verschiedenen staatlichen Ebenen) }\end{array}$} \\
\hline & $\begin{array}{l}\text { Zentrale staat- } \\
\text { liche Ebene }\end{array}$ & $\begin{array}{l}\text { Regionale } \\
\text { Ebene }\end{array}$ & Lokale Ebene & Gesamt & $\begin{array}{l}\text { Zentrale staat- } \\
\text { liche Ebene }\end{array}$ & $\begin{array}{l}\text { Regionale } \\
\text { Ebene }\end{array}$ & Lokale Ebene & Gesamt \\
\hline & (1) & (2) & (3) & (4) & (5) & (6) & (7) & (8) \\
\hline \multicolumn{9}{|l|}{ OECD-Länder } \\
\hline Australien & 41,2 & 58,8 & $\mathrm{~m}$ & 100,0 & 3,9 & 96,1 & $\mathrm{~m}$ & 100,0 \\
\hline Österreich & 75,7 & 14,3 & 10,0 & 100,0 & 43,1 & 46,5 & 10,4 & 100,0 \\
\hline Belgien & 21,2 & 74,7 & 4,1 & 100,0 & 22,3 & 73,5 & 4,1 & 100,0 \\
\hline Kanada ${ }^{1,2}$ & 3,7 & 74,3 & 21,9 & 100,0 & 3,1 & 13,0 & 83,9 & 100,0 \\
\hline Chile $^{3}$ & 91,9 & a & 8,1 & 100,0 & 49,9 & a & 50,1 & 100,0 \\
\hline Tschechien & 12,4 & 62,1 & 25,5 & 100,0 & 11,7 & 62,8 & 25,5 & 100,0 \\
\hline Dänemark ${ }^{2}$ & $\mathrm{~m}$ & $\mathrm{~m}$ & $\mathrm{~m}$ & 100,0 & 41,4 & $\mathrm{n}$ & 58,6 & 100,0 \\
\hline Estland & 70,0 & a & 30,0 & 100,0 & 27,6 & a & 72,4 & 100,0 \\
\hline Finnland & 41,8 & a & 58,2 & 100,0 & 10,1 & a & 89,9 & 100,0 \\
\hline Frankreich & 69,4 & 18,3 & 12,3 & 100,0 & 69,3 & 18,3 & 12,4 & 100,0 \\
\hline Deutschland & $\mathrm{m}$ & $\mathrm{m}$ & $\mathrm{m}$ & $\mathrm{m}$ & $\mathrm{m}$ & $\mathrm{m}$ & $\mathrm{m}$ & $\mathrm{m}$ \\
\hline Griechenland & $\mathrm{m}$ & $\mathrm{m}$ & $\mathrm{m}$ & $\mathrm{m}$ & $\mathrm{m}$ & $\mathrm{m}$ & $\mathrm{m}$ & $\mathrm{m}$ \\
\hline Ungarn & 62,1 & $x(3)$ & 37,9 & 100,0 & 20,4 & $x(7)$ & 79,6 & 100,0 \\
\hline Island & 26,8 & a & 73,2 & 100,0 & 26,5 & a & 73,5 & 100,0 \\
\hline Irland & 99,0 & a & 1,0 & 100,0 & 82,5 & a & 17,5 & 100,0 \\
\hline Israel & 91,2 & a & 8,8 & 100,0 & 70,5 & a & 29,5 & 100,0 \\
\hline Italien & 80,7 & 9,0 & 10,3 & 100,0 & 80,2 & 7,5 & 12,3 & 100,0 \\
\hline$J^{\prime} a p a n^{2}$ & 18,1 & 64,6 & 17,3 & 100,0 & 1,7 & 81,0 & 17,3 & 100,0 \\
\hline Korea & 67,9 & 29,1 & 3,0 & 100,0 & 0,9 & 29,9 & 69,2 & 100,0 \\
\hline Luxemburg & 80,7 & a & 19,3 & 100,0 & 76,6 & a & 23,4 & 100,0 \\
\hline Mexiko & 77,7 & 22,1 & 0,2 & 100,0 & 26,1 & 73,7 & 0,2 & 100,0 \\
\hline Niederlande & 90,3 & $\mathrm{n}$ & 9,7 & 100,0 & 87,5 & $\mathrm{n}$ & 12,5 & 100,0 \\
\hline Neuseeland & 100,0 & $\mathrm{n}$ & $\mathrm{n}$ & 100,0 & 100,0 & $\mathrm{n}$ & $\mathrm{n}$ & 100,0 \\
\hline Norwegen & 9,5 & $\mathrm{n}$ & 90,5 & 100,0 & 8,4 & $\mathrm{n}$ & 91,6 & 100,0 \\
\hline Polen & 4,4 & 1,7 & 94,0 & 100,0 & 3,3 & 1,6 & 95,1 & 100,0 \\
\hline Portugal & $\mathrm{m}$ & $\mathrm{m}$ & $\mathrm{m}$ & $\mathrm{m}$ & $\mathrm{m}$ & $\mathrm{m}$ & $\mathrm{m}$ & $\mathrm{m}$ \\
\hline Slowakei ${ }^{2}$ & 77,8 & a & 22,2 & 100,0 & 21,0 & a & 79,0 & 100,0 \\
\hline Slowenien & 89,7 & a & 10,3 & 100,0 & 88,9 & a & 11,1 & 100,0 \\
\hline Spanien & 14,0 & 79,7 & 6,4 & 100,0 & 13,0 & 80,6 & 6,4 & 100,0 \\
\hline Schweden & $\mathrm{m}$ & $\mathrm{m}$ & $\mathrm{m}$ & $\mathrm{m}$ & $\mathrm{m}$ & $\mathrm{m}$ & $\mathrm{m}$ & $\mathrm{m}$ \\
\hline Schweiz & 3,2 & 62,4 & 34,4 & 100,0 & 0,3 & 60,2 & 39,5 & 100,0 \\
\hline Türkei & 99,3 & 0,7 & $\mathrm{~m}$ & 100,0 & 96,2 & 3,8 & $\mathrm{~m}$ & 100,0 \\
\hline Vereinigtes Königreich & 26,6 & a & 73,4 & 100,0 & 26,6 & a & 73,4 & 100,0 \\
\hline Vereinigte Staaten & 13,7 & 33,4 & 52,9 & 100,0 & 0,5 & 1,5 & 98,0 & 100,0 \\
\hline OECD-Durchschnitt & 53,8 & 21,6 & 27,2 & 100,0 & 37,1 & 22,4 & 44,2 & 100,0 \\
\hline EU21-Durchschnitt & 57,2 & 17,3 & 26,5 & 100,0 & 42,7 & 18,2 & 40,2 & 100,0 \\
\hline \multicolumn{9}{|l|}{ Sonstige G20-Länder } \\
\hline Argentinien & 8,0 & 88,6 & 3,4 & 100,0 & 1,8 & 94,8 & 3,4 & 100,0 \\
\hline Brasilien & 19,9 & 47,5 & 32,7 & 100,0 & 12,1 & 46,7 & 41,2 & 100,0 \\
\hline China & $\mathrm{m}$ & $\mathrm{m}$ & $\mathrm{m}$ & $\mathrm{m}$ & $\mathrm{m}$ & $\mathrm{m}$ & $\mathrm{m}$ & $\mathrm{m}$ \\
\hline Indien & $\mathrm{m}$ & $\mathrm{m}$ & $\mathrm{m}$ & $\mathrm{m}$ & $\mathrm{m}$ & $\mathrm{m}$ & $\mathrm{m}$ & $\mathrm{m}$ \\
\hline Indonesien & $\mathrm{m}$ & $\mathrm{m}$ & $\mathrm{m}$ & $\mathrm{m}$ & $\mathrm{m}$ & $\mathrm{m}$ & $\mathrm{m}$ & $\mathrm{m}$ \\
\hline Russische Föderation & $\mathrm{m}$ & $\mathrm{m}$ & $\mathrm{m}$ & $\mathrm{m}$ & 2,1 & 32,4 & 65,5 & 100,0 \\
\hline Saudi-Arabien & $\mathrm{m}$ & $\mathrm{m}$ & $\mathrm{m}$ & $\mathrm{m}$ & $\mathrm{m}$ & $\mathrm{m}$ & $\mathrm{m}$ & $\mathrm{m}$ \\
\hline Südafrika & $\mathrm{m}$ & $\mathrm{m}$ & $\mathrm{m}$ & $\mathrm{m}$ & $\mathrm{m}$ & $\mathrm{m}$ & $\mathrm{m}$ & $\mathrm{m}$ \\
\hline G20-Durchschnitt & $\mathbf{m}$ & m & $\mathbf{m}$ & $\mathbf{m}$ & m & $\mathbf{m}$ & $\mathbf{m}$ & $\mathbf{m}$ \\
\hline
\end{tabular}

1. Referenzjahr 2009. 2. Einige Bildungsbereiche sind in anderen Bildungsbereichen enthalten. Einzelheiten s. Erläuterung von „x“ in Hinweise für den Leser. 3. Referenzjahr 2011.

Quelle: OECD. Argentinien: Statistikinstitut der UNESCO (World Education Indicators Programme). Hinweise s. Anhang 3 unter www.oecd.org/edu/eag.htm. StatLink: http://dx.doi.org/10.1787/888932849844

Erläuterung der Kennzeichnung fehlender Daten s. Hinweise für den Leser. 


\section{Wie hoch sind die Studiengebühren und welche öffentlichen Unterstützungs- leistungen erhalten Studierende?}

In den OECD- und G 20-Ländern gibt es signifikante Unterschiede bei der Höhe der von Bildungseinrichtungen des Tertiärbereichs erhobenen Studiengebühren. In acht OECD-Ländern erheben öffentliche Bildungseinrichtungen überhaupt keine Studiengebühren, in einem Drittel der 26 OECD-Länder mit verfügbaren Daten jedoch verlangen öffentliche Bildungseinrichtungen von inländischen Studierenden jährliche Studiengebühren von mehr als I.500 US-Dollar.

Hohe Studiengebühren werden meist in den Ländern erhoben, in denen private Einheiten (z. B. Unternehmen) auch am stärksten zur Finanzierung der Bildungseinrichtungen im Tertiärbereich beitragen.

In immer mehr OECD-Ländern werden für internationale Studierende höhere Studiengebühren als für inländische Studierende erhoben. Durchschnittlich 22 Prozent der öffentlichen Ausgaben für den Tertiärbereich betreffen finanzielle Unterstützungsleistungen an Studierende, private Haushalte und andere private Einheiten.

\section{Abbildung B5.1}

Verhältnis zwischen den durchschnittlichen Studiengebühren öffentlicher Bildungseinrichtungen und dem Anteil der Studierenden im Tertiärbereich A, die öffentliche Darlehen und/oder Stipendien/Zuschüsse erhalten (2011) Für inländische Studierende im Vollzeitstudium, in US-Dollar, kaufkraftbereinigt mittels KKP für das BIP, Studienjahr 2010/2011

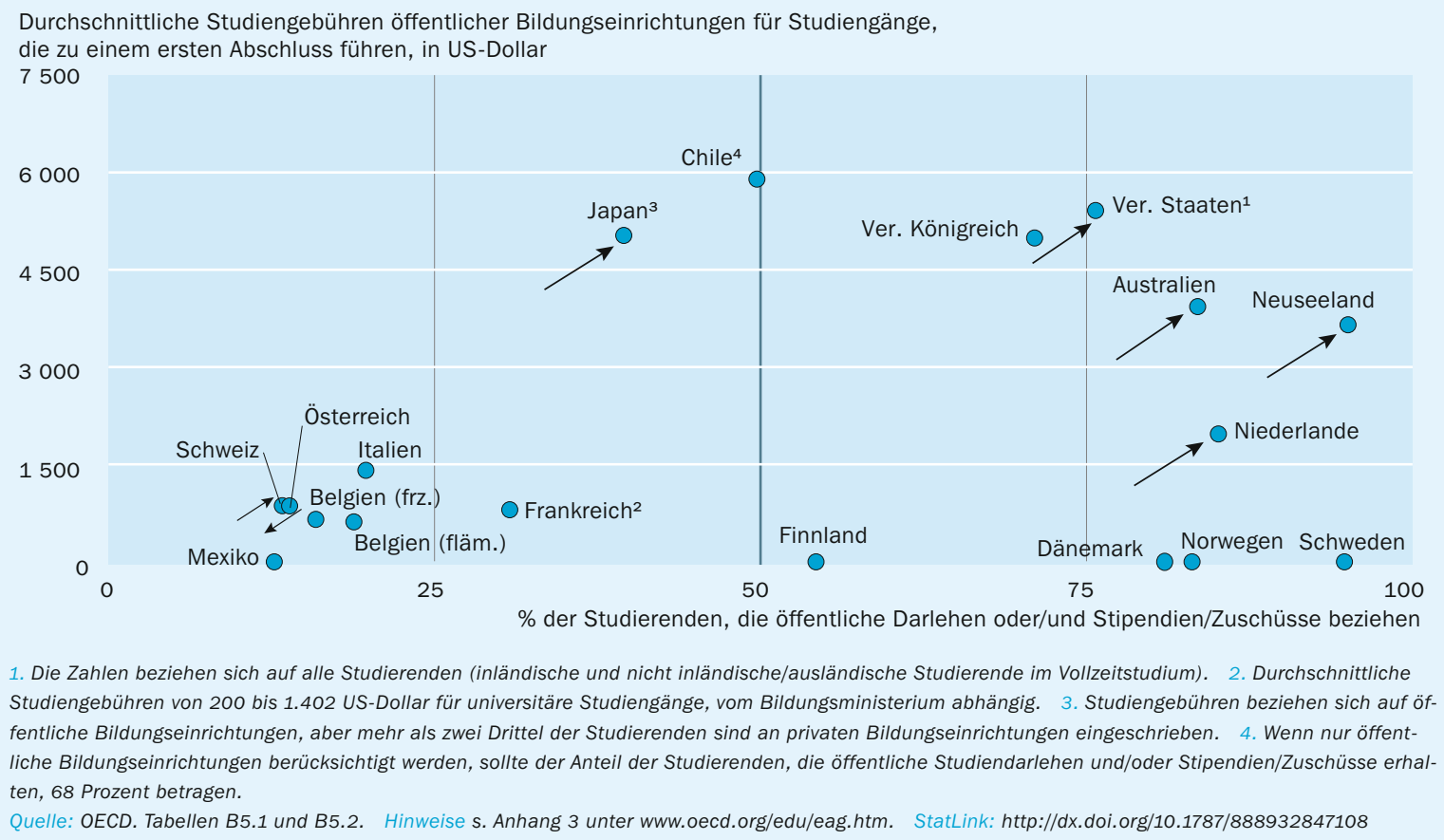

Erläuterung der Abbildung: Die Abbildung zeigt für den Tertiärbereich A das Verhältnis zwischen den jährlich von öffentlichen Bildungseinrichtungen erhobenen Studiengebühren und den an private Haushalte gezahlten öffentlichen Unterstützungsleistungen für den Lebensunterhalt von Studierenden. Der Pfeil zeigt an, wie sich die durchschnittlichen Studiengebühren sowie der Anteil der Studierenden, die öffentliche Unterstützungsleistungen erhalten, seit 1995 aufgrund von Reformen verändert haben. 


\section{Kontext}

Politische Entscheidungen über die Höhe der Studiengebühren von Bildungseinrichtungen wirken sich sowohl auf die Kosten eines Studiums für die Studierenden aus als auch auf die Ressourcen, die den Bildungseinrichtungen im Tertiärbereich zur Verfügung stehen. Öffentliche Unterstützungsleistungen an Studierende und ihre Familien dienen den Ländern auch als Mittel zur Steigerung der Bildungsbeteiligung, insbesondere von Schülern und Studierenden aus einkommensschwachen Familien, indem ein Teil der direkten und indirekten Bildungskosten übernommen wird. Hierdurch haben die Regierungen die Möglichkeit, Probleme des Zugangs zu Bildung und der Chancengleichheit anzugehen. Die Auswirkungen dieser Unterstützungsleistungen müssen daher - zumindest teilweise - anhand einer Untersuchung von Aufnahme, Weiterverfolgung und Abschluss einer Ausbildung im Tertiärbereich beurteilt werden.

Öffentliche Unterstützungsleistungen spielen auch bei der indirekten Finanzierung von Bildungseinrichtungen im Tertiärbereich eine Rolle. Finanzmittel für Bildungseinrichtungen über Studierende zu lenken kann auch ein Beitrag zu mehr Wettbewerb zwischen den Bildungseinrichtungen sein. Da Zuschüsse zu den Lebenshaltungskosten der Studierenden ein Erwerbseinkommen ersetzen können, können öffentliche Subventionen dazu beitragen, den Bildungsstand anzuheben, da die Studierenden so teilweise auf eine Erwerbstätigkeit neben dem Studium verzichten können. Diese Unterstützungsleistungen können in vielfältiger Weise bereitgestellt werden, u.a. als bedarfsabhängige Zuschüsse, als Familienbeihilfen für Studierende, als Steuerfreibeträge für Studierende oder ihre Eltern oder in Form sonstiger Transferleistungen an private Haushalte. Vor allem während einer Finanzkrise müssen die Regierungen das richtige Verhältnis zwischen diesen verschiedenen Formen der Unterstützung finden. Bei einer festen Gesamtsumme der Subventionen können öffentliche Unterstützungsleistungen wie Steuerermäßigungen oder Familienbeihilfen für einkommensschwache Studierende eine geringere Unterstützung darstellen, als dies bei bedarfsabhängigen Zuschüssen der Fall ist, da Erstere nicht spezifisch auf einkommensschwache Studierende abzielen. Sie können jedoch auf jeden Fall dazu beitragen, finanzielle Ungleichheiten zwischen Haushalten mit und ohne Kinder in Ausbildung abzubauen.

\section{Weitere wichtige Ergebnisse}

Rund die Hälfte der 26 OECD-Länder mit verfügbaren Daten erheben je nach Fachrichtung unterschiedlich hohe Studiengebühren für zu einem ersten Abschluss führende Studiengänge. Die Länder gehen in Bezug auf die Höhe der Studiengebühren im Zusammenhang mit den von den Studierenden gewählten Studiengängen nicht einheitlich vor. Die wichtigsten Kriterien für diese Differenzierung bei den Studiengebühren sind einerseits die unterschiedlich hohen öffentlichen Kosten für die einzelnen Studiengänge und andererseits die sich mit einem Abschluss ergebenden Arbeitsmarktchancen.

In den OECD-Ländern sind die Studiengebühren an öffentlichen und staatlich subventionierten privaten Bildungseinrichtungen im Allgemeinen für Studiengänge, die zu einem zweiten oder weiteren Abschluss führen, nicht wesentlich höher als die für Studiengänge, die zu 
einem ersten Abschluss führen. Ausnahmen sind hier Australien, Chile und das Vereinigte Königreich.

Die hohen Studienanfängerquoten im Tertiärbereich in einigen der Länder ohne Studiengebühren hängen vermutlich auch damit zusammen, dass es bei ihnen sehr gut entwickelte öffentliche Unterstützungsleistungen für Studierende gibt, und nicht nur damit, dass es keine Studiengebühren gibt.

OECD-Länder, in denen Studierende zwar Studiengebühren zahlen müssen, aber ausgesprochen hohe öffentliche Unterstützungsleistungen erhalten, haben keine unterdurchschnittlichen Studienanfängerquoten im Tertiärbereich A.

Systeme der Finanzhilfe, die für alle Studierenden Darlehen mit einkommensabhängiger Rückzahlung in Kombination mit bedarfsabhängigen Zuschüssen anbieten, können eine effiziente Möglichkeit darstellen, den Zugang und die Chancengleichheit für Studierende zu fördern und gleichzeitig die Kosten der Hochschulausbildung zwischen Staat und Studierenden aufzuteilen.

\section{Entwicklungstendenzen}

Wie in Bildung auf einen Blick 2012 berichtet, haben 14 der 25 Länder mit verfügbaren Daten ihr System der Studiengebühren seit 1995 reformiert. In allen I4 Ländern - mit Ausnahme von Island und der Slowakei - erfolgten diese Reformen parallel zu Änderungen der Höhe der öffentlichen Unterstützungsleistungen für Studierende.

In mehreren Ländern gab es seit 2009 weitere Veränderungen bei den Studiengebühren und den öffentlichen Unterstützungsleistungen für Studierende. Im Vereinigten Königreich beispielsweise wurden die Studiengebühren 2012 als Teil eines Regierungsprogramms zur Stabilisierung der Finanzen der Universitäten verdoppelt bzw. an einigen Universitäten fast verdreifacht. Die nachfolgend verwendeten Daten beziehen sich jedoch auf den Zeitraum 20I0/20II und spiegeln daher diese jüngsten Entwicklungen noch nicht wider. Korea führte 20II Reformen zur Verbesserung der öffentlichen Unterstützungsleistungen für Studierende im Hochschulbereich ein, um den Zugang und die Chancengleichheit im Tertiärbereich A zu verbessern.

\section{Analyse und Interpretationen}

\section{Studiengebühren für inländische Studierende an Bildungs- einrichtungen des Tertiärbereichs A}

Gegenwärtig gibt es heftige Debatten zu den bildungspolitischen Themen der Kosten im Hochschulwesen und der besten Möglichkeit zur Unterstützung der Studierenden, diese zu tragen. Die Höhe der von den Bildungseinrichtungen im Tertiärbereich erhobenen Studiengebühren sowie die Höhe und Art der von den einzelnen Ländern durch ihre jeweiligen Subventionssysteme für Studierende gewährten finanziellen Unterstützung können sich stark auf den Zugang zum und die Chancengleichheit im Tertiärbereich auswirken. 
Das richtige Verhältnis zwischen ausreichender Unterstützung der Bildungseinrichtungen durch Studiengebühren und Aufrechterhaltung des Zugangs zu Bildung und Chancengleichheit zu finden ist eine große Aufgabe. Einerseits vergrößern hohe Studiengebühren die Ressourcen, die Bildungseinrichtungen zur Verfügung stehen, unterstützen sie in ihren Bemühungen, auch weiterhin qualitativ hochwertige Studiengänge anzubieten und neue zu entwickeln, und können den Bildungseinrichtungen dabei helfen, mehr Studierende aufzunehmen. Aber sie können auch den Zugang zu Hochschulbildung für Studierende beschränken, insbesondere für Studierende aus einkommensschwachen Familien, wenn es kein ausgeprägtes System öffentlicher Unterstützungsleistungen gibt, mit dessen Hilfe die Kosten eines Studiums bezahlt bzw. erstattet werden. Daneben könnten hohe Studiengebühren manche Studierende davon abhalten, sich für Fachrichtungen mit langen Studiengängen zu entscheiden, wenn es keine ausreichenden Perspektiven auf dem Arbeitsmarkt gibt.

Andererseits können niedrige Studiengebühren Zugang und Chancengleichheit insbesondere von einkommensschwachen Bevölkerungsschichten fördern. Aber sie könnten auch die Möglichkeiten der Bildungseinrichtungen einschränken, ein hohes Ausbildungsniveau aufrechtzuerhalten, insbesondere angesichts der deutlichen Ausweitung des Tertiärbereichs in allen OECD-Ländern in den letzten Jahren. Die Belastungen der Haushalte aufgrund der globalen Wirtschaftskrise könnte es für Länder mit niedrigeren Studiengebühren außerdem schwieriger machen, dieses Modell auch in Zukunft weiterzuverfolgen.

Bei der durchschnittlichen Höhe der Studiengebühren, die von öffentlichen Bildungseinrichtungen des Tertiärbereichs A von inländischen Studierenden für zu einem ersten Abschluss führende Studiengänge erhoben werden, bestehen große Unterschiede zwischen den einzelnen Ländern. Die öffentlichen Bildungseinrichtungen in den fünf nordischen Ländern, die eine progressivere Besteuerung haben (Dänemark, Finnland, Island, Norwegen und Schweden), sowie in Mexiko, Polen und Slowenien erheben keine Studiengebühren. Im Gegensatz dazu erhebt ein Drittel der Länder mit verfügbaren Daten zu öffentlichen Bildungseinrichtungen Studiengebühren von mindestens I.500 US-Dollar, und in Chile, Japan, Korea und den Vereinigten Staaten sind es mehr als 5.00o US-Dollar. Währenddessen zahlen Studierende für ein Studium im Tertiärbereich A in Belgien, Frankreich, Italien, Österreich, der Schweiz, Spanien und der Türkei nur geringe Studiengebühren. Unter den EU2 I-Ländern mit verfügbaren Daten werden nur in den Niederlanden, der Slowakei und dem Vereinigten Königreich jährliche Studiengebühren für einen inländischen Vollzeitstudierenden von mehr als I.500 USDollar erhoben (Tab. B5.I und Abb. B5.2).

Die Studiengebühren für inländische Studierende für Studiengänge, die zu einem zweiten oder weiteren Abschluss führen, sind im Allgemeinen nicht wesentlich höher als für Studiengänge, die zu einem ersten Abschluss führen. Die Mehrzahl der Länder mit verfügbaren Daten verlangt Studiengebühren, die denen der Studiengänge, die zu einem ersten Abschluss führen, entsprechen oder nur geringfügig höher sind. Ausnahmen bilden hier Australien, Chile, Irland, Neuseeland und das Vereinigte Königreich. In Australien steigt die Höhe der Studiengebühren an öffentlichen Bildungseinrichtungen von Studiengängen, die zu einem ersten Abschluss führen, zu Studiengängen, die zu einem zweiten oder weiteren Abschluss führen, von 3.924 US-Dollar auf 
Abbildung B5.2

Durchschnittliche jährliche Studiengebühren für inländische Studierende im Vollzeitstudium an öffentlichen Bildungseinrichtungen des Tertiärbereichs A (2011)

In US-Dollar, kaufkraftbereinigt mittels KKP für das BIP, Studienjahr 2010/2011

Durchschnittliche jährliche Studiengebühren in US-Dollar

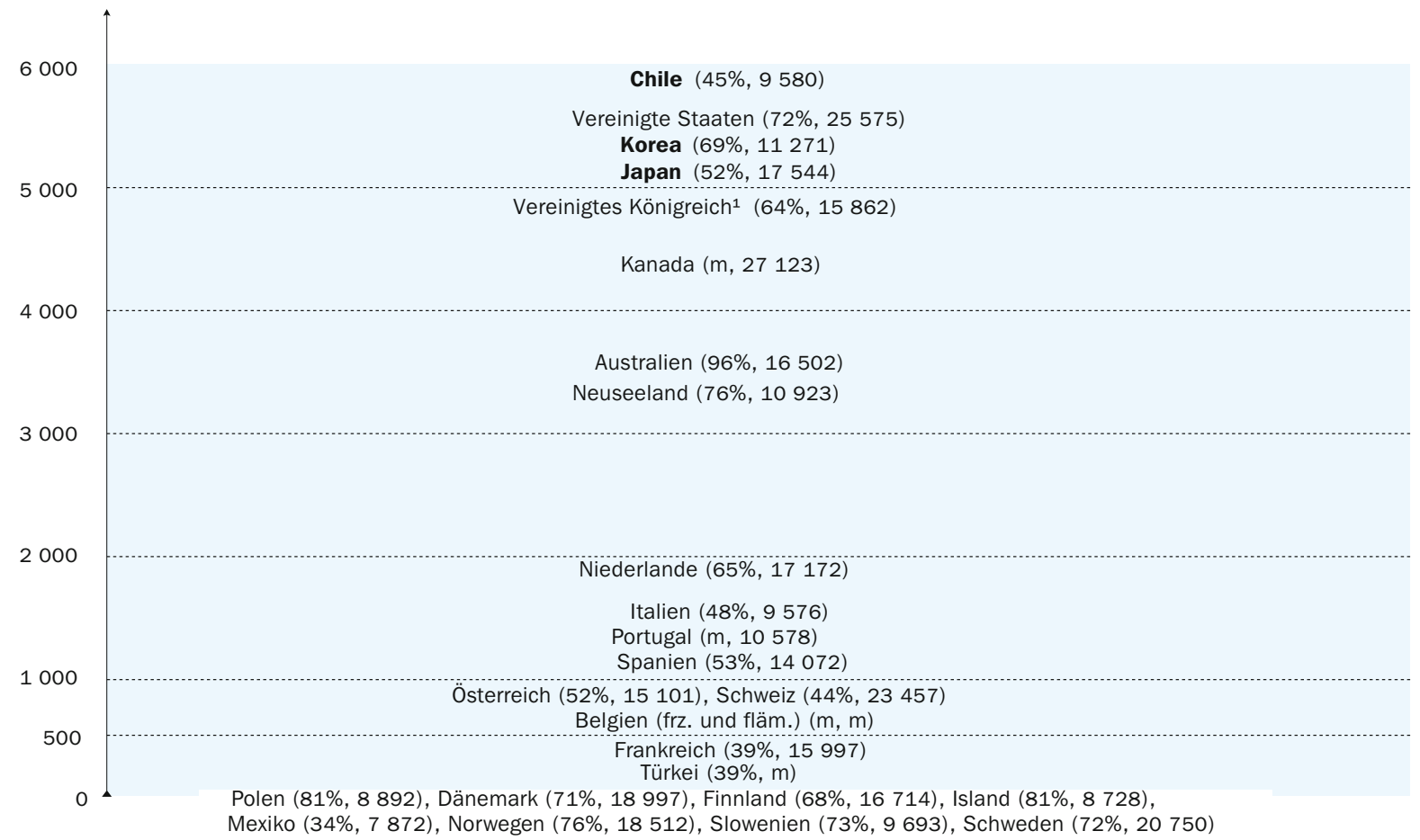

Anmerkung: Diese Abbildung zeigt die jährlichen Studiengebühren in US-Dollar, kaufkraftbereinigt mittels KKP. Fett gedruckte Ländernamen bedeuten, dass sich die Studiengebühren auf öffentliche Bildungseinrichtungen beziehen, jedoch mehr als zwei Drittel der Studierenden an privaten Bildungseinrichtungen eingeschrieben sind. Nach dem Ländernamen folgen in der runden Klammer die Netto-Studienanfängerquote und die Ausgaben pro Studierenden im Tertiärbereich A (in US-Dollar). In dieser Abbildung werden keine Stipendien, Zuschüsse oder Darlehen, die die Studiengebühren ganz oder teilweise abdecken, berücksichtigt. 1. In diesem Bildungsbereich gibt es keine öffentlichen Bildungseinrichtungen, und fast alle Studierenden sind in staatlich subventionierten privaten Bildungseinrichtungen eingeschrieben.

Quelle: OECD. Tabellen B1.1a, B5.1 und Indikator C3. Hinweise s. Anhang 3 unter www.oecd.org/edu/eag.htm. StatLink: http://dx.doi.org/10.1787/888932847127 Erläuterung der Kennzeichnung fehlender Daten s. Hinweise für den Leser.

6.099 US-Dollar, während sie an unabhängigen privaten Bildungseinrichtungen leicht sinkt. In Australien, Chile und im Vereinigten Königreich unterscheiden sich die Studiengebühren bei Studiengängen, die zu einem ersten Abschluss führen, auch nach dem Studienfach. Die Türkei ist dagegen das einzige Land, in dem die Gebühren für Studiengänge zur Erlangung eines zweiten oder weiteren Abschlusses an öffentlichen Bildungseinrichtungen niedriger sind (Tab B5.I und B5.3).

\section{Für ausländische Studierende sind die Studiengebühren oft höher}

Die nationalen Bestimmungen für Studiengebühren und Finanzhilfen an Studierende gelten im Allgemeinen für alle Studierenden an den Bildungseinrichtungen des jeweiligen Landes. Bei diesen bildungspolitischen Regelungen werden auch internationale Studierende berücksichtigt. Wird bei der Höhe der Studiengebühren oder der finanziellen Unterstützung im Studienland zwischen inländischen und internationalen Studierenden unterschieden, kann sich dies (zusammen mit anderen Faktoren) auf die Mobilität internationaler Studierender auswirken. Diese Unterschiede machen einige Länder für Studierende attraktiver, während Studierende von einem Studium in anderen 
abgehalten werden können (s. Indikator $\mathrm{C}_{4}$ ), besonders da immer mehr OECD-Länder von internationalen Studierenden höhere Studiengebühren verlangen.

In der Mehrzahl der Länder mit verfügbaren Daten können öffentliche Bildungseinrichtungen für den gleichen Studiengang unterschiedliche Studiengebühren von inländischen und internationalen Studierenden erheben. In Österreich beispielsweise betragen die durchschnittlichen Studiengebühren, die öffentliche Bildungseinrichtungen von Studierenden erheben, die nicht Bürger eines EU- oder EWR-Landes sind, das Doppelte der von Studierenden dieser Länder erhobenen Gebühren. Ähnliche Regelungen gibt es in Dänemark (seit 2006/2007), Irland, Kanada, den Niederlanden, Neuseeland (mit Ausnahme ausländischer Promotionsstudierender), Polen, Schweden (seit 20II), der Schweiz, der Slowakei, Slowenien, der Türkei, dem Vereinigten Königreich und den Vereinigten Staaten. In diesen Ländern werden je nach Staatsangehörigkeit bzw. Wohnsitz des Studierenden unterschiedlich hohe Studiengebühren erhoben (s. Indikator $\mathrm{C}_{4}$ und Kasten $\mathrm{C}_{4} \cdot 3$ ). In Australien stehen internationalen Studierenden nicht die gleichen Unterstützungen wie nationalen Studierenden zu.

\section{Es gibt in den verschiedenen Ländern keinen eindeutigen Zusammen- hang zwischen der Höhe der Studiengebühren und den von den Studierenden gewählten Studiengängen}

Rund die Hälfte der 26 OECD-Länder mit verfügbaren Daten erheben je nach Fachrichtung unterschiedlich hohe Studiengebühren für zu einem ersten Abschluss führende Studiengänge an öffentlichen Bildungseinrichtungen des Tertiärbereichs A. Das Spektrum der Studiengebühren ist in Chile und Neuseeland am größten, mit einem Unterschied zwischen den niedrigsten und den höchsten Studiengebühren von bis zu 2.963 US-Dollar in Chile und 2.744 US-Dollar in Neuseeland. In Chile belaufen sich die Studiengebühren für einen Studierenden der Erziehungswissenschaften auf 4.034 US-Dollar im Jahr, während sich die Studiengebühren für ein Studium der Agrarwissenschaften auf 6.997 US-Dollar belaufen (Tab. B5.3 und Abb. B5.3).

Der Hauptgrund für eine Differenzierung der Studiengebühren in Irland, Neuseeland und dem Vereinigten Königreich liegt in den unterschiedlich hohen öffentlichen Kosten für die einzelnen Studiengänge je nach Fachrichtung. In diesen Ländern sind die von den Bildungseinrichtungen erhobenen Gebühren umso höher, je höher die Kosten für die Studiengänge in den jeweiligen Fachrichtungen sind. In anderen Ländern jedoch liegt der Hauptgrund für die Differenzierung der Studiengebühren nach Fachrichtung des Studiengangs in der Priorität bestimmter Fächergruppen in der Hochschulpolitik. In Australien beispielsweise hängt diese Art Differenzierung mit auf dem Arbeitsmarkt nicht in ausreichendem Ausmaß angebotenen Kompetenzen und der Höhe der von Studienabgängern bestimmter Fachrichtungen zu erwartenden Gehälter zusammen (s. Kasten B5.I in Bildung auf einen Blick 2012). In den Vereinigten Staaten spiegeln die Unterschiede bei den Studiengebühren die Unterschiede zwischen Bildungseinrichtungen wider und nicht zwischen den einzelnen Fachrichtungen an einer Bildungseinrichtung. In der Regel sind die Studiengebühren innerhalb einer Bildungseinrichtung für alle Abschlüsse in Studiengängen des Tertiärbereichs A unabhängig von der jeweiligen Fachrichtung gleich. 
Abbildung B5.3

Bandbreite der Studiengebühren an öffentlichen Bildungseinrichtungen des Tertiärbereichs A für Studiengänge, die zu einem ersten Abschluss führen (2011)

Brutto-Studiengebühren in US-Dollar, kaufkraftbereinigt mittels KKP für das BIP, nach Fachrichtung (Studienjahr 2010/2011)

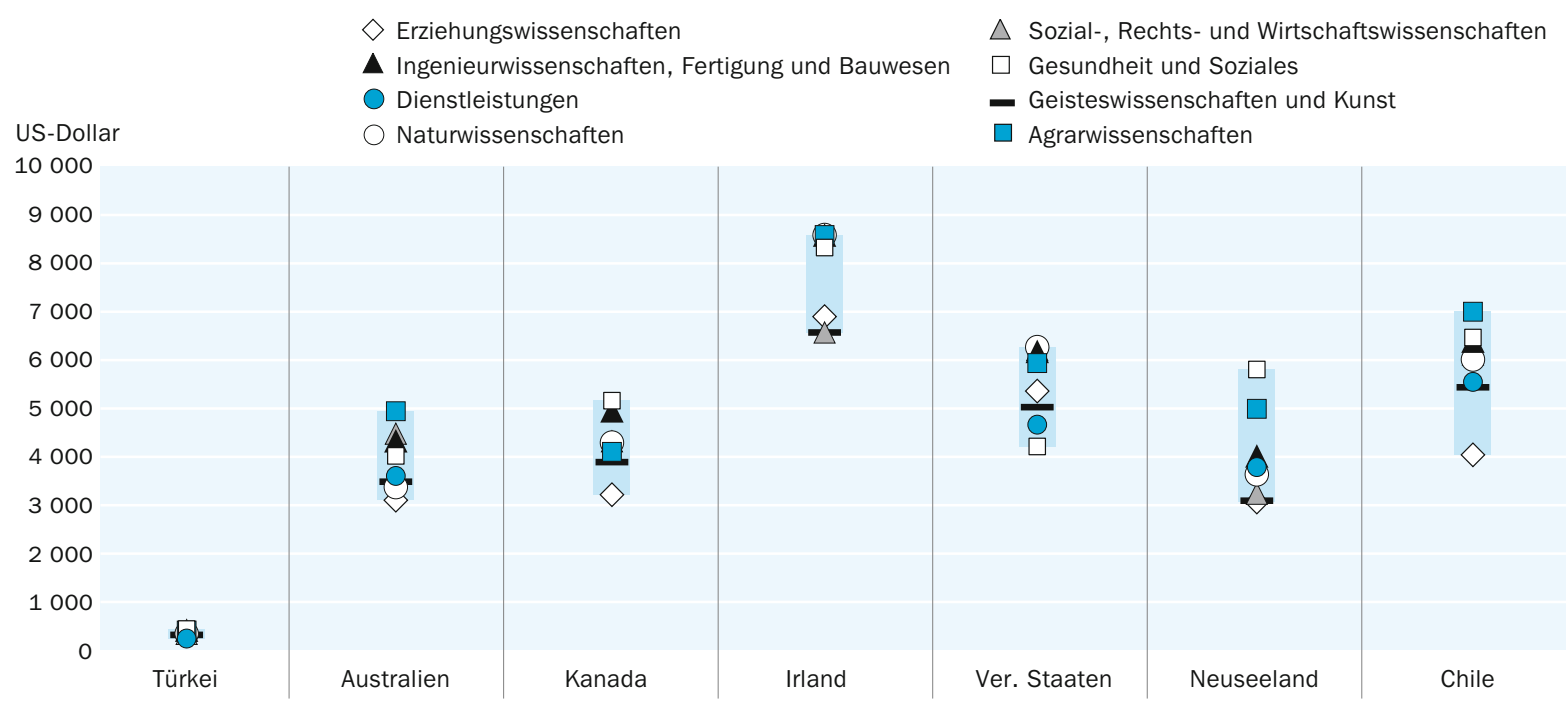

Anordnung der Länder in aufsteigender Reihenfolge des Unterschieds zwischen den niedrigsten und den höchsten Studiengebühren.

Quelle: OECD. Tabelle B5.3. Hinweise s. Anhang 3 unter www.oecd.org/edu/eag.htm. StatLink: http://dx.doi.org/10.1787/888932847146

Entgegen den Erwartungen sind Studiengebühren für Studiengänge in Fachrichtungen wie z. B. den Naturwissenschaften oder in Ingenieurwissenschaften nur in Irland deutlich höher. Die einzig klare Korrelation, die sich bei einem Vergleich der Studiengebühren der Länder nach Fachrichtungen ergibt, ist, dass die Studiengebühren für ein Studium der Erziehungswissenschaften in 5 von 7 Ländern mit verfügbaren entsprechenden Daten am niedrigsten sind. Diese sieben Länder gehören zu der Gruppe Länder mit hohen Studiengebühren und stark ausgeprägter Unterstützung für Studierende (s. Gruppe 2 im Folgenden). Die Türkei bildet hier eine deutliche Ausnahme, denn trotz relativ niedriger Studiengebühren werden diese differenziert und reichen von 290 US-Dollar bis 428 US-Dollar (Tab. B5.3 und Abb. B5.3).

\section{OECD-Länder nutzen unterschiedliche Kombinationen aus Zuschüssen und Darlehen zur Unterstützung der von Studierenden zu tragenden Bildungskosten}

In vielen OECD-Ländern stellt sich die zentrale Frage, ob die an private Haushalte geleisteten Finanzhilfen bei Studiengängen im Tertiärbereich A in erster Linie als $\mathrm{Zu}$ schüsse oder als Darlehen gewährt werden sollten. In den einzelnen Ländern werden zur Subventionierung der Lebenshaltungs- bzw. Bildungskosten der Studierenden unterschiedliche Kombinationen dieser beiden Arten von Unterstützungsleistungen eingesetzt. Steuerermäßigungen und/oder die steuerliche Anrechenbarkeit von Bildungsmaßnahmen werden in diesem Indikator nicht berücksichtigt. Die Befürworter von Studiendarlehen argumentieren, dass Darlehen die Reichweite der vorhandenen Mittel vergrößern. Wenn die als Zuschüsse ausgegebenen Gelder stattdessen zur Absicherung oder Subventionierung von Darlehen verwendet würden, stünden mehr Studierenden Finanzhilfen zur Verfügung, und mehr Studierende würden ein Studium aufnehmen. Darlehen verlagern außerdem einen Teil der Bildungskosten auf diejeni- 
gen, die auch am meisten von Hochschulbildung profitieren - nämlich die einzelnen Studierenden. Die Gegner von Studiendarlehen führen dagegen an, dass Studiendarlehen weniger als Zuschüsse dazu beitragen, einkommensschwache Schüler/Studierende zur Fortsetzung ihres Bildungswegs zu ermutigen. Ferner führen sie an, dass Darlehen sowohl aufgrund der verschiedenen Subventionen für Darlehensnehmer und -geber als auch der Verwaltungs- und Schuldendienstkosten weniger wirksam sein könnten als erwartet.

Unterstützungsleistungen an private Haushalte und andere private Einheiten machen in den OECD-Ländern im Durchschnitt rund 22 Prozent der öffentlichen Bildungshaushalte für den Tertiärbereich aus (Abb. B5.4). In Australien, Chile, Dänemark, Island, Japan, Neuseeland, den Niederlanden, Norwegen, dem Vereinigten Königreich und den Vereinigten Staaten machen öffentliche Unterstützungsleistungen mehr als 25 Prozent der öffentlichen Ausgaben für den Tertiärbereich aus. Nur in Mexiko, der Schweiz und Tschechien machen Unterstützungsleistungen weniger als 7 Prozent der öffentlichen Gesamtausgaben für den Tertiärbereich aus. In Tschechien werden Subventionen für Studienbeihilfen jedoch direkt an die Bildungseinrichtungen überwiesen, die für deren Verteilung unter den Studierenden verantwortlich sind (Tab. B5.4).

OECD-Untersuchungen (s. OECD, 2008) deuten darauf hin, dass ein belastungsfähiges System der finanziellen Unterstützung wichtig ist, um gute Ergebnisse der Studierenden im Tertiärbereich zu gewährleisten, und dass auch die Art der Unterstützung eine Rolle spielt. Abbildung B5.4 gibt eine Übersicht über die Anteile von Darlehen, Zuschüssen und Stipendien sowie anderen Unterstützungsleistungen für private Haushalte an den öffentlichen Bildungsausgaben im Tertiärbereich.

Mehr als ein Drittel der 3I Länder mit verfügbaren Daten gewähren ausschließlich Stipendien/Zuschüsse sowie Transfer- und sonstige Zahlungen an andere private Einheiten. Island vergibt ausschließlich Studiendarlehen, während es in anderen Ländern Kombinationen aus Studienzuschüssen und Darlehen gibt. Beide Formen der Unterstützung werden in Australien, Chile, Neuseeland, den Niederlanden, Norwegen, Schweden, dem Vereinigten Königreich und den Vereinigten Staaten besonders stark in Anspruch genommen.

In der Regel sind die Länder mit Studiendarlehen auch diejenigen Länder, in denen öffentliche Unterstützungsleistungen an private Haushalte den größten Teil der öffentlichen Gesamtausgaben für den Tertiärbereich ausmachen. In den meisten Fällen geben diese Länder auch einen überdurchschnittlich hohen Anteil ihrer Etats für den Tertiärbereich für Zuschüsse und Stipendien aus (Abb. B5.4 und Tab. B5.4).

\section{Länderspezifische Ansätze bei der Finanzierung des Tertiärbereichs}

Viele Länder verfolgen hinsichtlich des Tertiärbereichs ähnliche Ziele, z. B. eine Stärkung der wissensbasierten Wirtschaft, einen breiteren Zugang zum Tertiärbereich, die Förderung hoher Erfolgsquoten und Gewährleistung der Finanzstabilität der Hochschulsysteme. Es gibt jedoch wesentliche Unterschiede zwischen den einzelnen OECDLändern hinsichtlich der Aufteilung der Kosten für Bildung im Tertiärbereich auf den Staat, die Studierenden und ihre Familien und andere private Einheiten und hinsichtlich der finanziellen Unterstützung, die Studierende staatlicherseits erhalten können. 
Abbildung B5.4

Öffentliche Unterstützungsleistungen für eine Ausbildung im Tertiärbereich (2010)

Öffentliche Unterstützungsleistungen für Bildung an private Haushalte und andere private Einheiten als Prozentsatz der öffentlichen Gesamtausgaben für den Tertiärbereich, nach Art der Subvention

$\%$ der öffentlichen Gesamtausgaben für den Tertiärbereich Stipendien/Andere Zuschüsse an private Haushalte Transfer- und sonstige Zahlungen an andere private Einheiten Studiendarlehen

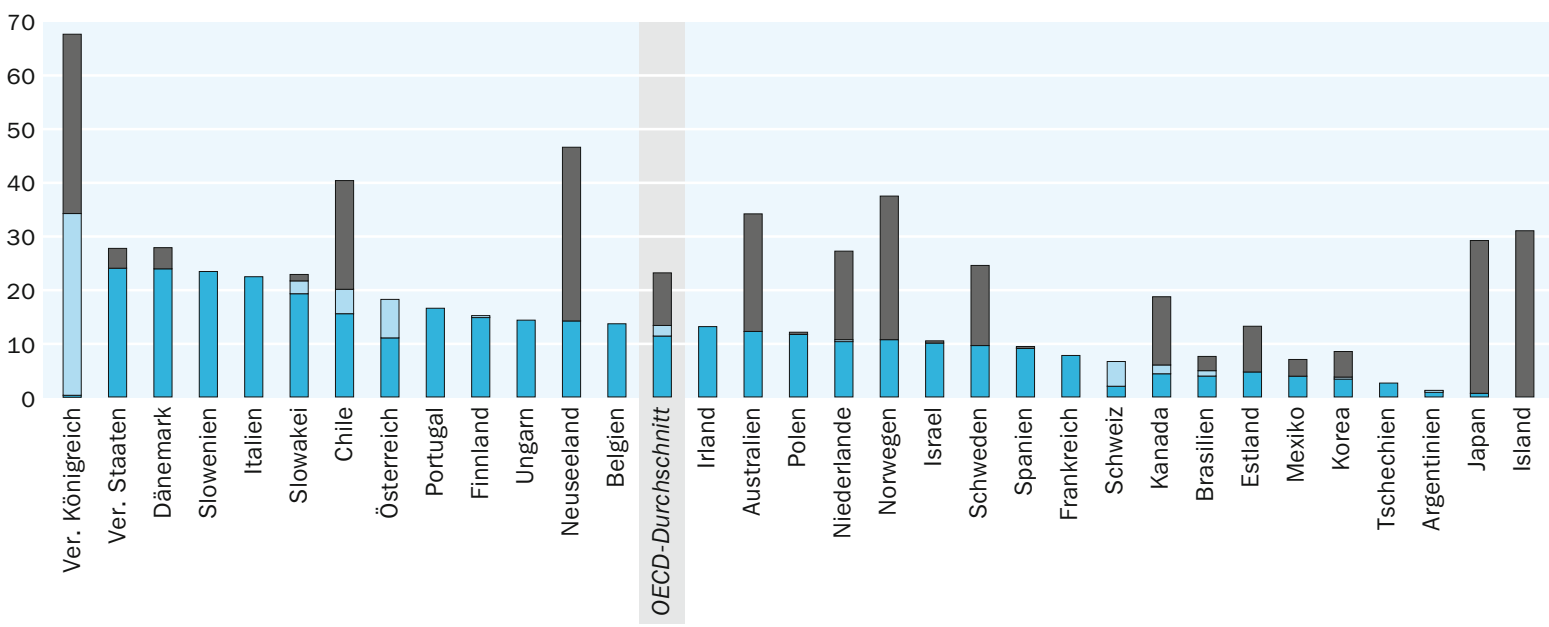

Anordnung der Länder in absteigender Reihenfolge des Anteils von „Stipendien/Andere Zuschüsse an private Haushalte“ und „Transfer- und sonstige Zahlungen an andere private Einheiten" an den öffentlichen Gesamtausgaben für den Tertiärbereich.

Quelle: OECD. Argentinien: Statistikinstitut der UNESCO (World Education Indicators Programme). Tabelle B5.4.

Hinweise s. Anhang 3 unter www.oecd.org/edu/eag.htm. StatLink: http://dx.doi.org/10.1787/888932847165

Wie vorstehend dargelegt unterscheiden sich die Kosten für den Tertiärbereich und die Höhe der Unterstützungsleistungen für die Studierenden in den einzelnen OECDLändern beträchtlich. Dieser Abschnitt systematisiert die in Ländern mit verfügbaren Daten verfolgten Ansätze bei der Finanzierung des Tertiärbereichs und analysiert die Auswirkungen des jeweiligen Modells auf den Zugang zum Tertiärbereich. Die Länder werden unter zwei Aspekten in vier Gruppen eingeteilt: die Höhe der Studiengebühren und die finanzielle Unterstützung, die über das System der Finanzbeihilfen für Studierende des Tertiärbereichs gewährt wird.

Es gibt kein einheitliches Finanzierungsmodell im Tertiärbereich A. Länder mit ähnlich hohen Studiengebühren im Tertiärbereich A können sich hinsichtlich des Anteils der Studierenden, die öffentliche Zuschüsse erhalten, unterscheiden und/oder auch hinsichtlich der durchschnittlichen Höhe dieser Zuschüsse (Tab. B5.I, B5.2, B5.3, B5.4 und Tab. B5.5 im Internet sowie Abb. B5.I). Da seit 1995 in vielen OECD-Ländern die Regelungen hinsichtlich der Studiengebühren an Bildungseinrichtungen des Tertiärbereichs reformiert wurden, haben einige Länder in diesem Zeitraum den einen Ansatz durch einen anderen ersetzt (s. Kasten B5.I in Bildung auf einen Blick 2012 und Abb. B5.I).

Gruppe 1: Länder ohne bzw. mit niedrigen Studiengebühren, aber relativ großzügiger finanzieller Unterstützung der Studierenden

Diese Gruppe umfasst die nordischen Länder (Dänemark, Finnland, Island, Norwegen und Schweden). In diesen Ländern gibt es ein progressiveres Steuersystem (OECD, 20II), die Studierenden bezahlen keine Studiengebühren und erhalten großzügige öf- 
fentliche Unterstützung für ihre Ausbildung im Tertiärbereich. Dafür sind die Einkommensteuersätze hoch. Mit 75 Prozent liegt die durchschnittliche Studienanfängerquote für den Tertiärbereich A in dieser Ländergruppe signifikant über dem OECD-Durchschnitt von 6o Prozent (s. Indikator $\mathrm{C}_{3}, \mathrm{Tab} . \mathrm{C}_{3}$.Ia). Die hohen Studienanfängerquoten könnten auch mit der Attraktivität der guten finanziellen Unterstützung dieser Länder für Studierende zusammenhängen und nicht nur damit, dass keine Studiengebühren anfallen. In diesen Ländern erhalten beispielsweise mehr als 55 Prozent der Studierenden öffentliche Zuschüsse, staatliche Darlehen oder eine Kombination aus beidem (Tab. B5.I und B5.2 sowie Abb. B5.I).

Diese Vorgehensweise bei der Finanzierung des Tertiärbereichs spiegelt die in diesen Ländern tief verwurzelten sozialen Werte wie Chancengleichheit und soziale Gerechtigkeit wider. Die Grundidee, dass der Staat seinen Bürgern eine kostenlose Ausbildung im Tertiärbereich ermöglichen sollte, ist eine Besonderheit der Bildungskultur dieser Länder: Die Finanzierung sowohl der Bildungseinrichtungen als auch der Studierenden in diesen Ländern basiert auf dem Grundsatz, dass der Zugang zum Tertiärbereich ein Recht und nicht ein Privileg ist. Dänemark und Schweden haben sich jedoch im Verlauf der letzten Io Jahre für die Einführung von Studiengebühren für internationale Studierende ( $a b$ 20II) entschieden, um die für Bildungseinrichtungen im Tertiärbereich zur Verfügung stehenden Ressourcen zu erhöhen; auch Island zieht dies in Betracht. Dabei besteht die Gefahr, dass einige internationale Studierende so von einem Studium in diesen Ländern abgehalten werden. Seit der Einführung der Reform ist die Zahl der internationalen Studierenden in Schweden gesunken: Zwischen Herbst 2010 und Herbst 20II sank die Zahl der Studierenden, die nicht an einem Austauschprogramm teilnahmen und von außerhalb des Europäischen Wirtschaftsraums und der Schweiz kamen, um fast 80 Prozent (Swedish National Agency for Higher Education, 2012).

\section{Gruppe 2: Länder mit hohen Studiengebühren und stark ausgeprägter Unterstützung für Studierende}

Diese zweite Ländergruppe umfasst Australien, Kanada, Neuseeland, die Niederlande, das Vereinigte Königreich und die Vereinigten Staaten. In diesen Ländern sind die finanziellen Barrieren für den Zugang zu Bildungseinrichtungen des Tertiärbereichs A auf den ersten Blick hoch, gleichzeitig werden jedoch Studierenden hohe öffentliche Unterstützungsleistungen gewährt. Die durchschnittliche Studienanfängerquote im Tertiärbereich A in dieser Ländergruppe liegt mit 76 Prozent signifikant über dem OECD-Durchschnitt und ist höher als in den meisten Ländern mit niedrigen Studiengebühren (mit Ausnahme der nordischen Länder). Die Niederlande und etwas weniger stark ausgeprägt auch das Vereinigte Königreich gehören seit 1995 zur Gruppe 2 (Abb. B5.I), nachdem sie vorher der Gruppe 4 zuzuordnen waren (Länder mit niedrigen Studiengebühren und einer weniger gut ausgebauten finanziellen Unterstützung für Studierende). In den Ländern der Gruppe 2 tragen tendenziell private Einheiten (z. B. Privatunternehmen und gemeinnützige Organisationen) am stärksten zur Finanzierung der Bildungseinrichtungen im Tertiärbereich bei. Anders ausgedrückt werden in den Ländern der Gruppe 2 die Bildungskosten gemeinsam vom Staat, den privaten Haushalten und Privatunternehmen getragen (Abb. B3.2 und Tab. B3.2b).

In allen Ländern dieser Gruppe liegen die von Bildungseinrichtungen des Tertiärbereichs A erhobenen Studiengebühren bei über I.500 US-Dollar, gleichzeitig erhalten 
mehr als 75 Prozent der Studierenden des Tertiärbereichs A öffentliche Unterstützungsleistungen (in Australien, Neuseeland, den Niederlanden, dem Vereinigten Königreich und den Vereinigten Staaten, den fünf Ländern mit verfügbaren Daten; Tab. B5.I und B5.2). Die Systeme zur finanziellen Unterstützung der Studierenden sind gut ausgebaut und tragen weitgehend den Bedürfnissen aller Studierenden Rechnung. Daher liegt der Anteil der Bildungsausgaben im Tertiärbereich, der in diesen Ländern in öffentliche Unterstützungsleistungen fließt, in fünf der sechs Länder über dem OECD-Durchschnitt von 22 Prozent: in Australien (34 Prozent), Neuseeland (47 Prozent), den Niederlanden (27 Prozent), dem Vereinigten Königreich (68 Prozent) sowie den Vereinigten Staaten (28 Prozent) und entspricht fast dem Durchschnitt für Kanada (ig Prozent) (Tab. B5.4).

In den Ländern dieser Gruppe ist die Studienanfängerquote im Tertiärbereich A ähnlich der in den anderen Ländergruppen. So gehören beispielsweise Australien mit 96 Prozent und Neuseeland mit 76 Prozent zu den Ländern mit den höchsten Studienanfängerquoten im Tertiärbereich $\mathrm{A}$, wobei dies teilweise auch auf den hohen Anteil internationaler Studierender im Tertiärbereich A zurückzuführen ist. Über dem OECDDurchschnitt von 6o Prozent lagen 2010 auch die Studienanfängerquoten im Tertiärbereich A in den Niederlanden (65 Prozent), dem Vereinigten Königreich (64 Prozent) und den Vereinigten Staaten (72 Prozent). In diesen Ländern liegen die Ausgaben pro Studierenden des Tertiärbereichs für eigentliche Bildungsdienstleistungen über dem OECD-Durchschnitt, und ihr Einkommensteueraufkommen als Prozentsatz des BIP ist im Vergleich zum OECD-Durchschnitt relativ hoch. Bei der Höhe der Einkommensbesteuerung sind die Niederlande ein Sonderfall, denn diese liegt unter dem OECDDurchschnitt (Tab. BI.Ib im Internet und Tab. C3.I).

OECD-Untersuchungen (OECD, 2008) deuten darauf hin, dass dieses Modell für Länder allgemein eine effektive Möglichkeit sein kann, die Studienanfängerquoten im Tertiärbereich zu erhöhen. Während einer Wirtschaftskrise können Studiengebühren jedoch eine beträchtliche finanzielle Belastung für Studierende und ihre Familien darstellen und einige davon abhalten, ein Studium im Tertiärbereich aufzunehmen, selbst wenn den Studierenden relativ hohe Unterstützungsleistungen zur Verfügung stehen. Dies ist in Kanada, dem Vereinigten Königreich und den Vereinigten Staaten ein viel diskutiertes Thema.

\section{Gruppe 3: Länder mit hohen Studiengebühren, aber einer weniger gut ausgebauten} finanziellen Unterstützung von Studierenden

In Chile, Japan und Korea entrichten die meisten Studierenden hohe Studiengebühren (an Bildungseinrichtungen im Tertiärbereich A durchschnittlich mehr als 4.500 USDollar), aber die finanzielle Unterstützung von Studierenden ist weniger gut ausgebaut als in den Ländern der Gruppen I und 2. Dieser Ansatz kann eine hohe finanzielle Belastung für Studierende und ihre Familien bedeuten. Die Studienanfängerquoten im Tertiärbereich A liegen in Chile mit 45 Prozent und Japan mit 52 Prozent unter dem OECD-Durchschnitt, in Korea mit 69 Prozent jedoch signifikant darüber. In Japan und Korea gibt es für einige Studierende mit sehr guten akademischen Leistungen, die Schwierigkeiten bei der Finanzierung ihres Studiums haben, die Möglichkeit, dass die Studien- und/oder Aufnahmegebühren verringert bzw. vollkommen erlassen werden. 
Japan und Korea zählen zu den Ländern, in denen der Anteil der öffentlichen Ausgaben für den Tertiärbereich, ausgedrückt als Prozentsatz des BIP, mit am niedrigsten ist (Tab. B4.I). Dies erklärt zum Teil den niedrigen Anteil Studierender, die öffentliche Darlehen erhalten. Es muss jedoch angemerkt werden, dass in beiden Ländern vor Kurzem Reformen zur Verbesserung der Unterstützung von Studierenden umgesetzt wurden. Damit nähern sich diese Länder der Gruppe 2 an.

\section{Gruppe 4: Länder mit niedrigen Studiengebühren und weniger gut ausgebauten finanziellen Unterstützungsleistungen für Studierende}

Die vierte Gruppe umfasst alle anderen europäischen Länder, für die Daten vorliegen (Belgien, Frankreich, Irland, Italien, Österreich, Polen, Portugal, die Schweiz, Spanien und Tschechien), sowie Mexiko. In all diesen Ländern sind die Studiengebühren verglichen mit Gruppe 2 und 3 verhältnismäßig niedrig, obwohl seit 1995 in einigen dieser Länder Reformen umgesetzt wurden, insbesondere in Italien und Österreich, um die von den öffentlichen Bildungseinrichtungen erhobenen Studiengebühren zu erhöhen (Abb. B5.I und Kasten B5.I). In den Ländern der Gruppe 4 sind die finanziellen Zugangsbarrieren zu einer Ausbildung im Tertiärbereich in Form von Studiengebühren relativ niedrig (oder es gibt wie in Irland und Mexiko keine Studiengebühren), während gleichzeitig auch die finanziellen Unterstützungsleistungen für Studierende, die überwiegend auf bestimmte Gruppen von Studierenden ausgerichtet sind, relativ niedrig sind. Die seitens öffentlicher Bildungseinrichtungen erhobenen Studiengebühren übersteigen in dieser Gruppe in keinem Fall I.30o US-Dollar, und in den Ländern mit verfügbaren Daten liegt der Anteil der Studierenden, die öffentliche Zuschüsse erhalten, bei weniger als 40 Prozent (Tab. B5.I und B5.2).

Für gewöhnlich sind die Bildungseinrichtungen in den Ländern der Gruppe 4 bei ihrer Finanzierung stark von öffentlichen Mitteln abhängig, und die Bildungsbeteiligung im Tertiärbereich liegt für gewöhnlich unter dem OECD-Durchschnitt. Die durchschnittliche Studienanfängerquote im Tertiärbereich A ist in dieser Ländergruppe mit 56 Prozent relativ niedrig. Sie wird jedoch in Belgien durch relativ hohe Studienanfängerquoten im Tertiärbereich B ausgeglichen. Die Ausgaben pro Studierenden im Tertiärbereich A sind ebenfalls vergleichsweise niedrig (s. Indikator BI und Abb. B5.2). Während hohe Studiengebühren potenziell ein Hindernis bei der Aufnahme eines Studiums im Tertiärbereich sein können, deuten die Daten der Länder der Gruppe 4 darauf hin, dass niedrigere Studiengebühren, die den Zugang zu Bildung eigentlich erleichtern sollten, nicht notwendigerweise eine Garantie für höhere Studienanfängerquoten oder eine bessere Qualität der Ausbildung im Tertiärbereich A sind.

In diesen Ländern können Studierende und ihre Familien Anspruch auf Unterstützungsleistungen haben, die seitens anderer Stellen als dem Bildungsministerium zur Verfügung gestellt werden (z. B. Wohnungsbeihilfen, Steuerermäßigungen und/oder die steuerliche Anrechenbarkeit von Ausbildungskosten), diese werden jedoch in dieser Analyse nicht berücksichtigt. In Frankreich beispielsweise machen bei den staatlichen Unterstützungsleistungen Wohnungsbeihilfen, die ungefähr ein Drittel der Studierenden erhalten, rund go Prozent der Stipendien/Zuschüsse aus. Polen stellt einen Sonderfall dar, da das Studium der meisten Studierenden an öffentlichen Einrichtungen vollständig durch die öffentliche Hand finanziert wird, während Teilzeitstudierende die Studienkosten in vollem Umfang selbst tragen müssen. 
In Ländern der Gruppe 4 gibt es entweder überhaupt keine Systeme der Darlehensfinanzierung durch öffentliche Darlehen oder staatlich garantierte Darlehen, oder sie stehen nur einem kleinen Teil der Studierenden in diesen Ländern zur Verfügung (Tab. B5.2). Gleichzeitig variieren die Höhe der öffentlichen Ausgaben und das Einkommensteueraufkommen als Prozentsatz des BIP in dieser Ländergruppe signifikant stärker als in den anderen Gruppen.

\section{Definitionen}

Bei den durchschnittlichen Studiengebühren, die öffentliche und private Bildungseinrichtungen des Tertiärbereichs A erheben, wird nicht zwischen unterschiedlichen Studiengängen unterschieden. Der Indikator liefert einen Überblick über die Studiengebühren in diesem Bildungsbereich nach Art der Bildungseinrichtung und zeigt die Anteile der Studierenden auf, die Stipendien/Zuschüsse zur vollständigen oder teilweisen Abdeckung der Studiengebühren erhalten bzw. nicht erhalten. Die Höhe der Studiengebühren und die entsprechenden Anteile der Studierenden sollten mit Vorsicht interpretiert werden, da sie aus dem gewichteten Durchschnitt der wichtigsten Studiengänge des Tertiärbereichs A resultieren und nicht alle Bildungseinrichtungen berücksichtigt sind.

Öffentliche Bildungsausgaben, die aus Transferzahlungen an Studierende, ihre Familien und andere private Einheiten bestehen, umfassen Mittel, die indirekt an Bildungseinrichtungen fließen können, wie z. B. Unterstützungsleistungen, die für die Zahlung von Studiengebühren genutzt werden, sowie Mittel, die - auch nicht indirekt - an Bildungseinrichtungen fließen, wie finanzielle Zuschüsse zu den Lebenshaltungskosten von Studierenden.

Öffentliche Subventionen an private Haushalte umfassen: Zuschüsse/Stipendien (nicht rückzahlbare Subventionen), öffentliche Studiendarlehen, die zurückzuzahlen sind, Familienbeihilfen oder Kindergeld, die an den Status als Studierender gebunden sind, öffentliche Unterstützungsleistungen in Form von Geld- oder Sachleistungen, besonders für Unterbringung, Transport, medizinische Versorgung, Bücher und Lernmittel, soziale Zwecke, Freizeitgestaltung und sonstige Zwecke, sowie Zinssubventionen für private Darlehen.

Nicht unterschieden wird jedoch bei den öffentlichen Unterstützungsleistungen zwischen den verschiedenen Arten von Zuschüssen bzw. Darlehen, wie z. B. Stipendien, Familienbeihilfen, und Subventionen in Form von Sachleistungen. Die Länder können die Studierenden und ihre Familien auch durch die Gewährung von Wohnungsbeihilfen, Steuerermäßigungen und/oder die steuerliche Anrechenbarkeit von Ausbildungskosten unterstützen. Diese Subventionen werden von diesem Indikator jedoch nicht erfasst. Daher können die in manchen Ländern den Studierenden gewährten Finanzhilfen deutlich zu niedrig angesetzt sein.

Häufig übernimmt der Staat auch gegenüber privaten Kreditgebern eine Bürgschaft für die Rückzahlung von Studiendarlehen. In einigen OECD-Ländern ist diese indirekte Form der Subventionierung ebenso bedeutend oder sogar noch bedeutender als die direkte Finanzhilfe an Studierende. Aus Gründen der besseren Vergleichbarkeit werden jedoch in diesem Indikator nur die öffentlichen Transferleistungen für private Darlehen 
an private Einheiten berücksichtigt und nicht das Gesamtvolumen der gewährten Darlehen. Einige der Tabellen enthalten trotzdem einige qualitative Informationen, um so auch einen Einblick in diese Art von Subvention zu gewähren.

Studiendarlehen beziehen sich auf die gesamte Bandbreite an Studiendarlehen, um ein Bild über die Höhe der Unterstützungsleistungen für die Studierenden zu vermitteln. Der Bruttobetrag der Darlehen stellt eine geeignete Kennzahl zur Ermittlung der Finanzhilfen an die gegenwärtigen Bildungsteilnehmer dar. Zins- und Tilgungszahlungen des Darlehensnehmers sollten jedoch bei der Ermittlung der durch Studiendarlehen entstehenden Nettokosten für die öffentlichen und privaten Darlehensgeber berücksichtigt werden. Diese Zahlungen werden jedoch in der Regel nicht von gegenwärtigen Studierenden, sondern von ehemaligen Studierenden geleistet und sind in diesem Indikator nicht erfasst. Außerdem fließen Darlehensrückzahlungen in den meisten Ländern nicht den Bildungsbehörden zu, sodass ihnen diese Mittel nicht zur Deckung anderer Bildungsausgaben zur Verfügung stehen. Die OECD-Indikatoren berücksichtigen bei der Diskussion der finanziellen Unterstützung für gegenwärtige Studierende die Gesamtsumme der Stipendien und Darlehen (brutto). Für einige OECD-Länder gestaltet es sich zudem schwierig, die Gesamtsumme der Darlehen an Studierende anzugeben. Zahlen zu Studiendarlehen sind daher mit Vorsicht zu interpretieren.

\section{Angewandte Methodik}

Die Daten beziehen sich auf das Haushaltsjahr 2010 und beruhen auf der von der OECD im Jahre 2012 durchgeführten UOE-Datenerhebung zur Bildungsstatistik (weitere Informationen s. Anhang 3 unter www.oecd.orgleduleag.htm).

Die Daten zu den Studiengebühren der Bildungseinrichtungen, den Finanzhilfen für Studierende und den seit 1995 umgesetzten Reformen wurden im Rahmen einer besonderen, 2012 durchgeführten Erhebung gewonnen und beziehen sich auf das Studienjahr 20I0/20II. Die Angaben zu den Studiengebühren und Darlehensbeträgen in Landeswährung werden in US-Dollar umgerechnet, indem der betreffende Betrag in Landeswährung durch den Kaufkraftparitätsindex (KKP) für das BIP geteilt wird. Die Höhe der Studiengebühren und die entsprechenden Anteile der Studierenden sind mit Vorsicht zu interpretieren, da sie aus dem gewichteten Durchschnitt der wichtigsten Studiengänge des Tertiärbereichs A resultieren und nicht alle Bildungseinrichtungen einbeziehen.

Öffentliche Kosten in Verbindung mit staatlich garantierten privaten Darlehen sind in den Subventionen an andere private Einheiten enthalten. Im Unterschied zu den öffentlichen Darlehen sind hierbei nur die Nettokosten der Darlehen enthalten.

Nicht enthalten ist der Geldwert von Steuerermäßigungen und der steuerlichen Anrechenbarkeit von Ausgaben für private Haushalte und Studierende. 
Die statistischen Daten für Israel wurden von den zuständigen israelischen Stellen bereitgestellt, die für sie verantwortlich zeichnen. Die Verwendung dieser Daten durch die OECD erfolgt unbeschadet des völkerrechtlichen Status der Golanhöhen, von OstJerusalem und der israelischen Siedlungen im Westjordanland.

\section{Weiterführende Informationen}

OECD (2008), Tertiary Education for the Knowledge Society: Volume 1 and Volume 2, OECD Publishing, http://dx.doi.org/10.1787/9789264046535-en.

OECD (20II), OECD Tax Statistics: Volume 2011, Issue I: Revenue Statistics, OECD Publishing, http:/|dx.doi.org/10.1787/ctpa-rev-data-en.

Swedish National Agency for Higher Education (2012), „Fewer students from Asia after the Tuition Reform", Statistical Analysis, Stockholm.

\section{Tabellen Indikator B5}

Tabelle B5.I: Geschätzte durchschnittliche jährliche Studiengebühren für inländische Studierende an Bildungseinrichtungen des Tertiärbereichs A (20II) StatLink: http://dx.doi.org/10.1787/888932849920

Tabelle B5.2: Verteilung der Finanzhilfen an Studierende im Vergleich zur Höhe der Studiengebühren an Bildungseinrichtungen des Tertiärbereichs A für inländische Studierende in einem Studiengang, der zu einem ersten Abschluss führt (20II)

StatLink: http:||dx.doi.org/10.1787/888932849939

Tabelle B5.3: Durchschnittliche Studiengebühren von Bildungseinrichtungen des Tertiärbereichs, nach Fachrichtung (20II)

StatLink: http://dx.doi.org/10.1787/888932849958

Tabelle B5.4: Öffentliche Unterstützungsleistungen an private Haushalte und andere private Einheiten als Prozentsatz der öffentlichen Gesamtausgaben für Bildung und des BIP, für den Tertiärbereich (2010)

StatLink: http://dx.doi.org/10.1787/888932849977

WEB Table B5.5: Public support for households and other private entities as a percentage of total public expenditure on education and GDP, for primary, secondary and post-secondary non-tertiary education (Öffentliche Unterstützungsleistungen an private Haushalte und andere private Einheiten als Prozentsatz der öffentlichen Gesamtausgaben für Bildung und des BIP, für den Primar-, Sekundar- und postsekundaren, nicht tertiären Bereich) (2010) StatLink: http://dx.doi.org/10.1787/888932849996 
Geschätzte durchschnittliche jährliche Studiengebühren für inländische Studierende an Bildungseinrichtungen des Tertiärbereichs $A^{1}$ (2011)

In US-Dollar, kaufkraftbereinigt, nach Art der Bildungseinrichtung und Abschlussstruktur, basierend auf Vollzeitäquivalenten, Studienjahr 2010/2011

Anmerkung: Studiengebühren und die entsprechenden Studierendenzahlen sollten mit Vorsicht interpretiert werden, da sie aus dem gewichteten Durchschnitt der wichtigsten Studiengänge des Tertiärbereichs A resultieren und nicht alle Bildungseinrichtungen berücksichtigt sind. Die angegebenen Zahlen können jedoch als gute Näherungswerte betrachtet werden, sie zeigen den Unterschied zwischen den einzelnen Ländern bei den von der Mehrzahl der Bildungseinrichtungen von der Mehrheit der Studierenden verlangten Studiengebühren.

\begin{tabular}{|c|c|c|c|c|c|c|c|c|c|c|c|}
\hline & \multirow{3}{*}{ 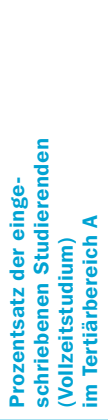 } & \multicolumn{3}{|c|}{$\begin{array}{l}\text { Prozentsatz der eingeschriebenen } \\
\text { Studierenden (Vollzeitstudium) } \\
\text { im Tertiärbereich A an: }\end{array}$} & \multicolumn{6}{|c|}{$\begin{array}{l}\text { Durchschnittliche jährliche Studiengebühren } \\
\text { in US-Dollar (für Studierende im Vollzeitstudium) an: }\end{array}$} & \multirow{3}{*}{ 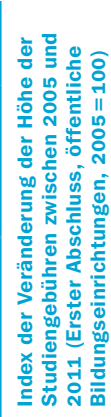 } \\
\hline & & \multirow{2}{*}{ 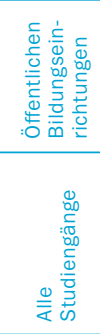 } & \multirow{2}{*}{ 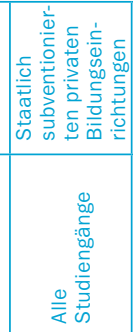 } & \multirow{2}{*}{ 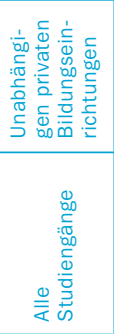 } & \multicolumn{2}{|c|}{$\begin{array}{c}\text { Öffentlichen } \\
\text { Bildungseinrichtungen }\end{array}$} & \multicolumn{2}{|c|}{$\begin{array}{c}\text { Staatlich } \\
\text { subventionierten } \\
\text { privaten Bildungs- } \\
\text { einrichtungen }\end{array}$} & \multicolumn{2}{|c|}{$\begin{array}{l}\text { Unabhängigen privaten } \\
\text { Bildungseinrichtungen }\end{array}$} & \\
\hline & & & & & 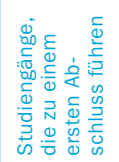 & 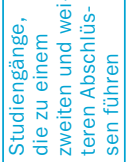 & 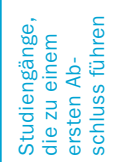 & 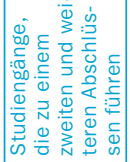 & 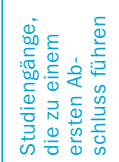 & 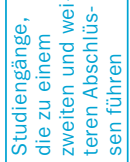 & \\
\hline & (1) & (2) & (3) & (4) & (5) & (6) & (7) & (8) & (9) & (10) & (11) \\
\hline \multicolumn{12}{|l|}{ OECD-Länder } \\
\hline Australien & 71 & 96 & a & 4 & 3924 & 6099 & a & a & 10110 & 9635 & 128 \\
\hline Österreich ${ }^{2}$ & $\mathrm{~m}$ & 84 & 13 & 3 & 860 & 860 & 860 & 860 & $\begin{array}{r}\text { Bis zu } \\
11735\end{array}$ & $\begin{array}{r}\text { Bis zu } \\
11735\end{array}$ & $\mathrm{~m}$ \\
\hline Belgien (fläm.) & 75 & 52 & 48 & $\mathrm{~m}$ & $\begin{array}{r}576 \\
\text { bis } 653\end{array}$ & $\begin{array}{r}576 \\
\text { bis } 653\end{array}$ & $\begin{array}{r}576 \\
\text { bis } 653\end{array}$ & $\begin{array}{r}576 \\
\text { bis } 653\end{array}$ & $\mathrm{~m}$ & $\mathrm{~m}$ & $\mathrm{~m}$ \\
\hline Belgien (frz.) & 84 & 33 & 67 & $\mathrm{~m}$ & 653 & 696 & 754 & 785 & $\mathrm{~m}$ & $\mathrm{~m}$ & $\mathrm{~m}$ \\
\hline Kanada & 82 & $\mathrm{~m}$ & $\mathrm{~m}$ & $\mathrm{~m}$ & 4288 & $\mathrm{~m}$ & $x(5)$ & $\mathrm{m}$ & $x(5)$ & $\mathrm{m}$ & 124 \\
\hline Chile & $\mathrm{m}$ & 23 & 18 & 59 & 5885 & 6345 & 6924 & 8757 & 6230 & 8357 & $\mathrm{~m}$ \\
\hline Tschechien & 97 & $\mathrm{~m}$ & $\mathrm{~m}$ & $\mathrm{~m}$ & $\mathrm{~m}$ & $\mathrm{~m}$ & $\mathrm{~m}$ & $\mathrm{~m}$ & $\mathrm{~m}$ & $\mathrm{~m}$ & $\mathrm{~m}$ \\
\hline Dänemark ${ }^{3}$ & 90 & $\mathrm{~m}$ & $\mathrm{~m}$ & $\mathrm{~m}$ & $\begin{array}{l}\text { Keine } \\
\text { Studien- } \\
\text { gebühren }\end{array}$ & $\begin{array}{l}\text { Keine } \\
\text { Studien- } \\
\text { gebühren }\end{array}$ & $\mathrm{m}$ & $\mathrm{m}$ & a & a & $\mathrm{m}$ \\
\hline Estland & 87 & $\mathrm{~m}$ & 93 & 7 & $\mathrm{~m}$ & $\mathrm{~m}$ & 3527 & 3786 & 5322 & 6699 & $\mathrm{~m}$ \\
\hline Finnland & 56 & 74 & 26 & a & $\begin{array}{l}\text { Keine } \\
\text { Studien- } \\
\text { gebühren }\end{array}$ & $\begin{array}{l}\text { Keine } \\
\text { Studien- } \\
\text { gebühren }\end{array}$ & $\begin{array}{l}\text { Keine } \\
\text { Studien- } \\
\text { gebühren }\end{array}$ & $\begin{array}{l}\text { Keine } \\
\text { Studien- } \\
\text { gebühren }\end{array}$ & a & a & $\mathrm{m}$ \\
\hline Frankreich & $\mathrm{m}$ & 86 & 5 & 9 & $\begin{array}{r}200 \\
\text { bis } 1402\end{array}$ & $\begin{array}{r}273 \\
\text { bis } 1402\end{array}$ & $\begin{array}{r}1138 \\
\text { bis } 8290\end{array}$ & $x(7)$ & $\mathrm{m}$ & $\mathrm{m}$ & 116 \\
\hline Deutschland & 94 & 96 & 4 & $\mathrm{x}$ & $\mathrm{m}$ & $\mathrm{m}$ & $\mathrm{m}$ & $\mathrm{m}$ & $\mathrm{m}$ & $\mathrm{m}$ & $\mathrm{m}$ \\
\hline Griechenland & 100 & $\mathrm{~m}$ & $\mathrm{~m}$ & $\mathrm{~m}$ & $\mathrm{~m}$ & $\mathrm{~m}$ & $\mathrm{~m}$ & $\mathrm{~m}$ & $\mathrm{~m}$ & $\mathrm{~m}$ & $\mathrm{~m}$ \\
\hline Ungarn & 65 & $\mathrm{~m}$ & $\mathrm{~m}$ & $\mathrm{~m}$ & $\mathrm{~m}$ & $\mathrm{~m}$ & $\mathrm{~m}$ & $\mathrm{~m}$ & $\mathrm{~m}$ & $\mathrm{~m}$ & $\mathrm{~m}$ \\
\hline Island & 71 & $\mathrm{~m}$ & $\mathrm{~m}$ & $\mathrm{~m}$ & $\mathrm{~m}$ & $\mathrm{~m}$ & $\mathrm{~m}$ & $\mathrm{~m}$ & $\mathrm{~m}$ & $\mathrm{~m}$ & $\mathrm{~m}$ \\
\hline Irland & 87 & $\mathrm{~m}$ & a & $\mathrm{m}$ & 6450 & 7036 & a & a & $\mathrm{m}$ & $\mathrm{m}$ & 136 \\
\hline Israel & 82 & $\mathrm{~m}$ & $\mathrm{~m}$ & $\mathrm{~m}$ & $\mathrm{~m}$ & $\mathrm{~m}$ & $\mathrm{~m}$ & $\mathrm{~m}$ & $\mathrm{~m}$ & $\mathrm{~m}$ & $\mathrm{~m}$ \\
\hline Italien & 100 & 90 & a & 10 & 1407 & $x(5)$ & a & a & 4406 & $x(9)$ & $\mathrm{m}$ \\
\hline Japan & 91 & 25 & a & 75 & 5019 & 5106 & a & a & 8039 & 7423 & 109 \\
\hline Korea & $\mathrm{m}$ & 23 & a & 77 & 5395 & $\mathrm{~m}$ & a & a & 9383 & $\mathrm{~m}$ & $\mathrm{~m}$ \\
\hline Luxemburg & 95 & $\mathrm{~m}$ & $\mathrm{~m}$ & $\mathrm{~m}$ & $\mathrm{~m}$ & $\mathrm{~m}$ & $\mathrm{~m}$ & $\mathrm{~m}$ & $\mathrm{~m}$ & $\mathrm{~m}$ & $\mathrm{~m}$ \\
\hline Mexiko & 95 & 67 & a & 33 & $\begin{array}{l}\text { Keine } \\
\text { Studien- } \\
\text { gebühren }\end{array}$ & $\begin{array}{l}\text { Keine } \\
\text { Studien- } \\
\text { gebühren }\end{array}$ & a & a & 5684 & $x(9)$ & $\mathrm{m}$ \\
\hline Niederlande & 86 & $\mathrm{~m}$ & a & $\mathrm{m}$ & 1966 & $x(5)$ & a & a & $\mathrm{m}$ & $\mathrm{m}$ & 113 \\
\hline Neuseeland & 60 & $\mathrm{~m}$ & $\mathrm{~m}$ & $\mathrm{~m}$ & 3645 & $x(5)$ & $\mathrm{m}$ & $\mathrm{m}$ & $\mathrm{m}$ & $\mathrm{m}$ & 135 \\
\hline Norwegen & 71 & 85 & 5 & 10 & $\begin{array}{l}\text { Keine } \\
\text { Studien- } \\
\text { gebühren }\end{array}$ & $\begin{array}{l}\text { Keine } \\
\text { Studien- } \\
\text { gebühren }\end{array}$ & $\mathrm{m}$ & $\mathrm{m}$ & 5868 & 7296 & $\mathrm{~m}$ \\
\hline Polen & 45 & 90 & a & 10 & $\mathrm{n}$ & $\mathrm{n}$ & a & a & 1242 & 1335 & $\mathrm{~m}$ \\
\hline Portugal $^{3}$ & $\mathrm{~m}$ & $\mathrm{~m}$ & $\mathrm{~m}$ & $\mathrm{~m}$ & $\mathrm{~m}$ & $\mathrm{~m}$ & $\mathrm{~m}$ & $\mathrm{~m}$ & $\mathrm{~m}$ & $\mathrm{~m}$ & $\mathrm{~m}$ \\
\hline Slowakei & 64 & 93 & a & 7 & $\begin{array}{r}\text { Maximum } \\
2916\end{array}$ & $x(5)$ & a & a & $\mathrm{m}$ & $\mathrm{m}$ & $\mathrm{m}$ \\
\hline Slowenien & 75 & 94 & 6 & 1 & $n$ & $\mathrm{n}$ & $\mathrm{n}$ & $\mathrm{n}$ & 11040 & 12144 & $\mathrm{~m}$ \\
\hline Spanien & 76 & 88 & a & 12 & 1129 & $\mathrm{~m}$ & a & a & $\mathrm{m}$ & $\mathrm{m}$ & $\mathrm{m}$ \\
\hline Schweden & 48 & 93 & 7 & $\mathrm{n}$ & $\begin{array}{l}\text { Keine } \\
\text { Studien- } \\
\text { gebühren }\end{array}$ & $\begin{array}{l}\text { Keine } \\
\text { Studien- } \\
\text { gebühren }\end{array}$ & $\begin{array}{l}\text { Keine } \\
\text { Studien- } \\
\text { gebühren }\end{array}$ & $\begin{array}{l}\text { Keine } \\
\text { Studien- } \\
\text { gebühren }\end{array}$ & $\mathrm{m}$ & $\mathrm{m}$ & $\mathrm{m}$ \\
\hline Schweiz & 89 & 95 & 3 & 2 & 863 & 863 & 863 & 863 & $\mathrm{~m}$ & $\mathrm{~m}$ & $\mathrm{~m}$ \\
\hline Türkei & 100 & 94 & a & 6 & 332 & 270 & a & a & m & $\mathrm{m}$ & 136 \\
\hline Ver. Königreich & 76 & $a$ & 100 & $\mathrm{n}$ & $a$ & a & 4980 & 7814 & m & $\mathrm{m}$ & $\mathrm{m}$ \\
\hline Vereinigte Staaten & 66 & 70 & a & 30 & 5402 & $\mathrm{~m}$ & a & a & 17163 & $\mathrm{~m}$ & 116 \\
\hline \multicolumn{12}{|l|}{ Sonst. G20-Länder } \\
\hline Brasilien & $\mathrm{m}$ & $\mathrm{m}$ & $\mathrm{m}$ & m & $\mathrm{m}$ & $\mathrm{m}$ & $\mathrm{m}$ & $\mathrm{m}$ & $\mathrm{m}$ & $\mathrm{m}$ & $\mathrm{m}$ \\
\hline Russische Föd. & 49 & $\mathrm{~m}$ & $\mathrm{~m}$ & $\mathrm{~m}$ & $\mathrm{~m}$ & $\mathrm{~m}$ & $\mathrm{~m}$ & $\mathrm{~m}$ & $\mathrm{~m}$ & $\mathrm{~m}$ & $\mathrm{~m}$ \\
\hline
\end{tabular}

1. Ohne Berücksichtigung möglicher Stipendien/Zuschüsse der Studierenden. 2. Einschließlich Studierender weiterführender forschungsorientierter Studiengänge. 3. Studiengebühren im Tertiärbereich insgesamt.

Quelle: OECD. Hinweise s. Anhang 3 unter www.oecd.org/edu/eag.htm. StatLink: http://dx.doi.org/10.1787/888932849920 Erläuterung der Kennzeichnung fehlender Daten s. Hinweise für den Leser. 
Tabelle B5.1 (Forts.)

Geschätzte durchschnittliche jährliche Studiengebühren für inländische Studierende an Bildungseinrichtungen des Tertiärbereichs $\mathrm{A}^{1}$ (2011)

In US-Dollar, kaufkraftbereinigt, nach Art der Bildungseinrichtung und Abschlussstruktur, basierend auf Vollzeitäquivalenten, Studienjahr 2010/2011

Anmerkung: Studiengebühren und die entsprechenden Studierendenzahlen sollten mit Vorsicht interpretiert werden, da sie aus dem gewichteten Durchschnitt der wichtigsten Studiengänge des Tertiärbereichs A resultieren und nicht alle Bildungseinrichtungen berücksichtigt sind. Die angegebenen Zahlen können jedoch als gute Näherungswerte betrachtet werden, sie zeigen den Unterschied zwischen den einzelnen Ländern bei den von der Mehrzahl der Bildungs einrichtungen von der Mehrheit der Studierenden verlangten Studiengebühren.

Kommentar

\begin{tabular}{l|l} 
& \multicolumn{1}{c}{ Kommentar } \\
\cline { 2 - 3 } $\begin{array}{l}\text { OECD-Länder } \\
\text { Australien }\end{array}$ & $\begin{array}{l}\text { 93 Prozent der inländischen Studierenden in öffentlichen Bildungseinrichtungen haben einen subventionierten Studienplatz und zahlen } \\
\text { im Durchschnitt eine Studiengebühr von 3.817 US-Dollar, einschl. HECS/HELP-Subventionen. Als Ergebnis von Regierungsreformen, die } \\
\text { darauf abzielten, die Zahl der Commonwealth-Stipendien bis 2012 zu verdoppeln, ist die Zahl der Stipendien für inländische Studie- } \\
\text { rende zwischen 2007 und 2009 signifikant gestiegen (ca. 50\%). Die neuen Stipendien sind hauptsächlich auf Studierende ausgerich- } \\
\text { tet, die Fächer belegen, für die eine nationale Priorität besteht, sowie auf Studierende, die zum Studium spezieller Fächer umziehen } \\
\text { mussten, und auf indigene Studierende. } \\
\text { Seit dem Sommersemester 2009 gelten Studiengebühren für inländische Studierende und Studierende aus EU/EWR-Ländern, wenn sie } \\
\text { die Regelstudienzeit für den Studiengang um mehr als zwei Semester überschreiten, sowie für Studierende aus Nicht-EU/EWR-Ländern } \\
\text { Österreich }\end{array}$
\end{tabular}
(mit Ausnahme von Studierenden aus den am wenigsten entwickelten Ländern).

Belgien (fläm.) $\quad$ Die Studiengebühren beziehen sich auf den Höchst- und Mindestbetrag, den Bildungseinrichtungen laut Gesetz erheben dürfen (indizierte Zahlen). Sie beziehen sich auf Studierende, die in Studiengängen, die zu einem ersten (Bachelor) oder zweiten (Master) Studienabschluss führen, eingeschrieben sind. Die Angaben beziehen sich nicht auf zu weiteren akadamischen Abschlüssen führende Studiengänge (z.B. „Master after Master“). Die Angaben beziehen sich auf Studierende ohne Stipendien (Studierende mit Stipendien zahlen geringere Studiengebühren, weitere Informationen s. Anhang 3).

Belgien (frz.) $\quad$ Die Studiengebühren sind an öffentlichen und privaten Bildungseinrichtungen gleich, die Studierendenzahlen aber unterschiedlich, sodass der gewichtete Durchschnitt ein anderer ist.

\section{Kanada \\ Chile}

Tschechien

Dänemark ${ }^{3}$

Estland $\quad$ In Estland gibt es ein zweigleisiges System. Studierende, die einen der staatlich finanzierten Studienplätze an einer Universität er-

Nur Studierende an Universitäten. Der Anteil der Studierenden, die Zuschüsse/Stipendien erhalten, ist geschätzt. Studierende aus EU/ EWR-Ländern und der Schweiz gelten als inländische Studierende. halten, zahlen keine Studiengebühren. Die Universitäten können Studiengebühren von den Studierenden erheben, die einen der über die staatlich finanzierten Studienplätze hinausgehenden Studienplätze erhalten. Die Universitäten können sowohl über die Höhe der Studiengebühren als auch die Zahl der Studierenden, die Studiengebühren zahlen müssen, selbst bestimmen. Bei den weiterführenden forschungsorientierten Studiengängen beispielsweise richten die Universitäten die meisten der zusätzlichen Studienplätze ohne Lehrveranstaltungen ein. In einem gewissen Ausmaß gilt dies auch für die Studiengänge, die zu einem zweiten oder weiteren Abschluss führen. Ohne Mitgliedsbeiträge für die Studierendenvertretung.

Finnland

Frankreich

Studiengebühren an öffentlichen Bildungseinrichtungen beziehen sich auf universitäre Studiengänge, die für die niedrigsten Studiengebühren vom Bildungsministerium abhängig sind, bei den höchsten Gebühren an öffentlichen Bildungseinrichtungen beziehen sie sich auf das Staatsexamen als „Psychomotricien(ne)“ (1.218 Euro). Bei den staatlich subventionierten privaten Bildungseinrichtungen

Deutschland Griechenland Ungarn

sland

sland beziehen sich die niedrigsten Studiengebühren in der Tabelle auf die Katholische Universität und die höchsten auf Kunsthochschulen.

Israel

talien

Die von öffentlichen Einrichtungen erhobenen Studiengebühren werden nur für in Undergraduate-Studiengänge eingeschriebene Vollzeitstudierende aus der EU direkt vom Staat übernommen. Etwa die Hälfte aller Studiengebühren wird von den privaten Haushalten getragen (vor allem für Teilzeitstudierende, Studierende in Postgraduate-Studiengängen und Studierende, die keine EU-Bürger sind). Das bedeutet, dass im Studienjahr 2010/2011 Studierende nur 1.500 Euro der angegebenen Studiengebühren gezahlt haben.

Jede Bildungseinrichtung legt ihr Gebührensystem fest, hierbei werden die wirtschaftlichen Verhältnisse der Familien der Studierenden nach Kriterien der Gleichheit und Solidarität berücksichtigt, die den allgemeinen Regeln, die auf nationaler Ebene festgelegt werden, gerecht werden. Die durchschnittlichen jährlichen Studiengebühren werden berechnet auf Grundlage der tatsächlich von den einzelnen Studierenden gezahlten Gebühren. Studierende, die keine Studiengebühren zahlen müssen, werden bei der Berechnung des Durchschnitts nicht berücksichtigt.

Japan $\quad$ Die durchschnittlichen jährlichen Studiengebühren enthalten nicht die von der Bildungseinrichtung verlangte Zulassungsgebühr für das

Korea erste Jahr.

Luxemburg

Mexiko

Niederlande

Neuseeland

Norwegen

Polen

Portugal

Slowakei

Vollzeitstudierende entrichten im Allgemeinen keine Studiengebühren. Aber Studierende, die in einem Studienjahr in zwei oder mehr Studiengängen einer öffentlichen Universität im gleichen Tertiärbereich eingeschrieben sind, müssen für den zweiten und jeden weiteren Studiengang für dieses Studienjahr Studiengebühren entrichten. Außerdem müssen Studierende, die die Regelstudienzeit überschreiten, für jedes weitere Studienjahr eine jährliche Studiengebühr entrichten.

Slowenien $\quad$ An öffentlichen und staatlich subventionierten privaten Einrichtungen: Vollzeitstudierende des ersten und zweiten Studienabschnitts zahlen keine Studiengebühren. Studierende des zweiten Abschnitts, die bereits über einen dem zweiten Abschnitt entsprechenden Abschluss/eine Qualifikation verfügen, zahlen jedoch Studiengebühren.

Spanien

Schweden

Schweiz

Türkei

Ver. Königreich

Vereinigte Staaten

Die Zahlen beziehen sich auf alle Studierenden (inländische und nicht inländische/ausländische Studierende im Vollzeitstudium).

Brasilien

Russische Föd.

1. Ohne Berücksichtigung möglicher Stipendien/Zuschüsse der Studierenden. 2. Einschließlich Studierender weiterführender forschungsorientierter Studiengänge.

3. Studiengebühren im Tertiärbereich insgesamt.

Quelle: OECD. Hinweise s. Anhang 3 unter www.oecd.org/edu/eag.htm. StatLink: http://dx.doi.org/10.1787/888932849920

Erläuterung der Kennzeichnung fehlender Daten s. Hinweise für den Leser. 
Verteilung der Finanzhilfen an Studierende im Vergleich zur Höhe der Studiengebühren an Bildungseinrichtungen des Tertiärbereichs A für inländische Studierende in einem Studiengang, der zu einem ersten Abschluss führt (2011) Basierend auf Vollzeitstudierenden, Studienjahr 2010/2011

\begin{tabular}{|c|c|c|c|c|c|c|c|c|}
\hline & \multicolumn{4}{|c|}{ Verteilung der Finanzhilfen an Studierende } & \multicolumn{4}{|c|}{$\begin{array}{l}\text { Verteilung der Stipendien/Zuschüsse zur Deckung } \\
\text { der Studiengebühren }\end{array}$} \\
\hline & \multicolumn{4}{|c|}{ Prozentsatz der Studierenden, die erhalten: } & \multicolumn{4}{|c|}{ Prozentsatz der Studierenden, die erhalten: } \\
\hline & $\begin{array}{c}\text { Nur öffentliche } \\
\text { Darlehen }\end{array}$ & $\begin{array}{c}\text { Nur Stipendien/ } \\
\text { Zuschüsse }\end{array}$ & $\begin{array}{l}\text { Öffentliche } \\
\text { Darlehen und } \\
\text { Stipendien/ } \\
\text { Zuschüsse }\end{array}$ & \begin{tabular}{|c|} 
Weder öffent- \\
liche Darlehen \\
noch \\
Stipendien/ \\
Zuschüsse
\end{tabular} & $\begin{array}{c}\text { Stipendien/ } \\
\text { Zuschüsse, die } \\
\text { höher sind als } \\
\text { die Studien- } \\
\text { gebühren }\end{array}$ & $\begin{array}{l}\text { Stipendien/ } \\
\text { Zuschüsse in } \\
\text { Höhe der } \\
\text { Studien- } \\
\text { gebühren }\end{array}$ & \begin{tabular}{|c|} 
Stipendien/ \\
Zuschüsse, \\
die die Studien- \\
gebühren teil- \\
weise abdecken
\end{tabular} & $\begin{array}{c}\text { Keine Stipen- } \\
\text { dien/Zuschüsse } \\
\text { zur Deckung } \\
\text { der Studien- } \\
\text { gebühren }\end{array}$ \\
\hline & (1) & (2) & (3) & (4) & (5) & (6) & (7) & (8) \\
\hline \multicolumn{9}{|l|}{ OECD-Länder } \\
\hline Australien ${ }^{1}$ & 81 & $\mathrm{n}$ & 2 & 16 & $\mathrm{n}$ & $\mathrm{n}$ & 3 & 97 \\
\hline Österreich & a & 16 & a & 86 & 15 & $\mathrm{n}$ & $\mathrm{n}$ & 85 \\
\hline Belgien (fläm.) ${ }^{1}$ & a & 19 & a & 81 & 19 & $x(5)$ & $x(5)$ & 81 \\
\hline Belgien (frz.) $)^{2}$ & $\mathrm{n}$ & $x(3)$ & 16 & 84 & 16 & $x(5)$ & $x(5)$ & 84 \\
\hline Kanada & $\mathrm{m}$ & $\mathrm{m}$ & $\mathrm{m}$ & $\mathrm{m}$ & $\mathrm{m}$ & $\mathrm{m}$ & $\mathrm{m}$ & $\mathrm{m}$ \\
\hline Chile & 32 & 13 & 4 & 50 & $\mathrm{n}$ & 3 & 14 & 82 \\
\hline Tschechien & $\mathrm{m}$ & $\mathrm{m}$ & a & $\mathrm{m}$ & $\mathrm{m}$ & $\mathrm{m}$ & $\mathrm{m}$ & $\mathrm{m}$ \\
\hline Dänemark ${ }^{3}$ & $\mathrm{n}$ & 53 & 28 & $\mathrm{~m}$ & 81 & $\mathrm{~m}$ & $\mathrm{~m}$ & $\mathrm{~m}$ \\
\hline Estland & $\mathrm{m}$ & $\mathrm{m}$ & $\mathrm{m}$ & $\mathrm{m}$ & 0 & 0 & 10 & 89 \\
\hline Finnland & a & 54 & a & 46 & a & a & a & a \\
\hline Frankreich ${ }^{3,4}$ & a & 31 & a & 69 & 24 & 7 & a & 69 \\
\hline Deutschland & $\mathrm{m}$ & $\mathrm{m}$ & $\mathrm{m}$ & $\mathrm{m}$ & $\mathrm{m}$ & $\mathrm{m}$ & $\mathrm{m}$ & $\mathrm{m}$ \\
\hline Griechenland & $\mathrm{m}$ & $\mathrm{m}$ & $\mathrm{m}$ & $\mathrm{m}$ & $\mathrm{m}$ & $\mathrm{m}$ & $\mathrm{m}$ & $\mathrm{m}$ \\
\hline Ungarn & $\mathrm{m}$ & $\mathrm{m}$ & $\mathrm{m}$ & $\mathrm{m}$ & $\mathrm{m}$ & $\mathrm{m}$ & $\mathrm{m}$ & $\mathrm{m}$ \\
\hline Island ${ }^{2}$ & 63 & $\mathrm{~m}$ & $\mathrm{~m}$ & 37 & a & a & a & 100 \\
\hline Irland ${ }^{4}$ & $\mathrm{~m}$ & 37 & $\mathrm{~m}$ & $\mathrm{~m}$ & 37 & $\mathrm{~m}$ & $\mathrm{~m}$ & $\mathrm{~m}$ \\
\hline Israel & $\mathrm{m}$ & $\mathrm{m}$ & $\mathrm{m}$ & $\mathrm{m}$ & $\mathrm{m}$ & $\mathrm{m}$ & $\mathrm{m}$ & $\mathrm{m}$ \\
\hline Italien & $\mathrm{n}$ & 19 & $\mathrm{n}$ & 80 & 8 & 4 & 7 & 81 \\
\hline Japan & 37 & 3 & $\mathrm{~m}$ & $\mathrm{~m}$ & $\mathrm{n}$ & $x(7)$ & 3 & $\mathrm{~m}$ \\
\hline Korea & $\mathrm{m}$ & $\mathrm{m}$ & $\mathrm{m}$ & $\mathrm{m}$ & a & 2 & 41 & 57 \\
\hline Luxemburg & $\mathrm{m}$ & $\mathrm{m}$ & $\mathrm{m}$ & $\mathrm{m}$ & $\mathrm{m}$ & $\mathrm{m}$ & $\mathrm{m}$ & $\mathrm{m}$ \\
\hline Mexiko 2,3 & 1 & 12 & $\mathrm{~m}$ & 87 & $\mathrm{~m}$ & $\mathrm{~m}$ & $\mathrm{~m}$ & $\mathrm{~m}$ \\
\hline Niederlande $^{4}$ & a & a & 85 & 15 & 68 & $\mathrm{n}$ & 17 & 15 \\
\hline Neuseeland & 53 & 6 & 37 & 5 & $\mathrm{~m}$ & $\mathrm{~m}$ & $\mathrm{~m}$ & $\mathrm{~m}$ \\
\hline Norwegen & 12 & 4 & 67 & $\mathrm{~m}$ & $\mathrm{~m}$ & $\mathrm{~m}$ & $\mathrm{~m}$ & $\mathrm{~m}$ \\
\hline Polen & $\mathrm{m}$ & $\mathrm{m}$ & $\mathrm{m}$ & $\mathrm{m}$ & $\mathrm{m}$ & $\mathrm{m}$ & $\mathrm{m}$ & $\mathrm{m}$ \\
\hline Portugal & $\mathrm{m}$ & $\mathrm{m}$ & $\mathrm{m}$ & $\mathrm{m}$ & $\mathrm{m}$ & $\mathrm{m}$ & $\mathrm{m}$ & $\mathrm{m}$ \\
\hline Slowakei & $\mathrm{m}$ & $\mathrm{m}$ & $\mathrm{m}$ & $\mathrm{m}$ & $\mathrm{m}$ & $\mathrm{m}$ & $\mathrm{m}$ & $\mathrm{m}$ \\
\hline Slowenien ${ }^{5,6}$ & a & 26 & $\mathrm{n}$ & $\mathrm{m}$ & $\mathrm{m}$ & $\mathrm{m}$ & $\mathrm{m}$ & $\mathrm{m}$ \\
\hline Spanien & $\mathrm{m}$ & $\mathrm{m}$ & $\mathrm{m}$ & $\mathrm{m}$ & 23 & 3 & 9 & 65 \\
\hline Schweden & $\mathrm{n}$ & 24 & 70 & 5 & a & a & a & a \\
\hline Schweiz & 2 & 10 & 1 & 87 & 13 & $\mathrm{n}$ & $n$ & 87 \\
\hline Türkei & $\mathrm{m}$ & $\mathrm{m}$ & $\mathrm{m}$ & $\mathrm{m}$ & 25 & $\mathrm{n}$ & $\mathrm{n}$ & 75 \\
\hline Vereinigtes Königreich² & $x(3)$ & 6 & 65 & 29 & $\mathrm{n}$ & $\mathrm{n}$ & $\mathrm{n}$ & 100 \\
\hline Vereinigte Staaten ${ }^{3}$ & 13 & 26 & 37 & 24 & $\mathrm{~m}$ & $\mathrm{~m}$ & $\mathrm{~m}$ & 37 \\
\hline \multicolumn{9}{|l|}{ Sonstige G20-Länder } \\
\hline Brasilien & $\mathrm{m}$ & $\mathrm{m}$ & $\mathrm{m}$ & $\mathrm{m}$ & $\mathrm{m}$ & $\mathrm{m}$ & $\mathrm{m}$ & $\mathrm{m}$ \\
\hline Russische Föderation & $\mathrm{m}$ & $\mathrm{m}$ & $\mathrm{m}$ & $\mathrm{m}$ & $\mathrm{m}$ & $\mathrm{m}$ & $\mathrm{m}$ & $\mathrm{m}$ \\
\hline
\end{tabular}

1. Ohne ausländische Studierende. 2. Daten beziehen sich auf das Studienjahr 2008/2009. 3. Verteilung der Studierenden im gesamten Tertiärbereich (nur öffentliche Universitäten, einschließlich Tertiärbereich B in Frankreich). 4. Nur öffentliche Bildungseinrichtungen. 5. Spalte (2) enthält nur Stipendien.

6. Daten beziehen sich auf das Studienjahr 2009/2010.

Quelle: OECD. Hinweise s. Anhang 3 unter www.oecd.org/edu/eag.htm. StatLink: http://dx.doi.org/10.1787/888932849939

Erläuterung der Kennzeichnung fehlender Daten s. Hinweise für den Leser. 
Tabelle B5.3

Durchschnittliche Studiengebühren von Bildungseinrichtungen des Tertiärbereichs, nach Fachrichtung (2011) Bruttobetrag der Studiengebühren in US-Dollar, kaufkraftbereinigt mittels KKP für das BIP, für inländische Vollzeitstudierende in einem Studiengang des Tertiärbereichs A, der zu einem ersten Abschluss führt (Studienjahr 2010/2011).

Anmerkung: Länder ohne Unterschiede bei den Studiengebühren nach Fachrichtung sind in dieser Tabelle nicht enthalten (Belgien [fläm.], Belgien [frz.], Dänemark, Finnland, Frankreich, Italien, Korea, Niederlande, Norwegen, Österreich, Schweden, Schweiz, Slowenien).

\begin{tabular}{|c|c|c|c|c|c|c|c|c|c|c|}
\hline & \multicolumn{9}{|c|}{$\begin{array}{l}\text { Durchschnittliche jährliche Studiengebühren für inländische Studierende im Vollzeit- } \\
\text { studium }{ }^{1} \text { in einem Studiengang des Tertiärbereichs A, der zu einem ersten Abschluss führt }\end{array}$} \\
\hline & & \multicolumn{9}{|c|}{2011} \\
\hline & & 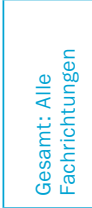 & 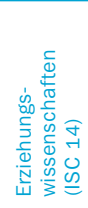 & 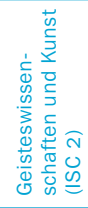 & 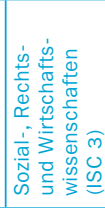 & 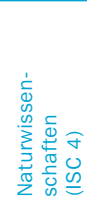 & 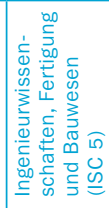 & 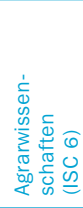 & 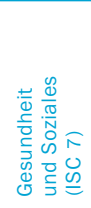 & 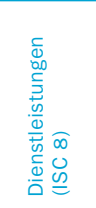 \\
\hline & & (1) & (2) & (3) & (4) & (5) & (6) & (7) & (8) & (9) \\
\hline OECD-Länder & & & & & & & & & & \\
\hline Australien & $\begin{array}{l}\text { Öffentliche Bildungseinrichtungen } \\
\text { Staatlich subventionierte private } \\
\text { Bildungseinrichtungen } \\
\text { Unabhängige private Bildungseinrichtungen }\end{array}$ & $\begin{array}{r}3924 \\
a \\
10110\end{array}$ & $\begin{array}{r}3095 \\
a \\
5803\end{array}$ & $\begin{array}{r}3477 \\
a \\
10617\end{array}$ & $\begin{array}{r}4472 \\
a \\
10497\end{array}$ & $\begin{array}{r}3367 \\
a \\
11017\end{array}$ & $\begin{array}{r}4325 \\
a \\
15494\end{array}$ & $\begin{array}{r}4937 \\
a \\
15227\end{array}$ & $\begin{array}{r}4013 \\
a \\
9771\end{array}$ & $\begin{array}{r}3597 \\
a \\
10787\end{array}$ \\
\hline Kanada & $\begin{array}{l}\text { Öffentliche Bildungseinrichtungen } \\
\text { Staatlich subventionierte private } \\
\text { Bildungseinrichtungen } \\
\text { Unabhängige private Bildungseinrichtungen }\end{array}$ & $\begin{array}{r}4288 \\
m \\
m\end{array}$ & $\begin{array}{r}3208 \\
m \\
m\end{array}$ & $\begin{array}{r}3883 \\
m \\
m\end{array}$ & $\begin{array}{r}4314 \\
\mathrm{~m} \\
\mathrm{~m}\end{array}$ & $\begin{array}{r}4286 \\
m \\
m\end{array}$ & $\begin{array}{r}4945 \\
m \\
m\end{array}$ & $\begin{array}{r}4095 \\
\mathrm{~m} \\
\mathrm{~m}\end{array}$ & $\begin{array}{r}5155 \\
m \\
m\end{array}$ & $\begin{array}{l}\mathrm{m} \\
\mathrm{m} \\
\mathrm{m}\end{array}$ \\
\hline Chile & $\begin{array}{l}\text { Öffentliche Bildungseinrichtungen } \\
\text { Staatlich subventionierte private } \\
\text { Bildungseinrichtungen } \\
\text { Unabhängige private Bildungseinrichtungen }\end{array}$ & $\begin{array}{l}5885 \\
6924 \\
6230\end{array}$ & $\begin{array}{l}4034 \\
4383 \\
4543\end{array}$ & $\begin{array}{l}5432 \\
6972 \\
6285\end{array}$ & $\begin{array}{l}6109 \\
7223 \\
6511\end{array}$ & $\begin{array}{l}6008 \\
7222 \\
5983\end{array}$ & $\begin{array}{l}6388 \\
7623 \\
6945\end{array}$ & $\begin{array}{l}6997 \\
7643 \\
6668\end{array}$ & $\begin{array}{l}6463 \\
7238 \\
6690\end{array}$ & $\begin{array}{l}5544 \\
6212 \\
5815\end{array}$ \\
\hline Estland & $\begin{array}{l}\text { Öffentliche Bildungseinrichtungen } \\
\text { Staatlich subventionierte private } \\
\text { Bildungseinrichtungen } \\
\text { Unabhängige private Bildungseinrichtungen }\end{array}$ & $\begin{array}{r}m \\
3527 \\
m\end{array}$ & $\begin{array}{r}m \\
3081 \\
m\end{array}$ & $\begin{array}{r}m \\
3439 \\
m\end{array}$ & $\begin{array}{r}m \\
3706 \\
m\end{array}$ & $\begin{array}{r}m \\
3145 \\
m\end{array}$ & $\begin{array}{r}m \\
3271 \\
m\end{array}$ & $\begin{array}{r}m \\
2927 \\
m\end{array}$ & $\begin{array}{r}m \\
3888 \\
m\end{array}$ & $\begin{array}{r}m \\
3284 \\
m\end{array}$ \\
\hline Irland & $\begin{array}{l}\text { Öffentliche Bildungseinrichtungen } \\
\text { (Universitäten) } \\
\text { Öffentliche Bildungseinrichtungen (IoT) } \\
\text { Staatlich subventionierte private } \\
\text { Bildungseinrichtungen } \\
\text { Unabhängige private Bildungseinrichtungen }\end{array}$ & $\begin{array}{r}7730 \\
4603 \\
m \\
m\end{array}$ & $\begin{array}{r}6895 \\
a \\
m \\
m\end{array}$ & $\begin{array}{r}6567 \\
4480 \\
m \\
m\end{array}$ & $\begin{array}{r}6567 \\
4480 \\
m \\
m\end{array}$ & $\begin{array}{r}8584 \\
4480 \\
m \\
m\end{array}$ & $\begin{array}{r}8584 \\
5218 \\
m \\
m\end{array}$ & $\begin{array}{r}8584 \\
a \\
m \\
m\end{array}$ & $\begin{array}{r}8326 \\
4480 \\
m \\
m\end{array}$ & $\begin{array}{r}a \\
4478 \\
a \\
a\end{array}$ \\
\hline Japan & $\begin{array}{l}\text { Öffentliche Bildungseinrichtungen } \\
\text { Staatlich subventionierte private } \\
\text { Bildungseinrichtungen } \\
\text { Unabhängige private Bildungseinrichtungen }\end{array}$ & $\begin{array}{r}5019 \\
a \\
8039\end{array}$ & $\begin{array}{l}a \\
a \\
m\end{array}$ & $\begin{array}{l}\mathrm{a} \\
\mathrm{a} \\
\mathrm{m}\end{array}$ & $\begin{array}{l}\mathrm{a} \\
\mathrm{a} \\
\mathrm{m}\end{array}$ & $\begin{array}{l}a \\
a \\
m\end{array}$ & $\begin{array}{l}\mathrm{a} \\
\mathrm{a} \\
\mathrm{m}\end{array}$ & $\begin{array}{l}a \\
a \\
m\end{array}$ & $\begin{array}{l}\mathrm{a} \\
\mathrm{a} \\
\mathrm{m}\end{array}$ & $\begin{array}{l}\mathrm{a} \\
\mathrm{a} \\
\mathrm{a}\end{array}$ \\
\hline Neuseeland & $\begin{array}{l}\text { Öffentliche Bildungseinrichtungen } \\
\text { Staatlich subventionierte private } \\
\text { Bildungseinrichtungen } \\
\text { Unabhängige private Bildungseinrichtungen }\end{array}$ & $\begin{array}{r}3645 \\
\mathrm{~m} \\
\mathrm{~m}\end{array}$ & $\begin{array}{r}3057 \\
\mathrm{~m} \\
\mathrm{~m}\end{array}$ & $\begin{array}{r}3084 \\
\mathrm{~m} \\
\mathrm{~m}\end{array}$ & $\begin{array}{r}3229 \\
m \\
m\end{array}$ & $\begin{array}{r}3630 \\
\mathrm{~m} \\
\mathrm{~m}\end{array}$ & $\begin{array}{r}4011 \\
\mathrm{~m} \\
\mathrm{~m}\end{array}$ & $\begin{array}{r}4987 \\
m \\
m\end{array}$ & $\begin{array}{r}5801 \\
m \\
m\end{array}$ & $\begin{array}{r}3780 \\
a \\
a\end{array}$ \\
\hline Polen & $\begin{array}{l}\text { Öffentliche Bildungseinrichtungen } \\
\text { Staatlich subventionierte private } \\
\text { Bildungseinrichtungen } \\
\text { Unabhängige private Bildungseinrichtungen }\end{array}$ & $\begin{array}{r}n \\
1242\end{array}$ & $\begin{array}{l}\mathrm{m} \\
\mathrm{m} \\
\mathrm{m}\end{array}$ & $\begin{array}{l}m \\
m \\
m\end{array}$ & $\begin{array}{l}\mathrm{m} \\
\mathrm{m} \\
\mathrm{m}\end{array}$ & $\begin{array}{l}\mathrm{m} \\
\mathrm{m} \\
\mathrm{m}\end{array}$ & $\begin{array}{l}\mathrm{m} \\
\mathrm{m} \\
\mathrm{m}\end{array}$ & $\begin{array}{l}\mathrm{m} \\
\mathrm{m} \\
\mathrm{m}\end{array}$ & $\begin{array}{l}\mathrm{m} \\
\mathrm{m} \\
\mathrm{m}\end{array}$ & $\begin{array}{l}\mathrm{a} \\
\mathrm{a} \\
\mathrm{a}\end{array}$ \\
\hline Spanien & $\begin{array}{l}\text { Öffentliche Bildungseinrichtungen } \\
\text { Staatlich subventionierte private } \\
\text { Bildungseinrichtungen } \\
\text { Unabhängige private Bildungseinrichtungen }\end{array}$ & $\begin{array}{r}1129 \\
\mathrm{a} \\
\mathrm{m}\end{array}$ & $\begin{array}{l}\mathrm{m} \\
\mathrm{a} \\
\mathrm{m}\end{array}$ & $\begin{array}{l}\mathrm{m} \\
\mathrm{a} \\
\mathrm{m}\end{array}$ & $\begin{array}{l}\mathrm{m} \\
\mathrm{a} \\
\mathrm{m}\end{array}$ & $\begin{array}{l}\mathrm{m} \\
\mathrm{a} \\
\mathrm{m}\end{array}$ & $\begin{array}{l}\mathrm{m} \\
\mathrm{a} \\
\mathrm{m}\end{array}$ & $\begin{array}{l}\mathrm{m} \\
\mathrm{a} \\
\mathrm{m}\end{array}$ & $\begin{array}{l}\mathrm{m} \\
\mathrm{a} \\
\mathrm{m}\end{array}$ & $\begin{array}{l}\mathrm{a} \\
\mathrm{a} \\
\mathrm{a}\end{array}$ \\
\hline Türkei & $\begin{array}{l}\text { Öffentliche Bildungseinrichtungen } \\
\text { Staatlich subventionierte private } \\
\text { Bildungseinrichtungen } \\
\text { Unabhängige private Bildungseinrichtungen }\end{array}$ & $\begin{array}{r}332 \\
a \\
m\end{array}$ & $\begin{array}{r}290 \\
a \\
m\end{array}$ & $\begin{array}{r}306 \\
a \\
m\end{array}$ & $\begin{array}{r}327 \\
a \\
m\end{array}$ & $\begin{array}{r}331 \\
a \\
m\end{array}$ & $\begin{array}{r}405 \\
\mathrm{a} \\
\mathrm{m}\end{array}$ & $\begin{array}{r}396 \\
\text { a } \\
\mathrm{m}\end{array}$ & $\begin{array}{r}428 \\
a \\
m\end{array}$ & $\begin{array}{r}231 \\
a \\
a\end{array}$ \\
\hline $\begin{array}{l}\text { Vereinigtes } \\
\text { Königreich }\end{array}$ & $\begin{array}{l}\text { Öffentliche Bildungseinrichtungen } \\
\text { Staatlich subventionierte private } \\
\text { Bildungseinrichtungen } \\
\text { Unabhängige private Bildungseinrichtungen }\end{array}$ & $\begin{array}{l}\mathrm{a} \\
\mathrm{m} \\
\mathrm{m}\end{array}$ & $\begin{array}{l}a \\
m \\
m\end{array}$ & $\begin{array}{l}a \\
m \\
m\end{array}$ & $\begin{array}{l}\mathrm{a} \\
\mathrm{m} \\
\mathrm{m}\end{array}$ & $\begin{array}{l}a \\
m \\
m\end{array}$ & $\begin{array}{l}a \\
m \\
m\end{array}$ & $\begin{array}{l}a \\
m \\
m\end{array}$ & $\begin{array}{l}a \\
m \\
m\end{array}$ & $\begin{array}{l}\mathrm{a} \\
\mathrm{m} \\
\mathrm{m}\end{array}$ \\
\hline $\begin{array}{l}\text { Vereinigte } \\
\text { Staaten }^{1}\end{array}$ & $\begin{array}{l}\text { Öffentliche Bildungseinrichtungen } \\
\text { Staatlich subventionierte private } \\
\text { Bildungseinrichtungen } \\
\text { Unabhängige private Bildungseinrichtungen }\end{array}$ & $\begin{array}{r}5402 \\
a \\
17163\end{array}$ & $\begin{array}{r}5354 \\
a \\
17840\end{array}$ & $\begin{array}{r}5021 \\
a \\
22736\end{array}$ & $\begin{array}{r}6203 \\
a \\
17333\end{array}$ & $\begin{array}{r}6263 \\
a \\
18584\end{array}$ & $\begin{array}{r}6176 \\
a \\
19347\end{array}$ & $\begin{array}{r}5933 \\
a \\
19192\end{array}$ & $\begin{array}{r}4207 \\
a \\
12549\end{array}$ & $\begin{array}{r}4659 \\
a \\
13800\end{array}$ \\
\hline
\end{tabular}

1. Die Zahlen beziehen sich auf alle Studierenden (inländische und nicht inländische/ausländische Studierende im Vollzeitstudium). Quelle: OECD. Hinweise s. Anhang 3 unter www.oecd.org/edu/eag.htm. StatLink: http://dx.doi.org/10.1787/888932849958 Erläuterung der Kennzeichnung fehlender Daten s. Hinweise für den Leser. 
Tabelle B5.4

Öffentliche Unterstützungsleistungen an private Haushalte und andere private Einheiten als Prozentsatz der öffentlichen Gesamtausgaben für Bildung und des BIP, für den Tertiärbereich (2010)

Direkte öffentliche Ausgaben für Bildungseinrichtungen und Subventionen für private Haushalte und andere private Einheiten

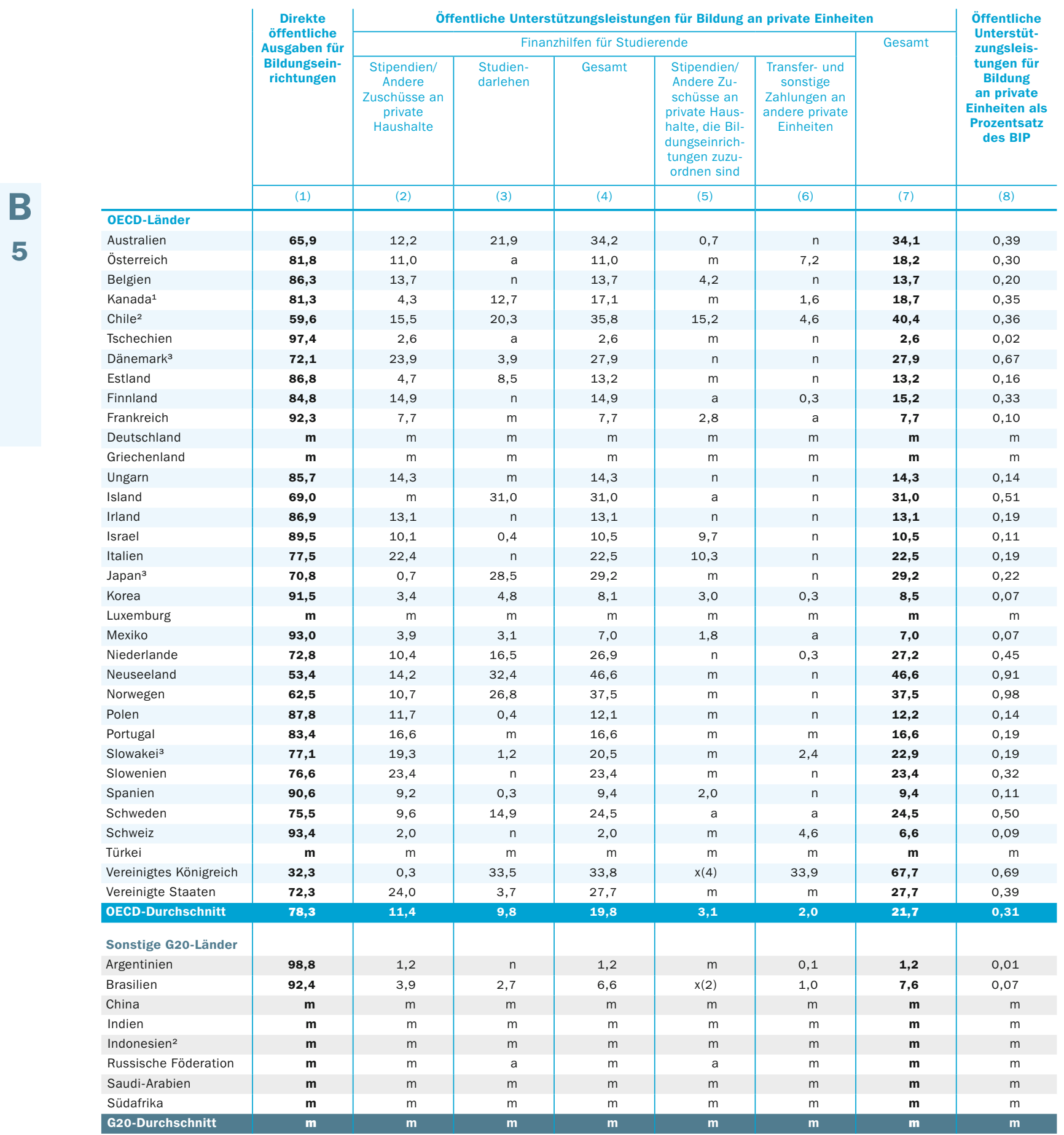

1. Referenzjahr 2009. 2. Referenzjahr 2011. 3. Einige Bildungsbereiche sind in anderen Bildungsbereichen enthalten. Einzelheiten s. Erläuterung von „x“ in Hinweise für den Leser.

Quelle: OECD. Argentinien: Statistikinstitut der UNESCO (World Education Indicators Programme). Hinweise s. Anhang 3 unter www.oecd.org/edu/eag.htm. StatLink: http://dx.doi.org/10.1787/888932849977

Erläuterung der Kennzeichnung fehlender Daten s. Hinweise für den Leser. 


\section{WEB Indikator B6}

steht im Internet zur Verfügung unter StatLink: http://dx.doï.org/10.1787/888932850015

\section{Wofür werden Finanzmittel im Bereich der Bildung ausgegeben?}

Im Durchschnitt werden in den OECD-Ländern mehr als 9I Prozent der Bildungsgesamtausgaben für laufende Ausgaben aufgewendet; dies trifft in den meisten OECD-Ländern und sonstigen G20-Ländern sowohl im Primar-, Sekundar- und postsekundaren, nicht tertiären Bereich zusammengenommen als auch im Tertiärbereich zu.

In I8 der 29 Länder mit verfügbaren Daten liegt im Tertiärbereich der Anteil der Investitionsausgaben an den Gesamtausgaben höher als im Primar-, Sekundarund postsekundaren, nicht tertiären Bildungsbereich zusammen. Dies könnte mit dem Wachstum des Tertiärbereichs in den letzten Jahren und der daraus resultierenden Notwendigkeit des Neubaus von Gebäuden zusammenhängen.

In den OECD- und sonstigen G20-Ländern, für die Daten zur Verfügung stehen, entfällt der Großteil der laufenden Ausgaben auf die Vergütung der im Bildungswesen Beschäftigten (Lehrkräfte und andere).

Die laufenden Ausgaben für andere Zwecke als die Vergütung von Beschäftigten sind im Tertiärbereich am höchsten und belaufen sich im Durchschnitt der OECDLänder auf 3I Prozent aller laufenden Ausgaben. Ein wesentlicher Grund hierfür könnten die im Vergleich mit den anderen Bildungsbereichen höheren Kosten für die Einrichtung und Ausrüstung der Bildungseinrichtungen im Tertiärbereich sein. 


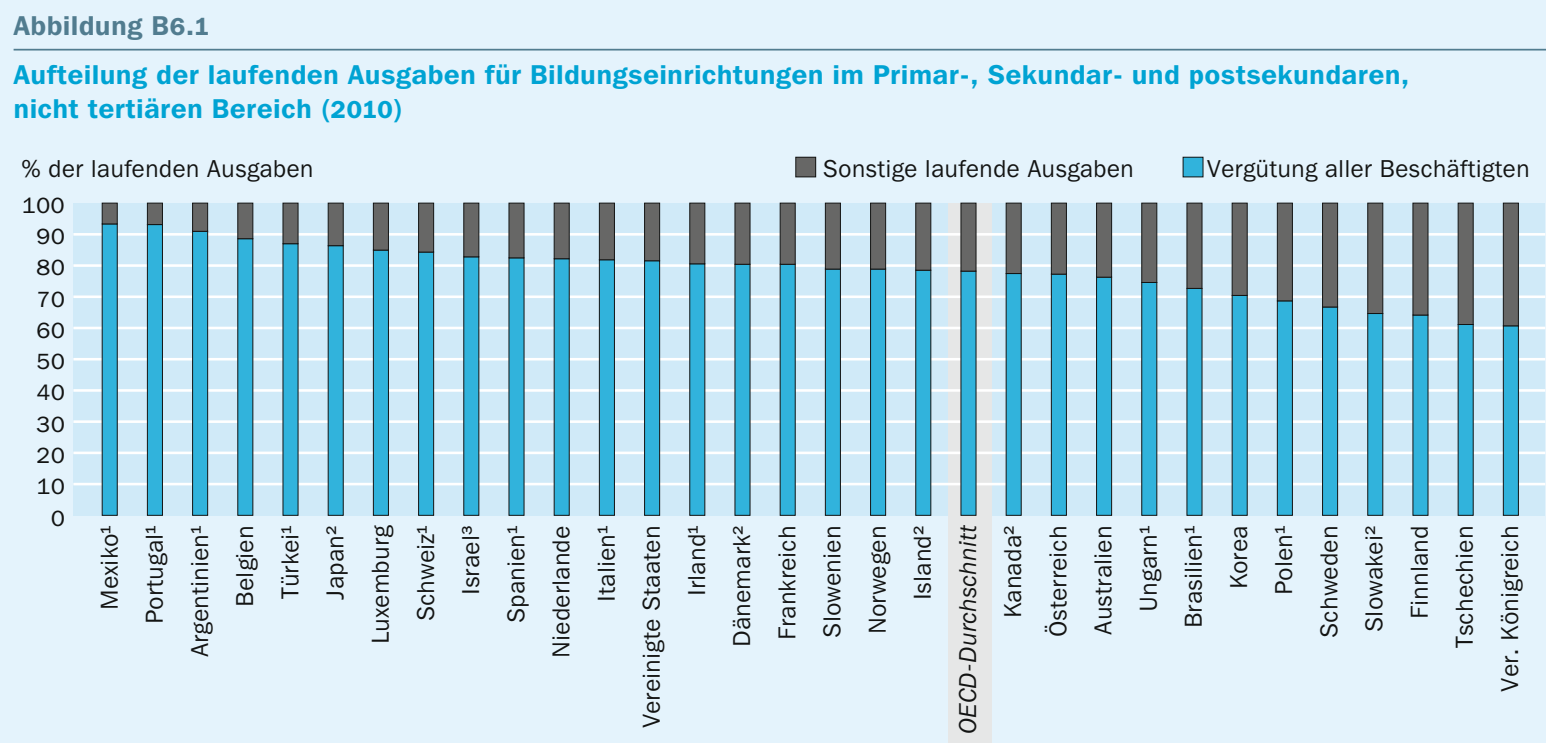

1. Nur öffentliche Bildungseinrichtungen. 2. Einige Bildungsbereiche sind in anderen Bildungsbereichen enthalten. Einzelheiten s. Erläuterung von „x“ in Hinweise für den Leser. 3. Die statistischen Daten für Israel wurden von den zuständigen israelischen Stellen bereitgestellt, die für sie verantwortlich zeichnen. Die Verwendung dieser Daten durch die OECD erfolgt unbeschadet des völkerrechtlichen Status der Golanhöhen, von Ost-Jerusalem und der israelischen Siedlungen im Westjordanland.

Anordnung der Länder in absteigender Reihenfolge des Anteils der Vergütung aller Beschäftigten im Primar-, Sekundar- und postsekundaren, nicht tertiären Bereich. Quelle: OECD. Argentinien: Statistikinstitut der UNESCO (World Education Indicators Programme). Südafrika: Statistikinstitut der UNESCO. Tabelle B6.2. Hinweise s. Anhang 3 unter www.oecd.org/edu/eag.htm. StatLink: http://dx.doi.org/10.1787/888932847184

\section{Abbildungen Indikator B6}

WEB Chart B6.I: Distribution of current expenditure on educational institutions for primary, secondary and post-secondary non-tertiary education (Aufteilung der laufenden Ausgaben für Bildungseinrichtungen im Primar-, Sekundar- und postsekundaren, nicht tertiären Bereich) (20I0)

StatLink: http:||dx.doi.org/10.1787/888932847184

WEB Chart B6.2: Distribution of current and capital expenditure on educational institutions (Aufteilung der Gesamtausgaben für Bildungseinrichtungen in laufende Ausgaben und Investitionsausgaben) (2010)

StatLink: http://dx.doi.org/10.1787/888932847203

\section{Tabellen Indikator B6}

WEB Table B6.I: Expenditure by primary and secondary educational institutions, by resource category (Ausgaben von Bildungseinrichtungen im Primar- und Sekundarbereich, nach Ausgabenkategorie) (2010) StatLink: http://dx.doi.org/10.1787/888932850034

WEB Table B6.2: Expenditure by educational institutions by resource category and level of education (Ausgaben von Bildungseinrichtungen, nach Ausgabenkategorie und Bildungsbereich) (2010)

StatLink: http:||dx.doi.org/10.1787/888932850053 


\section{Welche Faktoren beeinflussen die Höhe der Bildungsausgaben?}

Vier Faktoren beeinflussen die Bildungsausgaben in Bezug auf die Gehaltskosten der Lehrkräfte pro Schüler: die Unterrichtszeit der Schüler, die Zahl der von den Lehrkräften zu unterrichtenden (Zeit-)Stunden, die Vergütung der Lehrkräfte und die geschätzte Klassengröße. Somit können gleiche Gehaltskosten der Lehrkräfte pro Schüler auf völlig unterschiedlichen Kombinationen dieser vier Faktoren beruhen.

Es bestehen große Unterschiede zwischen den Ländern bei den Gehaltskosten der Lehrkräfte pro Schüler; in den meisten Ländern steigen die Gehaltskosten der Lehrkräfte mit dem Bildungsbereich, in dem sie unterrichten.

Zwischen 2005 und 20II stiegen in den meisten Ländern die Gehaltskosten der Lehrkräfte pro Schüler im Primar- und Sekundarbereich I beträchtlich. In den Ländern, für die Daten für beide Jahre vorliegen, stiegen sie im Durchschnitt um mehr als Io Prozent: im Primarbereich von 2.398 US-Dollar auf 2.627 US-Dollar und im Sekundarbereich I von 3.473 US-Dollar auf 3.818 US-Dollar.

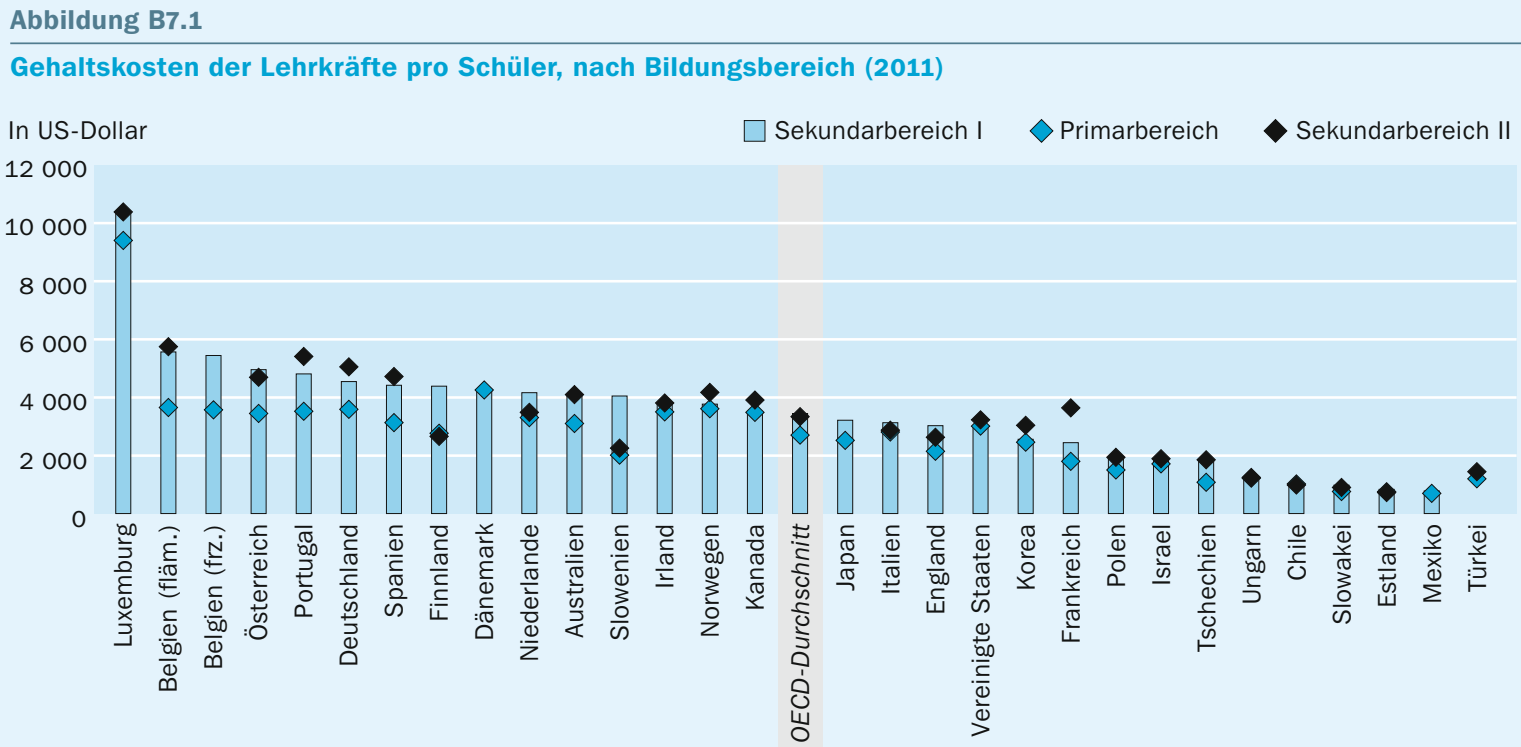




\section{Kontext}

Die Regierungen interessieren sich inzwischen verstärkt für das Verhältnis zwischen den in Bildung investierten Ressourcen und den erzielten Lernergebnissen. Sie wollen die Bevölkerung mit mehr und besserer Bildung versorgen, während sie gleichzeitig sicherstellen müssen, dass die öffentlichen Mittel effizient eingesetzt werden, besonders in Zeiten, in denen bei den öffentlichen Haushalten immer mehr gespart werden muss.

Die Vergütung der Lehrkräfte ist in der Regel der größte Ausgabenposten im Bildungswesen und somit auch der Ausgaben pro Schüler. Sie ist eine Funktion der Unterrichtszeit der Schüler, der Zahl der von den Lehrkräften zu unterrichtenden (Zeit-)Stunden, der Gehälter der Lehrkräfte und der Zahl der zum Unterrichten der Schüler benötigten Lehrkräfte, die von der geschätzten Klassengröße abhängt (Kasten B7.I). Unterschiede in den einzelnen Ländern bei diesen vier Faktoren können Unterschiede im Ausgabenniveau pro Schüler erklären. Ebenso kann ein bestimmtes Ausgabenniveau das Ergebnis verschiedener Kombinationen dieser Faktoren sein.

Dieser Indikator befasst sich damit, wie Länder ihre Mittel im Primar- und Sekundarbereich einsetzen, und untersucht, wie sich Veränderungen der bildungspolitischen Entscheidungen hinsichtlich dieser vier Faktoren zwischen den Jahren 2000, 2005 und 2010 auf die Höhe der Gehaltskosten der Lehrkräfte ausgewirkt haben. Manchmal sind diese Veränderungen jedoch nicht unbedingt das Ergebnis bildungspolitischer Entscheidungen, sondern ergeben sich eher aus demografischen Veränderungen, wie z. B. sinkenden Schülerzahlen. So würde sich beispielsweise in den Ländern, die in jüngster Zeit zurückgehende Schülerzahlen haben, auch die Klassengröße verringern, außer die Zahl der Lehrkräfte ginge gleichzeitig zurück.

\section{Weitere wichtige Ergebnisse}

Einem ähnlichen Ausgabenniveau verschiedener Länder können ganz unterschiedliche bildungspolitische Entscheidungen zugrunde liegen. Dies ist einer der Gründe, weshalb es keinen unmittelbaren Zusammenhang zwischen den Gesamtausgaben für Bildung und den Leistungen der Schüler gibt. So waren beispielsweise in Deutschland und in Portugal 20II die Gehaltskosten der Lehrkräfte pro Schüler im Sekundarbereich II ähnlich hoch, sie lagen in beiden Ländern über dem Durchschnitt. In Deutschland war dies hauptsächlich auf die signifikant über dem Durchschnitt liegenden Gehälter der Lehrkräfte zurückzuführen, in Portugal jedoch hauptsächlich auf unterdurchschnittlich kleine Klassengrößen.

Die Gehälter der Lehrkräfte erweisen sich in allen Bildungsbereichen am häufigsten als wichtigster Faktor für den Unterschied zu den durchschnittlichen Gehaltskosten der Lehrkräfte pro Schüler. Die geschätzte Klassengröße ist in allen Bildungsbereichen der zweitwichtigste Faktor für den Unterschied.

Die Gehälter der Lehrkräfte erweisen sich weniger häufig als wichtigster Faktor für den Unterschied zu den durchschnittlichen Gehaltskosten der Lehrkräfte pro Schüler, wenn man die unterschiedliche Wirtschaftskraft der einzelnen Länder berücksichtigt. 


\section{Entwicklungstendenzen}

Die gestiegenen Gehaltskosten der Lehrkräfte pro Schüler zwischen 2005 und $201 \mathrm{I}$ wurden am stärksten durch Veränderungen bei zwei Faktoren beeinflusst: die Gehälter der Lehrkräfte und die geschätzte Klassengröße. Zwischen 2005 und 20 I I stiegen die Gehälter der Lehrkräfte in den Ländern, für die Daten für beide Jahre zur Verfügung standen, im Primarbereich um durchschnittlich mehr als I4 Prozent und im Sekundarbereich I um durchschnittlich fast II Prozent, während die geschätzte Klassengröße im Primarbereich um durchschnittlich I8 Prozent und im Sekundarbereich I um durchschnittlich 6 Prozent zurückging. Die Unterschiede bei den zwei anderen Faktoren, der Unterrichtszeit der Schüler und den von den Lehrkräften zu unterrichtenden (Zeit-)Stunden, waren in den meisten Ländern geringer und beliefen sich in den Ländern mit verfügbaren Daten für beide Jahre im Durchschnitt auf 3 Prozent bzw. 4 Prozent.

In den meisten Ländern wurden zwischen 2005 und 20II im Primar- und Sekundarbereich I gleichzeitig die Gehälter der Lehrkräfte erhöht und die geschätzte Klassengröße verkleinert. Diese Veränderungen führten zu einem Anstieg der Gehaltskosten der Lehrkräfte. Italien und Ungarn sind die einzigen beiden Länder, in denen die Gehaltskosten der Lehrkräfte pro Schüler sowohl im Primar- als auch Sekundarbereich I zwischen 2005 und 201 I signifikant sanken.

Einige Länder haben seit 2005 Reformen durchgeführt, die sich auf die Gehaltskosten der Lehrkräfte pro Schüler auswirkten. So wurde beispielsweise in Ungarn 2006 die Zahl der zu unterrichtenden (Zeit-)Stunden für den Sekundarbereich erhöht, was die Zahl der in diesem Bildungsbereich benötigten Lehrkräfte erhöhte. Das wiederum erhöhte die Ausgaben für die Gehälter der Lehrkräfte. In Italien gab es eine Reform der Klassengröße, bei der die Zahl der Schüler pro Klasse leicht erhöht wurde. Dies führte zu einer Senkung der Gehaltskosten der Lehrkräfte pro Schüler (s. Tab. B7·5 in Bildung aufeinen Blick 2012).

\section{Analyse und Interpretationen}

\section{Die Gehaltskosten der Lehrkräfte pro Schüler ....}

Die Ausgaben pro Schüler spiegeln strukturelle und institutionelle Faktoren in Bezug auf die Organisation der Schulen und die Lehrpläne wider. Ausgaben lassen sich aufgliedern in die Vergütung von Lehrkräften und andere Ausgaben (definiert als alle sonstigen Ausgaben mit Ausnahme der Vergütung von Lehrkräften). Die Vergütung der Lehrkräfte ist in der Regel der größte Ausgabenposten im Bildungswesen. Somit bildet die Vergütung der Lehrkräfte geteilt durch die Anzahl der Schüler (hier als „Gehaltskosten der Lehrkräfte pro Schüler“ bezeichnet) den größten Posten der Ausgaben pro Schüler.

Die Vergütung der Lehrkräfte ergibt sich aus der Unterrichtszeit der Schüler, der Zahl der von den Lehrkräften zu unterrichtenden (Zeit-)Stunden, den Gehältern der Lehrkräfte und der Zahl der zum Unterrichten der Schüler benötigten Lehrkräfte, die von 


\section{Verhältnis zwischen den Gehaltskosten der Lehrkräfte pro Schüler und der Unterrichtszeit der Schüler, den zu unterrichtenden (Zeit-) Stunden der Lehrkräfte, den Gehältern der Lehrkräfte und der geschätzten Klassengröße}

Eine Möglichkeit, die Faktoren zu analysieren, die sich auf die Ausgaben pro Schüler auswirken, und das Ausmaß ihrer jeweiligen Auswirkung zu bestimmen, ist ein Vergleich der Unterschiede zwischen den nationalen Zahlen und dem OECDDurchschnitt. Bei dieser Analyse werden die Unterschiede bei den Ausgaben pro Schüler zwischen den einzelnen Ländern und dem OECD-Durchschnitt ermittelt und anschließend der Beitrag der verschiedenen Faktoren zu diesem Unterschied berechnet.

Dieses Vorgehen basiert auf einer mathematischen Korrelation zwischen den einzelnen berücksichtigten Faktoren und greift die in der kanadischen Publikation Education Statistics Bulletin (2005) vorgestellte Methode auf (s. Erläuterungen in Anhang 3). Bildungsausgaben sind mathematisch gesehen mit Faktoren verknüpft, die im Zusammenhang mit dem schulischen Umfeld eines Landes stehen (der Zahl der Unterrichtsstunden der Schüler, der Zahl der von den Lehrkräften zu unterrichtenden [Zeit-]Stunden, der geschätzten Klassengröße), und einem Faktor in Bezug auf die Lehrkräfte (das gesetzliche bzw. vertraglich vereinbarte Gehalt).

Die Ausgaben werden aufgegliedert in die Vergütung von Lehrkräften und sonstige Ausgaben (definiert als alle sonstigen Ausgaben mit Ausnahme der Vergütung der Lehrkräfte). Die „Gehaltskosten der Lehrkräfte pro Schüler“ (GKLS), d. h. die Vergütung der Lehrkräfte geteilt durch die Anzahl der Schüler, werden folgendermaßen ermittelt:

$$
\text { GKLS }=\text { GEHL } \times \text { UntZS } \times \frac{1}{\text { UntZL }} \times \frac{1}{\text { GKl }}=\frac{\text { GEHL }}{\text { SLR }}
$$

GEHL: Gehälter der Lehrkräfte (angesetzt anhand des gesetzlichen bzw. vertraglich vereinbarten Gehalts nach I5 Jahren Berufserfahrung)

UntZS: Unterrichtszeit der Schüler (angesetzt als die jährliche Zahl an [Zeit-]Stunden, die Schüler pro Jahr unterrichtet werden sollen)

UntZL: Unterrichtszeit der Lehrkräfte (angesetzt als Zahl der von Lehrkräften zu unterrichtenden [Zeit-]Stunden pro Jahr)

GKl: Größe der Klasse, eine Näherungsgröße für die Größe der Klasse

SLR: Schüler-Lehrkräfte-Relation

Mit Ausnahme der Größe der Klasse (die im Sekundarbereich II nicht berechnet wird, da sie schwer zu definieren und zu vergleichen ist, weil Schüler je nach Fach eventuell in verschiedenen Klassen unterrichtet werden) können die Werte für die verschiedenen Variablen aus den in Bildung auf einen Blick veröffentlichten Indikatoren (Kapitel D) entnommen werden. Zur Durchführung der Analyse wird jedoch ausgehend von der Schüler-Lehrkräfte-Relation und der Zahl der Unterrichts(zeit) stunden der Schüler und der Zahl der von den Lehrkräften zu unterrichtenden (Zeit-) 
Stunden eine „geschätzte“ Klassengröße angesetzt (Kasten D2.I). Da die geschätzte Klassengröße nur eine Näherungsgröße ist, sollte sie mit Vorsicht interpretiert werden.

Mithilfe dieser mathematischen Gleichung und eines Vergleichs der Werte für diese vier Faktoren in einem bestimmten Land mit dem OECD-Durchschnitt lässt sich sowohl der direkte als auch der indirekte Beitrag jedes einzelnen dieser vier Faktoren zum Unterschied in den Gehaltskosten pro Schüler in einem bestimmten Land und dem OECD-Durchschnitt bestimmen (weitere Informationen s. Anhang 3). Wenn beispielsweise nur zwei Faktoren zusammenwirken und ein Arbeiter einen um ıo Prozent höheren Stundenlohn erhält, während er gleichzeitig die Zahl seiner Arbeitsstunden um 20 Prozent erhöht, dann erhöht sich sein Lohn um 32 Prozent, und zwar aufgrund des direkten Beitrags jeder dieser beiden Variablen $(0, \mathrm{I}+0,2)$ sowie des indirekten Beitrags dieser Variablen aufgrund der Kombination dieser beiden Faktoren $(0, \mathrm{I} \times 0,2)$.

Um das Wohlstandsgefälle zwischen den einzelnen Ländern bei einem Vergleich der Gehaltskosten pro Schüler zu berücksichtigen, können die Gehaltskosten pro Schüler ebenso wie die Gehälter der Lehrkräfte durch das BIP pro Kopf dividiert werden (ausgehend von der Annahme, dass das BIP pro Kopf eine Näherungsgröße für den Wohlstand eines Landes ist). So können die „relativen“ Gehaltskosten pro Schüler einzelner Länder miteinander verglichen werden (s. Tab. von Bildung auf einen Blick 2013 im Internet).

der geschätzten Klassengröße abhängt (Kasten B7.I). Daher können Unterschiede in den einzelnen Ländern bei diesen vier Faktoren Unterschiede im jeweiligen Ausgabenniveau erklären. Ebenso kann ein bestimmtes Ausgabenniveau das Ergebnis verschiedener Kombinationen dieser Faktoren sein.

\section{... steigen in der Regel mit dem Bildungsbereich, in dem unterrichtet wird, auch wenn es große Unterschiede zwischen den einzelnen OECD-Ländern gibt}

Die Gehaltskosten der Lehrkräfte pro Schüler haben in allen OECD-Ländern eins gemeinsam: In der Regel steigen sie steil mit der Höhe des Bildungsbereichs, in dem unterrichtet wird. Doch in manchen Ländern (insbesondere Finnland, den Niederlanden und Slowenien) sind sie im Sekundarbereich II niedriger als im Sekundarbereich I. So lagen 20II in den OECD-Ländern mit verfügbaren Daten für die unterschiedlichen Bildungsbereiche die durchschnittlichen Gehaltskosten der Lehrkräfte pro Schüler im Primarbereich bei 2.757 US-Dollar, im Sekundarbereich I bei 3.456 US-Dollar und im Sekundarbereich II bei 3.420 US-Dollar (also etwas unter denen im Sekundarbereich I).

Die Unterschiede zwischen den einzelnen Bildungsbereichen bei den Gehaltskosten der Lehrkräfte pro Schüler variieren signifikant zwischen den einzelnen Ländern. 201 I lag der Unterschied zwischen den drei Bildungsbereichen in Chile und Ungarn bei weniger als 50 US-Dollar, aber in Belgien (frz.), Frankreich und Portugal bei mehr als I.80o US-Dollar und in Belgien (fläm.) und Slowenien bei mehr als 2.000 US-Dollar (Tab. B7.I und Abb. B7.I). 
Die Zunahme der Gehaltskosten der Lehrkräfte pro Schüler ist, je höher der Bildungsbereich ist, zum Teil auf steigende Gehälter der Lehrkräfte und die zunehmende Zahl an Unterrichtsstunden für Schüler in den höheren Bildungsbereichen zurückzuführen. Die durchschnittlichen Gehälter der Lehrkräfte in der OECD reichen von 38.136 US-Dollar im Primarbereich über 39.934 US-Dollar im Sekundarbereich I bis zu 4I.665 US-Dollar im Sekundarbereich II, während die Bandbreite der jährlichen Zahl an Unterrichtsstunden im OECD-Durchschnitt von 809 Stunden im Primarbereich über 926 Stunden im Sekundarbereich I bis zu 943 Stunden im Sekundarbereich II reicht. Der Anstieg hängt auch damit zusammen, dass die Zahl der von den Lehrkräften zu unterrichtenden (Zeit-)Stunden mit steigendem Bildungsbereich im Allgemeinen abnimmt, was impliziert, dass mehr Lehrkräfte für den Unterricht für eine bestimmte Schülerzahl notwendig sind (20II nahm der OECD-Durchschnitt der jährlich zu unterrichtenden [Zeit-]Stunden von 786 Stunden im Primarbereich auf 707 Stunden im Sekundarbereich I und 662 im Sekundarbereich II ab). Größere Klassen in den höheren Bildungsbereichen führen jedoch tendenziell zu niedrigeren Gehaltskosten pro Schüler (der OECD-Durchschnitt der geschätzten Klassengröße steigt von I6, I Schülern im Primarbereich über 17,3 Schüler im Sekundarbereich I auf 19,7 Schüler im Sekundarbereich II) (Tab. B7.2a und B7.2b sowie Tab. B7.2c im Internet).

\section{Zwischen 2005 und 2011 stiegen in den meisten Ländern die Gehalts- kosten der Lehrkräfte pro Schüler ...}

Die Gehaltskosten der Lehrkräfte pro Schüler innerhalb eines bestimmten Bildungsbereichs variieren auch im Laufe der Zeit. Diese Veränderungen der Gehaltskosten der Lehrkräfte pro Schüler werden nur für den Primarbereich und Sekundarbereich I analysiert, da für den Sekundarbereich II keine Trenddaten vorliegen. Die Analyse beschränkt sich auch auf Länder mit verfügbaren Daten sowohl für das Referenzjahr 2005 als auch für das Referenzjahr 20II (2I Länder sowohl für den Primarbereich als auch für den Sekundarbereich I), denn für 2000, 2005 und 20II liegen für weniger Länder Daten vor.

In den Ländern mit verfügbaren Daten für beide Jahre stiegen im Durchschnitt die Gehaltskosten der Lehrkräfte pro Schüler im Primarbereich und Sekundarbereich I um Io Prozent: im Primarbereich von 2.398 US-Dollar auf 2.626 US-Dollar und im Sekundarbereich I von 3.473 US-Dollar auf 3.818 US-Dollar (Abb. B7.2).

In beiden Bildungsbereichen stiegen in den meisten Ländern die Gehaltskosten der Lehrkräfte pro Schüler zwischen 2005 und 20Ir. Sie stiegen in Irland, Korea und der Türkei im Primarbereich und in Tschechien im Sekundarbereich I um mindestens 30 Prozent sowie in Israel im Primarbereich und Slowenien im Sekundarbereich I um mehr als 50 Prozent (Abb. B7.3).

Die größten Ausnahmen von diesem Anstieg der Gehaltskosten der Lehrkräfte pro Schüler im Zeitverlauf waren Italien und Ungarn, wo sie zwischen 2005 und $201 \mathrm{Im}$ Primarbereich um 26 Prozent bzw. II Prozent und im Sekundarbereich I um 25 Prozent bzw. I3 Prozent zurückgingen. Die Gehaltskosten der Lehrkräfte pro Schüler nahmen, wenn auch in geringerem Maß, auch im Sekundarbereich I in Frankreich (um 7 Prozent) und in den Vereinigten Staaten ab (um weniger als 4 Prozent im Primar- und Sekundarbereich I) (Abb. B7.2). 
Veränderung der Gehaltskosten der Lehrkräfte pro Schüler, nach Bildungsbereich $(2000,2005,2011)$

Gehaltskosten in 2011

Gehaltskosten in 2005

Gehaltskosten in 2000

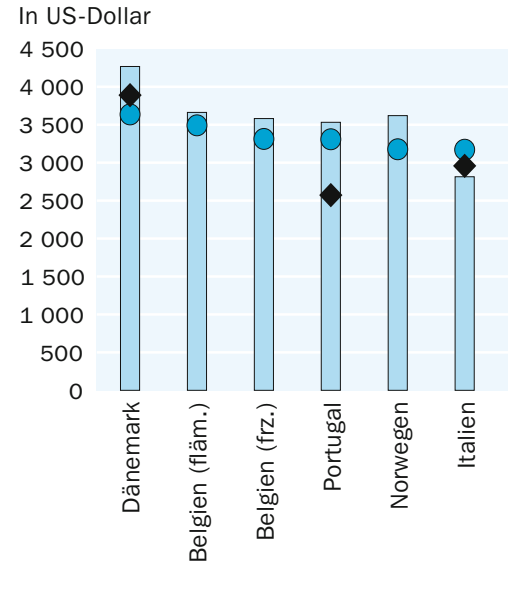

Primarbereich

In US-Dollar

6000

5500

5000

4500

4000

3500

3000

2500

2000

1500

1000

500

0
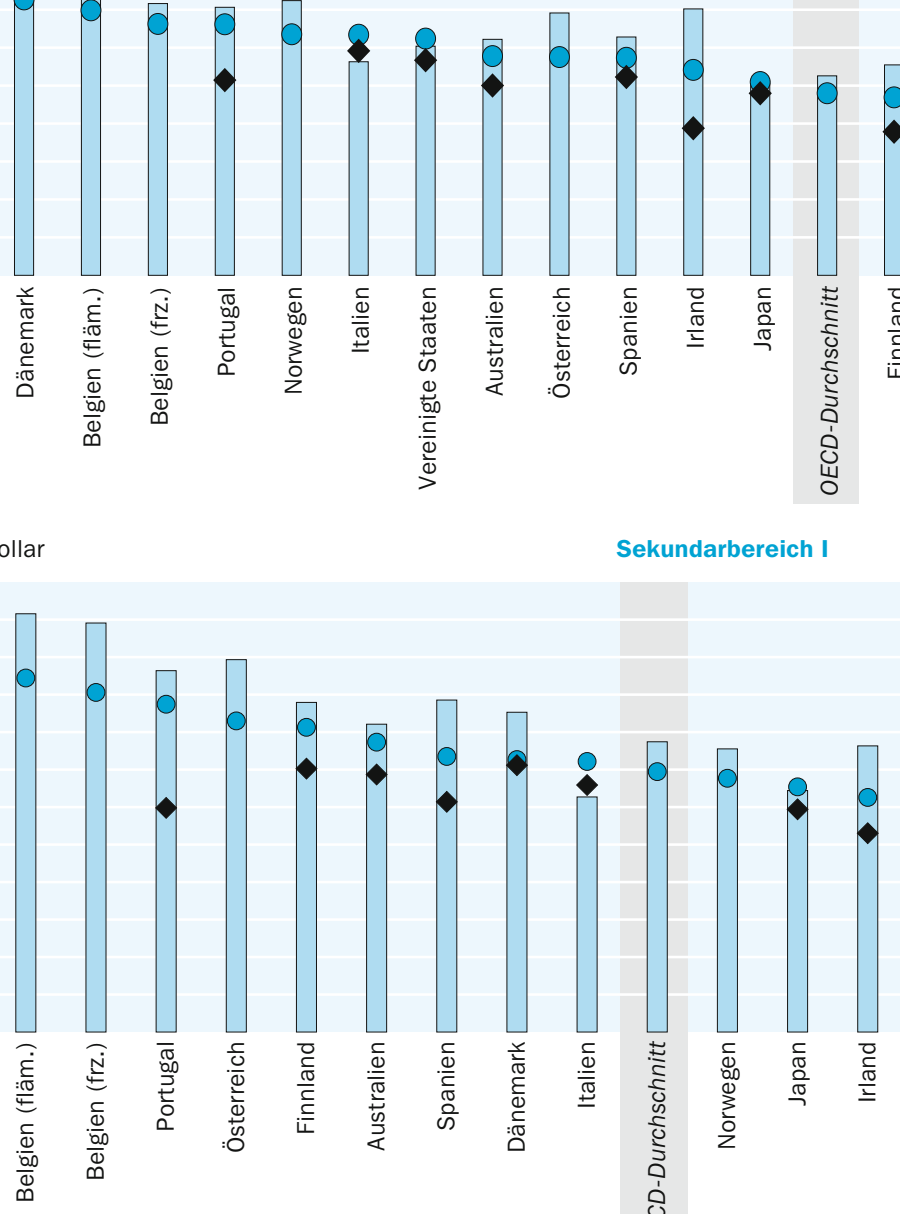

Sekundarbereich I
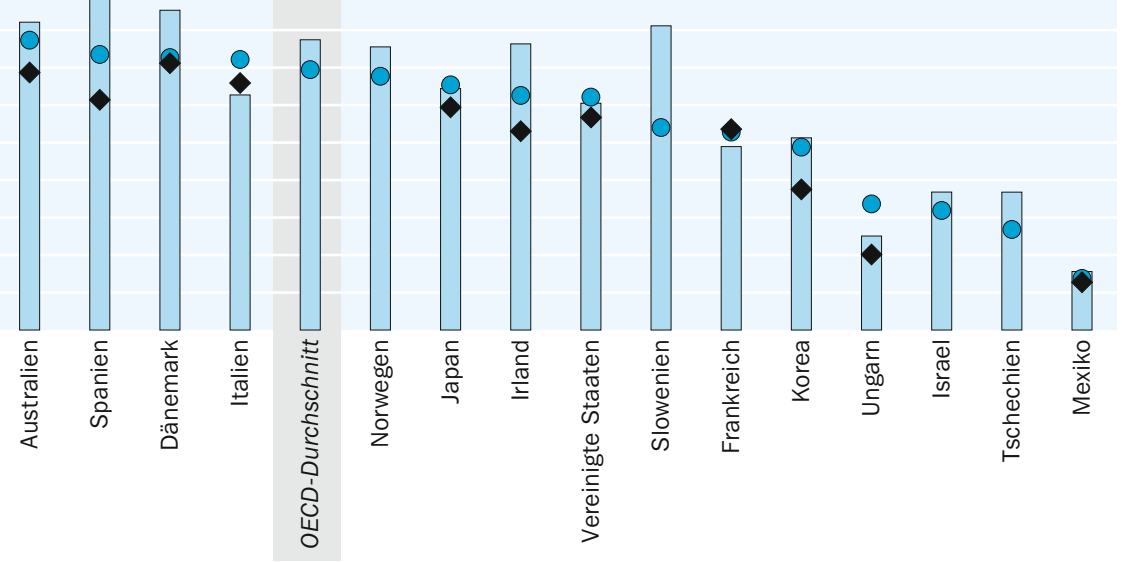

Anordnung der Länder in absteigender Reihenfolge der Gehaltskosten der Lehrkräfte pro Schüler im Jahr 2005.

Quelle: OECD. Tabellen B7.3 und B7.4a. Hinweise s. Anhang 3 unter www.oecd.org/edu/eag.htm. StatLink: http://dx.doi.org/10.1787/888932847241

\section{... und zwar hauptsächlich durch Veränderungen der Gehälter der Lehrkräfte und der Klassengrößen}

Von den vier für die Gehaltskosten der Lehrkräfte entscheidenden Faktoren sind zwei maßgeblich für die großen Unterschiede bei den Gehaltskosten verantwortlich: die Gehaltskosten der Lehrkräfte und die Klassengröße. Zwischen 2005 und 201 I stiegen in den Ländern mit verfügbaren Daten für diesen Zeitraum die Gehälter der Lehrkräfte (in konstanten Preisen ausgedrückt) im Primarbereich um durchschnittlich I4 Prozent und im Sekundarbereich I um durchschnittlich II Prozent, während gleichzeitig die geschätzte Klassengröße im Primarbereich um durchschnittlich I8 Prozent und im Sekundarbereich I um durchschnittlich 6 Prozent abnahm (Tab. B7.2a und B7.2b). 
Veränderung der Gehaltskosten der Lehrkräfte pro Schüler, der Gehälter der Lehrkräfte und der geschätzten Klassengröße im Primar- und Sekundarbereich I $(2005,2011)$

Veraänderung (in \%) zwischen 2005 und 2011
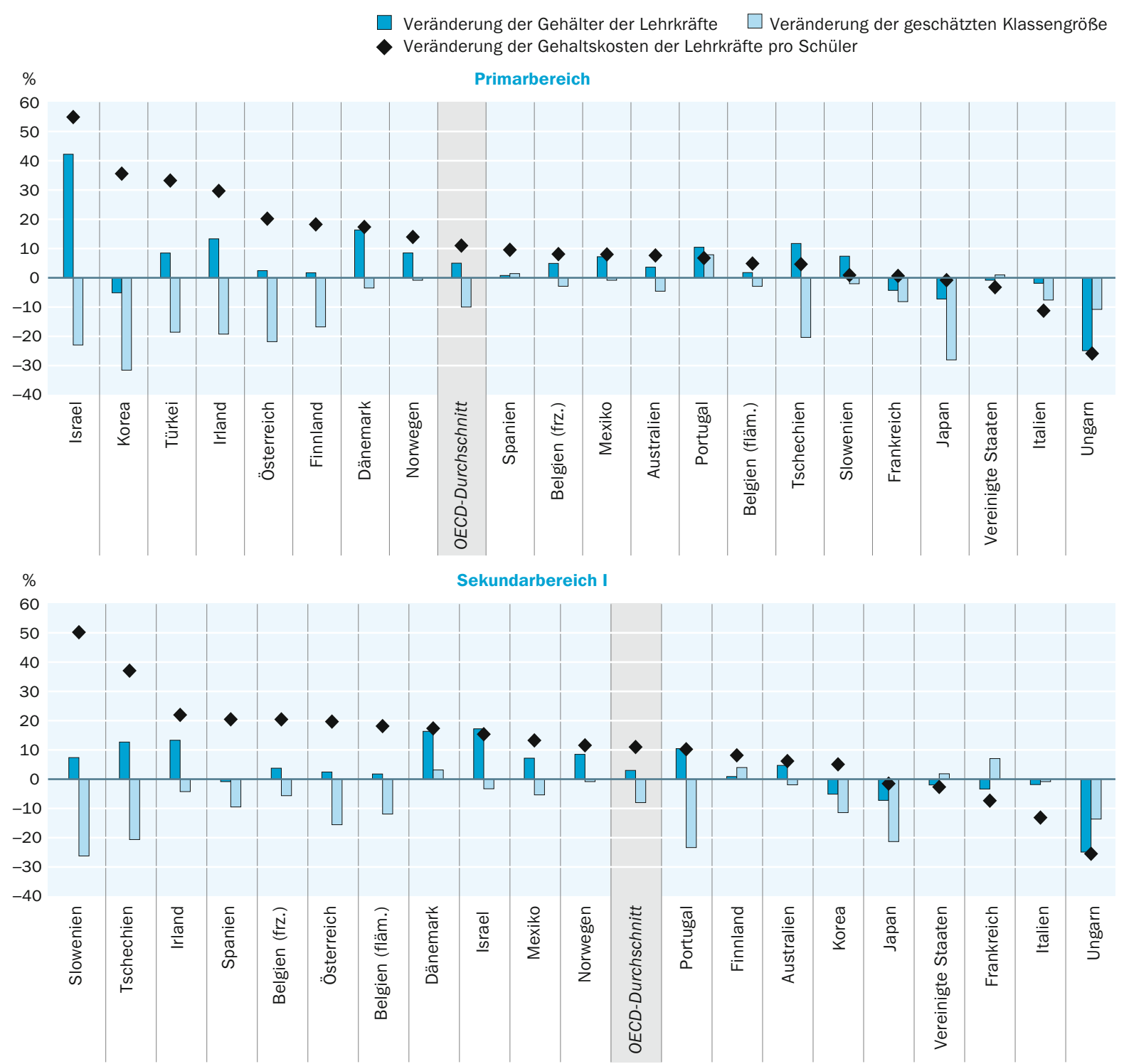

Anordnung der Länder in absteigender Reihenfolge der Veränderung der Gehaltskosten der Lehrkräfte pro Schüler zwischen 2005 und 2011.

Quelle: OECD. Tabellen B7.2a, B7.2b, B7.3 und B7.4a. Hinweise s. Anhang 2013 unter www.oecd.org/edu/eag.htm.

StatLink: http://dx.doi.org/10.1787/888932847260

In den meisten Ländern mit vergleichbaren Daten für 2005 und 20 II stiegen die Gehälter der Lehrkräfte in diesem Zeitraum real, mit der größten Steigerung - um mehr als 40 Prozent - in Israel im Primarbereich. In einigen Ländern sanken jedoch die Gehälter der Lehrkräfte, insbesondere in Ungarn (um 25 Prozent sowohl im Primar-als auch im Sekundarbereich I), was die gesunkenen Gehaltskosten der Lehrkräfte pro Schüler in diesem Land erklären könnte (Abb. B7·3).

Im Gegensatz hierzu ging in mehr als drei Viertel der Länder mit vergleichbaren Daten sowohl für 2005 als auch 201 I in diesem Zeitraum die geschätzte Klassengröße im 
Primar- und Sekundarbereich I tendenziell zurück, was zu einem Anstieg der Gehaltskosten der Lehrkräfte führte. Im Primarbereich war die Verringerung der Klassengröße in Ländern mit vergleichsweise hohen geschätzten Klassengrößen im Jahr 2005 (Israel, Japan, Korea und der Türkei) am größten. Im Sekundarbereich I waren die Verringerungen am ausgeprägtesten in Ländern mit vergleichsweise hohen geschätzten Klassengrößen im Jahr 2005 (Japan), aber auch in Ländern mit unterdurchschnittlich kleinen geschätzten Klassengrößen (Portugal). In Portugal waren die signifikanten Verringerungen der Klassengröße, die zu einem Anstieg der Gehaltskosten der Lehrkräfte führte, nicht die Folge von bildungspolitischen Entscheidungen, sondern eher die Folge von demografischen Veränderungen und sinkenden Schülerzahlen.

Im gleichen Zeitraum machten sowohl im Primarbereich als auch im Sekundarbereich I Veränderungen der Unterrichtszeit der Schüler und der zu unterrichtenden (Zeit-)Stunden der Lehrkräfte, der beiden anderen Faktoren mit Auswirkungen auf die Gehaltskosten der Lehrkräfte, im Durchschnitt weniger als 4,5 Prozent aus. Dies könnte ein Anzeichen dafür sein, wie viel politisches Feingefühl bei einer Umsetzung von bildungspolitischen Reformen in diesen Bereichen notwendig ist (s. Tab. B7.5 in Bildung aufeinen Blick 2012).

Dennoch änderten sich in einigen wenigen Ländern die Unterrichtszeit der Schüler und/oder die Zahl der von Lehrkräften zu unterrichtenden (Zeit-)Stunden signifikant. Am stärksten erhöhte sich die Zahl der von den Lehrkräften zu unterrichtenden (Zeit-) Stunden in Japan (um mehr als I50 Stunden im Primarbereich und um rund Ioo Stunden im Sekundarbereich I) und in Portugal (um 200 Stunden im Sekundarbereich I). Die sinkende Zahl von Unterrichtsstunden für Schüler in Italien (um I3 Prozent im Primarbereich und um 9 Prozent im Sekundarbereich I) ist einer der Hauptgründe für die gesunkenen Gehaltskosten der Lehrkräfte pro Schüler zwischen 2005 und 201 in diesem Land (Tab. B7.2a und B7.2b).

\section{Einem ähnlichen Ausgabenniveau verschiedener Länder können unterschiedliche bildungspolitische Entscheidungen zugrunde liegen ...} Hohe Ausgabenniveaus im Bildungsbereich lassen sich nicht notwendigerweise mit einem leistungsstärkeren Bildungssystem gleichsetzen. Dies ist keineswegs überraschend, denn auch wenn einzelne Länder ähnlich hohe Finanzmittel in Bildung investieren, ergreifen sie nicht notwendigerweise die gleichen bildungspolitischen Maßnahmen und Ansätze. So waren beispielsweise 20II in Deutschland und Portugal die Gehaltskosten der Lehrkräfte pro Schüler im Sekundarbereich II ähnlich hoch (5.063 US-Dollar bzw. 5.42I US-Dollar), in beiden Ländern lagen sie über dem Durchschnitt. In Deutschland lag dies hauptsächlich daran, dass die Gehälter der Lehrkräfte signifikant über den Durchschnittsgehältern liegen, während in Portugal eine unterdurchschnittliche geschätzte Klassengröße der Grund war. Auch in Israel, Polen und Tschechien liegen die Gehaltskosten der Lehrkräfte pro Schüler auf einem ähnlichen Niveau. Zwar sind die Gehälter der Lehrkräfte in diesen drei Ländern ähnlich hoch, aber die drei anderen Faktoren wirken sich in jedem der Länder unterschiedlich auf die Gehaltskosten der Lehrkräfte aus (Tab. B7.5 und Abb. B7.4a).

Außerdem können ähnliche bildungspolitischen Entscheidungen der Länder dennoch zu unterschiedlichen Gehaltskostenniveaus der Lehrkräfte pro Schüler führen. So er- 
Beitrag verschiedener Faktoren (in US-Dollar) zu den Gehaltskosten der Lehrkräfte pro Schüler im Sekundarbereich II (2011)
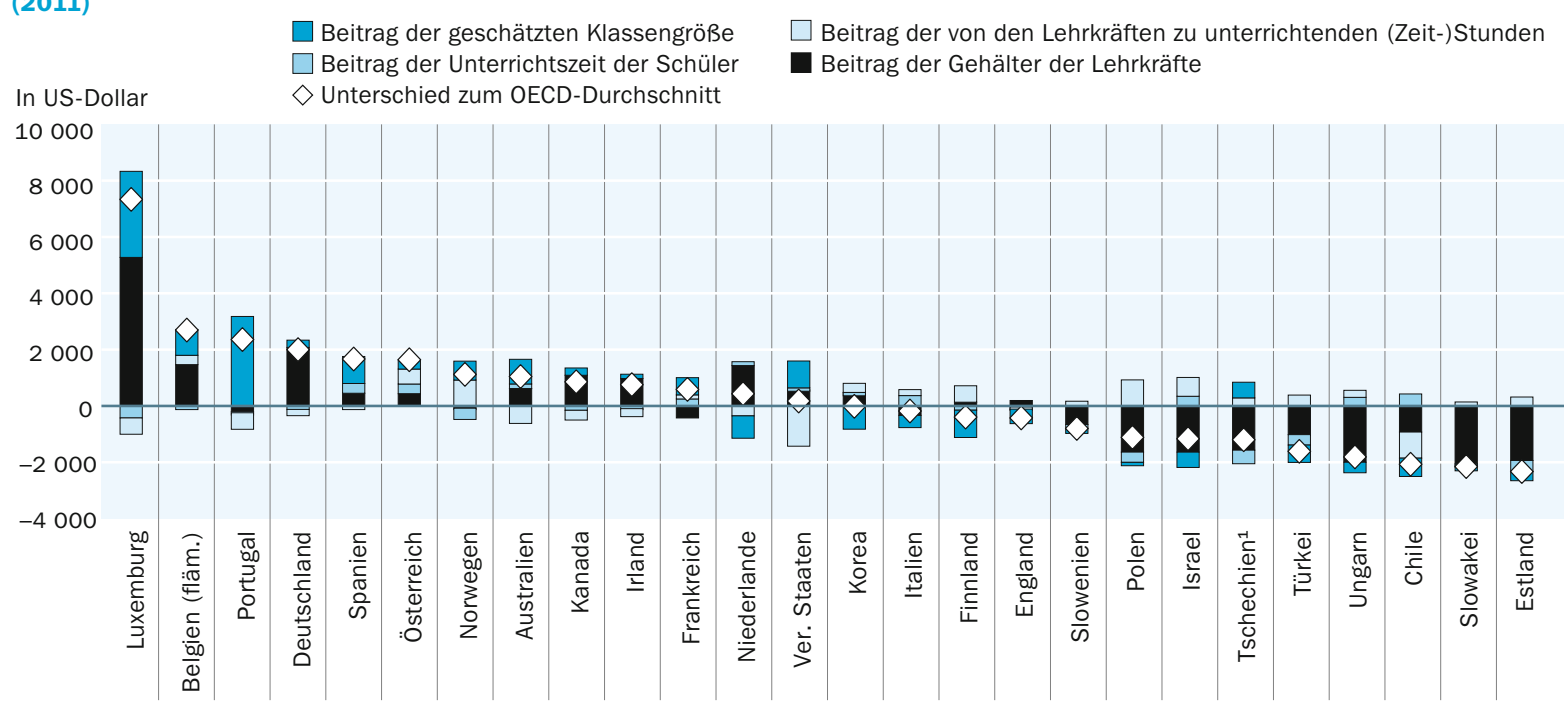

1. Der Beitrag der Unterrichtszeit ist auf Grundlage der Mindestunterrichtszeit berechnet.

Anordnung der Länder in absteigender Reihenfolge des Unterschieds zwischen den Gehaltskosten der Lehrkräfte pro Schüler und dem OECD-Durchschnitt. Quelle: OECD. Tabelle B7.5a. Hinweise s. Anhang 3 unter www.oecd.org/edu/eag.htm. StatLink: http://dx.doi.org/10.1787/888932847279

\begin{abstract}
Erläuterung der Abbildung: Die Abbildung zeigt den Beitrag der vier Faktoren (in US-Dollar) zu dem Unterschied in den Gehaltskosten der Lehrkräfte pro Schüler zwischen dem jeweiligen Land und dem OECD-Durchschnitt. So liegen beispielsweise die Gehaltskosten pro Schüler in den Vereinigten Staaten nahe am OECD-Durchschnitt (185 US-Dollar über dem OECD-Durchschnitt). Dies ist darauf zurückzuführen, dass die Auswirkungen von überdurchschnittlichen Gehältern der Lehrkräfte (+ 584 US-Dollar), einer überdurchschnittlichen jährlichen Unterrichtszeit der Schüler (+ 69 US-Dollar) und einer unterdurchschnittlichen geschätzten Klassengröße (+ 107 US-Dollar) von einer überdurchschnittlich hohen Zahl der von den Lehrkräften zu unterrichtenden (Zeit-)Stunden (-1.439 USDollar) ausgeglichen werden.
\end{abstract}

geben sich beispielsweise in Australien, Irland, Kanada und den Vereinigten Staaten die Gehaltskosten pro Schüler im Sekundarbereich II aus dem Zusammenwirken zweier gegenläufiger Faktoren: einer überdurchschnittlich hohen Zahl an von den Lehrkräften zu unterrichtenden (Zeit-)Stunden, die zu einer Verringerung der Gehaltskosten der Lehrkräfte pro Schüler im Vergleich zum OECD-Durchschnitt führt, und relativ kleiner Klassengrößen in Verbindung mit hohen Gehältern der Lehrkräfte pro Schüler, die zu einer Erhöhung der Gehaltskosten pro Schüler im Verhältnis zum OECD-Durchschnitt führen. Die Gehaltskosten pro Schüler, die sich aus dieser Kombination ergeben, liegen in diesen vier Ländern über dem OECD-Durchschnitt, sie reichen dabei jedoch von weniger als 200 US-Dollar über dem Durchschnitt in den Vereinigten Staaten bis zu rund I.000 US-Dollar über dem Durchschnitt in Australien (Tab. B7.5 und Abb. B7.4a).

... aber die Gehälter der Lehrkräfte wirken sich am stärksten auf die Unterschiede der Gehaltskosten der Lehrkräfte pro Schüler zwischen den einzelnen Ländern aus

Ein Vergleich der Gehaltskosten der Lehrkräfte pro Schüler mit dem OECD-Durchschnitt und wie die einzelnen vier Faktoren zu diesem Unterschied beitragen, ermöglicht zu untersuchen, wie stark sich die einzelnen Faktoren auf die Gehaltskosten der Lehrkräfte pro Schüler auswirken. 


\section{Die wichtigsten Faktoren der Gehaltskosten der Lehrkräfte pro Schüler, nach Bildungsbereich (2011)}

\begin{tabular}{|c|c|c|c|}
\hline & Primarbereich & Sekundarbereich I & Sekundarbereich II \\
\hline Gehalt & $\begin{array}{l}18 \text { Länder } \\
\text { AUS (+), BFL (+), BFR (+), } \\
\text { CAN (+), CHL (-), CZE (-), } \\
\text { DNK (+), EST (-), DEU (+), } \\
\text { HUN (-), IRL (+), ISR (-), } \\
\text { JPN (+), LUX (+), MEX (+), } \\
\text { NLD (+), POL (-), SVK (-) }\end{array}$ & $\begin{array}{l}16 \text { Länder } \\
\text { AUS (+), CAN (+), CHL (-), } \\
\text { CZE (-), DNK (+), ENG (+), } \\
\text { EST (-), DEU (+), HUN (-), } \\
\text { IRL (+), ISR (-), LUX (+), } \\
\operatorname{NLD~(+),~POL~(-),~SVK~}(-), \\
\operatorname{ESP}(+)\end{array}$ & $\begin{array}{l}14 \text { Länder } \\
\text { BFL (+), CAN (+), CZE (-), } \\
\text { EST (-), DEU (+), HUN (-), } \\
\text { IRL (+), ISR (-), LUX (+), } \\
\operatorname{NLD~(+),~POL~(-),~SVK~(-),~} \\
\text { SVN (-), TUR (-) }\end{array}$ \\
\hline $\begin{array}{l}\text { Zahl der Unterrichtszeit- } \\
\text { stunden der Schüler }\end{array}$ & $\begin{array}{l}3 \text { Länder } \\
\text { (FIN(-), KOR(-), SVN (-) }\end{array}$ & 0 Länder & 0 Länder \\
\hline $\begin{array}{l}\text { Zahl der von den Lehr- } \\
\text { kräften zu unterrichtenden } \\
\text { (Zeit-)Stunden }\end{array}$ & $\begin{array}{l}2 \text { Länder } \\
\text { FRA (-), USA (-) }\end{array}$ & $\begin{array}{l}2 \text { Länder } \\
\text { ITA (+), USA (-) }\end{array}$ & $\begin{array}{l}4 \text { Länder } \\
\text { AUT (+), CHL (-), NOR (+), } \\
\text { USA (-) }\end{array}$ \\
\hline Geschätzte Klassengröße & $\begin{array}{l}7 \text { Länder } \\
\text { AUT(+), ENG(-), ITA(+), } \\
\text { NOR(+), PRT(+), ESP(+), } \\
\text { TUR(-) }\end{array}$ & $\begin{array}{l}11 \text { Länder } \\
\text { AUT }(+), \operatorname{BFL}(+), \operatorname{BFR}(+), \\
\text { FIN (+), FRA }(-), \text { JAP }(-), \\
\text { KOR }(-), \operatorname{MEX}(-), \operatorname{NOR}(+), \\
\text { PRT }(+), \operatorname{SVN}(+)\end{array}$ & $\begin{array}{l}8 \text { Länder } \\
\text { AUS }(+), \operatorname{ENG}(-), \operatorname{FIN}(-), \\
\text { FRA }(+), \operatorname{ITA}(-), \operatorname{KOR}(-), \\
\text { PRT }(+), \operatorname{ESP}(+)\end{array}$ \\
\hline
\end{tabular}

Anmerkung: Plus- oder Minuszeichen zeigen an, ob der Faktor die Gehaltskosten der Lehrkräfte pro Schüler erhöht oder verringert. Quelle: OECD. Hinweise s. Anhang 3 unter www.oecd.org/edu/eag.htm.

Auflistung der verwendeten Ländercodes s. Hinweise für den Leser.

In allen Bildungsbereichen erweisen sich die Gehälter der Lehrkräfte am häufigsten als wichtigster Faktor für den Unterschied der durchschnittlichen Gehaltskosten der Lehrkräfte pro Schüler. Sie sind in den Ländern mit verfügbaren Daten für 201 I in I8 von 30 Ländern im Primarbereich, in I6 von 29 Ländern im Sekundarbereich I und in 14 von 26 Ländern im Sekundarbereich II der wichtigste Faktor. Dies trifft sowohl für die Länder mit den höchsten Gehaltskosten der Lehrkräfte pro Schüler als auch für die Länder mit den niedrigsten Gehaltskosten der Lehrkräfte pro Schüler zu.

Im Sekundarbereich II sind beispielsweise im Land mit den höchsten Gehaltskosten der Lehrkräfte pro Schüler (Luxemburg) die überdurchschnittlichen Gehälter der Lehrkräfte der wichtigste Faktor, genauso wie in den 8 Ländern mit den niedrigsten Gehaltskosten der Lehrkräfte pro Schüler (Estland, Israel, Polen, der Slowakei, Slowenien, Tschechien, der Türkei und Ungarn) (Abb. B7.4a).

Die geschätzte Klassengröße ist in jedem der Bildungsbereiche der zweitwichtigste Faktor für die Unterschiede (in 7 Ländern im Primarbereich, II Ländern im Sekundarbereich I und in 8 Ländern im Sekundarbereich II). Im Sekundarbereich II ist in zwei der fünf Länder mit den höchsten Gehaltskosten der Lehrkräfte pro Schüler (Portugal und Spanien) die unterdurchschnittliche geschätzte Klassengröße der wichtigste Faktor für die Abweichung von den durchschnittlichen Gehaltskosten der Lehrkräfte pro Schüler (Kasten B7.2). 
Die Gehälter der Lehrkräfte erweisen sich weniger häufig als wichtigster Faktor für den Unterschied zu den durchschnittlichen Gehaltskosten der Lehrkräfte pro Schüler, wenn man den unterschiedlichen Wohlstand der einzelnen Länder berücksichtigt

Das Gehaltsniveau der Lehrkräfte und im Gegenzug das Niveau der Gehaltskosten der Lehrkräfte pro Schüler hängen jedoch vom relativen Wohlstand eines Landes ab. Um das Wohlstandsgefälle zwischen den Ländern zu berücksichtigen, wurden die Gehälter der Lehrkräfte (und die Gehaltskosten pro Schüler) im Verhältnis zum BIP pro Kopf untersucht. Bei einem Vergleich der so ermittelten relativen Gehaltskosten der Lehrkräfte pro Schüler ergibt sich eine andere Reihenfolge der Länder (Abb. B7.4b im Internet). Im Vergleich zur Analyse in US-Dollar ändert sich jedoch nur die Position von einigen wenigen Ländern signifikant. Im Sekundarbereich II hat Luxemburg die höchsten Gehaltskosten der Lehrkräfte pro Schüler in US-Dollar (vor allem infolge des hohen Gehaltsniveaus in US-Dollar), nicht jedoch als Anteil des BIP pro Kopf, hier liegen sie am OECD-Durchschnitt. Somit führen die Gehälter der Lehrkräfte als Prozentsatz des BIP pro Kopf nicht zu höheren Gehaltskosten der Lehrkräfte pro Schüler als Prozentsatz des BIP pro Kopf (Tab. B7.5a und Abb. B7.4a sowie Tab. B7.5b und Abb. B7.4b im Internet).

Bereinigt um das Wohlstandsgefälle zwischen den einzelnen Ländern ergibt sich beim Vergleich der relativen Auswirkungen der einzelnen Faktoren für den Primar- und Sekundarbereich ein ähnliches Bild wie bei der Analyse basierend auf US-Dollar. Die Gehälter der Lehrkräfte (in Prozent des BIP pro Kopf) und die geschätzte Klassengröße sind in jedem der Bildungsbereiche die wichtigsten Faktoren für die Abweichungen von den durchschnittlichen Gehaltskosten der Lehrkräfte pro Schüler (Kasten B7.2 [Forts.] im Internet).

\section{Angewandte Methodik}

Die Daten für das Schuljahr 20II beruhen auf der UOE-Datenerhebung zur Bildungsstatistik sowie der Erhebung zu Lehrkräften und Lehrplänen, die beide 2012 von der OECD durchgeführt wurden. Die Daten für die Schuljahre 2000 und 2005 beruhen auf der UOE-Datenerhebung zur Bildungsstatistik und der Erhebung zu Lehrkräften und Lehrplänen, die beide von der OECD durchgeführt und in Bildung auf einen Blick 2013 (Trenddaten zu von Lehrkräften zu unterrichtenden [Zeit-]Stunden und Gehältern der Lehrkräfte) und in Bildung aufeinen Blick 2002 bzw. 2007 (Schüler-Lehrkräfte-Relation und Unterrichtszeit der Schüler) veröffentlicht wurden. Die Konsistenz der Daten für 2000, 2005 und 20II wurde überprüft (weitere Informationen s. Anhang 3 unter www. oecd.org/edu/eag.htm).

Die Gehaltskosten der Lehrkräfte pro Schüler wurden auf Grundlage der Gehälter der Lehrkräfte, der Unterrichtszeitstunden der Schüler, der Zahl der von den Lehrkräften zu unterrichtenden (Zeit-)Stunden sowie einer geschätzten Klassengröße (Näherungswert für die Klassengröße, s. Kasten D2.I) ermittelt. In den meisten Fällen wurden die Werte für diese Variablen Bildung auf einen Blick 2013 entnommen und beziehen sich auf die Schuljahre 20I0/20II, 2004/2005 bzw. 1999/2000. Die Daten für die Schuljahre 1999/2000 und 2004/2005 wurden, wenn in der aktuellen Ausgabe nicht verfügbar, 
Bildung auf einen Blick 2002 bzw. Bildung auf einen Blick 2007 entnommen. Die Daten für 2000 und 2005 wurden überprüft, um die Konsistenz mit den Daten für 20II zu gewährleisten. Die Gehälter der Lehrkräfte in Landeswährung werden in US-Dollar umgerechnet, indem der betreffende Betrag in Landeswährung durch den Kaufkraftparitätsindex (KKP-Index) für den privaten Verbrauch geteilt wird. Dabei kommt die in Indikator $\mathrm{D}_{3}$ bei den Gehältern der Lehrkräfte verwendete Methode zur Anwendung. Das Ergebnis sind die Gehaltskosten der Lehrkräfte pro Schüler ausgedrückt in US-Dollar, kaufkraftbereinigt. Weitere Einzelheiten zur Analyse dieser Faktoren s. Anhang 3 unter www.oecd.org/eduleag.htm.

Die statistischen Daten für Israel wurden von den zuständigen israelischen Stellen bereitgestellt, die für sie verantwortlich zeichnen. Die Verwendung dieser Daten durch die OECD erfolgt unbeschadet des völkerrechtlichen Status der Golanhöhen, von OstJerusalem und der israelischen Siedlungen im Westjordanland.

\section{Weiterführende Informationen}

OECD (2012), Bildung auf einen Blick 2012 - OECD-Indikatoren, W. Bertelsmann Verlag, Bielefeld.

\section{Tabellen Indikator B7}

Tabelle B7.I: Gehaltskosten der Lehrkräfte pro Schüler, nach Bildungsbereich (20II) StatLink: http://dx.doi.org/10.1787/888932850091

Tabelle B7.2a: Faktoren zur Berechnung der Gehaltskosten der Lehrkräfte pro Schüler im Primarbereich (2000, 2005 und 20II) StatLink: http:|/dx.doi.org/10.1787/888932850110

Tabelle B7.2b: Faktoren zur Berechnung der Gehaltskosten der Lehrkräfte pro Schüler im Sekundarbereich I (2000, 2005 und 20II) StatLink: http:|/dx.doi.org/10.1787/888932850129

WEB Table B7.2c: Factors used to compute the salary cost of teachers per student, in upper secondary education (Faktoren zur Berechnung der Gehaltskosten der Lehrkräfte pro Schüler im Sekundarbereich II) (20II)

StatLink: http://dx.doi.org/10.1787/888932850148

Tabelle B7.3: Beitrag verschiedener Faktoren zu den Gehaltskosten der Lehrkräfte pro Schüler im Primarbereich (2000, 2005 und 20II)

StatLink: http://dx.doi.org/10.1787/888932850167

Tabelle B7.4a: Beitrag verschiedener Faktoren zu den Gehaltskosten der Lehrkräfte pro Schüler im Sekundarbereich I (2000, 2005 und 20II)

StatLink: http:||dx.doi.org/10.1787/888932850186 
WEB Table B7.4b: Contribution of various factors to salary cost of teachers per student in lower secondary education, in percentage point of GDP per capita (Beitrag verschiedener Faktoren zu den Gehaltskosten der Lehrkräfte pro Schüler im Sekundarbereich I, in Prozentpunkten des BIP pro Kopf) (20II)

StatLink: http://dx.doi.org/10.1787/888932850205

Tabelle B7.5a: Beitrag verschiedener Faktoren zu den Gehaltskosten der Lehrkräfte pro Schüler im Sekundarbereich II (20II)

StatLink: http://dx.doi.org/10.1787/888932850224

WEB Table B7.5b: Contribution of various factors to salary cost of teachers per student, in upper secondary education (Beitrag verschiedener Faktoren zu den Gehaltskosten der Lehrkräfte pro Schüler im Sekundarbereich II (20II)

StatLink: http://dx.doi.org/10.1787/888932850243 
Gehaltskosten der Lehrkräfte pro Schüler, nach Bildungsbereich (2011)

In US-Dollar, kaufkraftbereinigt mittels KKP für den privaten Verbrauch, und als Prozentsatz des BIP pro Kopf

\begin{tabular}{|c|c|c|c|c|c|c|}
\hline & \multicolumn{3}{|c|}{$\begin{array}{l}\text { Gehaltskosten der Lehrkräfte pro Schüler } \\
\text { (in US-Dollar) }\end{array}$} & \multicolumn{3}{|c|}{$\begin{array}{l}\text { Gehaltskosten der Lehrkräfte pro Schüler } \\
\text { (als Prozentsatz des BIP pro Kopf) }\end{array}$} \\
\hline & Primarbereich & Sekundarbereich I & Sekundarbereich II & Primarbereich & Sekundarbereich I & Sekundarbereich II \\
\hline & (1) & (2) & (3) & (4) & (5) & (6) \\
\hline \multicolumn{7}{|l|}{ OECD-Länder } \\
\hline Australien & 3108 & 4105 & 4105 & 7,5 & 9,9 & 9,9 \\
\hline Österreich & 3455 & 4966 & 4703 & 8,3 & 12,0 & 11,4 \\
\hline Belgien (fläm.) & 3660 & 5578 & 5760 & 9,9 & 15,1 & 15,6 \\
\hline Belgien (frz.) & 3579 & 5455 & $\mathrm{~m}$ & 9,7 & 14,7 & $\mathrm{~m}$ \\
\hline Kanada & 3492 & 3492 & 3917 & 9,1 & 9,1 & 10,2 \\
\hline Chile & 1023 & 1001 & 984 & 5,5 & 5,3 & 5,3 \\
\hline Tschechien & 1079 & 1839 & 1856 & 4,6 & 7,8 & 7,8 \\
\hline Dänemark & 4265 & 4265 & $\mathrm{~m}$ & 11,5 & 11,5 & $\mathrm{~m}$ \\
\hline England & 2148 & 3033 & 2633 & 6,3 & 8,9 & 7,7 \\
\hline Estland & 753 & 835 & 725 & 4,0 & 4,4 & 3,8 \\
\hline Finnland & 2771 & 4396 & 2663 & 8,0 & 12,6 & 7,6 \\
\hline Frankreich & 1802 & 2446 & 3647 & 5,3 & 7,2 & 10,7 \\
\hline Deutschland & 3597 & 4555 & 5063 & 9,6 & 12,1 & 13,5 \\
\hline Griechenland & $\mathrm{m}$ & $\mathrm{m}$ & $\mathrm{m}$ & $\mathrm{m}$ & $\mathrm{m}$ & $\mathrm{m}$ \\
\hline Ungarn & 1220 & 1254 & 1246 & 6,4 & 6,5 & 6,5 \\
\hline Island & $\mathrm{m}$ & $\mathrm{m}$ & $\mathrm{m}$ & $\mathrm{m}$ & $\mathrm{m}$ & $\mathrm{m}$ \\
\hline Irland & 3509 & 3816 & 3816 & 9,5 & 10,3 & 10,3 \\
\hline Israel & 1714 & 1840 & 1893 & 6,8 & 7,3 & 7,5 \\
\hline Italien & 2813 & 3135 & 2878 & 9,1 & 10,2 & 9,3 \\
\hline Japan & 2525 & 3220 & $\mathrm{~m}$ & 8,3 & 10,6 & $\mathrm{~m}$ \\
\hline Korea & 2462 & 2563 & 3045 & 9,1 & 9,5 & 11,2 \\
\hline Luxemburg & 9425 & 10409 & 10409 & 11,5 & 12,7 & 12,7 \\
\hline Mexiko & 697 & 780 & $\mathrm{~m}$ & 4,8 & 5,4 & $\mathrm{~m}$ \\
\hline Niederlande & 3311 & 4172 & 3493 & 8,1 & 10,2 & 8,5 \\
\hline Neuseeland & $\mathrm{m}$ & $\mathrm{m}$ & $\mathrm{m}$ & $\mathrm{m}$ & $\mathrm{m}$ & $\mathrm{m}$ \\
\hline Norwegen & 3618 & 3776 & 4181 & 6,4 & 6,7 & 7,4 \\
\hline Polen & 1503 & 1881 & 1942 & 7,6 & 9,5 & 9,8 \\
\hline Portugal & 3530 & 4819 & 5421 & 15,6 & 21,4 & 24,0 \\
\hline Schottland & $\mathrm{m}$ & $\mathrm{m}$ & $\mathrm{m}$ & $\mathrm{m}$ & $\mathrm{m}$ & $\mathrm{m}$ \\
\hline Slowakei & 760 & 980 & 901 & 3,5 & 4,5 & 4,1 \\
\hline Slowenien & 2016 & 4057 & 2258 & 8,0 & 16,2 & 9,0 \\
\hline Spanien & 3139 & 4427 & 4729 & 10,8 & 15,2 & 16,2 \\
\hline Schweden & $\mathrm{m}$ & $\mathrm{m}$ & $\mathrm{m}$ & $\mathrm{m}$ & $\mathrm{m}$ & $\mathrm{m}$ \\
\hline Schweiz & $\mathrm{m}$ & $\mathrm{m}$ & $\mathrm{m}$ & $\mathrm{m}$ & $\mathrm{m}$ & $\mathrm{m}$ \\
\hline Türkei & 1199 & a & 1444 & 8,1 & a & 9,7 \\
\hline Vereinigte Staaten & 3018 & 3024 & 3235 & 6,3 & 6,3 & 6,7 \\
\hline OECD-Durchschnitt & 2706 & 3452 & 3344 & 8,0 & 10,1 & 9,9 \\
\hline
\end{tabular}

Quelle: OECD. Hinweise s. Anhang 3 unter www.oecd.org/edu/eag.htm. StatLink: http://dx.doi.org/10.1787/888932850091

Erläuterung der Kennzeichnung fehlender Daten s. Hinweise für den Leser. 
Faktoren zur Berechnung der Gehaltskosten der Lehrkräfte pro Schüler im Primarbereich (2000, 2005 und 2011)

\begin{tabular}{|c|c|c|c|c|c|c|c|c|c|c|c|c|}
\hline & \multicolumn{4}{|c|}{$\begin{array}{l}\text { Gehälter der Lehrkräfte (pro Jahr, in } \\
\text { US-Dollar, zu konstanten Preisen 2011) }\end{array}$} & \multicolumn{4}{|c|}{$\begin{array}{c}\text { Unterrichtszeit } \\
\text { (der Schüler, [Zeit-]Stunden pro Jahr) }\end{array}$} & \multicolumn{4}{|c|}{$\begin{array}{l}\text { Zu unterrichtende (Zeit-)Stunden } \\
\text { (der Lehrkräfte, [Zeit-]Stunden pro Jahr) }\end{array}$} \\
\hline & 2000 & 2005 & 2011 & $\begin{array}{l}\begin{array}{l}\text { Veränderung } \\
2005-2011 \\
\text { (in \%) }\end{array} \\
\end{array}$ & 2000 & 2005 & 2011 & $\begin{array}{l}\text { Veränderung } \\
2005-2011 \\
\quad \text { (in \%) }\end{array}$ & 2000 & 2005 & 2011 & $\begin{array}{l}\text { Veränderung } \\
2005-2011 \\
\text { (in \%) }\end{array}$ \\
\hline & (1) & (2) & (3) & (4) & (5) & (6) & (7) & (8) & (9) & (10) & (11) & (12) \\
\hline \multicolumn{13}{|l|}{ OECD-Länder } \\
\hline Australien ${ }^{1}$ & 43259 & 46821 & 48522 & 3,6 & 987 & 979 & 953 & $-2,6$ & 882 & 888 & 873 & $-1,8$ \\
\hline Österreich ${ }^{1}$ & 36755 & 40640 & 41633 & 2,4 & 833 & 812 & 750 & $-7,6$ & $\mathrm{~m}$ & 774 & 779 & 0,7 \\
\hline Belgien (fläm.) ${ }^{1}$ & 41107 & 44616 & 45413 & 1,8 & $\mathrm{~m}$ & 835 & 831 & $-0,6$ & 767 & 761 & 757 & $-0,6$ \\
\hline Belgien (frz.) ${ }^{1}$ & 39799 & 42325 & 44407 & 4,9 & 930 & 930 & 930 & 0,0 & 804 & 722 & 721 & $-0,1$ \\
\hline Kanada & $\mathrm{m}$ & $\mathrm{m}$ & 56349 & m & $\mathrm{m}$ & $\mathrm{m}$ & 919 & m & $\mathrm{m}$ & $\mathrm{m}$ & 799 & m \\
\hline Chile & $\mathrm{m}$ & $\mathrm{m}$ & 23623 & m & 1060 & $\mathrm{~m}$ & 1007 & m & $\mathrm{m}$ & 1001 & 1120 & 11,9 \\
\hline Tschechien ${ }^{1,2}$ & 10032 & 18067 & 20185 & 11,7 & 752 & 774 & 597 & $-22,9$ & $\mathrm{~m}$ & 813 & 840 & 3,3 \\
\hline Dänemark ${ }^{1}$ & 40483 & 43259 & 50332 & 16,3 & 790 & 763 & 754 & $-1,1$ & 640 & 640 & 650 & 1,6 \\
\hline England & 41270 & 45142 & 44269 & $-1,9$ & 890 & 900 & 861 & $-4,3$ & $\mathrm{~m}$ & $\mathrm{~m}$ & 684 & m \\
\hline Estland & 7580 & 9040 & 12306 & 36,1 & $\mathrm{~m}$ & 910 & 650 & $-28,6$ & 630 & 630 & 619 & $-1,7$ \\
\hline Finnland $^{1}$ & 31883 & 37252 & 37886 & 1,7 & 694 & 673 & 654 & $-2,7$ & 656 & 677 & 680 & 0,5 \\
\hline Frankreich ${ }^{1}$ & 36461 & 34640 & 33152 & $-4,3$ & 814 & 894 & 864 & $-3,4$ & 936 & 936 & 936 & 0,0 \\
\hline Deutschland & $\mathrm{m}$ & $\mathrm{m}$ & 58662 & m & 796 & 777 & 702 & $-9,7$ & 783 & 808 & 804 & $-0,4$ \\
\hline Griechenland & 29428 & 33122 & 28184 & $-14,9$ & 928 & 928 & 756 & $-18,5$ & 609 & 604 & 589 & $-2,5$ \\
\hline Ungarn ${ }^{1}$ & 11008 & 17465 & 13115 & $-24,9$ & 834 & 718 & 655 & $-8,8$ & 583 & 583 & 604 & 3,6 \\
\hline Island & 24242 & 27176 & 26991 & $-0,7$ & 692 & 792 & 857 & 8,2 & 629 & 671 & 624 & $-7,1$ \\
\hline Irland $^{1}$ & 41590 & 48498 & 54954 & 13,3 & 941 & 941 & 869 & $-7,6$ & 915 & 915 & 915 & 0,0 \\
\hline Israel $^{1}$ & 19175 & 19108 & 27174 & 42,2 & $\mathrm{~m}$ & 990 & 956 & $-3,4$ & 731 & 731 & 842 & 15,1 \\
\hline Italien ${ }^{1}$ & 31743 & 33597 & 32969 & $-1,9$ & 1020 & 1023 & 891 & $-12,9$ & 744 & 739 & 770 & 4,2 \\
\hline$J^{\prime a p a n}{ }^{1}$ & 50027 & 49311 & 45741 & $-7,2$ & 761 & 774 & 754 & $-2,6$ & 635 & 578 & 731 & 26,5 \\
\hline Korea $^{1}$ & 40550 & 50864 & 48251 & $-5,1$ & 737 & 703 & 632 & $-10,0$ & 865 & 883 & 812 & $-8,0$ \\
\hline Luxemburg & $\mathrm{m}$ & 71109 & 93397 & 31,3 & $\mathrm{~m}$ & 847 & 924 & 9,1 & $\mathrm{~m}$ & 774 & 810 & 4,5 \\
\hline Mexiko $^{1}$ & 17524 & 18273 & 19590 & 7,2 & 800 & 800 & 800 & 0,0 & 800 & 800 & 800 & 0,0 \\
\hline Niederlande & $\mathrm{m}$ & $\mathrm{m}$ & 52292 & $\mathbf{m}$ & 1000 & 1000 & 940 & $-6,0$ & 930 & 930 & 930 & 0,0 \\
\hline Neuseeland & 39040 & 39730 & 41755 & 5,1 & 985 & 985 & $\mathrm{~m}$ & m & $\mathrm{m}$ & $\mathrm{m}$ & 935 & m \\
\hline Norwegen $^{1}$ & $\mathrm{~m}$ & 34644 & 37585 & 8,5 & 703 & 713 & 748 & 4,9 & 713 & 741 & 741 & 0,0 \\
\hline Polen & $\mathrm{m}$ & 11233 & 16506 & 46,9 & $\mathrm{~m}$ & $\mathrm{~m}$ & 703 & m & $\mathrm{m}$ & $\mathrm{m}$ & 483 & m \\
\hline Portugal $^{1}$ & 31188 & 35696 & 39424 & 10,4 & 833 & 861 & 924 & 7,3 & 815 & 855 & 880 & 2,9 \\
\hline Schottland & 40470 & 49642 & 47984 & $-3,3$ & 950 & a & a & m & 950 & 893 & 855 & $-4,3$ \\
\hline Slowakei & $\mathrm{m}$ & $\mathrm{m}$ & 12858 & m & $\mathrm{m}$ & $\mathrm{m}$ & 698 & m & $\mathrm{m}$ & $\mathrm{m}$ & 846 & m \\
\hline Slowenien ${ }^{1}$ & $\mathrm{~m}$ & 29979 & 32193 & 7,4 & $\mathrm{~m}$ & 721 & 664 & $-7,9$ & $\mathrm{~m}$ & 690 & 690 & 0,0 \\
\hline Spanien $^{1}$ & 39008 & 41012 & 41339 & 0,8 & 795 & 794 & 875 & 10,3 & 880 & 880 & 880 & 0,0 \\
\hline Schweden & 31486 & 33436 & 34387 & 2,8 & 741 & 741 & 741 & 0,0 & $\mathrm{~m}$ & $\mathrm{~m}$ & $\mathrm{~m}$ & m \\
\hline Schweiz & 57771 & 59304 & $\mathrm{~m}$ & m & $\mathrm{m}$ & $\mathrm{m}$ & $\mathrm{m}$ & m & 884 & $\mathrm{~m}$ & $\mathrm{~m}$ & m \\
\hline Türkei $^{1}$ & 12811 & 23223 & 25189 & 8,5 & 796 & 864 & 864 & 0,0 & 639 & 639 & 639 & 0,0 \\
\hline Vereinigte Staaten ${ }^{1}$ & 44762 & 46469 & 46130 & $-0,7$ & 980 & 980 & 980 & 0,0 & 1080 & 1080 & 1097 & 1,6 \\
\hline OECD-Durchschnitt & 32980 & 36603 & 38136 & 6,6 & 853 & 847 & 809 & $-4,2$ & 780 & 781 & 786 & 1,7 \\
\hline $\begin{array}{l}\text { Durchschnitt von } \\
21 \text { Ländern, für die } \\
\text { alle Daten für } 2005 \\
\text { und } 2011 \text { vorliegen }\end{array}$ & & 33735 & 38328 & 13,6 & & 841 & 819 & $-2,6$ & & 791 & 805 & 1,8 \\
\hline
\end{tabular}

Anmerkung: Die Daten in dieser Tabelle wurden entweder Kapital D entnommen (Daten für 2000, 2005 und 2011 zu Gehältern der Lehrkräfte und zu unterrichtenden [Zeit-]Stunden) oder Bildung auf einen Blick 2002 bzw. 2007 (Daten zur Schüler-Lehrkräfte-Relation und zu unterrichtenden [Zeit-]Stunden). Einige der Daten für 2000 wurden überarbeitet, um die Konsistenz mit den Daten für 2011 zu gewährleisten.

1. Länder, für die alle Daten sowohl für 2005 als auch für 2011 vorliegen. 2. Aktuelle Unterrichtszeit für 2000 und 2005 , Mindestunterrichtszeit für 2011. Quelle: OECD. Hinweise s. Anhang 3 unter www.oecd.org/edu/eag.htm. StatLink: http://dx.doi.org/10.1787/888932850110 Erläuterung der Kennzeichnung fehlender Daten s. Hinweise für den Leser. 
Tabelle B7.2a (Forts.)

Faktoren zur Berechnung der Gehaltskosten der Lehrkräfte pro Schüler im Primarbereich (2000, 2005 und 2011)

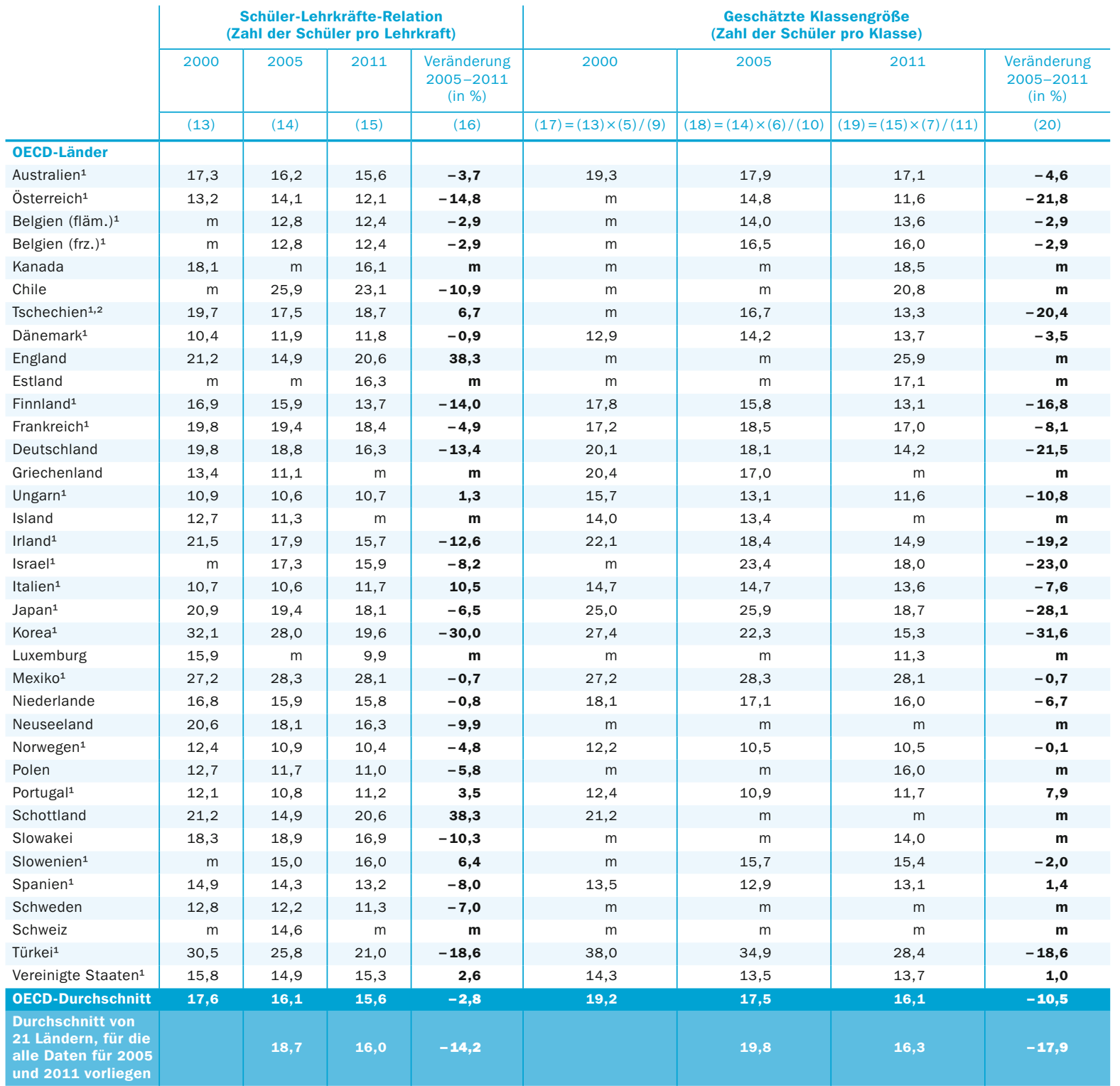

Anmerkung: Die Daten in dieser Tabelle wurden entweder Kapital D entnommen (Daten für 2000, 2005 und 2011 zu Gehältern der Lehrkräfte und zu unterrichtenden [Zeit-]Stunden) oder Bildung auf einen Blick 2002 bzw. 2007 (Daten zur Schüler-Lehrkräfte-Relation und zu unterrichtenden [Zeit-JStunden). Einige der Daten für 2000 wurden überarbeitet, um die Konsistenz mit den Daten für 2011 zu gewährleisten.

1. Länder, für die alle Daten sowohl für 2005 als auch für 2011 vorliegen. 2. Aktuelle Unterrichtszeit für 2000 und 2005 , Mindestunterrichtszeit für 2011. Quelle: OECD. Hinweise s. Anhang 3 unter www.oecd.org/edu/eag.htm. StatLink: http://dx.doi.org/10.1787/888932850110 Erläuterung der Kennzeichnung fehlender Daten s. Hinweise für den Leser. 
Tabelle B7.2b

Faktoren zur Berechnung der Gehaltskosten der Lehrkräfte pro Schüler im Sekundarbereich I (2000, 2005 und 2011)

\begin{tabular}{|c|c|c|c|c|c|c|c|c|c|c|c|c|}
\hline & \multicolumn{4}{|c|}{$\begin{array}{l}\text { Gehälter der Lehrkräfte (pro Jahr, in } \\
\text { US-Dollar, zu konstanten Preisen 2011) }\end{array}$} & \multicolumn{4}{|c|}{$\begin{array}{l}\text { Zahl der Unterrichtsstunden } \\
\text { (der Schüler, [Zeit-]Stunden pro Jahr) }\end{array}$} & \multicolumn{4}{|c|}{$\begin{array}{l}\text { Zu unterrichtende (Zeit-)Stunden } \\
\text { (der Lehrkräfte, [Zeit-]Stunden pro Jahr) }\end{array}$} \\
\hline & 2000 & 2005 & 2011 & $\begin{array}{l}\text { Veränderung } \\
2005-2011 \\
\text { (in \%) }\end{array}$ & 2000 & 2005 & 2011 & $\begin{array}{l}\text { Veränderung } \\
2005-2011 \\
\text { (in \%) }\end{array}$ & 2000 & 2005 & 2011 & $\begin{array}{l}\text { Veränderung } \\
2005-2011 \\
\text { (in \%) }\end{array}$ \\
\hline & (1) & (2) & (3) & (4) & (5) & (6) & (7) & (8) & (9) & (10) & (11) & (12) \\
\hline \multicolumn{13}{|l|}{ OECD-Länder } \\
\hline Australien $^{1}$ & 43277 & 46929 & 49144 & 4,7 & 1019 & 1014 & 1009 & $-0,5$ & 811 & 810 & 811 & 0,1 \\
\hline Österreich ${ }^{1}$ & 38306 & 44024 & 45105 & 2,5 & 1148 & 958 & 945 & $-1,4$ & $\mathrm{~m}$ & 607 & 607 & 0,0 \\
\hline Belgien (fläm.) ${ }^{1}$ & 43348 & 44616 & 45413 & 1,8 & $\mathrm{~m}$ & 960 & 955 & $-0,6$ & 682 & 690 & 671 & $-2,7$ \\
\hline Belgien (frz.) ${ }^{1}$ & 42363 & 42798 & 44407 & 3,8 & 1075 & 1020 & 1020 & 0,0 & 728 & 724 & 661 & $-8,7$ \\
\hline Kanada & $\mathrm{m}$ & $\mathrm{m}$ & 56349 & m & $\mathrm{m}$ & $\mathrm{m}$ & 923 & m & $\mathrm{m}$ & $\mathrm{m}$ & 743 & m \\
\hline Chile & $\mathrm{m}$ & $\mathrm{m}$ & 23623 & m & 1080 & $\mathrm{~m}$ & 1083 & m & $\mathrm{m}$ & 1001 & 1120 & 11,9 \\
\hline Tschechien ${ }^{1,2}$ & 10032 & 18067 & 20360 & 12,7 & 867 & 902 & 848 & $-5,9$ & $\mathrm{~m}$ & 647 & 630 & $-2,6$ \\
\hline Dänemark ${ }^{1}$ & 40483 & 43259 & 50332 & 16,3 & 890 & 880 & 930 & 5,7 & 640 & 640 & 650 & 1,6 \\
\hline England & 41270 & 45142 & 44269 & $-1,9$ & 940 & 933 & 912 & $-2,3$ & $\mathrm{~m}$ & $\mathrm{~m}$ & 695 & m \\
\hline Estland & 7580 & 9040 & 12306 & 36,1 & $\mathrm{~m}$ & 1073 & 770 & $-28,2$ & 630 & 630 & 619 & $-1,7$ \\
\hline Finnland $^{1}$ & 37426 & 40552 & 40917 & 0,9 & 808 & 815 & 913 & 12,1 & 570 & 592 & 595 & 0,5 \\
\hline Frankreich $^{1}$ & 39358 & 37412 & 36159 & $-3,3$ & 1042 & 1053 & 1081 & 2,6 & 648 & 648 & 648 & 0,0 \\
\hline Deutschland & $\mathrm{m}$ & $\mathrm{m}$ & 64491 & m & 903 & 872 & 890 & 2,0 & 732 & 758 & 757 & $-0,2$ \\
\hline Griechenland & 29428 & 33122 & 28184 & $-14,9$ & 1064 & 998 & 796 & $-20,2$ & 426 & 434 & 415 & $-4,4$ \\
\hline Ungarn ${ }^{1}$ & 11008 & 17465 & 13115 & $-24,9$ & 925 & 921 & 859 & $-6,7$ & 555 & 555 & 604 & 8,8 \\
\hline Island & 24242 & 27176 & 26991 & $-0,7$ & 809 & 872 & 987 & 13,1 & 629 & 671 & 624 & $-7,1$ \\
\hline Irland $^{1}$ & 42038 & 48498 & 54954 & 13,3 & 907 & 907 & 935 & 3,1 & 735 & 735 & 735 & 0,0 \\
\hline Israel $^{1}$ & 21313 & 21326 & 24997 & 17,2 & $\mathrm{~m}$ & 971 & 981 & 1,0 & 579 & 579 & 614 & 6,1 \\
\hline Italien ${ }^{1}$ & 34769 & 36597 & 35922 & $-1,8$ & 1020 & 1082 & 990 & $-8,5$ & 608 & 605 & 630 & 4,1 \\
\hline$J^{\prime a p a n}{ }^{1}$ & 50027 & 49311 & 45741 & $-7,2$ & 875 & 869 & 866 & $-0,4$ & 557 & 505 & 602 & 19,3 \\
\hline Korea $^{1}$ & 40405 & 50741 & 48146 & $-5,1$ & 867 & 867 & 850 & $-2,0$ & 570 & 621 & 621 & 0,0 \\
\hline Luxemburg & $\mathrm{m}$ & 92988 & 100013 & 7,6 & $\mathrm{~m}$ & 782 & 900 & 15,0 & $\mathrm{~m}$ & 642 & 739 & 15,1 \\
\hline Mexiko $^{1}$ & 22176 & 23240 & 24910 & 7,2 & 1167 & 1167 & 1167 & 0,0 & 1182 & 1047 & 1047 & 0,0 \\
\hline Niederlande & $\mathrm{m}$ & $\mathrm{m}$ & 63695 & m & 1067 & 1067 & 1000 & $-6,2$ & 867 & 750 & 750 & 0,0 \\
\hline Neuseeland & 39040 & 39730 & 42241 & 6,3 & 948 & 962 & $\mathrm{~m}$ & m & $\mathrm{m}$ & $\mathrm{m}$ & 848 & m \\
\hline Norwegen $^{1}$ & $\mathrm{~m}$ & 34644 & 37585 & 8,5 & 827 & 827 & 855 & 3,5 & 633 & 656 & 663 & 1,2 \\
\hline Polen & $\mathrm{m}$ & 11233 & 18806 & 67,4 & $\mathrm{~m}$ & $\mathrm{~m}$ & 800 & m & $m$ & $\mathrm{~m}$ & 478 & m \\
\hline Portugal $^{1}$ & 31188 & 35696 & 39424 & 10,4 & 842 & 905 & 950 & 5,0 & 595 & 564 & 774 & 37,2 \\
\hline Schottland & 40470 & 49642 & 47984 & $-3,3$ & $a$ & $a$ & a & m & 893 & 893 & 855 & $-4,3$ \\
\hline Slowakei & $\mathrm{m}$ & $\mathrm{m}$ & 12858 & m & $\mathrm{m}$ & $\mathrm{m}$ & 832 & m & $\mathrm{m}$ & $\mathrm{m}$ & 656 & m \\
\hline Slowenien ${ }^{1}$ & $\mathrm{~m}$ & 29979 & 32193 & 7,4 & $\mathrm{~m}$ & 791 & 817 & 3,2 & $\mathrm{~m}$ & 690 & 690 & 0,0 \\
\hline Spanien $^{1}$ & 42147 & 46027 & 45689 & $-0,7$ & 845 & 956 & 1050 & 9,8 & 564 & 713 & 713 & 0,0 \\
\hline Schweden & 31486 & 34286 & 35495 & 3,5 & 741 & 741 & 741 & 0,0 & $\mathrm{~m}$ & $\mathrm{~m}$ & $\mathrm{~m}$ & $\mathbf{a}$ \\
\hline Schweiz & 69185 & 67532 & $\mathrm{~m}$ & m & $\mathrm{m}$ & $\mathrm{m}$ & $\mathrm{m}$ & m & 859 & $\mathrm{~m}$ & $\mathrm{~m}$ & m \\
\hline Türkei & a & a & a & $\mathbf{a}$ & a & $a$ & a & $\mathbf{a}$ & $a$ & a & a & $\mathbf{a}$ \\
\hline Vereinigte Staaten ${ }^{1}$ & 44588 & 46876 & 45950 & $-2,0$ & 980 & 980 & 980 & 0,0 & 1080 & 1080 & 1068 & $-1,1$ \\
\hline OECD-Durchschnitt & 35267 & 38932 & 39934 & 5,6 & 946 & 936 & 926 & $-0,2$ & 699 & 696 & 707 & 2,6 \\
\hline $\begin{array}{l}\text { Durchschnitt von } \\
21 \text { Ländern, für die } \\
\text { alle Daten für } 2005 \\
\text { und } 2011 \text { vorliegen }\end{array}$ & & 36838 & 40800 & 10,8 & & 937 & 968 & 3,2 & & 701 & 731 & 4,2 \\
\hline
\end{tabular}

Anmerkung: Die Daten in dieser Tabelle wurden entweder Kapital D entnommen (Daten für 2000, 2005 und 2011 zu Gehältern der Lehrkräfte und zu unterrichtenden [Zeit-JStunden) oder Bildung auf einen Blick 2002 bzw. 2007 (Daten zur Schüler-Lehrkräfte-Relation und zu unterrichtenden [Zeit-JStunden). Einige der Daten für 2000 wurden überarbeitet, um die Konsistenz mit den Daten für 2011 zu gewährleisten.

1. Länder, für die alle Daten sowohl für 2005 als auch für 2011 vorliegen. 2. Aktuelle Unterrichtszeit für 2000 und 2005 , Mindestunterrichtszeit für 2011. Quelle: OECD. Hinweise s. Anhang 3 unter www.oecd.org/edu/eag.htm. StatLink: http://dx.doi.org/10.1787/888932850129

Erläuterung der Kennzeichnung fehlender Daten s. Hinweise für den Leser. 
Tabelle B7.2b (Forts.)

Faktoren zur Berechnung der Gehaltskosten der Lehrkräfte pro Schüler im Sekundarbereich I (2000, 2005 und 2011)

\begin{tabular}{|c|c|c|c|c|c|c|c|c|}
\hline & \multicolumn{4}{|c|}{$\begin{array}{l}\text { Schüler-Lehrkräfte-Relation } \\
\text { (Zahl der Schüler pro Lehrkraft) }\end{array}$} & \multicolumn{4}{|c|}{$\begin{array}{c}\text { Geschätzte Klassengröße } \\
\text { (Zahl der Schüler pro Klasse) }\end{array}$} \\
\hline & 2000 & 2005 & 2011 & $\begin{array}{l}\text { Veränderung } \\
2005-2011 \\
\quad \text { (in \%) }\end{array}$ & 2000 & 2005 & 2011 & $\begin{array}{l}\text { Veränderung } \\
2005-2011 \\
\text { (in \%) }\end{array}$ \\
\hline & (13) & (14) & (15) & (16) & $(17)=(13) \times(5) /(9)$ & $(18)=(14) \times(6) /(10)$ & $(19)=(15) \times(7) /(11)$ & $(20)$ \\
\hline \multicolumn{9}{|l|}{ OECD-Länder } \\
\hline Australien $^{1}$ & 12,6 & 12,1 & 12,0 & $-1,4$ & 15,8 & 15,2 & 14,9 & $-1,9$ \\
\hline Österreich ${ }^{1}$ & 9,8 & 10,6 & 9,1 & $-14,4$ & $\mathrm{~m}$ & 16,8 & 14,1 & $-15,6$ \\
\hline Belgien (fläm. $)^{1}$ & $\mathrm{~m}$ & 9,4 & 8,1 & $-13,8$ & $\mathrm{~m}$ & 13,1 & 11,6 & $-11,9$ \\
\hline Belgien (frz.) ${ }^{1}$ & $\mathrm{~m}$ & 9,4 & 8,1 & $-13,8$ & $\mathrm{~m}$ & 13,3 & 12,6 & $-5,6$ \\
\hline Kanada & 18,1 & $\mathrm{~m}$ & 16,1 & m & $\mathrm{m}$ & $\mathrm{m}$ & 20,0 & m \\
\hline Chile & $\mathrm{m}$ & 25,9 & 23,6 & $-9,0$ & $\mathrm{~m}$ & $\mathrm{~m}$ & 22,8 & m \\
\hline Tschechien ${ }^{1,2}$ & 14,7 & 13,5 & 11,1 & $-17,8$ & $\mathrm{~m}$ & 18,8 & 14,9 & $-20,6$ \\
\hline Dänemark ${ }^{1}$ & 11,4 & 11,9 & 11,8 & $-0,9$ & 15,8 & 16,4 & 16,9 & 3,2 \\
\hline England & 17,6 & 15,1 & 14,6 & $-3,3$ & $\mathrm{~m}$ & $\mathrm{~m}$ & 19,2 & m \\
\hline Estland & $\mathrm{m}$ & $m$ & 14,7 & m & $\mathrm{m}$ & $\mathrm{m}$ & 18,3 & $\mathbf{m}$ \\
\hline Finnland $^{1}$ & 10,7 & 10,0 & 9,3 & $-6,7$ & 15,1 & 13,7 & 14,3 & 4,0 \\
\hline Frankreich $^{1}$ & 14,7 & 14,2 & 14,8 & 4,3 & 23,6 & 23,0 & 24,7 & 7,0 \\
\hline Deutschland & 15,7 & 15,5 & 14,2 & $-8,8$ & 19,3 & 17,9 & 16,6 & $-6,8$ \\
\hline Griechenland & 10,8 & 7,9 & $\mathrm{~m}$ & m & 26,9 & 18,1 & $\mathrm{~m}$ & m \\
\hline Ungarn ${ }^{1}$ & 10,9 & 10,4 & 10,5 & 0,8 & 18,2 & 17,2 & 14,9 & $-13,6$ \\
\hline Island & 12,7 & 11,3 & $\mathrm{~m}$ & m & 16,3 & 14,7 & $\mathrm{~m}$ & m \\
\hline Irland $^{1}$ & 15,9 & 15,5 & 14,4 & $-7,1$ & 19,6 & 19,1 & 18,3 & $-4,2$ \\
\hline$|s r a e|^{1}$ & $\mathrm{~m}$ & 13,4 & 13,6 & 1,6 & $\mathrm{~m}$ & 22,4 & 21,7 & $-3,3$ \\
\hline Italien ${ }^{1}$ & 10,6 & 10,1 & 11,5 & 13,0 & 17,7 & 18,1 & 18,0 & $-0,8$ \\
\hline$J^{J a p a n^{1}}$ & 16,8 & 15,1 & 14,2 & $-5,8$ & 26,5 & 26,0 & 20,4 & $-21,3$ \\
\hline Korea $^{1}$ & 21,5 & 20,8 & 18,8 & $-9,7$ & 32,8 & 29,0 & 25,7 & $-11,4$ \\
\hline Luxemburg & $\mathrm{m}$ & 9,0 & 9,6 & 6,8 & $\mathrm{~m}$ & 11,0 & 11,7 & 6,7 \\
\hline Mexiko $^{1}$ & 34,8 & 33,7 & 31,9 & $-5,4$ & 34,3 & 37,6 & 35,6 & $-5,4$ \\
\hline Niederlande & 17,1 & 16,2 & 15,3 & $-6,0$ & 21,0 & 23,1 & 20,4 & $-11,9$ \\
\hline Neuseeland & 19,9 & 16,8 & 16,3 & $-3,1$ & $\mathrm{~m}$ & $m$ & $\mathrm{~m}$ & m \\
\hline Norwegen $^{1}$ & 9,9 & 10,2 & 10,0 & $-2,8$ & 12,9 & 12,9 & 12,8 & $-0,5$ \\
\hline Polen & 11,5 & 12,7 & 10,0 & $-21,4$ & $\mathrm{~m}$ & $m$ & 16,7 & m \\
\hline Portugal $^{1}$ & 10,4 & 8,2 & 8,2 & 0,2 & 14,8 & 13,1 & 10,0 & $-23,4$ \\
\hline Schottland & 17,6 & 15,1 & 14,6 & $-3,3$ & $\mathrm{~m}$ & $m$ & $\mathrm{~m}$ & m \\
\hline Slowakei & 13,5 & 14,1 & 13,1 & $-6,8$ & $\mathrm{~m}$ & $\mathrm{~m}$ & 16,7 & m \\
\hline Slowenien ${ }^{1}$ & $\mathrm{~m}$ & 11,1 & 7,9 & $-28,5$ & $\mathrm{~m}$ & 12,7 & 9,4 & $-26,2$ \\
\hline Spanien $^{1}$ & 13,7 & 12,5 & 10,3 & $-17,6$ & 20,6 & 16,8 & 15,2 & $-9,5$ \\
\hline Schweden & 12,8 & 12,0 & 11,3 & $-6,1$ & $\mathrm{~m}$ & $\mathrm{~m}$ & $\mathrm{~m}$ & m \\
\hline Schweiz & $\mathrm{m}$ & 11,7 & $\mathrm{~m}$ & m & $\mathrm{m}$ & $\mathrm{m}$ & $\mathrm{m}$ & m \\
\hline Türkei & $a$ & a & a & $\mathbf{a}$ & a & a & a & $\mathbf{a}$ \\
\hline Vereinigte Staaten ${ }^{1}$ & 16,3 & 15,1 & 15,2 & 0,7 & 14,8 & 13,7 & 13,9 & 1,9 \\
\hline OECD-Durchschnitt & 14,9 & 13,7 & 13,3 & $-6,2$ & 20,3 & 18,2 & 17,3 & $-7,4$ \\
\hline $\begin{array}{l}\text { Durchschnitt von } \\
21 \text { Ländern, für die } \\
\text { alle Daten für } 2005 \\
\text { und } 2011 \text { vorliegen }\end{array}$ & & 15,4 & 14,1 & $-8,7$ & & 19,8 & 18,6 & $-6,2$ \\
\hline
\end{tabular}

Anmerkung: Die Daten in dieser Tabelle wurden entweder Kapital D entnommen (Daten für 2000, 2005 und 2011 zu Gehältern der Lehrkräfte und zu unterrichtenden [Zeit-JStunden) oder Bildung auf einen Blick 2002 bzw. 2007 (Daten zur Schüler-Lehrkräfte-Relation und zu unterrichtenden (Zeit-JStunden). Einige der Daten für 2000 wurden überarbeitet, um die Konsistenz mit den Daten für 2011 zu gewährleisten.

1. Länder, für die alle Daten sowohl für 2005 als auch für 2011 vorliegen. 2. Aktuelle Unterrichtszeit für 2000 und 2005, Mindestunterrichtszeit für 2011. Quelle: OECD. Hinweise s. Anhang 3 unter www.oecd.org/edu/eag.htm. StatLink: http://dx.doi.org/10.1787/888932850129 Erläuterung der Kennzeichnung fehlender Daten s. Hinweise für den Leser. 
Tabelle B7.3

Beitrag verschiedener Faktoren zu den Gehaltskosten der Lehrkräfte pro Schüler im Primarbereich (2000, 2005 und 2011)

In US-Dollar, kaufkraftbereinigt mittels KKP für den privaten Verbrauch

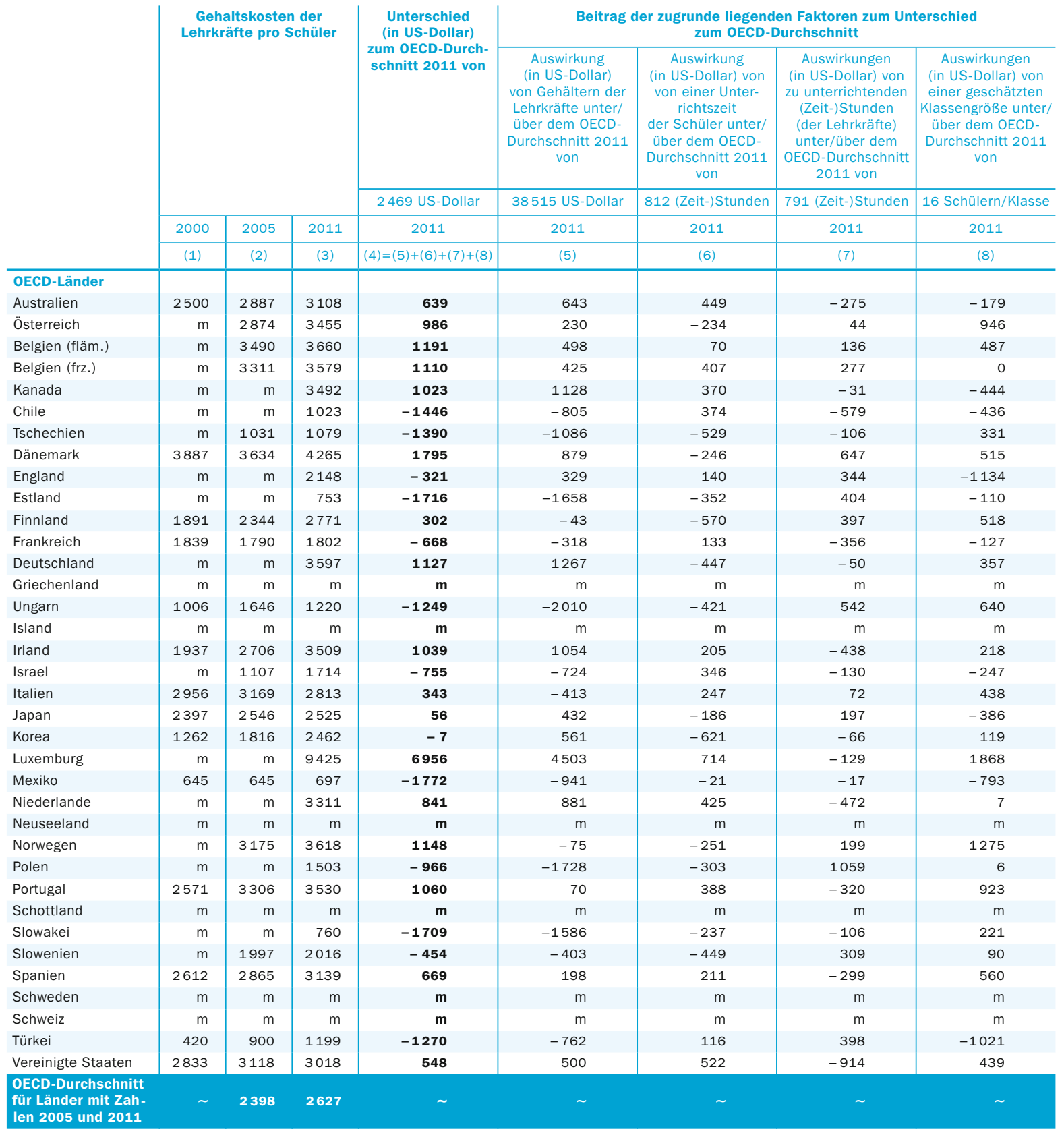

Quelle: OECD. Hinweise s. Anhang 3 unter www.oecd.org/edu/eag.htm. StatLink: http://dx.doi.org/10.1787/888932850167 Erläuterung der Kennzeichnung fehlender Daten s. Hinweise für den Leser. 
Beitrag verschiedener Faktoren zu den Gehaltskosten der Lehrkräfte pro Schüler im Sekundarbereich I (2000, 2005 und 2011)

In US-Dollar, kaufkraftbereinigt mittels KKP für den privaten Verbrauch

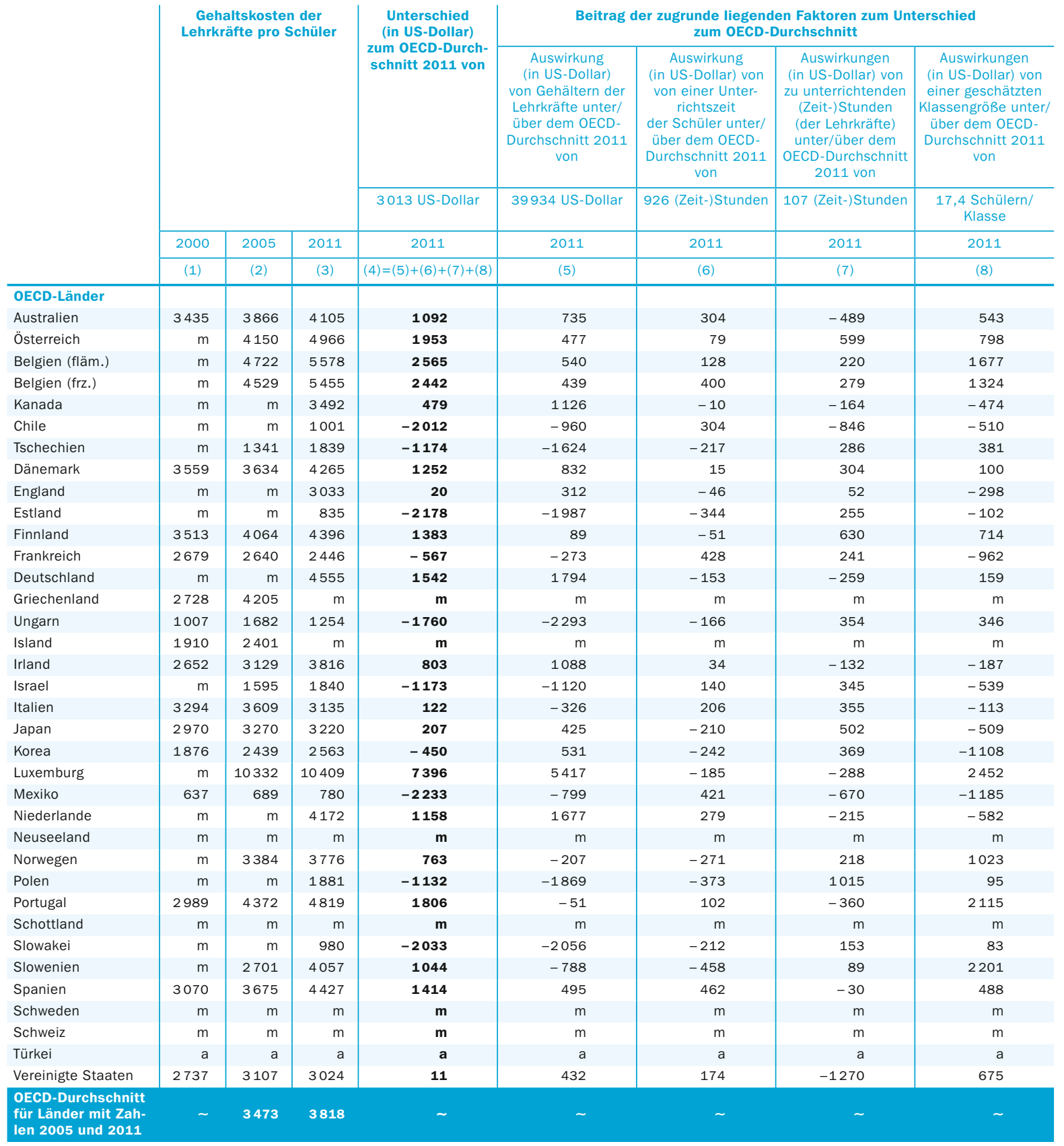

Quelle: OECD. Hinweise s. Anhang 3 unter www.oecd.org/edu/eag.htm. StatLink: http://dx.doi.org/10.1787/888932850186

Erläuterung der Kennzeichnung fehlender Daten s. Hinweise für den Leser. 
Beitrag verschiedener Faktoren zu den Gehaltskosten der Lehrkräfte pro Schüler im Sekundarbereich II (2011) In US-Dollar, kaufkraftbereinigt mittels KKP für den privaten Verbrauch

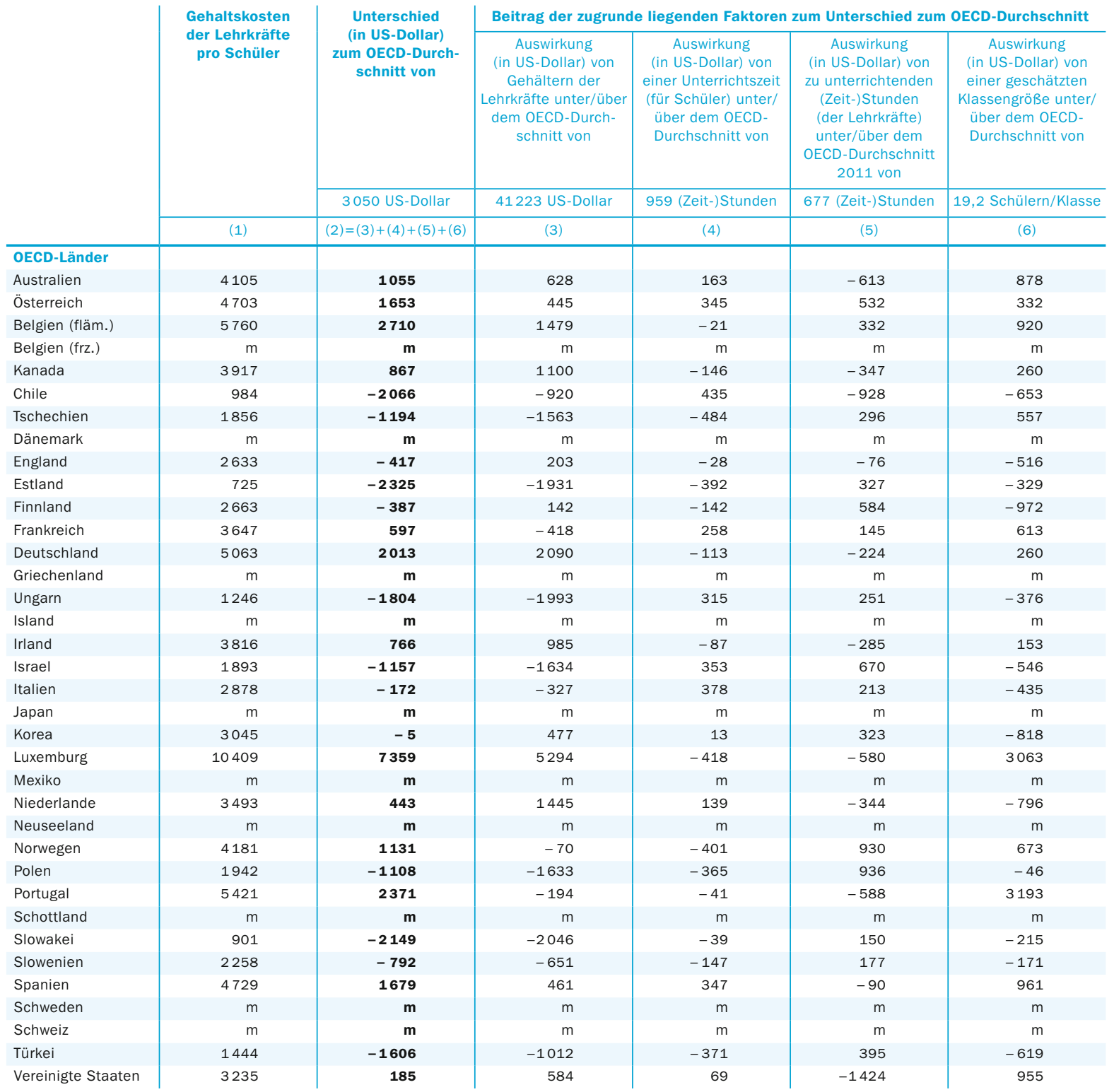

Quelle: OECD. Hinweise s. Anhang 3 unter www.oecd.org/edu/eag.htm. StatLink: http://dx.doi.org/10.1787/888932850224 Erläuterung der Kennzeichnung fehlender Daten s. Hinweise für den Leser. 


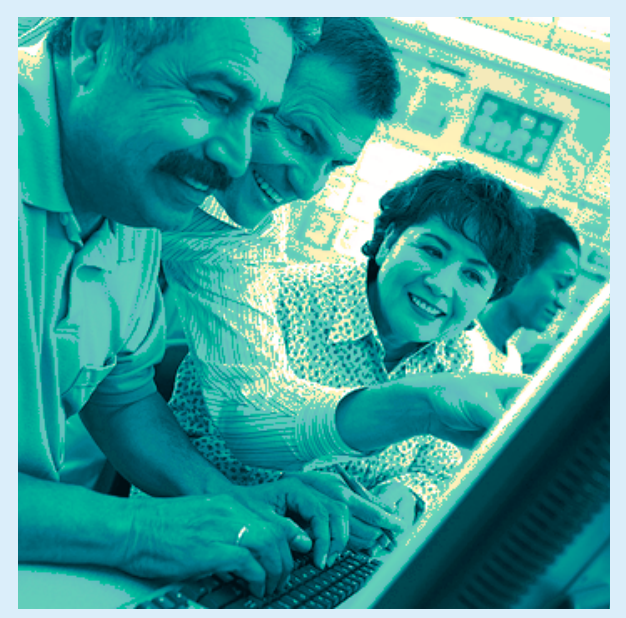

\section{Bildungszugang, Bildungsbeteiligung und Bildungsverlauf}

Indikator $\mathrm{CI}_{\mathrm{I}}$

Wer nimmt an Bildung teil?

StatLink: http:|/dx.doi.org/10.1787/888932850262

Indikator $\mathrm{C}_{2}$

Welche Systeme zur frühkindlichen Bildung gibt es weltweit?

StatLink: http:|/dx.doi.org/10.1787/888932850490

Indikator $\mathrm{C}_{3}$

Wie viele junge Erwachsene werden ein Studium im Tertiärbereich aufnehmen?

StatLink: http://dx.doi.org/10.1787/888932850566
Indikator $\mathrm{C}_{4}$

Wer studiert im Ausland und wo?

StatLink: http://dx.doi.org/10.1787/888932850718

Indikator $\mathrm{C}_{5}$

Der Übergang vom (Aus-)Bildungssystem zum Erwerbsleben: Wo sind die I5- bis 29-Jährigen?

StatLink: http://dx.doi.org/10.1787/888932850870 



\section{Wer nimmt an Bildung teil?}

Alle OECD- und sonstigen G20-Länder mit verfügbaren Daten weisen für das Alter von 5 bis I4 Jahren eine universelle Bildungsbeteiligung aus.

$201 \mathrm{I}$ lag die Bildungsbeteiligung der 15- bis I9-Jährigen in 31 der 39 OECD- und G20-Länder mit verfügbaren Daten bei über 75 Prozent.

Bei den 20- bis 29-Jährigen betrug die Bildungsbeteiligung 20II in allen OECDLändern, mit Ausnahme von Mexiko und dem Vereinigten Königreich, mehr als 20 Prozent.

Zwischen 1995 und 20II stieg die Bildungsbeteiligung der 20- bis 29-Jährigen in den OECD-Ländern mit verfügbaren Daten um mehr als ıo Prozentpunkte.

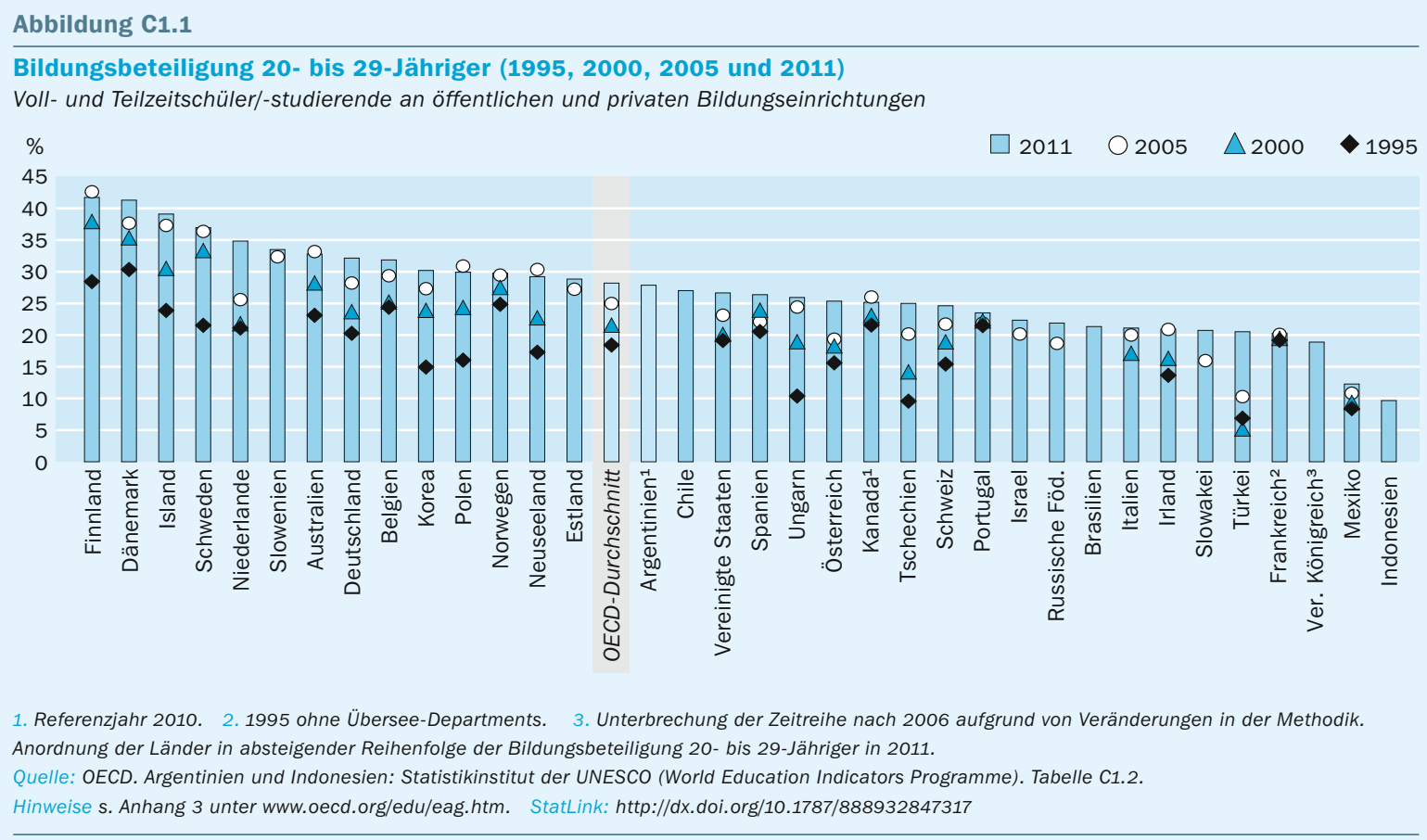

\section{Kontext}

In wirtschaftlich schwierigen Zeiten wird der Vorteil von Bildung für die Chancen auf dem Arbeitsmarkt noch deutlicher. Die Bildungssysteme in den OECD-Ländern und den meisten G20-Ländern bieten heute universellen Zugang zu Grundbildung, sodass inzwischen in den meisten Ländern auch zunehmend im Elementarbereich und im Sekundarbereich II eine universelle Bildungsbeteiligung gegeben ist (s. Indikator C2). Die Ausweitung des Sekundarbereichs II ist sowohl durch die steigende Nachfrage als auch bildungspolitische Veränderungen, wie flexiblere Lehrpläne, eine Umstrukturierung der berufsbildenden Bildungsgänge und Bemühungen, die Bildungsbeteiligung auf die gesamte Bevölkerung auszuweiten, vorangetrieben worden. Obwohl diese Veränderungen auch für den Tertiärbereich gelten, sind die Teilnahmequoten in diesem höheren Bildungsbereich deutlich niedriger. 
Ein Abschluss im Sekundarbereich II ist inzwischen zur Mindestanforderung für einen reibungslosen Übergang in den Arbeitsmarkt geworden und verringert das Risiko der Erwerbslosigkeit (s. Indikator A7). Hohe Erfolgsquoten im Sekundarbereich II sind ein wesentlicher Faktor für eine verbesserte Chancengleichheit (OECD, 20I0a; OECD, 20Ira), allerdings bestehen bei den Erfolgsquoten große Unterschiede zwischen den einzelnen OECD-Ländern (s. Indikator A2). In ihrem Bemühen, diesen Bildungsbereich weiter auszubauen und dazu beizutragen, einen guten Ertrag für den Einzelnen zu sichern, müssen die Bildungssysteme den Lernenden die Fähigkeiten und Kenntnisse vermitteln, die diese benötigen, um schnell eine Beschäftigung zu finden, sowie allgemeine Kompetenzen und Kenntnisse, die es ihnen ermöglichen, durch lebenslanges Lernen über ihr gesamtes Arbeitsleben hinweg die zunehmend flexibleren Übergänge nutzen zu können (OECD, 20Iob).

In den meisten OECD-Ländern stellt der Sekundarbereich II die letzte Phase der Schulpflicht dar, in der den Schülern ein Mindestmaß an Kenntnissen und Fähigkeiten vermittelt wird, um in den Arbeitsmarkt einzutreten und sie zu engagierteren Bürgern zu machen. Kompetenzen sind zur globalen Währung der Wirtschaft im 2I. Jahrhundert geworden. Mangelnde Investitionen in Kompetenzen verdammt Menschen zu einem Leben am Rande der Gesellschaft, verhindert Produktivitätssteigerungen trotz technologischen Fortschritts und beeinträchtigt die Wettbewerbsfähigkeit von Ländern in einer immer stärker auf Wissen basierenden Weltwirtschaft (OECD, 2013).

Der aufgrund demografischer Entwicklungen, wie beispielsweise einer abnehmenden Bevölkerung im Schulalter, bestehende Druck wird wahrscheinlich Einfluss auf künftige bildungspolitische Entscheidungen haben. Während in Ländern mit abnehmenden Schülerzahlen die Möglichkeit bestehen wird, die pro Schüler zur Verfügung stehenden Ressourcen zu erhöhen (s. Indikator BI) und die Schüler-Lehrkräfte-Relation zu verringern (s. Indikator D2), kann eine Umverteilung der Humanressourcen auf andere Bildungsbereiche langfristig zu planende Änderungen bei der Ausbildung und Anwerbung von Lehrkräften erfordern. Für Länder, in denen ein im historischen Vergleich hoher Bevölkerungsanteil im Schulalter zu erwarten ist, besteht die Möglichkeit, die zukünftige Erwerbsbevölkerung und deren Qualifikationsprofil durch Bildungsreformen zu gestalten. Aber der Druck auf die Bildungsbudgets dieser Länder wird, insbesondere in Anbetracht der aktuellen wirtschaftlichen Lage, wahrscheinlich zunehmen. Die potenziell in Zukunft zur Verfügung stehende höhere Zahl an qualifizierten Arbeitnehmern könnte zu einer Diskrepanz zwischen Qualifikation und Tätigkeit und niedrigeren öffentlichen und privaten Bildungserträgen führen (s. Indikator A9). Die in den letzten Jahrzehnten zu beobachtenden tief greifenden strukturellen Veränderungen auf dem globalen Arbeitsmarkt lassen jedoch darauf schließen, dass Menschen in zunehmend besser qualifizierten Bevölkerungen weiterhin sicher auf dem Arbeitsmarkt Fuß fassen werden, solange die Entwicklung hin zu immer mehr wissensbasierten Volkswirtschaften geht.

\section{Weitere wichtige Ergebnisse}

Nach den Beteiligungsdaten von 2011 kann ein 5-jähriges Kind in einem OECD-Land davon ausgehen, vor Erreichen des 40. Lebensjahres im Durchschnitt mehr als 17 Jahre in Vollzeit- oder 
Teilzeitausbildung zu verbringen. Die zu erwartende Bildungsdauer reicht von I4 Jahren in Luxemburg (wo die Mobilität der Schüler/Studierenden hoch ist) und I5 Jahren in Mexiko bis zu mehr als I 9 Jahren in Finnland, Island, Dänemark und Schweden.

2011 nahmen mindestens 90 Prozent der Bevölkerung in den OECD-Ländern durchschnittlich 13 Jahre an formaler Bildung teil. I5 der 33 Länder mit verfügbaren Daten liegen oberhalb und 9 der 33 Länder unterhalb dieses Durchschnitts.

\section{Entwicklungstendenzen}

Zwischen 2000 und 20 II stieg die Beteiligungsquote unter den I5- bis I9-Jährigen in nahezu allen OECD-Ländern kontinuierlich um rund 8 Prozentpunkte an, von durchschnittlich 76 Prozent im Jahr 2000 auf 84 Prozent im Jahr 20II. Während die Quote in diesem Zeitraum in der Türkei um mehr als 30 Prozentpunkte und in Mexiko, Portugal und Ungarn um rund 15 Prozentpunkte anstieg, blieb sie in Kanada (nur Daten bis 2010 verfügbar), Finnland, Griechenland, Israel, Norwegen, Österreich, Schweden und der Schweiz nahezu unverändert. In Frankreich fiel die Beteiligungsquote in dieser Altersgruppe in diesem Zeitraum von 87 auf 84 Prozent (Tab. Cr. 2 und Abb. Cr.2). 20II beliefen sich die Beteiligungsquoten für 15- bis I9-Jährige in Chile, Israel, Mexiko, Österreich, der Türkei und dem Vereinigten Königreich immer noch auf weniger als 80 Prozent.

\section{Analyse und Interpretationen}

In I9 in 33 OECD-Länder mit verfügbaren Daten für 20 II beginnt die universelle Bildungsbeteiligung, hier definiert als Beteiligung von über 9o Prozent der Bevölkerung einer für bestimmte Bildungsgänge typischen Altersgruppe, im Alter zwischen 3 und 4 Jahren, in den anderen 14 Ländern im Alter zwischen 5 und 6 Jahren. In fast zwei Drittel der OECD-Länder werden mindestens 75 Prozent der 3- bis 4-Jährigen entweder im Elementar- oder im Primarbereich unterrichtet; dieser Anteil ist im Durchschnitt in den EU-Ländern höher als in anderen OECD-Ländern ( 78 Prozent gegenüber 72 Prozent) (Tab. Cr.ra und Indikator C2). In Belgien, Frankreich, Island, Norwegen und Spanien lag 20 II die Bildungsbeteiligung der 3- bis 4-Jährigen bei mindestens 95 Prozent.

\section{Bildungsbeteiligung während der Schulpflicht}

Die Schulpflicht dauert in den einzelnen Ländern unterschiedlich lang. 20II reichte das typische Alter zu Beginn der Schulpflicht von 4 Jahren in Luxemburg und Mexiko bis zu 7 Jahren in Estland, Finnland, der Russischen Föderation, Schweden und Südafrika. Im Vereinigten Königreich und den Vereinigten Staaten reichte das typische Alter zu Beginn der Schulpflicht von 4 bis 5 Jahren bzw. 4 bis 6 Jahren. In allen OECDLändern besteht für den Primar- und Sekundarbereich I Schulpflicht, in den meisten dieser Länder auch für den Sekundarbereich II. Für die Altersgruppe der 5- bis I4-Jährigen liegen die Beteiligungsquoten bei mehr als 90 Prozent, d. h., in allen OECD- und sonstigen G20-Ländern gibt es für die Grundbildung eine universelle Bildungsbeteiligung. In den meisten Ländern, mit Ausnahme von Chile, China, Indonesien und der 


\section{Zu erwartende Jahre in Ausbildung}

Ausgehend von den Beteiligungszahlen in $201 \mathrm{r}$ können Kinder bei Eintritt in das Bildungssystem wahrscheinlich für jedes Altersjahr, für das in ihrem Land eine universelle Bildungsbeteiligung besteht, ein zusätzliches Jahr in Ausbildung erwarten.

Die Schätzung der erwarteten Jahre in Ausbildung umfasst jegliche Beteiligung an formaler Bildung, auch eine nicht kontinuierliche Teilnahme oder eine Teilnahme ohne Erwerb der formalen Abschlussqualifikation. Nach den Beteiligungsdaten von $20 I r$ kann ein 5-jähriges Kind in einem OECD-Land davon ausgehen, vor Erreichen des 40. Lebensjahres im Durchschnitt mehr als 17 Jahre an Bildung teilzunehmen. Genauer gesagt kann dieses Kind davon ausgehen, 16,5 Jahre in Vollzeitausbildung zu verbringen: 9, 4 Jahre im Primar- und Sekundarbereich I, 3,4 Jahre im Sekundarbereich II und 2,7 Jahre im Tertiärbereich. Außerdem kann es davon ausgehen, zusätzlich über einen Zeitraum von I,2 Jahren eine Teilzeitausbildung zu absolvieren, die größtenteils im Tertiärbereich erfolgen wird. Frauen können davon ausgehen, sich im Durchschnitt I6,7 Jahre in Vollzeitausbildung zu befinden, bei Männern sind es 16,3 Jahre. In den Ländern mit verfügbaren Daten reicht die voraussichtlich in Ausbildung verbrachte Zeit von I3,6 Jahren in Indonesien über mehr als ig Jahre in Dänemark, Island und Schweden bis zu fast 20 Jahren in Finnland (Tab. Cr.6a).

Die Teilnahme an einem Bildungsgang ist nicht auf eine bestimmte Altersgruppe beschränkt. Aufgrund der Daten für 20II lässt sich sagen, dass sich in Australien, Belgien, Finnland, Island und Neuseeland, ein signifikanter Anteil der Erwachsenenbevölkerung in Ausbildung befindet, insbesondere 40-Jährige und Ältere. Dies lässt sich durch einen höheren Anteil an Teilzeitausbildung und Bildungsgängen im Bereich des lebenslangen Lernens in diesen Ländern erklären. Zum Beispiel können Erwachsene in Schweden durch Systeme, die auf Leistungspunkten basieren, an formaler Bildung teilnehmen, um ihre Fähigkeiten und Kenntnisse zu erweitern.

Bei den zu erwartenden Jahren in Ausbildung handelt es sich nur um eine Schätzung der Jahre, die Menschen wahrscheinlich in Ausbildung verbringen werden. Dieser statistische Wert entspricht nicht den aktuell erzielten Bildungsabschlüssen und kann auch von den Prognosen für die in Zukunft zu erwartenden Bildungsabschlüsse abweichen, da die in einem Bildungsgang verbrachte Zeit innerhalb der Bevölkerung variieren kann.

Russischen Föderation lagen die Beteiligungsquoten dieser Altersgruppe im Jahr $201 \mathrm{I}$ bei über 95 Prozent (Tab. Cr.ra).

\section{Bildungsbeteiligung im Sekundarbereich II}

In den letzten Jahren haben die Länder die Vielfalt der Bildungsgänge im Sekundarbereich II erweitert. Diese Diversifizierung ist eine Folge der wachsenden Nachfrage nach Bildungsangeboten in diesem Bereich und einer Weiterentwicklung der Lehrpläne von der Vermittlung von Allgemeinwissen in allgemeinbildenden Bildungsgängen und 


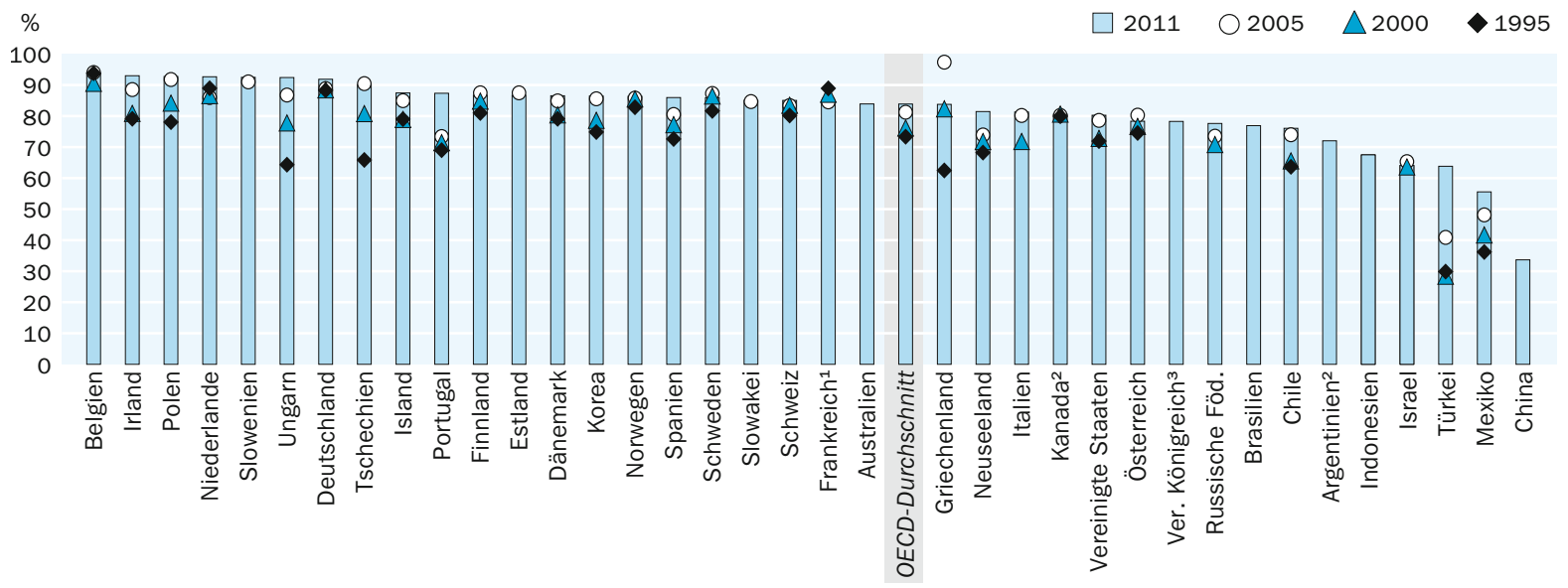

1. 1995 ohne Übersee-Departments. 2. Referenzjahr 2010. 3. Unterbrechung der Zeitreihe nach 2006 aufgrund von Veränderungen in der Methodik. Anordnung der Länder in absteigender Reihenfolge der Bildungsbeteiligung 15- bis 19-Jähriger in 2011.

Quelle: OECD. Argentinien, China und Indonesien: Statistikinstitut der UNESCO (World Education Indicators Programme). Tabelle C1.2.

Hinweise s. Anhang 3 unter www.oecd.org/edu/eag.htm. StatLink: http://dx.doi.org/10.1787/888932847336

praktischen Fertigkeiten in berufsbildenden Bildungsgängen zu umfassenderen Bildungsgängen, die beide Aspekte abdecken und flexiblere Übergänge ermöglichen.

Die Daten für 20II zeigen, dass die Beteiligung bei den I5- bis I9-Jährigen, d. h. der Altersgruppe, die sich normalerweise im Sekundarbereich II oder im Übergang zum Tertiärbereich befindet, in 26 der 39 OECD- und G20-Länder mit verfügbaren Daten bei mindestens 8o Prozent lag und in Belgien, Deutschland, Irland, den Niederlanden, Polen, Slowenien, Tschechien und Ungarn bei über 90 Prozent (Tab. Cr.ra). Im Gegensatz dazu beträgt der Anteil dieser Altersgruppe, der sich nicht in Ausbildung befindet, in Argentinien, Brasilien, Chile, Österreich, der Russischen Föderation und dem Vereinten Königreich mehr als 20 Prozent. In Indonesien, Israel (aufgrund des Wehrdienstes) und der Türkei liegt dieser Anteil bei über 30 Prozent, in Mexiko und China bei mehr als 40 Prozent bzw. 6o Prozent (Tab. Cr.ra und Abb. Cr.2)

Die Beteiligungsquoten der I5- bis I9-Jährigen stiegen in den OECD-Ländern zwischen I995 und 20II im Durchschnitt um I0,5 Prozentpunkte. Dies ist hauptsächlich auf eine Annäherung der Beteiligungsquoten in den einzelnen OECD-Ländern im Verlauf der letzten I6 Jahre zurückzuführen. Während die Beteiligungsquoten in diesem Zeitraum in Griechenland, Tschechien, der Türkei und Ungarn um mehr als 20 Prozentpunkte und in Mexiko, Polen und Portugal um fast ${ }_{5} 5$ Prozentpunkte und mehr anstiegen, blieben sie in Belgien, Kanada (nur Daten bis 2oro verfügbar) und Israel nahezu unverändert (Tab. Cr.2 und Abb. Cr.2).

In allen Ländern mit verfügbaren Daten besuchen mindestens 90 Prozent der 15 - bis ı6-Jährigen den Sekundarbereich II (mit Ausnahme der ı6-Jährigen in Argentinien sowie China, Indonesien, Mexiko, der Russischen Föderation und der Türkei). In den meisten OECD- und sonstigen G20-Ländern gehen die Beteiligungsquoten am stärksten am Ende des Sekundarbereichs II zurück. 
20 II betrug die Bildungsbeteiligung sowohl der I5-als auch der I6-Jährigen im Sekundarbereich II in 30 der 37 Länder mit verfügbaren Daten mehr als 9o Prozent. In Argentinien, Brasilien und der Russischen Föderation betrug die Beteiligungsquote in diesen Altersgruppen mehr als 85 Prozent (mit Ausnahme der I6-Jährigen in Argentinien und der Russischen Föderation, deren Beteiligungsquote 83 Prozent bzw. 69 Prozent betrug). In anderen Ländern gab es in diesen Altersgruppen größere Unterschiede in der Beteiligungsquote. In Indonesien lag der Wert für die I5-Jährigen beispielsweise bei go Prozent, bei den I6-Jährigen bei 77 Prozent. In China lag die Beteiligungsquote bei den I5-Jährigen bei 58 Prozent, bei den I6-Jährigen bei nur 42 Prozent.

Diese unterschiedlichen Beteiligungsquoten im Sekundarbereich II spiegeln unterschiedliche Abschlussanforderungen oder Altersbegrenzungen wider. In einigen Ländern, wie Belgien, Deutschland und Portugal, können ältere Schüler den Abschluss im Sekundarbereich II in Teilzeitunterricht erwerben. In den Niederlanden können Schüler über 20 an berufsbildenden Bildungsgängen des Sekundarbereichs II teilnehmen. Diese Ansätze, zusammen mit anderen Faktoren wie längeren (Aus-)Bildungsgängen, Klassenwiederholungen, einem späten Eintritt in den Arbeitsmarkt oder einer Berufstätigkeit parallel zur Ausbildung, haben zu einer größeren Zahl von älteren Teilnehmern im Sekundarbereich II geführt (s. Indikator A2). Daher besuchen in einigen OECD-Ländern rund 25 Prozent der 20-Jährigen noch den Sekundarbereich II. Hierzu gehören Dänemark (34 Prozent), Deutschland (24 Prozent), Island (35 Prozent), Luxemburg (27 Prozent) und die Niederlande (29 Prozent) (Tab. Cr.Ib im Internet).

\section{Berufliche Bildung}

In vielen Ländern zeigt sich in der letzten Zeit wieder ein verstärktes Interesse an beruflichen Bildungsgängen, da diese als wichtiges Mittel zur Gewährleistung eines reibungslosen Übergangs in den Arbeitsmarkt und zur Erlangung von Kenntnissen für all jene gesehen werden, die sonst keine Qualifikationen vorweisen könnten (OECD, 20roa). Ländern mit einem gut entwickelten und etablierten System der beruflichen Bildung einschließlich dualer Ausbildungsgänge ist es besser gelungen, die Jugenderwerbslosigkeit in Grenzen zu halten (s. Indikator $\mathrm{C}_{5}$ ). Gleichzeitig wird manchmal eine berufliche Ausbildung als weniger attraktiv als eine stärker akademisch ausgerichtete Ausbildung angesehen, und einige Forschungsergebnisse deuten darauf hin, dass eine berufliche Ausbildung das Risiko einer Erwerbslosigkeit im späteren Verlauf des Erwerbslebens erhöht (Hanushek et al., 20II).

In den meisten Ländern führt der erfolgreiche Abschluss einer dualen Berufsausbildung normalerweise zur Anerkennung eines Abschlusses des Sekundarbereichs II oder des postsekundaren Bereichs. In einigen Ländern können auch höhere Abschlüsse erworben werden wie beispielsweise das Advanced Diploma in Australien. Die Struktur der beruflichen Bildung unterscheidet sich in den einzelnen OECD-Ländern; es gibt verschiedene Kombinationen von berufsbildenden oder berufsvorbereitenden Bildungsgängen und dualen Ausbildungsgängen. In vielen Bildungssystemen können Schüler im Sekundarbereich II berufsbildende Bildungsgänge wählen, in einigen OECD-Ländern erfolgt die berufliche Ausbildung jedoch erst nach Abschluss des Sekundarbereichs II. Während beispielsweise Österreich, Spanien und Ungarn berufsbildende Bildungsgänge als höhere Stufe innerhalb des Sekundarbereichs II anbieten, werden sie in Kanada normalerweise im postsekundaren Bereich angeboten (s. Indikator A2). 
In rund einem Drittel der Länder mit Daten für das Jahr 201 I nehmen mehr als 50 Prozent der Teilnehmer im Sekundarbereich II - und mindestens 70 Prozent dieser Schüler in Belgien, Finnland, Österreich, der Slowakei und Tschechien - an berufsvorbereitenden oder berufsbildenden Bildungsgängen teil. In den übrigen zwei Drittel der Länder nimmt mehr als die Hälfte der Schüler im Sekundarbereich II an allgemeinbildenden und nicht an berufsbildenden Bildungsgängen teil. In Argentinien, Brasilien, Japan, Kanada, Korea und Mexiko beträgt dieser Anteil mehr als 75 Prozent. Nur in ungefähr einem Viertel der Länder werden im Sekundarbereich II auch berufsvorbereitende Bildungsgänge angeboten. Unter diesen weisen Irland (mit 33 Prozent) und die Russische Föderation (mit 23 Prozent) eine hohe Beteiligung in diesem Bildungsbereich auf (Tab. CI.3).

Betrachtet man die Beteiligungsquote der 15- bis I9-Jährigen an berufsbildenden Bildungsgängen im Sekundarbereich II, so scheint es, dass sie in Tschechien mit über 50 Prozent am höchsten ist. Mehr als 40 Prozent beträgt die Beteiligungsquote in dieser Altersgruppe beispielsweise in Belgien, Italien, Österreich, der Slowakei und Slowenien.

In den meisten Ländern wird die berufliche Bildung im Sekundarbereich II ausschließlich in der Schule vermittelt. In einer nicht unerheblichen Anzahl Länder werden jedoch auch Bildungsgänge, in denen schulische und betriebliche Ausbildung kombiniert werden, angeboten. In der Schweiz entfallen rund 6o Prozent der Beteiligungsquote im Sekundarbereich II auf solche dualen Bildungsgänge, in Dänemark, Deutschland, Österreich und Tschechien mehr als 30 Prozent (Tab. CI.3).

\section{Bildungsbeteiligung junger Erwachsener}

20II nahmen in den OECD-Ländern im Durchschnitt 28 Prozent der 20- bis 29-Jährigen an irgendeinem Bildungsgang teil. Dänemark, Finnland und Griechenland sind die Länder mit der höchsten Beteiligungsquote in dieser Altersgruppe (über 40 Prozent). In Island, den Niederlanden und Schweden betrug die Beteiligungsquote mindestens 35 Prozent. Eine Beteiligungsquote von unter ${ }_{5}$ Prozent bei dieser Altersgruppe war in Indonesien, Mexiko und Saudi-Arabien zu beobachten (Tab. Cr.Ia und Abb. Cr.I).

In den letzten 16 Jahren ist die Beteiligungsquote in dieser Altersgruppe in den OECDLändern im Durchschnitt um fast Io Prozentpunkte gestiegen. In Griechenland, Island, Korea, Schweden, Tschechien und Ungarn ist diese Quote in diesem Zeitraum um mehr als I5 Prozentpunkte gestiegen, während es in Frankreich, Kanada, Mexiko, Norwegen und Portugal nur ein Anstieg von weniger als 5 Prozentpunkten war (Tab. Cr.2 und Abb. CI.I).

In den meisten untersuchten Ländern sind die 20- bis 29-Jährigen in der Regel im Tertiärbereich eingeschrieben. 20II waren in den OECD-Ländern im Durchschnitt mehr als 37 Prozent der 20-Jährigen im Tertiärbereich eingeschrieben. In Korea betrug die Beteiligungsquote bei den 20-Jährigen in diesem Bildungsbereich fast 70 Prozent, während sie in Belgien, Slowenien und den Vereinigten Staaten bei mehr als 50 Prozent lag. Im Gegensatz dazu waren in Brasilien, Dänemark, Israel und der Schweiz nur höchstens 20 Prozent der 20- Jährigen im Tertiärbereich eingeschrieben (Tab. Cr.Ib im Internet). 
Die Wiederaufnahme oder Fortsetzung der Ausbildung ist eine Möglichkeit für Erwachsene, die ihre Fähigkeiten und Kenntnisse vertiefen und erweitern wollen, um den sich verändernden Anforderungen des Arbeitsmarktes besser gewachsen zu sein. In der aktuellen Situation hoher Erwerbslosigkeit und sich verändernder Kompetenzanforderungen auf den Arbeitsmärkten haben einige Länder, wie beispielsweise Chile, spezielle bildungspolitische Rahmenbedingungen geschaffen, um Erwachsene zur Aufnahme eines Studiums im Tertiärbereich B zu ermutigen.

\section{Geschlechtsspezifische Unterschiede}

Neuere Untersuchungen haben die Bedeutung eines mehr auf die Gleichstellung von Mann und Frau ausgerichteten Ansatzes herausgestellt, u. a. auch im Hinblick darauf, dass die Hälfte des Wirtschaftswachstums der letzten 50 Jahre in den OECD-Ländern auf einen höheren Bildungsstand zurückzuführen ist, der wiederum hauptsächlich durch eine verstärkte Beteiligung von Mädchen und Frauen in allen Bildungsbereichen erreicht wurde (OECD, 20I2c).

20 I lag die durchschnittliche Bildungsbeteiligung bei den I5- bis I9-jährigen Jungen in den OECD-Ländern bei 82 Prozent, bei den Mädchen dieser Altersgruppe bei 85 Prozent. In den meisten OECD- und G20-Ländern waren die Beteiligungsquoten in dieser Altersgruppe bei den Mädchen höher als bei den Jungen. Die größten geschlechtsspezifischen Unterschiede in dieser Altersgruppe gab es in Argentinien, wo 79 Prozent der Mädchen, aber nur 66 Prozent der Jungen an Bildung teilnahmen. Die Beteiligungsquoten in Israel, Kanada, der Russischen Föderation, Slowenien und den Vereinigten Staaten weisen einen geschlechtsspezifischen Unterschied von mehr als 5 Prozentpunkten zugunsten der Mädchen auf. In Indonesien und der Schweiz besteht ein geschlechtsspezifischer Unterschied bei den Beteiligungsquoten zugunsten der Jungen (I Prozentpunkt bzw. 3 Prozentpunkte). In der Türkei ist die Beteiligungsquote bei den I5- bis I9-jährigen Jungen um 6 Prozentpunkte höher als bei Mädchen dieser Altersgruppe. In Dänemark, Schweden und Ungarn besteht, wenn überhaupt, nur ein kleiner geschlechtsspezifischer Unterschied bei dieser Altersgruppe.

Bei den 20- bis 29-Jährigen ist der geschlechtsspezifische Unterschied bei den Beteiligungsquoten größer. Im Durchschnitt befinden sich in den OECD-Ländern 29 Prozent der Frauen und 26 Prozent der Männer dieser Altersgruppe in Ausbildung. Wie bei den I5- bis I9-Jährigen ist in den meisten OECD- und G20-Ländern die Beteiligungsquote bei den Frauen höher als bei den Männern, allerdings ist dies in weniger Ländern der Fall als bei der jüngeren Altersgruppe. Auch innerhalb der Länder gibt es größere Unterschiede. In Slowenien nehmen beispielsweise 42 Prozent der Frauen, aber nur 26 Prozent der Männer an Bildungsmaßnahmen teil. In Argentinien und Schweden ist die Beteiligungsquote bei den Frauen um ıo Prozentpunkte höher als bei den Männern. Der Unterschied von I6 Prozentpunkten zwischen der Beteiligungsquote von Männern und der von Frauen im Jahr $201 \mathrm{I}$ in Korea steht mit dem verzögerten Abschluss von Männern aufgrund ihrer Wehrpflicht in Zusammenhang.

In den meisten Ländern ist in der Altersgruppe der 30- bis 39-Jährigen die Beteiligungsquote bei Frauen höher als bei Männern. In dieser Altersgruppe haben Australien, Finnland, Island, Neuseeland und Schweden die höchste Beteiligungsquote bei den 
Frauen, wobei der geschlechtsspezifische Unterschied in Island und Schweden (mit mindestens 6 Prozentpunkten) am größten ist (Tab. Cr.ra).

\section{Teilzeitstudium}

Unabhängig davon, ob sie einen Studiengang im Tertiärbereich A oder B belegen, nehmen Studierende eher ein Vollzeit- als ein Teilzeitstudium auf. Gründe für eine Entscheidung zugunsten eines Teilzeitstudiums können u. a. eine gleichzeitig ausgeübte Berufstätigkeit, familiär bedingte Einschränkungen (dies gilt besonders für Frauen) sowie die Präferenz für verschiedene Fächer sein. Im Jahr 20II absolvierten im Durchschnitt aller OECD-Länder 73 Prozent der Studierenden im Tertiärbereich ein Vollzeitstudium, während 27 Prozent nur Teilzeit studierten. Im Tertiärbereich A und in weiterführenden forschungsorientierten Studiengängen beliefen sich die entsprechenden Zahlen auf 78 Prozent bzw. 22 Prozent (Tab. Cr.5 ).

In einigen Ländern studieren im Tertiärbereich B mehr Studierende Teilzeit als Vollzeit. In Australien, Neuseeland, den Niederlanden und den Vereinigten Staaten entschieden sich mehr als 50 Prozent der Studierenden in diesem Bildungsbereich für ein Teilzeitstudium und in der Schweiz und dem Vereinigten Königreich mehr als 7o Prozent.

In Polen, Schweden und der Russischen Föderation entschieden sich mehr als 50 Prozent der Studierenden im Tertiärbereich A und in weiterführenden forschungsorientierten Studiengängen für ein Teilzeitstudium - dies ist deutlich mehr als im OECD-Durchschnitt (2I Prozent). In Argentinien, Finnland, Neuseeland, der Slowakei, Ungarn und den Vereinigten Staaten entschieden sich mehr als 30 Prozent der Studierenden in diesen Bildungsbereichen für ein Teilzeitstudium.

\section{Die relative Größe des privaten und öffentlichen Sektors}

In den meisten Ländern findet Bildung vom Primarbereich bis zum Tertiärbereich überwiegend in öffentlichen Bildungseinrichtungen statt. In den OECD-Ländern waren 20II durchschnittlich 89 Prozent der Schüler im Primarbereich, 86 Prozent der Schüler im Sekundarbereich I und 8I Prozent der Schüler im Sekundarbereich II an öffentlichen Schulen. Rund 97 Prozent aller Schüler im Sekundarbereich I und 95 Prozent aller Schüler im Sekundarbereich II gingen entweder in eine öffentliche oder in eine staatlich subventionierte private Schule.

Je höher das Bildungsniveau, desto größer der Anteil vollständig privater Bildungseinrichtungen. Im Primarbereich beispielsweise sind etwas weniger als 3 Prozent der Schüler an vollständig privaten Bildungseinrichtungen, während dieser Anteil im Sekundarbereich I etwas mehr als 3 Prozent und im Sekundarbereich II mehr als 5 Prozent beträgt. Im Tertiärbereich ist der Anteil der Studierenden, die in privaten Bildungseinrichtungen eingeschrieben sind, deutlich größer. Im Tertiärbereich B sind rund 20 Prozent der Studierenden, im Tertiärbereich A und in weiterführenden forschungsorientierten Studiengängen I5 Prozent der Studierenden in vollständig privaten Bildungseinrichtungen eingeschrieben. Betrachtet man die vollständig privaten und staatlich subventionierten privaten Bildungseinrichtungen des Tertiärbereichs zusammen, so lässt sich feststellen, dass mehr als 4I Prozent der Studierenden im Tertiärbereich B und mindestens 29 Prozent im Tertiärbereich A und den weiterführenden forschungsorientierten Studiengängen eingeschrieben sind (Tab. Cr.4 und CI.5). 
Das Vereinigte Königreich ist das einzige Land, das angibt, dass Ioo Prozent aller Studierenden im Tertiärbereich B und im Tertiärbereich A sowie den weiterführenden forschungsorientierten Studiengängen an staatlich subventionierten privaten Bildungseinrichtungen eingeschrieben sind (Tab. Cr.5).

\section{Definitionen}

Die Bildungsgänge des Sekundarbereichs können anhand des Ausmaßes, in dem sie auf bestimmte Berufsfelder vorbereiten und zu einer auf dem Arbeitsmarkt verwertbaren Qualifikation führen, in drei Kategorien unterteilt werden:

Bei kombinierten schulischen und betrieblichen Bildungsgängen werden weniger als 75 Prozent des Lehrplans in der Bildungseinrichtung oder in einem Fernkurs behandelt. Diese Bildungsgänge können in Zusammenarbeit mit den Bildungsbehörden oder Bildungseinrichtungen angeboten werden; zu ihnen zählen auch die dualen Bildungsgänge, die Ausbildung in der Schule und am Arbeitsplatz nebeneinander beinhalten, sowie Bildungsgänge, die aus abwechselnden Phasen von Ausbildung in der Schule und am Arbeitsplatz bestehen (manchmal als „Sandwich-Bildungsgänge“ bezeichnet).

Allgemeinbildende Bildungsgänge sollen die Teilnehmer weder explizit auf bestimmte Berufsfelder noch auf den Eintritt in einen weiterführenden berufsbildenden oder fachspezifischen Bildungsgang vorbereiten (weniger als 25 Prozent des Inhalts des Bildungsgangs sind berufs- oder fachspezifisch).

Berufsuorbereitende Bildungsgänge sollen den Teilnehmern hauptsächlich als Einführung in die Arbeitswelt dienen und sie für den späteren Eintritt in einen berufsbildenden oder fachspezifischen Bildungsgang vorbereiten. Durch den erfolgreichen Abschluss dieser Bildungsgänge wird keine auf dem Arbeitsmarkt direkt verwertbare berufliche oder fachspezifische Qualifikation erworben (mindestens 25 Prozent des Inhalts des Bildungsgangs sind berufsbildend oder fachspezifisch).

Das Ausmaß der berufsbildenden bzw. allgemeinbildenden Ausrichtung des Bildungsganges ist nicht unbedingt ausschlaggebend dafür, ob die Teilnehmer eine Zugangsberechtigung für den Tertiärbereich erwerben. In verschiedenen OECD-Ländern haben Bildungsgänge mit berufsbildender Ausrichtung auch das Ziel, auf ein späteres Studium im Tertiärbereich vorzubereiten, während in anderen Ländern wiederum Bildungsgänge mit allgemeinbildender Ausrichtung nicht automatisch den direkten Zugang zur Hochschulbildung ermöglichen.

In schulischen Ausbildungsgängen erfolgt der Unterricht (entweder teilweise oder ausschließlich) in Bildungseinrichtungen. Dazu zählen u.a. spezielle Berufsausbildungszentren, die von öffentlichen oder privaten Stellen betrieben werden, und betriebliche Ausbildungszentren, sofern diese als Bildungseinrichtungen anerkannt sind. Diese Bildungsgänge können eine Komponente der Ausbildung am Arbeitsplatz umfassen, um in gewissem Umfang praktische Erfahrung am Arbeitsplatz zu gewinnen. Ausbildungen gelten als schulische Ausbildungsgänge, wenn mindestens 75 Prozent des 
Lehrplans in der Bildungseinrichtung behandelt werden, wobei Fernkurse eingeschlossen sein können.

Berufsbildende Bildungsgänge sollen die Teilnehmer auf die direkte Aufnahme einer Beschäftigung in bestimmten Berufsfeldern, ohne weitere berufliche Qualifizierung, vorbereiten. Durch den erfolgreichen Abschluss wird eine auf dem Arbeitsmarkt direkt verwertbare berufliche oder fachspezifische Qualifikation erworben.

Die berufsvorbereitenden und berufsbildenden Bildungsgänge können weiter in zwei Kategorien unterteilt werden - schulische Ausbildungen sowie kombinierte schulische und betriebliche Ausbildungen. Grundlage der Unterscheidung ist hierbei, inwieweit die Ausbildung einerseits in Bildungseinrichtungen und andererseits am Arbeitsplatz stattfindet.

\section{Angewandte Methodik}

Die Daten zur Bildungsbeteiligung beziehen sich auf das Schuljahr 2010/20II und beruhen auf der alljährlich von der OECD durchgeführten UOE-Datenerhebung zur Bildungsstatistik.

Die Zahlen basieren auf Personenzahlen (außer wenn etwas anderes angegeben ist), d. h., es wird nicht zwischen Vollzeit- und Teilzeitlernenden unterschieden, da in einigen Ländern entsprechende Teilzeitkonzepte/-modelle nicht anerkannt werden. In einigen OECD-Ländern wird die Teilzeitausbildung nur teilweise in den zur Verfügung gestellten Daten erfasst.

Die Berechnung der in den Tabellen Cr.ra und Cr.2 verwendeten Netto-Bildungsbeteiligung (ausgedrückt in Prozent) erfolgte, indem die Zahl der Lernenden einer bestimmten Altersgruppe in allen Bildungsbereichen durch die Gesamtzahl der Personen in der entsprechenden Altersgruppe in der Bevölkerung dividiert wurde. In Tabelle Cr.Ib (im Internet) wird die Netto-Bildungsbeteiligung für Schüler/Studierende in einem bestimmten Bildungsbereich berechnet.

In Tabelle Cr.2 basieren die Daten zur Entwicklung der Bildungsbeteiligung für die Jahre I995, 2000, 2001, 2002, 2003 und 2004 auf einer speziellen Erhebung, die im Januar 2007 in den OECD-Ländern und vier der damals sechs Partnerländer durchgeführt wurde (Brasilien, Chile, Israel und der Russischen Föderation).

$\mathrm{Zu}$ erwartende Jahre in Ausbildung werden als Anteil der Bevölkerung berechnet, der in einem spezifischen Alter am Bildungssystem teilnimmt, zusammengefasst für eine Altersgruppe. Hierbei wird im Wesentlichen davon ausgegangen, dass jeder Altersjahrgang mit vollständiger Bildungsbeteiligung einem vollen Jahr der erwarteten Bildungsbeteiligung für eine Person unterhalb dieses Altersjahrgangs entspricht.

Die statistischen Daten für Israel wurden von den zuständigen israelischen Stellen bereitgestellt, die für sie verantwortlich zeichnen. Die Verwendung dieser Daten durch 
die OECD erfolgt unbeschadet des völkerrechtlichen Status der Golanhöhen, von OstJerusalem und der israelischen Siedlungen im Westjordanland.

\section{Weiterführende Informationen}

Hanushek, E., L. Woessmann and L. Zhang, (20II), „General Education, Vocational Education, and Labor-Market Outcomes over the Life-Cycle“, IZA-Diskussionspapier Nr. 6083, Forschungsinstitut zur Zukunft der Arbeit, Oktober 201 I.

OECD (2010a), PISA 2009 Ergebnisse: Potenziale nutzen und Chancengerechtigkeit sichern - Sozialer Hintergrund und Schülerleistungen (Band II), http://dx.doi.org/10.1787/9789264095359de.

OECD (2010b), Learning for Jobs, OECD Reviews of Vocational Education and Training, OECD Publishing, http://dx.doi.org/10.1787/9789264087460-en.

OECD (20II), Equity and Quality in Education: Supporting Disadvantaged Students and Schools, OECD Publishing, http://dx.doi.org/10.1787/9789264130852-en.

OECD (20I2a), „How Has the Global Economic Crisis Affected People with Different Levels of Education?", Education Indicators in Focus, No. I, OECD Publishing, http://dx.doi. org/10.1787/5 kgfgpwlc6so-en.

OECD (2012b), „How Well Are Countries Educating Young People to the Level Needed for a Job and a Living Wage?", Education Indicators in Focus, No. 7, OECD Publishing, http://dx.doi.org/10.1787/5kg1d4fsqjow-en.

OECD (2012c), Closing the Gender Gap: Act Now, OECD Publishing, http://dx.doi.org/10.1787/ 9789264179370-en.

OECD (2013), Trends Shaping Education 2013, OECD Publishing, http:/|dx.doi.org/10.1787| trends_edu-2013-en.

\section{Tabellen Indikator C1}

Tabelle Cr.ra: Bildungsbeteiligung, nach Alter (20II)

StatLink: http:||dx.doi.org/10.1787/888932850281

WEB Table Cr.Ib: Transition characteristics from age 15 to 20 , by level of education (Übergangscharakteristika bei I5- bis 20-Jährigen, nach Bildungsbereich) (20II)

StatLink: http:||dx.doi.org/10.1787/888932850300

Tabelle Cr.2: Entwicklung der Bildungsbeteiligung (I995-20II)

StatLink: http:||dx.doi.org/10.1787/888932850319 
Tabelle Cr.3: Bildungsbeteiligung im Sekundarbereich II und im postsekundaren, nicht tertiären Bereich (20II)

StatLink: http://dx.doi.org/10.1787/888932850338

- Tabelle Cr.4: Verteilung der Schüler im Primar- und Sekundarbereich (in \%), nach Art der Bildungseinrichtung sowie Vollzeit- oder Teilzeitausbildung (20II)

StatLink: http:/|dx.doi.org/10.1787/888932850357

Tabelle CI.5: Verteilung der Studierenden im Tertiärbereich (in \%), nach Art der Bildungseinrichtung sowie Vollzeit- oder Teilzeitstudium (20II)

StatLink: http://dx.doi.org/10.1787/888932850376

Tabelle Cr.6a: Zu erwartende Jahre in Ausbildung für 5- bis 39-Jährige (20II)

StatLink: http://dx.doi.org/10.1787/888932850414

WEB Table Cr.6b: Expected years in education from the age of 5 ( $\mathrm{Zu}$ erwartende Jahre in Ausbildung ab dem Alter von 5 Jahren) (20II)

StatLink: http://dx.doi.org/10.1787/888932850433

WEB Table Cr.6c: Expected years in tertiary education (Zu erwartende Jahre Ausbildung im Tertiärbereich) (20II)

StatLink: http://dx.doi.org/10.1787/888932850452 
Bildungsbeteiligung, nach Alter (2011)

Voll- und Teilzeitschüler/-studierende an öffentlichen und privaten Bildungseinrichtungen

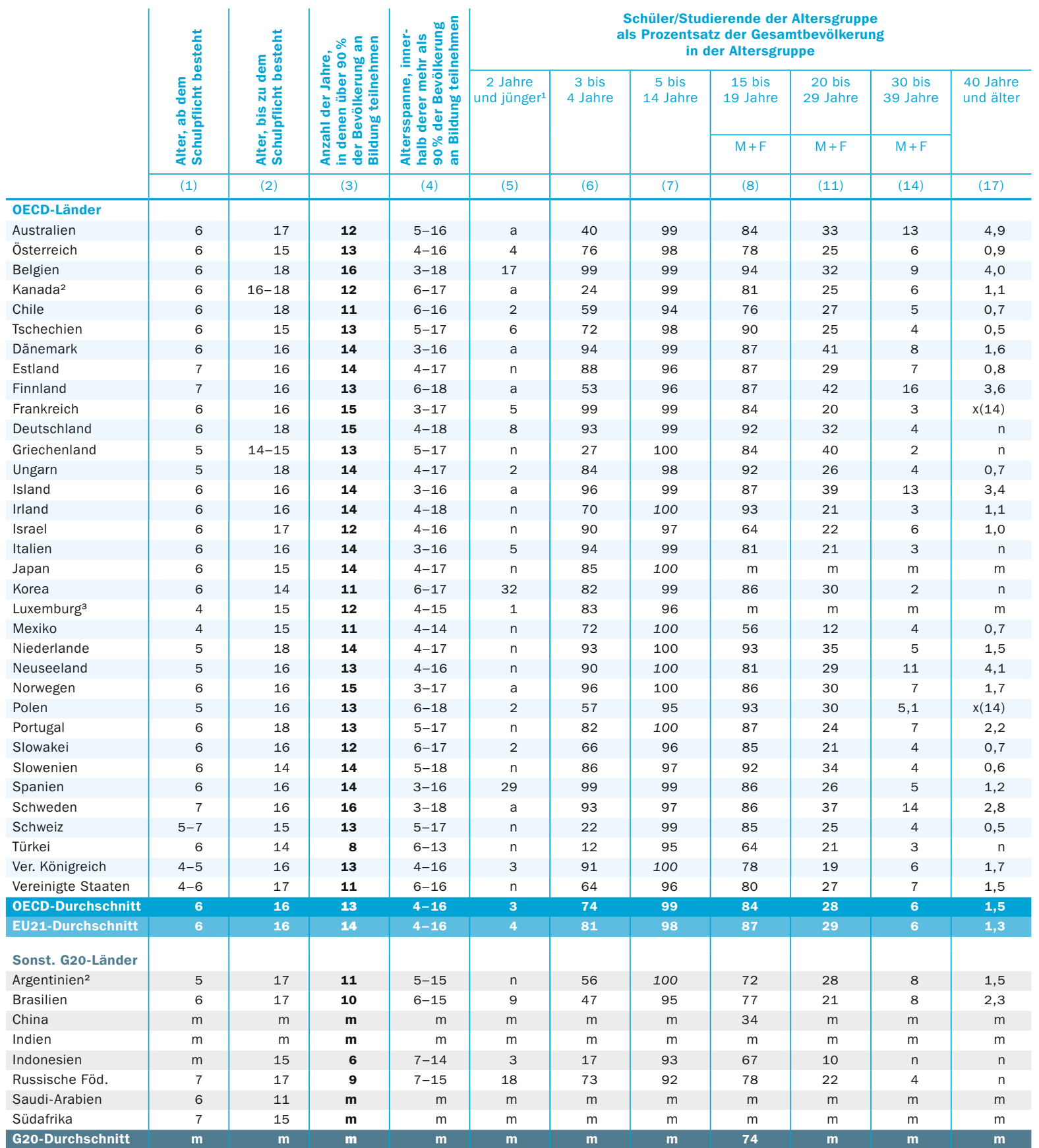

Anmerkung: Alter, bis zu dem Schulpflicht besteht, ist das Alter, in dem die Schulpflicht endet. So bedeutet beispielsweise eine Altersangabe von 18 (Jahren) in dieser Spalte, dass Schüler unter 18 Jahren gesetzlich zum Schulbesuch verpflichtet sind. Unterschiede im Erhebungsbereich der Bevölkerungsdaten und der Beteiligungsdaten bedeuten, dass die Teilnahmedaten von Ländern mit einem Nettoabgang von Schülern/Studierenden wie z. B. Luxemburg wohl zu niedrig angesetzt und Länder mit einem Nettozugang von Schülern/Studierenden wohl zu hoch angesetzt sind. Berechnete Beteiligungsquoten von über $100 \%$ sind kursiv angegeben. Die Beteiligungsquoten nach Geschlecht für die 15- bis 19-Jährigen, 20- bis 29-Jährigen und 30- bis 39-Jährigen stehen im Internet zur Verfügung (s. StatLink unten).

1. Nur institutionalisierter Elementarbereich. Dies ist aber nicht die einzige Form qualitativ hochwertiger frühkindlicher Bildung für Kinder unter 3 Jahren. Daher sollten Schlussfolgerungen hinsichtlich des Zugangs zu frühkindlicher Bildung und Betreuung und deren Qualität mit Vorsicht gezogen werden. In Ländern mit einem integrierten System aus frühkindlicher Bildung und Kinderbetreuung wird die Bildungsbeteiligung von Kindern im Alter von 2 Jahren und darunter mit „a“ (nicht anwendbar) angegeben. 2. Referenzjahr 2010. 3. Zu niedrig angesetzt, da viele in dem Land ansässige Schüler in Nachbarländern zur Schule gehen. Quelle: OECD. Argentinien, China, Indien, Indonesien, Saudi-Arabien und Südafrika: Statistikinstitut der UNESCO (World Education Indicators Programme). Hinweise s. Anhang 3 unter www.oecd.org/edu/eag.htm. StatLink: http://dx.doi.org/10.1787/888932850281 Erläuterung der Kennzeichnung fehlender Daten s. Hinweise für den Leser. 
Entwicklung der Bildungsbeteiligung (1995-2011)

Voll- und Teilzeitschüler/-studierende an öffentlichen und privaten Bildungseinrichtungen

\begin{tabular}{|c|c|c|c|c|c|c|c|c|c|c|c|c|}
\hline & \multicolumn{6}{|c|}{ 15- bis 19-jährige Schüler/Studierende } & \multicolumn{6}{|c|}{ 20- bis 29-jährige Schüler/Studierende } \\
\hline & \multicolumn{6}{|c|}{ als Prozentsatz der Gesamtbevölkerung in der Altersgruppe } & \multicolumn{6}{|c|}{ als Prozentsatz der Gesamtbevölkerung in der Altersgruppe } \\
\hline & 1995 & 2000 & 2005 & 2009 & 2010 & 2011 & 1995 & 2000 & 2005 & 2009 & 2010 & 2011 \\
\hline \multicolumn{13}{|l|}{ OECD-Länder } \\
\hline Australien & $\mathrm{m}$ & $\mathrm{m}$ & $\mathrm{m}$ & 80 & 81 & 84 & 23 & 28 & 33 & 32 & 32 & 33 \\
\hline Österreich & 75 & 77 & 80 & 79 & 78 & 78 & 16 & 18 & 19 & 23 & 25 & 25 \\
\hline Belgien & 94 & 91 & 94 & 93 & 93 & 94 & 24 & 25 & 29 & 30 & 30 & 32 \\
\hline Kanada & 80 & 81 & 80 & 81 & 81 & $\mathrm{~m}$ & 22 & 23 & 26 & 25 & 25 & $\mathrm{~m}$ \\
\hline Chile & 64 & 66 & 74 & 73 & 75 & 76 & $\mathrm{~m}$ & $\mathrm{~m}$ & $\mathrm{~m}$ & 23 & 25 & 27 \\
\hline Tschechien & 66 & 81 & 90 & 89 & 90 & 90 & 10 & 14 & 20 & 23 & 24 & 25 \\
\hline Dänemark & 79 & 80 & 85 & 84 & 85 & 87 & 30 & 35 & 38 & 37 & 38 & 41 \\
\hline Estland & $\mathrm{m}$ & $\mathrm{m}$ & 87 & 85 & 87 & 87 & $\mathrm{~m}$ & $\mathrm{~m}$ & 27 & 26 & 28 & 29 \\
\hline Finnland & 81 & 85 & 87 & 87 & 87 & 87 & 28 & 38 & 43 & 41 & 42 & 42 \\
\hline Frankreich & 89 & 87 & 85 & 84 & 84 & 84 & 19 & 19 & 20 & 19 & 20 & 20 \\
\hline Deutschland & 88 & 88 & 89 & 88 & 89 & 92 & 20 & 24 & 28 & 30 & 31 & 32 \\
\hline Griechenland & 62 & 82 & 97 & $\mathrm{~m}$ & 83 & 84 & 13 & 16 & 24 & $\mathrm{~m}$ & 40 & 40 \\
\hline Ungarn & 64 & 78 & 87 & 90 & 92 & 92 & 10 & 19 & 24 & 25 & 25 & 26 \\
\hline Island & 79 & 79 & 85 & 85 & 88 & 87 & 24 & 31 & 37 & 35 & 38 & 39 \\
\hline Irland & 79 & 81 & 89 & 92 & 96 & 93 & 14 & 16 & 21 & 19 & 21 & 21 \\
\hline Israel & $\mathrm{m}$ & 64 & 65 & 64 & 65 & 64 & $\mathrm{~m}$ & $\mathrm{~m}$ & 20 & 22 & 22 & 22 \\
\hline Italien & $\mathrm{m}$ & 72 & 80 & 82 & 83 & 81 & $\mathrm{~m}$ & 17 & 20 & 21 & 21 & 21 \\
\hline Japan & $\mathrm{m}$ & $\mathrm{m}$ & $\mathrm{m}$ & $\mathrm{m}$ & $\mathrm{m}$ & $\mathrm{m}$ & $\mathrm{m}$ & $\mathrm{m}$ & $\mathrm{m}$ & $\mathrm{m}$ & $\mathrm{m}$ & $\mathrm{m}$ \\
\hline Korea & 75 & 79 & 86 & 87 & 86 & 86 & 15 & 24 & 27 & 29 & 30 & 30 \\
\hline Luxemburg ${ }^{1}$ & 73 & 74 & 72 & $\mathrm{~m}$ & 77 & $\mathrm{~m}$ & $\mathrm{~m}$ & 5 & 6 & $\mathrm{~m}$ & 13 & $\mathrm{~m}$ \\
\hline Mexiko & 36 & 42 & 48 & 52 & 54 & 56 & 8 & 9 & 11 & 11 & 12 & 12 \\
\hline Niederlande & 89 & 87 & 86 & 90 & 91 & 93 & 21 & 22 & 26 & 29 & 30 & 35 \\
\hline Neuseeland & 68 & 72 & 74 & 81 & 79 & 81 & 17 & 23 & 30 & 32 & 30 & 29 \\
\hline Norwegen & 83 & 86 & 86 & 86 & 86 & 86 & 25 & 28 & 29 & 29 & 29 & 30 \\
\hline Polen & 78 & 84 & 92 & 93 & 93 & 93 & 16 & 24 & 31 & 31 & 30 & 30 \\
\hline Portugal & 69 & 71 & 73 & 85 & 86 & 87 & 22 & 22 & 22 & 24 & 24 & 24 \\
\hline Slowakei & $\mathrm{m}$ & $\mathrm{m}$ & 85 & 85 & 85 & 85 & $\mathrm{~m}$ & $\mathrm{~m}$ & 16 & 20 & 21 & 21 \\
\hline Slowenien & $\mathrm{m}$ & $\mathrm{m}$ & 91 & 91 & 92 & 92 & $\mathrm{~m}$ & $\mathrm{~m}$ & 32 & 34 & 34 & 34 \\
\hline Spanien & 73 & 77 & 81 & 81 & 84 & 86 & 21 & 24 & 22 & 22 & 24 & 26 \\
\hline Schweden & 82 & 86 & 87 & 87 & 86 & 86 & 22 & 33 & 36 & 34 & 36 & 37 \\
\hline Schweiz & 80 & 83 & 83 & 85 & 85 & 85 & 15 & 19 & 22 & 23 & 24 & 25 \\
\hline Türkei & 30 & 28 & 41 & 53 & 56 & 64 & 7 & 5 & 10 & 15 & 20 & 21 \\
\hline Vereinigtes Königreich & $\mathrm{m}$ & $\mathrm{m}$ & $\mathrm{m}$ & 74 & 77 & 78 & $\mathrm{~m}$ & $\mathrm{~m}$ & $\mathrm{~m}$ & 17 & 18 & 19 \\
\hline Vereinigte Staaten & 72 & 73 & 79 & 81 & 82 & 80 & 19 & 20 & 23 & 24 & 26 & 27 \\
\hline OECD-Durchschnitt & 73 & 76 & 81 & 82 & 83 & 84 & 18 & 22 & 25 & 26 & 27 & 28 \\
\hline $\begin{array}{l}\text { OECD-Durchschnitt } \\
\text { für Länder mit ver- } \\
\text { fügbaren Daten für } \\
\text { alle Referenzjahre }\end{array}$ & 73 & 77 & 82 & 83 & 83 & 85 & 18 & 22 & 26 & 27 & 28 & 29 \\
\hline EU21-Durchschnitt & 78 & 81 & 86 & 86 & 87 & 87 & 19 & 22 & 25 & 27 & 27 & 29 \\
\hline \multicolumn{13}{|l|}{ Sonstige G20-Länder } \\
\hline Argentinien & $\mathrm{m}$ & $\mathrm{m}$ & $\mathrm{m}$ & 70 & 72 & $\mathrm{~m}$ & $\mathrm{~m}$ & $\mathrm{~m}$ & $\mathrm{~m}$ & 27 & 28 & $\mathrm{n}$ \\
\hline Brasilien & $\mathrm{m}$ & $\mathrm{m}$ & $\mathrm{m}$ & 75 & 76 & 77 & $\mathrm{~m}$ & $\mathrm{~m}$ & $\mathrm{~m}$ & 21 & 20 & 21 \\
\hline China & $\mathrm{m}$ & $\mathrm{m}$ & $\mathrm{m}$ & $\mathrm{m}$ & 33 & 34 & $\mathrm{~m}$ & $\mathrm{~m}$ & $\mathrm{~m}$ & $\mathrm{~m}$ & $\mathrm{~m}$ & $\mathrm{~m}$ \\
\hline Indien & $\mathrm{m}$ & $\mathrm{m}$ & $\mathrm{m}$ & $\mathrm{m}$ & $\mathrm{m}$ & $\mathrm{m}$ & $\mathrm{m}$ & $\mathrm{m}$ & $\mathrm{m}$ & $\mathrm{m}$ & $\mathrm{m}$ & $\mathrm{m}$ \\
\hline Indonesien & $\mathrm{m}$ & $\mathrm{m}$ & $\mathrm{m}$ & 62 & 60 & 67 & $\mathrm{~m}$ & $\mathrm{~m}$ & $\mathrm{~m}$ & $\mathrm{~m}$ & $\mathrm{~m}$ & 10 \\
\hline Russische Föderation & $\mathrm{m}$ & 71 & 74 & $\mathrm{~m}$ & $\mathrm{~m}$ & 78 & $\mathrm{~m}$ & $\mathrm{~m}$ & 19 & $\mathrm{~m}$ & $\mathrm{~m}$ & 22 \\
\hline Saudi-Arabien & $\mathrm{m}$ & $\mathrm{m}$ & $\mathrm{m}$ & $\mathrm{m}$ & 87 & $\mathrm{~m}$ & $\mathrm{~m}$ & $\mathrm{~m}$ & $\mathrm{~m}$ & $\mathrm{~m}$ & 19 & $\mathrm{~m}$ \\
\hline Südafrika & $\mathrm{m}$ & $\mathrm{m}$ & $\mathrm{m}$ & $\mathrm{m}$ & $\mathrm{m}$ & $\mathrm{m}$ & $\mathrm{m}$ & $\mathrm{m}$ & $\mathrm{m}$ & $\mathrm{m}$ & $\mathrm{m}$ & $\mathrm{m}$ \\
\hline G20-Durchschnitt & m & m & m & m & 73 & 74 & m & m & $\mathbf{m}$ & m & m & $\mathbf{m}$ \\
\hline
\end{tabular}

Anmerkung: Die Spalten mit den Angaben für 2001, 2002, 2003, 2004, 2006, 2007 und 2008 sind im Internet verfügbar (s. StatLink unten). Quelle: OECD. Argentinien, China, Indonesien und Saudi-Arabien: Statistikinstitut der UNESCO (World Education Indicators Programme). Hinweise s. Anhang 3 unter www.oecd.org/edu/eag.htm. StatLink: http://dx.doi.org/10.1787/888932850319 Erläuterung der Kennzeichnung fehlender Daten s. Hinweise für den Leser. 


\section{Tabelle C1.3}

Bildungsbeteiligung im Sekundarbereich II und im postsekundaren, nicht tertiären Bereich (2011)

Bildungsbeteiligung an öffentlichen und privaten Bildungseinrichtungen, nach Ausrichtung des Bildungsgangs, Altersgruppe sowie Vollzeit-/Teilzeitausbildung

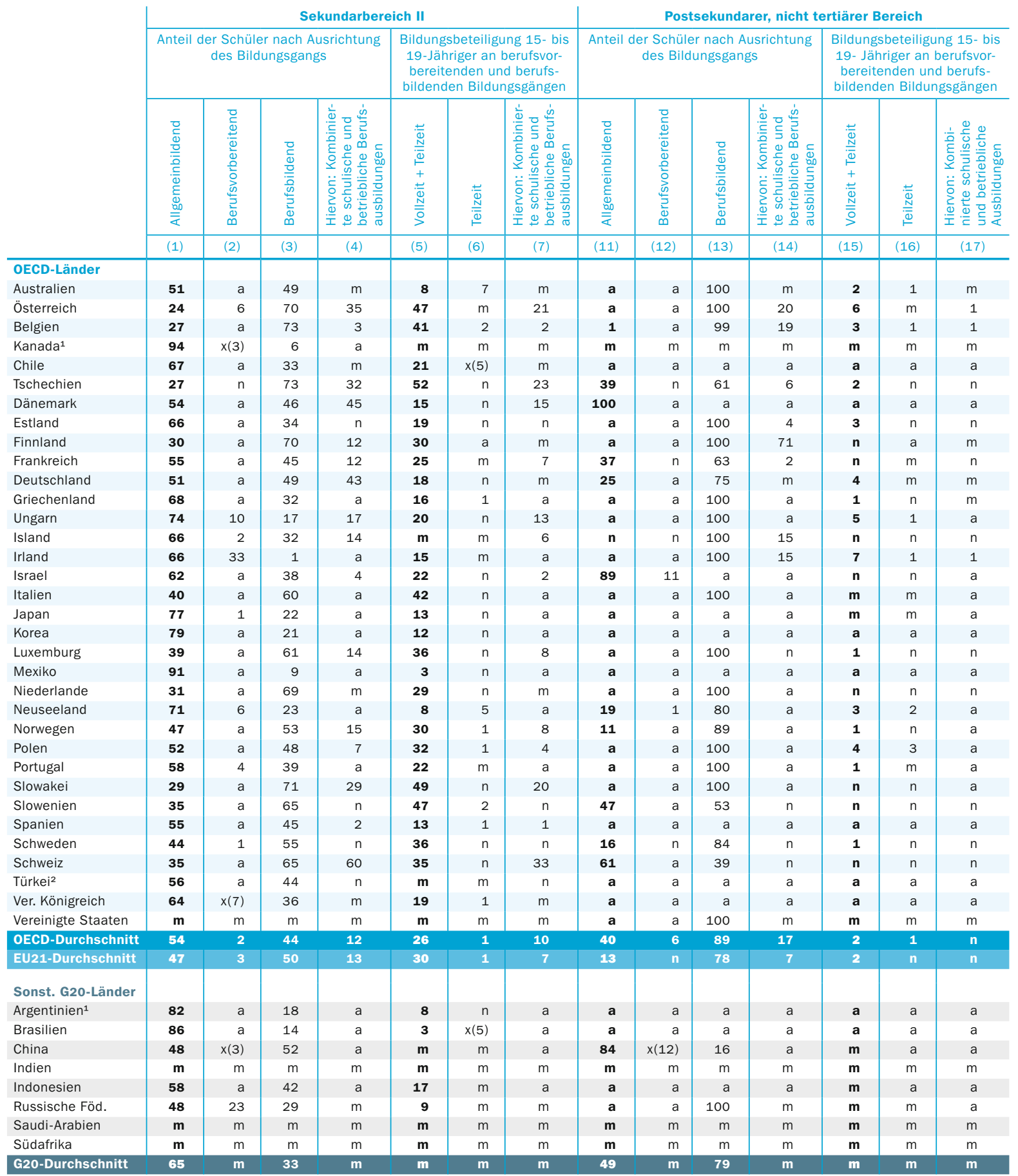

Anmerkung: Bei einem Vergleich der Beteiligungsquoten in diesem Bildungsbereich ist die unterschiedliche Dauer der Bildungsgänge im Sekundarbereich II in den einzelnen Ländern zu berücksichtigen. Spalten mit den Angaben zur Bildungsbeteiligung von 20- bis 24-Jährigen in berufsbildenden Bildungsgängen des Sekundarbereichs II sowie von 25- bis 29-Jährigen in berufsbildenden postsekundaren, nicht tertiären Bildungsgängen sind im Internet verfügbar (s. StatLink unten). Die Spalten (7), (10) im Internet, (17) und (20) im Internet basieren auf der geschätzten Zahl an Schülern in kombinierten schulischen und betrieblichen Berufsausbildungen für die jeweiligen Altersgruppen.

1. Referenzjahr 2010. 2. Ohne ISCED 3C.

Quelle: OECD. Argentinien, China und Indonesien: Statistikinstitut der UNESCO (World Education Indicators Programme).

Hinweise s. Anhang 3 unter www.oecd.org/edu/eag.htm. StatLink: http://dx.doi.org/10.1787/888932850338

Erläuterung der Kennzeichnung fehlender Daten s. Hinweise für den Leser. 
Tabelle C1.4

Verteilung der Schüler im Primar- und Sekundarbereich (in \%), nach Art der Bildungseinrichtung sowie Vollzeitoder Teilzeitausbildung (2011)

\begin{tabular}{|c|c|c|c|c|c|c|c|c|c|c|c|}
\hline & \multicolumn{9}{|c|}{ Art der Bildungseinrichtung } & \multirow{2}{*}{\multicolumn{2}{|c|}{$\begin{array}{c}\begin{array}{c}\text { Vollzeit-/Teilzeit- } \\
\text { ausbildung }\end{array} \\
\text { Primar- und } \\
\text { Sekundarbereich }\end{array}$}} \\
\hline & \multicolumn{3}{|c|}{ Primarbereich } & \multicolumn{3}{|c|}{ Sekundarbereich I } & \multicolumn{3}{|c|}{ Sekundarbereich II } & & \\
\hline & Öffentlich & \begin{tabular}{|c|} 
Staatlich \\
subventio- \\
niert privat
\end{tabular} & $\begin{array}{l}\text { Unabhän- } \\
\text { gig privat }\end{array}$ & Öffentlich & \begin{tabular}{|c|} 
Staatlich \\
subventio- \\
niert privat
\end{tabular} & $\begin{array}{l}\text { Unabhän- } \\
\text { gig privat }\end{array}$ & Öffentlich & \begin{tabular}{|c|} 
Staatlich \\
subventio- \\
niert privat
\end{tabular} & $\begin{array}{l}\text { Unabhän- } \\
\text { gig privat }\end{array}$ & Vollzeit & Teilzeit \\
\hline & (1) & $(2)$ & (3) & (4) & (5) & (6) & $(7)$ & (8) & (9) & $(10)$ & $(11)$ \\
\hline \multicolumn{12}{|l|}{ OECD-Länder } \\
\hline Australien ${ }^{1}$ & 69 & 31 & a & 64 & 36 & $\mathrm{~m}$ & 65 & 35 & $n$ & 83 & 17 \\
\hline Österreich & 94 & 6 & $x(2)$ & 91 & 9 & $x(5)$ & 90 & 10 & $x(8)$ & 100 & $\mathrm{n}$ \\
\hline Belgien & 46 & 54 & $\mathrm{~m}$ & 39 & 61 & $\mathrm{~m}$ & 43 & 57 & $\mathrm{~m}$ & 80 & 20 \\
\hline Kanada ${ }^{2}$ & 94 & 6 & $x(2)$ & 91 & 9 & $x(5)$ & 94 & 6 & $x(8)$ & 100 & a \\
\hline Chile & 41 & 52 & 7 & 46 & 47 & 7 & 39 & 54 & 7 & 100 & a \\
\hline Tschechien & 98 & 2 & a & 97 & 3 & a & 86 & 14 & a & 100 & $\mathrm{n}$ \\
\hline Dänemark & 86 & 14 & $\mathrm{n}$ & 73 & 26 & 1 & 98 & 2 & $\mathrm{n}$ & 97 & 3 \\
\hline Estland & 96 & $a$ & 4 & 96 & a & 4 & 97 & a & 3 & 95 & 5 \\
\hline Finnland & 98 & 2 & a & 95 & 5 & a & 82 & 18 & a & 100 & $a$ \\
\hline Frankreich & 85 & 14 & 1 & 78 & 22 & $\mathrm{n}$ & 69 & 31 & 1 & 100 & $\mathrm{~m}$ \\
\hline Deutschland & 96 & 4 & $x(2)$ & 91 & 9 & $x(5)$ & 92 & 8 & $x(8)$ & 100 & $\mathrm{n}$ \\
\hline Griechenland & 93 & a & 7 & 95 & $a$ & 5 & 96 & a & 4 & 98 & 2 \\
\hline Ungarn & 91 & 9 & a & 90 & 10 & a & 78 & 22 & a & 95 & 5 \\
\hline Island & 98 & 2 & $\mathrm{n}$ & 99 & 1 & $\mathrm{n}$ & 80 & 19 & 1 & 91 & 9 \\
\hline Irland & 99 & a & 1 & 100 & a & a & 98 & a & 2 & 100 & $\mathrm{n}$ \\
\hline Israel & 78 & 22 & $a$ & 84 & 16 & a & 93 & 7 & a & 100 & a \\
\hline Italien & 93 & a & 7 & 96 & a & 4 & 89 & 6 & 5 & 99 & 1 \\
\hline Japan & 99 & $\mathrm{a}$ & 1 & 93 & $\mathrm{a}$ & 7 & 69 & $\mathrm{a}$ & 31 & 99 & 1 \\
\hline Korea & 99 & a & 1 & 82 & 18 & a & 55 & 45 & a & 100 & a \\
\hline Luxemburg & 91 & $n$ & 9 & 81 & 10 & 8 & 84 & 7 & 9 & 100 & $n$ \\
\hline Mexiko & 92 & a & 8 & 89 & a & 11 & 83 & a & 17 & 100 & a \\
\hline Niederlande & 100 & $\mathrm{a}$ & $n$ & 97 & a & 3 & 92 & a & 8 & 97 & 3 \\
\hline Neuseeland & 98 & $n$ & 2 & 95 & $n$ & 5 & 83 & 9 & 8 & 91 & 9 \\
\hline Norwegen & 98 & 2 & $x(2)$ & 97 & 3 & $x(5)$ & 88 & 12 & $x(8)$ & 98 & 2 \\
\hline Polen & 97 & 1 & 2 & 95 & 1 & 3 & 85 & 1 & 13 & 94 & 6 \\
\hline Portugal & 88 & 4 & 8 & 84 & 6 & 10 & 78 & 5 & 17 & 100 & $\mathrm{~m}$ \\
\hline Slowakei & 94 & 6 & $\mathrm{n}$ & 94 & 6 & $\mathrm{n}$ & 86 & 14 & $n$ & 99 & 1 \\
\hline Slowenien & 100 & $\mathrm{n}$ & $\mathrm{n}$ & 100 & $n$ & $\mathrm{n}$ & 96 & 2 & 2 & 94 & 6 \\
\hline Spanien & 68 & 28 & 4 & 69 & 28 & 3 & 79 & 12 & 9 & 91 & 9 \\
\hline Schweden & 91 & 9 & $\mathrm{n}$ & 87 & 13 & $\mathrm{n}$ & 83 & 17 & $\mathrm{n}$ & 84 & 16 \\
\hline Schweiz & 95 & 2 & 3 & 92 & 3 & 5 & 89 & 7 & 4 & 100 & $\mathrm{n}$ \\
\hline Türkei & 98 & $a$ & 2 & $\mathbf{a}$ & a & a & 97 & a & 3 & 100 & $\mathrm{~m}$ \\
\hline Vereinigtes Königreich & 95 & $\mathrm{n}$ & 5 & 71 & 23 & 6 & 48 & 46 & 5 & 96 & 4 \\
\hline Vereinigte Staaten & 91 & a & 9 & 92 & a & 8 & 92 & a & 8 & 100 & a \\
\hline OECD-Durchschnitt & 89 & 8 & 3 & 86 & 11 & 3 & 81 & 14 & 5 & 97 & 4 \\
\hline EU21-Durchschnitt & 90 & 7 & 3 & 86 & 11 & 3 & 83 & 13 & 4 & 96 & 4 \\
\hline \multicolumn{12}{|l|}{ Sonstige G20-Länder } \\
\hline Argentinien ${ }^{2}$ & 76 & 18 & 6 & 78 & 17 & 6 & 71 & 21 & 8 & 100 & $\mathrm{n}$ \\
\hline Brasilien & 86 & a & 14 & 89 & $\mathrm{a}$ & 11 & 84 & a & 16 & 100 & $\mathrm{~m}$ \\
\hline China & 95 & 5 & $x(2)$ & 92 & 8 & $x(5)$ & 88 & 12 & $x(8)$ & 98 & 2 \\
\hline Indien & m & $\mathrm{m}$ & $\mathrm{m}$ & m & $\mathrm{m}$ & $\mathrm{m}$ & m & $\mathrm{m}$ & $\mathrm{m}$ & m & $\mathrm{m}$ \\
\hline Indonesien & 83 & a & 17 & 64 & a & 36 & 51 & a & 49 & 100 & a \\
\hline Russische Föderation & 99 & a & 1 & 100 & a & $n$ & 99 & a & 1 & 100 & $n$ \\
\hline Saudi-Arabien & m & $\mathrm{m}$ & $\mathrm{m}$ & m & $\mathrm{m}$ & $\mathrm{m}$ & m & $\mathrm{m}$ & $\mathrm{m}$ & m & $\mathrm{m}$ \\
\hline Südafrika & m & $\mathrm{m}$ & $\mathrm{m}$ & m & $\mathrm{m}$ & $\mathrm{m}$ & m & $\mathrm{m}$ & $\mathrm{m}$ & m & $\mathrm{m}$ \\
\hline G20-Durchschnitt & 91 & 11 & $\mathbf{m}$ & 85 & 18 & $\mathbf{m}$ & 78 & 23 & $\mathbf{m}$ & 98 & 3 \\
\hline
\end{tabular}

1. Ohne unabhängige private Bildungseinrichtungen. 2. Referenzjahr 2010.

Quelle: OECD. Argentinien, China und Indonesien: Statistikinstitut der UNESCO (World Education Indicators Programme).

Hinweise s. Anhang 3 unter www.oecd.org/edu/eag.htm. StatLink: http://dx.doi.org/10.1787/888932850357

Erläuterung der Kennzeichnung fehlender Daten s. Hinweise für den Leser. 
Verteilung der Studierenden im Tertiärbereich (in \%), nach Art der Bildungseinrichtung sowie Vollzeitoder Teilzeitstudium (2011)

\begin{tabular}{|c|c|c|c|c|c|c|c|c|c|c|c|c|c|c|}
\hline & \multicolumn{6}{|c|}{ Art der Bildungseinrichtung } & \multicolumn{8}{|c|}{ Vollzeit-/Teilzeitstudium } \\
\hline & \multicolumn{3}{|c|}{ Tertiärbereich B } & \multicolumn{3}{|c|}{$\begin{array}{c}\text { Tertiärbereich A und } \\
\text { weiterführende forschungs- } \\
\text { orientierte Studiengänge }\end{array}$} & \multicolumn{4}{|c|}{ Tertiärbereich B } & \multicolumn{4}{|c|}{$\begin{array}{l}\text { Tertiärbereich A und weiterführende } \\
\text { forschungsorientierte Studiengänge }\end{array}$} \\
\hline & \multirow{2}{*}{$\begin{array}{l}\text { Öffent- } \\
\text { lich }\end{array}$} & \multirow{2}{*}{$\begin{array}{l}\text { Staatlich } \\
\text { subven- } \\
\text { tioniert } \\
\text { privat }\end{array}$} & \multirow{2}{*}{$\begin{array}{l}\text { Unab- } \\
\text { hängig } \\
\text { privat }\end{array}$} & \multirow{2}{*}{$\begin{array}{l}\text { Öffent- } \\
\text { lich }\end{array}$} & \multirow{2}{*}{$\begin{array}{c}\text { Staatlich } \\
\text { subven- } \\
\text { tioniert } \\
\text { privat }\end{array}$} & \multirow{2}{*}{$\begin{array}{l}\text { Unab- } \\
\text { hängig } \\
\text { privat }\end{array}$} & \multirow{2}{*}{\begin{tabular}{|c|} 
Vollzeit \\
Männer \\
+ Frauen
\end{tabular}} & \multicolumn{3}{|c|}{ Teilzeitstudium } & \multirow{2}{*}{\begin{tabular}{|l|} 
Vollzeit \\
Männer \\
+ Frauen
\end{tabular}} & \multicolumn{3}{|c|}{ Teilzeitstudium } \\
\hline & & & & & & & & $M+F$ & Männer & Frauen & & $M+F$ & Männer & Frauen \\
\hline & (1) & (2) & (3) & (4) & (5) & (6) & (7) & (8) & (9) & (10) & (11) & (12) & (13) & (14) \\
\hline OECD-Länder & & & & & & & & & & & & & & \\
\hline Australien & 72 & 20 & 9 & 96 & a & 4 & 45 & 55 & 54 & 56 & 71 & 29 & 28 & 30 \\
\hline Österreich & 73 & 27 & $x(2)$ & 85 & 15 & $x(5)$ & m & $\mathrm{m}$ & $\mathrm{m}$ & $\mathrm{m}$ & $\mathbf{m}$ & $\mathrm{m}$ & $\mathrm{m}$ & $\mathrm{m}$ \\
\hline Belgien ${ }^{1}$ & 42 & 58 & $\mathrm{~m}$ & 44 & 56 & $\mathrm{~m}$ & 63 & 37 & 40 & 35 & 83 & 17 & 19 & 16 \\
\hline Kanada $^{2}$ & $\mathbf{m}$ & $\mathrm{m}$ & $\mathrm{m}$ & $\mathbf{m}$ & $\mathrm{m}$ & $\mathrm{m}$ & 88 & 12 & 11 & 13 & 77 & 23 & 21 & 24 \\
\hline Chile & 5 & 3 & 93 & 26 & 21 & 54 & $\mathbf{m}$ & $\mathrm{m}$ & $\mathrm{m}$ & $\mathrm{m}$ & $\mathbf{m}$ & $\mathrm{m}$ & $\mathrm{m}$ & $\mathrm{m}$ \\
\hline Tschechien & 71 & 28 & 1 & 86 & a & 14 & 93 & 7 & 8 & 7 & 97 & 3 & 2 & 4 \\
\hline Dänemark & 97 & 3 & 1 & 98 & 2 & $\mathrm{n}$ & 65 & 35 & 32 & 38 & 90 & 10 & 9 & 12 \\
\hline Estland & 52 & 20 & 28 & $\mathbf{n}$ & 94 & 6 & 90 & 10 & 13 & 9 & 87 & 13 & 16 & 11 \\
\hline Finnland & 100 & $\mathrm{n}$ & a & 74 & 26 & a & 100 & a & a & a & 56 & 44 & 49 & 41 \\
\hline Frankreich & 69 & 10 & 21 & 83 & 1 & 16 & m & $\mathrm{m}$ & $\mathrm{m}$ & $\mathrm{m}$ & $\mathbf{m}$ & $\mathrm{m}$ & $\mathrm{m}$ & $\mathrm{m}$ \\
\hline Deutschland & 57 & 43 & $x(2)$ & 94 & 6 & $x(5)$ & 87 & 13 & 23 & 7 & 87 & 13 & 15 & 12 \\
\hline Griechenland & 100 & a & a & 100 & a & a & 100 & a & a & a & 100 & a & a & a \\
\hline Ungarn & 51 & 49 & a & 87 & 13 & a & 75 & 25 & 20 & 27 & 66 & 34 & 30 & 38 \\
\hline Island & 26 & 74 & $\mathrm{n}$ & 82 & 18 & $\mathrm{n}$ & 60 & 40 & 53 & 25 & 73 & 27 & 24 & 30 \\
\hline Irland & 98 & a & 2 & 95 & a & 5 & 74 & 26 & 21 & 33 & 88 & 12 & 12 & 13 \\
\hline Israel & 36 & 64 & a & 10 & 76 & 14 & 100 & a & a & a & 83 & 17 & 17 & 18 \\
\hline Italien & 86 & a & 14 & 92 & a & 2 & 100 & a & a & a & $\mathbf{m}$ & $\mathrm{m}$ & $\mathrm{m}$ & $\mathrm{m}$ \\
\hline Japan & 8 & a & 92 & 25 & a & 75 & 97 & 3 & 2 & 3 & 91 & 9 & 7 & 12 \\
\hline Korea & 2 & a & 98 & 25 & a & 75 & $\mathbf{m}$ & $\mathrm{m}$ & $\mathrm{m}$ & $\mathrm{m}$ & $\mathbf{m}$ & $\mathrm{m}$ & $\mathrm{m}$ & $\mathrm{m}$ \\
\hline Luxemburg & m & $\mathrm{m}$ & $\mathrm{m}$ & m & $\mathrm{m}$ & $\mathrm{m}$ & m & $\mathrm{m}$ & $\mathrm{m}$ & $\mathrm{m}$ & m & $\mathrm{m}$ & $\mathrm{m}$ & $\mathrm{m}$ \\
\hline Mexiko & 95 & a & 5 & 67 & a & 33 & 100 & a & a & a & 100 & a & a & a \\
\hline Niederlande & 8 & a & 92 & 88 & a & 12 & 36 & 64 & 55 & 71 & 82 & 18 & 17 & 19 \\
\hline Neuseeland & 59 & 37 & 4 & 97 & 3 & $n$ & 36 & 64 & 62 & 65 & 61 & 39 & 37 & 41 \\
\hline Norwegen & 44 & 29 & 27 & 86 & 5 & 10 & 50 & 50 & 34 & 59 & 74 & 26 & 23 & 28 \\
\hline Polen & 81 & a & 19 & 69 & a & 31 & 68 & 32 & 32 & 32 & 47 & 53 & 50 & 55 \\
\hline Portugal & 100 & a & $\mathrm{n}$ & 78 & a & 22 & m & $\mathrm{m}$ & $\mathrm{m}$ & $\mathrm{m}$ & $\mathbf{m}$ & $\mathrm{m}$ & $\mathrm{m}$ & $\mathrm{m}$ \\
\hline Slowakei & 75 & 25 & $\mathrm{n}$ & 83 & $\mathrm{n}$ & 17 & 79 & 21 & 16 & 23 & 65 & 35 & 30 & 38 \\
\hline Slowenien & 78 & 5 & 17 & 88 & 7 & 5 & 57 & 43 & 44 & 42 & 79 & 21 & 22 & 21 \\
\hline Spanien & 79 & 14 & 7 & 86 & $\mathrm{n}$ & 14 & 94 & 6 & 4 & 8 & 73 & 27 & 29 & 26 \\
\hline Schweden & 56 & 44 & $\mathrm{n}$ & 93 & 7 & $\mathrm{n}$ & 90 & 10 & 12 & 9 & 49 & 51 & 49 & 53 \\
\hline Schweiz & 33 & 35 & 32 & 95 & 3 & 2 & 29 & 71 & 77 & 62 & 88 & 12 & 14 & 10 \\
\hline Türkei & 97 & a & 3 & 94 & a & 6 & 100 & $n$ & $\mathrm{n}$ & $\mathrm{n}$ & 100 & $\mathrm{n}$ & $\mathrm{n}$ & $\mathrm{n}$ \\
\hline Ver. Königreich & a & 100 & $\mathrm{n}$ & a & 100 & $\mathrm{n}$ & 28 & 72 & 72 & 73 & 76 & 24 & 22 & 26 \\
\hline Vereinigte Staaten & 78 & a & 22 & 70 & a & 30 & 48 & 52 & 51 & 52 & 66 & 34 & 31 & 36 \\
\hline OECD-Durchschnitt & 59 & 21 & 20 & 71 & 14 & 15 & 73 & 27 & 26 & 27 & 78 & 22 & 21 & 23 \\
\hline EU21-Durchschnitt & 68 & 21 & 12 & 75 & 16 & 8 & 76 & 24 & 23 & 24 & 76 & 24 & 23 & 24 \\
\hline Sonst. G20-Länder & & & & & & & & & & & & & & \\
\hline Argentinien ${ }^{2}$ & 61 & 16 & 23 & 79 & a & 21 & 95 & 5 & 7 & 4 & 54 & 46 & 46 & 45 \\
\hline Brasilien & 15 & a & 85 & 30 & a & 70 & $\mathbf{m}$ & $\mathrm{m}$ & $\mathrm{m}$ & $\mathrm{m}$ & m & $\mathrm{m}$ & $\mathrm{m}$ & $\mathrm{m}$ \\
\hline China & $\mathbf{m}$ & $\mathrm{m}$ & $\mathrm{m}$ & m & $\mathrm{m}$ & $\mathrm{m}$ & 72 & 28 & 29 & 26 & 79 & 21 & 21 & 20 \\
\hline Indien & m & $\mathrm{m}$ & $\mathrm{m}$ & m & $\mathrm{m}$ & $\mathrm{m}$ & m & $\mathrm{m}$ & $\mathrm{m}$ & $\mathrm{m}$ & m & $\mathrm{m}$ & $\mathrm{m}$ & $\mathrm{m}$ \\
\hline Indonesien & 51 & a & 49 & 35 & a & 65 & 100 & a & a & a & 100 & a & a & a \\
\hline Russische Föd. ${ }^{3}$ & 95 & a & 5 & 83 & a & 17 & 67 & 33 & 36 & 31 & 48 & 52 & 48 & 54 \\
\hline Saudi-Arabien & 100 & $\mathrm{n}$ & $\mathrm{n}$ & 95 & 5 & $\mathrm{n}$ & 100 & $\mathrm{n}$ & $\mathrm{n}$ & $\mathrm{n}$ & 75 & 25 & 33 & 19 \\
\hline Südafrika & 100 & $\mathrm{~m}$ & $\mathrm{~m}$ & 100 & $\mathrm{~m}$ & $\mathrm{~m}$ & 100 & $\mathrm{n}$ & $\mathrm{n}$ & $\mathrm{n}$ & 100 & $\mathrm{n}$ & $\mathrm{n}$ & $\mathrm{n}$ \\
\hline G20-Durchschnitt & m & $\mathbf{m}$ & m & $\mathbf{m}$ & m & $\mathbf{m}$ & 82 & 18 & 19 & 18 & 80 & 20 & 19 & 20 \\
\hline
\end{tabular}

1. Ohne unabhängige private Bildungseinrichtungen. 2. Referenzjahr 2010. 3. Einschreibungen auf ISCED-Stufe 3B sind im Tertiärbereich B enthalten. Quelle: OECD. Argentinien, China, Indonesien, Saudi-Arabien und Südafrika: Statistikinstitut der UNESCO (World Education Indicators Programme). Hinweise s. Anhang 3 unter www.oecd.org/edu/eag.htm. StatLink: http://dx.doi.org/10.1787/888932850376 Erläuterung der Kennzeichnung fehlender Daten s. Hinweise für den Leser. 
Zu erwartende Jahre in Ausbildung für 5- bis 39-Jährige (2011)

Zu erwartende Jahre in Ausbildung unter gleichbleibenden Rahmenbedingungen des Bildungssystems im jeweiligen Land (ohne [Aus-]

Bildung von Kindern, die jünger als 5 Jahre sind, und Personen, die älter als 40 Jahre sind), nach Geschlecht und Voll-/Teilzeitausbildung

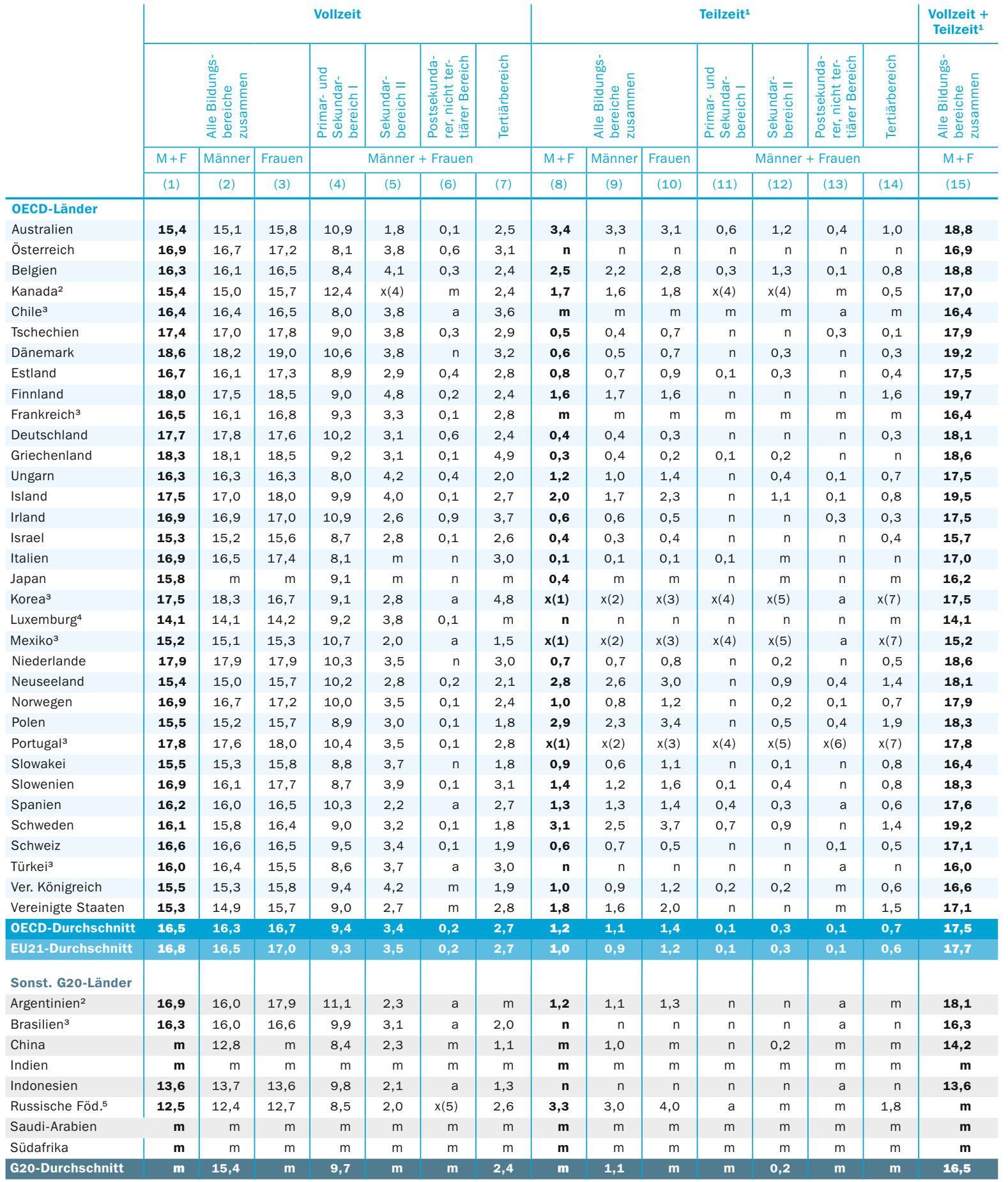

1. Die Angaben zu den zu erwartenden Jahren in Teilzeitausbildung sind mit Vorsicht zu interpretieren, da sie Unterschiede aufgrund unterschiedlicher Beteiligungsintensität in den einzelnen Ländern, Bildungsbereichen und Personen unterschiedlichen Alters widerspiegeln können. 2. Referenzjahr 2010.

3. Vollzeit und Teilzeit. 4. Eine hohe Zahl von Schülern/Studierenden, die ihre Ausbildung im Ausland absolvieren, und Immigration können sich auf die zu erwartenden Jahre in Ausbildung auswirken. 5. Einschreibungen auf ISCED-Stufe 3B sind im Tertiärbereich enthalten.

Quelle: OECD. Argentinien, China und Indonesien: Statistikinstitut der UNESCO (World Education Indicators Programme).

Hinweise s. Anhang 3 unter www.oecd.org/edu/eag.htm. StatLink: http://dx.doi.org/10.1787/888932850414

Erläuterung der Kennzeichnung fehlender Daten s. Hinweise für den Leser. 



\section{Welche Systeme zur frühkindlichen Bildung gibt es weltweit?}

In vielen OECD-Ländern wurden die Angebote im Bereich der frühkindlichen Bildung im Zusammenhang mit der veränderten Erwerbsquote von Frauen ausgeweitet. Ein verbesserter Zugang zu diesen Angeboten, ohne gleichzeitig ihre Qualität zu verbessern, ist jedoch keine Garantie für ein gutes Ergebnis für den Einzelnen und für die Gesellschaft.

Frühkindliche Bildung wird mit besseren Leistungen in der späteren schulischen Laufbahn in Verbindung gebracht. Im Alter von I5 Jahren erzielen Schüler, die mindestens ein Jahr an Unterricht im Elementarbereich teilgenommen haben, selbst nach Berücksichtigung des sozioökonomischen Hintergrunds bessere Ergebnisse bei der Schulleistungsstudie PISA als Schüler, die nicht an frühkindlicher Bildung teilgenommen haben.

In der Mehrzahl der OECD-Länder beginnt Bildung für die meisten Kinder inzwischen lange vor dem fünften Lebensjahr. In Belgien, Frankreich, Island, Italien, Norwegen, Schweden und Spanien nehmen mehr als go Prozent der 3-Jährigen an frühkindlicher Bildung teil.

In den OECD-Ländern nehmen mehr als drei Viertel aller 4-Jährigen (82 Prozent) an frühkindlicher Bildung teil, in den zur Europäischen Union gehörenden OECDLändern sind es 86 Prozent.

Abbildung C2.1

Bildungsbeteiligung 4-Jähriger im Elementar- und Primarbereich (2005 und 2011)

$\%$

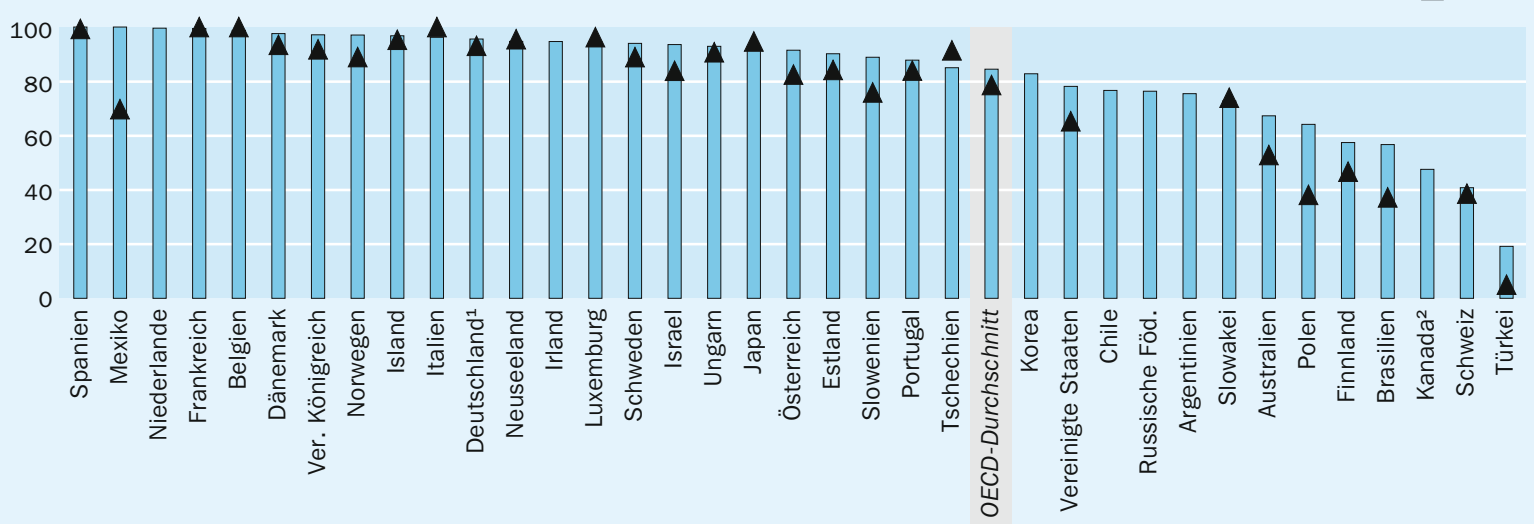

1. Referenzjahr 2006 anstelle 2005. 2. Referenzjahr 2010 anstelle 2011.

Anordnung der Länder in absteigender Reihenfolge der Bildungsbeteiligung 4-Jähriger im Jahr 2011.

Quelle: OECD. Argentinien: Statistikinstitut der UNESCO (World Education Indicators Programme). Tabelle C2.1.

Hinweise s. Anhang 3 unter www.oecd.org/edu/eag.htm. StatLink: http://dx.doi.org/10.1787/888932847393 


\section{Kontext}

Im Zuge sich verändernder Familienstrukturen ändert sich auch das relative Alter der Eltern. Mehr Frauen und Männer verlegen die Familiengründung auf einen späteren Zeitpunkt im Leben. Dies geschieht aus verschiedenen Gründen, u. a. aus einem Streben nach finanzieller Sicherheit und emotionaler Reife heraus, aufgrund einer längeren Suche nach einer stabilen Beziehung und des Wunsches nach einer beruflichen Karriere vor der Elternschaft. Da diese älteren Eltern wahrscheinlich auch erwerbstätig sind, besteht ein steigender Bedarf an frühkindlicher Betreuung. Ferner rückt die große Bedeutung der frühkindlichen Bildung für die kognitive und emotionale Entwicklung von Kindern immer stärker ins Bewusstsein. Daher hat in vielen Ländern die Gewährleistung der Qualität im Bereich der frühkindlichen Bildung und Betreuung politische Priorität erlangt.

Die Teilnahme an Angeboten zur frühkindlichen Bildung zu ermöglichen kann ferner für mehr Chancengleichheit sorgen und die schulischen Lernergebnisse insgesamt verbessern. Viele der in Bildungssystemen auftretenden Ungleichheiten sind bereits beim Eintritt der Schüler in das formale Bildungssystem offensichtlich und ziehen sich im Bildungsverlauf durch das gesamte Schulsystem hindurch (Entwisle et al., I997; Downey et al., 2004). Da sich die Ungleichheiten tendenziell verstärken, wenn die Unterrichtsteilnahme nicht verpflichtend ist, kann ein früherer Eintritt in das Schulsystem möglicherweise für mehr Chancengleichheit im Bildungsbereich sorgen. Darüber hinaus trägt der Besuch des Elementarbereichs zur Vorbereitung der Schüler auf den Eintritt in die formale Schulbildung und eine erfolgreiche schulische Laufbahn bei (Hart and Risely, I995; Heckman, 2000).

Das Bildungsangebot im Elementarbereich wird immer mehr ausgebaut; hierbei kommt es darauf an, die Bedürfnisse und Erwartungen der Eltern im Hinblick auf die Verfügbarkeit, die Kosten, die Qualität des Angebots und der Lehrkräfte sowie Rechenschaftspflichten zu berücksichtigen. Werden die Erwartungen der Eltern im Hinblick auf die Qualität des Angebots, Zugangsmöglichkeiten und Rechenschaftspflichten nicht erfüllt, kann es sein, dass einige Eltern für ihre Kinder tendenziell eher private Bildungs- und Betreuungseinrichtungen wählen oder ihre Kinder zu Zusatzangeboten außerhalb des formalen Bildungssystems schicken. Selbst bei staatlicher Förderung kann dies zu einer starken finanziellen Belastung der Eltern führen (Shin et al., 2009).

Es gibt in den OECD-Ländern viele verschiedene Systeme und Strukturen zur frühkindlichen Bildung und Betreuung. Entsprechend gibt es auch viele verschiedene Ansätze zur Unterscheidung zwischen Angeboten zur frühkindlichen Bildung und Angeboten zur Kinderbetreuung (s. Kasten C2.I). Diese Unterschiede sollten bei der Interpretation internationaler Vergleiche berücksichtigt werden.

\section{Weitere wichtige Ergebnisse}

\footnotetext{
Das Durchschnittsalter von Frauen bei der Geburt ihres ersten Kindes ist in den letzten 40 Jahren in allen OECD-Ländern gestiegen. Im Jahr 2009 war in Deutschland und dem Vereinigten Königreich das Durchschnittsalter bei der Geburt des ersten Kindes mit 30 Jahren am höchsten. Mexiko dagegen hatte mit etwas über 2I Jahren das jüngste Durchschnittsalter.
} 
Die öffentliche Finanzierung des Elementarbereichs ist in den europäischen Ländern der OECD tendenziell weiterentwickelt als in den nicht europäischen Ländern der OECD. Die private Finanzierung variiert erheblich zwischen den einzelnen Ländern und reicht von höchstens 5 Prozent in Belgien, Estland, Luxemburg und Schweden bis zu mindestens 25 Prozent in Argentinien, Australien, Japan, Korea, Österreich, Spanien und den Vereinigten Staaten.

Als Prozentsatz des BIP ausgedrückt belaufen sich die Ausgaben für den Elementarbereich auf durchschnittlich 0,6 Prozent des BIP. Zwischen den einzelnen Ländern gibt es große Unterschiede. Während beispielsweise in Australien und der Türkei höchstens o, I Prozent des BIP für den Elementarbereich ausgegeben werden, sind es in Dänemark, Island, Israel, Luxemburg, der Russischen Föderation und Spanien mindestens o,8 Prozent.

Die Schüler-Lehrkräfte-Relation ist auch ein wichtiger Indikator für die dem Elementarbereich bereitgestellten Ressourcen. Die Schüler-Lehrkräfte-Relation ohne nicht voll qualifizierte Beschäftigte (z. B. Hilfslehrkräfte) beträgt zwischen mehr als 20 Schülern pro Lehrkraft in Chile, China, Frankreich, Israel, Mexiko und der Türkei und weniger als 10 in Estland, Island, Neuseeland, Schweden und Slowenien.

Einige Länder bauen im Elementarbereich in starkem Maße auf Hilfslehrkräfte. I2 Länder weisen eine niedrigere Schüler-Kontaktpersonen-Relation als Schüler-LehrkräfteRelation aus. So ist die Schüler-Kontaktpersonen-Relation in Brasilien, Chile, China, Deutschland, Frankreich, Israel, Österreich, dem Vereinigten Königreich und den Vereinigten Staaten wesentlich niedriger als die Schüler-Lehrkräfte-Relation (um mindestens zwei Schüler).

\section{Entwicklungstendenzen}

In den letzten zehn Jahren wurde das Bildungsangebot im Elementarbereich in zahlreichen Ländern ausgeweitet. Diese verstärkte Fokussierung auf die frühkindliche Bildung hat in einigen Ländern zu einer Ausweitung der Schulpflicht auf jüngere Altersgruppen geführt, zu gebührenfreier Teilnahme an frühkindlicher Bildung, einem universellen Angebot an frühkindlicher Bildung und Betreuung sowie zur Einführung von Angeboten, bei denen die Betreuung der Kinder in formale Bildungsmaßnahmen im Elementarbereich integriert ist.

Im Durchschnitt der OECD-Länder mit Daten für 2005 und $201 \mathrm{I}$ ist im Bereich der frühkindlichen Bildung die Bildungsbeteiligung der 3-Jährigen von 64 Prozent im Jahr 2005 auf 70 Prozent im Jahr 201 I gestiegen. Für die 4-Jährigen gilt Ähnliches, hier stieg die Beteiligung von 78 Prozent im Jahr 2005 auf 84 Prozent im Jahr 20II. In Brasilien, Mexiko und Polen stieg die Beteiligung der 4-Jährigen an frühkindlicher Bildung zwischen 2005 und 201 I um mindestens 20 Prozentpunkte. 


\section{Analyse und Interpretationen}

In der Mehrheit der OECD-Länder verlief die Entwicklung der Bildungspolitik im Bereich der frühkindlichen Bildung und Betreuung parallel zur Entwicklung der Erwerbstätigkeit von Frauen. Bedingt durch das Wachstum der auf Wissen und Dienstleistungen basierenden Wirtschaft sind seit den I970er-Jahren immer mehr Frauen erwerbstätig. Da wirtschaftlicher Wohlstand von einer dauerhaft hohen Beschäftigungsquote abhängt, hat das Bestreben, mehr Frauen zu einem Eintritt in den Arbeitsmarkt zu bewegen, zu einem verstärkten staatlichen Interesse an einer Ausweitung der Dienstleistungen im Bereich der frühkindlichen Bildung und Betreuung geführt. Zwischen 1970 und 1990 haben insbesondere die europäischen Staaten eine familienfreundliche Politik mit neuen Bestimmungen zur Kinderbetreuung etabliert, um Paare zur Elternschaft zu ermutigen und für Frauen eine Vereinbarkeit von Familie und Beruf zu gewährleisten (OECD, 2013a und 2013b; OECD, 201ra).

Das Durchschnittsalter von Frauen bei der Geburt ihres ersten Kindes ist in den letzten 40 Jahren in allen OECD-Ländern gestiegen. 1970 lag das Durchschnittsalter von Frauen bei der Geburt ihres ersten Kindes in Island mit etwas über 2I Jahren am niedrigsten. Island war jedoch nicht die absolute Ausnahme: Von den 23 Ländern mit verfügbaren Daten lag in 5 weiteren Ländern der Durchschnitt unter 23 Jahren, und der Gesamtdurchschnitt aller Länder lag bei etwas über 24 Jahren. Dieses Alter stieg bis zum Jahr I995 im OECD-Durchschnitt auf mehr als 26 Jahre, bis 2009 auf knapp 28 Jahre. Trotz dieser Tendenz bestehen immer noch große Unterschiede zwischen einzelnen Ländern. Im Jahr 2009 war in Deutschland und dem Vereinigten Königreich das Durchschnittsalter bei der Geburt des ersten Kindes mit 30 Jahren am höchsten. Mexiko dagegen hatte mit etwas über 2I Jahren das jüngste Durchschnittsalter (Abb. C2.2).

Abbildung C2.2

Spätere Elternschaft

Durchschnittliches Alter, in dem Frauen ihr erstes Kind bekommen (1970, 1995 und 2009)

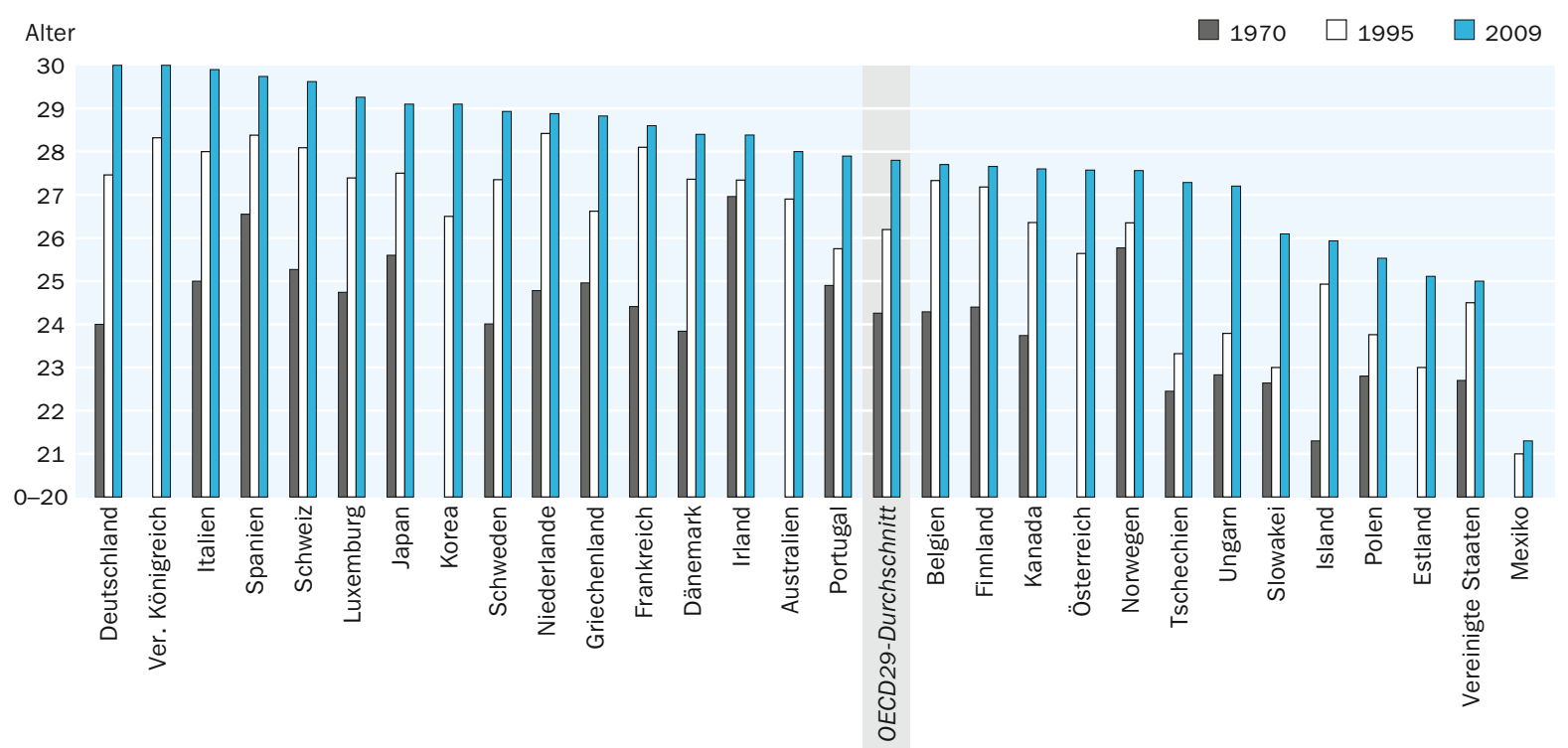




\section{Bildungsbeteiligung im Elementarbereich}

Für viele Kinder bildet der Elementarbereich die Eingangsstufe in den organisierten Unterricht und kann eine wesentliche Rolle in ihrer Entwicklung spielen. Die Bildungsbeteiligung im Primarbereich und Sekundarbereich I ist in allen OECD-Ländern relativ ähnlich. Im Elementarbereich dagegen bestehen deutliche Unterschiede in den OECDund sonstigen G20-Ländern, z. B. im Hinblick auf die Gesamtbeteiligung an Bildungsangeboten, das typische Eintrittsalter der Kinder, die Finanzierung und die Dauer der Angebote.

In der Mehrzahl der OECD-Länder beginnt Bildung für die meisten Kinder inzwischen lange vor dem fünften Lebensjahr. Insgesamt nehmen in den OECD-Ländern mehr als drei Viertel aller 4-Jährigen (82 Prozent) an Bildungsangeboten des Elementarbereichs teil. In den OECD-Ländern, die zur Europäischen Union gehören, sind dies durchschnittlich 86 Prozent. In diesem Alter beträgt die Beteiligung an frühkindlicher Bildung zwischen mehr als 95 Prozent in Belgien, Dänemark, Deutschland, Frankreich, Island, Italien, Mexiko, den Niederlanden, Norwegen, Spanien und dem Vereinigten Königreich und weniger als 6o Prozent in Brasilien, Finnland und der Türkei. Auch Kanada und die Schweiz gehören in diese Gruppe, da aber aus diesen Ländern keine Angaben zur Bildungsbeteiligung in integrierten Bildungsgängen vorliegen, kann die spezifische Bildungsbeteiligung nicht berechnet werden und wird wahrscheinlich oberhalb der hier angegebenen liegen (Tab. C2.I und Abb. C2.I).

Die Ergebnisse der internationalen Schulleistungsstudie PISA der OECD bestätigen diese Zahlen. Im Durchschnitt gaben in den OECD-Ländern 72 Prozent aller Teilnehmer an der PISA-Studie im Alter von I5 Jahren an, dass sie mehr als ein Jahr an Angeboten aus dem Elementarbereich teilgenommen hatten. Den Angaben der Schüler zufolge war vor Io Jahren in Belgien, Frankreich, Island, Japan, den Niederlanden und Ungarn die Bildungsbeteiligung im Elementarbereich für mehr als ein Jahr nahezu universell. In diesen Ländern gaben über 90 Prozent der 15 -Jährigen an, dass sie länger als ein Jahr an Angeboten im Elementarbereich teilgenommen hatten. Über 9o Prozent der Schüler in 27 OECD-Ländern hatten zumindest für einige Zeit an Angeboten aus dem Elementarbereich teilgenommen. In Frankreich, Japan, Ungarn und den Vereinigten Staaten waren es den Angaben zufolge mehr als 98 Prozent. In der Türkei ist frühkindliche Bildung selten. Dort hatten unabhängig von der Dauer der Teilnahme weniger als 30 Prozent der 15-Jährigen an Angeboten aus dem Elementarbereich teilgenommen. Eine Beteiligung am Elementarbereich von mehr als einem Jahr ist in Chile, Irland und Polen unüblich. In diesen Ländern hatten weniger als 50 Prozent der Schüler über eine derartige Zeitdauer an Angeboten aus dem Elementarbereich teilgenommen (s. OECD, 20I0, Tab. II.5.5 sowie Tab. C2.2 in diesem Indikator).

Bemerkenswert in diesem Zusammenhang ist, dass der PISA-Studie zufolge in den meisten Ländern Schüler, die mindestens ein Jahr an Angeboten des Elementarbereichs teilgenommen haben, tendenziell bessere Ergebnisse erzielen als Schüler, die nicht an frühkindlicher Bildung teilgenommen haben, selbst nach Berücksichtigung des sozioökonomischen Hintergrunds der Schüler. Die PISA-Untersuchungen zeigen außerdem, dass der Zusammenhang zwischen der Bildungsbeteiligung im Elementarbereich und den Leistungen in Schulsystemen mit einer längeren Beteiligungsdauer im Elementarbereich, niedrigeren Schüler-Lehrkräfte-Relationen im Elementarbereich und 


\section{Die Grenze zwischen frühkindlicher Bildung und Kinderbetreuung}

Es gibt in den OECD-Ländern viele verschiedene Systeme und Strukturen der frühkindlichen Bildung und Betreuung. Entsprechend gibt es auch viele verschiedene Ansätze zur Unterscheidung zwischen Angeboten zur frühkindlichen Bildung und Angeboten zur Kinderbetreuung. Da der Bildungscharakter von Angeboten der ISCED-Stufe o nur schwer direkt zu bewerten ist, werden verschiedene Näherungskriterien angewandt, um zu einer fachlichen Definition zu gelangen. Dazu gehört die Frage danach, ob das Angebot von qualifiziertem Personal durchgeführt wird, ob es in einem institutionalisierten Kontext stattfindet und auf welche Altersgruppe es ausgerichtet ist.

Um dem Leser von Bildung aufeinen Blick die Interpretation der Ergebnisse in diesem Indikator zu erleichtern, werden hier mehrere Beispiele aus den der OECD gemeldeten Daten dafür aufgeführt, wie einzelne Länder eine Unterscheidung zwischen Angeboten zur frühkindlichen Bildung und Angeboten zur Kinderbetreuung treffen und praktisch umsetzen.

In Ländern, in denen Angebote zur frühkindlichen Bildung und Angebote zur Kinderbetreuung in getrennten Einrichtungen stattfinden, ist die Unterscheidung zwischen frühkindlicher Bildung und Kinderbetreuung leicht zu treffen. In Belgien beispielsweise werden die unterschiedlichen Einrichtungen von verschiedenen Ministerien finanziert, wodurch sich Schätzungen erübrigen (s. Abb. I).

In Ländern mit kombinierten Bildungs- und Betreuungsangeboten („,integrierten“ Angeboten) stellt die Unterscheidung zwischen Bildungsangeboten und Betreuungsangeboten eine größere Herausforderung dar. OECD-Länder mit integrierten Angeboten zur frühkindlichen Bildung und Betreuung verfügen oft auch über reine Bildungsangebote. Mehr als die Hälfte aller OECD-Länder ist praktisch nicht in der Lage, bei integrierten Angeboten eine Unterscheidung zwischen der reinen Bildungskomponente und dem Betreuungsangebot zu treffen. Diese Länder, darunter Italien, Dänemark und die Vereinigten Staaten, haben sich mehrheitlich für die Erfassung aller dieser Daten unter der ISCED-Stufe o entschieden. Nur bei einer Minderheit der Länder fließen die integrierten Angebote des Elementarbereichs nicht in die Daten zur personellen Ausstattung (Australien, Norwegen), zu den Ausgaben (Korea) oder in die gesamte Datenerhebung (Griechenland, Kanada, die Schweiz) mit ein. Diese Unterschiede sollten bei der Interpretation internationaler Vergleiche berücksichtigt werden.

In Ländern, die bei ihren integrierten Angeboten den Versuch unternehmen, die Bildungskomponente separat auszuweisen, werden verschiedene Schätzverfahren eingesetzt, um die Daten zur Beteiligung, zu den Ausgaben und zum Personal zu trennen. Manche Länder, wie beispielsweise die Niederlande, Norwegen und Schweden, haben ein hälftiges Schätzverfahren gewählt, bei dem die Hälfte aller Werte für Beteiligung, Personal und Ausgaben der Bildungskomponente zugeschrieben werden. Andere Länder ziehen Datenerhebungen heran, weisen andere Anteile zu oder verwenden ein komplexeres Schätzverfahren. Finnland gewichtet beispielsweise die 
Ausgaben in integrierten Angeboten nach dem Alter des Kindes, während Estland den Ausgabenanteil auf 30 Prozent ansetzt.

Abbildung 1

Schematische Darstellung der verschiedenen Systeme im Elementarbereich (ISCED-Stufe 0) und der Datenerhebung innerhalb der OECD

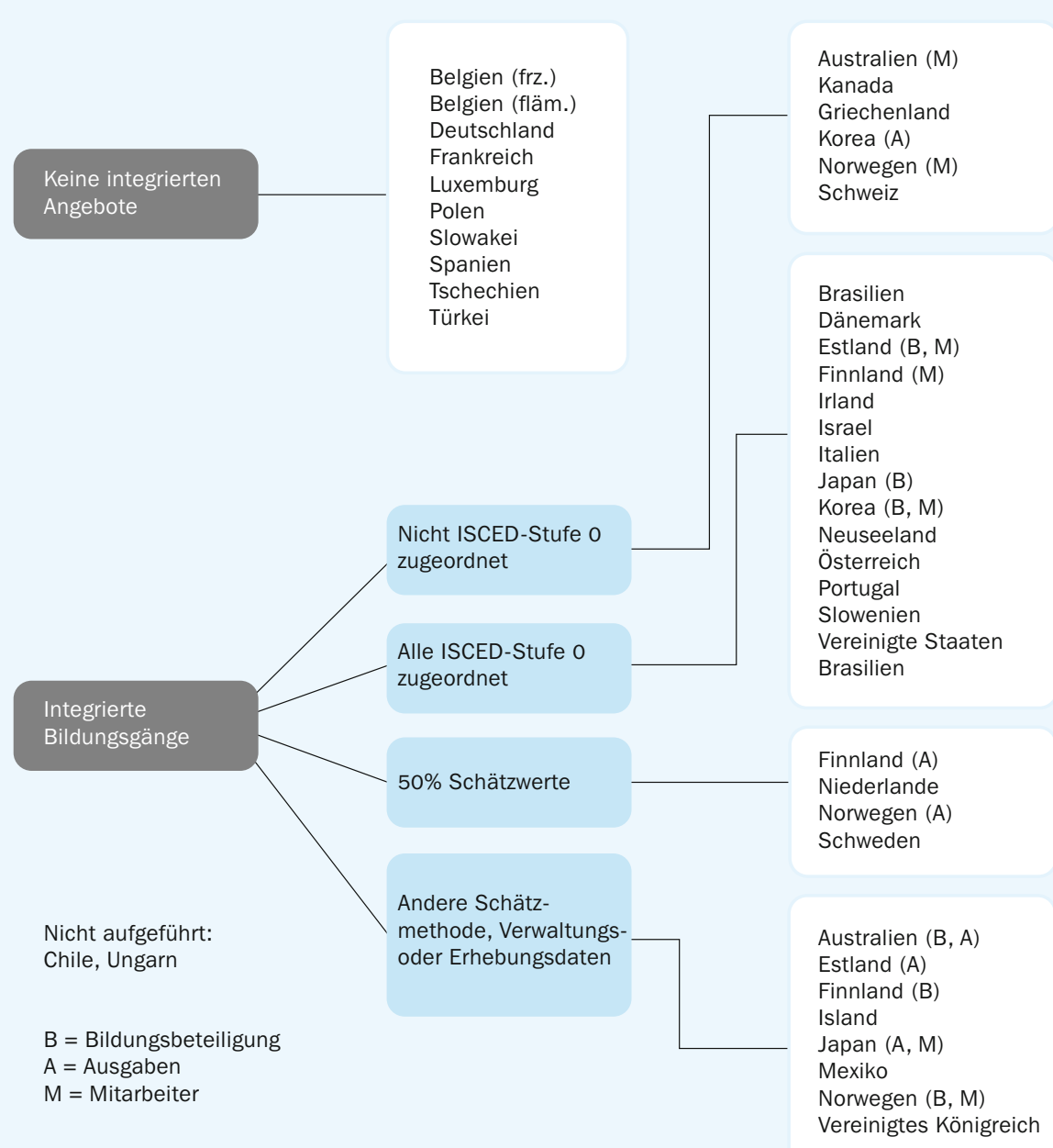

Die OECD-Länder arbeiten gemeinsam an einer Verbesserung der zur Verfügung gestellten Statistiken zur frühkindlichen Bildung. Diese Verbesserung, die die neue internationale Klassifizierung von ISCED-Bildungsgängen berücksichtigen wird, wird in ISCED 201 I umgesetzt werden.

In Abbildung I sind die Systeme zur frühkindlichen Bildung und die Ansätze zur Datenerfassung innerhalb der OECD und der Mitgliedstaaten dargestellt. Länderspezifische Informationen sind Anhang 3 der vorliegenden Veröffentlichung zu entnehmen. 
höheren öffentlichen Ausgaben pro Kind im Elementarbereich tendenziell stärker ausgeprägt ist (OECD, 20I0, Tab. II.5.6).

Angebote zur frühkindlichen Bildung für noch jüngere Kinder sind nicht so weit verbreitet. In einigen Ländern ist der Bedarf an frühkindlicher Bildung für Kinder im Alter von drei Jahren und darunter deutlich größer als das Angebot, und zwar selbst in Ländern, in denen die Möglichkeit eines langen Erziehungsurlaubs besteht. Belgien, Frankreich, Island, Italien, Norwegen und Spanien weisen die höchste Beteiligungsquote von 3-Jährigen an frühkindlicher Bildung auf. In Ländern, in denen Erziehungsurlaub nur begrenzt öffentlich finanziert wird, müssen viele erwerbstätige Eltern entweder Lösungen im privaten Sektor finden, wo der Zugang zu qualitativ hochwertigen Angeboten in hohem Maße von der Zahlungsfähigkeit der Eltern bestimmt wird, oder sich auf informelle Abmachungen mit Familienangehörigen, Freunden und Nachbarn verlassen (Tab. C2.I und Starting Strong III [OECD, 20Irb]).

Da frühkindliche Bildung dazu beiträgt, eine solide Grundlage für lebenslanges Lernen zu schaffen und für mehr Chancengleichheit auf dem weiteren Bildungsweg zu sorgen, haben einige Länder für einen nahezu universellen Zugang zum Elementarbereich ab einem Alter von drei Jahren Sorge getragen. Die Verfügbarkeit von Angeboten im Elementarbereich nimmt in den meisten Ländern schnell zu. In den OECD-Ländern mit verfügbaren Daten für 2005 und 20 I stieg die Bildungsbeteiligung im Durchschnitt bei den 3-Jährigen von 64 Prozent im Jahr 2005 auf 70 Prozent im Jahr 20II, bei den 4-Jährigen von 78 Prozent auf 84 Prozent. In Brasilien, Mexiko und Polen stieg die Beteiligung der 4-Jährigen in diesem Zeitraum um mindestens 20 Prozentpunkte (Tab. C2.I).

\section{Finanzierung der frühkindlichen Bildung}

Eine langfristig gesicherte öffentliche Finanzierung ist entscheidend für die Sicherung der weiteren Expansion und der Qualität frühkindlicher Bildungsgänge. Eine geeignete Finanzierung trägt dazu bei, dass qualifiziertes Personal eingestellt werden kann, das in der Lage ist, die kognitive, soziale und emotionale Entwicklung der Kinder zu unterstützen. Investitionen in Einrichtungen und Materialien zur frühkindlichen Bildung leisten außerdem einen Beitrag zur Förderung der Entwicklung eines kindgerechten Lernumfelds. In Ländern, in denen nicht genügend öffentliche Mittel zur Finanzierung eines qualitativ und quantitativ ausreichenden Angebots im Elementarbereich bereitgestellt werden, kann es sein, dass einige Eltern für ihre Kinder tendenziell eher private Bildungs- und Betreuungseinrichtungen wählen, was eine große finanzielle Belastung bedeuten kann (OECD, 20IIb); andere entscheiden sich möglicherweise dafür, zu Hause zu bleiben, was sich negativ auf die Erwerbstätigkeit von Frauen auswirken kann (OECD, 20Ira).

Mit öffentlichen Mitteln werden hauptsächlich öffentliche Bildungseinrichtungen finanziert, in einigen Ländern werden öffentliche Mittel in unterschiedlichem Ausmaß aber auch für private Bildungseinrichtungen eingesetzt. Die öffentlichen Ausgaben pro Schüler für öffentliche Einrichtungen im Elementarbereich sind in den OECD-Ländern im Durchschnitt mehr als doppelt so hoch wie die öffentlichen Ausgaben für private Einrichtungen im Elementarbereich (6.275 US-Dollar gegenüber 3.494 US-Dollar) (s. Tab. B3.4). In den OECD-Ländern betragen die (mit Mitteln aus öffentlichen und privaten Quellen finanzierten) jährlichen Ausgaben pro Schüler im Elementarbereich 
Ausgaben für Bildungseinrichtungen im Bereich frühkindliche Bildung als Prozentsatz des BIP (2010) Nach Herkunft der Mittel

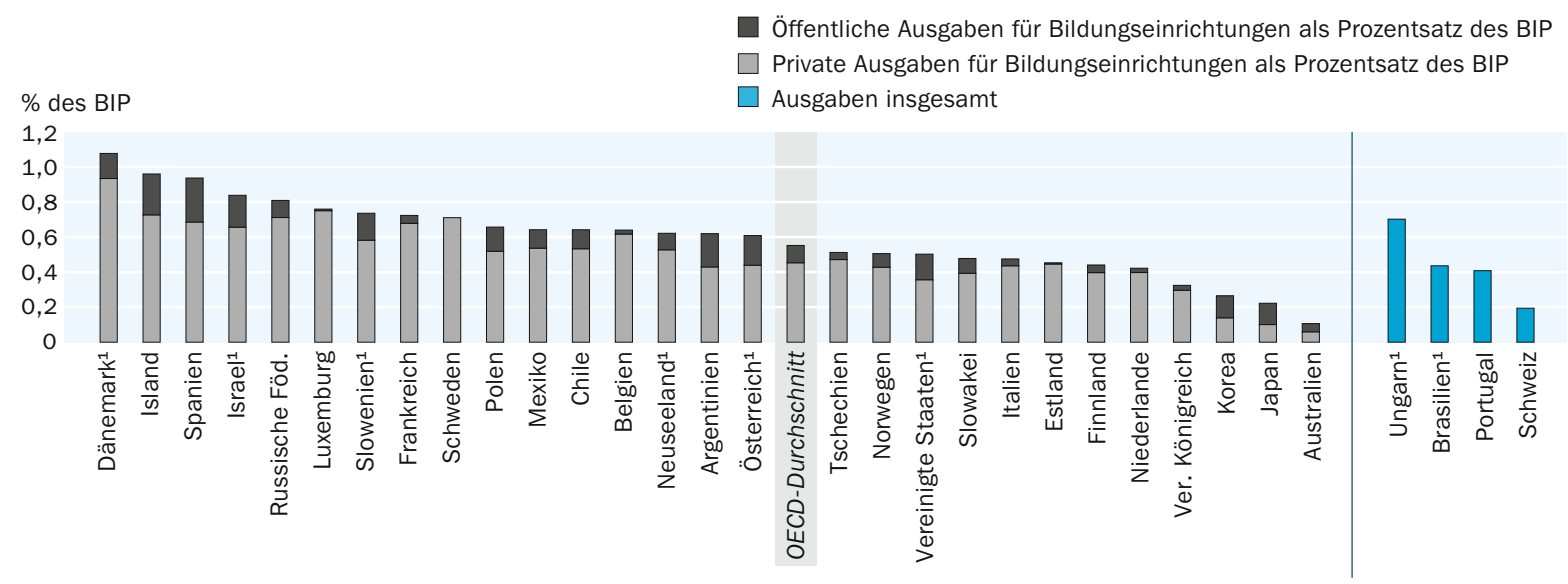

1. Einschließlich einiger Ausgaben für die Betreuung der Kinder.

Anordnung der Länder in absteigender Reihenfolge der öffentlichen und privaten Ausgaben für Bildungseinrichtungen.

Quelle: OECD. Argentinien: Statistikinstitut der UNESCO (World Education Indicators Programme). Tabelle C2.2.

Hinweise s. Anhang 3 unter www.oecd.org/edu/eag.htm. StatLink: http://dx.doi.org/10.1787/888932847431

für öffentliche und private Einrichtungen im Durchschnitt 6.762 US-Dollar. Allerdings variieren diese Ausgaben von höchstens 2.500 US-Dollar in Argentinien, Brasilien, Mexiko und der Türkei bis zu mehr als ro.00o US-Dollar in Luxemburg, Neuseeland und den Vereinigten Staaten (Tab. C2.2 und Tab. B3.4 in Indikator B3).

Die Ausgaben für den Elementarbereich belaufen sich im Durchschnitt auf o,6 Prozent des BIP der OECD insgesamt. Zwischen den einzelnen Ländern gibt es große Unterschiede. In Australien und der Türkei beispielsweise werden höchstens o, I Prozent des BIP für den Elementarbereich ausgegeben, während es in Dänemark, Island, Israel, Luxemburg, der Russischen Föderation und Spanien mindestens o,8 Prozent sind (Tab. C2.2 und Abb. C2.3). Diese Unterschiede erklären sich größtenteils durch die Bildungsbeteiligung, gesetzlich festgelegte Ansprüche und Kosten sowie das unterschiedliche Eintrittsalter in den Primarbereich, sie werden jedoch auch von dem Ausmaß beeinflusst, in dem private frühkindliche Bildung von diesem Indikator erfasst wird. Da für die Niederlande und die Schweiz keine Daten über integrierte Angebote vorliegen, sind die tatsächlichen Ausgaben für den Elementarbereich und die tatsächliche Beteiligung im Elementarbereich wahrscheinlich zu niedrig angesetzt (Einzelheiten s. Kasten C2.I); dies kann die Vergleichbarkeit der Daten mit denen anderer Länder beeinflussen. Schlussfolgerungen hinsichtlich des Zugangs zu Erziehung und Betreuung im Vorschulalter und deren Qualität sollten deshalb mit Vorsicht gezogen werden (Tab. C2.2 und Kasten C2.I).

Eine öffentliche Finanzierung des Elementarbereichs ist in den europäischen Ländern der OECD tendenziell stärker entwickelt als in den nicht europäischen Ländern. In Europa ist das Prinzip des universellen Bildungszugangs für 3-bis 6-Jährige allgemein anerkannt. Die meisten Länder dieser Region bieten allen Kindern vor dem Eintritt in den Primarbereich mindestens zwei Jahre gebührenfreier, öffentlich finanzierter frühkindlicher Bildung. Mit Ausnahme von Irland und den Niederlanden gibt es im Allge- 
meinen ab dem Alter von drei Jahren, in manchen Ländern sogar noch früher, und für mindestens zwei Jahre einen gesetzlichen Anspruch auf Bildungszugang. Verglichen mit dem Primar-, Sekundar- und postsekundaren, nicht tertiären Bildungsbereich entfällt mit I8 Prozent der größte Anteil privater Finanzierung auf Einrichtungen des Elementarbereichs. Dieser Anteil variiert jedoch erheblich zwischen den einzelnen Ländern und reicht von höchstens 5 Prozent in Belgien, Estland, Luxemburg und Schweden bis zu mindestens 25 Prozent in Argentinien, Australien, Japan, Korea, Österreich, Spanien und den Vereinigten Staaten (Tab. C2.2 und Starting Strong III [OECD, 20IIb]).

\section{Die Schüler-Lehrkräfte-Relation unterscheidet sich signifikant zwischen den einzelnen OECD-Ländern}

Untersuchungen zeigen, dass der Einsatz qualifizierterer Lehrkräfte ein anregendes Umfeld und einen pädagogisch hochwertigen Unterricht fördert und dass höherwertige Interaktionen zwischen den Kindern und den Mitarbeitern der Bildungseinrichtungen zu besseren Lernerfolgen führen (Heckman, 2000; Shin et al., 2009). Die Qualifikationen bilden zwar eines der aussagekräftigsten Kriterien für die Qualität der Mitarbeiter, sind aber doch nur ein Aspekt des Gesamtbilds. Die Qualifikationen geben einen Hinweis darauf, wie hoch der fachliche und der praktische Anteil der ursprünglichen Ausbildung des Personals ist, welche Möglichkeiten der beruflichen Weiterentwicklung und -bildung zur Verfügung stehen und tatsächlich in Anspruch genommen werden und über wie viele Jahre Erfahrung das Personal verfügt. Ferner können die Arbeitsbedingungen die berufliche Zufriedenheit beeinflussen, was sich höchstwahrscheinlich wiederum auf die Fähigkeit und die Bereitschaft des Personals auswirkt, eine Beziehung zu den Kindern aufzubauen und aufmerksam mit ihnen zu interagieren (Shin et al., 2009). Eine hohe Fluktuationsrate beeinträchtigt die Kontinuität der Betreuung, unterminiert Anstrengungen zur beruflichen Weiterbildung, führt zu allgemeinen Qualitätseinbußen und hat negative Auswirkungen auf die Lernerfolge der Kinder.

Die Schüler-Lehrkräfte-Relation ist ebenfalls ein wichtiger Indikator für die zu Bildungszwecken zur Verfügung gestellten Ressourcen. Sie wird berechnet, indem (gemessen in Vollzeitäquivalenten) die Zahl der Schüler eines bestimmten Bildungsbereichs durch die Zahl der Lehrkräfte des gleichen Bildungsbereichs und ähnlicher Bildungseinrichtungen dividiert wird. Diese Relation berücksichtigt jedoch weder die Unterrichtszeit der Schüler im Verhältnis zur Länge des Arbeitstages einer Lehrkraft noch, wie viel Zeit eine Lehrkraft auf das Unterrichten verwendet, und kann daher nicht als Klassengröße interpretiert werden. Die Zahl der Schüler pro Klasse umfasst unterschiedliche Faktoren, eine Differenzierung dieser Faktoren erlaubt jedoch, die Qualitätsunterschiede zwischen den Bildungssystemen der einzelnen Länder herauszuarbeiten (s. Indikator D2).

Tabelle C2.2 enthält Angaben zur Schüler-Lehrkräfte-Relation sowie zur Schüler-Kontaktpersonen-Relation (Lehrkräfte und nicht voll qualifizierte Beschäftigte, z. B. Hilfslehrkräfte) im Bereich frühkindliche Bildung. Einige Länder bauen im Elementarbereich in starkem Maße auf Hilfslehrkräfte. In I2 OECD- und G20-Ländern ist die gemeldete Schüler-Kontaktpersonen-Relation (Tab. C2.2, Spalte 4) niedriger als die Schüler-Lehrkräfte-Relation. So ist die Schüler-Kontaktpersonen-Relation in Brasilien, 
Abbildung C2.4

Schüler-Lehrkräfte-Relation im Bereich frühkindliche Bildung (2011)

Öffentliche und private Bildungseinrichtungen

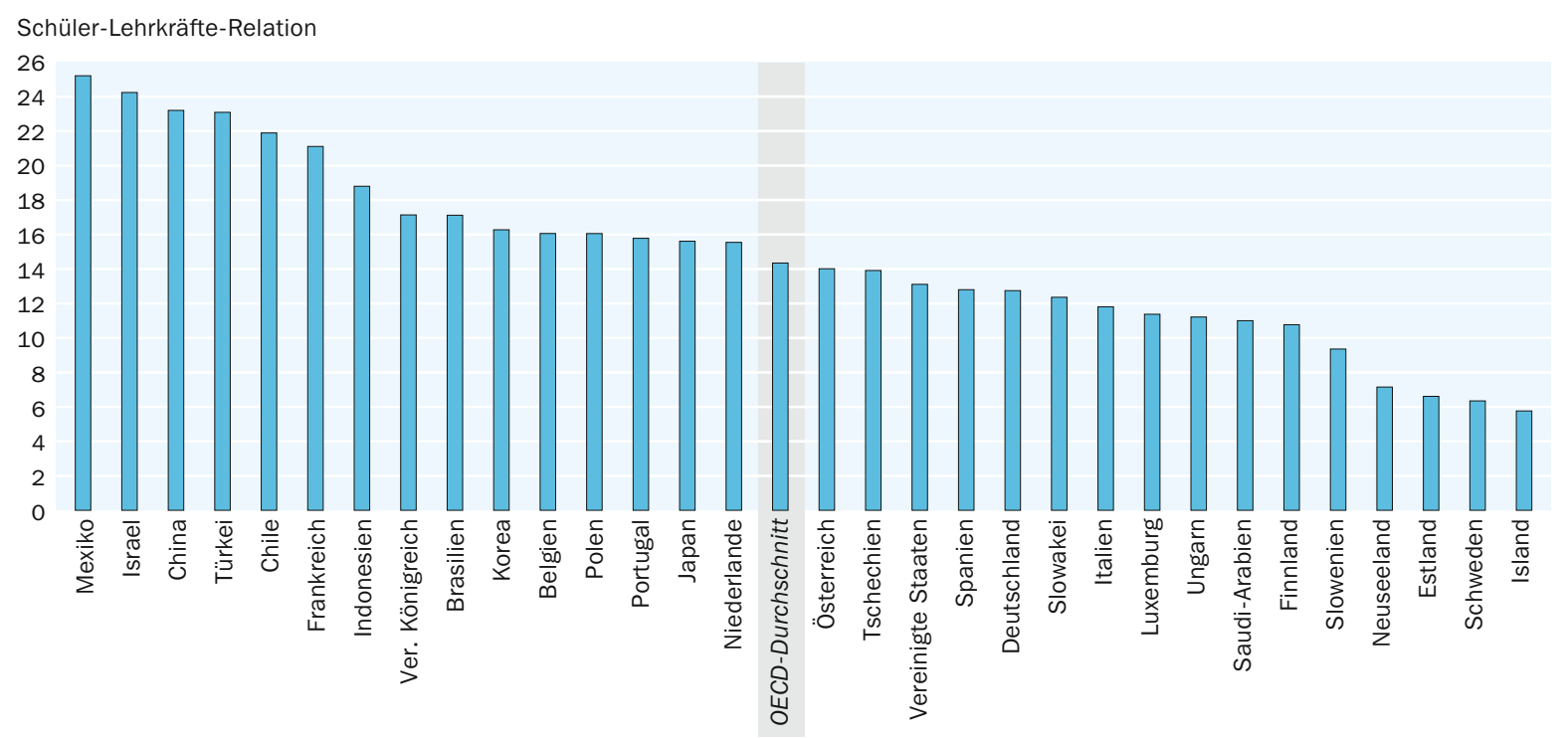

Hinweis: Die Zahlen sollten mit Vorsicht interpretiert werden, da in dem Indikator die Schüler-Lehrkräfte-Relation in Ländern verglichen wird, die „reine Bildungsangebote“ und „integrierte Bildungs- und Betreuungsangebote“ haben. In einigen Ländern sind die Anforderungen an die Mitarbeiter bei diesen beiden Bildungsangeboten sehr unterschiedlich.

Anordnung der Länder in absteigender Reihenfolge der Schüler-Lehrkräfte-Relation im Bereich frühkindliche Bildung.

Quelle: OECD. China, Indonesien und Saudi-Arabien: Statistikinstitut der UNESCO (World Education Indicators Programme). Tabelle C2.2.

Hinweise s. Anhang 3 unter www.oecd.org/edu/eag.htm. StatLink: http://dx.doi.org/10.1787/888932847450

Chile, China, Deutschland, Frankreich, Israel, Österreich und den Vereinigten Staaten wesentlich niedriger. Im Durchschnitt kommen allgemein in den OECD-Ländern im Elementarbereich aufjede Lehrkraft I4 Schüler. Die Schüler-Lehrkräfte-Relation (ohne Hilfslehrkräfte) beträgt zwischen mehr als 20 Schülern pro Lehrkraft in Chile, China, Frankreich, Israel, Mexiko und der Türkei und weniger als Io in Estland, Island, Neuseeland, Schweden und Slowenien (Tab. C2.2 und Abb. C2.4).

\section{Definitionen und angewandte Methodik}

Wie ist frühkindliche Bildung definiert?

Die frühkindliche Bildung (Elementarbereich, ISCED-Stufe o) ist definiert als erste Stufe organisierten Unterrichts, die jüngere Kinder hauptsächlich an eine schulähnliche Umgebung heranführen soll.

Die Unterscheidung zwischen Angeboten, die ISCED-Stufe o zugerechnet werden, und Angeboten, bei denen dies nicht der Fall ist, beruht hauptsächlich auf dem Bildungscharakter des Angebots. Da der Bildungscharakter dieser Angebote nur schwer direkt zu bewerten ist, werden verschiedene Näherungskriterien angewandt. Bildungsgänge der ISCED-Stufe o umfassen Angebote zur frühkindlichen Bildung, die

in einem Zentrum oder einer Schule stattfinden,

auf die Bildungs- und Entwicklungsbedürfnisse von Kindern zugeschnitten sind, 
sich in der Regel an Kinder im Alter von mindestens 3 Jahren und höchstens 6 Jahren richten und

über angemessen ausgebildetes (d. h. qualifiziertes) Personal verfügen, um den Kindern ein Bildungsangebot zu bieten.

Sie umfassen keine Angebote der frühkindlichen Bildung, die diese Kriterien nicht erfüllen.

Auf welche Weise werden Angebote zur frühkindlichen Bildung in Vollzeit- und Teilzeitangebote unterteilt und wie wirkt sich diese Unterteilung aus?

Zur Unterscheidung zwischen Vollzeit- und Teilzeitangeboten werden in Bildung auf einen Blick zwei Methoden verwendet:

I. basierend auf nationalen Definitionen für Angebote zur frühkindlichen Bildung,

2. ein Näherungsverfahren abgeleitet aus der Dauer der ersten Klassenstufe des Primarbereichs (ISCED-Stufe I).

Die Klassifizierungsmethoden unterscheiden sich zwar von Land zu Land, dies hat jedoch keinen Einfluss auf die Bildungsbeteiligung (Tab. C2.I), da diese auf dem Gesamtumfang der Bildungsbeteiligung als Anteil an der Bevölkerung unabhängig von einer Unterscheidung in Teilzeit und Vollzeit basiert. Es ist allerdings möglich, dass sich die unterschiedlichen Klassifizierungsmethoden auf die Ausgaben pro Kind und die Schüler-Lehrkräfte-Relation auswirken, da diese Daten auf vollzeitäquivalenten Schülerzahlen beruhen.

Worin unterscheiden sich reine Bildungsangebote und integrierte Angebote? In einigen Ländern beinhalten Programme zur frühkindlichen Bildung auch eine Betreuung. In Bildung auf einen Blick werden diese Angebote als integrierte Angebote bezeichnet, d.h., sie verbinden Bildung und Betreuung in einem Bildungsgang. Reine Bildungsangebote umfassen hauptsächlich Bildungsangebote für einen kurzen Zeitraum im Laufe des Tages. Berufstätige Eltern werden in der Regel zusätzliche Betreuungsangebote am Morgen und/oder am Nachmittag in Anspruch nehmen müssen.

Wird der Anteil der Ausgaben für die Betreuung bei integrierten Angeboten in Bildung auf einen Blick ausgewiesen?

ISCED-Stufe o konzentriert sich auf die Bildungsaspekte des Angebots. Daher sind die Ausgaben für die Betreuungskomponente von integrierten Angeboten in Bildung auf einen Blick nicht berücksichtigt. Die Länder, in denen sich die Ausgaben für Kinderbetreuung nicht von den in Bildung auf einen Blick erfassten Daten trennen lassen, sind in der Fußnote zu Tabelle C2.2 angegeben. Es ist wahrscheinlich, dass sich der Anteil der Ausgaben für die Kinderbetreuung von Land zu Land unterscheidet, daher sollten diese Ergebnisse mit Vorsicht interpretiert werden (weitere Einzelheiten s. Kasten C2.I).

Wie werden Unterschiede auf der nationalen Ebene dargestellt?

Manche Unterschiede auf der nationalen Ebene können hier nicht dargestellt werden, und in einigen Fällen wurden Informationen über den (Bildungs- bzw. Betreuungs-) Charakter von Angeboten vereinfacht. Es gibt zum Beispiel Länder, in denen sich das Eintrittsalter für Angebote zur frühkindlichen Bildung je nach Region oder rechtlicher 
Zuständigkeit unterscheidet. In diesen Fällen liefert der Indikator Informationen zu den am weitesten verbreiteten oder typischsten Angeboten.

Die statistischen Daten für Israel wurden von den zuständigen israelischen Stellen bereitgestellt, die für sie verantwortlich zeichnen. Die Verwendung dieser Daten durch die OECD erfolgt unbeschadet des völkerrechtlichen Status der Golanhöhen, von OstJerusalem und der israelischen Siedlungen im Westjordanland.

\section{Weiterführende Informationen}

Downey, D. B., P. T. von Hippel and B. A. Broh (2004), „Are Schools the Great Equalizer? Cognitive Inequality during the Summer Months and the School Year", American Sociological Review, Vol. 69, No. 5, pp. 613-635.

Entwisle, D. R., K. Alexander and L.S. Olson (1997), Children, Schools and Inequality, Westview, Boulder.

Hart, B. and I. Risley (1995), Meaningful Differences in the Everyday Experience of Young American Children, Paul H. Brookes Publishing, Baltimore.

Heckman, J. J. (2000), The Case for Investing in Disadvantaged Young Children, CESifo DICE Report, ifo Institut, München, Vol. 6, No. 2, pp. 3-8, o7.

OECD (2010), PISA 2009 Ergebnisse: Potenziale nutzen und Chancengerechtigkeit sichern - Sozialer Hintergrund und Schülerleistungen (Band II), http:|/dx.doi.org/10.1787/9789264095359-de.

OECD (201ra), How's Life?: Measuring Well-being, OECD Publishing, http:||dx.doi.org/ 10.1787/9789264121164-en.

OECD (20Irb), Starting Strong III: A Quality Toolbox for Early Childhood Education and Care, OECD Publishing, http:/|dx.doi.org/10.1787/9789264123564-en.

OECD (2013a), „How Do Early Childhood Education and Care (ECEC) Policies, Systems and Quality Vary across OECD Countries?" Education Indicators in Focus, February, http:/|dx.doi.org/10.1787/5k4gczkz4bq2-en.

OECD (2013b), Trends Shaping Education 2013, OECD Publishing, http://dx.doi.org/10.1787/ trends_edu-2013-en.

Shin, E., M. Jung and E. Park, E. (2009), „A Survey on the Development of the Preschool Free Service Model“, Research Report of the Korean Educational Development Institute, Seoul. 


\section{Tabellen Indikator C2}

Tabelle C2.I: Bildungsbeteiligung im Elementar- und Primarbereich, nach Alter $(2005,201 \mathrm{I})$

StatLink: http://dx.doi.org/10.1787/888932850509

Tabelle C2.2: Merkmale von Bildungsangeboten im Elementarbereich (2010, 20II) StatLink: http://dx.doi.org/10.1787/888932850528

Tabelle C2.3: Merkmale von reinen Bildungsangeboten und integrierten Angeboten im Bereich frühkindliche Bildung (20II)

StatLink: http:|/dx.doi.org/10.1787/888932850547 
Bildungsbeteiligung im Elementar- und Primarbereich, nach Alter (2005, 2011)

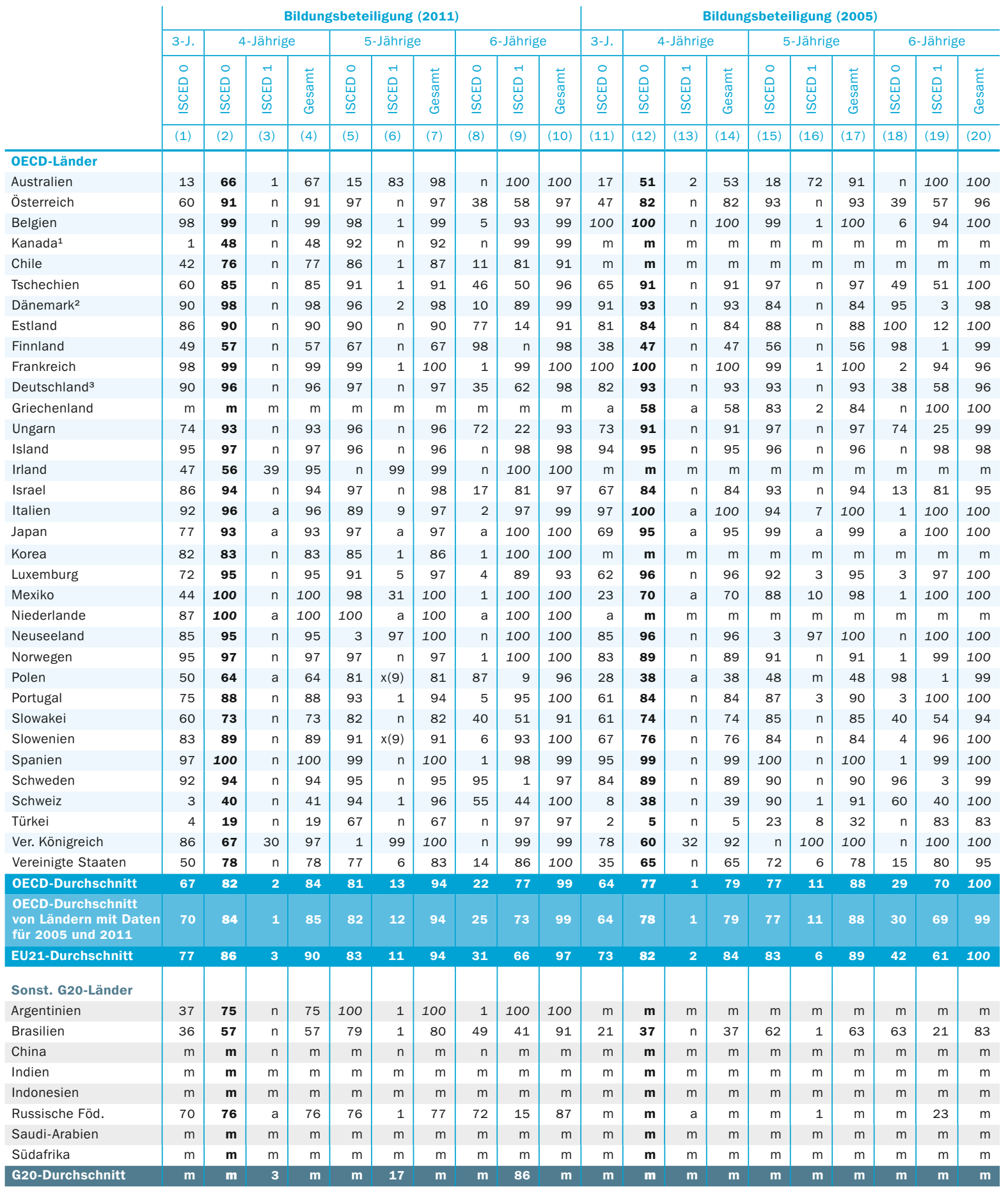

Anmerkung: Die Bildungsbeteiligung von kleinen Kindern sollte mit Vorsicht interpretiert werden. Unterschiede beim Referenzdatum für das Alter und dem Datum der Datenerhebung können dazu führen, dass Daten zu hoch angesetzt werden. Beteiligungsquoten können aufgrund von Schülern, die nicht gleich zu Beginn des Schuljahrs in die Bildungseinrichtung eintreten, zu niedrig angesetzt sein. Berechnete Quoten von über 100 Prozent werden durch 100 (kursiv) angegeben. 1. Referenzjahr 2010 anstelle 2011. Umfasst bei den öffentlichen Bildungseinrichtungen nur „Kindergarten“ und „Junior-Kindergarten“. 2. Seit 2011 sind Pflichtklassen ISCED-Stufe 1 zugeordnet. 3. Referenzjahr 2006 anstelle 2005.

Quelle: OECD. Argentinien und Indonesien: Statistikinstitut der UNESCO (World Education Indicators Programme).

Hinweise s. Anhang 3 unter www.oecd.org/edu/eag.htm. StatLink: http://dx.doi.org/10.1787/888932850509

Erläuterung der Kennzeichnung fehlender Daten s. Hinweise für den Leser. 
Tabelle C2.2

Merkmale von Bildungsangeboten im Elementarbereich $(2010,2011)$

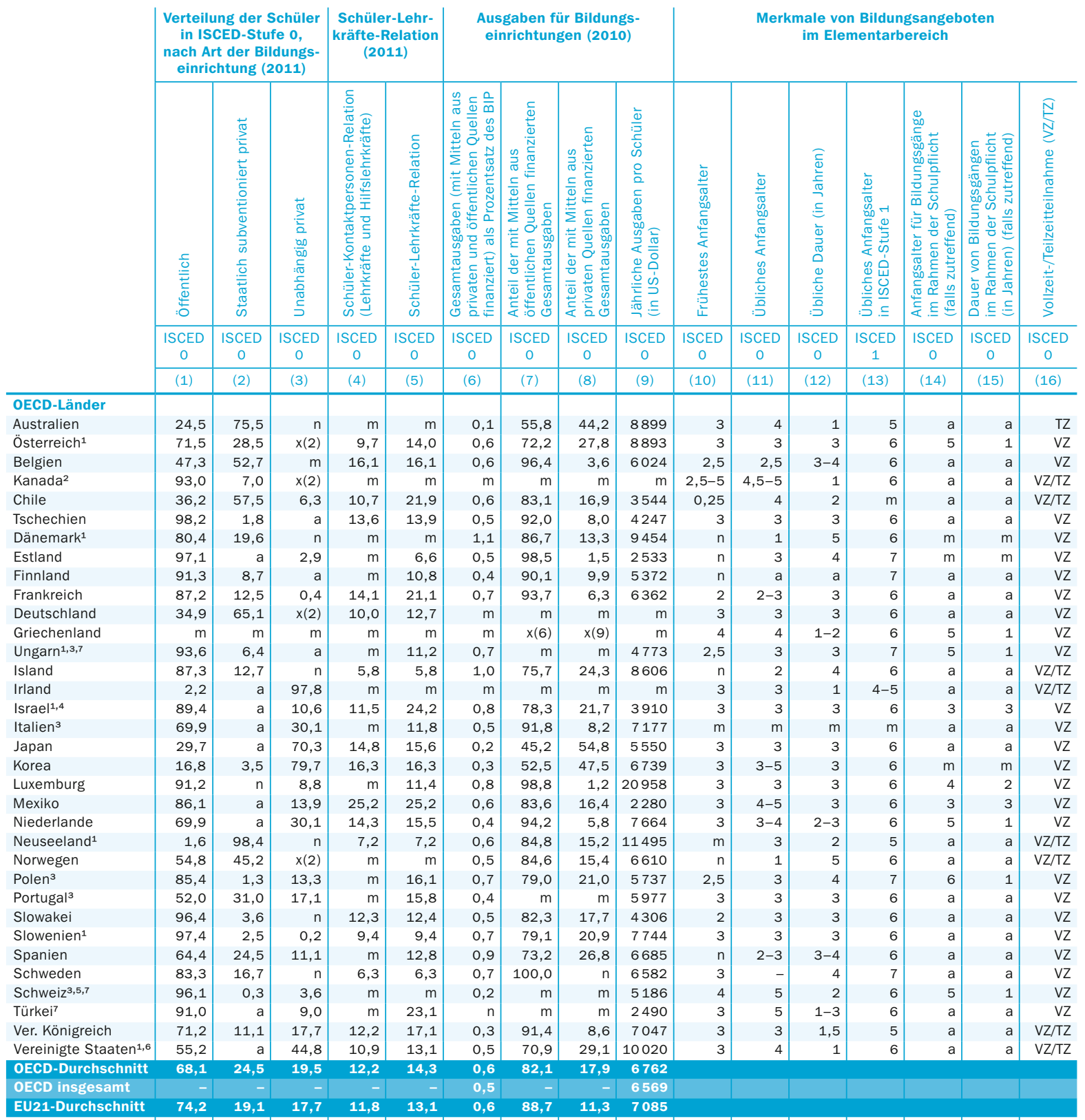

\begin{tabular}{|c|c|c|c|c|c|c|c|c|c|c|c|c|c|c|c|c|}
\hline \multicolumn{17}{|c|}{ Sonst. G20-Länder } \\
\hline Argentinien & 67,9 & 23,3 & 8,9 & $\mathrm{~m}$ & $\mathrm{~m}$ & 0,6 & 69,3 & 30,7 & 2427 & $\mathrm{~m}$ & $\mathrm{~m}$ & $\mathrm{~m}$ & $\mathrm{~m}$ & $\mathrm{~m}$ & $\mathrm{~m}$ & VZ \\
\hline Brasilien $^{1,7}$ & 71,8 & a & 28,2 & 12,6 & 17,1 & 0,4 & $\mathrm{~m}$ & $\mathrm{~m}$ & 2111 & $\mathrm{n}$ & 1 & 5 & 6 & 4 & 2 & VZ \\
\hline China & 53,0 & 47,0 & $x(2)$ & 20,6 & 23,2 & $\mathrm{~m}$ & $\mathrm{~m}$ & $\mathrm{~m}$ & $\mathrm{~m}$ & $\mathrm{~m}$ & $\mathrm{~m}$ & $\mathrm{~m}$ & $\mathrm{~m}$ & $\mathrm{~m}$ & $\mathrm{~m}$ & VZ \\
\hline Indien & $\mathrm{m}$ & $\mathrm{m}$ & $\mathrm{m}$ & $\mathrm{m}$ & $\mathrm{m}$ & $\mathrm{m}$ & $\mathrm{m}$ & $\mathrm{m}$ & $\mathrm{m}$ & $\mathrm{m}$ & $\mathrm{m}$ & $\mathrm{m}$ & $\mathrm{m}$ & $\mathrm{m}$ & $\mathrm{m}$ & $\mathrm{m}$ \\
\hline Indonesien & $\mathrm{m}$ & $\mathrm{m}$ & $\mathrm{m}$ & 17,3 & 18,8 & $\mathrm{~m}$ & $\mathrm{~m}$ & $\mathrm{~m}$ & $\mathrm{~m}$ & $\mathrm{~m}$ & $\mathrm{~m}$ & $\mathrm{~m}$ & $\mathrm{~m}$ & $\mathrm{~m}$ & $\mathrm{~m}$ & VZ \\
\hline Russische Föd. & 99,0 & a & 1,0 & $\mathrm{~m}$ & $\mathrm{~m}$ & 0,8 & 87,9 & 12,1 & $\mathrm{~m}$ & $\mathrm{~m}$ & $\mathrm{~m}$ & $\mathrm{~m}$ & $\mathrm{~m}$ & $\mathrm{~m}$ & $\mathrm{~m}$ & $\mathrm{~m}$ \\
\hline Saudi-Arabien & m & $\mathrm{m}$ & $\mathrm{m}$ & $\mathrm{m}$ & 11,0 & $\mathrm{~m}$ & $\mathrm{~m}$ & $\mathrm{~m}$ & $\mathrm{~m}$ & $\mathrm{~m}$ & $\mathrm{~m}$ & $\mathrm{~m}$ & $\mathrm{~m}$ & $\mathrm{~m}$ & $\mathrm{~m}$ & m \\
\hline Südafrika & $\mathrm{m}$ & $\mathrm{m}$ & $\mathrm{m}$ & $\mathrm{m}$ & $\mathrm{m}$ & $\mathrm{m}$ & $\mathrm{m}$ & $\mathrm{m}$ & $\mathrm{m}$ & $\mathrm{m}$ & $\mathrm{m}$ & $\mathrm{m}$ & $\mathrm{m}$ & $\mathrm{m}$ & $\mathrm{m}$ & $\mathrm{m}$ \\
\hline
\end{tabular}

1. Einschließlich einiger Ausgaben für die Betreuung der Kinder. 2. Bildungsgänge der ISCED-Stufe 0 werden in allen 13 Provinzen/Territorien angeboten, in zweien sind sie für alle Kinder obligatorisch. Frühestes Anfangsalter, typisches Anfangsalter und Dauer von Bildungsgängen der ISCED-Stufe 0 variieren je nach Provinz/Territorium. 3. Die Angaben zu den Ausgaben beziehen sich nur auf öffentliche Bildungseinrichtungen. 4. Durch ein kürzlich in Kraft getretenes Gesetz ist die Teilnahme an Bildungsgängen der ISCED-Stufe O landesweit obligatorisch und kostenfrei. Die Umsetzung erfolgt schrittweise ab $2013 . \quad 5$. Bildungsgänge der ISCED-Stufe 0 sind in einigen Kantonen für zwei Jahre obligatorisch, in anderen nur für ein Jahr. 6. Bildungsgänge der ISCED-Stufe 0 sind in rund einem Drittel der Bundesstaaten obligatorisch. 7. Nur öffentliche Ausgaben.

Quelle: OECD. Argentinien und Indonesien: Statistikinstitut der UNESCO (World Education Indicators Programme).

Hinweise s. Anhang 3 unter www.oecd.org/edu/eag.htm. StatLink: http://dx.doi.org/10.1787/888932850528

Erläuterung der Kennzeichnung fehlender Daten s. Hinweise für den Leser. 
Tabelle C2.3

Merkmale von reinen Bildungsangeboten und integrierten Angeboten im Bereich frühkindliche Bildung (2011)

Existenz und Merkmale von reinen Bildungsangeboten und integrierten Angeboten im Bereich frühkindliche Bildung

In Bildung auf einen Blick angegebene relative Anteile der Bildungsbeteiligung in reinen Bildungsangeboten und integrierten Angeboten im Bereich frühkindliche Bildung

\begin{tabular}{|c|c|c|c|c|c|c|c|c|c|}
\hline & \multicolumn{3}{|c|}{ Reine Bildungsangebote } & \multicolumn{3}{|c|}{$\begin{array}{l}\text { Integrierte Angebote (umfassen Bildungs- } \\
\text { angebote und Betreuungsleistung) }\end{array}$} & \multicolumn{3}{|c|}{$\begin{array}{l}\text { Relativer Anteil der Schülerzahlen, wie in } \\
\text { Bildung auf einen Blick angegeben (in \%) }\end{array}$} \\
\hline & $\begin{array}{c}\text { National } \\
\text { vorhanden }\end{array}$ & $\begin{array}{l}\text { Unterricht } \\
\text { durch } \\
\text { qualifizierte } \\
\text { Lehrkräfte }\end{array}$ & $\begin{array}{l}\text { Formaler } \\
\text { Lehrplan }\end{array}$ & $\begin{array}{c}\text { National } \\
\text { vorhanden }\end{array}$ & $\begin{array}{c}\text { Unterricht } \\
\text { durch } \\
\text { qualifizierte } \\
\text { Lehrkräfte }\end{array}$ & $\begin{array}{l}\text { Formaler } \\
\text { Lehrplan }\end{array}$ & $\begin{array}{l}\text { Reine } \\
\text { Bildungs- } \\
\text { angebote }\end{array}$ & $\begin{array}{l}\text { Integrierte } \\
\text { Angebote }\end{array}$ & Gesamt \\
\hline & (1) & (2) & (3) & (4) & (5) & (6) & (7) & (8) & (9) \\
\hline \multicolumn{10}{|l|}{ OECD-Länder } \\
\hline Australien & $\mathrm{Ja}$ & $\mathrm{Ja}$ & $\mathrm{Ja}$ & $\mathrm{Ja}$ & $\mathrm{Ja}$ & Ja & $x(9)$ & $x(9)$ & 100 \\
\hline Österreich & Ja & $\mathrm{Ja}$ & $\mathrm{Ja}$ & $\mathrm{Ja}$ & $\mathrm{Ja}$ & Nein & 3 & 97 & 100 \\
\hline Belgien & $\mathrm{Ja}$ & $\mathrm{Ja}$ & $\mathrm{Ja}$ & Nein & a & a & 100 & a & 100 \\
\hline Kanada & $\mathrm{Ja}$ & Ja & $\mathrm{Ja}$ & $\mathrm{Ja}$ & $\mathrm{Ja}$ & $\mathrm{Ja}$ & 100 & $\mathrm{~m}$ & 100 \\
\hline Chile & $\mathrm{Ja}$ & Ja & $\mathrm{Ja}$ & $\mathrm{Ja}$ & $\mathrm{Ja}$ & $\mathrm{Ja}$ & $\mathrm{x}(9)$ & $\mathrm{x}(9)$ & 100 \\
\hline Tschechien & $\mathrm{Ja}$ & $\mathrm{Ja}$ & $\mathrm{Ja}$ & Nein & a & a & 100 & a & 100 \\
\hline Dänemark & Nein & a & $\mathrm{a}$ & $\mathrm{Ja}$ & $\mathrm{Ja}$ & $\mathrm{Ja}$ & a & 100 & 100 \\
\hline Estland & Nein & a & a & $\mathrm{Ja}$ & $\mathrm{Ja}$ & $\mathrm{Ja}$ & a & 100 & 100 \\
\hline Finnland & Ja & $\mathrm{Ja}$ & $\mathrm{Ja}$ & $\mathrm{Ja}$ & $\mathrm{Ja}$ & $\mathrm{Ja}$ & 37 & 63 & 100 \\
\hline Frankreich & $\mathrm{Ja}$ & Ja & $\mathrm{Ja}$ & Nein & a & a & 100 & $a$ & 100 \\
\hline Deutschland & $\mathrm{Ja}$ & Ja & $\mathrm{Ja}$ & Nein & a & a & 100 & a & 100 \\
\hline Griechenland & $\mathrm{Ja}$ & Ja & $\mathrm{Ja}$ & $\mathrm{Ja}$ & $\mathrm{m}$ & $\mathrm{m}$ & 100 & $\mathrm{~m}$ & 100 \\
\hline Ungarn & Nein & a & a & $\mathrm{Ja}$ & $\mathrm{Ja}$ & $\mathrm{Ja}$ & a & 100 & 100 \\
\hline Island & $\mathrm{Ja}$ & Ja & $\mathrm{Ja}$ & $\mathrm{Ja}$ & $\mathrm{Ja}$ & $\mathrm{Ja}$ & 1 & 99 & 100 \\
\hline Irland & Nein & a & a & $\mathrm{Ja}$ & a & a & a & 100 & 100 \\
\hline Israel & $\mathrm{Ja}$ & $\mathrm{Ja}$ & $\mathrm{Ja}$ & $\mathrm{Ja}$ & $\mathrm{Ja}$ & Ja & 98 & 2 & 100 \\
\hline Italien & Nein & a & a & $\mathrm{Ja}$ & $\mathrm{m}$ & $\mathrm{m}$ & a & 100 & $\mathrm{~m}$ \\
\hline Japan & $\mathrm{Ja}$ & Ja & $\mathrm{Ja}$ & $\mathrm{Ja}$ & Variiert & Variiert & $x(9)$ & $\mathrm{x}(9)$ & 100 \\
\hline Korea & $\mathrm{Ja}$ & $\mathrm{Ja}$ & $\mathrm{Ja}$ & $\mathrm{Ja}$ & $\mathrm{Ja}$ & $\mathrm{Ja}$ & $x(9)$ & $\mathrm{x}(9)$ & 100 \\
\hline Luxemburg & $\mathrm{Ja}$ & $\mathrm{Ja}$ & $\mathrm{Ja}$ & Nein & a & a & 100 & a & 100 \\
\hline Mexiko & $\mathrm{Ja}$ & Ja & $\mathrm{Ja}$ & $\mathrm{Ja}$ & $\mathrm{Ja}$ & $\mathrm{Ja}$ & 99 & 1 & 100 \\
\hline Niederlande & $\mathrm{Ja}$ & $\mathrm{Ja}$ & $\mathrm{Ja}$ & $\mathrm{Ja}$ & Nein & Variiert & 70 & 30 & 100 \\
\hline Neuseeland & Nein & a & a & $\mathrm{Ja}$ & $\mathrm{Ja}$ & $\mathrm{Ja}$ & a & 100 & 100 \\
\hline Norwegen & Nein & a & a & $\mathrm{Ja}$ & $\mathrm{Ja}$ & $\mathrm{Ja}$ & a & 100 & 100 \\
\hline Polen & $\mathrm{Ja}$ & $\mathrm{Ja}$ & $\mathrm{Ja}$ & Nein & a & $a$ & 100 & a & 100 \\
\hline Portugal & Nein & a & $a$ & $\mathrm{Ja}$ & ja & ja & $\mathrm{a}$ & 100 & 100 \\
\hline Slowakei & $\mathrm{Ja}$ & $\mathrm{Ja}$ & $\mathrm{Ja}$ & Nein & a & a & 100 & a & 100 \\
\hline Slowenien & Nein & a & $\mathrm{a}$ & $\mathrm{Ja}$ & $\mathrm{Ja}$ & $\mathrm{Ja}$ & a & 100 & 100 \\
\hline Spanien & $\mathrm{Ja}$ & $\mathrm{Ja}$ & $\mathrm{Ja}$ & Nein & a & a & 100 & a & 100 \\
\hline Schweden & $\mathrm{Ja}$ & $\mathrm{Ja}$ & $\mathrm{Ja}$ & $\mathrm{Ja}$ & $\mathrm{Ja}$ & $\mathrm{Ja}$ & 30 & 70 & 100 \\
\hline Schweiz & $\mathrm{Ja}$ & $\mathrm{Ja}$ & $\mathrm{Ja}$ & $\mathrm{Ja}$ & $\mathrm{Ja}$ & $\mathrm{m}$ & 100 & $\mathrm{~m}$ & 100 \\
\hline Türkei & $\mathrm{Ja}$ & Ja & $\mathrm{Ja}$ & Nein & a & a & 100 & a & 100 \\
\hline Ver. Königreich & Ja & Ja & $\mathrm{Ja}$ & $\mathrm{Ja}$ & Variiert & Ja & $x(9)$ & $x(9)$ & 100 \\
\hline Vereinigte Staaten & $\mathrm{Ja}$ & Variiert & Variiert & $\mathrm{Ja}$ & Variiert & Variiert & $x(9)$ & $x(9)$ & 100 \\
\hline \multicolumn{10}{|l|}{ OECD-Durchschnitt } \\
\hline \multicolumn{10}{|l|}{ OECD insgesamt } \\
\hline \multicolumn{10}{|l|}{ EU21-Durchschnitt } \\
\hline \multicolumn{10}{|l|}{ Sonst. G20-Länder } \\
\hline Argentinien & $\mathrm{m}$ & $\mathrm{m}$ & $\mathrm{m}$ & $\mathrm{m}$ & $\mathrm{m}$ & $\mathrm{m}$ & $\mathrm{m}$ & $\mathrm{m}$ & $\mathrm{m}$ \\
\hline Brasilien & $\mathrm{Ja}$ & Ja & Nein & $\mathrm{Ja}$ & $\mathrm{Ja}$ & Nein & $\mathrm{x}(9)$ & $\mathrm{x}(9)$ & 100 \\
\hline China & $\mathrm{m}$ & $\mathrm{m}$ & $\mathrm{m}$ & $\mathrm{m}$ & $\mathrm{m}$ & $\mathrm{m}$ & $\mathrm{m}$ & $\mathrm{m}$ & $\mathrm{m}$ \\
\hline Indien & $\mathrm{m}$ & $\mathrm{m}$ & $\mathrm{m}$ & $\mathrm{m}$ & $\mathrm{m}$ & $\mathrm{m}$ & $\mathrm{m}$ & $\mathrm{m}$ & $\mathrm{m}$ \\
\hline Indonesien & $\mathrm{m}$ & $\mathrm{m}$ & $\mathrm{m}$ & $\mathrm{m}$ & $\mathrm{m}$ & $\mathrm{m}$ & $\mathrm{m}$ & $\mathrm{m}$ & $\mathrm{m}$ \\
\hline
\end{tabular}

Quelle: OECD. Spezielle Datenerhebung der INES-Arbeitsgruppe zu Bildungsangeboten im Bereich frühkindliche Bildung und Betreuung.

StatLink: http://dx.doi.org/10.1787/888932850547

Erläuterung der Kennzeichnung fehlender Daten s. Hinweise für den Leser. 



\section{Wie viele junge Erwachsene werden ein Studium im Tertiärbereich aufnehmen?}

Während im Durchschnitt 6o Prozent der heute in den OECD-Ländern lebenden jungen Erwachsenen im Lauf ihres Lebens wahrscheinlich einen (weitgehend theoretisch orientierten) Studiengang im Tertiärbereich A aufnehmen werden, werden nur 3 Prozent ein Studium in einem weiterführenden forschungsorientierten Studiengang aufnehmen.

Fast die Hälfte der jungen Erwachsenen in den OECD-Ländern wird vor Vollendung des 25. Lebensjahrs ein Studium im Tertiärbereich A beginnen.

Werden internationale Studierende nicht berücksichtigt, sind Polen und Slowenien die beiden einzigen Länder (der 17 Länder mit verfügbaren Daten), in denen rund 70 Prozent der jungen Erwachsenen vor ihrem 25. Geburtstag ein Studium im Tertiärbereich A aufnehmen werden.

Abbildung C3.1

Studienanfängerquoten im Tertiärbereich A (2011)
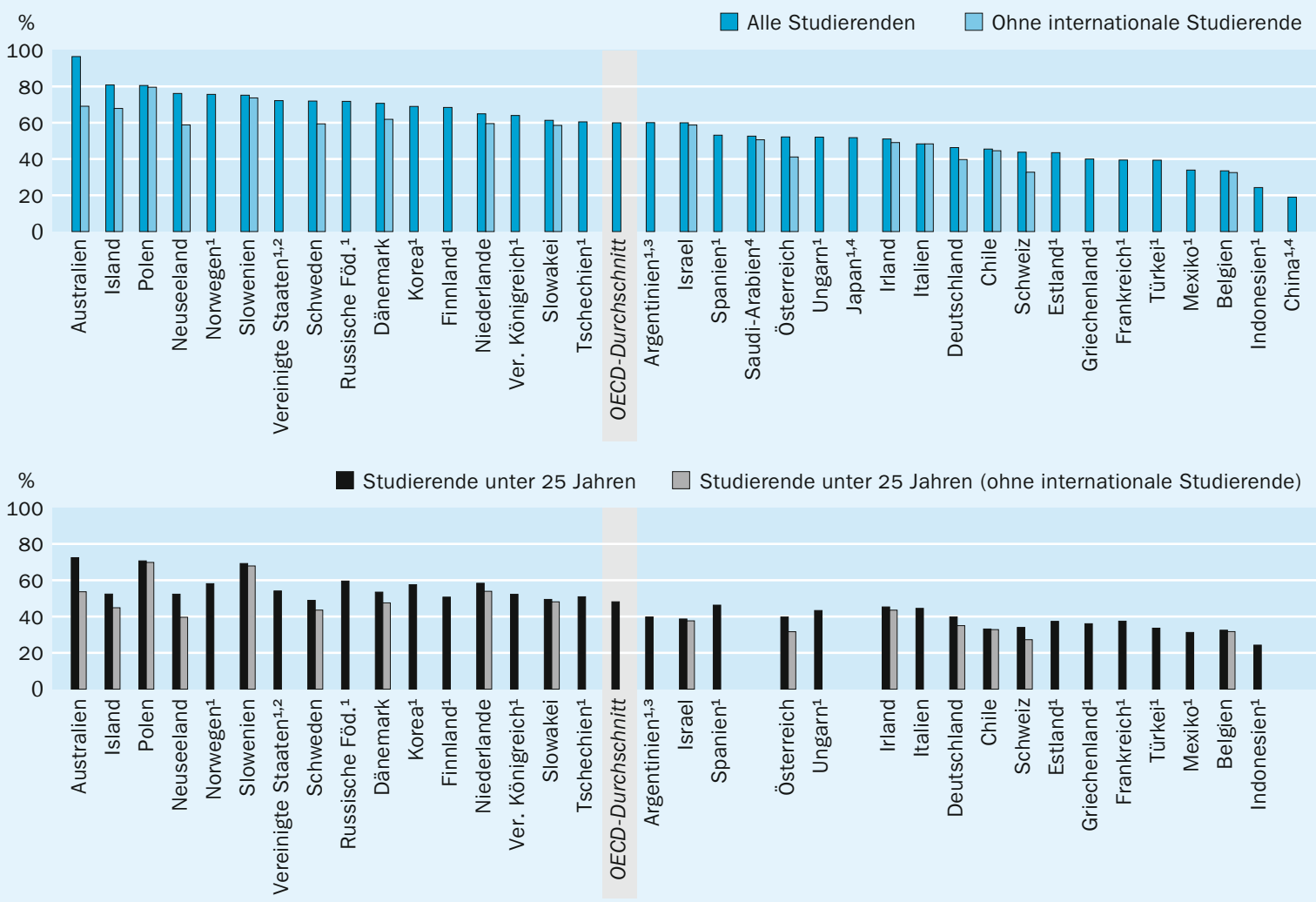

1. Es liegen keine Daten zu Studienanfängern vor, die internationale Studierende sind. 2. Studienanfängerquoten für den Tertiärbereich A enthalten auch Studienanfängerquoten für den Tertiärbereich B. 3. Referenzjahr 2010. 4. Es liegen keine nach Alter aufgeschlüsselten Studienanfängerzahlen vor. Anordnung der Länder in absteigender Reihenfolge der Studienanfängerquoten im Tertiärbereich A im Jahr 2011.

Quelle: OECD. Argentinien, China, Indonesien: Statistikinstitut der UNESCO (World Education Indicators Programme). Saudi-Arabien: Observatory on Higher Education. Tabellen C3.1a und C3.1b. Hinweise s. Anhang 3 unter www.oecd.org/edu/eag.htm. StatLink: http://dx.doi.org/10.1787/888932847469 


\section{Kontext}

Studienanfängerquoten stellen eine Schätzung des Anteils der Bevölkerung dar, der im Laufe des Lebens wahrscheinlich ein Studium im Tertiärbereich aufnehmen wird. Sie sind außerdem ein Hinweis auf die Zugangsmöglichkeiten zum Tertiärbereich und den Wert, der einer Ausbildung im Tertiärbereich beigemessen wird, sowie ein Anhaltspunkt dafür, in welchem Umfang die Bevölkerung die Fähigkeiten und Kenntnisse auf hohem Qualifikationsniveau erwirbt, die Grundvoraussetzung und Antriebsmotor für die wissensbasierten Volkswirtschaften von heute sind. Hohe Studienanfänger- und Beteiligungsquoten im Tertiärbereich lassen darauf schließen, dass eine hoch qualifizierte Erwerbsbevölkerung herangebildet und aufrechterhalten wird.

In den OECD-Ländern hat die Überzeugung, dass durch einen Hochschulabschluss erworbene Fähigkeiten und Kenntnisse einen höheren Stellenwert haben als die von Menschen mit einem niedrigeren Bildungsstand, ihre Ursache in der durchaus begründeten Befürchtung, dass „Routinetätigkeiten“ in Niedriglohnländer exportiert oder automatisiert werden können, sowie in dem wachsenden Verständnis dafür, dass Wissen und Innovation von zentraler Bedeutung für ein nachhaltiges Wirtschaftswachstum sind. Die Bildungseinrichtungen des Tertiärbereichs sehen sich nicht nur der Aufgabe gegenüber, den steigenden Bedarf durch die Erhöhung der Anzahl der angebotenen Studienplätze zu decken, sondern auch Studiengänge und Lehrmethoden an die unterschiedlichen Bedürfnisse einer neuen Generation von Studierenden anzupassen.

\section{Weitere wichtige Ergebnisse}

Während davon ausgegangen wird, dass 5 Prozent der Studierenden in Deutschland, der Schweiz und Slowenien im Laufe des Lebens einen weiterführenden forschungsorientierten Studiengang belegen werden, wird dies in Argentinien, Chile, Indonesien, Mexiko, SaudiArabien, Spanien und der Türkei wahrscheinlich bei weniger als I Prozent der Studierenden der Fall sein.

Im Durchschnitt aller OECD-Länder liegen die Studienanfängerquoten im Tertiärbereich A bei Frauen (mit 67 Prozent) immer noch höher als bei Männern (53 Prozent), bei weiterführenden forschungsorientierten Studiengängen jedoch bestehen nahezu keine geschlechtsspezifischen Unterschiede.

Basierend auf aktuellen Studienanfängerquoten wird davon ausgegangen, dass im Durchschnitt 19 Prozent der jungen Menschen von heute (20 Prozent der Frauen und 18 Prozent der Männer) im Laufe ihres Lebens einen (kürzeren und weitgehend beruflich ausgerichteten) Studiengang im Tertiärbereich B aufnehmen werden.

In allen Ländern mit Ausnahme von Finnland, Korea und Saudi-Arabien waren die am häufigsten von den Studienanfängern gewählte Fächergruppe die Sozial-, Rechts- und Wirtschaftswissenschaften. 


\section{Entwicklungstendenzen}

Zwischen I995 und 20II stiegen die Studienanfängerquoten im Tertiärbereich A im Durchschnitt der OECD-Länder um mehr als 20 Prozentpunkte, während sie sich im Tertiärbereich B kaum veränderten. Dieser Anstieg ist auf einen inzwischen in vielen Ländern erweiterten Zugang zum Tertiärbereich zurückzuführen, aber auch auf strukturelle Veränderungen in den Bildungssystemen einiger Länder, wie die Einrichtung neuer Studiengänge (um den Anforderungen der Arbeitsmärkte gerecht zu werden) oder kürzerer Studiengänge (im Rahmen der Umsetzung des Bologna-Prozesses). Ein weiterer Grund für die gestiegenen Anfängerquoten im Tertiärbereich ist die breitere Bewerberbasis, die inzwischen auch eine wesentlich höhere Zahl internationaler (s. Indikator $\mathrm{C}_{4}$ ) und älterer Studierender umfasst.

\section{Hinweis}

Anfängerquoten zeigen den geschätzten Prozentsatz einer Altersgruppe, der im Laufe des Lebens ein Studium im Tertiärbereich aufnehmen wird. Die Schätzung basiert auf der Zahl der Studienanfänger im Jahr 20 II und der Altersverteilung in dieser Gruppe. Daher basieren die Anfängerquoten auf der Annahme einer „synthetischen“ Kohorte, nach der die aktuellen Anfängerquoten die beste Schätzung für das Verhalten junger Erwachsener von heute im Laufe ihres Lebens darstellen. Anfängerquoten reagieren sensibel auf jede Änderung im Bildungssystem, wie die Einführung neuer Studiengänge (im Rahmen der Umsetzung des Bologna-Prozesses) oder Veränderungen der Zahl internationaler Studierender. Anfängerquoten können sehr hoch sein und in einem Zeitraum, in dem nicht in der Prognose enthaltene Personen beschließen, ein Studium aufzunehmen, sogar mehr als soo Prozent betragen (was eindeutig darauf hinweist, dass die Annahme einer synthetischen Kohorte nicht plausibel ist). In Australien beispielsweise sinkt die Anfängerquote im Tertiärbereich A um mehr als 25 Prozentpunkte, wenn internationale Studierende nicht berücksichtigt werden. In Portugal haben sich sehr viele Frauen über 25 dazu entschieden, ein Studium aufzunehmen, daher ist die Anfängerquote bei den Frauen von 2007 bis $201 \mathrm{I}$ um 40 Prozentpunkte gestiegen. 


\section{Analyse und Interpretationen}

\section{Zugang zum Tertiärbereich}

In den OECD-Ländern werden schätzungsweise 6o Prozent der jungen Erwachsenen von heute im Laufe ihres Lebens einen Studiengang im Tertiärbereich A aufnehmen, sofern die aktuellen Studienanfängerquoten auch für die Zukunft gelten. In mehreren Ländern werden wahrscheinlich mindestens 70 Prozent der jungen Erwachsenen ein Studium im Tertiärbereich aufnehmen, während es in Belgien, Chile, China, Indonesien und Mexiko wahrscheinlich höchstens 35 Prozent sein werden (Abb. C3.I).

Der Anteil derjenigen, die ein Studium im Tertiärbereich B aufnehmen, ist im Allgemeinen vor allem deshalb niedriger, weil diese Studiengänge in den meisten OECDLändern in geringerem Umfang angeboten werden. Die Bandbreite reicht von weniger als 5 Prozent in Island, Indonesien, Mexiko, Polen und der Slowakei bis zu mehr als 35 Prozent in Belgien, Korea und Neuseeland und mehr als 50 Prozent in Argentinien und Chile (Tab. C3.ra).

Im Gegensatz hierzu wird in Belgien und Chile davon ausgegangen, dass die Studienanfängerquoten im Tertiärbereich B höher als im Tertiärbereich A sein werden. In diesen beiden Ländern gleicht ein breiter Zugang zu Studiengängen im Tertiärbereich B vergleichsweise geringe Studienanfängerquoten im Tertiärbereich A aus (Abb. $\mathrm{C}_{3.2}$ ). Andere Länder, vor allem Israel und das Vereinigte Königreich, haben im eher theoretisch orientierten Tertiärbereich A Studienanfängerquoten, die ungefähr dem OECD-Durchschnitt entsprechen, und vergleichsweise hohe Studienanfängerquoten im eher berufsorientierten Tertiärbereich B. Obwohl Neuseeland zu den OECD-Ländern gehört, die für beide Tertiärbereiche mit die höchsten Studienanfängerquoten aufweisen, werden diese jedoch durch eine größere Zahl älterer und internationaler Studierender überhöht (Tab. C3.ra).

In einigen Ländern können hohe Anfängerquoten vorübergehende Phänomene widerspiegeln, wie z. B. Hochschulreformen im Rahmen der Umsetzung des Bologna-Prozesses, Auswirkungen der Wirtschaftskrise oder die Zunahme der Zahl internationaler Studierender.

Im Durchschnitt aller OECD-Länder mit vergleichbaren Daten stieg der Anteil der jungen Erwachsenen, die ein Studium im Tertiärbereich A aufnahmen, zwischen 2000 und 201 I um I3 Prozentpunkte und zwischen 1995 und 201 I um 2I Prozentpunkte (Tab. $C_{3}$.2a). Die Studienanfängerquoten bei diesen Studiengängen nahmen zwischen 2000 und $201 \mathrm{I}$ in Australien, Korea, Saudi-Arabien, der Slowakei und Tschechien um mehr als 20 Prozentpunkte zu. In Korea war der Anstieg (von 2007 auf 2008) vor allem auf eine Umklassifizierung der Studiengänge des Tertiärbereichs B in Studiengänge des Tertiärbereichs A zurückzuführen. Im Gegensatz hierzu sind Finnland, Neuseeland und Ungarn die einzigen OECD-Länder, in denen es einen Rückgang bei den Studienanfängerquoten für diese Studiengänge gab. In Ungarn wurde dieser Rückgang im gleichen Zeitraum jedoch durch eine signifikante Steigerung der Studienanfängerquoten im Tertiärbereich B ausgeglichen. In Neuseeland spiegelten Anstieg und Rückgang der Studienanfängerquoten von 2000 auf 20 II den Anstieg und Rückgang der Zahl internationaler Studierender in diesem Zeitraum wider (Abb. C3.2). 


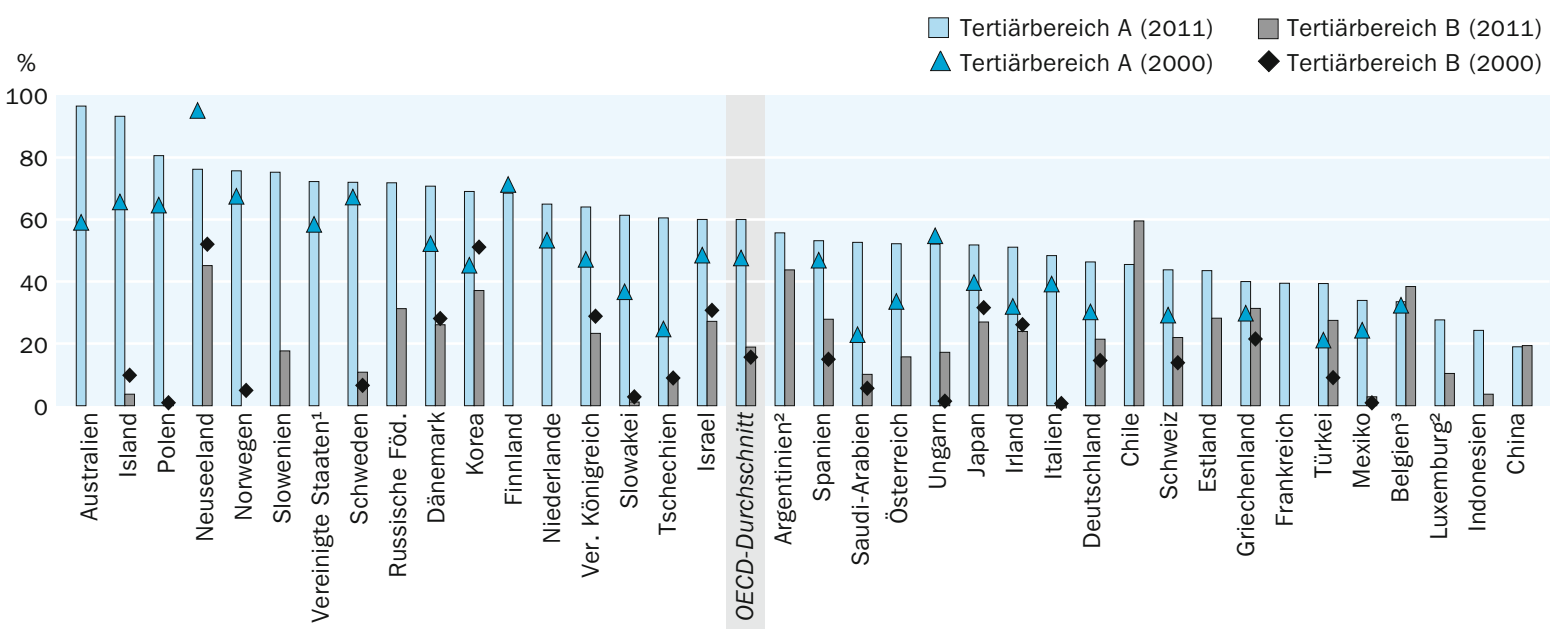

1. Studienanfängerquoten für den Tertiärbereich A enthalten auch Studienanfängerquoten für den Tertiärbereich B. 2. Referenzjahr 2010 anstelle 2011.

3. Referenzjahr 2001 anstelle 2000.

Anordnung der Länder in absteigender Reihenfolge der Studienanfängerquoten im Tertiärbereich A im Jahr 2011.

Quelle: OECD. Argentinien, China, Indonesien: Statistikinstitut der UNESCO (World Education Indicators Programme). Saudi-Arabien: Observatory on Higher

Education. Tabelle C3.2a. Hinweise s. Anhang 3 unter www.oecd.org/edu/eag.htm. StatLink: http://dx.doi.org/10.1787/888932847488

In den OECD-Ländern sind die Gesamtnettostudienanfängerquoten in Studiengängen des Tertiärbereichs B zwischen 2000 und 201 I relativ stabil geblieben, mit Ausnahme von Spanien, der Türkei und Ungarn, wo sie um mehr als Io Prozentpunkte stiegen, und Korea, wo sie um fast ${ }_{5}$ Prozentpunkte sanken (Abb. C3.2).

Rund 3 Prozent der heutigen Jugendlichen in den OECD-Ländern werden (unter Annahme der aktuellen Studienanfängerquoten) im Laufe ihres Lebens einen weiterführenden forschungsorientierten Studiengang belegen. Die Zahlen reichen in den Ländern mit vergleichbaren Daten von weniger als I Prozent in Argentinien, Chile, Indonesien, Mexiko, Saudi-Arabien, Spanien und der Türkei bis zu rund 5 Prozent in Deutschland, der Schweiz und Slowenien (Tab. C3.ra).

\section{Alter der Studienanfänger im Tertiärbereich}

20II waren im Durchschnitt der OECD-Länder 8I Prozent der Erststudienanfänger im Tertiärbereich A und 62 Prozent im Tertiärbereich B jünger als 25 Jahre. Außerdem waren 20 II rund 56 Prozent der Studierenden, die einen weiterführenden forschungsorientierten Studiengang aufnahmen, jünger als 30 Jahre (Tab. C3.Ib).

Das Alter der Studienanfänger im Tertiärbereich variiert aus unterschiedlichen Gründen zwischen den einzelnen OECD-Ländern, u.a. aufgrund von Unterschieden im typischen Abschlussalter für den Sekundarbereich II (s. Tab. XI.ra und XI.rb), der Aufnahmekapazität von Einrichtungen (Numerus clausus bei der Zulassung, eine von zahlreichen Methoden zur Beschränkung der Zulassungszahlen für Studierende) sowie der Opportunitätskosten des Eintritts in den Arbeitsmarkt, bevor ein Studium im Tertiärbereich aufgenommen wird. 
Während der jüngsten Wirtschaftskrise haben einige junge Erwachsene ihren Eintritt in den Arbeitsmarkt aufgeschoben und sind stattdessen im Bildungssystem verblieben. In einigen Ländern wurde außerdem für Menschen, die die Schule früh verlassen haben, der sogenannte zweite Bildungsweg ausgebaut, um die Qualifizierung der Arbeitskräfte zu verbessern und verstärkt Möglichkeiten zum Erwerb von praxisorientierten Kenntnissen und Fähigkeiten zu bieten. Nichtsdestotrotz verursacht ein späterer Eintritt in den Tertiärbereich höhere Kosten - sowohl für den Einzelnen als auch für den Staat. Er bedeutet, dass das produktive Potenzial dieser Menschen für einen gewissen Zeitraum nicht genutzt wird. Damit sinken die Steuereinnahmen, die staatlichen Ausgaben hingegen können steigen. Für ältere Studierende kann es schwieriger sein, Arbeit und Studium zu verbinden, was dazu führen kann, dass sie nicht in der Lage sind, ihr Studium rechtzeitig abzuschließen. Von staatlicher Seite werden inzwischen Maßnahmen zur Förderung eines rechtzeitigen Abschlusses eingeführt, da bekannt ist, dass Verzögerungen beim Erreichen eines Abschlusses zu höheren Ausbildungskosten führen.

Traditionellerweise nehmen Studierende das Studium im Tertiärbereich direkt nach dem Abschluss des Sekundarbereichs II auf, und das ist auch heute immer noch in vielen OECD-Ländern der Fall. So sind beispielsweise in Belgien, Indonesien, Italien und Mexiko mehr als 90 Prozent der Erststudienanfänger im Tertiärbereich A und B jünger als 25 Jahre. In anderen OECD-Ländern erfolgt der Übergang vom Sekundarbereich II zum Tertiärbereich unter Umständen erst später, z. B. aufgrund einer Zeit der Erwerbstätigkeit oder der Ableistung von Militärdienst. So sind beispielsweise in Island, Israel und Portugal nur zwei Drittel aller Erststudienanfänger im Tertiärbereich A jünger als 25 Jahre. In diesen Ländern ist die Altersspanne von Erststudienanfängern im Tertiärbereich A oder B wesentlich größer (Tab. C3.Ib).

Der Anteil der älteren Studienanfänger in einem derartigen Erststudium (Tertiärbereich A und B) kann ein Anzeichen für die Flexibilität dieser Studiengänge und ihrer Eignung für Studierende, die nicht der typischen Altersgruppe angehören, sein. Darüber hinaus kann er die Wertschätzung von Berufserfahrung vor der Aufnahme eines Hochschulstudiums widerspiegeln, was charakteristisch für die nordischen Länder und auch in Australien, Chile, Neuseeland, Österreich, Ungarn und den Vereinigten Staaten durchaus üblich ist, wo ein beträchtlicher Teil der Studierenden mit einem deutlich höheren Alter als dem typischen Eintrittsalter das Studium aufnimmt. Die Gründe unterscheiden sich stark von Land zu Land. In Australien beispielsweise nehmen junge Leute in zunehmendem Maße vor Beginn des Studiums ein Jahr Auszeit, dies war im Zeitraum 2009/2010 bei fast 25 Prozent der Schüler der Fall, und 5I Prozent von ihnen gaben „Arbeit“ als wichtigsten Grund hierfür an (Lumsden and Stanwick, 2012). In einigen Ländern müssen junge Erwachsene Wehrdienst leisten, der die Aufnahme eines Studiums verzögert. Dies ist in Israel der Fall, wo für I8- bis 2I-jährige Männer und I8- bis 20-jährige Frauen Wehrpflicht besteht.

\section{Auswirkungen internationaler Studierender auf die Studienanfänger- quoten im Tertiärbereich A}

Alle internationalen Studierenden, die sich zum ersten Mal in einem Land einschreiben, gelten per Definition als Studienanfänger, unabhängig von bereits absolvierten Bildungsgängen in anderen Ländern. Um die Auswirkungen internationaler Studierender auf die Studienanfängerquoten im Tertiärbereich A aufzuzeigen, enthalten die 
Tabellen $\mathrm{C}_{3}$.Ia und $\mathrm{C}_{3}$.Ib sowohl die unbereinigten als auch die bereinigten Studienanfängerquoten, d. h. die Studienanfängerquoten nach Abzug der internationalen Studierenden.

Unter den Ländern mit vergleichbaren Daten weist Australien mit 27 Prozentpunkten den höchsten Unterschied zwischen unbereinigten und bereinigten Studienanfängerquoten auf. Auch in Island, Neuseeland, Österreich, Schweden und der Schweiz wirkt sich die Anwesenheit internationaler Studierender stark auf die Studienanfängerquoten aus: Es ergeben sich Unterschiede von II bis I7 Prozentpunkten (Tab. C3.Ia).

Der erwartete Prozentsatz der Studienanfänger im Tertiärbereich A ändert sich deutlich, wenn ältere und internationale Studierende nicht berücksichtigt werden. Diese beiden Gruppen sind in einigen Ländern ein wesentlicher Bestandteil der studierenden Bevölkerung und können den zu erwartenden Anteil der jungen Erwachsenen von heute, die ein Studium aufnehmen werden, überhöhen. Werden internationale und ältere Studierende nicht berücksichtigt, sind Polen und Slowenien die beiden Länder mit dem höchsten Prozentsatz der Bevölkerung, der im Alter von unter 25 Jahren ein Studium im Tertiärbereich A aufnehmen wird. Der höhere Prozentsatz in Polen hängt mit dem Anstieg der Zahl der Absolventen des Sekundarbereichs II aufgrund der Bildungsreformen von 1999 zusammen. Diese Reformen waren darauf ausgerichtet, die Qualität der Bildung im Sekundar- und Tertiärbereich zu steigern und die Chancengleichheit zu erhöhen. Polen und Slowenien sind außerdem zwei der sechs Länder mit dem höchsten Anteil 25- bis 34-Jähriger, die mindestens über einen Abschluss im Sekundarbereich II verfügen (s. Indikator AI).

\section{Übergänge zwischen Tertiärbereich A und B}

In einigen Ländern werden Studiengänge im Tertiärbereich A und Tertiärbereich B von unterschiedlichen Arten von Bildungseinrichtungen angeboten. Immer häufiger jedoch bieten Universitäten oder andere Einrichtungen Studiengänge beider Bereiche an. Außerdem werden sich die beiden Bereiche im Hinblick aufCurricula, Ausrichtung und Lernergebnisse immer ähnlicher.

In einigen Ländern haben Absolventen des Tertiärbereichs B die Möglichkeit, zu Studiengängen des Tertiärbereichs A zugelassen zu werden, normalerweise zum zweiten oder dritten Studienjahr, oder sogar zu einem Masterstudiengang. Die Studienanfängerquoten für den Tertiärbereich A und den Tertiärbereich B zur Bestimmung der Gesamtstudienanfängerquoten für den Tertiärbereich einfach aufzuaddieren würde zu überhöhten Zahlen führen. Die Zulassung ist je nach Land oder Studiengang oft an bestimmte Bedingungen gebunden, wie z. B. das Bestehen einer besonderen Prüfung, vorherige persönliche oder berufliche Leistungen und/oder das Absolvieren eines „Brückenkurses“. In einigen Fällen können Studierende, die einen theoretisch orientierten Studiengang (im Tertiärbereich A) ohne Abschluss verlassen, ihr Studium im Tertiärbereich B (berufsorientiert) erfolgreich fortsetzen.

Studienanfängerquoten nach Fächergruppen (Tertiärbereich A und B) In fast allen Ländern ist ein großer Teil der Studierenden für ein Studium in der Fächergruppe Sozial-, Wirtschafts- oder Rechtswissenschaften eingeschrieben. 20II entfiel in allen Ländern, mit Ausnahme von Finnland, Korea und Saudi-Arabien, der höchste 
Abbildung $\mathbf{C 3 . 3}$

Verteilung der Studienanfänger nach Fächergruppe (2011)

Es werden nur die Fächergruppen aufgezeigt, in denen 2011 mehr als 20 Prozent der Studierenden ein Studium aufnahmen.

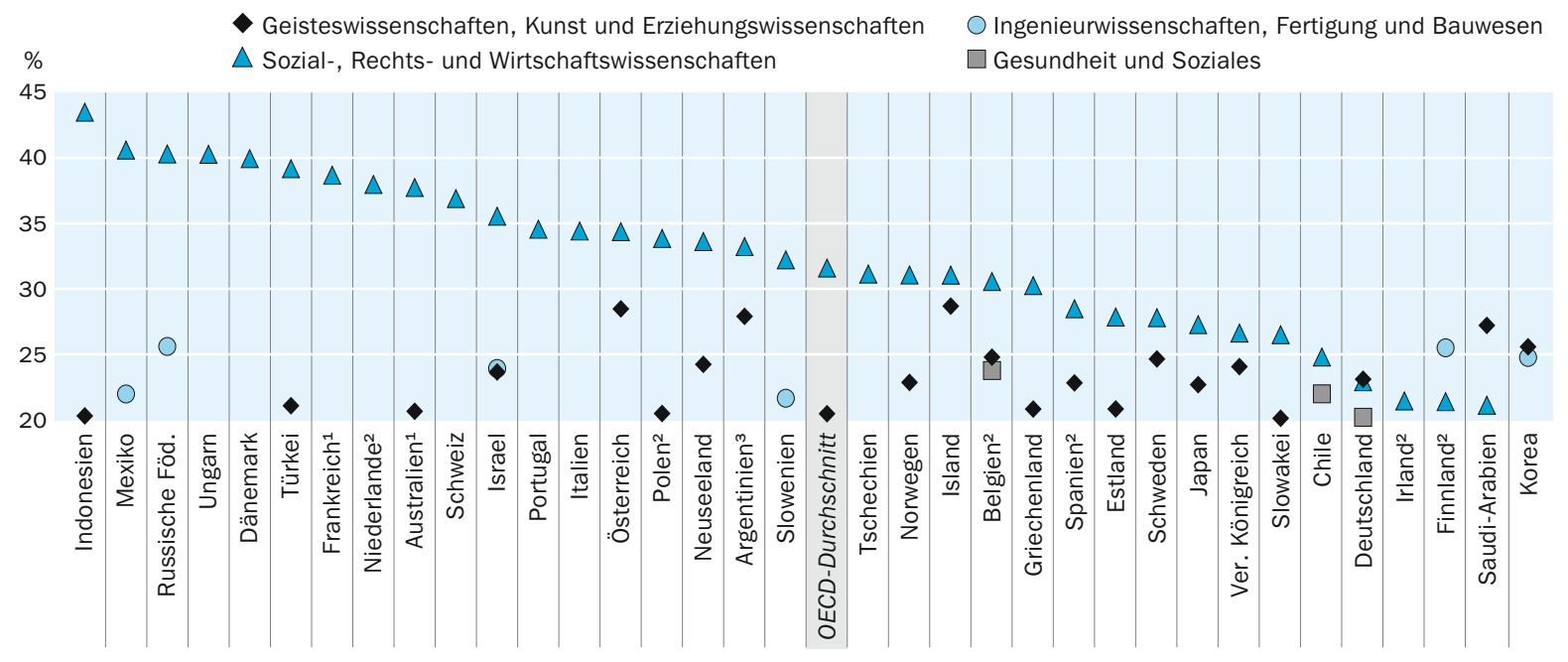

1. Ohne Studiengänge im Tertiärbereich B. 2. Ohne weiterführende forschungsorientierte Studiengänge. 3. Referenzjahr 2010.

Anordnung der Länder in absteigender Reihenfolge der Studienanfänger in den Sozial-, Rechts- und Wirtschaftswissenschaften im Jahr 2011.

Quelle: OECD. Argentinien, Indonesien: Statistikinstitut der UNESCO (World Education Indicators Programme). Saudi-Arabien: Observatory on Higher Education.

Tabelle Сз.за. Hinweise s. Anhang 3 unter www.oecd.org/edu/eag2013. StatLink: http://dx.doi.org/10.1787/888932847507

Anteil der Studienanfänger auf diese Fächergruppe. In Finnland wählten die meisten Studienanfänger einen Studiengang aus der Fächergruppe Ingenieurwissenschaften, Fertigung und Bauwesen, wohingegen in Korea und Saudi-Arabien die Fächergruppen Geisteswissenschaften, Kunst und Erziehungswissenschaften den größten Zulauf erfuhren (Abb. C3.3).

Studiengänge aus naturwissenschaftlich ausgerichteten Fächergruppen, dies umfasst die Natur- und Ingenieurwissenschaften, Fertigung und Bauwesen, werden weniger häufig gewählt. Im Durchschnitt entscheidet sich nur ein Viertel aller Studierenden für die Aufnahme eines Studiums in diesen Fächergruppen (Tab. C3.3a). Dieser geringe Anteil an der Gesamtzahl der Studierenden ist teilweise darauf zurückzuführen, dass Frauen in diesen Fächergruppen unterrepräsentiert sind. 20II haben sich im Durchschnitt nur I4 Prozent der weiblichen Studienanfänger im Tertiärbereich für einen Studiengang aus diesen Fächergruppen entschieden gegenüber 39 Prozent der männlichen Studienanfänger. Bei den Studienanfängern reicht der Anteil der Frauen in naturwissenschaftlich ausgerichteten Studiengängen von 5 Prozent in Belgien und Japan bis zu I9 Prozent in Griechenland, Indonesien, Italien und Mexiko, während der Anteil der Männer in diesen Studiengängen von I8 Prozent in Argentinien bis zu 58 Prozent in Finnland reicht (Tab. $\mathrm{C}_{3} \cdot 3 \mathrm{~b}$ im Internet).

Die Verteilung der Studienanfänger nach Fächergruppen fällt bei den weiterführenden forschungsorientierten Studiengängen ganz anders aus als für den Tertiärbereich insgesamt. Obwohl die Sozial-, Rechts-, Wirtschaftswissenschaften 20 I die beliebtesten Fächergruppen der Studierenden im Tertiärbereich waren, haben Promotionsstudierende naturwissenschaftlich ausgerichtete Studiengänge etwas stärker bevorzugt als diese Fächergruppen. Fast ein Viertel der Studierenden, die ein Promotionsstudium aufnah- 
Studienanfängerquoten bei weiterführenden forschungsorientierten Studiengängen und durchschnittliches Alter der Studienanfänger (2011)

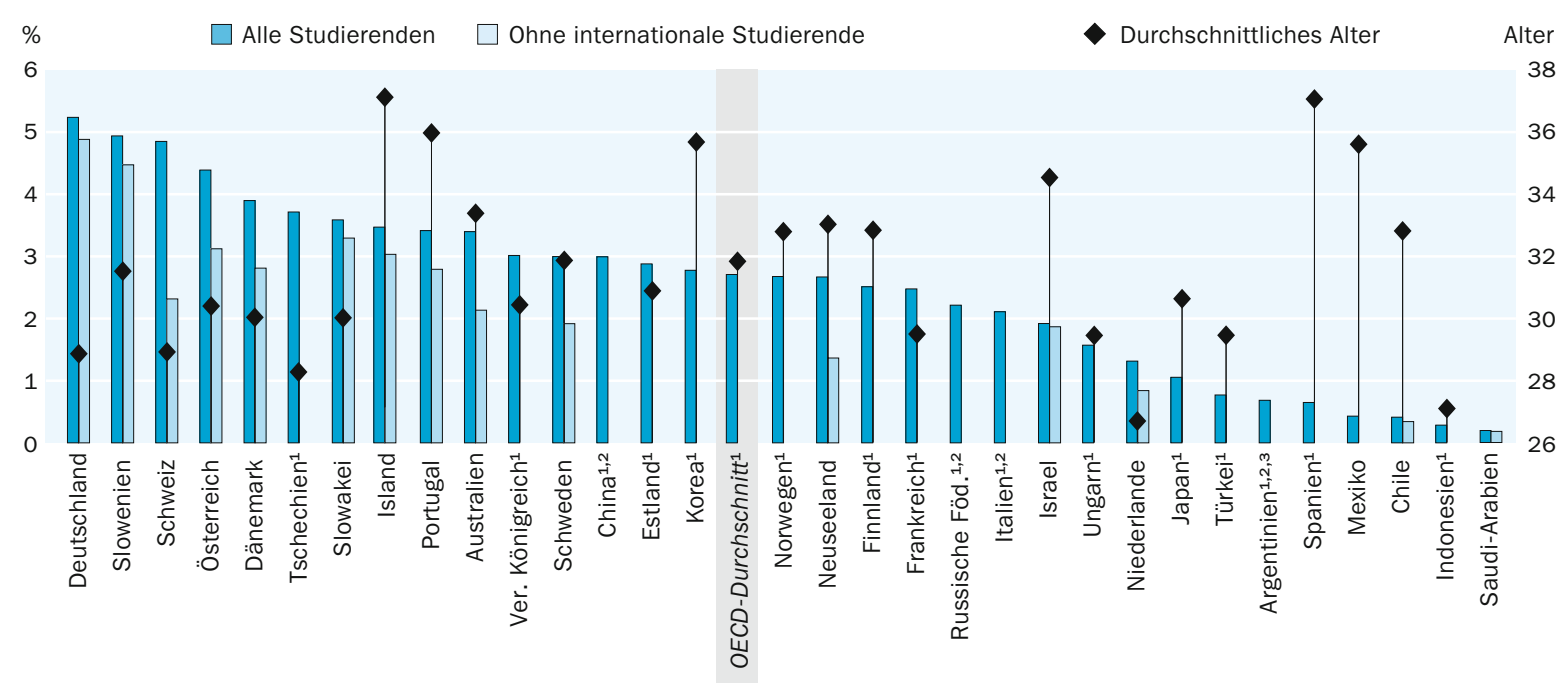

Anmerkung: Das durchschnittliche Alter bezieht sich auf ein gewichtetes durchschnittliches Alter, in der Regel das Alter der Studierenden zu Beginn des Kalenderjahrs. Die Studierenden können ein Jahr älter als das angegebene durchschnittliche Alter sein, wenn sie ihren Abschluss am Ende des Studienjahrs erwerben. Informationen zur Berechnung des durchschnittlichen Alters s. Anhang 3.

1. Es liegen keine Daten zu Studienanfängern vor, die internationale Studierende sind. 2. Es liegen keine nach Alter aufgeschlüsselten Studienanfängerzahlen vor. 3. Referenzjahr 2010.

Anordnung der Länder in absteigender Reihenfolge der Studienanfänger bei weiterführenden forschungsorientierten Studiengängen im Jahr 2011.

Quelle: OECD. Argentinien, China, Indonesien: Statistikinstitut der UNESCO (World Education Indicators Programme). Saudi-Arabien: Observatory on Higher Education. Tabelle C3.1a. Hinweise s. Anhang 3 unter www.oecd.org/edu/eag2013. StatLink: http://dx.doi.org/10.1787/888932847526

men, wählte die Naturwissenschaften (23 Prozent) - dieser Anteil ist mehr als doppelt so hoch wie der der Studienanfänger in dieser Fächergruppe (Io Prozent). In Chile, Frankreich und Israel entschieden sich mehr als 35 Prozent der Studierenden in einem weiterführenden forschungsorientierten Studiengang für die Naturwissenschaften.

Die Attraktivität bestimmter Fächergruppen variiert manchmal abhängig vom Bildungsbereich. In Dänemark beispielsweise nimmt jeder fünfte Promotionsstudierende ein weiterführendes forschungsorientiertes Studium in Mathematik und Statistik auf, wohingegen dieser Studiengang nur von I Prozent der dänischen Studierenden im Tertiärbereich gewählt wird (Tab. C3.3c im Internet).

\section{Weiterführende forschungsorientierte Studiengänge: Die Wissensfabrik der Gesellschaft}

Forschung auf Promotionsniveau ist von entscheidender Bedeutung für die Förderung von Innovationen und Wirtschaftswachstum und trägt signifikant zur nationalen und internationalen Wissensbasis bei. Für Unternehmen sind Länder, die einen leichten Zugang zu Forschungsvorhaben auf diesem Niveau bieten, von großem Interesse (Halse and Mowbray, 20II; Smith, 20I0), während Absolventen dieser Studiengänge von höheren Einkommen und besseren Beschäftigungsquoten profitieren (s. Indikatoren $\mathrm{A}_{5}$ und $\mathrm{A} 6$ ).

Viele OECD-Länder investieren stark, um Promotionsstudiengänge anbieten zu können. Abbildung $\mathrm{C}_{3} .4$ zeigt den Anteil der Studierenden in den OECD-Ländern, die ihr 
Studium bis zum höchsten akademischen Abschluss fortsetzen werden. In Deutschland, der Schweiz und - aufgrund der Umsetzung des Bologna-Prozesses (EC, 2013) in Slowenien - wird davon ausgegangen, dass jeder 20. Studierende einen weiterführenden forschungsorientierten Studiengang aufnehmen wird. In Argentinien, Chile, Indonesien, Mexiko, Saudi-Arabien, Spanien und der Türkei hingegen wird (unter Zugrundelegung der aktuellen Zahlen) erwartet, dass dies bei weniger als I Prozent der Studierenden im Lauf ihres Lebens der Fall sein wird (Tab. C3.ra).

Verschiedene Länder entwickeln zurzeit Promotionsstudiengänge, um internationale Studierende zu attrahieren, also Studierende, die aus ihrem Herkunftsland zwecks Studium in ein anderes Land gehen. Die besten Studierenden aus der ganzen Welt zu attrahieren trägt dazu bei sicherzustellen, dass ein Land bei Forschung und Innovation eine führende Rolle einnehmen kann (Smith, 2010). Mehr als die Hälfte der Studienanfänger in Promotionsstudiengängen in Neuseeland und der Schweiz sind internationale Studierende (Abb. C3.4). Außerdem stellten $201 \mathrm{I}$ - wie aus Indikator $\mathrm{C}_{4}$ ersichtlich - ausländische Studierende, also Studierende, die nicht Staatsbürger des Landes sind, in dem die Daten erhoben wurden, in Neuseeland (mit 40 Prozent), der Schweiz (49 Prozent) und dem Vereinigten Königreich (4I Prozent) einen Großteil der Studierenden in diesen Studiengängen.

Obwohl in den OECD-Ländern fast 6o Prozent der Studienanfänger ihr Studium in einem weiterführenden forschungsorientierten Studiengang vor ihrem 30. Geburtstag aufgenommen haben, bestehen zwischen den einzelnen Ländern signifikante Unterschiede. In Deutschland, Indonesien, den Niederlanden und Tschechien sind mehr als 75 Prozent der Studierenden bei Aufnahme eines Studiums in diesem Bildungsbereich jünger als 30 Jahre, während in Island, Israel, Korea, Mexiko, Portugal und Spanien das durchschnittliche Alter bei mehr als 35 Jahren liegt (Tab. C3.ra und C3.Ib).

Diese Unterschiede können auf mehrere Faktoren zurückzuführen sein. Sie könnten geringere Abbruchquoten und eine größere Bedeutung des Erwerbs spezieller Kompetenzen widerspiegeln. Einige Länder bieten spezielle Anreize, wie Studienbeihilfen, Stipendien, internationale Mobilitätsprogramme, Teilzeitbeschäftigungen und Fernstudiengänge, um Studierende zu motivieren, ihre Ausbildung auf diesem hohen Niveau fortzusetzen. Eine späte Aufnahme eines Promotionsstudiums könnte darauf hindeuten, dass diesen Studierenden geraten wurde, vor Fortführung ihrer formalen Ausbildung erst einige Berufserfahrung zu sammeln.

Die Promotionsstudiengänge sind der einzige Bildungsbereich, in dem nahezu keine geschlechtsspezifischen Unterschiede bestehen. Während in jedem anderen Bildungsbereich der Anteil der Frauen höher als der der Männer ist, ist dies der einzige Bildungsbereich, in dem der Anteil der Männer bei den Anfängern (und folglich bei den Absolventen) etwas höher als der der Frauen ist. Im Durchschnitt aller OECD-Länder nehmen 2,8 Prozent der Männer und 2,7 Prozent der Frauen ein Promotionsstudium auf (Tab. C3.ra). 


\section{Definitionen}

Studierende werden als internationale Studierende bezeichnet, wenn sie aus ihrem Herkunftsland zwecks Studium in ein anderes Land gekommen sind. Internationale Studierende, die im Rahmen eines Postgraduiertenstudiums zum ersten Mal an dem Bildungssystem eines Landes teilnehmen, gelten als Studienanfänger im Erststudium.

Studienanfänger im Erststudium sind Studierende, die sich zum ersten Mal in dem entsprechenden Bildungsbereich einschreiben.

Die Studienanfängerquote ist die geschätzte Wahrscheinlichkeit, mit der ein junger Erwachsener im Laufe des Lebens ein Studium im Tertiärbereich aufnehmen wird (ausgehend von den aktuellen Studienanfängerquoten).

\section{Angewandte Methodik}

Die Daten beziehen sich auf das Studienjahr 20I0/20II und beruhen auf der von der OECD im Jahre 2012 durchgeführten UOE-Datenerhebung zur Bildungsstatistik (weitere Informationen s. Anhang 3 unter www.oecd.org/eduleag.htm). Die Fächergruppen, die in der UOE-Datenerhebung verwendet wurden, entsprechen der überarbeiteten ISCED-97-Klassifizierung nach Fächergruppen. Diese Klassifizierung nach Fächergruppen wird auf alle Bildungsbereiche angewendet.

Die Daten zur Entwicklung der Studienanfängerquoten (Tab. C3.2a) für die Jahre I995, 2000, 2001, 2002, 2003 und 2004 basieren auf einer speziellen Erhebung, die im Januar 2007 in OECD-Ländern durchgeführt wurde.

Die Daten zu den Auswirkungen internationaler Studierender auf die Studienanfängerquoten basieren auf einer im Dezember 2012 von der OECD durchgeführten speziellen Erhebung.

Die Tabellen C3.ra, C3.rb, C3.2a und Tab. C3.2b im Internet enthalten die Summe der Netto-Studienanfängerquoten.

Die Netto-Studienanfängerquote eines speziellen Altersjahrgangs wird berechnet, indem die Zahl der Erststudienanfänger des speziellen Altersjahrgangs in den einzelnen Tertiärbereichen durch die Gesamtpopulation des entsprechenden Altersjahrgangs geteilt wird. Die Summe der Netto-Studienanfängerquoten wird berechnet, indem die Studienanfängerquoten der einzelnen Altersjahrgänge aufaddiert werden. Das Ergebnis zeigt die geschätzte Wahrscheinlichkeit, mit der ein Schulabgänger im Laufe des Lebens ein Studium im Tertiärbereich aufnehmen wird, sofern die heutigen altersspezifischen Studienanfängerquoten unverändert bleiben.

Das gewichtete Durchschnittsalter bei Aufnahme des Studiums wird berechnet, indem den Altersjahrgängen ein höheres Gewicht zugewiesen wird, in denen die Zahl der Studierenden, die in einen neuen Bildungsbereich eintreten, höher ist. Diese Variable vermittelt eine genaue Vorstellung vom durchschnittlichen Eintrittsalter. Sie wird in 
der vorliegenden Ausgabe von Bildung auf einen Blick zum ersten Mal verwendet, um die Erkenntnisse in diesem Indikator zu vertiefen. Weitere Informationen s. Anhang 3 unter www.oecd.orgleduleag.htm.

Nicht alle OECD-Länder unterscheiden zwischen Studierenden, die zum ersten Mal einen Studiengang des Tertiärbereichs aufnehmen, und Studierenden, die zwischen den Tertiärbereichen wechseln, einen Studiengang des Tertiärbereichs wiederholen oder nach einer gewissen Unterbrechung wieder aufnehmen. Daher können die Studienanfängerquoten für ein Erststudium im Tertiärbereich A und B aufgrund der unvermeidlichen Doppelzählung von Studienanfängern nicht einfach aufaddiert werden, um zu einer Gesamtstudienanfängerquote für den Tertiärbereich zu gelangen.

Die statistischen Daten für Israel wurden von den zuständigen israelischen Stellen bereitgestellt, die für sie verantwortlich zeichnen. Die Verwendung dieser Daten durch die OECD erfolgt unbeschadet des völkerrechtlichen Status der Golanhöhen, von OstJerusalem und der israelischen Siedlungen im Westjordanland.

\section{Weiterführende Informationen}

EC (2013), Slovenia: Third Cycle (PhD) Programmes, EURYPEDIA, European Encyclopedia on National Education Systems, European Commission, https:||webgate.ec.europa.eu/fpfis| mwikis/eurydice/index.php?title=Slovenia:Third_Cycle_(PhD)_Programmes.

Halse, C. and S. Mowbray (20II), The Impact of the Doctorate, Studies in Higher Education, No. 36, Vol. 5, pp. 513-525, http:/|www.tandfonline.com/doi/abs/10.1080/030750 79.2011 .594590$.

Lumsden, M. and J. Stanwick (2012), „Who Takes A Gap Year And Why?“ Longitudinal Surveys Of Australian Youth, Briefing Paper No. 28, National Centre for Vocational Education Research (NCVER), Adelaide, Australia.

OECD (2012), Bildung auf einen Blick 2012 - OECD-Indikatoren, W. Bertelsmann Verlag, Bielefeld.

Smith, A. (2010), „One Step Beyond: Making The Most Of Postgraduate Education“, Report for the UK Department for Business, Innovation and Skills, http:||www.bis.gov. uk/assets/biscore/corporate/docs/p/10-704-one-step-beyond-postgraduate-education.pdf. 


\section{Tabellen Indikator C3}

Tabelle C3.ra: Studienanfängerquoten im Tertiärbereich und durchschnittliches Alter der Studienanfänger (20II)

StatLink: http://dx.doi.org/10.1787/888932850585

Tabelle C3.rb: Studienanfängerquoten von jungen Menschen unterhalb des typischen Eintrittsalters (20II)

StatLink: http://dx.doi.org/10.1787/888932850604

Tabelle C3.2a: Entwicklung der Studienanfängerquoten im Tertiärbereich (I995-20II)

StatLink: http:||dx.doi.org/10.1787/888932850623

WEB Table $\mathrm{C}_{3} .2 \mathrm{~b}$ : Trends in entry rates at tertiary level, by gender (Entwicklung der Studienanfängerquoten im Tertiärbereich, nach Geschlecht) (2005-20II) StatLink: http:||dx.doi.org/10.1787/888932850642

Tabelle C3.3a: Studienanfänger im Tertiärbereich, nach Fächergruppe (20II) StatLink: http:|/dx.doi.org/10.1787/888932850661

WEB Table $\mathrm{C}_{3} \cdot 3 \mathrm{~b}$ : Distribution of tertiary new entrants, by field of education and gender (Verteilung der Studienanfänger im Tertiärbereich, nach Fächergruppe und Geschlecht) (20II)

StatLink: http://dx.doi.org/10.1787/888932850680

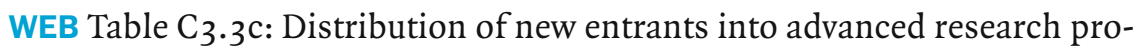
grammes, by field of education (Verteilung der Studienanfänger in weiterführenden forschungsorientierten Studiengängen, nach Fächergruppe) (20II)

StatLink: http://dx.doi.org/10.1787/888932850699 
Studienanfängerquoten im Tertiärbereich und durchschnittliches Alter der Studienanfänger (2011) Summe der Abschlussquoten der einzelnen Altersjahrgänge, nach Geschlecht und Ziel des Studiengangs

\begin{tabular}{|c|c|c|c|c|c|c|c|c|c|c|c|c|c|c|c|}
\hline & \multicolumn{5}{|c|}{ Tertiärbereich B } & \multicolumn{5}{|c|}{ Tertiärbereich A } & \multicolumn{5}{|c|}{$\begin{array}{l}\text { Weiterführende forschungsorientierte } \\
\text { Studiengänge }\end{array}$} \\
\hline & $\stackrel{L}{+}$ & 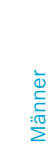 & $\begin{array}{l}\frac{c}{d} \\
\frac{0}{\pi} \\
\frac{\pi}{4}\end{array}$ & 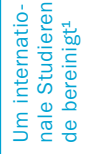 & 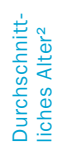 & $\stackrel{u}{\stackrel{+}{\Sigma}}$ & 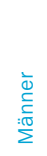 & 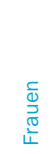 & 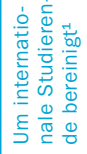 & 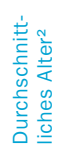 & $\begin{array}{l}\stackrel{u}{+} \\
\sum\end{array}$ & 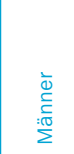 & 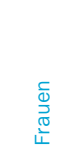 & 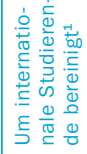 & 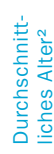 \\
\hline & (1) & (2) & (3) & (4) & (5) & (6) & (7) & (8) & (9) & (10) & (11) & (12) & (13) & (14) & (15) \\
\hline \multicolumn{16}{|l|}{ OECD-Länder } \\
\hline Australien & $\mathbf{m}$ & $\mathrm{m}$ & $\mathrm{m}$ & $\mathrm{m}$ & $\mathrm{m}$ & 96 & 83 & 110 & 69 & 23 & 3,4 & 3,4 & 3,4 & 2,1 & 33 \\
\hline Österreich & 16 & 14 & 17 & 15 & 30 & 52 & 47 & 58 & 41 & 24 & 4,4 & 4,5 & 4,3 & 3,1 & 30 \\
\hline Belgien & 38 & 32 & 45 & 38 & 20 & 33 & 32 & 35 & 33 & 19 & $\mathbf{m}$ & $\mathrm{m}$ & $\mathrm{m}$ & $\mathrm{m}$ & $\mathrm{m}$ \\
\hline Kanada & m & $\mathrm{m}$ & $\mathrm{m}$ & $\mathrm{m}$ & $\mathrm{m}$ & $\mathbf{m}$ & $\mathrm{m}$ & $\mathrm{m}$ & $\mathrm{m}$ & $\mathrm{m}$ & m & $\mathrm{m}$ & $\mathrm{m}$ & $\mathrm{m}$ & $\mathrm{m}$ \\
\hline Chile & 59 & 59 & 60 & 59 & 24 & 45 & 40 & 51 & 45 & 23 & 0,4 & 0,5 & 0,4 & 0,3 & 33 \\
\hline Tschechien & 9 & 5 & 13 & $\mathrm{~m}$ & 24 & 60 & 52 & 70 & $\mathrm{~m}$ & 23 & 3,7 & 4,0 & 3,4 & $\mathrm{~m}$ & 28 \\
\hline Dänemark & 26 & 26 & 26 & 23 & 30 & 71 & 60 & 82 & 62 & 24 & 3,9 & 4,2 & 3,6 & 2,8 & 30 \\
\hline Estland & 28 & 23 & 33 & $\mathrm{~m}$ & 24 & 43 & 38 & 50 & $\mathrm{~m}$ & 22 & 2,9 & 2,5 & 3,3 & $\mathrm{~m}$ & 31 \\
\hline Finnland & a & a & a & a & a & 68 & 61 & 76 & $\mathrm{~m}$ & 24 & 2,5 & 2,4 & 2,6 & $\mathrm{~m}$ & 33 \\
\hline Frankreich & $\mathbf{m}$ & $\mathrm{m}$ & $\mathrm{m}$ & $\mathrm{m}$ & $\mathrm{m}$ & 39 & 36 & 43 & $\mathrm{~m}$ & 20 & 2,5 & 2,7 & 2,3 & $\mathrm{~m}$ & 30 \\
\hline Deutschland & 21 & 14 & 29 & $\mathrm{~m}$ & 22 & 46 & 46 & 47 & 40 & 22 & 5,2 & 6,0 & 4,5 & 4,9 & 29 \\
\hline Griechenland & 31 & 34 & 29 & $\mathrm{~m}$ & 19 & 40 & 32 & 49 & $\mathrm{~m}$ & 20 & $\mathbf{m}$ & $\mathrm{m}$ & $\mathrm{m}$ & $\mathrm{m}$ & $\mathrm{m}$ \\
\hline Ungarn & 17 & 12 & 23 & $\mathrm{~m}$ & 22 & 52 & 48 & 56 & $\mathrm{~m}$ & 23 & 1,6 & 1,6 & 1,6 & $\mathrm{~m}$ & 29 \\
\hline Island & 4 & 5 & 4 & 4 & 34 & 81 & 68 & 94 & 68 & 26 & 3,5 & 2,7 & 4,3 & 3,0 & 37 \\
\hline Irland & 24 & 27 & 21 & 23 & 24 & 51 & 46 & 56 & 49 & 21 & $\mathbf{m}$ & $\mathrm{m}$ & $\mathrm{m}$ & $\mathrm{m}$ & $\mathrm{m}$ \\
\hline Israel & 27 & 26 & 28 & $\mathrm{~m}$ & 24 & 60 & 53 & 67 & 59 & 25 & 1,9 & 1,9 & 2,0 & 1,9 & 35 \\
\hline Italien & $\mathrm{n}$ & $\mathrm{n}$ & $\mathrm{n}$ & $\mathrm{n}$ & $\mathrm{m}$ & 48 & 41 & 56 & 48 & 20 & 2,1 & 2,0 & 2,2 & $\mathrm{~m}$ & $\mathrm{~m}$ \\
\hline Japan & 29 & 22 & 36 & $\mathrm{~m}$ & 18 & 52 & 57 & 46 & $\mathrm{~m}$ & 18 & 1,1 & 1,4 & 0,7 & $\mathrm{~m}$ & 31 \\
\hline Korea & 37 & 35 & 40 & $\mathrm{~m}$ & 21 & 69 & 68 & 70 & $\mathrm{~m}$ & 21 & 2,8 & 3,3 & 2,3 & $\mathrm{~m}$ & 36 \\
\hline Luxemburg & m & $\mathrm{m}$ & $\mathrm{m}$ & $\mathrm{m}$ & $\mathrm{m}$ & $\mathbf{m}$ & $\mathrm{m}$ & $\mathrm{m}$ & $\mathrm{m}$ & $\mathrm{m}$ & m & $\mathrm{m}$ & $\mathrm{m}$ & $\mathrm{m}$ & $\mathrm{m}$ \\
\hline Mexiko & 3 & 3 & 2 & $\mathrm{~m}$ & 20 & 34 & 34 & 34 & $\mathrm{~m}$ & 20 & 0,4 & 0,5 & 0,4 & $\mathrm{~m}$ & 36 \\
\hline Niederlande & $\mathrm{n}$ & $\mathrm{n}$ & $\mathrm{n}$ & $\mathrm{n}$ & $\mathrm{m}$ & 65 & 60 & 70 & 60 & 21 & 1,3 & 1,4 & 1,3 & 0,8 & 27 \\
\hline Neuseeland & 45 & 42 & 48 & 35 & 29 & 76 & 63 & 90 & 59 & 25 & 2,7 & 2,7 & 2,7 & 1,4 & 33 \\
\hline Norwegen & $\mathbf{n}$ & $\mathrm{n}$ & $\mathrm{n}$ & $\mathrm{m}$ & $\mathrm{m}$ & 76 & 64 & 88 & $\mathrm{~m}$ & 24 & 2,7 & 2,7 & 2,7 & $\mathrm{~m}$ & 33 \\
\hline Polen & 1 & $\mathrm{n}$ & 1 & $\mathrm{~m}$ & $\mathrm{~m}$ & 81 & 70 & 92 & 80 & 21 & m & $\mathrm{m}$ & $\mathrm{m}$ & $\mathrm{m}$ & $\mathrm{m}$ \\
\hline Portugal $^{3}$ & $\mathbf{n}$ & $n$ & $\mathrm{n}$ & $\mathrm{n}$ & 32 & 98 & 84 & 112 & 91 & 25 & 3,4 & 3,2 & 3,7 & 2,8 & 36 \\
\hline Slowakei & 1 & 1 & 2 & $\mathrm{~m}$ & $\mathrm{~m}$ & 61 & 52 & 71 & 59 & 23 & 3,6 & 3,6 & 3,6 & 3,3 & 30 \\
\hline Slowenien & 18 & 19 & 16 & 18 & 26 & 75 & 58 & 94 & 74 & 21 & 4,9 & 4,4 & 5,6 & 4,5 & 32 \\
\hline Spanien & 28 & 26 & 29 & $\mathrm{~m}$ & 23 & 53 & 46 & 61 & $\mathrm{~m}$ & 22 & 0,7 & 0,7 & 0,6 & $\mathrm{~m}$ & 37 \\
\hline Schweden & 11 & 11 & 11 & 11 & 27 & 72 & 62 & 82 & 59 & 25 & 3,0 & 3,1 & 2,9 & 1,9 & 32 \\
\hline Schweiz & 22 & 24 & 20 & $\mathrm{~m}$ & 29 & 44 & 42 & 46 & 33 & 24 & 4,9 & 5,2 & 4,5 & 2,3 & 29 \\
\hline Türkei & 27 & 31 & 24 & $\mathrm{~m}$ & 22 & 39 & 39 & 40 & $\mathrm{~m}$ & 21 & 0,8 & 0,9 & 0,7 & $\mathrm{~m}$ & 29 \\
\hline Ver. Königreich & 23 & 17 & 30 & $\mathrm{~m}$ & 33 & 64 & 57 & 72 & $\mathrm{~m}$ & 22 & 3,0 & 3,2 & 2,8 & $\mathrm{~m}$ & 30 \\
\hline Vereinigte Staaten & $x(6)$ & $x(7)$ & $x(8)$ & $\mathrm{m}$ & $\mathrm{m}$ & 72 & 65 & 79 & $\mathrm{~m}$ & 23 & $\mathbf{m}$ & $\mathrm{m}$ & $\mathrm{m}$ & $\mathrm{m}$ & $\mathrm{m}$ \\
\hline OECD-Durchschnitt & 19 & 18 & 20 & m & 24 & 60 & 53 & 67 & $\mathbf{m}$ & 22 & 2,7 & 2,8 & 2,7 & $\mathbf{m}$ & 32 \\
\hline EU21-Durchschnitt & 15 & 14 & 17 & $\mathrm{~m}$ & 24 & 59 & 51 & 67 & $\mathrm{~m}$ & 22 & 3,1 & 3,1 & 3,0 & m & 31 \\
\hline \multicolumn{16}{|l|}{ Sonst. G20-Länder } \\
\hline Argentinien ${ }^{4}$ & 51 & 32 & 71 & $\mathrm{~m}$ & 25 & 60 & 51 & 69 & $\mathrm{~m}$ & 24 & 0,7 & 0,6 & 0,8 & $\mathrm{~m}$ & $\mathrm{~m}$ \\
\hline Brasilien & m & $\mathrm{m}$ & $\mathrm{m}$ & $\mathrm{m}$ & $\mathrm{m}$ & $\mathbf{m}$ & $\mathrm{m}$ & $\mathrm{m}$ & $\mathrm{m}$ & $\mathrm{m}$ & $\mathbf{m}$ & $\mathrm{m}$ & $\mathrm{m}$ & $\mathrm{m}$ & $\mathrm{m}$ \\
\hline China & 19 & 18 & 21 & $\mathrm{~m}$ & $\mathrm{~m}$ & 19 & 18 & 21 & $\mathrm{~m}$ & $\mathrm{~m}$ & 3,0 & 3,0 & 3,0 & $\mathrm{~m}$ & $\mathrm{~m}$ \\
\hline Indien & m & $\mathrm{m}$ & $\mathrm{m}$ & $\mathrm{m}$ & $\mathrm{m}$ & $\mathbf{m}$ & $\mathrm{m}$ & $\mathrm{m}$ & $\mathrm{m}$ & $\mathrm{m}$ & $\mathbf{m}$ & $\mathrm{m}$ & $\mathrm{m}$ & $\mathrm{m}$ & $\mathrm{m}$ \\
\hline Indonesien & 4 & 3 & 4 & $\mathrm{~m}$ & 18 & 24 & 25 & 24 & $\mathrm{~m}$ & 18 & 0,3 & 0,3 & 0,2 & $\mathrm{~m}$ & 27 \\
\hline Russische Föd. & 31 & $x(1)$ & $x(1)$ & $\mathrm{m}$ & $\mathrm{m}$ & 72 & 65 & 78 & $\mathrm{~m}$ & 21 & 2,2 & $x(11)$ & $x(11)$ & $\mathrm{m}$ & $\mathrm{m}$ \\
\hline Saudi-Arabien & 10 & 15 & 5 & 10 & $\mathrm{~m}$ & 53 & 54 & 52 & 51 & $\mathrm{~m}$ & 0,2 & 0,2 & 0,2 & 0,2 & $\mathrm{~m}$ \\
\hline Südafrika & m & $\mathrm{m}$ & $\mathrm{m}$ & $\mathrm{m}$ & $\mathrm{m}$ & $\mathbf{m}$ & $\mathrm{m}$ & $\mathrm{m}$ & $\mathrm{m}$ & $\mathrm{m}$ & $\mathbf{m}$ & $\mathrm{m}$ & $\mathrm{m}$ & $\mathrm{m}$ & $\mathrm{m}$ \\
\hline G20-Durchschnitt & 17 & 24 & m & m & 53 & 49 & 56 & m & m & 2.0 & 2,1 & 1,8 & m & $\mathbf{m}$ & $\mathbf{m}$ \\
\hline
\end{tabular}

Anmerkung: Unterschiede im Erhebungsbereich der Bevölkerungsdaten und der Studienanfängerdaten bedeuten, dass die Studienanfängerquoten von Ländern mit einem Nettoabgang von Studierenden wohl zu niedrig angesetzt und Länder mit einem Nettozugang von Studierenden wohl zu hoch angesetzt sind. Bei den bereinigten Studienanfängerquoten ist dies weitgehend berücksichtigt. Länderspezifische Informationen s. Anhang 3. Weiterführende Informationen zu den zur Berechnung der (Brutto-/Netto-)Studienanfängerquoten verwendeten Methoden und dem entsprechenden Alter bei Aufnahme des Studiums s. Anhang 1. 1. Die bereinigten Studienanfängerquoten entsprechen den Studienanfängerquoten ohne Berücksichtigung internationaler Studierender. 2. Das durchschnittliche Alter bezieht sich auf ein gewichtetes durchschnittliches Alter, in der Regel das Alter der Studierenden zu Beginn des Kalenderjahrs. Die Studierenden können ein Jahr älter als das angegebene durchschnittliche Alter sein, wenn sie ihren Abschluss am Ende des Studienjahrs erwerben. Informationen zur Berechnung des durchschnittlichen Alters s. Anhang 3. 3. Anfängerquoten können zu hoch angesetzt sein, da sie alle Studierenden berücksichtigen, die zum ersten Mal in einem bestimmten Studiengang eingeschrieben sind, und nicht nur die Studierenden, die Studienanfänger im Tertiärbereich A oder B sind. 4. Referenzjahr 2010. Quelle: OECD. Argentinien, China, Indonesien: Statistikinstitut der UNESCO (World Education Indicators Programmme). Saudi-Arabien: Observatory on Higher Education. Hinweise s. Anhang 3 unter www.oecd.org/edu/eag.htm. StatLink: http://dx.doi.org/10.1787/888932850585 Erläuterung der Kennzeichnung fehlender Daten s. Hinweise für den Leser. 
Studienanfängerquoten von jungen Menschen unterhalb des typischen Eintrittsalters (2011)

Summe der Netto-Studienanfängerquoten der Altersjahrgänge bis 25 Jahre für Tertiärbereich A oder B und bis 30 Jahre für weiterführende forschungsorientierte Studiengänge, nach Geschlecht und Ziel des Studiengangs

\begin{tabular}{|c|c|c|c|c|c|c|c|c|c|c|c|c|c|c|c|}
\hline & \multicolumn{5}{|c|}{ Tertiärbereich B (jünger als 25 Jahre) } & \multicolumn{5}{|c|}{ Tertiärbereich A (jünger als 25 Jahre) } & \multicolumn{5}{|c|}{$\begin{array}{l}\text { Weiterführende forschungsorientierte } \\
\text { Studiengänge (jünger als } 30 \text { Jahre) }\end{array}$} \\
\hline & $\begin{array}{l}\frac{L}{+} \\
\sum\end{array}$ & 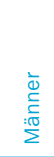 & $\begin{array}{l}\widetilde{\Xi} \\
\stackrel{\Phi}{\sigma} \\
\frac{\pi}{\hbar}\end{array}$ & 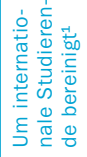 & 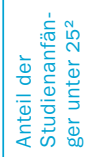 & $\begin{array}{l}u \\
\stackrel{+}{\Sigma}\end{array}$ & 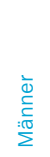 & 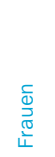 & 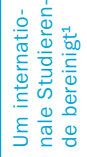 & 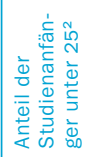 & $\begin{array}{l}\stackrel{L}{+} \\
\Sigma\end{array}$ & 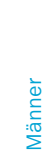 & 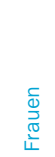 & 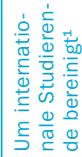 & 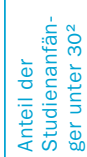 \\
\hline & (1) & (2) & (3) & (4) & (5) & (6) & (7) & (8) & (9) & (10) & (11) & (12) & (13) & (14) & (15) \\
\hline \multicolumn{16}{|l|}{ OECD-Länder } \\
\hline Australien & $\mathbf{m}$ & $\mathrm{m}$ & $\mathrm{m}$ & $\mathrm{m}$ & $\mathrm{m}$ & 72 & 62 & 83 & 54 & 74 & 1,6 & 1,6 & 1,6 & 0,9 & 48 \\
\hline Österreich & 7 & 7 & 8 & 7 & 44 & 40 & 34 & 46 & 32 & 75 & 2,9 & 2,8 & 2,9 & 2,1 & 65 \\
\hline Belgien & 37 & 31 & 43 & 36 & 95 & 32 & 31 & 34 & 32 & 97 & m & $\mathrm{m}$ & $\mathrm{m}$ & $\mathrm{m}$ & $\mathrm{m}$ \\
\hline Kanada & $\mathbf{m}$ & $\mathrm{m}$ & $\mathrm{m}$ & $\mathrm{m}$ & $\mathrm{m}$ & m & $\mathrm{m}$ & $\mathrm{m}$ & $\mathrm{m}$ & $\mathrm{m}$ & m & $\mathrm{m}$ & $\mathrm{m}$ & $\mathrm{m}$ & $\mathrm{m}$ \\
\hline Chile & 40 & 39 & 40 & 39 & 70 & 33 & 29 & 37 & 33 & 76 & 0,2 & 0,2 & 0,2 & 0,2 & 51 \\
\hline Tschechien & 8 & 5 & 11 & $\mathrm{~m}$ & 80 & 51 & 45 & 57 & $\mathrm{~m}$ & 81 & 3,1 & 3,2 & 2,9 & $\mathrm{~m}$ & 79 \\
\hline Dänemark & 12 & 12 & 11 & 9 & 43 & 53 & 44 & 63 & 48 & 76 & 2,5 & 2,9 & 2,1 & 1,7 & 61 \\
\hline Estland & 20 & 18 & 23 & $\mathrm{~m}$ & 72 & 37 & 33 & 42 & $\mathrm{~m}$ & 86 & 1,6 & 1,5 & 1,8 & $\mathrm{~m}$ & 60 \\
\hline Finnland & $\mathbf{a}$ & a & a & a & a & 51 & 46 & 55 & $\mathrm{~m}$ & 74 & 1,2 & 1,3 & 1,2 & $\mathrm{~m}$ & 50 \\
\hline Frankreich & $\mathbf{m}$ & $\mathrm{m}$ & $\mathrm{m}$ & $\mathrm{m}$ & $\mathrm{m}$ & 37 & 33 & 42 & $\mathrm{~m}$ & 95 & 1,7 & 1,8 & 1,6 & $\mathrm{~m}$ & 68 \\
\hline Deutschland & 16 & 9 & 24 & $\mathrm{~m}$ & 73 & 40 & 39 & 41 & 35 & 86 & 4,0 & 4,4 & 3,5 & 3,7 & 76 \\
\hline Griechenland & 29 & 32 & 27 & $\mathrm{~m}$ & 92 & 36 & 28 & 44 & $\mathrm{~m}$ & 87 & m & $\mathrm{m}$ & $\mathrm{m}$ & $\mathrm{m}$ & $\mathrm{m}$ \\
\hline Ungarn & 15 & 11 & 19 & $\mathrm{~m}$ & 84 & 43 & 40 & 47 & $\mathrm{~m}$ & 81 & 1,1 & 1,1 & 1,2 & $\mathrm{~m}$ & 68 \\
\hline Island & 1 & 1 & 1 & 1 & 18 & 52 & 45 & 60 & 45 & 66 & 1,1 & 1,1 & 1,1 & 0,9 & 33 \\
\hline Irland & 18 & 21 & 15 & 18 & 72 & 45 & 40 & 50 & 44 & 86 & m & $\mathrm{m}$ & $\mathrm{m}$ & $\mathrm{m}$ & $\mathrm{m}$ \\
\hline Israel & 18 & 13 & 24 & $\mathrm{~m}$ & 69 & 39 & 29 & 49 & 38 & 65 & 0,7 & 0,6 & 0,7 & 0,6 & 37 \\
\hline Italien & $\mathrm{n}$ & $n$ & $\mathrm{n}$ & $\mathrm{n}$ & $\mathrm{m}$ & 45 & 37 & 52 & $\mathrm{n}$ & 92 & m & $\mathrm{m}$ & $\mathrm{m}$ & $\mathrm{m}$ & $\mathrm{m}$ \\
\hline Japan & m & $\mathrm{m}$ & $\mathrm{m}$ & $\mathrm{m}$ & $\mathrm{m}$ & m & $\mathrm{m}$ & $\mathrm{m}$ & $\mathrm{m}$ & $\mathrm{m}$ & m & $\mathrm{m}$ & $\mathrm{m}$ & $\mathrm{m}$ & $\mathrm{m}$ \\
\hline Korea & 33 & 31 & 35 & $\mathrm{~m}$ & 87 & 58 & 56 & 59 & $\mathrm{~m}$ & 82 & 1,1 & 1,2 & 1,0 & $\mathrm{~m}$ & 36 \\
\hline Luxemburg & m & $\mathrm{m}$ & $\mathrm{m}$ & $\mathrm{m}$ & $\mathrm{m}$ & m & $\mathrm{m}$ & $\mathrm{m}$ & $\mathrm{m}$ & $\mathrm{m}$ & m & $\mathrm{m}$ & $\mathrm{m}$ & $\mathrm{m}$ & $\mathrm{m}$ \\
\hline Mexiko & 3 & 3 & 2 & $\mathrm{~m}$ & 94 & 31 & 31 & 31 & $\mathrm{~m}$ & 93 & 0,2 & 0,2 & 0,2 & $\mathrm{~m}$ & 41 \\
\hline Niederlande & $\mathrm{n}$ & $n$ & $n$ & $\mathrm{n}$ & 28 & 58 & 53 & 63 & 54 & 90 & 1,1 & 1,2 & 1,1 & 0,7 & 86 \\
\hline Neuseeland & 22 & 24 & 21 & 15 & 53 & 52 & 45 & 61 & 40 & 71 & 1,3 & 1,3 & 1,3 & 0,6 & 50 \\
\hline Norwegen & $n$ & $n$ & $n$ & $\mathrm{~m}$ & $\mathrm{~m}$ & 58 & 48 & 69 & $\mathrm{~m}$ & 77 & 1,4 & 1,5 & 1,3 & $\mathrm{~m}$ & 49 \\
\hline Polen & 1 & $\mathrm{n}$ & 1 & $\mathrm{~m}$ & $\mathrm{~m}$ & 71 & 62 & 80 & 70 & 86 & $\mathbf{m}$ & $\mathrm{m}$ & $\mathrm{m}$ & $\mathrm{m}$ & $\mathrm{m}$ \\
\hline Portuga| ${ }^{3}$ & $n$ & $\mathrm{n}$ & $\mathrm{n}$ & $\mathrm{n}$ & $\mathrm{m}$ & 69 & 58 & 80 & 65 & 64 & 1,3 & 1,2 & 1,5 & 1,1 & 34 \\
\hline Slowakei & 1 & 1 & 1 & $\mathrm{~m}$ & $\mathrm{~m}$ & 49 & 43 & 56 & 48 & 79 & 2,4 & 2,3 & 2,6 & 2,4 & 68 \\
\hline Slowenien & 11 & 13 & 9 & 11 & 59 & 69 & 53 & 86 & 68 & 90 & 3,0 & 2,8 & 3,3 & 2,7 & 59 \\
\hline Spanien & 22 & 21 & 23 & $\mathrm{~m}$ & 73 & 46 & 39 & 54 & $\mathrm{~m}$ & 81 & 0,2 & 0,2 & 0,2 & $\mathrm{~m}$ & 21 \\
\hline Schweden & 6 & 6 & 5 & 6 & 54 & 49 & 42 & 56 & 44 & 70 & 1,7 & 1,9 & 1,5 & 1,0 & 57 \\
\hline Schweiz & 10 & 11 & 10 & $\mathrm{~m}$ & 44 & 34 & 32 & 37 & 27 & 76 & 3,6 & 3,9 & 3,4 & 1,8 & 74 \\
\hline Türkei & 22 & 25 & 19 & $\mathrm{~m}$ & 81 & 34 & 32 & 35 & $\mathrm{~m}$ & 85 & $n$ & 0,5 & $n$ & $\mathrm{~m}$ & 66 \\
\hline Ver. Königreich & 8 & 6 & 9 & $\mathrm{~m}$ & 33 & 52 & 48 & 57 & $\mathrm{~m}$ & 81 & 1,8 & 1,9 & 1,7 & $\mathrm{~m}$ & 63 \\
\hline Vereinigte Staaten & $x(6)$ & $x(7)$ & $x(8)$ & $\mathrm{m}$ & $\mathrm{m}$ & 54 & 51 & 58 & $\mathrm{~m}$ & 77 & m & $\mathrm{m}$ & $\mathrm{m}$ & $\mathrm{m}$ & $\mathrm{m}$ \\
\hline OECD-Durchschnitt & 13 & 12 & 14 & m & 62 & 48 & 42 & 54 & m & 81 & 2 & 2 & 2 & m & 56 \\
\hline EU21-Durchschnitt & 11 & 10 & 12 & m & 60 & 49 & 43 & 55 & m & 83 & 2 & 2 & 2 & m & 61 \\
\hline \multicolumn{16}{|l|}{ Sonst. G20-Länder } \\
\hline Argentinien ${ }^{4}$ & 31 & 21 & 40 & $\mathrm{~m}$ & 61 & 40 & 35 & 45 & $\mathrm{~m}$ & 69 & m & $\mathrm{m}$ & $\mathrm{m}$ & $\mathrm{m}$ & $\mathrm{m}$ \\
\hline Brasilien & m & $\mathrm{m}$ & $\mathrm{m}$ & $\mathrm{m}$ & $\mathrm{m}$ & m & $\mathrm{m}$ & $\mathrm{m}$ & $\mathrm{m}$ & $\mathrm{m}$ & m & $\mathrm{m}$ & $\mathrm{m}$ & $\mathrm{m}$ & $\mathrm{m}$ \\
\hline China & m & $\mathrm{m}$ & $\mathrm{m}$ & $\mathrm{m}$ & $\mathrm{m}$ & m & $\mathrm{m}$ & $\mathrm{m}$ & $\mathrm{m}$ & $\mathrm{m}$ & m & $\mathrm{m}$ & $\mathrm{m}$ & $\mathrm{m}$ & $\mathrm{m}$ \\
\hline Indien & $\mathbf{m}$ & $\mathrm{m}$ & $\mathrm{m}$ & $\mathrm{m}$ & $\mathrm{m}$ & $\mathbf{m}$ & $\mathrm{m}$ & $\mathrm{m}$ & $\mathrm{m}$ & $\mathrm{m}$ & m & $\mathrm{m}$ & $\mathrm{m}$ & $\mathrm{m}$ & $\mathrm{m}$ \\
\hline Indonesien & 4 & 3 & 4 & $\mathrm{~m}$ & 100 & 24 & 25 & 24 & $\mathrm{~m}$ & 100 & $\mathbf{n}$ & $\mathrm{n}$ & $\mathrm{n}$ & $\mathrm{m}$ & 92 \\
\hline Russische Föd. & m & $\mathrm{m}$ & $\mathrm{m}$ & $\mathrm{m}$ & $\mathrm{m}$ & 60 & 54 & 65 & $\mathrm{~m}$ & 80 & m & $\mathrm{m}$ & $\mathrm{m}$ & $\mathrm{m}$ & $\mathrm{m}$ \\
\hline Saudi-Arabien & m & $\mathrm{m}$ & $\mathrm{m}$ & $\mathrm{m}$ & $\mathrm{m}$ & m & $\mathrm{m}$ & $\mathrm{m}$ & $\mathrm{m}$ & $\mathrm{m}$ & m & $\mathrm{m}$ & $\mathrm{m}$ & $\mathrm{m}$ & $\mathrm{m}$ \\
\hline Südafrika & m & $\mathrm{m}$ & $\mathrm{m}$ & $\mathrm{m}$ & $\mathrm{m}$ & m & $\mathrm{m}$ & $\mathrm{m}$ & $\mathrm{m}$ & $\mathrm{m}$ & m & $\mathrm{m}$ & $\mathrm{m}$ & $\mathrm{m}$ & $\mathrm{m}$ \\
\hline G20-Durchschnitt & m & $\mathbf{m}$ & $\mathbf{m}$ & $\mathbf{m}$ & m & m & m & m & m & m & m & m & m & m & m \\
\hline
\end{tabular}

Anmerkung: Unterschiede im Erhebungsbereich der Bevölkerungsdaten und der Studienanfängerdaten bedeuten, dass die Studienanfängerquoten von Ländern mit einem Nettoabgang von Studierenden wohl zu niedrig angesetzt und Länder mit einem Nettozugang von Studierenden wohl zu hoch angesetzt sind. Bei den bereinigten Studienanfängerquoten ist dies weitgehend berücksichtigt. Weiterführende Informationen zu den zur Berechnung der (Brutto-/Netto-)Studienanfängerquoten verwendeten Methoden und dem entsprechenden typischen Alter bei Aufnahme des Studiums s. Anhang 1.

1. Die bereinigten Studienanfängerquoten entsprechen den Studienanfängerquoten ohne Berücksichtigung internationaler Studierender. 2. Anteil der unter 25-jährigen Studienanfänger an allen Studienanfängern. 3. Anfängerquoten können zu hoch angesetzt sein, da sie alle Studierenden berücksichtigen, die zum ersten Mal in einem bestimmten Studiengang eingeschrieben sind, und nicht nur die Studierenden, die Studienanfänger im Tertiärbereich A oder B sind.

4. Referenzjahr 2010.

Quelle: OECD. Argentinien, Indonesien: Statistikinstitut der UNESCO (World Education Indicators Programmme).

Hinweise s. Anhang 3 unter www.oecd.org/edu/eag.htm. StatLink: http://dx.doi.org/10.1787/888932850604

Erläuterung der Kennzeichnung fehlender Daten s. Hinweise für den Leser. 
Entwicklung der Studienanfängerquoten im Tertiärbereich (1995-2011)

\begin{tabular}{|c|c|c|c|c|c|c|c|c|c|c|c|c|c|c|}
\hline & \multicolumn{7}{|c|}{ Tertiärbereich $\mathrm{A}^{\mathbf{1}}$} & \multicolumn{7}{|c|}{ Tertiärbereich B } \\
\hline & 1995 & 2000 & 2005 & 2008 & 2009 & 2010 & 2011 & 1995 & 2000 & 2005 & 2008 & 2009 & 2010 & 2011 \\
\hline & (1) & (2) & (7) & (10) & (11) & (12) & (13) & (14) & (15) & (20) & (23) & (24) & (25) & (26) \\
\hline \multicolumn{15}{|l|}{ OECD-Länder } \\
\hline Australien & $\mathrm{m}$ & 59 & 82 & 87 & 94 & 96 & 96 & $\mathrm{~m}$ & $\mathrm{~m}$ & $\mathrm{~m}$ & $\mathrm{~m}$ & $\mathrm{~m}$ & $\mathrm{~m}$ & $\mathbf{m}$ \\
\hline Österreich & 27 & 34 & 37 & 47 & 45 & 53 & 52 & $\mathrm{~m}$ & $\mathrm{~m}$ & 9 & 13 & 14 & 16 & 16 \\
\hline Belgien & $\mathrm{m}$ & $\mathrm{m}$ & 33 & 31 & 31 & 33 & 33 & $\mathrm{~m}$ & $\mathrm{~m}$ & 34 & 37 & 39 & 38 & 38 \\
\hline Kanada & $\mathrm{m}$ & $\mathrm{m}$ & $\mathrm{m}$ & $\mathrm{m}$ & $\mathrm{m}$ & $\mathrm{m}$ & $\mathbf{m}$ & $\mathrm{m}$ & $\mathrm{m}$ & $\mathrm{m}$ & $\mathrm{m}$ & $\mathrm{m}$ & $\mathrm{m}$ & m \\
\hline Chile $^{2}$ & $\mathrm{~m}$ & $\mathrm{~m}$ & 46 & $\mathrm{~m}$ & 44 & 47 & 45 & $\mathrm{~m}$ & $\mathrm{~m}$ & $\mathrm{~m}$ & $\mathrm{~m}$ & 59 & 58 & 59 \\
\hline Tschechien & $\mathrm{m}$ & 25 & 41 & 57 & 59 & 60 & 60 & $\mathrm{~m}$ & 9 & 8 & 9 & 8 & 9 & 9 \\
\hline Dänemark & 40 & 52 & 57 & 59 & 55 & 65 & 71 & 33 & 28 & 23 & 21 & 25 & 25 & 26 \\
\hline Estland & $\mathrm{m}$ & $\mathrm{m}$ & 55 & 42 & 42 & 43 & 43 & $\mathrm{~m}$ & $\mathrm{~m}$ & 33 & 31 & 30 & 29 & 28 \\
\hline Finnland & 39 & 71 & 73 & 70 & 69 & 68 & 68 & 32 & a & a & a & a & a & a \\
\hline Frankreich & $\mathrm{m}$ & $\mathrm{m}$ & $\mathrm{m}$ & $\mathrm{m}$ & $\mathrm{m}$ & $\mathrm{m}$ & 39 & $\mathrm{~m}$ & $\mathrm{~m}$ & $\mathrm{~m}$ & $\mathrm{~m}$ & $\mathrm{~m}$ & $\mathrm{~m}$ & $\mathrm{~m}$ \\
\hline Deutschland $^{3}$ & 26 & 30 & 36 & 36 & 40 & 42 & 46 & 15 & 15 & 14 & 14 & 19 & 21 & 21 \\
\hline Griechenland & 15 & 30 & 43 & 42 & $\mathrm{~m}$ & $\mathrm{~m}$ & 40 & 5 & 21 & 13 & 26 & $\mathrm{~m}$ & $\mathrm{~m}$ & 31 \\
\hline Ungarn & $\mathrm{m}$ & 55 & 68 & 57 & 53 & 54 & 52 & $\mathrm{~m}$ & 1 & 11 & 12 & 14 & 16 & 17 \\
\hline Island & $\mathrm{m}$ & 66 & 74 & 73 & 77 & 93 & 81 & $\mathrm{~m}$ & 10 & 7 & 6 & 4 & 4 & 4 \\
\hline Irland & $\mathrm{m}$ & 32 & 45 & 46 & 51 & 56 & 51 & $\mathrm{~m}$ & 26 & 14 & 20 & 25 & 28 & 24 \\
\hline Israel & $\mathrm{m}$ & 48 & 55 & 60 & 60 & 60 & 60 & $\mathrm{~m}$ & 31 & 25 & 26 & 27 & 29 & 27 \\
\hline Italien & $\mathrm{m}$ & 39 & 56 & 51 & 50 & 49 & 48 & $\mathrm{~m}$ & 1 & $\mathrm{n}$ & $\mathrm{n}$ & $n$ & $\mathrm{n}$ & $\mathbf{n}$ \\
\hline Japan & 31 & 40 & 44 & 48 & 49 & 51 & 52 & 33 & 32 & 31 & 29 & 27 & 27 & 29 \\
\hline Korea & 41 & 45 & 51 & 71 & 71 & 71 & 69 & 27 & 51 & 48 & 38 & 36 & 36 & 37 \\
\hline Luxemburg & $\mathrm{m}$ & $\mathrm{m}$ & $\mathrm{m}$ & 25 & 31 & 28 & $\mathbf{m}$ & $\mathrm{m}$ & $\mathrm{m}$ & $\mathrm{m}$ & $\mathrm{n}$ & 2 & 10 & m \\
\hline Mexiko & $\mathrm{m}$ & 24 & 27 & 30 & 31 & 33 & 34 & $\mathrm{~m}$ & 1 & 2 & 2 & 2 & 3 & 3 \\
\hline Niederlande & 44 & 53 & 59 & 62 & 63 & 65 & 65 & a & a & $a$ & $\mathrm{n}$ & $\mathrm{n}$ & $\mathrm{n}$ & $\mathrm{n}$ \\
\hline Neuseeland & 83 & 95 & 79 & 72 & 80 & 80 & 76 & 44 & 52 & 48 & 46 & 47 & 48 & 45 \\
\hline Norwegen & 59 & 67 & 73 & 71 & 77 & 76 & 76 & 5 & 5 & $\mathrm{n}$ & $\mathrm{n}$ & $\mathrm{n}$ & $\mathrm{n}$ & $\mathbf{n}$ \\
\hline Polen & 36 & 65 & 76 & 83 & 85 & 84 & 81 & 1 & 1 & 1 & 1 & 1 & 1 & 1 \\
\hline Portugal4 & $\mathrm{m}$ & $\mathrm{m}$ & $\mathrm{m}$ & 81 & 84 & 89 & 98 & $\mathrm{~m}$ & $\mathrm{~m}$ & $\mathrm{~m}$ & $\mathrm{n}$ & $\mathrm{n}$ & $\mathrm{n}$ & $\mathrm{n}$ \\
\hline Slowakei & 28 & 37 & 59 & 72 & 69 & 65 & 61 & 1 & 3 & $\mathrm{~m}$ & 1 & 1 & 1 & 1 \\
\hline Slowenien & $\mathrm{m}$ & $\mathrm{m}$ & 40 & 56 & 61 & 77 & 75 & $\mathrm{~m}$ & $\mathrm{~m}$ & 49 & 32 & 32 & 19 & 18 \\
\hline Spanien & $\mathrm{m}$ & 47 & 43 & 43 & 46 & 52 & 53 & 3 & 15 & 22 & 22 & 23 & 26 & 28 \\
\hline Schweden & 57 & 67 & 76 & 65 & 68 & 76 & 72 & $\mathrm{~m}$ & 7 & 7 & 10 & 11 & 12 & 11 \\
\hline Schweiz & 17 & 29 & 37 & 38 & 41 & 44 & 44 & 29 & 14 & 16 & 19 & 21 & 23 & 22 \\
\hline Türkei & 18 & 21 & 27 & 30 & 40 & 40 & 39 & 9 & 9 & 19 & 23 & 30 & 28 & 27 \\
\hline Vereinigtes Königreich & $\mathrm{m}$ & 47 & 51 & 57 & 61 & 63 & 64 & $\mathrm{~m}$ & 29 & 28 & 30 & 31 & 26 & 23 \\
\hline Vereinigte Staaten & 57 & 58 & 64 & 64 & 70 & 74 & 72 & $x(1)$ & $x(2)$ & $x(7)$ & $x(10)$ & $x(11)$ & $x(12)$ & $\mathbf{x}(\mathbf{1 3})$ \\
\hline OECD-Durchschnitt & 39 & 48 & 54 & 56 & 58 & 61 & 60 & 17 & 16 & 18 & 16 & 18 & 18 & 19 \\
\hline $\begin{array}{l}\text { OECD-Durchschnitt } \\
\text { für Länder mit verfüg- } \\
\text { baren Daten für die } \\
\text { Jahre } 2000 \text { und } 2011\end{array}$ & & 48 & & & & & 62 & & 17 & & & & & 20 \\
\hline EU21-Durchschnitt & 35 & 46 & 53 & 54 & 56 & 59 & 59 & 11 & 11 & 16 & 14 & 14 & 15 & 15 \\
\hline
\end{tabular}

\begin{tabular}{|c|c|c|c|c|c|c|c|c|c|c|c|c|c|c|}
\hline \multicolumn{15}{|l|}{ Sonstige G20-Länder } \\
\hline Argentinien & $\mathrm{m}$ & $\mathrm{m}$ & $\mathrm{m}$ & 47 & 56 & 60 & m & $\mathrm{m}$ & $\mathrm{m}$ & $\mathrm{m}$ & 44 & 46 & 51 & m \\
\hline Brasilien & $\mathrm{m}$ & $\mathrm{m}$ & $\mathrm{m}$ & $\mathrm{m}$ & $\mathrm{m}$ & $\mathrm{m}$ & m & $\mathrm{m}$ & $\mathrm{m}$ & $\mathrm{m}$ & $\mathrm{m}$ & $\mathrm{m}$ & $\mathrm{m}$ & m \\
\hline China & $\mathrm{m}$ & $\mathrm{m}$ & $\mathrm{m}$ & m & 17 & 17 & 19 & $\mathrm{~m}$ & $\mathrm{~m}$ & $\mathrm{~m}$ & $\mathrm{~m}$ & 19 & 19 & 19 \\
\hline Indien & $\mathrm{m}$ & $\mathrm{m}$ & $\mathrm{m}$ & $\mathrm{m}$ & $\mathrm{m}$ & $\mathrm{m}$ & m & $\mathrm{m}$ & $\mathrm{m}$ & $\mathrm{m}$ & $\mathrm{m}$ & $\mathrm{m}$ & $\mathrm{m}$ & m \\
\hline Indonesien & $\mathrm{m}$ & $\mathrm{m}$ & $\mathrm{m}$ & $\mathrm{m}$ & 22 & 22 & 24 & $\mathrm{~m}$ & $\mathrm{~m}$ & $\mathrm{~m}$ & $\mathrm{~m}$ & 5 & 5 & 4 \\
\hline Russische Föderation & $\mathrm{m}$ & $\mathrm{m}$ & 67 & 68 & 69 & 66 & 72 & $\mathrm{~m}$ & $\mathrm{~m}$ & 33 & 30 & 27 & 29 & 31 \\
\hline Saudi-Arabien & 24 & 23 & 37 & 42 & 43 & 48 & 53 & 4 & 6 & 10 & 12 & 15 & 11 & 10 \\
\hline Südafrika & $\mathrm{m}$ & $\mathrm{m}$ & $\mathrm{m}$ & $\mathrm{m}$ & $\mathrm{m}$ & $\mathrm{m}$ & m & $\mathrm{m}$ & $\mathrm{m}$ & $\mathrm{m}$ & $\mathrm{m}$ & $\mathrm{m}$ & $\mathrm{m}$ & m \\
\hline G20-Durchschnitt & m & m & m & m & 51 & 52 & 52 & m & m & m & m & 21 & 21 & 19 \\
\hline
\end{tabular}

Anmerkung: Die Spalten für die Studienanfängerquoten für die Jahre 2001-2004, 2006 und 2007, d.h. die Spalten (3) bis (6), (8) und (9), (16) bis (19), (21) und (22), sind im Internet verfügbar (s. StatLink unten). Weiterführende Informationen zu den zur Berechnung der (Brutto-/Netto-)Studienanfängerquoten verwendeten Methoden und dem entsprechenden typischen Alter bei Aufnahme des Studiums s. Anhang 1.

1. Studienanfängerquoten für den Tertiärbereich A enthalten für 1995, 2000 bis 2003 (mit Ausnahme Belgiens und Deutschlands) weiterführende forschungsorientierte Studiengänge. 2. Unterbrechung der Zeitreihe zwischen 2009 und 2010 aufgrund von Änderungen der angewandten Methodik (Einzelheiten s. Anhang 3). 3. Unterbrechung der Zeitreihe zwischen 2008 und 2009 aufgrund einer teilweisen Neueinstufung berufsbildender Bildungsgänge in ISCED 2 und ISCED 5B.

4. Anfängerquoten können zu hoch angesetzt sein, da sie alle Studierenden berücksichtigen, die zum ersten Mal in einem bestimmten Studiengang eingeschrieben sind, und nicht nur die Studierenden, die Studienanfänger im Tertiärbereich A oder B sind.

Quelle: OECD. Argentinien, China, Indonesien: Statistikinstitut der UNESCO (World Education Indicators Programme).

Hinweise s. Anhang 3 unter www.oecd.org/edu/eag.htm. StatLink: http://dx.doi.org/10.1787/888932850623

Erläuterung der Kennzeichnung fehlender Daten s. Hinweise für den Leser. 
Studienanfänger im Tertiärbereich, nach Fächergruppe (2011)

\begin{tabular}{|c|c|c|c|c|c|c|c|c|}
\hline & \begin{tabular}{|} 
Geisteswis- \\
senschaften, \\
Kunst und \\
Erziehungswis- \\
senschaften
\end{tabular} & $\begin{array}{l}\text { Gesundheit } \\
\text { und Soziales }\end{array}$ & $\begin{array}{l}\text { Sozial-, } \\
\text { Rechts- und } \\
\text { Wirtschafts- } \\
\text { wissen- } \\
\text { schaften }\end{array}$ & $\begin{array}{l}\text { Dienst- } \\
\text { leistungen }\end{array}$ & $\begin{array}{l}\text { Ingenieurwis- } \\
\text { senschaften, } \\
\text { Fertigung und } \\
\text { Bauwesen }\end{array}$ & $\begin{array}{l}\text { Naturwissen- } \\
\text { schaften }\end{array}$ & $\begin{array}{l}\text { Agrarwissen- } \\
\text { schaften }\end{array}$ & $\begin{array}{l}\text { Nicht bekannt } \\
\text { oder keine } \\
\text { Angabe }\end{array}$ \\
\hline & (1) & (4) & (5) & (6) & (7) & (8) & (13) & (14) \\
\hline \multicolumn{9}{|l|}{ OECD-Länder } \\
\hline Australien $^{1}$ & 21 & 16 & 38 & 4 & 9 & 12 & 1 & $\mathrm{n}$ \\
\hline Österreich & 28 & 7 & 34 & 3 & 16 & 10 & 1 & $\mathrm{n}$ \\
\hline Belgien² & 25 & 24 & 31 & 2 & 11 & 5 & 3 & $\mathrm{n}$ \\
\hline Kanada & $\mathrm{m}$ & $\mathrm{m}$ & $\mathrm{m}$ & $\mathrm{m}$ & $\mathrm{m}$ & $\mathrm{m}$ & $\mathrm{m}$ & $\mathrm{m}$ \\
\hline Chile & 16 & 22 & 25 & 11 & 17 & 6 & 2 & $\mathrm{n}$ \\
\hline Tschechien & 18 & 13 & 31 & 7 & 15 & 13 & 4 & $\mathrm{n}$ \\
\hline Dänemark & 16 & 20 & 40 & 3 & 12 & 8 & 2 & $\mathrm{n}$ \\
\hline Estland & 21 & 11 & 28 & 9 & 15 & 14 & 2 & $\mathrm{n}$ \\
\hline Finnland $^{2}$ & 15 & 19 & 21 & 7 & 25 & 9 & 2 & $\mathrm{n}$ \\
\hline Frankreich ${ }^{1}$ & 19 & 11 & 39 & 4 & 9 & 19 & $\mathrm{n}$ & $\mathrm{n}$ \\
\hline Deutschland $^{2}$ & 23 & 20 & 23 & 3 & 16 & 13 & 2 & 1 \\
\hline Griechenland & 21 & 9 & 30 & 2 & 17 & 14 & 5 & 1 \\
\hline Ungarn & 13 & 9 & 40 & 13 & 14 & 8 & 2 & $\mathrm{n}$ \\
\hline Island & 29 & 12 & 31 & 3 & 11 & 13 & 1 & $\mathrm{n}$ \\
\hline Irland $^{2}$ & 15 & 13 & 21 & 6 & 11 & 15 & 2 & 17 \\
\hline Israel & 24 & 6 & 36 & $\mathrm{n}$ & 24 & 8 & $\mathrm{n}$ & 1 \\
\hline Italien ${ }^{2}$ & 19 & 13 & 34 & 4 & 16 & 11 & 3 & $\mathrm{n}$ \\
\hline Japan & 23 & 15 & 27 & 9 & 14 & 2 & 2 & 7 \\
\hline Korea & 26 & 14 & 20 & 7 & 25 & 7 & 1 & $\mathrm{n}$ \\
\hline Luxemburg & $\mathrm{m}$ & $\mathrm{m}$ & $\mathrm{m}$ & $\mathrm{m}$ & $\mathrm{m}$ & $\mathrm{m}$ & $\mathrm{m}$ & $\mathrm{m}$ \\
\hline Mexiko & 14 & 9 & 41 & 2 & 22 & 10 & 2 & $\mathrm{n}$ \\
\hline Niederlande ${ }^{2}$ & 18 & 19 & 38 & 7 & 9 & 7 & 1 & 1 \\
\hline Neuseeland & 24 & 12 & 34 & 6 & 6 & 16 & 1 & $\mathrm{n}$ \\
\hline Norwegen & 23 & 17 & 31 & 7 & 8 & 10 & 1 & 3 \\
\hline Polen ${ }^{2}$ & 20 & 9 & 34 & 9 & 17 & 9 & 2 & $n$ \\
\hline Portugal & 19 & 14 & 35 & 7 & 16 & 8 & 1 & $n$ \\
\hline Slowakei & 20 & 18 & 26 & 6 & 17 & 10 & 3 & $\mathrm{n}$ \\
\hline Slowenien & 14 & 10 & 32 & 11 & 22 & 8 & 3 & $\mathrm{n}$ \\
\hline Spanien ${ }^{2}$ & 23 & 13 & 28 & 7 & 17 & 9 & 1 & $n$ \\
\hline Schweden & 25 & 13 & 28 & 3 & 19 & 11 & 1 & $\mathrm{n}$ \\
\hline Schweiz & 17 & 12 & 37 & 7 & 16 & 9 & 1 & 1 \\
\hline Türkei & 21 & 7 & 39 & 5 & 15 & 10 & 3 & $\mathrm{n}$ \\
\hline Vereinigtes Königreich & 24 & 17 & 27 & 2 & 8 & 14 & 1 & 7 \\
\hline Vereinigte Staaten & $\mathrm{m}$ & $\mathrm{m}$ & $\mathrm{m}$ & $\mathrm{m}$ & $\mathrm{m}$ & $\mathrm{m}$ & $\mathrm{m}$ & $\mathrm{m}$ \\
\hline OECD-Durchschnitt & 20 & 14 & 32 & 6 & 15 & 10 & 2 & 1 \\
\hline EU21-Durchschnitt & 19 & 14 & 31 & 6 & 15 & 11 & 2 & 1 \\
\hline \multicolumn{9}{|l|}{ Sonstige G20-Länder } \\
\hline Argentinien $^{3}$ & 28 & 13 & 33 & 5 & 8 & 10 & 3 & 1 \\
\hline Brasilien & $\mathrm{m}$ & $\mathrm{m}$ & $\mathrm{m}$ & $\mathrm{m}$ & $\mathrm{m}$ & $\mathrm{m}$ & $\mathrm{m}$ & $\mathrm{m}$ \\
\hline China & $\mathrm{m}$ & $\mathrm{m}$ & $\mathrm{m}$ & $\mathrm{m}$ & $\mathrm{m}$ & $\mathrm{m}$ & $\mathrm{m}$ & $\mathrm{m}$ \\
\hline Indien & $\mathrm{m}$ & $\mathrm{m}$ & $\mathrm{m}$ & $\mathrm{m}$ & $\mathrm{m}$ & $\mathrm{m}$ & $\mathrm{m}$ & $\mathrm{m}$ \\
\hline Indonesien & 20 & 5 & 43 & $\mathrm{n}$ & 16 & 10 & 5 & 1 \\
\hline Russische Föd. ${ }^{2}$ & 11 & 6 & 40 & 6 & 26 & 7 & 2 & 3 \\
\hline Saudi-Arabien & 27 & 5 & 21 & 1 & 6 & 1 & 28 & $\mathrm{~m}$ \\
\hline Südafrika & $\mathrm{m}$ & $\mathrm{m}$ & $\mathrm{m}$ & $\mathrm{m}$ & $\mathrm{m}$ & $\mathrm{m}$ & $\mathrm{m}$ & $\mathrm{m}$ \\
\hline G20-Durchschnitt & m & m & m & m & m & m & m & m \\
\hline
\end{tabular}

Anmerkung: Die Spalten mit getrennten Angaben zu „Geisteswissenschaften, Kunst und Erziehungswissenschaften“, d.h. die Spalten (2) und (3), sowie zu den einzelnen Naturwissenschaften, d.h. die Spalten (9) bis (12), sind im Internet verfügbar (s. StatLink unten).

1. Ohne Studiengänge im Tertiärbereich B. 2. Ohne weiterführende forschungsorientierte Studiengänge. 3. Referenzjahr 2009.

Quelle: OECD. Argentinien: Statistikinstitut der UNESCO (World Education Indicators Programme). Saudi-Arabien: Observatory on Higher Education. Hinweise s. Anhang 3 unter www.oecd.org/edu/eag.htm. StatLink: http://dx.doi.org/10.1787/888932850661 Erläuterung der Kennzeichnung fehlender Daten s. Hinweise für den Leser. 



\section{Wer studiert im Ausland und wo?}

20 II waren fast als 4,3 Millionen Studierende außerhalb ihres Heimatlandes im Tertiärbereich eingeschrieben. Australien, das Vereinigte Königreich, die Schweiz, Neuseeland und Österreich haben, in absteigender Reihenfolge, die höchsten Anteile internationaler Studierender an der Gesamtzahl der in ihrem Land eingeschriebenen Studierenden.

Studierende aus Asien stellen weltweit 53 Prozent der eingeschriebenen ausländischen Studierenden. In absoluten Zahlen kommen die meisten ausländischen Studierenden aus China, Indien und Korea.

20 II war die Zahl der in OECD-Ländern eingeschriebenen ausländischen Studierenden fast dreimal so hoch wie die Zahl der Staatsbürger aus OECD-Ländern, die im Ausland studierten. Bei den 2I EU-Mitgliedstaaten, die auch Mitglied der OECD sind (EU2I), kamen auf jeden im Ausland studierenden europäischen Staatsbürger 2,7 ausländische Studierende.

Rund 83 Prozent aller ausländischen Studierenden sind in G20-Ländern eingeschrieben, 77 Prozent in OECD-Ländern. Diese Anteile sind in den letzten zehn Jahren stabil geblieben.

Abbildung C4.1

Entwicklung der Zahl der außerhalb des Landes ihrer Staatsangehörigkeit eingeschriebenen Studierenden, nach Zielregion (2000 bis 2011)

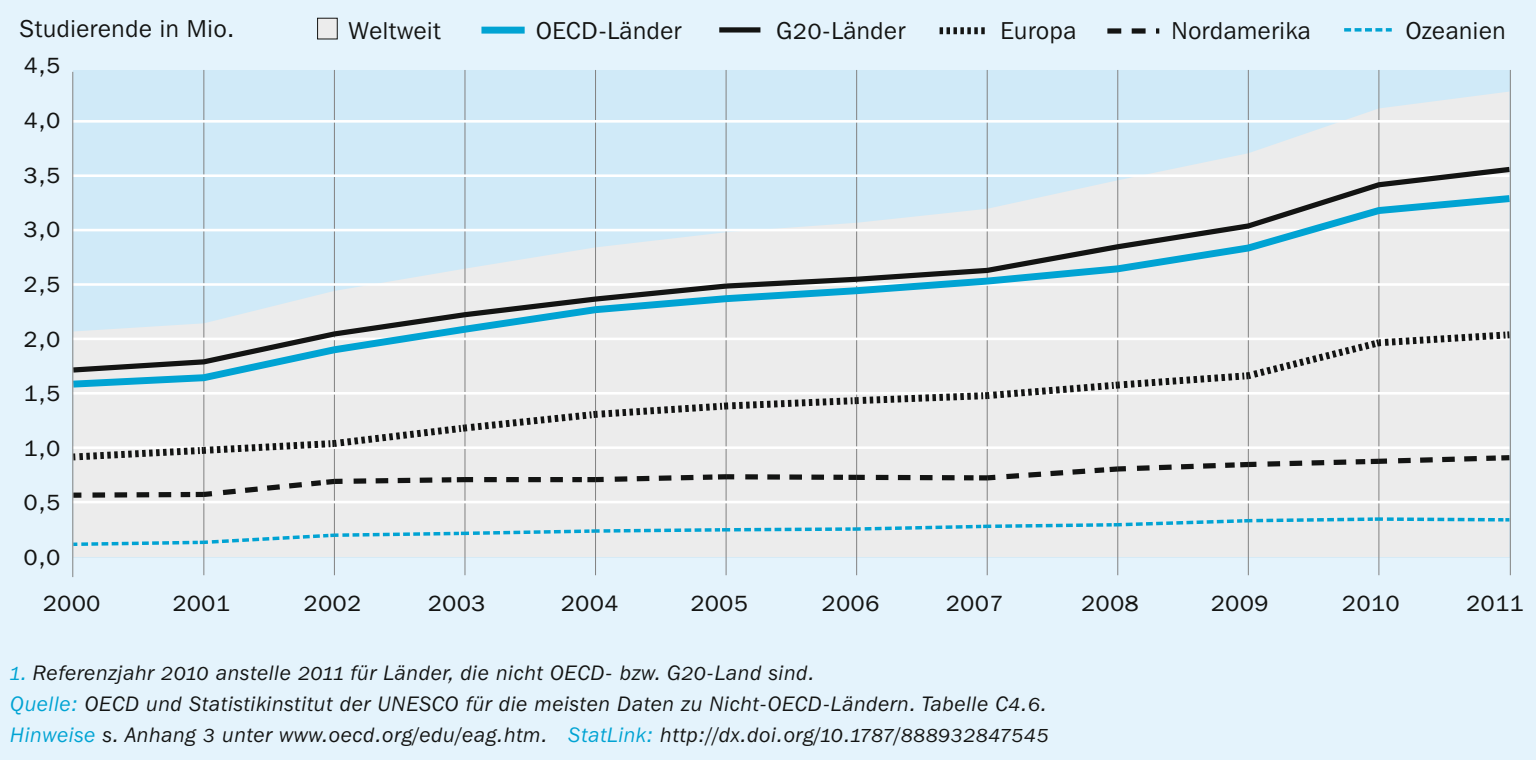




\section{Kontext}

Bedingt durch die zunehmende internationale Vernetzung der Volkswirtschaften und eine wachsende Bildungsteilnahme erwarten sowohl die Regierungen als auch die Bürger von der Ausbildung im Tertiärbereich, dass sie den Horizont der Studierenden erweitern und ihnen ein besseres Verständnis der Sprachen, Kulturen und betriebswirtschaftlichen Methoden anderer Länder ermöglichen. Eine Möglichkeit für Studierende, ihre Kenntnisse anderer Gesellschaften und Sprachen zu erweitern und so ihre Chancen in globalisierten Bereichen der Arbeitsmärkte zu verbessern, besteht darin, zum Studium ins Ausland zu gehen.

Die zum allgemeinen Anstieg der Mobilität Studierender führenden Faktoren reichen von der weltweit außerordentlich stark steigenden Nachfrage nach einer Ausbildung im Tertiärbereich und dem Wert, der einem Studium an angesehenen ausländischen Einrichtungen im postsekundaren Bereich beigemessen wird, über spezielle bildungspolitische Rahmenbedingungen zur Förderung der Mobilität von Studierenden in einer geografischen Region (wie dies in Europa der Fall ist) bis zur staatlichen Unterstützung Studierender, die bestimmte, in ihrem Herkunftsland stark nachgefragte Fachrichtungen studieren. Darüber hinaus betreiben einige Länder und Einrichtungen ein intensives Marketing, um Studierende aus dem Ausland zu gewinnen. Die zunehmende Mobilität der Studierenden im Tertiärbereich kann insbesondere für kleinere und/oder weniger entwickelte Bildungssysteme eine Chance sein, ihr Bildungsangebot kosteneffizienter zu gestalten. Denn durch sie können Länder in die Lage versetzt werden, ihre beschränkten Mittel auf diejenigen Bildungsangebote zu konzentrieren, in denen sie Größenvorteile erreichen können, bzw. die Bildungsbeteiligung im Tertiärbereich ohne die Notwendigkeit der Bereitstellung entsprechender Studienplätze im eigenen Land zu erhöhen. Für die Zielländer kann die Aufnahme internationaler Studierender nicht nur dazu beitragen, mit Bildungsangeboten im Hochschulbereich Einnahmen zu erzielen, sie kann auch Teil einer breiter angelegten Strategie zur Anwerbung hoch qualifizierter Einwanderer sein.

Ein signifikant hoher Teil der Studierenden aus G20-Ländern, die nicht Mitglied der OECD sind, gehört zu den leistungsfähigeren Studierenden, die naheliegende Kandidaten für eine öffentliche oder private Unterstützung sind, oder sie haben einen relativ günstigen sozioökonomischen Hintergrund. Damit kann die Mobilität Studierender nicht nur die Reputation der Studiengänge des Tertiärbereichs fördern, sondern den Bildungssystemen der Gastländer auch wirtschaftliche Vorteile bringen.

Angesichts der aktuellen wirtschaftlichen Situation können die sinkende Unterstützung mit Stipendien und Beihilfen, die der Förderung der Mobilität Studierender dienen sollen, sowie knappere Mittel der einzelnen Studierenden die Mobilität der Studierenden insgesamt verringern. Andererseits können begrenzte Möglichkeiten auf den Arbeitsmärkten der Herkunftsländer der Studierenden die Attraktivität eines Auslandsstudiums als Möglichkeit, im Wettbewerb einen Schritt voraus zu sein, erhöhen und so zu einer Steigerung der Mobilität Studierender beitragen.

Internationale Studierende wählen häufig andere Studiengänge als inländische Studierende (s. Indikator A4 in Bildung aufeinen Blick 2011), was entweder auf eine gewisse Spezialisierung der Länder bei den angebotenen Studiengängen, einen Mangel an 
entsprechenden Studiengängen im Herkunftsland und/oder bessere Beschäftigungsmöglichkeiten bei Belegung spezieller Fächergruppen schließen lässt.

In diesem Indikator handelt es sich bei „internationalen Studierenden“ bzw. „mobilen Studierenden “ um Studierende, die ausdrücklich zum Studium aus ihrem Herkunftsland in ein anderes Land gekommen sind. „Ausländische Studierende“ andererseits sind Studierende, die nicht Staatsbürger des Landes sind, in dem sie eingeschrieben sind, jedoch in manchen Fällen dort bereits seit vielen Jahren ihren dauerhaften Wohnsitz haben oder sogar dort geboren wurden. Internationale Studierende sind also im Allgemeinen eine Untergruppe der ausländischen Studierenden (s. Abschnitt Definitionen am Ende des Indikators).

\section{Weitere wichtige Ergebnisse}

In Australien, Deutschland, Frankreich, Kanada, dem Vereinigten Königreich und den Vereinigten Staaten zusammen studieren mehr als 50 Prozent aller ausländischen Studierenden weltweit.

Von den OECD-Ländern entsenden Deutschland, Frankreich, Italien, Japan, Kanada, Korea, die Slowakei, die Türkei und die Vereinigten Staaten die meisten internationalen Studierenden.

Internationale Studierende stellen in Australien, Neuseeland, Österreich, der Schweiz und dem Vereinigten Königreich mindestens 10 Prozent der eingeschriebenen Studierenden. In Australien, Neuseeland, den Niederlanden, der Schweiz und dem Vereinigten Königreich stellen sie auch mehr als 30 Prozent der in weiterführenden forschungsorientierten Studiengängen eingeschriebenen Studierenden.

\section{Entwicklungstendenzen}

Die Zahl der weltweit eingeschriebenen ausländischen Studierenden hat sich zwischen 2000 und 20 I m mehr als verdoppelt, die durchschnittliche jährliche Steigerung betrug fast 7 Prozent. In den OECD-Ländern spiegelt die Zahl der ausländischen Studierenden im Tertiärbereich den globalen Trend wider.

Mit 48 Prozent aller Studierenden im Auslandsstudium ist Europa das bevorzugte Ziel von Studierenden, die außerhalb ihres Herkunftslandes eingeschrieben sind, gefolgt von Nordamerika mit 2I Prozent aller internationalen Studierenden. Die Zahl der internationalen Studierenden in Ozeanien hat sich seit dem Jahr 2000 verdreifacht, obwohl weniger als Io Prozent aller ausländischen Studierenden dort studieren. Auch andere Regionen wie Asien sowie Lateinamerika und die Karibik haben steigende Zahlen internationaler Studierender, was die Internationalisierung von Universitäten in einer wachsenden Zahl von Ländern widerspiegelt (Tab. C4.6 und Abb. C4.I). 


\section{Analyse und Interpretationen}

In den letzten 30 Jahren ist die Zahl der außerhalb des Landes, dessen Staatsbürger sie sind, eingeschriebenen Studierenden außerordentlich stark gestiegen, von weltweit o,8 Millionen im Jahr I975 auf 4,3 Millionen im Jahr 20II, also auf das mehr als Fünffache (Kasten C4.I). Diese außerordentliche Steigerung ergibt sich aus dem Interesse an der Förderung akademischer, kultureller, gesellschaftlicher und politischer Bindungen zwischen Ländern, insbesondere während der Aufbauzeiten der Europäischen Union, sowie einem starken Anstieg des weltweiten Zugangs zu Bildung im Tertiärbereich und gesunkenen Reisekosten. Die wachsende Internationalisierung der Arbeitsmärkte für hoch qualifizierte Arbeitnehmer hat auch als Anreiz für die Studierenden gewirkt, im Laufe des Studiums Auslandserfahrungen zu sammeln.

Die meisten neuen ausländischen Studierenden kommen aus Ländern außerhalb des OECD-Gebiets und werden in den kommenden Jahren wahrscheinlich zu einem allmählichen Anstieg des Anteils ausländischer Studierender in weiterführenden forschungsorientierten Studiengängen in den OECD- und sonstigen G20-Ländern führen.

Die weltweite Mobilität Studierender spiegelt in großem Maß inter- und intraregionale Migrationsmuster wider. Die zunehmende Internationalisierung der Einschreibungen an den Bildungseinrichtungen des Tertiärbereichs der OECD-Länder und die hohe intraregionale Mobilität Studierender weisen auf die zunehmende Bedeutung regionaler Mobilität im Vergleich zur weltweiten Mobilität hin. Die Mobilitätsmuster Studierender in den europäischen Ländern sowie in Ostasien und Ozeanien spiegeln tendenziell auch die Entwicklung geopolitischer Großräume wider, wie engere Bindungen zwischen den Ländern im asiatisch-pazifischen Raum und die über die Europäische Union hinausgehende Zusammenarbeit unter den europäischen Ländern (UNESCO, 2009).

\section{Die wichtigsten Zielländer ausländischer Studierender}

83 Prozent der ausländischen Studierenden weltweit gehen für ein Auslandsstudium in eines der G20-Länder, während etwa 77 Prozent an Hochschulen in einem OECD-Land eingeschrieben sind. Innerhalb des OECD-Gebiets sind mit 40 Prozent die meisten ausländischen Studierenden weltweit in den EU2I-Ländern eingeschrieben. Darüber hinaus nehmen diese 2I Länder 98 Prozent der in EU-Ländern eingeschriebenen ausländischen Studierenden auf. Rund 75 Prozent der in den EU2I-Ländern eingeschriebenen ausländischen Studierenden stammen aus einem anderen EU2I-Mitgliedstaat, was zeigt, wie erfolgreich die Mobilitätspolitik der EU ist. Mit einem Anteil von 2I Prozent aller ausländischen Studierenden liegt Nordamerika bei der Attraktivität für ausländische Studierende an zweiter Stelle. Die Gruppe der internationalen Studierenden in dieser Region ist wesentlich heterogener als in der EU. Obwohl beispielsweise 57 Prozent der kanadischen Studierenden ihr Auslandsstudium in den Vereinigten Staaten absolvieren, stellen sie dort nur 4 Prozent der internationalen Studierenden. Ebenso entscheiden sich I5 Prozent der US-amerikanischen Studierenden für ein Auslandsstudium in Kanada, stellen dort aber nur 7 Prozent aller ausländischen Studierenden (Tab. $\mathrm{C}_{4 \cdot 3}, \mathrm{C}_{4} .4$ und $\mathrm{C}_{4} .6$ ).

20II waren mehr als die Hälfte der ausländischen Studierenden in Australien, Deutschland, Frankreich, Kanada, dem Vereinigten Königreich oder den Vereinigten Staaten 


\section{Langfristige Zunahme der Zahl der außerhalb des Landes ihrer Staatsangehörigkeit eingeschriebenen Studierenden}

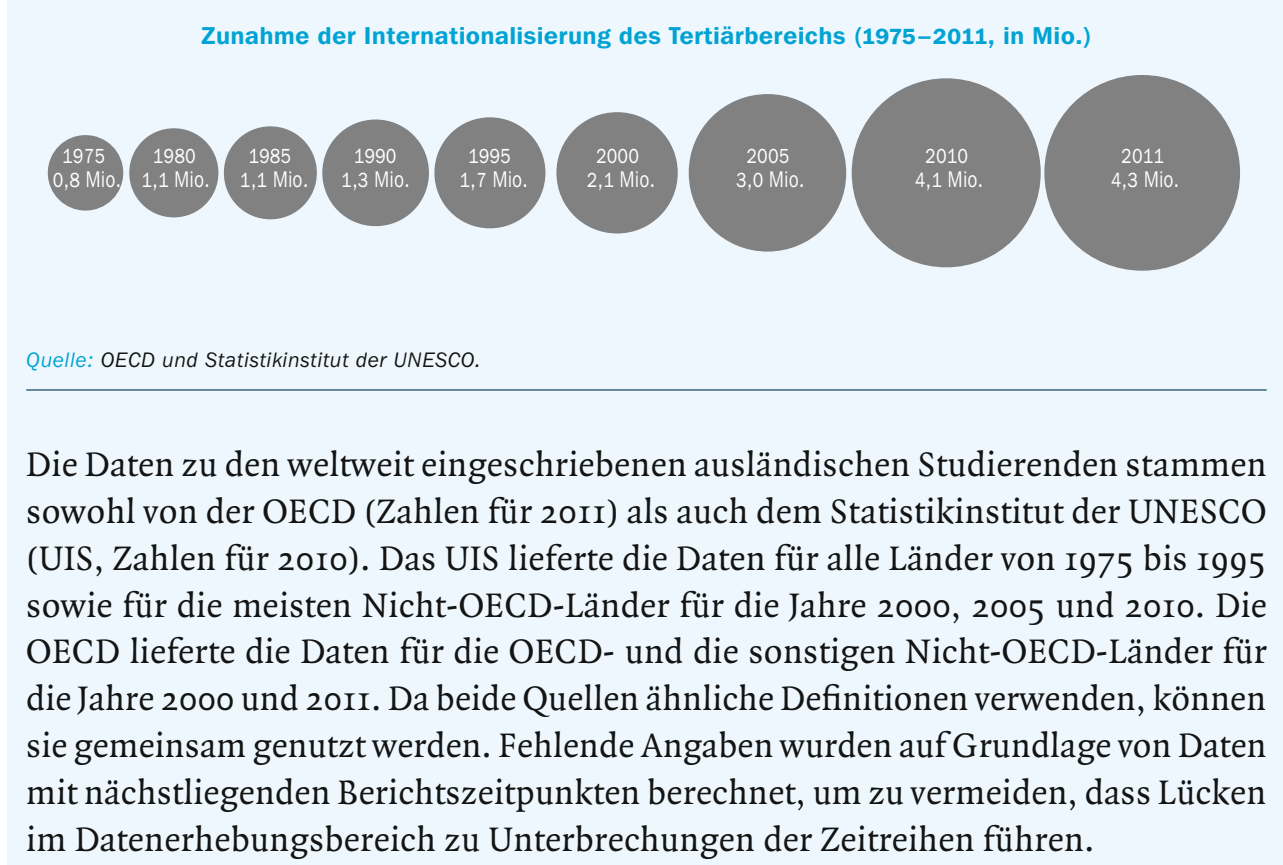

im Tertiärbereich eingeschrieben. Mit 17 Prozent aller ausländischen Studierenden waren die Vereinigten Staaten das größte Aufnahmeland (in absoluten Zahlen), gefolgt vom Vereinigten Königreich (13 Prozent), Australien (6 Prozent), Deutschland (6 Prozent), Frankreich (6 Prozent) und Kanada (5 Prozent). Obwohl diese Zielländer mehr als die Hälfte aller Studierenden, die im Ausland studieren, aufnehmen, sind in den letzten Jahren einige neue Akteure auf dem internationalen Bildungsmarkt aufgetreten (Abb. C4.2 und Tab. C4.7 im Internet). Abgesehen von den sechs wichtigsten Zielländern waren $201 r$ eine signifikante Zahl ausländischer Studierender in Japan (4 Prozent), der Russischen Föderation (4 Prozent) und Spanien (2 Prozent) eingeschrieben. Die Zahlen für Australien und die Vereinigten Staaten beziehen sich hierbei auf internationale Studierende (Tab. C4.4).

\section{Neue Akteure auf dem internationalen Bildungsmarkt}

Im Vergleich mit dem Jahr 2000 sank der Anteil der Vereinigten Staaten als Zielland internationaler Studierender von 23 Prozent auf 17 Prozent in 201 und der Anteil internationaler Studierender, die sich für Deutschland entschieden, um fast 3 Prozentpunkte. Im Gegensatz dazu stieg der Prozentsatz internationaler Studierender, die Australien, Korea, Neuseeland oder Spanien als Ziel wählten, um mindestens I Prozentpunkt, und der Anteil der Studierenden, die das Vereinigte Königreich und die Russische Föderation wählten, stieg um etwa 2 Prozentpunkte (Abb. C4.3). Einige dieser Änderungen unterstreichen die unterschiedlichen Schwerpunkte der Internationalisierungsansätze einzelner Länder, die von einer aktiven Vermarktung im asiatisch-pazifischen Raum bis zu einem eher lokalen und universitätsspezifischen Ansatz in den Vereinigten Staaten reichen. 


\section{Ausschlaggebende Faktoren bei der Wahl des Landes für ein Auslandsstudium \\ Die Unterrichtssprache}

Die Landessprache und die Unterrichtssprache sind manchmal bei der Auswahl des Landes für ein Auslandsstudium von entscheidender Bedeutung. Daher sind die Länder sowohl relativ als auch in absoluten Zahlen die wichtigsten Aufnahmeländer für ausländische Studierende, deren Unterrichtssprache weit verbreitet ist, wie beispielsweise Deutsch, Englisch, Französisch, Russisch und Spanisch. Japan ist eine bemerkenswerte Ausnahme: Trotz einer weltweit gering verbreiteten Unterrichtssprache hat Japan hohe Einschreibungszahlen ausländischer Studierender, von denen 93 Prozent aus Asien kommen (Tab. C4.3 und Abb. C4.2).

Die Vorherrschaft hauptsächlich englischsprachiger Zielländer wie Australien, Kanada, Neuseeland, das Vereinigte Königreich und die Vereinigten Staaten spiegelt wider, dass das Englische zunehmend zur Weltsprache wird. Ein weiterer Grund könnte sein, dass auslandsinteressierte Studierende im Heimatland höchstwahrscheinlich Englisch gelernt haben oder durch das Leben und Studieren in einem englischsprachigen Land ihre Englischkenntnisse vertiefen wollen. Daher können rund 40 Prozent des Gesamtanstiegs der Einschreibungen ausländischer Studierender weltweit zwischen 2000 und 20II durch einen Anstieg derartiger Einschreibungen in Australien, Irland, Kanada, dem Vereinigten Königreich und den Vereinigten Staaten erklärt werden (Tab. C4.7 im Internet). Verstärkend kommt hinzu, dass in vielen Ländern Englisch entweder Amts-

Abbildung C4.2

Verteilung ausländischer Studierender im Tertiärbereich, nach Zielland (2011)

Anteil ausländischer Studierender (in \%) in dem jeweiligen Zielland (gemäß Datenmeldung an die OECD)

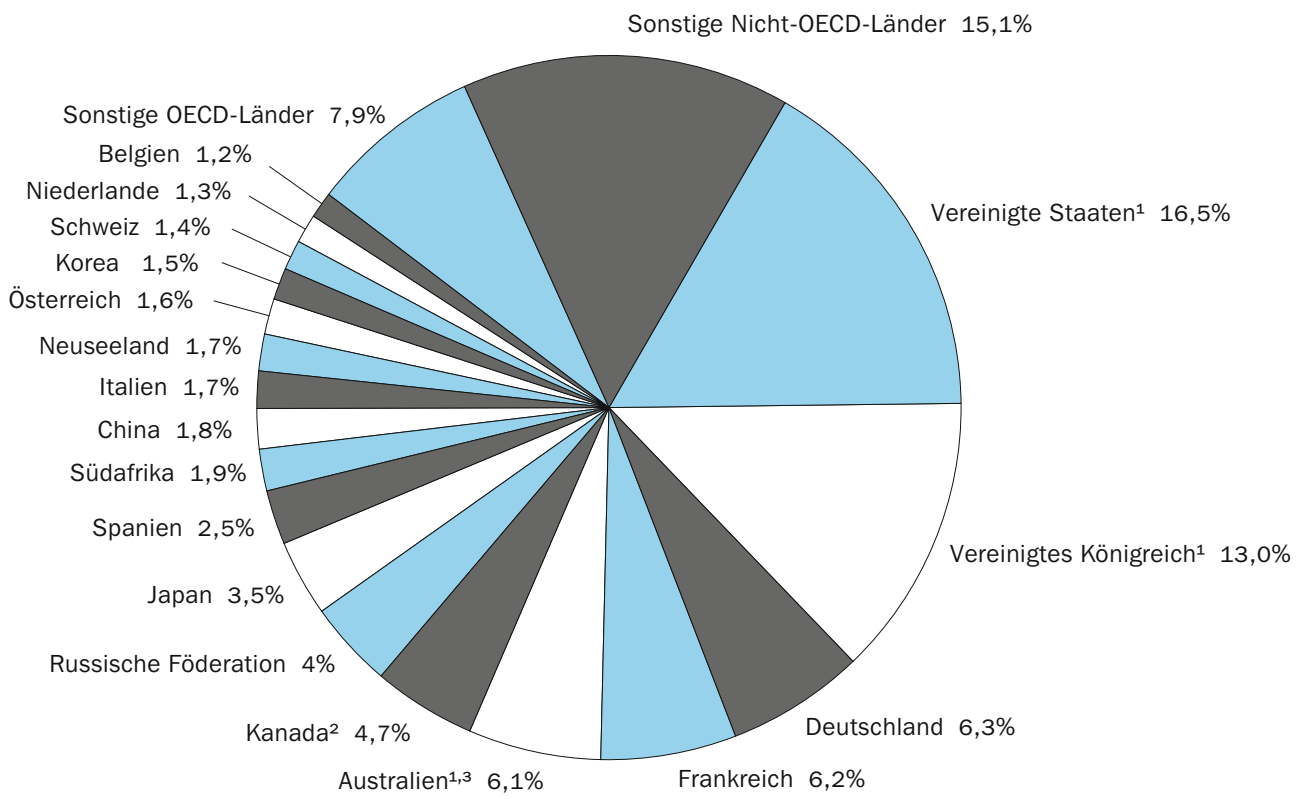

Anmerkung: Referenzjahr 2010 für Länder, die nicht OECD- bzw. G20-Land sind.

1. Die Daten beziehen sich auf internationale Studierende, die auf Grundlage ihres Wohnsitzstaates definiert sind. 2. Referenzjahr 2010.

3. Die Daten zu den Studierenden stammen aus unterschiedlichen Quellen und bilden daher die Verteilung nur näherungsweise ab.

Quelle: OECD und Statistikinstitut der UNESCO für die meisten Daten zu Nicht-OECD-Ländern. Tabelle C4.4 und Tabelle C4.7 im Internet.

Hinweise s. Anhang 3 unter www.oecd.org/edu/eag.htm. StatLink: http://dx.doi.org/10.1787/888932847564 


\title{
Abbildung C4.3
}

Entwicklung der Marktanteile im internationalen Bildungsmarkt (2000, 2011)

Anteil aller ausländischen Studierenden (in \%), die in bestimmten Zielländern eingeschrieben sind

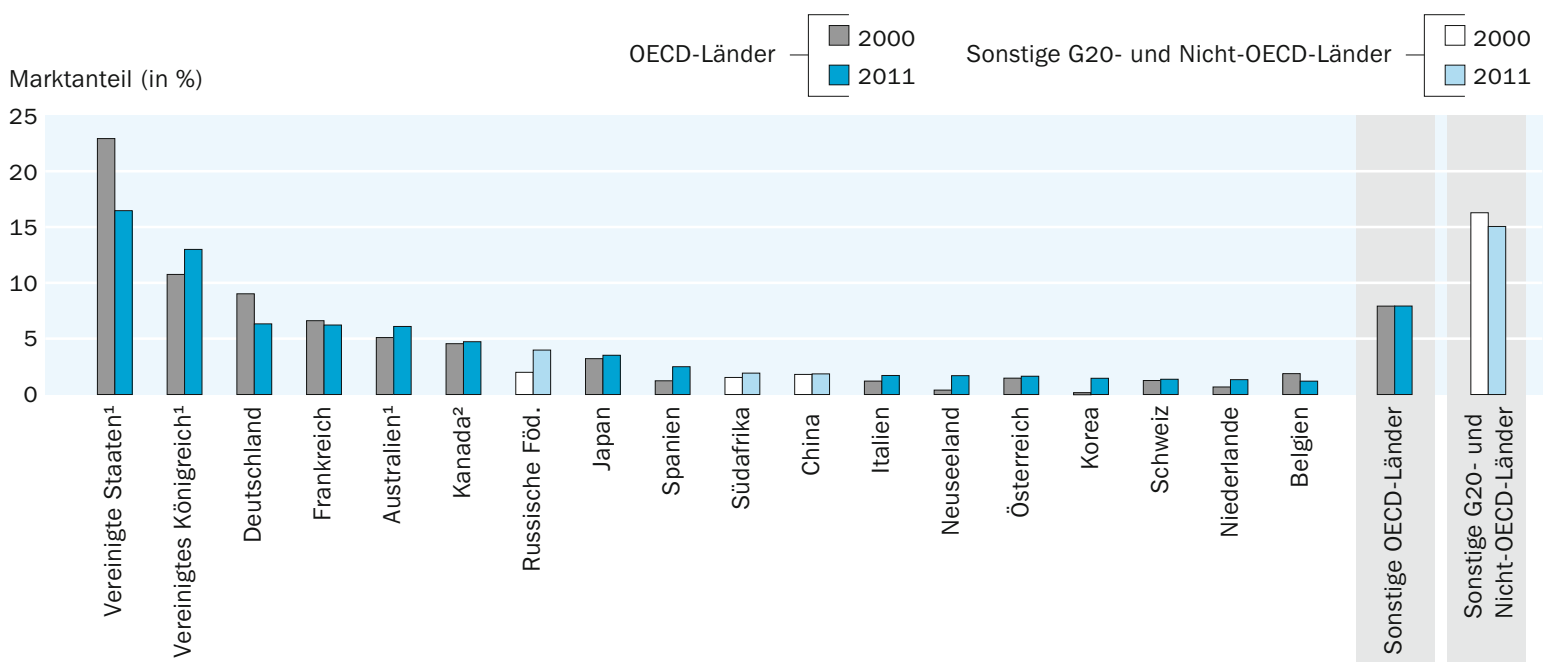

Anmerkung: Referenzjahr 2010 für Länder, die nicht OECD-bzw. G20-Land sind.

1. Die Daten beziehen sich auf internationale Studierende, die auf Grundlage ihres Wohnsitzstaates definiert sind. Für das Vereinigte Königreich beruhen die Daten für 2011 auf der Staatsbürgerschaft der Studierenden. 2. Referenzjahr 2010 anstelle 2011.

Anordnung der Länder in absteigender Reihenfolge der Marktanteile in 2011.

Quelle: OECD und Statistikinstitut der UNESCO für die meisten Daten zu Nicht-OECD-Ländern. Tabelle C4.7 im Internet.

Hinweise s. Anhang 3 unter www.oecd.org/edu/eag.htm. StatLink: http://dx.doi.org/10.1787/888932847583

sprache ist oder als Lingua franca verwendet wird. In sämtlichen englischsprachigen OECD-Ländern stammt zwischen einem Fünftel und einem Drittel der ausländischen Studierenden (und in Neuseeland die Hälfte der ausländischen Studierenden) aus einem anderen englischsprachigen Land. 20II kam im Durchschnitt aller OECD-Länder etwa jeder vierte Studierende aus einem Land, dessen Amtssprache oder verbreitet gesprochene Sprache der Sprache des Ziellandes entsprach (Tab. C4.5).

\author{
Kasten $\mathrm{C} 4.2$ \\ Länder mit englischsprachigen Studienangeboten im Tertiärbereich (2010) \\ Englisch als Unterrichtssprache \\ Alle oder fast alle Studiengänge werden auf Australien, Irland, Kanada ${ }^{1}$, Neuseeland, Vereinigtes Königreich, \\ Englisch angeboten. \\ Vereinigte Staaten \\ Zahlreiche Studiengänge werden auf Englisch \\ angeboten. \\ Dänemark, Finnland, Niederlande, Schweden \\ Einige Studiengänge werden auf Englisch \\ angeboten. \\ Belgien (fläm.) $)^{2}$, Deutschland, Frankreich, Island, Japan, Korea, Norwegen, \\ Polen, Portugal, Schweiz ${ }^{3}$, Slowakei, Tschechien, Türkei, Ungarn \\ Keine oder fast keine Studiengänge werden auf \\ Englisch angeboten. \\ Belgien (frz.), Brasilien, Chile, Griechenland, Israel, Italien, Luxemburg, \\ Mexiko $^{3}$, Österreich, Russische Föderation, Spanien \\ Anmerkung: Bei der Beurteilung, ob ein Land viele oder wenige Studiengänge auf Englisch anbietet, wurde die Bevölkerungsgröße \\ des Landes berücksichtigt. Daher fallen Deutschland und Frankreich in die Kategorie mit vergleichsweise wenigen englisch- \\ sprachigen Studienangeboten, obwohl sie in absoluten Zahlen mehr Studiengänge auf Englisch anbieten als Schweden. \\ 1. In Kanada sind Bildungseinrichtungen im Tertiärbereich entweder französischsprachig (hauptsächlich in Quebec) oder englisch- \\ sprachig. 2. Masterstudiengänge. 3. Je nach Ermessen der Bildungseinrichtung. \\ Quelle: OECD, zusammengetragen aus Broschüren für an einem Auslandsstudium interessierte Studierende von Cirius (Däne- \\ mark), DAAD (Deutschland), CIMO (Finnland), EduFrance (Frankreich), University of Iceland (Island), JPSS (Japan), NIED (Korea), \\ NUFFIC (Niederlande), SIU (Norwegen), OAD (Österreich), CRASP (Polen), Swedish Institute (Schweden), CHES und NARIC (Tsche- \\ chien), Middle-East Technical University (Türkei) und Campus Hungary (Ungarn).
}


Angesichts dieser Entwicklung bieten inzwischen immer mehr Bildungseinrichtungen in nicht englischsprachigen Ländern Studiengänge in Englisch an. Dieser Trend ist besonders in den Ländern ausgeprägt, in denen das Englische weit verbreitet ist, wie beispielsweise den nordischen Ländern (Kasten $\mathrm{C}_{4}$.2).

\section{Qualität der Studiengänge}

Internationale Studierende wählen ihr Zielland zunehmend nach der Qualität der angebotenen Studiengänge, die sich anhand einer Vielzahl von Informationen und Rankings zu Studiengängen ermitteln lässt, die inzwischen sowohl in gedruckter Form als auch im Internet zur Verfügung stehen. So lenken beispielsweise der hohe Anteil von Bildungseinrichtungen mit Spitzenrankings in den Hauptzielländern und das Aufkommen von Rankings für Institutionen, die sich in Ländern mit einem starken Zuwachs internationaler Studierender befinden, die Aufmerksamkeit auf die zunehmende Bedeutung von Qualität, wie sie von den Studierenden wahrgenommen wird, auch wenn es schwierig ist, einen direkten Zusammenhang zwischen den strukturellen Merkmalen der Mobilität Studierender und den Qualitätsbewertungen für einzelne Einrichtungen herzustellen.

\section{Studiengebühren}

In allen EU-Ländern gelten internationale Studierende aus anderen EU-Ländern hinsichtlich der Studiengebühren als inländische Studierende. In Irland gilt dies jedoch nur unter der Voraussetzung, dass Studierende aus dem EU-Ausland drei der fünf vorangegangenen Jahre in der EU, dem Europäischen Wirtschaftsraum (EWR) oder der Schweiz gelebt haben. Wird diese Bedingung erfüllt, haben Studierende aus dem EU-Ausland Anspruch auf ein kostenloses Studium in dem jeweiligen Studienjahr.

Während es in Finnland, Island und Schweden keine Studiengebühren gibt, werden in Deutschland von allen staatlich subventionierten privaten Einrichtungen und in einigen Bundesländern mittlerweile auch von öffentlichen Einrichtungen im Tertiärbereich Studiengebühren verlangt. In Dänemark werden Studierende aus Norwegen und Island sowie aus EU-Ländern wie inländische Studierende behandelt und zahlen daher keine Studiengebühren, da ihre Ausbildung voll subventioniert wird. Die meisten internationalen Studierenden, die nicht aus einem EU- oder EWR-Land kommen, müssen jedoch Studiengebühren in voller Höhe zahlen, wenngleich eine begrenzte Anzahl begabter Studierender aus diesen Ländern Stipendien erhalten kann, die einen Teil der Studiengebühren bzw. die gesamten Studiengebühren abdecken (Kasten C4.3).

In einigen Nicht-EU-Ländern, darunter Island, Japan, Korea, Norwegen und die Vereinigten Staaten, werden bei den Studiengebühren alle inländischen und internationalen Studierenden gleich behandelt. In Norwegen werden für inländische und internationale Studierende dieselben Studiengebühren angesetzt: An öffentlichen Bildungseinrichtungen gibt es keine Studiengebühren, während an einigen privaten Einrichtungen Gebühren erhoben werden. In Island müssen alle Studierenden Einschreibegebühren zahlen, und von Studierenden an privaten Bildungseinrichtungen werden zudem Studiengebühren verlangt. In Japan werden im Allgemeinen von inländischen und internationalen Studierenden Studiengebühren in gleicher Höhe erhoben, aber internationale Studierende mit einem Stipendium der japanischen Regierung müssen keine 


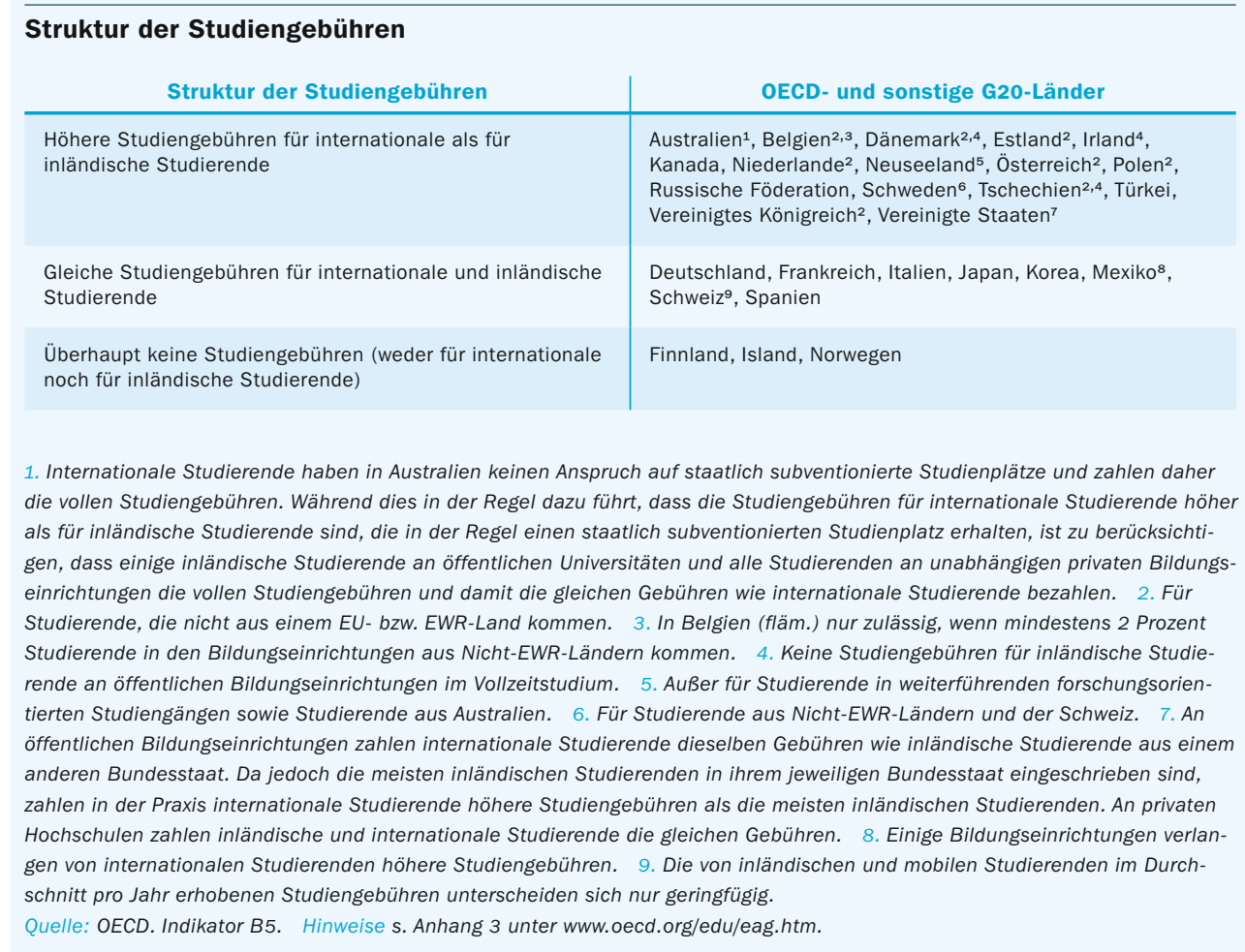

Studiengebühren zahlen, zudem gibt es zahlreiche Stipendien für internationale Studierende, die ihr Studium privat finanzieren.

In Korea variieren Studiengebühren und Unterstützungszahlungen für internationale Studierende in Abhängigkeit von der vertraglichen Vereinbarung zwischen der Bildungseinrichtung, von der sie kommen, und der Bildungseinrichtung, die sie in Korea besuchen. Im Allgemeinen zahlen die meisten internationalen Studierenden in Korea Studiengebühren, die etwas niedriger sind als die für inländische Studierende. In Neuseeland zahlen in der Regel internationale Studierende, mit Ausnahme von Studierenden in weiterführenden forschungsorientierten Studiengängen, höhere Studiengebühren, internationale Studierende aus Australien erhalten jedoch dieselben Unterstützungszahlungen wie inländische Studierende. In Australien (abgesehen von den in Kasten C4.3 aufgeführten Ausnahmen) und in Kanada zahlen in der Regel alle internationalen Studierenden höhere Studiengebühren als inländische Studierende. Dies trifft auch für die Russische Föderation zu, außer die Studierenden werden von der russischen Regierung unterstützt.

Die Tatsache, dass es in Finnland, Island und Norwegen keine Studiengebühren für internationale Studierende gibt und außerdem englischsprachige Studiengänge angeboten werden, erklärt wahrscheinlich teilweise den stetigen Anstieg der ausländischen Studierenden, der in einigen dieser Länder zwischen 2005 und $201 \mathrm{r}$ zu beobachten war (Tab. C4.I). Angesichts der hohen Kosten pro Studierenden führen internationale Studierende jedoch zu großen finanziellen Belastungen der Zielländer, wenn diese keine Studiengebühren erheben (s. Tab. BI.ra). Deshalb hat Dänemark, wo es vorher keine 
Studiengebühren gab, ab dem Studienjahr 2006/2007 Studiengebühren für internationale Studierende eingeführt, die nicht aus einem EU- oder EWR-Land kommen. In Finnland werden gegenwärtig ähnliche Überlegungen angestellt und ausprobiert, und Schweden hat mit Beginn des Studienjahrs 20II/20I2 für Studierende aus Nicht-EUoder Nicht-EWR-Ländern (durch Stipendien kompensierte) Studiengebühren eingeführt. Zukünftige Analysen werden darauf genauer eingehen.

Länder, die die vollen Bildungskosten an die internationalen Studierenden weitergeben, haben erhebliche wirtschaftliche Vorteile. Mehrere Länder im asiatisch-pazifischen Raum haben in der Tat internationale Bildung als expliziten Teil ihrer sozioökonomischen Entwicklungsstrategie definiert und verfolgen eine Politik, die darauf abzielt, ihre Bildungseinrichtungen für internationale Studierende attraktiv zu machen und dabei gewinnorientiert oder zumindest kostendeckend zu arbeiten. Australien und Neuseeland haben erfolgreich differenzierte Studiengebühren für internationale Studierende eingeführt, trotzdem stieg in diesen beiden Ländern die Zahl der ausländischen Studierenden stark an (Tab. C4.I). Dies zeigt, dass interessierte internationale Studierende nicht zwangsläufig durch Studiengebühren abgeschreckt werden, solange die Qualität der angebotenen Ausbildung hoch ist und die potenziellen Erträge die Investition als lohnend erscheinen lassen.

Wenn jedoch eine Entscheidung zwischen ähnlichen Bildungsangeboten erforderlich wird, spielen Kosten durchaus eine Rolle. In diesem Zusammenhang lässt sich der Rückgang des auf die Vereinigten Staaten entfallenden Anteils am internationalen Bildungsmarkt möglicherweise auf die im Vergleich mit anderen hauptsächlich englischsprachigen Zielländern, die ähnliche Studiengänge kostengünstiger anbieten, hohen Studiengebühren für internationale Studierende zurückführen (Abb. C4.3). Weiterführende forschungsorientierte Studiengänge in Neuseeland sind zum Beispiel seit 2005 attraktiver geworden, als die Studiengebühren für internationale Studierende auf die Höhe der Gebühren für inländische Studierende gesenkt wurden (Kasten C4·3).

Ein Anspruch auf öffentliche Mittel oder Unterstützungszahlungen für Studierende auch während eines Auslandsstudiums können die Kosten eines solchen Studiums reduzieren, wie sich in Chile, Finnland, Island, den Niederlanden, Norwegen und Schweden zeigt.

\section{Einwanderungsbestimmungen}

In den letzten Jahren hat eine Reihe von OECD-Ländern ihre Einwanderungsbestimmungen gelockert, um die zeitlich befristete oder dauerhafte Einwanderung internationaler Studierender in ihr Land zu fördern (OECD, 2008). So werden diese Länder für Studierende attraktiver, und die Erwerbsbevölkerung des jeweiligen Landes wird verstärkt. Daher könnten für einige Studierende neben den Studiengebühren auch Erwägungen zum Thema Einwanderung bei der Wahl des ausländischen Studienlandes eine Rolle spielen (OECD, 20II).

\section{Sonstige Faktoren}

Bei der Wahl der ausländischen Hochschule spielen auch andere Faktoren eine Rolle, wie beispielsweise die wissenschaftliche Reputation bestimmter Hochschulen oder Studiengänge, die Flexibilität der Studiengänge im Heimatland hinsichtlich der An- 
rechnung von Auslandsaufenthalten auf die Studienzeit und die zu erbringenden Prüfungsleistungen, die Anerkennung von im Ausland erworbenen Abschlüssen, das eingeschränkte Angebot im Tertiärbereich im Heimatland, restriktive Zulassungspraktiken zum Studium an den Hochschulen im Heimatland, Handelsbeziehungen, geografische oder geschichtlich bedingte Beziehungen zwischen einzelnen Ländern, zukünftige Beschäftigungsmöglichkeiten, kulturelle Aspekte und staatliche Regelungen zur erleichterten gegenseitigen Anrechnung von erworbenen Credits (Leistungspunkten).

\section{Ausmaß der internationalen Mobilität Studierender}

Von den Ländern mit verfügbaren Daten zu internationalen Studierenden weisen - gemessen am Anteil der internationalen Studierenden an der Gesamtzahl der eingeschriebenen Studierenden in ihrem Tertiärbereich - Australien, Neuseeland, Österreich, die Schweiz und das Vereinigte Königreich den höchsten Zustrom an Studierenden auf. In Australien kommen I9,8 Prozent der im Tertiärbereich des Landes eingeschriebenen Studierenden aus einem anderen Land. Gleichermaßen stellen internationale Studierende in Neuseeland I5, 6 Prozent, in Österreich I4,7 Prozent, in der Schweiz I6, 2 Prozent und im Vereinigten Königreich I6,8 Prozent der Gesamtzahl der in diesen Ländern eingeschriebenen Studierenden im Tertiärbereich. Andererseits machen sie in Chile, Norwegen, Polen und Slowenien weniger als 2 Prozent aus (Tab. C4.I und Abb. C4.4).

Unter den Ländern, in denen internationale Studierende auf der Grundlage des Staates definiert werden, dessen Staatsbürger sie sind, hatte Frankreich den größten Anteil ausländischer Studierender an allen Studierenden (II,9 Prozent). Andererseits belief sich dieser Anteil in Brasilien, China und der Türkei auf höchstens I Prozent (Tab. C4.I).

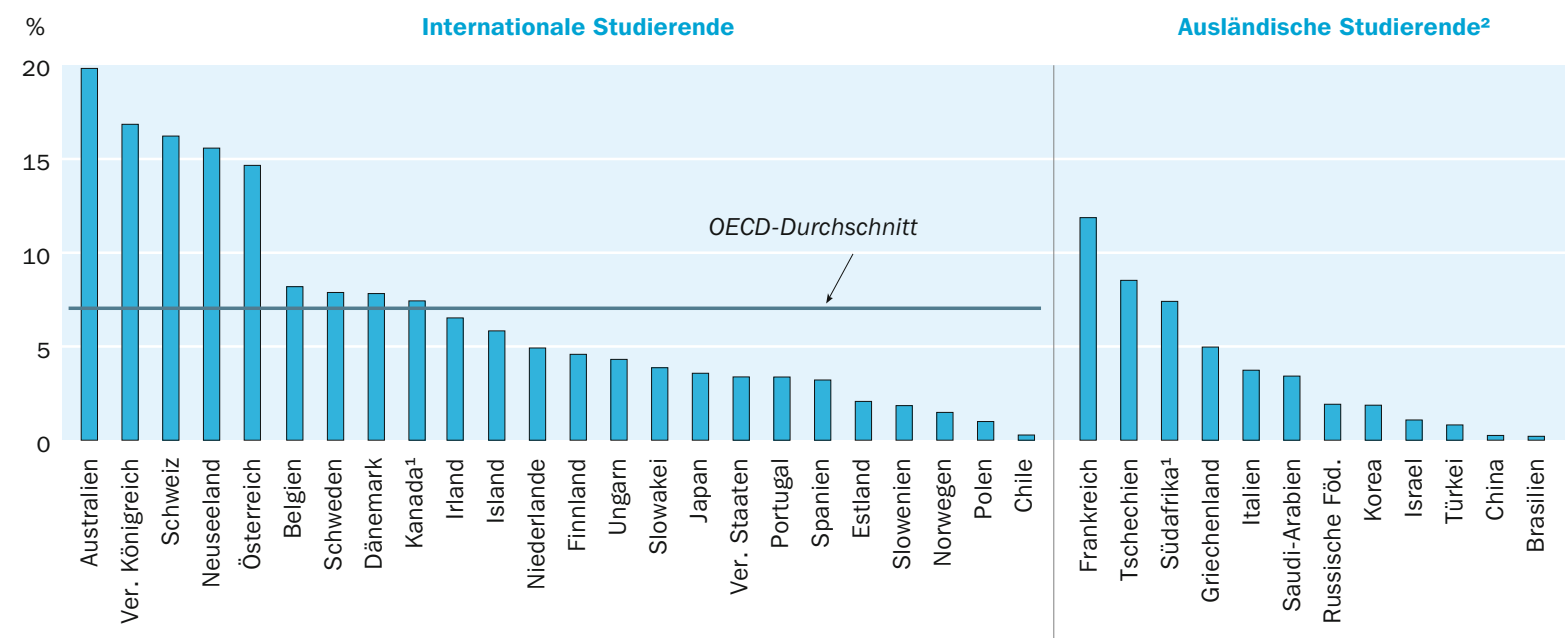

\footnotetext{
1. Referenzjahr 2010. 2. Ausländische Studierende sind auf der Grundlage des Landes, dessen Staatsbürger sie sind, definiert; diese Daten sind nicht mit den Daten zu internationalen Studierenden vergleichbar, daher werden sie getrennt aufgeführt.

Anordnung der Länder in absteigender Reihenfolge des Anteils internationaler bzw. ausländischer Studierender an der Gesamtzahl der Studierenden im Tertiärbereich.

Quelle: OECD und Statistikinstitut der UNESCO für die meisten Daten zu Nicht-OECD-Ländern. Tabelle C4.1.

Hinweise s. Anhang 3 unter www.oecd.org/edu/eag.htm. StatLink: http://dx.doi.org/10.1787/888932847602
} 


\section{Anteil internationaler Studierender nach Tertiärbereich}

Die Anteile internationaler Studierender an den verschiedenen Tertiärbereichen in den einzelnen Zielländern zeigen auch die der Mobilität Studierender zugrunde liegenden strukturellen Merkmale auf. 20II machten im Durschnitt aller OECD-Länder internationale Studierende fast 4 Prozent aller Einschreibungen bei den (in der Regel kürzeren und beruflich ausgerichteten) Studiengängen des Tertiärbereichs B aus. Den größten Anteil internationaler Studierender in derartigen Studiengängen gab es in Neuseeland mit 2I Prozent. Im Gegensatz hierzu machten 20II in den (größtenteils theoretisch ausgerichteten) Studiengängen des Tertiärbereichs A internationale Studierende im Durchschnitt der OECD-Länder 7 Prozent aller Einschreibungen in diesem Bildungsbereich aus. Australien hatte mit 2I Prozent aller Einschreibungen den größten Anteil internationaler Studierender in diesem Bildungsbereich (Tab. C4.I).

Alle Länder, die Daten angeben, mit Ausnahme Deutschlands, haben bei den weiterführenden forschungsorientierten Studiengängen mehr internationale Studierende als im Tertiärbereich A oder B. In der Schweiz beispielsweise stellen die internationalen Studierenden fast jeden zweiten Studierenden in den weiterführenden forschungsorientierten Studiengängen. In I 2 der 25 Länder, die Daten zu internationalen Studierenden gemeldet haben, sind mehr als 20 Prozent der in weiterführenden forschungsorientierten Studiengängen eingeschriebenen Studierenden internationale Studierende. Im Vereinigten Königreich stellen die internationalen Studierenden mehr als 40 Prozent aller in weiterführenden forschungsorientierten Studiengängen eingeschriebenen Studierenden, in Neuseeland und den Niederlanden sind es rund 40 Prozent. In Australien, Belgien, Irland, Schweden und den Vereinigten Staaten stellen die internationalen Studierenden mindestens 25 Prozent der Studierenden in diesen Studiengängen. Nimmt man die Staatsbürgerschaft als entscheidendes Kriterium, weist Frankreich den größten Teil ausländischer Studierender in diesem Bildungsbereich auf: mehr als 40 Prozent (Tab. C4.I). Diese hohen Anteile internationaler bzw. ausländischer Studierender könnten ein Hinweis auf die hohe Attraktivität der weiterführenden forschungsorientierten Studiengänge in diesen Ländern oder auf eine bevorzugte Anwerbung internationaler Studierender in den höheren Bildungsbereichen sein, um von deren potenziellem Beitrag zur nationalen Forschung und Entwicklung zu profitieren bzw. um sie später als hoch qualifizierte Einwanderer zu gewinnen.

Die Analyse der Verteilung internationaler und ausländischer Studierender in den einzelnen Zielländern aufgeschlüsselt nach Art des Tertiärbereichs gibt deutliche Hinweise auf die von den einzelnen Ländern angebotenen Studiengänge. In einigen Ländern besucht ein relativ großer Teil der internationalen Studierenden Bildungsgänge im Tertiärbereich B. Dies gilt für Chile, wo 44 Prozent der internationalen Studierenden in einem Studiengang des Tertiärbereichs B eingeschrieben sind, Griechenland (33 Prozent), Neuseeland (33 Prozent), Spanien (3I Prozent, ausländische Studierende), Belgien (22 Prozent) und Japan (22 Prozent) (Tab. C4.I).

In anderen Ländern ist ein hoher Prozentsatz der internationalen Studierenden in einem weiterführenden forschungsorientierten Studiengang eingeschrieben. Dies trifft insbesondere auf die Schweiz zu, wo sich 25 Prozent aller internationalen Studierenden in einem solchen Studiengang einschreiben. Diese Präferenz lässt sich auch in den Vereinigten Staaten beobachten, wo I9 Prozent der internationalen Studierenden in 
weiterführenden forschungsorientierten Studiengängen eingeschrieben sind, ebenso in Spanien (I8 Prozent), in Slowenien (I7 Prozent) und in Schweden (I5 Prozent).

In den Ländern, die nur Daten zu ausländischen Studierenden melden, wie Israel, die Russischen Föderation und Tschechien, sind go Prozent der ausländischen Studierenden in Studiengängen des Tertiärbereichs A eingeschrieben. In China sind 25 Prozent aller ausländischen Studierenden in weiterführenden forschungsorientierten Studiengängen eingeschrieben, in Frankreich II Prozent und in Brasilien ı Prozent (Tab. C4.I). Alle diese Zielländer werden vermutlich von einem entsprechenden Beitrag dieser hoch qualifizierten internationalen Studierenden zu ihren Forschung- und Entwicklungsprogrammen profitieren.

\section{Die Zusammensetzung der ausländischen Studierenden in den einzelnen Ländern}

\section{Die Mobilität Studierender in den OECD-Ländern}

Die Zahl der von den OECD-Ländern aufgenommenen internationalen Studierenden ist höher als die Zahl der aus diesen Ländern ins Ausland gehenden Studierenden. 20II waren in den OECD-Ländern pro OECD-Staatsbürger, der außerhalb des eigenen Herkunftslandes studierte, 2,9 ausländische Studierende eingeschrieben. In absoluten Zahlen sind dies 3,3 Millionen ausländische Studierende in OECD-Ländern verglichen mit mehr als einer Million Studierenden, die außerhalb des OECD-Landes eingeschrieben sind, dessen Staatsangehörigkeit sie besitzen. Während 93 Prozent der Staatsbürger von OECD-Ländern in einem anderen OECD-Land studieren, stammen mehr als zwei Drittel der ausländischen Studierenden in OECD-Ländern aus einem Nicht-OECDLand (Tab. C4.4 und $\mathrm{C}_{4.5}$ ).

Auf Ebene der einzelnen Länder variiert das Verhältnis stark. Während in Australien pro australischen Studierenden, der im Ausland studiert, fast 20 ausländische Studierende eingeschrieben sind, beträgt das Verhältnis in Mexiko o,I : I. Andere Länder mit einer hohen Zahl ausländischer Studierender per inländischen Studierenden im Auslandsstudium sind Neuseeland (I2 : I), das Vereinigte Königreich (I5 : I) und die Vereinigten Staaten (II : I). Zu den Ländern, die weniger als einen ausländischen Studierenden pro inländischen Studierenden im Auslandsstudium angeben, gehören Argentinien, Brasilien, Chile, Estland, Griechenland, Island, Israel, Korea, Mexiko, Norwegen, Polen, Portugal, Saudi-Arabien, die Slowakei, Slowenien und die Türkei (Tab. C4.5).

\section{Die wichtigsten Herkunftsregionen}

Studierende aus Asien bilden die größte Gruppe der internationalen Studierenden in den Ländern, die der OECD oder dem Statistikinstitut der UNESCO Daten zur Verfügung gestellt haben: 53 Prozent aller Studierenden in Zielländern, die Daten gemeldet haben. Die Anteile von Studierenden aus Asien an allen internationalen und ausländischen Studierenden sind in Korea (mit 94 Prozent), Japan (93 Prozent), Australien (8I Prozent), den Vereinigten Staaten (72 Prozent) und Neuseeland (68 Prozent) besonders groß. In den OECD-Ländern kommen 25 Prozent aller internationalen und ausländischen Studierenden aus europäischen Ländern (bzw. I7 Prozent aus den EU2I-Ländern), 9 Prozent aus Afrika, 6 Prozent aus Lateinamerika und der Karibik sowie 3 Prozent aus Nordamerika. Insgesamt stammen 30 Prozent der innerhalb der OECD eingeschriebenen internationalen Studierenden aus einem anderen OECD-Land (Tab. C4.3). 


\section{Die wichtigsten Herkunftsländer}

20II stellten Studierende aus China mit 2I Prozent aller internationalen Studierenden im OECD-Gebiet den größten Anteil aus Ländern, die Daten zur Verfügung gestellt haben (Tab. C4.3). Rund 25 Prozent aller im Ausland eingeschriebenen chinesischen Studierenden sind in den Vereinigten Staaten eingeschrieben, I2 Prozent entschieden sich für Australien, 7 Prozent für Korea, I3 Prozent für Japan und Io Prozent für das Vereinigte Königreich (Tab. C4.4). Die zweitgrößte Gruppe internationaler Studierender in OECD-Ländern kommt aus Indien ( 6,5 Prozent). Rund 46 Prozent der Studierenden aus Indien sind in den Vereinigten Staaten eingeschrieben, 22 Prozent im Vereinigten Königreich, 6 Prozent in Australien und 5 Prozent in Kanada (Tab. C4.4).

Auch bei einem Blick auf die einzelnen OECD-Länder zeigt sich, dass die Studierenden aus Asien und Europa eindeutig die größte Gruppe stellen. Studierende aus Deutschland, Frankreich und Korea stellen mit 3,9 Prozent, 2,0 Prozent bzw. 4,4 Prozent die größten Gruppen internationaler, in OECD-Ländern eingeschriebener Studierender, gefolgt von Studierenden aus den Vereinigten Staaten (I,6 Prozent), Kanada (I,5 Prozent), Italien (I,4 Prozent), Japan (I,2 Prozent) und der Slowakei (I,2 Prozent) (Tab. C4.3).

Ein großer Teil der ausländischen Studierenden in OECD-Ländern stammt aus benachbarten Ländern. In allen OECD-Ländern kamen 20Ir im Durchschnitt 2I Prozent aller ausländischen Studierenden aus Ländern, die eine Land- oder Seegrenze mit dem Zielland teilen. Eine verstärkte Mobilität aus Nachbarländern ergibt sich nicht nur aufgrund einer speziellen zentralen geografischen Lage, wie in Tschechien, sondern die Gründe können auch in Vorteilen bezüglich Kosten, Qualität und Zulassung zum Studium liegen, die für Studierende in benachbarten Ländern offensichtlicher sind. Auf der anderen Seite finden sich in den Ländern mit den höchsten Marktanteilen im Be-

Abbildung C4.5

Verteilung ausländischer Studierender im Tertiärbereich, nach Herkunftsregion (2011)

Anteil der weltweit eingeschriebenen ausländischen Studierenden im Tertiärbereich (in \%)

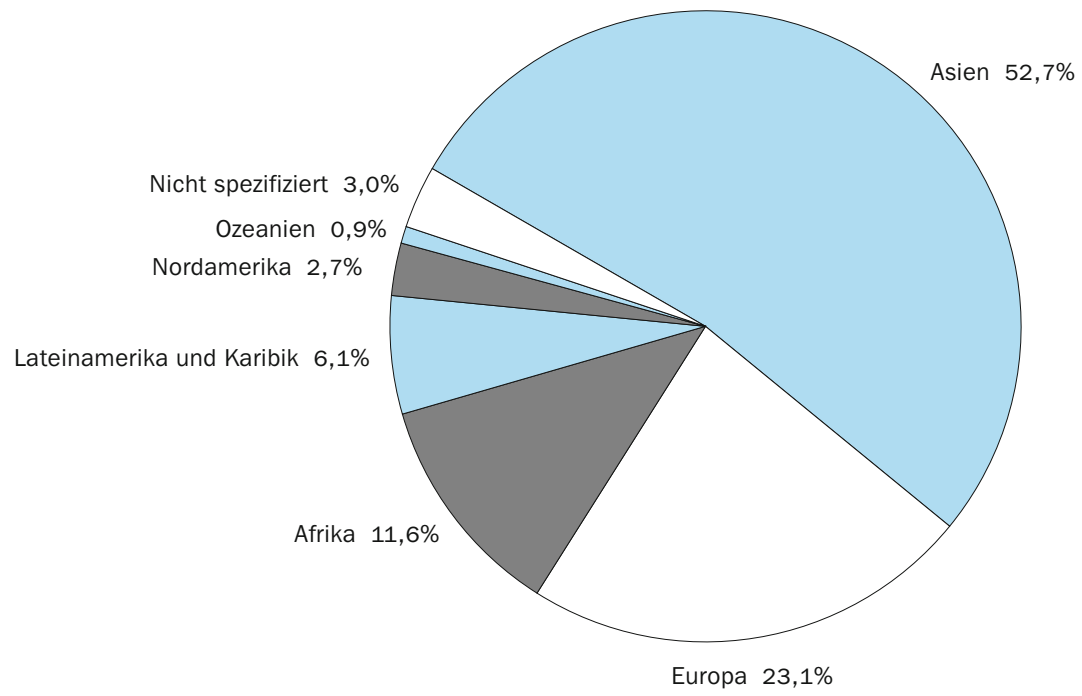

1. Referenzjahr 2010 für Länder, die nicht OECD-bzw. G20-Land sind.

Quelle: OECD und Statistikinstitut der UNESCO für die meisten Daten zu Nicht-OECD-Ländern. Tabelle C4.3.

Hinweise s. Anhang 3 unter www.oecd.org/edu/eag.htm. StatLink: http://dx.doi.org/10.1787/888932847621 
reich internationaler Bildung höhere Prozentsätze ausländischer Studierender aus nicht unmittelbar benachbarten Ländern, ebenso wie beispielsweise in Portugal und Spanien, die enge geschichtliche und kulturelle Bindungen mit anderen, weit entfernt liegenden Ländern haben (Tab. C4.5 und Tab. C4.7 im Internet).

In den OECD-Ländern findet sich der höchste Anteil von Studierenden aus benachbarten Ländern in Japan (8o Prozent), Korea (78 Prozent), Estland (wo 74 Prozent der ausländischen Studierenden aus Finnland, Lettland, der Russischen Föderation oder Schweden kommen), Griechenland (7o Prozent) und Tschechien (wo 67 Prozent der ausländischen Studierenden aus Deutschland, Österreich, Polen oder der Slowakei kommen). Auch Belgien, die Niederlande, Österreich, Polen, die Russische Föderation, die Schweiz, die Slowakei, Slowenien und Ungarn weisen hohe Anteile ausländischer Studierender aus benachbarten Ländern auf. Im Gegensatz hierzu kommen in Kanada nur 5 Prozent der ausländischen Studierenden aus den Vereinigten Staaten, und in den Vereinigten Staaten kommen nur 7 Prozent der Studierenden von den Bahamas, aus Kanada, Mexiko oder der Russischen Föderation (Tab. C4.5 und Tab. C.4.7 im Internet). Sprachliche Kriterien sind hauptsächlich für Studierende, die zum Auslandsstudium nach Portugal kommen, verantwortlich: 64 Prozent der ausländischen Studierenden in Portugal kommen aus Angola, Brasilien, Guinea-Bissau, Kap Verde, Mosambik, São Tomé und Príncipe oder Timor-Leste - alles Länder, in denen Portugiesisch Amtssprache ist (Tab. C4.5. und Tab. C4.7 im Internet).

Überlegungen hinsichtlich der Unterrichts- und Landessprache, kulturelle Aspekte, die geografische Nähe und die Ähnlichkeit der Bildungssysteme sind alles wichtige Faktoren, die Studierende bei der Wahl des Studienlandes abwägen. Geografische Erwägungen und unterschiedliche Zulassungsbedingungen (wie der Numerus clausus oder intensivere Auswahlverfahren für einige Studiengänge) erklären höchstwahrscheinlich die Konzentration von Studierenden aus Deutschland in Österreich, aus Belgien in Frankreich und den Niederlanden, aus Frankreich in Belgien, aus Kanada in den Vereinigten Staaten, aus Neuseeland in Australien usw. Überlegungen im Zusammenhang mit der Sprache und akademischen Traditionen erklären auch die tendenzielle Konzentration englischsprachiger Studierender in anderen Ländern des British Commonwealth bzw. in den Vereinigten Staaten, selbst wenn diese geografisch weit entfernt sind. Dies trifft auch auf andere geschichtlich geopolitisch verbundene Gebiete wie die frühere Sowjetunion, das Gebiet der Frankofonie sowie auf Lateinamerika zu. Auch Migrantennetzwerke spielen eine Rolle, wie am Beispiel der Konzentration von Studierenden mit portugiesischer Staatsangehörigkeit in Frankreich, Studierenden aus der Türkei in Deutschland oder Studierenden aus Mexiko in den Vereinigten Staaten deutlich wird.

\section{Definitionen}

Das Land der vorherigen Ausbildung ist das Land, in dem Studierende die für die Einschreibung in dem aktuellen Studiengang erforderliche Zulassungsberechtigung erhielten, d. h. bei internationalen Studierenden im Tertiärbereich A und im Tertiärbereich B das Land, in dem die Studierenden ihre Ausbildung im Sekundarbereich II oder im postsekundaren, nicht tertiären Bildungsbereich erhielten, und bei internationalen Studie- 
renden, die an weiterführenden forschungsorientierten Studiengängen teilnehmen, das Land ihres Studienabschlusses im Tertiärbereich A. Die jeweilige landesspezifische operationale Definition der Bezeichnung „internationale Studierende“ ist in den Tabellen und in Anhang 3 unter www.oecd.org/edu/eag.htm aufgeführt.

Ausländische Studierende sind Studierende, die nicht Staatsangehörige des Landes sind, in dem die Daten erhoben werden. Diese Klassifikation ist zwar pragmatisch und operational, eignet sich jedoch aufgrund der unterschiedlichen nationalen Regelungen zur Einbürgerung von Migranten für die Erfassung der Mobilität Studierender nicht. So ist Australien beispielsweise eher bereit, seinen Einwanderern eine Daueraufenthaltsgenehmigung zu erteilen, als die Schweiz. Das bedeutet, dass sogar bei einem ähnlich hohen Anteil ausländischer Studierender im Tertiärbereich beider Länder der Anteil der internationalen Studierenden in der Schweiz niedriger ist als in Australien. Daher ist bei der Interpretation von Daten, die auf dem Konzept der ausländischen Studierenden basieren, in Bezug auf die Mobilität Studierender sowie bei bilateralen Vergleichen Vorsicht angebracht.

Internationale oder mobile Studierende sind Studierende, die aus ihrem Herkunftsland zwecks Studium in ein anderes Land gekommen sind. Abhängig von den landesspezifischen Einwanderungsbestimmungen, Mobilitätsvereinbarungen, wie z. B. dem freien Personenverkehr innerhalb der EU und des EWR, und der Datenverfügbarkeit können internationale Studierende als Studierende definiert werden, bei denen es sich nicht um Personen mit dauerhaftem Wohnsitz oder gewöhnlichem Aufenthaltsort in ihrem Studienland handelt, bzw. alternativ als Studierende, die ihre vorherige Ausbildung in einem anderen Land, einschließlich einem anderen EU-Mitgliedstaat, absolviert haben.

Der dauerhafte Wohnsitz oder gewöhnliche Aufenthaltsort in dem Land, das Daten zur Verfügung gestellt hat, wird nach Maßgabe der jeweiligen nationalen Gesetze definiert. In der Praxis bedeutet dies ein für Studienzwecke erteiltes Visum oder eine Aufenthaltsgenehmigung oder die Wahl eines ausländischen Wohnsitzstaates in dem Jahr, das dem Einstieg in das Bildungssystem des Landes, das Daten zur Verfügung gestellt hat, vorausgeht.

\section{Angewandte Methodik}

Die Daten zu den internationalen und ausländischen Studierenden beziehen sich auf das Studienjahr 2010/20II (außer es ist etwas anderes angegeben) und beruhen auf der von der OECD im Jahre 2012 durchgeführten UOE-Datenerhebung zur Bildungsstatistik. Die in der UOE-Datenerhebung verwendeten Fächergruppen entsprechen der überarbeiteten ISCED-Klassifikation nach Fächergruppen. Diese Klassifizierung nach Fächergruppen wird auf alle Bildungsbereiche angewendet (Einzelheiten s. Anhang 3 unter www.oecd.org/eduleag. htm). Es wurden auch zusätzliche Daten vom Statistikinstitut der UNESCO verwendet, obwohl das Referenzjahr 2010 ist.

Die Daten über internationale und ausländische Studierende werden von den Zielländern anhand der erfolgten Einschreibungen erhoben. Die Daten zur Zahl internationaler und ausländischer Studierender wurden daher mit der gleichen Methode gewon- 
nen wie die zur Gesamtzahl der Studierenden, d. h., es werden die Unterlagen über die regulär in einem Studiengang eingeschriebenen Studierenden zugrunde gelegt.

Die inländischen und die internationalen Studierenden werden üblicherweise an einem bestimmten Tag oder innerhalb eines bestimmten Zeitraums während des Jahres gezählt. Damit lässt sich der Anteil der internationalen Studierenden bestimmen, die in einem Bildungssystem eingeschrieben sind, aber die tatsächliche Zahl der betreffenden Studierenden kann viel höher liegen, da viele Studierende für weniger als ein ganzes akademisches Jahr ins Ausland gehen oder an einem Austauschprogramm teilnehmen, das keine Einschreibung bei der ausländischen Bildungseinrichtung voraussetzt, wie beispielsweise bei Austauschprogrammen zwischen Universitäten oder kurzzeitigen Forschungsprojekten. Außerdem umfassen die Zahlen zu den internationalen Studierenden auch einige Studierende, die an einem Fernstudium teilnehmen, obwohl sie streng genommen keine internationalen Studierenden sind. Diese Art der Einschreibung im Fernstudium ist in Australien, dem Vereinigten Königreich und den Vereinigten Staaten sehr verbreitet (OECD, 2004).

Da die Daten zu den internationalen und ausländischen Studierenden im Zielland erhoben werden, beziehen sie sich eher auf die Studierenden, die in das betreffende Land gekommen sind, und nicht auf diejenigen, die aus dem betreffenden Land ins Ausland gehen. Die von diesem Indikator erfassten Zielländer umfassen alle OECD-Länder und sonstigen G20-Länder mit Ausnahme von Chile, Luxemburg, Mexiko, der Russischen Föderation und Slowenien sowie Länder, die ähnliche Daten an das Statistikinstitut der UNESCO melden. Diese Daten werden zur Ableitung weltweiter Zahlen verwendet sowie zur Analyse der Zielländer der Studierenden und der Entwicklungen der einzelnen Marktanteile.

Die Daten über Studierende im Auslandsstudium und die Trendanalysen basieren nicht auf Zahlen internationaler Studierender, sondern auf den Zahlen ausländischer Staatsbürger, für die länderübergreifend und im Zeitverlauf konsistente Daten leicht zugänglich sind. Eingeschriebene Studierende in Ländern, die weder gegenüber der OECD noch gegenüber dem Statistikinstitut der UNESCO Angaben über die Zahl der ausländischen Studierenden machten, bleiben in den Daten unberücksichtigt. Daher ist bei allen Aussagen über die Zahl der Studierenden, die ein Auslandsstudium absolvieren, deren Zahl wahrscheinlich zu niedrig angesetzt (Tab. C4.3). Dies gilt vor allem für die Länder, von denen zahlreiche Bürger in Ländern studieren, die der OECD oder dem Statistikinstitut der UNESCO keine Zahlen zu ausländischen Studierenden zur Verfügung stellen, wie beispielsweise China und Indien.

Die relativen Anteile der in einem Bildungssystem eingeschriebenen internationalen Studierenden wirken sich auf die Studienanfänger- und Abschlussquoten aus und können in einigen Bildungsbereichen oder Fächergruppen zu einem künstlichen Anstieg führen (s. Indikatoren A2 und $\mathrm{A}_{3}$ ). Sie können auch die berichtete Kombination von öffentlichen und privaten Ausgaben beeinflussen (s. Indikator B3).

In Ländern mit differenzierten Studiengebühren für internationale Studierende kann die Mobilität Studierender die finanzielle Ausstattung der Bildungseinrichtungen im Tertiärbereich verbessern und so zur Finanzierung des Bildungssystems beitragen. 
Andererseits können internationale Studierende angesichts der hohen Kosten pro Studierenden für Länder, in denen keine oder nur geringe Studiengebühren erhoben werden, eine bedeutende finanzielle Belastung darstellen (s. Indikator B5).

Studierende, die außerhalb ihres Herkunftslands studieren, repräsentieren jedoch nur einen Teil der Internationalisierung des Tertiärbereichs. In den letzten so Jahren sind neue Formen der grenzüberschreitenden Bildung entstanden, z. B. grenzüberschreitende Angebote von Bildungsgängen und Bildungseinrichtungen. Die grenzüberschreitende Bildung im Tertiärbereich hat sich jedoch aus verschiedenen Gründen in unterschiedlichen Regionen der Welt ganz unterschiedlich entwickelt. Eine detaillierte Analyse dieser Sachverhalte sowie der Auswirkungen der Internationalisierung des Tertiärbereichs auf Handel und Politik findet sich in OECD (2004).

Die statistischen Daten für Israel wurden von den zuständigen israelischen Stellen bereitgestellt, die für sie verantwortlich zeichnen. Die Verwendung dieser Daten durch die OECD erfolgt unbeschadet des völkerrechtlichen Status der Golanhöhen, von OstJerusalem und der israelischen Siedlungen im Westjordanland.

\section{Weiterführende Informationen}

Kelo, M., U. Teichler and B. Wächter (eds.) (2005), EURODATA: Student Mobility in European Higher Education, Verlags- and Mediengesellschaft, Bonn.

OECD (2004), Internationalisation and Trade in Higher Education: Opportunities and Challenges, OECD Publishing, http:/|dx.doi.org/10.1787/9789264015067-en.

OECD (2008), Tertiary Education for the Knowledge Society: Volume 1 and Volume 2, OECD Publishing, http://dx.doi.org/10.1787/978g264046535-en.

OECD (20II), International Migration Outlook 2011, OECD Publishing, http://dx.doi.org/ 10.1787/migr_outlook-2011-en.

UNESCO (2009), Global Education Digest 2009, UNESCO Institute for Statistics, Montreal.

UNESCO Institute for Statistics (20II), Education Database, www.uis.unesco.org (Zugriff am I. Juli 20II).

Varghese, N. V. (2009), Globalization, Economic Crisis and National Strategies for Higher Education Development, IIEP, UNESCO, Paris. 


\section{Tabellen Indikator C4}

Tabelle C4.I: Die Mobilität internationaler Studierender und ausländische Studierende im Tertiärbereich (2005, 20II)

StatLink: http://dx.doi.org/10.1787/888932850737

Tabelle C4.2: Verteilung internationaler und ausländischer Studierender im Tertiärbereich, nach Fächergruppe (20II)

StatLink: http:||dx.doi.org/10.1787/888932850756

Tabelle C4.3: Verteilung internationaler und ausländischer Studierender im Tertiärbereich, nach Herkunftsland (20II)

StatLink: http://dx.doi.org/10.1787/888932850775

Tabelle C4.4: Studierende, die in einem Land studieren, dessen Staatsbürger sie nicht sind, nach Zielland (20II)

StatLink: http://dx.doi.org/10.1787/888932850794

Tabelle C4.5: Mobilität ausländischer und internationaler Studierender (20II)

StatLink: http:|/dx.doi.org/10.1787/888932850813

Tabelle C4.6: Entwicklung der Zahl der eingeschriebenen ausländischen Studierenden, nach Zielregion und Herkunftsregion (2000 bis 20II)

StatLink: http://dx.doi.org/10.1787/888932850832

WEB Table C4.7: Number of foreign students in tertiary education, by country of origin and destination (20II) and market shares in international education (2000, 20II) (Zahl ausländischer Studierender im Tertiärbereich, nach Herkunfts- und Zielland [20II] sowie Anteile am internationalen Bildungsmarkt [2000, 20II]) StatLink: http://dx.doi.org/10.1787/888932850851 
Tabelle C4.1

Die Mobilität internationaler Studierender und ausländische Studierende im Tertiärbereich (2005, 2011)

Eingeschriebene internationale und ausländische Studierende als Prozentsatz aller Studierenden (internationaler und inländischer) und Verteilung der internationalen Mobilität nach Bildungsbereich

Bedeutung der Spalte (1) im oberen Teil der Tabelle (Internationale Studierende): 19, 8 Prozent der Studierenden im Tertiärbereich in Australien sind internationale Studierende und 16,2 Prozent der Studierenden im Tertiärbereich in der Schweiz sind internationale Studierende. Die in dieser Tabelle zusammengestellten Daten zur Mobilität internationaler Studierender sind die jeweils besten verfügbaren Näherungswerte für die Mobilität Studierender für jedes einzelne Land. Bedeutung der Spalte (1) im unteren Teil der Tabelle (Ausländische Studierende): 11,9 Prozent der Studierenden im Tertiärbereich in Frankreich sind nicht französische Staatsbürger und 1,9 Prozent der Studierenden im Tertiärbereich in Korea sind nicht koreanische Staatsbürger.

\begin{tabular}{|c|c|c|c|c|c|c|c|c|}
\hline \multicolumn{6}{|c|}{$\begin{array}{l}\text { Internationale bzw. ausländische Studierende als Prozentsatz } \\
\text { aller eingeschriebenen Studierenden im Tertiärbereich }\end{array}$} & \multicolumn{3}{|c|}{$\begin{array}{l}\text { Verteilung internationaler bzw. } \\
\text { ausländischer Studierender }\end{array}$} \\
\hline 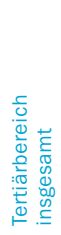 & 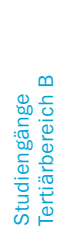 & 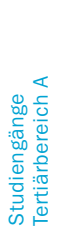 & 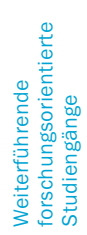 & 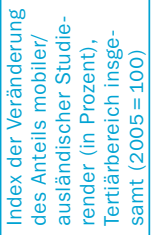 & 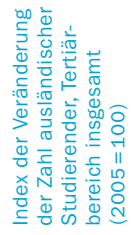 & 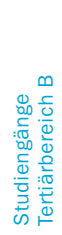 & 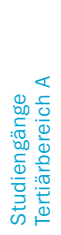 & 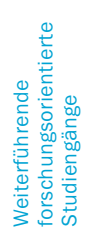 \\
\hline (1) & (2) & (3) & (4) & (5) & (6) & (7) & (8) & (9) \\
\hline
\end{tabular}

\begin{tabular}{|c|c|c|c|c|c|c|c|c|c|}
\hline \multirow{2}{*}{ OECD-Länder } & \multicolumn{9}{|c|}{ Internationale Studierende } \\
\hline & & & & & & & & & \\
\hline Australien & 19,8 & 13,5 & 20,8 & 30,7 & 115 & 148 & 12,5 & 81,6 & 5,8 \\
\hline Österreich & 14,7 & 2,0 & 15,7 & 21,5 & 133 & 205 & 1,4 & 88,0 & 10,6 \\
\hline Belgien & 8,2 & 3,6 & 11,5 & 29,8 & 126 & 114 & 21,7 & 67,8 & 10,5 \\
\hline Kanada $^{1,2}$ & 7,4 & 6,3 & 7,2 & 21,8 & m & 138 & 18,3 & 72,4 & 9,3 \\
\hline Chile & 0,3 & 0,3 & 0,3 & 4,4 & $\mathrm{~m}$ & 556 & 44,4 & 49,7 & 5,9 \\
\hline Dänemark & 7,8 & 11,1 & 6,7 & 22,6 & 177 & 170 & 18,4 & 71,7 & 9,9 \\
\hline Estland & 2,1 & 0,2 & 2,7 & 6,3 & 159 & 304 & 3,4 & 83,8 & 12,9 \\
\hline Finnland & 4,6 & $n$ & 4,2 & 9,5 & 128 & 186 & $\mathrm{n}$ & 86,0 & 14,0 \\
\hline Deutschland & m & $\mathrm{m}$ & 7,9 & 6,4 & m & 105 & $\mathrm{~m}$ & m & $\mathrm{m}$ \\
\hline Ungarn & 4,3 & 0,4 & 4,8 & 6,1 & 158 & 139 & 1,0 & 96,3 & 2,7 \\
\hline Island & 5,8 & 1,1 & 5,6 & 19,7 & $\mathrm{~m}$ & 256 & 0,4 & 91,1 & 8,6 \\
\hline Irland & 6,5 & 4,6 & 5,9 & 25,7 & 94 & 181 & 15,3 & 67,2 & 17,5 \\
\hline Japan & 3,6 & 4,0 & 3,1 & 18,5 & 126 & 120 & 22,0 & 68,1 & 9,9 \\
\hline Luxemburg & m & m & m & m & m & m & m & m & $\mathrm{m}$ \\
\hline Mexiko & m & $\mathrm{m}$ & $\mathrm{m}$ & $\mathrm{m}$ & $\mathrm{m}$ & $\mathrm{m}$ & $\mathrm{m}$ & $\mathrm{m}$ & $\mathrm{m}$ \\
\hline Niederlande & 4,9 & 0,1 & 4,6 & 36,1 & 105 & 182 & $n$ & 89,6 & 10,4 \\
\hline Neuseeland & 15,6 & 20,6 & 12,9 & 39,7 & 92 & 105 & 32,3 & 59,8 & 7,8 \\
\hline Norwegen & 1,5 & 0,5 & 1,4 & 4,6 & 80 & 124 & 0,1 & 89,0 & 10,9 \\
\hline Polen & 1,0 & 0,1 & 1,0 & 1,6 & $\mathrm{~m}$ & 225 & 0,1 & 97,0 & 2,9 \\
\hline Portugal & 3,4 & 1,0 & 3,1 & 9,0 & $\mathrm{~m}$ & 128 & $n$ & 87,6 & 12,4 \\
\hline Slowakei & 3,9 & 0,5 & 3,7 & 7,4 & 436 & 544 & 0,1 & 89,6 & 10,3 \\
\hline Slowenien & 1,8 & 0,7 & 1,8 & 8,3 & 190 & 185 & 7,1 & 76,2 & 16,7 \\
\hline Spanien & 3,2 & 6,3 & 2,0 & 16,6 & 329 & 236 & 30,7 & 51,1 & 18,2 \\
\hline Schweden & 7,9 & 0,3 & 7,5 & 26,8 & 178 & 127 & 0,2 & 84,6 & 15,1 \\
\hline Schweiz $^{3}$ & 16,2 & $\mathrm{~m}$ & 16,9 & 49,5 & 122 & 160 & $n$ & 75,2 & 24,8 \\
\hline Ver. Königreich ${ }^{4}$ & 16,8 & 5,4 & 18,3 & 40,9 & 121 & 176 & 5,7 & 85,5 & 8,8 \\
\hline Vereinigte Staaten ${ }^{4}$ & 3,4 & 1,0 & 3,3 & 28,0 & 99 & 120 & 6,8 & 73,7 & 19,4 \\
\hline OECD-Durchschnitt & 6,9 & 3,6 & 6,9 & 19,6 & 156 & 197 & 11,0 & $\mathbf{7 8 , 4}$ & 11,5 \\
\hline \multicolumn{10}{|l|}{ Sonst. G20-Länder } \\
\hline Argentinien & m & $\mathrm{m}$ & $\mathrm{m}$ & $\mathrm{m}$ & $\mathrm{m}$ & $\mathrm{m}$ & $\mathrm{m}$ & $\mathrm{m}$ & $\mathrm{m}$ \\
\hline \multirow[t]{2}{*}{ Indien } & m & $\mathrm{m}$ & $\mathrm{m}$ & $\mathrm{m}$ & $\mathrm{m}$ & $\mathrm{m}$ & $\mathrm{m}$ & $\mathrm{m}$ & $\mathrm{m}$ \\
\hline & \multicolumn{9}{|c|}{ Ausländische Studierende $^{5}$} \\
\hline \multicolumn{10}{|l|}{ OECD-Länder } \\
\hline Tschechien & 8,5 & 1,4 & 8,9 & 11,4 & 155 & 205 & 1,2 & 90,9 & 7,9 \\
\hline Frankreich & 11,9 & 4,4 & 13,1 & 42,2 & 110 & 113 & 9,3 & 79,5 & 11,2 \\
\hline Griechenland ${ }^{6,7}$ & 5,0 & 4,8 & 5,4 & m & 205 & $\mathrm{~m}$ & 33,3 & 66,7 & $n$ \\
\hline Israel & 1,1 & $\mathrm{~m}$ & 1,3 & 2,4 & m & $\mathrm{m}$ & n & 93,5 & 6,5 \\
\hline Italien & 3,7 & 7,9 & 3,6 & 10,5 & 167 & 164 & 0,5 & 94,3 & 5,2 \\
\hline Korea & 1,9 & 0,3 & 2,2 & 7,5 & 387 & 404 & 4,0 & 88,8 & 7,2 \\
\hline Türkei & 0,8 & 0,2 & 1,0 & 3,2 & 95 & 171 & 6,2 & 89,4 & 4,5 \\
\hline \multicolumn{10}{|l|}{ Sonst. G20-Länder } \\
\hline Brasilien & 0,2 & 0,1 & $n$ & 2,0 & 341 & 1292 & 8,7 & 81,5 & 9,7 \\
\hline China & 0,3 & $n$ & 0,4 & 1,0 & m & m & 0,7 & 74,6 & 24,7 \\
\hline Indonesien & m & $\mathrm{m}$ & m & m & $\mathrm{m}$ & $\mathrm{m}$ & m & m & m \\
\hline Russische Föd? & 1,9 & 0,6 & 2,3 & $\mathrm{~m}$ & 160 & 190 & 7,0 & 93,0 & $\mathrm{n}$ \\
\hline Saudi-Arabien & 3,4 & $\mathrm{~m}$ & $\mathrm{~m}$ & $\mathrm{~m}$ & $\mathrm{~m}$ & 271 & $\mathrm{~m}$ & $\mathrm{~m}$ & $\mathrm{~m}$ \\
\hline Südafrika ${ }^{1}$ & 7,4 & $\mathrm{~m}$ & $\mathrm{~m}$ & $\mathrm{~m}$ & $\mathrm{~m}$ & 165 & $\mathrm{~m}$ & $\mathrm{~m}$ & $\mathrm{~m}$ \\
\hline
\end{tabular}

1. Referenzjahr 2010. 2. Index der Veränderung basiert auf 2004=100 anstelle von 2005 und dem Referenzjahr 2010. 3. Ohne Studiengänge im Tertiärbereich B. 4. Internationale Studierende in Spalte (6). 5. Ausländische Studierende sind auf der Grundlage des Landes, dessen Staatsbürger sie sind, definiert; diese Daten sind nicht mit den Daten zu internationalen Studierenden vergleichbar, daher werden sie in der Tabelle getrennt aufgeführt. 6. Ohne private Bildungseinrichtungen. 7. Ohne weiterführende forschungsorientierte Studiengänge.

Quelle: OECD. China, Indonesien: Statistikinstitut der UNESCO (World Education Indicators Programme). Saudi-Arabien: Observatory on Higher Education. Südafrika: Statistikinstitut der UNESCO. Hinweise s. Anhang 3 unter www.oecd.org/edu/eag.htm. StatLink: http://dx.doi.org/10.1787/888932850737 Erläuterung der Kennzeichnung fehlender Daten s. Hinweise für den Leser. 
Verteilung internationaler und ausländischer Studierender im Tertiärbereich, nach Fächergruppe (2011)

\begin{tabular}{|c|c|c|c|c|c|c|c|c|c|}
\hline & \begin{tabular}{|} 
Geisteswis- \\
senschaften, \\
Kunst und \\
Erziehungs- \\
wissen- \\
schaften
\end{tabular} & $\begin{array}{l}\text { Gesundheit } \\
\text { und Soziales }\end{array}$ & $\begin{array}{c}\text { Sozial-, } \\
\text { Rechts- und } \\
\text { Wirtschafts- } \\
\text { wissen- } \\
\text { schaften }\end{array}$ & $\begin{array}{c}\text { Dienst- } \\
\text { leistungen }\end{array}$ & \begin{tabular}{|} 
Ingenieurwis- \\
senschaften, \\
Fertigung \\
und \\
Bauwesen
\end{tabular} & $\begin{array}{c}\text { Naturwissen- } \\
\text { schaften }\end{array}$ & $\begin{array}{c}\text { Agrarwissen- } \\
\text { schaften }\end{array}$ & $\begin{array}{c}\text { Nicht } \\
\text { bekannt } \\
\text { oder keine } \\
\text { Angabe }\end{array}$ & $\begin{array}{c}\text { Alle Fächer- } \\
\text { gruppen } \\
\text { zusammen }\end{array}$ \\
\hline & (1) & (4) & (5) & (6) & (7) & (8) & (13) & (14) & (15) \\
\hline & \multicolumn{9}{|c|}{ Internationale Studierende } \\
\hline \multicolumn{10}{|l|}{ OECD-Länder } \\
\hline Australien & 9 & 10 & 55 & 2 & 12 & 11 & 1 & $n$ & 100 \\
\hline Österreich ${ }^{1}$ & 23 & 9 & 39 & 1 & 13 & 12 & 2 & $\mathrm{n}$ & 100 \\
\hline Belgien & 17 & 32 & 21 & 2 & 14 & 8 & 5 & $\mathrm{n}$ & 100 \\
\hline Kanada $^{2}$ & 8 & 6 & 42 & 1 & 16 & 15 & 1 & 10 & 100 \\
\hline Chile & 14 & 11 & 39 & 9 & 13 & 11 & 4 & $\mathrm{n}$ & 100 \\
\hline Dänemark & 12 & 12 & 41 & 1 & 21 & 10 & 4 & $\mathrm{n}$ & 100 \\
\hline Estland & 22 & 9 & 44 & 1 & 5 & 9 & 10 & $n$ & 100 \\
\hline Finnland $^{1}$ & 11 & 9 & 28 & 7 & 32 & 11 & 2 & $\mathrm{n}$ & 100 \\
\hline Deutschland $^{1}$ & 25 & 6 & 27 & 2 & 23 & 15 & 2 & 1 & 100 \\
\hline Griechenland & $\mathrm{m}$ & $\mathrm{m}$ & $\mathrm{m}$ & $\mathrm{m}$ & $\mathrm{m}$ & $\mathrm{m}$ & $\mathrm{m}$ & $n$ & $\mathrm{~m}$ \\
\hline Ungarn & 12 & 44 & 19 & 3 & 9 & 4 & 9 & $n$ & 100 \\
\hline Island & 42 & 3 & 23 & 1 & 11 & 19 & 2 & $\mathrm{n}$ & 100 \\
\hline Irland & $\mathrm{m}$ & $\mathrm{m}$ & $\mathrm{m}$ & $\mathrm{m}$ & $\mathrm{m}$ & $\mathrm{m}$ & $\mathrm{m}$ & $\mathrm{m}$ & 100 \\
\hline Japan & 26 & 2 & 39 & 2 & 15 & 1 & 2 & 12 & 100 \\
\hline Korea & $\mathrm{m}$ & $\mathrm{m}$ & $\mathrm{m}$ & $\mathrm{m}$ & $\mathrm{m}$ & $\mathrm{m}$ & $\mathrm{m}$ & $\mathrm{m}$ & $\mathrm{m}$ \\
\hline Luxemburg & $\mathrm{m}$ & $\mathrm{m}$ & $\mathrm{m}$ & $\mathrm{m}$ & $\mathrm{m}$ & $\mathrm{m}$ & $\mathrm{m}$ & $\mathrm{n}$ & $\mathrm{m}$ \\
\hline Mexiko & $\mathrm{m}$ & $\mathrm{m}$ & $\mathrm{m}$ & $\mathrm{m}$ & $\mathrm{m}$ & $\mathrm{m}$ & $\mathrm{m}$ & $\mathrm{m}$ & $\mathrm{m}$ \\
\hline Niederlande $^{3}$ & 14 & 15 & 44 & 9 & 10 & 6 & 2 & 1 & 100 \\
\hline Neuseeland & 15 & 7 & 39 & 7 & 7 & 18 & 1 & 6 & 100 \\
\hline Norwegen & 33 & 10 & 29 & 5 & 5 & 13 & 2 & 3 & 100 \\
\hline Portugal & 18 & 8 & 40 & 6 & 17 & 10 & 2 & $\mathrm{n}$ & 100 \\
\hline Slowenien & 19 & 9 & 34 & 6 & 18 & 11 & 2 & $\mathrm{n}$ & 100 \\
\hline Spanien $^{1}$ & 12 & 18 & 19 & 2 & 10 & 7 & 1 & 31 & 100 \\
\hline Schweden & 13 & 10 & 24 & 1 & 32 & 19 & 1 & $\mathrm{n}$ & 100 \\
\hline Schweiz $^{1}$ & 21 & 7 & 33 & 3 & 16 & 17 & 1 & 2 & 100 \\
\hline Ver. Königreich & 15 & 9 & 44 & 2 & 15 & 13 & 1 & $\mathrm{n}$ & 100 \\
\hline Vereinigte Staaten & 15 & 7 & 33 & 2 & 18 & 17 & 1 & 7 & 100 \\
\hline \multicolumn{10}{|l|}{ Sonst. G20-Länder } \\
\hline Argentinien & $\mathrm{m}$ & $\mathrm{m}$ & $\mathrm{m}$ & $\mathrm{m}$ & $\mathrm{m}$ & $\mathrm{m}$ & $\mathrm{m}$ & $\mathrm{m}$ & $\mathrm{m}$ \\
\hline Brasilien & $\mathrm{m}$ & $\mathrm{m}$ & $\mathrm{m}$ & $\mathrm{m}$ & $\mathrm{m}$ & $\mathrm{m}$ & $\mathrm{m}$ & $\mathrm{m}$ & $\mathrm{m}$ \\
\hline China & $\mathrm{m}$ & $\mathrm{m}$ & $\mathrm{m}$ & $\mathrm{m}$ & $\mathrm{m}$ & $\mathrm{m}$ & $\mathrm{m}$ & $\mathrm{m}$ & $\mathrm{m}$ \\
\hline Indien & $\mathrm{m}$ & $\mathrm{m}$ & $\mathrm{m}$ & $\mathrm{m}$ & $\mathrm{m}$ & $\mathrm{m}$ & $\mathrm{m}$ & $\mathrm{m}$ & $\mathrm{m}$ \\
\hline Indonesien & $\mathrm{m}$ & $\mathrm{m}$ & $\mathrm{m}$ & $\mathrm{m}$ & $\mathrm{m}$ & $\mathrm{m}$ & $\mathrm{m}$ & $\mathrm{m}$ & $\mathrm{m}$ \\
\hline Russische Föd. & $\mathrm{m}$ & $\mathrm{m}$ & $\mathrm{m}$ & $\mathrm{m}$ & $\mathrm{m}$ & $\mathrm{m}$ & $\mathrm{m}$ & $\mathrm{m}$ & $\mathrm{m}$ \\
\hline Saudi-Arabien & $\mathrm{m}$ & $\mathrm{m}$ & $\mathrm{m}$ & $\mathrm{m}$ & $\mathrm{m}$ & $\mathrm{m}$ & $\mathrm{m}$ & $\mathrm{m}$ & $\mathrm{m}$ \\
\hline \multirow[t]{2}{*}{ Südafrika ${ }^{2}$} & $\mathrm{~m}$ & $\mathrm{~m}$ & $\mathrm{~m}$ & $\mathrm{~m}$ & $\mathrm{~m}$ & $\mathrm{~m}$ & $\mathrm{~m}$ & $\mathrm{~m}$ & $\mathrm{~m}$ \\
\hline & \multicolumn{9}{|c|}{ Ausländische Studierende ${ }^{4}$} \\
\hline \multicolumn{10}{|l|}{ OECD-Länder } \\
\hline Tschechien & 14 & 15 & 39 & 3 & 10 & 15 & 2 & $n$ & 100 \\
\hline Frankreich & 19 & 8 & 41 & 2 & 13 & 17 & $n$ & $\mathrm{n}$ & 100 \\
\hline Israel & 44 & 14 & 27 & $\mathrm{n}$ & 6 & 7 & 1 & $\mathrm{n}$ & 100 \\
\hline Italien & 20 & 18 & 33 & 2 & 20 & 6 & 2 & 1 & 100 \\
\hline Polen & 16 & 26 & 39 & 5 & 7 & 5 & 1 & $n$ & 100 \\
\hline Slowakei & 18 & 49 & 19 & 2 & 8 & 2 & 2 & $\mathrm{n}$ & 100 \\
\hline Türkei & 22 & 14 & 34 & 4 & 15 & 10 & 2 & $\mathrm{n}$ & 100 \\
\hline
\end{tabular}

Anmerkung: Die Spalten mit separater Darstellung der „Geisteswissenschaften, Kunst und Erziehungswissenschaften“, d.h. die Spalten (2) und (3), sowie der einzelnen Naturwissenschaften, d.h. die Spalten (9) bis (12), sind im Internet verfügbar (s. StatLink unten).

1. Ohne Studiengänge im Tertiärbereich B. 2. Referenzjahr 2010. 3. Ohne Studiengänge an privaten Bildungseinrichtungen. 4. Ausländische Studierende sind auf der Grundlage des Landes, dessen Staatsbürger sie sind, definiert; diese Daten sind nicht mit den Daten zu internationalen Studierenden vergleichbar, daher werden sie in der Tabelle getrennt aufgeführt.

Quelle: OECD. Hinweise s. Anhang 3 unter www.oecd.org/edu/eag.htm. StatLink: http://dx.doi.org/10.1787/888932850756

Erläuterung der Kennzeichnung fehlender Daten s. Hinweise für den Leser. 
Tabelle C4.3

Verteilung internationaler und ausländischer Studierender im Tertiärbereich, nach Herkunftsland (2011)

Zahl der im Tertiärbereich eingeschriebenen internationalen und ausländischen Studierenden der einzelnen Herkunftsländer als Prozentsatz aller internationalen und ausländischen Studierenden im Zielland (basierend auf Personenzahlen)

Die Tabelle zeigt für jedes Land den Anteil der internationalen Studierenden im Tertiärbereich, die ihren dauerhaften Wohnsitz in einem bestimmten Herkunftsland haben bzw. dort den vorgelagerten Bildungsbereich besucht haben. Wenn Daten zur Mobilität Studierender nicht zur Verfügung stehen, ist in der Tabelle der Anteil ausländischer Studierender im Tertiärbereich angegeben, die Staatsbürger eines bestimmten Herkunftslandes sind.

Bedeutung der Spalte (2): 14,3 Prozent der internationalen Studierenden im Tertiärbereich in Belgien kommen aus Frankreich, 9,7 Prozent der internationalen Studierenden im Tertiärbereich in Belgien kommen aus den Niederlanden usw.

Bedeutung der Spalte (6): 44,7 Prozent der internationalen Studierenden im Tertiärbereich in Estland kommen aus Finnland, 1,5 Prozent der internationalen Studierenden im Tertiärbereich in Estland kommen aus Italien usw.

Bedeutung der Spalte (22): 39,3 Prozent aller ausländischen Studierenden im Tertiärbereich in Österreich sind deutsche Staatsbürger, 2,5 Prozent der ausländischen Studierenden im Tertiärbereich in Österreich sind ungarische Staatsbürger usw.

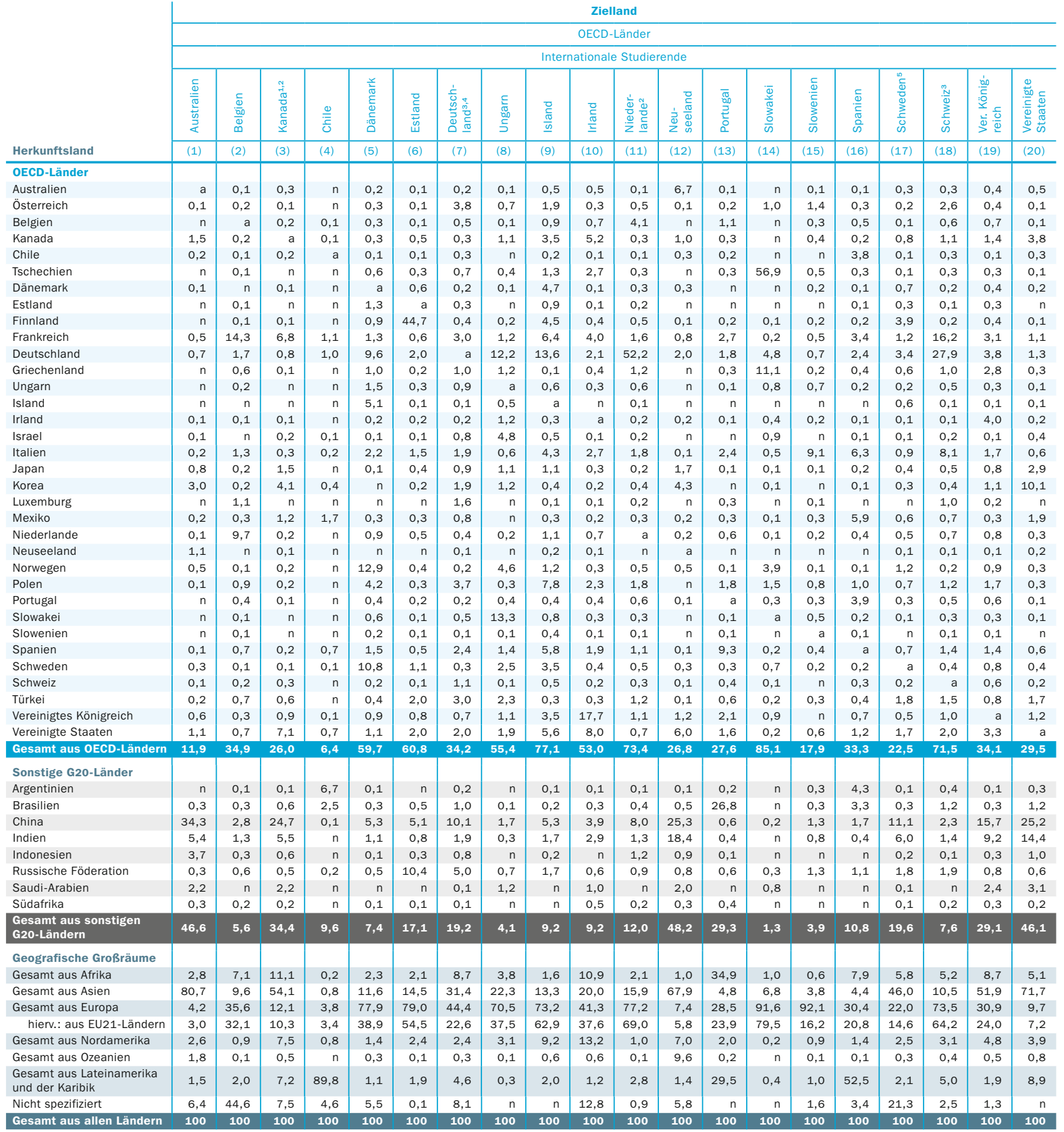

Anmerkung: Referenzjahr 2010 für Länder, die nicht OECD- bzw. G20-Land sind.

1. Referenzjahr 2010. 2. Ohne private Bildungseinrichtungen. 3. Ohne Studiengänge im Tertiärbereich B. 4. Ohne weiterführende forschungsorientierte Studiengänge (Deutschland: weiterführende forschungssorientierte Studiengänge sind nur in den geografischen Großräumen berücksichtigt). 5. Studierende, deren Herkunftsland nicht näher spezifiziert ist, kommen zum überwiegenden Teil aus den anderen nordischen Ländern. 6. Ausländische Studierende sind auf der Grundlage des Landes, dessen Staatsbürger sie sind, definiert; diese Daten sind nicht mit den Daten zu internationalen Studierenden vergleichbar, daher werden sie in der Tabelle getrennt aufgeführt.

Quelle: OECD. Hinweise s. Anhang 3 unter www.oecd.org/edu/eag.htm. StatLink: http://dx.doi.org/10.1787/888932850775

Erläuterung der Kennzeichnung fehlender Daten s. Hinweise für den Leser. 
Tabelle C4.3 (Forts.)

Verteilung internationaler und ausländischer Studierender im Tertiärbereich, nach Herkunftsland (2011)

Zahl der im Tertiärbereich eingeschriebenen internationalen und ausländischen Studierenden der einzelnen Herkunftsländer als Prozentsatz aller internationalen und ausländischen Studierenden im Zielland (basierend auf Personenzahlen)

Die Tabelle zeigt für jedes Land den Anteil der internationalen Studierenden im Tertiärbereich, die ihren dauerhaften Wohnsitz in einem bestimmten Her kunftsland haben bzw. dort den vorgelagerten Bildungsbereich besucht haben. Wenn Daten zur Mobilität Studierender nicht zur Verfügung stehen, ist in der Tabelle der Anteil ausländischer Studierender im Tertiärbereich angegeben, die Staatsbürger eines bestimmten Herkunftslandes sind.

Bedeutung der Spalte (2): 14,3 Prozent der internationalen Studierenden im Tertiärbereich in Belgien kommen aus Frankreich, 9,7 Prozent der internationalen Studierenden im Tertiärbereich in Belgien kommen aus den Niederlanden usw.

Bedeutung der Spalte (6): 44,7 Prozent der internationalen Studierenden im Tertiärbereich in Estland kommen aus Finnland, 1,5 Prozent der internationalen Studierenden im Tertiärbereich in Estland kommen aus Italien usw.

Bedeutung der Spalte (22): 39, 3 Prozent aller ausländischen Studierenden im Tertiärbereich in Österreich sind deutsche Staatsbürger, 2,5 Prozent der ausländischen Studierenden im Tertiärbereich in Österreich sind ungarische Staatsbürger usw.

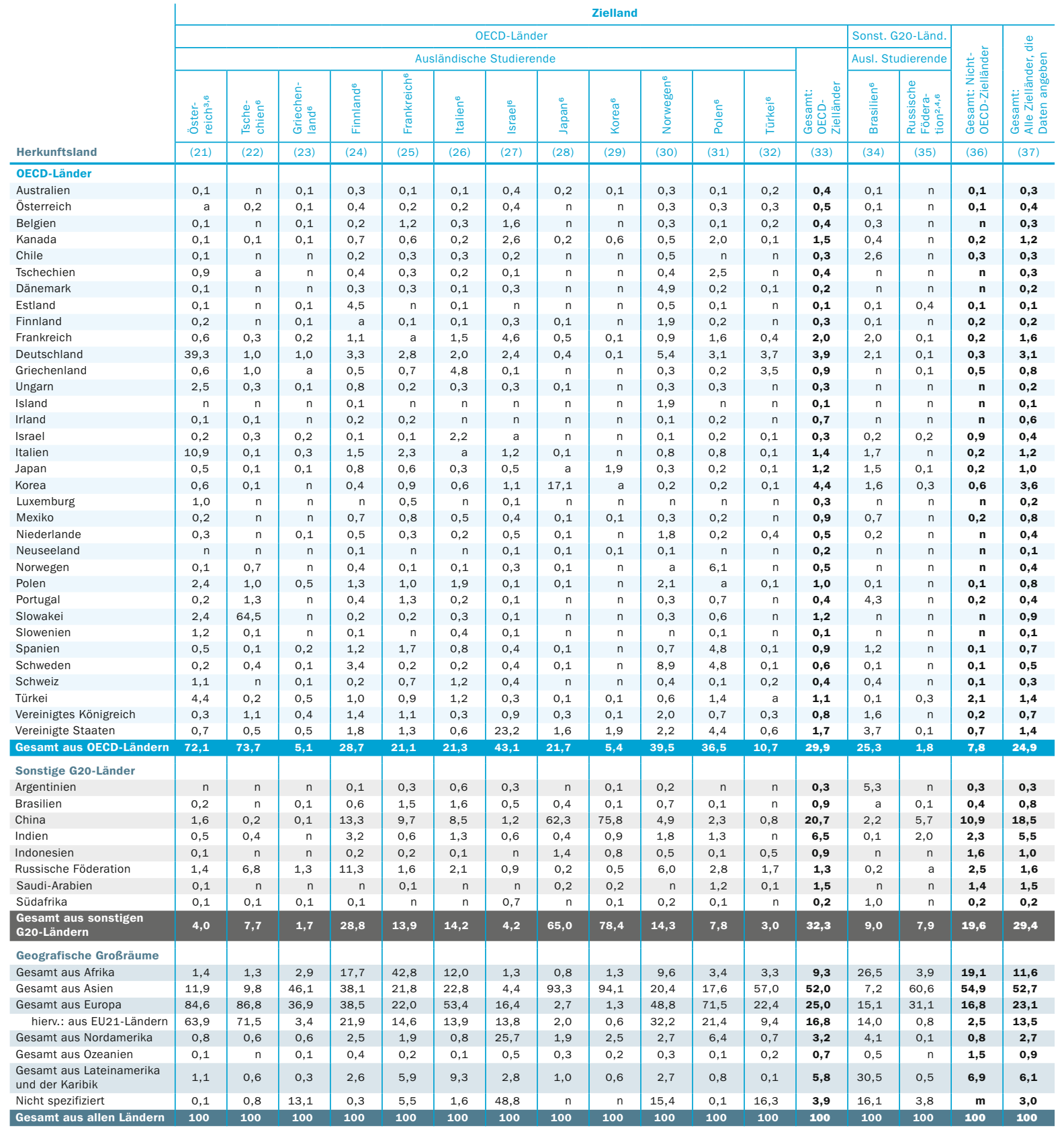

Anmerkung: Referenzjahr 2010 für Länder, die nicht OECD- bzw. G20-Land sind.

1. Referenzjahr 2010. 2. Ohne private Bildungseinrichtungen. 3. Ohne Studiengänge im Tertiärbereich B. 4. Ohne weiterführende forschungsorientierte Studiengänge (Deutschland: weiterführende forschungsorientierte Studiengänge sind nur in den geografischen Großräumen berücksichtigt). 5. Studierende, deren Herkunftsland nicht näher spezifiziert ist, kommen zum überwiegenden Teil aus den anderen nordischen Ländern. 6. Ausländische Studierende sind auf der Grundlage des Landes, dessen Staatsbürger sie sind, definiert; diese Daten sind nicht mit den Daten zu internationalen Studierenden vergleichbar, daher werden sie in der Tabelle getrennt aufgeführt.

Quelle: OECD. Hinweise s. Anhang 3 unter www.oecd.org/edu/eag.htm. StatLink: http://dx.doi.org/10.1787/888932850775 Erläuterung der Kennzeichnung fehlender Daten s. Hinweise für den Leser. 
Tabelle C4.4

Studierende, die in einem Land studieren, dessen Staatsbürger sie nicht sind, nach Zielland (2011)

Zahl der im Tertiärbereich eingeschriebenen ausländischen Studierenden in einem bestimmten Zielland als Prozentsatz aller im Ausland eingeschriebenen Studierenden (basierend auf Personenzahlen)

Die Tabelle zeigt den Anteil der Studierenden jedes Landes, die in einem bestimmten Zielland studieren.

Bedeutung der Spalte (2): 4,4 Prozent der tschechischen Studierenden im Auslandsstudium studieren in Österreich, 12,3 Prozent der italienischen Studierenden im Auslandsstudium studieren in Österreich usw.

Bedeutung der Zeile (1): 2,5 Prozent der australischen Studierenden im Auslandsstudium studieren in Frankreich, 21,4 Prozent der australischen Studierenden im Auslandsstudium studieren in Neuseeland usw.

Zielland

\begin{tabular}{|c|c|c|c|c|c|c|c|c|c|c|c|c|c|c|c|c|c|c|c|c|}
\hline \multirow[b]{4}{*}{ Herkunftsland } & \multicolumn{20}{|c|}{ Zielland } \\
\hline & \multicolumn{20}{|c|}{ OECD-Länder } \\
\hline & 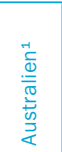 & $\begin{array}{l}\frac{N}{U} \\
\frac{0}{0} \\
\frac{0}{2} \\
\frac{0}{0} \\
: 0\end{array}$ & $\frac{\mathscr{c}}{\frac{\infty}{00}}$ & 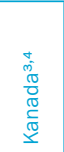 & $\frac{0}{\frac{E}{U}}$ & 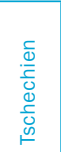 & 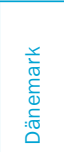 & 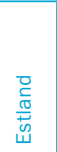 & 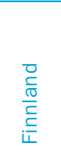 & 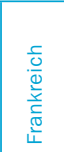 & 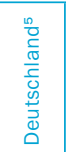 & 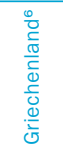 & $\begin{array}{l}\frac{5}{5} \\
\frac{\pi}{0} \\
5 \\
5\end{array}$ & $\begin{array}{l}\text { D } \\
\frac{\pi}{\omega} \\
\underline{\omega}\end{array}$ & 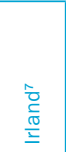 & $\begin{array}{l}\bar{d} \\
\frac{\pi}{0} \\
\underline{\omega}\end{array}$ & 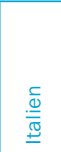 & 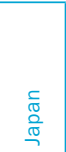 & 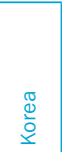 & $\begin{array}{l}\frac{d}{d} \\
\frac{0}{0} \\
\frac{C}{0} \\
\frac{\pi}{2} \\
\frac{D}{0} \\
\frac{d}{Z}\end{array}$ \\
\hline & (1) & (2) & (3) & (4) & (5) & (6) & (7) & (8) & (9) & $(10)$ & (11) & (12) & (13) & (14) & (15) & (16) & (17) & (18) & (19) & (20) \\
\hline \multicolumn{21}{|l|}{ OECD-Länder } \\
\hline Australien & a & 0,4 & 0,3 & 4,0 & $\mathrm{n}$ & 0,1 & 0,6 & $\mathrm{n}$ & 0,3 & 2,5 & 3,0 & 0,2 & 0,1 & $\mathrm{n}$ & 0,7 & 0,1 & 0,4 & 2,5 & 0,6 & 0,5 \\
\hline Österreich & 1,4 & a & 0,5 & 0,8 & $\mathrm{n}$ & 0,4 & 0,5 & $\mathrm{n}$ & 0,4 & 2,6 & 51,2 & 0,2 & 0,8 & 0,1 & 0,3 & 0,1 & 1,0 & 0,3 & 0,1 & 1,8 \\
\hline Belgien & 0,8 & 0,7 & a & 3,2 & $n$ & 0,1 & 0,6 & $\mathrm{n}$ & 0,3 & 24,8 & 8,4 & 0,3 & 0,1 & 0,1 & 0,4 & 0,5 & 1,5 & 0,4 & $n$ & 19,1 \\
\hline Kanada & 8,5 & 0,2 & 0,3 & a & $\mathrm{n}$ & 0,1 & 0,2 & $\mathrm{n}$ & 0,2 & 3,3 & 1,2 & 0,1 & 0,4 & 0,1 & 1,3 & 0,2 & 0,3 & 0,8 & 0,8 & 0,5 \\
\hline Chile & 4,2 & 0,3 & 0,9 & 3,3 & a & 0,1 & 0,3 & $\mathrm{n}$ & 0,2 & 6,9 & 4,6 & 0,1 & $n$ & $\mathrm{n}$ & $\mathrm{n}$ & 0,1 & 1,7 & 0,3 & 0,2 & 0,5 \\
\hline Tschechien & 0,7 & 4,4 & 0,7 & 0,7 & $n$ & a & 1,0 & $\mathrm{n}$ & 0,4 & 5,2 & 12,0 & 0,1 & 0,6 & 0,1 & 0,6 & $\mathrm{n}$ & 1,1 & 0,4 & 0,1 & 1,5 \\
\hline Dänemark & 2,4 & 0,8 & 0,6 & 1,5 & $n$ & 0,1 & a & 0,1 & 0,6 & 8,8 & 6,1 & 0,1 & 0,2 & 1,0 & 0,5 & 0,1 & 0,7 & 0,4 & $\mathrm{n}$ & 2,2 \\
\hline Estland & 0,4 & 1,3 & 0,5 & 0,2 & $n$ & 0,2 & 6,0 & a & 12,6 & 2,4 & 10,4 & 0,7 & 0,2 & 0,2 & 1,1 & $\mathrm{n}$ & 1,0 & 0,5 & $\mathrm{n}$ & 2,0 \\
\hline Finnland & 1,1 & 1,3 & 0,5 & 0,7 & $\mathrm{n}$ & 0,1 & 2,3 & 5,2 & a & 2,8 & 7,3 & 0,2 & 0,4 & 0,4 & 0,7 & 0,1 & 0,7 & 1,0 & $\mathrm{n}$ & 2,6 \\
\hline Frankreich & 1,7 & 0,5 & 22,2 & 12,0 & 0,1 & 0,2 & 0,5 & $\mathrm{n}$ & 0,2 & a & 8,3 & 0,1 & 0,3 & 0,1 & 0,8 & 0,2 & 1,4 & 0,9 & 0,1 & 1,3 \\
\hline Deutschland & 1,4 & 21,1 & 0,8 & 1,1 & 0,1 & 0,3 & 2,0 & $\mathrm{n}$ & 0,4 & 5,6 & a & 0,2 & 1,6 & 0,1 & 0,7 & 0,1 & 1,1 & 0,4 & 0,1 & 18,7 \\
\hline Griechenland & 0,1 & 1,0 & 1,5 & 0,3 & $n$ & 1,0 & 0,7 & $\mathrm{n}$ & 0,2 & 5,0 & 14,7 & a & 0,5 & $n$ & 0,2 & $n$ & 9,2 & 0,1 & $n$ & 3,0 \\
\hline Ungarn & 0,5 & 16,8 & 1,3 & 1,0 & $n$ & 1,0 & 3,3 & $\mathrm{n}$ & 1,2 & 5,9 & 18,7 & 0,2 & a & 0,1 & 0,9 & 0,1 & 1,9 & 0,8 & 0,1 & 3,7 \\
\hline Island & 0,6 & 0,8 & 0,3 & 1,1 & $\mathrm{n}$ & 0,1 & 42,5 & $\mathrm{n}$ & 0,4 & 1,0 & 2,8 & $n$ & 2,2 & a & 0,1 & $\mathrm{n}$ & 0,5 & 0,5 & $\mathrm{n}$ & 2,5 \\
\hline Irland & 0,9 & 0,2 & 0,3 & 0,9 & $\mathrm{n}$ & 0,2 & 0,3 & $\mathrm{n}$ & 0,1 & 1,9 & 1,4 & $\mathrm{n}$ & 0,7 & $\mathrm{n}$ & a & $\mathrm{n}$ & 0,1 & 0,1 & $\mathrm{n}$ & 0,7 \\
\hline Israel & 0,9 & 0,7 & 0,2 & 5,5 & $\mathrm{n}$ & 0,7 & 0,2 & $\mathrm{n}$ & 0,1 & 1,6 & 8,4 & 0,4 & 4,4 & $\mathrm{n}$ & 0,1 & a & 8,9 & 0,2 & $\mathrm{n}$ & 0,7 \\
\hline Italien & 0,7 & 12,3 & 3,4 & 0,7 & $\mathrm{n}$ & 0,1 & 0,9 & $\mathrm{n}$ & 0,4 & 9,8 & 14,1 & 0,2 & 0,2 & 0,1 & 0,8 & 0,1 & a & 0,3 & $\mathrm{n}$ & 1,9 \\
\hline Japan & 5,5 & 0,9 & 0,4 & 4,8 & $\mathrm{n}$ & 0,1 & 0,1 & $\mathrm{n}$ & 0,3 & 4,4 & 4,8 & 0,1 & 0,5 & $\mathrm{n}$ & 0,1 & $\mathrm{n}$ & 0,7 & a & 3,1 & 0,4 \\
\hline Korea & 5,7 & 0,3 & $\mathrm{n}$ & 6,2 & $\mathrm{n}$ & $\mathrm{n}$ & $\mathrm{n}$ & $\mathrm{n}$ & $\mathrm{n}$ & 1,7 & 3,4 & $\mathrm{n}$ & 0,2 & $n$ & $\mathrm{n}$ & $\mathrm{n}$ & 0,3 & 18,7 & a & 0,2 \\
\hline Luxemburg & 0,2 & 8,9 & 20,6 & 0,1 & $\mathrm{n}$ & $\mathrm{n}$ & $\mathrm{n}$ & $\mathrm{n}$ & $\mathrm{n}$ & 18,3 & 37,2 & $\mathrm{n}$ & 0,1 & $n$ & 0,1 & $\mathrm{n}$ & 0,3 & $\mathrm{n}$ & $\mathrm{n}$ & 1,3 \\
\hline Mexiko & 2,0 & 0,5 & 0,5 & 7,1 & 0,6 & $\mathrm{n}$ & 0,3 & $\mathrm{n}$ & 0,4 & 7,2 & 5,2 & $\mathrm{n}$ & $n$ & $\mathrm{n}$ & 0,1 & 0,1 & 1,3 & 0,6 & 0,2 & 0,9 \\
\hline Niederlande & 1,4 & 1,1 & 27,3 & 2,1 & $\mathrm{n}$ & 0,1 & 1,6 & $\mathrm{n}$ & 0,4 & 4,1 & 7,4 & 0,2 & 0,2 & 0,1 & 0,8 & 0,1 & 0,6 & 0,5 & $\mathrm{n}$ & a \\
\hline Neuseeland & 46,4 & 0,2 & 0,1 & 2,7 & $\mathrm{n}$ & 0,1 & 0,3 & $\mathrm{n}$ & 0,2 & 1,4 & 1,4 & $\mathrm{n}$ & 0,1 & $n$ & 0,5 & $\mathrm{n}$ & 0,2 & 1,3 & 1,0 & 0,3 \\
\hline Norwegen & 8,2 & 0,3 & 0,2 & 1,3 & $n$ & 1,5 & 18,9 & $\mathrm{n}$ & 0,4 & 1,8 & 2,3 & $\mathrm{n}$ & 4,4 & 0,1 & 0,2 & 0,1 & 0,4 & 0,5 & $\mathrm{n}$ & 2,2 \\
\hline Polen & 0,4 & 3,7 & 1,6 & 1,4 & $n$ & 0,8 & 2,7 & $\mathrm{n}$ & 0,5 & 5,7 & 23,0 & 0,4 & 0,2 & 0,2 & 2,3 & $\mathrm{n}$ & 3,0 & 0,3 & 0,1 & 2,4 \\
\hline Portugal & 0,5 & 0,5 & 3,9 & 1,1 & $\mathrm{n}$ & 2,1 & 0,6 & $\mathrm{n}$ & 0,2 & 14,5 & 8,1 & 0,1 & 0,3 & $n$ & 0,4 & $\mathrm{n}$ & 0,7 & 0,2 & $\mathrm{n}$ & 2,1 \\
\hline Slowakei & 0,2 & 4,7 & 0,3 & 0,3 & $n$ & 69,0 & 0,4 & $\mathrm{n}$ & 0,1 & 1,3 & 3,2 & $\mathrm{n}$ & 7,2 & $n$ & 0,4 & $n$ & 0,6 & 0,1 & $\mathrm{n}$ & 0,6 \\
\hline Slowenien & 0,8 & 26,7 & 1,0 & 0,8 & $\mathrm{n}$ & 0,7 & 1,6 & $\mathrm{n}$ & 0,6 & 2,9 & 15,6 & 0,1 & 0,6 & 0,1 & 0,2 & 0,1 & 9,6 & 0,5 & $\mathrm{n}$ & 3,6 \\
\hline Spanien & 0,5 & 1,0 & 3,2 & 0,7 & 0,2 & 0,1 & 1,2 & $\mathrm{n}$ & 0,6 & 13,7 & 16,3 & 0,2 & 0,7 & 0,2 & 1,3 & 0,1 & 1,8 & 0,4 & 0,1 & 2,8 \\
\hline Schweden & 4,0 & 0,9 & 0,4 & 1,0 & $\mathrm{n}$ & 0,7 & 13,3 & 0,1 & 2,7 & 2,3 & 3,2 & 0,1 & 2,2 & 0,2 & 0,5 & 0,1 & 0,7 & 1,1 & 0,1 & 1,5 \\
\hline Schweiz & 2,8 & 6,7 & 1,1 & 3,5 & 0,1 & 0,1 & 0,7 & $\mathrm{n}$ & 0,3 & 15,8 & 21,4 & 0,3 & 0,2 & 0,1 & 0,4 & 0,1 & 7,4 & 0,6 & 0,1 & 1,9 \\
\hline Türkei & 0,6 & 3,8 & 0,5 & 1,2 & $n$ & 0,1 & 0,7 & $\mathrm{n}$ & 0,2 & 2,8 & 38,2 & 0,2 & 0,5 & $n$ & 0,1 & $n$ & 1,1 & 0,2 & 0,1 & 1,5 \\
\hline Ver. Königreich & 4,1 & 0,6 & 0,8 & 6,2 & $\mathrm{n}$ & 1,1 & 1,6 & $\mathrm{n}$ & 0,6 & 8,0 & 5,5 & 0,4 & 0,5 & 0,1 & 10,6 & 0,1 & 0,7 & 1,3 & 0,2 & 2,7 \\
\hline Vereinigte Staaten & 4,6 & 0,7 & 0,5 & 15,4 & 0,1 & 0,3 & 0,6 & $\mathrm{n}$ & 0,5 & 5,6 & 6,5 & 0,3 & 0,5 & 0,1 & 6,9 & 1,5 & 0,7 & 4,0 & 1,9 & 1,0 \\
\hline $\begin{array}{l}\text { Gesamt aus OECD- } \\
\text { Ländern }\end{array}$ & 2,8 & 4,5 & 3,0 & 3,8 & 0,1 & 2,5 & 1,5 & 0,1 & 0,4 & 5,0 & 10,1 & 0,1 & 0,9 & 0,1 & 1,2 & 0,2 & 1,4 & 2,9 & 0,3 & 3,6 \\
\hline $\begin{array}{l}\text { Gesamt aus EU21- } \\
\text { Ländern }\end{array}$ & 1,2 & 7,0 & 5,0 & 2,6 & n & 4,2 & 1,7 & 0,1 & 0,5 & 6,1 & 9,8 & 0,2 & 1,0 & 0,1 & 1,3 & 0,1 & 1,6 & 0,5 & 0,1 & 5,6 \\
\hline \multicolumn{21}{|l|}{ Sonst. G20-Länder } \\
\hline Argentinien & 0,7 & 0,2 & 0,4 & 3,7 & 3,8 & $n$ & 0,2 & $n$ & 0,1 & 6,2 & 2,8 & 0,1 & $n$ & $\mathrm{n}$ & 0,1 & 0,1 & 3,2 & 0,5 & 0,3 & 0,3 \\
\hline Brasilien & 2,2 & 0,5 & 0,7 & 3,9 & 0,6 & 0,1 & 0,4 & $\mathrm{n}$ & 0,3 & 11,2 & 6,5 & 0,1 & 0,1 & $n$ & 0,2 & 0,1 & 3,4 & 1,8 & 0,1 & 0,6 \\
\hline China & 12,5 & 0,2 & 0,2 & 5,4 & $n$ & $n$ & 0,2 & $n$ & 0,3 & 3,6 & 3,0 & $n$ & $n$ & $n$ & 0,3 & $\mathrm{n}$ & 0,9 & 13,1 & 6,6 & 0,6 \\
\hline Indien & 6,3 & 0,2 & 0,2 & 5,2 & $n$ & 0,1 & 0,1 & $\mathrm{n}$ & 0,2 & 0,8 & 1,7 & $\mathrm{n}$ & $n$ & $n$ & 0,3 & $n$ & 0,4 & 0,3 & 0,3 & 0,3 \\
\hline Indonesien & 22,6 & 0,2 & 0,3 & 2,2 & $n$ & $n$ & 0,1 & $n$ & 0,1 & 1,1 & 5,3 & $\mathrm{n}$ & $n$ & $n$ & $n$ & $n$ & 0,2 & 5,1 & 1,2 & 2,3 \\
\hline Russische Föd. & 1,3 & 1,4 & 0,7 & 2,0 & $n$ & 3,6 & 0,5 & 1,8 & 2,5 & 5,9 & 18,4 & 0,6 & 0,2 & $\mathrm{n}$ & 0,3 & $\mathrm{n}$ & 2,1 & 0,5 & 0,5 & 0,8 \\
\hline Saudi-Arabien & 10,3 & 0,1 & $\mathrm{n}$ & 4,3 & $n$ & $n$ & $\mathrm{n}$ & $n$ & $n$ & 0,4 & 0,3 & $n$ & 0,3 & $n$ & 0,2 & $n$ & $n$ & 0,4 & 0,2 & $n$ \\
\hline Südafrika & 6,8 & 0,3 & 0,6 & 3,5 & $n$ & 0,3 & 0,2 & $\mathrm{n}$ & 0,2 & 1,0 & 1,3 & 0,3 & $\mathrm{n}$ & $n$ & 1,3 & 0,2 & 0,2 & 0,2 & 0,3 & 0,9 \\
\hline $\begin{array}{l}\text { Gesamt aus sons- } \\
\text { tigen G20-Ländern }\end{array}$ & 10,4 & 0,2 & 0,2 & 4,9 & 0,1 & 0,2 & 0,2 & 0,1 & 0,4 & 3,2 & 3,7 & $\mathbf{n}$ & 0,1 & $\mathbf{n}$ & 0,3 & $\mathbf{n}$ & 0,9 & 8,4 & 4,2 & 0,6 \\
\hline $\begin{array}{l}\text { Gesamt aus allen } \\
\text { Ländern }\end{array}$ & 6,1 & 1,6 & 1,2 & 4,7 & 0,3 & 0,9 & 0,7 & 0,1 & 0,4 & 6,2 & 6,3 & 0,8 & 0,4 & $\mathbf{n}$ & 0,5 & 0,1 & 1,7 & 3,5 & 1,5 & 1,3 \\
\hline
\end{tabular}

Anmerkung: Der Anteil der Studierenden im Auslandsstudium basiert nur auf der Gesamtzahl der in Ländern eingeschriebenen Studierenden, die Daten an die OECD und das Statistikinstitut der UNESCO melden. Referenzjahr 2010 für Länder, die nicht OECD-bzw. G20-Land sind.

1. Daten beziehen sich auf internationale Studierende. 2. Ohne Studiengänge im Tertiärbereich B. 3. Referenzjahr 2010. 4. Ohne private Bildungseinrichtungen. 5. Ohne weiterführende forschungsorientierte Studiengänge (Deutschland: weiterführende forschungsorientierte Studiengänge sind nur in den geografischen Großräumen berücksichtigt). 6. Gesamt basierend auf einer Schätzung des Statistikinstituts der UNESCO. 7. Ohne Teilzeitstudierende.

Quelle: OECD. Hinweise s. Anhang 3 unter www.oecd.org/edu/eag.htm. StatLink: http://dx.doi.org/10.1787/888932850794

Erläuterung der Kennzeichnung fehlender Daten s. Hinweise für den Leser. 
Tabelle C4.4 (Forts.)

Studierende, die in einem Land studieren, dessen Staatsbürger sie nicht sind, nach Zielland (2011)

Zahl der im Tertiärbereich eingeschriebenen ausländischen Studierenden in einem bestimmten Zielland als Prozentsatz aller im Ausland eingeschriebenen Studierenden (basierend auf Personenzahlen)

Die Tabelle zeigt den Anteil der Studierenden jedes Landes, die in einem bestimmten Zielland studieren.

Bedeutung der Spalte (2): 4, 4 Prozent der tschechischen Studierenden im Auslandsstudium studieren in Österreich, 12,3 Prozent der italienischen Studierenden im Auslandsstudium studieren in Österreich usw.

Bedeutung der Zeile (1): 2,5 Prozent der australischen Studierenden im Auslandsstudium studieren in Frankreich, 21,4 Prozent der australischen Studierenden im Auslandsstudium studieren in Neuseeland usw.

Zielland

\begin{tabular}{|c|c|c|c|c|c|c|c|c|c|c|c|c|c|c|c|c|c|}
\hline \multicolumn{18}{|c|}{ Zielland } \\
\hline \multicolumn{12}{|c|}{ OECD-Länder } & \multirow[b]{2}{*}{ 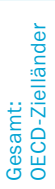 } & \multirow[b]{2}{*}{ 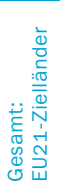 } & \multicolumn{2}{|c|}{ Sonst. G20-Ld. } & \multirow[b]{2}{*}{ 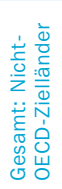 } & \multirow{2}{*}{ 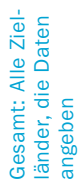 } \\
\hline 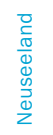 & $\begin{array}{l}c \\
0 \\
0 \\
0 \\
3 \\
0 \\
0 \\
z\end{array}$ & $\frac{\check{\Phi}}{0}$ & $\begin{array}{l}\bar{\pi} \\
0 \\
\vec{Z} \\
\frac{t}{0} \\
0\end{array}$ & $\begin{array}{l}\bar{\Phi} \\
\frac{\omega}{0} \\
\frac{0}{\omega} \\
\frac{0}{\omega}\end{array}$ & $\begin{array}{l}\frac{c}{\frac{d}{\sigma}} \\
\frac{0}{\omega} \\
\frac{\partial}{\omega}\end{array}$ & $\begin{array}{l}\frac{\bar{d}}{C} \\
\frac{0}{0} \\
\text { के }\end{array}$ & $\begin{array}{l}\frac{c}{d} \\
\frac{d}{0} \\
0 \\
3 \\
0 \\
0 \\
i\end{array}$ & 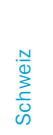 & $\begin{array}{l}\overline{\bar{Q}} \\
\text { 产 } \\
\vdots\end{array}$ & 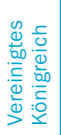 & 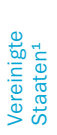 & & & 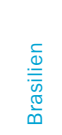 & 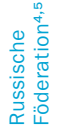 & & \\
\hline (21) & (22) & (23) & (24) & (25) & (26) & (27) & (28) & (29) & (30) & (31) & (32) & (33) & $(34)$ & (35) & $(36)$ & $(37)$ & (38) \\
\hline 21,4 & 0,3 & 0,1 & 0,2 & $\mathrm{n}$ & $\mathrm{n}$ & 0,5 & 0,8 & 0,9 & 0,5 & 26,9 & 28,1 & 96 & 38 & 0,1 & $n$ & 4 & 100 \\
\hline
\end{tabular}

\begin{tabular}{|c|c|c|c|c|c|c|c|c|c|c|c|c|c|c|c|c|c|c|}
\hline Herkunftsland & (21) & (22) & (23) & (24) & (25) & (26) & $(27)$ & (28) & (29) & (30) & (31) & (32) & (33) & (34) & (35) & (36) & (37) & (38) \\
\hline \multicolumn{19}{|l|}{ OECD-Länder } \\
\hline Australien & 21,4 & 0,3 & 0,1 & 0,2 & $n$ & $\mathrm{n}$ & 0,5 & 0,8 & 0,9 & 0,5 & 26,9 & 28,1 & 96 & 38 & 0,1 & $\mathrm{n}$ & 4 & 100 \\
\hline Österreich & 0,7 & 0,3 & 0,3 & 0,2 & 0,5 & 0,1 & 1,6 & 1,0 & 8,5 & 0,5 & 13,2 & 5,8 & 95 & 77 & 0,1 & 0,1 & 5 & 100 \\
\hline Belgien & 0,4 & 0,4 & 0,2 & 1,3 & $n$ & $n$ & 4,5 & 0,4 & 3,6 & 0,5 & 18,8 & 6,6 & 98 & 82 & 0,3 & 0,1 & 2 & 100 \\
\hline Kanada & 1,6 & 0,2 & 1,0 & 0,3 & $n$ & $n$ & 0,4 & 0,6 & 1,0 & $\mathrm{n}$ & 15,4 & 57,5 & 96 & 26 & 0,1 & $n$ & 4 & 100 \\
\hline Chile & 1,7 & 0,7 & $\mathrm{n}$ & 0,2 & $\mathrm{n}$ & $n$ & 27,7 & 1,0 & 1,0 & $n$ & 5,0 & 16,8 & 78 & 50 & 3,0 & $n$ & 22 & 100 \\
\hline Tschechien & 0,4 & 0,5 & 4,2 & 0,6 & 37,4 & 0,1 & 2,0 & 0,5 & 1,5 & 0,1 & 16,1 & 5,5 & 99 & 89 & $\mathrm{n}$ & 0,2 & 1 & 100 \\
\hline Dänemark & 2,2 & 10,0 & 0,6 & 0,1 & $\mathrm{n}$ & $\mathrm{n}$ & 1,3 & 10,2 & 1,4 & 0,3 & 30,9 & 13,8 & 97 & 64 & 0,1 & $\mathrm{n}$ & 3 & 100 \\
\hline Estland & 0,1 & 1,4 & 0,3 & 0,1 & 0,1 & $n$ & 1,8 & 4,1 & 0,6 & $n$ & 27,0 & 4,0 & 79 & 72 & 0,1 & 10,9 & 21 & 100 \\
\hline Finnland & 0,4 & 2,8 & 0,3 & 0,2 & 0,1 & $n$ & 1,6 & 23,9 & 1,2 & 0,1 & 22,9 & 5,5 & 87 & 73 & 0,1 & 0,5 & 13 & 100 \\
\hline Frankreich & 0,5 & 0,2 & 0,5 & 0,7 & $\mathrm{n}$ & $n$ & 4,5 & 0,6 & 8,1 & 0,1 & 21,4 & 10,0 & 97 & 63 & 0,4 & 0,1 & 3 & 100 \\
\hline Deutschland & 1,1 & 0,7 & 0,5 & 0,3 & 0,3 & $\mathrm{n}$ & 2,3 & 1,4 & 11,3 & 0,9 & 16,1 & 7,0 & 98 & 73 & 0,2 & 0,1 & 2 & 100 \\
\hline Griechenland & $\mathrm{n}$ & 0,1 & 0,1 & 0,1 & 2,5 & $n$ & 1,1 & 0,8 & 1,4 & 2,9 & 34,8 & 4,8 & 86 & 77 & $\mathrm{n}$ & 0,5 & 14 & 100 \\
\hline Ungarn & 0,6 & 0,5 & 0,7 & 0,4 & 0,8 & 0,1 & 1,9 & 1,3 & 2,3 & 0,1 & 23,1 & 6,2 & 96 & 83 & $n$ & 0,2 & 4 & 100 \\
\hline Island & 0,2 & 7,6 & 0,2 & $n$ & $n$ & $n$ & 0,6 & 11,3 & 0,7 & $n$ & 14,6 & 8,8 & 99 & 80 & $n$ & $n$ & 1 & 100 \\
\hline Irland & 1,1 & 0,1 & 0,2 & 0,1 & 0,1 & $n$ & 0,5 & 0,3 & 0,2 & $n$ & 84,6 & 4,2 & 99 & 92 & $n$ & $n$ & 1 & 100 \\
\hline Israel & 0,3 & 0,1 & 0,3 & $\mathrm{n}$ & 0,4 & $n$ & 0,7 & 0,1 & 0,5 & 0,1 & 3,9 & 14,6 & 54 & 32 & 0,1 & 2,0 & 46 & 100 \\
\hline Italien & 0,2 & 0,2 & 0,3 & 1,0 & 0,1 & 0,3 & 11,9 & 0,7 & 9,8 & $n$ & 19,5 & 6,8 & 97 & 78 & 0,4 & 0,1 & 3 & 100 \\
\hline Japan & 2,8 & 0,1 & 0,1 & $\mathrm{n}$ & $\mathrm{n}$ & $n$ & 0,5 & 0,6 & 0,7 & $n$ & 9,6 & 54,2 & 95 & 24 & 0,6 & 0,2 & 5 & 100 \\
\hline Korea & 2,5 & $\mathrm{n}$ & $n$ & $n$ & $n$ & $n$ & 0,1 & 0,1 & 0,2 & $n$ & 3,9 & 51,9 & 96 & 10 & 0,2 & 0,4 & 4 & 100 \\
\hline Luxemburg & 0,1 & $\mathrm{n}$ & $n$ & 0,4 & $n$ & $n$ & 0,3 & $\mathrm{n}$ & 5,2 & $n$ & 5,4 & 0,7 & 100 & 93 & $n$ & $\mathrm{n}$ & $\mathbf{n}$ & 100 \\
\hline Mexiko & 0,4 & 0,2 & 0,2 & 0,2 & $\mathrm{n}$ & $n$ & 10,4 & 0,6 & 1,2 & $n$ & 5,6 & 46,2 & 92 & 33 & 0,3 & 0,1 & 8 & 100 \\
\hline Niederlande & 2,5 & 1,4 & 0,2 & 0,6 & $\mathrm{n}$ & $\mathrm{n}$ & 2,3 & 1,6 & 2,5 & 0,6 & 30,1 & 8,6 & 99 & 79 & 0,1 & $n$ & 1 & 100 \\
\hline Neuseeland & a & 0,2 & 0,1 & $n$ & $n$ & $n$ & 0,3 & 0,5 & 0,6 & $n$ & 21,5 & 18,7 & 98 & 27 & $n$ & $n$ & 2 & 100 \\
\hline Norwegen & 1,3 & $\mathrm{a}$ & 8,1 & 0,1 & 2,0 & $n$ & 0,8 & 7,2 & 0,6 & $n$ & 24,3 & 10,3 & 98 & 75 & $n$ & 0,1 & 2 & 100 \\
\hline Polen & 0,1 & 0,8 & a & 0,7 & 0,3 & $n$ & 3,0 & 1,5 & 1,3 & $n$ & 38,7 & 3,9 & 99 & 90 & $\mathrm{n}$ & 0,1 & 1 & 100 \\
\hline Portugal & 0,1 & 0,2 & 0,6 & a & 0,1 & $\mathrm{n}$ & 15,7 & 0,6 & 6,1 & $\mathrm{n}$ & 30,0 & 4,1 & 93 & 80 & 2,7 & $n$ & 7 & 100 \\
\hline Slowakei & 0,1 & 0,1 & 0,4 & 0,1 & a & $n$ & 0,6 & 0,1 & 0,6 & $n$ & 8,1 & 1,2 & 100 & 97 & $n$ & 0,1 & $\mathbf{n}$ & 100 \\
\hline Slowenien & 0,4 & 0,2 & 0,5 & 1,0 & 0,1 & a & 2,8 & 0,6 & 1,7 & 0,2 & 12,6 & 5,6 & 91 & 81 & $n$ & 0,2 & 9 & 100 \\
\hline Spanien & 0,3 & 0,3 & 3,3 & 4,7 & 0,1 & $n$ & a & 1,2 & 4,6 & 0,1 & 25,4 & 12,7 & 98 & 77 & 0,5 & $n$ & 2 & 100 \\
\hline Schweden & 0,8 & 7,5 & 5,5 & 0,2 & 0,3 & $n$ & 1,4 & a & 1,7 & 0,2 & 26,5 & 16,0 & 95 & 62 & 0,1 & 0,1 & 5 & 100 \\
\hline Schweiz & 0,9 & 0,5 & 0,1 & 1,4 & 0,1 & $n$ & 3,4 & 0,8 & a & 0,4 & 13,4 & 10,4 & 95 & 75 & 0,5 & $n$ & 5 & 100 \\
\hline Türkei & 0,1 & 0,1 & 0,4 & 0,1 & $n$ & $n$ & 0,4 & 0,7 & 1,3 & a & 5,4 & 14,4 & 75 & 57 & $n$ & 0,6 & 25 & 100 \\
\hline Ver. Königreich & 17,9 & 0,9 & 0,4 & 0,4 & 0,2 & $n$ & 2,9 & 1,7 & 1,6 & 0,3 & a & 23,4 & 95 & 39 & 0,6 & 0,1 & 5 & 100 \\
\hline Vereinigte Staaten & 5,3 & 0,6 & 1,6 & 0,3 & $\mathrm{n}$ & $n$ & 1,9 & 1,1 & 1,2 & 0,3 & 25,4 & a & 90 & 55 & 0,9 & 0,2 & 10 & 100 \\
\hline $\begin{array}{l}\text { Gesamt aus OECD- } \\
\text { Ländern }\end{array}$ & 2,0 & 0,6 & 0,7 & 0,5 & 0,7 & $\mathbf{n}$ & 2,9 & 1,2 & 3,6 & 0,3 & 17,9 & 18,5 & 93 & 58 & 0,3 & 0,3 & 7 & 100 \\
\hline $\begin{array}{l}\text { Gesamt aus EU21- } \\
\text { Ländern }\end{array}$ & 1,6 & 0,8 & 0,8 & 0,7 & 1,1 & n & 3,6 & 1,5 & 5,6 & 0,5 & 23,4 & 7,9 & 96 & 75 & 0,3 & 0,2 & 4 & 100 \\
\hline \multicolumn{19}{|l|}{ Sonst. G20-Länder } \\
\hline Argentinien & 0,7 & 0,2 & $n$ & 0,3 & $n$ & $n$ & 35,7 & 0,3 & 0,9 & $n$ & 2,4 & 15,5 & 79 & 52 & 5,8 & $n$ & 21 & 100 \\
\hline Brasilien & 1,1 & 0,3 & 0,1 & 15,1 & $\mathrm{n}$ & $\mathrm{n}$ & 6,5 & 0,5 & 1,7 & $\mathrm{n}$ & 6,8 & 24,4 & 89 & 53 & a & 0,6 & 11 & 100 \\
\hline China & 2,2 & 0,1 & 0,1 & $n$ & $n$ & $n$ & 0,4 & 0,6 & 0,2 & $n$ & 10,0 & 24,7 & 85 & 20 & $n$ & 1,4 & 15 & 100 \\
\hline Indien & 4,4 & 0,1 & 0,1 & $\mathrm{n}$ & $n$ & $n$ & 0,2 & 0,9 & 0,4 & $n$ & 21,5 & 45,7 & 90 & 27 & $\mathrm{n}$ & 1,5 & 10 & 100 \\
\hline Indonesien & 1,3 & 0,2 & $n$ & $n$ & $n$ & $n$ & 0,1 & 0,2 & 0,3 & 0,3 & 3,2 & 15,9 & 63 & 13 & $n$ & 0,2 & 37 & 100 \\
\hline Russische Föd. & 0,9 & 1,4 & 0,9 & 0,3 & 0,1 & 0,1 & 2,2 & 1,2 & 1,5 & 0,7 & 6,5 & 6,5 & 65 & 50 & 0,1 & a & 35 & 100 \\
\hline Saudi-Arabien & 1,5 & $n$ & 0,5 & $n$ & 0,1 & $n$ & 0,1 & $n$ & $n$ & $n$ & 18,1 & 38,9 & 76 & 20 & $n$ & $n$ & 24 & 100 \\
\hline Südafrika & 21,0 & 0,3 & 0,1 & 0,8 & $\mathrm{n}$ & $n$ & 0,2 & 0,3 & 0,6 & $n$ & 33,4 & 13,1 & 87 & 41 & 1,2 & $n$ & 13 & 100 \\
\hline $\begin{array}{l}\text { Gesamt aus sons- } \\
\text { tigen G20-Ländern }\end{array}$ & 2,6 & 0,2 & 0,2 & 0,5 & $\mathbf{n}$ & $\mathbf{n}$ & 1,0 & 0,6 & 0,4 & 0,1 & 12,2 & 27,7 & 84 & 25 & 0,1 & 1,1 & 16 & 100 \\
\hline $\begin{array}{l}\text { Gesamt aus allen } \\
\text { Ländern }\end{array}$ & 1,7 & 0,4 & 0,5 & 0,5 & 0,2 & 0,1 & 2,5 & 1,2 & 1,4 & 0,7 & 13,0 & 16,5 & 77 & 40 & 0,3 & 4,0 & 23 & 100 \\
\hline
\end{tabular}

Anmerkung: Der Anteil der Studierenden im Auslandsstudium basiert nur auf der Gesamtzahl der in Ländern eingeschriebenen Studierenden, die Daten an die OECD und das Statistikinstitut der UNESCO melden. Referenzjahr 2010 für Länder, die nicht OECD-bzw. G20-Land sind.

1. Daten beziehen sich auf internationale Studierende. 2. Ohne Studiengänge im Tertiärbereich B. 3. Referenzjahr 2010.4 . Ohne private Bildungseinrichtungen. 5. Ohne weiterführende forschungsorientierte Studiengänge (Deutschland: weiterführende forschungsorientierte Studiengänge sind nur in den geografischen Großräumen berücksichtigt). 6. Gesamt basierend auf einer Schätzung des Statistikinstituts der UNESCO. 7. Ohne Teilzeitstudierende.

Quelle: OECD. Hinweise s. Anhang 3 unter www.oecd.org/edu/eag.htm. StatLink: http://dx.doi.org/10.1787/888932850794

Erläuterung der Kennzeichnung fehlender Daten s. Hinweise für den Leser. 
Tabelle C4.5

Mobilität ausländischer und internationaler Studierender (2011)

Regionale und grenzüberschreitende Mobilität, Ausmaß der Mobilität und Verwendung der Amtssprache des Ziellandes in den Herkunftsländern

\begin{tabular}{|c|c|c|c|c|}
\hline & $\begin{array}{c}\text { Anteil inländischer } \\
\text { Studierender, die im Ausland } \\
\text { eingeschrieben sind } \\
\text { (in \%) }\end{array}$ & $\begin{array}{c}\text { Zahl ausländischer } \\
\text { Studierender pro im Ausland } \\
\text { eingeschriebenen inlän- } \\
\text { dischen Studierenden }\end{array}$ & $\begin{array}{l}\text { Anteil ausländischer } \\
\text { Studierender aus } \\
\text { benachbarten Ländern }{ }^{1} \\
\text { (in \%) }\end{array}$ & $\begin{array}{l}\text { Anteil Studierender aus } \\
\text { Ländern mit derselben } \\
\text { Amtssprache (in \%) }\end{array}$ \\
\hline & (1) & (2) & (3) & (4) \\
\hline \multicolumn{5}{|l|}{ OECD-Länder } \\
\hline Australien & 1,2 & 19,9 & 36,0 & 18,4 \\
\hline Österreich & 5,3 & 4,1 & 58,6 & 52,8 \\
\hline Belgien & 3,1 & 3,9 & 51,2 & 66,3 \\
\hline Kanada $^{2}$ & 3,4 & 4,3 & 4,7 & 32,9 \\
\hline Chile & 1,2 & 0,9 & 31,9 & 55,9 \\
\hline Tschechien ${ }^{3}$ & 3,2 & 2,8 & 66,7 & $n$ \\
\hline Dänemark & 3,3 & 3,6 & 36,1 & $\mathrm{n}$ \\
\hline Estland & 7,7 & 0,5 & 73,9 & $n$ \\
\hline Finnland & 3,7 & 1,4 & 19,7 & 3,4 \\
\hline Frankreich ${ }^{3}$ & 3,8 & 3,4 & 14,9 & 28,8 \\
\hline Deutschland & 4,8 & 2,1 & 14,3 & 8,9 \\
\hline Griechenland ${ }^{3}$ & 5,8 & 0,9 & 70,0 & 40,3 \\
\hline Ungarn & 2,8 & 1,8 & 44,6 & $\mathrm{n}$ \\
\hline Island & 18,9 & 0,3 & 8,4 & $\mathrm{n}$ \\
\hline Irland & 13,0 & 0,8 & 17,1 & 51,2 \\
\hline |srael ${ }^{3}$ & 4,8 & 0,2 & $\mathrm{n}$ & $\mathrm{n}$ \\
\hline Italien ${ }^{3}$ & 3,2 & 1,2 & 30,6 & 5,2 \\
\hline Japan & 1,0 & 3,9 & 80,1 & $\mathrm{n}$ \\
\hline Korea $^{3}$ & 4,0 & 0,5 & 77,6 & $\mathrm{n}$ \\
\hline Luxemburg & $\mathrm{m}$ & $\mathrm{m}$ & $\mathrm{m}$ & $\mathrm{m}$ \\
\hline Mexiko & 1,0 & 0,1 & $\mathrm{~m}$ & $\mathrm{~m}$ \\
\hline Niederlande & 2,7 & 2,7 & 49,4 & 5,8 \\
\hline Neuseeland & 2,7 & 11,9 & 10,9 & 46,6 \\
\hline Norwegen & 7,1 & 1,0 & 25,6 & $\mathrm{n}$ \\
\hline Polen & 2,2 & 0,5 & 53,0 & $\mathrm{n}$ \\
\hline Portugal & 5,7 & 0,9 & 7,2 & 64,1 \\
\hline Slowakei & 14,1 & 0,3 & 61,3 & $\mathrm{n}$ \\
\hline Slowenien & 2,9 & 0,7 & 39,2 & 7,7 \\
\hline Spanien & 1,7 & 3,2 & 20,7 & 42,3 \\
\hline Schweden & 4,4 & 2,5 & 17,6 & 5,4 \\
\hline Schweiz & 5,3 & 4,9 & 50,2 & 54,6 \\
\hline Türkei ${ }^{3}$ & 2,1 & 0,4 & 29,9 & 9,5 \\
\hline Vereinigtes Königreich & 1,8 & 14,9 & 13,8 & 34,6 \\
\hline Vereinigte Staaten & 0,3 & 11,4 & 6,6 & 26,9 \\
\hline OECD insgesamt & 2,0 & 2,9 & 20,6 & 25,4 \\
\hline EU21 insgesamt & 3,6 & 2,7 & 23,3 & 26,7 \\
\hline \multicolumn{5}{|l|}{ Sonstige G20-Länder } \\
\hline Argentinien & 0,5 & 0,2 & $\mathrm{~m}$ & 73,5 \\
\hline Brasilien $^{3}$ & 0,5 & 0,4 & 25,9 & 27,4 \\
\hline China $^{3}$ & 2,3 & $\mathrm{~m}$ & $\mathrm{~m}$ & $\mathrm{~m}$ \\
\hline Indien & $\mathrm{m}$ & $\mathrm{m}$ & $\mathrm{m}$ & $\mathrm{m}$ \\
\hline Indonesien ${ }^{3}$ & 0,8 & $\mathrm{n}$ & $\mathrm{m}$ & $\mathrm{m}$ \\
\hline Russische Föderation ${ }^{3}$ & 0,8 & 2,4 & 60,3 & 37,2 \\
\hline Saudi-Arabien ${ }^{3}$ & 5,5 & 0,6 & 27,2 & 36,7 \\
\hline Südafrika ${ }^{3}$ & 1,5 & 6,6 & 47,1 & 51,3 \\
\hline
\end{tabular}

Anmerkung: Referenzjahr 2010 für Länder, die nicht OECD- bzw. G20-Land sind.

1. Als Nachbarländer gelten Länder, die gemeinsame Land- oder Seegrenzen mit dem Zielland haben. 2. Referenzjahr $2010 . \quad 3$. Inländische Studierende im Tertiärbereich werden berechnet als Gesamtzahl der Studierenden minus ausländische Studierende, nicht als Gesamtzahl minus internationale Studierende. Quelle: OECD. CIA World Factbook 2013 für Amtssprachen in den einzelnen Ländern. Hinweise s. Anhang 3 unter www.oecd.org/edu/eag.htm. StatLink: http://dx.doi.org/10.1787/888932850813

Erläuterung der Kennzeichnung fehlender Daten s. Hinweise für den Leser. 
Tabelle C4.6

Entwicklung der Zahl der eingeschriebenen ausländischen Studierenden, nach Zielregion und Herkunftsregion (2000 bis 2011)

Zahl eingeschriebener ausländischer Studierender (basierend auf Personenzahlen)

\begin{tabular}{|c|c|c|c|c|c|c|c|c|c|c|}
\hline \multirow{2}{*}{$\begin{array}{l}\text { In folgenden Zielregionen } \\
\text { eingeschriebene } \\
\text { ausländische Studierende }\end{array}$} & \multicolumn{5}{|c|}{ Zahl ausländischer Studierender } & \multicolumn{4}{|c|}{ Index der Veränderung (2010) } & \multirow{2}{*}{$\begin{array}{l}\text { In OECD-Ländern } \\
\text { eingeschriebene } \\
\text { ausländische } \\
\text { Studierende aus } \\
\text { folgenden Her- } \\
\text { kunftsregionen } \\
\text { (2011) }\end{array}$} \\
\hline & 2011 & 2010 & 2009 & 2005 & 2000 & $2010=100$ & $2009=100$ & $2005=100$ & $2000=100$ & \\
\hline Afrika & 176990 & 155293 & 147338 & 107851 & 99117 & 114 & 120 & 164 & 179 & 344784 \\
\hline Asien & 500947 & 486076 & 446055 & 322449 & 214744 & 103 & 112 & 155 & 233 & 1610203 \\
\hline Europa & 2033082 & 1968418 & 1665829 & 1388027 & 920140 & 104 & 122 & 146 & 221 & 916895 \\
\hline Nordamerika & 913464 & 880427 & 850966 & 738401 & 569640 & 104 & 107 & 124 & 160 & 102888 \\
\hline Lateinamerika und Karibik & 78760 & 77735 & 77546 & 39227 & 31058 & 101 & 102 & 201 & 254 & 209580 \\
\hline Ozeanien & 343298 & 350013 & 335305 & 251904 & 118646 & 98 & 102 & 136 & 289 & 26219 \\
\hline Weltweit & 4265579 & 4119002 & 3707756 & 2982588 & 2071963 & 104 & 115 & 143 & 206 & 3316209 \\
\hline OECD-Länder & 3283381 & 3181939 & 2838027 & 2373011 & 1588862 & 103 & 116 & 138 & 207 & 1053978 \\
\hline EU-Länder & 1734334 & 1686306 & 1413462 & 1201503 & 806286 & 103 & 123 & 144 & 215 & 736978 \\
\hline hiervon: in EU21-Ländern & 1695758 & 1647730 & 1378961 & 1174107 & 776672 & 103 & 124 & 144 & 218 & 623887 \\
\hline G20-Länder & 3550625 & 3418367 & 3040151 & 2488585 & 1718429 & 104 & 117 & 143 & 207 & 1659923 \\
\hline
\end{tabular}

Anmerkung: Diese Zahlen beruhen auf der Zahl ausländischer Studierender, die in OECD- und Nicht-OECD-Ländern eingeschrieben sind, die Daten an die OECD (Daten für 2011) und das Statistikinstitut der UNESCO (Daten für 2010) melden, um ein umfassendes Bild der weltweit eingeschriebenen ausländischen Studierenden zu vermitteln. Die Zahl der Länder, die Daten zur Verfügung stellen, hat im Laufe der Zeit zugenommen, daher wurden fehlende Zahlen gegebenenfalls berechnet, um die Vergleichbarkeit der Zeitreihen über die Jahre zu gewährleisten. Da einerseits Daten der UNESCO für Nicht-OECD-Länder berücksichtigt und andererseits fehlende Daten berechnet wurden, können die Schätzwerte der Zahl ausländischer Studierender von denen in früheren Ausgaben von Bildung auf einen Blick abweichen. Die Gesamtzahlen für die Jahre 2006 bis 2008 und 2001 bis 2004 sind im Internet verfügbar (s. StatLink unten).

Quelle: OECD und das Statistikinstitut der UNESCO für die meisten Daten zu Nicht-OECD-Ländern. Hinweise s. Anhang 3 unter www.oecd.org/edu/eag.htm.

StatLink: http://dx.doi.org/10.1787/888932850832

Erläuterung der Kennzeichnung fehlender Daten s. Hinweise für den Leser. 



\section{Der Übergang vom (Aus-)Bildungssystem zum Erwerbsleben: Wo sind die 15- bis 29-Jährigen?}

Während des Höhepunkts der Wirtschaftskrise sank im Durchschnitt der OECDLänder der Anteil der 15- bis 29-Jährigen, die nicht länger in Ausbildung, aber in Beschäftigung waren, von 4I Prozent (2008) auf 37 Prozent (20II).

20 II befanden sich im Durchschnitt der OECD-Länder I6 Prozent der I5- bis 29-Jährigen weder in Beschäftigung noch in einer Form der Ausbildung (diese Gruppe wird mit der englischen Abkürzung NEET bezeichnet - Not in employment, education or training).

Im Durchschnitt der OECD-Länder wollten fast 30 Prozent der I5- bis 29-Jährigen, die 201 I Teilzeit arbeiteten, gerne mehr arbeiten.

Abbildung C5.1

Anteil von Teilzeitbeschäftigung (TZ), unfreiwilliger Teilzeitbeschäftigung und Vollzeitbeschäftigung (VZ) unter 15- bis 29-Jährigen, die sich in Ausbildung bzw. nicht mehr in Ausbildung befinden (2011)

$\square$ Vollzeitbeschäftigt $\square$ Teilzeitbeschäftigt (ohne unfreiwillig teilzeitbeschäftigt) $\square$ Unfreiwillig teilzeitbeschäftigt

In Ausbildung
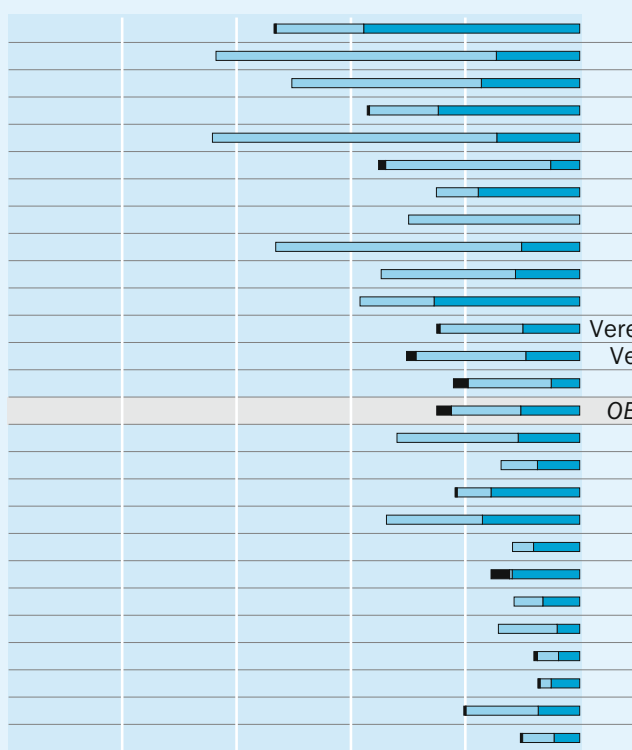

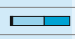

1

$\stackrel{\square}{\square+1}$
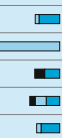

$\% 50$

40

30

20

10
Schweiz Niederlande $^{1}$ Australien $^{1}$ Österreich Dänemark ${ }^{1}$ Kanada Brasilien $^{1}$ Norwegen ${ }^{1}$ Island ${ }^{1}$

Neuseeland Deutschland reinigtes Königreich Schweden OECD-Durchschnit Finnland ${ }^{1}$ Mexiko ${ }^{1}$ Estland Slowenien ${ }^{1}$ Frankreich $^{1}$ Polen Luxemburg ${ }^{1}$ Irland ${ }^{1}$ Belgien Tschechien Israel Korea Chile Türkei $^{1}$ Spanien Slowakei $^{1}$ Japan $^{1,2}$ Griechenland Italien

Ungarn ${ }^{1}$

Nicht mehr in Ausbildung

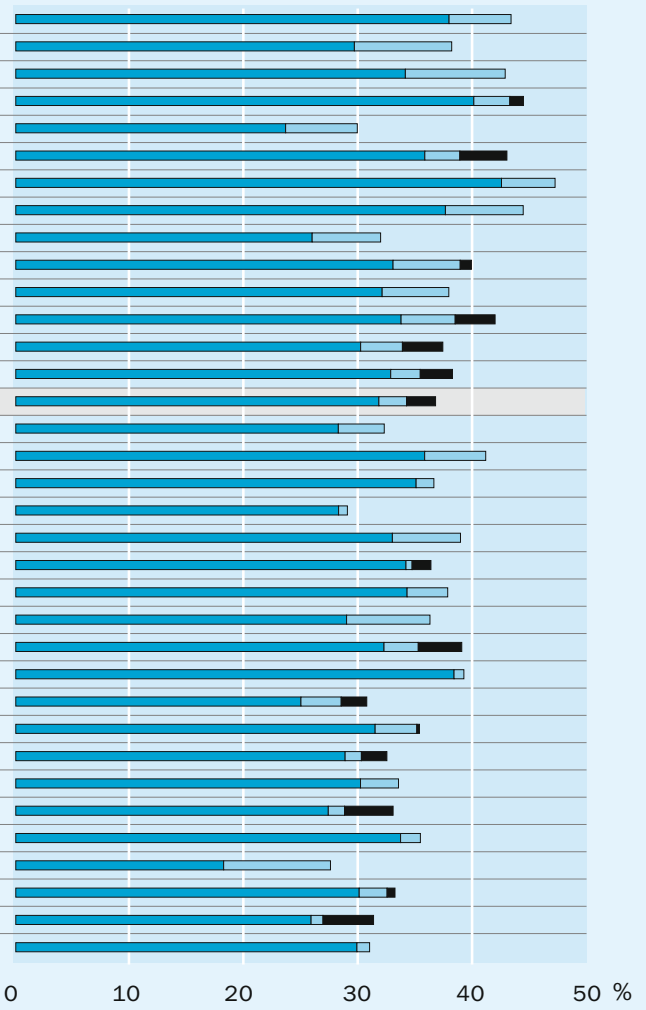

Anmerkung: In dieser Abbildung umfasst Teilzeit (TZ) auch unfreiwillige Teilzeit und unbekannt.

1. Es liegen keine Daten zu unfreiwilliger Teilzeitbeschäftigung vor. 2. Japan: Daten beziehen sich auf 15- bis 24-Jährige.

Anordnung der Länder in absteigender Reihenfolge der Gesamtbeschäftigung 15- bis 29-Jähriger.

Quelle: OECD. Tabelle C5.3a. Hinweise s. Anhang 3 unter www.oecd.ord/edu/eag.htm. StatLink: http://dx.doi.org/10.1787/888932847640 


\section{Kontext}

Die Länge und die Qualität der Schulausbildung des Einzelnen wirken sich ebenso auf den späteren Übergang von der Ausbildung in das Erwerbsleben aus wie die Arbeitsmarktbedingungen, das wirtschaftliche Umfeld und die demografischen Gegebenheiten. Auch nationale Gepflogenheiten spielen hier eine wichtige Rolle. So schließen beispielsweise junge Menschen in manchen Ländern in der Regel erst ihre Ausbildung ab und suchen dann einen Arbeitsplatz, während in anderen Ausbildung und Beschäftigung parallel stattfinden. In einigen Ländern gestaltet sich der Übergang von der (Aus-)Bildung in das Erwerbsleben bei Männern und Frauen recht ähnlich, während in anderen ein erheblicher Anteil der jungen Frauen sich nach dem Verlassen des Bildungssystems zunächst Vollzeit der Kindererziehung widmet und nicht in den Arbeitsmarkt eintritt.

Die Alterung der Bevölkerung in den OECD-Ländern sollte sich positiv auf die Beschäftigungslage junger Menschen in den OECD-Ländern auswirken, da - rein theoretisch - die Arbeitsplätze älterer Menschen, wenn sie den Arbeitsmarkt verlassen, den jungen Menschen zur Verfügung stehen. Während einer Rezession jedoch erschweren die hohen allgemeinen Erwerbslosenzahlen den Jüngeren den Übergang vom (Aus-)Bildungssystem zum Erwerbsleben erheblich, da erfahrene Arbeitskräfte den Berufsanfängern vorgezogen werden. Außerdem neigen junge Menschen bei ungünstiger Arbeitsmarktlage tendenziell dazu, ihre Ausbildung zu verlängern, da hohe Erwerbslosenquoten die Opportunitätskosten der Bildung/Ausbildung senken.

Um den Übergang junger Menschen vom Bildungssystem in Beschäftigung unabhängig von der jeweiligen konjunkturellen Lage zu erleichtern, sollte das (Aus-)Bildungssystem sicherstellen, dass die Absolventen mit den auf dem Arbeitsmarkt nachgefragten Kompetenzen ausgestattet werden und sich der Anteil der jungen Menschen, die sich weder in Ausbildung noch in Beschäftigung befinden, verringert. Unter diesen Umständen können öffentliche Investitionen in das Bildungssystem eine vernünftige Maßnahme zur Vermeidung von Erwerbslosigkeit und - durch den Aufbau nachgefragter Kompetenzen - eine Investition in künftiges Wirtschaftswachstum sein. Darüber hinaus könnten öffentliche Investitionen in Richtung potenzieller Arbeitgeber gelenkt werden, um als Anreiz für die Anstellung junger Menschen zu dienen.

\section{Weitere wichtige Ergebnisse}

Im Jahr 20II befanden sich in den OECD-Ländern im Durchschnitt 47 Prozent der 15- bis 29-Jährigen im Bildungssystem. Von den verbleibenden 53 Prozent waren 37 Prozent beschäftigt, 7 Prozent erwerbslos und g Prozent nicht im Arbeitsmarkt.

20 Ir konnten im Durchschnitt der OECD-Länder typische 15-Jährige davon ausgehen, ungefähr weitere 7,1 Jahre im formalen Bildungssystem zu verbleiben (gegenüber 6,8 Jahren 2007). Zusätzlich konnten sie damit rechnen, vor ihrem 30. Geburtstag für 5,6 Jahre beschäftigt, für insgesamt I Jahr erwerbslos und für I,4 Jahre nicht auf dem Arbeitsmarkt zu sein, d. h. weder in Ausbildung noch arbeitssuchend. 
15- bis 29-jährige Frauen hatten eine doppelt so hohe Wahrscheinlichkeit wie gleichaltrige Männer, nicht im Arbeitsmarkt zu sein. Während dieser Altersspanne konnte eine Frau erwarten, I,9 Jahre lang nicht zur Erwerbsbevölkerung zu gehören, gegenüber o,9 Jahren für einen Mann.

20II waren im Durchschnitt der OECD-Länder 14 Prozent der 25- bis 29-Jährigen ohne einen Abschluss im Sekundarbereich II erwerbslos, gegenüber 8 Prozent mit einem Abschluss im Sekundarbereich II oder dem postsekundaren, nicht tertiären Bereich und 6 Prozent mit einem Abschluss im Tertiärbereich.

\section{Entwicklungstendenzen}

Aufgrund der staatlichen Anstrengungen zur Anhebung des Bildungsstands kam es im Laufe der Jahre zu deutlichen Veränderungen bei der Bildungsteilnahme. 2000 befanden sich in den OECD-Ländern im Durchschnitt 4I Prozent der 15- bis 29-Jährigen im Bildungssystem, 20II war ihr Anteil auf 47 Prozent angestiegen (Tab. C5.4a).

Gleichzeitig fiel der Anteil der 15- bis 29-Jährigen, die nicht in Ausbildung, aber in Beschäftigung waren, von 44 Prozent auf 37 Prozent. Obwohl der Prozentsatz derjenigen in Ausbildung von 2000 bis 201 I ständig zunahm, gab es bei der Entwicklung der Beschäftigtenzahlen junger Erwachsener zwei große Einbrüche: das erste Mal zwischen 2000 und 2003 (-3,3 Prozentpunkte) und dann noch einmal zwischen 2008 und 20II (-3,7 Prozentpunkte). Diese Einbrüche der Beschäftigtenzahlen junger Erwachsener fielen mit dem Platzen der sogenannten „Internetblase“ (2000-2003) und der „Immobilienblase“ im Jahr 2008 zusammen. Der Anteil der I5- bis 29-Jährigen, die sich weder in Ausbildung noch in Beschäftigung befanden (NEET), blieb zwischen 2000 und 201 I mit rund 15 Prozent unverändert (Tab. C5.4a).

\section{Analyse und Interpretationen}

\section{Der Übergang vom Bildungssystem in das Erwerbsleben und die Krise} Der Übergang von der Ausbildung ins Erwerbsleben wird von der jeweiligen konjunkturellen Lage beeinflusst, was die jüngste Wirtschaftskrise deutlich gezeigt hat. 2000 befanden sich in den OECD-Ländern im Durchschnitt 44 Prozent der 15- bis 29-Jährigen nicht in Ausbildung, waren aber beschäftigt. Im Jahr 2008 ging dieser Anteil auf 4I Prozent zurück und sank im Jahr 20II auf 37 Prozent. Der Anteil derjenigen, die sich weder in Ausbildung noch in Beschäftigung befanden, verändert sich dagegen nur geringfügig von I5 Prozent im Jahr 2000 auf I4 Prozent 2008 und I6 Prozent im Jahr 20II (Tab. C5.4a).

Die Verschlechterung der Arbeitsmarktlage zwischen 2008 und 20II wirkte sich unterschiedlich auf die Altersgruppe der 15- bis I9-Jährigen und der 25- bis 29-Jährigen aus. 20II befand sich die große Mehrzahl der I5- bis I9-Jährigen (im Durchschnitt der OECD-Länder rund 86 Prozent) noch in Ausbildung, das waren 2 Prozentpunkte mehr als 2008. Dieser Anstieg des Anteils I5- bis I9-Jähriger in Ausbildung geschah parallel zu einem Rückgang von 2 Prozentpunkten des Anteils 15- bis I9-Jähriger, die sich in 
Beschäftigung und nicht in Ausbildung befanden. Während des gleichen Zeitraums fiel der Anteil der 15- bis I9-Jährigen, die sich nicht in Ausbildung, aber in Beschäftigung befanden, von 8,5 Prozent (2008) auf 6,2 Prozent (20II). Der Anteil derjenigen, die sich weder in Ausbildung noch in Beschäftigung befanden, blieb dagegen unverändert bei ungefähr 8 Prozent. Bei den 25- bis 29-Jährigen stieg im Durchschnitt der OECDLänder der Anteil derjenigen, die sich in Ausbildung befanden, von I4 Prozent im Jahr 2008 auf I6 Prozent im Jahr 20II, während die Beschäftigungsquote derjenigen, die sich nicht in Ausbildung befanden, im gleichen Zeitraum von 68 Prozent auf 64 Prozent zurückging. Dieser Rückgang bei den Beschäftigungsquoten der 25- bis 29-Jährigen, die sich nicht in Ausbildung befanden, steht im Zusammenhang mit einem Anstieg um I Prozentpunkt bei dem Anteil der 25- bis 29-Jährigen, die sich in Ausbildung befanden (von I4,4 Prozent in 2008 auf I5 $_{5} 8$ Prozent in 20II), und einem Anstieg des Anteils der 25- bis 29-Jährigen, die sich weder in Ausbildung noch in Beschäftigung befanden, um 3 Prozentpunkte (von 17,4 Prozent in 2008 auf 20 Prozent in 20II) (Tab. C5.4a).

In Ländern mit dualen Ausbildungsgängen im Sekundarbereich II und postsekundaren, nicht tertiären Bereich gelang der Übergang vom Bildungssystem in das Beschäftigungssystem meist reibungsloser. Australien, Belgien, Deutschland, Italien, Österreich, die Schweiz, die Slowakei, Tschechien und das Vereinigte Königreich bieten in diesen Bildungsbereichen duale Ausbildungsgänge an, wobei die Beteiligung daran in Belgien und Italien etwas geringer ist (Tab. $\mathrm{C}_{5}$.2a).

Trenddaten lassen einige Anzeichen der Erholung oder zumindest Verbesserungen von 20 Io auf 20 I erkennen: 20 von 34 Ländern gaben einen Anstieg des Anteils der I5- bis 29-Jährigen an, die sich in Beschäftigung, aber nicht mehr in Ausbildung befanden. In Estland und Schweden lag dieser Anstieg bei über 3 Prozentpunkten. Jedoch werden erst die Daten für 2012 belegen, ob sich dieser positive Trend weiter fortgesetzt hat (Tab. C5.4a).

\section{Junge Menschen, die sich in Beschäftigung befinden (unabhängig davon, ob sie sich in Ausbildung oder nicht in Ausbildung befinden) Die 15- bis 29-Jährigen}

Bei steigenden Erwerbslosigkeitsquoten, normalerweise während Zeiten einer angespannten Wirtschaftslage, könnte es für Schüler/Studierende schwieriger werden, eine Arbeitsstelle zu finden. Im Jahr 20II waren in den OECD-Ländern im Durchschnitt II Prozent der I5- bis 29-Jährigen beschäftigt, während sie sich in Ausbildung befanden (Tab. C5.2a).

In einigen Ländern kommt es häufig vor, dass man während der Ausbildung auch einer Beschäftigung nachgeht, außerdem kann es auch eine Folge der Arbeitsmarktlage und der Struktur des Bildungssystems (z. B. der Verfügbarkeit von Bildungsangeboten im Bereich berufsbildende Bildungsgänge) sein. In Dänemark und den Niederlanden hatten mehr als 32 Prozent der 15- bis 29-Jährigen einen Arbeitsplatz, während sie sich gleichzeitig in Ausbildung befanden. Daher überstieg die Beschäftigungsquote für Schüler/Studierende in dieser Altersgruppe in diesen Ländern sogar bei den jüngsten Altersgruppen 50 Prozent (Tab. C5.2a). 
In Belgien, Griechenland, Italien, der Slowakei, Spanien, Tschechien und Ungarn waren weniger als 5 Prozent der sich in Ausbildung befindenden 15- bis 29-Jährigen gleichzeitig beschäftigt, das sind weniger als I2 Prozent aller Schüler/Studierenden (Tab. $\mathrm{C}_{5.2 \mathrm{~d}}$ im Internet). Indikator A6 enthält weitere Angaben zu den Erwerbseinkommen von Schülern und Studierenden.

\section{Die jüngste Altersgruppe: die 15- bis I9-Jährigen}

Da die Bildungsteilnahme im Sekundarbereich II im Laufe der Jahre zugenommen hat, ist inzwischen die Zahl der I5- bis I9-Jährigen, die sich nicht im Bildungssystem befinden, gesunken. Diejenigen, die sich weder in Beschäftigung noch in (Aus-)Bildung befinden, sind besonders gefährdet. Personen mit einer Ausbildung unterhalb des Sekundarbereichs II werden weniger wahrscheinlich an Fort- und Weiterbildungsmaßnahmen teilnehmen, sich im lebenslangen Lernen engagieren und haben schlechter bezahlte Arbeitsplätze als Absolventen des Sekundarbereichs II. Da sie niedrigere Erwerbseinkommen haben, zahlen sie weniger Steuern, was zu geringeren Einkommensteuereinnahmen führt (OECD, 20I2a). Sie werden auch eher von öffentlicher Unterstützung abhängen - obwohl sie in den meisten Ländern wenig oder keine Unterstützung durch die Sozialsysteme erhalten. Im Vergleich zu den älteren Altersgruppen ist bei ihnen die Wahrscheinlichkeit doppelt so hoch, die Arbeitsplatzsuche aufzugeben und den Anschluss an den Arbeitsmarkt völlig zu verlieren (Quintini et al., 2007).

\section{Abbildung C5.2}

Anteil 15- bis 19-Jähriger, die sich nicht in Ausbildung und nicht in Beschäftigung befinden bzw. nicht im Arbeitsmarkt sind (2011)

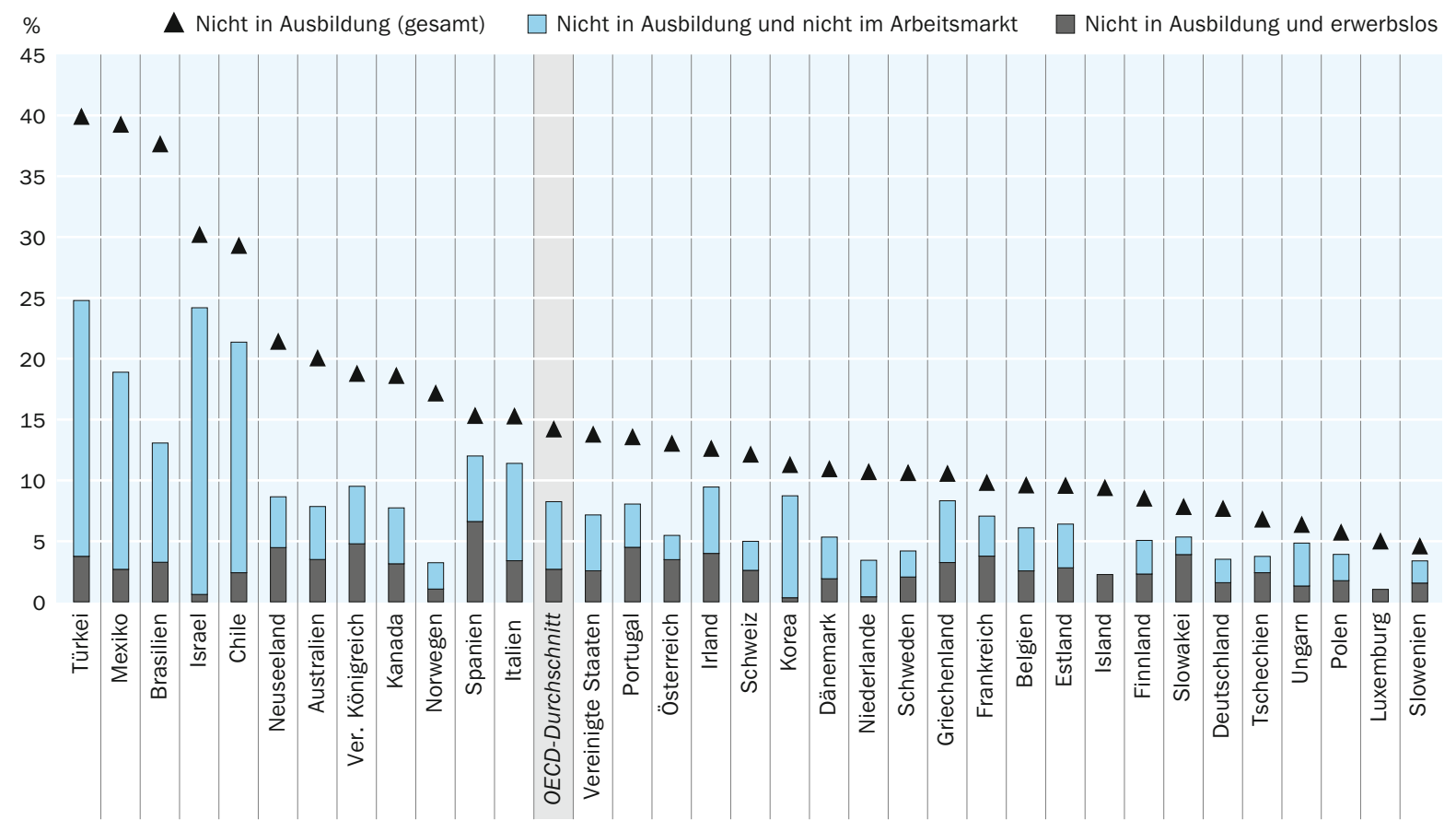


Die Beschäftigungsquote junger Menschen zwischen I5 und I9 Jahren ist in den einzelnen Ländern unterschiedlich. Wenn sich die Arbeitsmarktlage verschlechtert, spüren es junge Menschen am Übergang vom (Aus-)Bildungssystem zum Erwerbsleben meist am ehesten. Die Arbeitgeber besetzen die wenigen vorhandenen Arbeitsplätze eher mit erfahreneren Arbeitnehmern. Manchen Ländern gelingt es besser als anderen, 15- bis I9-Jährige in Beschäftigung zu bringen (dargestellt durch den Unterschied zwischen den Balken und den Dreiecken in Abb. C5.2). In Australien, Brasilien, Dänemark, Deutschland, Island, Kanada, Luxemburg, Mexiko, Neuseeland, den Niederlanden, Norwegen, Österreich, der Schweiz und Schweden ist jeder zweite junge Erwachsene, der sich nicht länger in Ausbildung befindet, in Beschäftigung. Dänemark und Island weisen trotz der Einbrüche zwischen 2008 und 20 II relativ hohe Beschäftigungsquoten

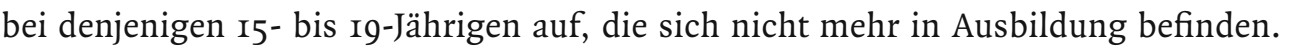
Dagegen ist in Griechenland, Israel (aufgrund des Wehrdienstes), Korea, Spanien und Ungarn weniger als einer von vier jungen Erwachsenen, die sich nicht mehr in Ausbildung befinden, erwerbstätig (Abb. $\mathrm{C}_{5.2}$ ).

\section{Junge Menschen, die weder beschäftigt sind noch einer Ausbildung nachgehen (NEET)}

Junge Erwachsene, die das Bildungssystem verlassen und auf eine schwierige Arbeitsmarktlage treffen, können erwerbslos sein oder völlig aus der Erwerbsbevölkerung ausscheiden. Erwerbslosen- und Beschäftigungsquoten sind hilfreiche Indikatoren dafür, wie junge Menschen auf dem Arbeitsmarkt zurechtkommen, aber bei diesen jungen Menschen ist die Wahrscheinlichkeit hoch, dass sie aus der Erwerbsbevölkerung ausscheiden und dann außerhalb des Arbeitsmarkts stehen (d. h. nicht beschäftigt sind und auch nicht aktiv nach einer Arbeitsstelle suchen; s. Abschnitt Definitionen am Ende des Indikators). Obwohl ein wachsender Anteil junger Menschen über die Schulpflicht hinaus im Bildungssystem verbleibt und daher auch als ,außerhalb des Arbeitsmarktes stehend" erfasst wird, wäre es irreführend, diese als eine stark gefährdete Gruppe anzusehen. Daher ist der Prozentsatz junger Menschen, die sich weder in Beschäftigung noch in (Aus-)Bildung befinden, eine bessere Kennzahl für die Probleme der jungen Menschen bei der Arbeitsplatzsuche, da sie nicht nur die nicht im Arbeitsmarkt stehenden, sondern auch die erwerbslosen jungen Menschen erfasst.

20 II befanden sich im Durchschnitt der OECD-Länder I6 Prozent der 15- bis 29-Jährigen weder in (Aus-)Bildung noch in Beschäftigung (7 Prozent waren erwerbslos und 9 Prozent nicht im Arbeitsmarkt), ebenso wie 8 Prozent der 15- bis I9-Jährigen (2,7 Prozent erwerbslos und 5,8 Prozent nicht im Arbeitsmarkt) und 20 Prozent der 25bis 29-Jährigen ( 8 Prozent erwerbslos und I2 Prozent nicht im Arbeitsmarkt). Bei den Angehörigen der NEET-Gruppe ist die Nichtteilnahme am Arbeitsmarkt ein größeres Problem als die Erwerbslosigkeit bei allen Altersgruppen. Die 6 Prozent I5- bis I9-Jährige, die nicht im Arbeitsmarkt waren, repräsentierten 40 Prozent der 15- bis I9-Jährigen, die sich nicht in Ausbildung befanden. Die I2 Prozent der 25- bis 29-Jährigen, die nicht im Arbeitsmarkt waren, repräsentierten I4 Prozent aller 25- bis 29-Jährigen, die sich nicht in Ausbildung befanden (Tab. C5.2d im Internet und Abb. C5.3). Von 2010 auf 201 I nahmen diese Anteile um jeweils 2 Prozentpunkte zu (OECD, 20I2b).

Sind viele junge Menschen weder in Ausbildung noch im Arbeitsmarkt, so kann dies einen konjunkturellen Abschwung widerspiegeln oder auf einen Bruch des traditio- 
Abbildung $\mathbf{C 5 . 3}$

Änderung des Anteils derjenigen, die sich weder in Ausbildung noch in Beschäftigung befinden (NEET), in den verschiedenen Altersgruppen (2011)

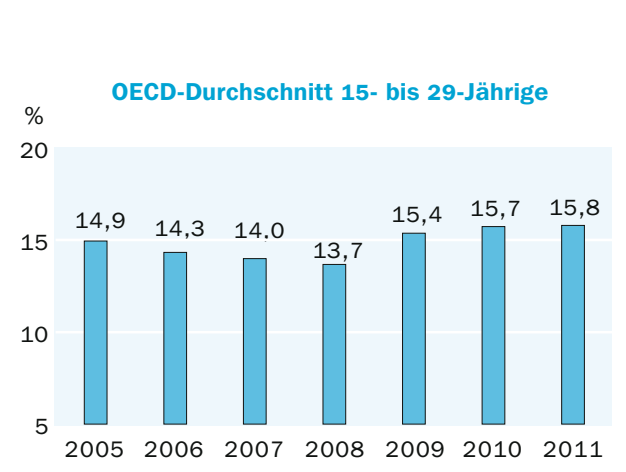

Anteil 15- bis 19-Jähriger, die sich 2008 und 2011 weder in Ausbildung noch in Beschäftigung befanden (in \%)
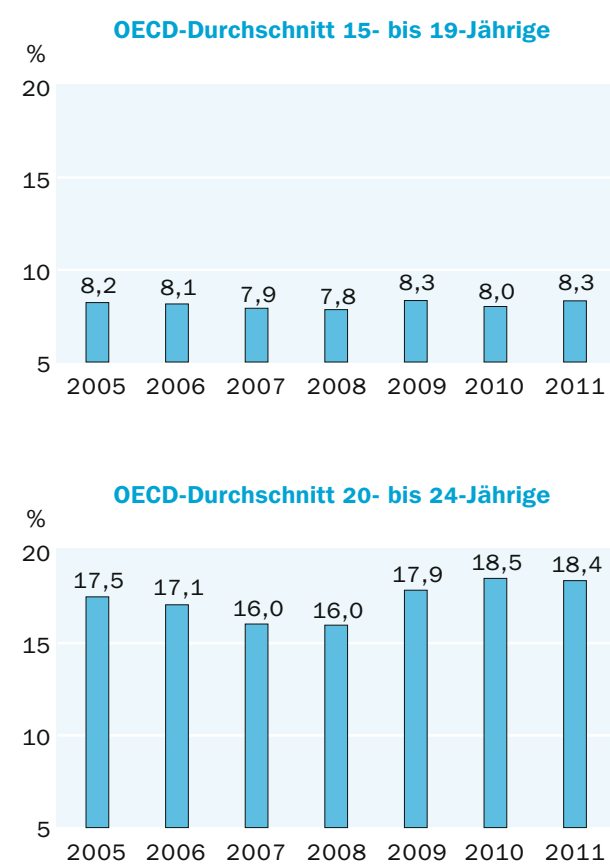

Veränderung zwischen 2008 und 2011 (in Prozentpunkten)

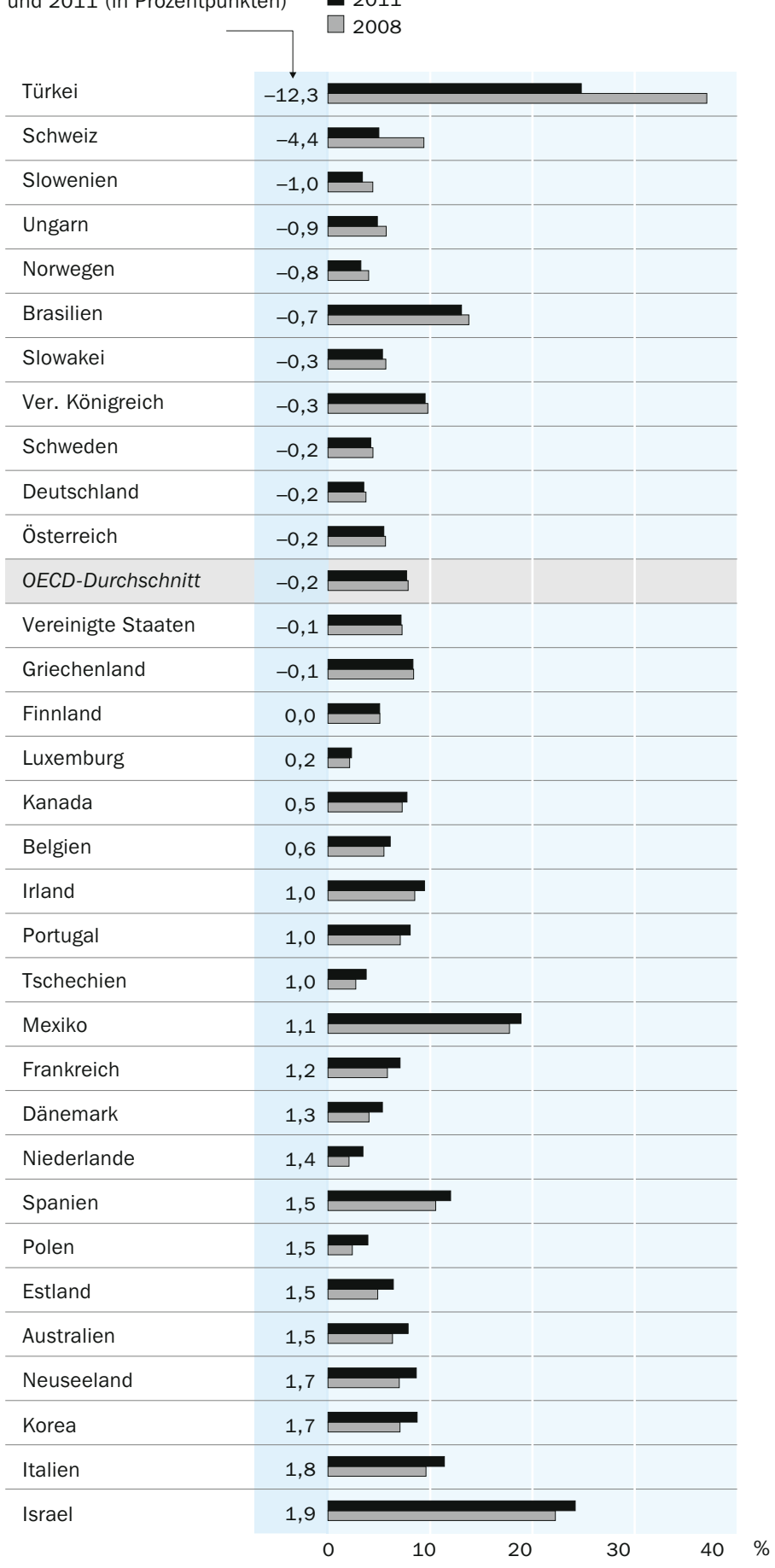


nellen Übergangs von der (Aus-)Bildung in das Erwerbsleben hinweisen. In einigen Ländern sehen die staatlichen Behörden die Gruppe der NEET mit Besorgnis, da junge Menschen, die sich weder in Ausbildung noch im Arbeitsmarkt befinden, ihren Platz potenziell eher im ,informellen Sektor“ finden, (d. h. in dem Teil der Wirtschaft, der im Gegensatz zum formalen Sektor, nicht der Besteuerung unterliegt, nicht auf irgendeine Weise staatlich überwacht wird oder in die Berechnung des Bruttosozialprodukts einfließt). Für die Angehörigen der NEET-Gruppe ist auch die Reintegration in den Arbeitsmarkt unwahrscheinlicher, häufig ergeben sich langfristige Folgen, die ihre künftigen Beschäftigungs- und Einkommenschancen beeinträchtigen, was wiederum auch den Verlust von Humankapital und Steuereinkommen für die Volkswirtschaften bedeuten kann. Zahlreiche Studien haben einen Zusammenhang zwischen Erwerbslosigkeit und schlechter psychischer Gesundheit, einschließlich Depressionen, nachgewiesen, was u. a. zu weiteren von der Gesellschaft zu tragenden Kosten führen kann (OECD, 2008).

Während der jüngsten Wirtschaftskrise ist die NEET-Gruppe gewachsen, da die Beschäftigungsquote bei den jungen Menschen und gering qualifizierten Arbeitskräften stark rückläufig war. Während die Erwerbslosenquoten vermutlich im Rahmen einer wirtschaftlichen Erholung sinken werden, wird es für die Regierungen schwieriger werden, diejenigen jungen Menschen in den Arbeitsmarkt zu integrieren, die sich vollständig aus dem Arbeitsmarkt zurückgezogen haben.

In Chile, Griechenland, Irland, Israel, Italien, Mexiko, Spanien und der Türkei waren $201 \mathrm{I}$ mehr als 20 Prozent der I5- bis 29-Jährigen weder in (Aus-)Bildung noch in Beschäftigung. In Griechenland und Spanien ist die Erwerbslosigkeit (mit I4,6 Prozent bzw. I7 Prozent) besonders besorgniserregend, das gilt gleichermaßen für die Nichterwerbsquote junger Menschen in diesen Ländern (7,I Prozent bzw. 7,5 Prozent). In Chile, Israel, Italien, Korea, Mexiko und der Türkei waren 201 I mehr als I5 Prozent der jungen Erwachsenen in dieser Altersgruppe nicht im Arbeitsmarkt und höchstens 8 Prozent erwerbslos.

Die Größe der NEET-Gruppe wird auch noch von anderen Faktoren beeinflusst. In Brasilien, Chile, Mexiko und der Türkei beispielsweise könnte der hohe Anteil der NEET auch Ausdruck der großen Anzahl von Frauen sein, die weder einer Ausbildung noch einer Beschäftigung nachgehen, da sie Hausfrauen und Mütter sind.

In Island, Luxemburg, den Niederlanden, Norwegen, Österreich, Schweden und der Schweiz waren weniger als Io Prozent der 15- bis 29-Jährigen weder in Ausbildung noch in Beschäftigung. In Island und Schweden ist Erwerbslosigkeit ein größeres Problem als die Nichtteilnahme am Arbeitsmarkt. In Luxemburg sind nahezu ebenso viel junge Menschen nicht im Arbeitsmarkt (3,7 Prozent) wie erwerbslos (3,6 Prozent), während in den Niederlanden, Norwegen, Österreich und der Schweiz die Nichtteilnahme am Arbeitsmarkt ein größeres Problem darstellt als die Erwerbslosigkeit (Tabelle $\left.\mathrm{C}_{5} \cdot 2 \mathrm{a}\right)$.

20II waren im Durchschnitt der OECD-Länder I8 Prozent der I5- bis 29-jährigen Frauen NEET (I2 Prozent nicht im Arbeitsmarkt und 6 Prozent erwerbslos) und I 3 Prozent der I5- bis 29-jährigen Männer (7 Prozent erwerbslos und 6 Prozent nicht im Arbeits-

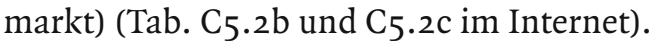




\section{Ein höherer Bildungsstand verringert die Erwerbslosenquote}

Im Durchschnitt reduziert ein Abschluss im Sekundarbereich II den Erwerbslosenanteil unter den sich nicht in Ausbildung befindenden 25- bis 29-Jährigen sehr stark. 20 II waren im Durchschnitt der OECD-Länder I4,o Prozent der 25- bis 29-Jährigen mit einem Abschluss unterhalb des Sekundarbereichs II erwerbslos, 7,9 Prozent derjenigen mit einem Abschluss im Sekundarbereich II und 6,5 Prozent derjenigen mit einem Abschluss im Tertiärbereich. Da der Abschluss eines Bildungsgangs im Sekundarbereich II inzwischen in den meisten OECD-Ländern zum Standard geworden ist (s. Indikator A2), haben junge Menschen, die keinen Abschluss in diesem Bereich erlangen, beim Eintritt in den Arbeitsmarkt eher Schwierigkeiten, eine Beschäftigung zu finden. In Irland, der Slowakei und Spanien beläuft sich der Anteil der 25- bis 29-Jährigen, die über keinen Abschluss im Sekundarbereich II verfügen und sich nicht in Ausbildung oder Beschäftigung befinden, auf mindestens 25 Prozent (Tab. C5.5b im Internet).

Mit zunehmendem Bildungsstand nimmt die Häufigkeit von Langzeiterwerbslosigkeit ab. Im Durchschnitt aller OECD-Länder beläuft sich der Anteil der 25- bis 29-Jährigen, die sich nicht in Ausbildung befinden und länger als sechs Monate erwerbslos waren, unter denjenigen mit einer Ausbildung unterhalb des Sekundarbereichs II auf 9, 3 Prozent, bei den Absolventen des Sekundarbereichs II auf 5 , I Prozent und bei den Absolventen des Tertiärbereichs auf 3,7 Prozent (Tab. C5.5 im Internet).

\section{Vollzeit-, Teilzeit- und unfreiwillige Teilzeitbeschäftigung}

Teilzeit zu arbeiten ist gut, sofern dies freiwillig geschieht, aber von den I5 Ländern mit verfügbaren Daten zu unfreiwilliger Teilzeitbeschäftigung gaben Belgien, Chile, Italien, Kanada, Polen, Schweden und Spanien an, dass mehr als die Hälfte der jungen Menschen, die sich nicht länger in Ausbildung befinden und Teilzeit arbeiten, nur unfreiwillig einer Teilzeitbeschäftigung nachgehen (Tab. C5.3a). Wenn Teilzeitbeschäftigungen nur unfreiwillig ausgeübt werden, ist dies ein Zeichen dafür, dass Schwierigkeiten bestehen, eine Vollzeitbeschäftigung zu finden, außerdem deutet es darauf hin, dass diese Beschäftigungen als prekär einzustufen sind. Teilzeitbeschäftigte werden nur langsamer als Vollzeitbeschäftigte auf der Erfahrungs- und Gehaltsskala nach oben steigen. Dadurch wird es für die Einzelnen potenziell schwieriger, sowohl beim Gehalt als auch bei der Position im Vergleich zu Vollzeitbeschäftigten „aufzuholen“ (OECD, 2010).

Die Arbeitsplatzqualität scheint für viele junge Beschäftigte ein Problem zu sein. Im Jahr 20II arbeiteten 5 Prozent der 15 - bis 29-Jährigen, die nicht mehr in Ausbildung waren, Teilzeit und 32 Prozent Vollzeit. In Australien, Belgien, Dänemark, Frankreich, Irland, Island, Kanada, Neuseeland, den Niederlanden, Norwegen, dem Vereinigten Königreich und den Vereinigten Staaten gingen zwischen 6 Prozent und fast Io Prozent der 15- bis 29-Jährigen nach Ende der Ausbildung einer Teilzeitbeschäftigung nach (Tab. C5·7).

Viele junge Menschen, die Teilzeit arbeiten, würden gerne mehr arbeiten. Im Durchschnitt der 17 Länder, die Angaben zu unfreiwilliger Teilzeitbeschäftigung machten oder zu Menschen, die gerne mehr arbeiten möchten und für Mehrarbeit zur Verfügung stehen, sind rund ein Drittel der I5- bis 29-Jährigen unterbeschäftigte Teilzeitarbeitskräfte. Dieser Anteil variiert jedoch von weniger als ro Prozent in Estland, Korea, Neuseeland, der Schweiz und Tschechien bis zu fast 6o Prozent in Chile und Spanien, 
Abbildung C5.4

Anteil der 15- bis 29-jährigen unfreiwillig Teilzeitbeschäftigten an der Gesamtzahl der Teilzeitbeschäftigten (2011) und Veränderung des Anteils der Teilzeitbeschäftigten (2008-2011)

Teilzeit (nicht in Ausbildung) (in \%)

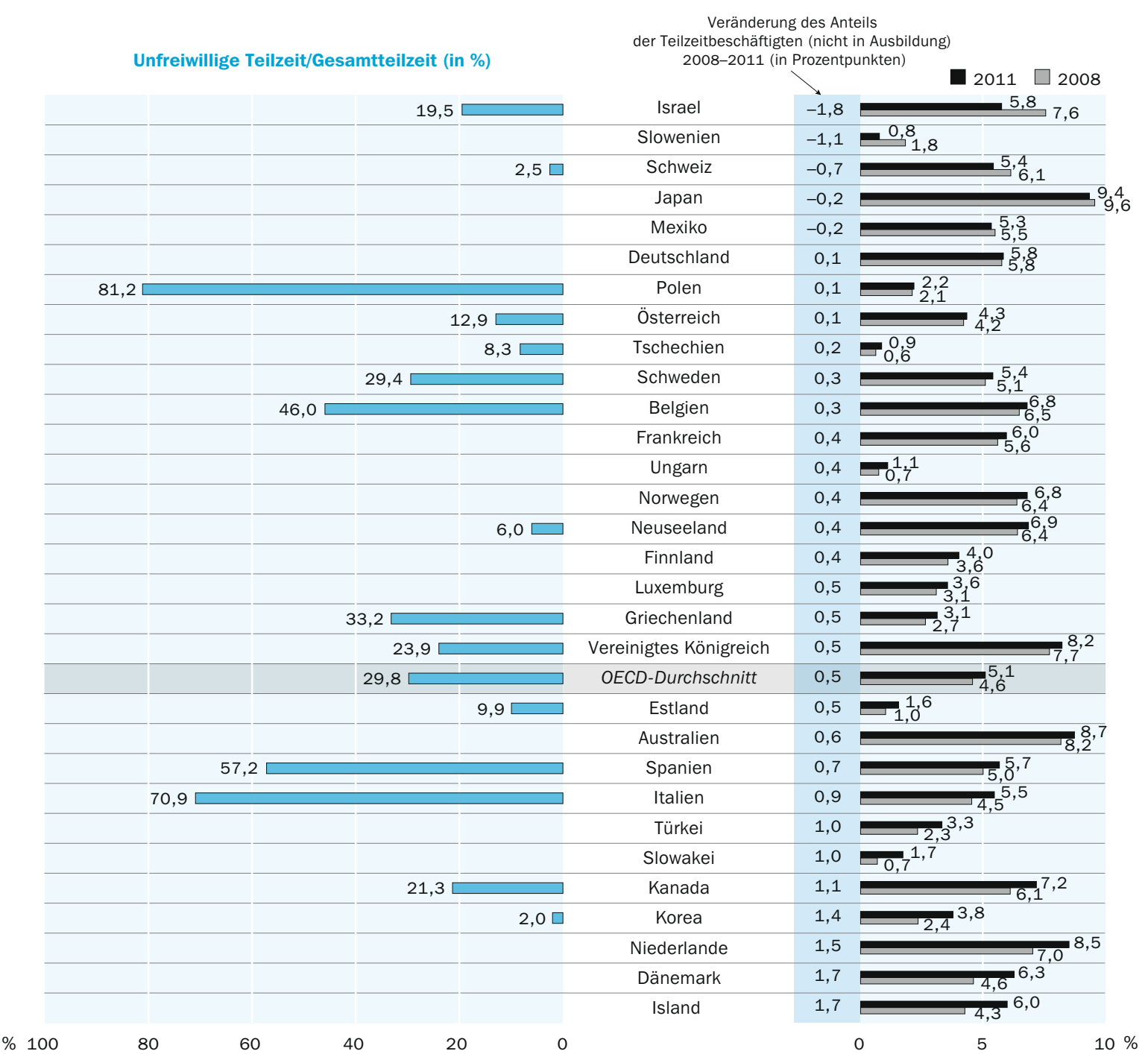

Anordnung der Länder in aufsteigender Reihenfolge der Veränderung des Anteils der Teilzeitbeschäftigten unter den 15- bis 29-Jährigen, die sich nicht mehr in Ausbildung befinden, zwischen 2008 und 2011 (in Prozentpunkten).

Quelle: OECD. Tabelle C5.7. Hinweise s. Anhang 3 unter www.oecd.org/edu/eag.htm. StatLink: http://dx.doi.org/10.1787/888932847697

70 Prozent in Italien und mehr als 8o Prozent in Polen. Eine Korrelation zwischen der Unterbeschäftigung von Teilzeitarbeitskräften und der Anzahl der Teilzeitarbeitskräfte bzw. der Entwicklung dieser Anzahl ist nicht zu erkennen (Abb. C5.4). Laut CEDEFOP ist in Bezug auf die Mitgliedstaaten der EU im Vergleich zu 2008 der Anteil junger Menschen, die Teilzeit arbeiten, obwohl sie lieber Vollzeit arbeiten würden, in allen EU-Ländern mit Ausnahme Deutschlands, wo deren Anteil nahezu unverändert blieb, angestiegen (CEDEFOP, 20I2).

Ein höherer Bildungsstand verbessert die wirtschaftlichen Chancen junger Menschen, aber die weltweite Verschlechterung der Konjunktur in den letzten Jahren hat es ihnen 
schwer gemacht, einen Arbeitsplatz zu finden. Im Durchschnitt der OECD-Länder nahm 2011 der Anteil der 15- bis 29-Jährigen, die sich nicht mehr in Ausbildung befanden und Teilzeit arbeiteten, mit zunehmendem Bildungsstand zu: 3 Prozent bei denjenigen mit einer Ausbildung unterhalb des Sekundarbereichs II, 6 Prozent bei Absolventen des Sekundarbereichs II und 7 Prozent bei Absolventen des Tertiärbereichs. Da mit einem höheren Bildungsabschluss die Wahrscheinlichkeit zunimmt, erwerbstätig zu sein, sinkt jedoch mit zunehmendem Bildungsstand der relative Anteil der Teilzeitbeschäftigten: II Prozent der beschäftigten 15- bis 29-Jährigen mit einem Abschluss im Tertiärbereich, die sich nicht länger in Ausbildung befinden, gehen einer Teilzeitbeschäftigung nach (7,3 Prozent von 63,6 Prozent), während dies bei I 8 Prozent der beschäftigten I5- bis 29-Jährigen mit einer Ausbildung unterhalb des Sekundarbereichs II, die sich nicht mehr in Ausbildung befinden, der Fall ist (3,I Prozent von I6,7 Prozent). Auch der relative Anteil unfreiwilliger Teilzeitbeschäftigung sinkt mit zunehmendem Bildungsstand: 6 Prozent der 15- bis 29-Jährigen mit einem Abschluss im Tertiärbereich, die sich nicht länger in Ausbildung befinden, gehen unfreiwillig einer Teilzeitbeschäftigung nach (3,9 Prozent von 63,6 Prozent), während dies bei 9 Prozent der beschäftigten 15 - bis 29-Jährigen mit einer Ausbildung unterhalb des Sekundarbereichs II, die sich nicht mehr in Ausbildung befinden, der Fall ist (I, 5 Prozent von $\mathrm{i} 6,7$ Prozent) (Tabelle $\mathrm{C}_{5} \cdot 6$ ).

Bei jungen Teilzeitbeschäftigten, die sich nicht länger in Ausbildung befinden, findet sich ein signifikant hoher geschlechtsspezifischer Unterschied (OECD, 2012c). 20II hatten im Durchschnitt der 34 OECD-Länder 15- bis 29-jährige Frauen eine doppelt so hohe Wahrscheinlichkeit wie Männer der gleichen Altersgruppe (6 Prozent gegenüber 3 Prozent), teilzeitbeschäftigt zu sein, wenn man sich nicht mehr in Ausbildung befand. Bei den 17 Ländern, die Angaben zu unfreiwilliger Teilzeit machten, war der Anteil junger Frauen, die unfreiwillig Teilzeit arbeiteten, höher als der junger Männer (3 Prozent gegenüber 2 Prozent). Als Teil der gesamten Teilzeitbeschäftigung nach Geschlecht jedoch war der Anteil unfreiwilliger Teilzeit bei den Männern höher als bei den Frauen. Männer arbeiten eher nicht Teilzeit, und wenn sie es doch tun, dann eher nicht aufgrund ihrer eigenen Entscheidung (Tab. $\mathrm{C}_{5} \cdot 3 \mathrm{~b}$ und $\mathrm{C}_{5 \cdot 3 \mathrm{C}}$ im Internet).

\section{Zu erwartende Jahre in Ausbildung}

Im Durchschnitt der OECD-Länder sind im Jahr $201 \mathrm{I}$ junge Menschen im Zeitraum zwischen ihrem 15. und 29. Geburtstag 7 Jahre in Ausbildung und fast 8 Jahre nicht in Ausbildung gewesen (Tab. C5.ra).

In den meisten OECD-Ländern ist die Bildungspolitik bemüht, junge Menschen zumindest zu einem Abschluss im Sekundarbereich II zu ermutigen. Das Ergebnis dieser Bemühungen lässt sich an der Bildungsteilnahme junger Menschen auch nach Ablauf der Schulpflicht ablesen. Außerdem hat sich die durchschnittliche Gesamtzahl der nach der Schulpflicht zu erwartenden Jahre in formaler Ausbildung im Laufe der letzten Io Jahre stark geändert (Tab. $\mathrm{C}_{5} \cdot 4 \mathrm{a}$ ).

20II haben in allen Ländern, außer in Chile, Deutschland, Irland, Japan, Korea, Luxemburg, Mexiko, den Niederlanden, der Schweiz und der Türkei, junge Frauen mehr Jahre in Ausbildung verbracht als junge Männer. Nur in Brasilien werden junge Frauen wahrscheinlich genauso viele Jahre in Ausbildung verbringen wie junge Männer (5 Jah- 
re). In der Slowakei und Slowenien können junge Frauen mit fast einem Jahr mehr Ausbildung rechnen als gleichaltrige junge Männer. Im Durchschnitt können I5- bis 29-jährige Männer davon ausgehen, 7 Jahre im Bildungssystem zu verbleiben, 6 Jahre in Beschäftigung, I Jahr erwerbslos und fast I Jahr nicht im Arbeitsmarkt zu sein. I5bis 29-jährige Frauen können davon ausgehen, 7 Jahre in Ausbildung zu sein, 5 Jahre erwerbstätig, weniger als I Jahr erwerbslos und fast 2 Jahre nicht im Arbeitsmarkt (Tab. $\mathrm{C}_{5}$.rb und $\mathrm{C}_{5}$.Ic im Internet).

\section{Definitionen}

Die Kategorie Beschäftigte umfasst Personen, die sich entsprechend der ILO-Definition in Beschäftigung befinden, hierbei ausgenommen wurden jedoch die Auszubildenden in dualen beruflichen Ausbildungsgängen, die schon gezählt wurden. Weitere Erläuterungen siehe Indikator A5 und Anhang 3.

Die Kategorie Vollzeitbeschäftigte umfasst Personen, die üblicherweise mindestens 30 Wochenstunden in ihrer Hauptbeschäftigung tätig sind. In einigen Ländern gelten Grenzwerte zwischen 30 und 36 Wochenstunden, andere verwenden einen selbst definierten Vollzeitstatus. Weitere Erläuterungen siehe Indikator A6 und Anhang 3.

Die Kategorie nicht im Arbeitsmarkt umfasst Personen, die weder beschäftigt noch erwerbslos sind, d. h. diejenigen, die nicht arbeitssuchend sind. Weitere Erläuterungen siehe Indikator A5 und Anhang 3.

NEET: Junge Menschen, die weder beschäftigt sind noch einer Ausbildung nachgehen.

Die Kategorie Teilzeit ist aufgeteilt in freiwillige Teilzeit, unfreiwillige Teilzeit und unbekannt. Unfreiwillige Teilzeit umfasst die nachfolgenden drei in Arbeitskräfteerhebungen erfassten Kategorien: Personen, die üblicherweise eine Vollzeitbeschäftigung ausüben, aber während der Erhebungswoche aus ökonomischen Gründen weniger Wochenstunden als üblich arbeiteten, unabhängig davon, wie viele Stunden sie weniger arbeiteten, bzw. Personen, die aus ökonomischen Gründen Teilzeit arbeiteten, Personen, die normalerweise Teilzeit arbeiten, weil sie keine Vollzeitstelle finden können, und Personen, die aus anderen Gründen Teilzeit arbeiten und die während der Erhebungswoche aus ökonomischen Gründen weniger als sonst üblich arbeiteten. Unfreiwillige Teilzeit umfasst auch Personen, die nicht notwendigerweise Vollzeit arbeiten wollen, sondern nur mehr Stunden.

Erwerbslose werden definiert als Personen, die während der Erhebungswoche nicht erwerbstätig waren (d. h. die weder eine Arbeit hatten noch wenigstens eine Stunde oder mehr abhängig beschäftigt oder selbstständig tätig waren), aktiv Arbeit suchten (d. h., die in den vier Wochen vor der Erhebungswoche gezielte Schritte unternommen hatten, um eine bezahlte Arbeitsstelle zu finden bzw. sich selbstständig zu machen) und dem Arbeitsmarkt zur Verfügung stehen (d. h. spätestens zwei Wochen nach der Erhebungswoche eine entgeltliche abhängige oder selbstständige Tätigkeit aufnehmen konnten). Weitere Erläuterungen siehe Indikator A5 und Anhang 3. 


\section{Angewandte Methodik}

Die Daten für diesen Indikator wurden im Rahmen der jährlichen OECD-Arbeitskräfteerhebung erhoben (die Daten bestimmter europäischer Länder stammen aus der jährlichen Europäischen Arbeitskräfteerhebung, s. Anhang 3) und beziehen sich normalerweise auf das erste Quartal oder den Durchschnitt der ersten drei Monate des Kalenderjahres, wodurch auf die Sommermonate beschränkte Beschäftigung unberücksichtigt bleibt.

Die erhobenen Daten können durchaus Unterschiede aufweisen. Einige Länder erfassen beispielsweise alle Beschäftigungsverhältnisse anstelle des Hauptbeschäftigungsverhältnisses, oder Teilzeitbeschäftigung bezieht sich auf weniger als 35 Wochenstunden anstelle von 30 Stunden. Einzelheiten zum Erhebungsbereich der unfreiwilligen Teilzeitbeschäftigung finden sich in Anhang 3.

Die statistischen Daten für Israel wurden von den zuständigen israelischen Stellen bereitgestellt, die für sie verantwortlich zeichnen. Die Verwendung dieser Daten durch die OECD erfolgt unbeschadet des völkerrechtlichen Status der Golanhöhen, von OstJerusalem und der israelischen Siedlungen im Westjordanland.

\section{Weiterführende Informationen}

CEDEFOP (2012), „Crisis Pushes Young People towards Involuntary Part-Time Jobs“, www.cedefop.europa.eu/EN/articles/19357.aspx.

OECD (2008), „Mental Health in OECD Countries“, OECD Policy Brief, November 2008, www.oecd.org/els/health-systems/41686440.pdf.

OECD (2009), Economic Surveys: Slovenia, OECD Publishing. http:/|dx.doi.org/10.1787/ eco_surveys-sun-200g-en.

OECD (2010), „How Good is Part-Time Work?“, in Employment Outlook 2010: Moving Beyond the Jobs Crisis, OECD Publishing (www.oecd.org/els/emp/48806797.pdf), http://dx.doi. org/10.1787/empl_outlook-2010-en.

OECD (2012a), Equity and Quality in Education: Supporting Disadvantaged Students and Schools, OECD Publishing, http://dx.doi.org/10.1787/9789264130852-en.

OECD (20I2b), Bildung auf einen Blick 2012 - OECD-Indikatoren, W. Bertelsmann Verlag, Bielefeld.

OECD (2012c), „Gender Equality in Education, Employment and Entrepreneurship: Final Report to the MCM 2012", Meeting of the OECD Council at Ministerial Level, Paris, 23-24 May 20I2, C/MIN (20I2) 5, www.oecd.org/social/family/50423364.pdf. 
Quintini, G., J. Martin and S. Martin (2007), „The Changing Nature of the School-toWork Transition Process in OECD Countries“, IZA Discussion Paper No. 2582, January 2007.

\section{Tabellen Indikator C5}

Tabelle $\mathrm{C}_{5}$.ra: Zu erwartende Jahre in Ausbildung und nicht in Ausbildung für I5- bis 29-Jährige, nach Erwerbsstatus (20II)

StatLink: http:|/dx.doi.org/10.1787/888932850889

WEB Table C5.Ib: Expected years in education and not in education for $15-29$ yearold men, by work status (Zu erwartende Jahre in Ausbildung und nicht in Ausbildung für I5- bis 29-jährige Männer, nach Erwerbsstatus) (20II) StatLink: http:||dx.doi.org/10.1787/888932850908

WEB Table C5.Ic: Expected years in education and not in education for $15-29$ yearold women, by work status ( $\mathrm{Zu}$ erwartende Jahre in Ausbildung und nicht in Ausbildung für I5- bis 29-jährige Frauen, nach Erwerbsstatus) (20II) StatLink: http://dx.doi.org/10.1787/888932850927

WEB Table C5.Id: Trends in expected years in education and not in education for I5-29 year-olds, by gender (Entwicklung der zu erwartenden Jahre in Ausbildung und nicht in Ausbildung für I5- bis 29-Jährige, nach Geschlecht) (1999-20II) StatLink: http://dx.doi.org/10.1787/888932850946

Tabelle C5.2a: Anteil I5- bis 29-Jähriger (in \%), die sich in Ausbildung bzw. nicht in Ausbildung befinden, nach Erwerbsstatus, einschließlich Dauer der Erwerbslosigkeit (20II)

StatLink: http://dx.doi.org/10.1787/888932850965

WEB Table $\mathrm{C}_{5} .2 \mathrm{~b}$ : Percentage of $\mathrm{I}_{5-29}$ year-old men in education and not in education, by work status, including duration of unemployment (Anteil I5- bis 29-jähriger Männer [in \%], die sich in Ausbildung bzw. nicht in Ausbildung befinden, nach Erwerbsstatus, einschließlich Dauer der Erwerbslosigkeit) (20II) StatLink: http://dx.doi.org/10.1787/888932850984

WEB Table C5.2c: Percentage of $15-29$ year-old women in education and not in education, by work status, including duration of unemployment (Anteil I5- bis 29-jähriger Frauen [in \%], die sich in Ausbildung bzw. nicht in Ausbildung befinden, nach Erwerbsstatus, einschließlich Dauer der Erwerbslosigkeit) (20II) StatLink: http:||dx.doi.org/10.1787/888932851003

WEB Table C5.2d: Percentage of young people in education and not in education, by age group and work status, including duration of unemployment (Anteil junger Menschen [in \%], die sich in Ausbildung bzw. nicht in Ausbildung befinden, nach Altersgruppe und Erwerbsstatus, einschließlich Dauer der Erwerbslosigkeit) (20II) StatLink: http:/|dx.doi.org/10.1787/888932851022 
Tabelle C5.3a: Anteil 15- bis 29-Jähriger (in \%), die sich in Ausbildung bzw. nicht in Ausbildung befinden, nach Erwerbsstatus, einschließlich Teilzeitbeschäftigten (20II)

StatLink: http:/|dx.doi.org/10.1787/888932851041

WEB Table $\mathrm{C}_{5} \cdot 3 \mathrm{~b}$ : Percentage of $15-29$ year-olds young men in education and not in education, by work status, including part-time workers (Anteil I5- bis 29-jähriger Männer [in \%], die sich in Ausbildung bzw. nicht in Ausbildung befinden, nach Erwerbsstatus, einschließlich Teilzeitbeschäftigten) (20II)

StatLink: http://dx.doi.org/10.1787/888932851060

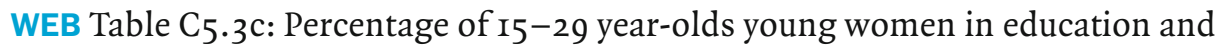
not in education, by work status, including part-time workers (Anteil I5-bis 29-jähriger Frauen [in \%], die sich in Ausbildung bzw. nicht in Ausbildung befinden, nach Erwerbsstatus, einschließlich Teilzeitbeschäftigten) (20II) StatLink: http:||dx.doi.org/10.1787/888932851079

WEB Table $\mathrm{C}_{5} \cdot 3 \mathrm{~d}$ : Percentage of young people in education and not in education, by 5 -year age group and work status, including part-time workers (Anteil junger Menschen [in \%], die sich in Ausbildung bzw. nicht in Ausbildung befinden, nach Altersgruppen von 5 Jahren und Erwerbsstatus, einschließlich Teilzeitbeschäftigten) (20II)

StatLink: http://dx.doi.org/10.1787/888932851098

Tabelle $\mathrm{C}_{5.4 \mathrm{a}}$ : Entwicklung des Anteils junger Menschen (in \%), die sich in Ausbildung und nicht in Ausbildung befinden (beschäftigt oder nicht beschäftigt), nach Altersgruppe (I997-20II)

StatLink: http:/|dx.doi.org/10.1787/888932851117

WEB Table $\mathrm{C}_{5.4 \mathrm{~b}}$ : Trends in the percentage of young men in education and not in education, employed or not, by 5-year age group (Entwicklung des Anteils junger Männer [in \%], die sich in Ausbildung bzw. nicht in Ausbildung befinden [beschäftigt oder nicht beschäftigt], nach Altersgruppen von 5 Jahren) (I997-20II) StatLink: http:|/dx.doi.org/10.1787/888932851136

WEB Table $\mathrm{C}_{5.4 \mathrm{C}}$ : Trends in the percentage of young women in education and not in education, employed or not, by 5-year age group (Entwicklung des Anteils junger Frauen [in \%], die sich in Ausbildung bzw. nicht in Ausbildung befinden [beschäftigt oder nicht beschäftigt], nach Altersgruppen von 5 Jahren)

(I997-20II)

StatLink: http:/|dx.doi.org/10.1787/888932851155

WEB Table C5.4d: Trends in the percentage of $15-29$ year-olds in education and not in education, employed or not, by educational attainment (Entwicklung des Anteils 15- bis 29-Jähriger [in \%], die sich in Ausbildung bzw. nicht in Ausbildung befinden [beschäftigt oder nicht beschäftigt], nach Bildungsstand (2006-20II)

StatLink: http:|/dx.doi.org/10.1787/888932851174 
Tabelle C5.5a: Anteil 15- bis 29-Jähriger (in \%), die sich in Ausbildung bzw. nicht in Ausbildung befinden, nach Bildungsstand und Erwerbsstatus, einschließlich Dauer der Erwerbslosigkeit (20II)

StatLink: http://dx.doi.org/10.1787/888932851193

WEB Table $\mathrm{C}_{5} \cdot 5 \mathrm{~b}$ : Percentage of $25-29$ year-olds in education and not in education, by educational attainment and work status (Anteil 25- bis 29-Jähriger [in \%], die sich in Ausbildung bzw. nicht in Ausbildung befinden, nach Bildungsstand und Erwerbsstatus) (20II)

StatLink: http:/|dx.doi.org/10.1787/888932851212

Tabelle $\mathrm{C}_{5} .6$ : Anteil I5- bis 29-Jähriger (in \%), die sich in Ausbildung bzw. nicht in Ausbildung befinden, nach Bildungsstand und Erwerbsstatus, einschließlich Teilzeitbeschäftigten (20II)

StatLink: http:||dx.doi.org/10.1787/888932851231

Tabelle C5.7: Entwicklung des Anteils I5- bis 29-Jähriger (in \%), die Vollzeit bzw. Teilzeit arbeiten und sich in Ausbildung bzw. nicht in Ausbildung befinden (2006-20II)

StatLink: http://dx.doi.org/10.1787/888932851250 
Tabelle C5.1a

Zu erwartende Jahre in Ausbildung und nicht in Ausbildung für 15- bis 29-Jährige, nach Erwerbsstatus (2011)

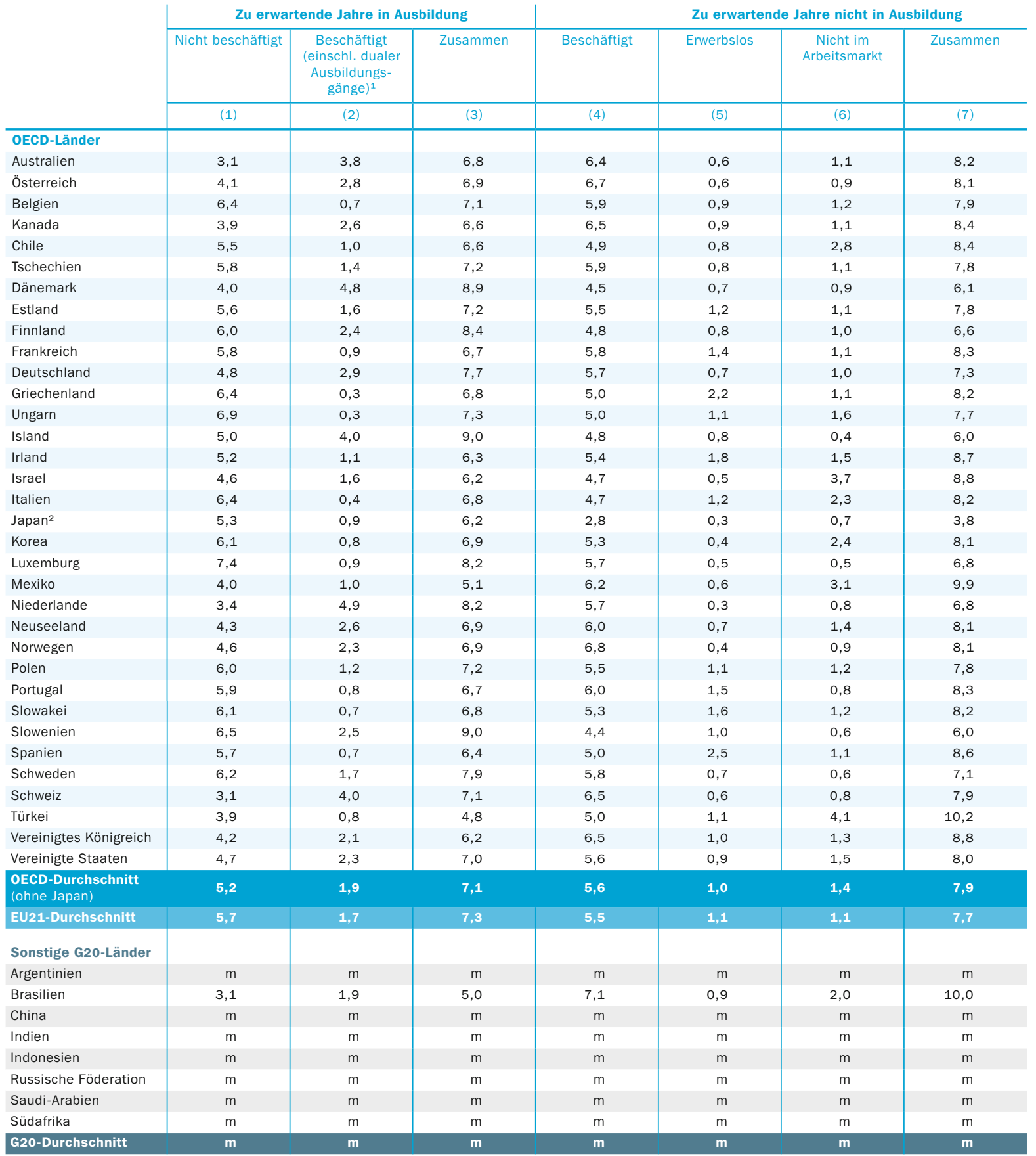

1. Teilnehmer an dualen Ausbildungsgängen gelten als sowohl in Ausbildung als auch beschäftigt, ohne Bezug auf ihren ILO-Erwerbsstatus. 2. Daten beziehen sich auf 15- bis 24-Jährige.

Quelle: OECD. Hinweise s. Anhang 3 unter www.oecd.org/edu/eag.htm. StatLink: http://dx.doi.org/10.1787/888932850889

Erläuterung der Kennzeichnung fehlender Daten s. Hinweise für den Leser. 
Anteil 15- bis 29-Jähriger (in \%), die sich in Ausbildung bzw. nicht in Ausbildung befinden, nach Erwerbsstatus, einschließlich Dauer der Erwerbslosigkeit (2011)

\begin{tabular}{|c|c|c|c|c|c|c|c|c|c|c|c|c|c|c|}
\hline & \multicolumn{6}{|c|}{ In Ausbildung } & \multicolumn{7}{|c|}{ Nicht in Ausbildung } & \multirow{3}{*}{ 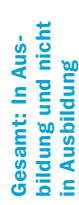 } \\
\hline & \multirow[b]{2}{*}{ 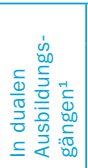 } & \multirow{2}{*}{ 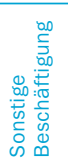 } & \multicolumn{2}{|c|}{ Erwerbslos } & \multirow[b]{2}{*}{ 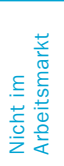 } & \multirow[b]{2}{*}{ 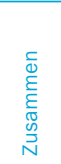 } & \multirow[b]{2}{*}{ 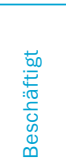 } & \multirow[b]{2}{*}{ 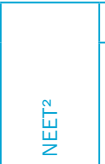 } & \multicolumn{3}{|c|}{ Erwerbslos } & \multirow[b]{2}{*}{ 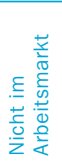 } & \multirow[b]{2}{*}{ 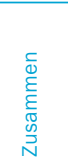 } & \\
\hline & & & 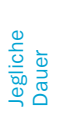 & 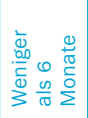 & & & & & 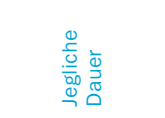 & 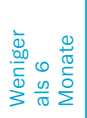 & 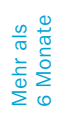 & & & \\
\hline & (1) & (2) & (3) & (4) & (5) & (6) & (7) & $\begin{array}{c}(8)= \\
(9)+(12)\end{array}$ & $\begin{array}{l}(9)=(10)+(11) \\
+ \text { unbekannt }\end{array}$ & (10) & (11) & $(12)$ & (13) & (14) \\
\hline \multicolumn{15}{|l|}{ OECD-Länder } \\
\hline Australien & 4,0 & 21,1 & 2,4 & 1,9 & 18,1 & 45,6 & 42,9 & 11,5 & 3,9 & 2,8 & 1,1 & 7,6 & 54,4 & 100 \\
\hline Österreich & 9,0 & 9,6 & 1,1 & 0,9 & 26,1 & 45,8 & 44,5 & 9,8 & 3,9 & 2,4 & 1,5 & 5,8 & 54,2 & 100 \\
\hline Belgien & 1,0 & 3,5 & 0,7 & 0,3 & 41,9 & 47,0 & 39,1 & 13,9 & 6,1 & 2,8 & 3,2 & 7,8 & 53,0 & 100 \\
\hline Kanada & a & 17,6 & 2,6 & 2,3 & 23,5 & 43,7 & 43,0 & 13,3 & 5,7 & 4,8 & 0,8 & 7,5 & 56,3 & 100 \\
\hline Chile & a & 6,8 & 1,8 & 1,7 & 35,2 & 43,8 & 32,5 & 23,7 & 5,4 & 5,1 & 0,2 & 18,3 & 56,2 & 100 \\
\hline Tschechien & 5,9 & 3,6 & 0,4 & 0,3 & 38,1 & 48,0 & 39,3 & 12,7 & 5,3 & 2,3 & 3,0 & 7,4 & 52,0 & 100 \\
\hline Dänemark & a & 32,1 & 4,6 & 3,5 & 22,4 & 59,1 & 29,9 & 11,0 & 4,9 & 3,5 & 1,4 & 6,0 & 40,9 & 100 \\
\hline Estland & a & 10,9 & 1,9 & 1,2 & 35,4 & 48,2 & 36,6 & 15,2 & 8,1 & 2,8 & 5,3 & 7,0 & 51,8 & 100 \\
\hline Finnland & a & 16,0 & 4,3 & 3,9 & 35,6 & 56,0 & 32,3 & 11,8 & 5,2 & 3,8 & 1,3 & 6,6 & 44,0 & 100 \\
\hline Frankreich & a & 5,9 & 0,4 & 0,3 & 38,4 & 44,6 & 39,0 & 16,4 & 9,3 & 4,4 & 4,8 & 7,1 & 55,4 & 100 \\
\hline Deutschland & 10,7 & 8,5 & 0,8 & 0,6 & 31,0 & 51,1 & 37,9 & 11,0 & 4,6 & 2,1 & 2,4 & 6,4 & 48,9 & 100 \\
\hline Griechenland & a & 2,2 & 1,2 & 0,6 & 41,6 & 45,0 & 33,2 & 21,8 & 14,6 & 5,3 & 9,4 & 7,1 & 55,0 & 100 \\
\hline Ungarn & a & 2,2 & 0,3 & c & 45,8 & 48,4 & 33,1 & 18,5 & 7,6 & 2,6 & 5,0 & 10,9 & 51,6 & 100 \\
\hline Island & a & 26,6 & 4,2 & 3,3 & 29,3 & 60,1 & 32,0 & 7,9 & 5,1 & 3,6 & $\mathrm{c}$ & 2,9 & 39,9 & 100 \\
\hline Irland & a & 7,1 & 1,1 & 0,5 & 33,5 & 41,7 & 36,3 & 22,0 & 12,0 & 3,3 & 8,6 & 10,0 & 58,3 & 100 \\
\hline Israel & a & 10,5 & 0,8 & 0,6 & 29,8 & 41,1 & 31,3 & 27,6 & 3,3 & 2,3 & 0,8 & 24,4 & 58,9 & 100 \\
\hline Italien & 0,1 & 2,5 & 0,7 & 0,3 & 42,2 & 45,5 & 31,3 & 23,2 & 8,2 & 2,8 & 5,4 & 15,0 & 54,5 & 100 \\
\hline Japan $^{3}$ & a & 9,1 & 0,3 & $\mathrm{~m}$ & 52,9 & 62,3 & 27,6 & 10,1 & 3,1 & $\mathrm{~m}$ & $\mathrm{~m}$ & 7,0 & 37,7 & 100 \\
\hline Korea & a & 5,2 & 0,5 & 0,5 & 40,2 & 45,9 & 35,3 & 18,8 & 2,8 & 2,6 & 0,2 & 16,0 & 54,1 & 100 \\
\hline Luxemburg & a & 5,9 & 0,9 & 0,8 & 48,2 & 54,9 & 37,8 & 7,2 & 3,6 & 1,7 & 1,9 & 3,7 & 45,1 & 100 \\
\hline Mexiko & a & 6,9 & 0,6 & 0,5 & 26,4 & 33,9 & 41,4 & 24,7 & 3,9 & 3,4 & 0,3 & 20,8 & 66,1 & 100 \\
\hline Niederlande & a & 32,4 & 2,5 & $\mathrm{~m}$ & 20,0 & 54,9 & 38,2 & 6,9 & 1,8 & $\mathrm{~m}$ & $\mathrm{~m}$ & 5,1 & 45,1 & 100 \\
\hline Neuseeland & $\mathrm{a}$ & 17,4 & 3,7 & 2,7 & 24,7 & 45,8 & 39,9 & 14,3 & 4,9 & 3,5 & 1,2 & 9,4 & 54,2 & 100 \\
\hline Norwegen & a & 15,3 & 1,8 & 1,6 & 29,0 & 46,1 & 45,4 & 8,5 & 2,8 & 1,9 & 0,7 & 5,7 & 53,9 & 100 \\
\hline Polen & a & 7,8 & 1,8 & 1,0 & 38,4 & 47,9 & 36,4 & 15,7 & 7,5 & 3,4 & 4,1 & 8,3 & 52,1 & 100 \\
\hline Portugal & $a$ & 5,3 & 2,0 & 1,0 & 37,5 & 44,8 & 39,9 & 15,3 & 10,2 & 4,4 & 5,8 & 5,1 & 55,2 & 100 \\
\hline Slowakei & 2,8 & 2,1 & 0,3 & $\mathrm{c}$ & 40,1 & 45,4 & 35,4 & 19,1 & 10,9 & 2,4 & 8,5 & 8,2 & 54,6 & 100 \\
\hline Slowenien & a & 16,9 & 2,1 & 1,1 & 41,2 & 60,2 & 29,1 & 10,7 & 6,7 & 2,9 & 3,8 & 4,0 & 39,8 & 100 \\
\hline Spanien & a & 4,7 & 3,1 & 1,2 & 34,6 & 42,5 & 33,1 & 24,4 & 17,0 & 5,9 & 10,3 & 7,5 & 57,5 & 100 \\
\hline Schweden & a & 11,1 & 6,1 & 4,4 & 35,4 & 52,6 & 38,4 & 9,0 & 4,9 & 3,5 & 1,1 & 4,1 & 47,4 & 100 \\
\hline Schweiz & 14,9 & 11,9 & 1,3 & 0,7 & 19,5 & 47,6 & 43,4 & 9,0 & 3,8 & 2,1 & 1,7 & 5,2 & 52,4 & 100 \\
\hline Türkei & a & 5,5 & 1,5 & 0,8 & 24,8 & 31,8 & 33,5 & 34,6 & 7,1 & 4,1 & 3,0 & 27,6 & 68,2 & 100 \\
\hline Ver. Königreich & 2,4 & 11,3 & 2,6 & 1,6 & 25,2 & 41,4 & 43,1 & 15,5 & 6,7 & 3,5 & 3,2 & 8,8 & 58,6 & 100 \\
\hline Vereinigte Staaten & a & 15,1 & 2,4 & 1,7 & 29,2 & 46,7 & 37,4 & 15,9 & 5,9 & 3,5 & 2,5 & 9,9 & 53,3 & 100 \\
\hline $\begin{array}{l}\text { OECD-Durchschnitt } \\
\text { (ohne Japan) }\end{array}$ & & 11,0 & 1,9 & 1,4 & 32,8 & 47,2 & 37,0 & 15,8 & 6,5 & 3,3 & 3,3 & 9,3 & 52,8 & 100 \\
\hline EU21-Durchschnitt & & 9,6 & 1,9 & 1,3 & 35,8 & 48,8 & 36,4 & 14,8 & 7,6 & 3,3 & 4,5 & 7,2 & 51,2 & 100 \\
\hline \multicolumn{15}{|l|}{ Sonst. G20-Länder } \\
\hline Argentinien & $\mathrm{m}$ & $\mathrm{m}$ & $\mathrm{m}$ & $\mathrm{m}$ & $\mathrm{m}$ & $\mathrm{m}$ & $\mathrm{m}$ & $\mathrm{m}$ & $\mathrm{m}$ & $\mathrm{m}$ & $\mathrm{m}$ & $\mathrm{m}$ & $\mathrm{m}$ & $m$ \\
\hline Brasilien & a & 12,5 & 2,6 & $\mathrm{~m}$ & 18,2 & 33,4 & 47,2 & 19,3 & 5,8 & $\mathrm{~m}$ & $\mathrm{~m}$ & 13,6 & 66,6 & 100 \\
\hline China & $\mathrm{m}$ & $\mathrm{m}$ & $\mathrm{m}$ & $\mathrm{m}$ & $\mathrm{m}$ & $\mathrm{m}$ & $\mathrm{m}$ & $\mathrm{m}$ & $\mathrm{m}$ & $\mathrm{m}$ & $\mathrm{m}$ & $\mathrm{m}$ & $\mathrm{m}$ & $\mathrm{m}$ \\
\hline Indien & $\mathrm{m}$ & $\mathrm{m}$ & $\mathrm{m}$ & $\mathrm{m}$ & $\mathrm{m}$ & $\mathrm{m}$ & $\mathrm{m}$ & $\mathrm{m}$ & $\mathrm{m}$ & $\mathrm{m}$ & $\mathrm{m}$ & $\mathrm{m}$ & $\mathrm{m}$ & $\mathrm{m}$ \\
\hline Indonesien & $\mathrm{m}$ & $\mathrm{m}$ & $\mathrm{m}$ & $\mathrm{m}$ & $\mathrm{m}$ & $\mathrm{m}$ & $\mathrm{m}$ & $\mathrm{m}$ & $\mathrm{m}$ & $\mathrm{m}$ & $\mathrm{m}$ & $\mathrm{m}$ & $\mathrm{m}$ & $\mathrm{m}$ \\
\hline Russische Föd. & $\mathrm{m}$ & $\mathrm{m}$ & $\mathrm{m}$ & $\mathrm{m}$ & $\mathrm{m}$ & $\mathrm{m}$ & $\mathrm{m}$ & $\mathrm{m}$ & $\mathrm{m}$ & $\mathrm{m}$ & $\mathrm{m}$ & $\mathrm{m}$ & $\mathrm{m}$ & $\mathrm{m}$ \\
\hline Saudi-Arabien & $\mathrm{m}$ & $\mathrm{m}$ & $\mathrm{m}$ & $\mathrm{m}$ & $\mathrm{m}$ & $\mathrm{m}$ & $\mathrm{m}$ & $\mathrm{m}$ & $\mathrm{m}$ & $\mathrm{m}$ & $\mathrm{m}$ & $\mathrm{m}$ & $\mathrm{m}$ & $\mathrm{m}$ \\
\hline Südafrika & $\mathrm{m}$ & $\mathrm{m}$ & $\mathrm{m}$ & $\mathrm{m}$ & $\mathrm{m}$ & $\mathrm{m}$ & $\mathrm{m}$ & $\mathrm{m}$ & $\mathrm{m}$ & $\mathrm{m}$ & $\mathrm{m}$ & $\mathrm{m}$ & $\mathrm{m}$ & $\mathrm{m}$ \\
\hline G20-Durchschnitt & $\mathbf{m}$ & $\mathbf{m}$ & m & m & m & $\mathbf{m}$ & $\mathbf{m}$ & m & m & $\mathbf{m}$ & m & m & m & m \\
\hline
\end{tabular}

1. Teilnehmer an dualen Ausbildungsgängen gelten als sowohl in Ausbildung als auch beschäftigt, ohne Bezug auf ihren ILO-Erwerbsstatus.

2. 15- bis 29-Jährige, die sich weder in Beschäftigung noch in Ausbildung befinden. 3. Daten beziehen sich auf 15- bis 24-Jährige.

Quelle: OECD. Hinweise s. Anhang 3 unter www.oecd.org/edu/eag.htm. StatLink: http://dx.doi.org/10.1787/888932850965

Erläuterung der Kennzeichnung fehlender Daten s. Hinweise für den Leser. 
Anteil 15- bis 29-Jähriger (in \%), die sich in Ausbildung bzw. nicht in Ausbildung befinden, nach Erwerbsstatus, einschließlich Teilzeitbeschäftigten (2011)

\begin{tabular}{|c|c|c|c|c|c|c|c|c|c|c|c|c|c|c|}
\hline & \multicolumn{7}{|c|}{ In Ausbildung } & \multicolumn{6}{|c|}{ Nicht in Ausbildung } & \multirow{3}{*}{ 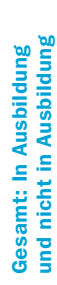 } \\
\hline & \multirow{2}{*}{ 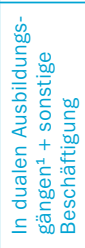 } & \multicolumn{3}{|c|}{ Beschäftigt, umfasst: } & \multirow[b]{2}{*}{$\begin{array}{l}\frac{\infty}{0} \\
\frac{0}{0} \\
\sum_{w}^{\frac{0}{2}}\end{array}$} & \multirow{2}{*}{ 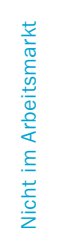 } & \multirow[b]{2}{*}{ 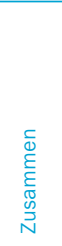 } & \multirow[b]{2}{*}{ 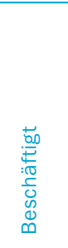 } & \multicolumn{3}{|c|}{ Beschäftigt, umfasst: } & \multirow[b]{2}{*}{$\frac{\stackrel{\sim}{w}}{z}$} & \multirow[b]{2}{*}{ 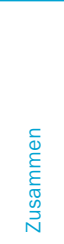 } & \\
\hline & & $\begin{array}{l}\frac{ \pm}{D} \\
\bar{N} \\
\end{array}$ & $\begin{array}{l}\widehat{N} \\
E \\
\frac{N}{N} \\
\frac{N}{\bar{N}}\end{array}$ & 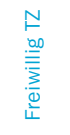 & & & & & $\begin{array}{l}\frac{+}{N} \\
\frac{N}{5}\end{array}$ & 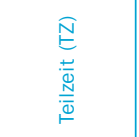 & 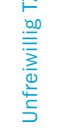 & & & \\
\hline & (1) & (2) & $\begin{array}{c}(3)=(4)+\text { un- } \\
\text { freiwillig TZ } \\
\text { + unbekannt }\end{array}$ & (4) & (5) & (6) & (7) & (8) & (9) & $\begin{array}{l}(10)=(11)+ \\
\text { freiwillige TZ } \\
\text { + unbekannt }\end{array}$ & (11) & $(12)$ & (13) & (14) \\
\hline \multicolumn{15}{|l|}{ OECD-Länder } \\
\hline Australien & 25,2 & 8,6 & 16,6 & $\mathrm{~m}$ & 2,4 & 18,1 & 45,6 & 42,9 & 34,1 & 8,7 & $\mathrm{~m}$ & 11,5 & 54,4 & 100 \\
\hline Österreich & 18,6 & 12,4 & 6,2 & 6,0 & 1,1 & 26,1 & 45,8 & 44,5 & 40,1 & 4,3 & 1,2 & 9,8 & 54,2 & 100 \\
\hline Belgien & 4,4 & 1,9 & 2,2 & 1,8 & 0,7 & 41,9 & 47,0 & 39,1 & 32,3 & 6,8 & 3,8 & 13,9 & 53,0 & 100 \\
\hline Kanada & 17,6 & 2,5 & 15,0 & 14,4 & 2,6 & 23,5 & 43,7 & 43,0 & 35,8 & 7,2 & 4,1 & 13,3 & 56,3 & 100 \\
\hline Chile & 6,8 & 4,3 & 2,5 & 1,4 & 1,8 & 35,2 & 43,8 & 32,5 & 28,9 & 3,7 & 2,2 & 23,7 & 56,2 & 100 \\
\hline Tschechien & 9,6 & 2,5 & 1,1 & 1,1 & 0,4 & 38,1 & 48,0 & 39,3 & 38,4 & 0,9 & $\mathrm{c}$ & 12,7 & 52,0 & 100 \\
\hline Dänemark & 32,1 & 7,2 & 24,9 & $\mathrm{~m}$ & 4,6 & 22,4 & 59,1 & 29,9 & 23,6 & 6,3 & $\mathrm{~m}$ & 11,0 & 40,9 & 100 \\
\hline Estland & 10,9 & 7,8 & 3,1 & 3,1 & 1,9 & 35,4 & 48,2 & 36,6 & 35,1 & 1,6 & $\mathrm{c}$ & 15,2 & 51,8 & 100 \\
\hline Finnland & 16,0 & 5,4 & 10,6 & $\mathrm{~m}$ & 4,3 & 35,6 & 56,0 & 32,3 & 28,3 & 4,0 & $\mathrm{~m}$ & 11,8 & 44,0 & 100 \\
\hline Frankreich & 5,9 & 4,0 & 1,8 & $\mathrm{~m}$ & 0,4 & 38,4 & 44,6 & 39,0 & 33,0 & 6,0 & $\mathrm{~m}$ & 16,4 & 55,4 & 100 \\
\hline Deutschland & 19,2 & 12,7 & 6,5 & $\mathrm{~m}$ & 0,8 & 31,0 & 51,1 & 37,9 & 32,1 & 5,8 & $\mathrm{~m}$ & 11,0 & 48,9 & 100 \\
\hline Griechenland & 2,2 & 1,3 & 0,9 & $\mathrm{c}$ & 1,2 & 41,6 & 45,0 & 33,2 & 30,1 & 3,1 & 0,7 & 21,8 & 55,0 & 100 \\
\hline Ungarn & 2,2 & 1,6 & 0,4 & $\mathrm{~m}$ & 0,3 & 45,8 & 48,4 & 33,1 & 29,9 & 1,1 & $\mathrm{~m}$ & 18,5 & 51,6 & 100 \\
\hline Island & 26,6 & 5,1 & 21,5 & $\mathrm{~m}$ & 4,2 & 29,3 & 60,1 & 32,0 & 26,0 & 6,0 & $\mathrm{~m}$ & 7,9 & 39,9 & 100 \\
\hline Irland & 7,1 & 2,0 & 5,1 & $\mathrm{~m}$ & 1,1 & 33,5 & 41,7 & 36,3 & 29,0 & 7,3 & $\mathrm{~m}$ & 22,0 & 58,3 & 100 \\
\hline Israel & 10,5 & 3,6 & 6,5 & 6,4 & 0,8 & 29,8 & 41,1 & 31,3 & 25,0 & 5,8 & 2,2 & 27,6 & 58,9 & 100 \\
\hline Italien & 2,6 & 1,2 & 1,4 & 1,0 & 0,7 & 42,2 & 45,5 & 31,3 & 25,9 & 5,5 & 4,4 & 23,2 & 54,5 & 100 \\
\hline$J^{J} a n^{3}$ & 9,1 & $\mathrm{~m}$ & 9,1 & $\mathrm{~m}$ & 0,3 & 52,9 & 62,3 & 27,6 & 18,2 & 9,4 & $\mathrm{~m}$ & 10,1 & 37,7 & 100 \\
\hline Korea & 5,2 & 2,2 & 2,9 & 2,9 & 0,5 & 40,2 & 45,9 & 35,3 & 31,5 & 3,8 & 0,1 & 18,8 & 54,1 & 100 \\
\hline Luxemburg & 5,9 & 3,2 & 2,5 & $\mathrm{~m}$ & 0,9 & 48,2 & 54,9 & 37,8 & 34,3 & 3,6 & $\mathrm{~m}$ & 7,2 & 45,1 & 100 \\
\hline Mexiko & 6,9 & 3,7 & 3,2 & $\mathrm{~m}$ & 0,6 & 26,4 & 33,9 & 41,4 & 35,8 & 5,3 & $\mathrm{~m}$ & 24,7 & 66,1 & 100 \\
\hline Niederlande & 32,4 & 7,3 & 24,5 & 24,5 & 2,5 & 20,0 & 54,9 & 38,2 & 29,7 & 8,5 & $\mathrm{~m}$ & 6,9 & 45,1 & 100 \\
\hline Neuseeland & 17,4 & 5,6 & 11,7 & $\mathrm{~m}$ & 3,7 & 24,7 & 45,8 & 39,9 & 33,1 & 6,9 & 1,0 & 14,3 & 54,2 & 100 \\
\hline Norwegen & 15,3 & c & 15,0 & $\mathrm{~m}$ & 1,8 & 29,0 & 46,1 & 45,4 & 37,6 & 6,8 & m & 8,5 & 53,9 & 100 \\
\hline Polen & 7,8 & 5,9 & 1,8 & 0,2 & 1,8 & 38,4 & 47,9 & 36,4 & 34,2 & 2,2 & 1,6 & 15,7 & 52,1 & 100 \\
\hline Portugal & 5,3 & $\mathrm{~m}$ & $\mathrm{~m}$ & $\mathrm{~m}$ & 2,0 & 37,5 & 44,8 & 39,9 & $\mathrm{~m}$ & $\mathrm{~m}$ & $\mathrm{~m}$ & 15,3 & 55,2 & 100 \\
\hline Slowakei & 4,9 & 1,8 & 0,3 & $\mathrm{~m}$ & 0,3 & 40,1 & 45,4 & 35,4 & 33,7 & 1,7 & $\mathrm{~m}$ & 19,1 & 54,6 & 100 \\
\hline Slowenien & 16,9 & 8,5 & 8,4 & $\mathrm{~m}$ & 2,1 & 41,2 & 60,2 & 29,1 & 28,3 & 0,8 & $\mathrm{~m}$ & 10,7 & 39,8 & 100 \\
\hline Spanien & 4,7 & 2,1 & 2,7 & 2,1 & 3,1 & 34,6 & 42,5 & 33,1 & 27,4 & 5,7 & 4,3 & 24,4 & 57,5 & 100 \\
\hline Schweden & 11,1 & 2,5 & 8,5 & 7,3 & 6,1 & 35,4 & 52,6 & 38,4 & 32,8 & 5,4 & 2,8 & 9,0 & 47,4 & 100 \\
\hline Schweiz & 26,7 & 18,9 & 7,8 & 7,8 & 1,3 & 19,5 & 47,6 & 43,4 & 38,0 & 5,4 & c & 9,0 & 52,4 & 100 \\
\hline Türkei & 5,5 & 4,3 & 1,2 & $\mathrm{~m}$ & 1,5 & 24,8 & 31,8 & 33,5 & 30,2 & 3,3 & $\mathrm{~m}$ & 34,6 & 68,2 & 100 \\
\hline Ver. Königreich & 13,7 & 5,0 & 7,5 & 7,2 & 2,6 & 25,2 & 41,4 & 43,1 & 33,8 & 8,2 & 3,5 & 15,5 & 58,6 & 100 \\
\hline Vereinigte Staaten & 15,1 & 4,7 & 10,4 & 9,6 & 2,4 & 29,2 & 46,7 & 37,4 & 30,2 & 7,2 & 3,5 & 15,9 & 53,3 & 100 \\
\hline $\begin{array}{l}\text { OECD-Durchschnitt } \\
\text { ohne Japan }\end{array}$ & 12,5 & 5,2 & 7,3 & 6,1 & 1,9 & 32,8 & 47,2 & 37,0 & 31,8 & 5,0 & 2,5 & 15,8 & 52,8 & 100 \\
\hline EU21-Durchschnitt & 11,1 & 4,8 & 6,0 & 5,4 & 1,9 & 35,8 & 48,8 & 36,4 & 31,6 & 4,4 & 2,8 & 14,8 & 51,2 & 100 \\
\hline \multicolumn{15}{|l|}{ Sonst. G20-Länder } \\
\hline Argentinien & $\mathrm{m}$ & $\mathrm{m}$ & $\mathrm{m}$ & $\mathrm{m}$ & $\mathrm{m}$ & $\mathrm{m}$ & $\mathrm{m}$ & $\mathrm{m}$ & $\mathrm{m}$ & $\mathrm{m}$ & $\mathrm{m}$ & $\mathrm{m}$ & $\mathrm{m}$ & $\mathrm{m}$ \\
\hline Brasilien & 12,5 & 8,9 & 3,7 & $\mathrm{~m}$ & 2,6 & 18,2 & 33,4 & 47,2 & 42,6 & 4,7 & $\mathrm{~m}$ & 19,3 & 66,6 & 100 \\
\hline China & $\mathrm{m}$ & $\mathrm{m}$ & $\mathrm{m}$ & $\mathrm{m}$ & $\mathrm{m}$ & $\mathrm{m}$ & $\mathrm{m}$ & $\mathrm{m}$ & $\mathrm{m}$ & $\mathrm{m}$ & $\mathrm{m}$ & $\mathrm{m}$ & $\mathrm{m}$ & $\mathrm{m}$ \\
\hline Indien & $\mathrm{m}$ & $\mathrm{m}$ & $\mathrm{m}$ & $\mathrm{m}$ & $\mathrm{m}$ & $\mathrm{m}$ & $\mathrm{m}$ & $\mathrm{m}$ & $\mathrm{m}$ & $\mathrm{m}$ & $\mathrm{m}$ & $\mathrm{m}$ & $\mathrm{m}$ & $\mathrm{m}$ \\
\hline Indonesien & $\mathrm{m}$ & $\mathrm{m}$ & $\mathrm{m}$ & $\mathrm{m}$ & $\mathrm{m}$ & $\mathrm{m}$ & $\mathrm{m}$ & $\mathrm{m}$ & $\mathrm{m}$ & $\mathrm{m}$ & $\mathrm{m}$ & $\mathrm{m}$ & $\mathrm{m}$ & $\mathrm{m}$ \\
\hline Russische Föd. & $\mathrm{m}$ & $\mathrm{m}$ & $\mathrm{m}$ & $\mathrm{m}$ & $\mathrm{m}$ & $\mathrm{m}$ & $\mathrm{m}$ & $\mathrm{m}$ & $\mathrm{m}$ & $\mathrm{m}$ & $\mathrm{m}$ & $\mathrm{m}$ & $\mathrm{m}$ & $\mathrm{m}$ \\
\hline Saudi-Arabien & $\mathrm{m}$ & $\mathrm{m}$ & $\mathrm{m}$ & $\mathrm{m}$ & $\mathrm{m}$ & $\mathrm{m}$ & $\mathrm{m}$ & $\mathrm{m}$ & $\mathrm{m}$ & $\mathrm{m}$ & $\mathrm{m}$ & $\mathrm{m}$ & $\mathrm{m}$ & $\mathrm{m}$ \\
\hline Südafrika & $\mathrm{m}$ & $\mathrm{m}$ & $\mathrm{m}$ & $\mathrm{m}$ & $\mathrm{m}$ & $\mathrm{m}$ & $\mathrm{m}$ & $\mathrm{m}$ & $\mathrm{m}$ & $\mathrm{m}$ & $\mathrm{m}$ & $\mathrm{m}$ & $\mathrm{m}$ & $\mathrm{m}$ \\
\hline G20-Durchschnitt & m & m & m & $\mathbf{m}$ & m & m & m & $\mathbf{m}$ & m & m & $\mathbf{m}$ & m & m & m \\
\hline
\end{tabular}

1. Teilnehmer an dualen Ausbildungsgängen gelten als sowohl in Ausbildung als auch beschäftigt, ohne Bezug auf ihren ILO-Erwerbsstatus.

2. 15- bis 29-Jährige, die weder beschäftigt sind noch sich in Ausbildung befinden. 3. Daten beziehen sich auf 15- bis 24-Jährige.

Quelle: OECD. Hinweise s. Anhang 3 unter www.oecd.org/edu/eag.htm. StatLink: http://dx.doi.org/10.1787/888932851041

Erläuterung der Kennzeichnung fehlender Daten s. Hinweise für den Leser. 
Tabelle C5.4a

Entwicklung des Anteils junger Menschen (in \%), die sich in Ausbildung und nicht in Ausbildung befinden (beschäftigt oder nicht beschäftigt), nach Altersgruppe (1997-2011) ${ }^{1}$

\begin{tabular}{|c|c|c|c|c|c|c|c|c|c|c|c|c|c|}
\hline & \multirow{4}{*}{\begin{tabular}{|l} 
Alters- \\
gruppe
\end{tabular}} & \multicolumn{3}{|c|}{2000} & \multicolumn{3}{|c|}{2005} & \multicolumn{3}{|c|}{2008} & \multicolumn{3}{|c|}{2011} \\
\hline & & \multirow{2}{*}{$\begin{array}{l}\text { In Aus- } \\
\text { bildung } \\
\text { Gesamt }\end{array}$} & \multicolumn{2}{|c|}{ Nicht in Ausbildung } & \multirow{2}{*}{$\begin{array}{l}\text { In Aus- } \\
\text { bildung } \\
\text { Gesamt }\end{array}$} & \multicolumn{2}{|c|}{ Nicht in Ausbildung } & \multirow{2}{*}{$\begin{array}{l}\text { In Aus- } \\
\text { bildung }\end{array}$} & \multicolumn{2}{|c|}{ Nicht in Ausbildung } & \multirow{2}{*}{$\begin{array}{l}\text { In Aus- } \\
\text { bildung } \\
\text { Gesamt }\end{array}$} & \multicolumn{2}{|c|}{ Nicht in Ausbildung } \\
\hline & & & $\begin{array}{l}\text { Beschäf- } \\
\text { tigt }\end{array}$ & $\begin{array}{c}\text { Nicht } \\
\text { beschäf- } \\
\text { tigt }\end{array}$ & & $\begin{array}{c}\text { Beschäf- } \\
\text { tigt }\end{array}$ & $\begin{array}{c}\text { Nicht } \\
\text { beschäf- } \\
\text { tigt }\end{array}$ & & $\begin{array}{l}\text { Beschäf- } \\
\text { tigt }\end{array}$ & $\begin{array}{c}\text { Nicht } \\
\text { beschäf- } \\
\text { tigt }\end{array}$ & & $\begin{array}{c}\text { Beschäf- } \\
\text { tigt }\end{array}$ & $\begin{array}{c}\text { Nicht } \\
\text { beschäf- } \\
\text { tigt }\end{array}$ \\
\hline & & (10) & (11) & (12) & (25) & (26) & (27) & (34) & (35) & (36) & (37) & (38) & (39) \\
\hline \multicolumn{14}{|l|}{ OECD-Länder } \\
\hline Australien & $15-19$ & 79,5 & 13,7 & 6,8 & 78,3 & 14,3 & 7,4 & 79,4 & 14,3 & 6,3 & 80,0 & 12,2 & 7,8 \\
\hline & $20-24$ & 35,9 & 50,9 & 13,3 & 39,4 & 49,0 & 11,6 & 39,3 & 50,0 & 10,7 & 42,1 & 46,2 & 11,7 \\
\hline & $25-29$ & 15,5 & 65,5 & 19,0 & 16,6 & 68,0 & 15,4 & 15,4 & 70,5 & 14,1 & 18,9 & 66,6 & 14,6 \\
\hline & $15-29$ & 42,8 & 44,0 & 13,2 & 45,0 & 43,5 & 11,4 & 44,4 & 45,2 & 10,4 & 45,6 & 42,9 & 11,5 \\
\hline Österreich & $15-19$ & $\mathrm{~m}$ & $\mathrm{~m}$ & $\mathrm{~m}$ & 84,4 & 8,7 & 6,9 & 84,3 & 10,0 & 5,6 & 87,0 & 7,5 & 5,5 \\
\hline & $20-24$ & $\mathrm{~m}$ & $\mathrm{~m}$ & $\mathrm{~m}$ & 30,4 & 57,2 & 12,4 & 32,3 & 56,3 & 11,4 & 36,0 & 53,6 & 10,5 \\
\hline & $25-29$ & $\mathrm{~m}$ & $\mathrm{~m}$ & $\mathrm{~m}$ & 12,0 & 74,6 & 13,4 & 14,6 & 71,7 & 13,7 & 19,1 & 68,1 & 12,8 \\
\hline & $15-29$ & $\mathrm{~m}$ & $\mathrm{~m}$ & $\mathrm{~m}$ & 41,3 & 47,7 & 11,0 & 42,6 & 47,0 & 10,4 & 45,8 & 44,5 & 9,8 \\
\hline Belgien & $15-19$ & 89,9 & 3,6 & 6,5 & 90,1 & 3,7 & 6,2 & 90,5 & 4,0 & 5,5 & 90,4 & 3,5 & 6,1 \\
\hline & $20-24$ & 43,8 & 40,2 & 16,0 & 38,1 & 43,6 & 18,3 & 41,5 & 44,4 & 14,1 & 43,1 & 39,8 & 17,1 \\
\hline & $25-29$ & 11,8 & 72,5 & 15,7 & 7,4 & 74,9 & 17,7 & 7,7 & 75,8 & 16,5 & 10,6 & 71,4 & 18,0 \\
\hline & $15-29$ & 46,9 & 40,2 & 12,9 & 44,4 & 41,4 & 14,2 & 45,9 & 42,0 & 12,1 & 47,0 & 39,1 & 13,9 \\
\hline Kanada & $15-19$ & 80,6 & 11,2 & 8,2 & 80,3 & 12,7 & 7,0 & 80,2 & 12,5 & 7,3 & 81,4 & 10,9 & 7,7 \\
\hline & $20-24$ & 35,8 & 48,5 & 15,7 & 39,2 & 46,4 & 14,5 & 38,9 & 48,1 & 13,0 & 40,1 & 45,3 & 14,6 \\
\hline & $25-29$ & 10,6 & 72,2 & 17,2 & 12,5 & 71,7 & 15,8 & 12,4 & 72,6 & 14,9 & 12,7 & 70,3 & 17,1 \\
\hline & $15-29$ & 42,5 & 43,9 & 13,7 & 44,0 & 43,5 & 12,4 & 43,8 & 44,5 & 11,7 & 43,7 & 43,0 & 13,3 \\
\hline Chile & $15-19$ & $\mathrm{~m}$ & $\mathrm{~m}$ & $\mathrm{~m}$ & $\mathrm{~m}$ & $m$ & $\mathrm{~m}$ & $\mathrm{~m}$ & $\mathrm{~m}$ & $\mathrm{~m}$ & 70,7 & 7,9 & 21,4 \\
\hline & $20-24$ & $\mathrm{~m}$ & $\mathrm{~m}$ & $\mathrm{~m}$ & $\mathrm{~m}$ & $\mathrm{~m}$ & $\mathrm{~m}$ & $\mathrm{~m}$ & $\mathrm{~m}$ & $\mathrm{~m}$ & 39,9 & 35,2 & 24,9 \\
\hline & $25-29$ & $\mathrm{~m}$ & $\mathrm{~m}$ & $\mathrm{~m}$ & $\mathrm{~m}$ & $\mathrm{~m}$ & $\mathrm{~m}$ & $\mathrm{~m}$ & $\mathrm{~m}$ & $\mathrm{~m}$ & 15,8 & 59,1 & 25,0 \\
\hline & $15-29$ & $\mathrm{~m}$ & $\mathrm{~m}$ & $\mathrm{~m}$ & $\mathrm{~m}$ & $\mathrm{~m}$ & $\mathrm{~m}$ & $\mathrm{~m}$ & $\mathrm{~m}$ & $\mathrm{~m}$ & 43,8 & 32,5 & 23,7 \\
\hline Tschechien & $15-19$ & 82,1 & 10,0 & 7,9 & 90,3 & 4,4 & 5,3 & 92,7 & 4,5 & 2,7 & 93,2 & 3,0 & 3,7 \\
\hline & $20-24$ & 19,7 & 60,0 & 20,3 & 35,9 & 47,5 & 16,6 & 44,8 & 44,7 & 10,6 & 50,0 & 37,2 & 12,8 \\
\hline & $25-29$ & 2,4 & 72,1 & 25,6 & 4,4 & 72,4 & 23,2 & 11,1 & 71,2 & 17,7 & 11,9 & 68,6 & 19,5 \\
\hline & $15-29$ & 31,7 & 49,7 & 18,5 & 39,5 & 44,6 & 15,9 & 46,6 & 42,5 & 10,9 & 48,0 & 39,3 & 12,7 \\
\hline Dänemark & $15-19$ & 89,9 & 7,4 & 2,7 & 88,4 & 7,3 & 4,3 & 86,3 & 9,7 & 4,0 & 89,1 & 5,6 & 5,3 \\
\hline & $20-24$ & 54,8 & 38,6 & 6,6 & 54,4 & 37,2 & 8,3 & 51,3 & 40,6 & 8,2 & 55,8 & 32,3 & 11,9 \\
\hline & $25-29$ & 36,1 & 56,4 & 7,5 & 27,0 & 61,3 & 11,6 & 23,7 & 67,6 & 8,6 & 29,3 & 54,5 & 16,2 \\
\hline & $15-29$ & 57,7 & 36,5 & 5,8 & 55,5 & 36,3 & 8,2 & 54,3 & 38,8 & 6,9 & 59,1 & 29,9 & 11,0 \\
\hline Estland & $15-19$ & $\mathrm{~m}$ & $\mathrm{~m}$ & $\mathrm{~m}$ & 92,0 & 2,9 & 5,2 & 88,8 & 6,3 & 4,9 & 90,5 & 3,2 & 6,4 \\
\hline & $20-24$ & $\mathrm{~m}$ & $\mathrm{~m}$ & $\mathrm{~m}$ & 50,9 & 32,7 & 16,3 & 46,5 & 42,8 & 10,7 & 48,5 & 35,7 & 15,8 \\
\hline & $25-29$ & $\mathrm{~m}$ & $\mathrm{~m}$ & $\mathrm{~m}$ & 14,2 & 61,8 & 24,0 & 14,9 & 66,6 & 18,5 & 17,6 & 61,6 & 20,8 \\
\hline & $15-29$ & $\mathrm{~m}$ & $\mathrm{~m}$ & $\mathrm{~m}$ & 54,0 & 31,3 & 14,8 & 49,9 & 38,7 & 11,3 & 48,2 & 36,6 & 15,2 \\
\hline Finnland & $15-19$ & $\mathrm{~m}$ & $\mathrm{~m}$ & $\mathrm{~m}$ & 90,2 & 4,5 & 5,2 & 90,3 & 4,6 & 5,1 & 91,5 & 3,4 & 5,1 \\
\hline & $20-24$ & $\mathrm{~m}$ & $\mathrm{~m}$ & $\mathrm{~m}$ & 52,8 & 34,1 & 13,0 & 50,5 & 37,5 & 12,0 & 52,4 & 33,3 & 14,3 \\
\hline & $25-29$ & $\mathrm{~m}$ & $\mathrm{~m}$ & $\mathrm{~m}$ & 25,7 & 60,3 & 14,0 & 29,2 & 58,4 & 12,4 & 26,5 & 57,9 & 15,6 \\
\hline & $15-29$ & $\mathrm{~m}$ & $\mathrm{~m}$ & $\mathrm{~m}$ & 55,4 & 33,7 & 10,9 & 56,2 & 34,0 & 9,9 & 56,0 & 32,3 & 11,8 \\
\hline Frankreich & $15-19$ & 88,2 & 4,8 & 7,0 & 90,5 & 3,2 & 6,3 & 90,3 & 3,9 & 5,8 & 90,2 & 2,7 & 7,1 \\
\hline & $20-24$ & 39,4 & 43,0 & 17,6 & 42,5 & 39,7 & 17,8 & 42,2 & 41,2 & 16,6 & 40,7 & 39,0 & 20,3 \\
\hline & $25-29$ & 5,9 & 73,7 & 20,4 & 5,1 & 75,1 & 19,8 & 5,2 & 75,1 & 19,7 & 4,9 & 73,6 & 21,5 \\
\hline & $15-29$ & 44,1 & 40,9 & 15,0 & 46,8 & 38,7 & 14,5 & 45,8 & 40,2 & 14,0 & 44,6 & 39,0 & 16,4 \\
\hline Deutschland & $15-19$ & 87,4 & 6,8 & 5,7 & 92,9 & 2,7 & 4,4 & 92,4 & 3,9 & 3,7 & 92,3 & 4,1 & 3,5 \\
\hline & $20-24$ & 34,1 & 49,0 & 16,9 & 44,2 & 37,1 & 18,7 & 46,7 & 39,3 & 14,0 & 49,0 & 38,5 & 12,6 \\
\hline & $25-29$ & 12,7 & 69,8 & 17,5 & 18,5 & 60,3 & 21,2 & 19,2 & 63,8 & 17,0 & 18,5 & 65,8 & 15,7 \\
\hline & $15-29$ & 44,9 & 41,8 & 13,3 & 52,2 & 33,1 & 14,7 & 52,3 & 36,1 & 11,6 & 51,1 & 37,9 & 11,0 \\
\hline Griechenland & $15-19$ & 82,6 & 8,1 & 9,3 & 82,2 & 6,1 & 11,7 & 86,8 & 4,8 & 8,4 & 89,5 & 2,2 & 8,3 \\
\hline & $20-24$ & 30,7 & 43,4 & 25,9 & 40,4 & 38,0 & 21,6 & 48,5 & 34,4 & 17,1 & 47,0 & 28,7 & 24,3 \\
\hline & $25-29$ & 5,1 & 65,8 & 29,2 & 6,4 & 69,8 & 23,7 & 8,9 & 70,0 & 21,1 & 9,8 & 60,2 & 30,0 \\
\hline & $15-29$ & 39,0 & 39,4 & 21,5 & 38,6 & 41,7 & 19,7 & 43,7 & 40,1 & 16,2 & 45,0 & 33,2 & 21,8 \\
\hline Ungarn & $15-19$ & 83,7 & 7,7 & 8,6 & 90,6 & 3,0 & 6,4 & 91,8 & 2,5 & 5,7 & 93,7 & 1,5 & 4,8 \\
\hline & $20-24$ & 32,3 & 45,7 & 22,0 & 46,6 & 34,5 & 18,9 & 48,4 & 33,2 & 18,4 & 47,9 & 29,7 & 22,4 \\
\hline & $25-29$ & 9,4 & 61,4 & 29,2 & 13,1 & 63,0 & 24,0 & 9,9 & 67,1 & 23,1 & 10,3 & 63,1 & 26,6 \\
\hline & $15-29$ & 40,7 & 39,1 & 20,2 & 46,3 & 36,5 & 17,2 & 47,2 & 36,5 & 16,3 & 48,4 & 33,1 & 18,5 \\
\hline
\end{tabular}

1. Die Zahlen für die Jahre 1997, 1998, 1999, 2001, 2002, 2003, 2004, 2006, 2007, 2009 und 2010 sind im Internet verfügbar (s. StatLink unten).

Quelle: OECD. Hinweise s. Anhang 3 unter www.oecd.org/edu/eag2012. StatLink: http://dx.doi.org/10.1787/888932851117

Erläuterung der Kennzeichnung fehlender Daten s. Hinweise für den Leser. 
Tabelle C5.4a (Forts. 1)

Entwicklung des Anteils junger Menschen (in \%), die sich in Ausbildung und nicht in Ausbildung befinden (beschäftigt oder nicht beschäftigt), nach Altersgruppe (1997-2011) ${ }^{1}$

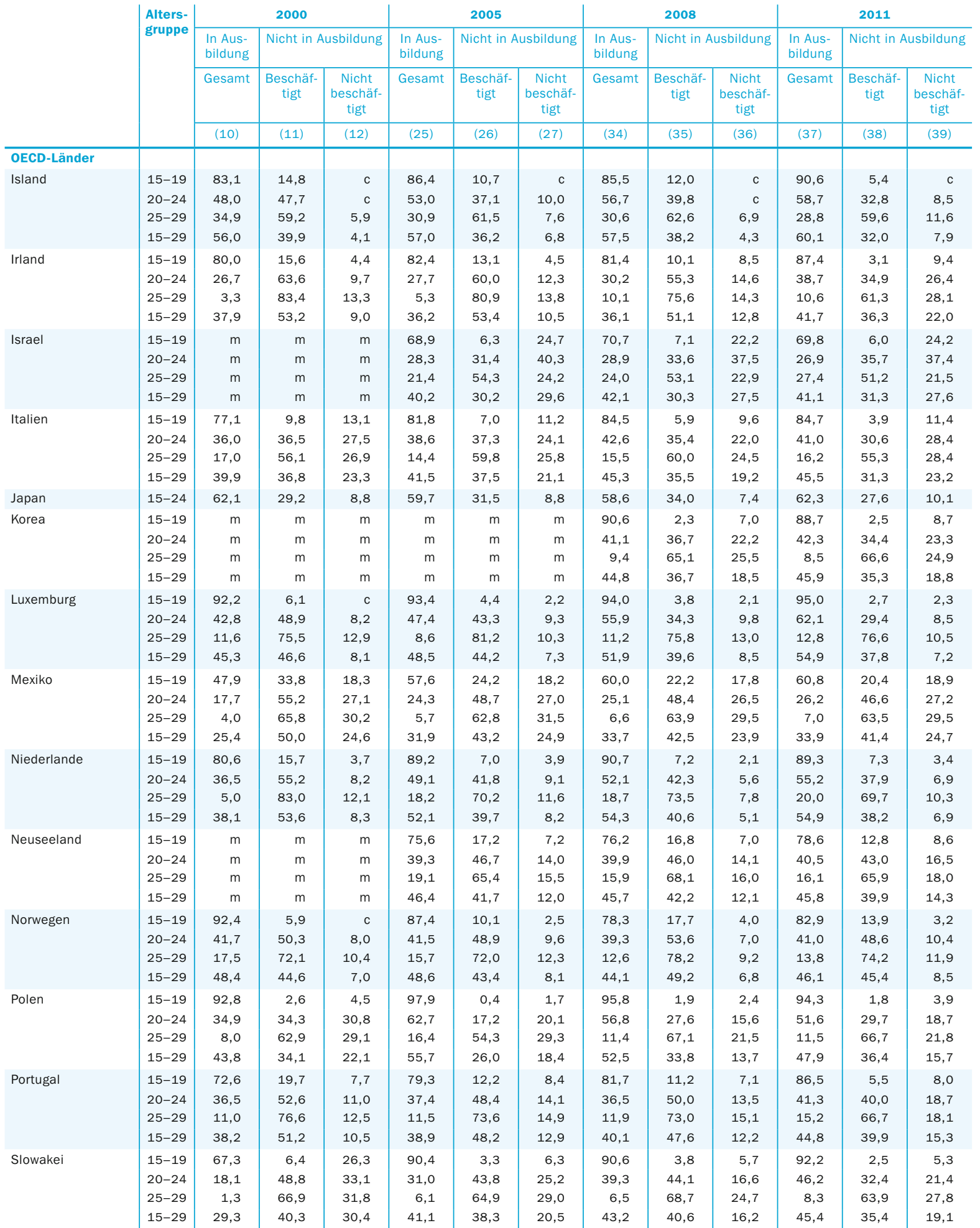


Tabelle C5.4a (Forts. 2)

Entwicklung des Anteils junger Menschen (in \%), die sich in Ausbildung und nicht in Ausbildung befinden (beschäftigt oder nicht beschäftigt), nach Altersgruppe (1997-2011) ${ }^{1}$

\begin{tabular}{|c|c|c|c|c|c|c|c|c|c|c|c|c|c|}
\hline & \multirow{4}{*}{$\begin{array}{l}\text { Alters- } \\
\text { gruppe }\end{array}$} & \multicolumn{3}{|c|}{2000} & \multicolumn{3}{|c|}{2005} & \multicolumn{3}{|c|}{2008} & \multicolumn{3}{|c|}{2011} \\
\hline & & \multirow{2}{*}{$\begin{array}{l}\text { In Aus- } \\
\text { bildung }\end{array}$} & \multicolumn{2}{|c|}{ Nicht in Ausbildung } & \multirow{2}{*}{$\begin{array}{l}\text { In Aus- } \\
\text { bildung }\end{array}$} & \multicolumn{2}{|c|}{ Nicht in Ausbildung } & \multirow{2}{*}{$\begin{array}{l}\text { In Aus- } \\
\text { bildung }\end{array}$} & \multicolumn{2}{|c|}{ Nicht in Ausbildung } & \multirow{2}{*}{$\begin{array}{l}\text { In Aus- } \\
\text { bildung } \\
\text { Gesamt }\end{array}$} & \multicolumn{2}{|c|}{ Nicht in Ausbildung } \\
\hline & & & $\begin{array}{c}\text { Beschäf- } \\
\text { tigt }\end{array}$ & $\begin{array}{c}\text { Nicht } \\
\text { beschäf- } \\
\text { tigt }\end{array}$ & & $\begin{array}{c}\text { Beschäf- } \\
\text { tigt }\end{array}$ & $\begin{array}{c}\text { Nicht } \\
\text { beschäf- } \\
\text { tigt }\end{array}$ & & $\begin{array}{c}\text { Beschäf- } \\
\text { tigt }\end{array}$ & $\begin{array}{l}\text { Nicht } \\
\text { beschäf- } \\
\text { tigt }\end{array}$ & & $\begin{array}{c}\text { Beschäf- } \\
\text { tigt }\end{array}$ & $\begin{array}{l}\text { Nicht } \\
\text { beschäf- } \\
\text { tigt }\end{array}$ \\
\hline & & (10) & (11) & (12) & (25) & (26) & (27) & (34) & (35) & (36) & (37) & (38) & (39) \\
\hline \multicolumn{14}{|l|}{ OECD-Länder } \\
\hline \multirow[t]{4}{*}{ Slowenien } & $15-19$ & $\mathrm{~m}$ & $\mathrm{~m}$ & $\mathrm{~m}$ & 92,4 & 2,7 & 4,9 & 92,2 & 3,4 & 4,4 & 95,4 & 1,2 & 3,4 \\
\hline & $20-24$ & $\mathrm{~m}$ & $\mathrm{~m}$ & $\mathrm{~m}$ & 55,7 & 31,3 & 13,0 & 60,6 & 29,2 & 10,3 & 68,7 & 20,0 & 11,3 \\
\hline & $25-29$ & $\mathrm{~m}$ & $\mathrm{~m}$ & $\mathrm{~m}$ & 24,6 & 63,9 & 11,5 & 26,9 & 63,2 & 9,9 & 27,1 & 57,3 & 15,6 \\
\hline & $15-29$ & $\mathrm{~m}$ & $\mathrm{~m}$ & $\mathrm{~m}$ & 55,5 & 34,4 & 10,1 & 57,1 & 34,5 & 8,5 & 60,2 & 29,1 & 10,7 \\
\hline Spanien & $15-19$ & 80,6 & 11,4 & 8,0 & 78,2 & 11,0 & 10,8 & 78,9 & 10,5 & 10,5 & 84,7 & 3,3 & 12,0 \\
\hline & $20-24$ & 44,6 & 40,3 & 15,0 & 35,1 & 45,5 & 19,4 & 34,0 & 46,5 & 19,4 & 40,8 & 30,0 & 29,2 \\
\hline & $25-29$ & 16,2 & 62,4 & 21,4 & 10,9 & 69,3 & 19,8 & 9,5 & 71,5 & 18,9 & 13,2 & 57,1 & 29,6 \\
\hline & $15-29$ & 45,0 & 39,8 & 15,3 & 37,1 & 45,7 & 17,2 & 36,3 & 46,9 & 16,8 & 42,5 & 33,1 & 24,4 \\
\hline Schweden & $15-19$ & 90,6 & 5,8 & 3,6 & 89,6 & 5,8 & 4,7 & 87,4 & 8,2 & 4,4 & 89,4 & 6,4 & 4,2 \\
\hline & $20-24$ & 42,1 & 47,2 & 10,7 & 42,5 & 44,1 & 13,4 & 39,5 & 47,5 & 12,9 & 43,4 & 43,7 & 12,9 \\
\hline & $25-29$ & 21,9 & 68,9 & 9,2 & 23,6 & 66,5 & 10,0 & 21,7 & 68,7 & 9,5 & 24,1 & 66,1 & 9,8 \\
\hline & $15-29$ & 50,2 & 41,9 & 7,9 & 52,9 & 38,0 & 9,2 & 51,3 & 39,9 & 8,7 & 52,6 & 38,4 & 9,0 \\
\hline Schweiz & $15-19$ & 84,6 & 7,5 & 7,9 & 85,3 & 7,2 & 7,5 & 82,9 & 7,7 & 9,4 & 87,9 & 7,1 & 5,0 \\
\hline & $20-24$ & 37,4 & 56,7 & 5,9 & 37,9 & 50,3 & 11,9 & 42,7 & 48,2 & 9,1 & 41,5 & 47,8 & 10,7 \\
\hline & $25-29$ & 15,1 & 73,9 & 11,0 & 12,3 & 75,9 & 11,8 & 14,4 & 75,5 & 10,1 & 17,7 & 71,4 & 10,9 \\
\hline & $15-29$ & 45,1 & 46,6 & 8,3 & 44,4 & 45,2 & 10,4 & 46,0 & 44,5 & 9,6 & 47,6 & 43,4 & 9,0 \\
\hline Türkei & $15-19$ & 39,2 & 29,6 & 31,2 & 45,8 & 18,1 & 36,1 & 44,7 & 18,2 & 37,1 & 60,1 & 15,1 & 24,8 \\
\hline & $20-24$ & 12,7 & 43,1 & 44,2 & 15,4 & 34,9 & 49,7 & 20,0 & 33,9 & 46,1 & 25,6 & 34,7 & 39,6 \\
\hline & $25-29$ & 2,9 & 58,8 & 38,3 & 4,0 & 50,2 & 45,8 & 4,9 & 51,6 & 43,5 & 8,9 & 50,9 & 40,2 \\
\hline & $15-29$ & 18,5 & 43,7 & 37,8 & 22,4 & 34,0 & 43,6 & 23,4 & 34,6 & 42,0 & 31,8 & 33,5 & 34,6 \\
\hline Vereinigtes & $15-19$ & 77,0 & 15,0 & 8,0 & 76,0 & 14,6 & 9,3 & 76,5 & 13,7 & 9,8 & 81,2 & 9,3 & 9,5 \\
\hline Königreich & $20-24$ & 32,4 & 52,2 & 15,4 & 32,1 & 51,0 & 16,8 & 28,3 & 53,4 & 18,3 & 33,1 & 47,8 & 19,1 \\
\hline & $25-29$ & 13,3 & 70,3 & 16,3 & 13,3 & 70,1 & 16,6 & 12,3 & 71,9 & 15,8 & 13,7 & 69,0 & 17,3 \\
\hline & $15-29$ & 40,0 & 46,6 & 13,3 & 41,2 & 44,6 & 14,2 & 38,2 & 47,1 & 14,8 & 41,4 & 43,1 & 15,5 \\
\hline Vereinigte Staaten & $15-19$ & 81,3 & 11,7 & 7,0 & 85,6 & 8,3 & 6,1 & 85,2 & 7,6 & 7,2 & 86,2 & 6,6 & 7,1 \\
\hline & $20-24$ & 32,5 & 53,1 & 14,4 & 36,1 & 48,4 & 15,5 & 36,9 & 45,9 & 17,2 & 39,9 & 41,6 & 18,5 \\
\hline & $25-29$ & 11,4 & 72,8 & 15,8 & 11,9 & 70,0 & 18,1 & 13,2 & 67,3 & 19,5 & 14,8 & 63,4 & 21,7 \\
\hline & $15-29$ & 43,1 & 44,6 & 12,2 & 45,2 & 41,7 & 13,1 & 45,3 & 40,1 & 14,6 & 46,7 & 37,4 & 15,9 \\
\hline OECD-Durchschnitt & $15-19$ & 80,1 & 11,4 & 9,4 & 83,7 & 8,3 & 8,2 & 83,8 & 8,5 & 7,8 & 85,6 & 6,2 & 8,3 \\
\hline & $20-24$ & 34,7 & 48,2 & 17,7 & 40,3 & 42,2 & 17,5 & 41,8 & 42,6 & 16,0 & 44,2 & 37,5 & 18,4 \\
\hline & $25-29$ & 12,2 & 68,7 & 19,1 & 14,1 & 67,1 & 18,8 & 14,4 & 68,3 & 17,4 & 15,8 & 64,2 & 20,0 \\
\hline & $15-29$ & 41,4 & 43,6 & 15,1 & 45,1 & 39,9 & 14,9 & 45,7 & 40,7 & 13,7 & 47,2 & 37,0 & 15,8 \\
\hline EU21-Durchschnitt & 15-19 & 83,2 & 9,2 & 7,9 & 87,7 & 6,1 & 6,2 & 88,0 & 6,4 & 5,6 & 89,9 & 4,0 & 6,1 \\
\hline & $20-24$ & 35,6 & 47,0 & 17,3 & 42,6 & 41,2 & 16,1 & 44,2 & 41,9 & 13,9 & 47,3 & 35,4 & 17,3 \\
\hline & $25-29$ & 11,3 & 69,3 & 19,4 & 13,7 & 68,0 & 18,3 & 14,3 & 69,4 & 16,4 & 15,8 & 64,5 & 19,7 \\
\hline & $15-29$ & 41,9 & 43,0 & 15,0 & 46,4 & 39,8 & 13,8 & 47,2 & 40,6 & 12,2 & 48,8 & 36,4 & 14,8 \\
\hline Sonst. G20-Länder & & & & & & & & & & & & & \\
\hline Argentinien & & $\mathrm{m}$ & $\mathrm{m}$ & $\mathrm{m}$ & $\mathrm{m}$ & $\mathrm{m}$ & $\mathrm{m}$ & $\mathrm{m}$ & $\mathrm{m}$ & $m$ & $m$ & $\mathrm{~m}$ & $\mathrm{~m}$ \\
\hline Brasilien & $15-19$ & $\mathrm{~m}$ & $\mathrm{~m}$ & $\mathrm{~m}$ & $\mathrm{~m}$ & $\mathrm{~m}$ & $\mathrm{~m}$ & 69,1 & 17,2 & 13,8 & 62,4 & 24,6 & 13,1 \\
\hline & $20-24$ & $\mathrm{~m}$ & $\mathrm{~m}$ & $\mathrm{~m}$ & $\mathrm{~m}$ & $\mathrm{~m}$ & $\mathrm{~m}$ & 23,8 & 53,7 & 22,5 & 22,5 & 53,2 & 24,3 \\
\hline & $25-29$ & $\mathrm{~m}$ & $\mathrm{~m}$ & $\mathrm{~m}$ & $\mathrm{~m}$ & $\mathrm{~m}$ & $\mathrm{~m}$ & 12,2 & 67,1 & 20,7 & 11,1 & 67,3 & 21,6 \\
\hline & $15-29$ & $\mathrm{~m}$ & $\mathrm{~m}$ & $\mathrm{~m}$ & $\mathrm{~m}$ & $\mathrm{~m}$ & $\mathrm{~m}$ & 35,4 & 45,7 & 19,0 & 33,4 & 47,2 & 19,3 \\
\hline China & & $\mathrm{m}$ & $\mathrm{m}$ & $\mathrm{m}$ & $\mathrm{m}$ & $\mathrm{m}$ & $\mathrm{m}$ & $\mathrm{m}$ & $\mathrm{m}$ & $\mathrm{m}$ & $\mathrm{m}$ & $\mathrm{m}$ & $m$ \\
\hline Indien & & $\mathrm{m}$ & $\mathrm{m}$ & $\mathrm{m}$ & $\mathrm{m}$ & $\mathrm{m}$ & $\mathrm{m}$ & $\mathrm{m}$ & $\mathrm{m}$ & $\mathrm{m}$ & $\mathrm{m}$ & $\mathrm{m}$ & $\mathrm{m}$ \\
\hline Indonesien & & $\mathrm{m}$ & $\mathrm{m}$ & $\mathrm{m}$ & $\mathrm{m}$ & $\mathrm{m}$ & $\mathrm{m}$ & $\mathrm{m}$ & $\mathrm{m}$ & $\mathrm{m}$ & $\mathrm{m}$ & $\mathrm{m}$ & $m$ \\
\hline Russische Föd. & & $\mathrm{m}$ & $\mathrm{m}$ & $\mathrm{m}$ & $\mathrm{m}$ & $\mathrm{m}$ & $\mathrm{m}$ & $\mathrm{m}$ & $\mathrm{m}$ & $\mathrm{m}$ & $\mathrm{m}$ & $\mathrm{m}$ & $\mathrm{m}$ \\
\hline Saudi-Arabien & & $\mathrm{m}$ & $\mathrm{m}$ & $\mathrm{m}$ & $\mathrm{m}$ & $\mathrm{m}$ & $\mathrm{m}$ & $\mathrm{m}$ & $\mathrm{m}$ & $\mathrm{m}$ & $\mathrm{m}$ & $\mathrm{m}$ & $\mathrm{m}$ \\
\hline Südafrika & & $\mathrm{m}$ & $\mathrm{m}$ & $\mathrm{m}$ & $\mathrm{m}$ & $\mathrm{m}$ & $\mathrm{m}$ & $\mathrm{m}$ & $\mathrm{m}$ & $\mathrm{m}$ & $\mathrm{m}$ & $\mathrm{m}$ & $\mathrm{m}$ \\
\hline G20-Durchschnitt & & $\mathbf{m}$ & $\mathbf{m}$ & $\mathbf{m}$ & $\mathbf{m}$ & $\mathbf{m}$ & $\mathbf{m}$ & $\mathbf{m}$ & $\mathbf{m}$ & $\mathbf{m}$ & $\mathbf{m}$ & $\mathbf{m}$ & $\mathbf{m}$ \\
\hline
\end{tabular}

1. Die Zahlen für die Jahre 1997, 1998, 1999, 2001, 2002, 2003, 2004, 2006, 2007, 2009 und 2010 sind im Internet verfügbar (s. StatLink unten). Quelle: OECD. Hinweise s. Anhang 3 unter www.oecd.org/edu/eag2012. StatLink: http://dx.doi.org/10.1787/888932851117 Erläuterung der Kennzeichnung fehlender Daten s. Hinweise für den Leser. 
Anteil 15- bis 29-Jähriger (in \%), die sich in Ausbildung bzw. nicht in Ausbildung befinden, nach Bildungsstand und Erwerbsstatus, einschließlich Dauer der Erwerbslosigkeit (2011)

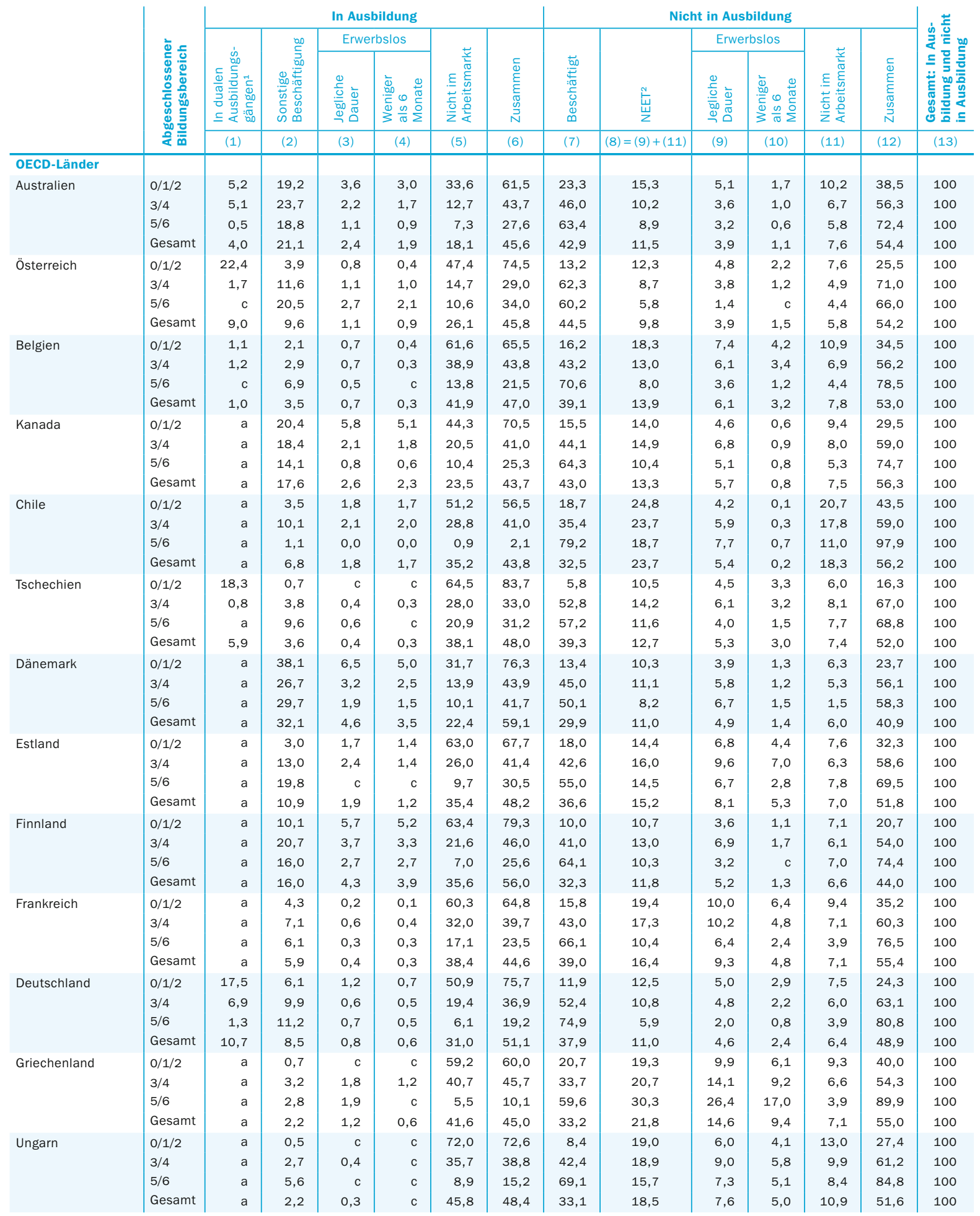

1. Teilnehmer an dualen Ausbildungsgängen gelten als sowohl in Ausbildung als auch beschäftigt, ohne Bezug auf ihren ILO-Erwerbsstatus.

2. 15- bis 29-Jährige, die weder beschäftigt sind noch sich in Ausbildung befinden. 3. Daten beziehen sich auf 15- bis 24-Jährige.

Quelle: OECD. Hinweise s. Anhang 3 unter www.oecd.org/edu/eag.htm. StatLink: http://dx.doi.org/10.1787/888932851193

Erläuterung der Kennzeichnung fehlender Daten s. Hinweise für den Leser. 
Tabelle C5.5a (Forts. 1)

Anteil 15- bis 29-Jähriger (in \%), die sich in Ausbildung bzw. nicht in Ausbildung befinden, nach Bildungsstand und Erwerbsstatus, einschließlich Dauer der Erwerbslosigkeit (2011)

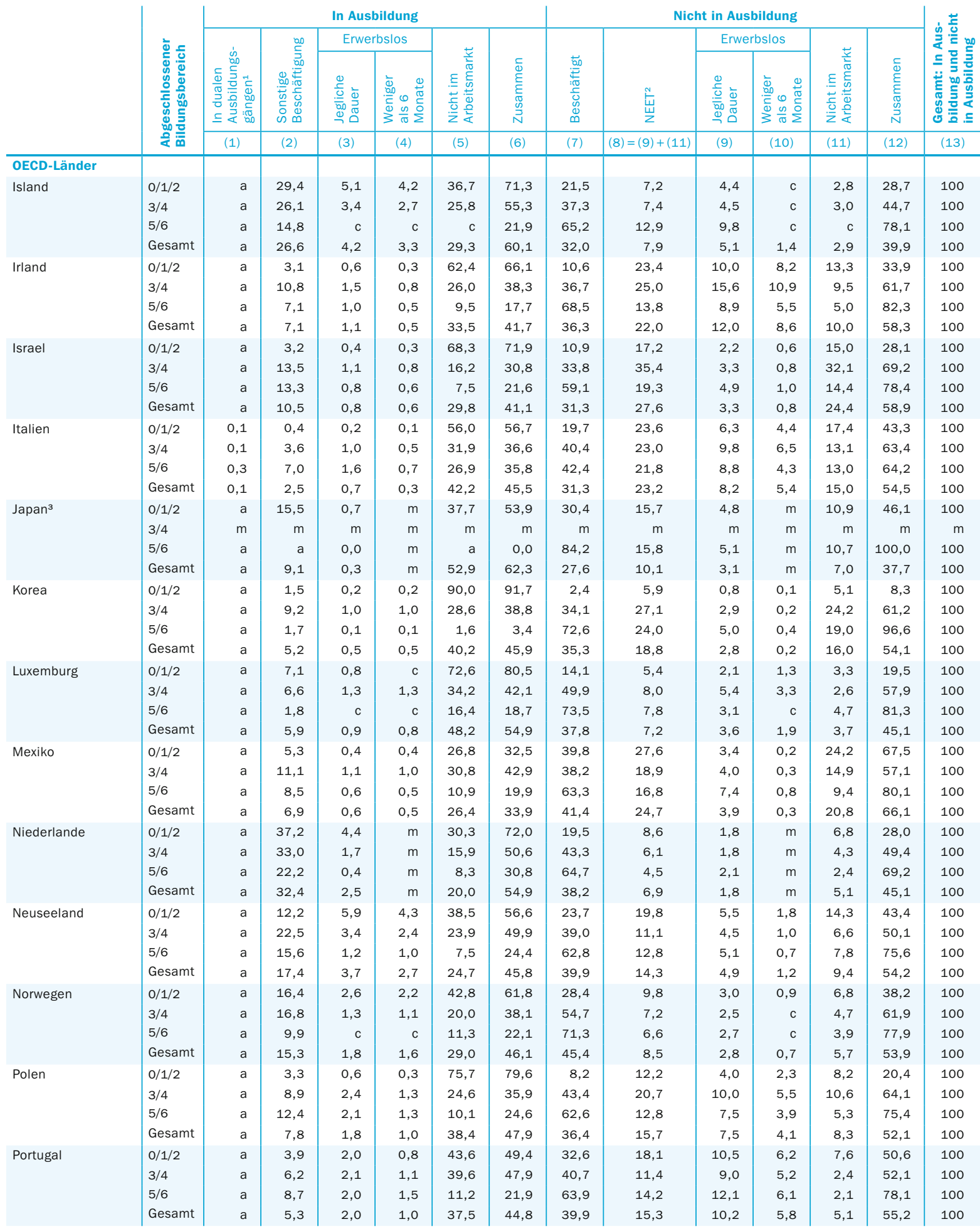

1. Teilnehmer an dualen Ausbildungsgängen gelten als sowohl in Ausbildung als auch beschäftigt, ohne Bezug auf ihren ILO-Erwerbsstatus.

2. 15- bis 29-Jährige, die weder beschäftigt sind noch sich in Ausbildung befinden. 3. Daten beziehen sich auf 15- bis 24-Jährige.

Quelle: OECD. Hinweise s. Anhang 3 unter www.oecd.org/edu/eag.htm. StatLink: http://dx.doi.org/10.1787/888932851193

Erläuterung der Kennzeichnung fehlender Daten s. Hinweise für den Leser. 
Tabelle C5.5a (Forts. 2)

Anteil 15- bis 29-Jähriger (in \%), die sich in Ausbildung bzw. nicht in Ausbildung befinden, nach Bildungsstand und Erwerbsstatus, einschließlich Dauer der Erwerbslosigkeit (2011)

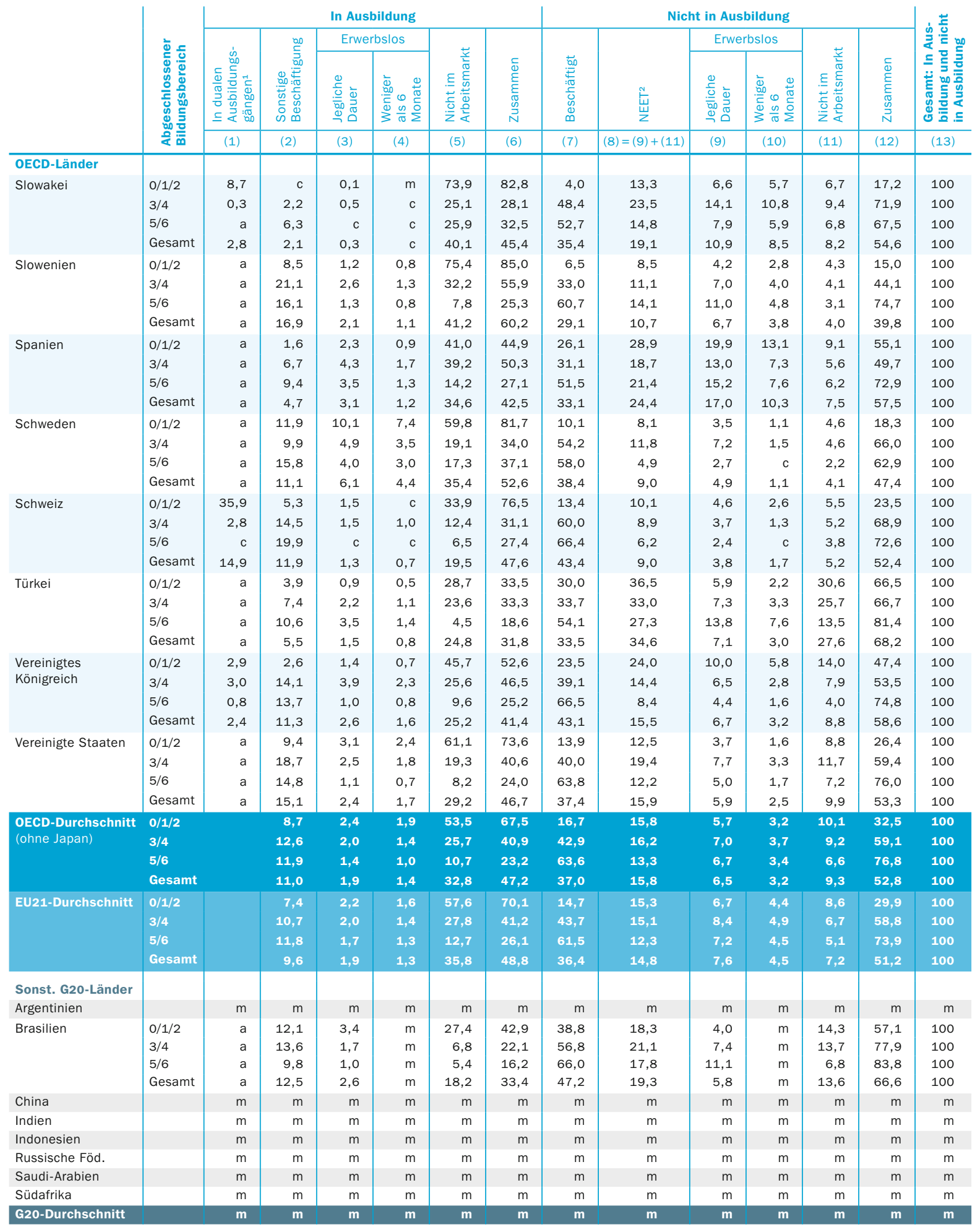

1. Teilnehmer an dualen Ausbildungsgängen gelten als sowohl in Ausbildung als auch beschäftigt, ohne Bezug auf ihren ILO-Erwerbsstatus.

2. 15- bis 29-Jährige, die weder beschäftigt sind noch sich in Ausbildung befinden. 3. Daten beziehen sich auf 15- bis 24-Jährige.

Quelle: OECD. Hinweise s. Anhang 3 unter www.oecd.org/edu/eag.htm. StatLink: http://dx.doi.org/10.1787/888932851193

Erläuterung der Kennzeichnung fehlender Daten s. Hinweise für den Leser. 
Tabelle C5.6

Anteil 15- bis 29-Jähriger (in \%), die sich in Ausbildung bzw. nicht in Ausbildung befinden, nach Bildungsstand und Erwerbsstatus, einschließlich Teilzeitbeschäftigten (2011)

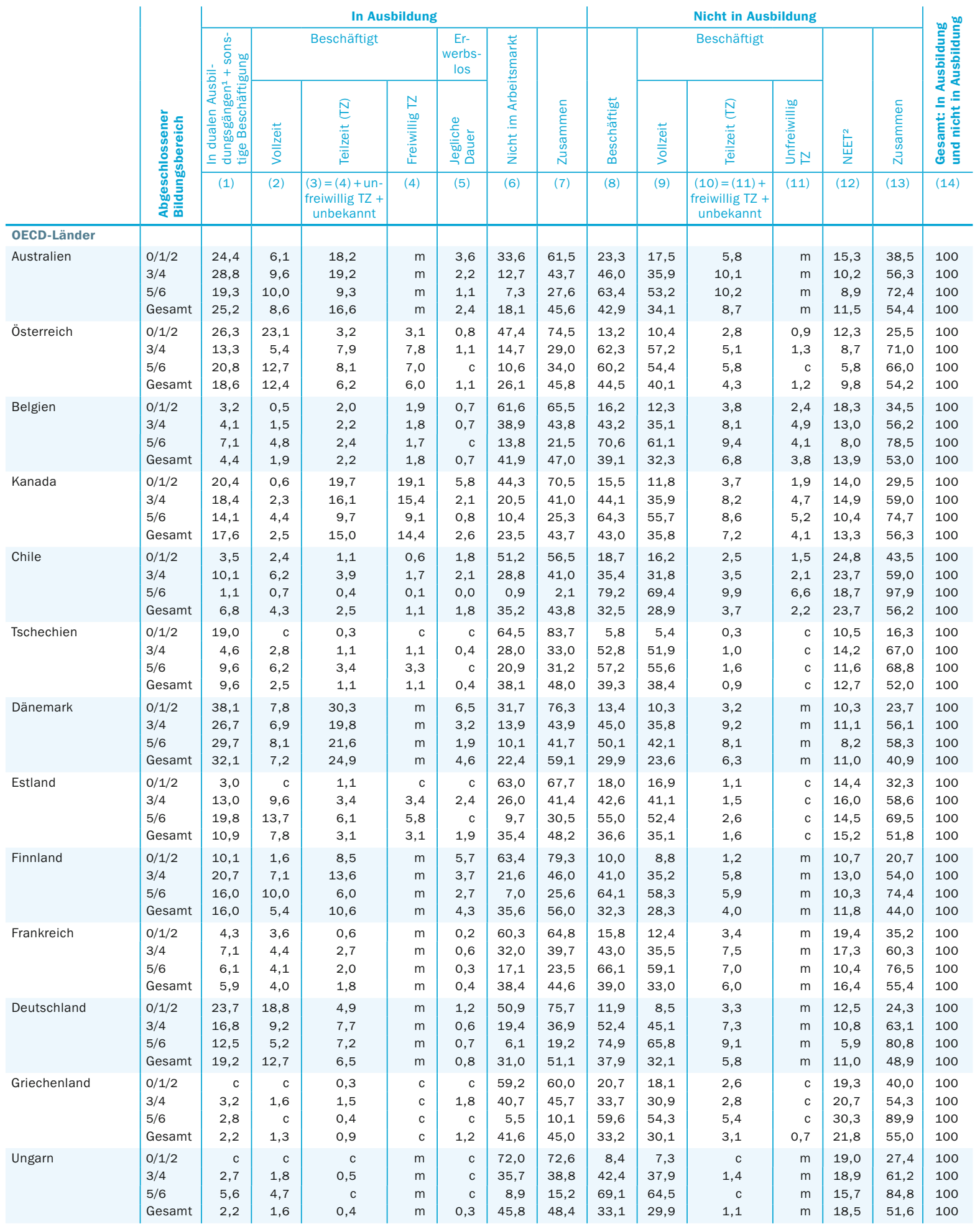

1. Teilnehmer an dualen Ausbildungsgängen gelten als sowohl in Ausbildung als auch beschäftigt, ohne Bezug auf ihren ILO-Erwerbsstatus.

2. 15- bis 29-Jährige, die weder beschäftigt sind noch sich in Ausbildung befinden. 3. Daten beziehen sich auf 15- bis 24-Jährige.

Quelle: OECD. Hinweise s. Anhang 3 unter www.oecd.org/edu/eag.htm. StatLink: http://dx.doi.org/10.1787/888932851231

Erläuterung der Kennzeichnung fehlender Daten s. Hinweise für den Leser. 
Tabelle C5.6 (Forts. 1)

Anteil 15- bis 29-Jähriger (in \%), die sich in Ausbildung bzw. nicht in Ausbildung befinden, nach Bildungsstand und Erwerbsstatus, einschließlich Teilzeitbeschäftigten (2011)

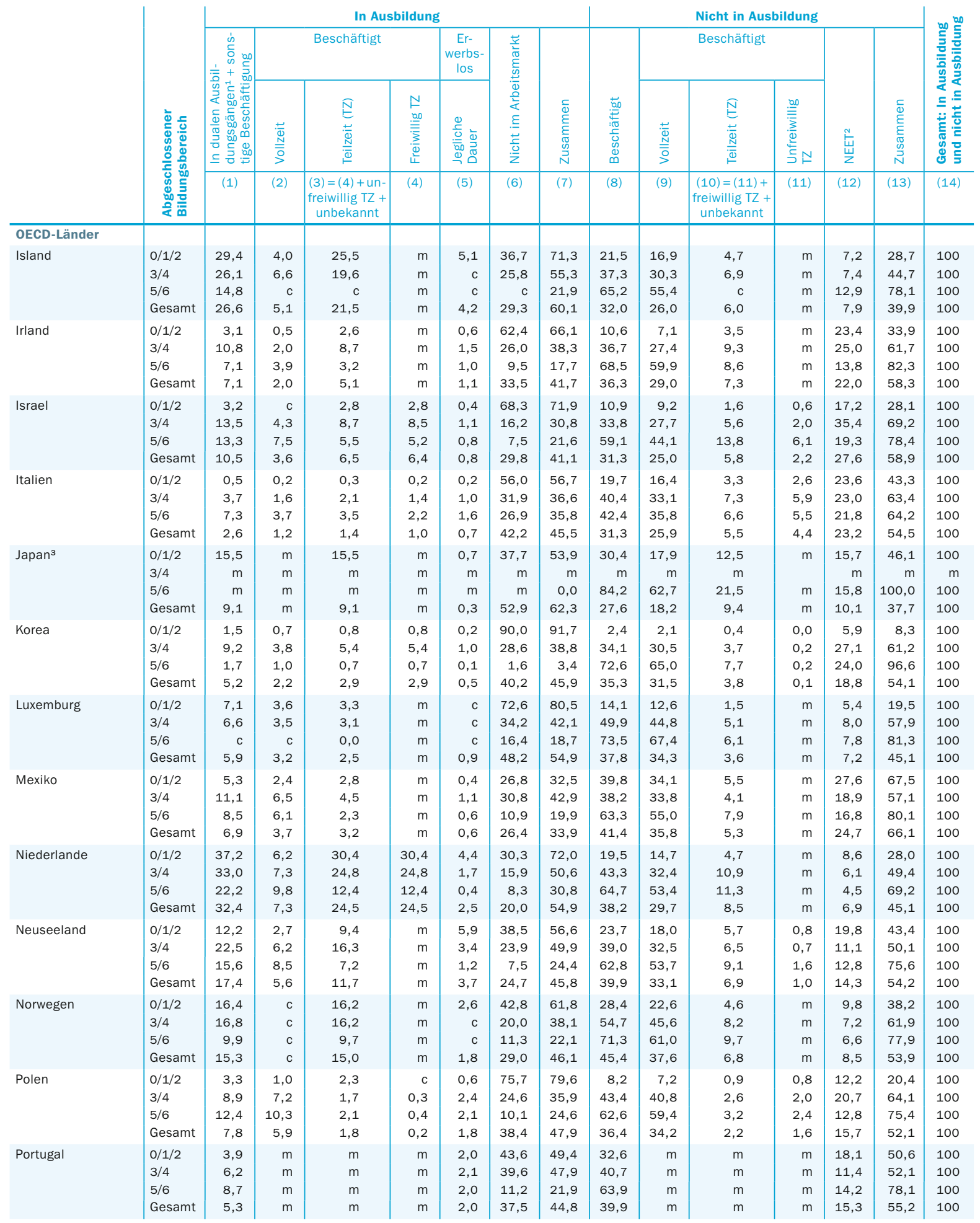

1. Teilnehmer an dualen Ausbildungsgängen gelten als sowohl in Ausbildung als auch beschäftigt, ohne Bezug auf ihren ILO-Erwerbsstatus.

2. 15- bis 29-Jährige, die weder beschäftigt sind noch sich in Ausbildung befinden. 3. Daten beziehen sich auf 15- bis 24-Jährige.

Quelle: OECD. Hinweise s. Anhang 3 unter www.oecd.org/edu/eag.htm. StatLink: http://dx.doi.org/10.1787/888932851231

Erläuterung der Kennzeichnung fehlender Daten s. Hinweise für den Leser. 
Tabelle C5.6 (Forts. 2)

Anteil 15- bis 29-Jähriger (in \%), die sich in Ausbildung bzw. nicht in Ausbildung befinden, nach Bildungsstand und Erwerbsstatus, einschließlich Teilzeitbeschäftigten (2011)

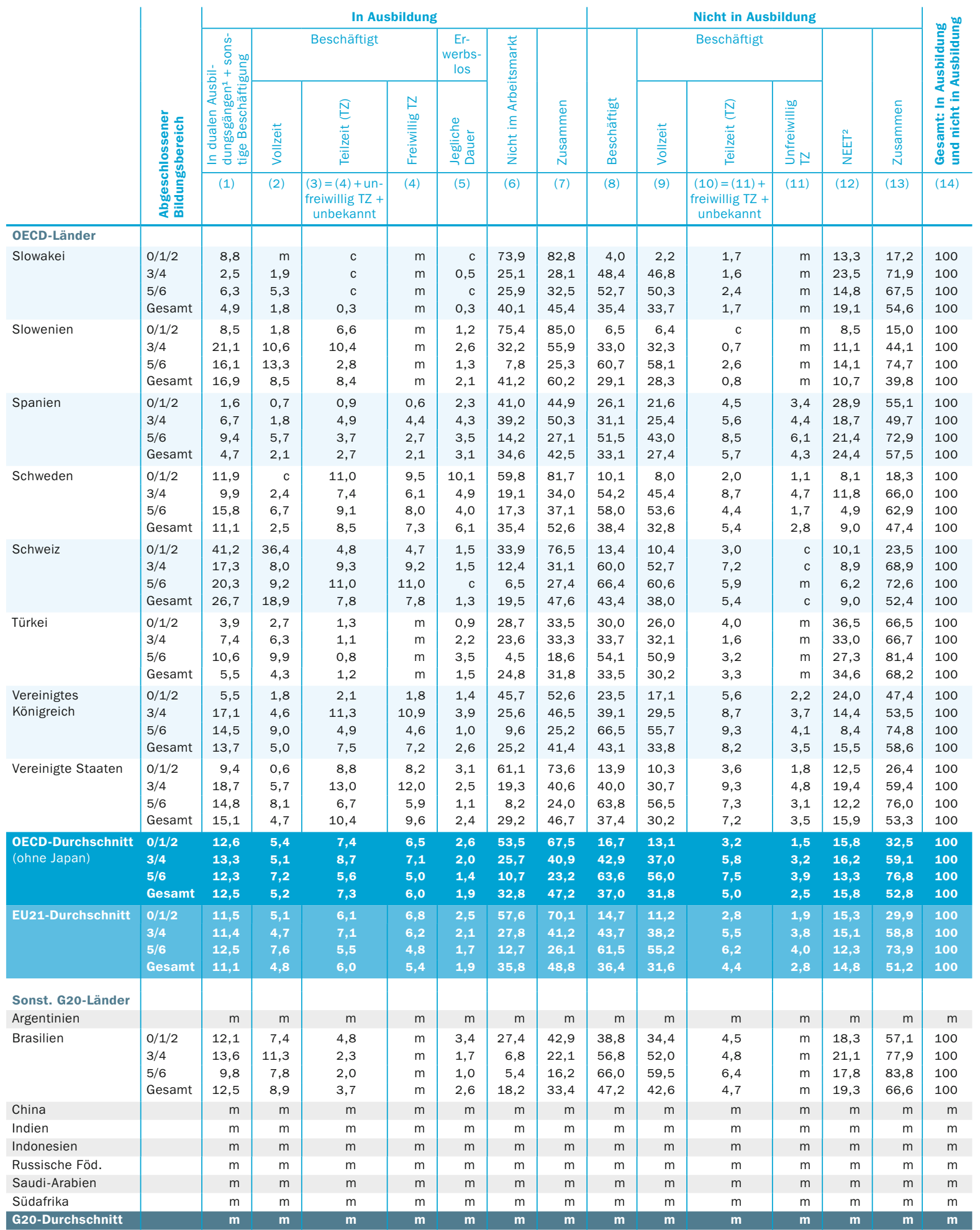

1. Teilnehmer an dualen Ausbildungsgängen gelten als sowohl in Ausbildung als auch beschäftigt, ohne Bezug auf ihren ILO-Erwerbsstatus.

2. 15- bis 29-Jährige, die weder beschäftigt sind noch sich in Ausbildung befinden. 3. Daten beziehen sich auf 15- bis 24-Jährige.

Quelle: OECD. Hinweise s. Anhang 3 unter www.oecd.org/edu/eag.htm. StatLink: http://dx.doi.org/10.1787/888932851231

Erläuterung der Kennzeichnung fehlender Daten s. Hinweise für den Leser. 
Tabelle C5.7

Entwicklung des Anteils 15- bis 29-Jähriger (in \%), die Vollzeit bzw. Teilzeit arbeiten und sich in Ausbildung bzw. nicht in Ausbildung befinden (2006-2011) ${ }^{1}$

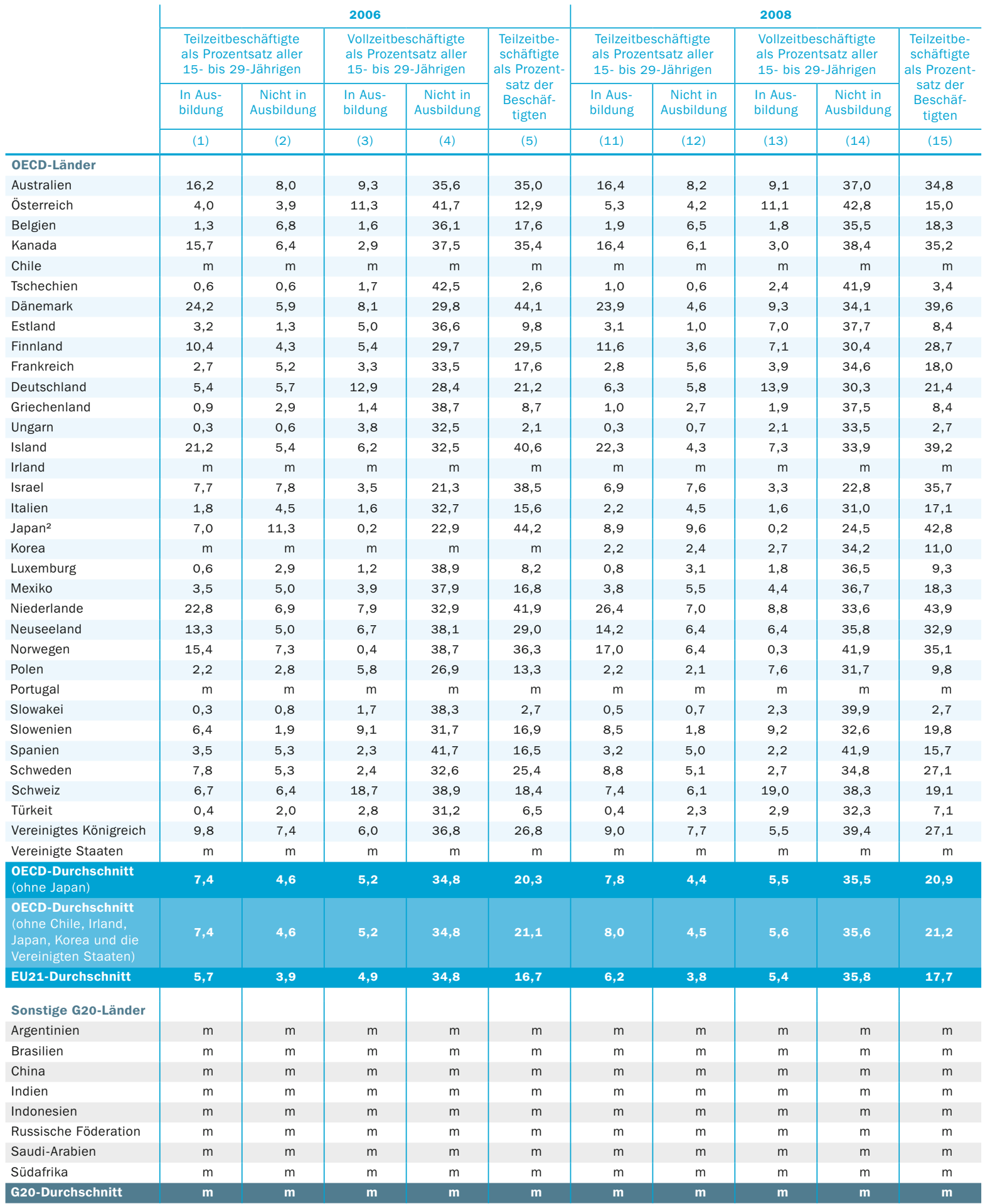

1. Die Daten für die Jahre 2007 und 2009 sind im Internet verfügbar (s. StatLink unten). 2. Daten beziehen sich auf 15- bis 24-Jährige. Quelle: OECD. Hinweise s. Anhang 3 unter www.oecd.org/edu/eag.htm. StatLink: http://dx.doi.org/10.1787/888932851250 Erläuterung der Kennzeichnung fehlender Daten s. Hinweise für den Leser. 
Tabelle C5.7 (Forts.)

Entwicklung des Anteils 15- bis 29-Jähriger (in \%), die Vollzeit bzw. Teilzeit arbeiten und sich in Ausbildung bzw. nicht in Ausbildung befinden (2006-2011) ${ }^{1}$

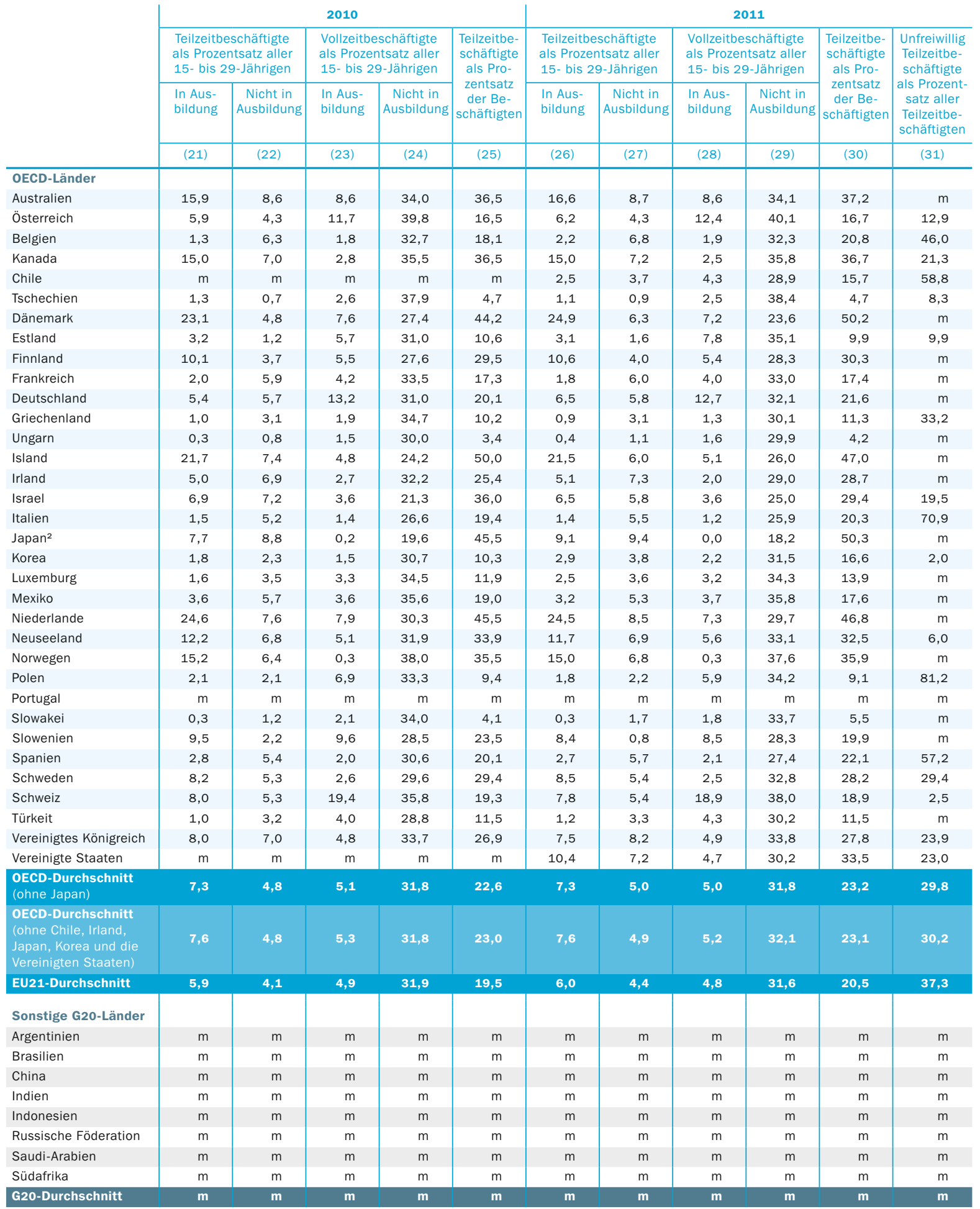

1. Die Daten für die Jahre 2007 und 2009 sind im Internet verfügbar (s. StatLink unten). 2. Daten beziehen sich auf 15- bis 24-Jährige. Quelle: OECD. Hinweise s. Anhang 3 unter www.oecd.org/edu/eag.htm. StatLink: http://dx.doi.org/10.1787/888932851250 Erläuterung der Kennzeichnung fehlender Daten s. Hinweise für den Leser. 


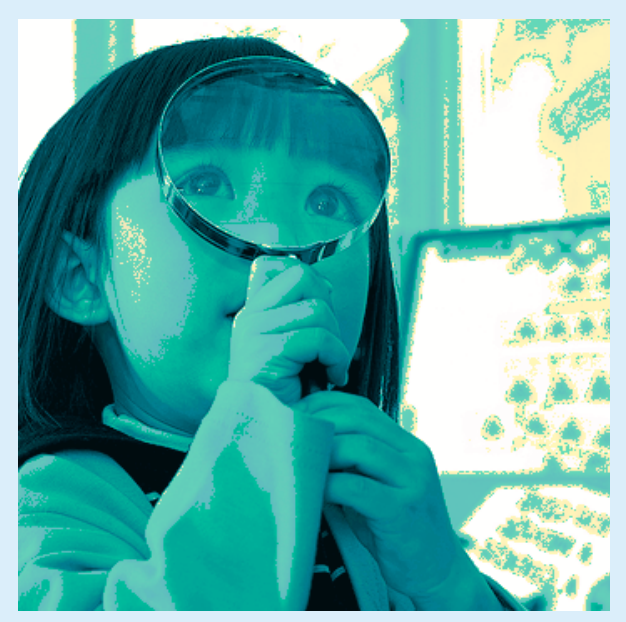

\section{Das Lernumfeld und die Organisation von Schulen}

Indikator Di

Wie viel Zeit verbringen Schüler im

Klassenzimmer?

StatLink: http://dx.doi.org/10.1787/888932851269

Indikator $\mathrm{D}_{2}$

Wie ist die Schüler-Lehrkräfte-Relation und wie groß sind die Klassen?

StatLink: http://dx.doi.org/10.1787/888932851573

Indikator $\mathrm{D}_{3}$

Wie hoch sind die Gehälter der Lehrkräfte?

http://dx.doi.org/10.1787/888932851744
Indikator $\mathrm{D}_{4}$

Wie viel Zeit unterrichten Lehrkräfte?

StatLink: http://dx.doi.org/10.1787/888932851934

WEB Indikator $\mathrm{D}_{5}$

Wie ist das demografische und das Qualifikationsprofil der Lehrerschaft?

StatLink: http://dx.doi.org/10.1787/888932851991 



\section{Wie viel Zeit verbringen Schüler im Klassenzimmer?}

In den OECD-Ländern sind für Schüler während des Besuchs des Primar- und Sekundarbereichs I im Durchschnitt 7.75I Stunden Unterricht vorgesehen, wobei der größte Teil dieser vorgesehenen Unterrichtszeit auf Pflichtunterricht entfällt.

Im Durchschnitt der OECD-Länder entfallen für Schüler des Primarbereichs 5I Prozent der Pflichtunterrichtszeit auf Lesen, Schreiben und Literatur, Mathematik und Naturwissenschaften, bei den Schülern des Sekundarbereichs I sind es 4I Prozent.

\section{Abbildung D1.1}

Vorgesehene Zahl an Unterrichtszeitstunden in öffentlichen Bildungseinrichtungen (2011)

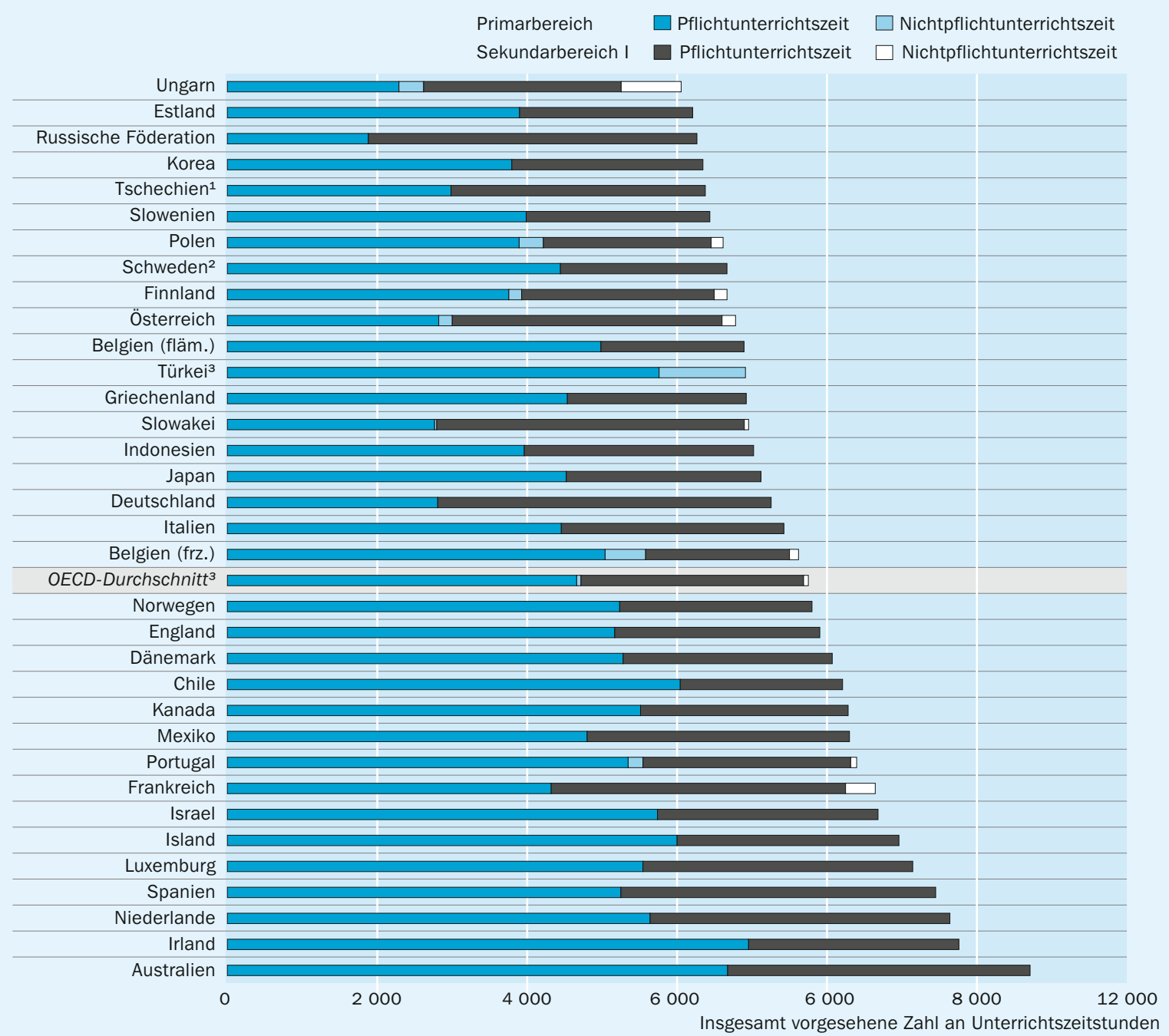

1. Mindestzahl an (Zeit-)Stunden pro Jahr. 2. Geschätzte Mindestzahl an (Zeit-)Stunden pro Jahr, da keine Aufteilung nach Altersgruppe verfügbar ist. 


\section{Kontext}

Ein Großteil der öffentlichen Investitionen in das Lernen der Schüler erfolgt in Form der Bereitstellung von formalem Unterricht im Klassenzimmer. Die Länder treffen verschiedene Entscheidungen im Zusammenhang mit der insgesamt für Unterricht vorgesehenen Zeit und den von den Schülern zu belegenden Pflichtfächern. Diese Entscheidungen spiegeln nationale und/oder regionale Prioritäten und Präferenzen in Bezug darauf wider, in welchem Alter die Schüler in welchen Fächern unterrichtet werden sollen. Üblicherweise legen die Länder per Gesetz oder Vorschrift bestimmte Anforderungen hinsichtlich der Unterrichtszeit fest. Meistens handelt es sich dabei um die Mindestzahl an Unterrichtszeitstunden, die eine Schule anbieten muss, da davon ausgegangen wird, dass ein ausreichendes Angebot an Unterrichtszeit eine Grundvoraussetzung für gute Lernergebnisse ist.

Es ist eine der zentralen Aufgaben der Bildungspolitik, die zur Verfügung stehenden Ressourcen auf die Bedürfnisse der Schüler abzustimmen und die zur Verfügung stehende Zeit optimal zu nutzen. Die Gehälter der Lehrkräfte, die Instandhaltung der Bildungseinrichtungen und die Bereitstellung sonstiger Bildungsressourcen sind die wichtigsten Kostenfaktoren von Bildung. Die Zeitdauer, für die den Schülern diese Bildungsressourcen zur Verfügung gestellt werden (wie zum Teil in diesem Indikator dargestellt), ist also bei der Zuweisung der Mittel von großer Bedeutung (s. Indikator B7, in dem die Faktoren aufgezeigt werden, die die Gehaltskosten der Lehrkräfte pro Schüler beeinflussen).

\section{Weitere wichtige Ergebnisse}

In den OECD-Ländern erhalten Schüler des Primarbereichs im Durchschnitt pro Jahr 791 (Zeit-)Stunden Pflichtunterricht und 802 (Zeit-)Stunden vorgesehenen Unterricht im Klassenzimmer. Schüler des Sekundarbereichs I erhalten im Durchschnitt II6 (Zeit-) Stunden mehr Pflichtunterricht pro Jahr als Schüler des Primarbereichs und I22 (Zeit-)Stunden mehr vorgesehenen Unterricht.

Der Anteil des für Lesen, Schreiben und Literatur vorgesehenen Pflichtteils des Lehrplans für Schüler des Primarbereichs variiert zwischen 15 Prozent in Indonesien und 38 Prozent in Ungarn, für Schüler des Sekundarbereichs I reicht er von 11 Prozent in Japan und Portugal bis zu 24 Prozent in Irland.

In allen OECD-Ländern, die Daten zur Verfügung gestellt haben, verbringen Schüler des Primarbereichs den größten Teil der Zeit mit Unterricht in Lesen, Schreiben und Literatur, und in den meisten dieser Länder entfällt auf den Unterricht in Mathematik der zweitgrößte Teil der Unterrichtszeit. In rund einem Drittel der Länder mit verfügbaren Daten verbringen auch die Schüler des Sekundarbereichs I den größten Teil der Zeit mit Unterricht in Lesen, Schreiben und Literatur, in 9 Ländern jedoch machen moderne Fremdsprachen den größten Teil des Kernpflichtteils des Lehrplans aus. In Dänemark und Luxemburg verbringen Schüler des Sekundarbereichs I mehr als 20 Prozent der Pflichtunterrichtszeit mit dem Unterricht in modernen Fremdsprachen.

In den OECD-Ländern entfallen durchschnittlich 6 Prozent der Pflichtunterrichtszeit im Primarbereich und 7 Prozent im Sekundarbereich I auf Unterricht im flexiblen Teil des Lehrplans. 
Während Tschechien und die Niederlande im Primar- und Sekundarbereich I innerhalb des Pflichtteils des Lehrplans vollkommene Flexibilität gewähren, ist in Griechenland, Luxemburg, Mexiko und Ungarn der flexible Teil des Lehrplans in beiden Bildungsbereichen vernachlässigbar klein.

\section{Analyse und Interpretationen}

\section{Insgesamt vorgesehene Unterrichtszeit}

Die insgesamt vorgesehene Unterrichtszeit ist ein Schätzwert der Zahl an Unterrichtszeitstunden, in denen Schüler auf der Grundlage offizieller Vorgaben sowohl im Pflichtteil als auch im Nichtpflichtteil des Lehrplans unterrichtet werden. In den OECDLändern sind für Schüler im Primarbereich im Durchschnitt 4.717 (Zeit-)Stunden Unterricht vorgesehen, für Schüler im Sekundarbereich I sind es durchschnittlich 3.034 (Zeit-)Stunden. Dabei handelt es sich überwiegend um Pflichtunterrichtsstunden (Tab. Di.r).

Die Zahl der Unterrichtszeitstunden für Schüler im Primar- und Sekundarbereich I variiert jedoch je nach Alter der Schüler. Während in zwei Drittel der OECD-Länder die Kinder beim Eintritt in den Primarbereich 6 Jahre alt sind, sind sie in 20 Prozent der OECD-Länder mindestens 7 Jahre alt. Nur in Australien, England, Irland, Neuseeland und Schottland beginnt der Besuch des Primarbereichs schon mit 5 Jahren. In Irland können schon 4-Jährige den Primarbereich besuchen, was auch rund 40 Prozent tun.

Auch bei der Dauer des Primarbereichs gibt es große Unterschiede zwischen den einzelnen Ländern. Im Durchschnitt dauert der Primarbereich sechs Jahre, dies variiert jedoch von vier Jahren in Deutschland, Österreich, der Russischen Föderation, der Slowakei und Ungarn über sieben Jahre in Australien, Dänemark, Island, Norwegen und Schottland bis zu acht Jahren in Irland und der Türkei. Der Sekundarbereich I dauert im Durchschnitt drei Jahre, aber hier reicht die Bandbreite von zwei Jahren in Belgien (fläm. und frz.) und Chile bis zu fünf Jahren in der Russischen Föderation und der Slowakei (Tab. Di.I).

In den OECD-Ländern sind für Schüler des Primar- und Sekundarbereichs I im Durchschnitt insgesamt 7.75I (Zeit-)Stunden Unterricht vorgesehen, wobei die festgelegte Zahl an Unterrichtszeitstunden von 6.054 (Zeit-)Stunden in Ungarn bis zu I0.710 Stunden in Australien reicht (Tab. Di.I). Diese Stundenzahl umfasst den Unterricht in Pflicht- und gegebenenfalls Wahlfächern, die Schulen den Schülern anbieten müssen.

Die jährliche Unterrichtszeit sollte im Zusammenhang mit der Dauer der Schulpflicht betrachtet werden. In einigen Ländern ist die Zeit der Schulpflicht kürzer, und das Arbeitspensum der Schüler ist in diesem Zeitraum größer, während in anderen Ländern die gleichmäßigere Verteilung des Arbeitspensums über mehr Schuljahre hinweg letztendlich insgesamt zu einer höheren Unterrichtsstundenzahl für alle führt. Tabelle Dr.3 im Internet zeigt die Altersspanne, während der sich mehr als go Prozent 
der Bevölkerung in schulischer Ausbildung befinden (s. Indikator Cr). Abbildung Di.I zeigt die insgesamt für Schüler des Primar- und Sekundarbereichs I zusammen vorgesehene Unterrichtszeit. Die vorgesehene Unterrichtszeit erfasst weder die Qualität der Lernangebote noch die Art oder Qualität der beteiligten Human- oder Sachressourcen (s. Indikator D2, in dem auf die Schüler-Lehrkräfte-Relation eingegangen wird).

In einigen Ländern bestehen bei der vorgesehenen Unterrichtszeit beträchtliche Unterschiede zwischen einzelnen Regionen oder Schularten. In vielen Ländern werden Entscheidungen zur Unterrichtsorganisation zwar von Schulbehörden getroffen, Entscheidungen zur Unterrichtszeit dagegen auf zentraler oder bundesstaatlicher Ebene gefällt. Die vorgesehene Unterrichtszeit kann sich auch von der tatsächlich unterrichteten Zeit unterscheiden, da sie nur die Zeit erfasst, in der Schüler formalen Unterricht im Klassenzimmer erhalten. Das ist jedoch nur ein Teil der Zeit, in der Schüler insgesamt unterrichtet werden. Unterricht wird auch außerhalb des Klassenzimmers und/ oder außerhalb der Schule erteilt. In einigen Ländern werden Schüler des Sekundarbereichs angehalten, zusätzlichen Unterricht in Fächern zu besuchen, die bereits in der Schule unterrichtet werden, um ihre Leistungen in diesen Fächern zu verbessern. Schüler können nach dem offiziellen Schulunterricht an Zusatzunterricht teilnehmen, bei dem es sich um Nachhilfeunterricht oder um Neigungskurse, angeboten durch einzelne Lehrer oder in Form von Gruppenunterricht durch Lehrer der Schule, oder um andere externe Angebote handeln kann. Dieser Unterricht kann durch staatliche Mittel finanziert oder von den Schülern und ihren Familien selbst bezahlt werden (Kasten Di.I in OECD, 20II).

\section{Pflichtunterrichtszeit}

Die Gesamtpflichtunterrichtszeit ist ein Schätzwert für die Zahl an Unterrichtszeitstunden, in denen Schüler sowohl im Kernpflichtteil als auch im Wahlpflichtteil des Lehrplans unterrichtet werden. In den OECD-Ländern erhalten Schüler im Verlauf des Besuchs des Primar- und Sekundarbereichs I zusammen im Durchschnitt 7.63 I (Zeit-) Stunden Pflichtunterricht (Tab. Di.I).

Die vorgesehene Unterrichtszeit ist in drei Viertel der Länder mit verfügbaren Daten im Primar- und Sekundarbereich I gleichzeitig vollständig Pflichtunterrichtszeit. In Belgien (frz.), Finnland, Österreich, Polen und Ungarn jedoch übersteigt die vorgesehene Unterrichtszeit die Pflichtunterrichtszeit um mindestens 5 Prozent.

Die durchschnittliche Gesamtpflichtunterrichtszeit im Klassenzimmer beläuft sich in den OECD-Ländern im Primarbereich auf 79I (Zeit-)Stunden pro Jahr und im Sekundarbereich I auf 907 (Zeit-)Stunden.

\section{Unterrichtszeit pro Fach}

Für Schüler des Primarbereichs entfallen im Durchschnitt 54 Prozent des Pflichtcurriculums auf drei Fächer: Lesen, Schreiben und Literatur (26 Prozent), Mathematik (I7 Prozent) und Kunst (II Prozent). Zusammen mit Sport (9 Prozent), Naturwissenschaften (7 Prozent) und Sozialkunde (7 Prozent) machen diese sechs Fächer in allen OECD- und sonstigen G20-Ländern mit verfügbaren Daten den größten Teil des Lehrplans dieser Altersgruppe aus. Moderne Fremdsprachen, Religion, praktische und berufsbezogene Kenntnisse und Kompetenzen, Technik und sonstige Fächer decken 
Unterrichtszeit pro Fach im Primarbereich (2011)

Als Prozentsatz der insgesamt vorgesehenen Pflichtunterrichtszeit

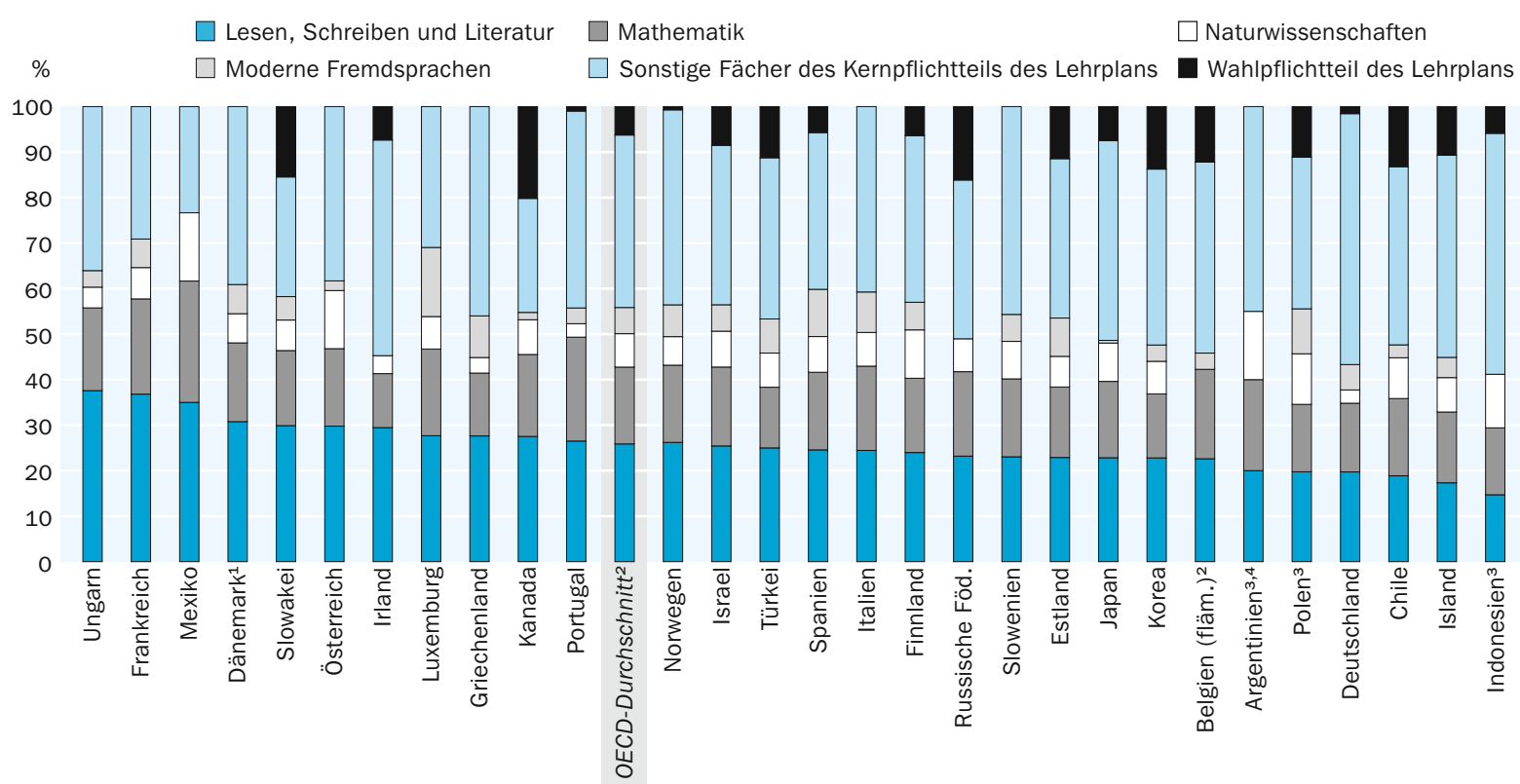

1. Ohne das erste Jahr des Primarbereichs. 2. Belgien (fläm.) ist in den Durchschnittswerten nicht enthalten. 3. Umfasst nur die letzten drei Jahre des Primarbereichs. 4. Referenzjahr 2010.

Anordnung der Länder in absteigender Reihenfolge des Anteils der für Lesen, Schreiben und Literatur vorgesehenen Unterrichtszeitstunden.

Quelle: OECD. Argentinien: Statistikinstitut der UNESCO (World Education Indicators Programme). Tabelle D1.2a.

Hinweise s. Anhang 3 unter www.oecd.org/edu/eag.htm. StatLink: http://dx.doi.org/10.1787/888932847773

die verbleibenden 17 Prozent des Kernpflichtteils des Lehrplans im Primarbereich ab (Tab. Di.2a und Abb. Dr.2a).

Im Durchschnitt nehmen Lesen, Schreiben und Literatur den größten Teil des Lehrplans im Primarbereich ein, aber ihr Anteil variiert stark. In Island und Indonesien beispielsweise machen Lesen, Schreiben und Literatur höchstens 17 Prozent der Pflichtunterrichtszeit aus, während es in Frankreich, Mexiko und Ungarn mindestens 35 Prozent sind. Die Unterschiede zwischen den einzelnen Ländern hinsichtlich des Anteils, der auf Mathematik und Kunst entfällt, sind noch größer. In Griechenland, Irland, Korea und der Türkei entfallen auf Mathematik höchstens I4 Prozent der Unterrichtszeit, in Argentinien, Belgien (fläm.), Frankreich, Mexiko und Portugal sind es mindestens 20 Prozent. In Israel, Mexiko und Polen macht Kunst 5 Prozent der Unterrichtszeit aus, während dieser Anteil in Dänemark, Deutschland, Estland, Finnland, Italien, Norwegen und Österreich bei mindestens 15 Prozent liegt.

Im Sekundarbereich I entfallen im Durchschnitt 43 Prozent des Pflichtcurriculums auf drei Fächer: Lesen, Schreiben und Literatur (I6 Prozent), moderne Fremdsprachen (I4 Prozent) und Mathematik (I3 Prozent). Außerdem sind im Durchschnitt 12 Prozent des Pflichtcurriculums der Sozialkunde und 12 Prozent den Naturwissenschaften gewidmet. Zusammen mit Kunst (8 Prozent) und Sport (8 Prozent) machen diese sieben Fächer in allen OECD- und sonstigen G20-Ländern mit verfügbaren Daten den größten Teil des Lehrplans dieser Altersgruppe aus. Technik, Religion, praktische und berufs- 
Unterrichtszeit pro Fach im Sekundarbereich I (2011)

Als Prozentsatz der insgesamt vorgesehenen Pflichtunterrichtszeit

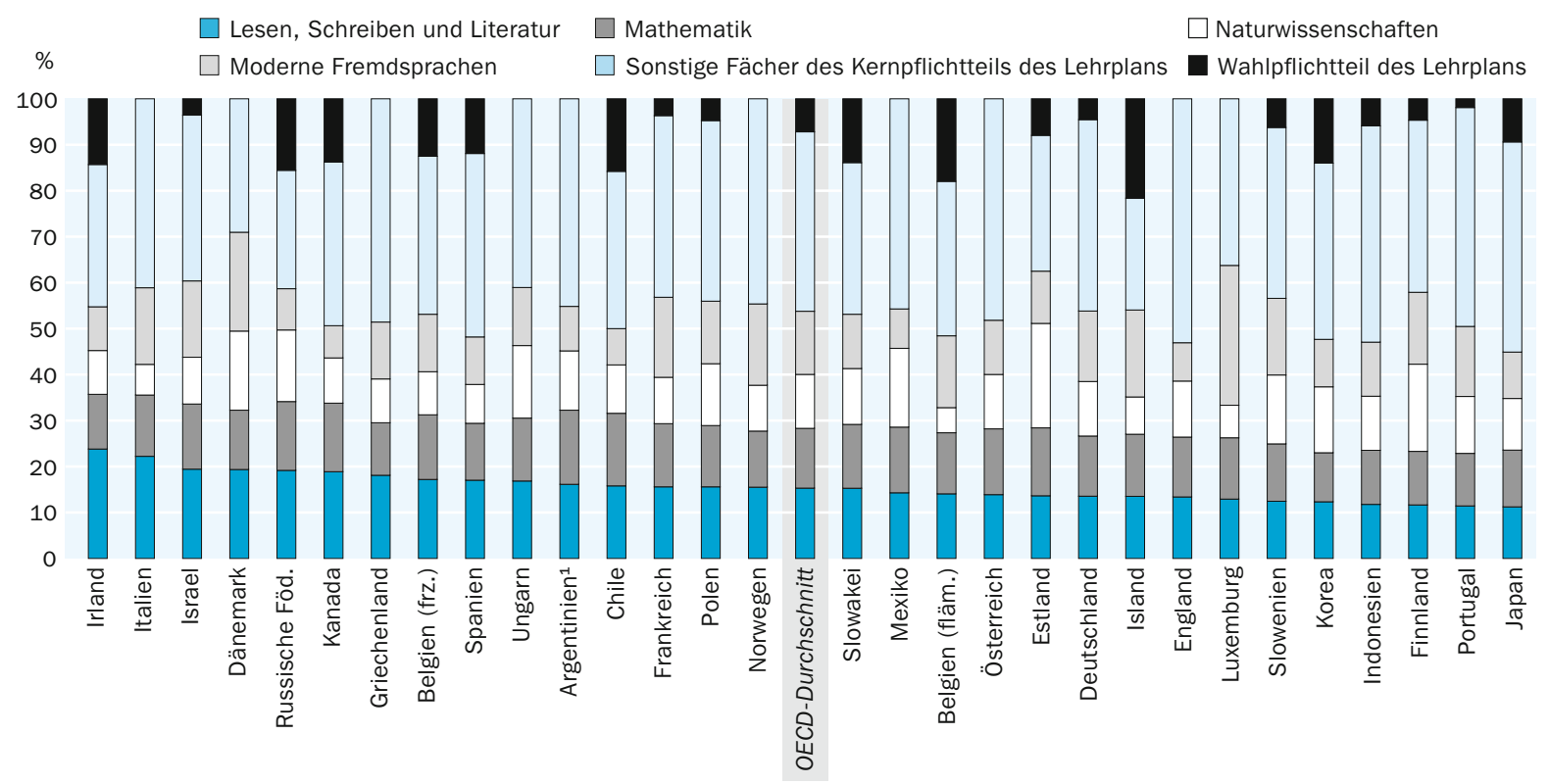

1. Referenzjahr 2010.

Anordnung der Länder in absteigender Reihenfolge des Anteils der für Lesen, Schreiben und Literatur vorgesehenen Unterrichtszeitstunden.

Quelle: OECD. Argentinien: Statistikinstitut der UNESCO (World Education Indicators Programme). Tabelle D1.2b.

Hinweise s. Anhang 3 unter www.oecd.org/edu/eag.htm. StatLink: http://dx.doi.org/10.1787/888932847792

bezogene Kompetenzen und sonstige Fächer decken die verbleibenden I2 Prozent des Kernpflichtteils des Lehrplans für Schüler dieses Bildungsbereichs ab (Tab. Dr.2b und Abb. Di.2b).

Die Aufteilung der Unterrichtszeit ändert sich jedoch nach dem Primarbereich. Der Unterricht in Lesen, Schreiben und Literatur reduziert sich von 26 Prozent des Unterrichts im Pflichtteil des Lehrplans auf 16 Prozent, stellt aber in rund einem Drittel der Länder immer noch den größten Teil der Pflichtunterrichtszeit dar. Auf den Unterricht in Mathematik entfallen statt 17 Prozent nun I3 Prozent der Pflichtunterrichtszeit. Umgekehrt nimmt der Unterricht sowohl in den Naturwissenschaften als auch in Sozialkunde von 7 Prozent des Pflichtcurriculums auf 12 Prozent zu, während der Unterricht in modernen Fremdsprachen von 6 Prozent auf I4 Prozent steigt. Der Unterricht in modernen Fremdsprachen macht in Belgien (fläm.), Dänemark, Deutschland, Frankreich, Island, Luxemburg, Norwegen, Portugal (zusammen mit anderen Fächern) und Slowenien den größten Teil des Pflichtteils des Lehrplans im Sekundarbereich I aus (Tab. Dr.2a und Dr.2b sowie Abb. Dr.2a und Dr.2b).

Im Sekundarbereich I gibt es zwischen den einzelnen Ländern bei der Verteilung der Unterrichtszeit auf die einzelnen Fächer innerhalb des Pflichtlehrplans große Unterschiede. In Japan und Portugal beispielsweise machen Lesen, Schreiben und Literatur II Prozent der Pflichtunterrichtszeit aus, während dieser Anteil in Irland und Italien bei mehr als 20 Prozent liegt. In Argentinien, Chile, England, Irland, Japan, Kanada, Korea, Mexiko, der Russischen Föderation und Spanien macht der Unterricht in 
modernen Fremdsprachen höchstens Io Prozent der Unterrichtszeit aus, während er in Belgien (fläm.), Deutschland, Finnland, Frankreich, Island, Israel, Italien, Norwegen, Portugal und Slowenien zwischen 15 und I9 Prozent der Pflichtunterrichtszeit ausmacht und in Dänemark und Luxemburg mehr als 20 Prozent (Tab. Di.2b). In Dänemark können sich Schüler des Sekundarbereichs I dafür entscheiden, in dieser Zeit ein anderes Fach zu belegen, haben dann aber nicht mehr die Möglichkeit, anschließend den allgemeinbildenden Sekundarbereich II zu besuchen.

Im Primar- und Sekundarbereich I gibt es also große Unterschiede bei der Aufteilung der Unterrichtszeit auf die einzelnen Fächer, je älter die Schüler werden. Im Durchschnitt der OECD-Länder entfallen 3I Prozent der Unterrichtszeit für 7-Jährige auf den Unterricht in Lesen, Schreiben und Literatur, bei den II-Jährigen sind es Iو Prozent und bei den I5-Jährigen schließlich I4 Prozent. Im Gegensatz hierzu entfallen bei den 7-Jährigen im Durchschnitt 2 Prozent der Unterrichtszeit auf den Unterricht in modernen Fremdsprachen, während es bei den II-Jährigen II Prozent sind und bei den I5-Jährigen dann 44 Prozent. Der Anteil der Unterrichtszeit, der auf den Unterricht in Naturwissenschaften entfällt, steigt von 7 Prozent für die 7-Jährigen auf 9 Prozent für die II-Jährigen und I2 Prozent für die I5-Jährigen. Bei Sozialkunde sind es 7 Prozent für die 9-Jährigen, Io Prozent für die II-Jährigen und I2 Prozent für die I5-Jährigen. Der Teil der Unterrichtszeit, der auf Kunst entfällt, sinkt von I2 Prozent für die 7-Jährigen auf II Prozent für die II-Jährigen und 4 Prozent für die I5-Jährigen, während der Anteil für Sport für 7- wie auch II-Jährige 9 Prozent beträgt und bei den I5-Jährigen auf 7 Prozent zurückgeht (Tab. Di.4b, Di.4f und Di.4j im Internet).

\section{Wahlpflichtteil des Lehrplans}

Im Durchschnitt der OECD-Länder entfallen im Primarbereich 6 Prozent der vorgesehenen Pflichtunterrichtszeit auf den flexiblen Teil des Lehrplans, im Sekundarbereich I sind es 7 Prozent. Innerhalb des Pflichtteils des Lehrplans können Schulen, Lehrkräfte und/oder Schüler in unterschiedlich starkem Ausmaß wählen, welche Fächer sie anbieten, unterrichten bzw. belegen möchten. Die Niederlande und Tschechien gewähren sowohl im Primar-als auch Sekundarbereich I innerhalb des Pflichtteils des Lehrplans vollständige Flexibilität (Ioo Prozent). In Tschechien ist im Primar- und Sekundarbereich I die Mindestzahl an Unterrichtseinheiten pro Fach festgelegt, aber es liegt im Ermessen der einzelnen Schule, die Unterrichtseinheiten auf die einzelnen Klassenstufen zu verteilen. In den Niederlanden sind die Leistungsziele für die einzelnen Fächer festgelegt, aber die Schulen entscheiden darüber, wie viel Zeit für die einzelnen Fächer und Bereiche des Lehrplans aufgebracht wird. Gefolgt werden diese beiden Länder bei der Flexibilität von Australien, wo 58 Prozent der Pflichtunterrichtszeit im Primarbereich und 46 Prozent im Sekundarbereich I auf den flexiblen Teil des Lehrplans entfallen.

Im Primarbereich entfallen in Kanada 20 Prozent der Pflichtunterrichtszeit auf den flexiblen Teil des Lehrplans, während es in der Russischen Föderation und der Slowakei I6 bzw. I5 Prozent sind. Einige Länder gewähren in bestimmten Klassenstufen vollständige Flexibilität: In Indonesien und Polen besteht während der ersten drei Jahre des Primarbereichs vollständige Flexibilität, während dies in Dänemark nur auf das erste Jahr des Primarbereichs zutrifft. 
Im Sekundarbereich I entfallen in Island 22 Prozent der Pflichtunterrichtszeit auf den flexiblen Teil des Lehrplans, während es in Belgien (fläm.) I8 Prozent sind und sowohl in Chile als auch der Russischen Föderation I6 Prozent. In Griechenland, Luxemburg, Mexiko und Ungarn dagegen ist der flexible Teil des Lehrplans sowohl im Primar-als auch Sekundarbereich I vernachlässigbar klein oder gleich null (Tab. Di.2a und Di.2b).

Aber auch innerhalb der einzelnen Länder gibt es Unterschiede bei der Aufteilung der Zeit: In Kanada beispielsweise werden der Lehrplan, die Unterrichtszeit sowie die Zahl der Unterrichtszeitstunden, die auf den flexiblen Teil des Lehrplans entfallen, und die Art und Weise, wie dieser flexible Teil gehandhabt wird, von den einzelnen Provinzen und Territorien entschieden. In England entscheidet die Schulleitung der einzelnen Schule sowohl über die Länge des Schultags als auch die einzelnen Unterrichtsstunden. In Finnland legen nationale Vorschriften die mindestens auf jedes einzelne Fach entfallende Unterrichtzeit fest, die Entscheidung über den Rest des Stundenplans liegt jedoch bei den lokalen Schulbehörden. In der Slowakei entwickeln die Schulen ihre eigenen Bildungsgänge, basierend auf einem nationalen Rahmen, der eine Reihe von Pflicht- und Wahlstunden enthält (s. Kasten Dr.I in OECD, 2012).

\section{Nichtpflichtunterrichtszeit}

Im Durchschnitt der OECD-Länder entfallen im Primarbereich 2 Prozent der Gesamtpflichtunterrichtszeit auf den Nichtpflichtteil des Lehrplans, im Sekundarbereich I sind es 3 Prozent. Trotzdem wird in einigen Ländern in beträchtlichem Umfang zusätzlich Unterricht angeboten, der nicht zwingend vorgeschrieben ist. Im Primarbereich belaufen sich in der Türkei zusätzliche Nichtpflichtstunden auf 20 Prozent der Gesamtpflichtunterrichtszeit, in Ungarn sind es I4 Prozent und in Belgien (frz.) II Prozent. Im Sekundarbereich I beläuft sich in Ungarn die Nichtpflichtunterrichtszeit auf 30 Prozent der Pflichtunterrichtszeit, in Argentinien sind es 20 Prozent und in Frankreich ro Prozent (Tab. Di.2a und Dr.2b).

\section{Definitionen}

Der Pflichtteil des Lehrplans bezieht sich auf den Umfang und die Aufteilung der Unterrichtsstunden, die von fast jeder öffentlichen Schule zu unterrichten und von fast jedem Schüler einer öffentlichen Bildungseinrichtung zu besuchen sind. Die Erfassung der Zeit, die für bestimmte Fächer vorgesehen ist, konzentriert sich eher auf den kleinsten gemeinsamen „Kern“ als auf die durchschnittlich pro Fach aufgewendete Zeit, da die Datenquellen (Vorgaben und Richtlinien) keine präziseren Angaben erlauben. Der Gesamtpflichtteil des Lehrplans enthält sowohl den Kernpflichtteil als auch den Wahlpflichtteil des Lehrplans.

Der Wahlpflichtteil des Lehrplans bezieht sich auf den Teil des Pflichtlehrplans, bei dem hinsichtlich der für ein bestimmtes Fach aufzubringenden Zeit und/oder der Auswahl zwischen verschiedenen Fächern eine gewisse Wahlfreiheit besteht.

Die Unterrichtszeit im Primar- und Sekundarbereich I sowie für 5- bis 15-Jährige bezieht sich auf die formal vorgeschriebene Zahl an Zeitstunden pro Schuljahr, die von der Schule für Unterrichtsaktivitäten im Klassenzimmer organisiert werden. Für Länder, in denen 
keine formalen Vorschriften zu der Unterrichtszeit vorliegen, wird die Zahl der Unterrichtszeitstunden anhand von Erhebungsdaten geschätzt. Stunden, die entfallen, wenn Schulen wegen gesetzlicher Feiertage oder Feierlichkeiten geschlossen sind, werden nicht berücksichtigt. In der vorgesehenen Unterrichtszeit nicht enthalten sind freiwillige Aktivitäten außerhalb der regulären Schulzeit, Hausaufgaben, Nachhilfe oder Selbststudium.

Die Unterrichtszeit für den am wenigsten anspruchsvollen Bildungsgang für 15-Jährige bezieht sich auf den Bildungsgang, der für Schüler vorgesehen ist, bei denen es am wenigsten wahrscheinlich ist, dass sie über die Zeit der Schulpflicht oder des Sekundarbereichs I hinaus weiter zur Schule gehen werden. Einen derartigen Bildungsgang für I5-Jährige gibt es möglicherweise je nach Einteilung in Leistungsgruppen oder anderen Differenzierungsstrategien nicht in jedem Land. In vielen Ländern haben die Schüler in allen oder den meisten Bildungsgängen die gleiche Unterrichtszeit, bei der Auswahl der Fächer gibt es jedoch gewisse Wahlmöglichkeiten. Wenn die Bildungsgänge recht lang sind und es grundlegende Unterschiede zwischen ihnen gibt, müssen die entsprechenden Entscheidungen oft frühzeitig getroffen werden.

Die vorgesehene Unterrichtszeit bezieht sich auf die Anzahl an Zeitstunden pro Jahr, die Schüler im Pflicht- und Nichtpflichtteil des Lehrplans unterrichtet werden.

Der Nichtpflichtteil des Lehrplans bezieht sich auf die durchschnittliche Unterrichtszeit, auf die Schüler zusätzlich zu den Pflichtunterrichtszeitstunden Anspruch haben. Die Fächer variieren oft von Schule zu Schule oder von Region zu Region und werden beispielsweise als „Wahlfächer“ angeboten.

Die typische Unterrichtszeit für I5-Jährige bezieht sich auf den Bildungsgang, den die meisten I5-Jährigen besuchen. Das kann ein Bildungsgang im Sekundarbereich I oder II sein, in den meisten Ländern handelt es sich um einen allgemeinbildenden Bildungsgang. Wenn das betreffende Bildungssystem die Schüler in diesem Alter unterschiedlichen Arten von Bildungsgängen zuordnet, wurde die durchschnittlich vorgesehene Unterrichtszeit für die wichtigsten üblichen Bildungsgänge geschätzt, gewichtet nach dem Anteil der Schüler in der Jahrgangsstufe, in der sich die meisten I5-Jährigen befinden. Wenn bei der typischen Unterrichtszeit auch berufsbildende Bildungsgänge berücksichtigt werden, ist nur der schulische Teil des Bildungsgangs in die Berechnungen eingeflossen.

\section{Angewandte Methodik}

Dieser Indikator erfasst die - offiziell vorgeschriebene - vorgesehene Unterrichtszeit als Kennzahl für die auf das formale Lernen zu verwendende Zeit im Klassenzimmer. Er zeigt aber nicht die tatsächliche Anzahl der Stunden, die Schüler unterrichtet werden, und auch das Lernen außerhalb des Klassenzimmers wird nicht erfasst. In den einzelnen Ländern können Unterschiede zwischen der vorgeschriebenen Mindestanzahl an Unterrichtszeitstunden und der tatsächlichen Zahl an Stunden, die Schüler unterrichtet wurden, bestehen. Eine von Regioplan Beleidsonderzoek in den Niederlanden durchgeführte Untersuchung zeigt, dass Faktoren wie Stundenpläne der Schu- 
len, der Ausfall von Unterrichtsstunden und die Abwesenheit von Lehrern dazu führen können, dass Schulen die offiziell vorgesehene Mindestanzahl an Unterrichtsstunden nicht regelmäßig erreichen (s. Kasten Di.I in OECD, 2007).

Dieser Indikator zeigt außerdem, wie die Mindestunterrichtszeit auf verschiedene Bereiche des Lehrplans aufgeteilt wird. Er zeigt die vorgesehene Nettoanzahl an Unterrichtszeitstunden für die Klassenstufen, in denen die Mehrzahl der Schüler zwischen 5 Jahre (wenn es um den Primarbereich geht) und I5 Jahre alt ist. Die Daten sind zwar aufgrund der unterschiedlichen Lehrplanvorgaben schwer über die einzelnen Länder hinweg zu vergleichen, sie geben aber dennoch einen Hinweis darauf, wie viel formale Unterrichtszeit für die Schüler als notwendig erachtet wird, damit sie die angestrebten Bildungsziele erreichen.

Die Daten über die Unterrichtszeit stammen aus der OECD/INES-Erhebung $2012 \mathrm{zu}$ Lehrern und Lehrplänen und beziehen sich auf das Schuljahr 2010/20II.

Hinweise zu den für diesen Indikator in den einzelnen Ländern verwendeten Definitionen und der angewandten Methodik s. Anhang 3 unter www.oecd.org/eduleag.htm.

Die statistischen Daten für Israel wurden von den zuständigen israelischen Stellen bereitgestellt, die für sie verantwortlich zeichnen. Die Verwendung dieser Daten durch die OECD erfolgt unbeschadet des völkerrechtlichen Status der Golanhöhen, von OstJerusalem und der israelischen Siedlungen im Westjordanland.

\section{Weiterführende Informationen}

OECD (2007), Bildung auf einen Blick 2007 - OECD-Indikatoren, W. Bertelsmann Verlag, Bielefeld.

OECD (20II), Bildung auf einen Blick 2011 - OECD-Indikatoren, W. Bertelsmann Verlag, Bielefeld.

OECD (2012), Bildung auf einen Blick 2012 - OECD-Indikatoren, W. Bertelsmann Verlag, Bielefeld.

\section{Tabellen Indikator D1}

Tabelle Dr.I: Pflichtunterrichtszeit und vorgesehene Unterrichtszeit in öffentlichen Bildungseinrichtungen (20II)

StatLink: http:||dx.doi.org/10.1787/888932851288

Tabelle Di.2a: Unterrichtszeit pro Fach im Primarbereich (20II)

StatLink: http:||dx.doi.org/10.1787/888932851307

Tabelle Di.2b: Unterrichtszeit pro Fach im Sekundarbereich I (20II)

StatLink: http:|/dx.doi.org/10.1787/888932851326 
WEB Table Dr.3: Compulsory and intended instruction time, by age (Pflichtunterrichtszeit und vorgesehene Unterrichtszeit, nach Alter) (20II)

StatLink: http:/|dx.doi.org/10.1787/888932851345

WEB Table Dr.4a: Instruction time per subject for 6-year-olds (Unterrichtszeit pro Fach für 6-Jährige) (20II)

StatLink: http://dx.doi.org/10.1787/888932851364

WEB Table Dr.4b: Instruction time per subject for 7-year-olds (Unterrichtszeit pro Fach für 7-Jährige) (20II)

StatLink: http:|/dx.doi.org/10.1787/888932851383

WEB Table Dr.4c: Instruction time per subject for 8-year-olds (Unterrichtszeit pro Fach für 8-Jährige) (20II)

StatLink: http:||dx.doi.org/10.1787/888932851402

WEB Table Dr.4d: Instruction time per subject for 9-year-olds (Unterrichtszeit pro Fach für 9-Jährige) (20II)

StatLink: http://dx.doi.org/10.1787/888932851421

WEB Table Di.4e: Instruction time per subject for Io-year-olds (Unterrichtszeit pro Fach für Io-Jährige) (20II)

StatLink: http:||dx.doi.org/10.1787/888932851440

WEB Table Di.4f: Instruction time per subject for II-year-olds (Unterrichtszeit pro Fach für II-Jährige) (20II)

StatLink: http:||dx.doi.org/10.1787/888932851459

WEB Table Di.4g: Instruction time per subject for I2-year-olds (Unterrichtszeit pro Fach für I2-Jährige) (20II)

StatLink: http://dx.doi.org/10.1787/888932851478

WEB Table Dr.4h: Instruction time per subject for 13 -year-olds (Unterrichtszeit pro Fach für I3-Jährige) (20II)

StatLink: http://dx.doi.org/10.1787/888932851497

WEB Table Di.4i: Instruction time per subject for I4-year-olds (Unterrichtszeit pro Fach für I4-Jährige) (20II)

StatLink: http:|/dx.doi.org/10.1787/888932851516

WEB Table Di.4j: Instruction time per subject for 15-year-olds (Unterrichtszeit pro Fach für I5-Jährige) (20II)

StatLink: http:|/dx.doi.org/10.1787/888932851535

WEB Table DI.4k: Instruction time per subject for 15 -year-olds in the leastdemanding programmes (Unterrichtszeit pro Fach für I5-Jährige in dem am wenigsten anspruchsvollen Bildungsgang) (20II)

StatLink: http://dx.doi.org/10.1787/888932851554 
Tabelle D1.1

Pflichtunterrichtszeit und vorgesehene Unterrichtszeit in öffentlichen Bildungseinrichtungen (2011) Nach Bildungsbereich

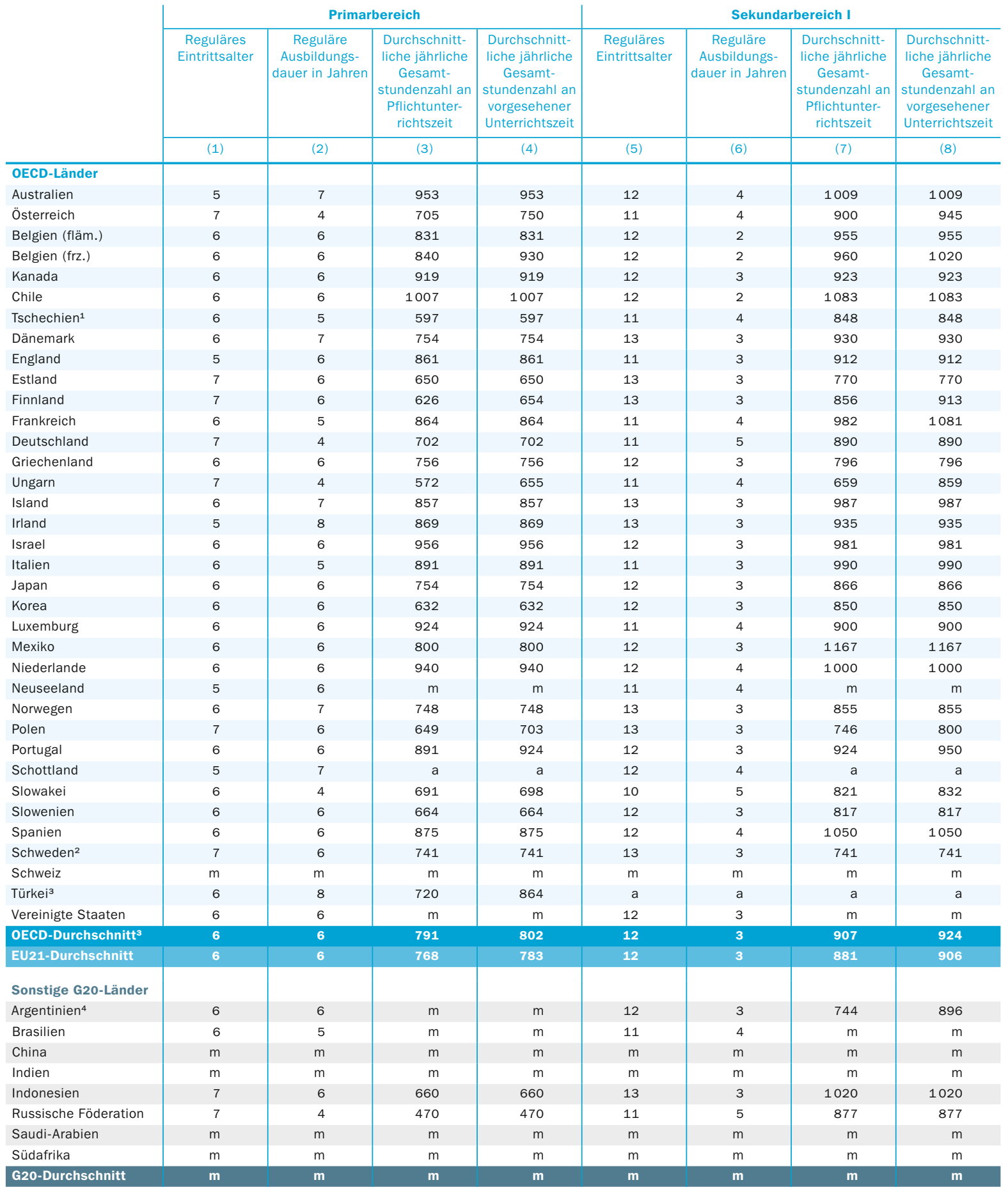

1. Mindestzahl an (Zeit-)Stunden pro Jahr. 2. Geschätzte Mindestzahl an (Zeit-)Stunden pro Jahr, da keine Aufteilung nach Altersgruppe verfügbar ist.

3. Die Türkei ist in den Durchschnittswerten nicht enhalten. 4. Referenzjahr 2010.

Quelle: OECD. Argentinien: Statistikinstitut der UNESCO (World Education Indicators Programme). Hinweise s. Anhang 3 unter www.oecd.org/edu/eag.htm.

StatLink: http://dx.doi.org/10.1787/888932851288

Erläuterung der Kennzeichnung fehlender Daten s. Hinweise für den Leser. 
Unterrichtszeit pro Fach im Primarbereich (2011)

Als Prozentsatz der insgesamt vorgesehenen Pflichtunterrichtszeit

\begin{tabular}{|c|c|c|c|c|c|c|c|c|c|c|c|c|c|c|c|}
\hline & \multicolumn{12}{|c|}{ Kernpflichtteil des Lehrplans } & \multirow[b]{2}{*}{ 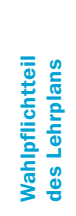 } & \multirow[b]{2}{*}{ 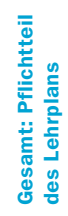 } & \multirow[b]{2}{*}{ 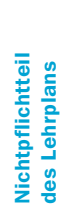 } \\
\hline & 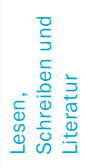 & 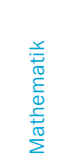 & 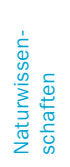 & $\begin{array}{l}\frac{0}{0} \\
\frac{5}{5} \\
\frac{1}{5} \\
\frac{.0}{N} \\
0 \\
0\end{array}$ & 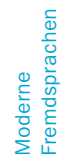 & 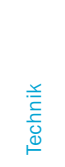 & $\begin{array}{l}\text { 苟 } \\
\text { 童 }\end{array}$ & $\begin{array}{l}\text { to } \\
\text { ì }\end{array}$ & 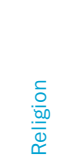 & 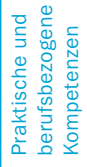 & 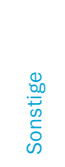 & 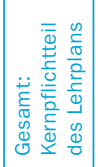 & & & \\
\hline & (1) & (2) & (3) & (4) & (5) & (6) & (7) & (8) & (9) & (10) & (11) & (12) & (13) & (14) & (15) \\
\hline \multicolumn{16}{|l|}{ OECD-Länder } \\
\hline Australien ${ }^{1}$ & $\mathrm{~m}$ & $\mathrm{~m}$ & $\mathrm{~m}$ & $\mathrm{~m}$ & $\mathrm{~m}$ & $\mathrm{~m}$ & $\mathrm{~m}$ & $\mathrm{~m}$ & $\mathrm{~m}$ & $\mathrm{~m}$ & $\mathrm{~m}$ & 42 & 58 & 100 & $\mathrm{n}$ \\
\hline Österreich² & 30 & 17 & 13 & $\mathrm{n}$ & 2 & $\mathrm{n}$ & 15 & 11 & 9 & $x(12)$ & 4 & 100 & $x(12)$ & 100 & 6 \\
\hline Belgien (fläm.) ${ }^{1}$ & 23 & 20 & $x(11)$ & $x(11)$ & 4 & $\mathrm{n}$ & 10 & 7 & 7 & $\mathrm{n}$ & 18 & 88 & 12 & 100 & $\mathrm{n}$ \\
\hline Belgien (frz.) $)^{1}$ & $x(11)$ & $x(11)$ & $x(11)$ & $x(11)$ & 2 & $x(11)$ & $x(11)$ & 7 & 7 & $\mathrm{n}$ & 83 & 100 & $\mathrm{n}$ & 100 & 11 \\
\hline Kanada & 27 & 18 & 8 & 7 & 2 & $n$ & 7 & 10 & $n$ & $\mathrm{n}$ & 1 & 80 & 20 & 100 & $\mathrm{n}$ \\
\hline Chile & 19 & 17 & 9 & 9 & 3 & 7 & 9 & 8 & 6 & $\mathrm{n}$ & 1 & 87 & 13 & 100 & $\mathrm{~m}$ \\
\hline Tschechien $^{1}$ & $x(13)$ & $x(13)$ & $x(13)$ & $x(13)$ & $x(13)$ & $x(13)$ & $x(13)$ & $x(13)$ & $\mathrm{n}$ & $\mathrm{n}$ & $\mathrm{n}$ & $x(13)$ & 100 & 100 & $\mathrm{~m}$ \\
\hline Dänemark ${ }^{3}$ & 31 & 17 & 6 & 4 & 6 & $n$ & 17 & 9 & 5 & $\mathrm{n}$ & 3 & 100 & $\mathrm{n}$ & 100 & $\mathrm{n}$ \\
\hline England & $\mathrm{m}$ & $\mathrm{m}$ & $\mathrm{m}$ & $\mathrm{m}$ & $\mathrm{m}$ & $\mathrm{m}$ & $\mathrm{m}$ & $\mathrm{m}$ & $\mathrm{m}$ & $\mathrm{m}$ & $\mathrm{m}$ & $\mathbf{m}$ & $\mathrm{m}$ & $\mathbf{m}$ & $\mathrm{m}$ \\
\hline Estland & 23 & 15 & 7 & 6 & 8 & 3 & 15 & 11 & $\mathrm{n}$ & $\mathrm{n}$ & $\mathrm{n}$ & 89 & 11 & 100 & $\mathrm{n}$ \\
\hline Finnland & 24 & 16 & 11 & 2 & 6 & $\mathrm{n}$ & 20 & 9 & 6 & $\mathrm{n}$ & $n$ & 94 & 6 & 100 & 5 \\
\hline Frankreich & 37 & 21 & 7 & 7 & 6 & $n$ & 9 & 13 & $x(4)$ & $\mathrm{n}$ & $\mathrm{n}$ & 100 & $\mathrm{n}$ & 100 & $\mathrm{n}$ \\
\hline Deutschland & 20 & 15 & 3 & 3 & 6 & 2 & 15 & 12 & 7 & $\mathrm{n}$ & 16 & 98 & 2 & 100 & $\mathrm{n}$ \\
\hline Griechenland & 28 & 14 & 3 & 16 & 9 & $n$ & 9 & 7 & 5 & $\mathrm{n}$ & 9 & 100 & $\mathrm{n}$ & 100 & $\mathrm{n}$ \\
\hline Ungarn & 38 & 18 & 5 & 2 & 4 & $n$ & 13 & 13 & $\mathrm{n}$ & 5 & 3 & 100 & $\mathrm{n}$ & 100 & 14 \\
\hline Island & 17 & 16 & 8 & 10 & 4 & 3 & 12 & 9 & $x(4)$ & 8 & 2 & 89 & 11 & 100 & $\mathrm{n}$ \\
\hline Irland & 29 & 12 & 4 & 8 & $x(13)$ & $\mathrm{n}$ & 12 & 4 & 11 & $\mathrm{n}$ & 13 & 93 & 7 & 100 & $n$ \\
\hline Israel & 25 & 17 & 8 & 9 & 6 & 1 & 5 & 6 & 11 & $\mathrm{n}$ & 3 & 91 & 9 & 100 & $\mathrm{n}$ \\
\hline Italien & 24 & 19 & 7 & 11 & 9 & $\mathrm{n}$ & 15 & 7 & 7 & $\mathrm{n}$ & $\mathrm{n}$ & 100 & $x(12)$ & 100 & $n$ \\
\hline Japan & 23 & 17 & 8 & 7 & 1 & $\mathrm{n}$ & 12 & 9 & $\mathrm{n}$ & $\mathrm{n}$ & 15 & 92 & 8 & 100 & $\mathrm{~m}$ \\
\hline Korea $^{4}$ & 23 & 14 & 7 & 7 & 4 & 1 & 10 & 7 & $\mathrm{n}$ & 1 & 12 & 86 & 14 & 100 & $\mathrm{n}$ \\
\hline Luxemburg ${ }^{5}$ & 28 & 19 & 7 & 2 & 15 & $\mathrm{n}$ & 11 & 10 & 7 & $\mathrm{n}$ & 1 & 100 & $\mathrm{n}$ & 100 & $\mathrm{n}$ \\
\hline Mexiko ${ }^{6}$ & 35 & 27 & 15 & 13 & $\mathrm{n}$ & $\mathrm{n}$ & 5 & 5 & $\mathrm{n}$ & $\mathrm{n}$ & $\mathrm{n}$ & 100 & $\mathrm{n}$ & 100 & $\mathrm{n}$ \\
\hline Niederlande $^{1}$ & $x(13)$ & $x(13)$ & $x(13)$ & $x(13)$ & $x(13)$ & $x(13)$ & $x(13)$ & $x(13)$ & $x(13)$ & $x(13)$ & $x(13)$ & $\mathbf{x}(\mathbf{1 3})$ & 100 & 100 & $\mathrm{n}$ \\
\hline Neuseeland & $\mathrm{m}$ & $\mathrm{m}$ & $\mathrm{m}$ & $\mathrm{m}$ & $\mathrm{m}$ & $\mathrm{m}$ & $\mathrm{m}$ & $\mathrm{m}$ & $\mathrm{m}$ & $\mathrm{m}$ & $\mathrm{m}$ & $\mathbf{m}$ & $\mathrm{m}$ & m & $\mathrm{m}$ \\
\hline Norwegen & 26 & 17 & 6 & 7 & 7 & $n$ & 15 & 11 & 8 & $\mathrm{n}$ & 2 & 99 & 1 & 100 & $\mathrm{n}$ \\
\hline Polen ${ }^{7}$ & 20 & 15 & 11 & 5 & 10 & 5 & 5 & 15 & $n$ & $n$ & 4 & 89 & 11 & 100 & 7 \\
\hline Portugal ${ }^{8}$ & 27 & 23 & 3 & 15 & 3 & $x(11)$ & 6 & 3 & $\mathrm{n}$ & $x(11)$ & 19 & 99 & 1 & 100 & 4 \\
\hline Schottland & a & a & a & a & a & a & a & a & a & a & a & a & a & a & a \\
\hline Slowakei & 30 & 16 & 7 & 2 & 5 & 2 & 9 & 8 & 4 & 1 & $\mathrm{n}$ & 85 & 15 & 100 & 1 \\
\hline Slowenien & 23 & 17 & 8 & 8 & 6 & 1 & 14 & 12 & $\mathrm{n}$ & 2 & 9 & 100 & $\mathrm{n}$ & 100 & $\mathrm{n}$ \\
\hline Spanien & 25 & 17 & 8 & 8 & 10 & $\mathrm{n}$ & 9 & 9 & $x(13)$ & $\mathrm{n}$ & 9 & 94 & 6 & 100 & $\mathrm{n}$ \\
\hline Schweden & $\mathrm{m}$ & $\mathrm{m}$ & $\mathrm{m}$ & $\mathrm{m}$ & $\mathrm{m}$ & $\mathrm{m}$ & $\mathrm{m}$ & $\mathrm{m}$ & $\mathrm{m}$ & $\mathrm{m}$ & $\mathrm{m}$ & m & $\mathrm{m}$ & m & $\mathrm{m}$ \\
\hline Schweiz & $\mathrm{m}$ & $\mathrm{m}$ & $\mathrm{m}$ & $\mathrm{m}$ & $\mathrm{m}$ & $\mathrm{m}$ & $\mathrm{m}$ & $\mathrm{m}$ & $\mathrm{m}$ & $\mathrm{m}$ & $\mathrm{m}$ & m & $\mathrm{m}$ & $\mathbf{m}$ & $\mathrm{m}$ \\
\hline Türkei & 25 & 13 & 8 & 11 & 8 & 3 & 9 & 7 & 4 & $n$ & 2 & 89 & 11 & 100 & 20 \\
\hline Vereinigte Staaten & $\mathrm{m}$ & $\mathrm{m}$ & $\mathrm{m}$ & $\mathrm{m}$ & $\mathrm{m}$ & $\mathrm{m}$ & $\mathrm{m}$ & $\mathrm{m}$ & $\mathrm{m}$ & $\mathrm{m}$ & $\mathrm{m}$ & m & $\mathrm{m}$ & $\mathbf{m}$ & $\mathrm{m}$ \\
\hline OECD-Durchschnitt ${ }^{1}$ & 26 & 17 & 7 & 7 & 6 & 1 & 11 & 9 & 4 & 1 & 5 & 94 & 6 & 100 & 2 \\
\hline EU21-Durchschnitt ${ }^{1}$ & 27 & 17 & 7 & 6 & 7 & 1 & 12 & 9 & 4 & 1 & 6 & 96 & 4 & 100 & 2 \\
\hline \multicolumn{16}{|l|}{ Sonst. G20-Länder } \\
\hline Argentinien & 20 & 20 & 15 & 15 & $n$ & $n$ & 10 & 10 & $\mathrm{n}$ & $n$ & 10 & 100 & $\mathrm{n}$ & 100 & $n$ \\
\hline Brasilien & $\mathrm{m}$ & $\mathrm{m}$ & $\mathrm{m}$ & $\mathrm{m}$ & $\mathrm{m}$ & $\mathrm{m}$ & $\mathrm{m}$ & $\mathrm{m}$ & $\mathrm{m}$ & $\mathrm{m}$ & $\mathrm{m}$ & $\mathbf{m}$ & $\mathrm{m}$ & m & $\mathrm{m}$ \\
\hline China & $\mathrm{m}$ & $\mathrm{m}$ & $\mathrm{m}$ & $\mathrm{m}$ & $\mathrm{m}$ & $\mathrm{m}$ & $\mathrm{m}$ & $\mathrm{m}$ & $\mathrm{m}$ & $\mathrm{m}$ & $\mathrm{m}$ & m & $\mathrm{m}$ & m & $\mathrm{m}$ \\
\hline Indien & $\mathrm{m}$ & $\mathrm{m}$ & $\mathrm{m}$ & $\mathrm{m}$ & $\mathrm{m}$ & $\mathrm{m}$ & $\mathrm{m}$ & $\mathrm{m}$ & $\mathrm{m}$ & $\mathrm{m}$ & $\mathrm{m}$ & m & $\mathrm{m}$ & $\mathbf{m}$ & $\mathrm{m}$ \\
\hline Indonesien 7 & 15 & 15 & 12 & 9 & $n$ & $n$ & 12 & 12 & 9 & 6 & 6 & 94 & 6 & 100 & $\mathrm{n}$ \\
\hline Russische Föd. & 23 & 19 & 7 & 9 & $\mathrm{n}$ & 7 & 9 & 9 & $\mathrm{n}$ & $\mathrm{n}$ & $\mathrm{n}$ & 84 & 16 & 100 & $\mathrm{n}$ \\
\hline Saudi-Arabien & $\mathrm{m}$ & $\mathrm{m}$ & $\mathrm{m}$ & $\mathrm{m}$ & $\mathrm{m}$ & $\mathrm{m}$ & $\mathrm{m}$ & $\mathrm{m}$ & $\mathrm{m}$ & $\mathrm{m}$ & $\mathrm{m}$ & $\mathbf{m}$ & $\mathrm{m}$ & $\mathbf{m}$ & $\mathrm{m}$ \\
\hline Südafrika & $\mathrm{m}$ & $\mathrm{m}$ & $\mathrm{m}$ & $\mathrm{m}$ & $\mathrm{m}$ & $\mathrm{m}$ & $\mathrm{m}$ & $\mathrm{m}$ & $\mathrm{m}$ & $\mathrm{m}$ & $\mathrm{m}$ & m & $\mathrm{m}$ & m & $\mathrm{m}$ \\
\hline G20-Durchschnitt & m & m & $\mathbf{m}$ & $\mathbf{m}$ & m & $\mathbf{m}$ & m & $\mathbf{m}$ & $\mathbf{m}$ & $\mathbf{m}$ & $\mathbf{m}$ & $\mathbf{m}$ & $\mathbf{m}$ & m & m \\
\hline
\end{tabular}

1. Australien, Belgien (fläm. und frz.), die Niederlande und Tschechien sind in den Durchschnittswerten nicht enthalten. 2. In den ersten beiden Jahren des Primarbereichs ist „Moderne Fremdsprachen“ unter "Gesamt: Kernpflichtteil des Lehrplans“ erfasst. 3. Ohne das erste Jahr des Primarbereichs. 4. In den ersten beiden Jahren des Primarbereichs sind „Naturwissenschaften“, „Sozialkunde“, „Technik“, „Kunst“, „Sport“ sowie „Praktische und berufsbezogene Kompetenzen“ unter "Sonstige“ erfasst. 5. Deutsch als Unterrichtssprache ist in „Lesen, Schreiben und Literatur“ zusätzlich zur Muttersprache Luxemburgisch enthalten. 6. In den ersten beiden Jahren des Primarbereichs ist „Sozialkunde“ unter „Naturwissenschaften“ erfasst. 7. Umfasst nur die letzten drei Jahre des Primarbereichs. 8. In den ersten vier Jahren des Primarbereichs ist „Naturwissenschaften“ unter "Sozialkunde “ erfasst, „Kunst" unter „Sonstige“, und es liegen keine Daten zum „Wahlpflichtteil des Lehrplans“ vor. 9. Referenzjahr 2010.

Quelle: OECD. Argentinien: Statistikinstitut der UNESCO (World Education Indicators Programme). Hinweise s. Anhang 3 unter www.oecd.org/edu/eag.htm. StatLink: http://dx.doi.org/10.1787/888932851307

Erläuterung der Kennzeichnung fehlender Daten s. Hinweise für den Leser. 
Unterrichtszeit pro Fach im Sekundarbereich I (2011)

Als Prozentsatz der insgesamt vorgesehenen Pflichtunterrichtszeit

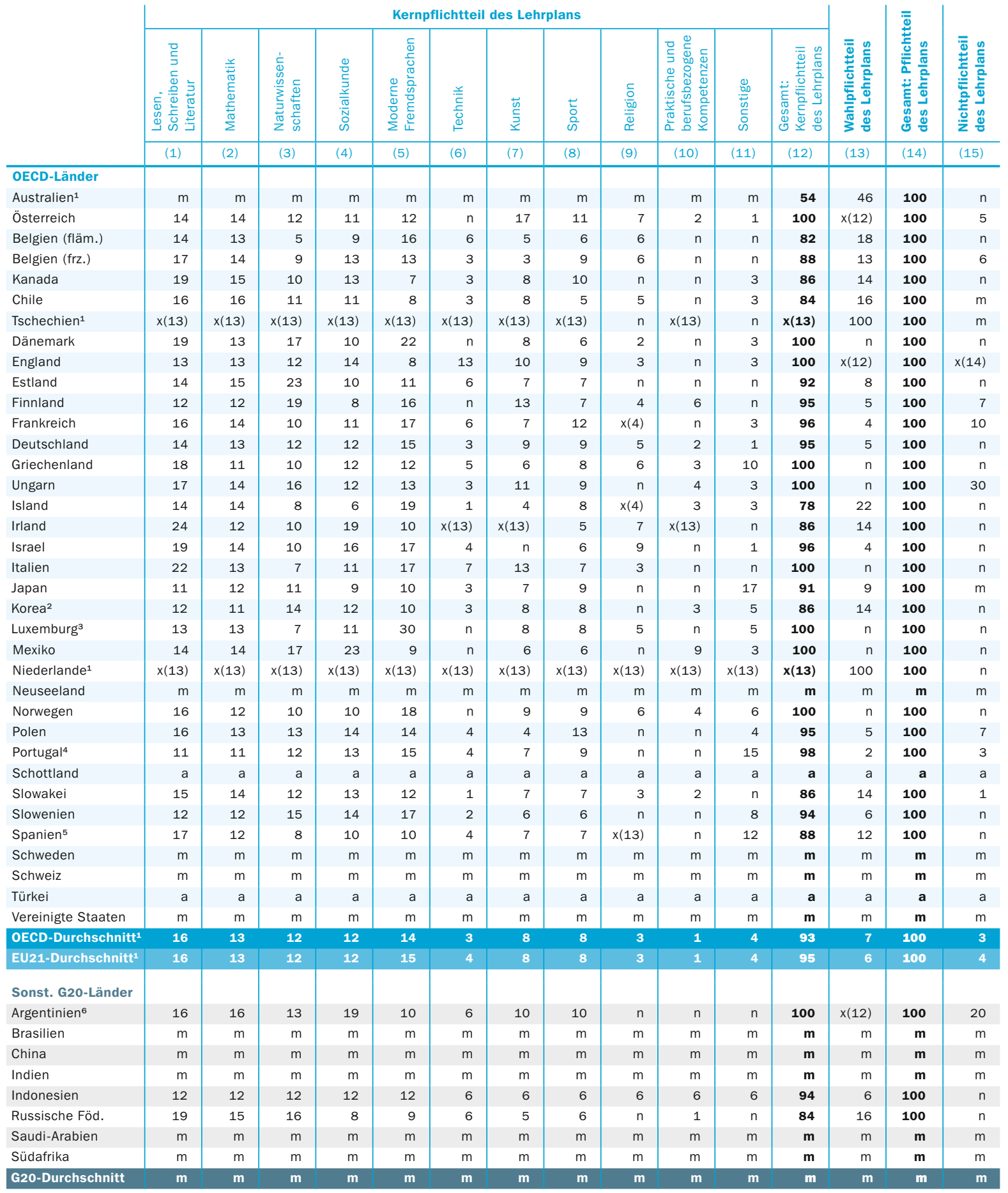

1. Australien, die Niederlande und Tschechien sind in den Durchschnittswerten nicht enthalten. 2. Im ersten Jahr des Sekundarbereichs I ist "Technik“ unter "Naturwissenschaften“ erfasst sowie „Praktische und berufsbezogene Kompetenzen“ unter "Sonstige“. 3. Deutsch als Unterrichtssprache ist in "Lesen, Schreiben und Literatur“ zusätzlich zur Muttersprache Luxemburgisch enthalten. 4. Im letzten Jahr im Sekundarbereich I ist "Technik“ unter "Kunst“ erfasst.

5. Im letzten Jahr im Sekundarbereich I sind „Naturwissenschaften“, „Technik“ und „Kunst“ unter „Wahlpflichtteil des Lehrplans“ erfasst. 6. Referenzjahr 2010. Quelle: OECD. Argentinien: Statistikinstitut der UNESCO (World Education Indicators Programme). Hinweise s. Anhang 3 unter www.oecd.org/edu/eag.htm. StatLink: http://dx.doi.org/10.1787/888932851326

Erläuterung der Kennzeichnung fehlender Daten s. Hinweise für den Leser. 


\section{Wie ist die Schüler-Lehrkräfte-Relation und wie groß sind die Klassen?}

Im Primarbereich beträgt die durchschnittliche Klassengröße im Durchschnitt der OECD-Länder mehr als 2I Schüler pro Klasse; in den G20-Ländern, die nicht Mitglied der OECD sind, sind die Klassen in der Regel jedoch größer.

Im Primarbereich sind die Klassen zwischen 2000 und 201 I tendenziell kleiner geworden, insbesondere in den Ländern, die relativ große Klassen hatten wie beispielsweise Korea und die Türkei.

Vom Primar- zum Sekundarbereich I steigt die Zahl der Schüler pro Klasse im Durchschnitt der OECD-Länder um mindestens 2 Schüler an.

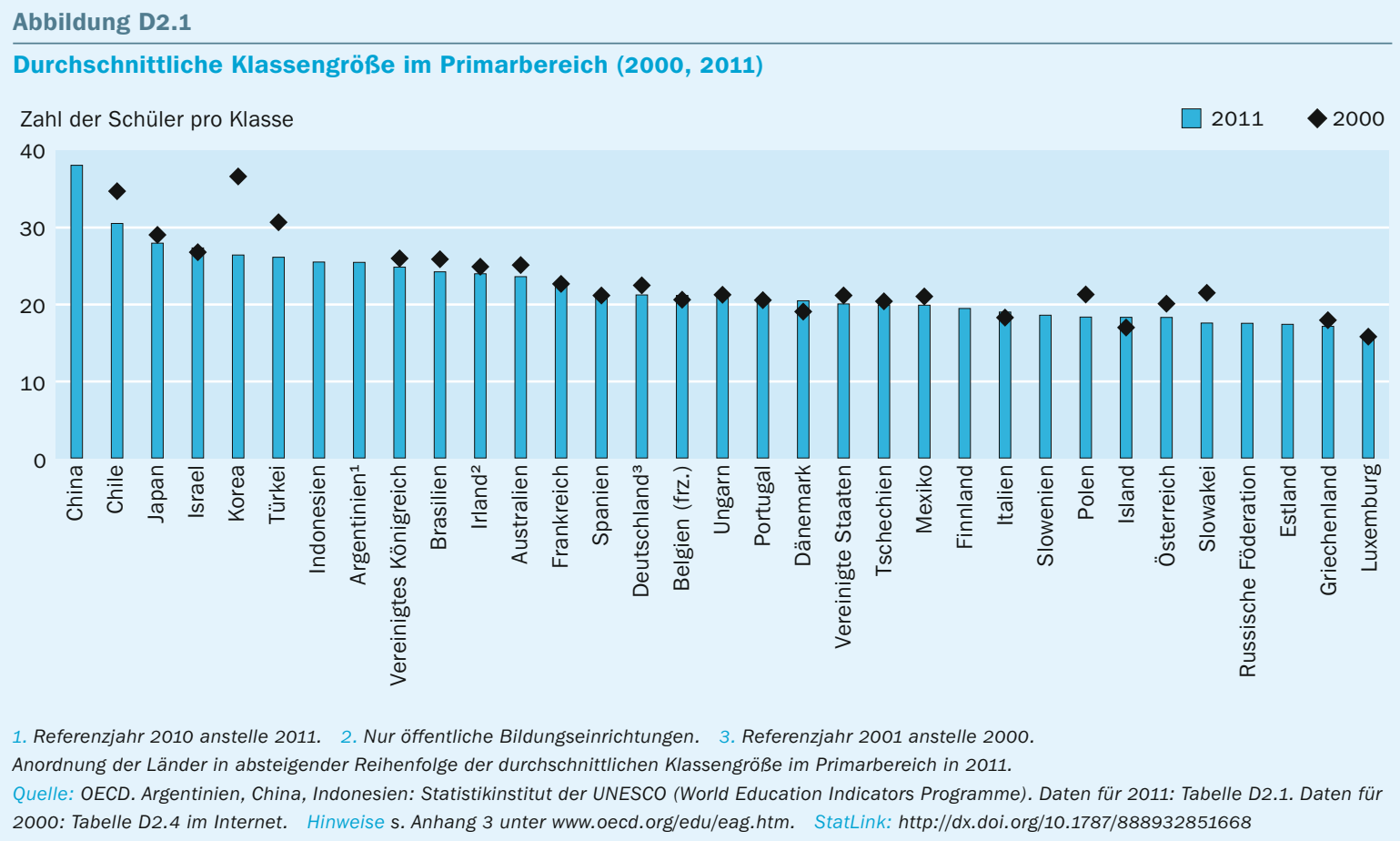

\section{Kontext}

Die Klassengröße und die Schüler-Lehrkräfte-Relation stellen viel diskutierte Aspekte der Ausbildung von Schülern dar. Zusammen mit der Gesamtunterrichtszeit der Schüler (s. Indikator Di), der durchschnittlichen Arbeitszeit der Lehrkräfte (s. Indikator D4) und der Aufteilung der Zeit der Lehrkräfte zwischen Unterrichten und anderen Pflichten handelt es sich um zwei der bestimmenden Faktoren für die Größe des Lehrkörpers in den einzelnen Ländern. Außerdem beeinflussen sie zusammen mit den Gehältern der Lehrkräfte (s. Indikator $\mathrm{D}_{3}$ ) und der Altersverteilung der Lehrkräfte (s. Indikator D5 im Internet) auch die laufenden Ausgaben für Bildung in erheblichem Ausmaß (s. Indikator B6 im Internet und Indikator B7). 
Kleinere Klassen werden oft positiv bewertet, denn sie ermöglichen den Lehrern, sich stärker auf die einzelnen Schüler zu konzentrieren, außerdem komme es zu weniger Störungen des Unterrichts, mit denen sich die Lehrkräfte auseinandersetzen müssen. Es gibt zwar einige Belege dafür, dass sich kleinere Klassen bei bestimmten Schülergruppen, z. B. Schülern mit sozioökonomisch ungünstigem Hintergrund, vorteilhaft auswirken (Finn, I998; Krueger, 2002; Piketty, T. and M. Valdenaire, 2006), insgesamt jedoch sind die Forschungsergebnisse darüber, wie sich die Klassengröße auf die Leistungen der Schüler auswirkt, nicht eindeutig. Die TALIS-Studie erbrachte keinen Beleg für eine direkte und ausgeprägte Korrelation zwischen der Klassengröße und der für Lehren und Lernen zur Verfügung stehenden Zeit (Kasten D2.I). Eher belegt ist eine mögliche positive Korrelation zwischen kleineren Klassen und verschiedenen Aspekten der Arbeitsbedingungen der Lehrer und der Lernergebnisse, z. B. durch mehr Spielraum für innovative Unterrichtsformen, eine positivere Arbeitshaltung und größere Arbeitszufriedenheit der Lehrkräfte (Hattie, 2009; OECD, 2009).

Die Schüler-Lehrkräfte-Relation ist ein Hinweis auf die Ressourcenverteilung im Bildungsbereich. Oft ist abzuwägen zwischen einer niedrigeren Schüler-Lehrkräfte-Relation und höheren Gehältern der Lehrkräfte, Investitionen in ihre berufliche Weiterentwicklung, höheren Investitionen in Unterrichtstechnologien oder dem verstärkten Einsatz von Hilfslehrkräften und anderen Hilfskräften, deren Gehalt oft deutlich unter dem qualifizierter Lehrkräfte liegt. Da immer mehr Kinder mit einem speziellen Bildungsbedarf in Regelklassen integriert werden, kann der verstärkte Einsatz von Fachpersonal und Unterstützungsdiensten die für eine Reduzierung der Schüler-Lehrkräfte-Relation erforderlichen Ressourcen einschränken.

\section{Weitere wichtige Ergebnisse}

In 27 der 30 Länder mit verfügbaren Daten nimmt die Schüler-Lehrkräfte-Relation zwischen dem Primar- und Sekundarbereich I ab, obwohl die Klassengröße zwischen diesen Bildungsbereichen im Allgemeinen steigt. Diese Abnahme der Schüler-Lehrkräfte-Relation spiegelt Unterschiede in der Unterrichtszeit der Schüler pro Jahr wider, die mit zunehmend höherem Bildungsbereich tendenziell zunimmt.

Im Durchschnitt der OECD-Länder ist die Schüler-Lehrkräfte-Relation im Sekundarbereich in privaten Bildungseinrichtungen etwas günstiger als in öffentlichen Bildungseinrichtungen. Dies ist besonders ausgeprägt in Mexiko, wo in öffentlichen Bildungseinrichtungen des Sekundarbereichs fast I7 Schüler mehr auf eine Lehrkraft kommen als in privaten Einrichtungen. Im Durchschnitt der OECD-Länder sind im Primarund Sekundarbereich I die Klassen in öffentlichen Einrichtungen höchstens um einen Schüler größer als in privaten Einrichtungen.

Die Klassengröße unterscheidet sich innerhalb der einzelnen Länder signifikant. Der Unterschied zwischen der kleinsten und der größten Klasse beträgt in Brasilien, Island, Malaysia, Mexiko und der Türkei 30 Schüler. Dies kann teilweise auf die unterschiedliche Größe der Gemeinde zurückzuführen sein, zu der die Schule gehört, oder auf die Unterschiede zwischen öffentlichen und privaten Schulen (Kasten D2.I). 


\section{Entwicklungstendenzen}

Zwischen 2000 und 20II ist die durchschnittliche Klassengröße in Ländern mit verfügbaren Daten für beide Jahre sowohl im Primar- als auch Sekundarbereich I um einen Schüler zurückgegangen, und die Unterschiede in der Klassengröße zwischen den einzelnen OECD-Ländern sind geringer geworden. Im Sekundarbereich I reichte die Klassengröße im Jahr 2000 beispielsweise von 17,4 Schülern in Island bis zu 38,5 Schülern in Korea und im Jahr 201 I von I6,7 Schülern in Estland bis zu 34, o Schülern in Korea. In einigen Ländern, die 2000 relativ kleine Klassen hatten, ist die Klassengröße jedoch gestiegen, insbesondere in Dänemark und Island.

\section{Analyse und Interpretationen}

\section{Durchschnittliche Klassengröße im Primar- und Sekundarbereich I}

Im Primarbereich betrug die durchschnittliche Klassengröße in den OECD-Ländern im Jahr 20II mehr als 2I Schüler pro Klasse. Berücksichtigt man alle Länder mit verfügbaren Daten, so variiert sie jedoch stark und reicht von weniger als I6 Schülern pro Klasse in Luxemburg bis zu mehr als 30 Schülern in Chile und China. In nahezu der Hälfte der Länder mit verfügbaren Daten liegt die Klassengröße im Primarbereich bei unter 20 Schülern: in Estland, Finnland, Griechenland, Island, Italien, Luxemburg, Mexiko, Österreich, Polen, der Russischen Föderation, der Slowakei, Slowenien und Tschechien.

Im Sekundarbereich II (allgemeinbildend) liegt in den OECD-Ländern die durchschnittliche Klassengröße bei mehr als 23 Schülern. Unter Berücksichtigung aller Länder mit verfügbaren Daten für diesen Bildungsbereich reicht diese Zahl von weniger als 20 Schülern in Estland, Island, Luxemburg, der Russischen Föderation, Slowenien und dem Vereinigten Königreich bis zu 34 Schülern pro Klasse in Korea und fast 53 Schülern in China (Tab. D2.I).

Vom Primar- zum Sekundarbereich I steigt die Zahl der Schüler pro Klasse tendenziell an. In Brasilien, China, Griechenland, Indonesien, Japan, Korea, Luxemburg, Mexiko und Polen beträgt der Anstieg der durchschnittlichen Klassengröße mehr als 4 Schüler. Im Vereinigten Königreich und - in geringerem Ausmaß - in Estland dagegen nimmt die Zahl der Schüler zwischen diesen beiden Bildungsbereichen ab (Abb. D2.2).

Zwischen 2000 und $201 \mathrm{I}$ ist in den Ländern mit verfügbaren Daten für beide Jahre die durchschnittliche Klassengröße im Primarbereich leicht zurückgegangen (2I,4 Schüler im Jahr 20II gegenüber 22,6 Schülern im Jahr 2000). Die Klassengröße ist eher in den Ländern zurückgegangen, in denen auch die Zahl der Schüler zurückgegangen ist. Dies ist jedoch teilweise auch darauf zurückzuführen, dass einige Länder während dieses Zeitraums Reformen im Hinblick auf die Klassengröße umgesetzt haben (s. Indikator B7 in Bildung auf einen Blick 2012). Unter den Ländern mit vergleichbaren Daten nahm die Klassengröße jedoch in Ländern wie Korea und der Türkei, die im Jahr 2000 größere Klassen hatten, deutlich ab (um mehr als 4 Schüler). Die Klassengröße 
Abbildung D2.2

Durchschnittliche Klassengröße in Bildungseinrichtungen, nach Bildungsbereich (2011)

Zahl der Schüler pro Klasse

60

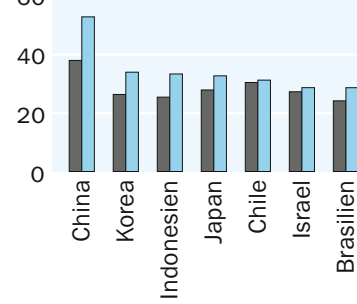

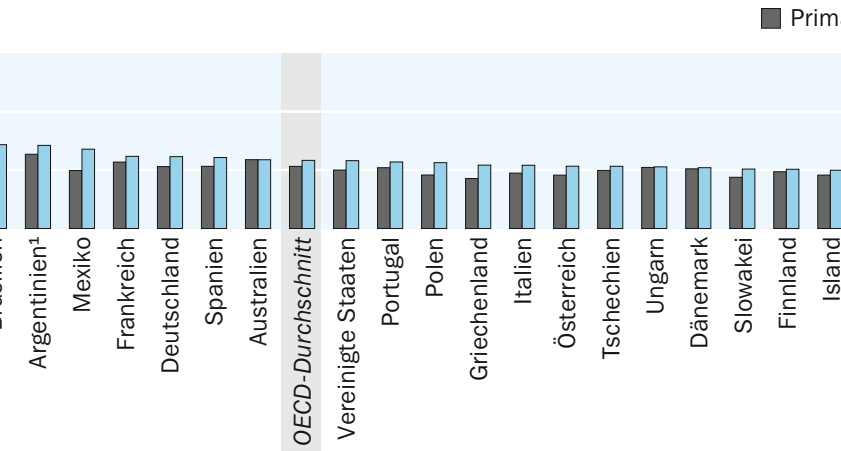

Primarbereich

Sekundarbereich I

Anordnung der Länder in absteigender Reihenfolge der durchschnittlichen Klassengröße im Sekundarbereich I.

Quelle: OECD. Argentinien, China, Indonesien: Statistikinstitut der UNESCO (World Education Indicators Programme). Tabelle D2.1.

Hinweise s. Anhang 3 unter www.oecd.org/edu/eag.htm. StatLink: http://dx.doi.org/10.1787/888932851687

in den Ländern mit den kleinsten Klassen im Jahr 2000 wie Dänemark, Island, Italien und Luxemburg dagegen nahm zu bzw. blieb konstant (Abb. D2.I). Im Sekundarbereich I hat sich der Abstand zwischen den kleinsten und den größten Klassen von 2000 bis 2011 verringert: In den OECD-Ländern mit vergleichbaren Daten für beide Jahre reichte 2000 die Klassengröße von I7,4 Schülern (Island) bis zu 38,5 Schülern (Korea) und im Jahr 2oII von r6,7 Schülern (Estland) bis zu 34,o Schülern (Korea) (Tab. D2.I und Tab. D2.4 im Internet).

Dieser Indikator zur Klassengröße ist auf den Primar- und Sekundarbereich I beschränkt, weil es in den höheren Bildungsbereichen schwierig ist, die Klassengröße zu bestimmen und zu vergleichen, da die Schüler hier je nach Fach häufig unterschiedlich zusammengesetzte Unterrichtsgruppen bilden. Im Sekundarbereich I bieten die TALIS-Daten einen tieferen Einblick in die unterschiedlichen Klassengrößen innerhalb der einzelnen Länder (Kasten D2.I).

Kasten D2.1

\section{Unterschiede bei der Klassengröße innerhalb der einzelnen Länder (TALIS 2008)}

Die internationale OECD-Studie über Lehren und Lernen (Teaching and Learning International Survey - TALIS) untersuchte die Bedingungen, die für ein effektives Lehren und Lernen in Schulen des Sekundarbereichs I erforderlich sind. Als Teil der erhobenen Hintergrundinformation wurden Lehrkräfte gebeten, die tatsächliche Zahl der Schüler in einer Klasse anzugeben, die sie typischerweise an einem spezifischen Tag einer Woche zu einem bestimmten Zeitpunkt in einem ihrer Hauptfächer unterrichten.

Im Durchschnitt der I9 OECD-Länder und OECD-Partnerländer, die an TALIS teilnahmen und die bei Bildung auf einen Blick berücksichtigt werden (insgesamt nahmen an TALIS 23 Länder teil), wurden 23,5 Schüler pro Klasse angegeben, was vergleich- 
bar mit der in diesem Indikator angegebenen durchschnittlichen Klassengröße für den Sekundarbereich I (allgemeinbildend) ist, wenn es auch Unterschiede bei der verwendeten Methodik gab. Der Unterschied bei der sich aus diesen beiden Datenquellen ergebenden durchschnittlichen Klassengröße für die einzelnen Länder beläuft sich in den meisten dieser Länder auf weniger als 2 Schüler, mit Ausnahme von Brasilien und Spanien, wo es fast 3 Schüler sind, und Mexiko, wo sich der Unterschied auf mehr als 9 Schüler beläuft. Zusätzlich erweitert TALIS die Analyse der Klassengröße durch Einblicke in die Varianz der Klassengröße innerhalb der einzelnen Länder.

In den bei TALIS teilnehmenden Ländern gibt es große Unterschiede bei den Klassengrößen im Sekundarbereich I. Die durchschnittliche Klassengröße variiert zwischen weniger als 20 Schülern in Belgien (fläm.), Island, Litauen, Malta und Slowenien und fast dem Doppelten hiervon in Mexiko (mit 37,7 Schülern).

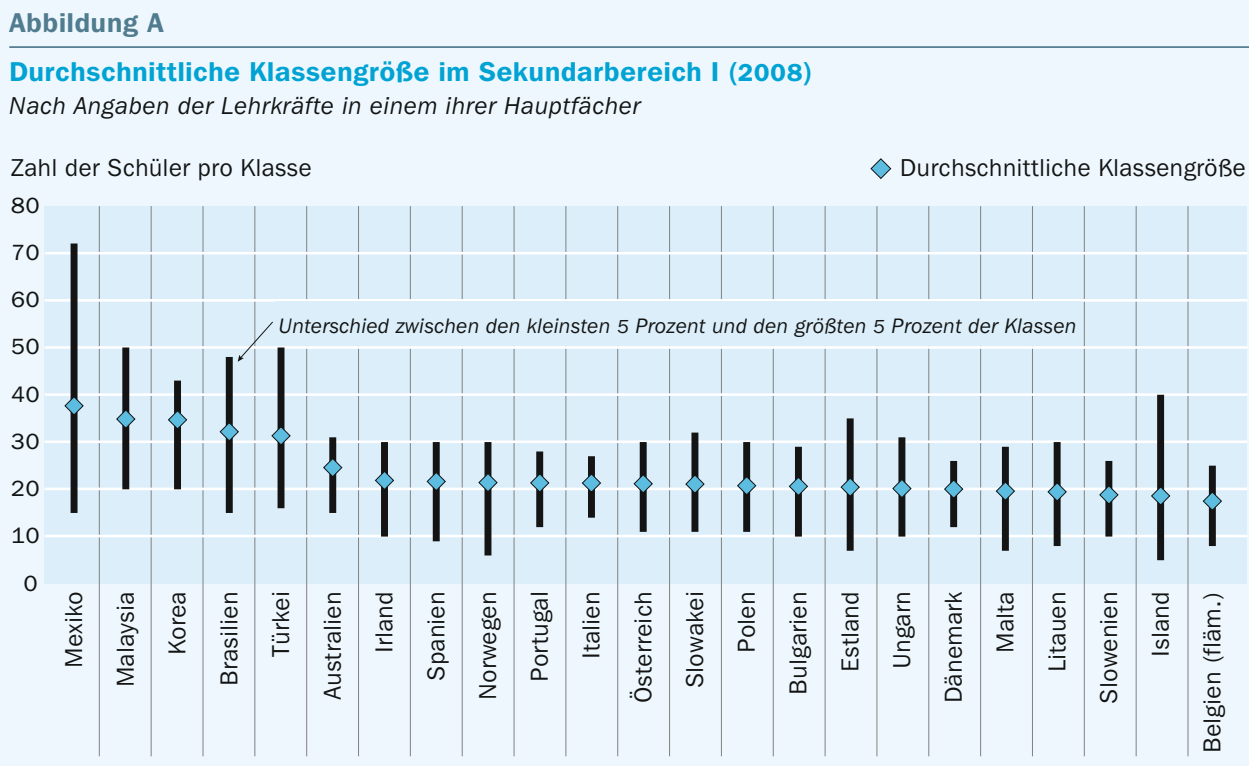

Anordnung der Länder in absteigender Reihenfolge der durchschnittlichen Klassengröße von Klassen, die Lehrkräfte im Sekundarbereich I nach ihren eigenen Angaben typischerweise in einem ihrer Hauptfächer unterrichten.

Quelle: OECD-TALIS-2008-Datenbank. Hinweise s. Anhang 3 unter www.oecd.org/edu/eag.htm.

StatLink: http://dx.doi.org/10.1787/888932855031

Aber auch innerhalb der einzelnen Länder gibt es eine große Varianz der Klassengröße (Abb. A). In Dänemark und Italien beläuft sich die Differenz zwischen den kleinsten 5 Prozent der Klassen und den größten 5 Prozent auf weniger als 15 Schüler, während es in Brasilien, Island, Malaysia, Mexiko und der Türkei mindestens 30 Schüler sind. Brasilien, Mexiko und die Türkei gehören zu den Ländern mit sowohl der größten durchschnittlichen Klassengröße als auch den größten Unterschieden bei der Klassengröße zwischen den einzelnen Schulen. Die Differenz zwischen der kleinsten und der größten Klassengröße in jedem einzelnen Land hängt jedoch nicht unbedingt mit der durchschnittlichen Klassengröße zusammen. In Island beispielsweise beläuft sich, trotz einer kleinen durchschnittlichen Klassengröße, der Unterschied zwischen den 5 Prozent der größten Klassen und den 5 Prozent der kleinsten Klassen auf 35 Schüler - der zweitgrößte Unterschied in diesen 
Ländern. Im Gegensatz hierzu weist Australien trotz relativ großer Klassen (mit 24,6 Schülern) mit den kleinsten Unterschied (I6 Schüler) zwischen den größten und den kleinsten 5 Prozent der Klassen auf.

Die Unterschiede bei der Klassengröße lassen sich auch in jedem dieser Länder mittels der Größe der Gemeinde, zu der die jeweilige Schule gehört, analysieren (s. Abb. B). In den meisten Ländern variiert die Klassengröße in Abhängigkeit von der Einwohnerzahl der Gemeinde, in der sich die Schule befindet. Die Klassengröße nimmt in der Hälfte der Länder mit verfügbaren Daten mit der Größe der entsprechenden Gemeinde zu. Die Unterschiede bei der Klassengröße zwischen Gemeinden ist besonders in den Ländern groß, in denen die Klassen - im Durchschnitt groß sind. So sind beispielsweise in Korea und der Türkei die durchschnittlichen Klassen in Gemeinden mit mehr als 100.000 Einwohnern mindestens um 6 Schüler pro Klasse größer als die durchschnittlichen Klassen in Gemeinden mit weniger als 15.000 Einwohnern. Im Gegensatz hierzu beträgt der Unterschied bei der Klassengröße zwischen großen und kleinen Gemeinden in Belgien (fläm.), Dänemark, Irland, Polen und Slowenien weniger als I Schüler pro Klasse.

Abbildung $B$
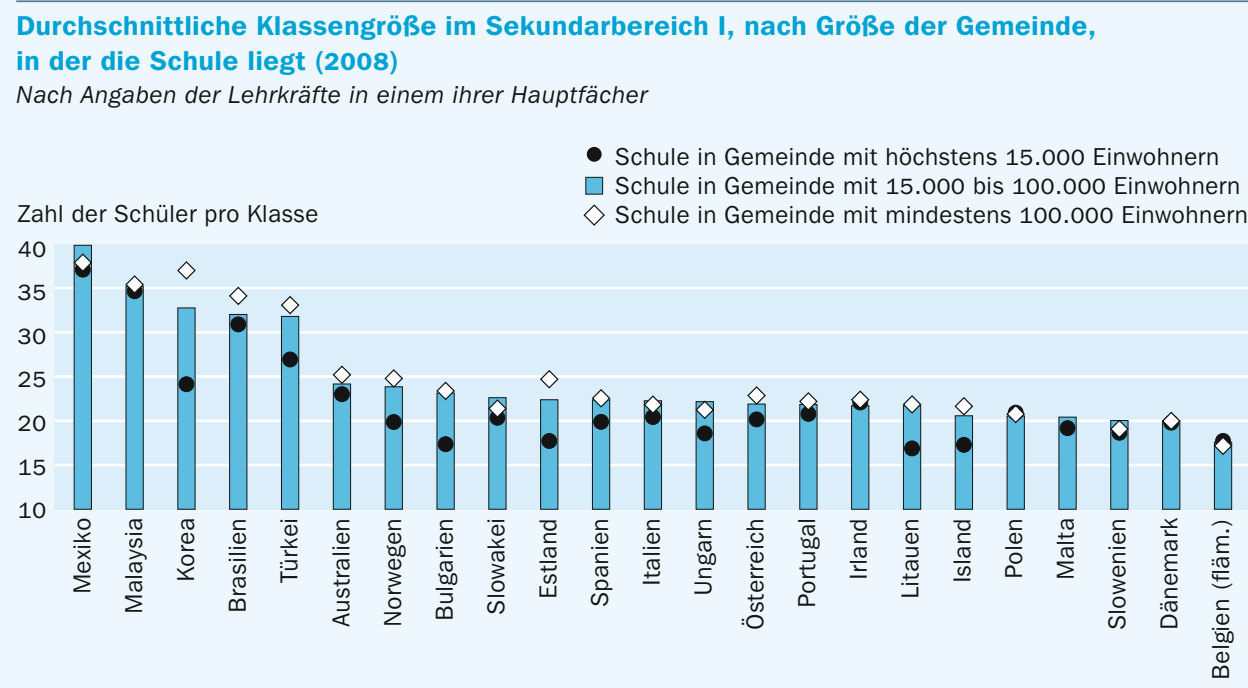

Anordnung der Länder in absteigender Reihenfolge der durchschnittlichen Klassengröße von Klassen, die Lehrkräfte im Sekundarbereich I nach ihren eigenen Angaben typischerweise in einem ihrer Hauptfächer unterrichten.

Quelle: OECD-TALIS-2008-Datenbank. Hinweise s. Anhang 3 unter www.oecd.org/edu/eag.htm.

StatLink: http://dx.doi.org/10.1787/888932855050

Eltern und politische Entscheidungsträger interessieren sich inzwischen für die Frage der Klassengröße, da man davon ausgeht, dass sie sich potenziell auf die Schülerleistungen auswirken kann (Ehrenberg et al., 200I). Es gibt jedoch kaum Belege für die Auswirkungen unterschiedlicher Klassengrößen auf die Leistungen der Schüler. Die Ergebnisse der TALIS-Studie brachten hier weitere Erkenntnisse. Die Lehrkräfte wurden gefragt, wie viel ihrer Zeit sie im Klassenzimmer auf administrative Aufgaben, die Wahrung von Ordnung in der Klasse und das tatsächliche Lehren und Lernen verwenden. Als Hinweis für eine Auswirkung der Klassengröße auf das Lernen der Schüler könnte eine negative Korrelation zwischen der Klassengröße und der angegebenen Zeit sein, die auf das tatsächliche Lehren und Lernen 
verwendet wird, sowie eine positive Korrelation zwischen der Klassengröße und der angegebenen Zeit, die auf die Wahrung von Ordnung in der Klasse verwendet wird. In den meisten Ländern, die an TALIS teilnahmen, gibt es einerseits eine signifikant positive Korrelation zwischen der Klassengröße und der Zeit, die für Wahrung von Ordnung in der Klasse verwendet wird, und andererseits eine negative Korrelation zwischen der Klassengröße und der Zeit, die auf das tatsächliche Lehren und Lernen verwendet wird. Aber diese Korrelationen sind nur schwach ausgeprägt und weisen eher auf eine schwache Verbindung zwischen diesen Faktoren hin. Außerdem sind in einigen Ländern die Korrelationen umgekehrt. In Belgien (fläm.), Irland, Malta, Polen, Portugal und Ungarn verwenden die Lehrkräfte umso weniger Zeit für die Wahrung der Ordnung in der Klasse und umso mehr Zeit für das tatsächliche Lehren und Lernen, je größer die Klasse ist. Daher bieten die Ergebnisse der TALIS-Umfrage keinen Beleg für eine direkte und ausgeprägte Korrelation zwischen der Klassengröße und der für das Lehren und Lernen verwendeten Zeit. Es sind wohl eher andere Faktoren, die diesen Zusammenhang beeinflussen, wie beispielsweise die Unterstützung, die Lehrkräfte dabei erhalten, disziplinarische Probleme in der Klasse anzugehen. So zeigen die Ergebnisse der TALIS-Umfrage, dass junge Lehrer (mit höchstens zwei Jahren Lehrerfahrung) mit größerer Wahrscheinlichkeit als erfahrenere Kollegen mehr Zeit zur Wahrung der Ordnung der Klasse verwenden und dass sie auch eher angeben, dass ihr Bedarf an Fortbildung in den Bereichen Klassenführung sowie Probleme bei der Disziplin und dem Verhalten der Schüler nicht gedeckt wurde (Jensen et al., 2012). Jungen Lehrkräften diese beruflichen Weiterbildungsmöglichkeiten zur Verfügung zu stellen, könnte die notwendige Unterstützung darstellen, damit sie ihre Zeit im Klassenzimmer effektiver für das tatsächliche Lehren und Lernen verwenden können.

\section{Schüler-Lehrkräfte-Relation}

Die Schüler-Lehrkräfte-Relation ergibt sich aus einer Gegenüberstellung der Zahl der Schüler und der Zahl der Lehrkräfte des gleichen Bildungsbereichs und ähnlicher Bildungseinrichtungen (jeweils gemessen in Vollzeitäquivalenten). Diese Relation berücksichtigt jedoch weder die Unterrichtszeit der Schüler im Verhältnis zur Länge des Arbeitstages einer Lehrkraft noch, wie viel Zeit eine Lehrkraft auf das Unterrichten verwendet. Daher kann sie nicht als Klassengröße interpretiert werden (Kasten D2.2).

Im Durchschnitt der OECD-Länder kommen im Primarbereich auf jede Lehrkraft weniger als I6 Schüler. Die Schüler-Lehrkräfte-Relation reicht von mehr als 28 Schülern pro Lehrkraft in Mexiko und mehr als 23 Schülern in Chile bis zu weniger als II Schülern in Island, Luxemburg, Norwegen und Ungarn (Abb. D2.3).

Auch im Sekundarbereich variiert die Schüler-Lehrkräfte-Relation, und zwar in größerem Ausmaß: Sie reicht von 30 Schülern pro Lehrkraft (in Vollzeitäquivalenten) in Mexiko bis zu weniger als II Schülern in Belgien, Luxemburg, Norwegen, Österreich, Polen, Portugal, Saudi-Arabien und Spanien. Im Durchschnitt der OECD-Länder beträgt die Schüler-Lehrkräfte-Relation im Sekundarbereich rund I4 (Tab. D2.2).

Wie die Unterschiede zwischen den Schüler-Lehrkräfte-Relationen erkennen lassen, kommen im Sekundarbereich weniger Schüler auf eine Lehrkraft (jeweils in Vollzeit- 


\section{Zusammenhang zwischen Klassengröße und Schüler-Lehrkräfte- Relation}

Die Berechnung der Zahl der Schüler pro Klasse berücksichtigt eine Reihe unterschiedlicher Faktoren: die Schüler-Lehrkräfte-Relation, die Zahl der Klassen oder Schüler, für die eine Lehrkraft verantwortlich ist, die Unterrichtszeit der Schüler im Vergleich zur Länge des Arbeitstags der Lehrkräfte, den Anteil der Zeit, die Lehrkräfte unterrichten, die Zusammenstellung der Klassen sowie die Praxis des Teamunterrichts.

In einer Schule mit 48 Vollzeitschülern und 8 Vollzeitlehrkräften beispielsweise beträgt die Schüler-Lehrkräfte-Relation $6: \mathrm{I}$. Wenn Lehrkräfte schätzungsweise eine 35-Stunden-Woche haben, wovon Io Zeitstunden auf den Unterricht entfallen, und wenn die Unterrichtszeit für jeden Schüler bei 40 Zeitstunden pro Woche liegt, dann lässt sich die durchschnittliche Klassengröße unabhängig von der Klassenzusammenstellung der Schüler wie folgt berechnen:

Geschätzte Klassengröße $=6$ Schüler pro Lehrkraft $\times$ (40 Unterrichtszeitstunden pro Schüler : Io Unterrichtszeitstunden pro Lehrkraft) $=24$ Schüler.

Unter Verwendung eines anderen Ansatzes ist die in Tabelle D2.I dargestellte Klassengröße definiert als die Zahl der Schüler in einem allgemeinen Kurs, basierend auf der höchsten Zahl der allgemeinen Kurse (normalerweise Pflichtkurse), ohne Unterricht in Kleingruppen. Daher wird die nach der beschriebenen Formel geschätzte Klassengröße der durchschnittlichen Klassengröße in Tabelle D2.I dann ziemlich nahekommen, wenn Unterricht in Kleingruppen weniger häufig vorkommt, wie dies im Primar- und Sekundarbereich I der Fall ist.

Aufgrund dieser Definitionen kann eine ähnliche Schüler-Lehrkräfte-Relation in verschiedenen Ländern zu unterschiedlichen Klassengrößen führen. Im Primarbereich weisen beispielsweise Japan und Tschechien eine ähnliche Schüler-LehrkräfteRelation auf (I8,I in Japan und I8,7 in Tschechien - Tab. D2.2), während sich die durchschnittliche Klassengröße in beiden Ländern sehr unterscheidet (27,9 in Japan und 19,9 in Tschechien - Tab. D2.I).

äquivalenten) als im Primarbereich. In den meisten Ländern nimmt die Schüler-Lehrkräfte-Relation zwischen dem Primar- und Sekundarbereich I ab, während gleichzeitig die Klassengröße tendenziell steigt. Dies gilt bis aufChile, Island und Mexiko für alle OECD-Länder.

Diese Abnahme der Schüler-Lehrkräfte-Relation spiegelt Unterschiede in der Unterrichtszeit pro Jahr wider, die mit zunehmend höherem Bildungsbereich tendenziell zunimmt (s. Indikator DI). Sie könnte aber auch auf zeitliche Verzögerungen bei der Anpassung der Zahl der Lehrkräfte an veränderte demografische Gegebenheiten oder auf Unterschiede bei den von Lehrkräften zu unterrichtenden (Zeit-)Stunden in den verschiedenen Bildungsbereichen zurückzuführen sein, die mit steigendem Bildungs- 


\section{Abbildung D2.3}

Lernende-Lehrende-Relation in Bildungseinrichtungen, nach Bildungsbereich (2011)
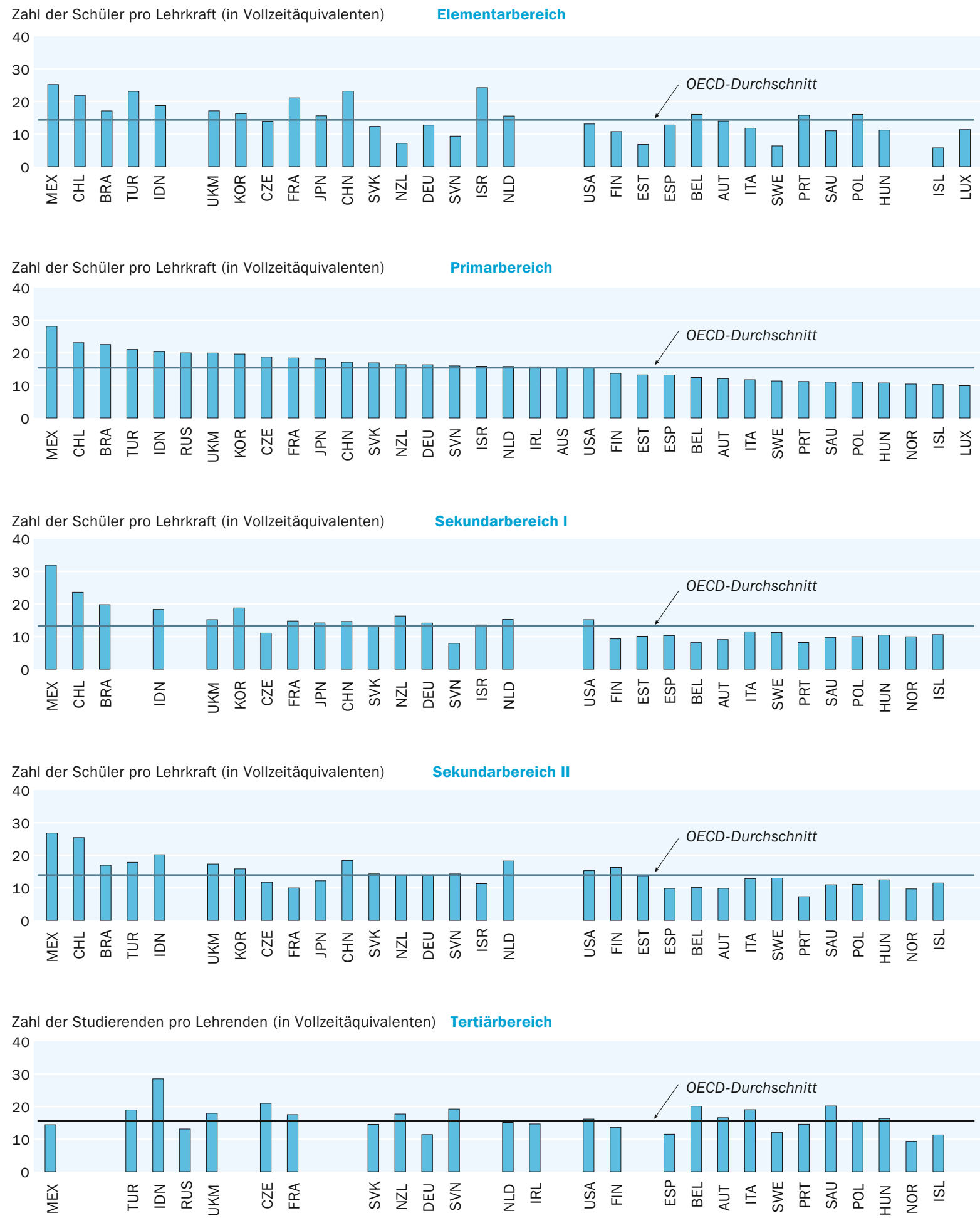

Anordnung der Länder in absteigender Reihenfolge der Schüler-Lehrkräfte-Relation im Primarbereich.

Quelle: OECD. China, Indonesien, Saudi-Arabien: Statistikinstitut der UNESCO (World Education Indicators Programme). Tabelle D2.2.

Hinweise s. Anhang 3 unter www. oecd.org/edu/eag.htm StatLink: http://dx.doi.org/10.1787/888932851706

Auflistung der verwendeten Ländercodes s. Hinweise für den Leser. 
bereich tendenziell abnehmen, während die Spezialisierung der Lehrer zunimmt. Dieser allgemeine Trend ist zwar über alle Länder hinweg zu beobachten, es gibt jedoch nur uneinheitliche Belege dafür, dass vom pädagogischen Standpunkt her in höheren Bildungsbereichen eine niedrigere Schüler-Lehrkräfte-Relation wünschenswert wäre.

Für den Elementarbereich (s. auch Indikator C2) enthält Tabelle D2.2 Angaben zur Schüler-Lehrkräfte-Relation sowie zur Schüler-Kontaktpersonen-Relation (Lehrkräfte und Hilfslehrkräfte). Einige Länder bauen im Elementarbereich in großem Umfang auf Hilfslehrkräfte. In I2 Ländern ist die gemeldete Schüler-Kontaktpersonen-Relation (Tab. D2.2, Spalte I) niedriger als die Schüler-Lehrkräfte-Relation. Nur in wenigen Ländern kommt eine große Zahl von Hilfslehrkräften zum Einsatz. So ist die SchülerKontaktpersonen-Relation in Brasilien, Chile, China, Deutschland, Frankreich, Israel, Österreich, dem Vereinigten Königreich und den Vereinigten Staaten wesentlich niedriger (um mindestens 2 Schüler) als die Schüler-Lehrkräfte-Relation. Dieser Unterschied ist in Chile und Israel besonders groß, wo die Schüler-Kontaktpersonen-Relation mindestens um Io Schüler niedriger ist als die Schüler-Lehrkräfte-Relation.

Im Tertiärbereich variiert die Studierende-Lehrende-Relation zwischen mindestens 20 Studierenden pro Lehrenden in Belgien, Indonesien, Saudi-Arabien, Südafrika und Tschechien und weniger als Io in Norwegen (Tab. D2.2). Allerdings sollten derartige Vergleiche für diesen Bildungsbereich mit Vorsicht durchgeführt werden, da hier immer noch Schwierigkeiten bei der Berechnung von vergleichbaren Vollzeitäquivalenten für Studierende und Lehrende bestehen. In 6 der I3 Länder mit vergleichbaren Daten für den Tertiärbereich ist die Studierende-Lehrende-Relation in den stärker berufsorientierten Studiengängen des Tertiärbereichs B niedriger als in den eher theoretisch orientierten Studiengängen des Tertiärbereichs A und weiterführenden forschungsorientierten Studiengängen. Die Türkei ist das einzige Land, das im Tertiärbereich bei den berufsorientierten Studiengängen des Tertiärbereichs B eine signifikant höhere Relation (53) als in den theoretisch ausgerichteten Studiengängen des Tertiärbereichs A und den weiterführenden forschungsorientierten Studiengängen aufweist (I5) (Tab. D2.2).

Die Klassengröße in öffentlichen und privaten Bildungseinrichtungen Für Eltern kann die Klassengröße ein wichtiger Faktor bei der Auswahl der Schule für ihre Kinder sein, daher könnten sich Unterschiede bei der durchschnittlichen Klassengröße zwischen öffentlichen und privaten Bildungseinrichtungen (und auch zwischen unterschiedlichen Arten der privaten Schulen) auf die Schülerzahlen dieser Einrichtungen auswirken.

In den OECD- und G20-Ländern mit verfügbaren Daten unterscheidet sich die durchschnittliche Klassengröße zwischen privaten und öffentlichen Bildungseinrichtungen sowohl im Primar-als auch im Sekundarbereich I in der Regel um nicht mehr als einen Schüler (Abb. D2.4 und Tab. D2.I). Es gibt jedoch deutliche Unterschiede zwischen den einzelnen Ländern. So ist beispielsweise in Brasilien, Israel, Polen, der Russischen Föderation, Tschechien, der Türkei und dem Vereinigten Königreich im Primarbereich die durchschnittliche Klassengröße in öffentlichen Bildungseinrichtungen um mindestens 4 Schüler pro Klasse größer als in privaten Bildungseinrichtungen. In all diesen Ländern, mit Ausnahme von Brasilien und Israel, ist jedoch der Anteil der privaten 


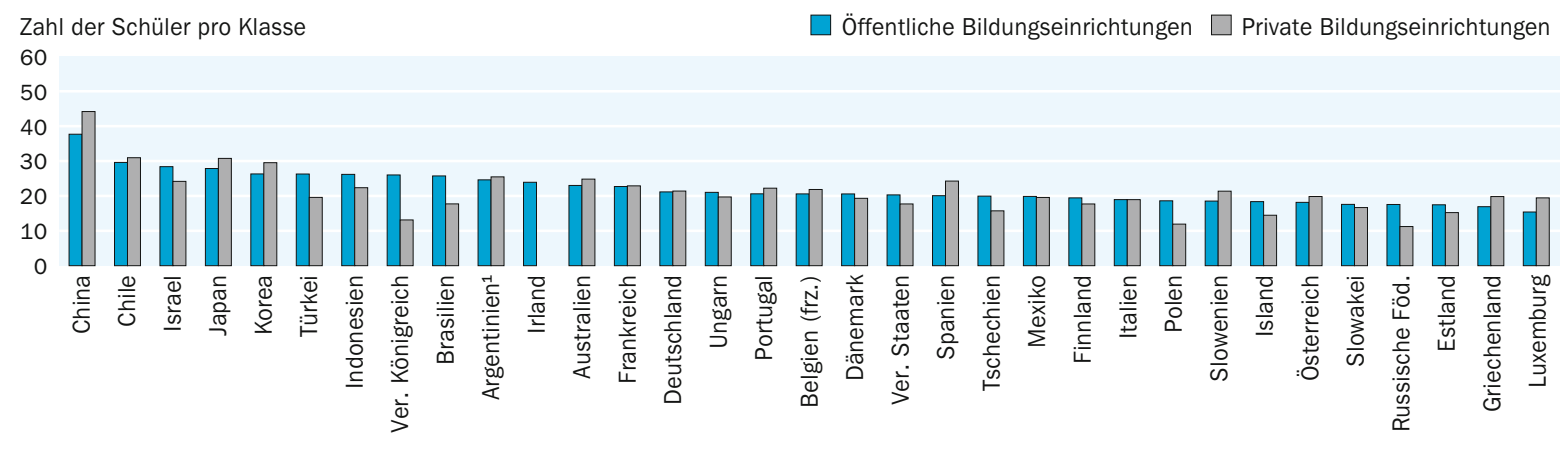

Sekundarbereich I

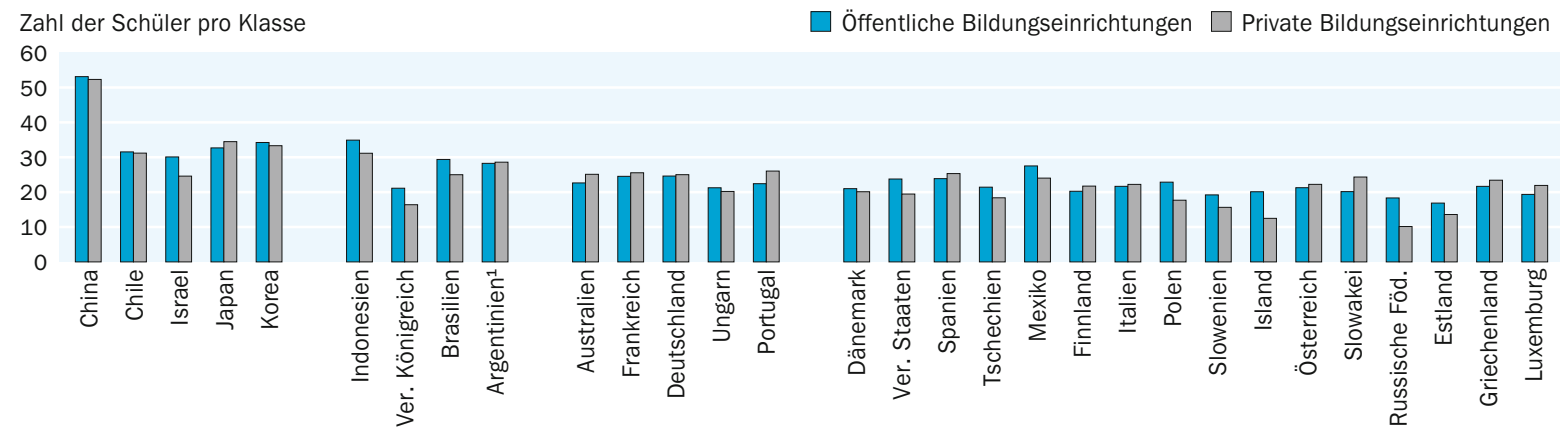

1. Referenzjahr 2010 anstelle 2011.

Anordnung der Länder in absteigender Reihenfolge der durchschnittlichen Klassengröße in öffentlichen Bildungseinrichtungen im Primarbereich.

Quelle: OECD. Argentinien, China, Indonesien: Statistikinstitut der UNESCO (World Education Indicators Programme). Tabelle D2.1.

Hinweise s. Anhang 3 unter www.oecd.org/edu/eag.htm. StatLink: http://dx.doi.org/10.1787/888932851725

Bildungseinrichtungen mit höchstens 5 Prozent der Schüler im Primarbereich relativ klein (s. Tab. Cr.4). Dagegen ist die durchschnittliche Klassengröße in privaten Bildungseinrichtungen in China, Luxemburg und Spanien (wo diese von mehr als 30 Prozent der Schüler besucht werden) um mindestens 4 Schüler größer als in öffentlichen Einrichtungen.

Der Vergleich der Klassengröße zwischen öffentlichen und privaten Bildungseinrichtungen ergibt auch für den Sekundarbereich I, wo es mehr private Bildungseinrichtungen gibt, ein uneinheitliches Bild. Die durchschnittliche Klassengröße im Sekundarbereich I ist in I3 OECD-Ländern in privaten Bildungseinrichtungen größer als in öffentlichen Einrichtungen, die Unterschiede sind jedoch tendenziell kleiner als im Primarbereich.

In Ländern mit einem größeren Anteil an privaten Bildungseinrichtungen im Primarund Sekundarbereich I (d. h. Länder, in denen mehr als ıo Prozent der Schüler dieser Bereiche private Bildungseinrichtungen besuchen) wie Argentinien, Australien, Belgien (frz.), Brasilien, Chile, Dänemark, Frankreich, Indonesien, Portugal und Spanien können große Unterschiede zwischen den Klassengrößen an öffentlichen und privaten Bildungseinrichtungen bestehen. In Spanien, einem der beiden Länder, in denen diese Unterschiede groß sind (ein Unterschied von mindestens 4 Schülern in beiden 
Bildungsbereichen in Brasilien sowie nur im Primarbereich in Spanien), haben jedoch private Bildungseinrichtungen tendenziell größere Klassen als öffentliche (s. Tab. Cr.4 und D2.I). Dies deutet darauf hin, dass in den Ländern, in denen sich ein erheblicher Teil der Schüler und Familien für private Bildungseinrichtungen entscheidet, die Klassengröße kein ausschlaggebender Faktor für diese Entscheidung ist.

Vergleicht man die Schüler-Lehrkräfte-Relation, so ergibt sich ein ähnliches Bild. Im Durchschnitt der Länder mit verfügbaren Daten ist die Schüler-Lehrkräfte-Relation in privaten Bildungseinrichtungen sowohl des Sekundarbereichs I als auch des Sekundarbereichs II etwas niedriger als in öffentlichen Bildungseinrichtungen (Tab. D2.3). Die größten Unterschiede zwischen öffentlichen und privaten Bildungseinrichtungen gibt es in Brasilien und Mexiko, wo in öffentlichen Bildungseinrichtungen des Sekundarbereichs I mindestens 8 Schüler mehr auf eine Lehrkraft kommen als in privaten Bildungseinrichtungen. Im Sekundarbereich II ist in Mexiko der Unterschied bei der Schüler-Lehrkräfte-Relation zwischen öffentlichen und privaten Bildungseinrichtungen (mehr als I7 Schüler Unterschied pro Lehrkraft) sogar noch größer als im Sekundarbereich I (I5 Schüler pro Lehrkraft).

In einigen Ländern ist jedoch die Schüler-Lehrkräfte-Relation in öffentlichen Bildungseinrichtungen niedriger als in privaten Bildungseinrichtungen. Der Unterschied ist in Spanien im Sekundarbereich I mit etwa I5 Schülern pro Lehrkraft in privaten Bildungseinrichtungen im Vergleich zu weniger als 9 Schülern pro Lehrkraft in öffentlichen Bildungseinrichtungen am größten.

\section{Definitionen}

Lehrende Beschäftigte (Lehrkräfte) umfasst zwei Kategorien:

- Hilfslehrkräfte und Lehr-|Forschungsassistenten umfassen nicht voll qualifizierte Beschäftigte oder Studierende, die die Lehrkräfte beim Unterrichten der Schüler unterstützen. Lehrkräfte sind voll qualifiziertes Personal, das direkt mit dem Unterrichten der Schüler befasst ist. Die Kategorie umfasst Lehrkräfte, Förderlehrer und andere Lehrkräfte, die mit Schülern als ganzer Klasse im Klassenzimmer, in kleinen Gruppen in einem Förderraum oder im Einzelunterricht innerhalb oder außerhalb des regulären Unterrichts arbeiten. Diese Kategorie umfasst auch Fachbereichsleiter, deren Aufgaben einen nur geringen Umfang an Unterricht beinhalten, während nicht voll qualifizierte Mitarbeiter, die die Lehrkräfte beim Unterricht unterstützen, wie Hilfslehrkräfte und andere Hilfskräfte, nicht zu dieser Kategorie gehören.

\section{Angewandte Methodik}

Die Daten beziehen sich auf das Schul-/Studienjahr 20I0/20II und beruhen auf der von der OECD im Jahre 2012 durchgeführten UOE-Datenerhebung zur Bildungsstatistik (weitere Einzelheiten s. Anhang 3 unter www.oecd.orgleduleag.htm). 
Die Berechnungen beziehen sich auf die Ausgaben öffentlicher Bildungseinrichtungen bzw. soweit verfügbar auf die Ausgaben sowohl öffentlicher als auch privater Bildungseinrichtungen.

Die Klassengröße wird berechnet, indem die Zahl der Schüler durch die Zahl der Klassen dividiert wird. Um die Vergleichbarkeit zwischen den einzelnen Ländern zu gewährleisten, werden spezielle Förderklassen nicht berücksichtigt. Die Daten beziehen sich ausschließlich auf reguläre Bildungsgänge im Primar- und Sekundarbereich I, Unterricht in Kleingruppen außerhalb des regulären Klassenunterrichts ist nicht erfasst.

Die Schüler-Lehrkräfte-Relation ergibt sich, wenn man (gemessen in Vollzeitäquivalenten) die Zahl der Schüler eines bestimmten Bildungsbereichs durch die Zahl der Lehrkräfte des gleichen Bildungsbereichs und ähnlicher Bildungseinrichtungen dividiert.

Die statistischen Daten für Israel wurden von den zuständigen israelischen Stellen bereitgestellt, die für sie verantwortlich zeichnen. Die Verwendung dieser Daten durch die OECD erfolgt unbeschadet des völkerrechtlichen Status der Golanhöhen, von OstJerusalem und der israelischen Siedlungen im Westjordanland.

\section{Weiterführende Informationen}

Ehrenberg, R. G., et al. (200I), „Class Size and Student Achievement“, Psychological Science in the Public Interest, Vol. 2, No. I, pp. I-30.

Finn, J. (1998), Class Size and Students at Risk: What is Known? What is Next?, US Department of Education, Office of Educational Research and Improvement, National Institute on the Education of At-Risk Students, Washington, DC.

Hattie, J. (2009), Visible Learning: A Synthesis of over 800 Meta-analyses Relating to Achievement, Routledge, London.

Jensen, B., et al. (2012), The Experience of New Teachers: Results from TALIS 2008, OECD Publishing, http://dx.doi.org/10.1787/9789264120952-en.

Krueger, A. B. (2002), „Economic Considerations and Class Size“, National Bureau of Economic Research Working Paper, No. 8875.

OECD (2009), Creating Effective Teaching and Learning Environments: First Results from TALIS, OECD Publishing, http://dx.doi.org/0.1787/9789264068780-en.

Piketty, T. and M. Valdenaire (2006), L'Impact de la taille des classes sur la réussite scolaire dans les écoles, collèges et lycées français : Estimations à partir du panel primaire 1997 et du panel secondaire 1995, Ministère de l'Éducation nationale, de l'Enseignement supérieur et de la Recherche, Direction de l'évaluation et de la prospective, Paris.

Hinweise zu den in Bezug auf diesen Indikator in den einzelnen Ländern verwendeten Definitionen und angewandten Methodik s. Anhang 3 unter www.oecd.org/eduleag.htm. 


\section{Tabellen Indikator D2}

Tabelle D2.I: Durchschnittliche Klassengröße, nach Art der Bildungseinrichtung und Bildungsbereich (20II)

StatLink: http://dx.doi.org/10.1787/888932851592

Tabelle D2.2: Lernende-Lehrende-Relation in Bildungseinrichtungen (20II) StatLink: http:/|dx.doi.org/10.1787/888932851611

Tabelle D2.3: Schüler-Lehrkräfte-Relation, nach Art der Bildungseinrichtung (20II)

StatLink: http:||dx.doi.org/10.1787/888932851630

WEB Table D2.4: Average class size, by type of institution and level of education (Durchschnittliche Klassengröße, nach Art der Bildungseinrichtung und Bildungsbereich) (2000)

StatLink: http://dx.doi.org/10.1787/888932851649 
Tabelle D2.1

Durchschnittliche Klassengröße, nach Art der Bildungseinrichtung und Bildungsbereich (2011) Berechnungen basierend auf der Zahl der Schüler und der Zahl der Klassen

\begin{tabular}{|c|c|c|c|c|c|c|c|c|c|c|}
\hline & \multicolumn{5}{|c|}{ Primarbereich } & \multicolumn{5}{|c|}{$\begin{array}{l}\text { Sekundarbereich I } \\
\text { (Allgemeinbildende Ausbildungsgänge) }\end{array}$} \\
\hline & \multirow{2}{*}{$\begin{array}{l}\text { Öffentliche } \\
\text { Bildungsein- } \\
\text { richtungen }\end{array}$} & \multicolumn{3}{|c|}{ Private Bildungseinrichtungen } & \multirow{2}{*}{\begin{tabular}{|c|} 
Gesamt: \\
Öffentliche \\
und private \\
Bildungsein- \\
richtungen
\end{tabular}} & \multirow{2}{*}{$\begin{array}{l}\text { Öffentliche } \\
\text { Bildungsein- } \\
\text { richtungen }\end{array}$} & \multicolumn{3}{|c|}{ Private Bildungseinrichtungen } & \multirow{2}{*}{$\begin{array}{l}\text { Gesamt: } \\
\text { Öffentliche } \\
\text { und private } \\
\text { Bildungsein- } \\
\text { richtungen }\end{array}$} \\
\hline & & \begin{tabular}{|c|} 
Gesamt: \\
Private \\
Bildungsein- \\
richtungen
\end{tabular} & \begin{tabular}{|c|} 
Staatlich \\
subventio- \\
nierte \\
private \\
Bildungsein- \\
richtungen
\end{tabular} & \begin{tabular}{|c|} 
Unabhän- \\
gige private \\
Bildungsein- \\
richtungen
\end{tabular} & & & \begin{tabular}{|c|} 
Gesamt: \\
Private \\
Bildungsein- \\
richtungen
\end{tabular} & \begin{tabular}{|c|} 
Staatlich \\
subventio- \\
nierte \\
private \\
Bildungsein- \\
richtungen
\end{tabular} & \begin{tabular}{|c|} 
Unabhän- \\
gige private \\
Bildungsein- \\
richtungen
\end{tabular} & \\
\hline & (1) & (2) & (3) & (4) & (5) & (6) & (7) & (8) & (9) & (10) \\
\hline \multicolumn{11}{|l|}{ OECD-Länder } \\
\hline Australien & 23,0 & 24,8 & 24,8 & a & 23,5 & 22,6 & 25,0 & 25,0 & a & 23,5 \\
\hline Österreich & 18,2 & 19,8 & $x(2)$ & $x(2)$ & 18,2 & 21,2 & 22,2 & $x(7)$ & $x(7)$ & 21,3 \\
\hline Belgien & $\mathrm{m}$ & $\mathrm{m}$ & $\mathrm{m}$ & a & m & $\mathrm{m}$ & $\mathrm{m}$ & $\mathrm{m}$ & a & m \\
\hline Belgien (frz.) & 20,6 & 21,8 & 21,8 & $\mathrm{~m}$ & 21,1 & $\mathrm{~m}$ & $\mathrm{~m}$ & $\mathrm{~m}$ & $\mathrm{~m}$ & m \\
\hline Kanada & $\mathrm{m}$ & $\mathrm{m}$ & $\mathrm{m}$ & $\mathrm{m}$ & m & $\mathrm{m}$ & $\mathrm{m}$ & $\mathrm{m}$ & $\mathrm{m}$ & m \\
\hline Chile & 29,6 & 31,0 & 32,4 & 23,8 & 30,4 & 31,5 & 31,1 & 32,4 & 24,7 & 31,3 \\
\hline Tschechien & 19,9 & 15,7 & 15,7 & a & 19,9 & 21,4 & 18,3 & 18,3 & a & 21,3 \\
\hline Dänemark & 20,6 & 19,3 & 19,3 & a & 20,4 & 20,9 & 20,1 & 20,1 & a & 20,8 \\
\hline Estland & 17,5 & 15,2 & a & 15,2 & 17,4 & 16,8 & 13,6 & a & 13,6 & 16,7 \\
\hline Finnland & 19,4 & 17,7 & 17,7 & a & 19,4 & 20,2 & 21,7 & 21,7 & a & 20,3 \\
\hline Frankreich & 22,7 & 22,9 & $x(2)$ & $x(2)$ & 22,7 & 24,5 & 25,5 & 25,7 & 14,0 & 24,7 \\
\hline Deutschland & 21,2 & 21,4 & 21,4 & $x(3)$ & 21,2 & 24,5 & 24,9 & 24,9 & $x(8)$ & 24,6 \\
\hline Griechenland & 16,9 & 19,8 & a & 19,8 & 17,1 & 21,6 & 23,4 & a & 23,4 & 21,7 \\
\hline Ungarn & 21,0 & 19,7 & 19,7 & a & 20,9 & 21,2 & 20,1 & 20,1 & a & 21,1 \\
\hline Island & 18,4 & 14,5 & 14,5 & a & 18,3 & 20,1 & 12,5 & 12,5 & a & 19,9 \\
\hline Irland & 23,9 & $\mathrm{~m}$ & a & $\mathrm{m}$ & $\mathbf{m}$ & $\mathrm{m}$ & $\mathrm{m}$ & $\mathrm{m}$ & $\mathrm{m}$ & $\mathbf{m}$ \\
\hline Israel & 28,4 & 24,2 & 24,0 & a & 27,3 & 30,0 & 24,5 & 23,4 & a & 28,7 \\
\hline Italien & 18,9 & 18,9 & a & 18,9 & 18,9 & 21,6 & 22,2 & a & 22,2 & 21,6 \\
\hline Japan & 27,9 & 30,8 & a & 30,8 & 27,9 & 32,6 & 34,4 & a & 34,4 & 32,7 \\
\hline Korea & 26,3 & 29,5 & a & 29,5 & 26,3 & 34,1 & 33,2 & 33,2 & a & 34,0 \\
\hline Luxemburg & 15,4 & 19,4 & 18,1 & 19,5 & 15,7 & 19,3 & 21,9 & 19,6 & 25,6 & 19,7 \\
\hline Mexiko & 19,9 & 19,6 & a & 19,6 & 19,8 & 27,4 & 24,0 & a & 24,0 & 27,1 \\
\hline Niederlande & $\mathrm{m}$ & $\mathrm{m}$ & $\mathrm{m}$ & $\mathrm{m}$ & $\mathbf{m}$ & $\mathrm{m}$ & $\mathrm{m}$ & $\mathrm{m}$ & $\mathrm{m}$ & $\mathbf{m}$ \\
\hline Neuseeland & $\mathrm{m}$ & $\mathrm{m}$ & $\mathrm{m}$ & $\mathrm{m}$ & $\mathbf{m}$ & $\mathrm{m}$ & $\mathrm{m}$ & $\mathrm{m}$ & $\mathrm{m}$ & $\mathbf{m}$ \\
\hline Norwegen & a & a & a & $a$ & $\mathbf{a}$ & a & $a$ & a & a & $\mathbf{a}$ \\
\hline Polen & 18,6 & 11,9 & 11,1 & 12,2 & 18,3 & 22,8 & 17,6 & 23,8 & 15,8 & 22,5 \\
\hline Portugal & 20,6 & 22,2 & 24,2 & 21,5 & 20,8 & 22,4 & 26,0 & 25,7 & 26,4 & 22,8 \\
\hline Slowakei & 17,6 & 16,7 & 16,7 & $n$ & 17,5 & 20,1 & 24,3 & 24,3 & $\mathrm{n}$ & 20,3 \\
\hline Slowenien & 18,5 & 21,4 & 21,4 & $\mathrm{n}$ & 18,5 & 19,2 & 15,6 & 15,6 & $\mathrm{n}$ & 19,2 \\
\hline Spanien & 20,1 & 24,3 & 24,6 & 22,2 & 21,3 & 23,8 & 25,3 & 25,7 & 21,8 & 24,3 \\
\hline Schweden & $\mathrm{m}$ & $\mathrm{m}$ & $\mathrm{m}$ & $\mathrm{m}$ & m & $\mathrm{m}$ & $\mathrm{m}$ & $\mathrm{m}$ & $\mathrm{m}$ & m \\
\hline Schweiz & $\mathrm{m}$ & $\mathrm{m}$ & $\mathrm{m}$ & $\mathrm{m}$ & m & $\mathrm{m}$ & $\mathrm{m}$ & $\mathrm{m}$ & $\mathrm{m}$ & m \\
\hline Türkei & 26,3 & 19,6 & a & 19,6 & 26,1 & a & a & a & a & $\mathbf{a}$ \\
\hline Vereinigtes Königreich & 26,0 & 13,1 & 29,0 & 12,4 & 24,8 & 21,1 & 16,4 & 19,2 & 10,1 & 19,5 \\
\hline Vereinigte Staaten & 20,3 & 17,7 & a & 17,7 & 20,0 & 23,7 & 19,4 & a & 19,4 & 23,2 \\
\hline OECD-Durchschnitt & 21,3 & 20,5 & 21,0 & 20,2 & 21,2 & 23,4 & 22,5 & 22,8 & 21,2 & 23,3 \\
\hline EU21-Durchschnitt & 19,9 & 19,0 & 20,0 & 18,1 & 19,9 & 21,8 & 22,0 & 22,4 & 19,9 & 21,8 \\
\hline \multicolumn{11}{|l|}{ Sonstige G20-Länder } \\
\hline Argentinien ${ }^{1}$ & 24,6 & 25,5 & 29,5 & 24,1 & 25,4 & 28,2 & 28,5 & 30,1 & 26,9 & 28,4 \\
\hline Brasilien & 25,7 & 17,7 & a & 17,7 & 24,2 & 29,3 & 24,9 & a & 24,9 & 28,7 \\
\hline China & 37,7 & 44,2 & $x(2)$ & $x(2)$ & 38,0 & 53,0 & 52,2 & $x(7)$ & $x(7)$ & 52,9 \\
\hline Indien & $\mathrm{m}$ & $\mathrm{m}$ & $\mathrm{m}$ & $\mathrm{m}$ & m & $\mathrm{m}$ & $\mathrm{m}$ & $\mathrm{m}$ & $\mathrm{m}$ & m \\
\hline Indonesien & 26,2 & 22,4 & a & 22,4 & 25,4 & 34,8 & 31,1 & a & 31,1 & 33,4 \\
\hline Russische Föderation & 17,5 & 11,2 & a & 11,2 & 17,5 & 18,3 & 10,1 & a & 10,1 & 18,2 \\
\hline Saudi-Arabien & $\mathrm{m}$ & $\mathrm{m}$ & $\mathrm{m}$ & $\mathrm{m}$ & m & $\mathrm{m}$ & $\mathrm{m}$ & $\mathrm{m}$ & $\mathrm{m}$ & m \\
\hline Südafrika & $\mathrm{m}$ & $\mathrm{m}$ & $\mathrm{m}$ & $\mathrm{m}$ & m & $\mathrm{m}$ & $\mathrm{m}$ & $\mathrm{m}$ & $\mathrm{m}$ & $\mathbf{m}$ \\
\hline G20-Durchschnitt & 24,3 & 22,6 & $\sim$ & $\sim$ & 24,1 & 26,4 & 24,8 & $\sim$ & $\sim$ & 26,2 \\
\hline
\end{tabular}

1. Referenzjahr 2010.

Quelle: OECD. Argentinien, China, Indonesien: Statistikinstitut der UNESCO (World Education Indicators Programme).

Hinweise s. Anhang 3 unter www.oecd.org/edu/eag.htm. StatLink: http://dx.doi.org/10.1787/888932851592

Erläuterung der Kennzeichnung fehlender Daten s. Hinweise für den Leser. 
Lernende-Lehrende-Relation in Bildungseinrichtungen (2011) Nach Bildungsbereich (basierend auf Vollzeitäquivalenten)

\begin{tabular}{|c|c|c|c|c|c|c|c|c|c|c|}
\hline & \multicolumn{2}{|c|}{ Elementarbereich } & \multirow{2}{*}{$\begin{array}{l}\text { Primarbe- } \\
\text { reich }\end{array}$} & \multicolumn{3}{|c|}{ Sekundarbereich } & \multirow{2}{*}{$\begin{array}{c}\text { Postsekun- } \\
\text { darer, nicht } \\
\text { tertiärer } \\
\text { Bereich }\end{array}$} & \multicolumn{3}{|c|}{ Tertiärbereich } \\
\hline & \begin{tabular}{|c|} 
Relation \\
Schüler zu \\
Kontaktper- \\
sonen (Lehrer \\
und Hilfslehr- \\
kräfte)
\end{tabular} & \begin{tabular}{|c|} 
Relation \\
Schüler zu \\
Lehrkräften
\end{tabular} & & $\begin{array}{l}\text { Sekundar- } \\
\text { bereich I }\end{array}$ & $\begin{array}{l}\text { Sekundar- } \\
\text { bereich II }\end{array}$ & $\begin{array}{l}\text { Sekundar- } \\
\text { bereich } \\
\text { insgesamt }\end{array}$ & & $\begin{array}{c}\text { Tertiär- } \\
\text { bereich B }\end{array}$ & \begin{tabular}{|l} 
Tertiärbereich \\
A und wei- \\
terführende \\
forschungs- \\
orientierte \\
Studiengänge
\end{tabular} & $\begin{array}{c}\text { Tertiär- } \\
\text { bereich } \\
\text { insgesamt }\end{array}$ \\
\hline & (1) & (2) & (3) & (4) & (5) & (6) & (7) & (8) & (9) & (10) \\
\hline \multicolumn{11}{|l|}{ OECD-Länder } \\
\hline Australien ${ }^{1,2}$ & $\mathrm{~m}$ & $\mathrm{~m}$ & 15,6 & $x(6)$ & $x(6)$ & 12,0 & $\mathrm{~m}$ & $\mathrm{~m}$ & 14,7 & $\mathrm{~m}$ \\
\hline Österreich & 9,7 & 14,0 & 12,1 & 9,1 & 9,8 & 9,4 & 10,4 & $\mathrm{n}$ & 16,6 & 16,6 \\
\hline Belgien ${ }^{3}$ & 16,1 & 16,1 & 12,4 & 8,1 & 10,1 & 9,4 & $x(5)$ & $x(10)$ & $x(10)$ & 20,1 \\
\hline$K$ anada ${ }^{2,4}$ & $\mathrm{~m}$ & $x(4)$ & $x(4)$ & 15,9 & 14,2 & 15,3 & $\mathrm{~m}$ & $\mathrm{~m}$ & 17,7 & $\mathrm{~m}$ \\
\hline Chile & 10,7 & 21,9 & 23,1 & 23,6 & 25,4 & 24,8 & a & $\mathrm{m}$ & $\mathrm{m}$ & $\mathrm{m}$ \\
\hline Tschechien & 13,6 & 13,9 & 18,7 & 11,1 & 11,7 & 11,4 & 18,2 & 17,8 & 21,3 & 21,0 \\
\hline Dänemark & $\mathrm{m}$ & $\mathrm{m}$ & $x(4)$ & 11,8 & $\mathrm{~m}$ & $\mathrm{~m}$ & $\mathrm{~m}$ & $\mathrm{~m}$ & $\mathrm{~m}$ & $\mathrm{~m}$ \\
\hline Estland & $\mathrm{m}$ & 6,8 & 13,2 & 10,1 & 13,7 & 11,9 & 16,4 & $\mathrm{~m}$ & $\mathrm{~m}$ & $\mathrm{~m}$ \\
\hline Finnland & $\mathrm{m}$ & 10,8 & 13,7 & 9,3 & 16,3 & 13,1 & $x(5)$ & $\mathrm{n}$ & 13,6 & 13,6 \\
\hline Frankreich ${ }^{3}$ & 14,1 & 21,1 & 18,4 & 14,8 & 10,0 & 12,3 & $x(8)$ & 20,9 & 16,7 & 17,5 \\
\hline Deutschland & 10,0 & 12,7 & 16,3 & 14,2 & 13,8 & 14,0 & 14,5 & 14,1 & 10,9 & 11,4 \\
\hline Griechenland & $\mathrm{m}$ & $\mathrm{m}$ & $\mathrm{m}$ & $\mathrm{m}$ & $\mathrm{m}$ & $\mathrm{m}$ & $\mathrm{m}$ & $\mathrm{m}$ & $\mathrm{m}$ & $\mathrm{m}$ \\
\hline Ungarn & $\mathrm{m}$ & 11,2 & 10,7 & 10,5 & 12,4 & 11,5 & 13,5 & 20,4 & 15,9 & 16,3 \\
\hline Island & 5,8 & 5,8 & 10,2 & 10,6 & 11,5 & 11,1 & $x(5,10)$ & $x(10)$ & $x(10)$ & 11,3 \\
\hline Irland $^{2}$ & $\mathrm{~m}$ & $\mathrm{~m}$ & 15,7 & $x(6)$ & $x(6)$ & 14,4 & $x(6)$ & $x(10)$ & $x(10)$ & 14,6 \\
\hline$\left.\right|^{\left.s r a e\right|^{2}}$ & 11,5 & 24,2 & 15,9 & 13,6 & 11,3 & 12,2 & $\mathrm{~m}$ & $\mathrm{~m}$ & $\mathrm{~m}$ & $\mathrm{~m}$ \\
\hline Italien ${ }^{2}$ & $\mathrm{~m}$ & 11,8 & 11,7 & 11,5 & 12,8 & 12,2 & $\mathrm{~m}$ & 7,5 & 19,1 & 19,0 \\
\hline Japan & 14,8 & 15,6 & 18,1 & 14,2 & 12,2 & 13,1 & $x(5,10)$ & $\mathrm{m}$ & $\mathrm{m}$ & $\mathrm{m}$ \\
\hline Korea & 16,3 & 16,3 & 19,6 & 18,8 & 15,8 & 17,2 & a & $\mathrm{m}$ & $\mathrm{m}$ & $\mathrm{m}$ \\
\hline Luxemburg & $\mathrm{m}$ & 11,4 & 9,9 & $x(6)$ & $x(6)$ & 9,6 & $\mathrm{~m}$ & $\mathrm{~m}$ & $\mathrm{~m}$ & $\mathrm{~m}$ \\
\hline Mexiko & 25,2 & 25,2 & 28,1 & 31,9 & 26,8 & 29,9 & a & 15,8 & 14,4 & 14,4 \\
\hline Niederlande & 14,3 & 15,5 & 15,8 & 15,3 & 18,2 & 16,7 & 19,5 & 16,2 & 15,1 & 15,1 \\
\hline Neuseeland & 7,2 & 7,2 & 16,3 & 16,3 & 13,9 & 15,1 & 22,6 & 18,0 & 17,6 & 17,7 \\
\hline Norwegen² & $\mathrm{m}$ & $\mathrm{m}$ & 10,4 & 10,0 & 9,7 & 9,8 & $x(5)$ & $x(10)$ & $x(10)$ & 9,3 \\
\hline Polen & $\mathrm{m}$ & 16,1 & 11,0 & 10,0 & 11,1 & 10,6 & 15,0 & 9,0 & 15,7 & 15,6 \\
\hline Portugal ${ }^{5}$ & $\mathrm{~m}$ & 15,8 & 11,2 & 8,2 & 7,3 & 7,7 & $x(5,10)$ & $x(10)$ & $x(10)$ & 14,6 \\
\hline Slowakei & 12,3 & 12,4 & 16,9 & 13,1 & 14,3 & 13,7 & 14,1 & 10,0 & 14,6 & 14,5 \\
\hline Slowenien & 9,4 & 9,4 & 16,0 & 7,9 & 14,3 & 11,0 & $x(5)$ & $x(10)$ & $x(10)$ & 19,2 \\
\hline Spanien & $\mathrm{m}$ & 12,8 & 13,2 & 10,3 & 9,8 & 10,1 & a & 9,8 & 12,0 & 11,5 \\
\hline Schweden & 6,3 & 6,3 & 11,3 & 11,3 & 13,0 & 12,2 & 24,2 & $x(10)$ & $x(10)$ & 12,1 \\
\hline Schweiz & $\mathrm{m}$ & $\mathrm{m}$ & $\mathrm{m}$ & $\mathrm{m}$ & $\mathrm{m}$ & $\mathrm{m}$ & $\mathrm{m}$ & $\mathrm{m}$ & m & $\mathrm{m}$ \\
\hline Türkei & $\mathrm{m}$ & 23,1 & 21,0 & a & 17,8 & 17,8 & a & 53,0 & 15,0 & 18,9 \\
\hline Vereinigtes Königreich & 12,2 & 17,1 & 19,9 & 15,2 & 17,3 & 16,3 & a & $x(10)$ & $x(10)$ & 17,9 \\
\hline Vereinigte Staaten & 10,9 & 13,1 & 15,3 & 15,2 & 15,3 & 15,2 & 17,8 & $x(10)$ & $x(10)$ & 16,2 \\
\hline OECD-Durchschnitt & 12,2 & 14,4 & 15,4 & 13,3 & 13,9 & 13,6 & 16,9 & 15,2 & 15,7 & 15,6 \\
\hline EU21-Durchschnitt & 11,8 & 13,1 & 14,1 & 11,2 & 12,7 & 12,0 & 16,2 & 14,0 & 15,6 & 15,9 \\
\hline \multicolumn{11}{|l|}{ Sonstige G20-Länder } \\
\hline Argentinien & $\mathrm{m}$ & $\mathrm{m}$ & $\mathrm{m}$ & $\mathrm{m}$ & $\mathrm{m}$ & $\mathrm{m}$ & a & $\mathrm{m}$ & $\mathrm{m}$ & $\mathrm{m}$ \\
\hline Brasilien & 12,6 & 17,1 & 22,5 & 19,8 & 16,9 & 18,5 & a & $\mathrm{m}$ & $\mathrm{m}$ & $\mathrm{m}$ \\
\hline China & 20,6 & 23,2 & 17,1 & 14,6 & 18,4 & 16,3 & $\mathrm{~m}$ & $\mathrm{~m}$ & $\mathrm{~m}$ & $\mathrm{~m}$ \\
\hline Indien & $\mathrm{m}$ & $\mathrm{m}$ & $\mathrm{m}$ & $\mathrm{m}$ & $\mathrm{m}$ & $\mathrm{m}$ & $\mathrm{m}$ & $\mathrm{m}$ & $\mathrm{m}$ & $\mathrm{m}$ \\
\hline Indonesien & 17,3 & 18,8 & 20,3 & 18,3 & 20,1 & 19,1 & a & $x(10)$ & $x(10)$ & 28,5 \\
\hline Russische Föderation² & $\mathrm{m}$ & $\mathrm{m}$ & 20,0 & $x(6)$ & $x(6)$ & 8,7 & $x(6)$ & 10,5 & 13,9 & 13,1 \\
\hline Saudi-Arabien & $\mathrm{m}$ & 11,0 & 11,0 & 9,8 & 10,9 & 10,3 & a & $x(10)$ & $x(10)$ & 20,2 \\
\hline Südafrika ${ }^{4}$ & $\mathrm{~m}$ & $\mathrm{~m}$ & $\mathrm{~m}$ & $\mathrm{~m}$ & $\mathrm{~m}$ & $\mathrm{~m}$ & a & $x(10)$ & $x(10)$ & 27,6 \\
\hline G20-Durchschnitt & 15,4 & 17,4 & 18,3 & 15,3 & 15,9 & 15,5 & $\sim$ & $\sim$ & $\sim$ & $\sim$ \\
\hline
\end{tabular}

1. Im Sekundarbereich II nur allgemeinbildende Bildungsgänge. 2. Nur öffentliche Bildungseinrichtungen (Australien: nur im Tertiärbereich A und in weiterführenden forschungsorientierten Studiengängen; Kanada: nur im Tertiärbereich; Irland: nur im Tertiärbereich; Italien: vom Elementar- bis zum Sekundarbereich; Russische Föderation: nur im Primar- und Sekundarbereich). 3. Ohne unabhängige private Bildungseinrichtungen. 4. Referenzjahr 2010. 5. Angaben beziehen sich auf die Zahl der Lehrkräfte im Primar-, Sekundar- und postsekundaren, nicht tertiären Bereich.

Quelle: OECD. China: Statistikinstitut der UNESCO (World Education Indicators Programme). Saudi-Arabien: Statistikinstitut der UNESCO und Observatory on Higher Education. Südafrika: Statistikinstitut der UNESCO. Hinweise s. Anhang 3 unter www.oecd.org/edu/eag.htm. StatLink: http://dx.doi.org/10.1787/888932851611 Erläuterung der Kennzeichnung fehlender Daten s. Hinweise für den Leser. 
Schüler-Lehrkräfte-Relation, nach Art der Bildungseinrichtung (2011) Nach Bildungsbereich (basierend auf Vollzeitäquivalenten)

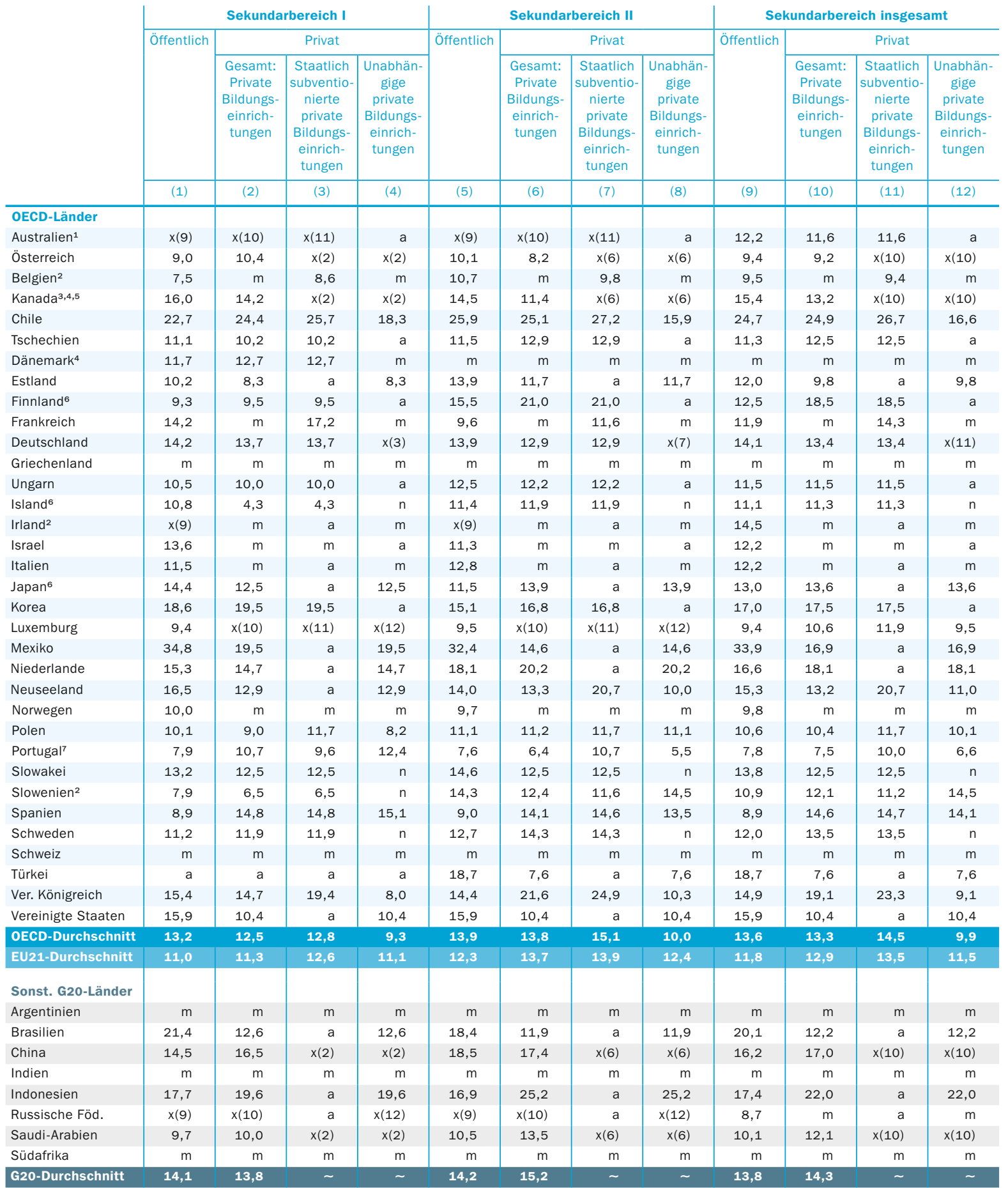

1. Im Sekundarbereich I und II nur allgemeinbildende Bildungsgänge. 2. Sekundarbereich II umfasst auch postsekundaren, nicht tertiären Bereich.

3. Referenzjahr 2010. 4. Sekundarbereich I umfasst auch Primarbereich. 5. Sekundarbereich I umfasst auch Elementarbereich. 6. Sekundarbereich II enthält auch Bildungsgänge des postsekundaren Bereichs. 7. Angaben beziehen sich auf die Zahl der Lehrkräfte im Primar-, Sekundar- und postsekundaren, nicht tertiären Bereich.

Quelle: OECD. China: Statistikinstitut der UNESCO (World Education Indicators Programme). Saudi-Arabien, Südafrika: Statistikinstitut der UNESCO. Hinweise s. Anhang 3 unter www.oecd.org/edu/eag.htm. StatLink: http://dx.doi.org/10.1787/888932851630

Erläuterung der Kennzeichnung fehlender Daten s. Hinweise für den Leser. 



\section{Wie hoch sind die Gehälter der Lehrkräfte?}

Die gesetzlichen bzw. vertraglich vereinbarten Gehälter von Lehrkräften mit I 5 Jahren Berufserfahrung belaufen sich im Durchschnitt auf 36.135 US-Dollar im Elementarbereich, 38.136 US-Dollar im Primarbereich, 39.934 US-Dollar im Sekundarbereich I und 4I.665 US-Dollar im Sekundarbereich II.

Im Durchschnitt der OECD-Länder liegen die Gehälter von Lehrkräften im Elementarbereich bei 80 Prozent der Gehälter von 25- bis 64 -jährigen ganzjährig Vollzeitbeschäftigten mit einem Abschluss im Tertiärbereich, im Primarbereich bei 82 Prozent, im Sekundarbereich I bei 85 Prozent und im Sekundarbereich II bei 89 Prozent dieses Vergleichswerts.

Abbildung D3.1

Gehälter von Lehrkräften im Sekundarbereich I (2011)

Gesetzliche bzw. vertraglich vereinbarte Jahresgehälter von Lehrkräften nach 15 Jahren Berufserfahrung (mit Mindestausbildung) an öffentlichen Bildungseinrichtungen, in US-Dollar (kaufkraftbereinigt)
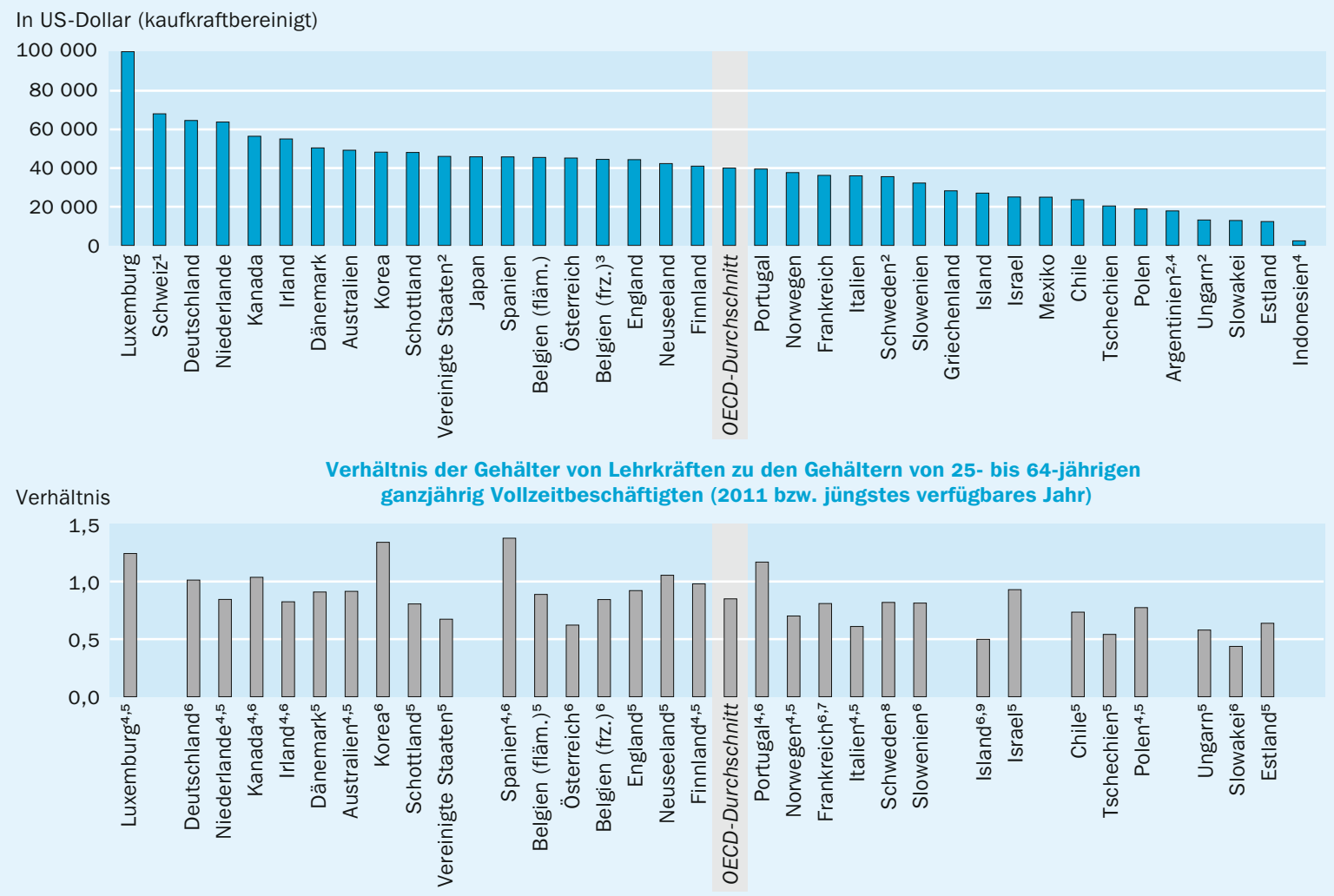

1. Gehälter nach 11 Jahren Berufserfahrung. 2. Tatsächliche Grundgehälter. 3. Gehälter von Lehrkräften mit typischen Qualifikationen anstelle der Mindestausbildung. 4. Referenzjahr 2010. 5. Verhältnis der durchschnittlichen tatsächlichen Gehälter einschließlich Bonus- und Zulagezahlungen von 25- bis 64-jährigen Lehrkräften zu Gehältern von 25- bis 64-jährigen ganzjährig Vollzeitbeschäftigten mit einem Abschluss im Tertiärbereich. 6. Verhältnis der gesetzlichen bzw. vertraglich vereinbarten Gehälter nach 15 Jahren Berufserfahrung (mit Mindestausbildung) zu den Gehältern von 25- bis 64-jährigen ganzjährig Vollzeitbeschäftigten mit einem Abschluss im Tertiärbereich. 7. Referenzjahr 2009. 8. Verhältnis der durchschnittlichen tatsächlichen Gehälter von 25- bis 64-jährigen Lehrkräften (ohne Bonus- und Zulagezahlungen) zu Gehältern von 25- bis 64-jährigen ganzjährig Vollzeitbeschäftigten mit einem Abschluss im Tertiärbereich. 9. Referenzjahr 2006.

Anordnung der Länder in absteigender Reihenfolge des Gehalts von Lehrkräften im Sekundarbereich I nach 15 Jahren Berufserfahrung (mit Mindestausbildung).

Quelle: OECD. Argentinien: Statistikinstitut der UNESCO (World Education Indicators Programme). Tabellen D3.1 und D3.2.

Hinweise s. Anhang 3 unter www.oecd.org/edu/eag.htm. StatLink: http://dx.doi.org/10.1787/888932847811 


\section{Kontext}

Die Gehälter der Lehrkräfte sind der größte Einzelposten bei den Kosten der formalen Schulausbildung, und sie wirken sich unmittelbar auf die Attraktivität des Lehrerberufs aus. Sie beeinflussen die Entscheidung, eine Lehrerausbildung zu absolvieren, nach erzieltem Abschluss Lehrkraft zu werden (da die Entscheidungen der Absolventen bei der Berufswahl mit den als Lehrkraft und in anderen Berufen zu erzielenden relativen Einkommen und ihrer im Laufe der Zeit zu erwartenden Steigerung verbunden sind), nach einer Karriereunterbrechung in den Lehrerberuf zurückzukehren und/ oder den Lehrerberuf weiterhin auszuüben (da im Allgemeinen mit steigendem Gehalt die Neigung zu einem Berufswechsel sinkt) (OECD, 2005). Die stark angewachsenen Staatsschulden, u. a. aufgrund der staatlichen Reaktionen auf die Finanzkrise Ende 2008, führten zu der nachdrücklichen Forderung an die Politik, die Staatsausgaben zu senken - insbesondere im Bereich der Beschäftigten im öffentlichen Dienst. Da Gehalt und Arbeitsbedingungen wichtige Faktoren sind, wenn es darum geht, kompetente und hoch qualifizierte Lehrkräfte anzuwerben, weiterzubilden und zu halten, sollte die Politik in ihrem Bemühen, sowohl die Qualität des Unterrichts als auch langfristig tragfähige Bildungshaushalte sicherzustellen, die Auswirkungen von Gehaltsveränderungen bei den Lehrkräften sorgsam abwägen (s. Indikator B6 im Internet und Indikator $\mathrm{B} 7$ ).

\section{Weitere wichtige Ergebnisse}

In den meisten OECD-Ländern steigen die Gehälter der Lehrkräfte, je höher der Bildungsbereich ist, in dem sie unterrichten. So liegt beispielsweise in Belgien, Dänemark, Finnland, Indonesien, Polen, der Schweiz und Ungarn das Gehalt einer Lehrkraft im Sekundarbereich II mit I5 Jahren Berufserfahrung mindestens 25 Prozent über dem einer Lehrkraft im Elementarbereich mit gleich langer Berufserfahrung.

Die Höchstgehälter sind im Elementar-, Primar- sowie im Sekundarbereich I und II im Durchschnitt um 58, 59, 61 bzw. 62 Prozent höher als die Anfangsgehälter, wobei diese Differenz tendenziell am größten ist, wenn eine Lehrkraft viele Jahre benötigt, um alle Gehaltsstufen zu durchlaufen. In Ländern, in denen die Höchstgehälter erst nach frühestens 30 Jahren erreicht werden, sind die Gehälter auf dieser Gehaltsstufe im Durchschnitt 78 Prozent höher als die Anfangsgehälter.

Die von Lehrkräften mit maximaler Qualifikation in der obersten Gehaltsstufe bezogenen Höchstgehälter belaufen sich im Durchschnitt auf 47.243 US-Dollar pro Jahr im Elementarbereich, 49.609 US-Dollar im Primarbereich, 52.697 USDollar im Sekundarbereich I und 53.449 US-Dollar im Sekundarbereich II. Jedoch variiert der für eine höhere Qualifikation gewährte Gehaltszuschlag. Lehrkräfte im Primarbereich, die über die maximale Qualifikation verfügen, verdienen beispielsweise in Israel, Mexiko, Polen und Slowenien mindestens 30 Prozent mehr als Lehrkräfte im Primarbereich mit Mindestausbildung und ähnlicher Berufserfahrung. In etwa 40 Prozent der Länder besteht jedoch kein Unterschied.

In 9 der 2I Länder mit verfügbaren Daten sind die durchschnittlichen Jahresgehälter von Lehrkräften im Sekundarbereich II, einschließlich Bonuszahlungen und Zulagen, mindestens Io Prozent höher als die gesetzlichen bzw. vertraglich vereinbarten Gehälter für Lehrkräfte im Sekundarbereich II mit I5 Jahren Berufserfahrung. 


\section{Entwicklungstendenzen}

Zwischen 2000 und 20II war in den meisten Ländern mit verfügbaren Daten ein realer Anstieg der Lehrergehälter zu beobachten. Bemerkenswerte Ausnahmen sind hier Frankreich und Japan, wo die Gehälter der Lehrkräfte während dieser Zeit real sanken. In einigen Ländern hat sich die Wirtschaftskrise 2008 unmittelbar auf die Gehälter von Lehrkräften ausgewirkt - zwischen 2009 und 201 I wurden sie in diesen Ländern entweder eingefroren oder gekürzt.

\section{Analyse und Interpretationen}

\section{Gesetzliche bzw. vertraglich vereinbarte Gehälter von Lehrkräften}

Die Gehälter der Lehrkräfte sind nur eine Komponente der Gesamtvergütung der Lehrkräfte. Diese kann auch Zusatzleistungen wie beispielsweise eine Art Ortszulage für das Unterrichten in abgelegenen Gebieten, Familienzulagen, Fahrpreisermäßigungen im öffentlichen Verkehr sowie Steuerermäßigungen beim Erwerb kultureller Güter enthalten. In den OECD-Ländern gibt es auch große Unterschiede hinsichtlich der Besteuerung und Sozialversicherungssysteme. Diese Komponenten sollten bei einem Vergleich der Gehälter zwischen den Ländern immer berücksichtigt werden.

Die Gehälter der Lehrkräfte variieren stark zwischen den einzelnen Ländern. Die Gehälter für Lehrkräfte an Schulen des Sekundarbereichs I mit mindestens I5 Jahren Berufserfahrung reichen von weniger als 15.000 US-Dollar in Estland, Indonesien, der Slowakei und Ungarn über mindestens 6o.00o US-Dollar in Deutschland, den Niederlanden und der Schweiz (für Lehrkräfte mit mindestens II Jahren Berufserfahrung) bis zu mehr als I00.000 US-Dollar in Luxemburg (Tab. D3.I und Abb. D3.I).

In den meisten OECD-Ländern steigen die Gehälter der Lehrkräfte, je höher der Bildungsbereich ist, in dem sie unterrichten. In Belgien, Dänemark, Indonesien, den Niederlanden, Polen, der Slowakei und Tschechien verdienen Lehrkräfte im Sekundarbereich II mit I5 Jahren Berufserfahrung zwischen 20 und 30 Prozent mehr als Lehrkräfte im Elementarbereich mit gleicher Berufserfahrung, in Finnland und der Schweiz (Lehrkräfte mit II Jahren Berufserfahrung) sind es rund 50 Prozent mehr. In Finnland und der Slowakei ist dies hauptsächlich auf den Unterschied zwischen den Gehältern für Lehrkräfte im Elementar- und Primarbereich zurückzuführen. In den Niederlanden ist der größte Unterschied zwischen dem Primar- und Sekundarbereich I zu beobachten, wohingegen in Belgien die Gehälter von Lehrern des Sekundarbereichs II signifikant höher als in den anderen Bildungsbereichen sind. Die Unterschiede zwischen den Gehältern in den einzelnen Bildungsbereichen sollten unter Berücksichtigung der für den Lehrerberuf in dem jeweiligen Bildungsbereich erforderlichen Qualifikationen interpretiert werden (s. Indikator D5 „Wie ist das demografische und das Qualifikationsprofil der Lehrerschaft?" in OECD, 2012).

In Australien, Kanada, Korea und der Türkei besteht zwischen den Gehältern von Lehrkräften mit I5 Jahren Berufserfahrung im Sekundarbereich II und im Elementarbereich 
ein Unterschied von weniger als 5 Prozent; in England, Griechenland, Portugal, Schottland und Slowenien sind die Gehälter für die Lehrkräfte aller Bildungsbereiche gleich. In Estland, Irland und Japan trifft dies auch auf die Gehälter der Lehrkräfte im Primarsowie im Sekundarbereich I und II zu. Im Gegensatz dazu sinken in Argentinien die Gehälter der Lehrkräfte, je höher der Bildungsbereich ist, in dem sie unterrichten: Eine Lehrkraft im Sekundarbereich II verdient I5 Prozent weniger als eine Lehrkraft an einer Schule im Elementarbereich, obwohl eine Lehrkraft im Sekundarbereich II doppelt so viele Zeitstunden unterrichten muss (s. Indikator D4). In Israel besteht zwischen den Gehältern von Lehrkräften, die an Schulen des Sekundarbereichs II unterrichten, und denen von Lehrkräften an Schulen des Elementarbereichs ein Unterschied von I8 Prozent zugunsten der Lehrkräfte im Elementarbereich. Dies ist hauptsächlich auf die schrittweise Einführung der „Neue Horizonte“ überschriebenen Reform im Primarund Sekundarbereich I seit 2008 zurückzuführen, die zu einer Steigerung der Gehälter der Lehrkräfte im Elementar-, Primar- und Sekundarbereich I führte. Eine weitere, 2012 eingeleitete Reform wird auch zu einem Anstieg der Gehälter für Lehrkräfte im Sekundarbereich II führen. In Luxemburg haben Lehrkräfte im Primarbereich mit I5 Jahren Berufserfahrung vor einer 2009 in Kraft getretenen Reform etwa 50 Prozent weniger verdient als Lehrkräfte im Sekundarbereich mit gleicher Berufserfahrung. Inzwischen beträgt der Unterschied zwischen den Gehältern der Lehrkräfte im Primar- und Sekundarbereich jedoch weniger als io Prozent.

Unterschiede zwischen den Gehältern der Lehrkräfte in den verschiedenen Bildungsbereichen können sowohl die Vorgehensweise von Schulen und Bildungssystemen bei der Anwerbung und dauerhaften Bindung von Lehrkräften in den einzelnen Bildungsbereichen beeinflussen als auch das Ausmaß, in dem Lehrkräfte zwischen den einzelnen Bildungsbereichen wechseln.

\section{Mindest- und Höchstgehälter von Lehrkräften}

Die Bildungssysteme stehen bei der Anwerbung hoch qualifizierter Absolventen als Lehrkräfte großen Herausforderungen gegenüber. Forschungsergebnisse lassen erkennen, dass Gehälter und alternative Beschäftigungsmöglichkeiten einen wesentlichen Einfluss auf die Attraktivität des Lehrerberufs haben (Santiago, 2004). Die Anfangsgehälter von Lehrkräften im Verhältnis zu anderen nicht lehrenden Tätigkeiten und die zu erwartenden Einkommenssteigerungen haben großen Einfluss darauf, ob sich Absolventen auch wirklich für den Lehrerberuf entscheiden. Länder, die das Angebot an Lehrkräften erweitern möchten, insbesondere Länder mit einer alternden Lehrerschaft und/oder einer wachsenden Bevölkerung im Schulalter, könnten sich überlegen, attraktivere Anfangsgehälter und Karriereaussichten anzubieten. Um jedoch eine gut qualifizierte Lehrerschaft sicherzustellen, sind nicht nur Anstrengungen zur Anwerbung und Auswahl nur der kompetentesten und am höchsten qualifizierten Lehrkräfte erforderlich, sondern man muss sich auch um die Bindung guter Lehrkräfte bemühen.

Im Sekundarbereich I verdienen Lehrkräfte (mit Mindestausbildung) bei Berufseintritt im Durchschnitt 30.2I6 US-Dollar. Dieses Mindestgehalt variiert zwischen weniger als 5.000 US-Dollar in Argentinien, Estland, Indonesien, Polen, der Slowakei und Ungarn und mehr als 40.000 US-Dollar in Dänemark, Deutschland, Luxemburg und der Schweiz. 
Mindest- und Höchstgehälter von Lehrkräften im Sekundarbereich I (2011)

Gesetzliche bzw. vertraglich vereinbarte Jahresgehälter von Lehrkräften an öffentlichen Bildungseinrichtungen, in US-Dollar (kaufkraftbereinigt)

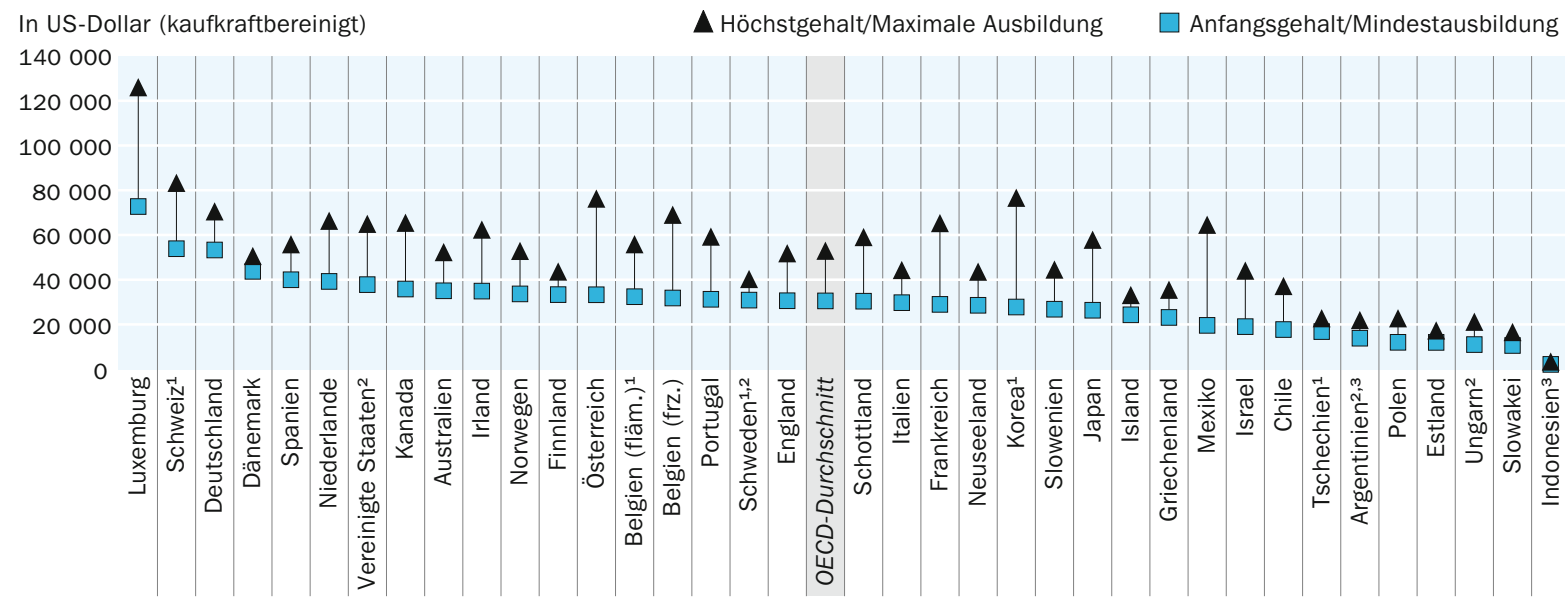

1. Höchstgehalt/Mindestausbildung. 2. Tatsächliche Grundgehälter. 3. Referenzjahr 2010.

Anordnung der Länder in absteigender Reihenfolge der Anfangsgehälter von Lehrkräften im Sekundarbereich I (mit Mindestausbildung).

Quelle: OECD. Argentinien: Statistikinstitut der UNESCO (World Education Indicators Programme). Tab. D3.5 im Internet.

Hinweise s. Anhang 3 unter www.oecd.org/edu/eag.htm. StatLink: http://dx.doi.org/10.1787/888932847830

Für Lehrkräfte (mit maximalen Qualifikationen) in der obersten Gehaltsstufe liegt das Gehalt im Durchschnitt bei 52.697 US-Dollar. Diese oberste Gehaltsstufe variiert von weniger als 20.000 US-Dollar in Estland, Indonesien und der Slowakei bis zu mindestens 75.000 US-Dollar in Korea, Österreich und der Schweiz und mehr als 125.000 US-Dollar in Luxemburg. In den meisten Ländern, deren Anfangsgehälter unter dem OECD-Durchschnitt liegen, sind auch die Höchstgehälter niedriger. Ausnahmen sind hier Frankreich, Japan, Korea und Mexiko, wo die Anfangsgehälter mindestens 5 Prozent unter dem OECD-Durchschnitt liegen, die Höchstgehälter jedoch deutlich darüber liegen. Für Australien, Dänemark und Norwegen gilt das Gegenteil. In diesen Ländern liegen die Anfangsgehälter mindestens ro Prozent über dem OECD-Durchschnitt, die gesetzlich bzw. vertraglich vereinbarten Höchstgehälter hingegen im OECD-Durchschnitt (Abb. D3.2 und Tab. D3.5 im Internet).

Eine Reihe von Ländern hat verhältnismäßig flache Gehaltsstrukturen. Zum Beispiel beträgt der Unterschied zwischen dem Anfangsgehalt und dem Höchstgehalt in Dänemark im Elementar-, Primar- und Sekundarbereich I weniger als 30 Prozent, dies gilt auch für Finnland, Norwegen, Schweden und Tschechien im Elementarbereich.

Aufgrund geringer finanzieller Anreize kann es in diesen Ländern schwieriger sein, Lehrkräfte zu binden, wenn diese sich der obersten Gehaltsstufe nähern. Komprimierte Gehaltsskalen haben jedoch auch Vorteile. Es wird oft angeführt, dass für Organisationen mit geringeren internen Gehaltsunterschieden ein größeres Vertrauen, ein offenerer Informationsaustausch und mehr Kollegialität unter den Mitarbeitern charakteristisch sind. 


\section{Zusatzvergütungen: Anreizprogramme und Zulagen}

Zusätzlich zu den allgemeinen Gehaltsgruppen kommen im Bildungswesen in zunehmendem Maße Regelungen für Zusatzvergütungen und sonstige Formen der besonderen Anerkennung für Lehrkräfte zum Einsatz. In Verbindung mit dem Anfangsgehalt können solche zusätzlichen Vergütungen die Entscheidung beeinflussen, den Lehrerberuf zu ergreifen bzw. ihn langfristig auszuüben. Es wurden Daten dazu erfasst, ob Lehrkräfte Zusatzvergütungen erhalten können und auf welcher Ebene über ihre Gewährung entschieden wird (Tab. D3.6a, D3.6b, D3.6c und D3.6d im Internet sowie Anhang 3 unter www.oecd.orgleduleag.htm).

Zusatzvergütungen werden meistens aufgrund besonderer Verantwortlichkeiten oder Arbeitsbedingungen gewährt, wie z. B. das Unterrichten an stärker benachteiligten Schulen, insbesondere an Schulen in sehr armen Vierteln, oder an Schulen mit einem hohen Anteil von Schülern, die zu Hause nicht die Unterrichtssprache sprechen. Diese Schulen haben häufig Schwierigkeiten bei der Anwerbung von Lehrkräften, und oft unterrichten an diesen Schulen auch weniger erfahrene Lehrkräfte (OECD, 2005). Derartige Zusatzvergütungen werden in fast drei Viertel der Länder gewährt.

Zusatzvergütungen für Lehrkräfte aufgrund der Qualifikationen, Ausbildung und Leistung der Lehrkräfte sind in den OECD-Ländern und sonstigen G2o-Ländern ebenfalls sehr verbreitet. Die häufigsten Zusatzvergütungen sind Vergütungen für eine Erstausbildung und/oder eine Qualifikation, die über die für den Lehrberuf erforderlichen Mindestanforderungen hinausgeht. Mehr als drei Viertel der Länder gewähren derartige Zusatzvergütungen. Außerdem bietet die Hälfte der 38 Länder mit verfügbaren Daten Zusatzvergütungen für Lehrkräfte mit herausragenden Leistungen. In I5 der I 9 Länder, die diesen Leistungsanreiz bieten, kann auf Schulebene über seine Gewährung entschieden werden.

In der Hälfte der OECD-Länder gibt es Zusatzvergütungen aufgrund demografischer Merkmale der Lehrkräfte (Familienstand oder Alter), meistens handelt es sich um jährliche Zahlungen.

Im Gegensatz dazu sind die Gehälter in der obersten Gehaltsstufe in Belgien (frz., Elementar-, Primar- und Sekundarbereich I), Chile, Frankreich (Sekundarbereich I und II), Israel, Japan (Primar- und Sekundarbereich), Korea, Österreich, Polen (Elementarund Primarbereich) und Ungarn (Sekundarbereich II) mindestens doppelt so hoch wie die Anfangsgehälter und in Mexiko (Elementar-, Primar- und Sekundarbereich I) sogar mehr als dreimal so hoch (Abb. D3.2 und Tab. D3.5 im Internet).

Auch die Gehaltszulage für eine höhere Qualifikation variiert in der obersten Gehaltsstufe zwischen den Ländern. Im Sekundarbereich I besteht in II der 32 Länder, für die Daten für beide Qualifikationsstufen vorliegen, für Lehrkräfte in der obersten Gehaltsstufe kein Unterschied zwischen den Gehältern von Lehrkräften mit Mindestausbildung und Lehrkräften, die über die höchstmögliche Qualifikation verfügen. Lehrkräfte 
in der obersten Gehaltsstufe, die über die maximale Qualifikation verfügen, verdienen jedoch in Belgien (frz.), Frankreich, Israel, Norwegen, Schottland und Slowenien mindestens 20 Prozent mehr als Lehrkräfte mit gleicher Berufserfahrung, die aber nur über die Mindestausbildung verfügen. Dieser Gehaltsunterschied reicht bis zu 57 Prozent in Mexiko. Ein ähnliches Bild zeigt sich im Sekundarbereich II (Tab. D3.I und Tab. D3.5 im Internet).

Bei der Analyse der Gehaltsstrukturen von Lehrkräften ist zu berücksichtigen, dass nicht alle Lehrkräfte die Spitze der Gehaltsskala erreichen. In Italien beispielsweise befanden sich 20II weniger als 5 Prozent aller Lehrkräfte in der obersten Gehaltsstufe.

\section{Berufserfahrung und Gehaltsstufen}

Die Gehaltsstrukturen legen die Gehälter der Lehrkräfte zu unterschiedlichen Zeitpunkten in ihrer beruflichen Laufbahn fest. Auch eine Entgeltumwandlung, die Mitarbeiter für den Verbleib in einem Unternehmen, einer Organisation bzw. die dauerhafte Zugehörigkeit zu einem bestimmten Berufsstand sowie für die Erfüllung festgesetzter Leistungskriterien belohnt, kann Bestandteil des Gehalts sein. Die OECD-Daten über die Gehälter von Lehrkräften beschränken sich auf Angaben zu den gesetzlichen bzw. vertraglich vereinbarten Gehältern an vier Punkten der Gehaltsskala: die Anfangsgehälter, die Gehälter nach Io Jahren Berufserfahrung, nach I5 Jahren Berufserfahrung und die Höchstgehälter. Die in diesem Indikator untersuchten Gehälter sind jeweils bezogen auf Lehrkräfte mit der für eine Lehrqualifikation erforderlichen Mindestausbildung. Wie oben erläutert, können weitere Qualifikationen in einigen Ländern zu zusätzlichen Gehaltssteigerungen führen.

In den OECD-Ländern sind die gesetzlichen bzw. vertraglich vereinbarten Gehälter für Lehrkräfte mit Io und I5 Jahren Berufserfahrung im Sekundarbereich I im Durchschnitt um 25 bzw. 35 Prozent höher als die Anfangsgehälter. Außerdem liegen die Gehälter in der obersten Gehaltsstufe, die im Durchschnitt nach 24 Jahren Berufserfahrung erreicht wird, im Durchschnitt 6r Prozent über den Anfangsgehältern. In Israel, Italien, Korea, Spanien und Ungarn erreichen Lehrkräfte im Sekundarbereich I erst nach frühestens 35 Dienstjahren das Höchstgehalt. Im Gegensatz hierzu erreichen Lehrkräfte im Sekundarbereich I in Australien, Dänemark, Estland, Neuseeland und Schottland die oberste Gehaltsstufe nach 6 bis 9 Dienstjahren (Tab. D3.I und D3.2).

Während die Gehaltssteigerungen in etwas mehr als der Hälfte der 32 OECD-Länder mit entsprechenden Daten gleichmäßig verlaufen, sind die Stufen innerhalb der Gehaltsskala in den restlichen Ländern unterschiedlich groß.

\section{Gesetzliche bzw. vertraglich vereinbarte Gehälter pro Netto- Unterrichtszeitstunde}

Das durchschnittliche gesetzliche bzw. vertraglich vereinbarte Gehalt je Unterrichtszeitstunde mit I5 Jahren Berufserfahrung liegt im Primarbereich bei 49 US-Dollar, im Sekundarbereich I bei 58 US-Dollar und an allgemeinbildenden Schulen des Sekundarbereichs II bei 66 US-Dollar. Die Gehälter je Unterrichtszeitstunde sind in Argentinien, Chile, Estland, Indonesien, Mexiko (Primar- und Sekundarbereich I), der Slowakei, Tschechien (Primarbereich) und Ungarn am niedrigsten - höchstens 30 USDollar. Im Gegensatz dazu betragen die Gehälter je Unterrichtszeitstunde in Belgien, 
Dänemark, Deutschland und Japan im Sekundarbereich II und in Luxemburg in allen Bildungsbereichen mindestens 90 US-Dollar (Tab. D3.2).

Da Lehrkräfte im Sekundarbereich weniger (Zeit-)Stunden unterrichten müssen als Lehrkräfte im Primarbereich, sind ihre Gehälter je Unterrichtszeitstunde in der Regel höher als in den vorgelagerten Bildungsbereichen, und zwar selbst in Ländern, in denen die gesetzlichen bzw. vertraglich vereinbarten Gehälter ähnlich hoch sind (s. Indikator D4). Im Durchschnitt der OECD-Länder liegt das Gehalt je Unterrichtszeitstunde für eine Lehrkraft im Sekundarbereich II um ungefähr 3I Prozent über dem einer Lehrkraft im Primarbereich (Tab. D3.2). In Schottland besteht kein Unterschied, während in Dänemark das Gehalt von Lehrkräften im Sekundarbereich II je Unterrichtszeitstunde doppelt so hoch wie das Gehalt von Lehrkräften im Primarbereich ist. Im Gegensatz hierzu beläuft sich in Argentinien das Gehalt je Unterrichtszeitstunde für eine Lehrkraft im Sekundarbereich auf weniger als 50 Prozent des Gehalts einer Lehrkraft im Primarbereich.

Der Gehaltsunterschied zwischen Lehrkräften im Primar- und Sekundarbereich bleibt bei einem Vergleich der Gehälter pro Arbeitsstunde jedoch nicht unbedingt bestehen. So unterscheiden sich beispielsweise in Portugal die Gehälter der Lehrkräfte pro Unterrichtszeitstunde im Primarbereich um I4 Prozent von denen im Sekundarbereich II, obwohl die gesetzlichen bzw. vertraglich vereinbarten Gehälter und Arbeitszeiten in beiden Bereichen dieselben sind. Der Unterschied erklärt sich aus der Tatsache, dass Lehrkräfte an Schulen im Primarbereich mehr Zeit mit unterrichtenden Tätigkeiten verbringen als Lehrkräfte an Schulen im Sekundarbereich II (s. Tab. D4.I).

\section{Entwicklungen seit 2000}

Zwischen 2000 und $201 \mathrm{I}$ war in den meisten Ländern ein realer Anstieg der Gehälter der Lehrkräfte zu beobachten. In Dänemark, Estland, Irland und Portugal stiegen die Gehälter in allen Bildungsbereichen um mindestens 20 Prozent. In Tschechien (Primar- und Sekundarbereich I) und der Türkei (Sekundarbereich II) haben sich die Gehälter in den letzten zehn Jahren verdoppelt. Nur in Frankreich und Japan sanken die Gehälter der Lehrkräfte real um fast ro Prozent (Tab. D3.4 und Abb. D3.3). In den meisten Ländern sind die Gehälter seit 2005 in geringerem Maß gestiegen als zwischen 2000 und 2005. Ausnahmen sind Belgien (frz., Sekundarbereich I und II), Dänemark, Estland, Israel und Mexiko (Primar- und Sekundarbereich I) sowie Neuseeland, wo der größte Anstieg der Gehälter von Lehrkräften nach 2005 erfolgte.

Diese Analyse der Entwicklungstendenzen bei den Gehältern beruht auf den Gehältern von Lehrkräften mit I5 Jahren Berufserfahrung (eine Näherungsgröße für Lehrkräfte in der Mitte der beruflichen Laufbahn); an bestimmten Punkten der beruflichen Laufbahn als Lehrkraft können die Gehälter jedoch schneller ansteigen als an anderen. Länder, in denen ein Mangel an Lehrkräften herrscht, können beispielsweise die Anfangsgehälter für Lehrkräfte anheben, um durch derartig gezielte Maßnahmen die Attraktivität des Lehrerberufs zu erhöhen (OECD, 2005). In Frankreich wurden im Jahr $20 I I$ die Gehälter für Lehrkräfte mit weniger als sieben Jahren Berufserfahrung angehoben, wobei die Gehaltssteigerung für Berufseinsteiger am stärksten ausfiel. 


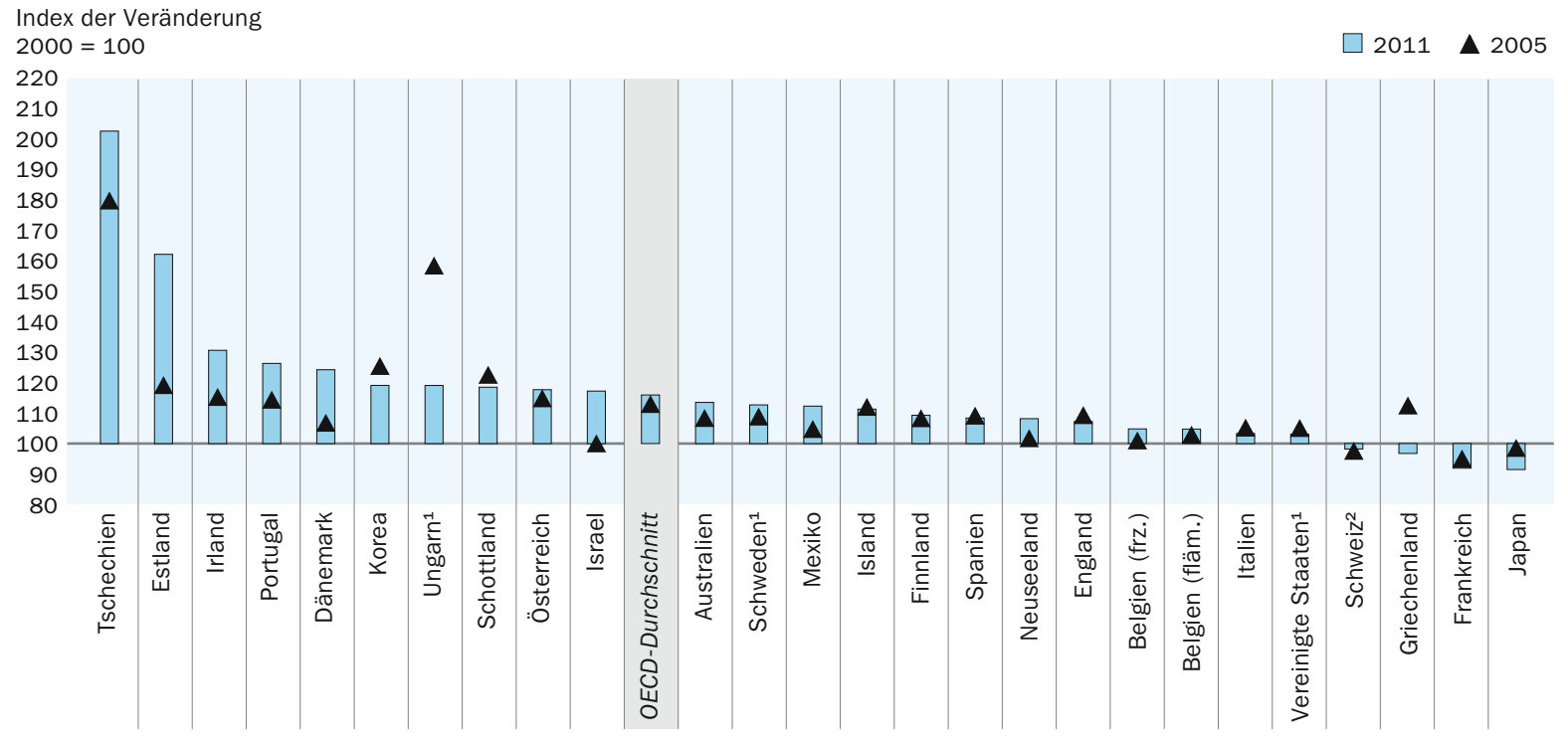

1. Tatsächliche Grundgehälter. 2. Gehälter nach 11 Jahren Berufserfahrung.

Anordnung der Länder in absteigender Reihenfolge des Index der Veränderung zwischen 2000 und 2011 der Gehälter von Lehrkräften im Sekundarbereich I mit 15 Jahren Berufserfahrung.

Quelle: OECD. Tabelle D3.4. Hinweise s. Anhang 3 unter www.oecd.org/edu/eag.htm. StatLink: http://dx.doi.org/10.1787/888932847849

In den meisten Ländern waren die Steigerungen bzw. Rückgänge der Lehrergehälter im Primar- und Sekundarbereich (I und II) in etwa gleich hoch. In der Türkei stiegen jedoch die Gehälter der Lehrkräfte im Sekundarbereich II zwischen 2000 und 20 II deutlich stärker als im Primarbereich, in Island und Tschechien dagegen war im selben Zeitraum ein deutlich stärkerer Anstieg im Primar- und Sekundarbereich I als im Sekundarbereich II zu beobachten. In Israel stiegen die Lehrergehälter im Primarbereich deutlich stärker an als in allen anderen Bildungsbereichen. Dies war hauptsächlich auf die schrittweise Einführung der „Neue Horizonte“ überschriebenen Reform im Primarund Sekundarbereich I zurückzuführen, die 2008 begann und das Ergebnis einer Vereinbarung zwischen den Bildungsbehörden und der israelischen Lehrergewerkschaft (des Primar- und Sekundarbereichs I) war. Diese Reform verbindet u. a. höhere Gehälter der Lehrkräfte mit längeren Arbeitszeiten (s. Indikator D4). 20 II betraf diese Reform 8o Prozent der vollzeitäquivalenten Lehrkräfte im Primarbereich, 26 Prozent derjenigen im Sekundarbereich I und 8 Prozent derjenigen im Elementarbereich. Im selben Jahr vereinbarte die israelische Regierung mit der Gewerkschaft der Lehrkräfte im Sekundarbereich II ein ähnliches Programm für den Sekundarbereich II. Da diese Reformen noch nicht vollständig umgesetzt sind, ist davon auszugehen, dass auch die Gehälter im Sekundarbereich I und II noch signifikant ansteigen werden.

\section{Die tatsächlichen Durchschnittsgehälter von Lehrkräften}

Die in diesem Indikator von den meisten Ländern angegebenen gesetzlichen bzw. vertraglich vereinbarten Gehälter sind zu unterscheiden sowohl von den tatsächlichen Ausgaben für Gehälter, die von staatlicher Seite zu leisten sind, als auch von den Durchschnittsgehältern der Lehrkräfte, die auch durch andere Faktoren beeinflusst werden, 


\section{Auswirkungen der Wirtschaftskrise}

Die Wirtschafts- und Finanzkrise, die die Weltwirtschaft in den letzten Monaten des Jahres 2008 traf, hat signifikante Auswirkungen auf die Gehälter von Beamten und Beschäftigten des öffentlichen Dienstes insgesamt gehabt. Der Druck, zur Reduzierung der Staatsschulden die staatlichen Ausgaben zu kürzen, führte in immer mehr Ländern zu Einschnitten bei den Gehältern von Lehrkräften und anderen Beschäftigten im öffentlichen Dienst. Im Durchschnitt der OECD-Länder mit verfügbaren Daten gingen die Gehälter von Lehrkräften zwischen 2009 und 201 in in allen Bildungsbereichen zum ersten Mal seit 2000 um rund 2 Prozent zurück.

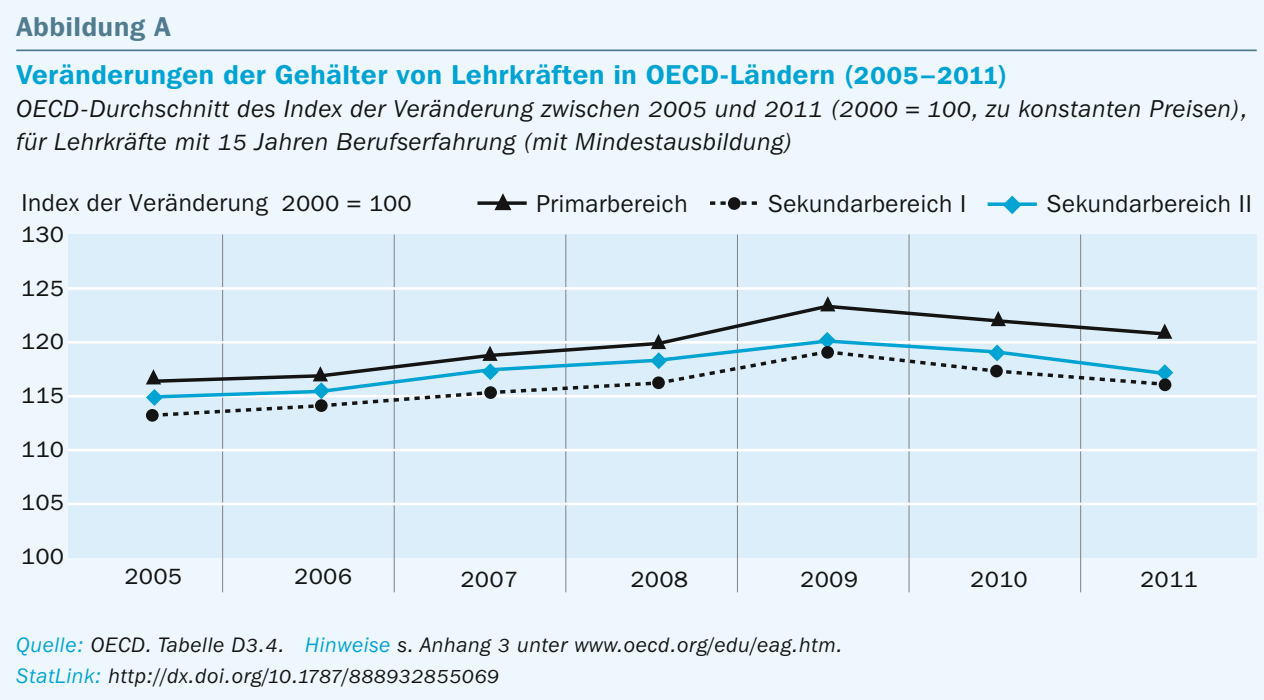

So hatte die Wirtschaftskrise beispielsweise in Estland, Griechenland, Irland, Spanien und Ungarn deutliche Auswirkungen auf die Gehälter der Lehrkräfte. In Estland wurden die Mindestgehälter von Lehrkräften im Jahr 2009 auf das Niveau von 2008 gekürzt und sind seit dieser Zeit auf diesem Niveau eingefroren. In Griechenland waren die Gehälter von Lehrkräften 20 Io und 201 r von verschiedenen Kürzungen bei den Zusatzleistungen und Zulagen betroffen. Als Ergebnis sanken die Bruttogehälter zwischen 2009 und 201 r real um I7 Prozent. Zusätzlich gingen in Griechenland durch die Einführung einer Solidaritätssteuer auch die Nettogehälter der Lehrkräfte zurück. Diese Steuer erhöhte die steuerliche Belastung der ohnehin schon geringeren Bruttogehälter der Lehrkräfte, darüber hinaus werden die von den Lehrkräften zu entrichtenden Versicherungsbeiträge noch immer anhand der früheren höheren Gehälter berechnet. In Ungarn wurde 2009 das I3. Monatsgehalt (ein Bonus, der allen Beschäftigten gezahlt wurde) ausgesetzt. Auch wenn allen Beschäftigten des öffentlichen Dienstes, deren Gehalt unter einem bestimmten Einkommensniveau lag, ein Ausgleichsbonus gezahlt wurde, so war doch das Grundgehalt der Lehrkräfte stark betroffen. In Spanien mussten alle Beamten im Juli 2010 Einschnitte bei den Gehältern hinnehmen. Die Höhe dieser Einschnitte war vom Jahresgehalt abhängig, betraf aber sowohl das Grundgehalt als auch die Zulagen. In Irland wurden die Gehälter der Lehrkräfte im Rahmen einer Gehaltsreduzierung für den gesamten öffentlichen Dienst ab dem I. Januar 2oro gesenkt. Darüber hinaus 
werden Lehrkräfte, die ihre Tätigkeit nach dem I. Januar 201 I aufgenommen haben, nach einer neuen Gehaltsskala bezahlt, die mehr als ro Prozent niedriger ist als diejenige für Lehrkräfte, die vor diesem Stichtag eingestellt wurden. In anderen Ländern wurden nach 20 I ähnliche Maßnahmen umgesetzt.

Die Wirtschaftskrise könnte sich auch auf das Angebot an Lehrkräften auswirken. In Zeiten schwacher Konjunktur bei hoher Akademikererwerbslosigkeit und nur niedrigen Akademikergehältern könnte die Arbeit als Lehrkraft für Hochschulabsolventen attraktiver erscheinen als andere Berufe (OECD, 2005).

wie z. B. die Altersstruktur und die Berufserfahrung der Lehrerschaft sowie im Vergütungssystem enthaltene Bonuszahlungen und Zulagen.

Tabelle D3.3 enthält die durchschnittlichen tatsächlichen Jahresgehälter von 25-bis 64-jährigen Lehrkräften, einschließlich aller Bonuszahlungen, Zulagen und Zusatzvergütungen. In Chile, Estland (Primar- und Sekundarbereich), Island (Sekundarbereich II), Israel (Sekundarbereich), Polen (Elementar-, Primar- und Sekundarbereich I) und Ungarn sind die durchschnittlichen Gehälter, einschließlich Bonuszahlungen und Zulagen, mindestens 20 Prozent höher als die gesetzlichen bzw. vertraglich vereinbarten Gehälter für Lehrkräfte mit I 5 Jahren Berufserfahrung. Im Gegensatz dazu sind die durchschnittlichen gesetzlichen bzw. vertraglich vereinbarten Gehälter von 25- bis 64-jährigen Lehrkräften in Luxemburg (Elementar- und Primarbereich), den Niederlanden, Schottland und Tschechien (Elementarbereich) im Durchschnitt um mindestens 5 Prozent niedriger als die gesetzlichen bzw. vertraglich vereinbarten Gehälter für Lehrkräfte mit I5 Jahren Berufserfahrung (Tab. D3·3).

In einigen Ländern variieren die durchschnittlichen tatsächlichen Gehälter von Lehrkräften zwischen den einzelnen Bildungsbereichen stärker als die durchschnittlichen gesetzlichen bzw. vertraglich vereinbarten Gehälter für Lehrkräfte mit I 5 Jahren Berufserfahrung. In England, Israel, Norwegen und Tschechien ist der Unterschied zwischen den durchschnittlichen tatsächlichen Gehältern der Lehrkräfte im Sekundarbereich II und den durchschnittlichen tatsächlichen Gehältern der Lehrkräfte im Elementarbereich um mindestens ro Prozentpunkte höher als die Differenz bei den gesetzlichen bzw. vertraglich vereinbarten Gehältern. In Israel liegen im Sekundarbereich II die gesetzlichen bzw. vertraglich vereinbarten Gehälter von Lehrkräften I8 Prozent unter denen von Lehrkräften des Elementarbereichs, bei den durchschnittlichen tatsächlichen Gehältern ist es jedoch genau umgekehrt: Lehrkräfte des Sekundarbereichs II erhalten im Durchschnitt io Prozent mehr als Lehrkräfte des Elementarbereichs. In Polen sind die gesetzlichen bzw. vertraglich vereinbarten Gehälter im Elementar- und Primarbereich zwar ähnlich, dennoch unterscheiden sich die tatsächlichen Gehälter um I5 Prozent. Das Gegenteil ist beim Primar- und Sekundarbereich II der Fall. Die Bandbreite der Bonuszahlungen in den einzelnen Bildungsbereichen kann diese Unterschiede teilweise erklären (s. Anhang 3 unter www.oecd.orgleduleag.htm).

\section{Die Gehälter von Lehrkräften im Vergleich zu Gehältern von Beschäftigten mit einem Abschluss im Tertiärbereich}

Die Neigung junger Menschen, eine Ausbildung zur Lehrkraft aufzunehmen, sowie ausgebildeter Lehrkräfte, die Lehrtätigkeit auch wirklich aufzunehmen bzw. langfris- 
tig auszuüben, wird auch dadurch beeinflusst, in welchem Verhältnis die Gehälter der Lehrkräfte zu denen anderer Berufe stehen, die eine ebenso hohe Qualifikation erfordern, und welche Gehaltssteigerungen zu erwarten sind. In allen OECD-Ländern ist für die Tätigkeit als Lehrkraft ein Abschluss im Tertiärbereich erforderlich (s. Indikator D5 „Wie ist das demografische und das Qualifikationsprofil der Lehrerschaft?" in OECD, 2012), daher ist die mögliche Alternative einer Ausbildung zur Lehrkraft ein anderer Studiengang. Um das Gehaltsniveau in verschiedenen Ländern - bei vergleichbaren Ausgangsbedingungen auf dem Arbeitsmarkt - zu interpretieren, werden daher die Gehälter der Lehrkräfte mit denen anderer Berufstätiger mit vergleichbarem Bildungsstand verglichen, und zwar mit 25 - bis 64 -jährigen ganzjährig Vollzeitbeschäftigten mit einem Abschluss im Tertiärbereich.

Die Gehälter von Lehrkräften im Elementarbereich liegen im Durchschnitt bei 8o Prozent der Gehälter von 25- bis 64-jährigen ganzjährig Vollzeitbeschäftigten mit einem Abschluss im Tertiärbereich, im Primarbereich bei 82 Prozent, im Sekundarbereich I bei 85 Prozent und im Sekundarbereich II bei 89 Prozent dieses Vergleichswerts. Im Sekundarbereich II verdienen Lehrkräfte in II der 3I Länder mit verfügbaren Daten mindestens ebenso viel wie andere Beschäftigte mit einem Abschluss im Tertiärbereich (Tab. D3.2 und Abb. D3.I). Die relativen Gehälter der Lehrkräfte sind in Korea, Luxemburg (Sekundarbereich I und II) und Spanien am höchsten, wo die Gehälter der Lehrkräfte mindestens 20 Prozent höher sind als die von Beschäftigten mit einem vergleichbaren Abschluss. Die niedrigsten relativen Gehälter für Lehrkräfte verglichen mit den Gehältern anderer Berufstätiger mit vergleichbarem Bildungsabschluss finden sich im Primarbereich und Sekundarbereich I in Island, in allen Bildungsbereichen in der Slowakei und im Elementarbereich in Tschechien, wo sich die gesetzlichen bzw. vertraglich vereinbarten Gehälter für Lehrkräfte mit 15 Jahren Berufserfahrung im Durchschnitt auf höchstens 50 Prozent der Gehälter von ganzjährig Vollzeitbeschäftigten mit einem Abschluss im Tertiärbereich belaufen.

\section{Definitionen}

Die tatsächlichen Gehälter von 25- bis 64-jährigen Lehrkräften beziehen sich auf das durchschnittliche Jahresgehalt, das 25 - bis 64 -jährige vollzeitbeschäftigte Lehrkräfte vor Steuern erhalten. Hierzu gehören tätigkeitsbezogene Zahlungen, wie jährliche Bonuszahlungen, ergebnisabhängige Bonuszahlungen, finanzielle Zulagen für Urlaub und Lohnfortzahlung im Krankheitsfall. Einkommen aus anderen Quellen, wie staatliche Transferzahlungen, Kapitalerträge und andere nicht direkt mit der beruflichen Tätigkeit in Verbindung stehende Einkommensarten, sind nicht erfasst.

Zulagen zum Grundgehalt sind definiert als jegliche Abweichung beim Gehalt zwischen dem, was eine bestimmte Lehrkraft als Einkommen für die an der Schule geleistete Arbeit tatsächlich bezieht, und dem Betrag, der ausschließlich aufgrund der persönlichen Erfahrung (d. h. der Anzahl der Berufsjahre als Lehrkraft) gewährt werden würde. Zulagen können dauerhaft oder zeitlich befristet sein und dazu führen, dass eine Lehrkraft in den „außertariflichen Bereich“, in eine andere Gehaltskala oder auf die nächsthöhere Gehaltsstufe derselben Gehaltsskala gelangt. 
Die Gehälter von Beschäftigten mit einem Abschluss im Tertiärbereich sind die durchschnittlichen Gehälter von 25- bis 64-jährigen ganzjährig Vollzeitbeschäftigten mit einem Abschluss der ISCED-Stufen $5 \mathrm{~A} / 5 \mathrm{~B} / 6$. Der Indikator zu den relativen Gehältern ist für das letzte Jahr berechnet, für das Daten zu den Gehältern vorliegen. Bei Ländern, für die Daten zu den Gehältern von Lehrkräften und von anderen Beschäftigten nicht für dasselbe Jahr vorliegen (z. B. Australien, Italien und Schweden), wurde der Indikator mittels der Deflatoren für den privaten Konsum inflationsbereinigt. Die Referenzstatistiken für die Einkommen von Beschäftigten mit einem Abschluss im Tertiärbereich sind in Anhang 2 und 3 aufgeführt.

Die Gehälter von Lehrkräften mit 15 Jahren Berufserfahrung beziehen sich auf das reguläre Jahresgehalt einer Vollzeitlehrkraft mit der für eine Lehrerqualifikation erforderlichen Mindestausbildung und I5 Jahren Berufserfahrung.

Die Anfangsgehälter beziehen sich auf das durchschnittliche reguläre Bruttojahresgehalt einer Vollzeitlehrkraft am Anfang der Lehrerlaufbahn mit der für eine Lehrerqualifikation erforderlichen Mindestausbildung; die Höchstgehälter dagegen beziehen sich auf das maximale Jahresgehalt (an der Spitze der Gehaltsskala) einer Vollzeitlehrkraft mit der maximal in Bezug auf das Gehalt anerkannten Qualifikation.

Gesetzliche bzw. vertraglich vereinbarte Gehälter beziehen sich auf reguläre Gehälter gemäß offiziellen Gehaltsskalen. Die angegebenen Gehälter sind Bruttogehälter (die vom Arbeitgeber für die Arbeit bezahlte Gesamtsumme) abzüglich der Arbeitgeberbeiträge zur Sozial- und Rentenversicherung (entsprechend den gültigen Gehaltsskalen). Die Gehälter werden vor Steuer, d.h. vor Abzug der Einkommensteuer, angegeben. In Tabelle D3.2 wird für das Gehalt pro Nettozeitstunde Kontakt (Unterrichtszeitstunde) das gesetzliche bzw. vertraglich vereinbarte Jahresgehalt einer Lehrkraft durch die Anzahl der jährlichen Netto-Unterrichtszeitstunden (s. Tab. D4.I) geteilt.

\section{Angewandte Methodik}

Die Daten zu den gesetzlichen bzw. vertraglich vereinbarten Gehältern und den Zulagen für Lehrkräfte stammen aus der OECD/INES-Erhebung von 2012 zu Lehrkräften und Lehrplänen. Die Daten beziehen sich auf das Schuljahr 2010/20II und sind entsprechend den offiziellen Regelungen für öffentliche Einrichtungen angegeben.

Bei der Berechnung der gesetzlichen bzw. vertraglich vereinbarten Gehälter von Vollzeitlehrkräften im Verhältnis zur Zahl der von ihnen jährlich zu unterrichtenden (Zeit-) Stunden wird keine Anpassung der Gehälter an die Zeit, die Lehrkräfte mit verschiedenen anderen unterrichtsbezogenen Aktivitäten verbringen, vorgenommen. Da der Anteil der mit der Erteilung von Unterricht verbrachten Arbeitszeit von Lehrkräften in den OECD-Ländern unterschiedlich hoch ist, ist bei der Interpretation der gesetzlichen bzw. vertraglich vereinbarten Gehälter pro Netto-Unterrichtszeitstunde Vorsicht geboten (s. Indikator $\mathrm{D}_{4}$ ). Allerdings kann diese Kenngröße zur Schätzung der Kosten für die von Lehrkräften tatsächlich im Klassenzimmer verbrachte Zeit dienen. 
Die Bruttogehälter der Lehrkräfte werden mittels KKP für den privaten Konsum aus den „Volkswirtschaftlichen Gesamtrechnungen der OECD“ kaufkraftbereinigt dargestellt. In Ausgaben von Bildung auf einen Blick vor 2012 wurden die Gehälter mittels KKP für das BIP kaufkraftbereinigt dargestellt. Daher ist kein direkter Vergleich der Gehälter der Lehrkräfte in US-Dollar (Tab. D3.I) in dieser Ausgabe von Bildung aufeinen Blick mit den in Ausgaben vor 2012 präsentierten möglich. Tabelle D3.4 enthält Angaben zu Entwicklungstendenzen bei den Gehältern von Lehrkräften. In Ergänzung zu Tabelle D3.I, bei der es sich um eine Darstellung der Gehälter von Lehrkräften in US-Dollar, kaufkraftbereinigt mittels KKP, handelt, enthält Anhang 2 eine Tabelle mit den Gehältern von Lehrkräften in Landeswährung. Referenzzeitraum für die Gehälter der Lehrkräfte ist der Zeitraum zwischen dem I. Juli 2010 und dem 30. Juni 20II. Referenzzeitraum für die Kaufkraftparitäten ist 2010/20II.

Zur Berechnung der Veränderungen der Gehälter von Lehrkräften (Tab. D3.4) erfolgte die Umrechnung der Gehälter auf die Preise von 2000 mittels des Deflators für den privaten Konsum.

Beim Verhältnis der Gehälter von Lehrkräften zu ganzjährig Vollzeitbeschäftigten mit einem Abschluss im Tertiärbereich im Alter von 25 bis 64 Jahren werden bei den Ländern mit verfügbaren Daten für die Berechnung die durchschnittlichen Jahresgehälter von 25- bis 64-jährigen Lehrkräften (einschließlich Bonus- und Zulagenzahlungen) zugrunde gelegt (s. Tab. D3.3). Für die anderen Länder basiert die Berechnung auf den Gehältern von Lehrkräften mit I5 Jahren Berufserfahrung (mit Mindestausbildung). Tabelle D3.2 enthält Angaben zu der für das jeweilige Land verwendeten Methodik.

Hinweise zu den für jedes Land verwendeten Definitionen und angewandten Methodiken s. Anhang 3 unter www.oecd.org/eduleag.htm.

Die statistischen Daten für Israel wurden von den zuständigen israelischen Stellen bereitgestellt, die für sie verantwortlich zeichnen. Die Verwendung dieser Daten durch die OECD erfolgt unbeschadet des völkerrechtlichen Status der Golanhöhen, von OstJerusalem und der israelischen Siedlungen im Westjordanland.

\section{Weiterführende Informationen}

OECD (2005), Stärkere Professionalisierung des Lehrerberufs - Wie gute Lehrer gewonnen, gefördert und gehalten werden können, OECD Publishing.

http://dx.doi.org/10.1787/9789264018044-en (engl. Fassung)

OECD (2012), Bildung auf einen Blick 2012 - OECD-Indikatoren, W. Bertelsmann Verlag, Bielefeld.

Santiago, P. (2004), „The Labour Market for Teachers“, in G. Johnes and J. Johnes (eds.), International Handbook on the Economics of Education, Edward Elgar, Cheltenham. 


\section{Tabellen Indikator D3}

Tabelle D3.I: Gesetzliche bzw. vertraglich vereinbarte Gehälter von Lehrkräften zu unterschiedlichen Zeitpunkten in ihrer beruflichen Laufbahn (20II)

StatLink: http://dx.doi.org/10.1787/888932851763

Tabelle D3.2: Vergleich der Gehälter von Lehrkräften (20II)

StatLink: http:|/dx.doi.org/10.1787/888932851782

Tabelle D3·3: Durchschnittliche tatsächliche Gehälter von Lehrkräften (20II)

StatLink: http://dx.doi.org/10.1787/888932851801

Tabelle D3.4: Entwicklung der Gehälter von Lehrkräften zwischen 2000 und $201 \mathrm{I}$

StatLink: http:|/dx.doi.org/10.1787/888932851820

WEB Table D3.5: Minimum and maximum teachers' salaries (Mindest- und Höchstgehälter von Lehrkräften) (20II)

StatLink: http:||dx.doi.org/10.1787/888932851839

WEB Table D3.6a: Criteria determining base salary and additional payments for teachers in public institutions (Kriterien für das Grundgehalt und Zusatzvergütungen von Lehrkräften an öffentlichen Bildungseinrichtungen) (20II)

StatLink: http://dx.doi.org/10.1787/888932851858

WEB Table D3.6b: Decisions made by school principal on payments for teachers in public institutions (Entscheidungen von Schulleitern über Zahlungen an Lehrkräfte an öffentlichen Bildungseinrichtungen) (20II)

StatLink: http://dx.doi.org/10.1787/888932851877

WEB Table D3.6c: Decisions made by local or regional authority on payments for teachers in public institutions (Entscheidungen lokaler oder regionaler Behörden über Zahlungen an Lehrkräfte an öffentlichen Bildungseinrichtungen) (20II) StatLink: http:||dx.doi.org/10.1787/888932851896

WEB Table D3.6d: Decisions made by the national authority on payments for teachers in public institutions (Entscheidungen der nationalen Behörde über Zahlungen an Lehrkräfte an öffentlichen Bildungseinrichtungen) (20II)

StatLink: http://dx.doi.org/10.1787/888932851915 


\section{Tabelle D3.1}

Gesetzliche bzw. vertraglich vereinbarte Gehälter von Lehrkräften zu unterschiedlichen Zeitpunkten in ihrer beruflichen Laufbahn (2011)

Jahresgehälter von Lehrkräften an öffentlichen Bildungseinrichtungen, in US-Dollar (kaufkraftbereinigt mittels KKP für den privaten Verbrauch)

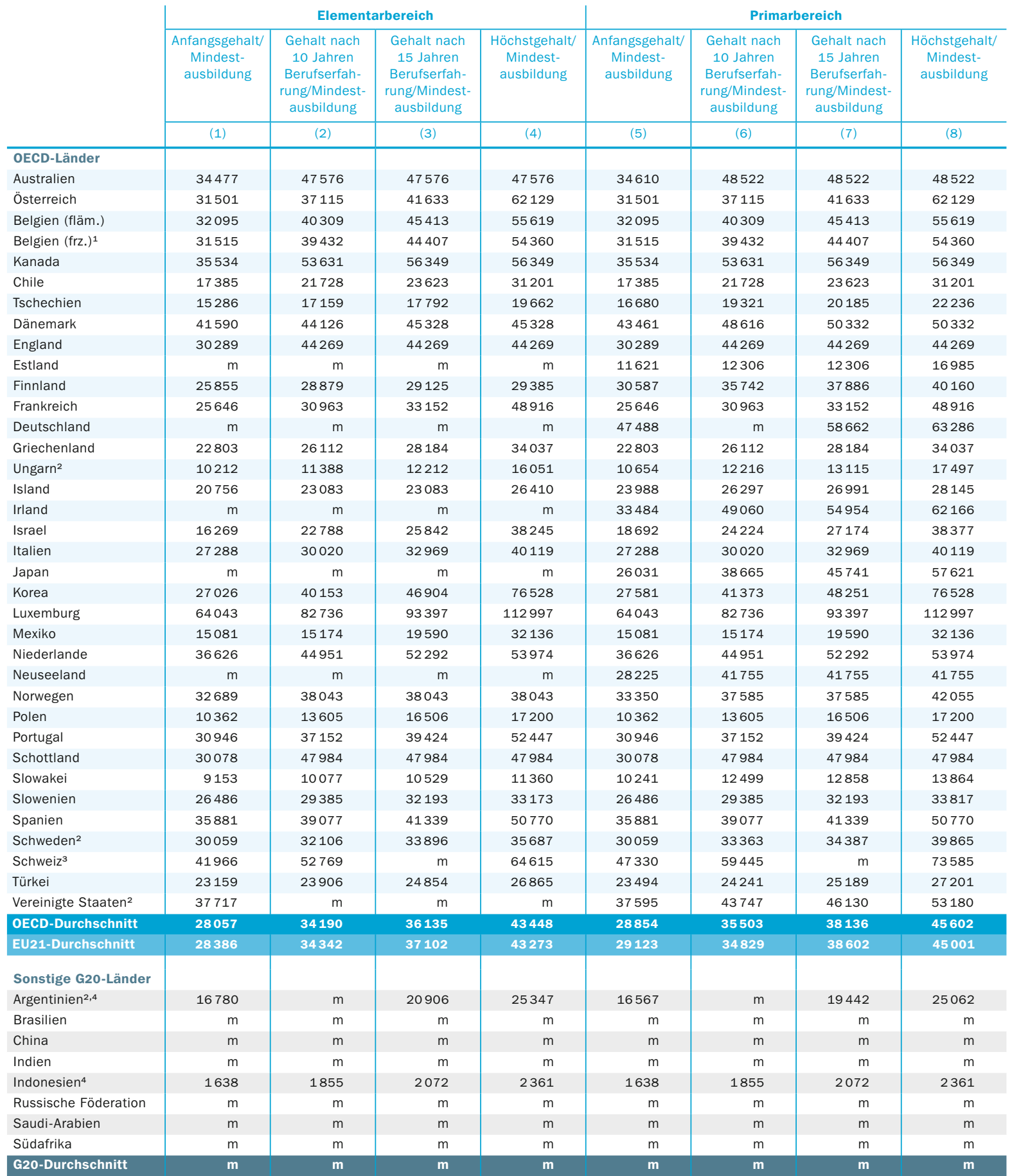

1. Gehälter von Lehrkräften mit typischen Qualifikationen anstelle der Mindestausbildung. Anhang 3 enthält Informationen zu den Gehältern von Lehrkräften mit Mindestqualifikation. 2. Tatsächliche Grundgehälter. 3. Spalten (2), (6), (10) und (14): Gehalt nach 11 Jahren Berufserfahrung. 4. Referenzjahr 2010. Quelle: OECD. Argentinien: Statistikinstitut der UNESCO (World Education Indicators Programme). Hinweise s. Anhang 3 unter www.oecd.org/edu/eag.htm. StatLink: http://dx.doi.org/10.1787/888932851763

Erläuterung der Kennzeichnung fehlender Daten s. Hinweise für den Leser. 
Tabelle D3.1 (Forts.)

Gesetzliche bzw. vertraglich vereinbarte Gehälter von Lehrkräften zu unterschiedlichen Zeitpunkten in ihrer beruflichen Laufbahn (2011)

Jahresgehälter von Lehrkräften an öffentlichen Bildungseinrichtungen, in US-Dollar (kaufkraftbereinigt mittels KKP für den privaten Verbrauch)

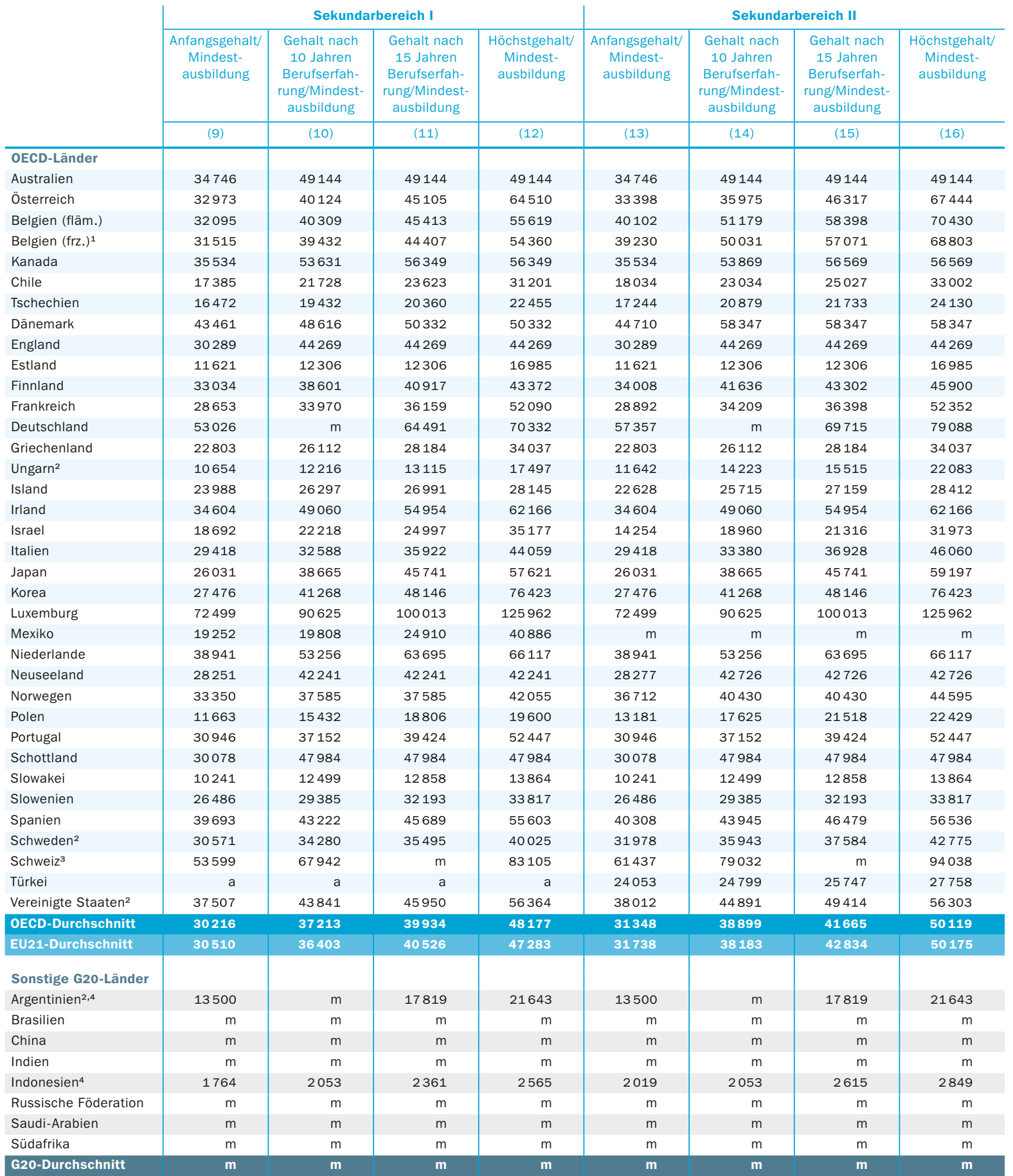

1. Gehälter von Lehrkräften mit typischen Qualifikationen anstelle der Mindestausbildung. Anhang 3 enthält Informationen zu den Gehältern von Lehrkräften mit Mindestqualifikation. 2. Tatsächliche Grundgehälter. 3. Spalten (2), (6), (10) und (14): Gehalt nach 11 Jahren Berufserfahrung. 4. Referenzjahr 2010. Quelle: OECD. Argentinien: Statistikinstitut der UNESCO (World Education Indicators Programme). Hinweise s. Anhang 3 unter www.oecd.org/edu/eag.htm. StatLink: http://dx.doi.org/10.1787/888932851763

Erläuterung der Kennzeichnung fehlender Daten s. Hinweise für den Leser. 
Tabelle D3.2

Vergleich der Gehälter von Lehrkräften (2011)

In Relation zu anderen Beschäftigten mit einer Ausbildung im Tertiärbereich und anderen Lehrkräften

\begin{tabular}{|c|c|c|c|c|c|c|c|c|c|c|c|c|c|}
\hline & \multicolumn{4}{|c|}{$\begin{array}{l}\text { Verhältnis der Gehälter von } \\
\text { Lehrkräften zu Gehältern von } \\
\text { 25- bis } 64 \text {-jährigen ganzjährig } \\
\text { Vollzeitbeschäftigten mit einem } \\
\text { Abschluss im Tertiärbereich }\end{array}$} & \multicolumn{4}{|c|}{$\begin{array}{l}\text { Verhältnis des Höchstgehalts } \\
\text { zum Anfangsgehalt }\end{array}$} & \multirow{2}{*}{$\begin{array}{l}\text { Jahre } \\
\text { zwischen } \\
\text { Anfangs- } \\
\text { und } \\
\text { Höchst- } \\
\text { gehalt } \\
\text { (Sekun- } \\
\text { darbe- } \\
\text { reich I) }\end{array}$} & \multicolumn{3}{|c|}{$\begin{array}{c}\text { Gehalt je Nettostunde } \\
\text { Kontakt (Unterrichtszeit- } \\
\text { stunde) nach } 15 \text { Jahren } \\
\text { Berufserfahrung }\end{array}$} & \multirow{2}{*}{\begin{tabular}{|} 
Verhältnis des Ge- \\
halts pro Unter- \\
richtszeitstunde \\
von Lehrkräften des \\
Sekundarbereichs II \\
zu Lehrkräften des \\
Primarbereichs \\
(nach 15 Jahren \\
Berufserfahrung)
\end{tabular}} \\
\hline & $\begin{array}{c}\text { Elemen- } \\
\text { tarbe- } \\
\text { reich }\end{array}$ & $\begin{array}{l}\text { Primar- } \\
\text { bereich }\end{array}$ & $\begin{array}{l}\text { Sekun- } \\
\text { darbe- } \\
\text { reich I }\end{array}$ & $\begin{array}{l}\text { Sekun- } \\
\text { darbe- } \\
\text { reich II }\end{array}$ & $\begin{array}{c}\text { Elemen- } \\
\text { tarbe- } \\
\text { reich }\end{array}$ & $\begin{array}{l}\text { Primar- } \\
\text { bereich }\end{array}$ & $\begin{array}{l}\text { Sekun- } \\
\text { darbe- } \\
\text { reich I }\end{array}$ & $\begin{array}{l}\text { Sekun- } \\
\text { darbe- } \\
\text { reich II }\end{array}$ & & $\begin{array}{l}\text { Primar- } \\
\text { bereich }\end{array}$ & $\begin{array}{l}\text { Sekun- } \\
\text { darbe- } \\
\text { reich I }\end{array}$ & $\begin{array}{l}\text { Sekun- } \\
\text { darbe- } \\
\text { reich II }\end{array}$ & \\
\hline & (1) & (2) & (3) & (4) & (5) & (6) & (7) & (8) & (9) & (10) & (11) & (12) & (13) \\
\hline \multicolumn{14}{|l|}{ OECD-Länder } \\
\hline Australien 1,2 & 0,91 & 0,92 & 0,91 & 0,91 & 1,38 & 1,40 & 1,41 & 1,41 & 9 & 56 & 61 & 61 & 1,10 \\
\hline Österreich ${ }^{3}$ & 0,57 & 0,57 & 0,62 & 0,64 & 1,97 & 1,97 & 1,96 & 2,02 & 34 & 53 & 74 & 79 & 1,47 \\
\hline Belgien (fläm.) ${ }^{1}$ & 0,89 & 0,90 & 0,89 & 1,17 & 1,73 & 1,73 & 1,73 & 1,76 & 27 & 60 & 68 & 93 & 1,55 \\
\hline Belgien (frz.) ${ }^{3}$ & 0,84 & 0,84 & 0,84 & 1,08 & 1,72 & 1,72 & 1,72 & 1,75 & 27 & 62 & 67 & 95 & 1,54 \\
\hline Kanada $^{2,3}$ & 1,04 & 1,04 & 1,04 & 1,04 & 1,59 & 1,59 & 1,59 & 1,59 & 11 & 71 & 76 & 76 & 1,07 \\
\hline Chile $^{1}$ & 0,73 & 0,73 & 0,73 & 0,77 & 1,79 & 1,79 & 1,79 & 1,83 & 30 & 21 & 21 & 23 & 1,06 \\
\hline Tschechien $^{1}$ & 0,42 & 0,54 & 0,54 & 0,58 & 1,29 & 1,33 & 1,36 & 1,40 & 27 & 24 & 32 & 36 & 1,50 \\
\hline Dänemark ${ }^{1}$ & 0,83 & 0,91 & 0,91 & 1,10 & 1,09 & 1,16 & 1,16 & 1,31 & 8 & 77 & 77 & 158 & 2,04 \\
\hline England $^{1}$ & 0,83 & 0,83 & 0,92 & 0,92 & 1,46 & 1,46 & 1,46 & 1,46 & 12 & 65 & 64 & 64 & 0,98 \\
\hline Estland $^{1}$ & $\mathrm{~m}$ & 0,64 & 0,64 & 0,64 & $\mathrm{~m}$ & 1,46 & 1,46 & 1,46 & 7 & 20 & 20 & 22 & 1,09 \\
\hline Finnland $^{1,2}$ & 0,75 & 0,89 & 0,98 & 1,10 & 1,14 & 1,31 & 1,31 & 1,35 & 20 & 56 & 69 & 78 & 1,41 \\
\hline Frankreich ${ }^{3,4}$ & 0,75 & 0,75 & 0,81 & 0,82 & 1,91 & 1,91 & 1,82 & 1,81 & 34 & 35 & 56 & 56 & 1,59 \\
\hline Deutschland ${ }^{3}$ & m & 0,92 & 1,01 & 1,09 & $\mathrm{~m}$ & 1,33 & 1,33 & 1,38 & 28 & 73 & 85 & 98 & 1,34 \\
\hline Griechenland & $\mathrm{m}$ & m & m & $\mathrm{m}$ & 1,49 & 1,49 & 1,49 & 1,49 & 33 & 48 & 68 & 68 & 1,42 \\
\hline Ungarn 1,5 & 0,52 & 0,58 & 0,58 & 0,66 & 1,57 & 1,64 & 1,64 & 1,90 & 40 & 22 & 22 & 26 & 1,18 \\
\hline Island ${ }^{3,6}$ & $\mathrm{~m}$ & 0,50 & 0,50 & 0,61 & 1,27 & 1,17 & 1,17 & 1,26 & 18 & 43 & 43 & 50 & 1,15 \\
\hline Irland ${ }^{2,3}$ & 0,82 & 0,82 & 0,82 & 0,82 & $\mathrm{~m}$ & 1,86 & 1,80 & 1,80 & 22 & 60 & 75 & 75 & 1,25 \\
\hline$\left.\right|_{\text {srael }} ^{1}$ & 0,85 & 0,95 & 0,93 & 0,94 & 2,35 & 2,05 & 1,88 & 2,24 & 36 & 32 & 41 & 41 & 1,27 \\
\hline Italien ${ }^{1,2}$ & 0,58 & 0,58 & 0,61 & 0,65 & 1,47 & 1,47 & 1,50 & 1,57 & 35 & 43 & 57 & 59 & 1,37 \\
\hline Japan & $\mathrm{m}$ & $\mathrm{m}$ & $\mathrm{m}$ & $\mathrm{m}$ & $\mathrm{m}$ & 2,21 & 2,21 & 2,27 & 34 & 63 & 76 & 90 & 1,43 \\
\hline Korea $^{3}$ & 1,31 & 1,34 & 1,34 & 1,34 & 2,83 & 2,77 & 2,78 & 2,78 & 37 & 59 & 78 & 79 & 1,33 \\
\hline Luxemburg ${ }^{1,2}$ & 1,08 & 1,08 & 1,24 & 1,24 & 1,76 & 1,76 & 1,74 & 1,74 & 30 & 115 & 135 & 135 & 1,17 \\
\hline Mexiko & $\mathrm{m}$ & $\mathrm{m}$ & $\mathrm{m}$ & $\mathrm{m}$ & 2,13 & 2,13 & 2,12 & $\mathrm{~m}$ & 14 & 24 & 24 & $\mathrm{~m}$ & $\mathrm{~m}$ \\
\hline Niederlande $^{1,2}$ & $\mathrm{~m}$ & 0,70 & 0,84 & 0,84 & 1,47 & 1,47 & 1,70 & 1,70 & 15 & 56 & 85 & 85 & 1,51 \\
\hline Neuseeland $^{1}$ & $\mathrm{~m}$ & 1,03 & 1,05 & 1,08 & $\mathrm{~m}$ & 1,48 & 1,50 & 1,51 & 8 & 45 & 50 & 56 & 1,26 \\
\hline Norwegen ${ }^{1,2}$ & 0,61 & 0,70 & 0,70 & 0,75 & 1,16 & 1,26 & 1,26 & 1,21 & 16 & 51 & 57 & 77 & 1,53 \\
\hline Polen $^{1,2}$ & 0,66 & 0,76 & 0,77 & 0,75 & 1,66 & 1,66 & 1,68 & 1,70 & 20 & 34 & 39 & 46 & 1,33 \\
\hline Portugal $^{2,3}$ & 1,17 & 1,17 & 1,17 & 1,17 & 1,69 & 1,69 & 1,69 & 1,69 & 34 & 45 & 51 & 51 & 1,14 \\
\hline Schottland ${ }^{1}$ & 0,81 & 0,81 & 0,81 & 0,81 & 1,60 & 1,60 & 1,60 & 1,60 & 6 & 56 & 56 & 56 & 1,00 \\
\hline Slowakei ${ }^{3}$ & 0,36 & 0,44 & 0,44 & 0,44 & 1,24 & 1,35 & 1,35 & 1,35 & 32 & 15 & 20 & 21 & 1,35 \\
\hline Slowenien ${ }^{3}$ & 0,81 & 0,81 & 0,81 & 0,81 & 1,25 & 1,28 & 1,28 & 1,28 & 13 & 51 & 51 & 56 & 1,10 \\
\hline Spanien ${ }^{2,3}$ & 1,23 & 1,23 & 1,38 & 1,40 & 1,41 & 1,41 & 1,40 & 1,40 & 38 & 47 & 64 & 67 & 1,43 \\
\hline Schweden ${ }^{5,7}$ & 0,75 & 0,82 & 0,82 & 0,87 & 1,19 & 1,33 & 1,31 & 1,34 & a & $\mathrm{m}$ & $\mathrm{m}$ & $\mathrm{m}$ & $\mathrm{m}$ \\
\hline Schweiz $^{8}$ & $\mathrm{~m}$ & $\mathrm{~m}$ & $\mathrm{~m}$ & $\mathrm{~m}$ & 1,54 & 1,55 & 1,55 & 1,53 & 27 & $\mathrm{~m}$ & $\mathrm{~m}$ & $\mathrm{~m}$ & $\mathrm{~m}$ \\
\hline Türkei & $\mathrm{m}$ & $\mathrm{m}$ & $\mathrm{m}$ & $\mathrm{m}$ & 1,16 & 1,16 & a & 1,15 & a & 39 & a & 45 & 1,15 \\
\hline Ver. Staaten ${ }^{1,5}$ & 0,65 & 0,66 & 0,67 & 0,70 & $\mathrm{~m}$ & 1,41 & 1,50 & 1,48 & $\mathrm{~m}$ & 42 & 43 & 47 & 1,12 \\
\hline OECD-Durchschnitt & 0,80 & 0,82 & 0,85 & 0,89 & 1,58 & 1,59 & 1,61 & 1,62 & 24 & 49 & 58 & 66 & 1,31 \\
\hline EU21-Durchschnitt & 0,77 & 0,80 & 0,84 & 0,89 & 1,51 & 1,54 & 1,54 & 1,58 & 25 & 51 & 61 & 69 & 1,35 \\
\hline \multicolumn{14}{|l|}{ Sonst. G20-Länder } \\
\hline Argentinien 5,9 & $\mathrm{~m}$ & $\mathrm{~m}$ & $\mathrm{~m}$ & $\mathrm{~m}$ & $\mathrm{~m}$ & 1,51 & 1,60 & 1,60 & 25 & 27 & 12 & 12 & 0,46 \\
\hline Brasilien & $\mathrm{m}$ & $\mathrm{m}$ & $\mathrm{m}$ & $\mathrm{m}$ & $\mathrm{m}$ & $\mathrm{m}$ & $\mathrm{m}$ & $\mathrm{m}$ & $\mathrm{m}$ & $\mathrm{m}$ & $\mathrm{m}$ & $\mathrm{m}$ & $\mathrm{m}$ \\
\hline China & $\mathrm{m}$ & $\mathrm{m}$ & $\mathrm{m}$ & $\mathrm{m}$ & $\mathrm{m}$ & $\mathrm{m}$ & $\mathrm{m}$ & $\mathrm{m}$ & $\mathrm{m}$ & $\mathrm{m}$ & $\mathrm{m}$ & $\mathrm{m}$ & $\mathrm{m}$ \\
\hline Indien & $\mathrm{m}$ & $\mathrm{m}$ & $\mathrm{m}$ & $\mathrm{m}$ & $\mathrm{m}$ & $\mathrm{m}$ & $\mathrm{m}$ & $\mathrm{m}$ & $\mathrm{m}$ & $\mathrm{m}$ & $\mathrm{m}$ & $\mathrm{m}$ & $\mathrm{m}$ \\
\hline Indonesien ${ }^{9}$ & $\mathrm{~m}$ & $\mathrm{~m}$ & $\mathrm{~m}$ & $\mathrm{~m}$ & 1,44 & 1,44 & 1,45 & 1,41 & 32 & 2 & 4 & 3 & 1,68 \\
\hline Russische Föd. & $\mathrm{m}$ & $\mathrm{m}$ & $\mathrm{m}$ & $\mathrm{m}$ & $\mathrm{m}$ & $\mathrm{m}$ & $\mathrm{m}$ & $\mathrm{m}$ & $\mathrm{m}$ & $\mathrm{m}$ & $\mathrm{m}$ & $\mathrm{m}$ & $\mathrm{m}$ \\
\hline Saudi-Arabien & $\mathrm{m}$ & $\mathrm{m}$ & $\mathrm{m}$ & $\mathrm{m}$ & $\mathrm{m}$ & $\mathrm{m}$ & $\mathrm{m}$ & $\mathrm{m}$ & $\mathrm{m}$ & $\mathrm{m}$ & $\mathrm{m}$ & $\mathrm{m}$ & $\mathrm{m}$ \\
\hline Südafrika & $\mathrm{m}$ & $\mathrm{m}$ & $\mathrm{m}$ & $\mathrm{m}$ & $\mathrm{m}$ & $\mathrm{m}$ & $\mathrm{m}$ & $\mathrm{m}$ & $\mathrm{m}$ & $\mathrm{m}$ & $\mathrm{m}$ & $\mathrm{m}$ & $\mathrm{m}$ \\
\hline G20-Durchschnitt & $\mathbf{m}$ & m & $\mathbf{m}$ & m & m & m & m & m & m & m & m & m & m \\
\hline
\end{tabular}

1. Spalten (1), (2), (3) und (4): Verhältnis der durchschnittlichen tatsächlichen Gehälter, einschließlich Bonus- und Zulagezahlungen, von 25- bis 64-jährigen Lehrkräften zu den Gehältern von 25- bis 64-Jährigen ganzjährig Vollzeitbeschäftlgten mit einem Abschluss im Tertiärbereich. 2. Spalten (1), (2), (3) und (4): Referenzjahr 2010. 3. Spalten (1), (2), (3) und (4): Verhältnis der gesetzlichen bzw. vertraglich vereinbarten Gehälter nach 15 Jahren Berufserfahrung (mit Mindestausbildung) zu den Gehältern von 25- bis 64-jährigen ganzjährig Vollzeitbeschäftigten mit einem Abschluss im Tertiärbereich. 4. Spalten (1), (2), (3) und (4): Referenzjahr 2009. 5. Spalten (5) bis (13): Tatsächliche Grundgehälter (ohne Bonus- und Zulagezahlungen). 6. Spalten (1), (2), (3) und (4): Referenzjahr 2006. 7. Spalten (1), (2), (3) und (4): Verhältnis der durchschnittlichen tatsächlichen Gehälter von 25- bis 64-jährigen Lehrkräften (ohne Bonus- und Zulagezahlungen) zu Gehältern von 25- bis 64-jährigen ganzjährig Vollzeitbeschäftigten mit einem Abschluss im Tertiärbereich. 8. Gehälter nach 11 Jahren Berufserfahrung. 9. Spalten (5) bis (13): Referenzjahr 2010.

Quelle: OECD. Argentinien: Statistikinstitut der UNESCO (World Education Indicators Programme). Hinweise s. Anhang 3 unter www.oecd.org/edu/eag.htm. StatLink: http://dx.doi.org/10.1787/888932851782

Erläuterung der Kennzeichnung fehlender Daten s. Hinweise für den Leser. 
Tabelle D3.3

Durchschnittliche tatsächliche Gehälter von Lehrkräften (2011)

Durchschnittliche Jahresgehälter von 25- bis 64-jährigen Lehrkräften an öffentlichen Bildungseinrichtungen (einschließlich Bonus- und Zulagezahlungen), in US-Dollar (kaufkraftbereinigt mittels KKP für den privaten Verbrauch)

\begin{tabular}{|c|c|c|c|c|}
\hline & Elementarbereich & Primarbereich & Sekundarbereich I & Sekundarbereich II \\
\hline & (1) & (2) & (3) & (4) \\
\hline \multicolumn{5}{|l|}{ OECD-Länder } \\
\hline Australien & 48138 & 49299 & 49058 & 49060 \\
\hline Österreich & $\mathrm{m}$ & $\mathrm{m}$ & $\mathrm{m}$ & $\mathrm{m}$ \\
\hline Belgien (fläm.) & 46772 & 47188 & 46754 & 61447 \\
\hline Belgien (frz.) & $\mathrm{m}$ & $\mathrm{m}$ & $\mathrm{m}$ & $\mathrm{m}$ \\
\hline Kanada & $\mathrm{m}$ & $\mathrm{m}$ & $\mathrm{m}$ & $\mathrm{m}$ \\
\hline Chile & 31447 & 31447 & 31447 & 33101 \\
\hline Tschechien $^{1}$ & 15116 & 19349 & 19360 & 20831 \\
\hline Dänemark & 48652 & 53182 & 53182 & 64080 \\
\hline England & 47002 & 47002 & 51913 & 51913 \\
\hline Estland $^{2}$ & $\mathrm{~m}$ & 15030 & 15030 & 15030 \\
\hline Finnland $^{3}$ & 35183 & 40855 & 44747 & 50282 \\
\hline Frankreich & $\mathrm{m}$ & $\mathrm{m}$ & $\mathrm{m}$ & $\mathrm{m}$ \\
\hline Deutschland & $\mathrm{m}$ & $\mathrm{m}$ & $\mathrm{m}$ & $\mathrm{m}$ \\
\hline Griechenland & $\mathrm{m}$ & $\mathrm{m}$ & $\mathrm{m}$ & $\mathrm{m}$ \\
\hline Ungarn & 15284 & 17087 & 17087 & 19404 \\
\hline Island ${ }^{4}$ & $\mathrm{~m}$ & $\mathrm{~m}$ & $\mathrm{~m}$ & 35014 \\
\hline Irland & $\mathrm{m}$ & $\mathrm{m}$ & $\mathrm{m}$ & $\mathrm{m}$ \\
\hline Israel & 27569 & 30829 & 30183 & 30453 \\
\hline Italien & 32833 & 32833 & 35346 & 36725 \\
\hline Japan & $\mathrm{m}$ & $\mathrm{m}$ & $\mathrm{m}$ & $\mathrm{m}$ \\
\hline Korea & $\mathrm{m}$ & $m$ & $\mathrm{~m}$ & $m$ \\
\hline Luxemburg & 88519 & 88519 & 101706 & 101706 \\
\hline Mexiko & $\mathrm{m}$ & $\mathrm{m}$ & $\mathrm{m}$ & $\mathrm{m}$ \\
\hline Niederlande & 48353 & 48353 & 56918 & 56918 \\
\hline Neuseeland & $\mathrm{m}$ & 42216 & 43095 & 43974 \\
\hline Norwegen & 39069 & 43196 & 43196 & 46319 \\
\hline Polen & 21929 & 25325 & 25645 & 25077 \\
\hline Portugal & $\mathrm{m}$ & $\mathrm{m}$ & $\mathrm{m}$ & $\mathrm{m}$ \\
\hline Schottland & 45393 & 45393 & 45393 & 45393 \\
\hline Slowakei & $\mathrm{m}$ & $\mathrm{m}$ & $\mathrm{m}$ & $\mathrm{m}$ \\
\hline Slowenien & $\mathrm{m}$ & $\mathrm{m}$ & $m$ & $\mathrm{~m}$ \\
\hline Spanien & $\mathrm{m}$ & $\mathrm{m}$ & $\mathrm{m}$ & $\mathrm{m}$ \\
\hline Schweden 5 & 32351 & 35079 & 35165 & 37552 \\
\hline Schweiz & $\mathrm{m}$ & $\mathrm{m}$ & $\mathrm{m}$ & 77527 \\
\hline Türkei & $\mathrm{m}$ & $\mathrm{m}$ & $\mathrm{m}$ & $\mathrm{m}$ \\
\hline Vereinigte Staaten & 49069 & 50120 & 51166 & 53235 \\
\hline Länderdurchschnitt & 39569 & 40121 & 41915 & 45478 \\
\hline \multicolumn{5}{|l|}{ Sonstige G20-Länder } \\
\hline Argentinien & $\mathrm{m}$ & $\mathrm{m}$ & $\mathrm{m}$ & $\mathrm{m}$ \\
\hline Brasilien & $\mathrm{m}$ & $\mathrm{m}$ & $\mathrm{m}$ & $\mathrm{m}$ \\
\hline China & $\mathrm{m}$ & $\mathrm{m}$ & $\mathrm{m}$ & $\mathrm{m}$ \\
\hline Indien & $\mathrm{m}$ & $\mathrm{m}$ & $\mathrm{m}$ & $\mathrm{m}$ \\
\hline Indonesien & $\mathrm{m}$ & $m$ & $\mathrm{~m}$ & $\mathrm{~m}$ \\
\hline Russische Föderation ${ }^{2}$ & 17875 & 17875 & 17875 & 17875 \\
\hline Saudi-Arabien & $\mathrm{m}$ & $\mathrm{m}$ & $\mathrm{m}$ & $\mathrm{m}$ \\
\hline Südafrika & $\mathrm{m}$ & $\mathrm{m}$ & $\mathrm{m}$ & $\mathrm{m}$ \\
\hline
\end{tabular}

1. Einschließlich der Gehälter von Lehrkräften ohne Qualifikation. 2. Durchschnittliche tatsächliche Gehälter von allen Lehrkräften, unabhängig von dem Bildungsbereich, in dem sie unterrichten. 3. Nur Spalte (1): Bezieht sich auf Lehrer des Elementarbereichs, die an Schulen des Primarbereichs arbeiten.

4. Referenzjahr 2010. 5. Durchschnittliche tatsächliche Gehälter von Lehrkräften, ohne Bonus- und Zulagezahlungen.

Quelle: OECD. Hinweise s. Anhang 3 unter www.oecd.org/edu/eag.htm. StatLink: http://dx.doi.org/10.1787/888932851801

Erläuterung der Kennzeichnung fehlender Daten s. Hinweise für den Leser. 
Tabelle D3.4

Entwicklung der Gehälter von Lehrkräften zwischen 2000 und 2011

Index der Veränderung der gesetzlichen bzw. vertraglich vereinbarten Gehälter von Lehrkräften mit 15 Jahren Berufserfahrung (mit Mindestausbildung) $(2000=100)$, nach Bildungsbereich, mittels KKP für den privaten Verbrauch auf konstante Preise umgerechnet

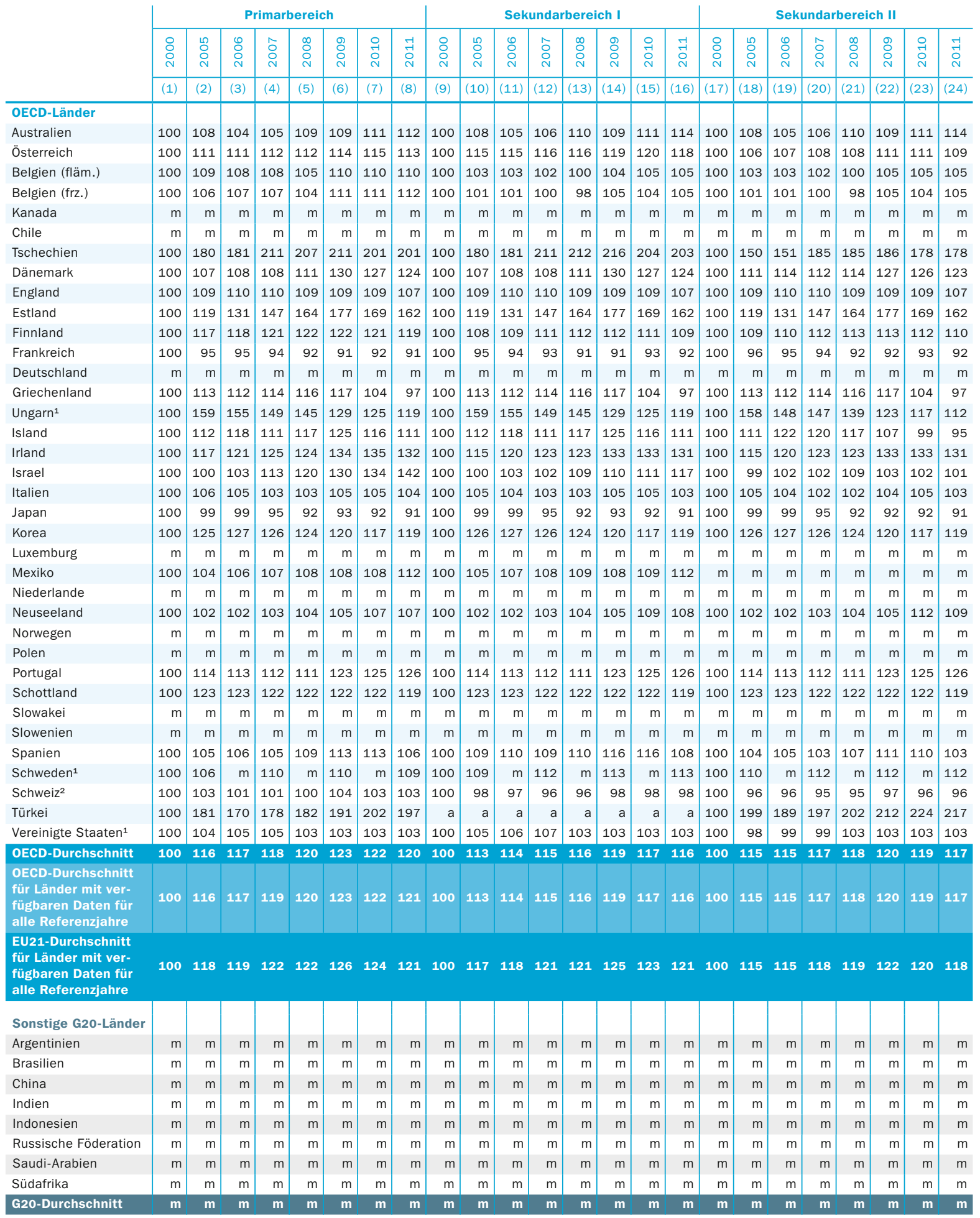

1. Tatsächliche Grundgehälter. 2. Gehälter nach 11 Jahren Berufserfahrung.

Quelle: OECD. Hinweise s. Anhang 3 unter www.oecd.org/edu/eag.htm. StatLink: http://dx.doi.org/10.1787/888932851820

Erläuterung der Kennzeichnung fehlender Daten s. Hinweise für den Leser. 


\section{Wie viel Zeit unterrichten Lehrkräfte?}

Die Zahl der von Lehrern an öffentlichen Bildungseinrichtungen pro Jahr zu unterrichtenden (Zeit-)Stunden beträgt im Durchschnitt 994 (Zeit-)Stunden im Elementarbereich, 790 (Zeit-)Stunden im Primarbereich, 709 (Zeit-)Stunden im Sekundarbereich I und 664 (Zeit-)Stunden im Sekundarbereich II.

In fast der Hälfte der Länder mit verfügbaren Daten stieg oder sank die Zahl der von den Lehrkräften zu unterrichtenden (Zeit-)Stunden zwischen 2000 und $201 \mathrm{I}$ im Primar-, Sekundarbereich I und/oder II um mindestens Io Prozent.

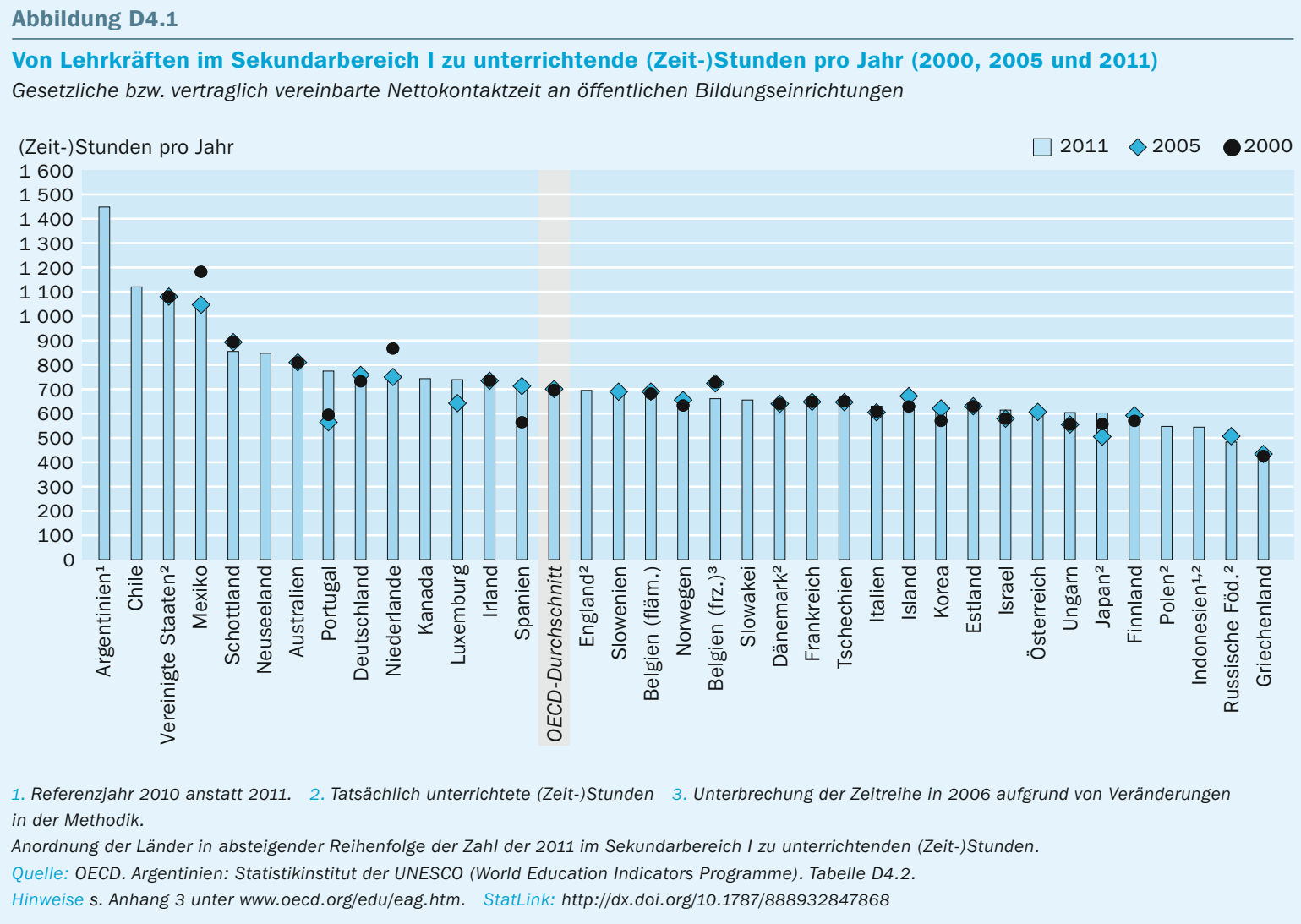

\section{Kontext}

Obwohl die gesetzliche bzw. vertraglich vereinbarte Arbeits- und Unterrichtszeit die tatsächliche Arbeitsbelastung der Lehrkräfte nur zu einem Teil bestimmen, gewähren sie doch einen interessanten Einblick in die unterschiedlichen Anforderungen an Lehrkräfte in den verschiedenen Ländern. Die Unterrichtszeit und das Ausmaß nicht unmittelbar unterrichtsbezogener Aufgaben können auch die Attraktivität des Lehrerberufs beeinflussen. Dieser Indikator zeigt einige weitere wichtige Faktoren auf, die zusammen mit den Gehältern der Lehrkräfte (s. Indikator D3) und der durchschnittlichen Klassengröße (s. Indikator D2) die Arbeitsbedingungen der Lehrkräfte bestimmen. 
Der Anteil der gesetzlichen bzw. vertraglich vereinbarten Arbeitszeit, die im Unterricht verbracht wird, gibt Aufschluss darüber, wie viel Zeit für nicht unterrichtende Tätigkeiten, wie Unterrichtsvorbereitung, Korrekturen, interne Fortbildung und Besprechungen, zur Verfügung steht. Wenn die Unterrichtsverpflichtungen einen großen Teil der gesetzlichen bzw. vertraglich vereinbarten Arbeitszeit ausmachen, kann dies darauf hindeuten, dass weniger (Arbeits-)Zeit für Aufgaben wie Schülerbeurteilungen und Unterrichtsvorbereitung aufgewendet wird.

Zusammen mit Faktoren wie der Klassengröße und der Schüler-Lehrkräfte-Relation (s. Indikator D2), der Unterrichtszeit der Schüler (s. Indikator Di) und den Gehältern der Lehrkräfte (s. Indikator $\mathrm{D}_{3}$ ) beeinflusst die Zeit, die Lehrkräfte unterrichten, auch die von den einzelnen Ländern für Bildung aufzuwendenden Finanzmittel (s. Indikator $\mathrm{B} 7)$.

\section{Weitere wichtige Ergebnisse}

Die durchschnittliche Zahl der von Lehrkräften an öffentlichen Schulen des Elementarbereichs zu unterrichtenden (Zeit-)Stunden beträgt 994 Stunden pro Jahr, reicht jedoch von 450 Stunden in Indonesien bis zu mehr als I 500 Stunden in Island, Norwegen und Schweden.

Lehrkräfte an öffentlichen Schulen des Primarbereichs unterrichten im Durchschnitt 790 (Zeit-) Stunden pro Jahr, dies reicht aber von weniger als 600 Stunden in Griechenland und der Russischen Föderation bis zu mehr als I.000 Stunden in Chile und den Vereinigten Staaten.

Die Zahl der von Lehrkräften an öffentlichen Schulen des Sekundarbereichs I zu unterrichtenden (Zeit-)Stunden beträgt im Durchschnitt 709 Stunden pro Jahr, reicht jedoch von weniger als 4I5 Stunden in Griechenland bis zu mehr als I.000 Stunden in Argentinien, Chile, Mexiko und den Vereinigten Staaten.

Im Sekundarbereich II liegt die Zahl der zu unterrichtenden (Zeit-)Stunden an öffentlichen Bildungseinrichtungen bei durchschnittlich 664 Stunden im Jahr, sie reicht jedoch von 369 Stunden in Dänemark bis zu r.448 Stunden in Argentinien.

Die von Lehrkräften zu unterrichtende Zahl an (Zeit-)Stunden ist im Elementarbereich durchschnittlich rund 30 Prozent höher als im Primarbereich; die Zeit, die Lehrkräfte in der Schule arbeiten müssen, oder ihre Gesamtarbeitszeit sind in diesen beiden Bildungsbereichen jedoch oft gleich.

Die Vorgaben für die Arbeitszeit der Lehrkräfte unterscheiden sich erheblich in den einzelnen Ländern. In den meisten Ländern ist offiziell festgelegt, wie viele (Zeit-)Stunden Lehrkräfte pro Jahr arbeiten müssen. In einigen Ländern wird die Unterrichtszeit nur in Form der Zahl der pro Woche zu gebenden Unterrichtseinheiten festgelegt, und es werden möglicherweise Annahmen getroffen, wie viel Zeit zusätzlich pro Unterrichtseinheit (innerhalb oder außerhalb der Schule) notwendig ist. 


\section{Entwicklungstendenzen}

In fast der Hälfte der Länder mit verfügbaren Daten gab es zwischen 2000 und $201 \mathrm{I}$ im Primar-, Sekundarbereich I und/oder II einen Anstieg bzw. eine Reduzierung der Zahl der von Lehrkräften zu unterrichtenden (Zeit-)Stunden um mindestens Io Prozent. In den meisten Ländern, in denen es zu einer deutlichen Veränderung kam, stieg die Zahl der zu unterrichtenden (Zeit-)Stunden in diesem Zeitraum an. Nur in einigen wenigen Ländern kam es zu außerordentlich großen Veränderungen bei den zu unterrichtenden (Zeit-)Stunden: In Portugal und Spanien nahm ihre Zahl im Sekundarbereich um mehr als 25 Prozent zu.

\section{Analyse und Interpretationen}

\section{Zahl der von Lehrkräften zu unterrichtenden (Zeit-)Stunden}

In allen Bildungsbereichen gibt es zwischen den einzelnen Ländern Unterschiede hinsichtlich der Zahl an (Zeit-)Stunden, die Lehrkräfte an einer öffentlichen Schule durchschnittlich pro Jahr unterrichten müssen.

Im Elementarbereich unterscheidet sich die Zahl der an öffentlichen Bildungseinrichtungen zu unterrichtenden (Zeit-)Stunden mehr zwischen den einzelnen Ländern als in allen anderen Bildungsbereichen. Die Zahl der Unterrichtstage reicht von I4I Tagen in Frankreich bis zu 232 Tagen in Indonesien, und die Zahl der von Lehrkräften zu unterrichtenden (Zeit-)Stunden reicht von weniger als 700 Stunden in England, Finnland, Indonesien, Korea und Mexiko bis zu mehr als I.500 Stunden in Island, Norwegen und Schweden. Im Durchschnitt der OECD müssen Lehrkräfte in diesem Bildungsbereich 994 Stunden im Jahr unterrichten, verteilt auf 40 Wochen oder 193 Unterrichtstage.

Lehrkräfte im Primarbereich müssen im Durchschnitt 790 (Zeit-)Stunden pro Jahr unterrichten. In den meisten Ländern mit verfügbaren Daten müssen Lehrkräfte zwischen 3 und 6 (Zeit-)Stunden am Tag unterrichten. Ausnahmen sind Chile, Frankreich und die Vereinigten Staaten, wo Lehrkräfte mehr als 6 (Zeit-)Stunden am Tag unterrichten, sowie Indonesien, wo Lehrkräfte weniger als 3 (Zeit-)Stunden am Tag unterrichten. Es bestehen keine einheitlichen Regelungen für die Verteilung der zu unterrichtenden (Zeit-)Stunden über das Jahr. So müssen beispielsweise in Spanien Lehrkräfte im Primarbereich 880 (Zeit-)Stunden pro Jahr unterrichten, rund Ioo (Zeit-) Stunden mehr als im Durchschnitt der OECD-Länder. Diese Stunden sind jedoch auf eine geringere Zahl von Unterrichtstagen verteilt als im OECD-Durchschnitt, da Lehrkräfte in Spanien im Primarbereich durchschnittlich 5 (Zeit-)Stunden pro Tag unterrichten, während der OECD-Durchschnitt bei 4,3 (Zeit-)Stunden liegt. Im Gegensatz dazu ist in Korea die Zahl der Unterrichtstage der Lehrkräfte im Primarbereich sehr hoch, im Durchschnitt mehr als 5 Tage pro Woche, allerdings beläuft sich die durchschnittliche Unterrichtszeit pro Tag nur auf 3,7 (Zeit-)Stunden.

Lehrkräfte im Sekundarbereich I unterrichten im Durchschnitt 709 (Zeit-)Stunden pro Jahr. In den OECD-Ländern, die zur Europäischen Union gehören, müssen Lehrkräfte 
im Durchschnitt 665 (Zeit-)Stunden pro Jahr unterrichten - fast 45 (Zeit-)Stunden weniger als der Durchschnitt aller OECD-Länder. Im Sekundarbereich I liegt die zu unterrichtende Zeit zwischen weniger als 600 (Zeit-)Stunden in Finnland, Griechenland, Indonesien, Polen und der Russischen Föderation und mehr als I.00o (Zeit-) Stunden in Argentinien, Chile, Mexiko und den Vereinigten Staaten.

Im Durchschnitt ist eine Lehrkraft im Sekundarbereich II (allgemeinbildend) verpflichtet, 664 (Zeit-)Stunden pro Jahr zu unterrichten. Nur in sechs Ländern übersteigt die zu unterrichtende Zeit 800 (Zeit-)Stunden: in Argentinien, Australien, Chile, Mexiko, Schottland und den Vereinigten Staaten. In Dänemark, Griechenland und der Russischen Föderation dagegen sind die Lehrkräfte nur zu weniger als 500 (Zeit-)Stunden Unterricht im Jahr verpflichtet. Lehrkräfte in Dänemark, Finnland, Griechenland, Israel, Japan, Korea, Norwegen und der Russischen Föderation unterrichten im Durchschnitt pro Tag höchstens 3 (Zeit-)Stunden, während es in Chile und den Vereinigten Staaten mehr als 5 (Zeit-)Stunden pro Tag und in Argentinien bis zu 8 (Zeit-)Stunden pro Tag sind. Diese Unterschiede könnten teilweise darauf zurückzuführen sein, dass einige Länder Pausen zwischen den Unterrichtseinheiten zur Unterrichtszeit zählen, andere aber nicht (Tab. D4.I und Abb. D4.2).

\section{Unterschiede in der Zahl der zu unterrichtenden (Zeit-)Stunden zwischen den einzelnen Bildungsbereichen}

In den meisten Ländern müssen Lehrkräfte im Sekundarbereich II weniger (Zeit-)Stunden unterrichten als im Elementarbereich. Ausnahmen sind Chile und Schottland, wo Lehrkräfte unabhängig vom Bildungsbereich dieselbe Anzahl (Zeit-)Stunden unterrichten müssen, sowie Argentinien, England, Indonesien und Mexiko, wo Lehrkräfte im Sekundarbereich II mehr (Zeit-)Stunden unterrichten müssen als Lehrkräfte im Elementarbereich (Tab. D4.I und Abb. D4.2).

Der größte Unterschied in der Zahl der zu unterrichtenden (Zeit-)Stunden besteht zwischen dem Elementar- und Primarbereich. In den OECD-Ländern müssen Lehrkräfte im Elementarbereich durchschnittlich 30 Prozent mehr Zeit im Klassenzimmer verbringen als Lehrkräfte im Primarbereich. In Estland, Island und Norwegen ist die Zahl der jährlich zu unterrichtenden (Zeit-)Stunden für Lehrkräfte im Elementarbereich mindestens doppelt so hoch wie für Lehrkräfte im Primarbereich. Auch wenn sich die Pflichten der Lehrkräfte in diesen beiden Bildungsbereichen wahrscheinlich voneinander unterscheiden, so können sich beträchtliche Unterschiede in den Arbeitsbedingungen zwischen dem Elementarbereich und den anderen Bildungsbereichen auf die Attraktivität des Lehrerberufs im Elementarbereich auswirken.

In Frankreich, Griechenland, Israel, Korea und Tschechien ist die Zahl der jährlich zu unterrichtenden (Zeit-)Stunden für Lehrkräfte im Primarbereich um mindestens 30 Prozent höher als im Sekundarbereich I. Im Gegensatz dazu beträgt der Unterschied in den Vereinigten Staaten höchstens 3 Prozent, und in Chile, Dänemark, Estland, Island, Schottland, Slowenien und Ungarn besteht überhaupt kein Unterschied. Argentinien, England und Mexiko sind die einzigen Länder, in denen Lehrkräfte im Primarbereich weniger (Zeit-)Stunden unterrichten müssen als Lehrkräfte im Sekundarbereich I. 
Von Lehrkräften pro Jahr zu unterrichtende (Zeit-)Stunden, nach Bildungsbereich (2011)

Gesetzliche bzw. vertraglich vereinbarte Nettokontaktzeitstunden an öffentlichen Bildungseinrichtungen

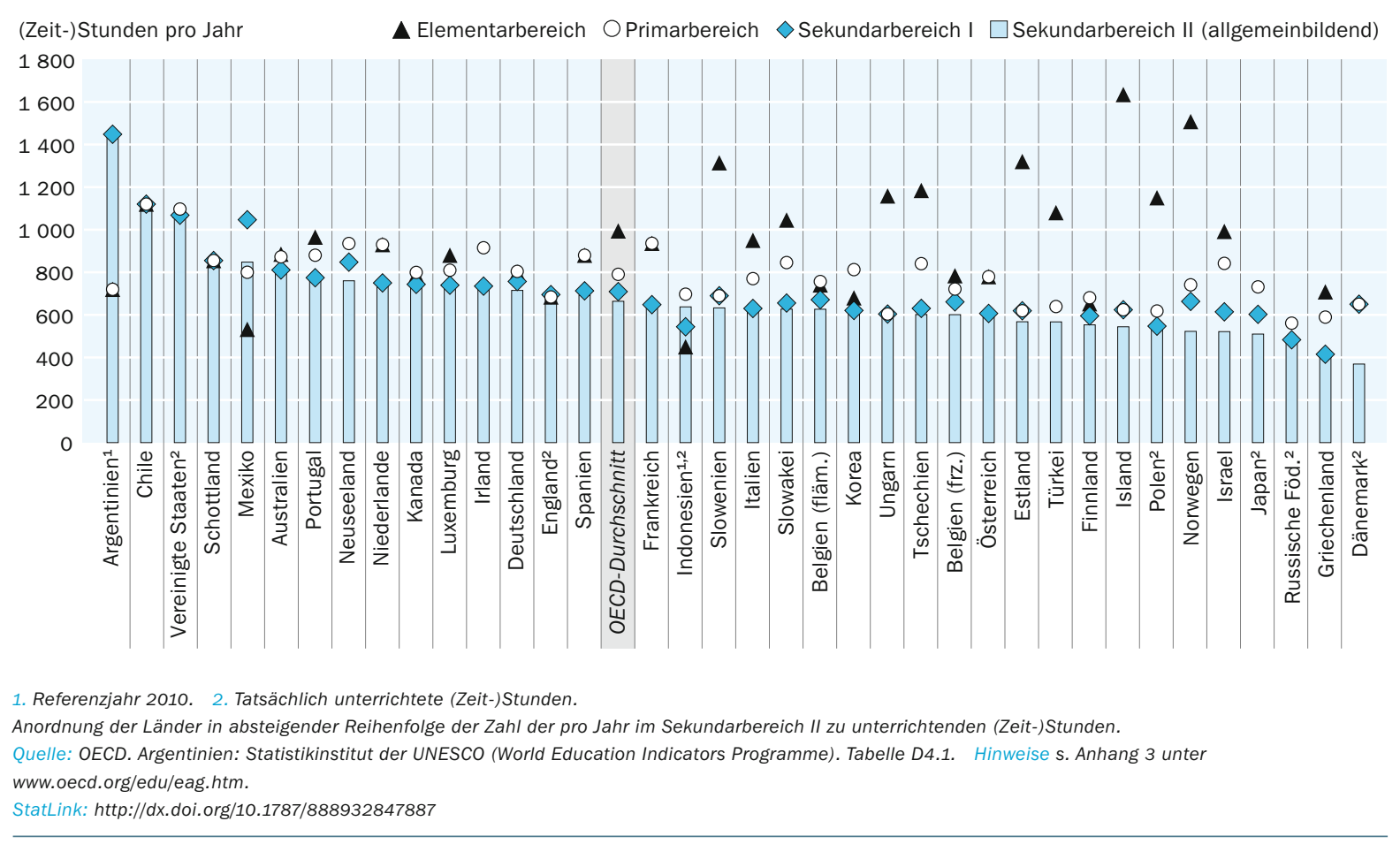

In den meisten Ländern gibt es nur geringe Unterschiede zwischen den im Sekundarbereich I und II zu unterrichtenden (Zeit-)Stunden. Jedoch ist in Mexiko und Norwegen die Zahl der jährlich zu unterrichtenden (Zeit-)Stunden im Sekundarbereich I mindestens 20 Prozent höher als im Sekundarbereich II, in Dänemark sind es sogar mehr als 75 Prozent.

\section{Entwicklung der von Lehrkräften zu unterrichtenden (Zeit-)Stunden}

In fast der Hälfte der Länder mit verfügbaren Daten hat die Zahl der zu unterrichtenden (Zeit-)Stunden zwischen 2000 und $201 \mathrm{I}$ in einem oder mehreren Bildungsbereichen um mindestens Io Prozent variiert. In den meisten Ländern, in denen es zu einer deutlichen Veränderung kam, stieg die Zahl der zu unterrichtenden (Zeit-)Stunden in diesem Zeitraum (Tab. D4.2 und Abb. D4.I).

In Israel und Japan belief sich diese Steigerung im Primarbereich zwischen 2000 und 2011 auf 15 Prozent. In Israel war diese Steigerung der Unterrichts- und Arbeitszeit einer der angestrebten Effekte der Schulreform „Neue Horizonte“, die seit 2008 schrittweise umgesetzt wird. Eine der Hauptmaßnahmen dieser Reform bestand darin, die Arbeitswoche der Lehrkräfte (bei großzügigerer Vergütung) zu verlängern, um Unterricht in Kleingruppen zu ermöglichen. Die Arbeitszeit der Lehrer wurde von 30 auf 36 (Zeit-)Stunden pro Woche erhöht und beinhaltet nun in Schulen des Primarbereichs fünf Stunden Unterricht in Kleingruppen. Im Gegenzug stiegen die Gehälter beträchtlich (s. Indikator $\mathrm{D}_{3}$ ). 
Lehrkräfte an Schulen des Sekundarbereichs in Portugal und Spanien mussten 20 II mehr als 25 Prozent mehr (Zeit-)Stunden unterrichten als im Jahr 2000 (und im Sekundarbereich II in Portugal bis zu 50 Prozent mehr). In Luxemburg mussten 20II Lehrkräfte im Sekundarbereich I5 Prozent mehr (Zeit-)Stunden unterrichten als im Jahr 2005. Die von Lehrkräften zu unterrichtenden (Zeit-)Stunden stiegen auch in Island und Korea im Sekundarbereich II um rund I5 Prozent.

Im Gegensatz dazu sank die Netto-Unterrichtszeit zwischen 2000 und $201 \mathrm{I}$ in Mexiko (Sekundarbereich I), den Niederlanden (Sekundarbereich I und II) und in Schottland (Primarbereich) um rund Io Prozent. In Schottland war die Reduzierung Teil der Vereinbarung mit den Lehrkräften „Der Lehrerberuf im 2I. Jahrhundert“, durch die $200 \mathrm{I}$ eine 35-Stunden-Arbeitswoche für alle Lehrkräfte eingeführt wurde sowie für Lehrkräfte im Primar-, Sekundar- und Sonderschulbereich eine schrittweise Reduzierung der maximalen Unterrichtszeit auf 22,5 (Zeit-)Stunden pro Woche. Selbst nach dieser Reduzierung der Nettokontaktzeit müssen Lehrkräfte dieser Bildungsbereiche in Schottland jedoch immer noch mehr (Zeit-)Stunden unterrichten als im Durchschnitt der OECD-Länder.

\section{Arbeitszeit der Lehrkräfte}

In den meisten Ländern müssen die Lehrkräfte auf Grundlage offizieller Regelungen eine bestimmte Zahl an (Zeit-)Stunden pro Woche arbeiten (unterrichtende und nicht unterrichtende Tätigkeiten), um ein Vollzeitgehalt zu erhalten. Einige Länder legen aber auch fest, wie viel Zeit die Lehrkräfte in der Schule verbringen müssen. Innerhalb dieses Rahmens gibt es jedoch zwischen den einzelnen Ländern Unterschiede hinsichtlich der weiteren Bestimmungen, wie viel Zeit unterrichtend und wie viel Zeit mit anderen Aktivitäten zu verbringen ist (Abb. D4.3).

In Australien, Belgien (fläm., Elementar- und Primarbereich), Chile, England, Estland, Finnland, Frankreich (Elementar- und Primarbereich), Griechenland, Indonesien, Irland (Primar- und Sekundarbereich), Island, Israel, Kanada, Luxemburg, Mexiko, Neuseeland (Primar- und Sekundarbereich), Norwegen, Portugal, Schweden, Spanien, der Türkei und den Vereinigten Staaten wird die Zeit festgelegt, die die Lehrkräfte in der Schule sowohl für Unterricht als auch für nicht unmittelbar unterrichtsbezogene Aktivitäten zur Verfügung stehen müssen. In rund zwei Drittel dieser Länder unterscheidet sich die Zeit, die Lehrkräfte im Sekundarbereich II und im Elementarbereich in der Schule zur Verfügung stehen müssen, um weniger als ıo Prozent (Tab. D4.I).

In Deutschland, Frankreich (Sekundarbereich I und II), Japan, Korea, den Niederlanden (Primar- und Sekundarbereich I und II), Österreich (Elementar-, Primar- und Sekundarbereich I), Schottland, Tschechien und Ungarn ist die Jahresarbeitszeit der Lehrkräfte, die sie in der Schule oder an einem anderen Ort zu erbringen haben, festgelegt, aber es gibt keine festgelegte Aufteilung zwischen der Zeit, die einerseits an der Schule zu verbringen ist und andererseits außerhalb der Schule zu erbringen ist.

In Schweden wird zwar die Gesamtarbeitszeit pro Jahr in Tarifverträgen festgelegt, die Zahl der Wochenarbeitsstunden und die Aufteilung der Arbeitszeit der Lehrkräfte (in Unterricht und nicht unterrichtende Tätigkeiten) wird jedoch - in Abstimmung mit den örtlichen Lehrerverbänden - von der Schulleitung festgelegt. 
Außerdem können sich die Arbeitszeiten und Unterrichtsverpflichtungen von Lehrkräften im Verlauf ihres Berufslebens ändern. Während manche Lehrkräfte am Anfang ihrer Berufstätigkeit als Teil ihrer Einführungsphase möglicherweise weniger Lehrverpflichtungen haben, ermutigen manche Länder auch ältere Lehrkräfte dazu, im Lehrerberuf zu bleiben, indem sie ihre Pflichten breiter fächern und die Unterrichtszeit verkürzen. In Griechenland beispielsweise reduziert sich die Zahl der zu unterrichtenden (Zeit-)Stunden in Abhängigkeit von der Zahl der Dienstjahre einer Lehrkraft. Im Sekundarbereich müssen Lehrkräfte 2I Unterrichtseinheiten pro Woche unterrichten. Nach 6 Jahren sinken die Unterrichtsverpflichtungen auf ig Unterrichtseinheiten pro Woche und nach I2 Jahren auf I 8 Unterrichtseinheiten. Nach 20 Dienstjahren müssen Lehrkräfte 16 Unterrichtseinheiten pro Woche unterrichten, d.h. mehr als 25 Prozent weniger als Lehrkräfte, die am Beginn ihrer Laufbahn stehen. Die verbleibenden Stunden der Pflichtarbeitszeit müssen die Lehrkräfte jedoch in der Schule anwesend sein.

\section{Zeit außerhalb des Unterrichts}

Obwohl die Unterrichtszeit einen erheblichen Anteil der Arbeitsbelastung der Lehrkräfte ausmacht, sollte bei der Untersuchung der Anforderungen an die Lehrkräfte in unterschiedlichen Ländern auch die für die Schülerbenotung, die Unterrichtsvorbereitung, die Korrekturarbeit, Fortbildungen und Lehrerkonferenzen benötigte Zeit berücksichtigt werden. Die für diese Aufgaben außerhalb des Unterrichts zur Verfügung stehende Zeit ist von Land zu Land verschieden, und wenn die Unterrichtsverpflichtungen einen großen Teil der gesetzlichen bzw. vertraglich vereinbarten Arbeitszeit ausmachen, kann dies darauf hindeuten, dass weniger (Arbeits-)Zeit für Aufgaben wie Schülerbeurteilungen und Unterrichtsvorbereitung aufgewendet wird.

In den 22 Ländern, in denen sowohl die Anzahl der zu unterrichtenden (Zeit-)Stunden als auch die Gesamtarbeitszeit vorgegeben wird, variiert der Anteil der Arbeitszeit, die Lehrkräfte im Unterricht verbringen, von weniger als 40 Prozent in Dänemark, Island, Japan, der Türkei und Ungarn im Primar- und Sekundarbereich I und II bis zu 65 Prozent in Indonesien (Primarbereich). In I3 Ländern ist der Anteil der mit Aufgaben außerhalb des Unterrichts verbrachten Arbeitszeit im Sekundarbereich höher als im Primarbereich (Tab. D4.I und Abb. D4.3).

In den 20 Ländern, die sowohl die zu unterrichtenden (Zeit-)Stunden als auch die Zahl an Stunden festlegen, die Lehrkräfte im Primar-, Sekundarbereich I oder II in der Schule anwesend sein müssen, reicht der Prozentsatz der Arbeitszeit, die Lehrkräfte im Unterricht verbringen, von weniger als 40 Prozent in Estland (Sekundarbereich II), Griechenland (Sekundarbereich) und Island (Primar- und Sekundarbereich) bis zu Ioo Prozent in Mexiko (Primarbereich). In 9 Ländern ist der Anteil der mit Aufgaben außerhalb des Unterrichts verbrachten Arbeitszeit im Sekundarbereich höher als im Primarbereich.

In Belgien (fläm., Sekundarbereich), Belgien (frz.), Italien, den Niederlanden (Elementarbereich), Österreich (Sekundarbereich II), der Russischen Föderation und Slowenien ist nicht offiziell festgelegt, wie viel Zeit für Aktivitäten außerhalb des Unterrichts aufgewendet werden muss. Dies bedeutet allerdings nicht, dass die Lehrkräfte in der Gestaltung anderer Aufgaben völlig frei sind. In Belgien (fläm.) gibt es zwar keine Vorschriften hinsichtlich der für Unterrichtsvorbereitung, Korrektur von Klassenarbeiten, 
Abbildung D4.3

Auf das Unterrichten entfallende Arbeitszeit der Lehrkräfte (in \%), nach Bildungsbereich (2011)

Netto-Unterrichtszeit als Prozentsatz der gesetzlichen bzw. vertraglich vereinbarten Arbeitszeit und der Arbeitszeit, für die Anwesenheits-

pflicht an der Schule besteht

Anteil der Gesamtarbeitszeit, der auf das Unterrichten entfällt $\square$ Anteil der Arbeitszeit in der Schule, der auf das Unterrichten entfällt
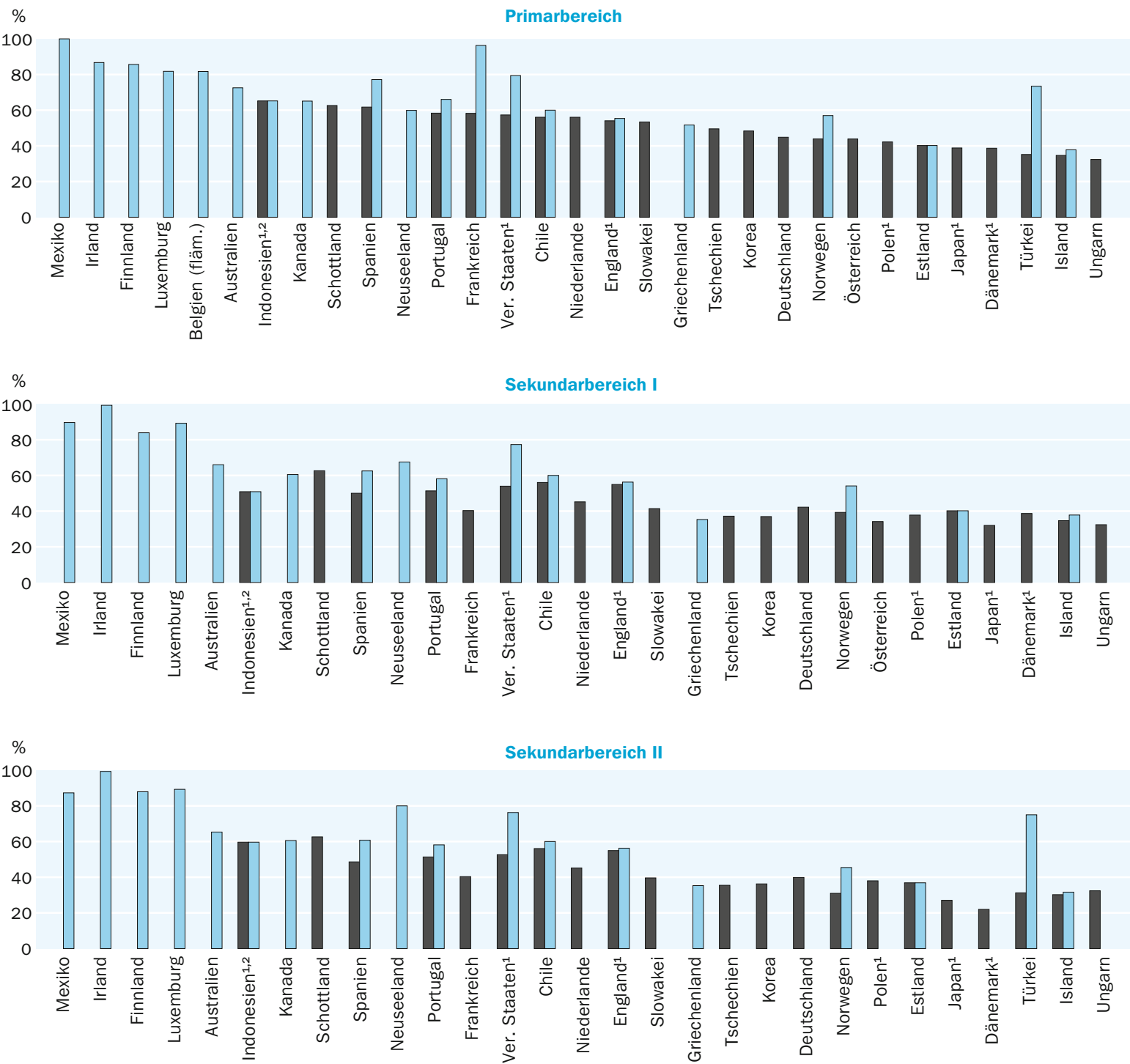

1. Tatsächlich unterrichtete (Zeit-)Stunden. 2. Referenzjahr 2010.

Anordnung der Länder in absteigender Reihenfolge des Anteils der auf das Unterrichten entfallenden Arbeitszeit von Lehrkräften im Primarbereich (in \%).

Quelle: OECD. Tabelle D4.1. Hinweise s. Anhang 3 unter www.oecd.org/edu/eag.htm. StatLink: http://dx.doi.org/10.1787/888932847906

Benotung von Hausaufgaben usw. aufzuwendenden Zeit, es werden jedoch zusätzliche Stunden in der Schule für Aufgaben außerhalb des Unterrichts auf Schulebene festgelegt. In Italien sind bis zu 8o Stunden nicht unterrichtender Tätigkeit in der Schule pro Jahr verpflichtend festgelegt. Von diesen 80 Stunden entfallen bis zu 40 Stunden Pflichtarbeitszeit pro Jahr auf Gesamtlehrerkonferenzen, Planungstage und Besprechungen mit Eltern, die verbleibenden 40 Stunden auf Klassenkonferenzen. 


\section{Definitionen}

Die Zahl der Unterrichtstage wird berechnet als Zahl der Unterrichtswochen multipliziert mit der Anzahl Tage, die eine Lehrkraft pro Woche unterrichtet, abzüglich der Tage, an denen die Schule wegen Ferien geschlossen ist.

Die Zahl der Unterrichtswochen bezieht sich auf die Zahl der Wochen mit Unterricht ohne die Ferienzeiten.

Die Unterrichtszeit bzw. die Zahl der von Lehrkräften zu unterrichtenden (Zeit-)Stunden wird definiert als die Zahl an geplanten (Zeit-)Stunden pro Jahr, die eine Vollzeitlehrkraft auf der Grundlage der offiziellen Vorschriften mit dem Unterrichten einer Gruppe oder Klasse verbringt. Sie wird normalerweise berechnet aus der Zahl der Unterrichtstage pro Jahr multipliziert mit der Anzahl (Zeit-)Stunden, die eine Lehrkraft pro Tag unterrichtet (ohne Zeiten, die offiziell als Pausen zwischen einzelnen Unterrichtseinheiten oder Blöcken von Unterrichtseinheiten vorgesehen sind). Einige Länder melden Schätzwerte für die Unterrichtszeit, die auf Erhebungsdaten basieren. Im Primarbereich sind kurze Pausen zwischen den einzelnen Unterrichtseinheiten, während derer die Lehrkraft für die Klasse verantwortlich ist, enthalten.

Die Arbeitszeit bezieht sich auf die Zahl der gemäß offiziellen Vorschriften von einer Vollzeitlehrkraft zu arbeitenden (Zeit-)Stunden. Nicht enthalten sind vergütete Überstunden. Entsprechend den offiziellen Vorschriften in einem bestimmten Land kann sich die Arbeitszeit beziehen auf:

- direkt für den Unterricht aufgewendete Zeit und andere lehrplanbezogene Tätigkeiten für die Schüler, wie Haus- und Klassenarbeiten, und

Zeit, die in direktem Zusammenhang mit dem Unterricht steht, sowie Stunden, die anderen unterrichtsbezogenen Tätigkeiten gewidmet sind, z. B. Unterrichtsvorbereitung, Beratung der Schüler, Korrekturen von Haus- und Klassenarbeiten, Tätigkeiten zur beruflichen Weiterentwicklung, Besprechungen mit den Eltern, Lehrerkonferenzen und allgemeine schulische Aufgaben.

Die Arbeitszeit in der Schule bezieht sich auf die Arbeitszeit, die Lehrkräfte in der Schule arbeiten müssen, und enthält sowohl die Unterrichtszeit als auch Zeit für Tätigkeiten außerhalb des Unterrichts.

\section{Angewandte Methodik}

Die Daten stammen aus der OECD/INES-Erhebung 2012 zu Lehrkräften und Lehrplänen und beziehen sich auf das Schuljahr 2010/20II.

Bei der Interpretation der Unterschiede bei der Zahl der zu unterrichtenden (Zeit-) Stunden zwischen den einzelnen Ländern sollte man jedoch berücksichtigen, dass die Nettokontaktzeit, wie sie diesem Indikator zugrunde liegt, nicht unbedingt den Unterrichtsverpflichtungen entspricht. Die Kontaktzeit selbst repräsentiert zwar einen beträchtlichen Bestandteil der Unterrichtsverpflichtungen, aber bei einem Vergleich müssen auch die Vorbereitung der Stunden sowie die erforderliche Nachbereitung 
(einschließlich der Korrektur der Schülerarbeiten) berücksichtigt werden. Andere wichtige Elemente, wie z. B. die Zahl der unterrichteten Fächer, die Zahl der zu unterrichtenden Schüler und wie viele Jahre eine einzelne Lehrkraft dieselben Schüler unterrichtet, sollten ebenfalls berücksichtigt werden.

Hinweise zu den für jedes Land verwendeten Definitionen und angewandten Methodiken s. Anhang 3 unter www.oecd.orgleduleag.htm.

Die statistischen Daten für Israel wurden von den zuständigen israelischen Stellen bereitgestellt, die für sie verantwortlich zeichnen. Die Verwendung dieser Daten durch die OECD erfolgt unbeschadet des völkerrechtlichen Status der Golanhöhen, von OstJerusalem und der israelischen Siedlungen im Westjordanland.

\section{Tabellen Indikator D4}

Tabelle D4.I: Aufteilung der Arbeitszeit von Lehrkräften (20II)

StatLink: http:/|dx.doi.org/10.1787/888932851953

Tabelle D4.2: Zahl der zu unterrichtenden (Zeit-)Stunden pro Jahr (2000 und 2005-20II)

StatLink: http:/|dx.doi.org/10.1787/888932851972 
Aufteilung der Arbeitszeit von Lehrkräften (2011)

Zahl der Unterrichtswochen, Unterrichtstage, Netto-Unterrichtszeitstunden und Gesamtarbeitszeit von Lehrkräften an öffentlichen Bildungseinrichtungen im Verlauf des Schuljahrs

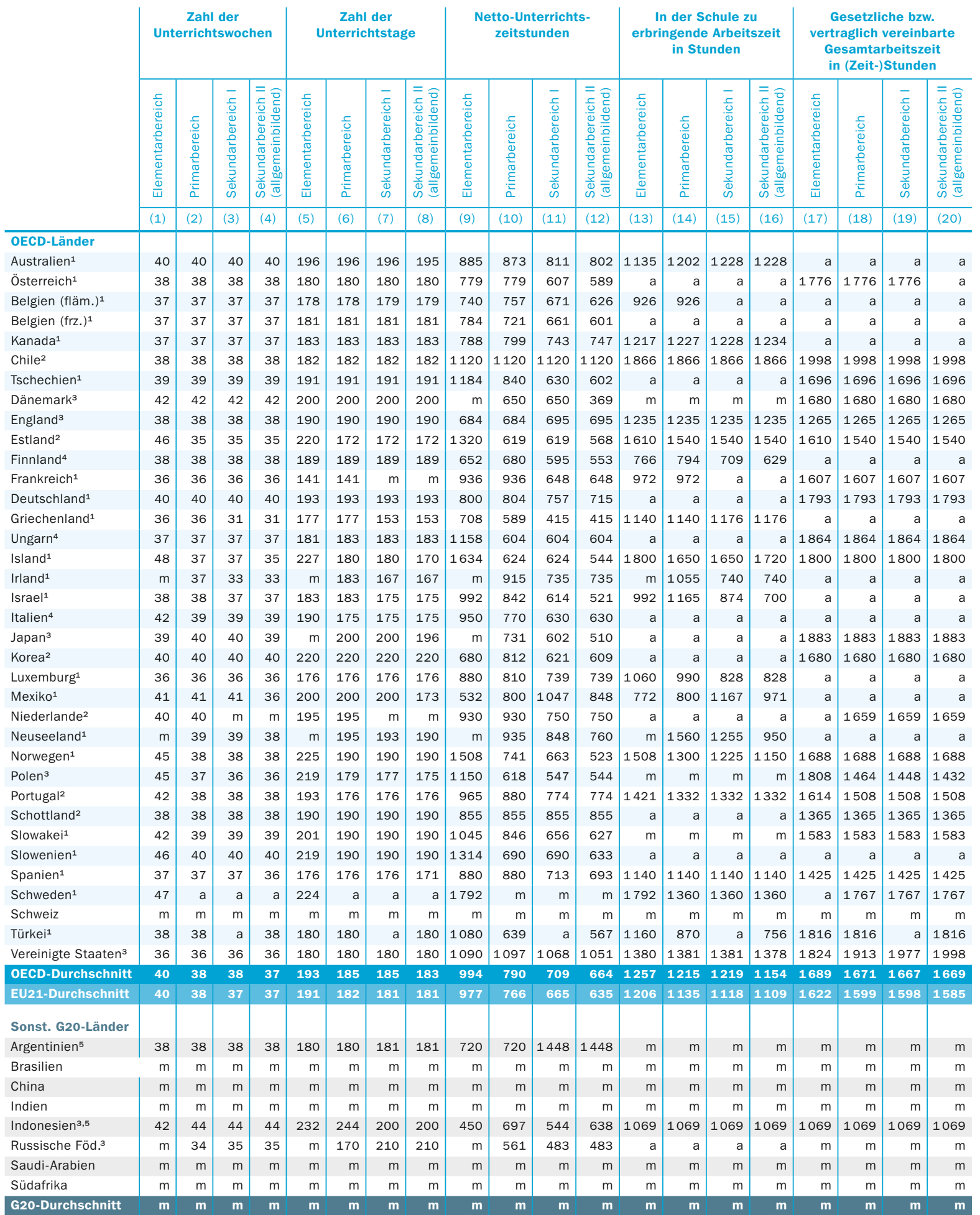

1. In der Regel zu unterrichtende (Zeit-)Stunden. 2. Höchstens zu unterrichtende (Zeit-)Stunden 3. Tatsächlich zu unterrichtende (Zeit-)Stunden.

4. Mindestens zu unterrichtende (Zeit-)Stunden. 5. Referenzjahr 2010.

Quelle: OECD. Argentinien: Statistikinstitut der UNESCO (World Education Indicators Programme). Hinweise s. Anhang 3 unter www.oecd.org/edu/eag.htm.

StatLink: http://dx.doi.org/10.1787/888932851953

Erläuterung der Kennzeichnung fehlender Daten s. Hinweise für den Leser. 
Tabelle D4.2

Zahl der zu unterrichtenden (Zeit-)Stunden pro Jahr (2000 und 2005-2011)

Gesetzliche bzw. vertraglich vereinbarte Netto-Kontaktzeitstunden pro Jahr an öffentlichen Bildungseinrichtungen, nach Bildungsbereich

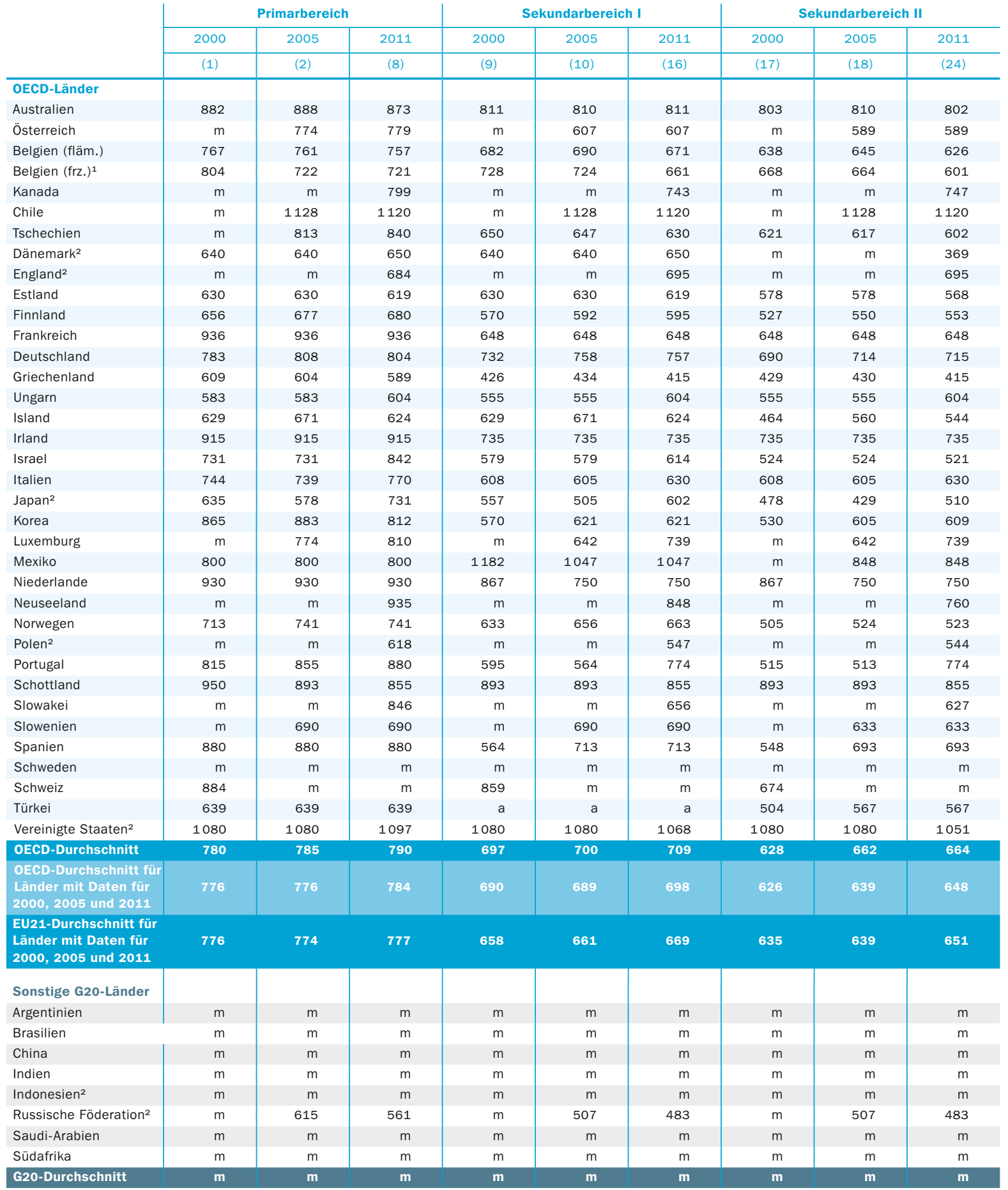

Anmerkung: Die Angaben für die Jahre 2006, 2007, 2008, 2009 und 2010 sind im Internet verfügbar (s. StatLink unten).

1. Unterbrechung der Zeitreihe in 2006 aufgrund von Veränderungen in der Methodik. 2. Tatsächlich zu unterrichtende (Zeit-)Stunden.

Quelle: OECD. Argentinien: Statistikinstitut der UNESCO (World Education Indicators Programm). Hinweise s. Anhang 3 unter www.oecd.org/edu/eag.htm.

StatLink: http://dx.doi.org/10.1787/888932851972

Erläuterung der Kennzeichnung fehlender Daten s. Hinweise für den Leser. 


\section{WEB Indikator D5}

steht im Internet zur Verfügung unter StatLink: http://dx.doi..org/10.1787/888932851991

\section{Wie ist das demografische und das Qualifikationsprofil der Lehrerschaft?}

$201 \mathrm{I}$ waren in I9 von 3I OECD- und sonstigen G20-Ländern mindestens 6o Prozent der Lehrkräfte im Sekundarbereich mindestens 40 Jahre alt. In Deutschland, Estland, Italien, Österreich und Tschechien gehören mindestens 70 Prozent dieser Altersgruppe an.

Im Durchschnitt der OECD-Länder sind zwei Drittel der Lehrkräfte und sonstigen Beschäftigten an Schulen und Einrichtungen des Tertiärbereichs weiblich, der Anteil der Frauen sinkt jedoch mit jedem höheren Bildungsbereich: von 97 Prozent im Elementarbereich über 82 Prozent im Primarbereich, 68 Prozent im Sekundarbereich I, 56 Prozent im Sekundarbereich II bis auf 4I Prozent im Tertiärbereich.

In I3 OECD-Ländern müssen Lehrkräfte in einigen oder sämtlichen Bildungsbereichen zur Fortsetzung ihres Beschäftigungsverhältnisses an Fort- und Weiterbildungen teilnehmen.

Abbildung D5.1

Altersaufbau der Lehrerschaft im Sekundarbereich (2011)

Alter der Lehrkräfte an Bildungseinrichtungen, nach Altersgruppe

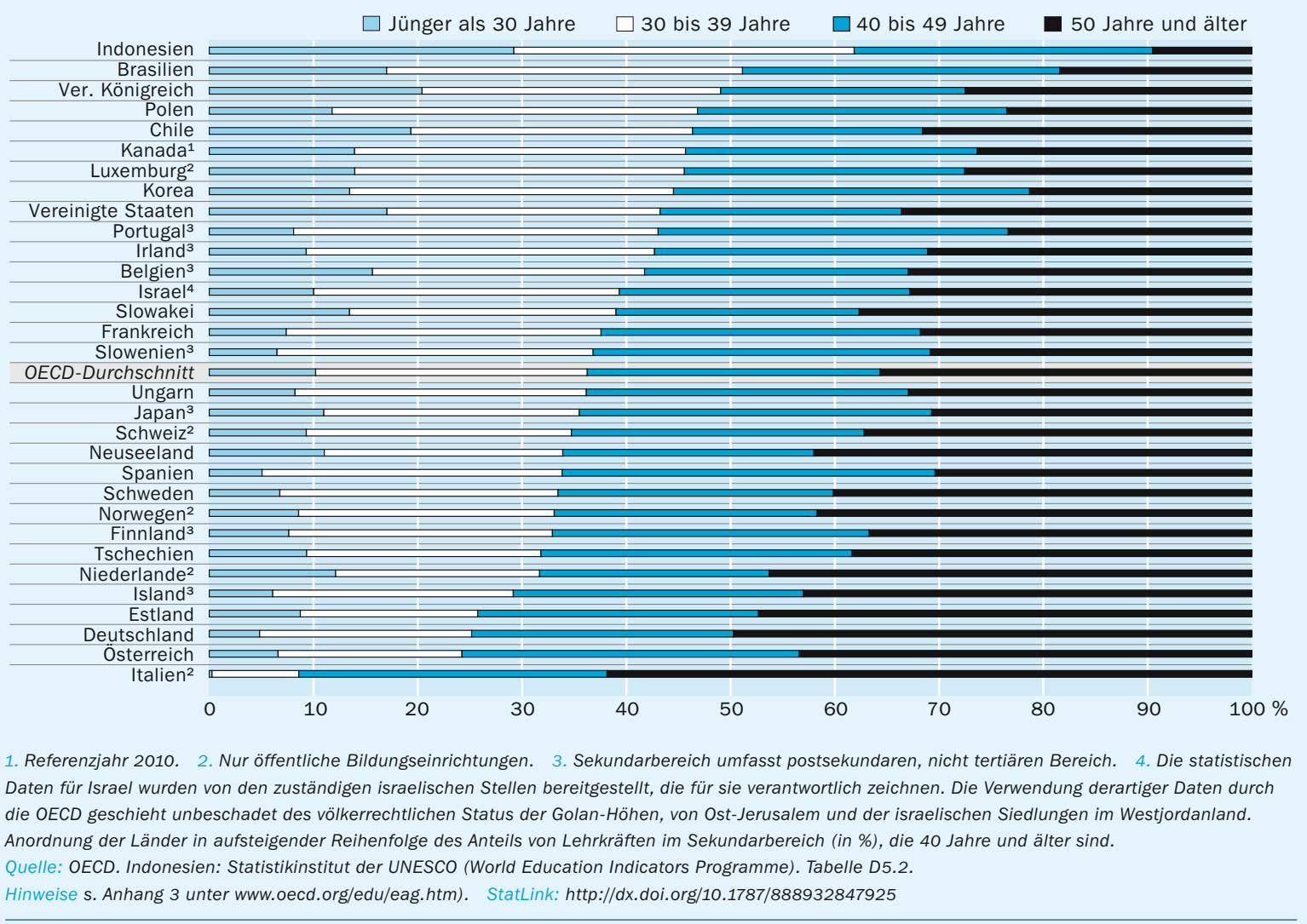




\section{Indikator D5 Abbildungen}

WEB Chart D5.I: Age distribution of teachers in secondary education (Altersaufbau der Lehrerschaft im Sekundarbereich) (20II)

StatLink: http://dx.doi.org/10.1787/888932847925

WEB Chart D5.2: Gender distribution of teachers (Geschlechtsspezifische Zusammensetzung der Lehrerschaft)(20II)

StatLink: http://dx.doi.org/10.1787/888932847944

WEB Chart D5: Age distribution of teachers in primary education (Altersaufbau der Lehrerschaft im Primarbereich) (20II)

StatLink: http://dx.doi.org/10.1787/888932847963

\section{Indikator D5 Tabellen}

WEB Table D5.I: Age distribution of teachers (Altersaufbau der Lehrerschaft) (20II)

StatLink: http://dx.doi.org/10.1787/888932852010

WEB Table D5.2: Age distribution of teachers (Altersaufbau der Lehrerschaft) (20II, I998)

StatLink: http:|/dx.doi.org/10.1787/888932852029

WEB Table D5.3: Gender distribution of teachers (Geschlechtsspezifische Zusammensetzung der Lehrerschaft) (20II)

StatLink: http://dx.doi.org/10.1787/888932852048 
Merkmale der Bildungssysteme 
Tabelle X1.1a

Abschlussquoten im Sekundarbereich II: Typisches Abschlussalter und Art der Abschlussquote

(Brutto- bzw. Nettoabschlussquote) (2011)

Das typische Abschlussalter bezieht sich auf das Alter der Schüler zu Beginn des Schuljahres; die Schüler werden im Allgemeinen ein Jahr älter sein, wenn der Abschluss gegen Ende des Schuljahres erfolgt. Bei der Berechnung der Bruttoabschlussquoten wird das typische

Abschlussalter verwendet.

\begin{tabular}{|c|c|c|c|c|c|c|c|}
\hline & \multicolumn{7}{|c|}{ Typisches Abschlussalter } \\
\hline & \multirow[t]{2}{*}{ Erstabschluss } & \multicolumn{2}{|c|}{ Ausrichtung des Bildungsgangs } & \multicolumn{4}{|c|}{ Weitere Ausbildung/Arbeitsmarkteintritt } \\
\hline & & Allgemeinbildend & $\begin{array}{l}\text { Berufs- } \\
\text { vorbereitend/ } \\
\text { Berufsbildend }\end{array}$ & ISCED $3 A$ & ISCED 3B & ISCED 3 C (kurz) ${ }^{1}$ & ISCED $3 c$ (lang) $^{1}$ \\
\hline \multicolumn{8}{|l|}{ OECD-Länder } \\
\hline Australien & 17 & 17 & 17 & 17 & a & a & 17 \\
\hline Österreich & $17-18$ & $17-18$ & $17-19$ & $17-18$ & $17-19$ & $14-15$ & $16-17$ \\
\hline Belgien & 18 & 18 & 18 & 18 & a & 18 & 18 \\
\hline Kanada & $17-18$ & $17-18$ & $17-18$ & $17-18$ & a & a & $17-18$ \\
\hline Chile & 17 & 17 & 17 & 17 & a & a & a \\
\hline Tschechien & $18-20$ & $19-20$ & $18-20$ & $19-20$ & $19-20$ & a & $18-19$ \\
\hline Dänemark & $18-19$ & $18-19$ & $20-21$ & $18-19$ & a & 27 & $20-21$ \\
\hline Estland & 19 & 19 & 19 & 19 & $18-19$ & a & 19 \\
\hline Finnland & 19 & 19 & 19 & 19 & a & a & a \\
\hline Frankreich & $17-19$ & $17-18$ & $16-19$ & $17-18$ & $18-20$ & $16-18$ & $18-20$ \\
\hline Deutschland & $19-20$ & $19-20$ & $19-20$ & $19-20$ & $19-20$ & $19-20$ & a \\
\hline Griechenland & $\mathrm{m}$ & $\mathrm{m}$ & $\mathrm{m}$ & $\mathrm{m}$ & a & $\mathrm{m}$ & $\mathrm{m}$ \\
\hline Ungarn & 18 & 18 & $18-19$ & 18 & a & 18 & $18-19$ \\
\hline Island & $\mathrm{m}$ & $\mathrm{m}$ & $\mathrm{m}$ & $\mathrm{m}$ & $\mathrm{m}$ & $\mathrm{m}$ & $\mathrm{m}$ \\
\hline Irland & $18-19$ & 18 & 19 & 18 & a & 19 & 18 \\
\hline Israel & 17 & 17 & 17 & 17 & a & a & 17 \\
\hline Italien & 18 & 18 & 18 & 18 & 18 & 17 & a \\
\hline Japan & 17 & 17 & 17 & 17 & 17 & 15 & 17 \\
\hline Korea & 18 & 18 & 18 & 18 & a & a & 18 \\
\hline Luxemburg & $17-20$ & $17-18$ & $17-20$ & $17-19$ & $18-20$ & $16-18$ & $17-19$ \\
\hline Mexiko & $17-18$ & $17-18$ & $17-18$ & $17-18$ & a & a & $17-18$ \\
\hline Niederlande & $17-19$ & 17 & 19 & 17 & a & a & 18 \\
\hline Neuseeland & $17-18$ & $17-18$ & $17-18$ & 18 & 17 & 17 & 17 \\
\hline Norwegen & $18-20$ & 18 & $19-20$ & 18 & a & $\mathrm{m}$ & $19-20$ \\
\hline Polen & $18-19$ & 19 & 20 & 19 & a & a & 19 \\
\hline Portugal & 17 & 17 & 18 & $\mathrm{~m}$ & $\mathrm{~m}$ & $\mathrm{~m}$ & $\mathrm{~m}$ \\
\hline Slowakei & $18-19$ & 18 & $18-19$ & $18-19$ & a & 17 & $17-18$ \\
\hline Slowenien & 18 & 18 & $16-18$ & 18 & 18 & 16 & 17 \\
\hline Spanien & 17 & 17 & 17 & 17 & 17 & 17 & 17 \\
\hline Schweden & 18 & 18 & 18 & 18 & 18 & 18 & 18 \\
\hline Schweiz & $18-20$ & $18-20$ & $18-20$ & $18-20$ & $18-20$ & $17-19$ & $18-20$ \\
\hline Türkei & 17 & 17 & 17 & 17 & a & $\mathrm{m}$ & a \\
\hline Vereinigtes Königreich & 16 & 16 & 16 & 18 & 18 & 16 & 16 \\
\hline $\begin{array}{l}\text { Vereinigte Staaten } \\
\text { Sonstige G20-Länder }\end{array}$ & 17 & 17 & $\mathrm{~m}$ & 17 & $\mathrm{~m}$ & $\mathrm{~m}$ & $\mathrm{~m}$ \\
\hline Argentinien & $\mathrm{m}$ & 17 & 17 & 17 & a & a & a \\
\hline Brasilien & $17-18$ & 17 & 18 & $17-18$ & $17-18$ & a & a \\
\hline China & 17 & 17 & 17 & 17 & $\mathrm{~m}$ & 17 & 17 \\
\hline Indien & $\mathrm{m}$ & $\mathrm{m}$ & $\mathrm{m}$ & $\mathrm{m}$ & $\mathrm{m}$ & $\mathrm{m}$ & $\mathrm{m}$ \\
\hline Indonesien & 17 & 17 & 17 & 17 & 17 & a & a \\
\hline Russische Föderation & 17 & 17 & 17 & 17 & 17 & 16 & 17 \\
\hline Saudi-Arabien & $\mathrm{m}$ & $\mathrm{m}$ & $\mathrm{m}$ & $\mathrm{m}$ & $\mathrm{m}$ & $\mathrm{m}$ & $\mathrm{m}$ \\
\hline Südafrika & $\mathrm{m}$ & $\mathrm{m}$ & $\mathrm{m}$ & $\mathrm{m}$ & $\mathrm{m}$ & $\mathrm{m}$ & $\mathrm{m}$ \\
\hline
\end{tabular}

1. Dauer ISCED 3C: kurz - mindestens 1 Jahr kürzer als ISCED-3A/3B-Bildungsgänge; lang - ähnlich lang wie ISCED-3A/3B-Bildungsgänge.

Quelle: OECD. Argentinien, China, Indonesien: Statistikinstitut der UNESCO (World Education Indicators Programme).

Hinweise s. Anhang 3 unter www.oecd.org/edu/eag.htm. StatLink: http://dx.doi.org/10.1787/888932852086

Erläuterung der Kennzeichnung fehlender Daten s. Hinweise für den Leser. 
Tabelle X1.1a (Forts.)

Abschlussquoten im Sekundarbereich II: Typisches Abschlussalter und Art der Abschlussquote (Brutto- bzw. Nettoabschlussquote) (2011)

\begin{tabular}{|c|c|c|c|c|c|c|c|}
\hline & \multicolumn{7}{|c|}{ Art der Abschlussquote: Brutto- bzw. Nettoabschlussquote } \\
\hline & \multirow{2}{*}{$\begin{array}{l}\text { Absolventen mit } \\
\text { Erstabschluss }\end{array}$} & \multicolumn{2}{|c|}{ Ausrichtung des Bildungsgangs } & \multicolumn{4}{|c|}{ Weitere Ausbildung/Arbeitsmarkteintritt } \\
\hline & & Allgemeinbildend & $\begin{array}{l}\text { Berufs- } \\
\text { vorbereitend/ } \\
\text { Berufsbildend }\end{array}$ & ISCED $3 \mathrm{~A}$ & ISCED 3B & ISCED 3 C (kurz) ${ }^{1}$ & ISCED 3c (lang) ${ }^{1}$ \\
\hline \multicolumn{8}{|l|}{ OECD-Länder } \\
\hline Australien & $\mathrm{m}$ & netto & netto & netto & a & a & netto \\
\hline Österreich & netto & netto & netto & netto & netto & netto & netto \\
\hline Belgien & $\mathrm{m}$ & netto & netto & netto & a & netto & netto \\
\hline Kanada & netto & netto & netto & netto & a & a & netto \\
\hline Chile & netto & netto & netto & netto & a & a & a \\
\hline Tschechien & netto & netto & netto & netto & brutto & a & netto \\
\hline Dänemark & netto & netto & netto & netto & a & netto & netto \\
\hline Estland & $\mathrm{m}$ & netto & netto & netto & netto & a & netto \\
\hline Finnland & netto & netto & netto & netto & a & a & a \\
\hline Frankreich & $\mathrm{m}$ & netto & netto & netto & netto & netto & netto \\
\hline Deutschland & brutto & brutto & brutto & brutto & brutto & brutto & a \\
\hline Griechenland & $\mathrm{m}$ & $\mathrm{m}$ & $\mathrm{m}$ & $\mathrm{m}$ & $\mathrm{m}$ & $\mathrm{m}$ & $\mathrm{m}$ \\
\hline Ungarn & netto & netto & netto & netto & a & $\mathrm{m}$ & netto \\
\hline Island & $\mathrm{m}$ & $\mathrm{m}$ & $\mathrm{m}$ & $\mathrm{m}$ & $\mathrm{m}$ & $\mathrm{m}$ & $\mathrm{m}$ \\
\hline Irland & netto & netto & netto & netto & a & netto & netto \\
\hline Israel & netto & netto & netto & netto & a & a & netto \\
\hline Italien & brutto & netto & brutto & netto & brutto & brutto & a \\
\hline Japan & brutto & brutto & brutto & brutto & brutto & $\mathrm{m}$ & brutto \\
\hline Korea & brutto & brutto & brutto & brutto & a & a & brutto \\
\hline Luxemburg & netto & netto & netto & netto & netto & netto & netto \\
\hline Mexiko & netto & netto & netto & netto & a & a & netto \\
\hline Niederlande & netto & netto & netto & netto & a & a & netto \\
\hline Neuseeland & $\mathrm{m}$ & $\mathrm{m}$ & $\mathrm{m}$ & $\mathrm{m}$ & $\mathrm{m}$ & $\mathrm{m}$ & $\mathrm{m}$ \\
\hline Norwegen & netto & netto & netto & netto & a & $\mathrm{m}$ & netto \\
\hline Polen & netto & netto & netto & netto & a & a & netto \\
\hline Portugal & netto & netto & netto & $\mathrm{m}$ & $\mathrm{m}$ & $\mathrm{m}$ & $\mathrm{m}$ \\
\hline Slowakei & netto & netto & netto & netto & a & netto & netto \\
\hline Slowenien & brutto & netto & brutto & netto & brutto & netto & brutto \\
\hline Spanien & brutto & brutto & brutto & brutto & brutto & brutto & brutto \\
\hline Schweden & netto & netto & netto & netto & $\mathrm{n}$ & $\mathrm{n}$ & netto \\
\hline Schweiz & $\mathrm{m}$ & brutto & brutto & brutto & brutto & brutto & brutto \\
\hline Türkei & netto & netto & netto & netto & a & $\mathrm{m}$ & a \\
\hline Vereinigtes Königreich & brutto & $\mathrm{m}$ & $\mathrm{m}$ & $\mathrm{m}$ & $\mathrm{m}$ & brutto & brutto \\
\hline $\begin{array}{l}\text { Vereinigte Staaten } \\
\text { Sonstige G20-Länder }\end{array}$ & netto & $\mathrm{m}$ & $\mathrm{m}$ & $\mathrm{m}$ & $\mathrm{m}$ & $\mathrm{m}$ & $\mathrm{m}$ \\
\hline Argentinien & $\mathrm{m}$ & netto & netto & netto & a & a & a \\
\hline Brasilien & $\mathrm{m}$ & netto & netto & netto & netto & a & a \\
\hline China & brutto & brutto & brutto & brutto & $\mathrm{m}$ & brutto & brutto \\
\hline Indien & $\mathrm{m}$ & $\mathrm{m}$ & $\mathrm{m}$ & $\mathrm{m}$ & $\mathrm{m}$ & $\mathrm{m}$ & $\mathrm{m}$ \\
\hline Indonesien & $\mathrm{m}$ & netto & netto & netto & netto & a & a \\
\hline Russische Föderation & $\mathrm{m}$ & brutto & brutto & brutto & brutto & brutto & brutto \\
\hline Saudi-Arabien & $\mathrm{m}$ & $\mathrm{m}$ & $\mathrm{m}$ & $\mathrm{m}$ & $\mathrm{m}$ & $\mathrm{m}$ & $\mathrm{m}$ \\
\hline Südafrika & $\mathrm{m}$ & $\mathrm{m}$ & $\mathrm{m}$ & $\mathrm{m}$ & $\mathrm{m}$ & $\mathrm{m}$ & $\mathrm{m}$ \\
\hline
\end{tabular}

1. Dauer ISCED 3C: kurz - mindestens 1 Jahr kürzer als ISCED-3A/3B-Bildungsgänge; lang - ähnlich lang wie ISCED-3A/3B-Bildungsgänge.

Quelle: OECD. Argentinien, China, Indonesien: Statistikinstitut der UNESCO (World Education Indicators Programm).

Hinweise s. Anhang 3 unter www.oecd.org/edu/eag.htm. StatLink: http://dx.doi.org/10.1787/888932852086

Erläuterung der Kennzeichnung fehlender Daten s. Hinweise für den Leser. 
Tabelle X1.1b

Abschlussquoten im postsekundaren, nicht tertiären Bereich: Typisches Abschlussalter und Art der Abschlussquote (Brutto- bzw. Nettoabschlussquote) (2011)

Das typische Abschlussalter bezieht sich auf das Alter der Schüler zu Beginn des Schuljahres; die Schüler werden im Allgemeinen ein Jahr älter sein, wenn der Abschluss gegen Ende des Schuljahres erfolgt. Bei der Berechnung der Bruttoabschlussquoten wird das typische Abschlussalter verwendet.

\begin{tabular}{|c|c|c|c|c|c|c|c|c|}
\hline & \multicolumn{4}{|c|}{ Typisches Abschlussalter } & \multirow{2}{*}{\multicolumn{4}{|c|}{$\begin{array}{c}\text { Art der Abschlussquote: Brutto- bzw. Nettoabschlussquote } \\
\text { Weitere Ausbildung/Arbeitsmarkteintritt }\end{array}$}} \\
\hline & \multirow[t]{2}{*}{ Erstabschluss $^{1}$} & \multicolumn{3}{|c|}{ Weitere Ausbildung/Arbeitsmarkteintritt } & & & & \\
\hline & & ISCED 4A & ISCED 4B & ISCED $4 \mathrm{C}$ & $\begin{array}{c}\text { Absolventen mit } \\
\text { Erstabschluss }\end{array}$ & ISCED 4A & ISCED 4B & ISCED 4C \\
\hline \multicolumn{9}{|l|}{ OECD-Länder } \\
\hline Australien & $18-20$ & a & a & $18-20$ & netto & a & a & netto \\
\hline Österreich & $18-19$ & $18-19$ & $19-20$ & $23-24$ & netto & netto & netto & netto \\
\hline Belgien & $19-21$ & 19 & $19-21$ & $19-21$ & $\mathrm{~m}$ & netto & netto & netto \\
\hline Kanada & $\mathrm{m}$ & $\mathrm{m}$ & $\mathrm{m}$ & $30-34$ & $\mathrm{~m}$ & $\mathrm{~m}$ & $\mathrm{~m}$ & $\mathrm{~m}$ \\
\hline Chile & a & a & a & a & a & a & a & a \\
\hline Tschechien & $20-22$ & $20-22$ & a & $20-22$ & netto & netto & a & brutto \\
\hline Dänemark & 21 & 21 & a & a & netto & netto & a & a \\
\hline Estland & 21 & $a$ & 21 & a & $\mathrm{m}$ & a & netto & a \\
\hline Finnland & $35-39$ & a & a & $35-39$ & netto & a & a & netto \\
\hline Frankreich & $\mathrm{m}$ & $\mathrm{m}$ & $\mathrm{m}$ & $\mathrm{m}$ & $\mathrm{m}$ & brutto & a & brutto \\
\hline Deutschland & 22 & 22 & 22 & a & brutto & brutto & brutto & a \\
\hline Griechenland & $\mathrm{m}$ & $\mathrm{m}$ & $\mathrm{m}$ & $\mathrm{m}$ & $\mathrm{m}$ & $\mathrm{m}$ & $\mathrm{m}$ & $\mathrm{m}$ \\
\hline Ungarn & a & a & a & $19-20$ & netto & a & a & netto \\
\hline Island & $\mathrm{m}$ & $\mathrm{m}$ & $\mathrm{m}$ & $\mathrm{m}$ & $\mathrm{m}$ & $\mathrm{m}$ & $\mathrm{m}$ & $\mathrm{m}$ \\
\hline Irland & 23 & a & a & 23 & netto & a & a & netto \\
\hline Israel & $\mathrm{m}$ & $\mathrm{m}$ & $\mathrm{m}$ & a & $\mathrm{m}$ & $\mathrm{m}$ & $\mathrm{m}$ & a \\
\hline Italien & 20 & a & a & 20 & brutto & a & a & brutto \\
\hline Japan & 18 & 18 & 18 & 18 & $\mathrm{~m}$ & $\mathrm{~m}$ & $\mathrm{~m}$ & $\mathrm{~m}$ \\
\hline Korea & a & a & a & a & a & a & a & a \\
\hline Luxemburg & $21-25$ & a & a & $21-25$ & netto & a & a & netto \\
\hline Mexiko & a & a & a & a & a & a & a & a \\
\hline Niederlande & 20 & a & a & 20 & netto & a & a & netto \\
\hline Neuseeland & 18 & 18 & 18 & 18 & netto & netto & netto & netto \\
\hline Norwegen & $20-22$ & $20-22$ & a & $21-22$ & netto & netto & a & netto \\
\hline Polen & 21 & $a$ & a & 21 & netto & a & a & netto \\
\hline Portugal & 21 & $\mathrm{~m}$ & $\mathrm{~m}$ & $\mathrm{~m}$ & netto & $\mathrm{m}$ & $\mathrm{m}$ & $\mathrm{m}$ \\
\hline Slowakei & $20-21$ & $20-21$ & a & a & netto & netto & a & a \\
\hline Slowenien & $19-20$ & $19-20$ & $19-20$ & a & netto & netto & netto & a \\
\hline Spanien & a & a & a & a & a & a & a & a \\
\hline Schweden & $19-22$ & $\mathrm{~m}$ & $\mathrm{~m}$ & $19-22$ & netto & $\mathrm{n}$ & $\mathrm{n}$ & netto \\
\hline Schweiz & $21-23$ & $21-23$ & $21-23$ & a & $\mathrm{m}$ & brutto & brutto & a \\
\hline Türkei & a & a & a & a & a & a & a & a \\
\hline Vereinigtes Königreich & a & a & a & a & a & a & a & a \\
\hline $\begin{array}{l}\text { Vereinigte Staaten } \\
\text { Sonstige G20-Länder }\end{array}$ & $\mathrm{m}$ & $\mathrm{m}$ & $\mathrm{m}$ & $\mathrm{m}$ & $\mathrm{m}$ & $\mathrm{m}$ & $\mathrm{m}$ & $\mathrm{m}$ \\
\hline Argentinien & a & a & a & a & a & a & a & a \\
\hline Brasilien & a & a & a & a & a & a & a & a \\
\hline China & 18 & 18 & 18 & 18 & $\mathrm{~m}$ & brutto & brutto & brutto \\
\hline Indien & $\mathrm{m}$ & $\mathrm{m}$ & $\mathrm{m}$ & $\mathrm{m}$ & $\mathrm{m}$ & $\mathrm{m}$ & $\mathrm{m}$ & $\mathrm{m}$ \\
\hline Indonesien & a & a & a & a & a & a & a & a \\
\hline Russische Föderation & 18 & a & a & 18 & $\mathrm{~m}$ & a & a & brutto \\
\hline Saudi-Arabien & $\mathrm{m}$ & $\mathrm{m}$ & $\mathrm{m}$ & $\mathrm{m}$ & $\mathrm{m}$ & $\mathrm{m}$ & $\mathrm{m}$ & $\mathrm{m}$ \\
\hline Südafrika & $\mathrm{m}$ & $\mathrm{m}$ & $\mathrm{m}$ & $\mathrm{m}$ & $\mathrm{m}$ & $\mathrm{m}$ & $\mathrm{m}$ & $\mathrm{m}$ \\
\hline
\end{tabular}

1. „Erstabschluss“ bezieht sich auf die Studierenden. Es handelt sich um den ersten Abschluss, den Studierende im Tertiärbereich erlangen. „Erster Abschluss“ und "Zweiter Abschluss" beziehen sich auf konsekutive Studiengänge: z. B. 1. Abschluss: Bachelor, 2. Abschluss: Master.

Quelle: OECD. Argentinien, China, Indonesien: Statistikinstitut der UNESCO (World Education Indicators Programme).

Hinweise s. Anhang 3 unter www.oecd.org/edu/eag.htm. StatLink: http://dx.doi.org/10.1787/888932852105

Erläuterung der Kennzeichnung fehlender Daten s. Hinweise für den Leser. 
Tabelle X1.1c

Abschlussquoten im Tertiärbereich: Typisches Abschlussalter und Art der Abschlussquote

(Brutto- bzw. Nettoabschlussquote) (2011)

Das typische Abschlussalter bezieht sich auf das Alter der Studierenden zu Beginn des Studienjahres; die Studierenden werden im Allgemeinen ein Jahr älter sein, wenn der Abschluss gegen Ende des Studienjahres erfolgt. Bei der Berechnung der Bruttoabschlussquoten wird das typische Abschlussalter verwendet.

\begin{tabular}{|c|c|c|c|c|c|c|c|}
\hline & \multicolumn{7}{|c|}{ Typisches Abschlussalter } \\
\hline & \multirow{2}{*}{$\begin{array}{l}\text { Erstabschluss }^{1} \\
\text { Tertiärbereich B }\end{array}$} & \multirow{2}{*}{$\begin{array}{c}\text { Tertiärbereich B } \\
\text { (Erster } \\
\text { Abschluss) }\end{array}$} & \multirow{2}{*}{$\begin{array}{l}\text { Erstabschluss }^{1} \\
\text { Tertiärbereich A }\end{array}$} & \multicolumn{3}{|c|}{ Tertiärbereich A (erster und zweiter Abschluss) ${ }^{1}$} & \multirow{2}{*}{$\begin{array}{l}\text { Weiterführende } \\
\text { forschungs- } \\
\text { orientierte } \\
\text { Studiengänge }\end{array}$} \\
\hline & & & & $\begin{array}{l}3 \text { bis weniger } \\
\text { als } 5 \text { Jahre }\end{array}$ & 5 bis 6 Jahre & Mehr als 6 Jahre & \\
\hline \multicolumn{8}{|l|}{ OECD-Länder } \\
\hline Australien & $20-21$ & $20-21$ & $21-22$ & $21-22$ & $22-23$ & 24 & $26-29$ \\
\hline Österreich & $21-23$ & $21-23$ & $23-25$ & $22-24$ & $24-26$ & a & $27-29$ \\
\hline Belgien & $21-22$ & $21-22$ & 21 & $\mathrm{~m}$ & $\mathrm{~m}$ & $\mathrm{~m}$ & $27-29$ \\
\hline Kanada & $21-24$ & $21-24$ & $22-24$ & 22 & $23-24$ & 25 & $27-29$ \\
\hline Chile & $22-25$ & $22-25$ & $23-26$ & $23-26$ & $24-26$ & $25-26$ & $30-34$ \\
\hline Tschechien & 22 & 22 & $22-24$ & $22-23$ & $25-26$ & a & $30-34$ \\
\hline Dänemark & $23-25$ & $23-25$ & 24 & 24 & 26 & $25-29$ & $30-34$ \\
\hline Estland & 22 & 22 & $22-24$ & 22 & 24 & $a$ & $30-34$ \\
\hline Finnland & $30-34$ & $30-34$ & $25-29$ & 24 & a & a & $30-34$ \\
\hline Frankreich & $\mathrm{m}$ & $\mathrm{m}$ & $\mathrm{m}$ & $\mathrm{m}$ & $\mathrm{m}$ & $\mathrm{m}$ & $\mathrm{m}$ \\
\hline Deutschland & $21-23$ & $21-23$ & $24-27$ & $24-26$ & $25-27$ & a & $28-29$ \\
\hline Griechenland & $\mathrm{m}$ & $\mathrm{m}$ & $\mathrm{m}$ & $\mathrm{m}$ & $\mathrm{m}$ & $\mathrm{m}$ & $\mathrm{m}$ \\
\hline Ungarn & 20 & 20 & $22-24$ & $21-23$ & $23-24$ & $a$ & $30-34$ \\
\hline Island & $\mathrm{m}$ & $\mathrm{m}$ & $\mathrm{m}$ & $\mathrm{m}$ & $\mathrm{m}$ & $\mathrm{m}$ & $\mathrm{m}$ \\
\hline Irland & $20-21$ & $20-21$ & 21 & 21 & 23 & 25 & 27 \\
\hline Israel & $m$ & a & 26 & 26 & $28-29$ & 217 & $30-34$ \\
\hline Italien & $22-23$ & $22-23$ & 23 & 23 & 25 & a & $30-34$ \\
\hline Japan & 19 & 19 & $21-23$ & 21 & 23 & $a$ & 26 \\
\hline Korea & 20 & 20 & $22-24$ & $22-26$ & $24-25$ & a & $30-34$ \\
\hline Luxemburg & $\mathrm{m}$ & $\mathrm{m}$ & $\mathrm{m}$ & $\mathrm{m}$ & $\mathrm{m}$ & $\mathrm{m}$ & $\mathrm{m}$ \\
\hline Mexiko & 20 & 20 & 23 & 23 & $23-26$ & $\mathrm{~m}$ & $24-28$ \\
\hline Niederlande & $\mathrm{m}$ & 27 & 23 & 23 & a & a & $28-29$ \\
\hline Neuseeland & $19-21$ & $19-21$ & $21-23$ & $21-23$ & 23 & 24 & $27-28$ \\
\hline Norwegen & 24 & 24 & $22-27$ & $22-23$ & $24-25$ & $26-27$ & $30-34$ \\
\hline Polen & 22 & 22 & $23-25$ & 23 & 25 & a & $25-29$ \\
\hline Portugal & 0 & 3 & 22 & 22 & $40-99$ & a & $30-34$ \\
\hline Slowakei & $21-22$ & $21-22$ & $21-22$ & $21-22$ & $23-24$ & a & $26-28$ \\
\hline Slowenien & $23-25$ & $23-25$ & $23-25$ & $23-24$ & $24-25$ & a & 28 \\
\hline Spanien & $19-21$ & $19-21$ & $22-23$ & $20-22$ & $22-23$ & $a$ & $30-34$ \\
\hline Schweden & $21-23$ & $21-23$ & 25 & 25 & 25 & $n$ & $30-34$ \\
\hline Schweiz & $23-29$ & $23-29$ & $24-26$ & $24-26$ & $25-27$ & $25-27$ & $30-34$ \\
\hline Türkei & 21 & 21 & $22-24$ & $23-24$ & $25-26$ & $30-34$ & $30-34$ \\
\hline Vereinigtes Königreich & $19-24$ & $19-24$ & $20-25$ & $20-22$ & $22-24$ & $23-25$ & $25-29$ \\
\hline $\begin{array}{l}\text { Vereinigte Staaten } \\
\text { Sonstige G20-Länder }\end{array}$ & 19 & 19 & 21 & 21 & 23 & 24 & 26 \\
\hline Argentinien & $\mathrm{m}$ & $20-24$ & $\mathrm{~m}$ & $20-24$ & $25-29$ & a & $25-29$ \\
\hline Brasilien & $\mathrm{m}$ & $\mathrm{m}$ & $22-24$ & $22-24$ & $\mathrm{~m}$ & $\mathrm{~m}$ & $30-34$ \\
\hline China & 20 & 20 & 21 & 21 & 22 & 22 & 27 \\
\hline Indien & $\mathrm{m}$ & $\mathrm{m}$ & $\mathrm{m}$ & $\mathrm{m}$ & $\mathrm{m}$ & $\mathrm{m}$ & $\mathrm{m}$ \\
\hline Indonesien & 24 & 24 & 22 & 22 & 24 & 26 & 27 \\
\hline Russische Föderation & 20 & 20 & 22 & 21 & 22 & 23 & $25-26$ \\
\hline Saudi-Arabien & 19 & 19 & 21 & 21 & $22-23$ & 24 & 26 \\
\hline Südafrika & 20 & 20 & 21 & 21 & 22 & 22 & 25 \\
\hline
\end{tabular}

Anmerkung: Wenn Daten zum Tertiärbereich A, aufgegliedert nach der Dauer der Studiengänge, verfügbar waren, ist die Abschlussquote für alle Studiengänge die Summe der Abschlussquoten, aufgegliedert nach der Dauer der Studiengänge.

1. „Erstabschluss“ bezieht sich auf die Studierenden. Es handelt sich um den ersten Abschluss, den Studierende im Tertiärbereich erlangen. „Erster Abschluss“ und „Zweiter Abschluss“ beziehen sich auf konsekutive Studiengänge: z. B. 1. Abschluss: Bachelor, 2. Abschluss: Master.

Quelle: OECD. Argentinien, China und Indonesien: Statistikinstitut der UNESCO (World Education Indicators Programme). Saudi-Arabien: Observatory on Higher Education. Hinweise s. Anhang 3 unter www.oecd.org/edu/eag.htm. StatLink: http://dx.doi.org/10.1787/888932852124 Erläuterung der Kennzeichnung fehlender Daten s. Hinweise für den Leser. 
Tabelle X1.1c (Forts.)

Abschlussquoten im Tertiärbereich: Typisches Abschlussalter und Art der Abschlussquote (Brutto- bzw. Nettotoabschlussquote) (2011)

\begin{tabular}{|c|c|c|c|c|c|c|c|c|c|c|c|c|}
\hline & \multicolumn{12}{|c|}{ Art der Abschlussquote: Brutto- bzw. Nettotoabschlussquote } \\
\hline & \multicolumn{4}{|c|}{ Tertiärbereich B (ISCED 5B) } & \multicolumn{6}{|c|}{ Tertiärbereich A (ISCED 5A) } & \multirow{2}{*}{\multicolumn{2}{|c|}{$\begin{array}{l}\text { Weiterführende } \\
\text { forschungsorien- } \\
\text { tierte Studiengänge } \\
\text { (ISCED 6) }\end{array}$}} \\
\hline & \multicolumn{2}{|c|}{ Erstabschluss $^{1}$} & \multicolumn{2}{|c|}{ Erster Abschluss ${ }^{1}$} & \multicolumn{2}{|c|}{ Erstabschluss $^{1}$} & \multicolumn{2}{|c|}{ Erster Abschluss ${ }^{1}$} & \multicolumn{2}{|c|}{ Zweiter Abschluss $^{1}$} & & \\
\hline & 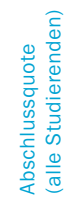 & 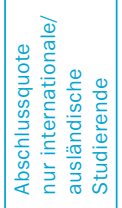 & 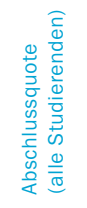 & 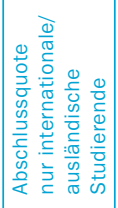 & 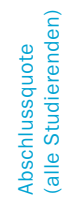 & 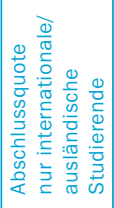 & 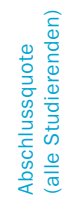 & 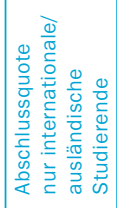 & 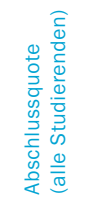 & 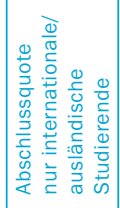 & 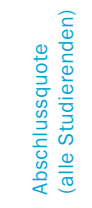 & 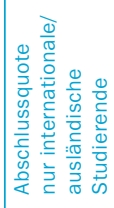 \\
\hline \multicolumn{13}{|l|}{ OECD-Länder } \\
\hline Australien & netto & netto & netto & netto & netto & netto & netto & netto & netto & netto & netto & netto \\
\hline Österreich & netto & netto & netto & netto & netto & netto & netto & netto & netto & netto & netto & netto \\
\hline Belgien & $\mathrm{m}$ & $\mathrm{m}$ & netto & netto & $\mathrm{m}$ & $\mathrm{m}$ & netto & netto & netto & netto & netto & netto \\
\hline Kanada & netto & netto & netto & netto & netto & netto & netto & netto & netto & netto & netto & netto \\
\hline Chile & $\mathrm{m}$ & $\mathrm{m}$ & netto & $\mathrm{m}$ & $\mathrm{m}$ & $\mathrm{m}$ & netto & $\mathrm{m}$ & netto & $\mathrm{m}$ & netto & $\mathrm{m}$ \\
\hline Tschechien & netto & $\mathrm{m}$ & netto & $\mathrm{m}$ & netto & $\mathrm{m}$ & netto & $\mathrm{m}$ & netto & $\mathrm{m}$ & netto & $\mathrm{m}$ \\
\hline Dänemark & netto & netto & netto & netto & netto & netto & netto & netto & netto & netto & netto & netto \\
\hline Estland & $\mathrm{m}$ & $\mathrm{m}$ & netto & $\mathrm{m}$ & $\mathrm{m}$ & $\mathrm{m}$ & netto & $\mathrm{m}$ & netto & $\mathrm{m}$ & netto & $\mathrm{m}$ \\
\hline Finnland & netto & netto & netto & $\mathrm{n}$ & netto & $\mathrm{m}$ & netto & netto & netto & netto & netto & netto \\
\hline Frankreich & $\mathrm{m}$ & $\mathrm{m}$ & brutto & $\mathrm{m}$ & $\mathrm{m}$ & $\mathrm{m}$ & brutto & $\mathrm{m}$ & brutto & $\mathrm{m}$ & brutto & $\mathrm{m}$ \\
\hline Deutschland & brutto & $\mathrm{m}$ & brutto & $\mathrm{m}$ & netto & netto & netto & netto & netto & netto & netto & netto \\
\hline Griechenland & $\mathrm{m}$ & $\mathrm{m}$ & $\mathrm{m}$ & $\mathrm{m}$ & $\mathrm{m}$ & $\mathrm{m}$ & $\mathrm{m}$ & $\mathrm{m}$ & $\mathrm{m}$ & $\mathrm{m}$ & $\mathrm{m}$ & $\mathrm{m}$ \\
\hline Ungarn & netto & $\mathrm{m}$ & netto & $\mathrm{m}$ & netto & $\mathrm{m}$ & netto & $\mathrm{m}$ & netto & $\mathrm{m}$ & netto & $\mathrm{m}$ \\
\hline Island & netto & netto & netto & netto & netto & netto & netto & netto & netto & netto & netto & netto \\
\hline Irland & netto & netto & netto & netto & netto & netto & netto & netto & netto & netto & netto & netto \\
\hline Israel & $\mathrm{m}$ & $\mathrm{m}$ & $\mathrm{m}$ & $\mathrm{m}$ & netto & $\mathrm{m}$ & netto & $\mathrm{m}$ & netto & $\mathrm{m}$ & netto & $\mathrm{m}$ \\
\hline Italien & brutto & $\mathrm{m}$ & brutto & brutto & netto & $\mathrm{m}$ & netto & $\mathrm{m}$ & $\mathrm{m}$ & $\mathrm{m}$ & $\mathrm{m}$ & $\mathrm{m}$ \\
\hline Japan & brutto & $\mathrm{m}$ & brutto & $\mathrm{m}$ & brutto & $\mathrm{m}$ & brutto & $\mathrm{m}$ & brutto & $\mathrm{m}$ & brutto & $\mathrm{m}$ \\
\hline Korea & $\mathrm{m}$ & $\mathrm{m}$ & netto & $\mathrm{m}$ & $\mathrm{m}$ & $\mathrm{m}$ & netto & $\mathrm{m}$ & netto & $\mathrm{m}$ & netto & $\mathrm{m}$ \\
\hline Luxemburg & $\mathrm{m}$ & $\mathrm{m}$ & $\mathrm{m}$ & $\mathrm{m}$ & $\mathrm{m}$ & $\mathrm{m}$ & $\mathrm{m}$ & $\mathrm{m}$ & $\mathrm{m}$ & $\mathrm{m}$ & $\mathrm{m}$ & $\mathrm{m}$ \\
\hline Mexiko & netto & $\mathrm{m}$ & netto & $\mathrm{m}$ & netto & $\mathrm{m}$ & netto & $\mathrm{m}$ & brutto & $\mathrm{m}$ & brutto & $\mathrm{m}$ \\
\hline Niederlande & netto & netto & netto & $\mathrm{m}$ & netto & netto & netto & netto & netto & netto & brutto & $\mathrm{m}$ \\
\hline Neuseeland & netto & netto & netto & netto & netto & netto & netto & netto & netto & netto & netto & netto \\
\hline Norwegen & netto & netto & netto & netto & netto & netto & netto & netto & netto & netto & netto & netto \\
\hline Polen & netto & $\mathrm{m}$ & netto & $\mathrm{m}$ & netto & netto & netto & netto & brutto & netto & brutto & brutto \\
\hline Portugal & netto & netto & netto & netto & netto & netto & netto & netto & netto & netto & netto & netto \\
\hline Slowakei & netto & $\mathrm{m}$ & netto & $\mathrm{m}$ & netto & netto & netto & netto & netto & netto & netto & netto \\
\hline Slowenien & netto & netto & netto & netto & netto & netto & netto & netto & netto & netto & netto & netto \\
\hline Spanien & netto & $\mathrm{m}$ & netto & $\mathrm{m}$ & netto & $\mathrm{m}$ & netto & $\mathrm{m}$ & netto & $\mathrm{m}$ & netto & $\mathrm{m}$ \\
\hline Schweden & netto & netto & netto & netto & netto & netto & netto & netto & netto & netto & netto & netto \\
\hline Schweiz & brutto & $\mathrm{m}$ & brutto & $\mathrm{m}$ & netto & $\mathrm{m}$ & netto & netto & netto & netto & netto & netto \\
\hline Türkei & netto & $\mathrm{m}$ & netto & $\mathrm{m}$ & brutto & $\mathrm{m}$ & netto & $\mathrm{m}$ & netto & $\mathrm{m}$ & netto & $\mathrm{m}$ \\
\hline Ver. Königreich & netto & $\mathrm{m}$ & netto & netto & netto & $\mathrm{m}$ & netto & netto & netto & netto & netto & netto \\
\hline Vereinigte Staaten & brutto & brutto & brutto & brutto & brutto & brutto & brutto & brutto & brutto & brutto & brutto & brutto \\
\hline \multicolumn{13}{|l|}{ Sonst. G20-Länder } \\
\hline Argentinien & $m$ & $\mathrm{~m}$ & brutto & $\mathrm{m}$ & $\mathrm{m}$ & $\mathrm{m}$ & brutto & $\mathrm{m}$ & brutto & $\mathrm{m}$ & brutto & $\mathrm{m}$ \\
\hline Brasilien & $\mathrm{m}$ & $\mathrm{m}$ & netto & $\mathrm{m}$ & $\mathrm{m}$ & $\mathrm{m}$ & netto & $\mathrm{m}$ & netto & $\mathrm{m}$ & netto & $\mathrm{m}$ \\
\hline China & $\mathrm{m}$ & $\mathrm{m}$ & brutto & $\mathrm{m}$ & $\mathrm{m}$ & $\mathrm{m}$ & brutto & $\mathrm{m}$ & brutto & $\mathrm{m}$ & brutto & $\mathrm{m}$ \\
\hline Indien & $\mathrm{m}$ & $\mathrm{m}$ & $\mathrm{m}$ & $\mathrm{m}$ & $\mathrm{m}$ & $\mathrm{m}$ & $\mathrm{m}$ & $\mathrm{m}$ & $\mathrm{m}$ & $\mathrm{m}$ & $\mathrm{m}$ & $\mathrm{m}$ \\
\hline Indonesien & $\mathrm{m}$ & $\mathrm{m}$ & netto & $\mathrm{m}$ & $\mathrm{m}$ & $\mathrm{m}$ & netto & $\mathrm{m}$ & netto & $\mathrm{m}$ & netto & $\mathrm{m}$ \\
\hline Russische Föd. & $\mathrm{m}$ & $\mathrm{m}$ & brutto & $\mathrm{m}$ & $\mathrm{m}$ & $\mathrm{m}$ & brutto & $\mathrm{m}$ & brutto & $\mathrm{m}$ & brutto & $\mathrm{m}$ \\
\hline Saudi-Arabien & brutto & brutto & brutto & brutto & brutto & brutto & brutto & brutto & brutto & brutto & brutto & brutto \\
\hline Südafrika & $\mathrm{m}$ & $\mathrm{m}$ & brutto & $\mathrm{m}$ & $\mathrm{m}$ & $\mathrm{m}$ & brutto & $\mathrm{m}$ & brutto & $\mathrm{m}$ & brutto & $\mathrm{m}$ \\
\hline
\end{tabular}

1. „Erstabschluss“ bezieht sich auf die Studierenden. Es handelt sich um den ersten Abschluss, den Studierende im Tertiärbereich erlangen. „Erster Abschluss“ und „Zweiter Abschluss“ beziehen sich auf konsekutive Studiengänge: z. B. 1. Abschluss: Bachelor, 2. Abschluss: Master.

Quelle: OECD. Argentinien, China und Indonesien: Statistikinstitut der UNESCO (World Education Indicators Programme). Saudi-Arabien: Observatory on Higher Education. Südafrika: Statistikinstitut der UNESCO. Hinweise s. Anhang 3 unter www.oecd.org/edu/eag.htm. StatLink: http://dx.doi.org/10.1787/888932852124 Erläuterung der Kennzeichnung fehlender Daten s. Hinweise für den Leser. 
Studienanfängerquoten: Typisches Eintrittsalter und Art der Studienanfängerquote (Brutto- bzw. Nettoanfängerquote) (2011)

\begin{tabular}{|c|c|c|c|c|c|c|c|c|c|}
\hline & \multirow{2}{*}{\multicolumn{3}{|c|}{ Typisches Eintrittsalter }} & \multirow{2}{*}{\multicolumn{3}{|c|}{$\begin{array}{c}\begin{array}{c}\text { Art der Studienanfängerquote: } \\
\text { Brutto- bzw. Nettoabschlussquote }\end{array} \\
\text { Alle Studierenden }\end{array}$}} & \multirow{2}{*}{\multicolumn{3}{|c|}{$\begin{array}{c}\begin{array}{c}\text { Art der Studienanfängerquote: } \\
\text { Brutto- bzw. Nettoabschlussquote }\end{array} \\
\text { Internationale Studierende }\end{array}$}} \\
\hline & & & & & & & & & \\
\hline & ISCED 5A & ISCED 5B & ISCED 6 & ISCED 5A & ISCED 5B & ISCED 6 & ISCED 5A & ISCED 5B & ISCED 6 \\
\hline \multicolumn{10}{|l|}{ OECD-Länder } \\
\hline Australien & 18 & 18 & $22-23$ & netto & $\mathrm{m}$ & netto & netto & $\mathrm{m}$ & netto \\
\hline Österreich & $19-20$ & $20-21$ & $25-26$ & netto & netto & netto & netto & netto & netto \\
\hline Belgien & 18 & 18 & $\mathrm{~m}$ & netto & netto & $\mathrm{m}$ & $\mathrm{m}$ & $\mathrm{m}$ & $\mathrm{m}$ \\
\hline Kanada & $\mathrm{m}$ & $\mathrm{m}$ & $\mathrm{m}$ & $\mathrm{m}$ & $\mathrm{m}$ & $\mathrm{m}$ & $\mathrm{m}$ & $\mathrm{m}$ & $\mathrm{m}$ \\
\hline Chile & $18-19$ & $18-19$ & $24-28$ & netto & netto & netto & netto & netto & netto \\
\hline Tschechien & $19-20$ & $19-20$ & $24-25$ & netto & netto & netto & $\mathrm{m}$ & $\mathrm{m}$ & $\mathrm{m}$ \\
\hline Dänemark & $20-21$ & $20-21$ & $25-27$ & netto & netto & netto & netto & netto & netto \\
\hline Estland & 19 & 19 & 24 & netto & netto & netto & $\mathrm{m}$ & $\mathrm{m}$ & $\mathrm{m}$ \\
\hline Finnland & 19 & 19 & $m$ & netto & a & netto & $\mathrm{m}$ & a & $\mathrm{m}$ \\
\hline Frankreich & $\mathrm{m}$ & $\mathrm{m}$ & $\mathrm{m}$ & netto & $\mathrm{m}$ & netto & $\mathrm{m}$ & $\mathrm{m}$ & $\mathrm{m}$ \\
\hline Deutschland & $19-21$ & $18-21$ & $\mathrm{~m}$ & netto & netto & netto & netto & $\mathrm{m}$ & netto \\
\hline Griechenland & $\mathrm{m}$ & $\mathrm{m}$ & $\mathrm{m}$ & $\mathrm{m}$ & $\mathrm{m}$ & $\mathrm{m}$ & $\mathrm{m}$ & $\mathrm{m}$ & $\mathrm{m}$ \\
\hline Ungarn & 19 & 19 & 24 & netto & netto & netto & $\mathrm{m}$ & $\mathrm{m}$ & $\mathrm{m}$ \\
\hline Island & $\mathrm{m}$ & $\mathrm{m}$ & $\mathrm{m}$ & $\mathrm{m}$ & $\mathrm{m}$ & $\mathrm{m}$ & $\mathrm{m}$ & $\mathrm{m}$ & $\mathrm{m}$ \\
\hline Irland & 18 & 18 & $\mathrm{~m}$ & netto & netto & $\mathrm{m}$ & netto & netto & $\mathrm{m}$ \\
\hline Israel & $22-24$ & 18 & $27-29$ & netto & netto & netto & $\mathrm{m}$ & $\mathrm{m}$ & $\mathrm{m}$ \\
\hline Italien & 19 & ok & 24 & netto & $\mathrm{n}$ & brutto & netto & netto & netto \\
\hline Japan & 18 & 18 & 24 & netto & netto & netto & $\mathrm{m}$ & $\mathrm{m}$ & $\mathrm{m}$ \\
\hline Korea & 18 & 18 & $24-29$ & netto & netto & netto & brutto & brutto & $\mathrm{m}$ \\
\hline Luxemburg & $\mathrm{m}$ & $\mathrm{m}$ & $\mathrm{m}$ & $\mathrm{m}$ & $\mathrm{m}$ & $\mathrm{m}$ & $\mathrm{m}$ & $\mathrm{m}$ & $\mathrm{m}$ \\
\hline Mexiko & 18 & 18 & 24 & netto & netto & netto & $\mathrm{m}$ & $\mathrm{m}$ & $\mathrm{m}$ \\
\hline Niederlande & $18-19$ & $17-18$ & $\mathrm{~m}$ & netto & netto & netto & netto & netto & netto \\
\hline Neuseeland & 18 & 18 & $23-24$ & netto & netto & netto & netto & netto & netto \\
\hline Norwegen & $19-20$ & 19 & $26-27$ & netto & netto & netto & $\mathrm{m}$ & $\mathrm{m}$ & $\mathrm{m}$ \\
\hline Polen & $19-20$ & $19-20$ & $\mathrm{~m}$ & netto & netto & $\mathrm{m}$ & netto & $\mathrm{m}$ & $\mathrm{m}$ \\
\hline Portugal & 18 & 22 & $24-29$ & netto & netto & netto & netto & netto & netto \\
\hline Slowakei & 19 & 19 & 24 & netto & netto & netto & netto & $\mathrm{m}$ & netto \\
\hline Slowenien & 19 & $19-20$ & $24-26$ & netto & netto & netto & netto & netto & netto \\
\hline Spanien & 18 & $19-20$ & $26-29$ & netto & netto & netto & $\mathrm{m}$ & $\mathrm{m}$ & $\mathrm{m}$ \\
\hline Schweden & 19 & 19 & $25-27$ & netto & netto & netto & netto & netto & netto \\
\hline Schweiz & $19-21$ & $20-25$ & $25-27$ & netto & netto & netto & netto & $\mathrm{m}$ & netto \\
\hline Türkei & $18-19$ & $18-19$ & $25-26$ & netto & netto & netto & $\mathrm{m}$ & $\mathrm{m}$ & $\mathrm{m}$ \\
\hline Vereinigtes Königreich & 18 & 18 & $22-24$ & netto & netto & netto & $\mathrm{m}$ & $\mathrm{m}$ & $\mathrm{m}$ \\
\hline $\begin{array}{l}\text { Vereinigte Staaten } \\
\text { Sonstige G20-Länder }\end{array}$ & 18 & 18 & 24 & netto & $\mathrm{m}$ & $\mathrm{m}$ & brutto & $\mathrm{m}$ & $\mathrm{m}$ \\
\hline Argentinien & 18 & 18 & 25 & netto & netto & brutto & $\mathrm{m}$ & $\mathrm{m}$ & $\mathrm{m}$ \\
\hline Brasilien & $\mathrm{m}$ & $\mathrm{m}$ & $\mathrm{m}$ & $\mathrm{m}$ & $\mathrm{m}$ & $\mathrm{m}$ & $\mathrm{m}$ & $\mathrm{m}$ & $\mathrm{m}$ \\
\hline China & 17 & 17 & 21 & brutto & brutto & brutto & $\mathrm{m}$ & $\mathrm{m}$ & $\mathrm{m}$ \\
\hline Indien & $\mathrm{m}$ & $\mathrm{m}$ & m & $\mathrm{m}$ & $\mathrm{m}$ & $\mathrm{m}$ & $\mathrm{m}$ & $\mathrm{m}$ & $\mathrm{m}$ \\
\hline Indonesien & 18 & 18 & $25-26$ & netto & netto & netto & $\mathrm{m}$ & $\mathrm{m}$ & $\mathrm{m}$ \\
\hline Russische Föderation & $17-19$ & 18 & $23-24$ & netto & brutto & brutto & $\mathrm{m}$ & $\mathrm{m}$ & $\mathrm{m}$ \\
\hline Saudi-Arabien & $18-22$ & 18 & 24 & brutto & brutto & brutto & brutto & brutto & brutto \\
\hline Südafrika & $\mathrm{m}$ & $\mathrm{m}$ & $\mathrm{m}$ & $\mathrm{m}$ & $\mathrm{m}$ & $\mathrm{m}$ & $\mathrm{m}$ & $\mathrm{m}$ & $\mathrm{m}$ \\
\hline
\end{tabular}

Quelle: OECD. Argentinien, China, Indonesien: Statistikinstitut der UNESCO (World Education Indicators Programme). Saudi-Arabien: Observatory on Higher Education. Hinweise s. Anhang 3 unter www.oecd.org/edu/eag.htm. StatLink: http://dx.doi.org/10.1787/888932852143 Erläuterung der Kennzeichnung fehlender Daten s. Hinweise für den Leser. 


\section{Tabelle X1.2a}

Für die Berechnung der Indikatoren verwendete Haushalts- und Schuljahre, OECD-Länder

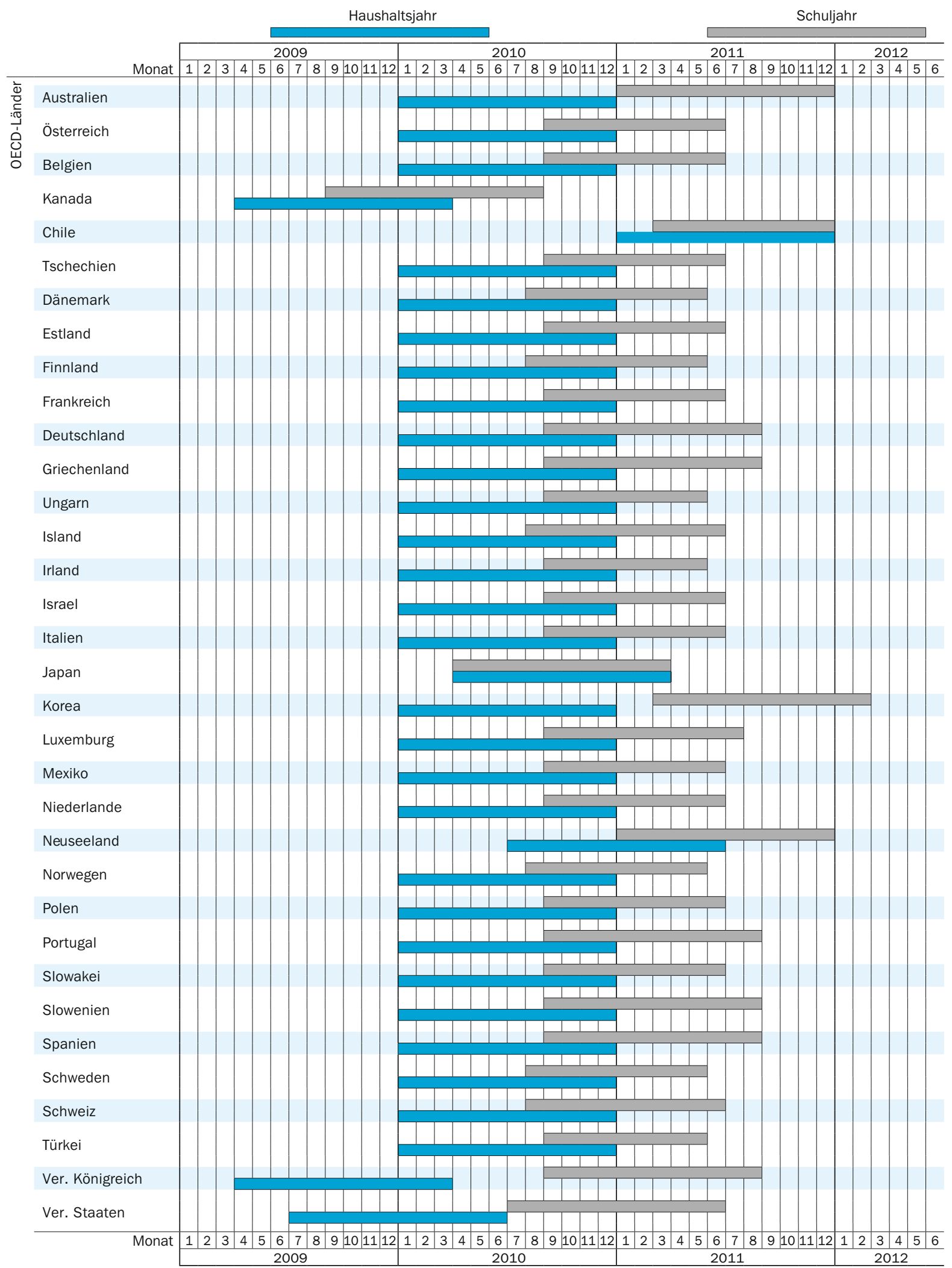


Tabelle X1.2b

Für die Berechnung der Indikatoren verwendete Haushalts- und Schuljahre, sonstige G20-Länder

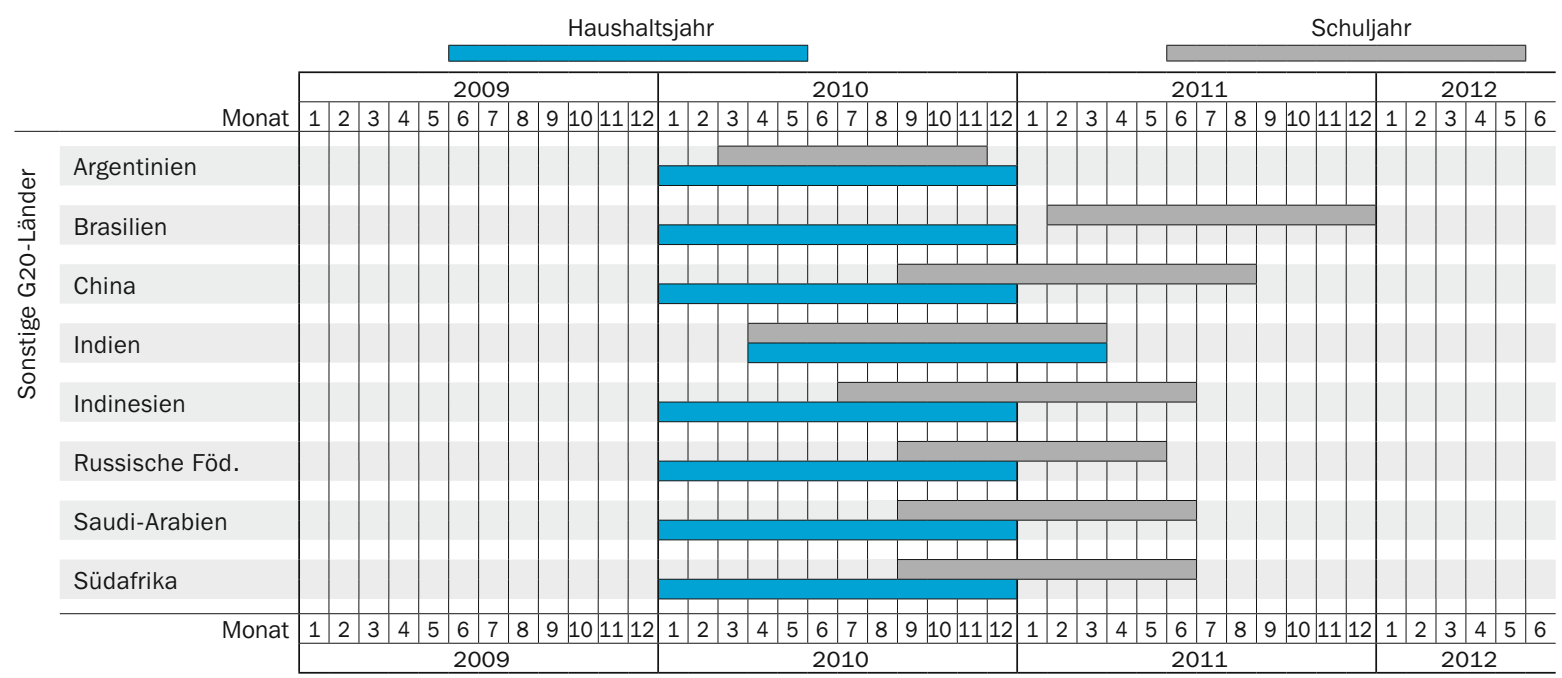

Quelle: OECD. Argentinien, China, Indonesien: Statistikinstitut der UNESCO (World Education Indicators Programme). Saudi-Arabien: Observatory on Higher Education. Südafrika: Statistikinstitut der UNESCO. Hinweise s. Anhang 3 unter www.oecd.org/edu/eag.htm. StatLink: http://dx.doi.org/10.1787/888932852181 

Statistische Bezugsdaten 
Tabelle X2.1

Überblick über das wirtschaftliche Umfeld anhand grundlegender Kennzahlen (Referenzzeitraum: Kalenderjahr 2010, zu konstanten Preisen von 2010)

\begin{tabular}{|c|c|c|c|c|}
\hline & $\begin{array}{l}\text { Öffentliche Gesamtausgaben } \\
\text { als Prozentsatz des BIP }\end{array}$ & $\begin{array}{c}\text { BIP pro Kopf } \\
\text { (in US-Dollar, } \\
\text { kaufkraftbereinigt) }\end{array}$ & $\begin{array}{l}\text { BIP-Deflator } \\
(2005=100)\end{array}$ & $\begin{array}{l}\text { BIP-Deflator } \\
(2000=100)\end{array}$ \\
\hline & (1) & (2) & (3) & (4) \\
\hline \multicolumn{5}{|l|}{ OECD-Länder } \\
\hline Australien & 33,8 & 40801 & 123,5 & 146,5 \\
\hline Österreich & 52,5 & 40411 & 109,1 & 118,0 \\
\hline Belgien & 52,7 & 37878 & 110,5 & 122,7 \\
\hline Kanada $^{1}$ & 40,5 & 40136 & 111,4 & 125,3 \\
\hline Chile $^{2}$ & 23,2 & 17312 & 121,3 & 173,6 \\
\hline Tschechien & 43,8 & 25364 & 106,8 & 120,0 \\
\hline Dänemark & 57,6 & 40600 & 114,1 & 128,1 \\
\hline Estland & 40,6 & 20093 & 127,2 & 163,4 \\
\hline Finnland & 55,8 & 36030 & 109,0 & 114,0 \\
\hline Frankreich & 56,6 & 34395 & 109,4 & 120,5 \\
\hline Deutschland & 47,5 & 37661 & 104,9 & 110,6 \\
\hline Griechenland & $\mathrm{m}$ & 27539 & 114,7 & 134,5 \\
\hline Ungarn & 49,7 & 20625 & 121,9 & 167,2 \\
\hline Island & 51,5 & 35509 & 148,8 & 181,0 \\
\hline Irland & 66,4 & 41000 & 94,0 & 113,5 \\
\hline Israel & 43,8 & 26552 & 109,6 & 116,6 \\
\hline Italien & 50,4 & 32110 & 109,4 & 124,9 \\
\hline Japan & 40,9 & 35238 & 94,2 & 87,8 \\
\hline Korea & 30,1 & 28829 & 112,4 & 129,5 \\
\hline Luxemburg & 42,8 & 84672 & 120,3 & 138,9 \\
\hline Mexiko & 25,7 & 15195 & 130,1 & 181,5 \\
\hline Niederlande & 51,2 & 41682 & 107,1 & 123,2 \\
\hline Neuseeland & 35,7 & 29629 & 116,0 & 131,5 \\
\hline Norwegen $^{3}$ & 57,8 & 44825 & 120,5 & 138,6 \\
\hline Polen & 45,3 & 20034 & 114,4 & 129,9 \\
\hline Portugal & 51,4 & 25519 & 109,5 & 127,3 \\
\hline Slowakei & 40,0 & 23194 & 106,3 & 132,4 \\
\hline Slowenien & 49,8 & 26649 & 113,5 & 147,0 \\
\hline Spanien & 45,7 & 31574 & 110,6 & 136,0 \\
\hline Schweden & 52,2 & 39251 & 111,2 & 119,0 \\
\hline Schweiz & 33,0 & 48962 & 107,8 & 111,9 \\
\hline Türkei & 39,0 & 15775 & 144,7 & 451,0 \\
\hline Vereinigtes Königreich & 50,2 & 35299 & 112,8 & 126,2 \\
\hline $\begin{array}{l}\text { Vereinigte Staaten } \\
\text { Sonstige G20-Länder }\end{array}$ & 42,7 & 46548 & 111,0 & 125,1 \\
\hline Argentinien & $\mathrm{m}$ & 15868 & $\mathrm{~m}$ & $\mathrm{~m}$ \\
\hline Brasilien & 32,1 & 12537 & 138,7 & 219,3 \\
\hline China & $\mathrm{m}$ & 7554 & 127,6 & 149,4 \\
\hline Indien & $\mathrm{m}$ & $\mathrm{m}$ & $\mathrm{m}$ & $\mathrm{m}$ \\
\hline Indonesien & $\mathrm{m}$ & 4638 & 175,4 & 278,0 \\
\hline Russische Föderation & 39,0 & 19811 & 175,9 & 386,8 \\
\hline Saudi-Arabien & $\mathrm{m}$ & $\mathrm{m}$ & $\mathrm{m}$ & $\mathrm{m}$ \\
\hline Südafrika & $\mathrm{m}$ & 10542 & 145,2 & 205,0 \\
\hline
\end{tabular}

1. Referenzjahr 2009. 2. Referenzjahr 2011 anstelle 2010. Der BIP-Deflator bezieht sich auf 2001-2011 anstelle $2000-2010$ sowie auf $2006-2011$ anstelle 2005-2010. 3. Für Norwegen wird der BIP-Festlandmarktwert verwendet.

Quelle: OECD. Hinweise s. Anhang 3 unter www.oecd.org/edu/eag.htm. StatLink: http://dx.doi.org/10.1787/888932852219

Erläuterung der Kennzeichnung fehlender Daten s. Hinweise für den Leser. 


\begin{tabular}{|c|c|c|c|c|c|c|c|}
\hline & $\begin{array}{l}\text { Bruttoinlands- } \\
\text { produkt } \\
\text { (in Mio. Landes- } \\
\text { währung) }{ }^{2}\end{array}$ & $\begin{array}{c}\text { Bruttoinlands- } \\
\text { produkt } \\
\text { (angepasst an } \\
\text { das Haushalts- } \\
\text { jahr) }\end{array}$ & \begin{tabular}{|c|} 
Öffentliche \\
Gesamtausgaben \\
(in Mio. \\
Landeswährung)
\end{tabular} & $\begin{array}{l}\text { Gesamtbevölke- } \\
\text { rung in Tausend } \\
\text { (Schätzung } \\
\text { zur Mitte des } \\
\text { Jahres) }\end{array}$ & \begin{tabular}{|c} 
Kaufkraftparität \\
(KKP) für das BIP \\
$($ US-Dollar $=1)$
\end{tabular} & \begin{tabular}{|c} 
Kaufkraftparität \\
$($ KKP) für das BIP \\
(Eurozone $=1$ )
\end{tabular} & $\begin{array}{c}\text { Kaufkraftparität } \\
\text { (KKP) für den } \\
\text { privaten } \\
\text { Verbrauch } \\
\text { (US-Dollar = 1) }\end{array}$ \\
\hline & (1) & (2) & (3) & (4) & (5) & (6) & (7) \\
\hline \multicolumn{8}{|l|}{ OECD-Länder } \\
\hline Australien & 1401168 & & 473579 & 22446 & 1,530 & 1,889 & 1,581 \\
\hline Österreich & 286397 & & 150328 & 8388 & 0,845 & 1,043 & 0,857 \\
\hline Belgien & 356125 & & 187615 & 10883 & 0,864 & 1,067 & 0,906 \\
\hline Kanada ${ }^{4}$ & 1624608 & 1576830 & 638212 & 33730 & 1,200 & 1,482 & 1,300 \\
\hline Chile $^{5}$ & 120232603 & & 27847954 & 17268 & 402,196 & 496,538 & 370,164 \\
\hline Tschechien & 3799547 & & 1665240 & 10517 & 14,243 & 17,584 & 15,565 \\
\hline Dänemark & 1761116 & & 1014512 & 5546 & 7,821 & 9,656 & 8,571 \\
\hline Estland & 14323 & & 5811 & 1340 & 0,532 & 0,657 & 0,621 \\
\hline Finnland & 178796 & & 99835 & 5363 & 0,925 & 1,142 & 1,002 \\
\hline Frankreich & 1937261 & & 1095602 & 64824 & 0,869 & 1,073 & 0,902 \\
\hline Deutschland & 2496200 & & 1185750 & 81757 & 0,811 & 1,001 & 0,850 \\
\hline Griechenland & 222152 & & 114213 & 11308 & 0,713 & 0,881 & 0,779 \\
\hline Ungarn & 26607339 & & 13227838 & 10000 & 129,005 & 159,265 & 145,007 \\
\hline Island & 1536512 & & 791880 & 318 & 136,066 & 167,983 & 145,921 \\
\hline Irland & 156487 & & 103923 & 4476 & 0,853 & 1,053 & 0,962 \\
\hline Israel & 813938 & & 356355 & 7624 & 4,021 & 4,964 & 4,47 \\
\hline Italien & 1553083 & & 782301 & 60483 & 0,800 & 0,987 & 0,839 \\
\hline Japan $^{6}$ & 481773200 & 478985700 & 196120100 & 128057 & 106,765 & 131,809 & 121,366 \\
\hline Korea & 1173274900 & & 353006600 & 49410 & 823,673 & 1016,881 & 910,471 \\
\hline Luxemburg & 39906 & & 17085 & 508 & 0,929 & 1,146 & 0,994 \\
\hline Mexiko & 13043195 & & 3355288 & 108292 & 7,927 & 9,786 & 8,953 \\
\hline Niederlande & 588740 & & 301213 & 16612 & 0,850 & 1,050 & 0,882 \\
\hline Neuseeland & 197068 & & 70450 & 4384 & 1,517 & 1,873 & 1,607 \\
\hline Norwegen $^{7}$ & 1985014 & & 1148189 & 4889 & 9,058 & 11,182 & 9,806 \\
\hline Polen & 1416585 & & 642088 & 38187 & 1,852 & 2,286 & 1,992 \\
\hline Portugal & 172670 & & 88726 & 10637 & 0,636 & 0,785 & 0,715 \\
\hline Slowakei & 65869 & & 26348 & 5430 & 0,523 & 0,646 & 0,58 \\
\hline Slowenien & 35607 & & 17748 & 2049 & 0,652 & 0,805 & 0,708 \\
\hline Spanien & 1048883 & & 479645 & 46073 & 0,721 & 0,890 & 0,790 \\
\hline Schweden & 3337531 & & 1743435 & 9378 & 9,067 & 11,194 & 9,464 \\
\hline Schweiz & 574314 & & 189408 & 7786 & 1,506 & 1,860 & 1,654 \\
\hline Türkei & 1098799 & & 428909 & 73003 & 0,954 & 1,178 & 1,147 \\
\hline Vereinigtes Königreich & 1466569 & 1412028 & 735606 & 62262 & 0,667 & 0,824 & 0,705 \\
\hline Vereinigte Staaten & 14419400 & 14280450 & 6153839 & 309774 & 1 & 1,235 & 1 \\
\hline \multicolumn{3}{|l|}{ Eurozone } & \multicolumn{5}{|c|}{0,810} \\
\hline \multicolumn{8}{|l|}{ Sonstige G20-Länder } \\
\hline Argentinien & 1442655 & & $\mathrm{~m}$ & 40519 & 2224 & 2770 & $\mathrm{~m}$ \\
\hline Brasilien & 3770085 & & 1211373 & 190756 & 1,577 & 1,946 & $\mathrm{~m}$ \\
\hline China & 40151280 & & $\mathrm{~m}$ & 1340910 & 3,964 & $\mathrm{~m}$ & $\mathrm{~m}$ \\
\hline Indien & $\mathrm{m}$ & & $\mathrm{m}$ & $\mathrm{m}$ & 18,525 & $\mathrm{~m}$ & $\mathrm{~m}$ \\
\hline Indonesien 5 & 7427086082 & & $\mathrm{~m}$ & 242206 & 6610,849 & 8161,542 & $\mathrm{~m}$ \\
\hline Russische Föderation & 45172748 & & 17616656 & 142850 & 15,963 & 19,707 & 17,415 \\
\hline Saudi-Arabien 5 & $\mathrm{~m}$ & & $\mathrm{~m}$ & $\mathrm{~m}$ & $\mathrm{~m}$ & $m$ & $\mathrm{~m}$ \\
\hline Südafrika & 2664269 & & $\mathrm{~m}$ & 50034 & 5,051 & $\mathrm{~m}$ & $\mathrm{~m}$ \\
\hline
\end{tabular}

1. Angaben zu BIP, KKP und öffentlichen Gesamtausgaben für Länder der Eurozone in Euro. 2. BIP in Australien sowie BIP und öffentliche Gesamtausgaben in Neuseeland für das Haushaltsjahr berechnet. 3. Bei Ländern, für die das BIP nicht für denselben Referenzzeitraum wie die Daten zu den Bildungsfinanzen angegeben wurde, wurde das BIP geschätzt als $w_{t-1}\left(B I P_{t-1}\right)+w_{t}\left(B I P_{t}\right)$, mit $w_{t}$ und $w_{t-1}$ als Gewichtung für die entsprechenden Anteile der beiden Referenzzeiträume für das BIP innerhalb des Haushaltsjahres für Bildung. In Kapitel B wurden für Japan, Kanada, das Vereinigte Königreich und die Vereinigten Staaten Anpassungen vorgenommen. 4. Referenzjahr 2009. 5. Referenzjahr 2011. 6. Öffentliche Gesamtausgaben an das Haushaltsjahr angepasst. 7. Für Norwegen wird der BIP-Festlandmarktwert verwendet.

Quelle: OECD. Hinweise s. Anhang 3 unter www.oecd.org/edu/eag.htm. StatLink: http://dx.doi.org/10.1787/888932852238 Erläuterung der Kennzeichnung fehlender Daten s. Hinweise für den Leser. 
Tabelle X2.2b

Grundlegende statistische Bezugsdaten (Referenzzeitraum: Kalenderjahr 1995, 2000, 2005, 2010) ${ }^{1}$

\begin{tabular}{|c|c|c|c|c|c|c|c|c|c|c|}
\hline & \multicolumn{3}{|c|}{$\begin{array}{l}\text { Bruttoinlandsprodukt } \\
\text { (in Mio. Landeswährung, } \\
\text { zu jeweiligen Preisen) }\end{array}$} & \multicolumn{3}{|c|}{$\begin{array}{l}\text { Öffentliche Gesamtausgaben } \\
\text { (in Mio. Landeswährung, } \\
\text { zu jeweiligen Preisen) }\end{array}$} & \multicolumn{4}{|c|}{$\begin{array}{c}\text { Veränderung des BIP } \\
(2005=100, \text { zu konstanten Preisen }\end{array}$} \\
\hline & 1995 & 2000 & 2005 & 1995 & 2000 & 2005 & 1995 & 2000 & 2005 & 2010 \\
\hline & (1) & (2) & (3) & (4) & (5) & (6) & (7) & (8) & (9) & (10) \\
\hline \multicolumn{11}{|l|}{ OECD-Länder } \\
\hline Australien & 529705 & 706895 & 994803 & 184270 & 225913 & 309431 & 70 & 84 & 100 & 114 \\
\hline Österreich & 174794 & 208474 & 245243 & 98361 & 108175 & 122585 & 79 & 92 & 100 & 107 \\
\hline Belgien & 207927 & 252543 & 303435 & 108336 & 123943 & 157976 & 80 & 92 & 100 & 106 \\
\hline Kanada & 810426 & 1076577 & 1373845 & 392886 & 442560 & 539234 & 72 & 88 & 100 & 106 \\
\hline Chile $^{2}$ & $\mathrm{~m}$ & $\mathrm{~m}$ & 82018171 & $\mathrm{~m}$ & $\mathrm{~m}$ & 15327440 & 62 & 76 & 100 & 121 \\
\hline Tschechien & 1533676 & 2269695 & 3116056 & 798790 & 915413 & 1340123 & 75 & 82 & 100 & 114 \\
\hline Dänemark & 1019545 & 1293963 & 1545257 & 604404 & 694479 & 815717 & 82 & 94 & 100 & 100 \\
\hline Estland & 2767 & 6160 & 11182 & 17866 & 34815 & 3757 & 51 & 71 & 100 & 101 \\
\hline Finnland & 96064 & 132195 & 157429 & 58947 & 63794 & 79325 & 69 & 88 & 100 & 104 \\
\hline Frankreich & 1196181 & 1439603 & 1718047 & 650606 & 744119 & 920351 & 81 & 92 & 100 & 103 \\
\hline Deutschland & 1848500 & 2047500 & 2224400 & 1014050 & 923360 & 1043450 & 89 & 97 & 100 & 107 \\
\hline Griechenland & 88742 & 135043 & 193050 & 40783 & 63627 & 86097 & 69 & 82 & 100 & 100 \\
\hline Ungarn & 5727829 & 13089047 & 22018283 & 3197916 & 6251647 & 11032047 & 71 & 82 & 100 & 99 \\
\hline Island & 454013 & 683747 & 1025740 & $\mathrm{~m}$ & 286259 & 433346 & 64 & 81 & 100 & 101 \\
\hline Irland & 53787 & 105775 & 163037 & 21841 & 32836 & 54993 & 48 & 78 & 100 & 102 \\
\hline Israel & 289555 & 506173 & 600011 & 149518 & 239809 & 273209 & 71 & 90 & 100 & 124 \\
\hline Italien & 952158 & 1198292 & 1436379 & 497487 & 550032 & 688251 & 87 & 95 & 100 & 99 \\
\hline Japan & 501706900 & 509860000 & 503903000 & 181284700 & 193917400 & 183659700 & 90 & 94 & 100 & 101 \\
\hline Korea & 409653600 & 603236000 & 865240900 & 83399300 & 135324800 & 230062600 & 62 & 80 & 100 & 121 \\
\hline Luxemburg & 15108 & 21998 & 30270 & 5996 & 8270 & 12573 & 62 & 84 & 100 & 110 \\
\hline Mexiko & 2013954 & 6020649 & 9220649 & 384960 & 1139998 & 1979808 & 70 & 91 & 100 & 109 \\
\hline Niederlande & 305261 & 417960 & 513407 & 172305 & 184612 & 229965 & 77 & 94 & 100 & 107 \\
\hline Neuseeland & 94545 & 117508 & 160573 & 31743 & $\mathrm{~m}$ & 62645 & 72 & 83 & 100 & 106 \\
\hline Norwegen $^{3}$ & 806858 & 1113894 & 1464974 & 480575 & 626569 & 818805 & 73 & 87 & 100 & 112 \\
\hline Polen & 337222 & 744378 & 983302 & 147561 & 294012 & 427147 & 66 & 86 & 100 & 126 \\
\hline Portugal & 87841 & 127317 & 154269 & 36447 & 52237 & 70363 & 78 & 96 & 100 & 102 \\
\hline Slowakei & 19319 & 31177 & 49314 & 9392 & 16255 & 18730 & 67 & 79 & 100 & 126 \\
\hline Slowenien & 10357 & 18566 & 28722 & 0 & 8636 & 13011 & 68 & 84 & 100 & 109 \\
\hline Spanien & 447205 & 629907 & 909298 & 198730 & 246542 & 349501 & 70 & 85 & 100 & 104 \\
\hline Schweden & 1809575 & 2265447 & 2769375 & 1175180 & 1248029 & 1491382 & 74 & 88 & 100 & 108 \\
\hline Schweiz & 383096 & 432405 & 479088 & 139873 & 151837 & 176236 & 85 & 94 & 100 & 111 \\
\hline Türkei & 10435 & 166658 & 648932 & $\mathrm{~m}$ & $\mathrm{~m}$ & $\mathrm{~m}$ & 65 & 80 & 100 & 117 \\
\hline Ver. Königreich & 733266 & 975294 & 1262710 & 322956 & 381199 & 553045 & 73 & 86 & 100 & 103 \\
\hline $\begin{array}{l}\text { Vereinigte Staaten } \\
\text { Sonst. G20-Länder }\end{array}$ & 7359300 & 9898800 & 12564300 & 2732629 & 3353547 & 4563353 & 72 & 89 & 100 & 103 \\
\hline Brasilien & 646192 & 1179482 & 2147944 & 224283 & 394349 & 670514 & $m$ & $\mathrm{~m}$ & $\mathrm{~m}$ & $\mathrm{~m}$ \\
\hline Russische Föd. & 499375940 & 1389769900 & 2774281100 & $\mathrm{~m}$ & 2016630 & 7380575 & 69 & 74 & 100 & 119 \\
\hline
\end{tabular}

1. Angaben zu BIP und öffentlichen Gesamtausgaben für Länder der Eurozone in Euro. 2. Referenzjahre 1996, 2001,2006 und 2011 anstelle 1995, 2000,2005 und 2010. 3. Für Norwegen wird der BIP-Festlandmarktwert verwendet.

Quelle: OECD. Hinweise s. Anhang 3 unter www.oecd.org/edu/eag.htm. StatLink: http://dx.doi.org/10.1787/888932852257

Erläuterung der Kennzeichnung fehlender Daten s. Hinweise für den Leser. 
Gesetzliche bzw. vertraglich vereinbarte Gehälter von Lehrkräften zu unterschiedlichen Zeitpunkten in ihrer beruflichen Laufbahn (2011)

Jahresgehälter von Lehrkräften an öffentlichen Bildungseinrichtungen, in Landeswährung

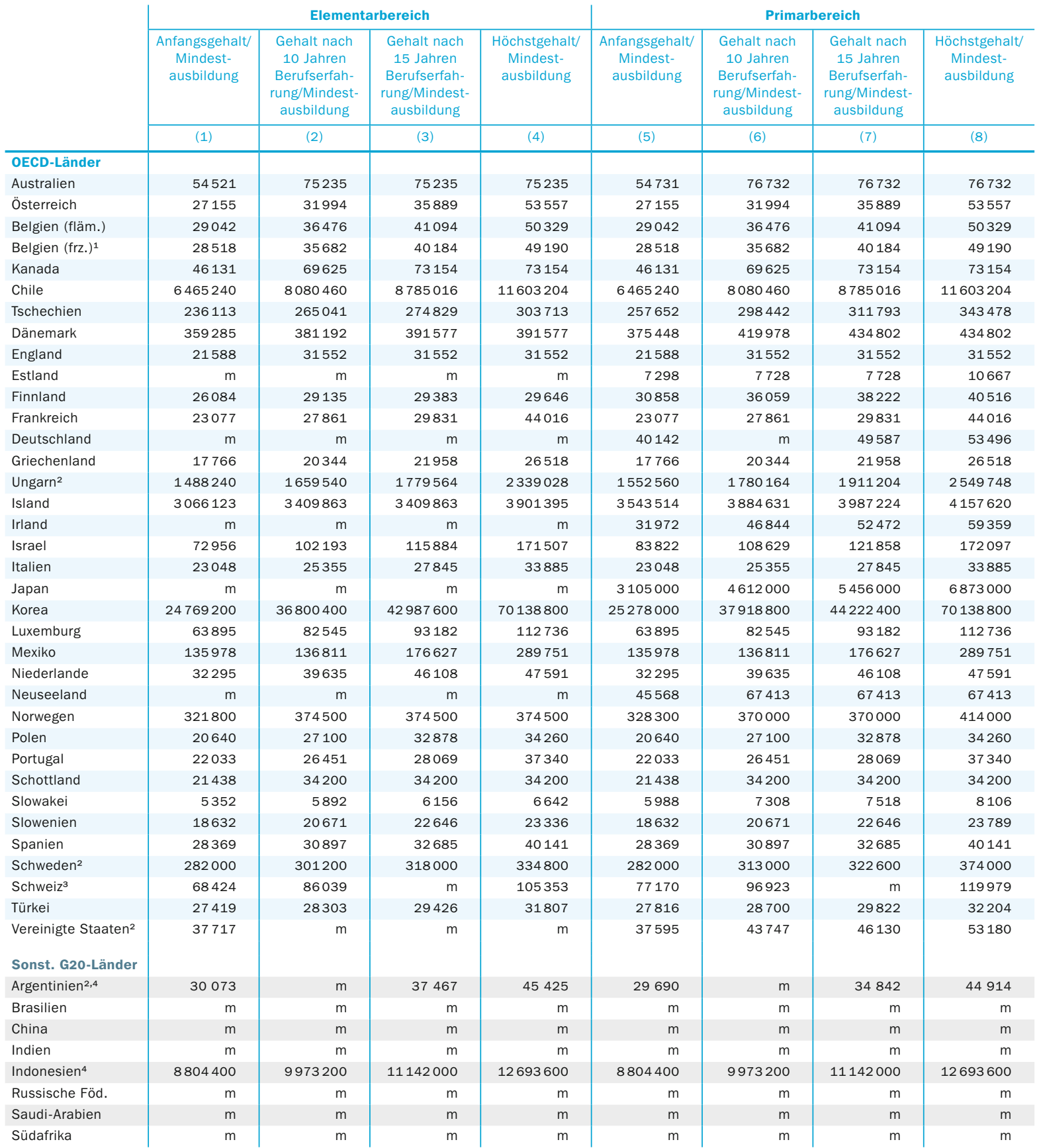

1. Gehälter von Lehrkräften mit den typischen Qualifikationen anstelle der Mindestausbildung. Weitere Hinweise zu den Gehältern von Lehrkräften mit Mindestausbildung s. Anhang 3. 2. Tatsächliche Grundgehälter. 3. Spalten (2), (6), (10) und (14): Gehalt nach 11 Jahren Berufserfahrung. 4. Referenzjahr 2010. Quelle: OECD. Hinweise s. Anhang 3 unter www.oecd.org/edu/eag.htm. StatLink: http://dx.doi.org/10.1787/888932852295 Erläuterung der Kennzeichnung fehlender Daten s. Hinweise für den Leser. 
Tabelle X2.3a (Forts.)

Gesetzliche bzw. vertraglich vereinbarte Gehälter von Lehrkräften zu unterschiedlichen Zeitpunkten in ihrer beruflichen Laufbahn (2011)

Jahresgehälter von Lehrkräften an öffentlichen Bildungseinrichtungen, in Landeswährung

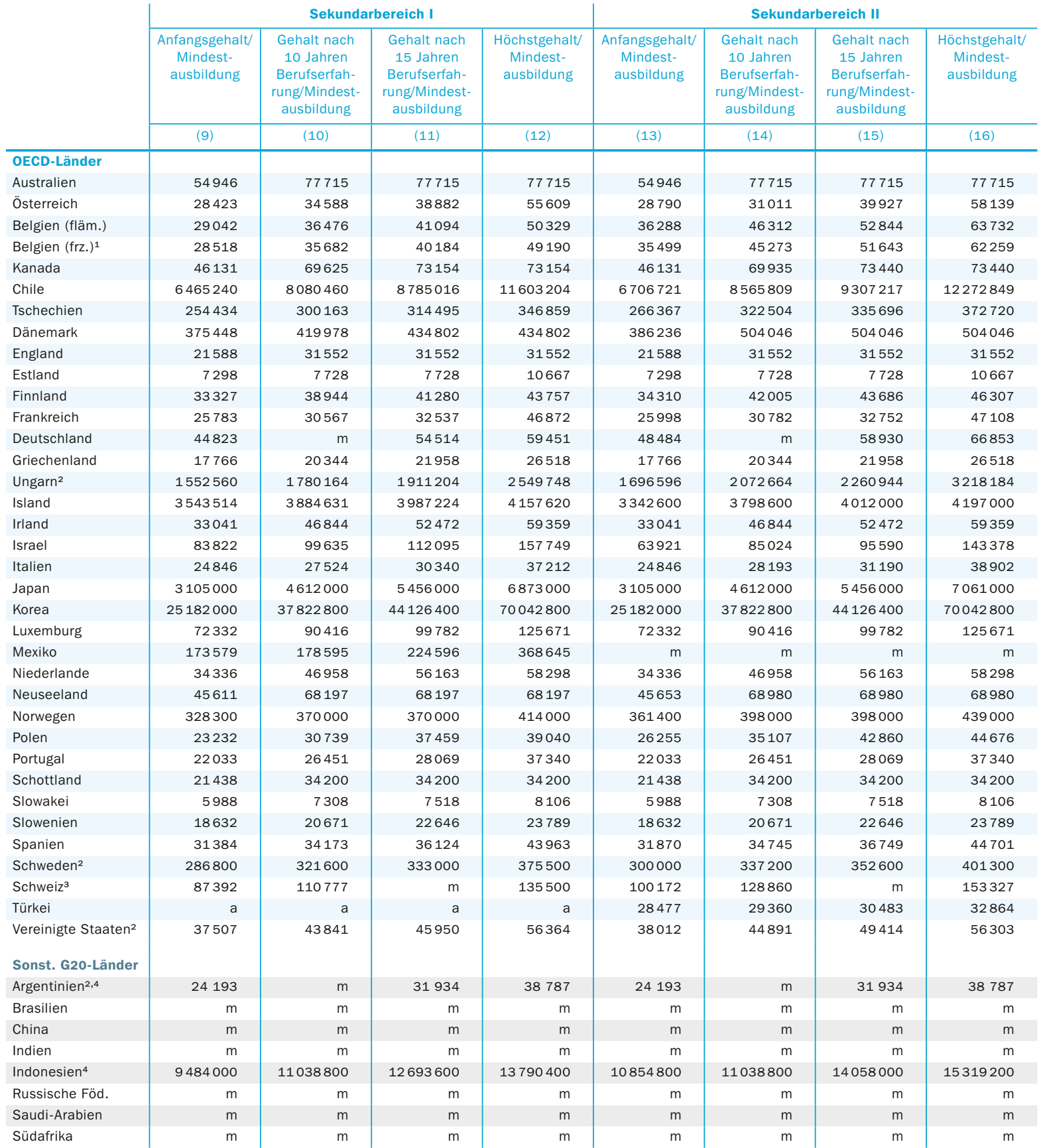

1. Gehälter von Lehrkräften mit den typischen Qualifikationen anstelle der Mindestausbildung. Weitere Hinweise zu den Gehältern von Lehrkräften mit Mindestausbildung s. Anhang 3. 2. Tatsächliche Grundgehälter. 3. Spalten (2), (6), (10) und (14): Gehalt nach 11 Jahren Berufserfahrung. 4. Referenzjahr 2010. Quelle: OECD. Hinweise s. Anhang 3 unter www.oecd.org/edu/eag.htm. StatLink: http://dx.doi.org/10.1787/888932852295 
Entwicklung der Gehälter von Lehrkräften zwischen 2000 und $2011^{1}$

Gesetzliche bzw. vertraglich vereinbarte Jahresgehälter von Lehrkräften an öffentlichen Bildungseinrichtungen nach 15 Jahren Berufserfahrung (Mindestausbildung), nach Bildungsbereich, in Landeswährung

\begin{tabular}{|c|c|c|c|c|c|c|c|c|c|c|c|c|}
\hline & \multicolumn{8}{|c|}{ Primarbereich } & \multicolumn{4}{|c|}{ Sekundarbereich I } \\
\hline & 2000 & 2005 & 2006 & 2007 & 2008 & 2009 & 2010 & 2011 & 2000 & 2005 & 2006 & 2007 \\
\hline & (1) & (2) & (3) & (4) & (5) & (6) & (7) & (8) & (9) & (10) & (11) & (12) \\
\hline \multicolumn{13}{|l|}{ OECD-Länder } \\
\hline Australien & 50995 & 62240 & 61243 & 63977 & 68586 & 70696 & 73706 & 76732 & 51016 & 62384 & 62106 & 64984 \\
\hline Österreich & 25826 & 31050 & 31935 & 32830 & 33717 & 34848 & 35526 & 35889 & 26916 & 33635 & 34418 & 35467 \\
\hline Belgien (fläm.) & 29579 & 35417 & 36390 & 37236 & 37432 & 39670 & 40042 & 41094 & 31191 & 35417 & 36390 & 37236 \\
\hline Belgien (frz.) & 28638 & 33598 & 34825 & 35697 & 35917 & 38872 & 38875 & 40184 & 30482 & 33973 & 34825 & 35697 \\
\hline Kanada & $\mathrm{m}$ & $\mathrm{m}$ & $\mathrm{m}$ & $\mathrm{m}$ & $\mathrm{m}$ & $\mathrm{m}$ & 71608 & 73154 & $\mathrm{~m}$ & $\mathrm{~m}$ & $\mathrm{~m}$ & $\mathrm{~m}$ \\
\hline Chile & $\mathrm{m}$ & $\mathrm{m}$ & 4430124 & 4636394 & $\mathrm{~m}$ & 8257733 & 8493461 & 8785016 & $\mathrm{~m}$ & $\mathrm{~m}$ & 4430124 & 4636394 \\
\hline Tschechien & 125501 & 250559 & 254921 & 302856 & 309994 & 323789 & 310711 & 311793 & 125501 & 250559 & 254921 & 302856 \\
\hline Dänemark & 285200 & 332015 & 341001 & 346569 & 362222 & 434439 & 434802 & 434802 & 285200 & 332015 & 341001 & 346569 \\
\hline England & 23193 & 27123 & 28005 & 28707 & 29427 & 30148 & 30842 & 31552 & 23193 & 27123 & 28005 & 28707 \\
\hline Estland & 3068 & 4379 & 5039 & 6013 & 7264 & 8038 & 7728 & 7728 & 3068 & 4379 & 5039 & 6013 \\
\hline Finnland & 26506 & 33171 & 33868 & 35299 & 36540 & 37417 & 37769 & 38222 & 31115 & 36109 & 36867 & 38123 \\
\hline Frankreich & 27288 & 28395 & 28791 & 29097 & 29271 & 29438 & 29674 & 29831 & 29456 & 30667 & 31068 & 31274 \\
\hline Deutschland & $\mathrm{m}$ & $\mathrm{m}$ & $\mathrm{m}$ & $\mathrm{m}$ & $\mathrm{m}$ & 46134 & 47647 & 49587 & $\mathrm{~m}$ & $\mathrm{~m}$ & $\mathrm{~m}$ & $\mathrm{~m}$ \\
\hline Griechenland & 16292 & 21237 & 21872 & 22989 & 24146 & 25001 & 22707 & 21958 & 16292 & 21237 & 21872 & 22989 \\
\hline Ungarn ${ }^{2}$ & 897168 & 1944576 & 1970676 & 1983240 & 2059668 & 1914504 & 1916568 & 1911204 & 897168 & 1944576 & 1970676 & 1983240 \\
\hline Island & 1884000 & 2573556 & 2837950 & 2830814 & 3268766 & 3987224 & 3987224 & 3987224 & 1884000 & 2573556 & 2837950 & 2830814 \\
\hline Irland & 33370 & 46591 & 49421 & 52177 & 53221 & 55916 & 53620 & 52472 & 33729 & 46591 & 49421 & 52177 \\
\hline Israel & 68421 & 73496 & 77475 & 86089 & 94432 & 105899 & 112005 & 121858 & 76048 & 82030 & 86256 & 86838 \\
\hline Italien & 20849 & 25234 & 25528 & 25799 & 26470 & 27374 & 27645 & 27845 & 22836 & 27487 & 27797 & 28095 \\
\hline Japan & 6645000 & 6236000 & 6235725 & 5958000 & 5753000 & 5720000 & 5555000 & 5456000 & 6645000 & 6236000 & 6235725 & 5958000 \\
\hline Korea & 26757000 & 39712000 & 40841220 & 41387505 & 42003300 & 42003300 & 42003257 & 44222400 & 26661000 & 39616000 & 40745220 & 41291505 \\
\hline Luxemburg & $\mathrm{m}$ & 62139 & 63692 & 65284 & 64244 & 67230 & 93182 & 93182 & $\mathrm{~m}$ & 81258 & 83289 & 85371 \\
\hline Mexiko & 86748 & 124082 & 130526 & 137323 & 145917 & 155022 & 163419 & 176627 & 109779 & 157816 & 166107 & 174854 \\
\hline Niederlande & $\mathrm{m}$ & $\mathrm{m}$ & $\mathrm{m}$ & 39463 & 40543 & 42654 & 44288 & 46108 & $\mathrm{~m}$ & $\mathrm{~m}$ & $\mathrm{~m}$ & 47427 \\
\hline Neuseeland & 49450 & 54979 & 56628 & 58327 & 60660 & 63086 & 65609 & 67413 & 49450 & 54979 & 56628 & 58327 \\
\hline Norwegen & $\mathrm{m}$ & 302000 & 305000 & 313000 & 327300 & 337800 & 349000 & 370000 & $\mathrm{~m}$ & 302000 & 305000 & 313000 \\
\hline Polen & $\mathrm{m}$ & 19022 & $\mathrm{~m}$ & $\mathrm{~m}$ & 26944 & 28902 & 30785 & 32878 & $\mathrm{~m}$ & 19022 & $\mathrm{~m}$ & $\mathrm{~m}$ \\
\hline Portugal & 17180 & 22775 & 23186 & 23541 & 23987 & 26763 & 27038 & 28069 & 17180 & 22775 & 23186 & 23541 \\
\hline Schottland & 22743 & 29827 & 30602 & 31241 & 32052 & 32855 & 33666 & 34200 & 22743 & 29827 & 30602 & 31241 \\
\hline Slowakei & $\mathrm{m}$ & $\mathrm{m}$ & $\mathrm{m}$ & $\mathrm{m}$ & $\mathrm{m}$ & 7276 & 7492 & 7518 & $\mathrm{~m}$ & $\mathrm{~m}$ & $\mathrm{~m}$ & $\mathrm{~m}$ \\
\hline Slowenien & $\mathrm{m}$ & 17939 & 19025 & 20005 & 20911 & 22361 & 22433 & 22646 & $\mathrm{~m}$ & 17939 & 19025 & 20005 \\
\hline Spanien & 22701 & 28122 & 29347 & 29934 & 32193 & 33754 & 33889 & 32685 & 24528 & 31561 & 32922 & 33580 \\
\hline Schweden ${ }^{2}$ & 248300 & 283200 & $\mathrm{~m}$ & 298800 & $\mathrm{~m}$ & 313600 & $\mathrm{~m}$ & 322600 & 248300 & 290400 & $\mathrm{~m}$ & 306300 \\
\hline Schweiz $^{3}$ & 85513 & 90483 & 89909 & 91017 & 92617 & 96918 & 96241 & 96923 & 102409 & 103037 & 102985 & 104157 \\
\hline Türkei & 2638 & 17166 & 17609 & 19822 & 22114 & 25043 & 28144 & 29822 & a & a & a & a \\
\hline $\begin{array}{l}\text { Ver. Staaten² } \\
\text { Sonstige } \\
\text { G20-Länder }\end{array}$ & 35323 & 40734 & 42404 & 43633 & 44172 & 44788 & 45226 & 46130 & 35185 & 41090 & 42775 & 44015 \\
\hline Argentinien ${ }^{2}$ & $\mathrm{~m}$ & $\mathrm{~m}$ & $\mathrm{~m}$ & $\mathrm{~m}$ & $\mathrm{~m}$ & 30574 & 34842 & $\mathrm{~m}$ & $\mathrm{~m}$ & $\mathrm{~m}$ & $\mathrm{~m}$ & $\mathrm{~m}$ \\
\hline Brasilien & $\mathrm{m}$ & $\mathrm{m}$ & $\mathrm{m}$ & $\mathrm{m}$ & $\mathrm{m}$ & $\mathrm{m}$ & $\mathrm{m}$ & $\mathrm{m}$ & $\mathrm{m}$ & $\mathrm{m}$ & $\mathrm{m}$ & $\mathrm{m}$ \\
\hline China & $\mathrm{m}$ & $\mathrm{m}$ & $\mathrm{m}$ & $\mathrm{m}$ & $\mathrm{m}$ & $\mathrm{m}$ & $\mathrm{m}$ & $\mathrm{m}$ & $\mathrm{m}$ & $\mathrm{m}$ & $\mathrm{m}$ & $\mathrm{m}$ \\
\hline Indien & $\mathrm{m}$ & $\mathrm{m}$ & $\mathrm{m}$ & $\mathrm{m}$ & $\mathrm{m}$ & $\mathrm{m}$ & $\mathrm{m}$ & $\mathrm{m}$ & $\mathrm{m}$ & $\mathrm{m}$ & $\mathrm{m}$ & $\mathrm{m}$ \\
\hline Indonesien & $\mathrm{m}$ & $\mathrm{m}$ & $\mathrm{m}$ & 11142000 & 11142000 & 11142000 & 11142000 & $\mathrm{~m}$ & $\mathrm{~m}$ & $\mathrm{~m}$ & $\mathrm{~m}$ & 11142000 \\
\hline Russische Föd. & $\mathrm{m}$ & $\mathrm{m}$ & $\mathrm{m}$ & $\mathrm{m}$ & $\mathrm{m}$ & $\mathrm{m}$ & $\mathrm{m}$ & $\mathrm{m}$ & $\mathrm{m}$ & $\mathrm{m}$ & $\mathrm{m}$ & $\mathrm{m}$ \\
\hline Saudi-Arabien & $\mathrm{m}$ & $\mathrm{m}$ & $\mathrm{m}$ & $\mathrm{m}$ & $\mathrm{m}$ & $\mathrm{m}$ & $\mathrm{m}$ & $\mathrm{m}$ & $\mathrm{m}$ & $\mathrm{m}$ & $\mathrm{m}$ & $\mathrm{m}$ \\
\hline Südafrika & $\mathrm{m}$ & $\mathrm{m}$ & $\mathrm{m}$ & $\mathrm{m}$ & $\mathrm{m}$ & $\mathrm{m}$ & $\mathrm{m}$ & $\mathrm{m}$ & $\mathrm{m}$ & $\mathrm{m}$ & $\mathrm{m}$ & $\mathrm{m}$ \\
\hline
\end{tabular}

1. Angaben zu den Gehältern der Lehrkräfte in Ländern der aktuellen Eurozone in Euro. 2. Tatsächliche Grundgehälter. 3. Gehälter nach 11 Jahren Berufserfahrung.

Quelle: OECD. Argentinien: Statistikinstitut der UNESCO (World Education Indicators Programme). Hinweise s. Anhang 3 unter www.oecd.org/edu/eag. htm. StatLink: http://dx.doi.org/10.1787/888932852314

Erläuterung der Kennzeichnung fehlender Daten s. Hinweise für den Leser. 
Tabelle X2.3b (Forts.)

Entwicklung der Gehälter von Lehrkräften zwischen 2000 und $2011^{1}$

Gesetzliche bzw. vertraglich vereinbarte Jahresgehälter von Lehrkräften an öffentlichen Bildungseinrichtungen nach 15 Jahren Berufserfahrung (Mindestausbildung), nach Bildungsbereich, in Landeswährung

\begin{tabular}{|c|c|c|c|c|c|c|c|c|c|c|c|c|}
\hline & \multicolumn{4}{|c|}{ Sekundarbereich I } & \multicolumn{8}{|c|}{ Sekundarbereich II } \\
\hline & 2008 & 2009 & 2010 & 2011 & 2000 & 2005 & 2006 & 2007 & 2008 & 2009 & 2010 & 2011 \\
\hline & (13) & (14) & (15) & (16) & (17) & (18) & (19) & (20) & (21) & (22) & (23) & (24) \\
\hline \multicolumn{13}{|l|}{ OECD-Länder } \\
\hline Australien & 69794 & 70696 & 73706 & 77715 & 51016 & 62384 & 62106 & 64984 & 69794 & 70696 & 73706 & 77715 \\
\hline Österreich & 36455 & 37664 & 38451 & 38882 & 29728 & 34265 & 35273 & 36493 & 37508 & 38787 & 39535 & 39927 \\
\hline Belgien (fläm.) & 37432 & 39670 & 40042 & 41094 & 39886 & 45301 & 46477 & 47644 & 47976 & 50852 & 51454 & 52844 \\
\hline Belgien (frz.) & 35917 & 38872 & 38875 & 40184 & 39207 & 43704 & 44750 & 45820 & 46039 & 50106 & 50108 & 51643 \\
\hline Kanada & $\mathrm{m}$ & $\mathrm{m}$ & 71608 & 73154 & $\mathrm{~m}$ & $\mathrm{~m}$ & $\mathrm{~m}$ & $\mathrm{~m}$ & $\mathrm{~m}$ & $\mathrm{~m}$ & 71886 & 73440 \\
\hline Chile & $\mathrm{m}$ & 8257733 & 8493461 & 8785016 & $\mathrm{~m}$ & $\mathrm{~m}$ & 4638231 & 4852425 & $\mathrm{~m}$ & 8638812 & 9004818 & 9307217 \\
\hline Tschechien & 316173 & 330923 & 314897 & 314495 & 152941 & 255125 & 258535 & 323566 & 337024 & 347334 & 334084 & 335696 \\
\hline Dänemark & 362222 & 434439 & 434802 & 434802 & 335000 & 404229 & 424212 & 423426 & 436926 & 497723 & 504046 & 504046 \\
\hline England & 29427 & 30148 & 30842 & 31552 & 23193 & 27123 & 28005 & 28707 & 29427 & 30148 & 30842 & 31552 \\
\hline Estland & 7264 & 8038 & 7728 & 7728 & 3068 & 4379 & 5039 & 6013 & 7264 & 8038 & 7728 & 7728 \\
\hline Finnland & 39464 & 40411 & 40791 & 41280 & 32681 & 38263 & 39066 & 40396 & 41805 & 42808 & 43168 & 43686 \\
\hline Frankreich & 31461 & 31641 & 32258 & 32537 & 29456 & 30895 & 31296 & 31525 & 31715 & 31896 & 32472 & 32752 \\
\hline Deutschland & $\mathrm{m}$ & 50929 & 52784 & 54514 & $\mathrm{~m}$ & $\mathrm{~m}$ & $\mathrm{~m}$ & $\mathrm{~m}$ & $\mathrm{~m}$ & 55533 & 57150 & 58930 \\
\hline Griechenland & 24146 & 25001 & 22707 & 21958 & 16292 & 21237 & 21872 & 22989 & 24146 & 25001 & 22707 & 21958 \\
\hline Ungarn² & 2059668 & 1914504 & 1916568 & 1911204 & 1128996 & 2432388 & 2358240 & 2474508 & 2474388 & 2298900 & 2262636 & 2260944 \\
\hline Island & 3268766 & 3987224 & 3987224 & 3987224 & 2220000 & 3014000 & 3446964 & 3619000 & 3840000 & 4025000 & 4012000 & 4012000 \\
\hline Irland & 53221 & 55916 & 53620 & 52472 & 33729 & 46591 & 49421 & 52177 & 53221 & 55916 & 53620 & 52472 \\
\hline Israel & 95405 & 99247 & 102514 & 112095 & 75097 & 80052 & 84190 & 85118 & 93786 & 91563 & 93450 & 95590 \\
\hline Italien & 28831 & 29824 & 30121 & 30340 & 23518 & 28259 & 28574 & 28880 & 29637 & 30661 & 30966 & 31190 \\
\hline Japan & 5753000 & 5720000 & 5555000 & 5456000 & 6649000 & 6237000 & 6235725 & 5958000 & 5753000 & 5720000 & 5555000 & 5456000 \\
\hline Korea & 41907300 & 41907300 & 41907257 & 44126400 & 26661000 & 39616000 & 40745220 & 41291505 & 41907300 & 41907300 & 41907257 & 44126400 \\
\hline Luxemburg & 93772 & 101058 & 99782 & 99782 & $\mathrm{~m}$ & 81258 & 83289 & 85371 & 93772 & 101058 & 99782 & 99782 \\
\hline Mexiko & 185616 & 196707 & 209350 & 224596 & $\mathrm{~m}$ & $m$ & $\mathrm{~m}$ & $m$ & $\mathrm{~m}$ & $\mathrm{~m}$ & $\mathrm{~m}$ & $\mathrm{~m}$ \\
\hline Niederlande & 48615 & 50955 & 53984 & 56163 & $\mathrm{~m}$ & $m$ & $\mathrm{~m}$ & 47427 & 48615 & 50955 & 53984 & 56163 \\
\hline Neuseeland & 60660 & 63086 & 67295 & 68197 & 49450 & 54979 & 56628 & 58327 & 60660 & 63086 & 68980 & 68980 \\
\hline Norwegen & 327300 & 337800 & 349000 & 370000 & $\mathrm{~m}$ & 321000 & 324000 & 332500 & 347300 & 362800 & 376400 & 398000 \\
\hline Polen & 30850 & 32920 & 35071 & 37459 & $\mathrm{~m}$ & 19022 & $\mathrm{~m}$ & $\mathrm{~m}$ & 35459 & 37670 & 40120 & 42860 \\
\hline Portugal & 23987 & 26763 & 27038 & 28069 & 17180 & 22775 & 23186 & 23541 & 23987 & 26763 & 27038 & 28069 \\
\hline Schottland & 32052 & 32855 & 33666 & 34200 & 22743 & 29827 & 30602 & 31241 & 32052 & 32855 & 33666 & 34200 \\
\hline Slowakei & $\mathrm{m}$ & 7276 & 7492 & 7518 & $\mathrm{~m}$ & $\mathrm{~m}$ & $\mathrm{~m}$ & $\mathrm{~m}$ & $\mathrm{~m}$ & 7276 & 7498 & 7518 \\
\hline Slowenien & 20911 & 22361 & 22433 & 22646 & $\mathrm{~m}$ & 17939 & 19025 & 20005 & 20911 & 22361 & 22433 & 22646 \\
\hline Spanien & 35200 & 37669 & 37820 & 36124 & 26366 & 32293 & 33666 & 34339 & 36818 & 38459 & 38613 & 36749 \\
\hline Schweden ${ }^{2}$ & $\mathrm{~m}$ & 324000 & $\mathrm{~m}$ & 333000 & 264700 & 313600 & $\mathrm{~m}$ & 326900 & $\mathrm{~m}$ & 342300 & $\mathrm{~m}$ & 352600 \\
\hline Schweiz ${ }^{3}$ & 105874 & 110096 & 109537 & 110777 & 121629 & 120602 & 121187 & 122259 & 124936 & 129158 & 127839 & 128860 \\
\hline Türkei & a & a & a & a & 2441 & 17403 & 18074 & 20329 & 22650 & 25625 & 28883 & 30483 \\
\hline $\begin{array}{l}\text { Ver. Staaten² } \\
\text { Sonstige } \\
\text { G20-Länder }\end{array}$ & 44000 & 44614 & 45049 & 45950 & 37838 & 41044 & 42727 & 43966 & 47317 & 47977 & 48446 & 49414 \\
\hline Argentinien ${ }^{2}$ & $\mathrm{~m}$ & 26455 & 31934 & $\mathrm{~m}$ & $\mathrm{~m}$ & $\mathrm{~m}$ & $\mathrm{~m}$ & $\mathrm{~m}$ & $\mathrm{~m}$ & 26455 & 31934 & $\mathrm{~m}$ \\
\hline Brasilien & $\mathrm{m}$ & $\mathrm{m}$ & $\mathrm{m}$ & $\mathrm{m}$ & $\mathrm{m}$ & $\mathrm{m}$ & $\mathrm{m}$ & $\mathrm{m}$ & $\mathrm{m}$ & $\mathrm{m}$ & $\mathrm{m}$ & $\mathrm{m}$ \\
\hline China & $\mathrm{m}$ & $\mathrm{m}$ & $\mathrm{m}$ & $\mathrm{m}$ & $\mathrm{m}$ & $\mathrm{m}$ & $\mathrm{m}$ & $\mathrm{m}$ & $\mathrm{m}$ & $\mathrm{m}$ & $\mathrm{m}$ & $\mathrm{m}$ \\
\hline Indien & $\mathrm{m}$ & $\mathrm{m}$ & $\mathrm{m}$ & $\mathrm{m}$ & $\mathrm{m}$ & $\mathrm{m}$ & $\mathrm{m}$ & $\mathrm{m}$ & $\mathrm{m}$ & $\mathrm{m}$ & $\mathrm{m}$ & $\mathrm{m}$ \\
\hline Indonesien & 12693600 & 12693600 & 12693600 & $\mathrm{~m}$ & $\mathrm{~m}$ & $\mathrm{~m}$ & $\mathrm{~m}$ & 11142000 & 14058000 & 14058000 & 14058000 & $\mathrm{~m}$ \\
\hline Russische Föd. & $\mathrm{m}$ & $\mathrm{m}$ & $\mathrm{m}$ & $\mathrm{m}$ & $\mathrm{m}$ & $\mathrm{m}$ & $\mathrm{m}$ & $\mathrm{m}$ & $\mathrm{m}$ & $\mathrm{m}$ & $\mathrm{m}$ & $\mathrm{m}$ \\
\hline Saudi-Arabien & $\mathrm{m}$ & $\mathrm{m}$ & $\mathrm{m}$ & $\mathrm{m}$ & $\mathrm{m}$ & $\mathrm{m}$ & $\mathrm{m}$ & $\mathrm{m}$ & $\mathrm{m}$ & $\mathrm{m}$ & $\mathrm{m}$ & $\mathrm{m}$ \\
\hline Südafrika & $\mathrm{m}$ & $\mathrm{m}$ & $\mathrm{m}$ & $\mathrm{m}$ & $\mathrm{m}$ & $\mathrm{m}$ & $\mathrm{m}$ & $\mathrm{m}$ & $\mathrm{m}$ & $\mathrm{m}$ & $\mathrm{m}$ & $\mathrm{m}$ \\
\hline
\end{tabular}

1. Angaben zu den Gehältern der Lehrkräfte in Ländern der aktuellen Eurozone in Euro. 2. Tatsächliche Grundgehälter. 3. Gehälter nach 11 Jahren Berufserfahrung.

Quelle: OECD. Argentinien: Statistikinstitut der UNESCO (World Education Indicators Programme). Hinweise s. Anhang 3 unter www.oecd.org/edu/eag.htm. StatLink: http://dx.doi.org/10.1787/888932852314

Erläuterung der Kennzeichnung fehlender Daten s. Hinweise für den Leser. 
Statistische Bezugsdaten zur Berechnung der Gehälter von Lehrkräften (2000, 2005-2011)

\begin{tabular}{|c|c|c|c|c|c|c|c|c|c|c|c|c|}
\hline & \multicolumn{3}{|c|}{$\begin{array}{l}\text { Kaufkraftparität für den } \\
\text { privaten Verbrauch (KKP) }\end{array}$} & \multicolumn{8}{|c|}{ Deflator des privaten Verbrauchs $(2000=100)$} & \multirow{2}{*}{$\begin{array}{l}\text { Referenz- } \\
\text { jahr für die } \\
\text { Angaben von } \\
\text { Gehältern } \\
\text { in } 2011\end{array}$} \\
\hline & 2010 & 2011 & $\begin{array}{l}\text { Januar } \\
2011\end{array}$ & $\begin{array}{l}\text { Januar } \\
2000\end{array}$ & $\begin{array}{c}\text { Januar } \\
2005\end{array}$ & $\begin{array}{c}\text { Januar } \\
2006\end{array}$ & $\begin{array}{c}\text { Januar } \\
2007\end{array}$ & $\begin{array}{c}\text { Januar } \\
2008\end{array}$ & $\begin{array}{c}\text { Januar } \\
2009\end{array}$ & $\begin{array}{l}\text { Januar } \\
2010\end{array}$ & $\begin{array}{c}\text { Januar } \\
2011\end{array}$ & \\
\hline & (1) & $(2)$ & (3) & (4) & (5) & (6) & (7) & (8) & (9) & (10) & (11) & $(12)$ \\
\hline \multicolumn{13}{|l|}{ OECD-Länder } \\
\hline Australien & 1,58 & 1,58 & 1,58 & 100 & 113 & 116 & 120 & 124 & 127 & 131 & 134 & 2011 \\
\hline Österreich & 0,86 & 0,87 & 0,86 & 100 & 109 & 111 & 114 & 116 & 118 & 119 & 123 & 2010/2011 \\
\hline Belgien (fläm.) ${ }^{2}$ & 0,91 & 0,90 & 0,90 & 100 & 110 & 113 & 117 & 120 & 122 & 123 & 126 & Jan. 2011 \\
\hline Belgien (frz.) ${ }^{2}$ & 0,91 & 0,90 & 0,90 & 100 & 110 & 113 & 117 & 120 & 122 & 123 & 126 & $2010 / 2011$ \\
\hline Kanada & 1,30 & 1,30 & 1,30 & 100 & 109 & 111 & 113 & 115 & 116 & 117 & 119 & $2010 / 2011$ \\
\hline Chile & 370,16 & 373,60 & 371,88 & 100 & 117 & 121 & 126 & 133 & 139 & 141 & 145 & 2011 \\
\hline Tschechien & 15,57 & 15,33 & 15,45 & 100 & 111 & 112 & 115 & 119 & 122 & 123 & 123 & 2010/2011 \\
\hline Dänemark & 8,57 & 8,71 & 8,64 & 100 & 109 & 111 & 113 & 115 & 117 & 120 & 123 & $2010 / 2011$ \\
\hline England $^{3}$ & 0,70 & 0,72 & 0,71 & 100 & 107 & 110 & 113 & 116 & 119 & 122 & 127 & $2010 / 2011$ \\
\hline Estland & 0,62 & 0,63 & 0,63 & 100 & 120 & 125 & 133 & 144 & 148 & 149 & 155 & $2010 / 2011$ \\
\hline Finnland & 1,00 & 1,02 & 1,01 & 100 & 107 & 108 & 110 & 113 & 116 & 118 & 121 & 2010/2011 \\
\hline Frankreich & 0,90 & 0,90 & 0,90 & 100 & 110 & 112 & 114 & 117 & 118 & 118 & 120 & 2010/2011 \\
\hline Deutschland & 0,85 & 0,84 & 0,85 & 100 & 107 & 109 & 110 & 112 & 113 & 114 & 116 & $2010 / 2011$ \\
\hline Griechenland & 0,78 & 0,78 & 0,78 & 100 & 116 & 120 & 124 & 128 & 131 & 134 & 139 & 2011 \\
\hline Ungarn & 145,01 & 146,45 & 145,73 & 100 & 137 & 141 & 149 & 158 & 165 & 172 & 179 & 2011 \\
\hline Island & 145,92 & 149,52 & 147,72 & 100 & 122 & 128 & 135 & 148 & 169 & 182 & 190 & $2010 / 2011$ \\
\hline Irland & 0,96 & 0,95 & 0,95 & 100 & 120 & 122 & 125 & 128 & 125 & 119 & 119 & 2010/2011 \\
\hline Israel & 4,47 & 4,50 & 4,48 & 100 & 108 & 110 & 111 & 115 & 119 & 122 & 126 & $2010 / 2011$ \\
\hline Italien & 0,84 & 0,85 & 0,84 & 100 & 114 & 117 & 120 & 123 & 125 & 126 & 129 & $2010 / 2011$ \\
\hline Japan & 121,37 & 117,19 & 119,28 & 100 & 95 & 95 & 94 & 94 & 93 & 91 & 90 & $2010 / 2011$ \\
\hline Korea & 910,47 & 922,55 & 916,51 & 100 & 118 & 121 & 123 & 127 & 131 & 135 & 139 & 2011 \\
\hline Luxemburg & 0,99 & 1,00 & 1,00 & 100 & 111 & 114 & 117 & 120 & 123 & 124 & 127 & $2010 / 2011$ \\
\hline Mexiko & 8,95 & 9,08 & 9,02 & 100 & 137 & 142 & 148 & 155 & 166 & 175 & 182 & $2010 / 2011$ \\
\hline Niederlande & 0,88 & 0,88 & 0,88 & 100 & 114 & 117 & 119 & 121 & 121 & 122 & 124 & $2010 / 2011$ \\
\hline Neuseeland & 1,61 & 1,62 & 1,61 & 100 & 109 & 112 & 115 & 118 & 122 & 124 & 127 & 2011 \\
\hline Norwegen & 9,81 & 9,88 & 9,84 & 100 & 110 & 112 & 113 & 116 & 119 & 122 & 124 & 2010/2011 \\
\hline Polen & 1,99 & 1,99 & 1,99 & 100 & 117 & 119 & 122 & 126 & 130 & 133 & 138 & $2010 / 2011$ \\
\hline Portugal & 0,71 & 0,71 & 0,71 & 100 & 116 & 119 & 123 & 126 & 126 & 126 & 129 & $2010 / 2011$ \\
\hline Schottland ${ }^{3}$ & 0,70 & 0,72 & 0,71 & 100 & 107 & 110 & 113 & 116 & 119 & 122 & 127 & $2010 / 2011$ \\
\hline Slowakei & 0,58 & 0,59 & 0,58 & 100 & 131 & 136 & 141 & 146 & 149 & 150 & 154 & $2010 / 2011$ \\
\hline Slowenien & 0,71 & 0,70 & 0,70 & 100 & 131 & 134 & 138 & 145 & 150 & 151 & 154 & $2010 / 2011$ \\
\hline Spanien & 0,79 & 0,79 & 0,79 & 100 & 118 & 122 & 126 & 130 & 132 & 133 & 136 & $2010 / 2011$ \\
\hline Schweden & 9,46 & 9,30 & 9,38 & 100 & 107 & 109 & 110 & 112 & 115 & 117 & 119 & 2011 \\
\hline Schweiz & 1,65 & 1,61 & 1,63 & 100 & 103 & 104 & 106 & 108 & 110 & 110 & 110 & 2011 \\
\hline Türkei & 1,15 & 1,22 & 1,18 & 100 & 359 & 392 & 423 & 460 & 496 & 529 & 575 & 2011 \\
\hline $\begin{array}{l}\text { Vereinigte Staaten } \\
\text { Sonst. G20-Länder }\end{array}$ & 1,00 & 1,00 & 1,00 & 100 & 111 & 114 & 117 & 121 & 123 & 124 & 127 & $2010 / 2011$ \\
\hline Argentinien ${ }^{4}$ & 1,72 & 1,87 & 1,79 & $\mathrm{~m}$ & $\mathrm{~m}$ & $\mathrm{~m}$ & $\mathrm{~m}$ & $\mathrm{~m}$ & $\mathrm{~m}$ & $\mathrm{~m}$ & $\mathrm{~m}$ & 2010 \\
\hline Brasilien & $\mathrm{m}$ & $\mathrm{m}$ & $\mathrm{m}$ & 100 & 154 & 163 & 171 & 181 & 192 & 204 & 217 & $\mathrm{~m}$ \\
\hline China & $\mathrm{m}$ & $\mathrm{m}$ & $\mathrm{m}$ & $\mathrm{m}$ & $\mathrm{m}$ & $\mathrm{m}$ & $\mathrm{m}$ & $\mathrm{m}$ & $\mathrm{m}$ & $\mathrm{m}$ & $\mathrm{m}$ & $\mathrm{m}$ \\
\hline Indien & $\mathrm{m}$ & $\mathrm{m}$ & $\mathrm{m}$ & $\mathrm{m}$ & $\mathrm{m}$ & $\mathrm{m}$ & $\mathrm{m}$ & $\mathrm{m}$ & $\mathrm{m}$ & $\mathrm{m}$ & $\mathrm{m}$ & $\mathrm{m}$ \\
\hline Indonesien 4 & 5285,50 & 5467,13 & 5376,31 & 100 & 164 & 185 & 211 & 240 & 261 & 275 & 291 & 2010 \\
\hline Russische Föd. & 17,41 & 18,46 & 17,94 & $\mathrm{~m}$ & $\mathrm{~m}$ & $\mathrm{~m}$ & $\mathrm{~m}$ & $\mathrm{~m}$ & $\mathrm{~m}$ & $\mathrm{~m}$ & $\mathrm{~m}$ & 2011 \\
\hline Saudi-Arabien & $\mathrm{m}$ & $\mathrm{m}$ & $\mathrm{m}$ & $\mathrm{m}$ & $\mathrm{m}$ & $\mathrm{m}$ & $\mathrm{m}$ & $\mathrm{m}$ & $\mathrm{m}$ & $\mathrm{m}$ & $m$ & $\mathrm{~m}$ \\
\hline Südafrika & $\mathrm{m}$ & $\mathrm{m}$ & $\mathrm{m}$ & $\mathrm{m}$ & $\mathrm{m}$ & $\mathrm{m}$ & $\mathrm{m}$ & $\mathrm{m}$ & $\mathrm{m}$ & $\mathrm{m}$ & $\mathrm{m}$ & $\mathrm{m}$ \\
\hline
\end{tabular}

1. Angaben zu KKP und BIP für Länder der aktuellen Eurozone in Euro. 2. Angaben zu KKP und Deflator beziehen sich auf ganz Belgien. 3. Angaben zu KKP und Deflator beziehen sich auf das Vereinigte Königreich. 4. Referenzjahr 2010.

Quelle: OECD. Argentinien: Statistikinstitut der UNESCO (World Education Indicators Programme). Hinweise s. Anhang 3 unter www.oecd.org/edu/eag.htm.

StatLink: http://dx.doi.org/10.1787/888932852333

Erläuterung der Kennzeichnung fehlender Daten s. Hinweise für den Leser. 


\section{Allgemeine Hinweise}

\section{Definitionen}

Das Bruttoinlandsprodukt (BIP) entspricht der Wertschöpfung der von inländischen Herstellern produzierten Waren und Dienstleistungen, einschließlich Handel und Transport, abzüglich des Werts für den Zwischenverbrauch des Käufers plus Importzölle. Das BIP wird in der jeweiligen Landeswährung (in Millionen) angegeben. Für Länder, die diese Informationen für ein Bezugsjahr angeben, das vom Kalenderjahr abweicht (z. B. Australien und Neuseeland), werden Anpassungen durch lineare Gewichtung des jeweiligen BIP zwischen zwei aufeinanderfolgenden nationalen Bezugsjahren entsprechend dem Kalenderjahr vorgenommen.

Der BIP-Deflator wird berechnet durch Division des BIP zu Marktpreisen durch das BIP zu konstanten Preisen. Er liefert einen Hinweis auf das relative Preisniveau in einem Land.

Das BIP pro Kopf ist das Bruttoinlandsprodukt (in US-Dollar, kaufkraftbereinigt) dividiert durch die Bevölkerungszahl.

Die Kaufkraftparitäts-Umrechnungskurse (KKP) sind die Währungsumrechnungskurse, die die Kaufkraft verschiedener Währungen ausgleichen. Dies bedeutet, dass man mit einer bestimmten Geldsumme, wenn sie anhand der KKP-Kurse in die verschiedenen Währungen umgerechnet wird, in allen Ländern den gleichen Waren- und Dienstleistungskorb erwerben kann. Daher werden durch Verwendung der KKP-Währungsumrechnungskurse die Preisniveau-Unterschiede zwischen den Ländern aufgehoben. Werden Ausgaben bezogen auf das BIP für verschiedene Länder mithilfe der KKP in eine einheitliche Währung umgerechnet, werden sie praktisch mit den gleichen internationalen Preisen ausgedrückt, sodass Vergleiche zwischen den Ländern nur die Unterschiede im Volumen der gekauften Waren und Dienstleistungen widerspiegeln.
Die öffentlichen Gesamtausgaben, wie bei der Berechnung der Indikatoren verwendet, entsprechen den nicht rückzahlbaren laufenden Ausgaben und Investitionsausgaben auf allen Ebenen des Staates. Die laufenden Ausgaben umfassen die konsumtiven Ausgaben (z. B. Arbeitsentgelte für Mitarbeiter, Verbrauch von Vorprodukten und -dienstleistungen, Verbrauch von Sachvermögen und Militärausgaben), geleistete Besitzeinkommen, Subventionen und andere geleistete Transferzahlungen (z.B. Sozialversicherungen, Sozialhilfe, Renten und sonstige Wohlfahrtsleistungen). Investitionsausgaben sind Ausgaben zum Erwerb und/oder der Wertsteigerung von Gütern des Anlagevermögens, Grundstücken, immateriellen Vermögensgegenständen, Staatsanleihen und nicht militärischen Sachvermögen und Ausgaben zur Finanzierung von Nettokapitaltransfers.

\section{Quellen}

Die Ausgabe des Jahres 2013 der National Accounts of OECD Countries: Detailed Tables, Volume II.

Der theoretische Rahmen der OECD National Accounts wird seit vielen Jahren von der UN-Publikation A System of National Accounts vorgegeben, die I968 erschien. Im Jahr 1993 erschien eine überarbeitete Fassung (häufig als SNA93 bezeichnet).

OECD Analytical Database, Januar 2013. 


\section{Quellen, Methoden und technische Hinweise}

Anhang 3 zu Quellen und Methoden

liegt nur in elektronischer Form vor.

Er kann eingesehen werden unter

www.oecd.org/eduleag.htm. 



\section{Mitwirkende an dieser Publikation}

Viele Personen haben bei der Erstellung dieser Publikation mitgewirkt. Nachfolgend sind die Namen der Ländervertreter, Forscher und Experten aufgeführt, die an den INES-Sitzungen teilgenommen und bei den vorbereitenden Arbeiten für die Veröffentlichung dieser Ausgabe von Bildung aufeinen Blick 2013 - OECD-Indikatoren aktiv mitgewirkt haben.

Die OECD möchte ihnen allen an dieser Stelle für ihren wertvollen Beitrag danken. 


\section{INES-Beratergruppe}

Vorsitz: Norwegen

Netzwerkvorsitzende: Frau Anne-Berit KAVLI

Herr Scott MATHESON (Australien)

Frau Florence LEFRESNE (Frankreich)

Frau Pascale POULET-COULIBANDO (Frankreich)

Herr Paolo SESTITO (Italien)

Herr Ryo WATANABE (Japan)
Herr Marcel SMITS VAN WAESBERGHE (Niederlande)

Frau Anne-Berit KAVLI (Norwegen)

Herr Hans-Åke ÖSTRÖM (Schweden)

Frau Michaela SOJDROVA (Tschechien)

Herr Daniel McGRATH (Vereinigte Staaten)

\section{INES-Arbeitsgruppe}

Vorsitz: Australien

Netzwerkvorsitzender: Herr Scott MATHESON

Frau Maria Laura ALONSO (Argentinien)

Frau Marcela JÁUREGUI (Argentinien)

Frau Stephanie BOWLES (Australien)

Herr Paul CMIEL (Australien)

Herr Stuart FAUNT (Australien)

Frau Ashlee HOLLIS (Australien)

Frau Cheryl HOPKINGS (Australien)

Frau Joanna KORDIS (Australien)

Frau Shannon MADDEN (Australien)

Frau Margaret PEARCE (Australien)

Herr Mark UNWIN (Australien)

Herr Philippe DIEU (Belgien)

Frau Isabelle ERAUW (Belgien)

Frau Nathalie JAUNIAUX (Belgien)

Frau Cathy MISSION-FIEVET (Belgien)

Herr Guy STOFFELEN (Belgien)

Herr Raymond VAN DE SIJPE (Belgien)

Frau Ann VAN DRIESSCHE (Belgien)

Herr Daniel Jaime CAPISTRANO DE OLIVEIRA (Brasilien)

Frau Carla D'Lourdes DO NASCIMENTO (Brasilien)

Frau Juliana MARQUES DA SILVA (Brasilien)

Frau Ana Carolina SILVA CIROTTO (Brasilien)

Herr Patricio BRICKLE CUEVAS (Chile)

Frau Eliana CHAMIZO (Chile)

Herr Fabian GREDIG (Chile)

Herr Francisco LAGOS MARIN (Chile)

Herr Gabriel Alonso UGARTE VERA (Chile)

Frau Stine ALBECK SEITZBERG (Dänemark)

Herr Jens ANDERSEN (Dänemark)

Herr Henrik BANG (Dänemark)

Frau Katja BEHRENS (Dänemark)

Herr Erik CHRISTIANSEN (Dänemark)

Herr Peter Bohnstedt Anan HANSEN (Dänemark)

Herr Leo Elmbirk JENSEN (Dänemark)

Herr Kristian ORNSHOLT (Dänemark)

Herr Signe Tychsen PHILIP (Dänemark)

Herr Jens Brunsborg STORM (Dänemark)

Frau Maria SVANEBORG (Dänemark)

Herr Thorbjorn TODSEN (Dänemark)

Herr Hans-Werner FREITAG (Deutschland)

Herr Heinz-Werner HETMEIER (Deutschland)

Frau Christiane KRÜGER-HEMMER ( Deutschland)
Herr Marco MUNDELIUS (Deutschland)

Herr Martin SCHULZE (Deutschland)

Frau Eveline VON GAESSLER (Deutschland)

Frau Katrin WERY (Deutschland)

Herr Heinrich WIRTZ (Deutschland)

Frau Tiina ANNUS (Estland)

Frau Kristi PLOOM (Estland)

Frau Teresa OLIVEIRA (Europäische Kommission)

Herr Jan PAKULSKI (Europäische Kommission)

Frau Christine COIN (Eurostat, Europäische

Kommission)

Frau Ana Maria MARTINEZ PALOU (Eurostat,

Europäische Kommission)

Herr Timo ERTOLA (Finnland)

Herr Ville HEINONEN (Finnland)

Herr Matti KYRÖ (Finnland)

Frau Riikka RAUTANEN (Finnland)

Herr Mika TUONONEN (Finnland)

Herr Cedric AFSA (Frankreich)

Frau Pierrette BRIANT (Frankreich)

Herr Luc BRIERE (Frankreich)

Frau Florence DEFRESNE (Frankreich)

Frau Florence LEFRESNE (Frankreich)

Frau Valérie LIOGIER (Frankreich)

Frau Claude MALẼGUE (Frankreich)

Frau Hélène MICHAUDON (Frankreich)

Frau Pascale POULET-COULIBANDO (Frankreich)

Herr Robert RAKOCEVIC (Frankreich)

Frau Marguerite RUDOLF (Frankreich)

Frau Dimitra FARMAKIOUTOU (Griechenland)

Frau Maria FASSARI (Griechenland)

Herr Konstantinos KAMPANAKIS (Griechenland)

Frau Akrivi NIKOLAKOPOULOU (Griechenland)

Frau Athena PLESSA-PAPADAKI (Griechenland)

Frau Ida KINTAMANI (Indonesien)

Herr Gary Ó DONNCHADHA (Irland)

Herr Diarmuid REIDY (Irland)

Frau Nicola TICKNER (Irland)

Herr Gunnar J. ÁRNASON (Island)

Herr Julius BJORNSSON (Island)

Frau Asta URBANCIC (Island)

Frau Sophie ARTSEV (Israel)

Herr Assaf ASHKENAZI (Israel) 
Frau Yael ATIYAH (Israel)

Herr Yoav AZULAY (Israel)

Herr Yonatan BAR ON (Israel)

Frau Nava BRENNER (Israel)

Frau Livnat GAVRIELOV (Israel)

Herr Yosef GIDANIAN (Israel)

Herr Yonatan HUBARA (Israel)

Herr Aviel KRENTZLER (Israel)

Herr Daniel LEVI-MAZLOUM (Israel)

Herr Haim PORTNOY (Israel)

Frau Gianna BARBIERI (Italien)

Herr Massimiliano CICCIA (Italien)

Frau Daniela DI ASCENZO (Italien)

Frau Paola DI GIROLAMO (Italien)

Frau Maria Teresa MORANA (Italien)

Frau Claudia PIZZELLA (Italien)

Herr Paolo SESTITO (Italien)

Herr Paolo TURCHETTI (Italien)

Herr Jugo IMAIZUMI (Japan)

Frau Nami JINDA (Japan)

Frau Erina KAGA (Japan)

Herr Takashi MURAO (Japan)

Herr Tatsushi NISHIZAWA (Japan)

Herr Keisuke OTANI (Japan)

Herr Naoki OYAKE (Japan)

Herr Hiromi SASAI (Japan)

Frau Kumiko TANSHO (Japan)

Frau Yuka UZUKI (Japan)

Herr Patric BLOUIN (Kanada)

Herr Patrice DE BROUCKER (Kanada)

Frau Marie-France CHOUINARD (Kanada)

Frau Shannon DELBRIDGE (Kanada)

Frau Louise GALARNEAU (Kanada)

Herr Tomasz GLUSZYNSKI (Kanada)

Frau Amanda HODGKINSON (Kanada)

Frau Marie LAVALLEE (Kanada)

Herr Michael MARTIN (Kanada)

Frau Dallas MORROW (Kanada)

Herr Enzo PIZZOFERRATO (Kanada)

Frau Miriam RABKIN (Kanada)

Frau Sarah STRAPPS (Kanada)

Herr Janusz ZIEMINSKI (Kanada)

Herr Hong Seon CHO (Korea)

Herr Moonyoung EOM (Korea)

Frau Sung Bin MOON (Korea)

Herr Thierry HUART (Luxemburg)

Herr Jérôme Levy (Luxemburg)

Frau Charlotte MAHON (Luxemburg)

Frau Elisa MAZZUCATO (Luxemburg)

Herr Claude SCHABER (Luxembourg)

Herr Antonio ÁVILA DÍAZ (Mexiko)

Frau Cynthia CABRERA CARDENAS (Mexiko)

Herr Gerardo FRANCO BARRALES (Mexiko)

Herr René GÓMORA CASTILLO (Mexiko)

Herr Juan Manuel HERNÁNDEZ VÁZQUEZ (Mexiko)
Herr Héctor Virgilio ROBLES VASQUEZ (Mexiko)

Frau Annette SANTOS (Mexiko)

Herr Oscar SILVA (Mexiko)

Herr Lorenzo VERGARA LÓPEZ (Mexiko)

Frau Julia ARNOLD (Neuseeland)

Herr David SCOTT (Neuseeland)

Frau Danielle ANDARABI (Niederlande)

Frau Linda DE PAEPE (Niederlande)

Herr Hugo ELBERS (Niederlande)

Herr Mark GROEN (Niederlande)

Herr Hans RUESINK (Niederlande)

Herr Dick TAKKENBERG (Niederlande)

Frau Pauline THOOLEN (Niederlande)

Frau Anouschka VAN DER MEULEN (Niederlande)

Herr Fred WENTINK (Niederlande)

Frau Marie ARNEBERG (Norwegen)

Herr Sadiq Kwesi BOATENG (Norwegen)

Frau Anne Katrine MORTENSEN (Norwegen)

Herr Terje RISBERG (Norwegen)

Frau Anne-Marie RUSTAD HOLSETER (Norwegen)

Frau Sabine MARTINSCHITZ (Österreich)

Herr Mark NÉMET (Österreich)

Herr Wolfgang PAULI (Österreich)

Frau Helga POSSET (Österreich)

Frau Natascha RIHA (Österreich)

Frau Barbara ANTOSIEWICZ (Polen)

Frau Hanna GOLASZEWSKA (Polen)

Frau Renata KORZENIOWSKA-PUCULEK (Polen)

Frau Malgorzata KRZYSZTOFIK (Polen)

Herr Andrzej KURKIEWCZ (Polen)

Herr Slawomir NALECZ (Polen)

Frau Anna NOWOZYNSKA (Polen)

Frau Isabel CORREIA (Portugal)

Frau Janine COSTA (Portugal)

Frau Teresa KOL DE ALVARENGA (Portugal)

Frau Mónica LUENGO (Portugal)

Herr Carlos Alberto MALACA (Portugal)

Frau Sandrine MIRANDA (Portugal)

Frau Rute NUNES (Portugal)

Herr Joao PEREIRA DE MATOS (Portugal)

Herr José RAFAEL (Portugal)

Herr Nuno Miguel RODRIGUES (Portugal)

Herr Joaquim SANTOS (Portugal)

Herr Mark AGRANOVICH (Russische Föderation)

Herr Evgeny BUTKO (Russische Föderation)

Frau Anna FATEEVA (Russische Föderation)

Frau Irina SELIVERSTOVA (Russische Föderation)

Herr Ahmed F. HAYAJNEH (Saudi-Arabien)

Frau Anna ERIKSSON (Schweden)

Herr Andreas FRODELL (Schweden)

Herr Maria GÖSTHERSTRÖM (Schweden)

Frau Marie KAHLROTH (Schweden)

Frau Eva-Marie LARSSON (Schweden)

Herr Torbjörn LINDQVIST (Schweden)

Herr Hans-Åke ÖSTRÖM (Schweden) 
Herr Kenny PETERSSON (Schweden)

Frau Vera HERRMANN (Schweiz)

Frau Katrin HOLENSTEIN (Schweiz)

Herr Emanuel VON ERLACH (Schweiz)

Herr Stefan C. WOLTER (Schweiz)

Herr Peter BRODNIANSKY (Slowakei)

Frau Alzbeta FERENCICOVA (Slowakei)

Herr Frantisek ZAJICEK (Slowakei)

Frau Andreja BARLE LAKOTA (Slowenien)

Frau Ksenija BREGAR-GOLOBIC (Slowenien)

Herr Branimir JABLANOVIĆ (Slowenien)

Frau Helga KOCEVAR (Slowenien)

Frau Breda LOŽAR (Slowenien)

Frau Dusa MARJETIC (Slowenien)

Frau Sabina MELAVC (Slowenien)

Herr Mitja SARDOC (Slowenien)

Frau Tatjana SKRBEC (Slowenien)

Frau Irena SVETIN (Slowenien)

Frau Jadranka TUŠ (Slowenien)

Herr Eduardo DE LA FUENTE FUENTE (Spanien)

Herr Jesús IBAÑEZ MILLA (Spanien)

Herr Joaquín MARTÍN MUÑOZ (Spanien)

Frau Cristina MONEO OCAÑA (Spanien)

Herr Valentín RAMOS SALVADOR (Spanien)

Herr Ismael SANZ LABRADOR (Spanien)

Frau Carmen UREÑA UREÑA (Spanien)

Frau Bheki MPANZA (Südafrika)
Frau Helena CIZKOVA (Tschechien)

Frau Michaela KLENHOVA (Tschechien)

Herr Lubomir MARTINEC (Tschechien)

Frau Hümeyra ALTUNTAŞ (Türkei)

Frau Filiz BAŞÖREN ALAN (Türkei)

Herr Derhan DOĞAN (Türkei)

Frau Dilek GÜLEÇYÜZ (Türkei)

Frau Nur SALMANOĞLU (Türkei)

Herr Serdar YILMAZ (Türkei)

Frau Alison KENNEDY (UNESCO)

Herr Said Ould Ahmedou VOFFAL (UNESCO)

Frau Tünde HAGYMÁSY (Ungarn)

Frau Anna IMRE (Ungarn)

Frau Judit KÁDÁR-FÜLÖP (Ungarn)

Herr Tibor KÖNYVESI (Ungarn)

Herr László LIMBACHER (Ungarn)

Frau Lorna BERTRAND (Vereinigtes Königreich)

Frau Elisabeth BOYLING (Vereinigtes Königreich)

Herr Anthony CLARKE (Vereinigtes Königreich)

Herr Stephen HEWITT (Vereinigtes Königreich)

Frau Emily KNOWLES (Vereinigtes Königreich)

Herr Stephen LEMAN (Vereinigtes Königreich)

Frau Rachel DINKES (Vereinigte Staaten)

Frau Jennifer HARWOOD (Vereinigte Staaten)

Frau Jana KEMP (Vereinigte Staaten)

Frau Ashley ROBERTS (Vereinigte Staaten)

Herr Thomas SNYDER (Vereinigte Staaten)

\section{Netzwerk zu den Arbeitsmarktergebnissen sowie den wirtschaftlichen} und sozialen Auswirkungen des Lernens (LSO)

Vorsitz: Kanada

Netzwerkvorsitzender: Herr Patrice DE BROUCKER

Herr Paul CMIEL (Australien)

Frau Shannon MADDEN (Australien)

Herr Scott MATHESON (Australien)

Frau Margaret PEARCE (Australien)

Frau Ariane BAYE (Belgien)

Frau Isabelle ERAUW (Belgien)

Frau Genevieve HINDRYCKX (Belgien)

Herr Daniel Jaime CAPISTRANO DE OLIVEIRA (Brasilien)

Frau Carla D'Lourdes DO NASCIMENTO (Brasilien)

Frau Juliana MARQUES DA SILVA (Brasilien)

Frau Ana Carolina SILVA CIROTTO (Brasilien)

Herr Marco SERAFINI (CEDEFOP)

Herr Fabián GREDIG (Chile)

Frau Paulina HUAIQUIMIL (Chile)

Herr David INOSTROZA (Chile)

Herr Fabián RAMIREZ (Chile)

Frau Alexandra RUEDA (Chile)

Herr Gabriel UGARTE (Chile)

Herr Jens ANDERSEN (Dänemark)

Herr Thorbjørn TODSEN (Dänemark)

Herr Andreas ALBRECHT (Deutschland)

Herr Martin A. SCHULZE (Deutschland)
Herr Hans-Werner FREITAG (Deutschland)

Frau Christiane KRÜGER-HEMMER (Deutschland)

Herr Marco MUNDELIUS (Deutschland)

Frau Angelika TRAUB (Deutschland)

Frau Eveline VON GAESSLER (Deutschland)

Frau Tiina ANNUS (Estland)

Frau Kristi PLOOM (Estland)

Frau Katrin REIN (Estland)

Herr Jens FISHER-KOTTENSTEDE (Europäische

Kommission)

Frau Marta BECK-DOMZALSKA (Eurostat, Europäische Kommission)

Herr Sylvain JOUHETTE (Eurostat, Europäische

Kommission)

Frau Irja BLOMQVIST (Finnland)

Frau Aila REPO (Finnland)

Herr Cédric AFSA (Frankreich)

Frau Pascale POULET-COULIBANDO (Frankreich)

Herr Vasileios KARAVITIS (Griechenland)

Herr Georgios VAFIAS (Griechenland)

Frau Guillian GOLDEN (Irland)

Frau Nicola TICKNER (Irland)

Frau Ásta M. URBANCIC (Island) 
Herr Yosef GIDANIAN (Israel)

Herr David MAAGAN (Israel)

Herr Haim PORTNOY (Israel)

Frau Francesca BRAIT (Italien)

Frau Raffaella CASCIOLI (Italien)

Frau Angela FERRUZZA (Italien)

Herr Gaetano PROTO (Italien)

Frau Liana VERZICCO (Italien)

Frau Nami JINDA (Japan)

Frau Erina KAGA (Japan)

Frau Yuka UZUKI (Japan)

Herr Patric BLOUIN (Kanada)

Frau Amanda HODGKINSON (Kanada)

Frau Dallas MORROW (Kanada)

Herr Patrick TAYLOR (Kanada)

Frau Jihee CHOI (Korea)

Herr Moonyoung EOM (Korea)

Frau Gloria HUIJUNG CHU (Korea)

Frau Sung Bin MOON (Korea)

Herr Cheonsoo PARK (Korea)

Frau Young Sun RA (Korea)

Herr Sun Young WOO (Korea)

Herr Jérôme LEVY (Luxemburg)

Frau Karin MEYER (Luxemburg)

Herr Jos NOESEN (Luxemburg)

Herr Juan Manuel HERNÁNDEZ VÁZQUEZ (Mexiko)

Herr Héctor ROBLES (Mexiko)

Frau Julia ARNOLD (Neuseeland)

Frau Frances KELLY (Neuseeland)

Herr David SCOTT (Neuseeland)

Herr Roger SMYTH (Neuseeland)

Herr Sander BALJE (Niederlande)

Frau Linda DE PAEPE (Niederlande)

Herr Ted REININGA (Niederlande)

Herr Marcel SMITS VAN WAESBERGHE (Niederlande)

Herr Dick TAKKENBERG (Niederlande)

Frau Pauline THOOLEN (Niederlande)

Herr Roy TJOA (Niederlande)

Herr Francis VAN DER MOOREN (Niederlande)

Herr Bernard VERLAAN (Niederlande)

Herr Sadiq-Kwesi BOATENG (Norwegen)

Herr Lars NERDRUM (Norwegen)

Frau Ragnhild NERSTEN (Norwegen)
Frau Anne-Marie RUSTAD HOLSETER (Norwegen)

Herr Andreas GRIMM (Österreich)

Herr Mark NÉMET (Österreich)

Herr Jacek MASLANKOWSKI (Polen)

Frau Anna NOWOZYNSKA (Polen)

Herr Carlos Alberto MALACA (Portugal)

Herr Joaquim SANTOS (Portugal)

Herr Mark AGRANOVICH (Russische Föderation)

Frau Anna FATEEVA (Russische Föderation)

Herr Torbjörn LINDQVIST (Schweden)

Herr Kenny PETERSSON (Schweden)

Herr Russell SCHMIEDER (Schweden)

Frau Wayra CABALLERO LIARDET (Schweiz)

Herr Emanuel VON ERLACH (Schweiz)

Herr Frantisek BLANAR (Slowakei)

Frau Gabriela JAKUBOVÁ (Slowakei)

Frau Lubomíra SRNÁNKOVÁ (Slowakei)

Herr Juraj HOMOLA (Slowakei)

Frau Helga KOCEVAR (Slowenien)

Frau Tatjana SKRBEC (Slowenien)

Frau Raquel ÁLVAREZ-ESTEBAN (Spanien)

Frau Carmen UREÑA UREÑA (Spanien)

Frau Sona FORTOVA (Tschechien)

Frau Vendula KAŠPAROVA (Tschechien)

Frau Michaela KLENHOVA (Tschechien)

Frau Jitka KONRADOVA (Tschechien)

Frau Hümeyra ALTUNTAŞ (Türkei)

Herr Dilek GÜLEÇYÜZ (Türkei)

Herr Cengiz SARAÇOĞLU (Türkei)

Herr Serdar YILMAZ (Türkei)

Frau Alison Kennedy (UNESCO)

Frau Judit KÁDÁR-FÜLÖP (Ungarn)

Herr László LIMBACHER (Ungarn)

Frau Eva TOT (Ungarn)

Herr Anthony CLARKE (Vereinigtes Königreich)

Herr Stephen HEWITT (Vereinigtes Königreich)

Frau Emily KNOWLES (Vereinigtes Königreich)

Herr Stephen LEMAN (Vereinigtes Königreich)

Frau Rachel DINKES (Vereinigte Staaten)

Frau Ashley ROBERTS (Vereinigte Staaten)

Frau Erin ROTH (Vereinigte Staaten)

Frau Kimberly TAHAN (Vereinigte Staaten)

Herr Thomas SNYDER (Vereinigte Staaten)

\footnotetext{
auf Systemebene (NESLI)

Vorsitz: Vereinigte Staaten

Netzwerkvorsitzender: Herr Thomas SNYDER

Frau Stephanie BOWLES (Australien)

Herr Paul CMIEL (Australien)

Frau Shannon MADDEN (Australien)

Herr Scott MATHESON (Australien)

Herr Philippe DIEU (Belgien)

Frau Nathalie JAUNIAUX (Belgien)
}

Netzwerk für Informationen zu Bildungsstrukturen, -politiken und -praktiken
Frau Helene LENOIR (Belgien)

Herr Raymond VAN DE SIJPE (Belgien)

Frau Ann VAN DRIESSCHE (Belgien)

Herr Daniel Jaime CAPISTRANO DE OLIVEIRA (Brasilien)

Frau Carla D'Lourdes DO NASCIMENTO (Brasilien)

Frau Juliana MARQUES DA SILVA (Brasilien)

Frau Ana Carolina SILVA CIROTTO (Brasilien) 
Herr Gabriel Alonso UGARTE VERA (Chile) Herr Claus Schreiner ANDERSEN (Dänemark) Herr Jorgen Balling RASMUSSEN (Dänemark) Frau Amalie SCHMIDT (Dänemark) Frau Pia BRUGGER (Deutschland) Herr Heinz-Werner HETMEIER (Deutschland) Frau Christiane KRÜGER-HEMMER (Deutschland) Herr Marco MUNDELIUS (Deutschland) Frau Tiina ANNUS (Estland) Frau Kristi PLOOM (Estland) Herr Jan PAKULSKI (Europäische Kommission) Frau Nathalie BAIDAK (Eurydice) Frau Arlette DELHAXHE (Eurydice) Herr Stanislav RANGUELOV (Eurydice) Frau Petra PACKALEN (Finnland) Herr Mika VÄISÄNEN (Finnland) Frau Kristiina VOLMARI (Finnland) Frau Florence LEFRESNE (Frankreich) Herr Robert RAKOCEVIC (Frankreich) Frau Dimitra FARMAKIOTOU (Griechenland) Frau Maria FASSARI (Griechenland) Frau Chrysi HATZAKI (Griechenland) Frau Eudokia KARDAMITSI (Griechenland) Herr Stylianos MERKOURIS (Griechenland) Herr Konstantinos PAPACHRISTOS (Griechenland) Frau Ida KINTAMANI (Indonesien) Herr Gary Ó DONNCHADHA (Irland) Frau Nicola TICKNER (Irland) Herr Gunnar J. ÁRNASON (Island) Frau Asta URBANCIC (Island) Frau Sophie ARTSEV (Israel) Herr Assaf ASHKENAZI (Israel) Herr Yoav AZULAY (Israel) Herr Yosef GIDANIAN (Israel) Herr Daniel LEVI-MAZLOUM (Israel) Herr Haim PORTNOY (Israel) Frau Gianna BARBIERI (Italien) Frau Lucia DE FABRIZIO (Italien) Frau Nami JINDA (Japan) Frau Erina KAGA (Japan) Frau Yuka UZUKI (Japan) Frau Shannon DELBRIDGE (Kanada) Frau Sung Bin MOON (Korea) Herr Moonyoung EOM (Korea) Herr Gilles HIRT (Luxemburg) Herr Jérôme LEVY (Luxemburg)
Herr Antonio ÁVILA DÍAZ (Mexiko)

Herr Juan Martín SOCA DE IÑIGO (Mexiko)

Frau Kathy LIU (Neuseeland)

Herr Cyril MAKO (Neuseeland)

Frau Jennyfer IMPERATOR (Niederlande)

Herr Hans RUESINK (Niederlande)

Herr Marcel SMITS VAN WAESBERGHE (Niederlande)

Herr Dick VAN VLIET (Niederlande)

Herr Kjetil HELGELAND (Norwegen)

Herr Christian KRENTHALLER (Österreich)

Frau Kristin SJOHOLM-SCHMID (Österreich)

Frau Renata KARNAS (Polen)

Frau Katarzyna MALEC (Polen)

Frau Anna NOWOŻYŃSKA (Polen)

Herr Joaquim SANTOS (Portugal)

Frau Ana VITORINO (Portugal)

Herr Mark AGRANOVICH (Russische Föderation)

Frau Anna FATEEVA (Russische Föderation)

Frau Camilla THINSZ FJELLSTROM (Schweden)

Frau Helena WINTGREN (Schweden)

Frau Rejane DEPPIERRAZ (Schweiz)

Frau Katrin MÜHLEMANN (Schweiz)

Frau Alzbeta FERENCICOVA (Slowakei)

Frau Andreja BARLE LAKOTA (Slowenien)

Frau Ksenija BREGAR GOLOBIC (Slowenien)

Herr Mitja SARDOC (Slowenien)

Herr Matija VILFAN (Slowenien)

Herr Antonio DEL SASTRE (Spanien)

Herr Joaquin MARTIN (Spanien)

Herr Valentín RAMOS SALVADOR (Spanien)

Herr Ismael SANZ LABRADOR (Spanien)

Frau Michaela KLENHOVA (Tschechien)

Frau Stanislava RADOTINSKA HVEZDOVA (Tschechien)

Frau Hümeyra ALTUNTAŞ (Türkei)

Frau Filiz BAŞÖREN ALAN (Türkei)

Frau Dilek GÜLEÇYÜZ (Türkei)

Frau Anna IMRE (Ungarn)

Frau Judit KÁDÁR-FÜLÖP (Ungarn)

Frau Lorna BERTRAND (Vereinigtes Königreich)

Frau Elisabeth BOYLING (Vereinigtes Königreich)

Herr Anthony CLARKE (Vereinigtes Königreich)

Herr Stephen HEWITT (Vereinigtes Königreich)

Herr Stephen LEMAN (Vereinigtes Königreich)

Frau Emily KNOWLES (Vereinigtes Königreich)

Frau Rachel DINKES (Vereinigte Staaten)

Frau Jana KEMP (Vereinigte Staaten)

\section{Sonstige Mitwirkende an dieser Publikation}

Herr Samuel E. ABRAMS (NESLI-Berater)

Frau Anna BORKOWSKY (LSO-Beraterin)

BRANTRA SPRL (Übersetzung)

Frau Sally Caroline HINCHCLIFFE (Edition)

Frau Marion SCHNEPF (Layout)
Herr Dan SHERMAN (LSO-Berater)

Frau Fung Kwan TAM (Layout) 


\section{Weiterführende OECD-Publikationen}

Synergies for Better Learning: An International Perspective on Evaluation and Assessment (2013) ISBN 978-92-64-I9064-I http://dx.doi.org/10.1787/9789264190658-en

Teachers for the 21st Century: Using Evaluation to Improve Teaching (2013)

ISBN 978-92-64-I9385-7

http://dx.doi.org/10.1787/9789264193864-en

Trends Shaping Education 2013 (2013)

ISBN 978-92-64-I7708-6

http://dx.doi.org/10.1787/trends_edu-2013-en

International Migration Outlook 2013 (2013)

ISBN 978-92-64-200I5-9

http://dx.doi.org/migr_outlook-2013-en

Bessere Kompetenzen, bessere Arbeitsplätze, ein besseres Leben: Ein strategisches Konzept für die Kompetenzpolitik (2012)

ISBN 978-92-64-I7946-2

http:/|dx.doi.org/10.1787/9789264179479-de

Gleichstellung der Geschlechter: Zeit zu handeln (2012)

ISBN 978-92-64-I9033-7

http://dx.doi.org/10.1787/9789264190344-de

Equity and Quality in Education: Supporting Disadvantaged Students and Schools (2012)

ISBN 978-92-64-I3084-5

http://dx.doi.org/10.1787/9789264130852-en

Health at a Glance: OECD Indicators (2011)

ISBN 978-92-64-III53-0

http:|/dx.doi.org/10.1787/health_glance-2011-en

How's Life?: Measuring Well-being (2011)

ISBN 978-92-64-III6I-5

http://dx.doi.org/10.1787/9789264121164-en

Starting Strong III: Eine Qualitäts-Toolbox für die F frühkindliche Bildung, Betreuung und Erziehung (2011)

ISBN 978-92-64-202I8-4

http://dx.doi.org/10.1787/9789264202184-de

PISA 2009 Results: Students On Line: Digital Technologies and Performance (Volume VI) (2011) ISBN 978-92-64-II29I-9

http:||dx.doi.org/10.1787/9789264112995-en

PISA 2009 Ergebnisse: Was Schülerinnen und Schüler wissen und können: Schülerleistungen in Lesekompetenz, Mathematik und Naturwissenschaften (Band 1) (2010)

ISBN 978-37639-4736-2

http:|/dx.doi.org/10.1787/9789264095335-de
PISA 2009: Potenziale nutzen und Chancengerechtigkeit sichern (2010)

http:|/dx.doi.org/10.1787/9789264095359-de

PISA 2009 Results: Learning to Learn: Student Engagement, Strategies and Practices (Volume III) (2010)

ISBN 978-92-64-09I47-4

http://dx.doi.org/10.1787/9789264083943-en

PISA 2009 Ergebnisse: Was macht eine Schule erfolgreich? Lernumfeld und schulische Organisation in PISA (Band 4) (2010)

http://dx.doi.org/10.1787/9789264095410-de

PISA 2009 Ergebnisse: Lernfortschritte im globalen Wettbewerb - Veränderungen bei den Schülerleistungen seit 2000 (Band 5) (2010)

http://dx.doi.oxrg/10.1787/9789264098077-de

Improving Health and Social Cohesion through Education (2010)

ISBN 978-92-64-08630-2

http:||dx.doi.org/10.1787/9789264086319-en

OECD-Studien zur Berufsbildung: Lernen für die Arbeitswelt (2010)

ISBN 978-92-64-08783-5

http://dx.doi.org/10.1787/9789264087842-de

Creating Effective Teaching and Learning Environments: First Results from TALIS (2009)

ISBN 978-92-64-05605-3

http://dx.doi.org/10.1787/9789264072992-en

Tertiary Education for the Knowledge Society:

Volume 1 and Volume 2 (2008)

ISBN 978-92-64-04652-8

http://dx.doi.org/10.1787/9789264046535-en

Understanding the Social Outcomes of Learning (2007)

ISBN 978-92-64-03310-8

http:/|dx.doi.org/10.1787/9789264034181-en

Internationalisation and Trade in Higher Education: Opportunities and Challenges (2004)

ISBN 978-92-64-0I504-3

http:/|dx.doi.org/10.1787/9789264015067-en

Die OECD-Publikationen können im OECD-OnlineBookshop eingesehen und erworben werden: www.oecdbookshop.org 


\section{ORGANISATION FÜR WIRTSCHAFTLICHE ZUSAMMENARBEIT UND ENTWICKLUNG}

Die OECD ist ein in seiner Art einzigartiges Forum, in dem die Regierungen von 34 demokratischen Staaten gemeinsam an der Bewältigung von Herausforderungen der Globalisierung im Wirtschafts-, Sozial- und Umweltbereich arbeiten. Die OECD steht auch in vorderster Linie bei den Bemühungen um ein besseres Verständnis der neuen Entwicklungen und durch sie ausgelöster Befürchtungen, indem sie Untersuchungen zu Themen wie Corporate Governance, Informationswirtschaft oder Bevölkerungsalterung durchführt. Die Organisation bietet den Regierungen einen Rahmen, der es ihnen ermöglicht, ihre Politikerfahrungen auszutauschen, nach Lösungsansätzen für gemeinsame Probleme zu suchen, empfehlenswerte Praktiken aufzuzeigen und auf eine Koordinierung nationaler und internationaler Politiken hinzuarbeiten.

Die OECD-Mitgliedstaaten sind: Australien, Belgien, Chile, Dänemark, Deutschland, Estland, Finnland, Frankreich, Griechenland, Irland, Island, Israel, Italien, Japan, Kanada, Korea, Luxemburg, Mexiko, Neuseeland, die Niederlande, Norwegen, Österreich, Polen, Portugal, Schweden, Schweiz, die Slowakische Republik, Slowenien, Spanien, die Tschechische Republik, Türkei, Ungarn, das Vereinigte Königreich und die Vereinigten Staaten. Die Kommission der Europäischen Gemeinschaften nimmt an den Arbeiten der OECD teil.

OECD Publishing sorgt dafür, dass die Ergebnisse der statistischen Analysen und der Untersuchungen der Organisation zu wirtschaftlichen, sozialen und umweltpolitischen Themen sowie die von den Mitgliedstaaten vereinbarten Übereinkommen, Leitlinien und Standards weite Verbreitung finden. 


\section{Bildung auf einen Blick 2013 OECD-INDIKATOREN}

Bildung auf einen Blick - OECD-Indikatoren ist die maßgebliche Quelle für präzise und relevante Informationen zum Stand der Bildung weltweit. Bildung auf einen Blick bietet Daten zu den Strukturen, der Finanzierung und der Leistungsfähigkeit der Bildungssysteme von mehr als 40 Ländern, einschließlich der OECD- und G20-Partnerländer.

Mit mehr als 100 Abbildungen, 200 Tabellen und 100.000 Zahlen bietet Bildung auf einen Blick die wesentlichen Informationen zum Output der Bildungseinrichtungen, den Auswirkungen des Lernens in den einzelnen Ländern, zu den in Bildung finanzierten Finanz- und Humanressourcen, zu Bildungszugang, Bildungsbeteiligung und Bildungsverlauf sowie zum Lernumfeld und zur Organisation der Schulen.

Neue Aspekte in der Ausgabe von 2013 sind:

- Aktualisierte Daten zur Wirtschaftskrise, die belegen, dass Bildung der beste Schutz gegen Erwerbslosigkeit ist

- Spezifischere Daten zur Ausrichtung von Bildungsgängen (allgemeinbildend/berufsbildend) im Sekundar- und Tertiärbereich

- Eine Analyse des Zusammenhangs zwischen Beschäftigungsverhältnis (Vollzeit, Teilzeit, unfreiwillige Teilzeit) und jeweiligem Bildungsstand

- Eine Untersuchung der Beziehung zwischen einzelnen Fächergruppen und Studiengebühren, Erwerbslosenquoten und Einkommenszuschlägen

- Ein Indikator zu den Erfolgsquoten im Tertiärbereich: Wie viele der Studienanfänger schließen ihr Studium letztendlich erfolgreich ab?

- Ein Indikator zu der Beziehung zwischen dem erreichten Bildungsstand und den beiden gesundheitsrelevanten Problemen: Fettleibigkeit und Rauchen

- Trenddaten der Jahre 1995 bis 2010/2011 für alle zentralen Indikatoren.

Die den Tabellen und Abbildungen dieser Ausgabe zugrunde liegenden Excel-Tabellen können über die jeweils darunter abgegebenen StatLinks eingesehen werden. Die Tabellen und Abbildungen sowie die gesamte OECD-Online-Bildungsdatenbank sind über die Website der OECD unter www. oecd.org/edu/eag.htm frei zugänglich.

Inhalt

Kapitel A: Bildungsergebnisse und Bildungserträge

Kapitel B: Die in Bildung investierten Finanz- und Humanressourcen

Kapitel C: Bildungszugang, Bildungsbeteiligung und Bildungsverlauf

Kapitel D: Das Lernumfeld und die Organisation von Schulen

Diese Studie ist in der OECD iLibrary veröffentlicht, die alle Bücher, periodisch erscheinenden Publikationen und statistischen Datenbanken der OECD enthält: www.oecd-ilibrary.org. Für weitere Informationen können Sie sich gerne an oecdilibrary@oecd.org wenden. 